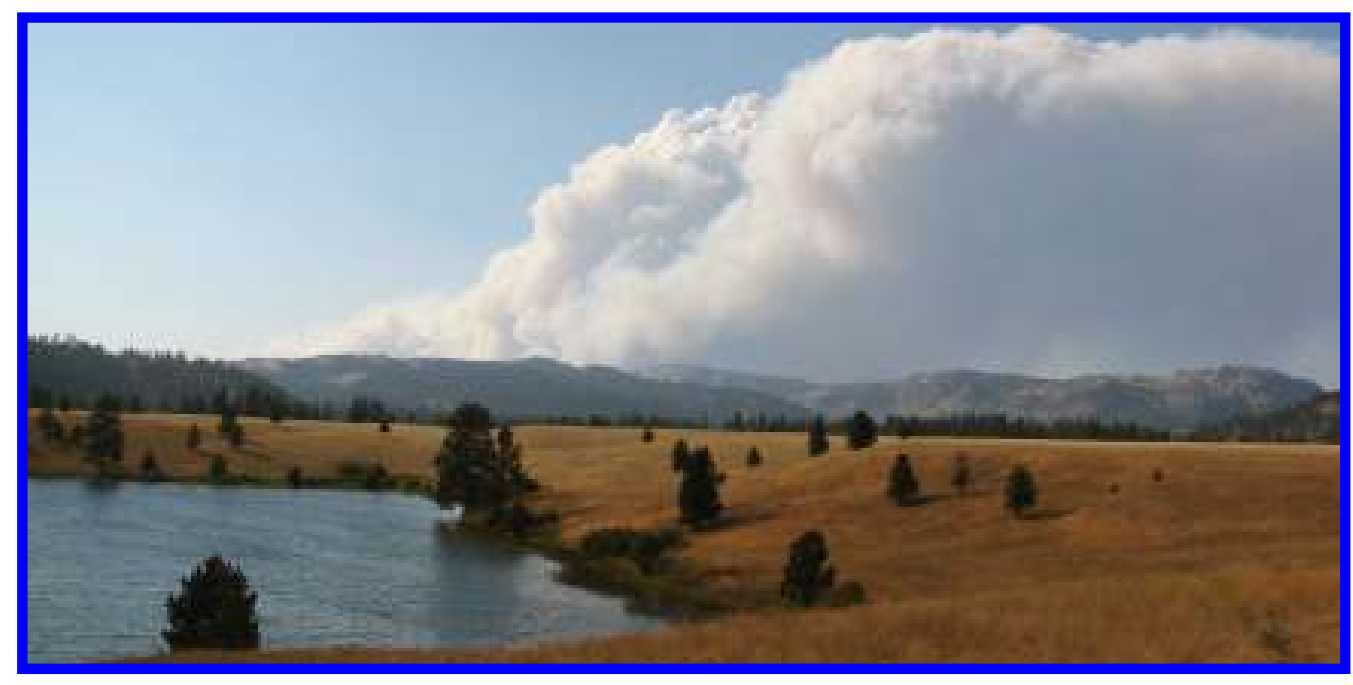

The Big Blackfoot River Fisheries and Restoration Investigations for 2006 and 2007

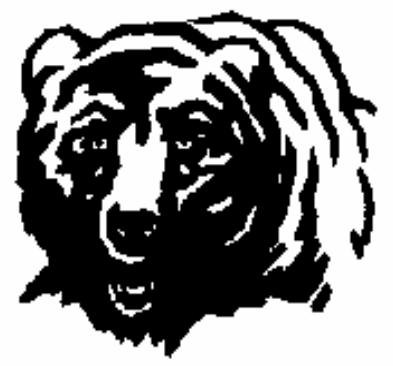

Montana Fish, Wildlife and Parks
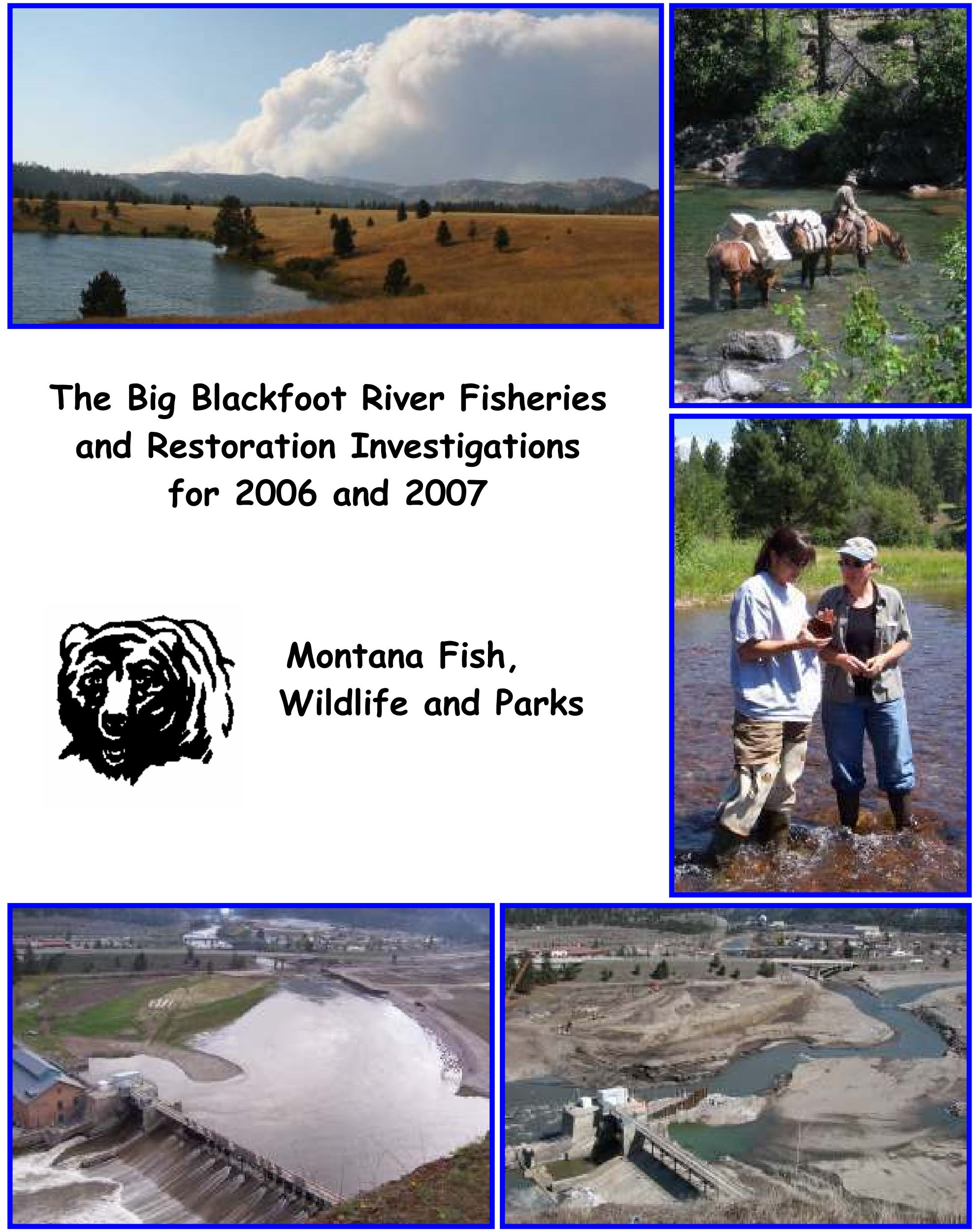


\title{
The Big Blackfoot River Fisheries and Restoration Investigations for 2006 and 2007
}

\author{
by \\ Ron Pierce, Craig Podner, Michael Davidson, \\ Ladd Knotek and John Thabes
}
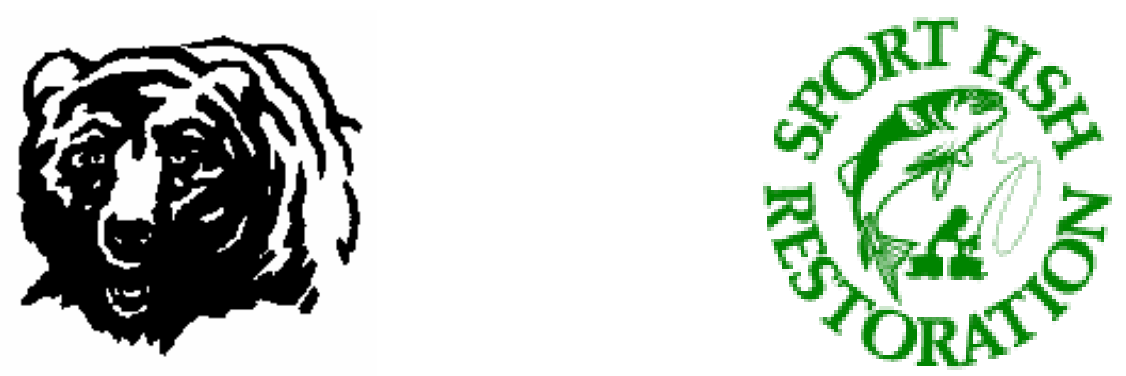

Montana Fish, Wildlife and Parks

3201 Spurgin Road

Missoula, MT 59804

June 2008 


\section{TABLE OF CONTENTS}

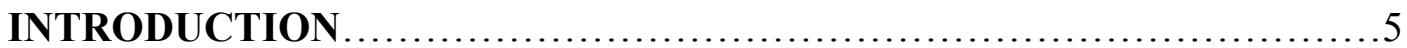

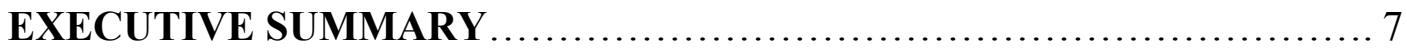

Bull Trout Recovery................................................ 11

Westslope Cutthroat Trout Recovery ...................................15

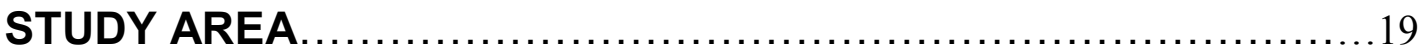

\section{PROCEDURES}

Fish Population Estimators......................................... 23

Water Temperature..................................................... 25

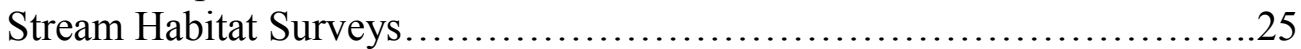

Whirling Disease Sentinel Cage Exposures............................. 26

WSCT Genetic Testing.............................................26

Working with Private Landowners................................. 27

Natural Channel Design................................................... 28

\section{RESULTS/DISCUSSION}

PART I: Blackfoot River Environment

Blackfoot River Discharge ......................................... 30

Blackfoot River and Tributary Temperatures............................. 31

\section{PART II: Blackfoot River Trout Populations}

Lower River (Johnsrud and Scotty Brown Bridge Sections).................35

Middle River (Wales Creek, Canyon and Poorman/Dalton Sections)..........35

Upper River (Upper Blackfoot Mining Complex Area)................... 38

\section{PART III: Restoration: tributary assessments}

Ashby Creek....................................................... 44

Bear Creek........................................................ 45

Blanchard Creek..................................................... 46

Braziel Creek............................................................. 47

Chamberlain Creek........................................................ 49

Copper Creek..................................................... 50

Cottonwood Creek................................................. 51

(Enders) Spring Creek ................................................ 53

Frazier Creek........................................................ 55

Gold Creek..................................................... 56

Hoyt Creek...................................................... 57

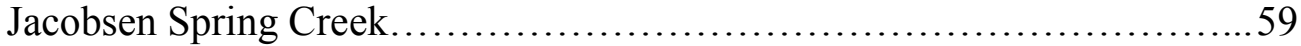

Kleinschmidt Creek.................................................... 61

Lincoln Spring Creek ................................................. 62

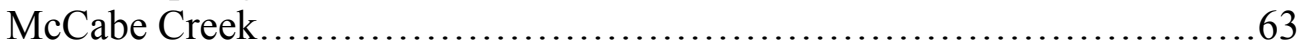




\section{PART III: Restoration: tributary assessments (cont.)}

Monture Creek......................................................... 64

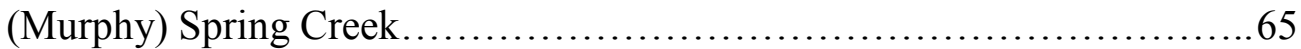

Nevada Spring Creek................................................... 66

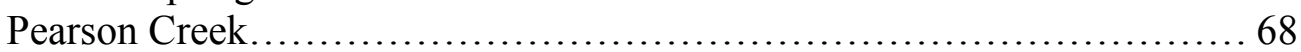

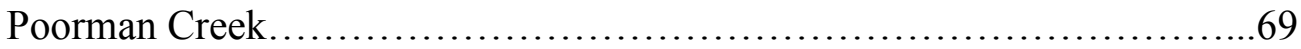

Rock Creek..................................................... 70

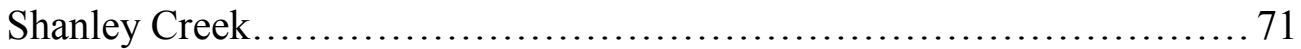

Snowbank Creek................................................ 72

Tamarack Creek......................................................... 73

Warren Creek........................................................ 74

Wasson Creek................................................... 76

Willow Creek, Bear Gulch and Sauerkraut Creeks......................... 78

PART IV: Fisheries and Aquatic Assessments in the Clearwater Basin........ 84 Selected Tributaries

Blind Canyon Creek.................................................... 86

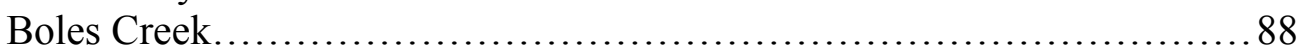

Deer Creek........................................................ 90

East Fork Clearwater River....................................... 92

Marshall Creek...................................................... 94

Morrell Creek.....................................................97

Trail Creek........................................................... 100

West Fork Clearwater River........................................ 103

Clearwater River Sections

Section I: Big Blackfoot River to Salmon Lake............................ 106

Section II: Salmon Lake to Seeley Lake....................................109

Section III: Seeley Lake to Emily A Dam................................. 111

Section IV: Emily A dam to Rainy Lake............................... 114

Section V: Rainy Lake to Clearwater Lake........................... 117

PART V: Whirling Disease Investigations ............................... 121

1. Pilot assessment of the association between stonefly assemblages and the incidence and severity of whirling disease in tributaries of the Blackfoot River, Montana................................................. 123

2. Exploratory assessment of association between invertebrate "EPT" taxa and the incidence and severity of whirling disease in tributaries of the Blackfoot River, Montana

3. Environmental conditions linked to Myxobolus cerebralis infection in basin-fed streams of the Blackfoot Watershed, Montana

4. Relationships of migratory (hybrid) rainbow trout spawning life histories to risk of Myxobolus cerebralis infection in the Blackfoot Basin.

PART V: Whirling Disease Investigations (cont.) 
5. Status review of Mountain Whitefish (Prosopium williamsoni) in the Blackfoot Basin: a pilot study help identify risk of whirling disease. ...

\section{RESULTS PART VI: Other Special Studies}

1. Fluvial westslope cutthroat trout movements and restoration relationships in the upper Blackfoot Basin, Montana................................ 174

2. A stream restoration and native fish conservation prioritization strategy for the Blackfoot River Basin

RESULTS PART VII: Backcountry fisheries Investigations

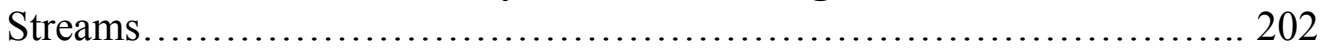

Lakes

RECOMMENDATIONS. 267

ACKNOWLEDGEMENTS .268

LITERATURE CITED. .269

APPENDICES 271

Appendix A: Summary of catch and size statistics for Blackfoot tributaries, 2006-07. Appendix B: Summary of two-pass estimates for Blackfoot tributaries, 2006-07. Appendix C: Mark and recapture estimates for the Blackfoot River, 2006. Appendix D: Summary of stream discharge measurements for 2006-07. Appendix E: Restoration streams and table of activities through 2007.

Appendix F: Potential restoration projects in the Blackfoot drainage through 2007. Appendix G: Restoration streams and cooperators through 2007.

Appendix H: Summary of water temperature in the Blackfoot drainage, 2006-07. Appendix I: Summary of water chemistry readings for 2006 and 2007.

Appendix J: Westslope cutthroat trout genetic sampling sites and results, 2006-07 Appendix K: Blackfoot Basin restoration prioritization scorecard through 2007. 


\section{INTRODUCTION}

The Blackfoot River Basin is the site of a "wild trout" restoration and conservation initiative. This initiative began 20-years ago (1988-89) when fisheriesrelated assessments identified 1) the over-harvest of native trout, 2) stream degradation (at a basin-scale), and 3) toxic mine waste (in the headwaters) as primary threats to Blackfoot River fisheries (Peters and Spoon 1989, Peters 1990). These findings led to the initial adoption of protective angling regulations in 1990 followed by the implementation of pilot-level restoration projects. Early project successes led to the development of a private lands restoration methodology for the Blackfoot River and the expansion of tributary restoration from the mid-1990s to the present. While the guiding philosophy of wild trout conservation provides the foundation for this endeavor, the cooperation of many resource agencies, conservation groups and private landowners (i.e. Blackfoot Cooperators - see below) form the social and technical network necessary to fund and implement the initiative. This initiative provides a more specific framework for the recovery of dwindling stocks of imperiled native fish when integrated with targeted harvest regulations, site-specific restoration and landscape protection measures often undertaken in remote but critical areas of the watershed.

Fisheries restoration in the Blackfoot is an iterative process in which the scope and scale of restoration expands as information and stakeholder cooperation is generated. This iterative process usually begins with fisheries assessments, which often lead to restoration measures of individual tributary stocks, and so involves methods such as enhancing flows in rearing areas, preventing juvenile fish loss to irrigation in migration corridors, reconstructing altered streams, fencing livestock from spawning areas, while expanding these types of actions to adjacent tributaries as human-induced limiting factors are identified and as opportunities allow.

Including the backcountry and upper-river mining areas, Montana Fish, Wildlife and Parks (FWP) has now inventoried (or otherwise assessed) 182 streams, including all major tributary streams within the Blackfoot River basin during the last 20-years. Excluding the backcountry, we have identified human-induced fisheries impairments on a great majority $(>90 \%)$ of low-elevation water bodies (Appendix F). With information derived from these and related investigations, and with the cooperation of many stakeholders, the Blackfoot Cooperators have now targeted $\sim 50$ tributaries with $>600$ individual fisheries-related projects (Appendix E). Correcting environmental (riparian) damage over large tracts of mixed land ownership involves protection (e.g. conservation easements) and restoration of biologically important but fisheries-impaired streams. Improving habitat involves both passive (e.g. compatible grazing) and active (e.g. channel reconstruction) measures depending on the degree of degradation and a stream's recovery potential. The geographic focus of restoration has been lower-river tributaries and bull trout "core area" streams; however, fisheries restoration and conservation measures are now expanding to streams in the Lincoln Valley and Clearwater River basin and other peripheral areas of the Blackfoot Basin, such as the Nevada Creek and Potomac Valley.

In addition to the scale and scope of restoration, stakeholder involvement in the fisheries initiative continues to expand among non-profit groups (NPG), agencies and landowners. The Big Blackfoot Chapter of Trout Unlimited (BBCTU) is a leading NPG with a full-time project manager dedicated to restoration oversight. The Blackfoot 
Challenge (BC) helps by coordinating Total Maximum Daily Load (TMDL) studies and fund-raising for water quality impaired streams and facilitates conservation easements and landowner educational programs. Likewise, the North Powell Conservation District (NPCD), The Nature Conservancy (TNC) and Five Valleys Land Trust (FVLT) are engaged in the development of certain fisheries-related conservation projects. TNC specifically has made a great contribution by protecting $\sim 90,000$ acres of industrial forestland and streams within from development. The combined services of federal agencies - U.S. Fish and Wildlife Service - Partners for Fish and Wildlife (USFWS), Natural Resource Conservation Service (NRCS), U. S. Forest Service (USFS) and Bureau of Reclamation (BOR) provide a wide range of resource expertise, project funding and technical services. The Bonneville Power Administration (BPA), the Trout Unlimited Western Water Project and Department of Natural Resource Conservation (DNRC) are helping coordinate drought mitigation, instream flow and water-leasing projects. Northwestern Energy (NWE) - Milltown Mitigation Funds help cost-share FWP research, monitoring and reporting (i.e. this report and all field studies described). Private landowners, including Plum Creek Timber Company, private foundations and others also contribute significant resources to fisheries-related projects. Together this affiliation - the Blackfoot Cooperators, form the general support base of the Blackfoot River Fisheries Restoration Initiative. A general summary of their support by individual stream is located in Appendix G.

This expansion continues to generate new fisheries initiatives and restoration opportunities. One recent initiative - the NRCS sponsored Expedited EQIP Bull Trout and Westslope Cutthroat Trout Conservation program directed $\$ 2,000,000$ in federal (Farm Bill) resources to 13 "priority" native trout streams. A second initiative - the Native Fisheries Habitat Conservation Plan (HCP) - a cooperative venture related to the BC Blackfoot Community Project recently placed an $\sim 8,000$-acres easement dedicated to native fish conservation on former Plum Creek Timber Company lands (Results Part III). Other important fisheries projects involve the ongoing removal of Milltown at the mouth of the Blackfoot River and the impending clean-up of the Mike Horse Mine, a contaminated mining area that poses extreme ecological risk to the upper Blackfoot River. Despite the many fisheries improvement projects, adverse human pressure upon salmonid habitat (and native trout specifically) in the Blackfoot River Basin is widespread, and as described in this report, these pressures will continue to pose a daunting conservation challenge well into the future. 


\section{EXECUTIVE SUMMARY}

The 2006-2007 reporting period ended with the eighth straight year of drought (Results Part I). During this time, the Blackfoot River Basin was subject to extreme wildfires, increasing water temperatures, and the Blackfoot River set a new (recent) record for warming (Figure 1). Through this 8-year period of warming, the flow regime of the Blackfoot Basin has expressed a pattern of early runoff, and a consistent lowering of the spring hydrograph and lower summer base-flows (Figure 2).

During the last two years, we surveyed fish populations in seven established Blackfoot River monitoring sites, and added two new survey sites to the upper-most reach of the Blackfoot River (Results Part II). Lower Blackfoot River surveys identified relatively high trout population abundance (densities and biomass) in the lower river near Johnsrud but very low population abundance in the middle Blackfoot River below Nevada Creek (Figure 3, Results Part II, Appendix C).

Low salmonid densities in the middle Blackfoot River relate to weak recruitment of juvenile fish to river populations and other

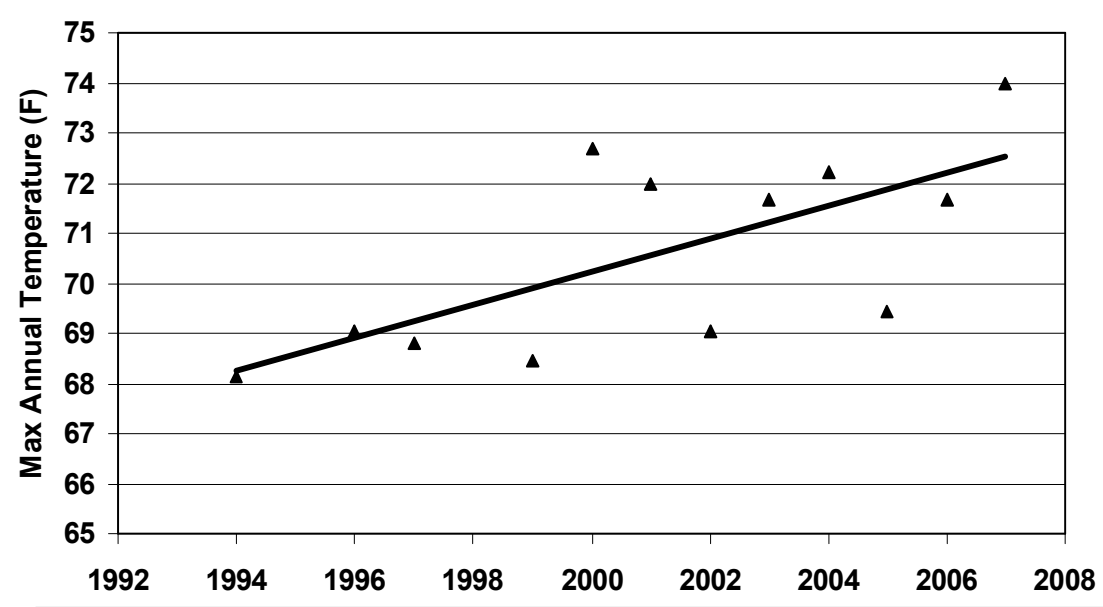

Figure 1. Maximum annual water temperatures for the lower Blackfoot River downstream of Belmont Creek, 1994-2007.

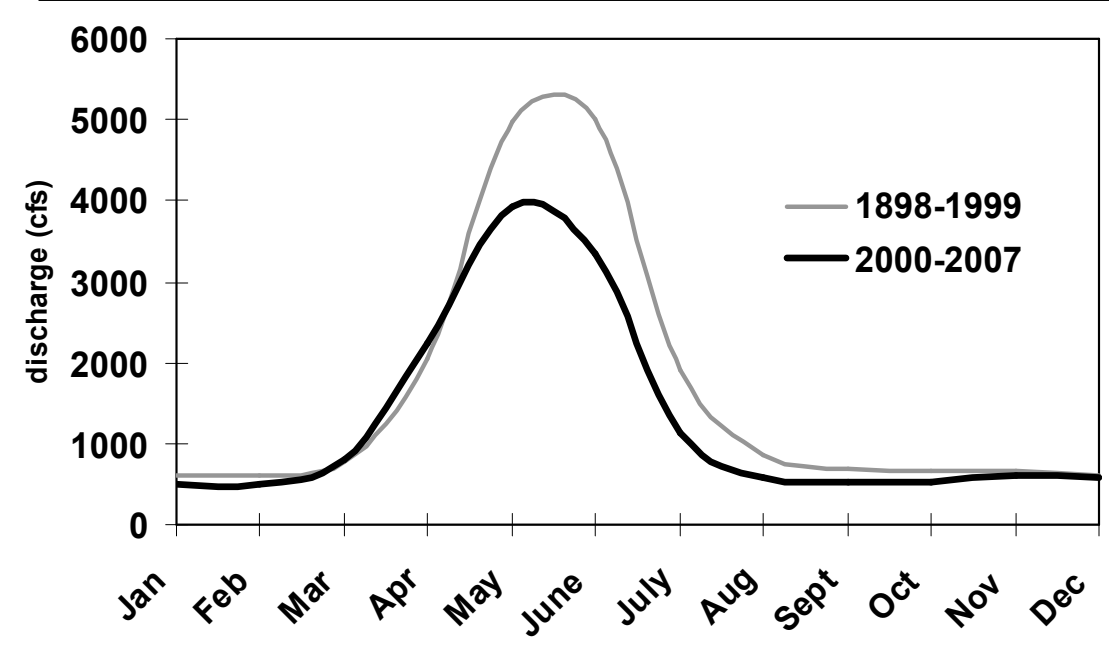

Figure 2. Blackfoot River mean hydrograph (1898-1999) and the 2000-2007 mean hydrograph (USGS Bonner guage). factors. Limited recruitment stems from low number of natural tributaries upstream of Nevada Creek and adverse alterations of tributaries between the North Fork and Lincoln. The middle Blackfoot River has potential for greatly improved fisheries through restoration and with the cooperation of nearby landowners. Westslope cutthroat trout (WSCT) specifically 
have potential for improvement through targeted tributary restoration as identified in a radiotelemetry WSCT study involving spawning movements (Results Part VI).

Based on past and recent fish population studies in the upper Blackfoot River, we again report on impacted fisheries in the area of the

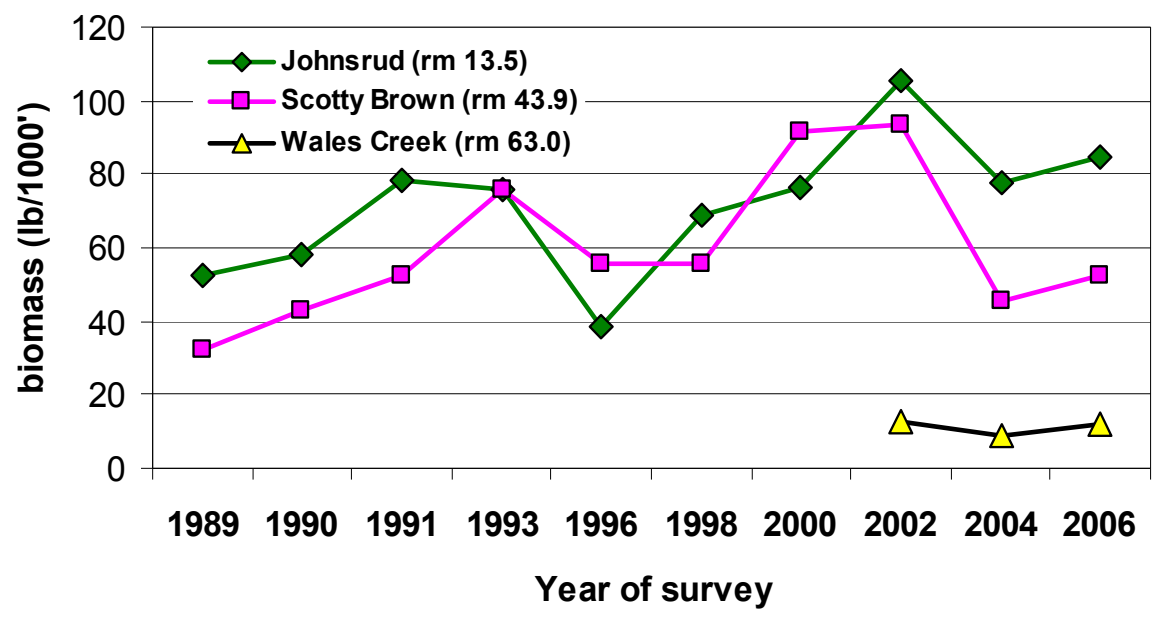

Figure 3. Total trout biomass estimates (fish $>6.0$ ") for the three lower Blackfoot River sampling locations, 1989-2006.

Mike Horse Mine where WSCT have expressed a declining trend in densities for $>30$ years (Results Part II). Two mining companies (Asarco and Atlantic Richfield Company) are identified as responsible for cleanup costs $(\$ 37,000,000)$ as announced by the Montana's Governor Brian Schweitzer and Attorney General Mike McGrath on April $25^{\text {th }}, 2008$. With cleanup slated to begin, the removal of streamside contaminants and restoration of riparian habitats are both necessary for a meaningful level of WSCT improvement in the mine-impact area. With successful remediation and restoration project, the damaged area has potential to recover resident WSCT and perhaps increase downstream recruitment of fluvial WSCT to the middle Blackfoot River (Results Part II, VI).

In addition to river assessments, we present the results of fisheries and habitat assessments for 29 tributaries undergoing restoration (Results Part III). The results of these restoration-related investigations identify great promise for improvement to wild trout fisheries in the presence of river warming and whirling disease once damaging land (riparian) activities and other human-related factors limiting populations are corrected. In addition to identifying many successes, these assessments shed light on the complexities of native fish recovery and the inherent challenges of ensuring successful restoration on (private and public) lands managed for agricultural purposes. Our assessments identify not only a great need to continue restoration actions, but also a fundamental need to continue to track restoration progress to help ensure projects meet their intended outcomes.

In Results Part IV, we report on important tributaries of the Clearwater River basin as well as five reaches of mainstem Clearwater River. The Clearwater River drainage is the largest tributary to the Big Blackfoot River by drainage area. The Clearwater system is a unique drainage within the Blackfoot Watershed and it supports exceptional and diversified aquatic resources, including many native fish populations with unique life history traits. Because of the interconnected nature of stream, river and lake environments, species richness is high and adfluvial migratory life forms are common. The Clearwater Basin supports some of the only natural and currently viable adfluvial bull trout populations in the region. Fisheries emphasis and restoration 
accomplishments on streams in the greater Blackfoot Basin have generally not yet included the Clearwater system. The need for relevant fisheries information has recently become imminent as the rapid conversion of corporate timberlands to smaller residential properties has forced natural resource managers and conservation advocates to prioritize lands for protection and acquisition. With the recent completion of fisheries work in the Clearwater Basin, we are now able to integrate key findings into the broader Blackfoot River fisheries restoration prioritization strategy (Pierce et al, 2006). The new prioritization is located in Results Part VI (Appendix K). This inclusion of the Clearwater Basin into the broader prioritization strategy represents an initial attempt to direct conservation efforts to important native fish populations.

With the introduction of the exotic parasite Myxobolus cerebralis, whirling disease has expanded in recent years. It is now firmly established at the lower elevations of the watershed where infection among salmonids, particularly rainbow trout, vary within and between streams (Results Part V). The escalation of the disease (severity and distribution) as measured by histological scores of rainbow trout exposed to $M$. cerebralis corresponds with an increase in cranial deformities in Blackfoot River rainbow trout, as well as a recent decline in rainbow trout in the middle Blackfoot River downstream of Monture Creek, a highly infected spawning stream.

In 2006-07, we explored certain biotic (benthic) relationships of the M. cerebralis parasite within the Blackfoot Basin. We began this work by exploring relationships between the incidence and severity of disease (as measured on the MacConnell Baldwin scale from sentinel cage exposures) and stonefly and EPT (Ephemeroptera, Plecoptera and Trichoptera) assemblages (Results Part V). Significant negative correlations were demonstrated between measures of disease and several metric relationships, including EPT richness and pollution sensitive taxa richness. Our findings further identified cold stenothermic species only in streams where infections went undetected (Results Part V).

To further assess ecological relationships of whirling disease, we then investigated physical relationships between a group of five-landscape and four reachscale environmental conditions and the presence of infected fish for 13 basin-fed tributaries to the Blackfoot River. In this study, infections were present and severity of disease was high in meandering streams (e.g. Monture Creek) in broad valleys with gentle relief and warmer summer temperatures. Conversely, streams with higher gradients, lower levels of fine sediment within the substrate, low summer temperatures and stenothermic species supported little to no infection despite the near proximity of higher infection rates in adjacent waters (Results Part V). Basic applications of this research relate to the need to continue to implement a more sensitive level of streamside management in environments prone to infection, while maintaining cold-water environments where possible.

In a companion study also geared towards restoration and management applications of sport fisheries, we identified the relative spawning use of variously infected streams by fluvial Blackfoot River rainbow trout using radio telemetry (Results Part V). This study confirmed dispersed spawning throughout colder, higher gradient tributaries of the lower Blackfoot Basin in areas where infections remain low. However, a majority of rainbow trout from the middle Blackfoot River spawned in lower Monture Creek (a warmer lower-gradient stream) in waters highly infected by $M$. cerebralis. Concentrated spawning within a single, localized and highly infected stream raises 
concern for an additive level of recruitment loss to trout populations in the middle Blackfoot River. This reach of river has long been identified with recruitment problems brought on by drought, low winter survival of juvenile fish, and human-related habitat impairments in spawning tributaries. To offset potential RBT losses in disease prone waters of the middle Blackfoot Basin, stakeholders should 1) better manage riparian areas for channel stability, increased shade and erosion reduction, 2) promote native fish recovery and migratory life histories, and 3) restore (or enhance) habitats favoring salmonid life stages less affected by the pathogen.

As our ability to predict whirling disease in the Blackfoot Valley improves, we are now beginning to examine the influence of $M$. cerebralis on mountain whitefish (Results Part V), a species now expressing the clinical signs of whirling disease within western Montana (and the Blackfoot River), but whose susceptibility remains in question. This evaluation began with a status review of the species in the Blackfoot Basin (Results Part V). This review identifies the middle Blackfoot River as supporting relatively high densities of juvenile whitefish; however this distribution also overlaps with the presence of $M$. cerebralis and high severity of disease in other species (e.g. rainbow trout). Recent sampling of mountain whitefish in the upper Blackfoot River has identified low juvenile densities where high infections are now prevalent. A pilot-level mountain whitefish telemetry study planned for 2008 will attempt to identify whitefish spawning sites, similar to the rainbow trout telemetry study, and in so doing help identify disease risk at the local scale. These investigations should coincide with controlled lab studies examining the susceptibility of whitefish to the parasite, which hopefully will lead to sentinel exposures of age- 0 whitefish within the wild.

In Results Part VII, we also report on stream and lake assessments in the "backcountry" of the Blackfoot Basin. This work identifies native species in high abundance throughout the upper Monture basin, but non-native Oncorhynchus hybrids throughout the upper North Fork upstream of the North Fork Falls in relatively low abundance. Hybrids above the North Fork Falls are self-sustaining and their presence is traced to historical stocking in (at least) two high mountain lakes. Our surveys suggest non-natives in the upper North Fork are poorly suited to the backcountry environment. Because of very low population densities, these fisheries provide only minimal ecological value. Furthermore, this backcountry source of non-native hybrids poses risks of hybridization to native WSCT in downstream waters. Options to convert these nonnatives to a native species (i.e. WSCT) capable of thriving in the backcountry environment should be further explored.

In summary, this report consolidates the results of recent FWP Blackfoot River fisheries restoration and related investigations. Our objectives are to: 1) summarize the status of Blackfoot River wild trout and their environments; 2) summarize fisheriesrelated monitoring in tributaries undergoing restoration; 3) report on a whirling disease investigations, 4) present the results and management considerations stemming from both rainbow trout and westslope cutthroat trout telemetry studies; 5) present the current status of backcountry fisheries investigations; and 6) help guide future fisheries restoration and other conservation actions basin-wide and to specifically expand native fish protection measures to the Clearwater River basin. 


\section{Bull Trout Recovery}

Bull trout is a "species of special concern" in Montanan and a species listed as "threatened" under the Endangered Species Act. The Blackfoot Basin supports streamresident and migratory (i.e. fluvial and adfluvial) bull trout. The recovery of migratory bull trout in the Blackfoot Basin fundamentally relies on restoration and protection of "core areas" i.e. critical waters and watershed that provide for the spawning, rearing and movement (Figure 4). Within these areas, migratory bull trout exhibit local adaptations that involve spawning in discrete areas, tributary use by early life-stages, large home ranges, extensive migrations at higher flows, and seasonal use of larger, more productive river (or lake) habitats. Migratory bull trout also require complex habitats, colder water, groundwater upwelling for spawning and lower sediment and more tributary access than currently exists in many areas of the Blackfoot Watershed. Stream resident bull trout require similar environments and complete their life-cycle in tributary streams. Adfluvial bull trout are rare in the upper Clark Fork Basin but occupy the Clearwater chain of lakes and migrate to tributaries for spawning and rearing. The life-histories of fluvial bull trout

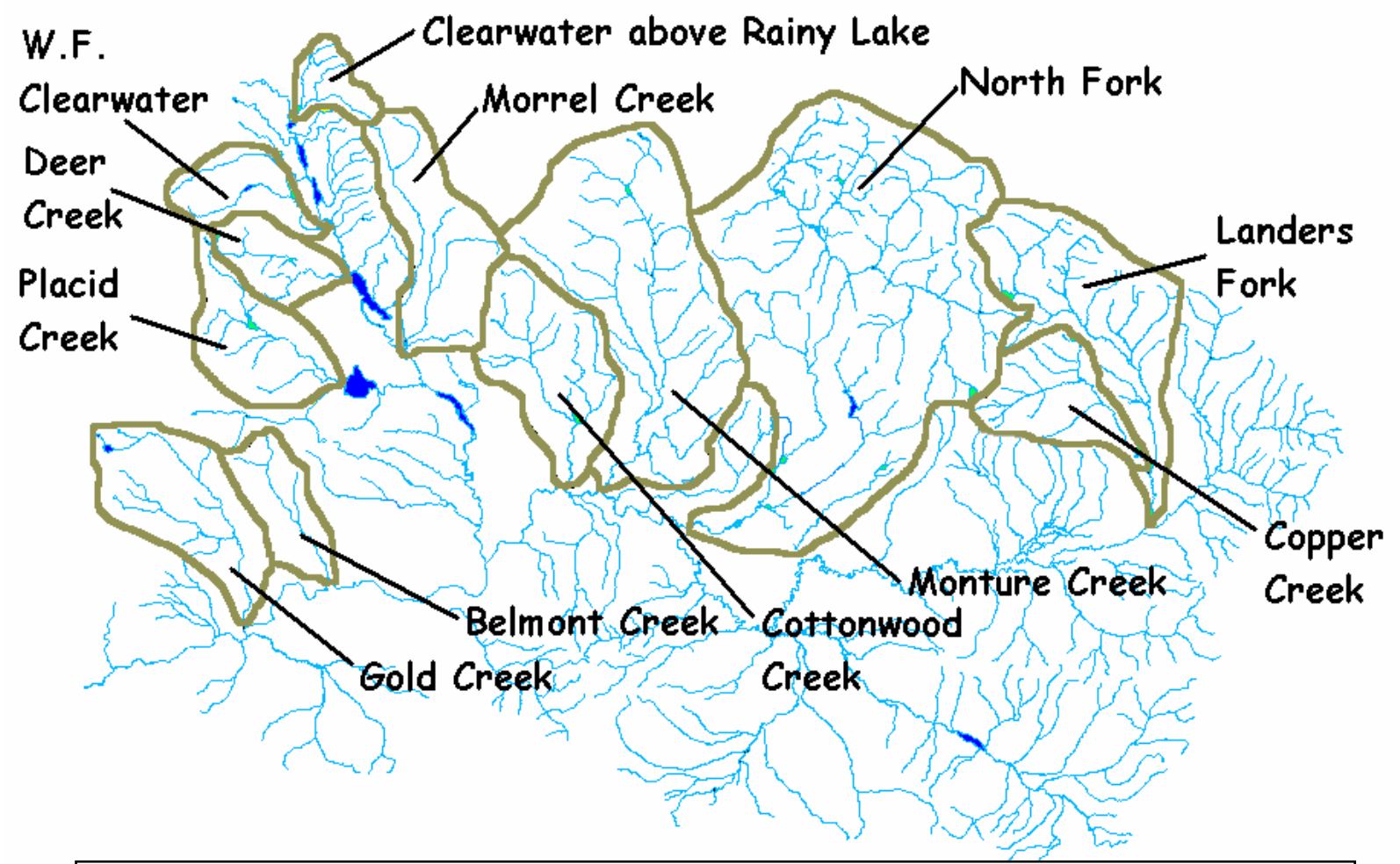

Figure 4. Bull trout "core areas" for the Blackfoot Basin (MBTRT 1996).

have been extensively studied in the Blackfoot basin (Swanberg 1997, Schmetterling 2003, Pierce et al. 2005) and are the primary focus of current recovery actions. Until recently, there has been very little applied research (or restoration) directed to the recovery of adfluvial bull trout within the Clearwater Basin.

In 2006-2007, FWP and a University of Montana graduate student captured, radio-tagged and tracked $>50$ adult adfluvial bull trout from the Clearwater chain of lakes 
and Clearwater River. Study objectives were to identify migration patterns, spawning areas, conservation needs and the impacts of several upstream migration barriers on the main stem river between the Clearwater lakes. This study identified several migratory components of the Clearwater population and complex movements between and among the various lakes. Three spawning tributaries (Morrell Creek, West Fork Clearwater and East Fork Clearwater) were identified as the primary spawning and rearing habitats for adfluvial bull trout. Adult bull trout from Salmon and Seeley Lakes migrated either up (Salmon Lake) or downriver (Seeley Lake) before ascending Morrell Creek for spawning. Seeley Lake fish also expressed upstream movements and, combined with the downstream migrants from Lake Inez and Lake Alva, ascended the West Fork drainage. Bull trout from Rainy Lake, and to a lesser extent Lake Alva, migrated up the Clearwater River and spawned in the East Fork drainage. At this early stage of the study, primary concern include the dewatering and entrainment of migratory bull trout in Morrell Creek, fragmentation of key migratory corridors (mainly due to dams) on the mainstem Clearwater River and development pressures along existing subdivisions. Landscapelevel development pressures on Plum Creek Timber Company holdings in many of the important tributary drainages are considered a primary long-term threat to bull trout in the Clearwater basin. Fisheries inventories were also completed on all perennial tributaries $(>25)$ to the Clearwater River. In addition to streams identified in telemetry studies, Boles Creek, Deer Creek, Camp Creek and Trail Creek drainage were identified as supporting bull trout.

Since 1990 , many actions targeting the
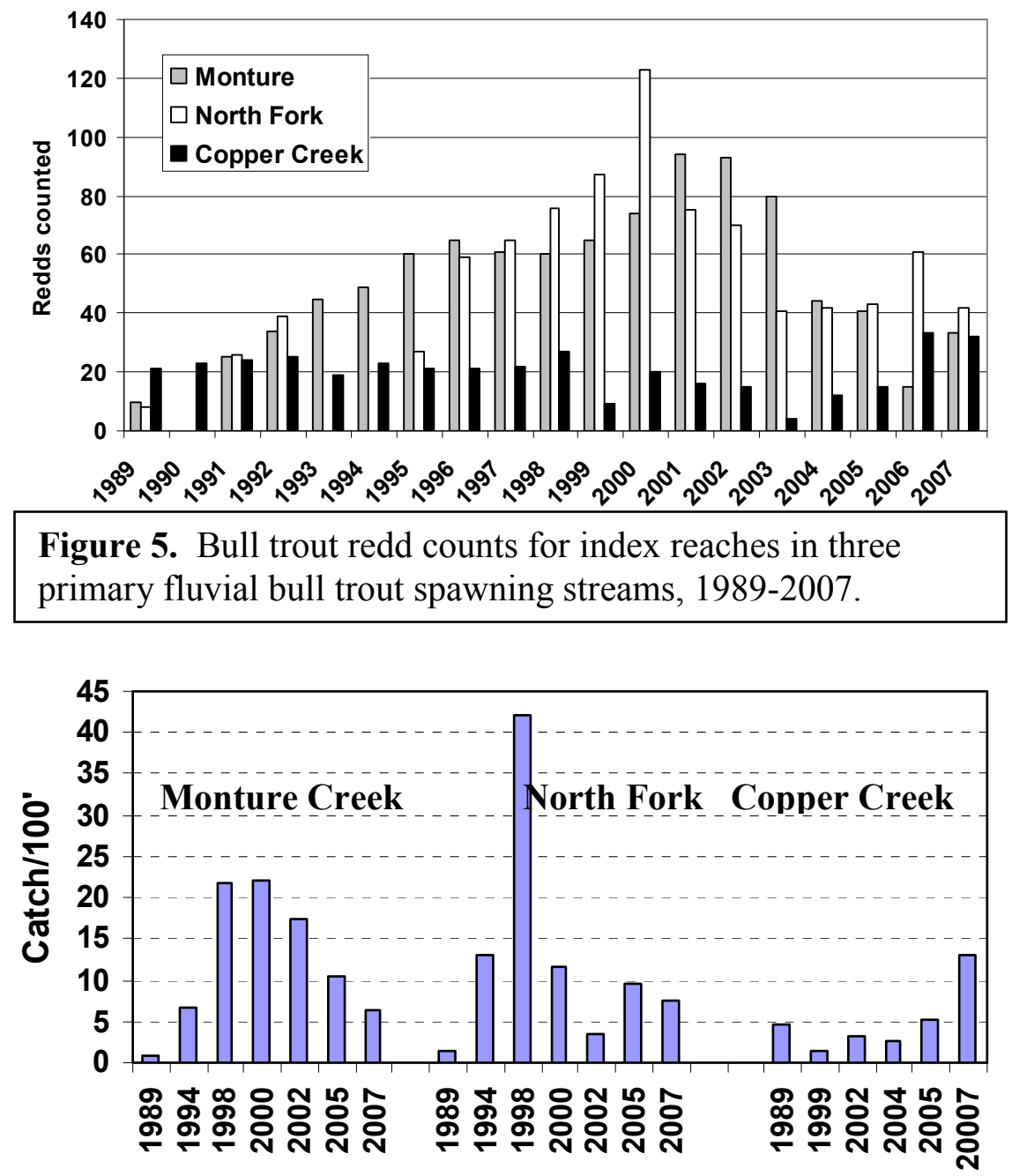

Figure 6. CPUE for juvenile bull trout near spawning sites of three primary spawning streams, 1989-2007. 
recovery of fluvial bull trout in the Blackfoot Watershed were completed (Pierce et al 2005), and many others are ongoing. In 2006 and 2007, the Blackfoot Cooperators developed habitat restoration projects in five core areas, and these included: 1) enhancing instream flows, improving fish passage flows and riparian fencing on Cottonwood Creek; 2) channel reconstruction in Hoyt Creek, a tributary to Monture Creek; 3) flow enhancement on Murphy Spring Creek, 4) and the reconstruction of Jacobsen and Enders Spring Creeks, and continued habitat work on both Rock Creek and Kleinschmidt Creek (all are in the North Fork Blackfoot River basin). Bull trout recovery work in the development phases includes 1) improving access, ditch screening and instream flows in Snowbank Creek (a tributary of Copper Creek), and 2) fish screening and flow enhancement on Morrell Creek. Other recent important bull trout recovery actions include the restoration of fish passage at Milltown dam, and a native fish Habitat Conservation Plan (HCP) conservation easement on Sauerkraut Creek.

Following the adoption of protective harvest regulations and the initiation of initial bull trout recovery actions, bull trout densities in the lower Blackfoot River increased during the 1990s, with an inclination towards large fish (Pierce et al 2004). However, with the onset of drought in 2000, all measures of fluvial bull trout abundance showed declines, with the exception of Copper Creek (Figure 2, Results Part III). Bull trout declines correspond with an 8-year trend of increasing water temperatures and low stream flows. During this period increasing water temperatures have reduced thermally suitable bull trout (summer) habitat in the lower reaches of several core areas with recent water temperatures $>70^{\circ} \mathrm{F}$ (Figure 7, Appendix H). This warming includes areas such as lower Monture Creek (Results Part III), an area identified as refugia for fluvial bull trout during periods of river warming (Swanberg 1997). If global warming trends continue as predicted, a reduction in thermally suitable streams adjacent to seasonally unsuitable habitat (e.g. Blackfoot River) is expected to reduce populations to incrementally smaller patches of habitat over a range of spatial scales (Reiman et al. 2008). The cumulative effects of warming and other human-induced adverse influences to bull trout habitat clearly identifies the need to continue restoration in core area streams where local humaninduced warming, dewatering and habitat degradation is identified (Appendix F) and can be corrected.

Redd surveys in index reaches show notable declines in both Monture Creek and the North Fork with declined of $65 \%$ and $66 \%$ from recent highs (Figure 5). Conversely, total redd counts in Copper Creek in 2006-07 have increased sharply (75\%) above the long-term (1989-2005) mean (Results Part III). These recent increases appear to relate to increased stream productivity as the result of wildfire (Results Part III). Similar to redd counts, juvenile bull trout densities have declined near Monture Creek and the North Fork spawning area, whereas densities of juvenile bull trout in Copper Creek have recently increased (Figure 6).

Bull trout declines were also detected in the lower Blackfoot River at both Johnsrud and Scotty Brown monitoring locations between 2000 and 2006. In the Scotty Brown section of the lower Blackfoot River, bull trout ( $>6.0$ ") densities declined from 7.7 to 4.4 bull trout/1000' between 2000 and 2006 (Results Part II). Bull trout were present in the Canyon Section in low densities in 1999 but absent from our 2006 surveys. Likewise densities in the upper Blackfoot River appear very low (Appendix C). 

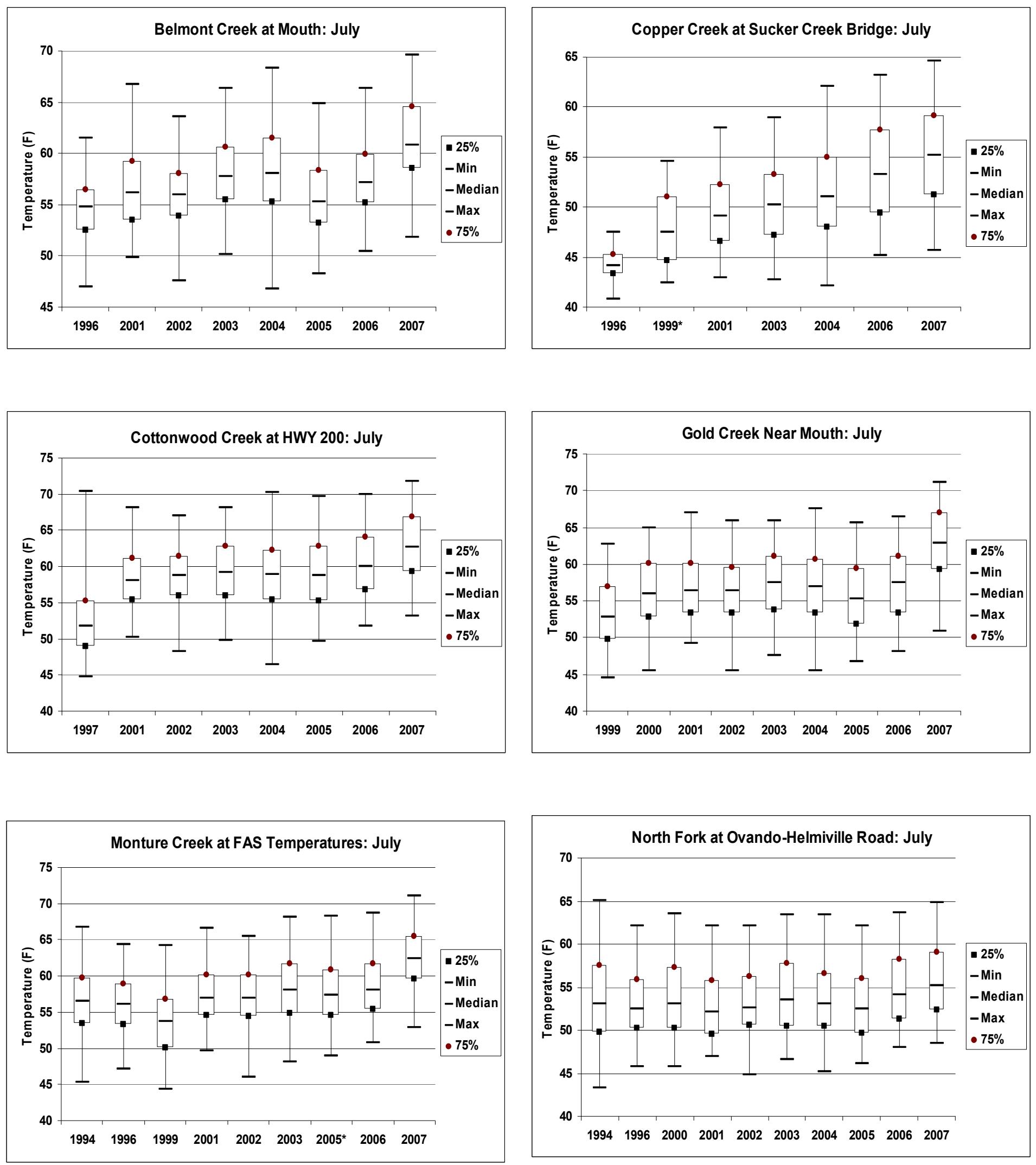

Figure 7. Summary of July water temperatures at monitoring sites in the lower reaches of six bull trout core areas. 
Surveys of juvenile Bull trout in upper Cottonwood Creek indicate low, but stable juvenile densities (Results Part III). However, livestock degradation of riparian areas has damaged bull trout habitat in middle Cottonwood Creek. Recent fish population surveys have failed to detect bull trout in the middle reach of Cottonwood Creek. Despite a general decline in bull trout at a basin-scale, monitoring has detected bull trout expansion in certain streams where improved fish passage and beneficial habitat restoration work has been completed. Examples of this expansion include Murphy Spring Creek, Nevada Spring Creek and Snowbank Creek (Results Part III).

Although bull trout are particularly sensitive to many threats, at this time whirling disease appears to be less of a concern for bull trout than for other salmonids. Compared with WSCT, rainbow trout and brook trout, bull trout exhibit a greater physiological resistance to whirling disease (Vincent 2002). In 2006, we continued to monitor whirling disease near bull trout spawning and rearing areas of Cottonwood Creek, Monture Creek and the North Fork, using sentinel fish exposures. The tests indicate that whirling disease is not yet present at these locations; however, the disease is present at various levels in lower reaches of these streams. With increased warming, whirling disease is expected to expand in the upstream direction (Results Part V).

\section{Westslope Cutthroat Trout Conservation}

WSCT is also a "species of special concern" that has declined over much of their historic range within the last century. In Montana, these declines are most pronounced east of the Continental Divide in the upper Missouri River drainage (Shepard et al. 2003). In the Blackfoot Watershed, WSCT occupy $\sim 90 \%$ of historical range. Genetically unaltered WSCT dominate the upper basin upstream of the North Fork (Figure 8); whereas, introgressed tributary stocks are also common in the lower basin (including Clearwater sub-basin), and these test at levels that generally exceed $90 \%$ "genetic purity" (Figure 8, Appendix J). Historical accounts suggest WSCT were once abundant in river systems of western Montana (Lewis 1805, Shepard et al. 2005), where populations expressed a range of migratory (fluvial and adfluvial) and stream-resident life history traits. WSCT in the Blackfoot Basin still posses these three life history traits with 1) fluvial fish in the Blackfoot River (and tributaries), 2) stream-resident WSCT within smaller segments of tributaries, and 3) adfluvial fish in Clearwater Basin chain-of-lakes and nearby streams. Because of their low densities, unique life histories and high recreational value, fluvial WSCT of the Blackfoot River have become a guiding conservation target within the Blackfoot Basin. WSCT of the Blackfoot River typically occupy a large home-range and spawn in tributaries where the young rear before they migrate to a large river to mature (Results Part VI). WSCT have become increasingly rare as a result of habitat loss and degradation, competition with non-native fishes, genetic introgression and fish passage barriers (McIntyre and Reiman 1995, Shepard 2003), all of which are present primarily at the mid-to low elevations of the Blackfoot Basin. 


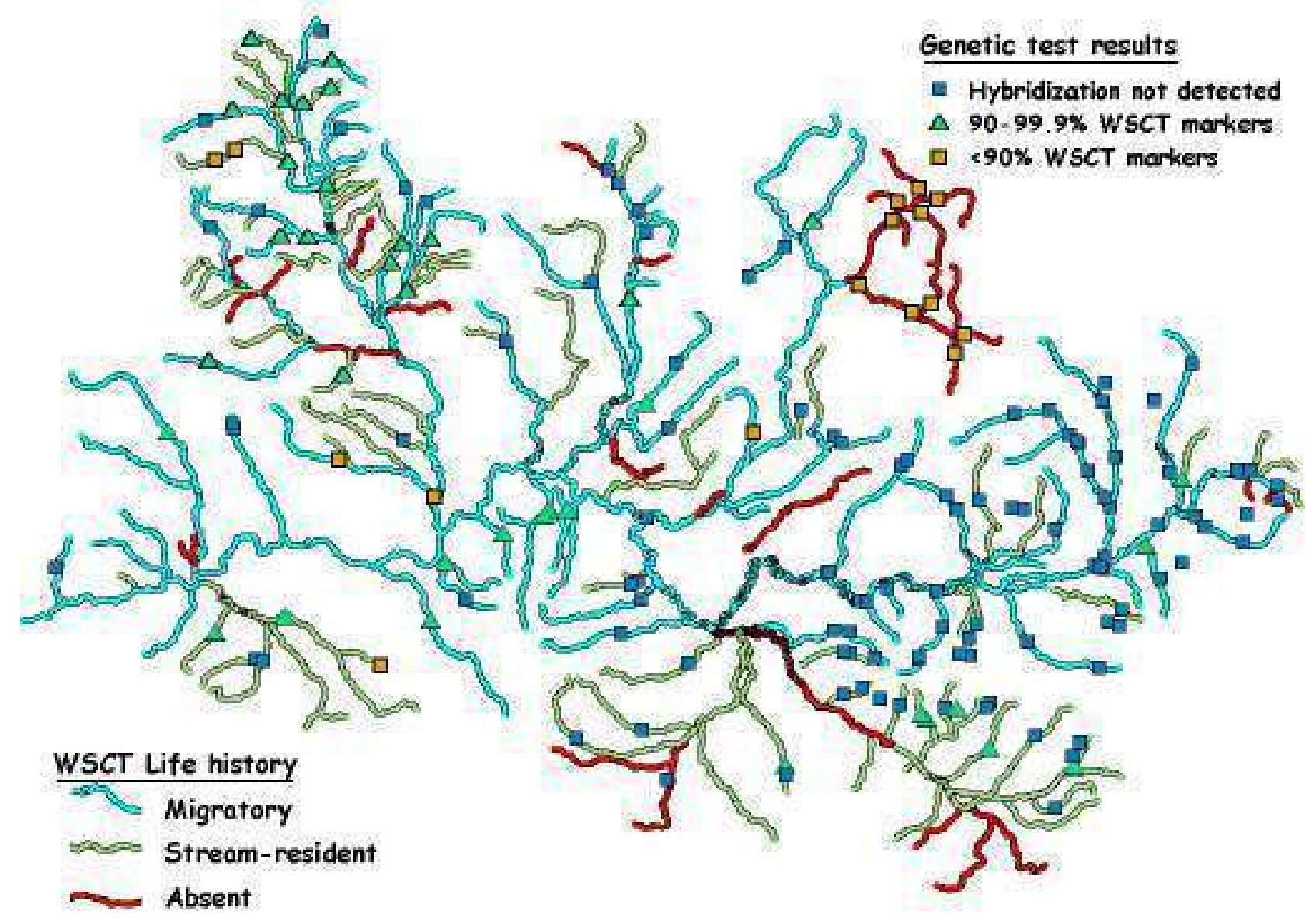

Figure 8. Generalized WSCT life history traits and summary of genetic test results.

As identified in many Blackfoot fisheries studies (Results Part III and V), human alterations to WSCT habitat are pervasive throughout the tributary system and adversely influence many spawning and rearing areas of both resident and migratory WSCT stocks. As reflected in nearby tributaries, population trends at long-term monitoring sites in the Blackfoot River identify fluvial WSCT as: 1) declining in the upper river; 2) at static and very low densities in the middle river; but 3) increasing in abundance in the lower river (Figure 9, Results Part II).

WSCT declines in the upper river upstream of Lincoln correspond with the release of toxic mine waste and related a population collapse within and downstream of the Upper Blackfoot Mining Complex (Spence 1975, Peters 1990, Stratus 2007, Results Part II). Extremely low densities of WSCT in the middle-to upper river reflect habitat loss and limited spawning opportunity in a majority of adjacent streams (Pierce et al 2000, 2001, 2002, 2004, Results Part III). As identified in a recent telemetry study, WSCT use of tributaries of the middle Blackfoot River was not detected over a large contiguous area ( $\sim 3 \%$ of the upper basin above the North Fork) despite WSCT populations in the headwaters of nearby tributaries. This loss of spawning access and opportunity stems from disrupted migration corridors and habitat loss (i.e. riparian degradation) in the lower reaches of tributaries. The expressed loss of recruitment to the 
Blackfoot River is expressed in extremely low WSCT densities in two mid-river sampling sites (river mile 63.0 and 95.3, Figure 9). Conversely, WSCT in the restoration focus area of lower Blackfoot River have significantly increased. These increases stem from the cumulative influences of protective regulations, increased fish passage and habitat restoration targeted at primary spawning tributaries such as Chamberlain Creek and many other streams (Results Part III).

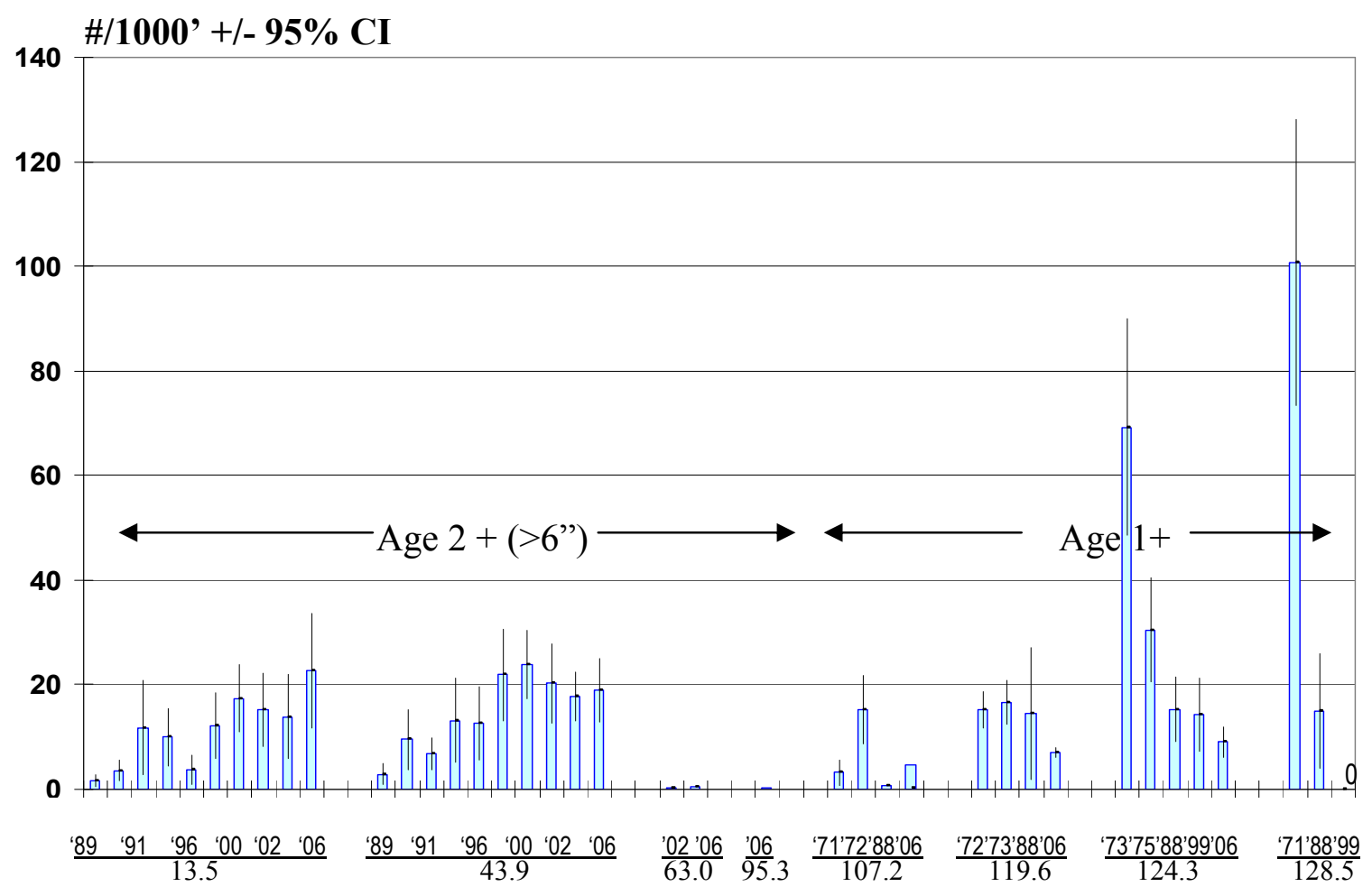

Figure 9. WSCT densities at eight sampling locations on the Blackfoot River. The horizontal axis shows the year of survey and the river-mile mid-point of the survey.

In concert with fluvial bull trout recovery, the focus of WSCT recovery is reestablishing the fluvial life-history form by: 1) reducing or eliminating "controllable" sources of anthropogenic mortality; 2) maintaining and restoring existing spawning and rearing habitats; 3) restoring damaged habitats; 4) improving connectivity from the Blackfoot River to fluvial spawning areas; while 5) maintaining genetically "pure" population isolates (e.g. Ashby Creek, Results Part III). Most of the current WSCTrelated work ( $\sim 40$ streams) occurs in bull trout core areas or tributaries to the lower Blackfoot River (Pierce et al. 1997; 2001; 2002; 2004; 2006; Results Part III).

The distribution of whirling disease generally conforms to low-elevations of the basin below many known WSCT spawning and rearing sites with some exceptions, including Chamberlain Creek, an important fluvial WSCT spawning stream in lower Blackfoot Watershed. Despite high infection rates in test fish (rainbow trout), continued population monitoring of WSCT in Chamberlain Creek identify stable densities (Results Part III and V). The recovery of WSCT within Chamberlain and Wasson Creeks provides model examples of WSCT recovery within a tributary with benefit the broader WSCT metapopulation of the Blackfoot River. 
During 2006 and 2007, we completed fisheries inventories to the backcountry of the watershed, including tributaries in the upper Monture, upper North Fork and upper Cottonwood Basins (Results Part VII). Inventories identified a WSCT-dominated community in relatively high abundance throughout the upper Monture basin. Upstream of the Monture Falls, we found a population of WSCT that tested genetically pure (Results Part VII, Appendix J). Although inventories are not yet complete, to date we failed to identify WSCT in the upper North Fork upstream of the North Fork Falls. At this time, it is unclear whether WSCT were ever present to this headwater area of the North Fork; however, our findings of a single sculpin upstream of the North Fork Falls indicate some level of post-glacial native fish passage and presence. Oncorhynchus hybrids above the North Fork Falls are now self-sustaining and their presence is traced to historical stocking in Lower Twin and Parker Lakes. Downstream of the North Fork Falls, we found naturalized rainbow trout in Camp Lake and Lake Otatsy (Results Part V). Likewise, the Cottonwood Lakes surveys identified a rainbow population upstream of a genetically pure WSCT population. These rainbow-dominated backcountry environments all place nearby populations of WSCT at increased risk of introgression (Results Part V, Appendix J). 


\section{STUDY AREA}

The Blackfoot River, located in west-central Montana, begins at the junction of Beartrap and Anaconda Creeks (within the Upper Blackfoot Mining Complex), and flows west 132 miles from the base of the Continental Divide to its confluence with the Clark Fork River at Bonner, MT (Figure 10). The Blackfoot River is one of twelve renowned "blue ribbon" trout rivers in Montana with a 1972 appropriated "Murphy" in-stream flow water right of $700 \mathrm{cfs}$ at the USGS Bonner (\#12340000) gauging station. The 50-year mean annual discharge is 1,554 (cfs) near the mouth (USGS 2008 provisional data). This river system drains a 2,320-mile ${ }^{2}$ watershed through a 3,700-mile stream network, of which 1,900 miles are perennial streams capable of supporting fishes. The physical geography of the watershed ranges from high-elevation glaciated alpine meadows, timbered forests at the mid-elevations, to prairie pothole topography on the valley floor. Glacial landforms, moraine and outwash, glacial lake sediments and erratic boulders cover the floor of the entire Blackfoot River valley and exert a controlling influence on the habitat features of the Blackfoot River and the lower reaches of most tributaries. The Blackfoot River is a free flowing river to its confluence with the Clark Fork River where Milltown dam, a run-of-the-river hydroelectric facility eliminated upstream fish passage from 1907 when the dam was constructed to its removal in 2008. In April 2008, the first uninhibited movements of fish from the Clark Fork to the Blackfoot River were documented.

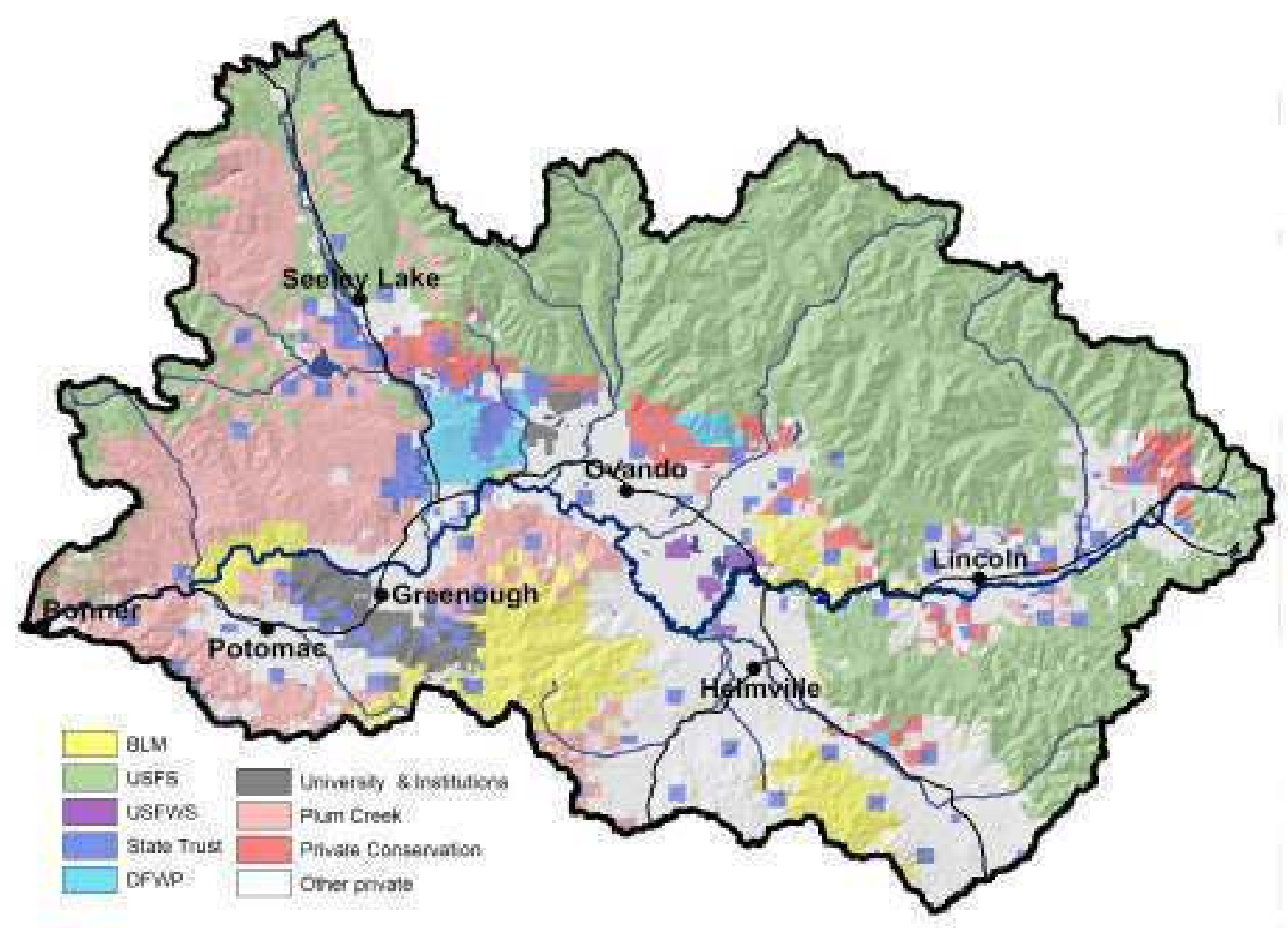

Figure 10. Land ownership map of the Blackfoot River Watershed. 
The Blackfoot River is also one of the most popular, scenic, physically diverse and biologically complex rivers in western Montana. Segments of the river system however support low densities of wild trout due to an array of natural conditions and human impairments. Densities of imperiled native trout (westslope cutthroat trout (WSCT) - Oncorhynchus clarki lewisi and bull trout - Salvelinus confluentus) are particularly low. Natural limiting factors involve drought stressors, areas of high instream sediment loads, low instream productivity, naturally intermittent tributaries, summer warming and periods of severe icing of the lower mainstem river channel. Human impairments apply to mining-related contamination in the upper Blackfoot Basin, the loss of upstream fish passage at the mouth of the Blackfoot River, expansion of exotic organisms including whirling disease at the low elevations of the watershed, and pervasive human-induced perturbations to habitats on $>90 \%$ of tributaries. The sum of natural conditions and human impairments produce an array of trout assemblages that vary regionally within the watershed and longitudinally among river and tributary reaches.

Current land ownership in the Blackfoot watershed is approximately $42 \%$ National Forest, 25\% private ownership, 19\% Plum Creek Timber Company, 7\% State of Montana, and 6\% Bureau of Land Management. In general, public lands and large tracts of Plum Creek Timber Company properties comprise large forested tracts in mountainous areas of the watershed, while private lands occupy the foothills and lower valley areas (Figure 10). Traditional land-use in the basin includes mining, timber harvest, agriculture and recreation activities, all of which have contributed to habitat degradation or fish population declines. Excluding the backcounty and the upper Blackfoot mining area, 158 inventoried streams or river reaches, 145 have been altered, degraded or otherwise identified as fisheries-impaired (Pierce et al. 2005, Appendix F). The majority of habitat degradation occurs on the valley floor and foothills of the Blackfoot watershed and largely on private agricultural ranchlands. However, problems also extend to commercial timber areas, mining districts, and state and federal public lands.

Distribution patterns of most salmonids generally conform to the physical geography of the landscape, with species richness increasing longitudinally in the downstream direction (Figure 11). Species assemblages and densities of fish can also vary greatly at the lower elevations of the watershed. Native species of the Blackfoot Watershed are bull trout (Salvelinus confluentus), westslope cutthroat trout (Oncorhynchus clarki lewisi), mountain whitefish (Prosopium williamsoni), pigmy whitefish (Prosopium coulteri), longnose sucker (Catostomus catostomus), largescale sucker (Catostomus macrocheilus), northern pikeminnow (Ptychocheilus oregonensis), peamouth (Mylocheilus caurinus), redside shiner (Richardsonius balteatus), longnose dace (Rhinichthys cataractae) slimy sculpin (Cottus cognatus) and mottled sculpin (Cottus bairdi). Non-native species of the Blackfoot Watershed include rainbow trout (Oncorhynchus mykiss), kokanee (O. nerka), Yellowstone cutthroat trout (O. clarki bouvieri), brown trout (Salmo trutta), brook trout (Salvelinus fontinalis), artic grayling (Thymallus arcticus), white sucker (Catostomus commersoni), fathead minnow (Pimephales pomelas), northern pike (Esox lucius), brook stickleback (Culaea inconstans), Pumpkinseed (Lepomis gibbosus), largemouth bass (Micropterus salmoides) and yellow perch (Perca flavescens). 

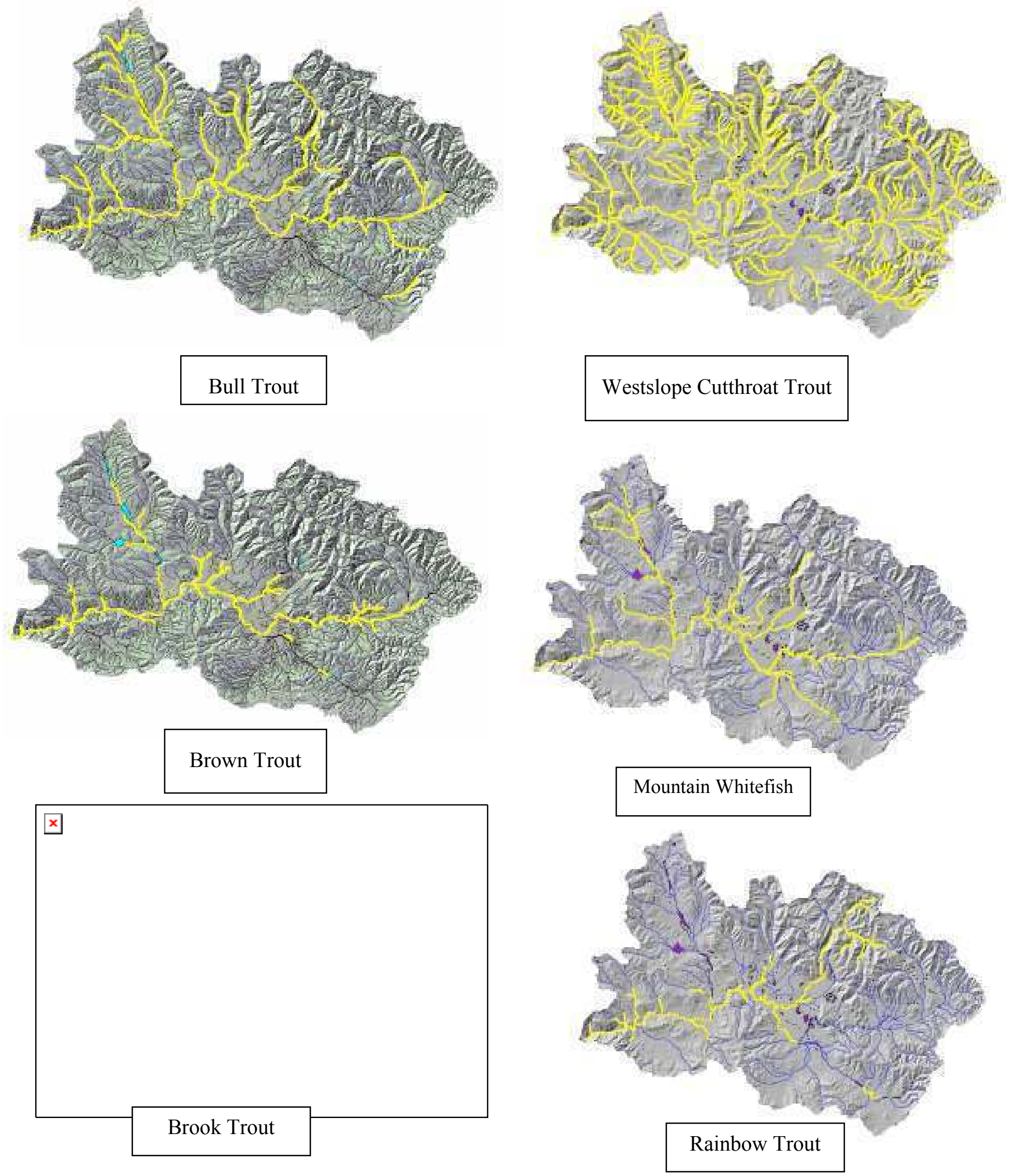

Figure 11. Generalized distribution of six salmonids within the Blackfoot Basin. 
Most salmonids (WSCT, bull trout, rainbow trout and brown trout) in the main stem river system exhibit fluvial life-history characteristics, whereas tributaries support both migratory and resident populations. Native fishes within the Clearwater basin also exhibit adfluvial life-histories. WSCT has a basin-wide distribution and is the most abundant species in the upper reaches of the tributary system. Bull trout distribution extends from the main stem Blackfoot River to headwaters of larger tributaries north of the Blackfoot River main stem, including the Clearwater River Basin. Rainbow trout distribution is limited to the Blackfoot River downstream of Nevada Creek and lower reaches of the lower river tributaries, with the exception of Nevada Creek upstream and downstream of Nevada Reservoir. Rainbow trout occupy $\sim 10 \%$ of the perennial streams in the Blackfoot watershed, with river populations reproducing primarily in the lower portions of larger south-flowing tributaries. The exception to this is the upper North Fork within the Scapegoat Wilderness where self-sustaining lake populations have expanded to nearby tributaries. Brown trout inhabit $\sim 15 \%$ of the perennial stream system with a distribution that extends from the Landers Fork down the length of the Blackfoot River and into the lower foothills of the tributary system. Brook trout are widely distributed in tributaries, but rare in the main stem Blackfoot River below the Landers Fork. 


\section{PROCEDURES}

Methods associated with Results Part II, III, IV and VII are identified below; those related to Special Projects are located in Results Part V and VI.

\section{Fish Population Estimators}

Fish were captured using a boat or backpack mounted electrofishing unit. In small streams, we used a battery powered (Smith/Root) backpack mounted DC electrofishing unit. The anode (positive electrode) was a hand-held wand equipped with a 1-foot-diameter hoop; the cathode (negative electrode), a braided steel wire. On the Blackfoot River, we used an aluminum drift boat mounted with a Coffelt Model VVP-15 rectifier and 5,000 watt generator. The hull of the boat serves as the cathode and two fiberglass booms, each with four steel cable droppers, serve as anodes. We used direct current (DC) waveform with output less than 1000 watts, which is an established method to significantly reduce spinal injuries in fish associated with electrofishing (Fredenberg 1992). Juvenile trout including young-of-the year (YOY) were sampled in the tributaries from August to November. Extra effort was used to sample stream edges and around cover to enable comparisons of densities between years and sampling sections. Captured fish were anesthetized with either tricaine methanesulfonate (MS-222) or clove oil, weighed (g) and measured (mm) for total length (TL). For this report, we converted all weights and lengths to standard units.

Fish population surveys relied on mark-and-recapture or multiple-pass depletion density estimators and a simple catch-per-unit-effort (CPUE) statistic for small stream surveys. For the Blackfoot River below Lincoln we used mark-and-recapture density estimator. Using this method, estimates are considered valid if recaptures $\geq 4$ fish. We used depletion estimator on the upper-most mainstem of the Blackfoot River (upstream of Lincoln) and for small stream density estimates. Age classes were based on lengthfrequency analyses.

For all Blackfoot River population surveys using mark-and-recapture, we also estimated biomass and calculated condition factor using Fisheries Analysis Plus software $(\mathrm{FA}+)$. The formulas for these calculations are:

$$
N=\frac{(m+1)(c+1)-1}{r+1}
$$

$$
\text { Biomass Estimate }=N(W t)
$$

$$
C F=\left(W t_{L} / L_{L}\right) 100,000
$$

$N=$ population point estimate

$m=$ the number of marked fish

$c=$ the number of fish captured in the recapture sample

$r=$ the number of marked fish captured in the recapture sample

$C F=$ condition factor

$W t_{L}=$ average weight of length group

$L_{L}=$ average length of length group 
Standard deviations (SD) for the mark-and-recaputure surveys were calculated using the equation:

$$
S D=\operatorname{sqrt}\left\{((m+1)(c+1)(m-r)(c-r)) /\left((r+1)^{2}(r+2)\right)\right\}
$$

The $95 \%$ confidence intervals (CI) were calculated using the equation:

$$
1.96 * S D
$$

For fish population estimates in small streams, we used a standard two-pass depletion estimator and standard equations for calculating variance (Leathe 1983). For this estimator:

Where:

$$
\begin{aligned}
& N=\frac{\left(\underline{n}_{1}\right)^{2}}{n_{1}-n_{2}} \\
& P=\underline{n_{1}-n_{2}} \\
& n_{1}
\end{aligned}
$$

$N=$ point estimate,

$n_{1}=$ the number of fish collected on the first pass

$n_{2}=$ number of fish captured on the second pass

$P=$ probability of capture $(>0.5$ for $n>50$ or $>0.6$ for $n<50$ for valid estimates)

And,

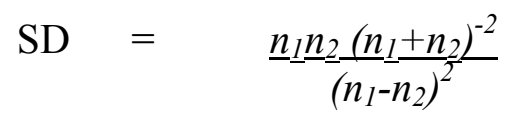

And, the $95 \%$ confidence interval for $\mathrm{N}=1.96(\mathrm{SD})$.

In those few cases where a three-pass estimator was necessary, we used a maximum likelihood estimator using the Lockwood and Schneider. (2000) formula:

$$
N=[n+1 / n-T+1][k n-X-T+1+(k-i) / k n-X+2+(k-i)]_{\mathrm{i}}<1.0
$$

Where $n$ is the smallest integer satisfying Equation. Probability of capture $(p)$ and variance of $N$ are then estimated by:

$$
\frac{p=T}{k N-X}
$$

Variance of $N=$

$$
\frac{N(N-T)}{T^{2}-N(N-T)\left[(k p)^{2} /(1-p)\right]}
$$

Where,

$$
\begin{aligned}
& N=\text { point estimate } \\
& i=\text { pass number, } \\
& k=\text { number of removals (passes), } \\
& C_{i}=\text { number of fish caught in } \mathrm{i}^{\text {th }} \text { sample, } \\
& X=\text { an intermediate statistic used below, } \\
& T=\text { total number of fish caught in all passes. } \\
& \text { Standard error of } N=\text { Square root of variance of } N .
\end{aligned}
$$


95\% Confidence intervals (CI) were calculated using $N+2$ (Standard error)

For initial small stream population assessments, we commonly use a single pass catch-per-unit effort (CPUE) method as a simple index of relative abundance (Appendix A). From monitoring sections with both CPUE and depletion estimates, we also recently developed linear regressions to help predict densities from CPUE (Pierce et al 2004). These regressions confirm correlations between CPUE and density estimates for fish $<4.0$ " $\left(\mathrm{y}=1.7236 \mathrm{x}-0.1513 ; \mathrm{R}^{2}=0.86 ; \mathrm{P}=<0.001\right)$ and for fish $>4.0$ " $(\mathrm{y}=1.3162 \mathrm{x}+0.5495$; $\mathrm{R}^{2}=0.86 ; \mathrm{P}=<0.001$ ).

Although these regressions demonstrate CPUE to be a simple predictor of population density, estimates derived from these equations do not have a confidence interval like the actual (depletion) population density estimate, and should be used with caution. For this report, we use either CPUE or actual depletion estimates for tributary assessments. CPUE refers to the number of fish collected in a single electrofishing pass and is adjusted per 100' of stream (i.e. CPUE of 8 means 8 fish captured per 100' of sampled stream). Actual population estimates are referred to as density/100'. CPUE catch statistics are located in Appendix A. Depletion estimates are located in Appendix B. Mark-and-recapture, biomass and condition factors for the Blackfoot River are located in Appendix C.

\section{Stream Temperatures}

Water temperatures $\left({ }^{\circ} \mathrm{F}\right)$ were recorded at either 48 or 72 -minute intervals using Hobo temperature or tidbit data loggers. All raw data plot for each station and monthly summary statistics are located in Appendix H. For this report we also standardized many temperatures summaries using July (the identified period of peak warming) data and display median, quartile and minimum and maximum temperatures values consistent with other (TMDL) temperature summaries within the Blackfoot River Basin.

Objectives of the temperature data collections are many, and they include: 1) continue long-term data collections at established monitoring sites; 2) profile temperatures over the length of the river; 3 ) identify and monitor thermal properties of tributaries entering the river; 4) identify thermal regimes favorable and unfavorable for trout; 5) monitor temperature triggers used in the Blackfoot Emergency Drought Plan; 6) monitor stream restoration projects; and 7) establish winter baseline and influence of upwelling in bull trout spawning area; 8) assess relationships of water temperature to movements of rainbow trout; and 9) compile data for future studies.

\section{Stream Habitat Surveys}

Basic habitat surveys methods for small stream focus on precision, repeatability and efficiency. We sampled a minimum of every third habitat unit and began in a randomly selected downstream habitat unit and proceeded upstream. When habitats were sub-sampled ( $50 \%, 33 \%$ or $25 \%$ intensity), we began at a selected pool and measured: 1$)$ maximum pool depth and the downstream riffle crest depth to calculate the residual depth, 2) wetted width and bank-full width at the maximum pool depth and at the riffle crest, and 3) total pool length. Pool frequency was then calculated by measuring the survey distances using either 1:24,000 scale maps or aerial photos. A total census of large wood ( $>4$ " DBH and $>6$ ') was performed for all habitat units throughout the entire 
length of the survey on all streams. Wohlman pebble counts were conducted at a minimum of one representative riffle. Stream discharge was measured using a MarshMcBirney flow meter at the start location. We also noted overhead canopy and understory vegetation, stream bank stability, stream degradation and Rosgen channel-type.

\section{Whirling Disease Sentinel Cage Studies}

Whirling disease surveys involving sentinel fish exposures were undertaken throughout the Blackfoot Watershed in 2006 and 2007. Sentinel cage studies are controlled experiments used to detect levels of whirling disease. Cages consist of an $18 \mathrm{x}$ 24 " cylindrical screened container placed into a stream site, which allows stream water to flow through the cage. Each cage contained 50 uninfected rainbow trout or WSCT (35$60 \mathrm{~mm}$ ) supplied by a state fish hatchery. Timing of field exposure was based on anticipated mean daily temperatures in the 50's (F), which correlates with peak triactinomyxon (TAM) production, and corresponds to peak infection rates in fish (Vincent 2000), except in spring creeks (Kleinschmidt and Nevada Spring Creek) where recent research indicated peak infection occurred in late winter and early Spring (Anderson 2004). The exposure period for each live cage was standardized at 10 days. At the end of the 10-day exposure period, the trout were transferred to Pony, MT, where they were held for an additional 80 days at a constant $50^{\circ} \mathrm{F}$ temperature to insure the WD infection if present would reach its maximum intensity (Vincent 2000). At the end of the holding period, all surviving fish were sacrificed and sent to the Washington State University Animal Disease Diagnostic Laboratory at Pullman, WA. At the lab, the heads were histologically examined using the MacConnell-Baldwin histological grading scale, which ranks infection intensity from 0 (absent) to 5 (severe) (Baldwin et al. 2000). The results of this histological rating were presented as mean grade infection. Mean grade infections above 2.7 are likely to result in population level declines (Vincent 2000). Each sentinel cage also had an accompanying thermograph to establish mean daily water temperatures during the exposure period.

\section{WSCT Genetic Investigations}

In 2006 and 2007, we tested Oncorhynchus genetic composition in WSCT habitat throughout the backcountry and Clearwater basin (Appendix J). Samples consisted of fin-clips taken from a minimum 25 individual fish when possible, unless hybridization was identified phynotypically in which case we relied on a small sample to confirm observations. Samples collected were immediately preserved in $95 \%$ ethyl alcohol at stream-side and taken to the University of Montana, Conservation Genetics Laboratory for analysis, where one of two methods of genetic analysis was used. The Paired Interspersed Nuclear DNA Element-PCR (PINE-PCR) method is used in 2006 to determine each fish's genetic characteristics at 21 regions of nuclear DNA. In 2007, a more recent methodology - the "indel" technique-was also employed (Ostberg and Rodriguez 2004: Appendix J). Both methods distinguish WSCT, from rainbow trout and Yellowstone cutthroat trout and can be used to determine whether a sample came from a suspected genetically pure population of one of these fishes or one in which hybridization between two or all three of them has occurred. With a sample size of 25 fish, the PINESPCR method has a $95 \%$ chance of identifying as little as $1 \%$ introgression; whereas, the newer indel method has a $99 \%$ chance of detecting as little as $1 \%$ introgression with the 
25 fish sample.

\section{Working with Private Landowners}

Typically, each tributary restoration project involves multiple landowners, professional disciplines, funding sources, and involvement of the watershed groups. Restoration has focused on addressing obvious impacts to fish populations such as migration barriers, stream de-watering, fish losses to irrigation canals, and degraded riparian areas. All projects are cooperative endeavors between private landowners and the restoration team, and occur throughout the drainage. Projects are facilitated at the local level by agency resource specialists in cooperation with two watershed groups (BBCTU and BC) or local government groups such as the North Powell Conservation District (NPCD) or state and federal agencies such as the Montana Fish, Wildlife and Parks (FWP) or U.S. Fish and Wildlife Service, Partners for Fish and Wildlife (USFWS). The non-profit (501(c)3 status of watershed groups provide a mechanism for generating tax-deductible private funds.

FWP biologists identify priorities by performing fisheries studies, communicating biological findings, review proposed fisheries projects, provide funding support and monitor fisheries on completed projects. Federal (USFWS, USFS and NRCS) biologists and other agency specialists (BOR, DNRC) help develop and fund projects usually in conjunction with watershed groups (BBCTU) and landowners and FWP. Agency staff and project leaders generally enlist help from interagency personnel or consultants including range conservationists, hydrologists, engineers, and water right specialists as necessary. Watershed groups (NPG) help with fundraising, administration of budgets, bid solicitation, apply for permits, oversee consultants and contractors, assist with landowner contacts, coordinate volunteers, help resolve local conflicts and address other social issues.

Project funding comes from many sources including landowner contributions, private donations, foundation grants, state and federal agencies. Project managers from the agencies and watershed groups jointly undertake fundraising. BBCTU generally obtains project permits on behalf of cooperating landowners. Project bids (consulting and construction) conform to State and Federal procurement policies. These policies included the development of a Blackfoot watershed qualified vendors lists (QVL) derived through a competitive process managed primarily through BBCTU. A minimal project cost triggers use of the QVL. The watershed groups solicit bids from the QVL for both consulting and contractor services. Bid-contracts are signed between the watershed group and the selected vendor upon bid acceptance.

Depending on the specific project, landowners are responsible for certain costs, construction and project maintenance. Addressing the source of stream degradation usually requires developing riparian/upland management options sensitive to the requirements of fish and other riparian-dependent species. Written agreements (10-30 year period) with landowners to maintain projects are arranged with cooperators on each project. These agreements vary by funding source and may include agencies, the NPCD and/or the Fish and Habitat Committee of BBCTU. Landowner awareness of the habitat requirements of fish and wildlife, and their full participation and commitment to project goals and objectives are crucial to the long-term success of the restoration initiative. We encourage landowners to participate fully in all phases of restoration from fish population 
data collection and problem identification to project development and monitoring of completed projects. Although many restoration projects have been completed in the Blackfoot River watershed, this effort is still educational at a broad level and is far from complete.

Natural Channel Design and Fish Habitat Restoration (from Brown, Decker, Pierce and Brant 2001)

Habitat restoration relies on both passive and active methods. Passive methods rely on riparian management changes by addressing the source of fisheries impairments, which generally require incorporating grazing BMPs in degraded riparian areas, shrub plantings, enhancing instream flows and screening irrigation ditches. Active restoration involves entering the channel with machinery and reconstructing severely damaged channels or restoring habitat features (e.g. wood) if necessary for fisheries improvement.

For channel reconstruction and habitat restoration in the Blackfoot River drainage, we rely on a natural channel design philosophy (NCDP). This philosophy requires a multidisciplinary approach to stream restoration along with an understanding of historical riparian land use. Project complexity and risk define a specific combination of design methods. Methods involve a geomorphic approach that fits the proper stream to the proper stream valley. The Rosgen stream classification provides the basis of this approach (Rosgen 1994; Rosgen 1996). NCDP quantifies channel shape, pattern, and gradient (Rosgen 1996). Riparian health, instream habitat, and fish population surveys, along with measurements of discharge, sediment, and bed and bank stability, permit the assessment and evaluation of existing and potential channel conditions as well as biological attributes of the project. The NCDP aims to restore natural channel stability, or dynamic equilibrium, and habitat to impaired streams. Streams in dynamic equilibrium are generally more biologically productive, and provide higher quality and more complex habitat than altered or unstable streams. Geomorphic indicators (bankfull channel), prediction analysis (reference reaches and dimensionless ratios), and method validation (regional curves) define naturally functioning channels, and provide the basis for natural channel design.

At the reach level, stream geomorphology is quantified in both project and reference reaches. The reference reach should be naturally functioning, provide optimal fish habitat, and serve as a model for the design channel. "Bankfull" indicators and other geomorphic variables are measured in both reaches. Bankfull elevation, a geomorphic indicator signifying the point of incipient flooding, coincides with the stage above which the stream accesses its floodplain or flood-prone area (Rosgen 1996). By doing the work that creates the average morphologic channel characteristics, bankfull discharge forms and maintains the channel over time (Dunne and Leopold 1978). Channel pattern (plan view characteristics), dimension (channel size and shape), and profile (longitudinal elevations and gradients) are measured. Appropriate designs may include creating aquatic habitat, prescribing a revegetation plan, and constructing an appropriate floodplain.

Synthesizing reference reach field data and incorporating regional stream information helps identify design channel parameters. Regional data and dimensionless ratios help predict channel attributes relative to the watershed area and bankfull characteristics. Watershed discharge, sediment entrainment, and bankfull channel cross 
sections are then hydraulically modeled to validate bankfull discharge. Design dimensions are developed relative to bankfull discharge. Comparing design dimensions to dimensionless ratios and a reference reach database further validates the design.

The final restoration design seeks to mimic a stream in dynamic equilibrium with its watershed, and to provide a diverse and complex channel capable of conveying flows, transporting sediment, and integrating essential habitat features related to fish population recovery goals. Vegetation colonization through mature shrub and sod mat transplanting, as well as other revegetation efforts; along with woody materials and rock provide immediate fish habitat and temporary bank stability. These structures allow for shrub colonization which, when established, provides long-term channel stability and habitat complexity. Proper land management is essential to the success of these methodologies. Most restoration projects necessarily incorporate compatible grazing strategies and other land management changes. 


\section{RESULTS PART I: BLACKFOOT RIVER ENVIRONMENT}

\section{Blackfoot River Discharge: Provisional USGS data at the Bonner gauging station \#12340000}

During 2006 and 2007, the Blackfoot River watershed was subject to a $7^{\text {th }}$ and $8^{\text {th }}$ year of consecutive drought. During this time, mean basin discharge was 1,480 cfs (in 2006) and 1,254 cfs (in 2007), compared to the long-term mean of $1,563 \mathrm{cfs}$ (Figure 12, Table 1). Since the advent of current drought (in 2000), annual flows in the Blackfoot River at the USGS Bonner gauging station averaged $\quad 83 \%$ (range, 60 - 95\%) of normal; minimum monthly flows ranged from $47-80 \%$ of normal; and late summer low flows

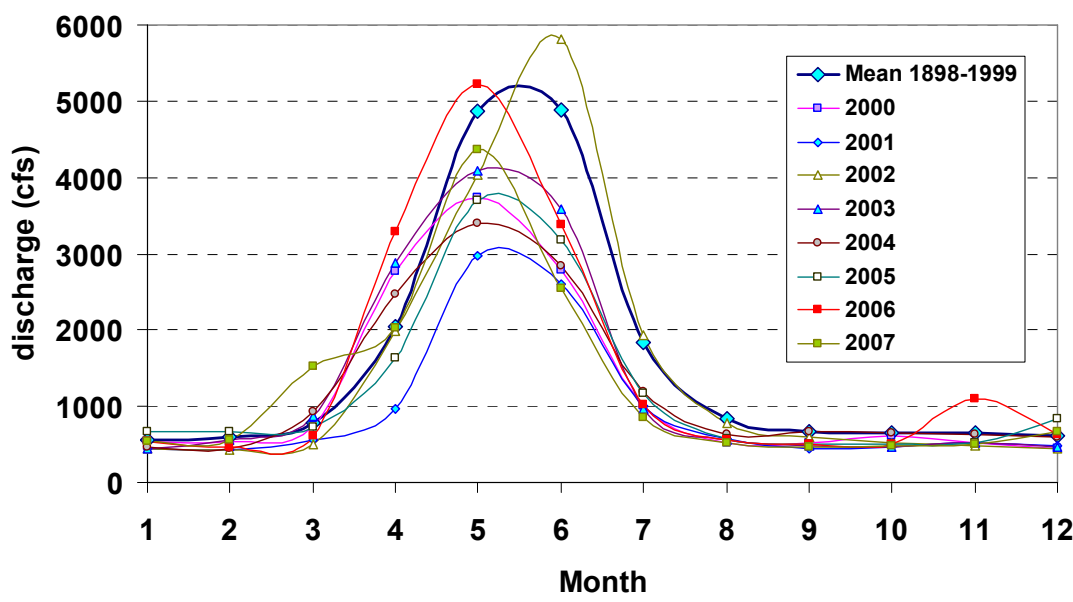
(July and August) averaged 62-71\% of normal. In 2007 mid-summer flows (July and August) fell to 47 and $61 \%$ of normal (Table 1). Through this 8-year drought, the flow regime of the Blackfoot Basin has expressed a pattern of early runoff, a consistent lowering of "flushing" flows and below normal base-flows during the late summer.

Based on wetted-riffle surveys, FWP identified a "minimum instream flow" value

\begin{tabular}{|c|c|c|c|c|c|c|c|c|c|c|c|c|}
\hline & Jan & Feb & Mar & Apr & May & June & July & Aug & Sept & Oct & Nov & Dec \\
\hline Mean 1898-1999 & 554 & 599 & 781 & 2052 & 4867 & 4877 & 1844 & 831 & 670 & 653 & 649 & 606 \\
\hline 2000 & 542 & 532 & 744 & 2770 & 3741 & 2779 & 1004 & 528 & 521 & 608 & 517 & 450 \\
\hline 2001 & 445 & 421 & 560 & 959 & 2980 & 2595 & 996 & 584 & 441 & 472 & 520 & 477 \\
\hline 2002 & 455 & 429 & 503 & 1980 & 4036 & 5814 & 1939 & 788 & 600 & 517 & 487 & 439 \\
\hline 2003 & 441 & 553 & 881 & 2885 & 4081 & 3579 & 970 & 554 & 491 & 467 & 520 & 471 \\
\hline 2004 & 458 & 438 & 932 & 2471 & 3402 & 2838 & 1181 & 635 & 670 & 650 & 625 & 598 \\
\hline 2005 & 670 & 668 & 726 & 1626 & 3690 & 3178 & 1167 & 579 & 504 & 504 & 518 & 841 \\
\hline 2006 & 530 & 460 & 604 & 3279 & 5217 & 3379 & 1019 & 558 & 497 & 497 & 1097 & 633 \\
\hline 2007 & 542 & 559 & 1531 & 2025 & 4365 & 2545 & 861 & 511 & 461 & 483 & 503 & 672 \\
\hline Mean 2000-07 & 510 & 508 & 810 & 2249 & 3939 & 3338 & 1142 & 592 & 523 & 524 & 598 & 573 \\
\hline $\begin{array}{c}\% \text { of }(1898-1999) \\
\text { normal }\end{array}$ & 92 & 85 & 104 & 109 & 81 & 68 & 62 & 71 & 78 & 80 & 92 & 95 \\
\hline
\end{tabular}

Table 1. Provisional mean monthly flow statistics for the Blackfoot River at the USGS Bonner gauge: the historical (1898-1999 mean and monthly flow statistics from 2000-2007). 
for "blue-ribbon" lower Blackfoot River near Bonner, MT at 700 cfs (FWP historical files). Below $700 \mathrm{cfs}$, water recedes from riffles of the lower River at an accelerated rate (Figure 13), and this process reduces productivity and the ability of the river to sustain productive fisheries. Flow records identify the Blackfoot River fell below $700 \mathrm{cfs}$ an average of 221 days $(61 \%)($ range $=189-259$ or $52-71 \%$ ) per year from 2000 through 2007 , compared to a historic (1898-2007) mean of 192 days per year.

\section{Wetted Perimeter (FT)}

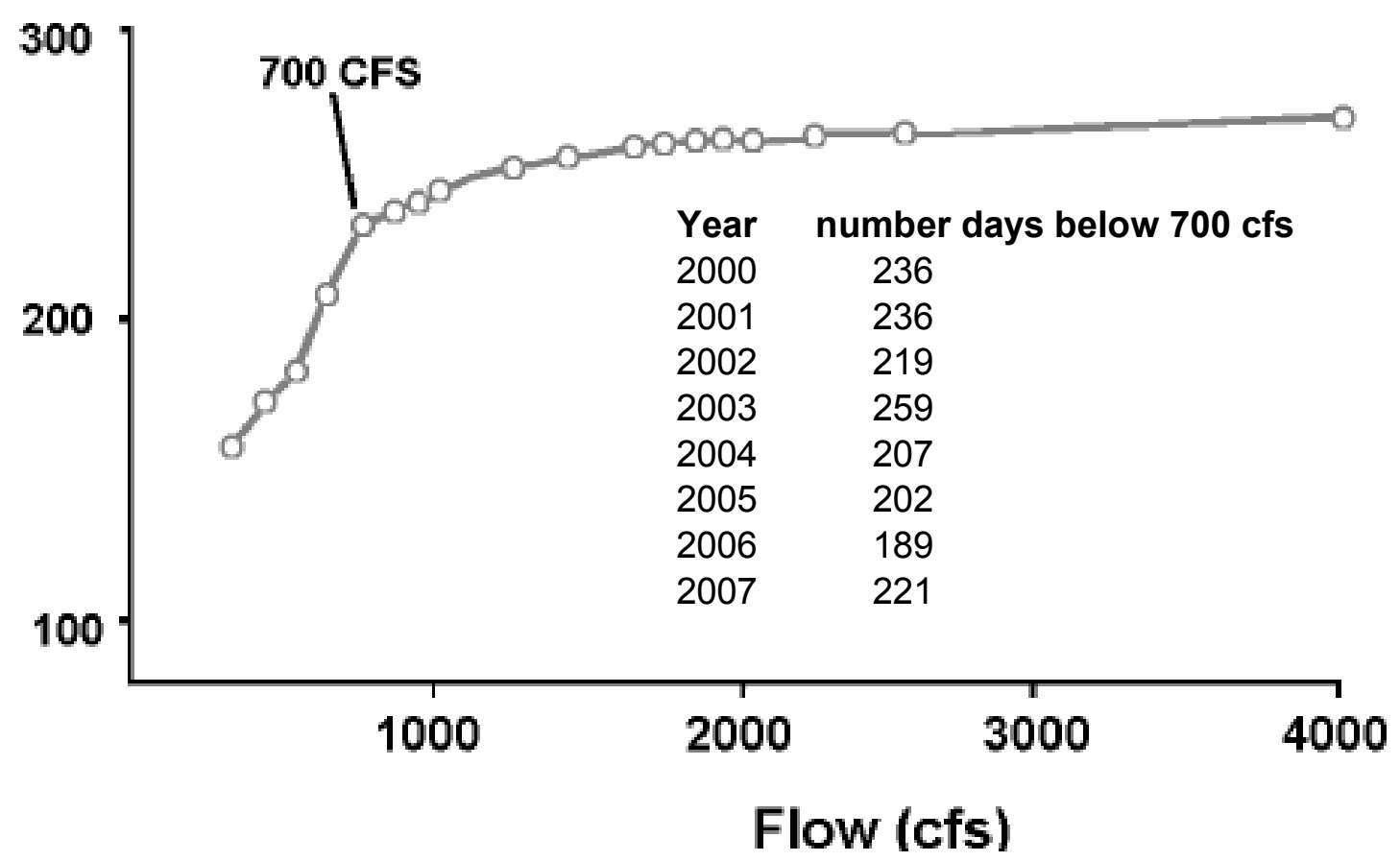

Figure 13. Minimum instream value of $700 \mathrm{cfs}$ for the Blackfoot River based on wetted-perimeter riffle surveys (FWP historical files). The table shows the number of days Blackfoot River flows at the Bonner guage fell below minimum (700 cfs) instream flows from 2000 through 2007.

\section{Blackfoot River and tributary temperatures}

Temperatures studies during 2006 and 2007 involved: 1) baseline and long-term data collections at established sites throughout the Blackfoot watershed; 2) assessments of restoration projects; 3) identifying thermal regimes (natural and anthropogenic) favorable and unfavorable for trout; 4) monitoring temperature triggers of the Blackfoot Emergency Drought Plan; 5) relating rainbow trout migrations and spawning to thermal properties of the river and tributary system; and 6) predictions of whirling disease. Summaries and integration of water temperature data are found throughout this report. All raw and summary data for all monitoring sites are also located in Appendix $\mathrm{H}$.

In sum, we collected 60 water temperature samples, including 48 individual samples at 25 tributaries sites (Appendix H, Results Part III), along with 12 samples at 6 
sites in the Blackfoot River during 2006 and 2007 (Figure 14). These data sets show a wide range of seasonal, spatial and inter-annual summer temperatures for waters of the Blackfoot River. This data includes temperatures commonly $>70{ }^{\circ} \mathrm{F}$, which we define (in this report) above the optimal range of most salmonids and temperatures $>65{ }^{\circ} \mathrm{F}$, which are considered harmful to bull trout.

A summary of all July water temperature data for five long-term monitoring sites of the Blackfoot River is shown on Figure 15. These plots identify a recent warming trend, as well as reach-related temperature differences such as warming of the Blackfoot River between the Cutoff and Raymond Bridge sections, as well as cooling influence of the North Fork (mile 54.1) between the Raymond Bridge and Scotty Brown sections of the Blackfoot River.

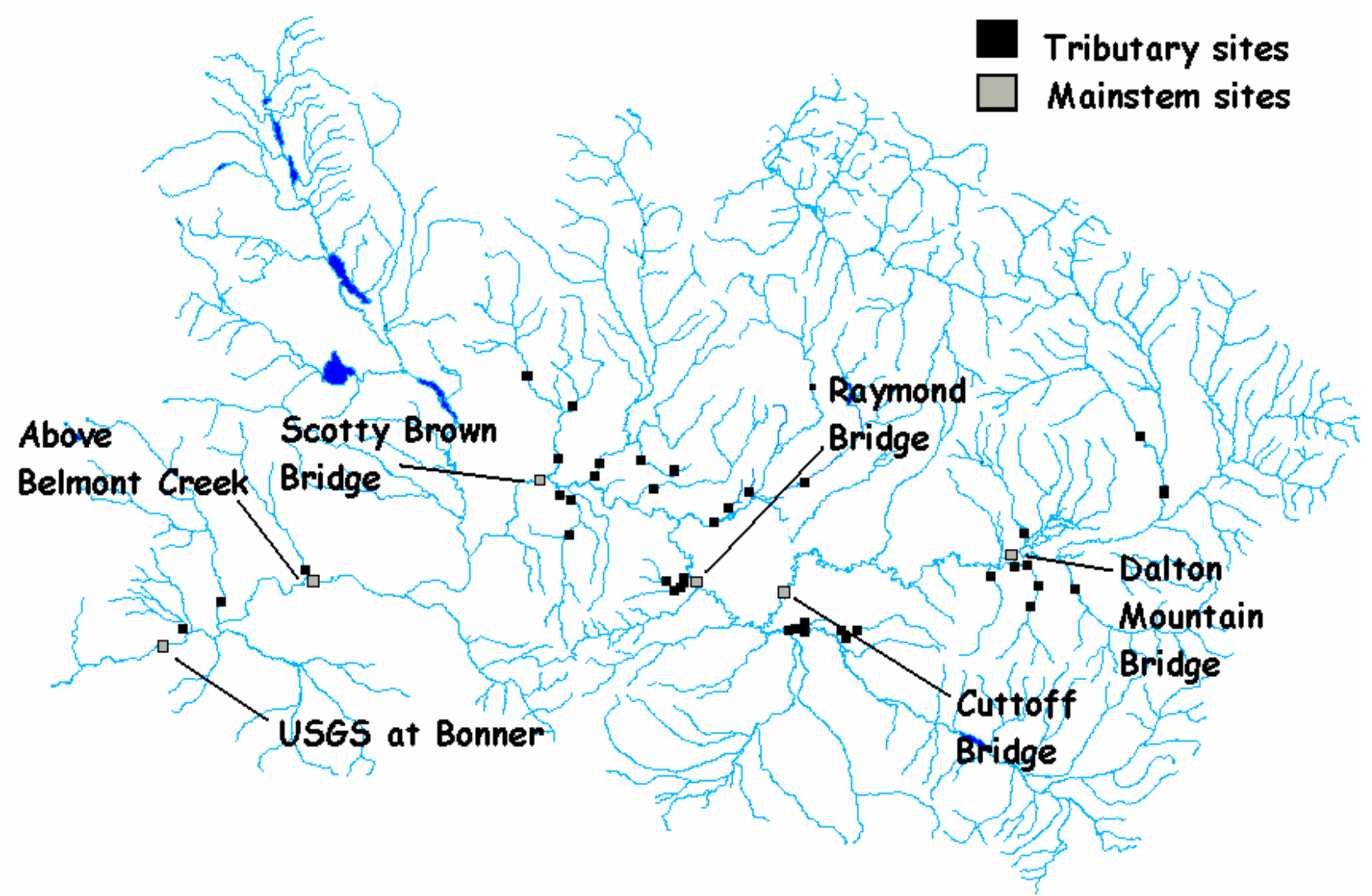

Figure 14. Temperature data collection sites in the Blackfoot Watershed for 2006 and 2007. Names identify Blackfoot River monitoring sites and relate to July summary graphs in Figure 13. 
Blackfoot River above Belmont Creek

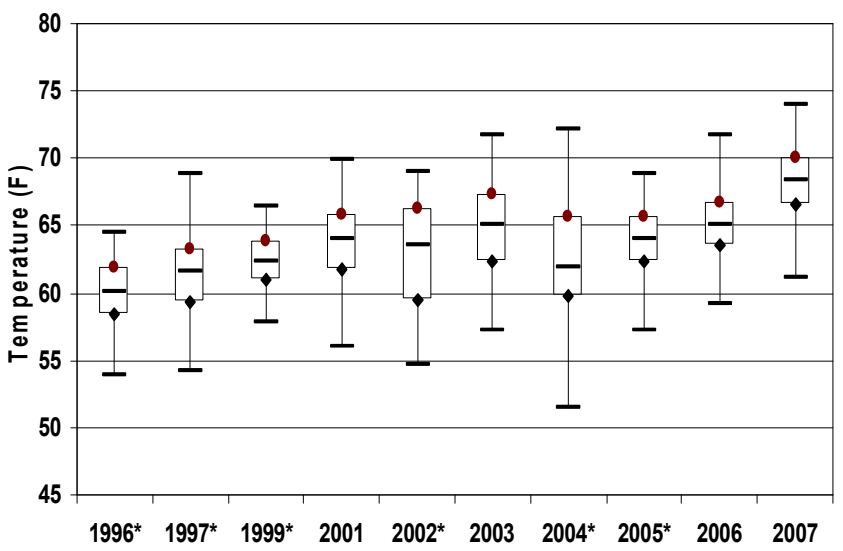

Blackfoot River at Scotty Brown Bridge

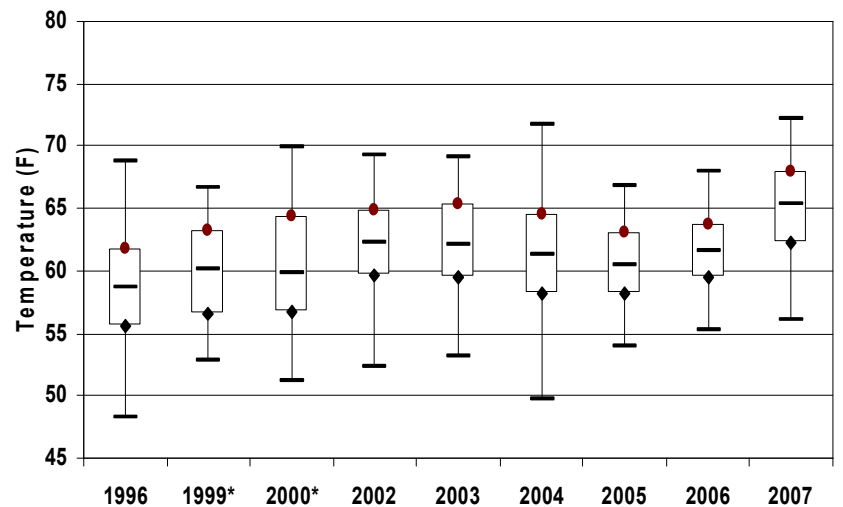

Blackfoot River at USGS Bonner Guage

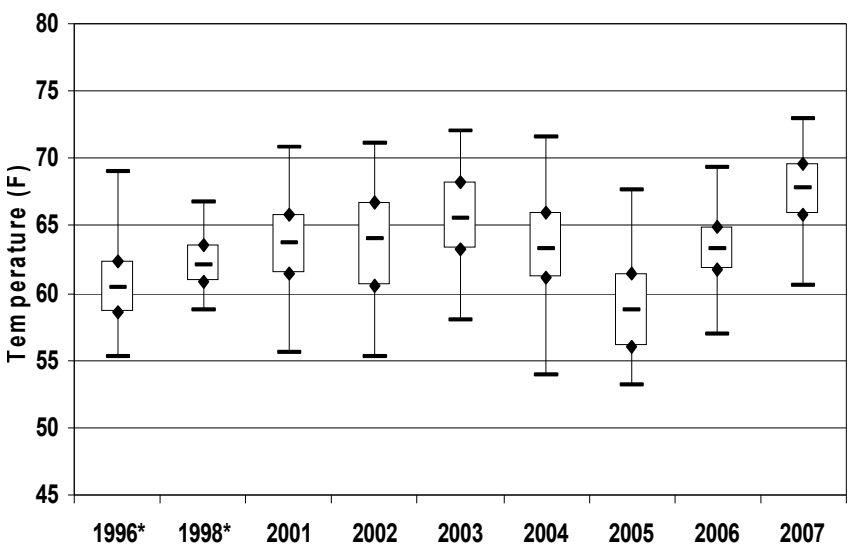

Blackfoot River at Raymond Bridge

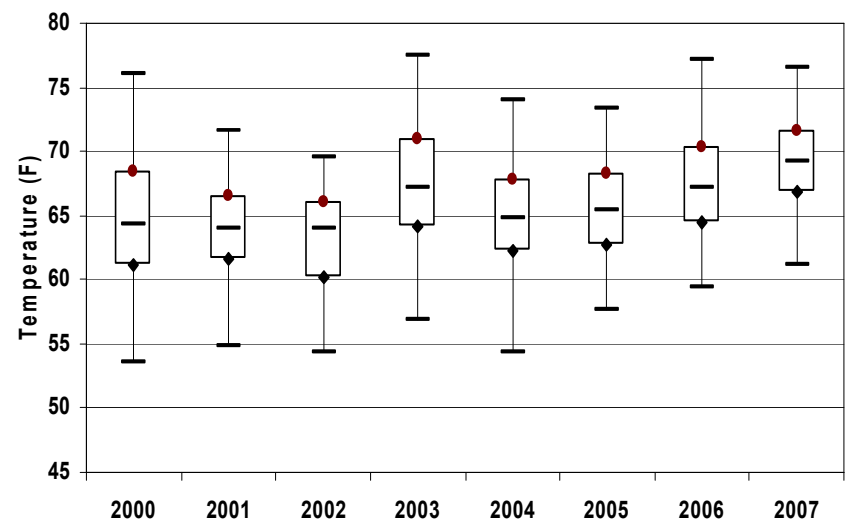

Blackfoot River at the Cutoff Bridge

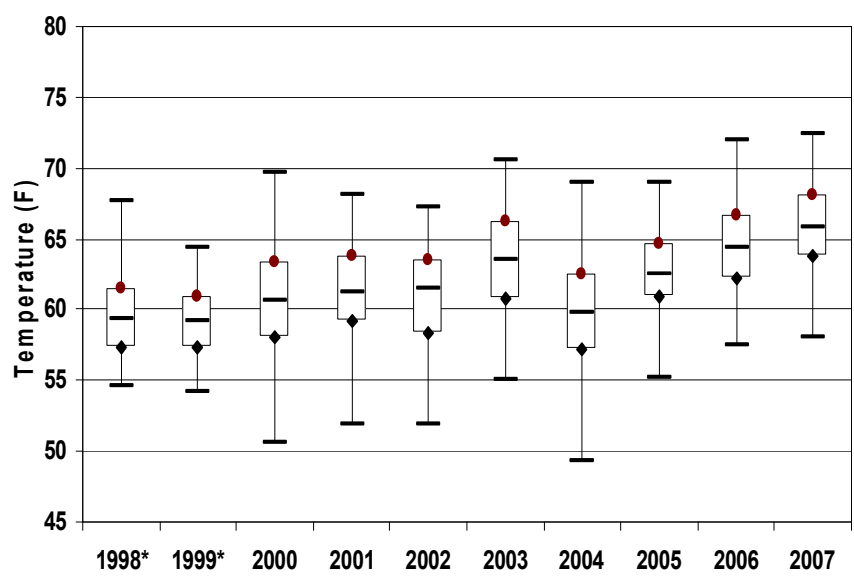

Figure 15. July water temperatures at five long-term monitoring sites in the Blackfoot River (* identify months with incomplete data). 


\section{RESULTS PART II: BLACKFOOT RIVER TROUT POPULATIONS}

In 2006, FWP completed fish population surveys in seven (of eight) previously established monitoring sites on the mainstem of the Blackfoot River (Figure 16). Three lower river sites were surveyed in May and these are: 1) the Johnsrud section (at rivermile mid-point 13.5); 2), Scotty Brown Bridge section (mid-point 43.9), and the Wales Creek section (mid-point 63.0) - a site established in 2002 downstream of Nevada Creek. Then in September of 2006, we resurveyed two established upper river survey sections located between Nevada Creek and the town of Lincoln, MT. These are 1) the Canyon section (mid-point at 95.3) and 2) Pooman/Dalton Section (mid-point 107.2).

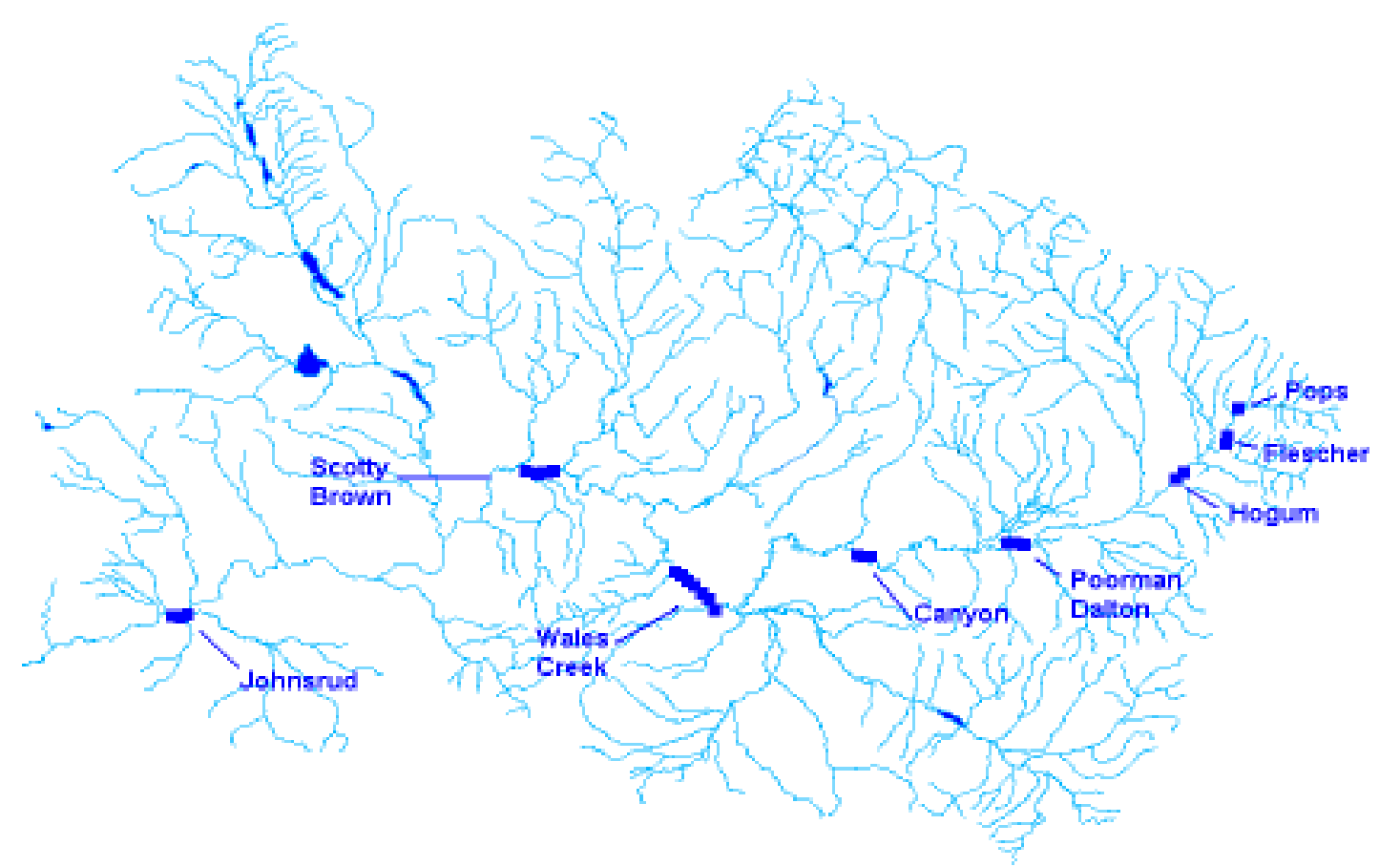

Figure 16. Location map: Eight long-term Blackfoot River fish population survey sites. All but the Pops Place section were resampled in 2006.

During the fall of 2006, we also sampled fish populations (where present) in the upper-most Blackfoot River within and downstream of the Upper Blackfoot Mining Complex. Populations surveys include two new (unnamed) upstream sites within the mining complex, as well as the Hogum (mile 119.6) and Flesher Sections (mile 124.3), both of which were established downstream of the mining complex in 1972 and 1973, respectively. We attempted to access the Pops Place Section (mile 128.5), a survey site established in 1971 and last surveyed in 1999, but we were denied access to the survey site. These upper Blackfoot River surveys were undertaken in anticipation of a miningrelated cleanup in the area of the Mike Horse Mine tailings dam. Depending on the specific survey methods employed, all population estimates and related statistics for all Blackfoot River survey sites are located in Appendices A, B or C. 


\section{Lower Blackfoot River Survey Sections}

Johnsrud section: The 2006 trout species composition ( $\%$ of total catch for fish $>6.0$ ") in the Johnsrud section was $69 \%$ rainbow trout $(n=722), 17 \%$ brown trout $(n=180), 12 \%$ WSCT $(n=129)$ and $2 \%$ bull trout $(n=20)$. The total trout point estimate (fish $>6.0$ ") for the Johnsrud section increased from 130 to $187 \mathrm{fish} / 1000$ ' an increase of $30 \%$ between 2004 and 2006. The total trout biomass estimate for fish $>6.0$ " in the Johnsrud Section in 2006 was $84.9 \mathrm{lbs} / 1000^{\prime}$ compared to $77.6 \mathrm{lbs} / 1000$ ' in 2004.

Densities of native WSCT (> 6.0") increased from 14.0 to 23 fish/1000' (Figure 17). Because of small sample size and a low recapture rate, we were unable to generate a valid bull trout estimate. However, catch statistics suggest lower densities compared to past years. The 2004 point estimate for brown trout (> 6.0") showed an increase from 19 in 2004 to 22 fish/1000' in 2006 (Figure 17). The density estimate for rainbow trout (>6.0") indicates a notable increases from 90/1000' in 2004 to 140/1000' in 2006 (Figure 15). In 2006, we observed no northern pike in the Johnsrud section, compared with one in 2004, two in 2002, six in 2000, two in 1998, one in 1996, and none prior to 1996.

Scotty Brown Bridge section: The 2006 percent trout composition in the Scotty Brown Bridge Section was 31\% rainbow trout $(n=166), 33 \%$ WSCT $(n=176), 29 \%$ brown trout $(n=156)$, and $7 \%$ bull trout $(n=40)$. Total trout densities (fish $>6.0$ ") increased from 50.0 to $62.0 \mathrm{fish} / 1000$ ' between 2004 and 2006. The total trout biomass estimate for fish $>6.0$ " in the Scotty Brown Section in 2006 was $52.2 \mathrm{lbs} / 1000$ ' up slightly from 48.1 in 2004.

Density estimates for rainbow trout (fish $>6.0$ "), shown in Figure 17, identify an increase from 9.0 in 2004 to 23 fish/1000' in 2006. Likewise, brown trout (fish $>6.0$ ") density increased from 10 fish/1000' in 2004 to 16 fish/1000' in 2006 (Figure 17). Estimated bull trout densities (fish $>6.0$ ") increased from 2.0 to 4.0 fish/1000' between 2004 and 2006 (Figure 17). WSCT densities (fish >6.0") were static at 19 in 2006 compared to 18 fish/1000' in 2004 (Figure 17). Despite these modest increases, densities of all species remain below pre-drought (e.g. 2000) population levels (Figure 17).

\section{Middle Blackfoot River Survey Sections}

Wales Creek Section: This section, located between the North Fork Blackfoot River and Nevada Creek suffers from impaired water quality (high levels of fine sediment, summer water temperatures, and nutrient levels) and degraded tributaries, which limits juvenile trout production and recruitment to this reach of the Blackfoot River (Pierce et al. 2001; 2004, 2007).

In May 2006, trout species composition (\% of total catch for fish $>6.0$ ") in the Wales Creek section was $87 \%$ brown trout $(n=117), 7 \%$ rainbow trout $(n=9), 4 \%$ WSCT $(n=5)$ and $2 \%$ bull trout $(n=3)$. We estimated total trout density (fish $>6.0 \%)$ for the Wales Creek section at 11 fish /1000' in 2006 compared to 9.1 in 2004 . Of the total trout estimate, the brown trout (fish $>6.0^{\prime \prime}$ ) point estimate was 8 fish/1000'. Similar to past years (2002 and 2004), we were unable to generate density estimates for rainbow trout, WSCT and bull trout due to the low population densities within the section. The total trout biomass estimate for fish $>6.0$ " in the Wales Creek in 2006 was $11.7 \mathrm{lbs} / 1000$ ' In 2006, we also sub-sampled for mountain whitefish in the Wales Creek section 
Johnsrud Section

Rainbow Trout

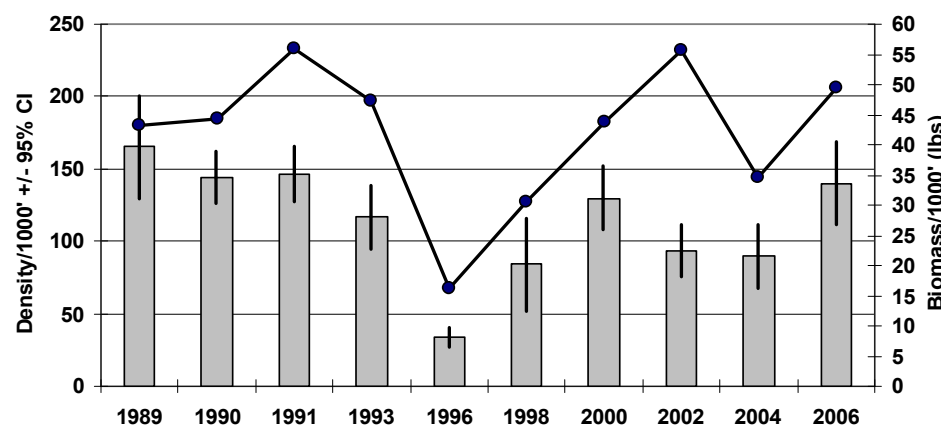

Brown Trout

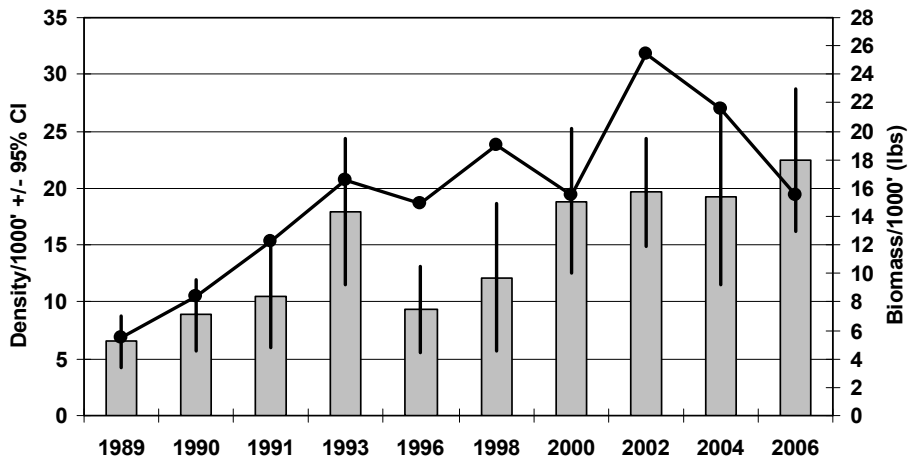

Westslope Cutthroat Trout

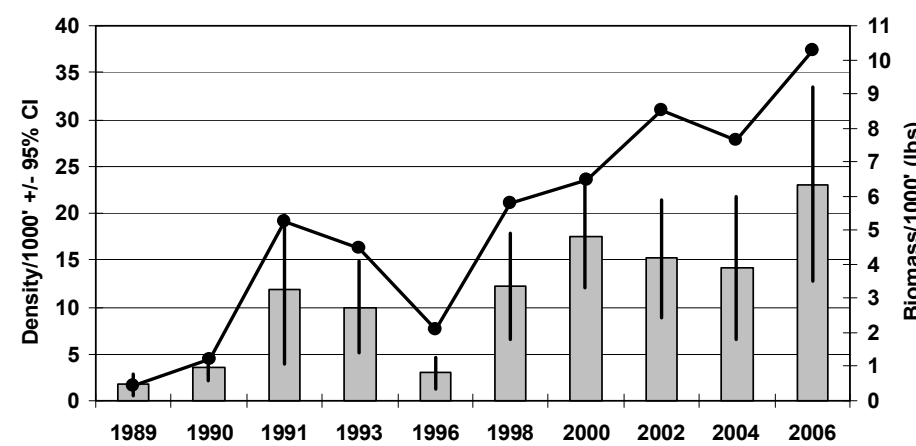

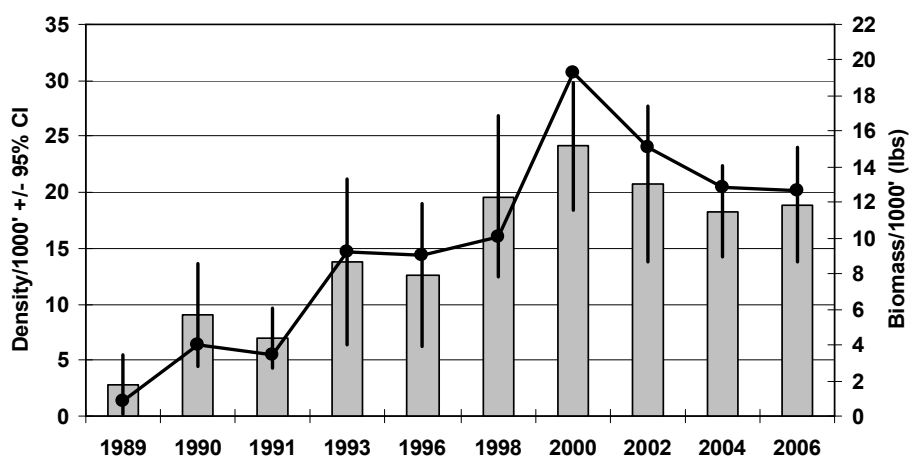

Bull trout

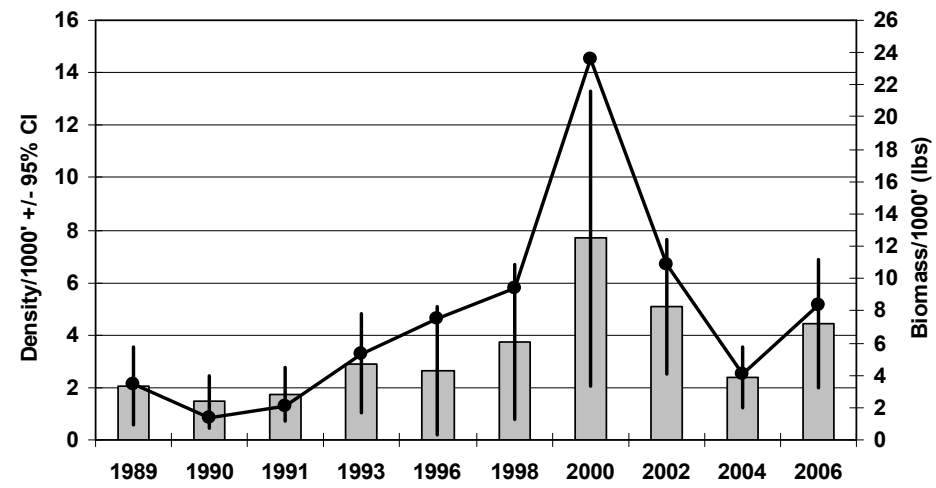

\section{Westslope Cutthroat Trout}
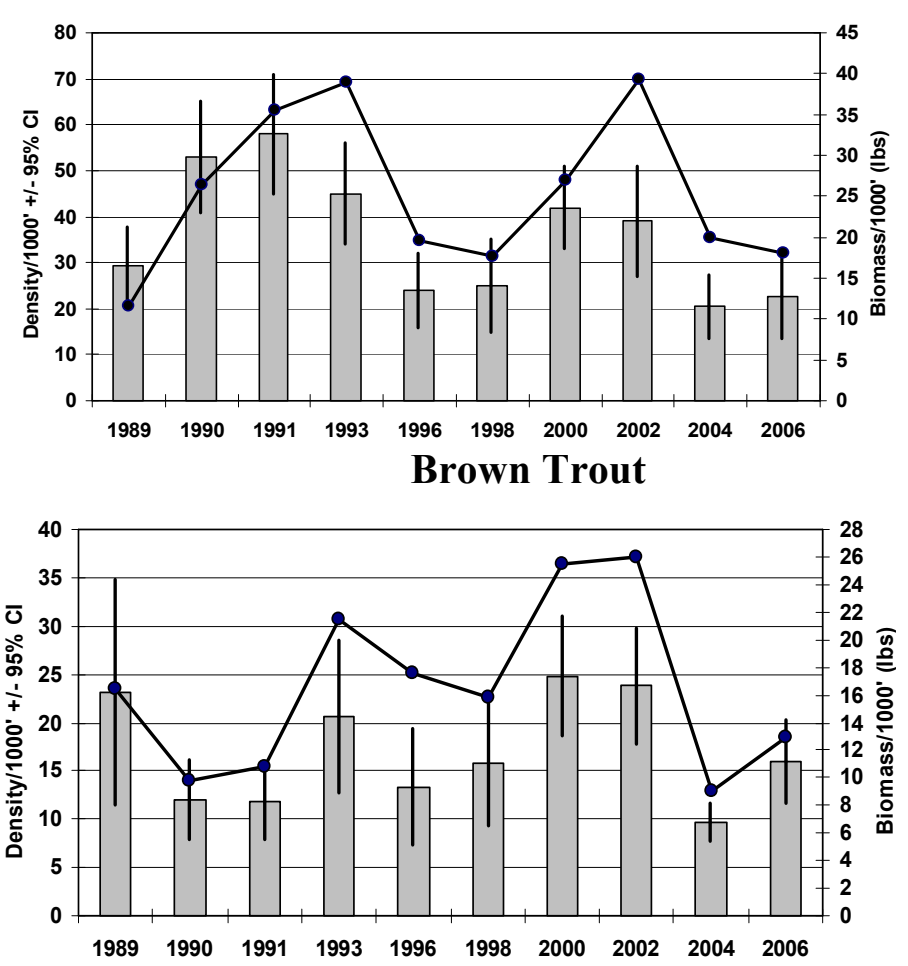
to help identify population status of the species within the Blackfoot River. These results are located in the mountain whitefish status review, Results Part V.

Canyon section: Fish populations in the Canyon section were sampled in 2006, 1999, 1988 and 1971. In 2006, brown trout $(n=31)$ continued to dominate the salmonid community by comprising $80 \%$ of the sample, followed by $20 \%$ WSCT $(n=8)$. Bull trout were present in low numbers in 1999, but absent in the 2006 survey. The total trout estimate (fish $>6.0$ ") in the Canyon Section declined from 52 fish/1000' in 1999 to 15 fish/1000' in 2006 . Similar to previous samples, a reliable estimate of age I brown trout was not attained in 2006. The density estimate of the Age II and older brown trout

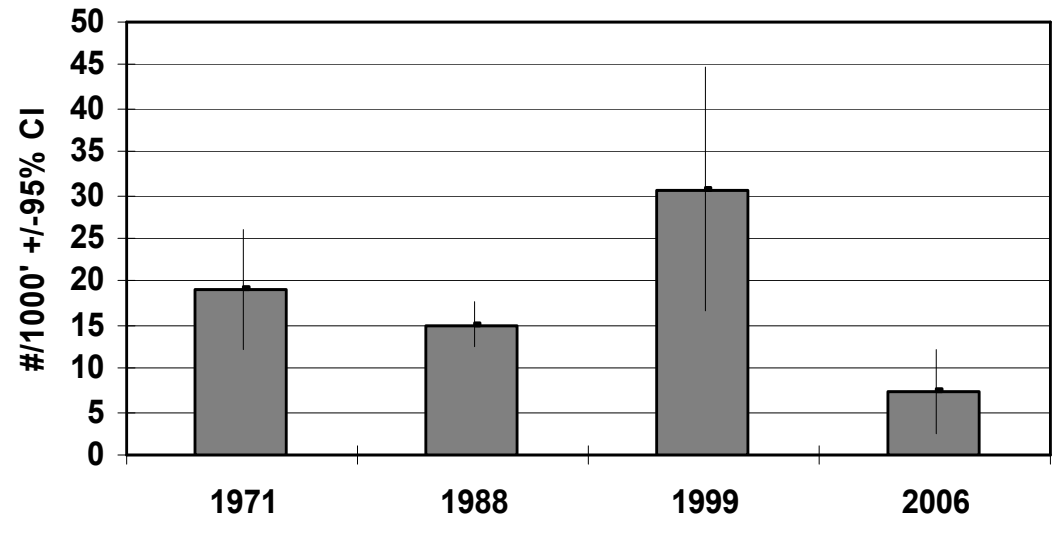

Figure 18. Estimated densities of age- 2 and older brown trout in the Canyon Section of the Blackfoot River, 1971, 1988, 1999 and 2006.

(fish > 8.5") identified large decline from 33 fish in 1999 to 7.2 fish/1000' in 2006 (Figure 18). Similar to the Wales Creek section, we surveyed mountain whitefish in the Canyon section for the first time. The results of that targeted survey are reported in the mountain whitefish status review in Results Part V.

Poorman/Dalton section: Fish populations were sampled in the Pooman/Dalton section (mile mid-point at 107.2) in 2006 for the first time since 1988. In 2006, brown trout $(n=192)$ continued to dominate the salmonid community followed by WSCT $(n=14)$, bull trout $(n=2)$ and brook trout $(n=1)$. The total trout estimate (age 1 and older) increased from 50 to 60

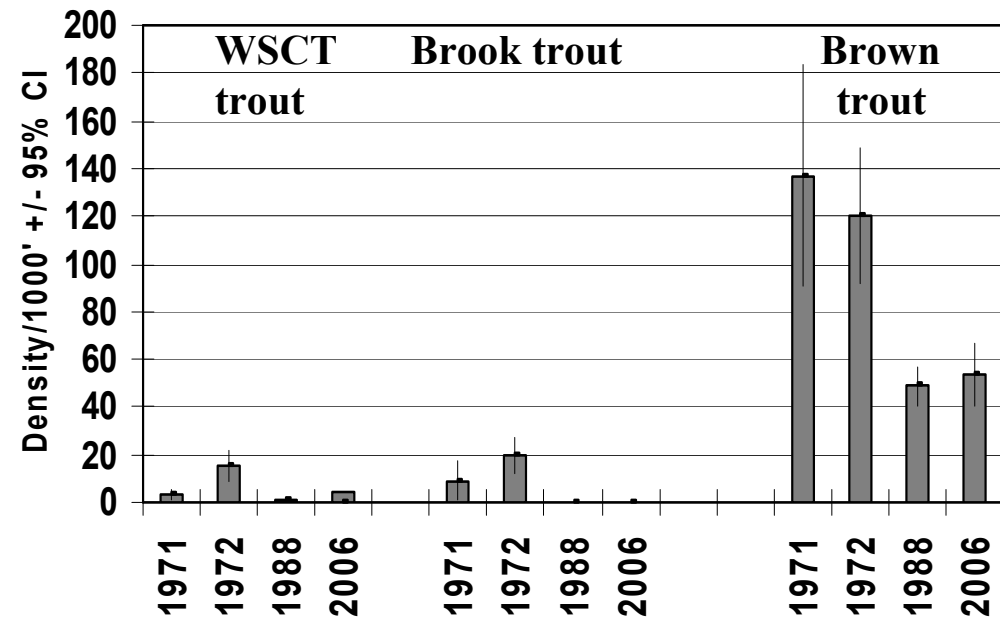

Figure 19. Estimated densities of age 1 and older WSCT (left), brook trout (middle) and brown trout (right) in the Poorman/Dalton section of the Blackfoot River 1971, 1972, 1988 and 2006.

fish/1000' in 2006 (Figure 19). Both 1988 and 2006 samples were taken following periods of protracted drought. 


\section{Upper Blackfoot River Surveys: Upper Blackfoot Mining Complex}

This section summarizes FWP fisheries investigations upstream, within and downstream of the Upper Blackfoot Mining Complex. This summary includes not only the most recent (2006) fisheries investigations, but also the long-term ( $>30$ years) fisheries changes, some of which pre-date the release of toxic mine waste into the headwaters of the upper Blackfoot River (Spence 1975). For a full summary of miningrelated aquatic resource damages in the upper Blackfoot River Basin, the reader is referred to the Stratus (2007) resource damage report to the State of Montana Natural Resource Damage Program, Department of Justice.

\section{Introduction}

Several hard-rock mines are located within Upper Blackfoot Mining Complex (UBMC), located about 15-miles east of Lincoln, of which the Mike Horse Mine is the largest. Beginning in 1898, the Mike Horse Mine produced lead, zinc, and copper, and in 1941 the Mike Horse tailings dam was constructed on lower Beartrap Creek using contaminated mine tailings. About 30-years after that and in anticipation of expanded mining, FWP established a baseline fisheries inventory in the UBMC in 1971-1973 (Spence 1975).

In June 1975 during a heavy "rain on snow" flood event, the Mike Horse tailings dam washed-out and released an estimated $200,000 \mathrm{yd}^{3}$ of contaminated tailings into

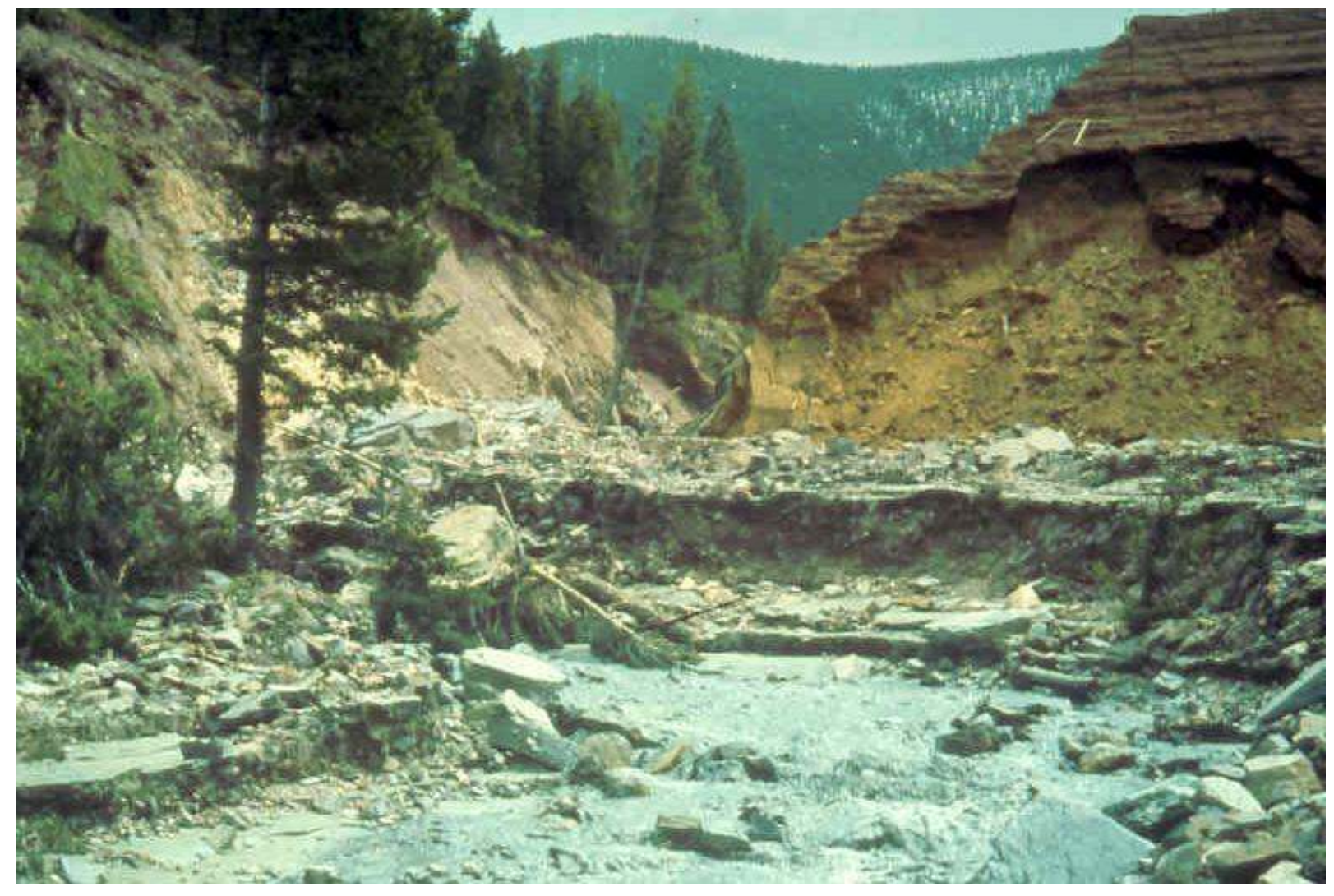

Figure 20. Photo taken immediately downstream of the Mike Horse tailings dam following its collapse in 1975 (photo by Spence 1975). 
Beartrap Creek, the upper Blackfoot River and adjacent floodplains (see photo Figure 20). The breach of the Mike Horse tailings dam and associated mining wastes within the UBMC resulted in 1) the acute and chronic contamination of the upper Blackfoot River (Stratus 2007), 2) the collapse of fisheries (Spence 1975, Peters and Spoon 1989, Pierce et al 2000), and 3) the physical downstream migration of heavy metals and the biological uptake of toxins within the aquatic food web (Moore et al 1991). The upper-river location and toxic nature of existing contaminants continue to pose significant ecological risks to the future of the mainstem Blackfoot River (Stratus 2007). In anticipation of a meaningful cleanup, FWP completed a series of fish population surveys throughout the UBMC in 2006. Our purpose was to identify the spatial and temporal nature of fish population declines, identify the status of nearby populations and provide information to help guide settlement discussions and aid in restoration planning in a manner that helps recover fisheries within the impact area.

\section{Study Area}

The very headwaters of Blackfoot River begin within the UBMC at the junction of Beartrap and Anaconda Creeks (Figure 21). In 2006, FWP fisheries crews surveyed 11 new sites within the immediate and known impact area, and we resurveyed two historical monitoring sites downstream of UBMC that were established prior to the failure Mike Horse tailings dam (Spence 1975, Figure 20).

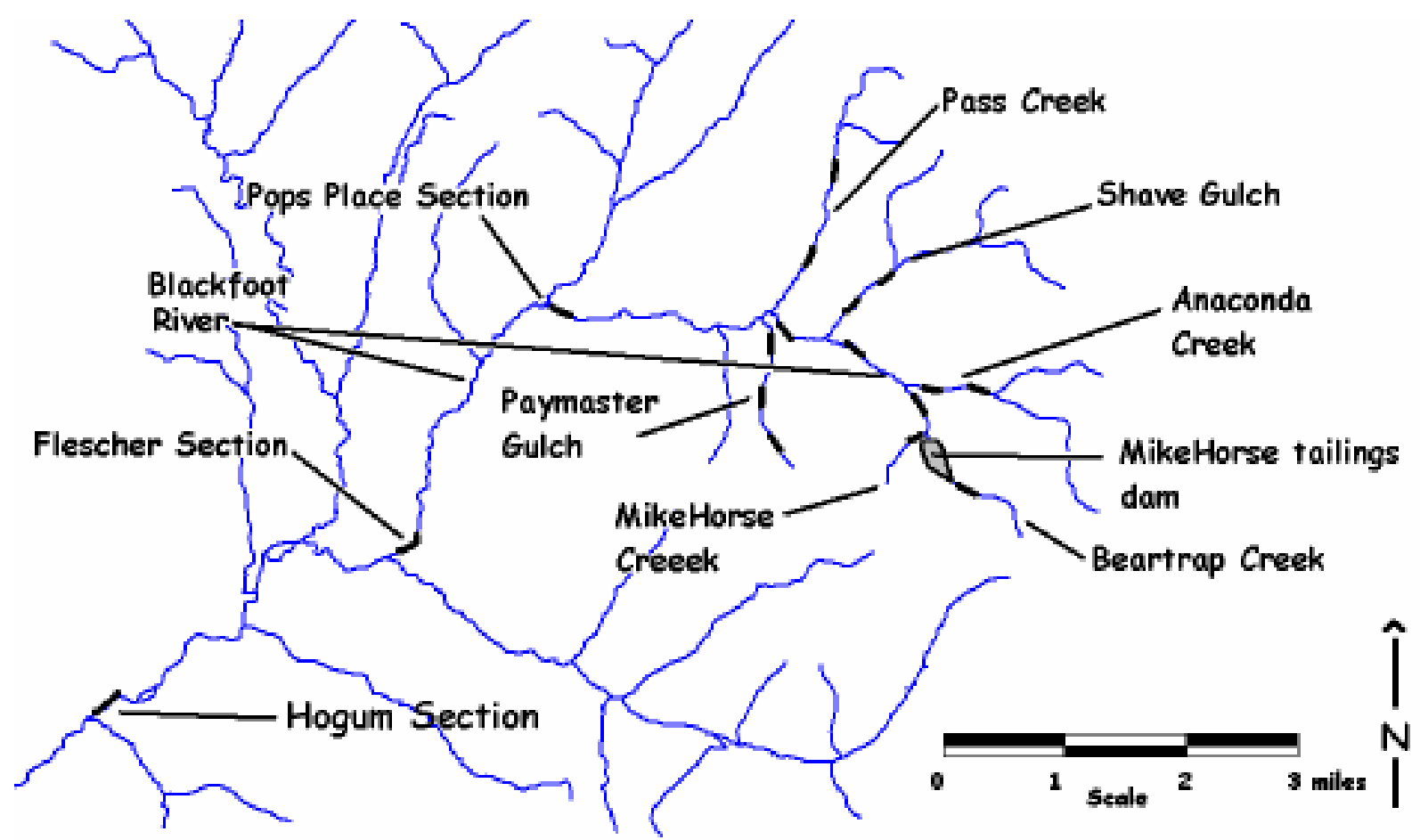

Fish Population survey sites

Figure 21. Study area: Upper Blackfoot River and tributary fish populations survey sites completed in 2006. 


\section{Methods}

We performed single pass electrofishing CPUE surveys at all sites and depletion population estimate surveys at two downstream long-term monitoring (Flescher and Hogum) sections (see Procedures Section). We also established an undisturbed "control" to compare native fish densities, and to help identify the current level fisheries impairments in the upper Blackfoot River. The control, located on upper Cottonwood Creek (Blackfoot Clearwater Game Range) was surveyed at the same time as the upper river, using identical methods. The control contained a similar fish community, and similar valley and channel types as both the Hogum and Flescher sections. In addition to fish population sampling, we collected water

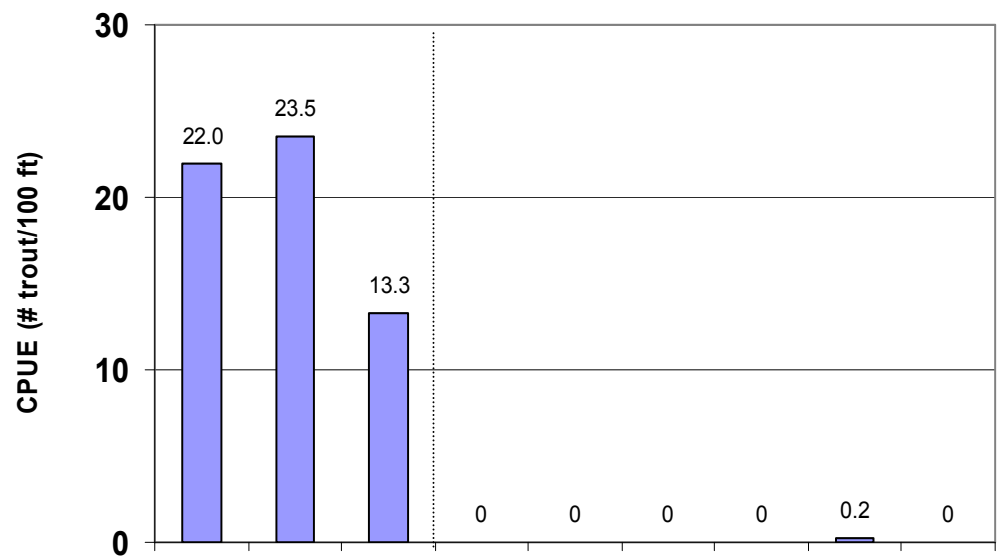
chemistry readings $(\mathrm{pH}$,

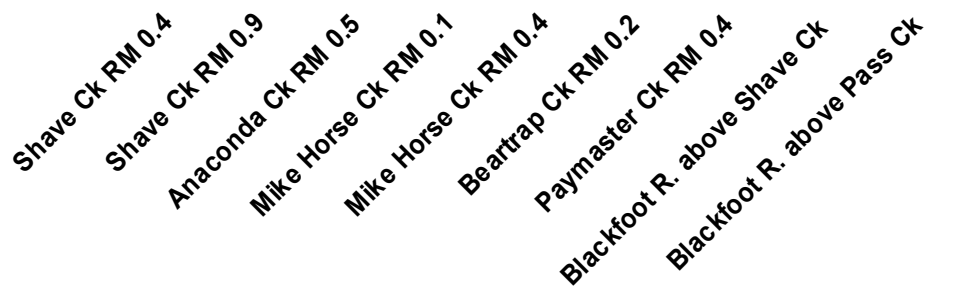

Figure 22. WSCT CPUE in the UBMC, 2006: The first three sites (left) are tributaries upstream of mine waste. The remaining sites are exposed to hazardous substances from UBMC. A total of one cutthroat trout was found in all impacted sites combined.

TDS and conductivity) at all sites (Appendix I).

\section{Results}

Fish population survey statistics are located in Appendices $A$ and B. A comparison of the WSCT CPUE upstream of and within the immediate area of mining contamination is shown in Figure 22. All water quality readings are located in Appendix I.

Our fisheries

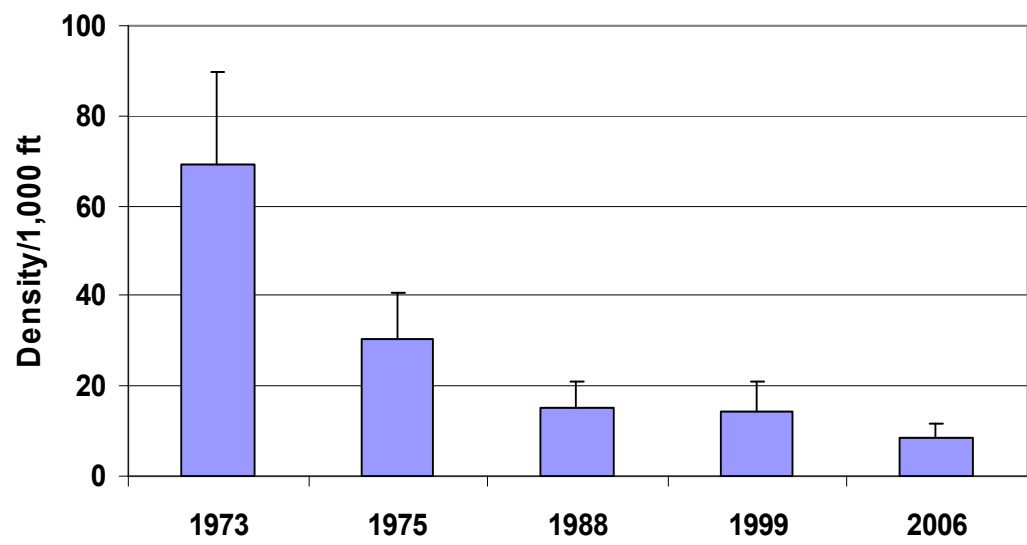

Figure 23. Estimated age 1 and older WSCT densities in the Flesher reach of the upper Blackfoot River between 1973 and 2006. 
surveys show highly impacted tributaries such as Mike Horse Creek, Beartrap Creek, and Paymaster Creek contained no fish. Only one WSCT was found in the upper-most reach of the Blackfoot River, upstream of Shave Creek (Figure 22). We found no WSCT in the Blackfoot River upstream of Pass Creek although brook trout were present in very low abundance (Appendix A). Conversely, upstream of the mine impacts, WSCT were sampled in much higher abundance in Anaconda Creek, and in two separate reaches of Shave Creek. Brook trout were also common in Pass Creek and present in both Shave Creek and Anaconda Creek (Appendix A).

Fish population surveys in the Flesher Section of the upper Blackfoot River have occurred five times between 1973 and 2006 (Figure 23). The 2006 survey of age 1 and older WSCT densities identify a $>30$-year trend of decreasing WSCT densities in the upper Blackfoot River. The comparison of the Cottonwood Creek control to the 2006 densities in the Blackfoot River (Flescher and Hogum sections) is presented in (Figure 24). This comparison shows significantly lower densities in the impact verses the control sites.
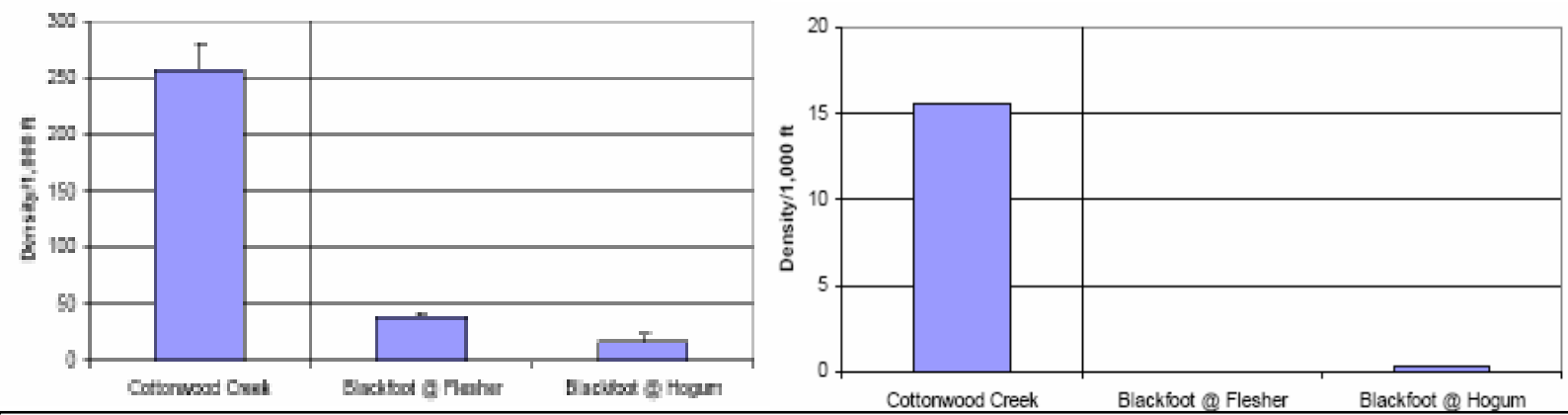

Figure 24. WSCT density (left, all ages) and bull trout density (right, all ages) in Cottonwood Creek (control site) compared to the Flescher and Hogum reaches of the upper Blackfoot River, September 2006.

\section{Discussion}

The UBMC has been identified with high concentrations of arsenic, cadmium, lead, copper manganese and zinc. These toxic substances are found in the surface water, floodplains and groundwater and within the biota (Stratus 2007). Fish population surveys in this and earlier studies show the area of mining impacts begin in the mining complex and include the headwaters of certain perennial tributaries (Paymaster, Beartrap and MikeHorse Creek) as well also the lower reaches of Anaconda Creek and extend down the Blackfoot River from the headwater to Flesher and Hogum sections. Unlike other streams where water chemistry $(\mathrm{pH})$ was tested, Paymaster Creek tested as acidic with a $\mathrm{pH}$ as low as 4.0 and was identified as fishless. Relatively unimpacted headwater stream upstream of the mining area still contain predominantly WSCT populations. Although populations have been greatly reduced, exisiting headwater populations have potential for expansion in the dowsntream direction under suitable clean-up conditions. In addtion to stream-resident populations, a proper clean-up has potential to benefit migratory (fluvial) WSCT based on the location of spawning sites identified in a recent FWP telemetry study (Pierce et al 2007, Results Part VI)). 
FWP has periodically monitored fish population in the UBMC since the early 1970s (Spence 1975, Peters and Spoon 1989, Pierce et al 2000). These surveys identify a substantial long-term decline in age 1 and older WSCT. In the Pop's Place sample site, near the marsh area in the UBMC, the estimated density of age 1 and older WSCT in 1971, before the Mike Horse tailings dam failure in 1975, was approximately 100 fish/1,000' (Spence 1975). In 1988, after the release of toxic Mike Horse tailings into the Blackfoot River, the WSCT population declined to an estimated 15 fish/1,000' (Peters and Spoon 1989). By 1999, no age 1 and older WSCT were sampled at the Pop's Place monitoring section (Pierce and Podner, 2000). In 2006, we attempted to access the Pops Place section, but were denied access to the survey site.

Few young of the year (YOY) WSCT have been found at Pop's Place during any of the sampling events, including the 1971 sampling prior to the dam failure. Given the multitude of contaminant sources in the UBMC, it is likely that mine-related stress affected the age 0 WSCT at least as early as 1971 (Stratus 2007). Populations of nonnative adult brook trout, which typically are not as sensitive to metals toxicity as are the native cutthroat trout (Nehring and Goettl, 1974), did not decline substantially at Pop's Place between 1971 and 1999.

Population declines in the Flescher Section are consistent with the upstream spatial and temporal patterns of declining WSCT densities in the downstream direction. Before the 1975 tailings dam breach, the estimated WSCT density at Flesher section was 69 age 1 and older fish/1,000'. Shortly after the dam breach (1975), WSCT density dropped to 30 fish/1,000' (Spence 1975). By 1988 the WSCT density declined further to an estimated 15/1,000' (Peters and Spoon 1989), and in 2006, the estimated WSCT density was less than $9 / 1,000$ feet. By contrast, adult brook trout densities at Flesher were relatively stable from 1973 to 2006 . In 1973, the WSCT densities at Flesher section were nearly three times higher than the non-native brook trout density. The decline in the WSCT population, coupled with little change in brook trout density, suggest a speciesselective toxicity, which has led to a dominance of the non-native trout, albeit at low densities. Cottonwood Creek was selected as a background area to estimate baseline conditions for the upper Blackfoot River. Fish population data were collected in the upper Blackfoot and in Cottonwood Creek in September 2006 using the same field methods and in similar environments. The native trout populations in the Flesher and Hogum reaches of the Blackfoot River were substantially lower than the populations in Cottonwood Creek. The densities of WSCT (all ages) in both the Flesher and Hogum reaches of the upper Blackfoot River were over five times lower than WSCT densities in Cottonwood Creek control site.

Bull trout are also reduced in the Blackfoot River compared to Cottonwood Creek. The density of bull trout (all ages) in Cottonwood Creek was $>15 / 1,000$ '. By contrast, in the upper Blackfoot River, only one bull trout was found in the Flesher and Hogum reaches combined, a length of 6,500'. Brook trout were present at all locations; the density of brook trout (all ages) at Cottonwood Creek (22/1,000') was between the density in the upper Blackfoot at Flesher (52/1,000') and Hogum (5/1,000'). Whether through direct toxicological effects or sub-acute impacts such as avoidance, it is highly likely that the reduced native trout populations downstream of the UBMC are the result of releases of hazardous substances from upstream mine sites. 
Fluvial WSCT are currently in very low abundance in the upper Blackfoot River. A recently completed telemetry study identified extensive spawning migrations of adult WSCT telemetered downstream of Lincoln to upstream spawning sites (see related study in Results Part VI, Pierce et al 2007). This study identified fluvial WSCT spawning in the upper Blackfoot River near the Hogum and Flescher survey sections in the area of mining-related declines. These results identify mine-related impacts not only resident WSCT at a local scale but also fluvial WSCT stocks over a much broader area. These findings suggest the recovery of fluvial WSCT stocks should be fully considered as primary (habitat) targets when developing specific restoration actions in the UBMC. 


\section{RESULTS PART III: RIVER RESTORATION TRIBUTARY ASSESSMENTS}

Results Part III summarizes recent (2006-07) inventory and monitoring activities for 29 restoration project streams. Nine previous FWP reports spanning the 1988-2005 fisheries investigations provide additional information to these and earlier restoration endeavors (Peters and Spoon 1989, Peters 1990; Pierce and Peters 1991; Pierce, Peters and Swanberg 1997; Pierce and Schmetterling 1999; Pierce and Podner 2000; Pierce, Podner and McFee, 2001; 2002: Pierce, Anderson and Podner 2004, Pierce and Podner 2006). All fish population survey results (catch and size statistics and density estimates) for these 29 streams are located in Appendices A and B. Summaries of all related data (discharge, temperature, water chemistry, and WSCT genetics) collected during the 200607 period are located in Appendices D, H, I and J, respectively. The locations of individual study streams and fish population survey sites are located below in Figure 1.

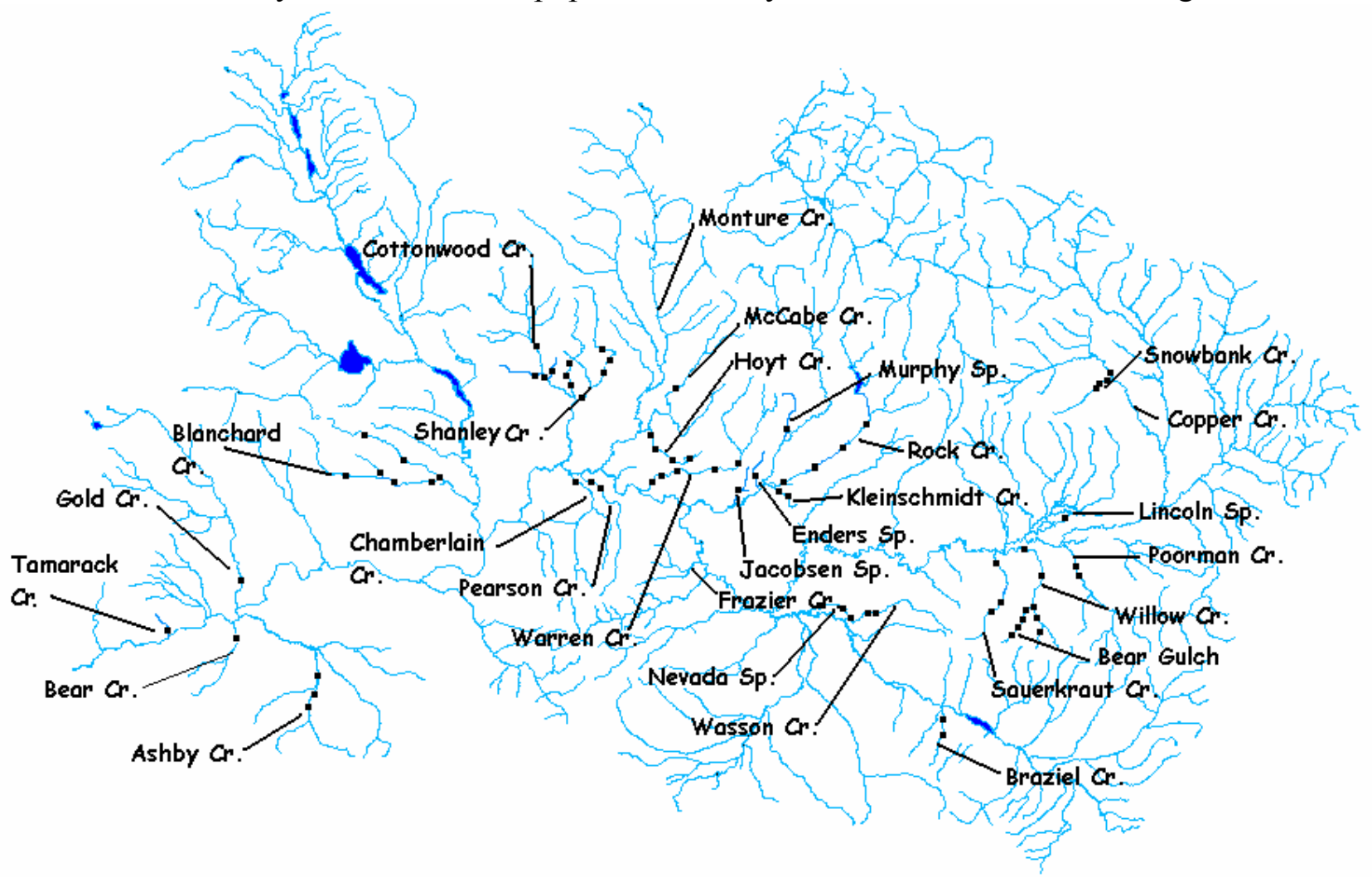

Figure 1. Location map with 29 restoration-related study streams and fish population survey sites undertaken in 2006 and 2007.

\section{Ashby Creek}

Restoration objectives: Protect the genetic purity of a WSCT population in the upper Ashby Creek watershed by using an existing wetland complex as a migration barrier, and improve WSCT habitat by creating a natural channel that provides complexity, increases riffle-pool habitat features and available spawning substrate and increase shade and small diameter wood recruitment to the stream channel. Improve and re-establish wetland functionality. 


\section{Project Summary}

Ashby Creek is a $2^{\text {nd }}$ order tributary to Camas Creek in the Union Creek basin that supports a genetically pure WSCT population. The upper reaches of Ashby Creek originate in forested areas on Plum Creek and BLM properties before entering private ranch lands near mile 3.0. Historical and recent agricultural practices significantly Ashby Alterations have diversion for irrigation and channel ditching to increase farmable acreage, livestock degraded stream banks, loss of woody plant communities, irrigationrelated dewatering and the draining of downstream wetlands.

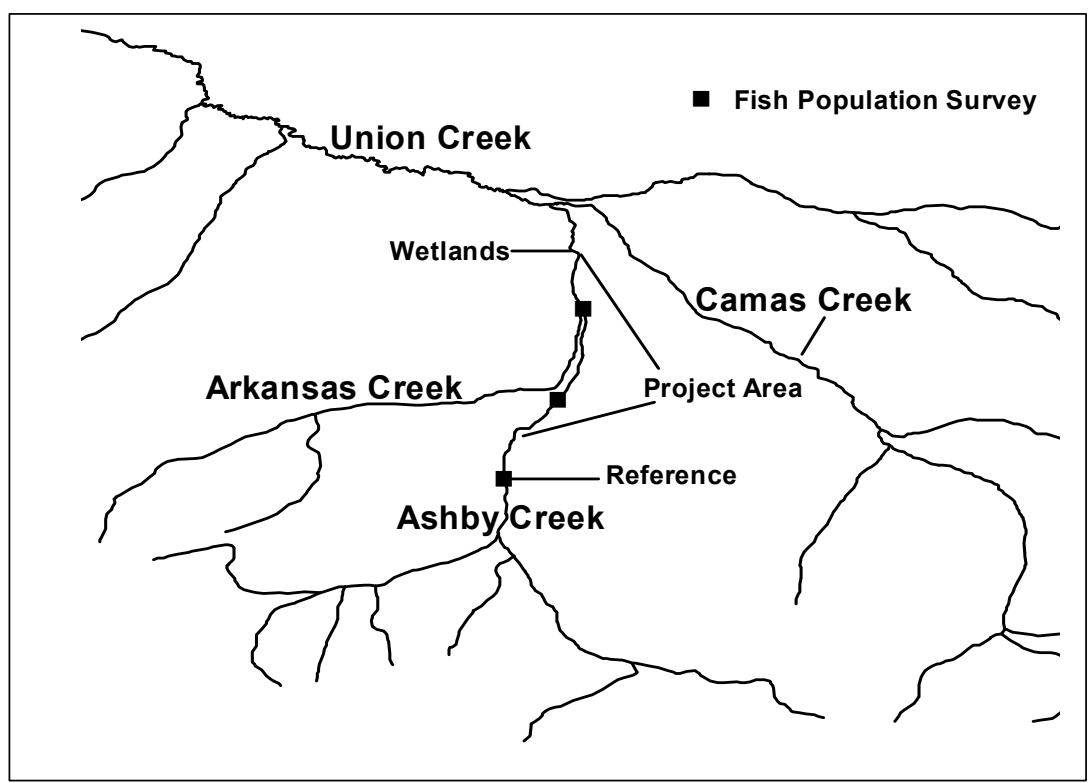

Figure 2. Ashby Creek stream channel restoration project area and fish population survey locations, 2007.

Over the past several years a comprehensive restoration project plan was developed, and finally implemented in 2007. The project included 1) reconstruction of three miles of stream that had been historically ditched, 2) enhanced instream flows, 3 ) improved upstream fish passage and the installation of a fish screen at a diversion point, 4) riparian grazing changes, and 5) shrub plantings. This project also connected Ashby Creek to an 80-acre scrub-shrub wetland in a manner that is designed to inhibit the upstream movement of fish (Figure 2).

Fish Populations and other monitoring activities

In 2005, we established pre-project fish population survey sites at an upstream reference at mile 4.0. In 2007 we also established two fish population survey sites in the new channel at mile 3.0 and a downstream survey site at mile 2.0. At this early stage of post-project monitoring, we have identified no fish within either of the two new (treatment area) population-monitoring sites (Appendix A).

\section{Bear Creek}

Restoration Objectives: Restore habitat degraded by historical activities in the channel, restore fish passage and thermal refugia, and improve recruitment of trout to the Blackfoot River. 


\section{Project Summary}

Bear Creek, a small $2^{\text {nd }}$ order tributary to the lower Blackfoot River, flows six miles north to its mouth where it enters the Blackfoot River at rm 12.2 with a base-flow of 3-5 cfs. Bear Creek is one of the colder tributaries to the lower Blackfoot River.

Located on industrial forest and agricultural lands, Bear Creek has a long history of adverse habitat changes, which include placement of undersized culverts, road drainage and siltation, irrigation, channelization of the stream, excessive riparian grazing

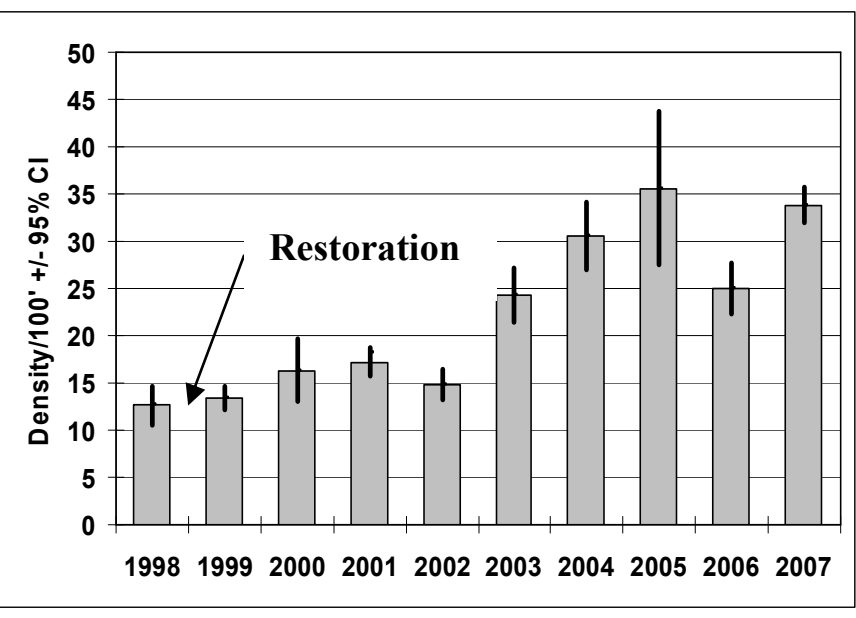

Figure 3. Densities of age 1 and older rainbow trout for Bear Creek at mile 1.1, 1998-2007. and streamside timber harvest (Pierce et al. 1997; Pierce and Schmetterling 1999). At least one road crossing is still considered a barrier to movement. Prior to restoration activities, these fisheries impairments contributed to the loss of migration corridors and the simplification and degradation of salmonid habitat. Many of these impairments were corrected in the late 1990s, and these included: 1) upgrading culverts and addressing road drainage problems; 2) improving water control structures at irrigation diversions; 3) reconstructing 2,000' of channel; 4) enhancing habitat complexity on an additional 2,000' of stream; 5) shrub plantings; and 6) the development of compatible riparian grazing systems for one mile of stream.

Fish Populations and other monitoring activities

Bear Creek supports predominately rainbow trout and lower numbers of brown trout and brook trout in the lower stream, along WSCT in the upper basin and very low densities of juvenile bull trout. Following restoration actions in 1999, fisheries monitoring has identified Bear Creek as an increasingly important spawning and rearing tributary to the lower Blackfoot River sport fishery.

In 2006 and 2007, we continued to monitor fisheries in a reconstructed section (mile 1.1) of Bear Creek (Figure 3, Appendix A and B). This monitoring has identified a general trend of increasing densities of juvenile rainbow trout. We also tested for whirling disease at mile 1.1 in 2006 and found no infection.

\section{Blanchard Creek}

Blanchard Creek is a small $2^{\text {nd }}$ order tributary to the lower Clearwater River entering at mile 2.9. It suffers from a long history of adverse activities resulting in riparian and fish habitat degradation. These include changes to the hydrograph $(12 \%$ above natural) related to extensive timber harvest (DNRC unpublished data), side-casting of road grade materials to the stream channel by Missoula County road maintenance crews, excessive livestock degradation to the riparian area, channel instability and chronic dewatering through irrigation. Lower Blanchard Creek was the site of a water 
lease during the 1990s that provided minimal ( $3 \mathrm{cfs}$ ) instream flows. Enhanced base flows led to a large increase in the abundance of juvenile rainbow trout, which identified

\begin{tabular}{llll} 
Channel measurements & & & \\
\hline Stream channel length ( ft ) & $12,566 f t$ & & \\
Sinuosity & 1.11 & & 157 \\
Total \# Pools & 157 & Total \# Riffles & 52 \\
\# Pools Sampled & 52 & \# Riffle Sampled & $12.5 / 1000 f t$ \\
Pool Frequency & $12.5 / 100$ fft & Riffle Frequency & $10(19 \%)$ \\
\# Pools Measured with LWD & $21(40 \%)$ & \# Riffle Measured with LWD & $29 \pm 24(4-113)$ \\
Pool Length & $29 \pm 15(9-77)$ & Riffle Length & $512 \pm 411(41-$ \\
Wetted Pool Surface Area & $475 \pm 272(59-1367)$ & Wetted Riffle Surface Area & $2083)$ \\
Maximum Pool Depth & $2.0 \pm 0.5(1.0-3.1)$ & Maximum Riffle Depth & $10.2(0.4-1.2$ \\
Wetted Pool Width @ Max Depth & $15 \pm 5(7-33)$ & Wetted Riffle Width @ Max Depth & $18 \pm 5(9-31)$ \\
Wetted Pool Width @Riffle Crest & $18 \pm 5(6-36)$ & Bankfull Width @ Max Riffle Depth & $32 \pm 11(14-68)$ \\
Bankfull Width @Max Pool Depth & $25 \pm 7(10-49)$ & & \\
Bankfull Width @Riffle Crest & $31 \pm 11(14-69)$ & & \\
Riffle Crest Depth & $0.6 \pm 0.1(0.3-1)$ & & \\
Residual Pool Depth & $1.3 \pm 0.5(0.5-2.4)$ & & \\
Mean Wetted Width of Pools & $17 \pm 5(7-33)$ & & \\
\hline \hline
\end{tabular}

All measurements in standard (ft) units

Table 1. Stream habitat survey results for the lower 2.3 miles of Blanchard Creek.

Blanchard Creek as a productive rainbow-spawning stream when minimum instream flows were maintained (Pierce et al 2004). The water lease was recently terminated, and lower Blanchard Creek now is again chronically dewatered during the irrigation season. Lower Blanchard Creek is now the site of a high-density subdivision proposal.

Fish Populations and other monitoring activities

In 2006 and 2007, we completed a stream habitat survey from the mouth to the confluence of the North Fork (at mile 2.3). We also conducted fish population surveys at three headwater locations (mile 3.3, 5.6 and 9.4). Results of the habitat survey are located in Table 1. Rainbow trout were present only at mile 3.3 (CPUE = 4.3) and WSCT increased in the upstream direction (Appendix A).

\section{Braziel Creek}

Braziel Creek drains a small watershed $\left(\sim 4.5\right.$ miles $\left.^{2}\right)$ located along the southeastern foothills of Hoodoo Mountain, just south-southeast of Helmville. This $2^{\text {nd }}-$ order tributary is $\sim 3.9$ miles in length, maintains a mean gradient of $480 \% \mathrm{mile}$, and generates an estimated base-flow of 0.5-1.0 cfs before entering Nevada Creek at mile 24.5 about 2.0 miles downstream of the Nevada Creek reservoir. The upper 2.1 miles of Braziel Creek flows through Bureau of Land Management land and the lower 1.8 miles of stream flows through private ranch lands (Figure 4). 
Livestock

grazing has heavily impacted the riparian under-story vegetation of alder and grasses on lower Braziel Creek. Below the BLM properties, the riparian over-story consists of sparsely mixed community of ponderosa pine and Douglas fir. Intense livestock hoof-shear has left the stream banks and channel heavily degraded, over-widened and shallow. Fish habitat consisted of small pocket pools created by large boulders, small woody debris jams, undercut banks and young overhanging conifers. Large woody debris recruitment to the stream channel is minimal. A culvert observed at the West Fork road crossing (mile 1.5) was perched approximately 10-12 inches, thereby creating a possible fish barrier. Our observations of the Braziel Creek riparian area on BLM properties identified a healthier riparian area and stable banks.

Fish population monitoring and other monitoring activities

Fish population survey sites were established at two sites (mile 0.7 and 1.4) on lower Braziel Creek in 2006. A comparison of the CPUE for age 1 and older WSCT between the sites identify noticeably lower densities at the lower site compared to the upper site (Figure 5). WSCT YOY were common at both sampling sites. Sculpins were abundant at mile 0.7 , but absent from the mile 1.4 survey site.

\section{Chamberlain Creek}

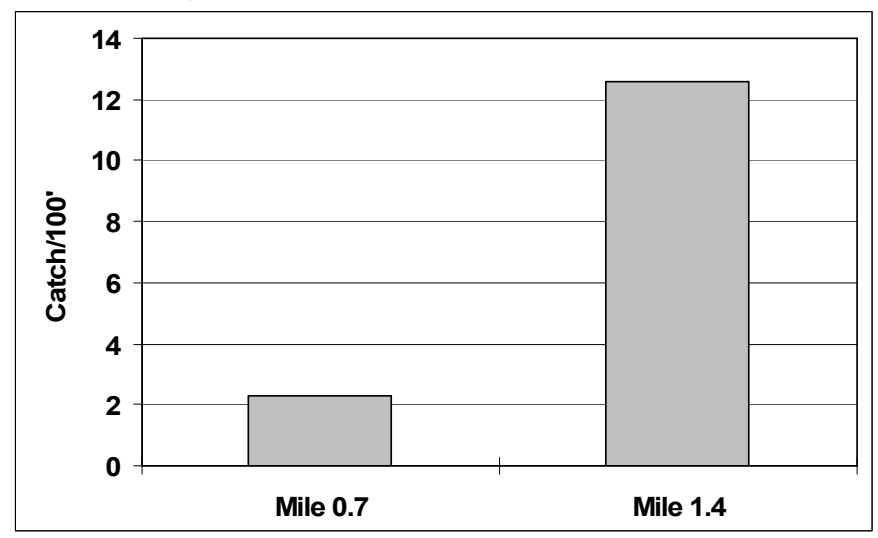

Figure 5. CPUE for age 1 and older WSCT at two locations on Braziel Creek, 2006.

Restoration objectives: Improve access to spawning areas; improve rearing conditions for WSCT; improve recruitment of WSCT to the Blackfoot River; provide thermal refuge and rearing opportunities for fluvial bull trout. 


\section{Project Summary}

Chamberlain Creek is a small Garnet Mountain tributary to the middle Blackfoot River, entering near rm 43.9 with a base-flow of 2-3 cfs. Prior to 1990, sections of lower Chamberlain Creek was dewatered and severely altered (grazing and channelization), leading to sharp declines in WSCT densities (Peters 1990). During the early 1990s, Chamberlain Creek was also one of the first comprehensive restoration projects within the Blackfoot Basin. Restoration emphasized road drainage repairs, riparian livestock management changes, fish habitat restoration, irrigation upgrades (consolidation of ditches, water conservation, elimination of fish entrainment and fish installation on a diversion), conservation easements and improved stream flows through water leasing.

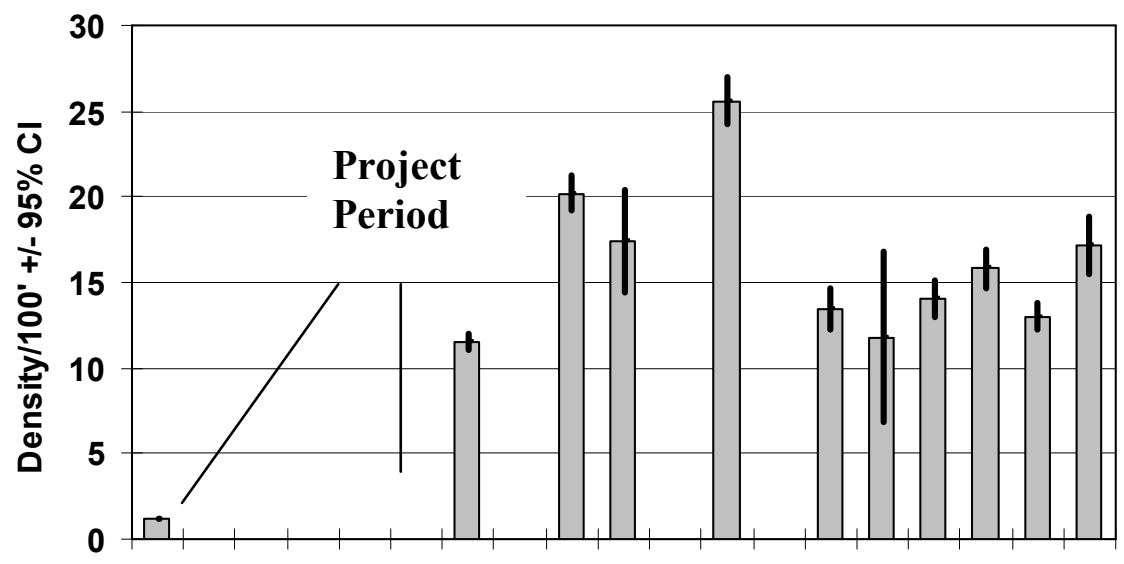

Restoration

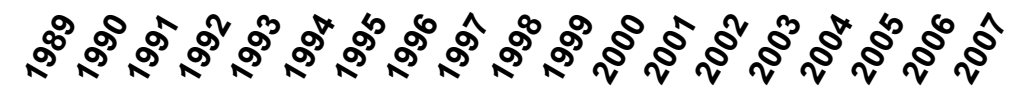

Figure 7. Densities of age 1 and older WSCT in Chamberlain Creek at mile 0.1, 1989-2007.

occurred throughout the drainage with emphasis in the lower mile of stream.

$\underline{\text { Fish Populations and other monitoring activities }}$

Chamberlain Creek is a WSCT-dominated stream over its entire length although lower reaches also support rainbow and brown trout in low abundance. Following restoration and WSCT recovery in lower Chamberlain Creek, radio telemetry identified Chamberlain Creek as a primary spawning stream for fluvial WSCT from the Blackfoot River (Schmetterling 2001). In 2006-07, we continued to monitor fish population

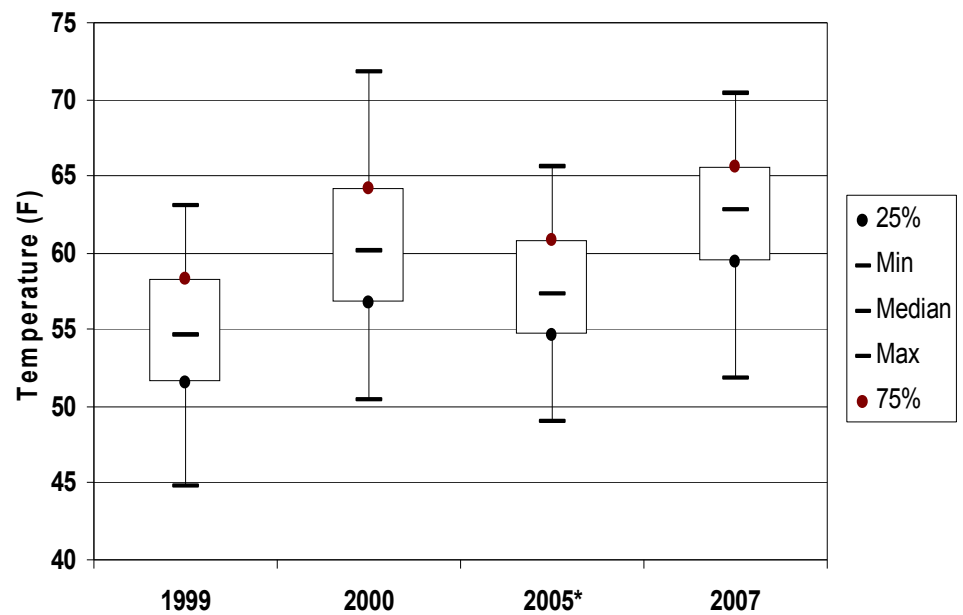

Figure 8. July water temperatures for Chamberlain Creek at stream mile 0.1, 1999, 2000, 2005 and 2007. 
densities, water temperature and whirling disease in the restoration area near the mouth.

Fish population surveys at mile 0.1 identify $>10$ years of stable densities of age 1 and older WSCT (Figure 7). Periodic water temperature monitoring suggest recent warming (Figure 8, Appendix $\mathrm{H}$ )

In 2007, we continued to test Chamberlain Creek for whirling disease (using sentinel exposures) at an established downstream monitoring site (mile 0.1), and at two upstream (miles 0.7 and 3.8) locations. The two lower sentinel cages were placed up-and downstream of artificial ponds to help assess whether these stream-connected ponds might contribute to a high severity of disease as previously identified (Pierce et al 2006). This test identified mean grade infection rates were slightly higher downstream of the ponds than upstream of the ponds (mean grade infection $=1.89$ below verses 1.21 above). Interpreting these results however remains difficult as the mean grade infection at mile 0.1 was notably lower in 2007 (1.89) than 3.78 when last tested in 2005. Consistent with earlier exposures, whirling disease was not detected at mile 3.8 .

\section{Copper Creek}

Copper Creek, the largest tributary to the lower Landers Fork entering at mile 3.6, is a critical spawning and rearing stream for genetically pure fluvial WSCT and fluvial bull trout in the upper Blackfoot River drainage. Copper Creek supports an entirely native fish community basin-wide, and provides the only major spawning migration of fluvial bull trout in the upper Blackfoot River basin. Copper Creek's consistent coldwater temperatures help moderate temperatures in the lower Landers Fork.

During August 2003, the Snow/Talon wildfire on the Helena National Forest ran through the Copper Creek drainage. This high intensity, stand replacement fire burned significant portions of the basin including a fluvial bull trout spawning site approximately three weeks prior to spawning.

Fish Populations and other monitoring activities

In 2006-07, we continued fish population and temperature monitoring in Copper Creek in the area of the Snow/Talon wildfire. This monitoring included bull trout redd counts, surveys of juvenile trout abundance.

Following the wildfire, bull trout redd counts have shown a substantial increase in the total number of redds in Copper Creek (Executive Summary). Similar to redd counts, electrofishing surveys at a long-term monitoring site (mile 6.2) indicate a post-fire increase in the numbers of age $0+$ native fish (Figure 6, Appendix A). Water temperature monitoring identifies a significant warming in Copper Creek, in the post-fire environment

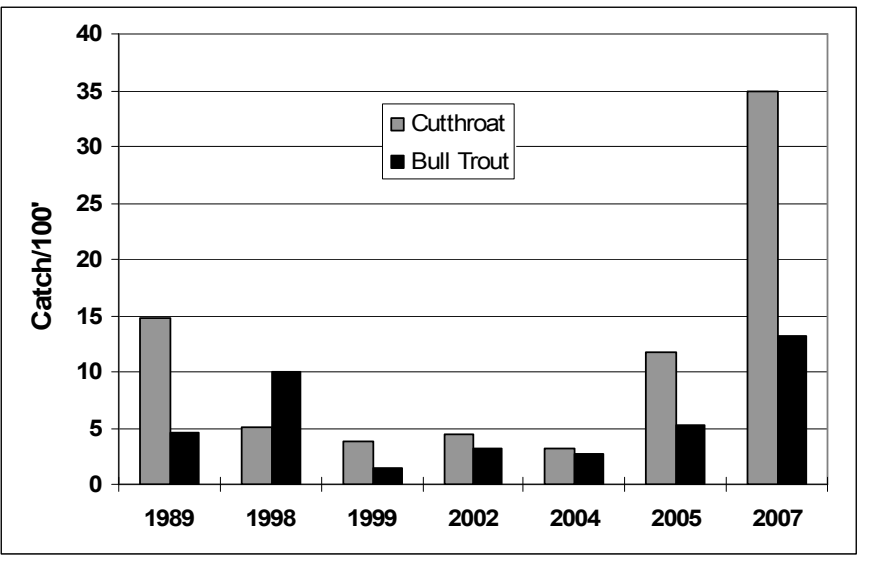

Figure 6. CPUE for age $0+$ native trout at stream mile 6.2 in Copper Creek, 1989-2007. 
Summary). We interpret the fisheries increases as a response to increased water temperature and sunlight, and a nitrogen influx from the burn area, all of which would contribute to enhanced secondary productivity as expressed by the native fish community.

\section{Cottonwood Creek}

Restoration objectives: improve degraded habitat; eliminate fish losses to irrigation ditches; and restore instream flows and migration corridors for native fish.

\section{Project Summary}

Cottonwood Creek, a $3^{\text {rd }}$ order stream, flows $\sim 16$-miles south from the Cottonwood Lakes and enters the middle Blackfoot River at rm 43 with a baseflow of $\sim 15$ cfs. Genetically pure WSCT and bull trout dominate the headwaters of Cottonwood Creek. Rainbow trout, brook trout and brown trout dominate middle to lower stream reaches. Cottonwood Creek is considered a "core area" and was designated as "proposed critical habitat" under the ESA for the recovery of bull trout.

Cottonwood Creek has been the focus of irrigation-related fisheries improvements since 1996. In 2006-07, fisheries improvements were undertaken in both the middle and upper reaches of Cottonwood Creek. In upper Cottonwood Creek, the Blackfoot Cooperators replaced an undersized (and perched) culvert at mile 15.9. This project restored fish passage to $\sim 1.0$ mile of stream, while

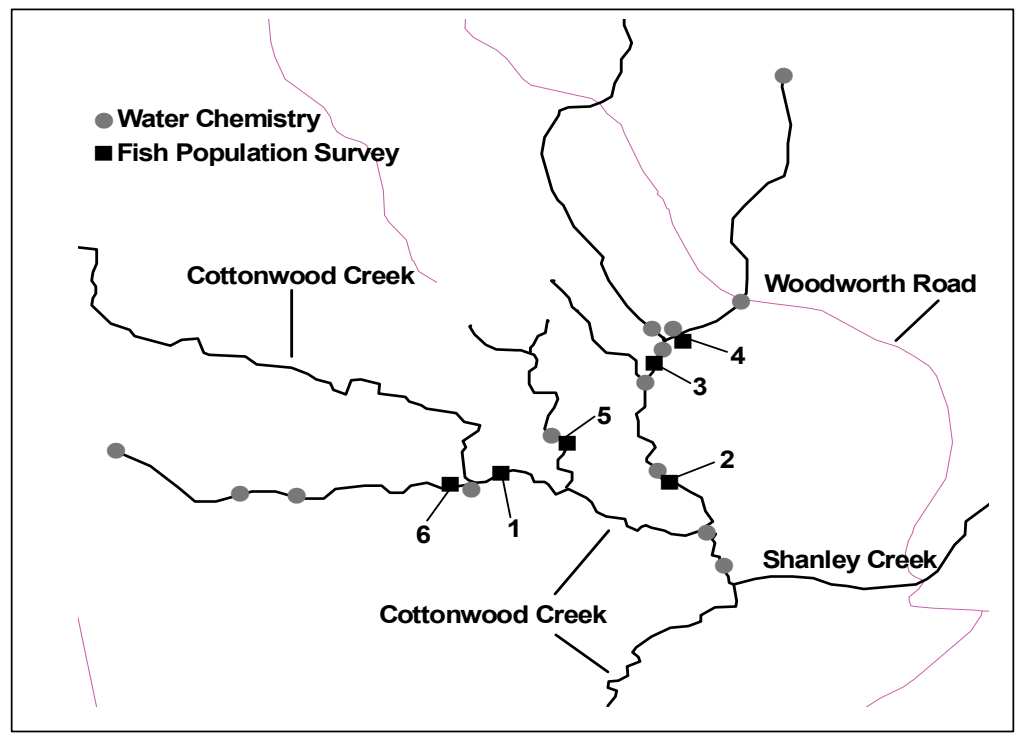

Figure 9. Cottonwood Creek and adjoining spring creek complexes and fish population survey locations,

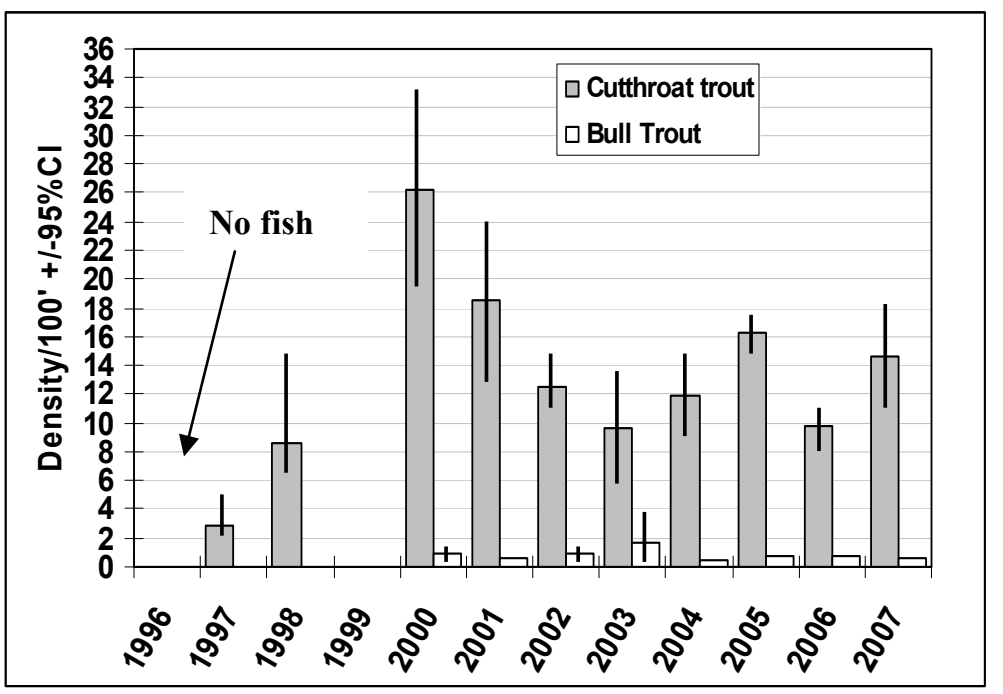

Figure 10. Densities for age 1 and older native salmonids in Cottonwood Creek at mile 12.0, 19962007. 
correcting channel incision and erosion problems downstream of the culvert. Grazing and irrigation-related projects are now the focus of developing projects on public lands along middle Cottonwood Creek. These developing projects result from livestock-related degradation of riparian areas on the both the University of Montana (Bandy Experimental Ranch) and FWP (Blackfoot Clearwater Game Range - Dryer Ranch) properties. Additional fisheries impacts involve the unauthorized use of an FWP diversion during the native fish migration period. This use has compromised native fish migrations to upstream spawning areas in recent years.

In an attempt to address these concerns, both $U$ of M and FWP have assessed their properties and are identifying steps to make necessary changes. These assessments include fish population surveys and spawning site surveys (this report, Pierce et al 2006), as well as a series of riparian health assessments conducted by the $U$ of $M$ Forestry School in 2007. On the FWP properties, corrective measures include 1) the exclusion of livestock from immediate stream banks and degraded spring creek complexes, 2) upgrades at three stream crossing, 3) off-stream water developments, 3) the removal of a diversion, and 4) dedication of irrigation water rights to instream flows. On the Bandy Ranch, irrigation pump sites are being modified and attempts to correct riparian grazing problems are being pursued. Corrective measures, if successful, are expected to improve riparian health along the middle of Cottonwood Creek, while enhancing native fish conditions in middle and upper reaches of Cottonwood Creek.

\section{Fish Populations and other monitoring activities}

In 2006 and 2007, we continued to monitor fish populations in upper Cottonwood Creek (mile 12.0) where enhanced flow, irrigation ditch screening and diversion upgrades were made. Prior to 1997 this section was completely dewatered during late summer and fall by irrigation. We also resurveyed middle Cottonwood Creek (mile 7.5) in 2007 as well as three nearby spring creeks on FWP lands (Figure 9). The middle Cottonwood Creek and nearby spring creek monitoring sites were originally established in 1991 prior to the current level of riparian degradation (Pierce et al. 1997).

At the upper Cottonwood Creek monitoring site (mile

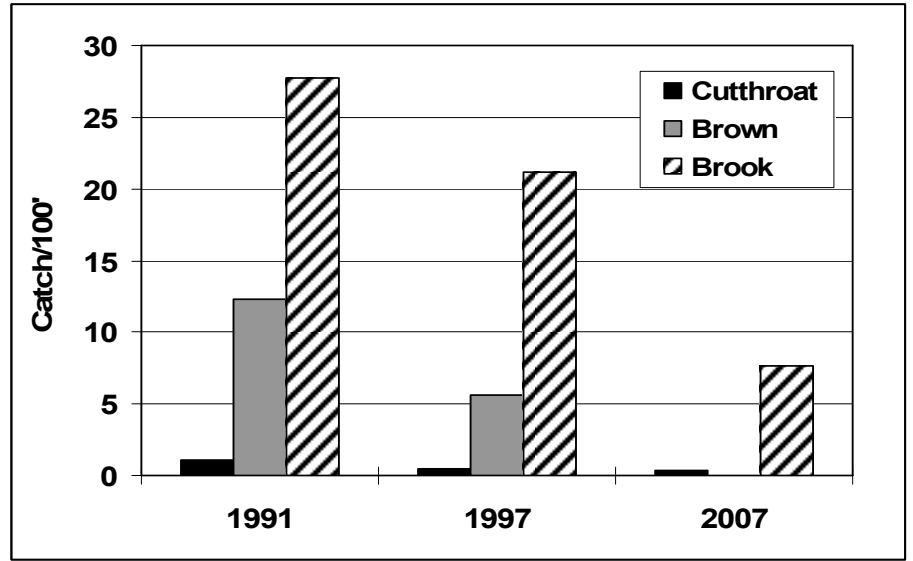

Figure 11. CPUE for salmonids in Cottonwood Creek at mile 7.5 in 1991, 1997 and 2007. 12.0), age 1 and older WSCT have remained stable in recent years, following an initial increase in the late 1990s. Bull trout densities have remained static at low densities (Figure 10). By contrast, fisheries at the middle Cottonwood Creek (mile 7.5) monitoring site show community-level decline in the area of livestock over-use (Figure 11). Likewise, sampling on three adjoining spring creeks (entering middle Cottonwood Creek as miles 6.4, 6.7 and 7.5) show declines in species richness and abundance. In 1991, 
brown trout were identified throughout the spring creeks, and WSCT were present in two of three spring creeks. However, in replicate 2007 surveys, all trout species were identified in reduced densities in areas where riparian conditions have deteriorated. Brown trout were found in low densities in only one spring creek, and WSCT were absent from all spring creek samples. Brook trout have also expressed declines compared to 1991 (Pierce et al 1997, Appendix A).

Water temperature monitoring in lower Cottonwood Creek shows continued warming since 2001 (see Figure 7 in Executive Summary). Sentinel exposures near the mouth (mile 1.1) from 2006 and 2007 show a continuous high severity of whirling disease (mean grades of 3.96 and 4.25 , respectively).

\section{Enders Spring Creek}

Restoration objectives: Restore the spring creek to natural "C4-type" spawning channel, reduce water temperatures to level suitable for bull trout, reduce instream sediment levels, enhance habitat quality utilizing in-stream structures, vegetation and provide suitable substrate for spawning.

\section{Project Summary}

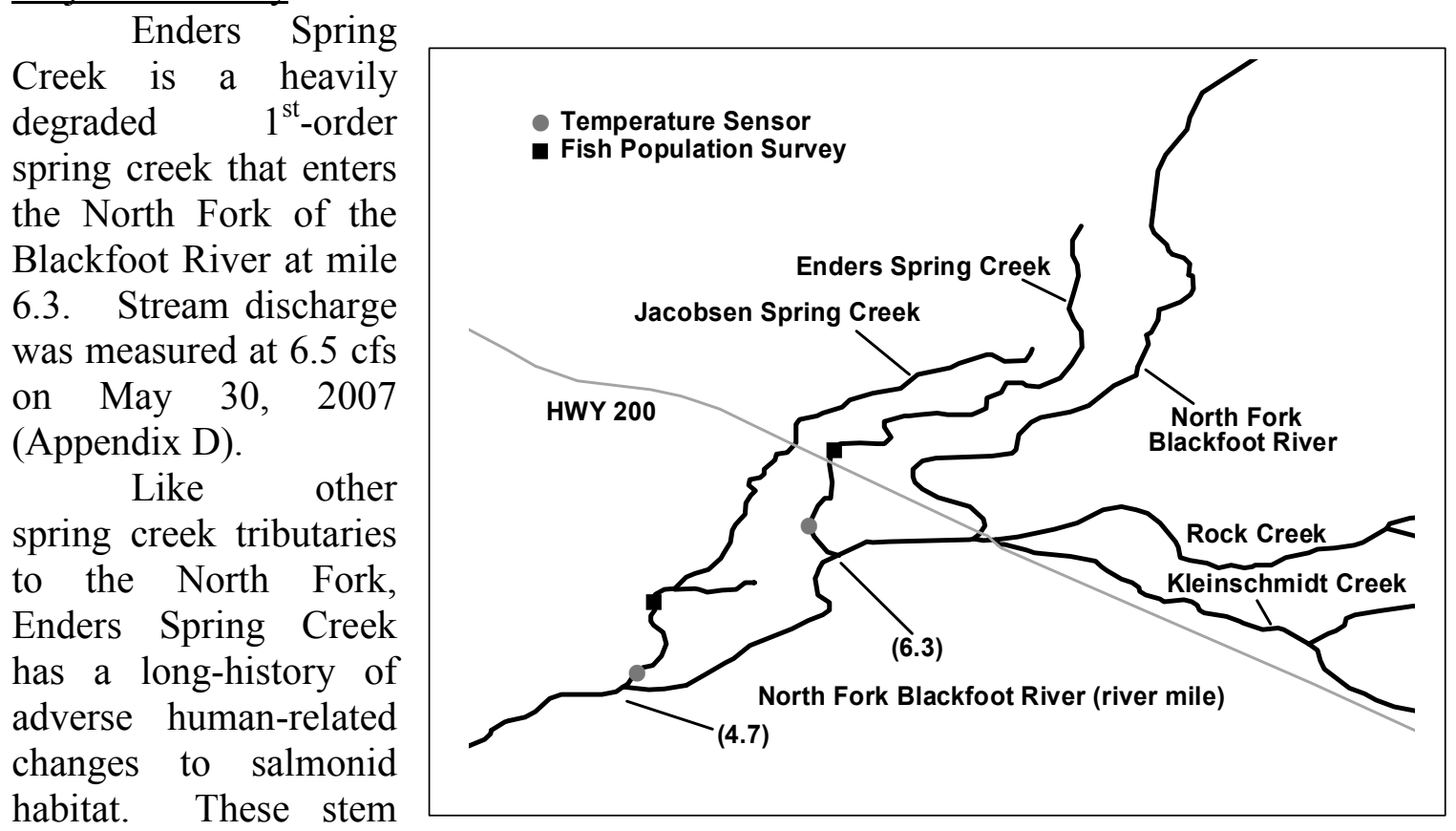

from past agricultural activities and include the loss of sinuosity, channel widening and

Figure 12. Enders Spring Creek stream channel restoration project area and fish population survey location, 2007.

heavy sediment loading in pools and glides. Enders Spring Creek is the last major spring creek to the North Fork that requires active restoration.

Restoration will include two-miles of complete channel reconstruction similar to the Jacobsen Spring Creek project (see Jacobsen Spring Creek), and this work is slated for 2008. Like all other spring creeks restoration projects on the North Fork, ensuring compatible grazing strategies will be critical to the future success of this project. 
Fish Populations and other monitoring activities

In 2006 and
2007 in advance of
channel reconstruction,
we conducted a series
of baseline studies that
included fish
population surveys at
mile 0.5, and a habitat
(channel) survey that
also included water
temperature, water
chemistry, substrate
and discharge
measurements.

survey

Fish population

primarily brook trout,

brown trout, mountain whitefish at low densities and very low densities of bull trout
Channel measurements

Stream Channel Length

Sinuosity

Channel Gradient

Width / Depth Ratio

Total \# Pools

\# Pools Sampled

Pool Frequency

\# Pools Measured with LWD

Pool Length

Wetted Pool Surface Area

Maximum Pool Depth

Wetted Pool Width @ Max Pool Depth

Wetted Width @ Riffle Crest

Bankfull Width @ Max Pool Depth

Bankfull Width @ Riffle Crest

Riffle Crest Depth

Residual Pool Depth

All measuements in standard (ft) units

Table 2. Summary of pre-project habitat survey results for Enders Spring Creek.

(Appendix A). The habitat survey measured low sinuosity, high W/D ratios and bankfull widths ranging from 8-68' (Table 2). Pre-project (2007) water temperature recorded maximum summer temperature of $60.1^{\circ} \mathrm{F}$ near the mouth (Appendix $\mathrm{H}$ ). Although a Wolman pebble count at mile 0.1 identified a graveldominated $(\mathrm{D} 75=$ $68 \mathrm{~mm}, \mathrm{D} 50=31 \mathrm{~mm}$ and $\quad$ D25 $=9 \mathrm{~mm}$ ) substrate in a representative riffle, heavy loading of fine sediment was noted in pools and glides.

\begin{tabular}{lr} 
Frazier Creek \\
\multicolumn{2}{r}{ In 2006, } \\
FWP explored \\
fisheries restoration \\
opportunities in \\
Frazier & Creek. \\
Frazier & Creek, a \\
small & $3^{\text {rd }}$-order
\end{tabular}

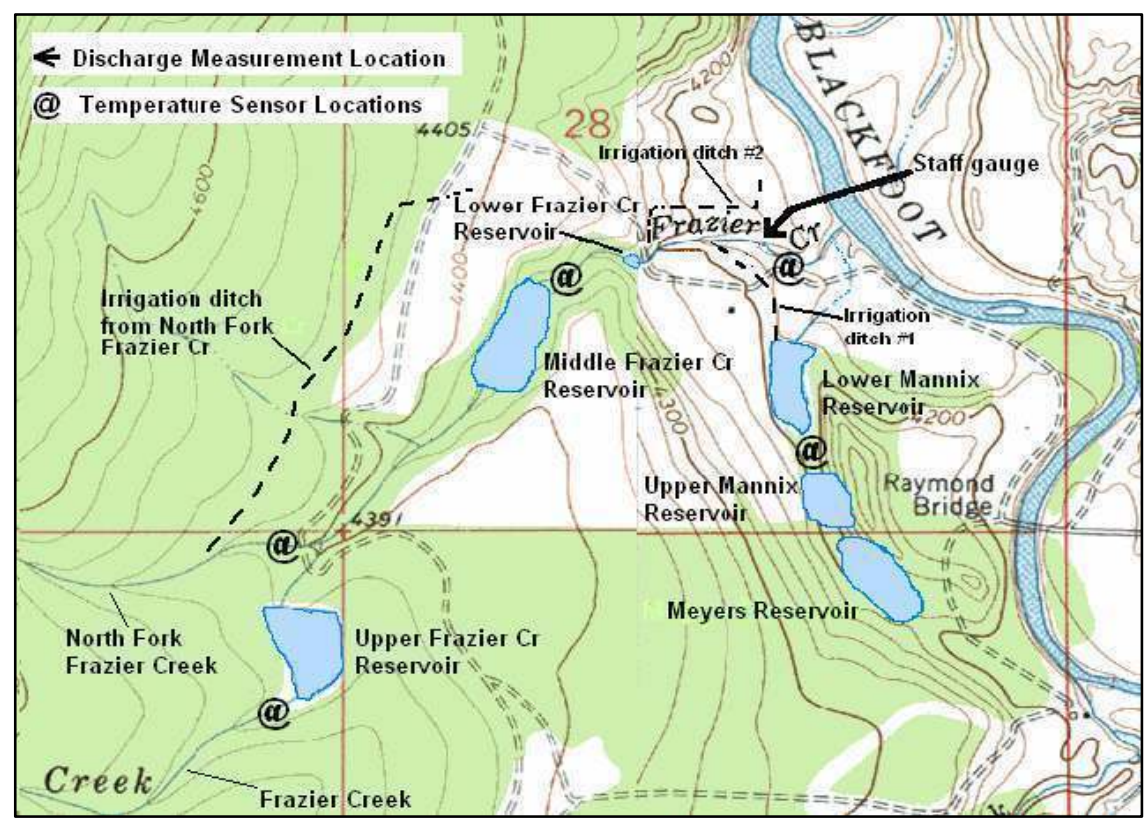

Figure 13. Stage discharge staff and water temperature sensor locations in the Frazier Creek drainage, 2007. 
basin with 3.8-miles of perennial stream, enters the middle Blackfoot River at river-mile 59.4 from the Garnet Mountains. Frazier Creek is one of several small Garnet Mountain tributaries to the middle Blackfoot River that currently support no known fluvial WSCT use due to instream reservoirs as well as other fisheries impairments (Results Part V, Appendix F).

The North Fork of Frazier Creek is $\sim 2.0$ miles in length and enters Frazier Creek at mile 1.0 with an estimated base-flow of $0.3 \mathrm{cfs}$. Both the mainstem and North Fork provide water for intensive irrigation via two large instream reservoirs, one smaller (empty) reservoir on the mainstem and three irrigation diversions (Figure 13). In fish-bearing water above the middle reservoir, Frazier Creek is fragmented at two locations by the upper reservoir and a partial fish passage barrier (perched culvert) at mile 0.3 on the lower reaches of the North Fork. The stream is segmented into sections of 2.6-miles above the upper reservoir, 0.7miles above the middle reservoir and 1.7-miles above a culvert (fish passage) barrier on the North Fork.

In addition to fragmented habitat, the stream channel and riparian vegetation on the lower 0.3-miles of Frazier Creek suffers from past livestock grazing. The mainstem riparian understory

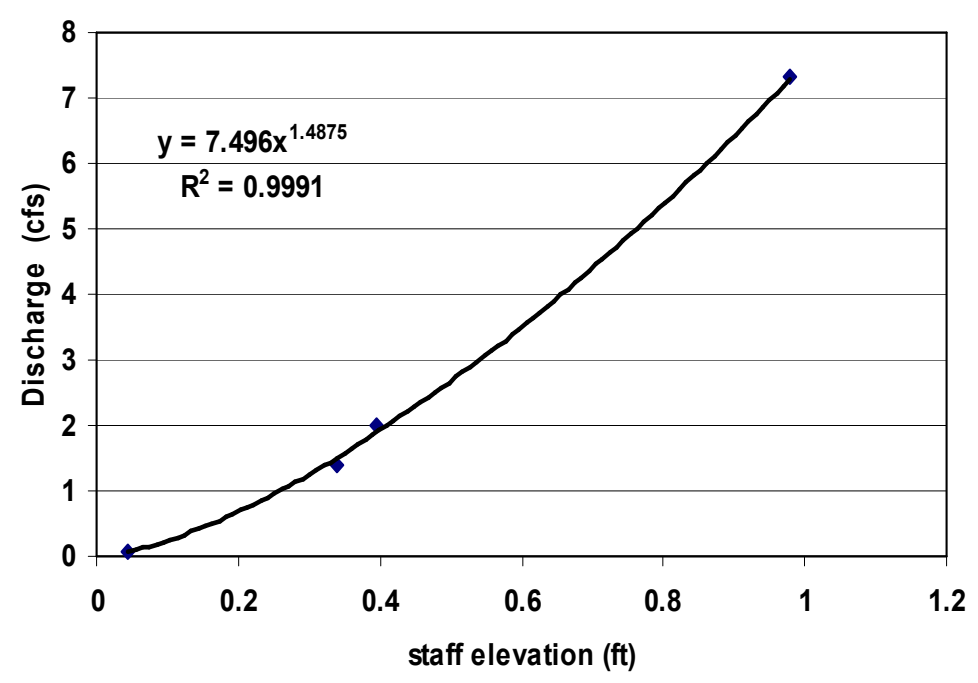

Figure 14. Stage discharge curve developed for Frazier Creek at mile 0.2 in Mav 2007.

\begin{tabular}{|c|c|c|}
\hline Date & Staff reading & Discharge \\
\hline 31-May-07 & 0.54 & ${ }^{*} 0.08$ \\
\hline 31-May-07 & 0.83 & ${ }^{*} 1.39$ \\
\hline 31-May-07 & 0.89 & ${ }^{*} 2.01$ \\
\hline 31-May-07 & 1.47 & ${ }^{*} 7.33$ \\
\hline 6-Jun-07 & 0.55 & ${ }^{* *} 0.11$ \\
\hline 8-Jun-07 & 0.8 & ${ }^{* *} 1.31$ \\
\hline 12-Jun-07 & 0.81 & ${ }^{* *} 1.38$ \\
\hline 18-Jun-07 & 0.68 & ${ }^{* *} 0.63$ \\
\hline 2-Jul-07 & 0.55 & ${ }^{* *} 0.11$ \\
\hline 18-Jul-07 & 0.55 & ${ }^{* *} 0.11$ \\
\hline 8-Aug-07 & 0.48 & ${ }^{* *} 0.0$ \\
\hline 12-Sep-07 & 0.5 & ${ }^{* *} 0.01$ \\
\hline 15-Sep-07 & 0.57 & ${ }^{* *} 0.18$ \\
\hline 27-Sep-07 & 0.56 & ${ }^{* *} 0.14$ \\
\hline 22-Oct-07 & 0.65 & ${ }^{* *} 0.49$ \\
\hline
\end{tabular}

* Discharge used to build rating curve ** Discharge calculated from staff reading

Table 3. Staff readings and discharge measurement on lower Frazier Creek, May through October 2007. vegetation above the middle and upper reservoirs and along the North Fork drainage show signs of heavy degradation from livestock grazing; however, the over-story is relatively dense providing shade to the stream channel. 
Flow and temperature monitoring

We investigated stream flow and temperature relationships in Frazier Creek during the summer of 2007. On May 31, 2007, we placed staff plate near the mouth (mile 0.2) and regulated reservoir outflows in order to develop a stage-discharge rating curve that would served to monitor stream flows during the irrigation season (Figure 14). Eleven staff readings were then taken on lower Frazier Creek and these recorded a discharge range $1.4 \mathrm{cfs}$ in June to no-flow in September (Table 3). During the flow evaluation, the majority of the water from upper Frazier Creek was stored in reservoirs and for irrigation use. The outlet flow to Frazier Creek was primarily from reservoir seepage.

Temperature sensors were placed at five locations (Figure 13, Appendix H). Maximum temperatures increased from $68^{\circ} \mathrm{F}$ to $78^{\circ} \mathrm{F}$ between the upper site (mile 1.2) located upstream of the upper Frazier Creek reservoir and the next downstream site (mile 0.4) downstream the middle reservoir. Sensors recorded some moderation in temperatures near the mouth (mile 0.1 ) with maximum temperature at $\sim 73^{\circ} \mathrm{F}$.

\section{Fish populations}

Frazier Creek supports a genetically "pure" disjunct population of stream-resident WSCT with no other fish species (Pierce et al 2006). Both Frazier Creek reservoirs provide holding areas for WSCT with reproduction and rearing occurring in the isolated reaches above each reservoir (Pierce et al 2000). Because of the fragmented headwaters and the loss of fisheries in the lower reaches, Frazier Creek is lacking sport fishery value to the Blackfoot River (Pierce et al 2005). Reestablishing complete upstream WSCT connectivity from the Blackfoot River is currently in conflict with irrigation practices and a concern given the potential for invasive (e.g. hybridizing) species, particularly under existing environmental (e.g. degraded habitat) conditions. However this stream-resident WSCT population has conservation value and potential for improvement by eliminating headwater fragmentation, ditch screening and implementing alternative riparian grazing strategies

\section{Gold Creek}

Restoration objectives: Restore pool habitat and morphological complexity; restore thermal refugia for Blackfoot River native fish species.

\section{Summary}

Gold Creek is the largest tributary to the lower Blackfoot River, entering at mile 13.5. The majority (90\%) of the Gold Creek watershed is industrial forest. Past harvest of riparian conifers combined with the actual removal of large wood from the channel reduced habitat complexity on the lower three-miles of Gold Creek. The result of this fish habitat simplification was low densities of age 1 and older fish. In 1996, we installed 66 habitat structures made of native material (rock and wood) constructing 61 new pools in the 3-mile section (Schmetterling and Pierce 1999). Prior to restoration work (1996), we established a baseline fish population survey section (mile 1.9) in the treated area for future monitoring. 
Fish Populations and other monitoring activities

Gold Creek is a major spawning tributary to the lower Blackfoot River for bull trout, WSCT, rainbow trout, and brown trout. Resident brook trout also inhabit the drainage. Gold Creek's mainstem and confluence area provides thermal refugia for Blackfoot River bull trout during periods of river warming.

In 2006 and 2007, we continued to monitor 1) postrestoration fish population monitoring in the project area (mile

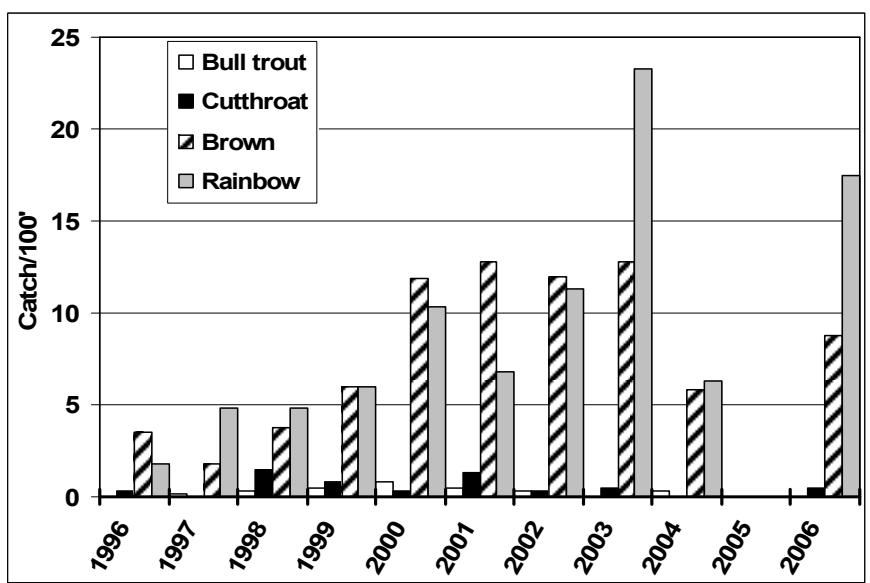

Figure 15. CPUE for age $1+$ fish in Gold Creek at mile 1.9, 1996 - 2006. 1.9), 2) bull trout redds, and 3) water temperatures and whirling disease near the mouth.

Fish population surveys show a 10-year upward trend in CPUE for fish $>4.0$ " within the restoration project area (Figure 15). However, these samples identify consistently low bull trout densities, and in 2006 we failed to detect bull trout in the monitoring sites. Our bull trout redd counts identified only one redd in 2007 and none in 2006 compared to seven in 2005 . Water temperature recordings at mile 1.9 show a nineyear warming trend (Executive Summary, Appendix H). Whirling disease tests in 2006 and 2007 near the mouth of Gold Creek have recorded no infection.

\section{Hoyt Creek}

Restoration objectives: Project objectives were to restore Hoyt Creek to its historic floodplain elevation for channel stability, wetland values, and irrigation efficiency improvement; maximize cooling influence on water temperatures, reduce sediment production in the downstream direction, maximize the quality of undercut bank habitat through riparian vegetation root mass and develop and implement a grazing management plan.

\section{$\underline{\text { Project Summary }}$}

Hoyt Creek, a small

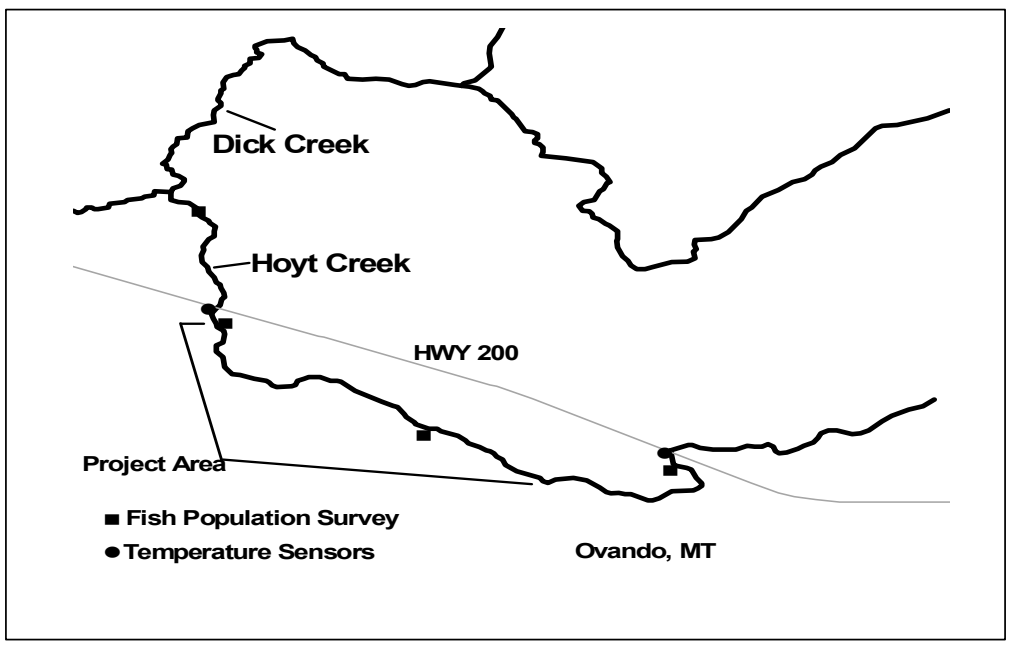

Figure 16. Hoyt Creek stream restoration project area, temperature sensor and fish population monitoring locations, 2006-2007.

$1^{\text {st }}$ order spring-fed tributary to Dick Creek, originates from alluvial aquifers located just 
north of Ovando and flows $\sim 4.5$ miles through private agriculture ranchland (Figure 16). Hoyt Creek has a history of agricultural impacts to fisheries, and these include channel instability (incision), irrigation dewatering, suppressed riparian vegetation, elevated water temperatures and damage to stream banks.

In 2006, middle Hoyt Creek (mile 1.3 to 3.4 ) underwent 1) channel reconstruction to an "E4-type" channel, 2) the restoration of 334-acres of herbaceous wetland, and 3) the placement of rock cross-vane diversion structure at two irrigation ditches. The stream channel substrate

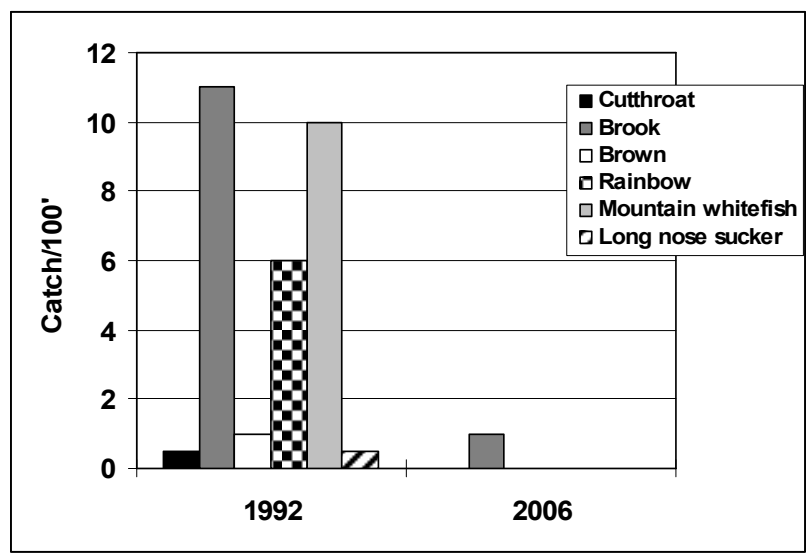

Figure 17. CPUE for fish sampled in Hoyt Creek at mile 0.2, 1992 and 2006. throughout the project was lined with gravel/cobble to assure the stability of the channel features and provide habitat. In 2007, native trees and shrubs were planted to facilitate riparian vegetation recovery.

\section{Fish Populations and other monitoring activities}

In 2006 and 2007, we completed several fish population surveys. These including a resurvey of a site established in 1992 near the mouth (mile 0.2), plus three upstream surveys (mile 1.2, 2.7 and 4.3) related to the reconstruction project (Appendix A). The original (1992) survey near the mouth was taken prior to the introduction $M$. cerebralis and the spread of whirling disease. We also recorded water temperatures (before/after and upstream/downstream) at two sites (Appendix H).

A comparison of the 1992 and 2006 fish population survey results at mile 0.2 identify a significant community-level loss of fish species in lower Hoyt Creek (Figure 17). This loss is difficult to explain; however, whirling disease is severe in nearby waters and may be a contributor although drought and adverse changes to physical habitat cannot be discounted.

At this early phase of postrestoration monitoring, fish populations at the two upstream sites have shown no response (Appendix A and $\mathrm{B})$. Water temperature at the downstream (mile 1.3) monitoring site identifies temperatures $>75^{\circ} \mathrm{F}$, which

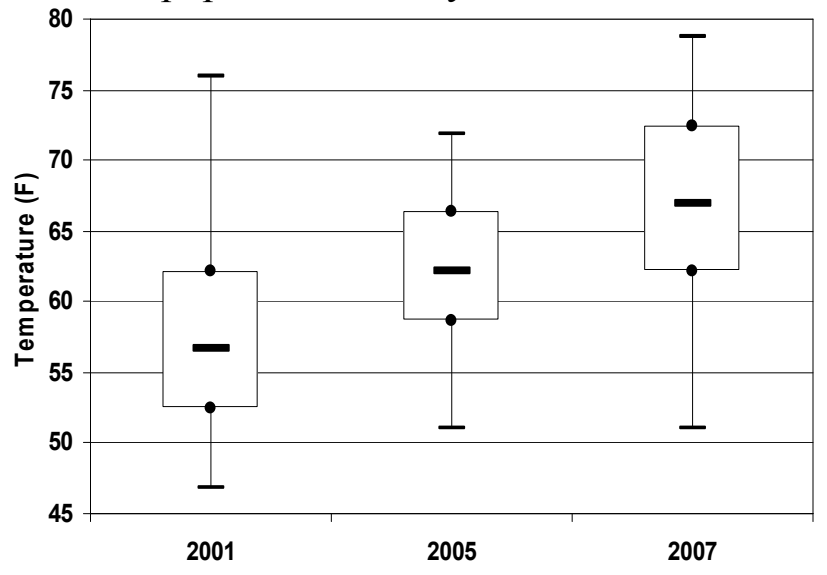

Figure 18. July water temperatures for Hoyt Creek at mile 1.3 for 2001, 2005 and 2007. exceed the suitable range necessary for salmonids (Figure 18). Summary statistics for all water temperature monitoring are located in Appendix H. 


\section{Jacobsen Spring Creek}

Restoration objectives: Maximize secondary instream productivity; maximize quality of shoreline rearing areas; restore spawning site potential by reducing levels of fine sediment in riffles to a level suitable for spawning; reduce summer water temperatures suitable for bull trout $\left(<60^{\circ} \mathrm{F}\right)$; provide high quality pools with high level of complex maximize use of existing channel beltwidth and existing shoreline areas.

\section{Project Summary}

Jacobsen Spring Creek forms from two spring creeks that merge at mile 0.7 and generate a base-flow of 4-7cfs near the mouth

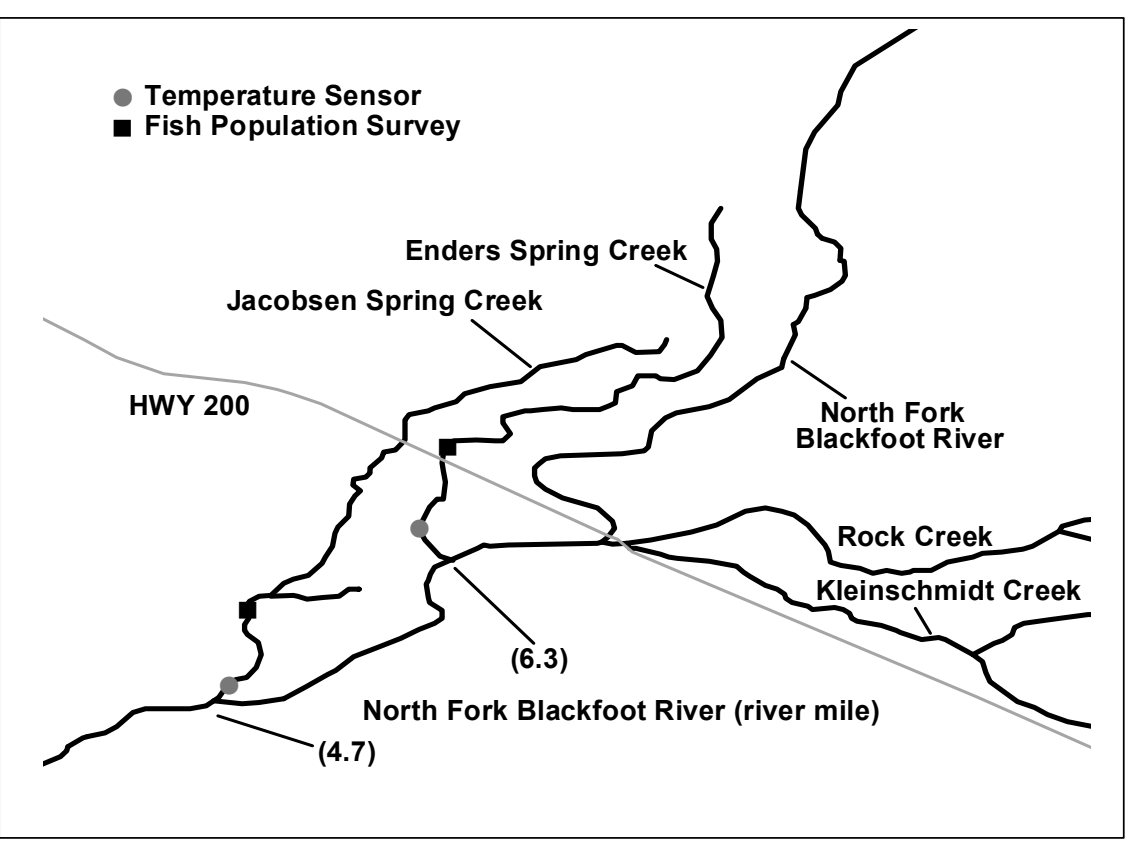

Figure 19. Jacobsen Spring Creek stream channel restoration area and fish population survey location, 2007.

(Figure 19). This small

spring creek system enters the North Fork of the Blackfoot River at mile 4.7. According to landowner accounts, Jacobsen Spring Creek historically supported both bull trout and WSCT.

Jacobsen Spring Creek was severely degraded due to historic grazing and timber

\section{Channel measurements}

Stream Channel Length

Sinuosity

Total \# Pools

\# Sampled Pools

Pool Frequency

\# Pools Measured with LWD

Pool Length

Wetted Pool Surface Area

Maximum Pool Depth

Wetted Pool Width @ Max Depth

Wetted Width @ Riffle Crest

Bankfull Width @ Max Pool Depth

Bankfull Width @ Riffle Crest

Riffle Crest Depth

Residual Pool Depth
Pre-restoration

3150

1.2

19

10

$6.0 / 1000 \mathrm{ft}$

$9(90 \%)$

$37 \pm 21(14-79)$

$858 \pm 626(224-1859)$

$1.7 \pm 0.7(0.9-3.3)$

$20 \pm 10(9-44)$

$24 \pm 12(8-47)$

$21 \pm 10(9-44)$

$24+12(8-47)$

$0.6 \pm 0.2(0.4-0.9)$

$1.1+0.7(0.3-3)$

Post-restoration \% change

\begin{tabular}{cc}
3800 & 20.6 \\
1.4 & 16.7 \\
58 & 205 \\
29 & 190 \\
$15.3 / 1000 \mathrm{ft}$ & 155 \\
$28(97 \%)$ & 211 \\
$21 \pm 6(13-34)$ & 43 \\
$208 \pm 52(112-299)$ & -76 \\
$3 \pm 0.4(2-3.4)$ & 76 \\
$11 \pm 2(7-14)$ & -45 \\
$9 \pm 2(7-14)$ & -62 \\
$12 \pm 2(9-19)$ & -43 \\
$11 \pm 2(8-16)$ & -54 \\
$1 \pm 0.2(0.5-1.5)$ & 67 \\
$1.7 \pm 0.3(0.8-2.2)$ & 55 \\
\hline
\end{tabular}

All measurementsin standard (ft) units

Table 4. Pre-and post restoration channel measurements for the lower 0.7 miles of Jacobsen Spring Creek. 
harvest practices, the consequences of which include an over-widened stream channel, low sinuosity, elevated water temperatures and excessive sediment loading (Pierce et al 2006). However, early habitat investigations identified the spring creek as possessing the basic habitat components necessary for improved fisheries such as stable groundwater inflows, gravel substrate and a relatively dense riparian spruce forest that has potential to provide shade, complexity, and wood to the stream channel.

Between 2005 and 2007, the entire 17,220' of Jacobsen Spring Creek (both channels) was

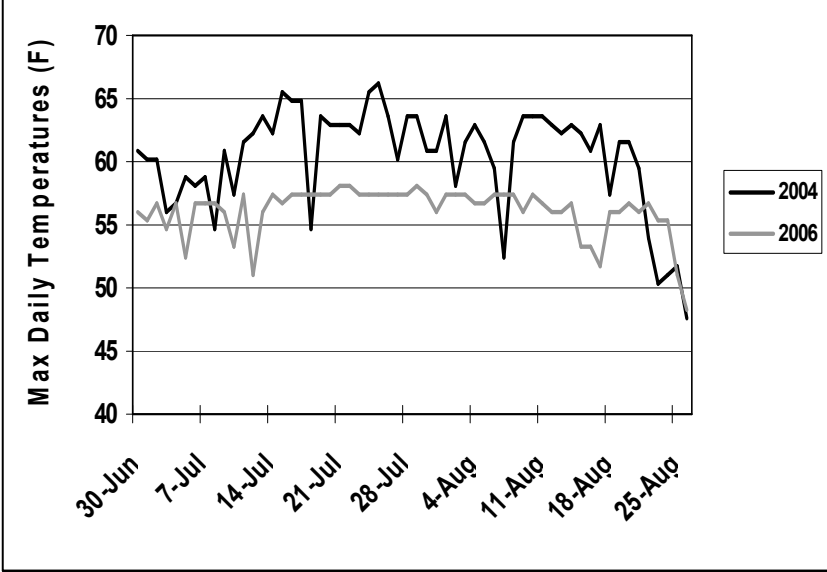

Figure 20. Pre (2004) and post-project (2006) max \min daily waters temperatures for Jacobsen Spring Creek near mouth, summer 2004 and 2006. reconstructed. The project emphasized a deep and narrow channel with higher sinuosity, the inclusion of backwater and shoreline rearing areas, gravel in pool tail-outs, and the placement of instream wood and sod mats on the stream banks to facilitate recovery. The project also included shrub plantings and the adoption of livestock management changes consistent with project objectives.

Fish Populations and other monitoring activities

In 2006-07, we returned to at our pre-project baseline monitoring locations and completed 1) a post-project habitat survey downstream of mile $0.7,2$ ) a fish population survey site (mile 0.6 ) established in 2005, and 3) water temperature monitoring site near the mouth.

A comparison of the preand post habitat survey results are presented in Table 4. Among the changes to the physical channel, our survey results show a $48 \%$ decrease in the wettedwidth of the channel and a $76 \%$ increase in pool depth. Water temperature changes include a $10^{\circ} \mathrm{F}$ reduction in maximum summer temperatures between the pre-project (2004) and postproject (2006) (Figure 20,

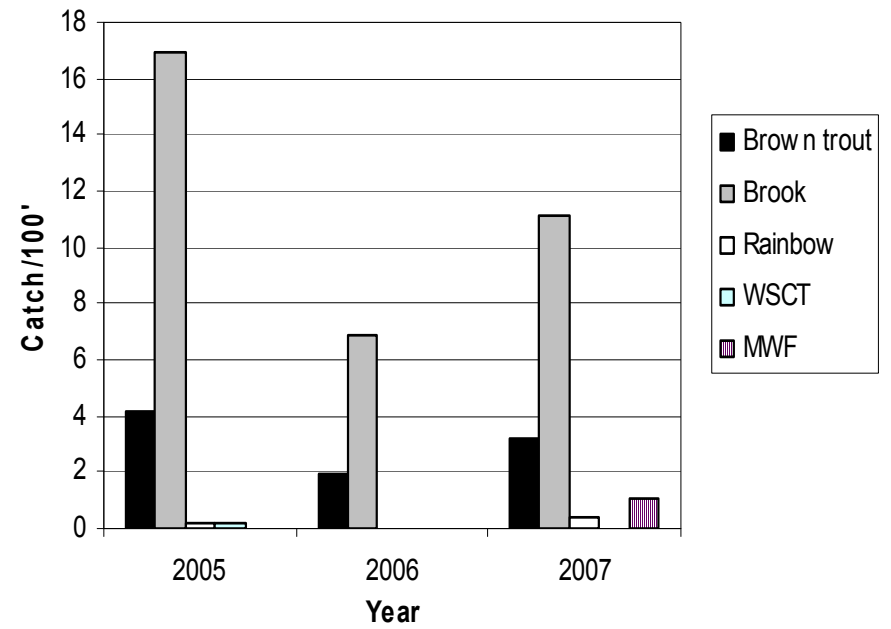

Figure 21. CPUE for salmonids in Jacobsen Spring Creek at stream mile 0.6, 2005-2007. Appendix $\mathrm{H})$. 
At this early stage of post-project fisheries monitoring, fisheries have expressed no appreciable change (Figure 21); however, rainbow trout spawning (redds) were identified in Jacobsen Spring Creek in the spring of 2007 and rainbow alevins were present in constructed backwater areas during the 2007 surveys. Mountain whitefish, absent from previous surveys, were also identified in the new channel in 2007. With summer temperatures now cooler than lower North Fork, Jacobsen spring creek should attract an increased level of bull trout use in the future.

\section{Kleinschmidt Creek}

Restoration objectives: Reduce whirling disease infection levels; restore stream channel morphology for all life stages of trout; increase recruitment of trout to the Blackfoot River; and restore thermal refugia and rearing areas for North Fork Blackfoot River bull trout.

\section{Project Summary}

Kleinschmidt Creek, a spring creek tributary with a base flow of $\sim 9 \mathrm{cfs}$, joins with Rock Creek at mile 0.1 before entering the North Fork of the Blackfoot River at mile 6.2. Kleinschmidt Creek has a long history of stream degradation involving livestock over-use and channel alterations related to instream rock dams, undersized culverts and highway channelization (Pierce 1991). Restoration of Kleinschmidt Creek began in 1991, and expanded substantially in 2001 with 6,250 ' of stream reconstructed to a longer $\left(8,494^{\prime}\right)$, narrower, deeper and more sinuous channel. The work has reduced water maximum water temperatures from a high of $\sim 70^{\circ} \mathrm{F}$ to $<60^{\circ} \mathrm{F}$ (Pierce et al 2006). In 2006 restoration continued with $\sim 600^{\prime}$ of channel reconstruction and riparian grazing changes in the upper-most perennial section of stream. Summaries of pre-and post-project fisheries and related assessments (water temperatures, discharge, substrates, channel morphometrics and whirling disease) are described in Pierce et al. 1997; 2002; 2004; and 2006.

Fish Populations and other monitoring

During the 2006 and 2007, we resurveyed at two locations (mile 0.5 and 0.8 ) of lower Kleinschmidt Creek established in 1998 prior to channel reconstruction. These sites were established to assess

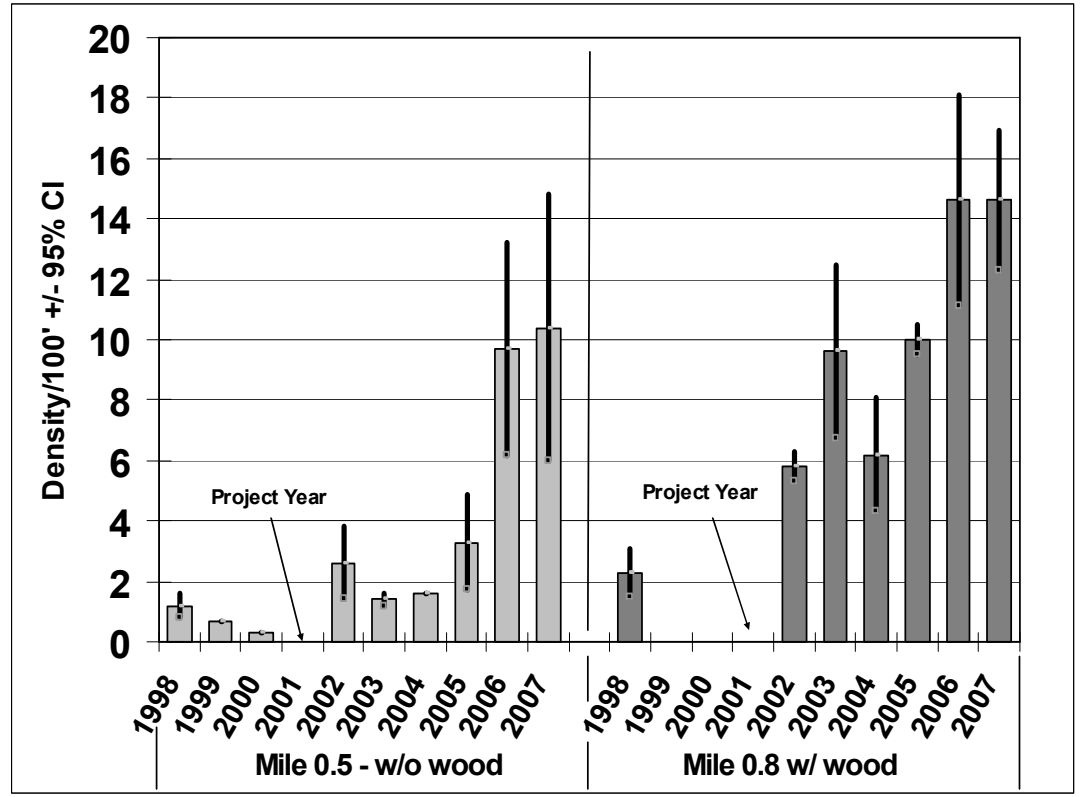

Figure 22. Estimated densities of age 1 and older brown trout in two sections of Kleinschmidt Creek, 1998-2007. 
restoration techniques involving the placement of large instream wood into E4-type channels. We placed no instream wood in the reconstructed channel at mile 0.5, whereas the rest of the channel, including the mile 0.8 survey site, included instream wood placements.

Both sites show higher densities of age 1 and older brown trout compared to the pre-project periods; however the section with wood has continuously recorded higher brown trout densities (Figure 22). WSCT and bull trout were not detected in the two monitoring section between 1998 and 2003; however both native species were consistently identified in very low densities in the section with wood (mile 0.8) in recent years.

\section{Lincoln Spring Creek}

Restoration objectives: Improve overall habitat conditions, improve spawning and rearing habitat for salmonids, eliminate fish passage barriers, and improve water quality conditions.

\section{Project Summary}

Lincoln Spring Creek is a large spring creek tributary to Keep Cool Creek, which enters the Blackfoot River at mile 105.2. This $1^{\text {st }}$-order, low-gradient spring creek is $\sim 6.3$ miles in length (Figure 23) and originates from an alluvial aquifer under the Lincoln Valley and generates variable base-flow that seasonally rises and falls with the aquifer. The stream flows west through private ranchland and the town of Lincoln before entering Keep Cool Creek at mile 0.6. It is primarily a gravel based stream with a surrounding spruce riparian over-story.

Fisheries-related impairments include irrigation practices, heavy livestock grazing and residential impacts and undersized culverts. The activities have suppressed riparian vegetation and contribute to an over-widened and shallow stream channel, fine sediment loading and generally simplified fish habitat.

The
Blackfoot
Cooperators led
by BBCTU are
currently
reconstructing the
upper $\sim 8,000$ ' of
Lincoln Spring
Creek (mile 2.9 to
4.6). Specific
restoration

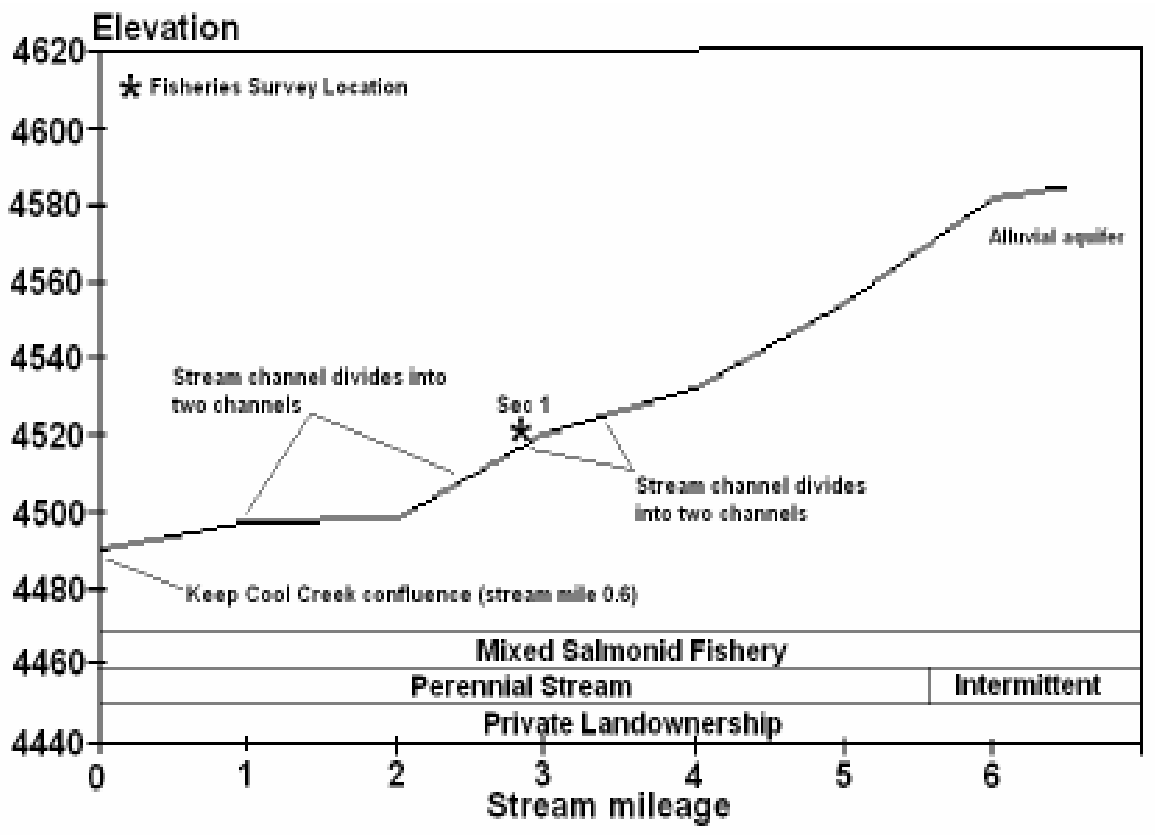

Figure 23. Longitudinal profile for Lincoln Spring Creek. 
improvements include a more narrow and deepening channel with increased stream sinuosity, placement of instream wood, re-vegetate stream banks, removal of three undersized culverts and irrigation ditch screening. The project hopes to benefit salmonids by reducing temperature and sediment levels and restoring movement corridors.

Fish Populations and other monitoring activities

Based on historical accounts, Lincoln Spring Creek once supported bull trout and WSCT. In 2007, we conducted a pre-restoration fish population survey at mile 2.8 in Lincoln Spring Creek. Sampling recorded a brook trout salmonid community with sculpins (Appendix A and B). Native salmonids were not detected in this or previous Lincoln Spring creek surveys (Pierce et al. 1997).

\section{McCabe Creek}

Restoration objective: Restore instream flows and habitat conditions for bull trout and WSCT. Eliminate entrainment of WSCT to irrigation ditches

\section{Project Summary}

McCabe Creek, a cold basin-fed tributary to lower Dick Creek, enters at stream mile 3.8 with a base flow of $\sim 4 \mathrm{cfs}$. McCabe Creek begins as a steep mountain stream in its headwaters, before entering knob-and-kettle topography in the lower basin. In lower reaches, McCabe Creek passes through a beaverinfluenced wetland bog before entering Dick Creek, a lower tributary to Monture Creek.

McCabe Creek has a long history of adverse fisheries impacts related to channel alterations and agricultural activities. These include intensive riparian grazing, physical alterations to the channel,

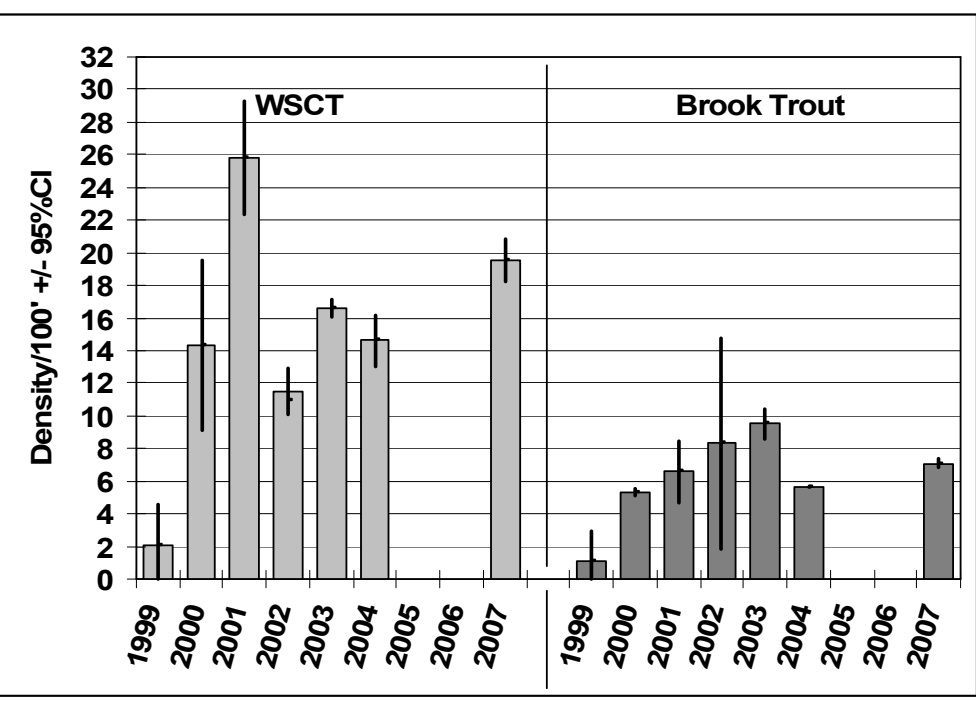

Figure 24. Densities of age 1 and older fish in McCabe Creek at mile 2.2, 1999-2007. poorly designed road crossings, chronic dewatering, and fish losses to irrigation ditches.

A comprehensive restoration project for McCabe Creek began in 1999 and continued through 2002 (Pierce et al. 2004). This project: 1) consolidated four irrigation ditches into one pipeline and screened the intake; 2) converted flood to sprinkler irrigation thereby enhanced stream flows by $3-5 ; 3$ ) restored habitat conditions including the placement of instream wood and shrub plantings along $1 / 2$ mile of stream; 4) implemented grazing changes and developed off-stream livestock water; and 5) replaced a county road culvert with an open-bottom box culvert. Benefits to fish population relate 
to increasing stream flows, reducing water temperatures in Dick Creek, eliminating WSCT losses to ditches, and restoring habitat complexity to a damaged stream channel.

\section{Fish Populations}

McCabe Creek is a WSCT dominated stream, with brook trout present in lower stream reaches. Due to cool summer temperatures, McCabe Creek likely supported bull trout historically. In 1999, prior to restoration, we established a fish population survey section in a degraded section of stream (mile 2.2), an area of low habitat complexity and chronic low flows.

In 2006, we continued to monitor fisheries at mile 2.2 (Figure 24). Both WSCT and brook trout (age 1 and older) have increased in the project area compared to the preproject (1999) condition. Less encouraging is an increase in brook trout at the monitoring site.

\section{Monture Creek}

Restoration objectives: Restore habitat for spawning and rearing bull trout and WSCT; improve recruitment of bull trout and WSCT to the Blackfoot River; improve staging areas and thermal refugia for fluvial bull trout.

\section{Project Summary}

Monture Creek, a large tributary to the middle Blackfoot River, is a primary spawning and rearing tributary for fluvial bull trout and fluvial WSCT (Swanberg 1997, Schmetterling 2001). Monture Creek also serves as thermal refugia for fluvial bull trout during periods of Blackfoot River warming. Reproduction of WSCT and bull trout occurs primarily in the mid-to-upper basin. Fluvial rainbow trout inhabit and reproduce the lower portions of the drainage (Results Part V). Brook trout are found in the lower basin downstream of the intermittent reach at mile 14 (Results Part VII). In addition to monitoring in the lower Monture Basin, in 2006-07 we also inventoried tributary fisheries and lakes in the backcountry of the upper Monture Creek basin and several tributaries (Results Part VII).

Riparian areas in the mid-to-lower reaches of Monture Creek have a long history of riparian timber harvest and improper grazing practices, with resulting adverse impacts to riparian habitats (Fitzgerald 1997). All lower tributaries of Monture Creek from Dunham Creek downstream likewise were identified as fisheries-impaired (Appendix F). Many identified problems were corrected through a decade of cooperative restoration activities (Pierce et al. 1997; Pierce et al. 2001), which contributed to improving the health of Monture Creek. Despite improvement, excessive livestock access continues in certain riparian areas of lower Monture Creek.

\section{Fish Populations and other monitoring}

Monitoring for 2006 and 2007 period included: 1) bull trout redd counts; 2) assessments of juvenile bull trout abundance at one long-term monitoring station; 3 ) water temperature monitoring; 4) continued whirling disease studies; and 5) radio telemetry study involving fluvial rainbow trout from the Blackfoot River.

Bull trout redd counts have been upward trending since restrictive angling regulations in 1990, but also show a sharp recent decline (see Figure 5 Executive 
Summary). This downturn is consistent with other drought-related bull trout declines in the lower Blackfoot Basin. Likewise, assessments of juvenile bull trout abundance at a long-term monitoring station revealed increases through the 1990s, but also a recent decline proportional to declining redds (see Figure 6 Executive Summary).

Results from a rainbow trout telemetry study clearly identify lower Monture Creek as the primary spawning tributary for the middle Blackfoot River upstream of Clearwater River. Spawning occurred primarily in lower Monture Creek, but extended upstream as far as lower Dunham Creek (Results Part V).

Lower Monture Creek first tested positive for whirling disease in 2000. Since then, whirling disease in the primary rainbow spawning areas have increased to a severe level (mean grade infection $>4.0$ on the MacConnell Baldwin scale, Results Part V). Conversely, whirling disease tests near native fish spawning areas located on the National Forest (mile 12.6) have failed to detect the disease in both 2006 and 2007.

Water temperature monitoring in 2006-2007 was completed at two sites (miles 2.0 and 12.9). This data shows significant warming in the downstream direction (Appendix $\mathrm{H})$ and a long-term ( $>10$-year) trend of increasing temperatures in lower Monture Creek (see Figure 7 Executive Summary).

\section{Murphy Spring Creek}

Restoration objectives: Restore habitat conditions suitable to WSCT and juvenile bull trout; prevent irrigation ditch losses; maintain minimum instream flows and provide rearing and recruitment for fluvial bull trout and cutthroat trout to the North Fork.

\section{Project Summary}

Murphy Spring Creek, a small WSCT dominated tributary, originates on the north side of Ovando Mountain and flows six miles south and enters the North Fork at mile 9.9. Murphy Spring Creek has a history of irrigation impacts and fish passage problems (Pierce et al. 2006). Irrigation problems involve chronic dewatering and entrainment of WSCT to the Murphy ditch at mile 1.8. Fish passage problems involved an undersized culvert at mile 0.5 and the defunct condition of the Murphy diversion. The culvert reduced the upstream movement of juvenile bull trout from the North Fork, while the diversion reduced downstream movement of WSCT from the headwaters to the North

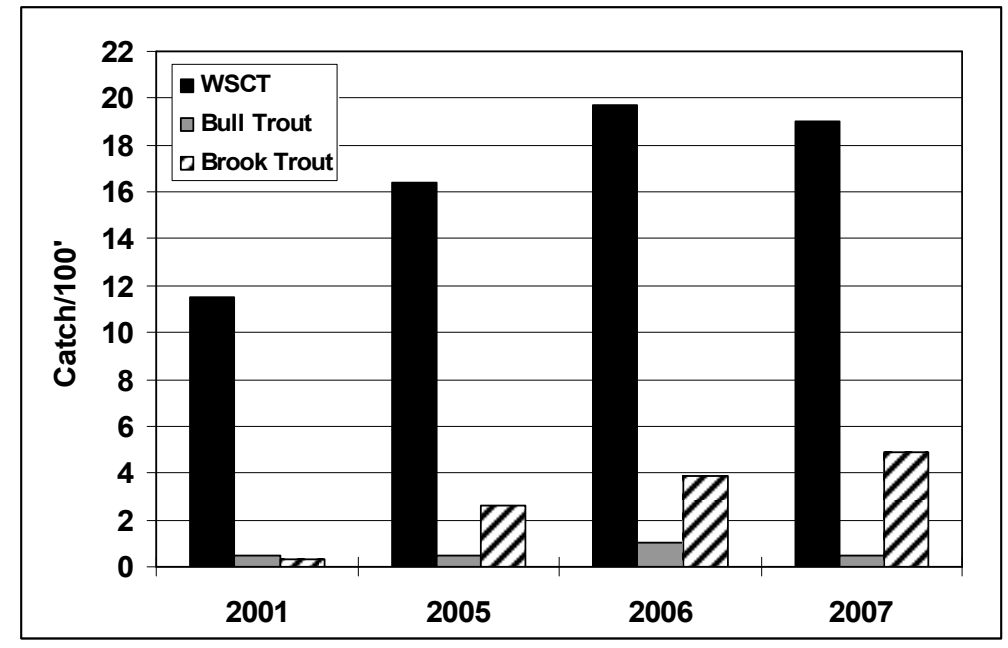

Figure 25. CPUE for salmonids in Murphy Spring Creek at mile 0.6, 2001-2007.

Fork through dewatering and entrainment. 
The Murphy Spring Creek restoration project began in 1998 with the installation of a new diversion fitted with a Denil fish ladder. In 2000, we replaced the culvert with a larger baffled culvert designed to allow the upstream movement of YOY bull trout. In 2004-05, the Blackfoot Cooperators expanded restoration actions by developing an instream flow agreement that granted habitat maintenance flows as well as a 2.2 cfs minimal instream flow in Murphy Spring Creek. In 2006, a Coanda fish screen was placed at a diversion as a measure to eliminated losses of WSCT.

Fish population and other monitoring activities

Fish population surveys conducted in 2006 and 2007 show a modest increase in numbers for all salmonids. Prior to 2001, bull trout were absent from this location. Brook trout densities have also increased at this site (Figure 25).

\section{Nevada Spring Creek}

Restoration objectives: Restore habitat suitable for cold-water trout; improve downstream water quality, and reduce thermal stress in Nevada Creek and the Blackfoot River.

\section{Project Summary}

Nevada Spring Creek, a tributary of lower Nevada Creek, originates from an artesian spring and flows through agricultural lands to its junction with Nevada Creek at mile 6.2. The spring source produces between six and nine cfs. Nevada Spring Creek is joined near the source by Wasson Creek, a small, basin-fed tributary that brings and additional base flow approximately two cfs during the nonirrigation season. Water temperatures at the artesian source are a constant yeararound $44^{\circ} \mathrm{F}$.

Restoration of Nevada Spring Creek has been ongoing for several years. A habitat restoration project for the entire 4.2 miles of Nevada

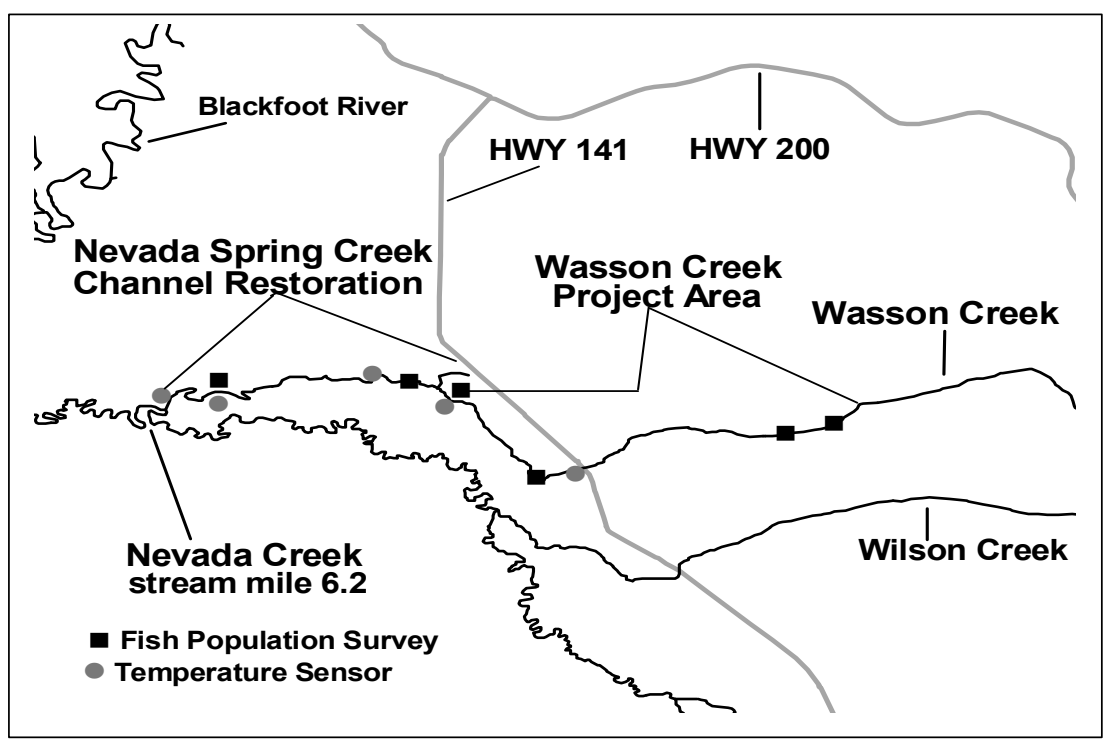

Figure 26. Nevada Spring Creek stream channel restoration project area and fish population survey and temperature sensor locations, 2007.

Spring Creek was completed between 2001 and 2004. The project entailed the complete reconstruction of Nevada Spring Creek, riparian grazing changes, instream flow enhancement, wetland restoration and shrub plantings. Prior to restoration, summer water temperatures in the lower portion of Nevada Spring Creek exceeded $>75^{\circ} \mathrm{F}$ due in part an over-widened channel (Pierce et al. 2002). This warming and agricultural runoff 
from adjacent lands contributed to water quality degradation, and created unsuitable habitat conditions for coldwater salmonids in the lower portion of Nevada Spring Creek (Pierce et al. 2002). A complete before and after summary of channel measurements is located in a previous monitoring report (Pierce et al. 2006).

Fish populations and other monitoring activities

Prior to channel restoration, Nevada Spring Creek supported low densities of brown trout in upper reaches and non-game species (redside shiners, northern pikeminnow, and largescale sucker) in lower reaches (Pierce et al 2002). WSCT were historically abundant in Nevada Spring Creek based on accounts by a long-term landowner (Frank Potts, personal communication).

In 2006 and 2007, we continued post-project fish population monitoring at two sites (mile 3.5 (upper site near the

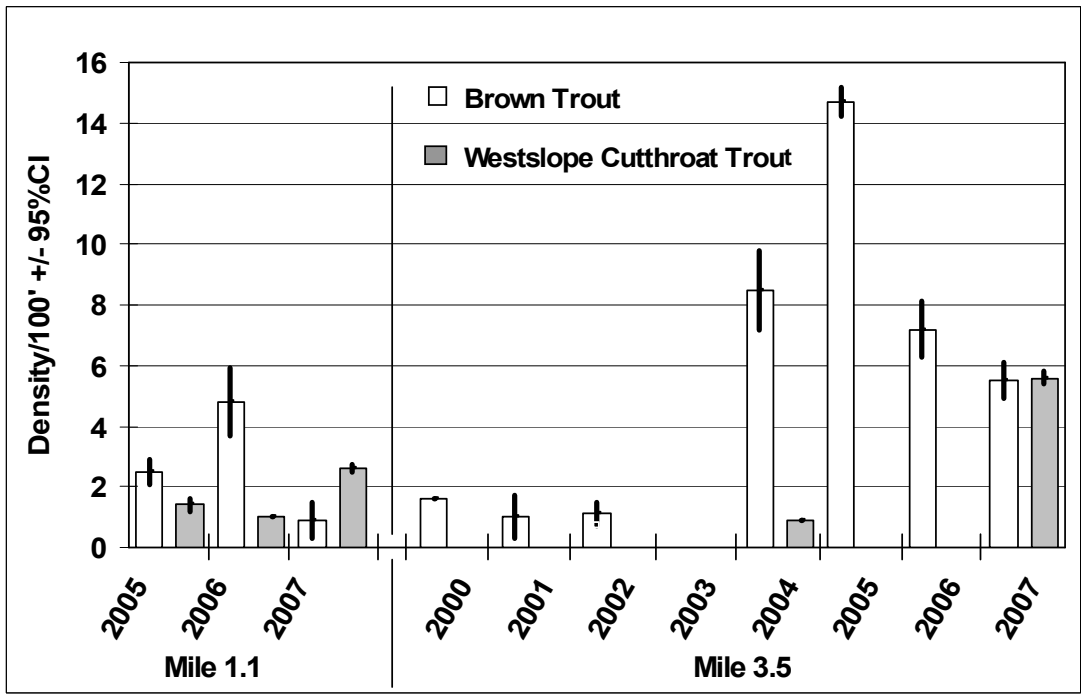

Figure 27 Densities for age 1 and older salmonids at two locations on Nevada Spring Creek, 2000-07.

source) and 1.1 (lower site)), and water temperatures and whirling disease monitoring near the mouth. spring Near the densities of age 1 and older brown trout have recently declined; however, WSCT densities show a large recent increase (Figure 27). The brown trout decline

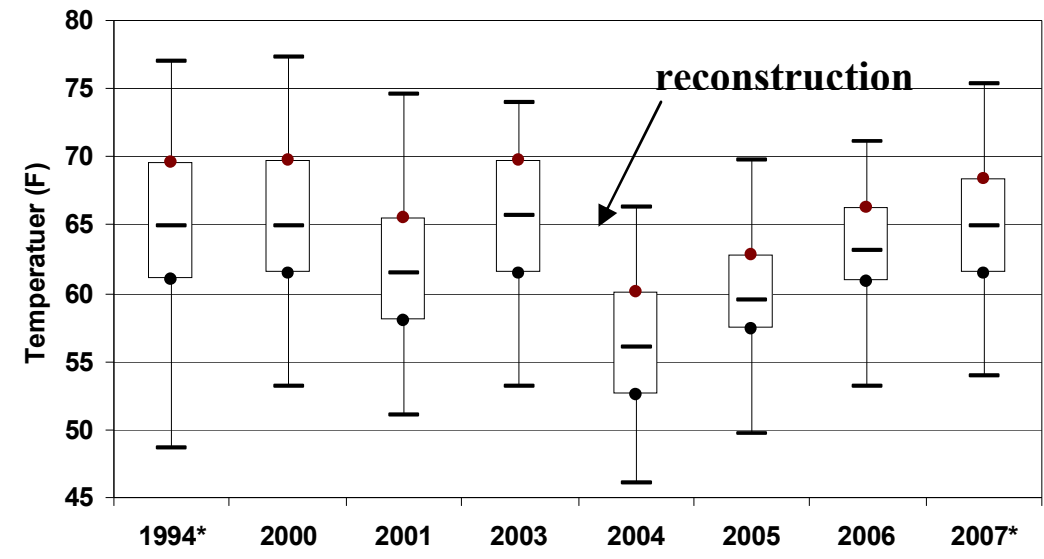

Figure 28. July water temperatures for Nevada Spring Creek near the mouth, 1994, and 2000-2007. appears to relate to a reduction in juvenile recruitment. By contrast, the sharp increase in WSCT densities coincides with upstream restoration and the screening of fish from two upstream irrigation ditches in Wasson Creek (see Wasson Creek section). 
Water temperature monitoring near the mouth shows recent increases in water temperature from 2004 through 2007 with temperatures now approaching pre-project levels (Figure 28). These increases began one year after channel reconstruction and result from loss of cooler spring water to off-channel wetland cells. In 2007, the warming exceeded $>75^{\circ} \mathrm{F}$. Options to correct to this problem are now being examined.

Whirling disease monitoring in 2006 found a mean 1.97 grade infection compared to 2.2 of 2005 (Results Part IV).

\section{Pearson Creek}

Restoration objectives: Improve status of WSCT population and increase recruitment of fluvial WSCT to the Blackfoot River.

\section{Project Summary}

Pearson Creek is a small $2^{\text {nd }}$ order tributary to Chamberlain Creek with a baseflow of one cfs. Pearson Creek has a history of channel alterations and adverse irrigation and riparian land management (grazing and timber harvest) practices in its lower two-miles of channel. Beginning in 1994, Pearson Creek has been the focus of a holistic restoration project involving channel reconstruction and instream habitat work, instream flow enhancement (water leasing), conservation easements and riparian grazing changes. Additional riparian grazing

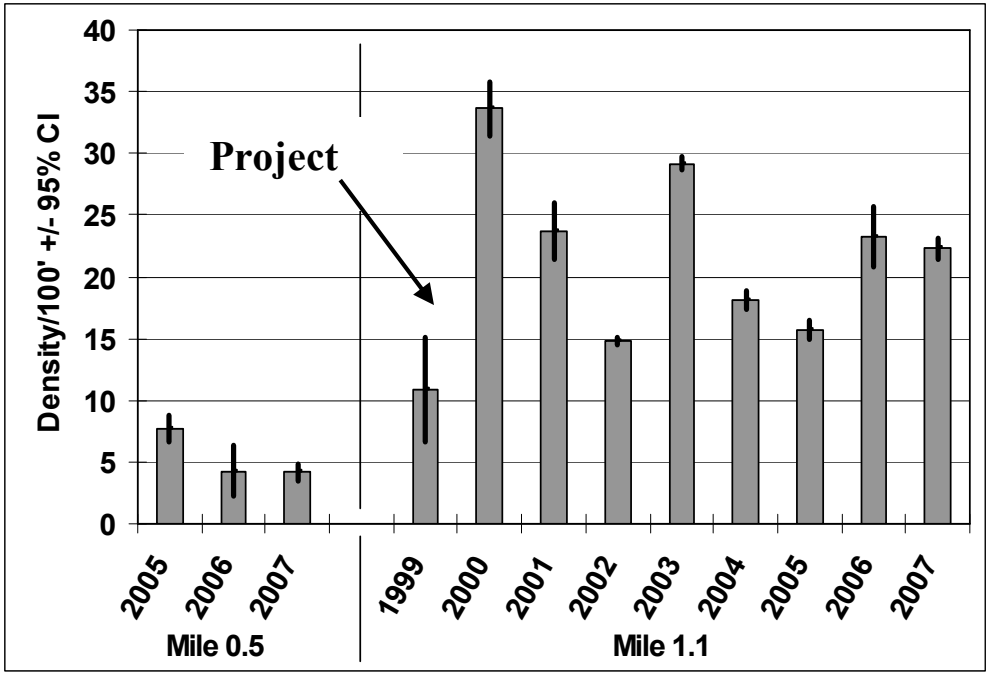

Figure 29. Densities of age 1 and older WSCT in Pearson Creek at miles 0.5 and 1.1, 1999-2007. improvements completed in 2006 included riparian corridor fencing for the lower two miles of stream, off-stream water developments and armoring a road crossing.

\section{Fish Populations}

Pearson Creek is a fluvial WSCT spawning stream connected to the Chamberlain Creek WSCT population. In 2006 and 2007, we continued fish population monitoring at two sites in lower Pearson Creek. The upstream site (mile 1.1) was established in 1999 prior to instream restoration activities. Following an initial increase between 1999 and 2000, age 1 and older WSCT have remained static at higher densities. In 2005, we established the downstream site (mile 0.5 ) following the degradation of stream banks by cattle. Fish population sampling results for both sites are summarized in Figure 29. 


\section{Poorman Creek}

Restoration objectives: Improve riparian habitat conditions and enhance instream flows; restore migration corridors; improve recruitment of native fish to the Blackfoot River.

\section{Project Summary}

Poorman Creek, one of the larger tributaries from the Garnet Mountains and it enters the Blackfoot River at river mile 108. Poorman Creek has been identified with hardrock and placer mining, irrigation dewatering, fish losses to ditches, channel instability, excessive riparian grazing pressure, subdivision impacts and multiple undersized culverts. Beginning in 2002 and continuing through the present, a comprehensive

restoration projects was implemented on lower Poorman Creek.

Restoration projects involved instream flow enhancement and ditch screening through the flood-to-sprinkler irrigation conversion, culvert to bridge replacements and riparian grazing changes (corridor fencing, off-stream water) and shrub plantings. Lower Poorman Creek is now entering the passive recovery phase. The recovery of riparian plant communities and

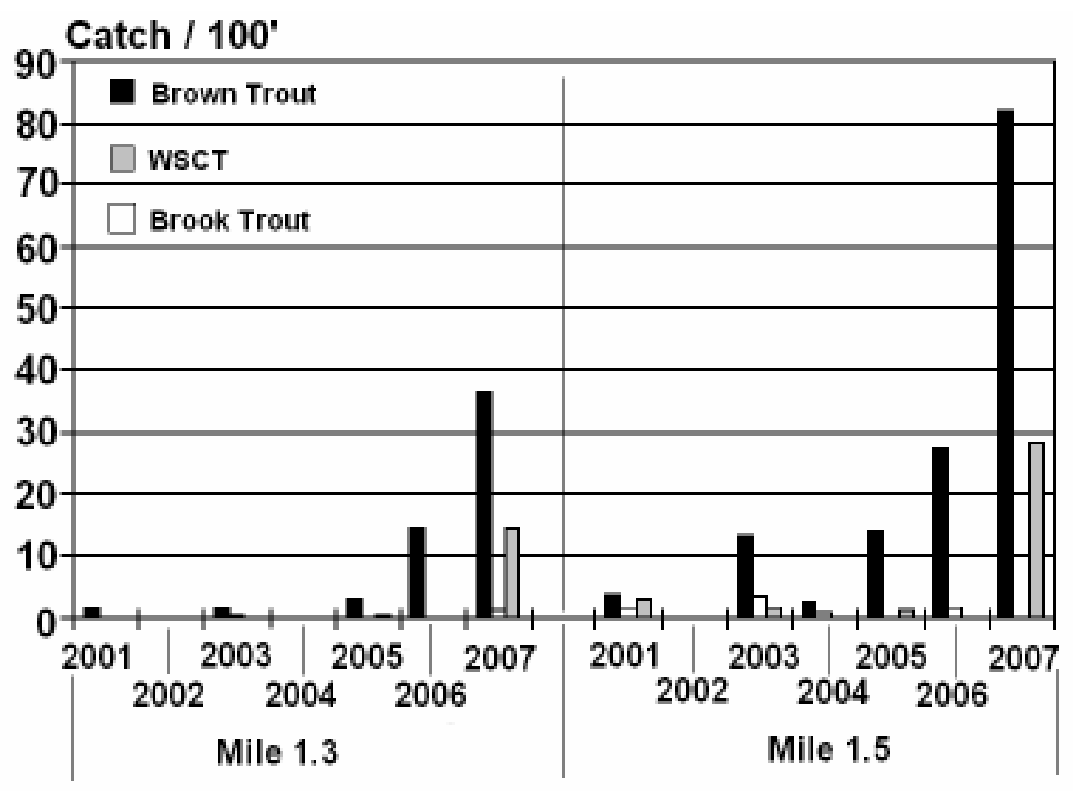
improved channel

Figure 30. CPUE for fish in Poorman Creek at two locations, 2001-2007.

stability now hinges on the continuation of compatible grazing practices, a process expected to take several years. Several upstream culverts were also recently replaced with structures that allow fish passage on the Stemple Pass County Road through the combined assistance of the Blackfoot Cooperators.

Fish Populations and other monitoring activities

Poorman Creek supports genetically pure WSCT, brown trout and brook trout, and is one of only two known Garnet Mountain stream that still supports bull trout reproduction. Native fish densities increase in the upstream direction while non-native fish occupy lower Poorman Creek.

In 2006-07, we repeated fish population surveys at two sites (mile 1.3 and 1.5) in lower Poorman Creek (Figure 30). In 2001, these sites were established up-and downstream of active irrigation diversion and prior to flow enhancement and passive restoration actions. Recent survey results suggest an initial favorable population response 
for brown trout and WSCT (mostly age 0 fish) up-and downstream of the irrigation conversion project area.

Water temperature and whirling disease monitoring was conducted in 2007 at mile 2.2. Water temperature statistical results are found in Appendix H. Whirling disease identified a sharp increase in the severity of whirling disease with a mean grade infection of 4.69 compared to 0.78 in 2004.

\section{Rock Creek}

Restoration objectives: Restore migration corridors for native fish; restore natural stream morphology to improve spawning and rearing conditions for all fish using the system.

\section{Project Summary}

Rock Creek, a basin-fed stream over most of its length, receives significant groundwater inflows downstream of mile 1.6. Rock Creek is the largest tributary to the lower North Fork of the Blackfoot River, but has been degraded over most of its 8.2-mile length due to a wide range of past channel alterations and riparian management activities (Pierce 1990; Pierce et al. 1997, 2006). Rock Creek has also been the focus of continued restoration since 1990. Restoration actions involved working with 13 separate landowners on grazing improvements, instream flow enhancement, and channel reconstruction and revegetation.

"Active" restoration is now completed over the entire length of Rock Creek and its primary tributaries, the South Fork of Rock Creek, Salmon Creek and Dry Creek. From this time forward, project success hinges on the ability of all cooperators to managing instream flows and livestock in riparian area, while allowing the passive recolonization of woody riparian plants. Recovery of riparian areas, including plant communities, will take many years.

Fish Populations and other monitoring activities Rock Creek supports a mixed salmonid community. Rock creek provides spawning of brown trout and rainbow trout in lower reaches, a resident brook trout population, limited bull trout rearing and a migration corridor for

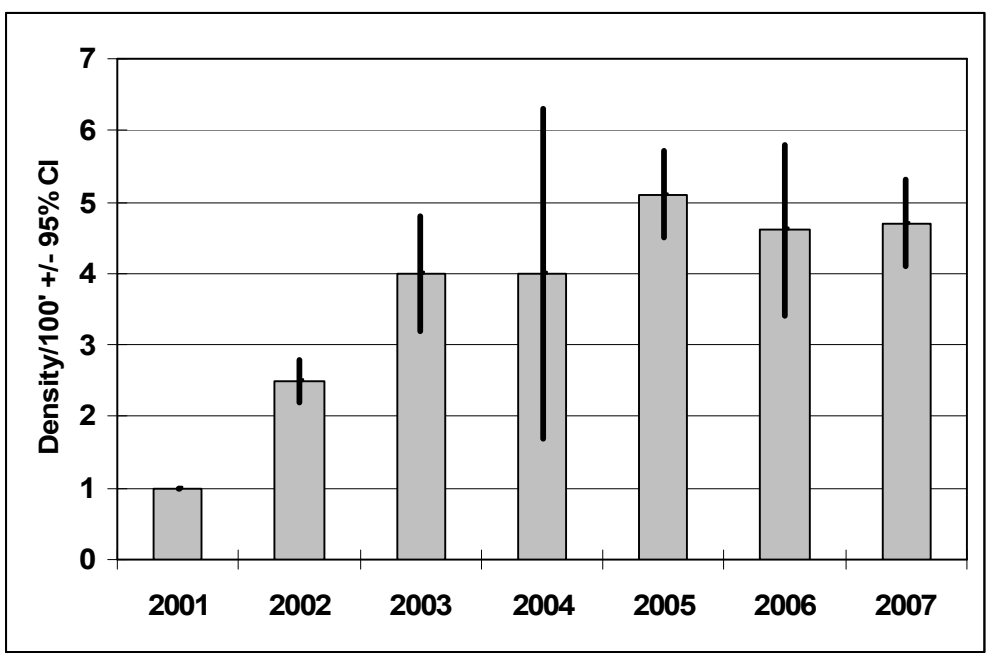

Figure 31. Densities of age 1 and older brown trout in Rock Creek at mile 1.6, 2001-2007.

fluvial WSCT to headwater areas.

In 2006 and 2007, we continued to monitor fish populations in lower Rock Creek (mile 1.6) where the stream was reconstructed in 1999. We also resurveyed fish populations at three upstream sites (miles 3.9, 6.4 and 7.5) established in 1994 or 1996. 
We also monitored water temperatures at a site established upstream of the gaining reach (mile 1.7) to identify whether restoration actions have influenced water temperature conditions across Kleinschmidt Flat.

Following a period of increase, fish population surveys in lower Rock Creek (mile 1.6) show a stable brown trout-dominated community with no significant changes in densities in the last few years (Figure 31). At this site, a bull trout was recorded in 2006 for the first time since 2001. Surveys at the three upstream monitoring sites recorded low densities of WSCT and brown trout at all three survey locations. Brook trout were found at all sampling locations.

In 2007, we identified moderate densities of age- 0 Oncorhynchus (presumed WSCT) in moderated densities at the mile 6.4 sampling location. Summaries of catch and size statistics and density estimates are located in Appendix A and $\mathrm{B}$.

July 2007 water temperatures at mile 1.7 show continued high water temperature problems $\left(>80^{\circ} \mathrm{F}\right)$ on Kleinschmidt Flat (Figure 32). These temperatures clearly demonstrate the need for the continued (passive) recovery of

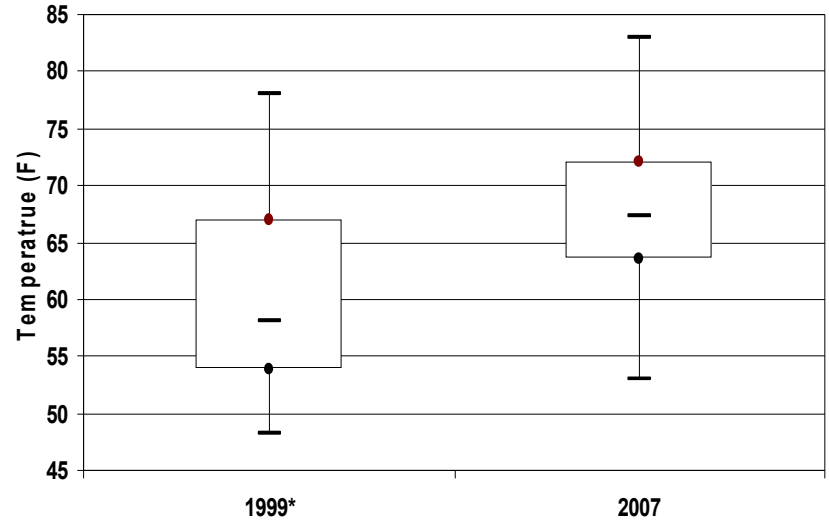

Figure 32. July water temperatures for Rock Creek at mile 1.7, 1999 and 2007. woody plants (and increased shade) along the channel.

\section{Shanley Creek}

Restoration objectives: Restore habitat for all fish species; restore migration corridors for native fish; reduce loss of fish to irrigation ditches; maintain instream flows.

\section{Project Summary}

Shanley Creek is the primary tributary to Cottonwood Creek. At a total length of 10.3 miles, Shanley Creek is a small $2^{\text {nd }}$ order stream with an estimated base-flow of 3-4 cfs. Since 1994, Shanley Creek has been the focus of several riparian improvement projects with emphasis on correcting riparian grazing problems and screening an irrigation canal to reduce fish losses. In 2006, we observed excessive livestock grazing on University of Montana ( $\mathrm{U}$ of $\mathrm{M}$ ) properties and established grazing plans were no longer followed on neighboring private lands. An assessment of $U$ of $M$ riparian areas by the Forestry School identified riparian health as "at risk" due to cattle-related impacts. 
Fish Populations and other monitoring activities In 2006, we longitudinally surveyed fish population at four sites (Figure 33). These surveys included a new upstream site (mile 2.0) upstream of the Bandy diversion in a segment of stream with less livestock disturbance and without the influence of irrigation.

These surveys show twice the fish in the upstream sites compare to the lower sites and a sharp decrease in WSCT near the mouth.

We also tested lower Shanley Creek for whirling

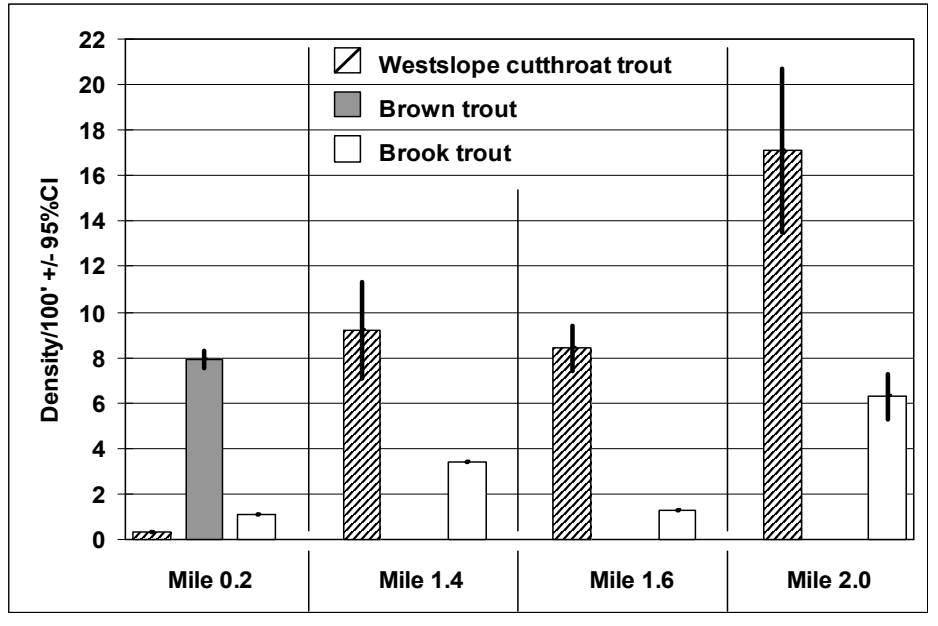

Figure 33. Densities for age 1 and older salmonids sampled at four locations on Shanley Creek, 2006. disease for first time in 2007. This test identified a severe mean grade infection of 4.9.

\section{Snowbank Creek}

Restoration objectives: Restore migration corridor for native fish; enhance instream flows; eliminate loss of bull trout and WSCT to irrigation ditch; improve recruitment of native fish to Blackfoot River.

\section{Introduction}

Snowbank Creek is a $1^{\text {st }}$ order tributary flowing 4.4 miles through the Helena National Forest and enters Copper Creek at mile 5.9. Snowbank Creek was identified as fisheries impaired in 2003 during an assessment of a defunct diversion at mile 0.4. The Snowbank diversion was constructed in 1962 to divert water to create a put-and-take fishery at Snowbank Lake (FWP historical files). We identified fisheries impairments in lower Snowbank Creek to include: 1) native fish entrainment from a diversion to Snowbank Lake; 2) fish passage problems at the diversion and a culvert near the mouth; 3) dewatering

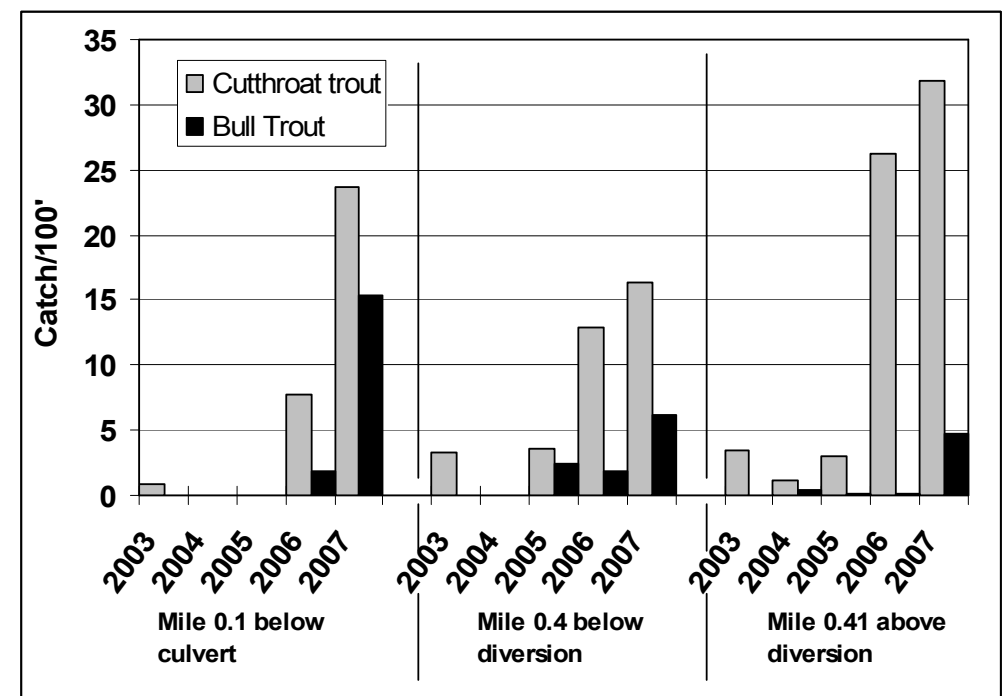

Figure 34. CPUE for native fish at three locations on Snowbank Creek, 2003 - 2007. 
below the diversion; and 4) the lack of a legitimate water right that would allow the legal use of Snowbank Creek water for Snowbank Lake (Pierce et al 2004, 2006). Because of the water right problem, the diversion to Snowbank Lake was closed in 2005. In 2007, the USFS obtained a water right that allows the filling of Snowbank Lake. This right provides for restored fish passage, fish screening at the diversion and a minimal instream flow of $4 \mathrm{cfs}$ in lower Snowbank Creek during base-flow periods.

\section{Fish Populations and other monitoring activities}

In August 2006 and 2007, we continued fish population surveys near the mouth (mile 0.1) and up-and downstream of the diversion (located at mile 0.4) at monitoring sites established in 2003 (Figure 34, Appendix A). Our surveys identify both WSCT and bull trout densities have increased sharply with enhanced stream flows. Juvenile bull trout absent from original surveys have now recolonized lower Snowbank Creek. Sampling above the diversion also recorded higher YOY densities for both native species, in addition to finding an adult bull trout that negotiated its way passed the diversion (Appendix B). The presence of adult bull trout during the pre-spawning period and YOY above the diversion suggests bull trout reproduction may be occurring.

\section{Tamarack Creek}

\section{Description}

Tamarack Creek is a heavily altered small $1^{\text {st }}$-order stream (1.5 miles in length) located on the southeast slopes of Lockwood Point, which historically entered the Blackfoot River at river mile 7.7. At some point, Tamarack Creek was historically rechanneled and diverted to an artificial lake (Lockwood Lake). The original channel is now seasonally dewatered and flows under Highway 200 through a perched culvert that no longer provides upstream fish passage (Figure 35).

Below the diversion, the riparian vegetation consists of canary grass, noxious weeds and snowberry. Fish habitat consists of overhanging canary grass and manmade pools. Above the valley floor, the riparian vegetation consists of a Douglas fir and ponderosa pine canopy with an understory of rocky mountain maple, willow, snowberry, grasses and forbs. Fish habitat in the upper section is composed of plunge pools formed by large boulders and LWD, some undercut banks and dense under-story vegetation. Extensive logging and road building has occurred on the higher

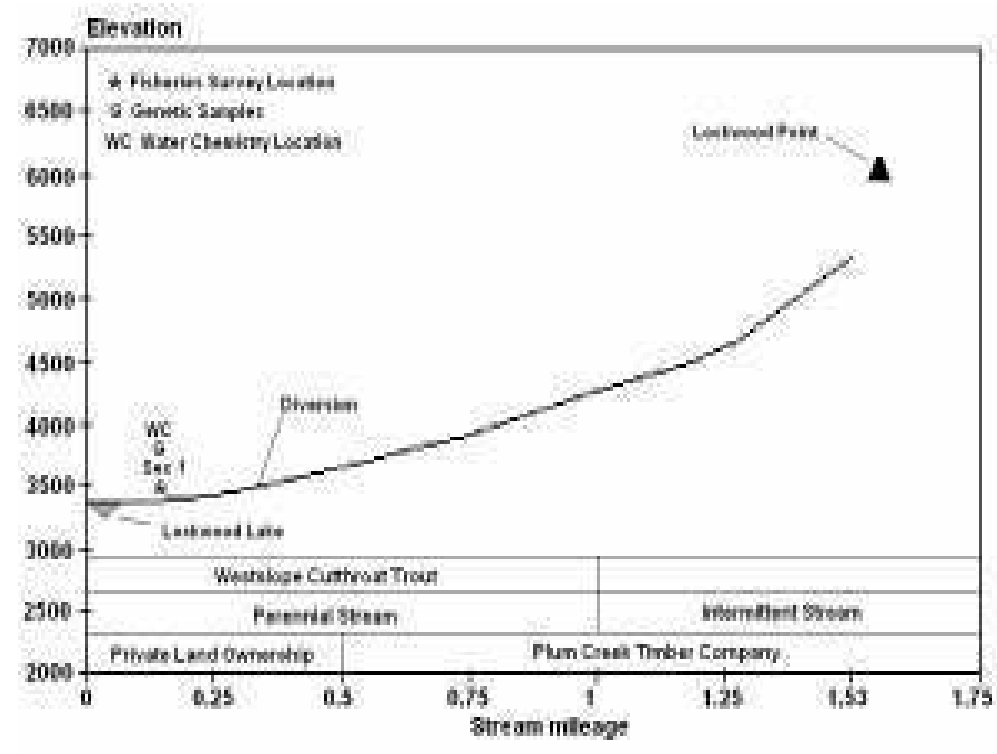

Figure 35. Longitudinal profile for Tamarack Creek. 
slopes, and landowner accounts report high turbidity during periods of heavy precipitation.

Fish populations and other monitoring

In 2007, we performed a fish population survey in Tamarack Creek (mile 0.1) for the first time. This survey recorded low densities (CPUE $=6.2)$ of resident WSCT. Although no other fish species were observed in the stream sample pumpkinseed sunfish were observed in Lockwood Lake. Stream discharge was measured at $0.38 \mathrm{cfs}$ at stream mile 0.1. A WSCT genetic sample $(\mathrm{n}=27)$ was taken at the monitoring site, the results of which are pending.

\section{Warren Creek}

Restoration Objectives: Restore riparian vegetation and stream habitat for all life stages of trout; improve spawning and rearing conditions; increase recruitment of trout to the middle Blackfoot River; moderate whirling disease.

\section{Project Summary}

Warren Creek, a small tributary to the middle Blackfoot River, originates on Ovando Mountain and flows 12 miles southwest through knob-and-kettle topography to its confluence with the Blackfoot River at $\mathrm{rm} 50$ (Figure 36). Warren Creek water is used for irrigated hay production and livestock watering. Irrigation causes the middle section of Warren Creek to dewater, although the lower section gains inflow from springs and maintains perennial base-flows of 3-5 cfs. Some riparian areas in mid-tolower Warren Creek were cleared, heavily grazed, dredged and historically straightened in some cases with dynamite (Don McNally, personal communication). These actions all contribute to extensive degradation

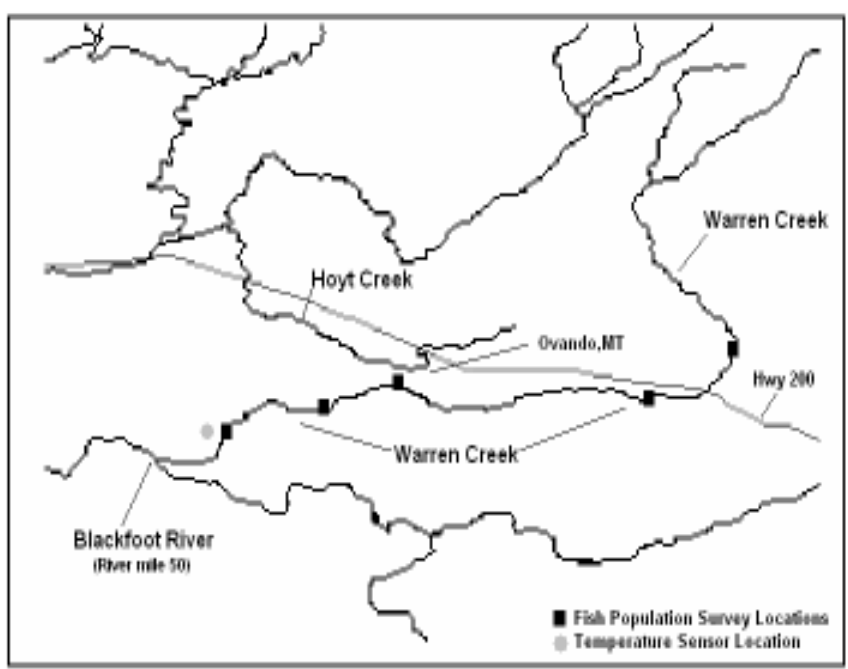

Figure 36. Warren Creek project areas and monitoring sites, 2007.

of salmonid habitat over the length of Warren Creek.

Since 1995, Warren Creek has been the focus of extensive restoration actions. The actions involve removal of several streamside corrals, implementation of grazing plans, shrub planting, several miles of channel reconstruction, instream flow enhancement near the mouth, wetland restoration and the enrollment of private landowners in conservation easement programs. In 2006 a re-entry into a channel reconstruction project (between mile 5.1 and 6.8) was needed to correct channel incision problem in a newly constructed segment of Warren Creek. 
Fish Populations and other monitoring activities

In 2006 and 2007, FWP continued to monitor fish populations at five locations (miles 8.2, 6.7, 3.6, 2.1 and 1.1), all in areas of previous restoration actions (Figure 37).

The mile 8.2 monitoring site was established in 1995 to monitor fish population response to a riparian grazing project. Since grazing exclusions were put into effect, the stream has evolved from an " $F$ " channel to a more stable "E" channel and fish population densities have increased in response to favorable habitat changes. Monitoring at this site shows a

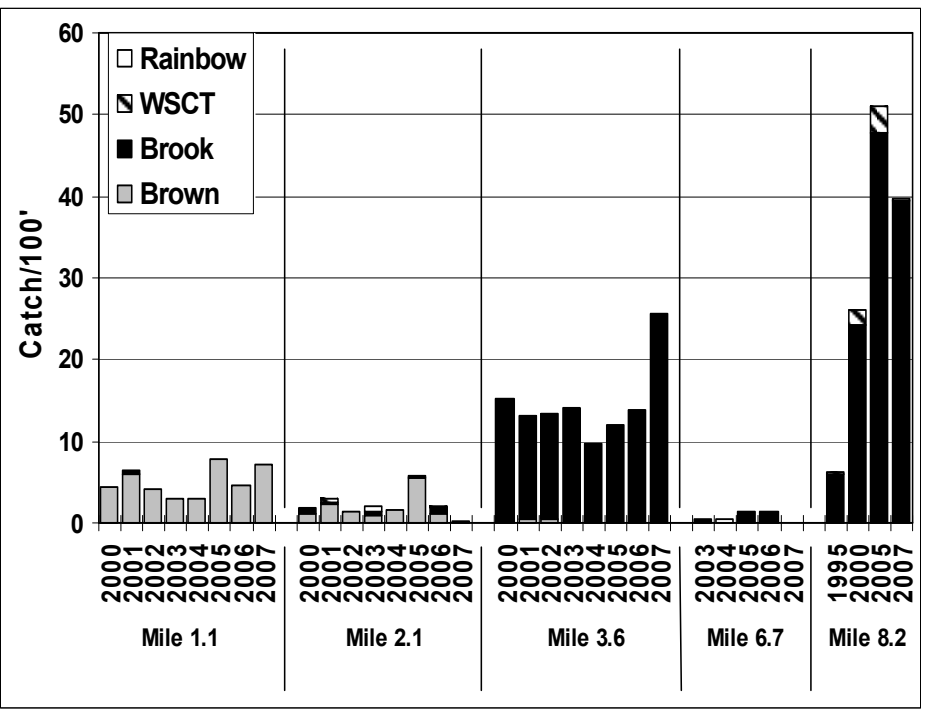

Figure 37. CPUE for salmonids at five sites in Warren Creek, 2000-2007. high level of success.

Fish population surveys conducted at mile 6.7 includes two years of prerestoration baseline (2003 and 2004) and three years of post-restoration monitoring (2005-2007). Sampling in 2006 revealed very low densities of brook trout, and in 2007 we found no fish within the monitoring section. During the 2007 fish population survey, cattle grazing impacts were observed in this project area. Thus, this section of Warren Creek continues to suffer degradation to the banks, vegetation and channel despite attempts at restoration.

The three downstream monitoring sites (mile 3.6, 2.1 and 1.1) are in an area of channel

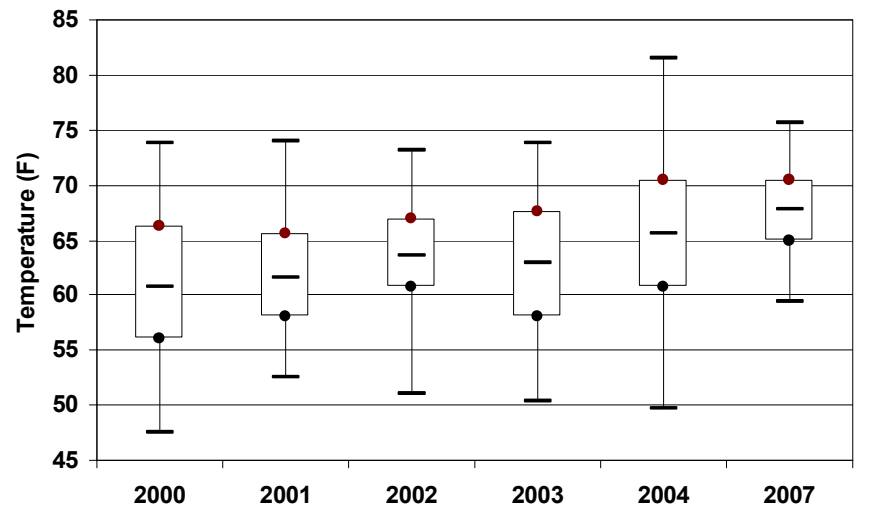
reconstruction and grazing

Figure 38. July water temperatures for lower Warren Creek (mile 1.1), 2000-2007. enclosures completed in 2000. Fish populations at these sites have remained generally static; however, we recorded a recent decline in densities at mile 2.1, due perhaps to channel dewatering caused by beaver. We continue to observe suspected clinical signs of whirling disease (opercular deformities) in a high percentage of sampled brook trout throughout Warren Creek.

Water temperature monitoring at mile 1.1 suggest Warren Creek is warming with summer temperatures $\left(>75^{\circ} \mathrm{F}\right)$ in exceeding levels considered stressful to salmonids 
(Figure 38). These results identify a need to establish woody species and/or identify irrigation-related options to cool the stream.

\section{Wasson Creek}

The goal of the Wasson Creek project is to "ensure that Wasson Creek will be a significant source of WSCT recruitment to Nevada Spring Creek, Nevada Creek and the Blackfoot River, and provide sufficient forage production for economic sustainability to ranchlands, while demonstrating a successful collaborative effort."

\begin{abstract}
Restoration Objectives:
Restore channel

maintenance and minimal instream flows; restore migration corridors in lower Wasson Creek in order to provide recruitment of WSCT to Nevada Spring Creek; restore channel conditions to support spawning and rearing conditions in lower Wasson Creek; prevent fish losses to irrigation ditches; prevent the introduction of unwanted fish into the drainage.
\end{abstract}

\section{Project Summary}

Wasson Creek is a small $2^{\text {nd }}$-order basin-fed tributary to Nevada Spring Creek. Wasson Creek begins on the Helena National Forest and enters private ranchland near mile 4.0. Wasson Creek joins Nevada Spring Creek $\sim 100$ ' below the (artesian) spring source, bringing a base-flow of $\sim 2$ cfs during the non-irrigation season. Wasson Creek has a long history of fisheries-related impairments that include fish passage barriers throughout the system, irrigation dewatering and entrainment

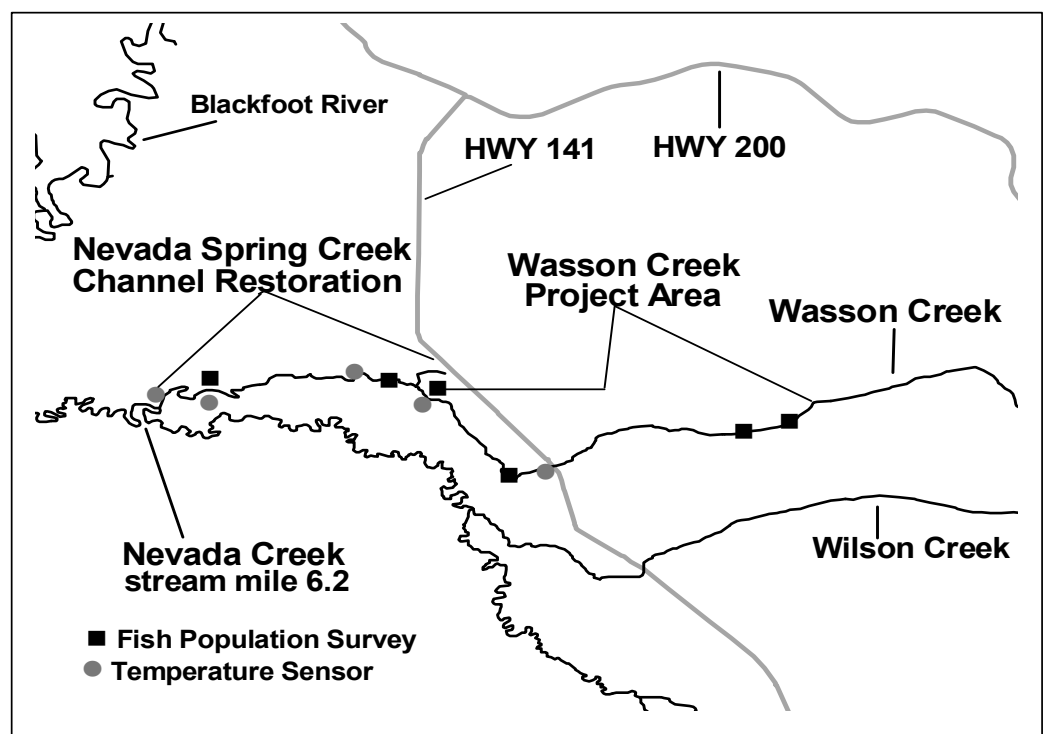

Figure 39. Wasson Creek stream restoration project area and fish population survey and temperature sensor locations, 2007.

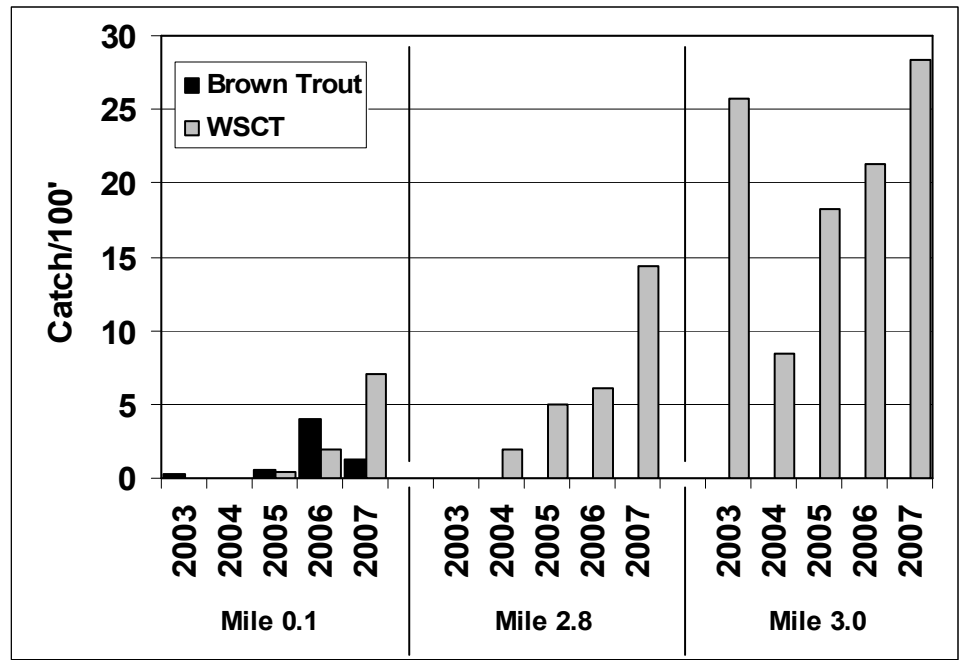

Figure 40. CPUE for WSCT and brown trout at three monitoring sites in Wasson Creek, 2003-2007. 
of fish to ditches, excessive livestock damage to streambanks, channel straightening and water quality impairments from agricultural runoff.

Fisheries elements of the project include: 1) grazing management over the length of the project; 2) irrigation changes to accommodate instream flows (low flows and channel maintenance) and fish passage; and 3) channel reconstruction and floodplain containment in the lower (Pierce et al. 2006).

The final element to the project was the installation of two fish screens at two irrigation diversions in the spring of 2007. With the exception of grazing changes on upstream properties, Wasson Creek is now entering the recovery phase of the project.

\section{Fish Populations and other monitoring activities}

To assess the restoration project, we repeated fish population sampling at three locations (mile 0.1, 2.8 and 3.0) and continued water temperature monitoring near the mouth (mile 0.1) through 2007.

Our surveys identify the Wasson Creek WSCT population as now expanding in size (densities and distribution) through the lower project area (Figure 40). The 2007 sampling specifically identified a noticeable increase in WSCT downstream of mile 2.8 following the recent installation of fish screens.

Water temperature monitoring at the mouth show the stream has been cooling since 2004 (Figure 41, Appendix H). This cooling appears to result from cumulative restoration measures including the early recovery of streamside plants, increased flows, and the passive narrowing of the channel in response to stream-side grazing changes. Whirling disease monitoring testing in 2007 near mile 1.4 found no infection.

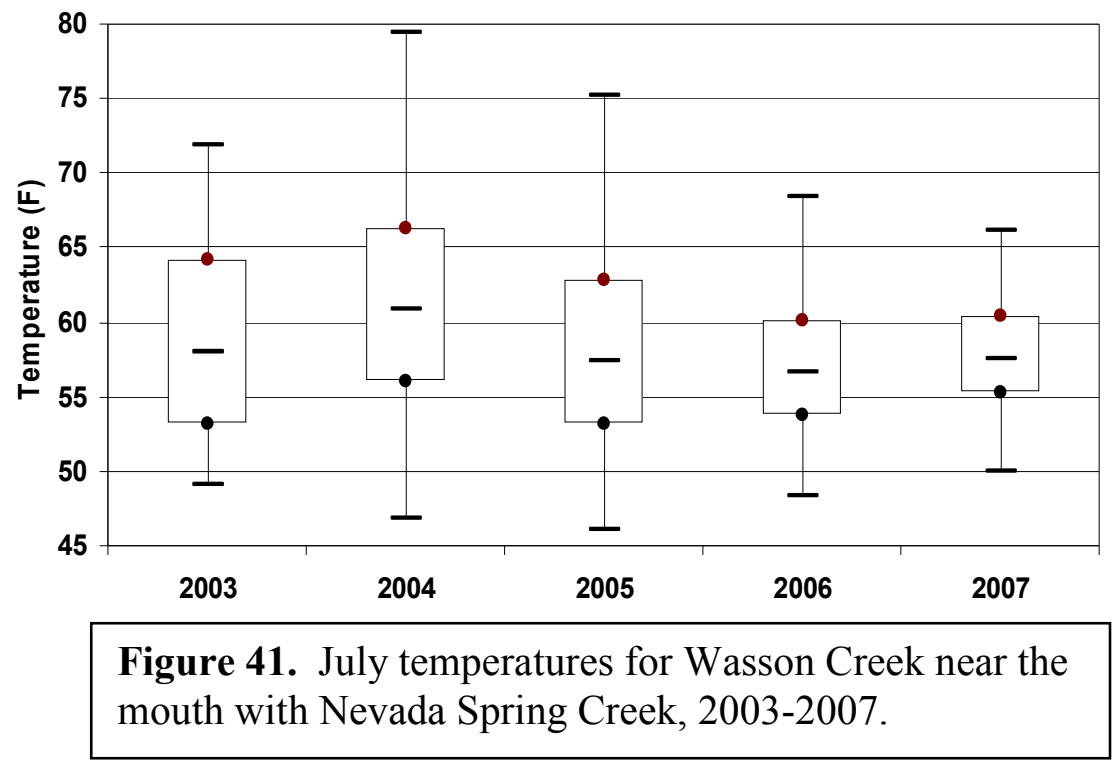




\section{Willow Creek, Bear Gulch and Sauerkraut Creeks: A contiguous native fish Habitat Conservation Plan (HC) in the upper Blackfoot Basin.}

\section{Introduction}

Within the upper Blackfoot Basin near Lincoln, Willow Creek, Bear Gulch (a tributary to Willow Creek) Sauerkraut Creek, and two miles of the Blackfoot River all fall within a contiguous area of private land located in foothills the Garnet Mountains south of Lincoln. This area adjoins the Helena National Forest and small parcels of State land. In April 2008, 8,000 acres the private land in this contiguous area was recently placed under a Native Fish Habitat Conservation Plan (HCP) easement (Figure 42). The easement, the first of its kind within the Blackfoot Basin, is an outcome of the Blackfoot Challenge Community Project effort to secure the future of some 89,000 acres formerly owned by Plum Creek Real Estate Investment Trust (REIT).

The specific purpose of this easement is to enhance the recovery of WSCT and bull trout in concert with the existing Habitat Conservation Plan appurtenant to the lands formerly owned by Plum Creek REIT. In so doing, the proposed conservation easement would conserve fish and wildlife habitat by preventing subdivision, development, and other forms of habitat loss, and perpetuate the ranching and logging lifestyle of the private landowners on the land under easement. The streams encumbered and other nearby streams support genetically pure WSCT, low densities of bull trout in certain areas, as well as non-native fish (e.g. brook trout and brown trout) in lower reaches of most streams.

On the western portion the project area is Sauerkraut Creek, a small $2^{\text {nd }}$-order tributary that enters the Blackfoot River at river-mile 102.1. Stream gradients range from $530 \%$ mile between stream mile 7.0 and 6.0 to $80 \%$ mile in the lower mile of stream. The perennial mainstem Sauerkraut Creek is seven miles in length. WSCT occupy the entire stream as well as (at least) one unnamed tributary (in section 32) to lower Sauerkraut Creek. The headwaters of Sauerkraut Creek are located on the Helena National Forest and the lower three miles of land is located on private lands, most of which $(\sim 2.25$ miles $)$ falls within the HCP area (Figure 42).

On the eastern portion of the project area is Willow Creek, a $2^{\text {nd }}$ order tributary to the upper Blackfoot River, entering at river-mile 102.5. Stream gradients below the confluence of the West Fork range from 200\%/mile between stream mile 6.0 and 5.0 and decrease to $5-20 \% /$ mile between stream mile 1.0 and the mouth. Land ownerships on the lower 6.0 miles of stream are mixed private lands, which include HCP parcels as well as non-encumbered private land. The primary tributary to lower Willow Creek is Bear Gulch, a small perennial stream that is currently biologically disjunct near its confluence with Willow Creek. The majority of the Bear Creek basin falls within the HCP boundary.

\section{Baseline Assessments}

In 2007, FWP conducted fish population and related surveys (water temperature and discharge) in Willow Creekm, Sauerkraut Creek and Bear Gulch. In addition to FWP surveys, channel morphology (e.g. sediment, cross sections, reference and departure conditions), riparian health and grazing practices were also assessed (Watershed Consulting 2007). These surveys were intended to serve as an easement baseline, help 


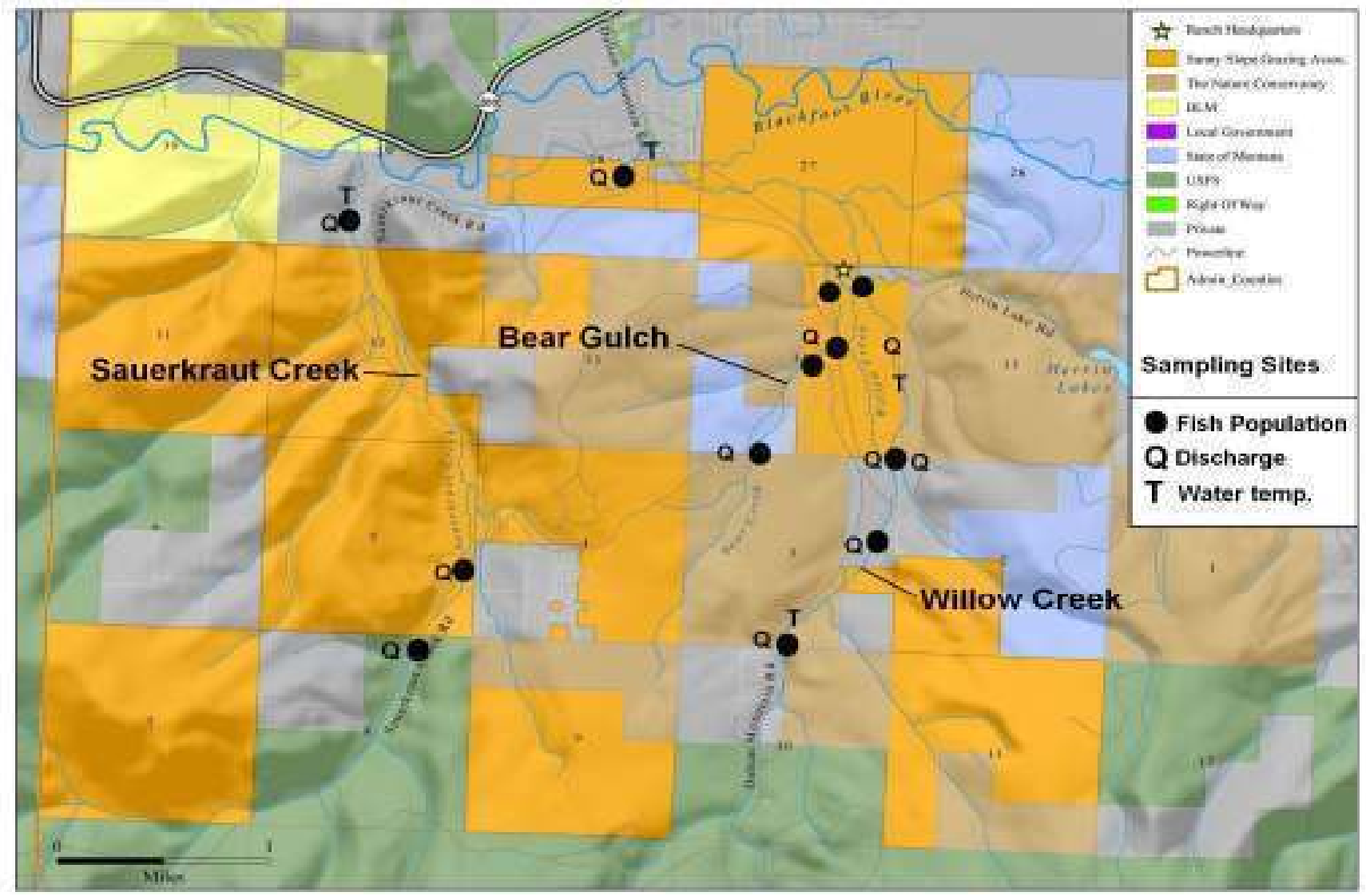

Figure 42. Location map showing checker-board landownership and the 2007 fish population, water temperature and stream discharge survey sites.

identify restoration actions and provide a basis for long-term monitoring.

Fish population surveys were conducted longitudinally at three to five locations per stream (Figure 42). Upstream sites were selected in reference reaches and lower reach survey sites were taken in areas identified as fisheries impaired. Specific fisheries survey objectives were to 1) determine the distribution and densities of species with emphasis on trout; 2) help assess the downstream influences of anthropogenic actions; 3 ) identify relationships of tributary fish communities to those of the Blackfoot River; and 3) help identify restoration objectives and management needs.

We also completed water temperature recordings at four locations, including lower Sauerkraut Creek and three sites on Willow Creek and instantaneous discharge longitudinally at ten locations on the three study streams between 7/23-26/2007 (Figure 42).

We timed the flow measurements to coincide with the lower Blackfoot River flows receding to "minimal flow" thresholds of $\sim 700 \mathrm{cfs}$ at the Bonner USGS gauging station. We assumed that tributaries reflected general basin (lower Blackfoot River) conditions, and that our study streams, where not dewatered by irrigation and were likewise near minimal instream flow values. We compared these measured flow values with minimum instream flow values generated from the FWP Blackfoot Basin "Montana Method" minimum instream flow model to approximate minimum instream (and departure) flow values for both Willow Creek and Sauerkraut Creek.

\section{FWP Survey Results}

Figure 44 show the relative abundance (CPUE) for all salmonids sampled in the 
project area. Related catch and size statistics and population density estimates are located in Appendices A and B. The Sauerkraut Creek surveys identify WSCT at all sampling sites and very low densities of bull trout at both upper and lower sampling sites. Densities of WSCT show a significant decline in the downstream direction between mile 3.2 and 2.7.

Salmonid abundances then increased significantly in the downstream direction between miles 2.7 and 0.2 . Brook trout and brown trout increase in the downstream direction. The Willow identified WSCT in Table 5. Summary of 12 stream discharge measurements, July 2007. the headwater areas of the Willow Creek basin (upstream of 4.7); however, our surveys identified the loss of the all salmonids between stream mile 4.7 and 3.6. This absence of salmonids extends to the Willow Creek confluence with the Blackfoot River.

Plots of all raw water temperature data are located in Appendix

\begin{tabular}{|c|c|c|c|c|c|c|}
\hline \multirow[b]{2}{*}{ Location } & \multirow[b]{2}{*}{ Date } & \multirow{2}{*}{$\begin{array}{c}\text { Stream } \\
\text { mile }\end{array}$} & \multirow{2}{*}{$\begin{array}{c}\text { Discharge } \\
\text { (cfs) }\end{array}$} & \multicolumn{3}{|c|}{ Sampling location } \\
\hline & & & & \begin{tabular}{|l} 
Legal Description \\
\end{tabular} & Lat & Long \\
\hline Bear Gulch & $7 / 24 / 2007$ & 1.2 & 0.03 & T13N,R9W, S3B & N46.91521 & W112.72527 \\
\hline Bear Gulch & $7 / 23 / 2007$ & 0.7 & 0.01 & T14N,R9W,S34D & N46.92245 & W112.71989 \\
\hline Sauerkraut $\mathrm{Cr}$ & $7 / 26 / 2007$ & 3 & 0.93 & T13N,R9W,S8A & N46.90111 & W112.75749 \\
\hline Sauerkraut $\mathrm{Cr}$ & $7 / 26 / 2007$ & 2.7 & 0.51 & TT13N,R9W,S5D & N46.90537 & W112.75443 \\
\hline Sauerkraut $\mathrm{Cr}$ & $7 / 26 / 2007$ & 0.15 & 1.76 & T14N,R9W,S29C & N46.93233 & W112.76775 \\
\hline Willow Creek & $7 / 23 / 2007$ & 5.7 & 1.26 & T13N,R9W,S3C & N46.90171 & W112.72139 \\
\hline Willow Creek & $7 / 24 / 2007$ & 5.2 & 1.41 & T13N,R9W,S3A & N46.90910 & W112.71300 \\
\hline $\begin{array}{l}\text { Willow Creek (west } \\
\text { channel) }\end{array}$ & $7 / 25 / 2007$ & 4.7 & 0.72 & T14N,R9W,S34D & N46.91595 & W112.71220 \\
\hline $\begin{array}{l}\text { Willow Creek (east } \\
\text { channel) }\end{array}$ & $7 / 25 / 2007$ & 4.7 & 1.78 & T14N,R9W,S34D & N46.91635 & W112.71190 \\
\hline Irrigation Ditch & $7 / 24 / 2007$ & 4.3 & 0.51 & T14N,R9W,S34A & N46.92299 & W112.71372 \\
\hline Irrigation Ditch & $7 / 24 / 2007$ & 4.1 & 0.32 & T14N,R9W,S34A & N46.92464 & W112.71288 \\
\hline Willow Creek & $7 / 24 / 2007$ & 4.1 & 0.57 & T14N,R9W,S34A & N46.92444 & W112.71313 \\
\hline Willow Creek & $7 / 24 / 2007$ & 1.7 & 0.86 & T14N,R9W,S28A & N46.93544 & W112.73946 \\
\hline
\end{tabular}

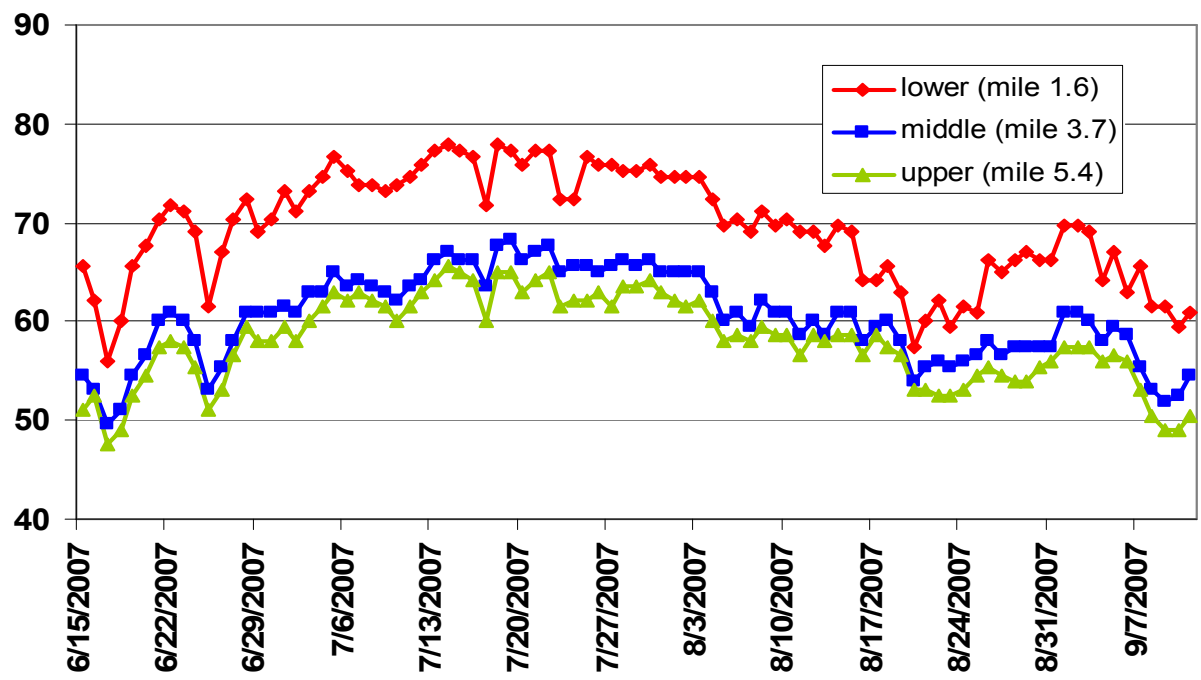

Figure 43. Summary of maximum daily water temperatures $\left({ }^{\circ} \mathrm{F}\right)$ for three monitoring sites on Willow Creek, Summer 2007.

H. Plots of maximum daily water temperatures for Willow Creek are located in Figure 43. Measurements of stream discharge (including primary ditches on Willow Creek) are summarized in Table 5. Sauerkraut showed surprisingly high temperatures of $>73^{\circ} \mathrm{F}$. Water temperatures collected on Willow Creek show large increases $\left(10^{\circ} \mathrm{F}\right)$ between monitoring stations at mile 3.7 and 1.6 and maximum temperatures $>77^{\circ} \mathrm{F}$. 


\section{Discussion}

The restoration needs of native fish vary within and among the three study streams, although populations in all three streams reflect common sets of humanrelated limiting factors that influence both the distribution and abundance of fish. As expected, densities of WSCT were higher in the upper reaches of all three streams where habitat conditions are at (or near) natural reference conditions. Moving in the downstream direction, adverse (human-related) changes to the WSCT habitats result in significant population decreases in reaches of all three-study streams.

Bull trout were found only in Sauerkraut Creek in very low densities. These bull trout are believed to be migratory fish from the Blackfoot River using Sauerkraut Creek for rearing purposes. Limited bull trout rearing within small Garnet Mountain is consistently identified in small nonspawning streams where suitable native fish (cold and clean) habitats and biological connection to the Blackfoot River persist. Recently, radiotelemetry studies identified spawning migrations of Blackfoot River WSCT in Sauerkraut Creek. These findings of migratory use indicate Sauerkraut Creek still provides for the life-history
Figure 44. CPUE for salmonids in Willow Creek (top), Bear Gulch (middle) and Sauerkraut Creek (bottom).

\section{CPUE for salmonids at five sampling locations on Willow Creek}

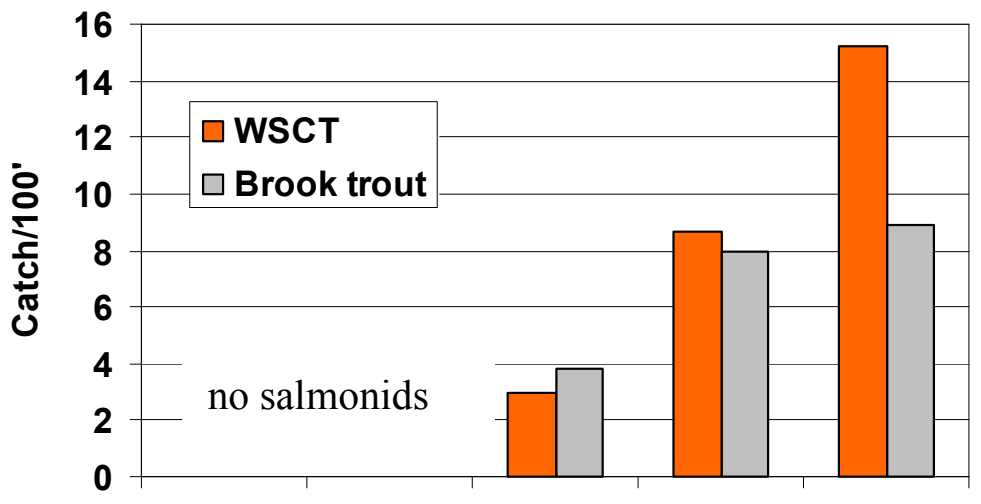

Mile 1.7 Mile 3.6 Mile 4.7 Mile 5.2 Mile 5.7

CPUE for WSCT in Bear Gulch at four sampling locations
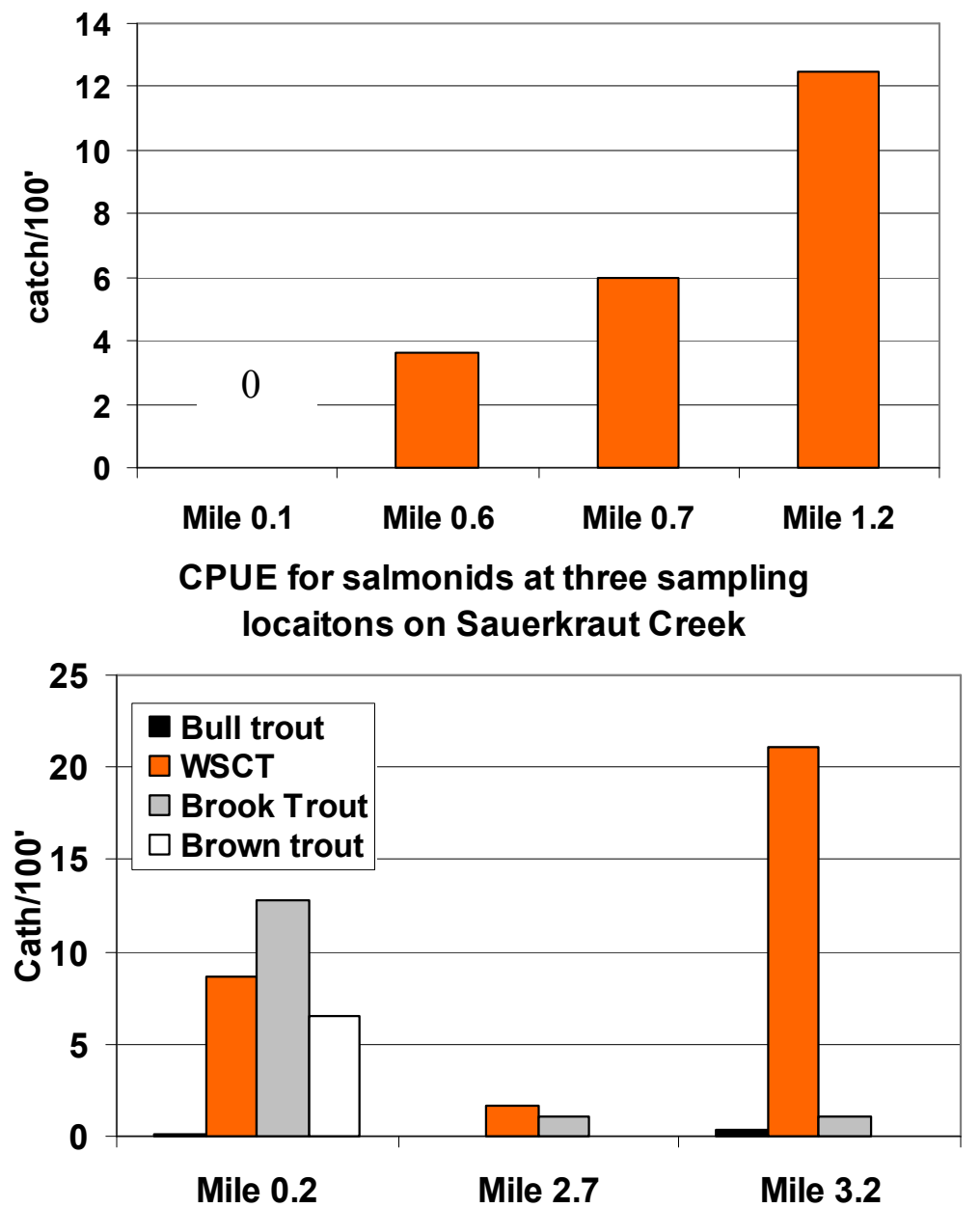
needs of migratory Blackfoot River native fish. WSCT are identified as distributed throughout the length of Sauerkraut Creek although densities decreased significantly in a highly disturbed (mining area) segment of stream immediately downstream of the HNF boundary. Our surveys identify the greatest restoration needs for Sauerkraut Creek within a localized area.

This stream segment has a history of placer mining, diversions and excessive grazing. These activities have altered riparian vegetation, damaged channels reduced flow and limit native fisheries. Channel reconstruction, grazing management and other restoration actions should be considered in this area. In the downstream direction, excessive riparian grazing has likewise impaired native fish habitats. Restoration actions in the downstream direction should (at a minimum) include passive restoration action (grazing changes) and improvements to at least one road crossing.

We recorded water temperatures higher than expected with a maximum of $73^{\circ} \mathrm{F}$ near the mouth of Sauerkraut Creek. Record high temperatures basin-wide in 2007, reduction of riparian vegetation and recent increases in local beaver activity near the mouth all likely contribute to this warming. Measured flows up and downstream of the impacted sites indicate minimum base flow values range from $\sim 1.0 \mathrm{cfs}$ at mile 3.0 and from $\sim 1.8 \mathrm{cfs}$ to $\sim 2.7 \mathrm{cfs}$ near the mouth. This range minimum instream flows near the mouth represent measured flows (1.8 cfs at mile 0.15$)$ and modeled flows $(2.7 \mathrm{cfs}$ at the mouth). The lower-most western (unnamed) tributary to Sauerkraut Creek also supports WSCT. Restoration needs have not been assessed for this stream.

Compared to Sauerkraut Creek, the influences of riparian degradation are more pronounced in Willow Creek. Bull trout were absent from the Willow Creek surveys, and WSCT densities decrease sharply upon entering more intensively managed pasturelands. Our surveys identified a sharp decreasing trend in WSCT densities in the downstream direction beginning at mile 5.7. Between stream-mile 4.7 and 3.6, salmonid populations were absent, and this absence of all salmonids continues to the lower Willow Creek confluence area. This absence includes more tolerant salmonids such as brook and brown trout usually found in lower reaches of adjacent tributaries. These species were present in 1999.

Fish population surveys identified a disjunct population of WSCT in Bear Gulch with no other fish species present. WSCT were absent near the Bear Gulch confluence with Willow Creek

Stream surveys identify damaged (incised and over-widened) channels, dewatering, fish passage barriers (culverts and diversions), impacts to vegetation and elevated water temperatures all within the lower five miles Willow Creek. In lower Willow Creek, maximum water temperature increase $10^{\circ} \mathrm{F}$ between mile 3.7 and 1.6 where temperatures exceeded $78^{\circ} \mathrm{F}$. These findings of unsuitable native fish habitat confirm comprehensive restoration is needed for the lower five miles stream if some level of WSCT recovery to occur. Stream flow measurements suggest minimum instream flow values range from $\sim 2.3 \mathrm{cfs}$ at mile 4.7 (based on measured flows) to a minimum flow $\sim 2.8$ at the mouth (based on the Montana Method model). Willow Creek is reported as supporting a population of western pearlshell mussels. WPM is a long-lived, highly sensitive species with great conservation value. We made no observations of an existing mussel population during our fieldwork. A more comprehensive survey of fresh water mussels should be considered. 
Similar to Willow Creek, densities of WSCT in Bear Gulch decrease significantly in the downstream direction. Similar to Willow Creek, we found no WSCT upon entering primary pasturelands. Assessments indicate dewatering and channel alterations (widening and degraded stream banks) near the mouth contribute to isolation and decreasing population trends in the downstream direction. Similar to other channels evaluated, grazing management changes are necessary for fisheries improvements in Bear Gulch. 


\section{Fisheries and Aquatic Assessments in the Clearwater River Watershed}

In terms of drainage area, the Clearwater River is the largest tributary system to the Big Blackfoot River. This complex system is comprised of an interconnected series of lakes and river sections, with many smaller coldwater tributary streams that enter throughout. The main stem flows south from its headwaters near Ptarmigan Mountain and the Swan River divide to the confluence with the Big Blackfoot River west of Ovando. Tributary basins stretch from the Swan Mountain divide and Bob Marshall Wilderness border on the east to the upper Jocko River divide (Flathead Indian Reservation) on the west.

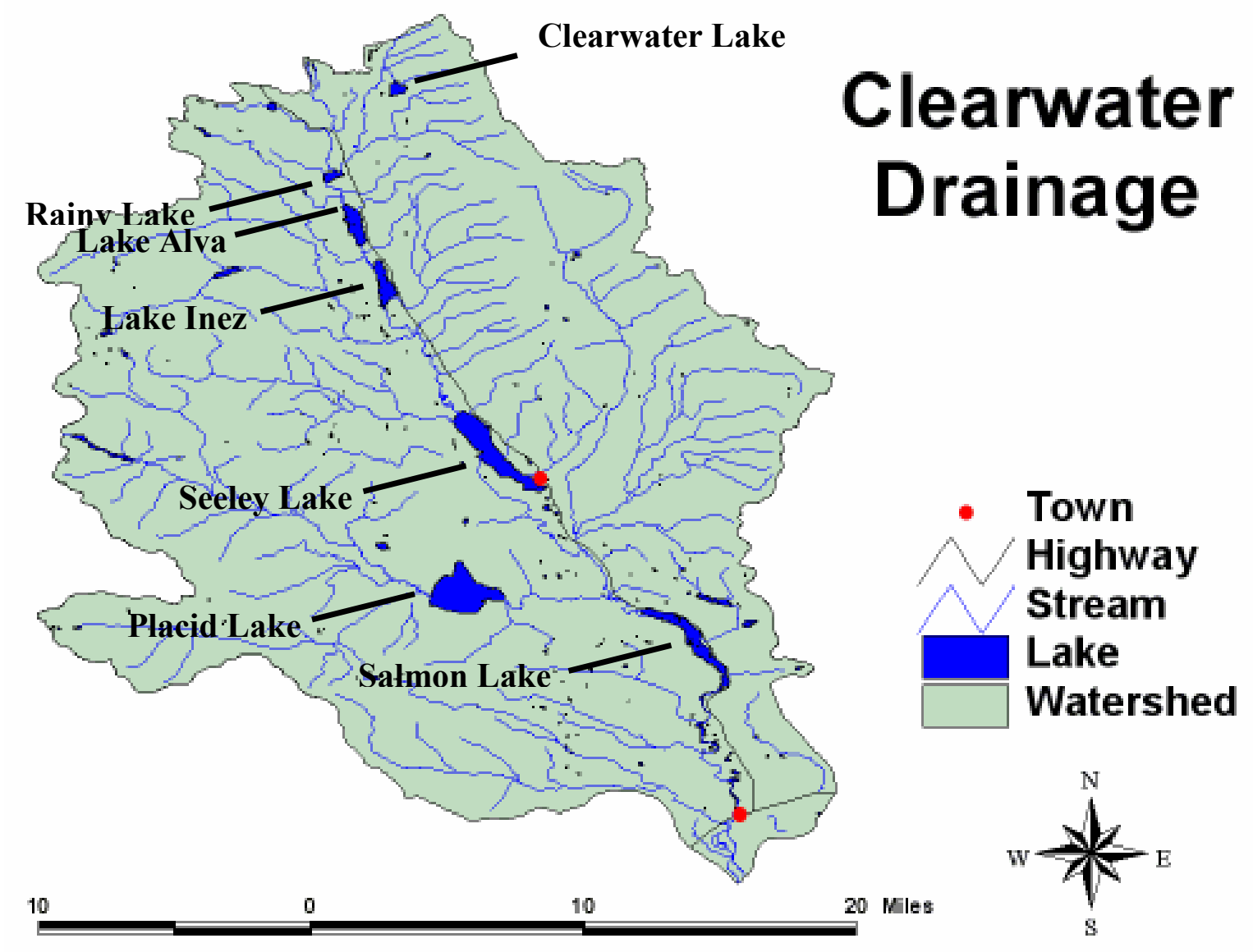

Figure 1. Map of the Clearwater River watershed and Clearwater chain of lakes.

The Clearwater System is a unique drainage within the Blackfoot Watershed and Clark Fork Basin for a number of reasons. The drainage still supports exceptional and diversified aquatic resources, including many native fish populations with unique life history characteristics. Because of the interconnected stream and lake environments, species richness is high and adfluvial migratory life forms are common. The Clearwater Drainage supports some of the only natural and currently viable adfluvial bull trout populations in the region. These resources are largely intact due to the predominant public land (USFS and DNRC) and the Plum Creek Timber (PC) Company land base in the watershed that has (thus far) 
precluded widespread subdivision and human development. Despite high aquatic resource value, this system has also been unique in the Blackfoot watershed because of the absence of data describing population trends, habitat use and key liming factors for native fish and other aquatic species. Fisheries emphasis and restoration accomplishments on streams in the greater Blackfoot and Clark Fork basins have generally not yet included the Clearwater system. The need for information has recently become imminent as the rapid conversion of corporate timberlands to smaller residential properties has forced natural resource managers and conservation advocates to prioritize lands for protection and acquisition.

The need for updated and accurate aquatic resource information prompted a recent largescale effort to collect baseline data for the Clearwater watershed. Since 2005 this effort has focused on the tributary and river systems, and emphasized native trout species (bull trout and WSCT). Assessments that are underway include:

1) Basin-wide stream sampling (electrofishing) to determine fish species distribution and relative abundance in all fish-bearing reaches and amphibian presence/absence.

2) Sampling and analysis of Oncorhynchus spp. genetic composition to identify where genetically non-introgressed WSCT populations persist.

3) Adfluvial bull trout telemetry involving all known viable lake populations.

4) Bull trout redd counts in known spawning tributaries for migratory populations.

5) Assessment of main stem Clearwater River barriers to upstream fish passage (graduate student project in cooperation with the USFS and the University of Montana).

6) Assessment of road crossings on private lands to identify barriers to upstream fish passage and limiting factors for natural stream processes.

7) Assessment of stream protection practices on private lands; specifically riparian clearing and compliance with Montana stream protection laws.

8) Monitoring of temperature regimes in major tributaries and main stem reaches.

9) Collection of wetted perimeter and flow measurements on numerous tributaries.

These efforts supplement ongoing lake monitoring by FWP and tributary habitat assessment and fish passage work by the USFS. Since all of these activities are ongoing, results will be reported in subsequent documents. However, the following sections describe basic information for key river sections and tributaries that support bull trout and migratory WSCT populations. These streams (in alphabetical order) are highlighted to emphasize their importance within the basin. Waters supporting bull trout and migratory WSCT are prioritized because these are Species of Concern in Montana and federally listed as Threatened under the Endangered Species Act (bull trout). These streams likely also represent the most intact and critical aquatic habitats for protection in the Clearwater System as native trout are an excellent indicator of habitat quality due to their sensitivity to humancaused perturbations and complex life-histories. 


\section{Summaries for Selective Clearwater Drainage Streams}

\section{Blind Canyon Creek}

Blind Canyon Creek is a secondorder tributary of Trail Creek located two miles northeast of the town of Seeley Lake in the Morrell Creek watershed. The main stem flows generally west, then south, from its headwaters near Devine Peak and Morrell Mountain. It has no major tributaries.

Blind Canyon Creek is an important stream for native salmonids in the Clearwater drainage, with limited use (inferred) by migratory life history forms. High biological ranking and prioritization of this watershed relative

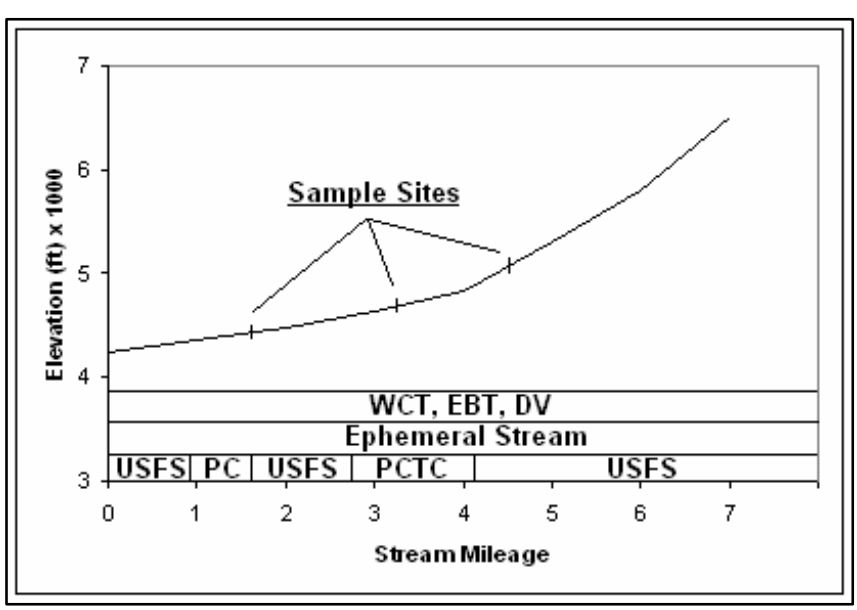

Figure 2. Longitudinal profile for Blind Canyon Creek.

to other Clearwater Drainage streams (see stream prioritization section) reflect relatively high habitat quality, abundant WSCT, and the presence of stream-resident bull trout. Boles Creek likely supports migratory WSCT and possibly adfluvial bull trout population, although this has yet to be verified.

\section{$\underline{\text { Land Ownership and Habitat Conditions }}$}

Lower and middle Blind Canyon Creek flows through a "checkerboard" of public (USFS) land and industrial forest (Plum Creek Timber Company-PC) land (Figure 2). The upper drainage $\left(\sim 5 \mathrm{mi}^{2}\right)$ consists entirely of roadless USFS holdings. Blind Canyon Creek enters Trail Creek at approximately river mile 3.9. Stream gradients range from $700 \mathrm{ft} / \mathrm{mile}$ $(\sim 13.3 \%)$ near its headwaters to about $116 \mathrm{ft} / \mathrm{mile}(\sim 2.2 \%)$ near its mouth at Trail Creek.

The majority of the upper Blind Canyon Creek watershed consists of functional, nondegraded aquatic, riparian and terrestrial habitats. The upper drainage is primarily intact forest, with large roadless tracts. Riparian areas, water quality and channel morphology are largely intact, providing shade, instream habitat complexity, consistent recruitment of woody debris and adequate stream buffers. However, the lower 4.2 miles of the Blind Canyon Creek watershed is approximately half industrial forest and has higher road densities and recent logging, with some examples of poor road drainage that lead to increased water temperatures, increased sediment levels, and decreased habitat quality. Overall, riparian corridors are intact, helping to mitigate land management-related impacts.

The impact of road crossings and the road matrix are unknown for Blind Canyon Creek. There are at least two crossings on the main stem channel and one is a bridge that likely does not prevent upstream fish passage or significantly impair natural stream integrity. There is also an undersized culvert on a small, ephemeral tributary (section 20) that has been determined to be a partial barrier to fish movement. The density and location of roads in certain sections is also a concern, particularly where the road encroaches on the stream and riparian corridor in middle reaches. 


\section{Temperature Regime}

Little data is available which describes the water temperature regime in Blind Canyon Creek. Water temperatures collected in conjunction with other investigations (i.e., electrofishing surveys) in late June and early July indicate a range of $8-11.5^{\circ} \mathrm{C}$. It is unlikely that temperatures exceed optimal levels for native trout $\left(\sim 15^{\circ} \mathrm{C}\right)$ later in the summer. Native salmonids, including bull trout and WSCT, require cold water in spawning, staging and rearing habitats. Future monitoring of water temperatures is planned for Blind Canyon Creek.

\section{$\underline{\text { Fish Populations }}$}

Since 1995, three locations on Blind Canyon Creek have been sampled using backpack electrofishing to determine fish species composition and Oncorhynchus spp. genetic contribution (see Figure 3). These locations were at stream miles 1.6, 3.3, and 4.5. These samples indicated that Blind Canyon Creek is dominated by native species, primarily WSCT. Bull trout and brook trout were also documented at all three sites. Most of the WSCT are mildly genetically introgressed, having hybridized with rainbow trout. Surveys and genetic analyses conducted in 2006 and 2007 suggest that the average genetic contribution of WSCT is $99.7 \%$ for the population. Sculpins have been documented in the lower end of Blind Canyon Creek.

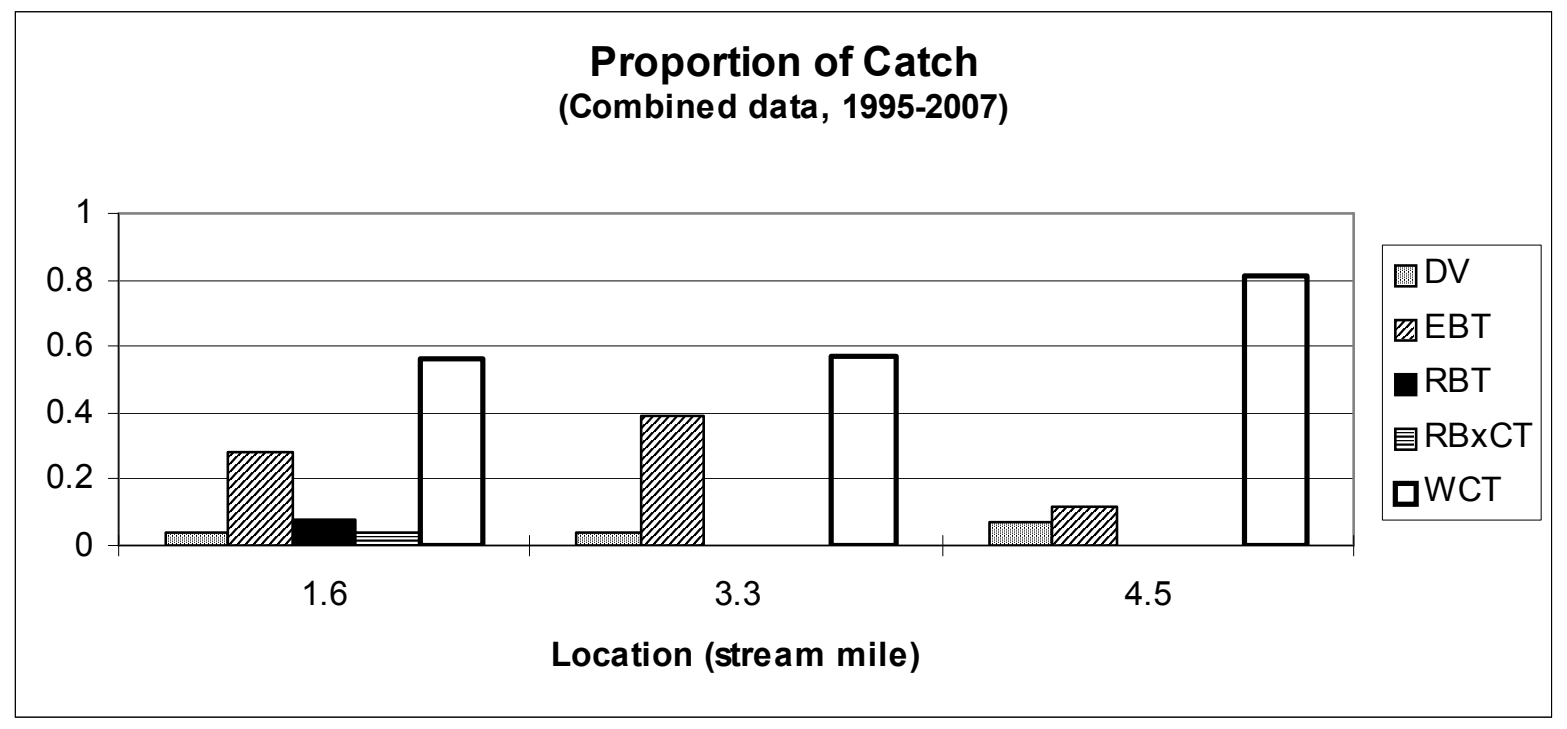

Figure 3. Proportion of catch for salmonid species at three sites on Blind Canyon Creek, 1995-2007.

Amphibian Community

Tailed frogs have been observed at the lower two sample sites on Blind Canyon Creek. Failure to detect Columbia spotted frogs does not necessarily indicate absence. 


\section{Boles Creek}

Boles Creek is a secondorder tributary of Placid Creek located approximately six miles southwest of the town of Seeley Lake. The main stem flows generally east, then north, from its headwaters near Gold Creek Peak and Elk Meadow. Boles Creek enters Placid Creek just upstream of Placid Lake. It's most major tributary is an unnamed stream that enters from the south and originates at Spook Lake.

Boles Creek is an important

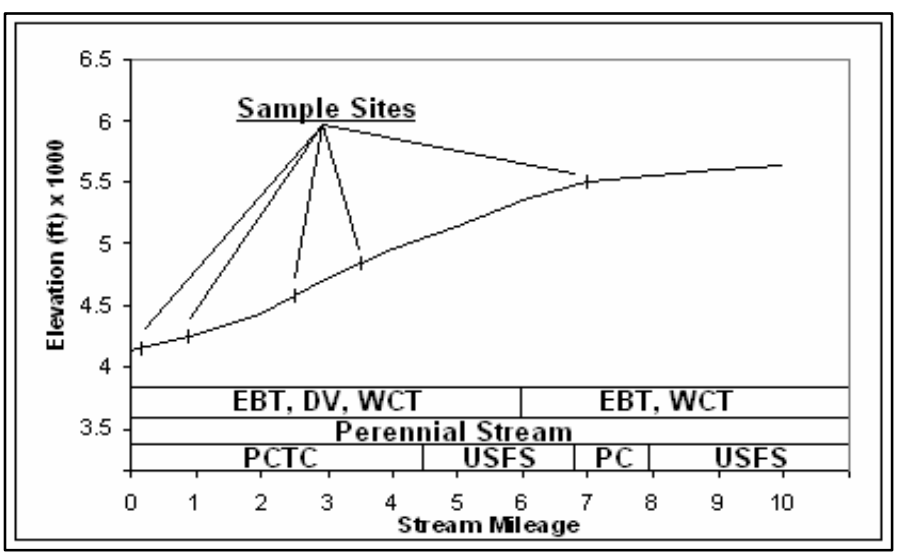

Figure 4. Longitudinal profile for Boles Creek.

stream for native salmonids in the Clearwater drainage, with apparent limited use by migratory life history forms. High biological ranking and prioritization of this watershed relative to other Clearwater Drainage streams (see stream prioritization section) reflect relatively abundant stream-resident bull trout and WSCT populations, and high habitat quality. Boles Creek may also support modest adfluvial bull trout and WSCT populations, although this has yet to be verified and warrants further investigation. These migratory populations likely reside in Placid Lake and use Boles Creek for spawning and rearing.

\section{Land Ownership and Habitat Conditions}

Boles Creek flows through a "checkerboard" of public (USFS) land and industrial forest (PC) land (Figure 4). It enters Placid Creek at approximately river mile 0.2, just upstream of Placid Lake. Stream gradients range from $300 \mathrm{ft} / \mathrm{mile}(\sim 5.7 \%)$ near stream mile 3 to about $33 \mathrm{ft} /$ mile $(\sim 0.6 \%)$ near the headwaters at Elk Meadow. No major dewatered reaches have been observed and human water use is limited.

The Boles Creek watershed consists of marginally functional, semi-degraded aquatic, riparian and terrestrial habitats. The entire drainage is a checkerboard of primarily intact forest and managed industrial forest with high road densities and logging. Where Boles Creek flows through USFS lands, riparian areas, water quality and channel morphology are largely intact, providing shade, instream habitat complexity, consistent recruitment of woody debris and adequate stream buffers. However, portions of the road system lie directly adjacent to the main stem and encroach on the stream corridor in many locations. Where Boles Creek flows through industrial forest, high road densities are evident. Riparian encroachment and road drainage lead to increased water temperatures, increased sediment levels, and decreased habitat quality. Recent wildfires in upper and middle portions of the drainage $(2003,2007)$ have also had a significant impact on the stream. These will undoubtedly contribute to increased water temperature and sediment levels in the short term. Wildfires also expedited timber management (salvage) activities in 2007-2008.

Road locations, maintenance and stream crossings may be limiting factors for native fish populations, but need to be more thoroughly assessed. Boles Creek has a total of four crossings that cross the main stem channel. Two of these crossings are bridges that likely 
have little impact on fish movement or natural stream integrity. The others are open-bottom arch and circular culverts which do not likely impede fish movement at most flow levels.

\section{$\underline{\text { Temperature Regime }}$}

The water temperatures in Boles Creek have not been rigorously monitored. Water temperatures collected in conjunction with other investigations have been marginal, ranging from $12^{\circ} \mathrm{C}$ to $16.5^{\circ} \mathrm{C}$ in late June and early July (2006). It is likely that temperatures often exceed optimal levels for native fish later in the summer. Native salmonids, particularly bull trout, require cold water in spawning, staging and rearing habitats. Non-native salmonids, such as brook trout and brown trout, are generally more tolerant of warmer temperatures. Bull trout become stressed when subjected to maximum daily temperatures above $15^{\circ} \mathrm{C}$ $\left(\sim 18^{\circ} \mathrm{C}\right.$ for $\left.\mathrm{WSCT}\right)$. It is likely that maximum water temperatures are a limiting factor for native trout in Boles Creek. More comprehensive data will be collected to evaluate water temperature in 2008.

$\underline{\text { Fish Populations }}$

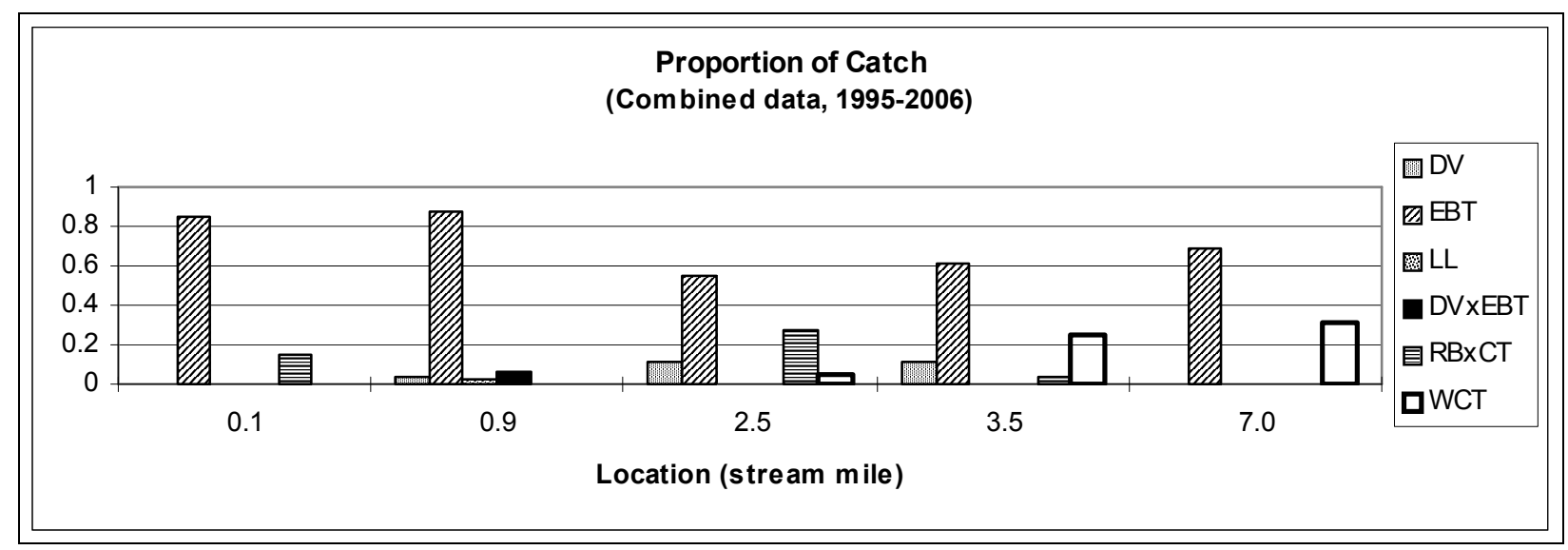

Figure 5. Proportion of catch for trout species at five locations on Boles Creek in 1995-2006.

Since 1995, five locations on Boles Creek have been sampled by backpack electrofishing to determine fish species distribution and Oncorhynchus spp. genetic composition (see Figure 5). These locations were at stream miles 0.1, 0.9, 2.5, 3.5, and 7.0. These samples have indicated that Boles Creek is dominated by non-native species, primarily brook trout. Native fish populations appear to be genetically introgressed. WSCT have been hybridized with rainbow trout and genetic analyses (2006, FWP, unpublished data) suggest a hybrid swarm with $>98 \%$ WSCT genetic contribution. Although the population has not been tested, morphological characteristics indicate that bull trout $\mathrm{x}$ brook trout hybrid individuals are common. Sculpins, longnose suckers, and a brown trout have also been observed in lower stream reaches.

\section{Amphibian Community}

Anecdotal observations suggest that tailed frogs are common at the majority of sites on Boles Creek. Lack of data on other species does not confirm absence. 


\section{Deer Creek}

Deer Creek is a third-order tributary of the Clearwater River system located approximately three miles northwest of the town of Seeley Lake. This stream flows directly into Seeley Lake at the northwest corner of the lake. Deer Creek flows generally east and drains the area between the Marshall Creek and Placid Creek watersheds. It has one major tributary (Fawn Creek), which enters from the south at stream mile 3.4 and two smaller

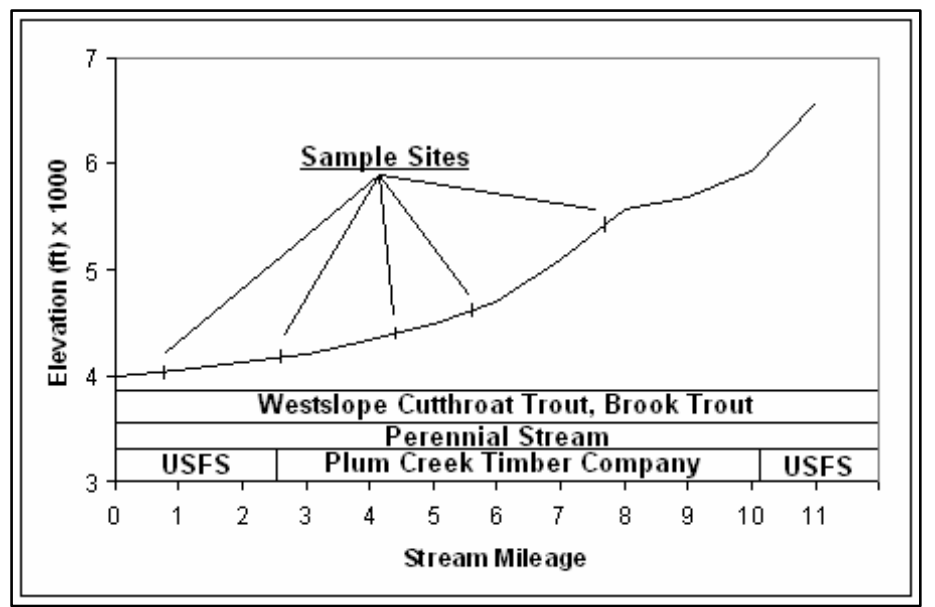

Figure 6. Longitudinal profile for Deer Creek. tributaries. These include Sheep Creek, which enters from the south (mile 6) and an unnamed tributary that enters from the north (mile 8).

Deer Creek is an important stream for native salmonids in the Clearwater drainage, particularly for WSCT. Bull trout have also been detected in low densities, but population viability is questionable. Because the stream flows directly into Seeley Lake, use by adfluvial trout is likely. However, this has not been verified. High biological ranking and prioritization of this watershed relative to other Clearwater Drainage streams (see prioritization section) reflect relatively high habitat quality, relatively abundant WSCT populations, and high potential for use by migratory life forms.

\section{$\underline{\text { Land Ownership and Habitat Conditions }}$}

Most of Deer Creek flows through industrial forest (PC) land (Figure 6). The uppermost $\sim 1$ mile lies on USFS lands. Deer Creek enters the Clearwater River at river mile 24.8 (Seeley Lake). Stream gradients range from $635 \mathrm{ft} / \mathrm{mile}(\sim 12.0 \%)$ near the stream's headwaters to about $49 \mathrm{ft} /$ mile $(\sim 0.9 \%)$ near its confluence with Seeley Lake. No major dewatered reaches have been observed and human water use is currently minimal.

The majority of the Deer Creek watershed consists of large tracts of undeveloped timber land with high road densities and extensive timber management. Riparian areas have been compromised by past logging in some areas and the stream is likely affected by impacts associated with the extensive road matrix (e.g., increased sediment levels and water temperatures, altered hydrology). Only the extreme upper watershed $\left(\sim 1 \mathrm{mi}^{2}\right)$ is comprised of intact, roadless forest. Middle and lower portions of the drainage still maintain high stream habitat quality and generally intact stream corridors that are capable of recovery where impacts have been observed.

Road maintenance and stream crossings on Plum Creek Timber Company roads need to be thoroughly evaluated. There are currently five stream crossings on the main stem of Deer Creek. These crossings are all bridges that likely have little impact on fish movement or natural stream integrity. There are also two crossings of Fawn Creek. Both are pipe-arch culverts that are suspected to be partial barriers to fish movement. Additionally, there is one crossing of Sheep Creek. It is also a pipe-arch culvert that is suspected to be a partial barrier to fish movement. 


\section{$\underline{\text { Temperature Regime }}$}

The water temperature regime in Deer Creek has not been rigorously monitored. Anecdotal water temperatures collected in conjunction with other investigations have been marginal, ranging from $9^{\circ} \mathrm{C}$ to $18^{\circ} \mathrm{C}$ in mid-summer (July and August) 2006. It is likely that temperatures often exceed optimal levels for native fish throughout the summer. Native salmonids, particularly bull trout, require cold water in spawning, staging and rearing habitats. Non-native salmonids, such as brook trout and brown trout, are generally more tolerant of warmer temperatures. Bull trout become stressed when subjected to maximum daily temperatures $>15^{\circ}$ Celsius $\left(>18^{\circ} \mathrm{C}\right.$ for WSCT). It is likely that maximum water temperatures in Deer Creek are a limiting factor for native trout populations.

$\underline{\text { Fish Populations }}$

Since 1995, five locations on Deer Creek have been sampled by backpack electrofishing to determine fish species distribution and Oncorhynchus spp. genetic composition (see Figure 7). These locations were at stream miles 0.8, 2.6, 4.4, 5.6, and 7.7. These samples indicate that Deer Creek is dominated by WSCT (native) and brook trout (introduced). However, the population of WSCT has been slightly hybridized with rainbow trout. Bull trout were observed in very low densities in 1995 and 2000, but have not been detected in Deer Creek since. The upper end of Deer Creek has been sampled in 2000 and 2006 at stream mile 7.7, and no fish were documented either time. A very high-gradient area near stream mile 7.4 is likely a total fish barrier. Lower reaches of Deer Creek have a higher proportion of non-native species (primarily brook trout) relative to middle and upper reaches. Brown trout and long nose dace have been documented in Deer Creek in very low numbers, and sculpins are present throughout the fish-bearing portion of the drainage.

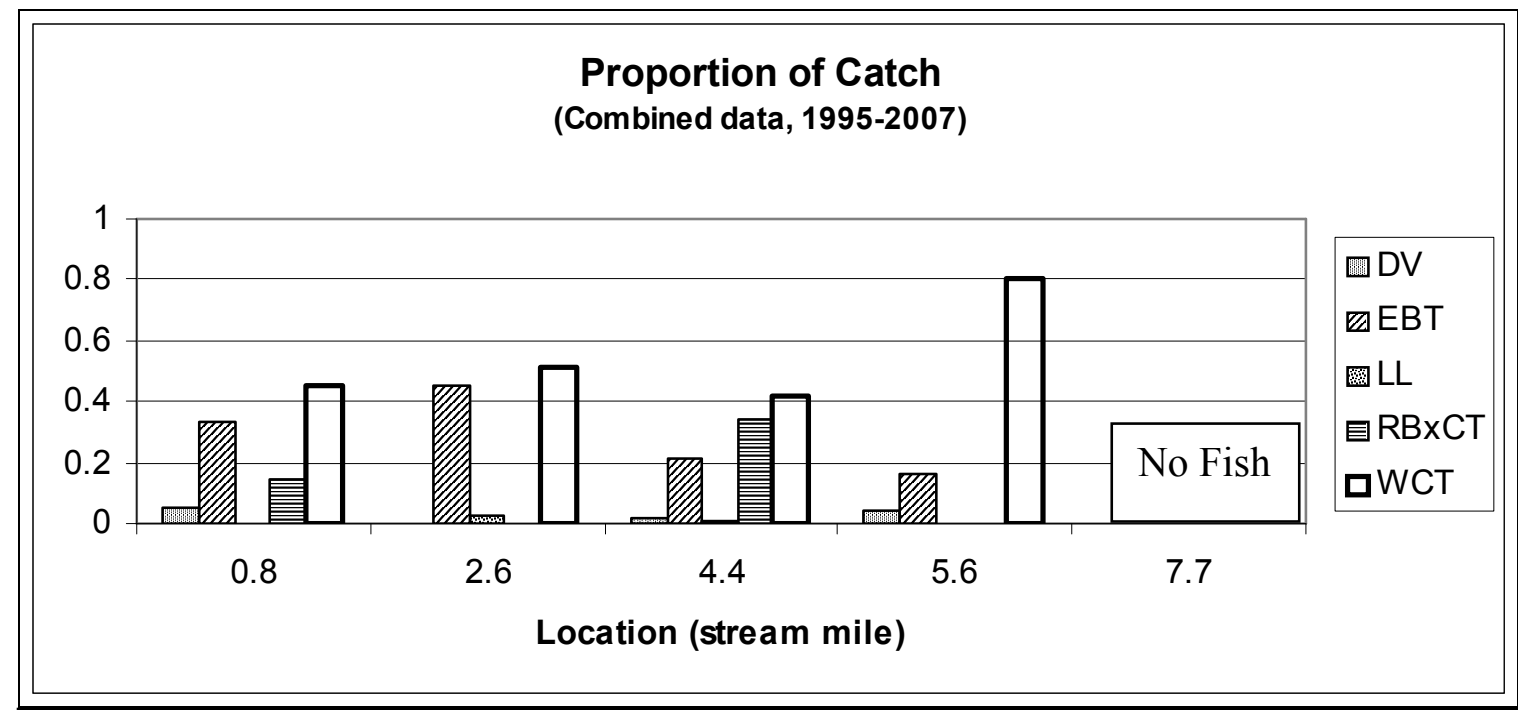

Figure 7. Proportion of catch for trout species at five locations on Deer Creek in 1995-2007.

Surveys and genetic analyses conducted by FWP in 2006 suggest that the Deer Creek WSCT population is a hybrid swarm with a $99.5 \%$ WSCT genetic contribution. However, a limited sample also suggests that the population of WSCT found in Sheep Creek may be genetically non-introgressed. This is significant because most WSCT populations in the 
Clearwater River drainage have been mildly hybridized with introduced rainbow trout, Yellowstone WSCT or both.

\section{Amphibian Community}

Tailed frogs have been observed at nearly every sample site on Deer Creek. Columbia spotted frogs have also been observed in multiple sites on Deer Creek. Occurrence of both species seems to be widespread in the Deer Creek drainage.

\section{East Fork Clearwater River}

The East Fork of the Clearwater River (hereafter, "East Fork") is a second-order tributary to the Clearwater River, located approximately 13 miles northnorthwest of the town of Seeley Lake. It flows generally west from its headwaters near Sunday Mountain. It has one major tributary, an un-named stream that enters from the north at stream mile 1.2.

The East Fork is a very important stream for native salmonids in the Clearwater drainage, particularly migratory life

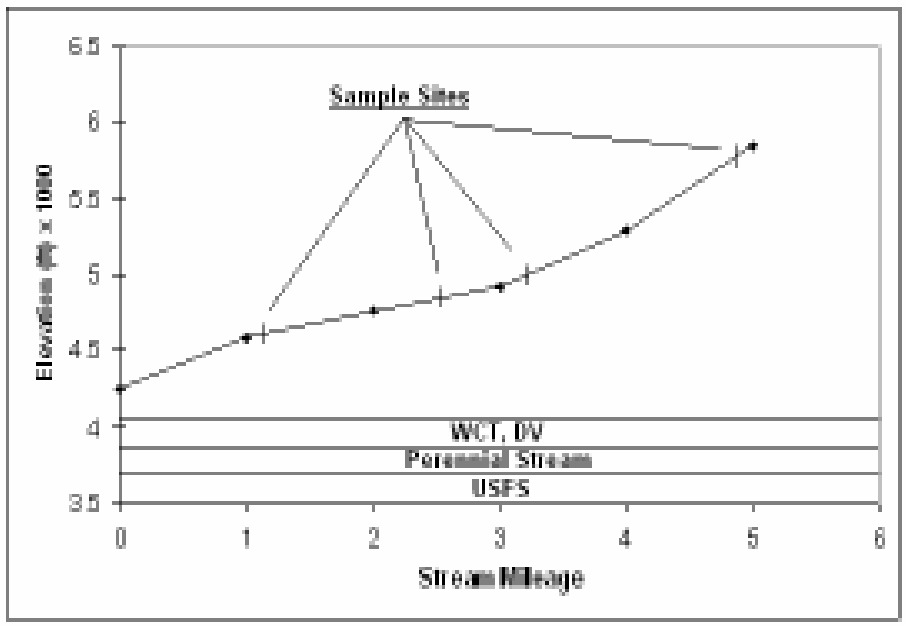

Figure 8. Longitudinal profile for East Fork Clearwater River.

history forms. High biological ranking and prioritization of this watershed relative to other Clearwater Drainage streams (see stream prioritization section) reflect relatively abundant adfluvial and stream-resident bull trout and WSCT populations and high habitat quality. Native salmonid populations in the East Fork are likely not as abundant as those in the West Fork Clearwater or Morrell Creek, but this stream is a very important stronghold for these species in the watershed.

The East Fork supports one of the four known adfluvial spawning populations in the Clearwater Drainage. This stream is particularly important for the viability and persistence of the Rainy Lake bull trout population, as it is currently the only spawning stream accessible via upstream and downstream movement of adults and sub-adults. Currently, a dam on the main stem Clearwater River (at stream mile 38.6) below Rainy Lake acts a complete barrier to upstream fish passage. Recent radio telemetry investigations have demonstrated that adfluvial bull trout emigrate downstream from Rainy Lake. When this occurs, fish are unable to return to Rainy Lake or the primary spawning tributary (East Fork).

\section{$\underline{\text { Land Ownership and Habitat Conditions }}$}

The East Fork watershed lies entirely on USFS lands (Figure 8). It enters the Clearwater River (outlet of Clearwater Lake) at approximately river mile 40.4, upstream of Rainy Lake. Stream gradients range from $557 \mathrm{ft} / \mathrm{mile}(\sim 10.5 \%)$ near the headwaters to about $166 \mathrm{ft} /$ mile $(\sim 3.1 \%)$ near stream mile 2 .

The majority of the East Fork watershed consists of functional, non-degraded aquatic, riparian and terrestrial habitats. The entire drainage is primarily intact forest, with modest 
road densities and limited past logging. Riparian areas, water quality and channel morphology are largely intact, providing shade, instream habitat complexity, consistent recruitment of woody debris and adequate stream buffers along the entire main stem. Although the lower mile of the East Fork does have a road running very near it that may contribute elevated excess sediment, the USFS has recently completed road BMP upgrades and road crossing improvements in the watershed that have reduced any recognized impacts.

The water temperature regime in the East Fork represents one of the lowest anywhere in the Clearwater River or Blackfoot River drainages. Native salmonids, particularly bull trout, require cold water in spawning, staging and rearing habitats. Non-native species, such as brook trout, are generally more tolerant of warmer water temperatures. Bull trout become stressed when subjected to maximum daily temperatures $>15^{\circ} \mathrm{C}\left(>\sim 18^{\circ} \mathrm{C}\right.$ for WSCT). Nearly all other larger streams (capable of supporting bull trout) in the Clearwater River drainage exceed this temperature during summer months. Because the East Fork typically does not exceed $15^{\circ} \mathrm{C}$ (see Figure 9), native fish and other species are able use this tributary as a thermal refuge, as well as for spawning and other life stages.

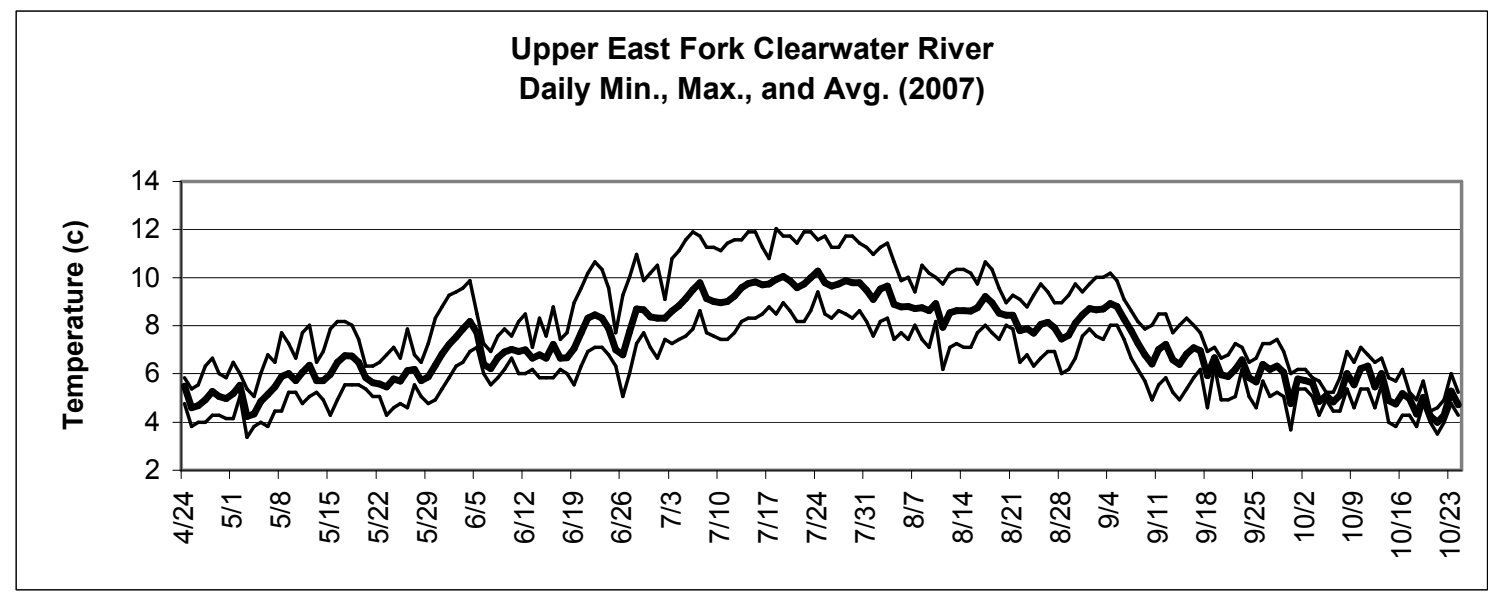

Figure 9. Temperature data from the Upper East fork Clearwater River in 2007.

Fish Populations

Since 1995, six locations have been sampled using backpack electrofishing to determine fish species composition and Oncorhynchus genetic composition. These locations were at stream miles $1.1,2.5,3.2$, and 4.9 , as well as two sites in the un-named tributary that enters the East Fork at stream mile 1.1 from the north. These investigations have revealed that the stream is dominated by native species (Figure 10). Brook trout have been found in the main stem of the Clearwater River, just 1.5 miles upstream of the mouth of the East Fork, and may eventually move into the East Fork. Brook trout were not observed in Rainy Lake or any of the drainage upstream of the lake until the late 1990s when they were illegally introduced into Clearwater Lake. Sculpins have also been observed in the upper end of the unnamed tributary. 


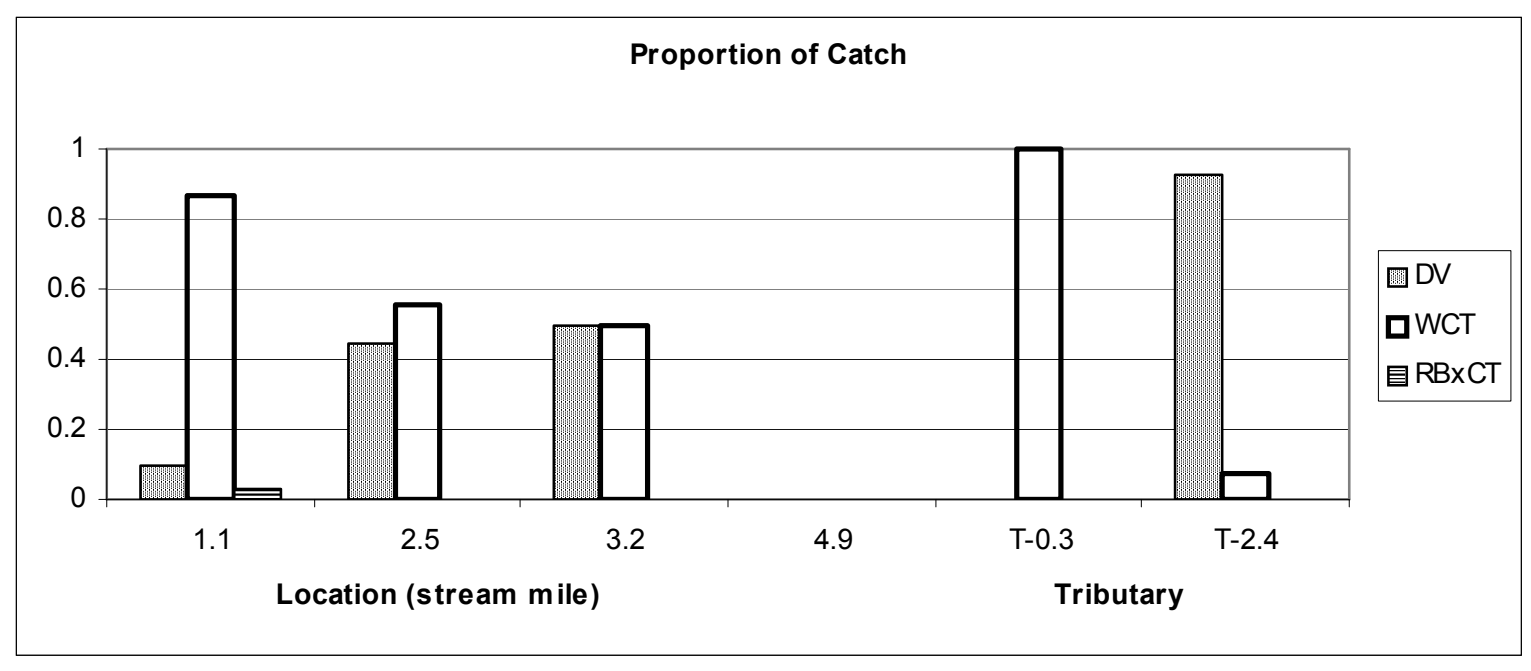

Figure 10. Proportion of catch for salmonids at six locations on the East Fork of the Clearwater River in 1995-2007.

Although the East Fork of the Clearwater River is strongly dominated by native species, the population of WSCT has been hybridized with rainbow trout and Yellowstone WSCT. Surveys and genetic analyses conducted in 2006 and 2007 suggest that the average genetic contribution of WSCT is $97 \%$ for the population.

\section{$\underline{\text { Amphibian Community }}$}

Although not rigorously investigated, it appears that the amphibian community of the East Fork of the Clearwater River is limited. Tailed frogs have been documented in the lower end of the unnamed tributary. No other amphibians were observed during limited stream surveys, but Columbia spotted frogs and other species may be present.

\section{Marshall Creek}

Marshall Creek is a second order tributary of the West Fork of the Clearwater River (hereafter, West Fork) located 6-10 miles northwest of the town of Seeley Lake. It flows generally east and drains the divide between the Clearwater River and Jocko River watersheds, near Sunset Peak. It has no major tributaries, although it does flow through Lake Marshall. Marshall Creek essentially consists of two

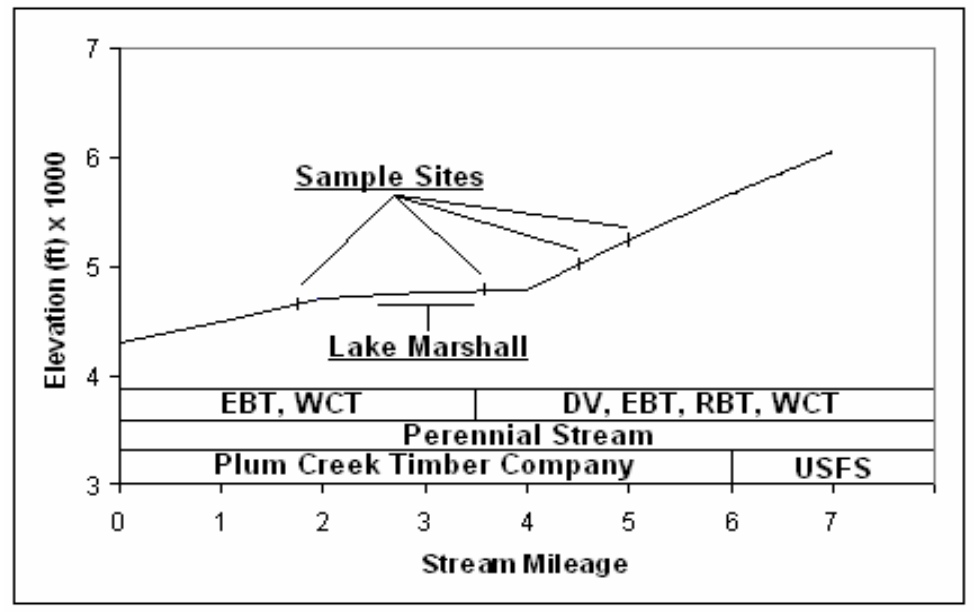

Figure 11. Longitudinal profile for Marshall Creek. reaches: 1) the upper reach from headwaters to Lake Marshall and 2) the outlet of Lake Marshall to the confluence with the West Fork. 
Marshall Creek is an important stream for native salmonids in the Clearwater drainage, particularly for migratory bull trout. High biological ranking and prioritization of this watershed relative to other Clearwater Drainage streams (see prioritization section) reflect relatively high aquatic habitat quality and the presence of bull trout in Lake Marshall and in stream reaches upstream of the lake. Limited data is available for the lower reach between the lake outlet and West Fork.

Marshall Creek supports a small, disjunct adfluvial bull trout population and represents one of four known adfluvial spawning populations in the Clearwater Drainage. Upper Marshall Creek appears to be the only spawning stream utilized by adfluvial bull trout from Lake Marshall (based on the distribution of juvenile fish). Very high water temperatures (typical of lake outlets) in Marshall Creek downstream of Lake Marshall likely discourage use by bull trout from June-September and likely makes this reach unsuitable as year-round juvenile rearing habitat. Recent radio-telemetry investigations have demonstrated that adfluvial bull trout in the West Fork of the Clearwater River enter lower Marshall Creek in the spring, when water temperatures were low, and returned to the West Fork after a short time. Upper Marshall Creek also supports an abundant migratory rainbow trout population that was previously introduced into the lake. This population has hybridized with and overwhelmed the native WSCT population in the upper drainage.

\section{$\underline{\text { Land Ownership and Habitat Conditions }}$}

Most of Marshall Creek flows through industrial forest (PC) land (Figure 11), although the uppermost $\sim 2$ miles lie on USFS lands. Marshall Creek enters the West Fork of the Clearwater River at river mile 4.9. Stream gradients range from $445 \mathrm{ft} / \mathrm{mile}(\sim 8.4 \%)$ near stream mile 5 to about $5 \mathrm{ft} /$ mile $(<1 \%)$ just above Lake Marshall.

The majority of the Marshall Creek watershed consists of large tracts of undeveloped land with high road densities and logging (primarily industrial forest). Riparian areas have been compromised by past logging in some areas, and the stream is likely affected by poor road drainage. These factors likely contribute to increased sediment levels and water temperatures, and decreased habitat quality. However, the headwaters are comprised of intact, roadless forest and functional riparian and aquatic habitats. Middle and lower portions of the drainage still maintain high stream habitat quality and generally intact stream corridors that are capable of recovery where impacts have been observed.

Two stream crossings have been built in the Marshall Creek drainage and both cross the main stem channel. These crossings are both bridges that likely have little impact on fish movement or natural stream integrity.

The water temperature regime in Marshall Creek downstream of Lake Marshall is above the optimal range of temperatures for native salmonids. Although data from 2007 (Figure 12) were biased by unusually low water and warm temperatures, this section of stream was not nearly as resilient as other coldwater tributaries in the drainage under these conditions. However, the water temperatures in Marshall Creek upstream of Lake Marshall have not been monitored. Water temperatures collected in conjunction with electrofishing investigations indicate a range of $8.5^{\circ}-12^{\circ} \mathrm{C}$ in early to mid-September. It is unlikely that temperatures often exceed optimal levels for native salmonids later in the summer, but future monitoring will be conducted to confirm this. Native salmonids, particularly bull trout and WSCT, require cold water in spawning, staging and rearing habitats. Non-native species, such as brook trout and rainbow trout, are generally more tolerant of warmer temperatures. Bull trout become stressed when subjected to maximum daily temperatures $>15^{\circ} \mathrm{C}\left(>18^{\circ} \mathrm{C}\right.$ 
for WSCT), which occurred regularly for approximately twelve weeks in 2007 downstream of the lake. In this system, native salmonids may use lake stratification as a thermal refuge during warm summer months.

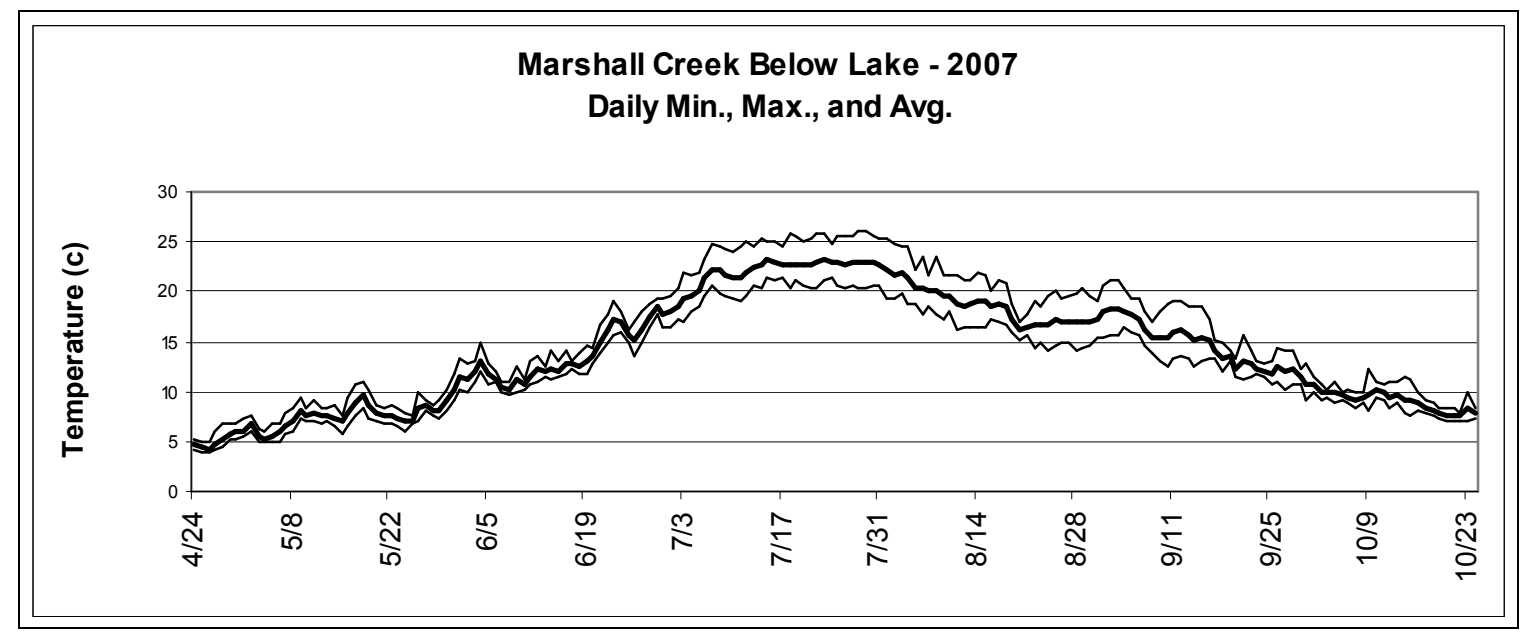

Figure 12. Temperature data from Marshall Creek downstream of Lake Marshall.

$\underline{\text { Fish Populations }}$

Since 1995, four locations on Marshall Creek have been sampled using backpack electrofishing to determine fish species composition and Oncorhynchus spp. genetic contribution (see Figure 13). These locations were at stream miles 1.8, 3.6, 4.5, and 5.0. These samples have indicated that Marshall Creek is dominated by non-native species, primarily brook trout and rainbow trout.

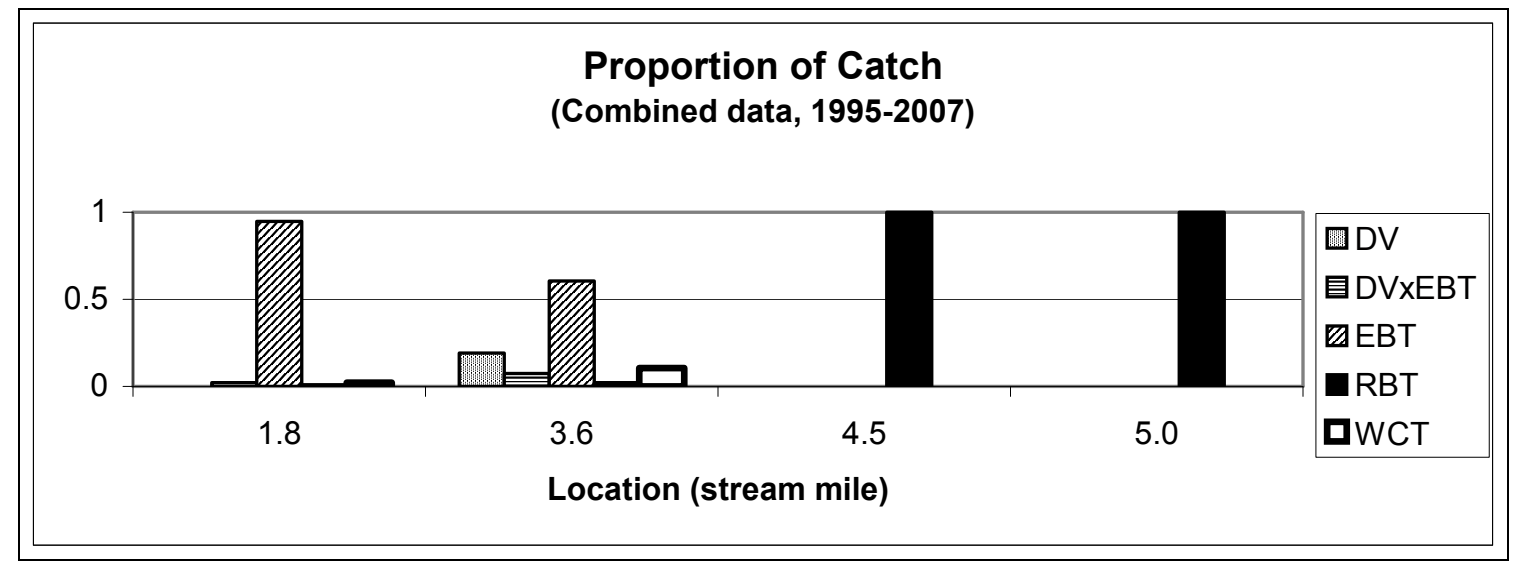

Figure 13. Proportion of catch for salmonids at four locations on Marshall Creek in 1995-2007.

The bull trout population inhabiting the lake and upper stream reaches currently exists at very low densities based on electrofishing and lake gill net surveys. The population of WSCT has been hybridized with rainbow trout. Surveys and genetic analyses conducted in 2006 and 2007 suggest that the average genetic contribution of WSCT is less than 5\% for the population upstream of the lake. Since 1971, WSCT are the only fish species that have been 
stocked in the Marshall Creek drainage, all in Lake Marshall. Prior to this (post 1942), rainbow trout and unspecified WSCT were stocked in Lake Marshall periodically. In addition, the only known stocking of Lake Dinah (at the headwaters of Marshall Creek) was with rainbow trout in 1941. Although the bull trout population has not been genetically tested, multiple bull trout $\mathrm{x}$ brook trout hybrid individuals have been observed in upper Marshall Creek. Long nose dace and mountain whitefish have also been found in the lower end of Marshall Creek. Species captured in Lake Marshall gill net surveys include mountain whitefish and longnose sucker, in addition to the salmonids species already mentioned.

\section{Amphibian Community}

Tailed frogs have been documented at the majority of sites on Marshall Creek. Columbia spotted frogs and other species have not been observed, but may be present.

\section{Morrell Creek}

Morrell Creek is a third order tributary of the Clearwater River located near the town of Seeley Lake. The main stem flows generally southward from its headwaters near Matt Mountain and Sunday Mountain. Major tributaries, most of which form the Trail Creek system and Drew Creek, converge and enter Morrell Creek at stream mile 0.5. These streams are described in separate sections of this report.

Morrell Creek is a very important stream for native salmonids in the Clearwater drainage, particularly

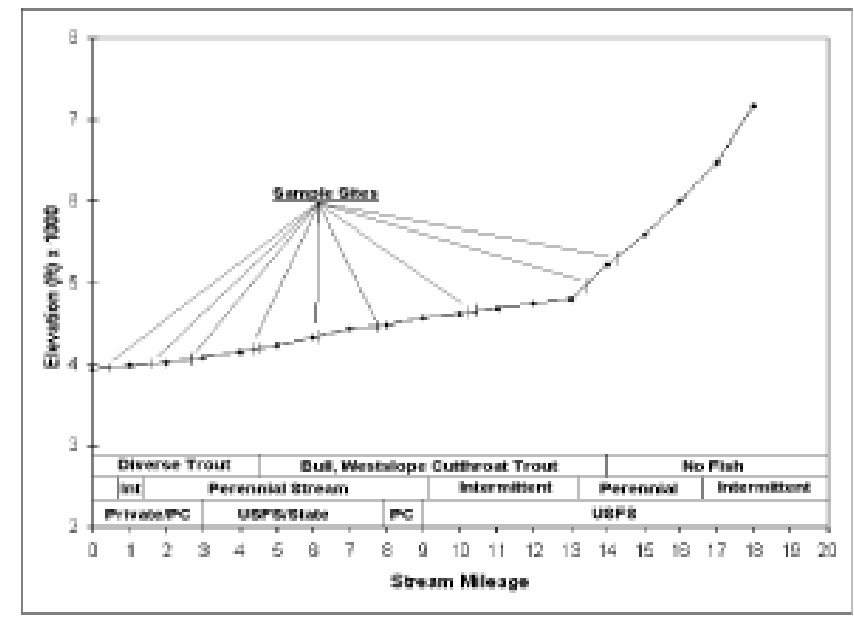

Figure 14. Longitudinal profile for Morrell Creek. migratory life history forms. High biological ranking and prioritization of this watershed relative to other Clearwater Drainage streams (see stream prioritization section) reflect relatively abundant adfluvial and stream-resident bull trout and WSCT populations and high habitat quality. Morrell Creek supports one of the two largest adfluvial bull trout populations in the upper Clark Fork Basin and represents one of four known adfluvial spawning populations in the Clearwater Drainage. Morrell Creek is particularly important for the viability and persistence of the Seeley Lake and Salmon Lake bull trout populations, as it is currently the only spawning stream readily accessible to these fish. Morrell Creek also supports an abundant migratory WSCT population and a genetically non-introgressed streamresident population in upper reaches.

\section{$\underline{\text { Land Ownership and Habitat Conditions }}$}

Most of Morrell Creek flows through public (USFS and DNRC) land and industrial forest (one section of PC) land (Figure 14), but the lower three miles flow through highly developed private lands, including the Double Arrow Golf Course and Subdivision. The stream enters the Clearwater River at approximately river mile 17.3, between Seeley Lake and Salmon Lake. Stream gradients range from $690 \mathrm{ft} / \mathrm{mile}(\sim 13 \%)$ near the headwaters to about $40 \mathrm{ft} /$ mile $(\sim 0.8 \%)$ near the mouth. 
The majority of the Morrell Creek watershed consists of functional, non-degraded aquatic, riparian and terrestrial habitats. The upper drainage is primarily intact forest, with large roadless tracts and some sections with modest road densities and logging (primarily industrial forest). Riparian areas, water quality and channel morphology are largely intact, providing shade, instream habitat complexity, consistent recruitment of woody debris and adequate stream buffers along middle and upper reaches. However, the lower 2.5 miles of Morrell Creek are plagued with detrimental land-use practices, including stream encroachment, removal of riparian vegetation, poor road drainage, and excessive water diversion, which contributes to stream dewatering and fish entrainment losses in irrigation ditches. These problems lead to increased water temperatures, increased sediment levels, and decreased habitat quality. A $\sim 0.25-0.5$ mile stretch of stream that dewaters in low water years in the fall (stream mile 1.0) prevents upstream and downstream movement of fish, which is particularly problematic for migrating adult bull trout attempting to reach spawning areas. A natural dewatered section is also present at stream mile 9.5-10.5. This section typically loses surface flows in August and remains dry until late fall or spring runoff.

Road maintenance and stream crossings on USFS and county roads could be improved, but are not considered a limiting factor for fish in this drainage. Road crossings on Morrell Creek are nearly all bridges and are not considered impairments to upstream fish passage or natural stream integrity.

\section{Temperature Regime}

Water temperatures in Morrell Creek are cold relative to other tributaries in the Clearwater River drainage (see Figures 15-17). Native salmonids, particularly bull trout and WSCT populations, require cold water in spawning, staging and rearing habitats. Non-native salmonids, such as brook trout and brown trout, are generally more tolerant of warmer temperatures. Bull trout become stressed when subjected to maximum daily temperatures above $15^{\circ} \mathrm{C}\left(\sim 18^{\circ} \mathrm{C}\right.$ for WSCT). Nearly all third order or larger streams in the Clearwater River drainage frequently exceed this temperature. Abundant native fish are an indication of relatively intact habitat quality and water quality (see figures $2,3,4$ ); native fish are able to use Morrell Creek during all stages of their lives.

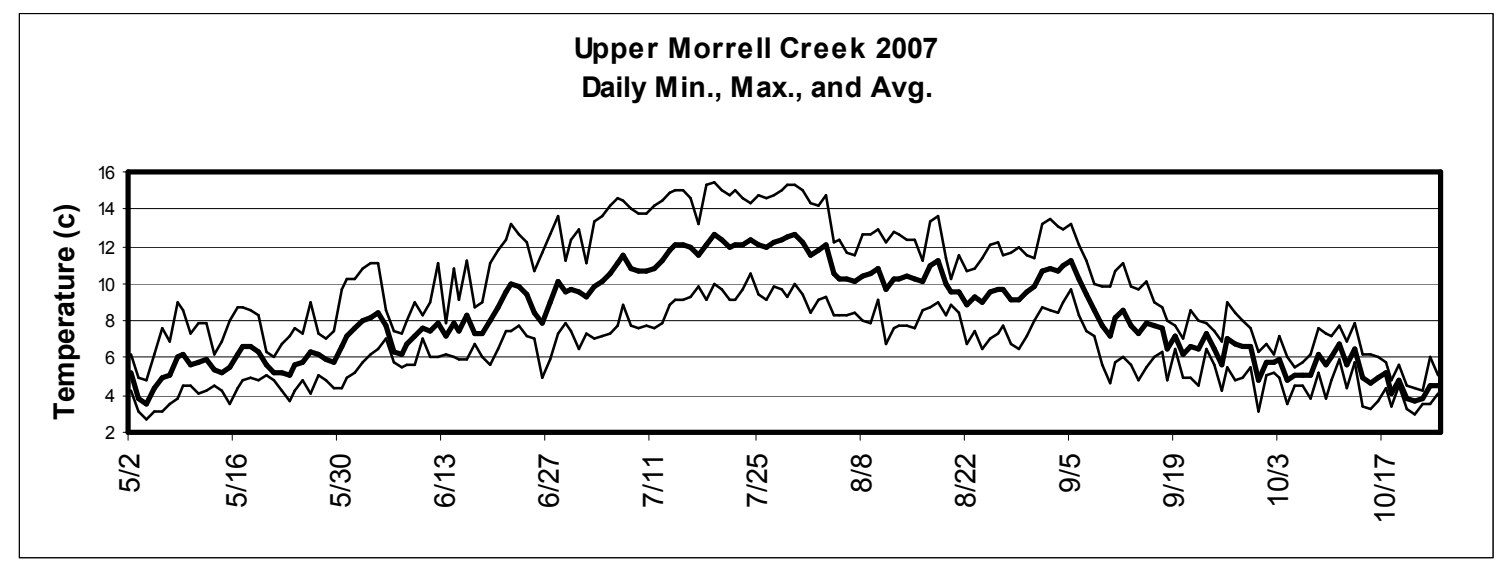

Figure 15. Temperature data from upper Morrell Creek in 2007. 


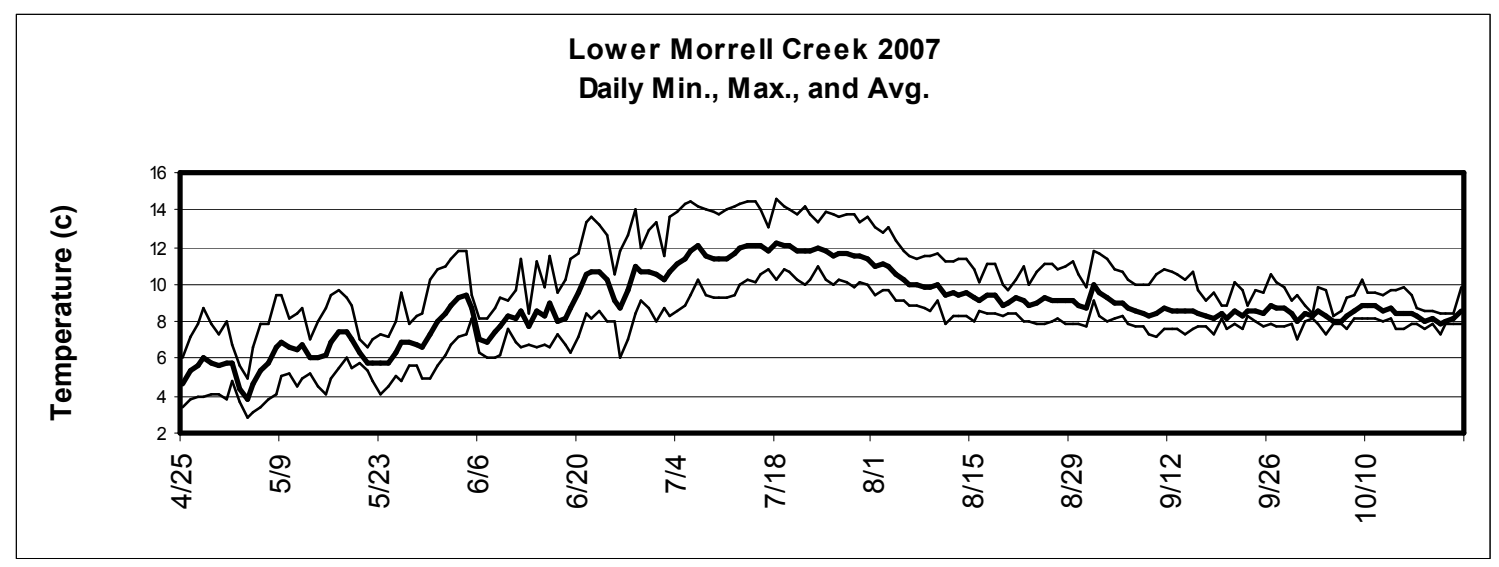

Figure 16. Temperature data from lower Morrell Creek in 2007.

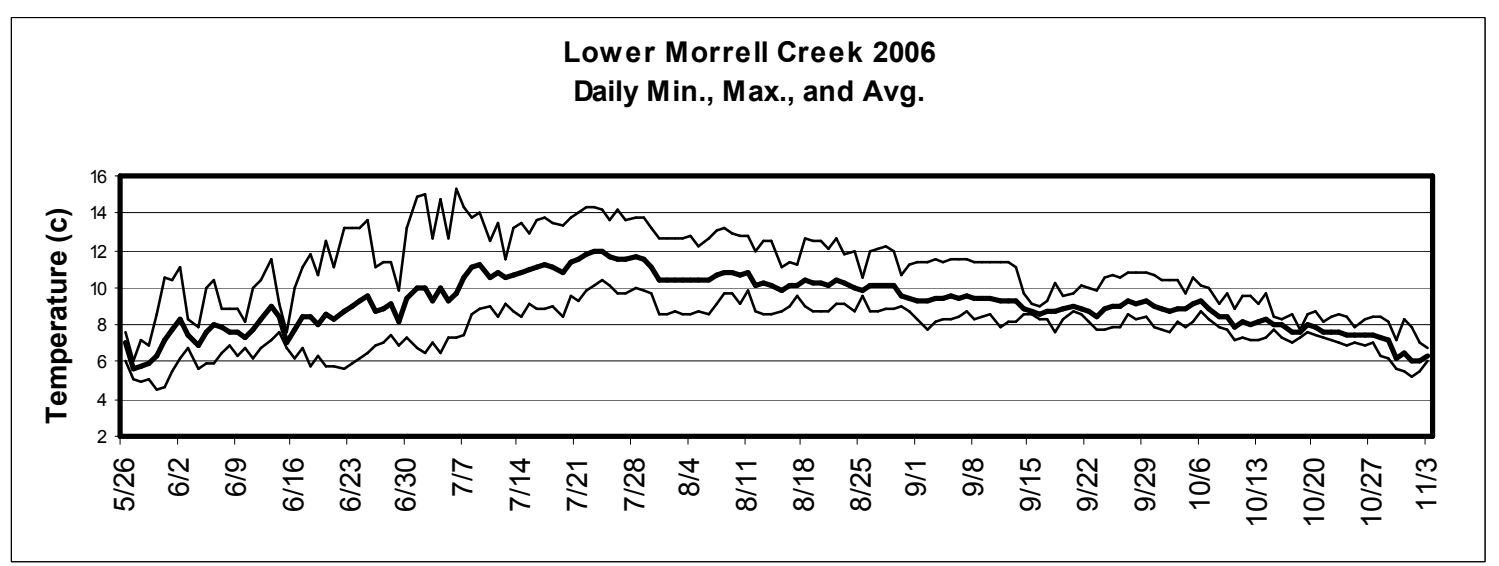

Figure 17. Temperature data from lower Morrell Creek in 2006.

\section{Fish Populations}

Since 1995, thirteen locations on Morrell Creek have been sampled for fish species composition and Oncorhynchus spp. genetic analysis (see Figure 18). These locations were at stream miles $0.4,1.6,2.6,4.4,4.5,6.1,7.8,10.2,10.5,13.4$, and 14.2, as well as two sites in the unnamed tributary that enters Morrell Creek from the north, just downstream of Morrell Falls, at (tributary) stream miles 0.8 and 1.3. These samples have indicated that the majority of Morrell Creek is dominated by native species. However, as is often the case with degraded habitats, the lower end of Morrell Creek ( $\sim 3$ miles) is dominated by non-native species (brown trout and brook trout) and WSCT x rainbow trout hybrids. Hybrids have been detected throughout lower portions of the Morrell Creek system, but upper reaches (above stream mile 9.5) appear to be non-introgressed. Although not rigorously investigated, sculpins are present in Morrell Creek from stream mile 4.5 to Morrell Falls and possibly in the lower 4.5 miles as well. Morrell Falls is at stream mile 13.8, and is a barrier to fish movement. Surveys conducted in 2007 (stream mile 14.2) revealed no fish above Morrell Falls in Grizzly Basin. 


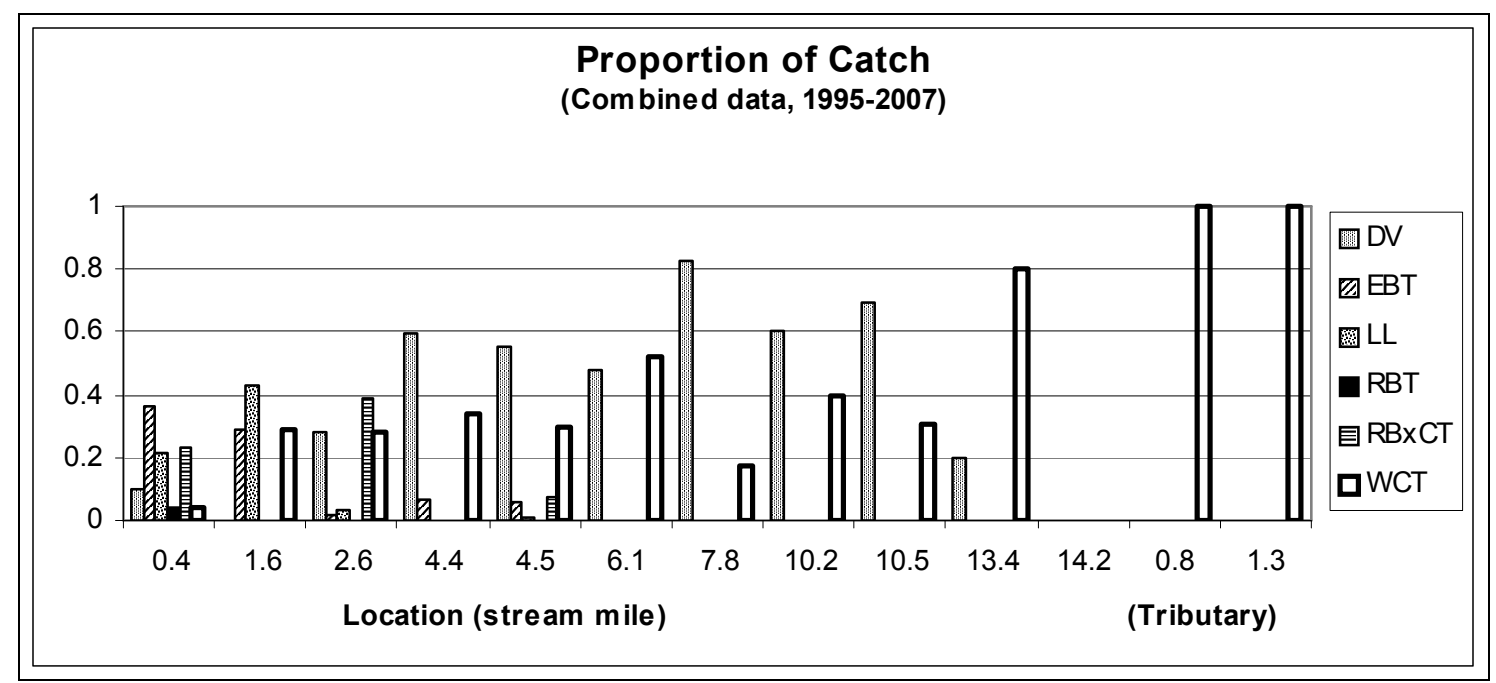

Figure 18. Proportion of catch for salmonids at thirteen locations on Morrell Creek in 1995-2007.

Adult bull trout implanted with radio transmitters in 2006 in Seeley Lake and Morrell Creek provided important information on migration timing, habitat use, spawning behavior, and limiting factors. These findings will be summarized in the Clearwater bull trout telemetry project report.

Surveys and genetic analyses conducted in 2007 suggest that the population of WSCT found in upper Morrell Creek (above the intermittent stretch from stream mile $\sim 9.5$ to $\sim 10.5$ ) is genetically non-introgressed. This is significant because most WSCT populations in the Clearwater River drainage (including lower Morrell Creek and the Trail Creek drainage) have been mildly hybridized with introduced Yellowstone WSCT, rainbow trout, or both. WSCT make up $>99 \%$ (genetic contribution) of Oncorhynchus populations in middle and lower reaches of Morrell Creek.

\section{Amphibian Community}

Tailed frogs have been observed from stream mile 4.5 to above Morrell Falls, and possibly in the lower 4.5 miles also. Columbia spotted frogs have also been observed in Morrell Creek. However, locations are anecdotal and distribution appears to be limited.

\section{Trail Creek}

Trail Creek is a thirdorder tributary of Morrell Creek, located just east of the town of Seeley Lake. It flows generally south and drains the west side of the Pyramid Pass area between

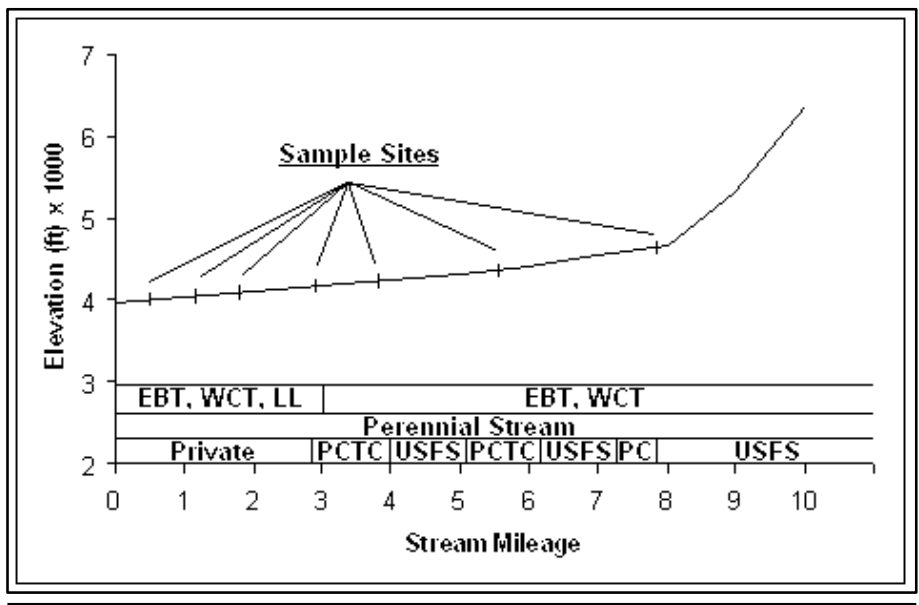

Figure 19. Longitudinal profile for Trail Creek. 
Pyramid Peak and Devine Peak. The Trail Creek drainage includes three major tributaries, Blind Canyon Creek, Swamp Creek and Mountain Creek, which all enter from the east between stream mile 2.0 and 3.9. Blind Canyon Creek is described in a separate section of this report, while other tributaries will be included in subsequent reports.

Trail Creek is an important stream for native salmonids in the Clearwater drainage, particularly migratory life history forms. High biological ranking and prioritization of this watershed relative to other Clearwater Drainage streams (see prioritization section) reflect relatively high habitat quality, relatively abundant migratory and stream resident WSCT populations (upper reaches), and high potential for use by migratory and stream resident bull trout.

\section{$\underline{\text { Land Ownership and Habitat Conditions }}$}

Most of Trail Creek flows through public (USFS) land and industrial forest (three sections of PC land), but the lower two miles flow through highly developed private lands, including the Double Arrow Golf Course and Subdivision (Figure 19). Trail Creek enters Morrell Creek at approximately stream mile 0.8, on the Double Arrow Golf Course. Stream gradients range from $1055 \mathrm{ft} / \mathrm{mile}(\sim 20 \%)$ near the headwaters to about $50 \mathrm{ft} / \mathrm{mile}(\sim 0.9 \%)$ near stream mile 3.

The upper and middle portions of Trail Creek watershed consist of generally functional aquatic, riparian and terrestrial habitats. These reaches lie within "checkerboard" ownership of primarily intact USFS holdings and managed industrial forest with higher road densities and logging. Only the extreme upper watershed $\left(\sim 4 \mathrm{mi}^{2}\right)$ is comprised of intact, roadless forest and fully functioning riparian and aquatic habitats. Where Trail Creek flows through other USFS lands, riparian areas, water quality and channel morphology are largely intact, providing shade, instream habitat complexity, consistent recruitment of woody debris and adequate stream buffers. On industrial forest properties, habitat quality varies with management intensity and road characteristics. Riparian corridors have been maintained (consistent with Montana SMZ laws), but removal of some riparian vegetation and road drainage issues likely contribute to increased sediment levels and decreased habitat quality.

Middle portions of the drainage still maintain relatively high stream habitat quality and stream corridors are capable of recovery where impacts have been observed and addressed. However, the lower two miles of Trail Creek are plagued with detrimental landuse practices, including stream encroachment, removal of riparian vegetation, and poor road drainage. As the stream passes through the Double Arrow Subdivision and Golf Course, riparian clearing and human encroachment are common.

Road maintenance and stream crossings on USFS, PC, and Missoula County roads could be improved, and may be a limiting factor for fish in this drainage. Trail Creek has at least six crossings that cross the main stem channel. Only one of these crossings has been surveyed, and it has been determined to be a partial barrier for fish passage. More comprehensive surveys of the crossings of Trail Creek will be conducted in the near future.

\section{Temperature Regime}

The water temperature regime of Trail Creek is cold relative to other tributaries in the Clearwater River drainage (see Figure 20). Native salmonids, particularly bull trout and WSCT populations, require cold water in spawning, staging and rearing habitats. Non-native salmonids, such as brook trout and brown trout, are generally more tolerant of warmer temperatures. Bull trout become stressed when subjected to maximum daily temperatures 
above $15^{\circ} \mathrm{C}\left(>\sim 18^{\circ} \mathrm{C}\right.$ for WSCT). Nearly all third-order or larger streams in the Clearwater River drainage frequently exceed this temperature.

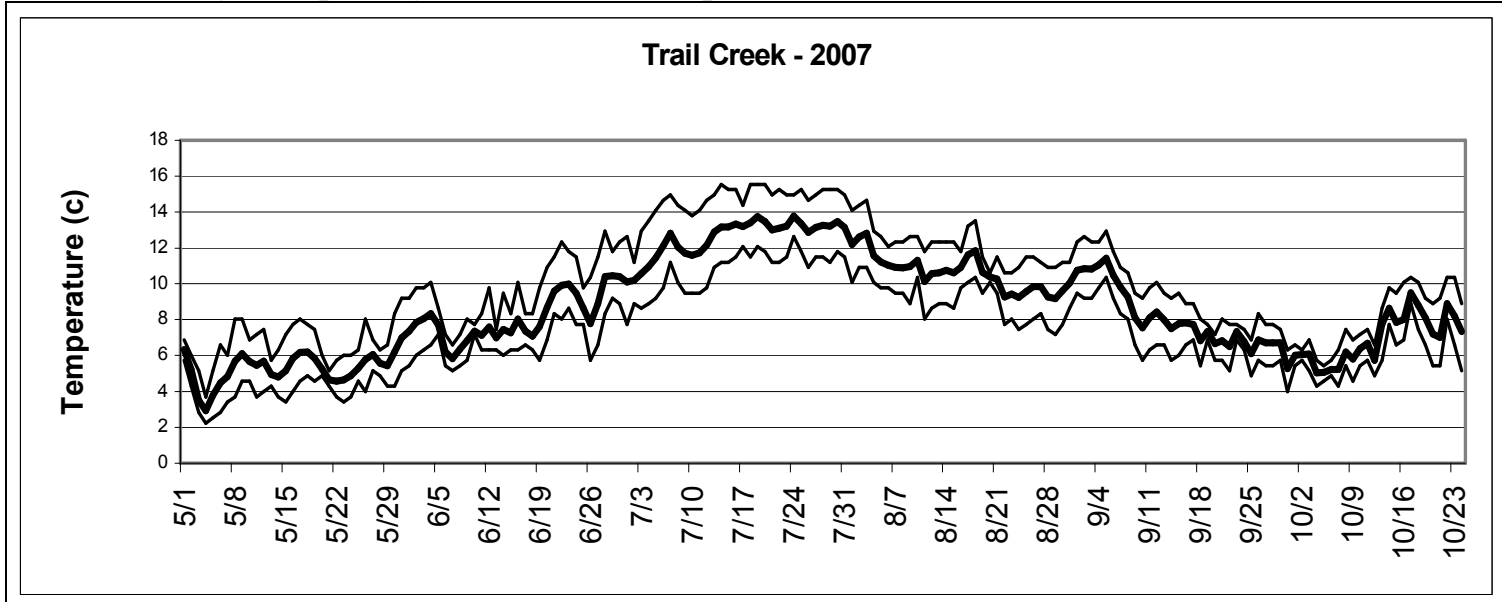

Figure 20. Temperature data from Trail Creek in 2007 at stream mile $\sim 3.8$.

$\underline{\text { Fish Populations }}$

Since 1995, seven locations on Trail Creek have been sampled for fish species composition and Oncorhynchus spp. genetic analysis (see Figure 21). These locations were at stream miles $0.5,1.2,1.8,2.9,3.8,5.5$, and 7.8. These samples indicate that most of Trail Creek is strongly dominated by non-native brook trout. However, despite relatively low densities of native fish species in Trail Creek, the population of WSCT found in upper reaches appears to be non-introgressed. Bull trout were found in Trail Creek surveys conducted in 1995 and 2002. Since then, the only evidence of bull trout in Trail Creek was a bull trout $\mathrm{x}$ brook trout hybrid observed in 2006. Brown trout have also been found in lower Trail Creek, in 2002 and 2006. Although not rigorously investigated, sculpins appear to be present in Morrell Creek from stream mile 2 to the top upper extent of fish-bearing reaches. They likely also inhabit the lower 2 miles, but this has not been verified.

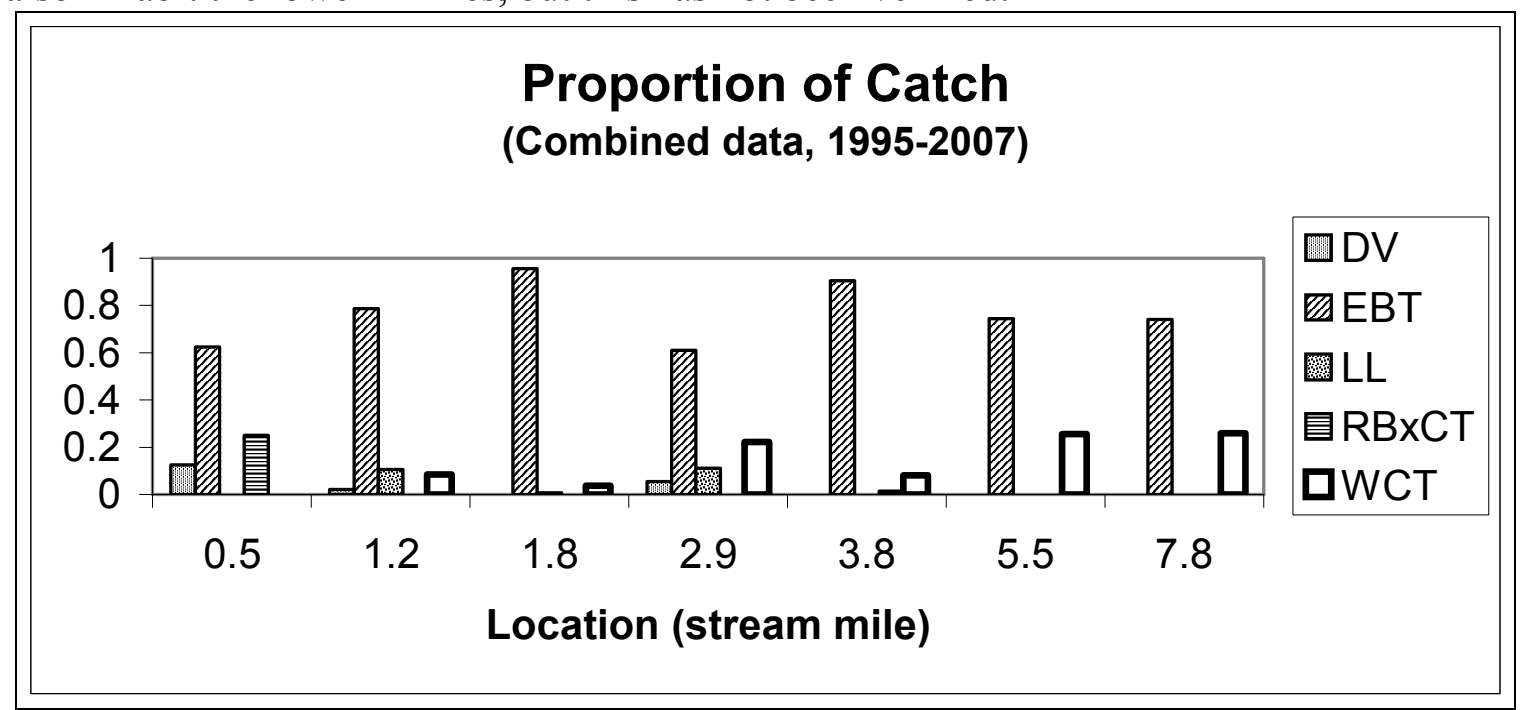

Figure 21. Proportion of catch for salmonid species at seven sites on Trail Creek, 1995-2007. 
Bull trout and other migratory species have been inhibited by an irrigation diversion dam near the mouth for at least two decades. In 2001, a Denil fish ladder was installed on the structure to provide upstream fish passage. Fish entrainment in the ditch and stream dewatering has also been issues at this location.

Surveys and genetic analyses conducted in 2006 and 2007 suggest that the population of WSCT found in upper Trail Creek (above stream mile 6) may be genetically nonintrogressed. In middle and lower portions of the stream, the WSCT population is hybridized with rainbow trout, but the WSCT genetic contribution is $>98 \%$. Most WSCT populations in the Clearwater River drainage (including lower Trail Creek and lower Morrell Creek) have been mildly hybridized with introduced Yellowstone WSCT, rainbow trout, or both.

\section{Amphibian Community}

Although not rigorously investigated, tailed frogs have been observed in Trail Creek above stream mile 3.8. Columbia spotted frogs have not been noted in Trail Creek. Failure to detect Columbia spotted frogs does not necessarily indicate absence.

\section{West Fork Clearwater River}

The West Fork of the Clearwater River (hereafter "West Fork") is a third-order tributary of the Clearwater River located approximately six miles northwest of the town of Seeley Lake. It flows generally southeast and drains the divide between the Clearwater River and Swan River watersheds, near Sunset Peak. There is only one major tributary, Marshall Creek, which enters the West Fork at stream mile 4.9. Marshall Creek is described in a separate section of this report.

The West Fork is a very important stream for native salmonids in the Clearwater drainage, particularly migratory life history forms. High biological ranking and prioritization of this watershed relative to other Clearwater Drainage streams (see prioritization section) reflect relatively abundant adfluvial and stream-resident bull trout and WSCT populations, and high habitat quality.

The West Fork supports one of the largest adfluvial bull trout populations in the upper Clark Fork Basin and represents one of four known adfluvial spawning populations in the Clearwater Drainage. The West Fork is particularly important for the viability and persistence of the Lake Inez and Lake Alva bull trout populations, as it is apparently the only suitable spawning stream accessible to these fish. Currently, a dam on the main stem Clearwater River (stream mile 29.3) between Seeley Lake and the mouth of the West Fork completely blocks upstream fish passage from downstream areas, including Seeley Lake and Salmon Lake. Recent radiotelemetry investigations have demonstrated that a large number of adfluvial bull trout from

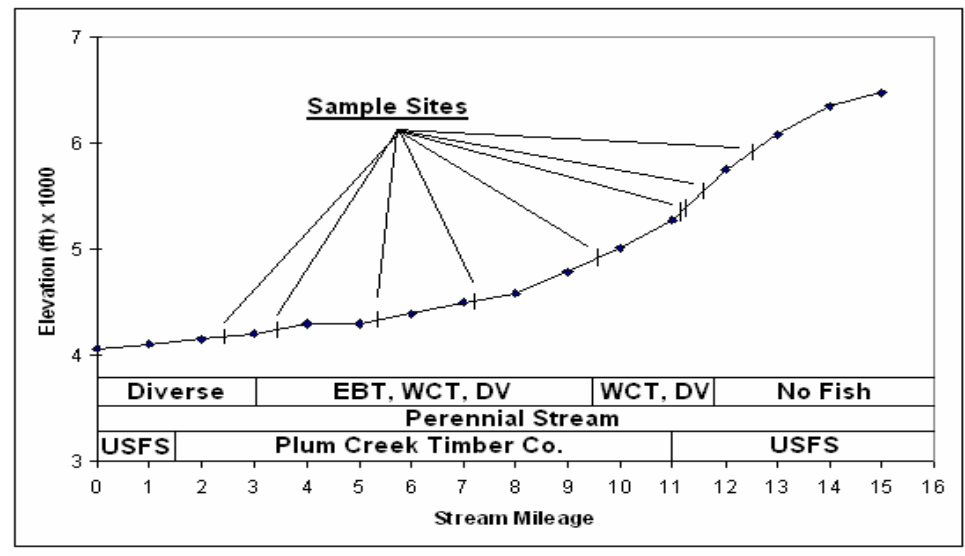

Figure 22. Longitudinal profile for the West Fork Clearwater River. 
Seeley Lake attempt to migrate into the West Fork of the Clearwater River, but are impeded by the dam. Other native fish populations, such as WSCT and mountain whitefish, are likely also impacted. Interim (manual) passage of bull trout was begun in 2007 and a permanent fish passage solution is being developed. The West Fork also supports an abundant migratory WSCT population and a genetically non-introgressed stream-resident population in upper reaches.

\section{Land Ownership and Habitat Conditions}

Most of the West Fork flows through industrial forest (PC) land (Figure 22). The uppermost $\sim 4$ miles lies on USFS holdings and the lower $\sim 1.5$ miles flows through privately owned and USFS lands. The West Fork enters the Clearwater River between Seeley Lake and Lake Inez. Stream gradients range from $470 \mathrm{ft} / \mathrm{mile}(\sim 9 \%)$ near stream mile 12 to about 50 $\mathrm{ft} /$ mile $(\sim 0.9 \%)$ near the mouth.

The majority of the West Fork watershed consists of large tracts of undeveloped land with high road densities and logging (primarily industrial forest). Riparian areas have been compromised by past logging in some areas, and the stream is likely affected by poor road drainage. These factors likely contribute to increased sediment levels and water temperatures, and decreased habitat quality. However, the upper watershed $\left(\sim 7 \mathrm{mi}^{2}\right)$ is comprised of intact, roadless forest and functional riparian and aquatic habitats. Middle and lower portions of the drainage still maintain high stream habitat quality and generally intact stream corridors that are capable of recovery where impacts have been observed. Three stream crossings have been built in the West Fork drainage and all cross the main stem channel. These crossings are all bridges that likely have little impact on fish movement or natural stream integrity.

The water temperature regime in the West Fork is above the optimal range of temperatures for native salmonids. Although data from 2007 (Figures 23 and 24) were biased by unusually low water and warm temperatures, this stream was not nearly as resilient as other coldwater tributaries in the drainage under these conditions. Native salmonids, particularly bull trout and WSCT, require cold water in spawning, staging and rearing habitats. Non-native species, such as brook trout and brown trout, are generally more tolerant of warmer temperatures. Bull trout become stressed when subjected to maximum daily temperatures $>15^{\circ} \mathrm{C}\left(\sim 18^{\circ} \mathrm{C}\right.$ for WSCT), which occurred regularly for approximately six weeks in 2007. The detrimental effects of these extreme temperatures likely contributed to high rates of adult bull trout mortality observed in 2007.

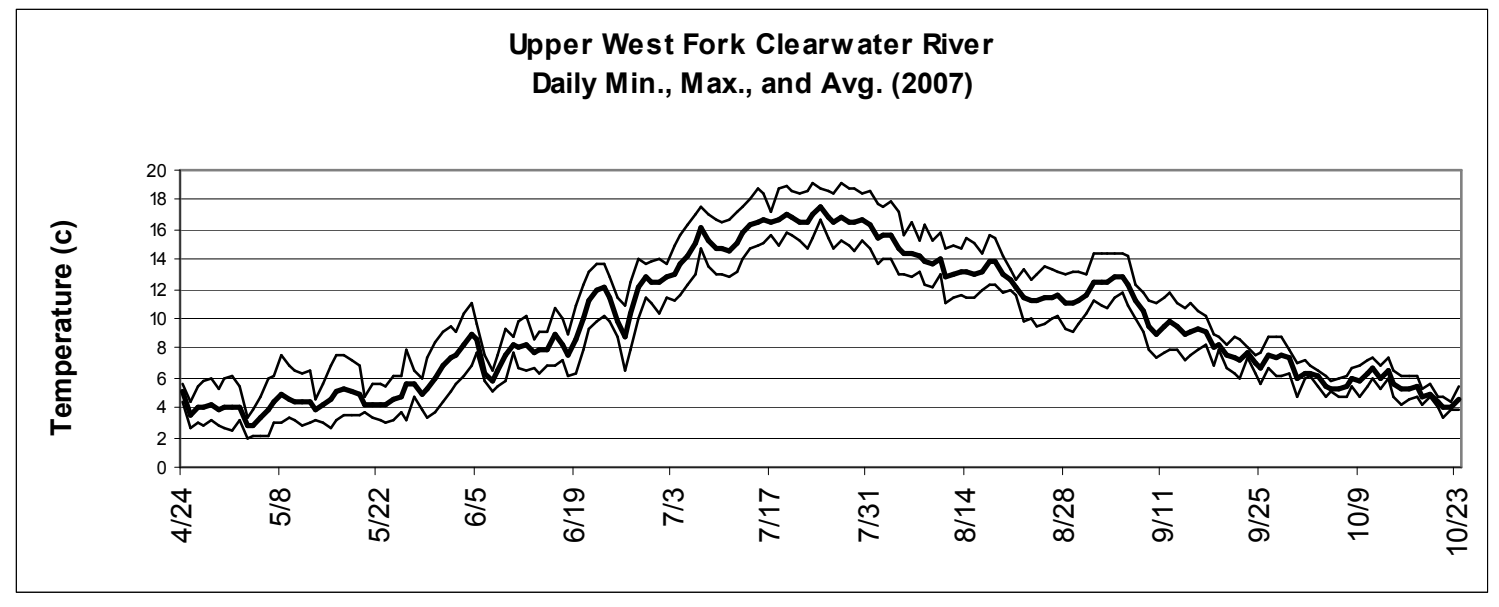

Figure 23. Temperature data from upper West Fork of the Clearwater River. 


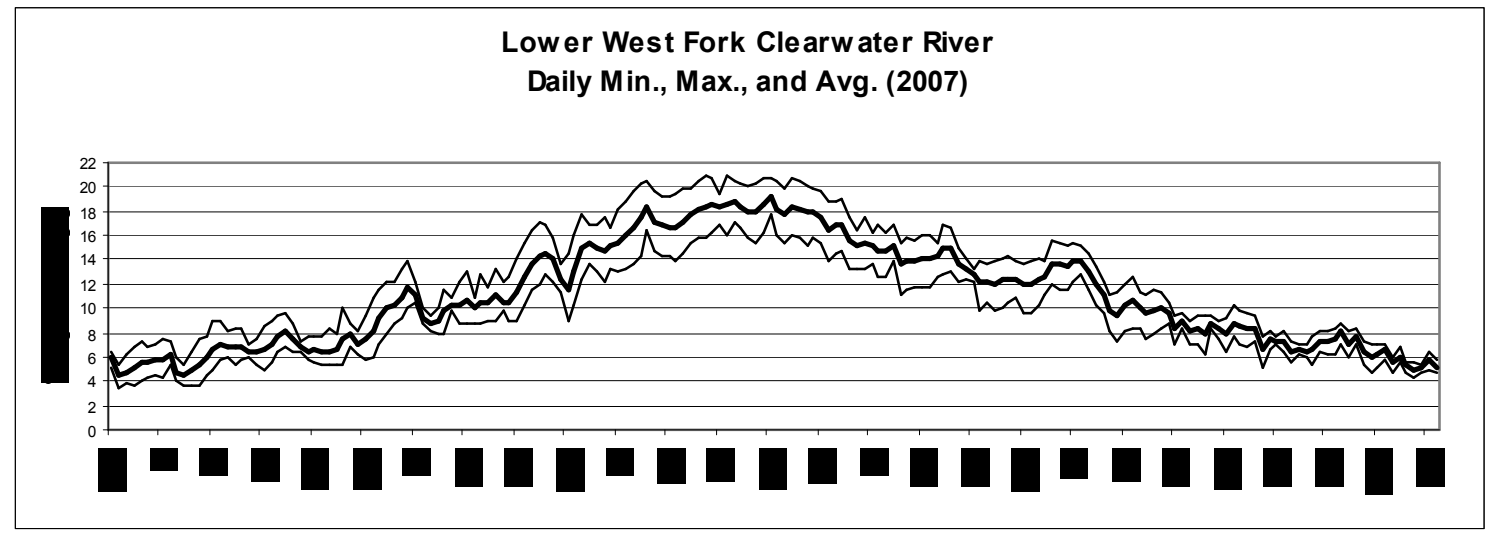

Figure 24. Temperature data from lower West Fork Clearwater River.

\section{$\underline{\text { Fish Populations }}$}

Since 1995, nine locations have been sampled to determine fish species composition and Oncorhynchus spp. genetic composition (Figure 25). These locations were at stream miles $2.4,3.5,5.3,7.1,9.6,11.1,11.2,11.6$, and 12.7. These investigations have revealed that, while the upper end of the stream is dominated by native species, non-native brook trout strongly dominate the lower $\sim 8$ miles of the West Fork. Sculpins are common throughout the drainage, and both long-nosed dace and mountain whitefish are present in the lower $\sim 4$ miles. A very high-gradient section near stream mile 12 appears to be a migration barrier. Surveys conducted in 2007 at stream mile 12.7 revealed no fish above the high gradient section.

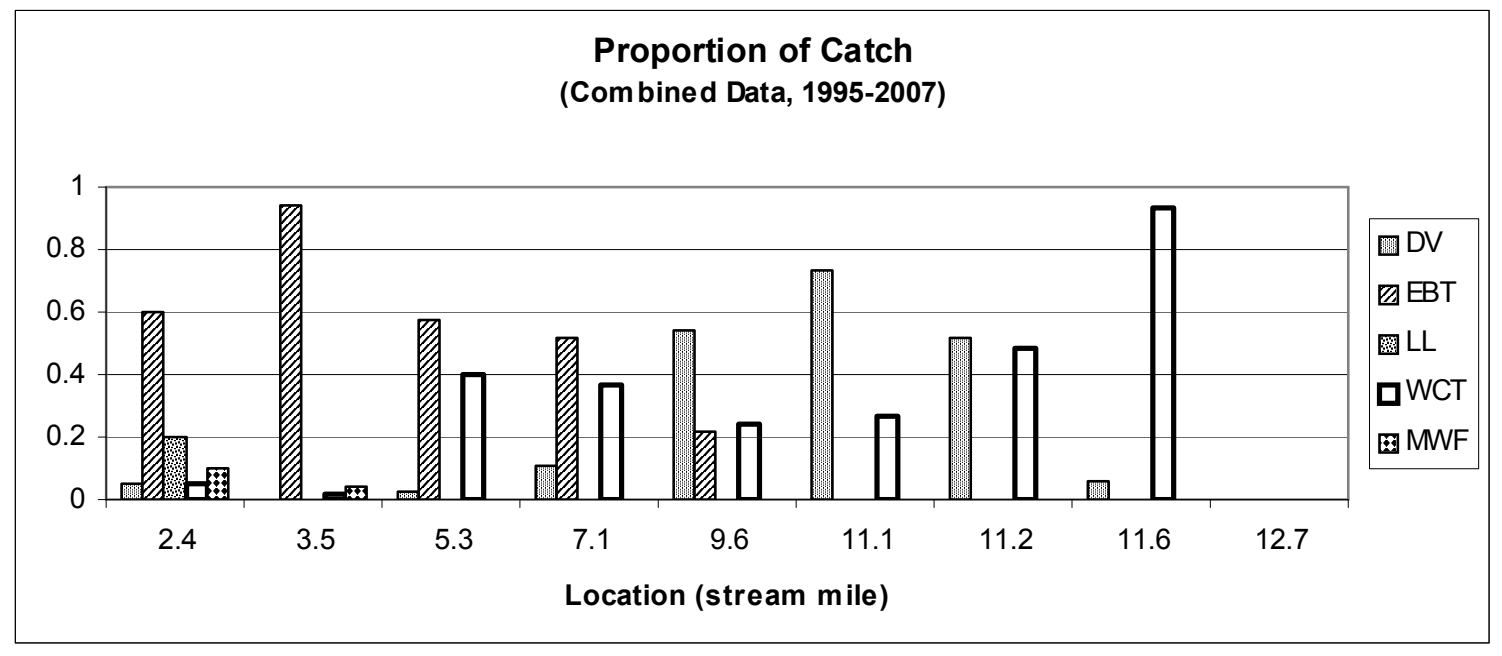

Figure 25. Proportion of catch for salmonids at nine locations on the West Fork of the Clearwater River in 1995-2007.

Surveys and genetic analyses conducted in 2006 and 2007 suggest that the population of WSCT found in the upper-most fish-bearing reach $(\sim$ mile 11$)$ of the West Fork is genetically non-introgressed. WSCT ( $>99 \%$ genetic contribution) in middle and lower portions of the stream (below mile 11) have been hybridized with rainbow trout and 
Yellowstone WSCT. Most WSCT populations in the Clearwater River drainage have been mildly hybridized with one or both of these introduced Oncorhynchus species.

\section{Amphibian Community}

Tailed frogs are present throughout the fish-bearing waters of the West Fork. Columbia spotted frogs have also been observed in the lower half of the drainage. Failure to detect them in upper reaches does not confirm their absence.

\section{Clearwater River Main Stem Sections}

\section{Clearwater River Section I}

(Big Blackfoot River to Salmon Lake).

The Clearwater River is the largest tributary drainage (fourthorder) of the Big Blackfoot River. The main stem Clearwater system is comprised of an interconnected series of lakes and river sections, with many smaller tributary streams that enter throughout. The main stem flows south from its headwaters near Ptarmigan Mountain and the Swan River divide to the confluence with the Big Blackfoot River west of Ovando. Its major tributaries include the East Fork of the Clearwater River, West Fork of the Clearwater River, Camp Creek, Morrell Creek, and the Placid Creek system (Owl Creek).

Clearwater River Section I is the reach from the Salmon Lake outlet to the mouth. This reach encompasses Black "Lake", Blanchard "Lake" and Elbow "Lake", which are actually just wider, lower gradient portions of the river. The only major tributary stream in this section is Blanchard Creek, which enters from the west at stream mile 2.8. Two smaller tributaries, Lost Horse (mile 5) and Lost Prairie (mile 6) Creeks, also enter from the west. Characteristics of all of these drainages will be summarized in a future report.

Clearwater River Section I is an important stream for salmonids in the Clearwater drainage, particularly migratory life history forms and sport fish. This reach is seasonally inhabited by salmonids and is suspected to be an important migratory corridor for fish moving between the Blackfoot River and upper Clearwater system. The extent of use of this corridor has not been determined for bull trout, WSCT or other native fish species, and definitely warrants further investigation. Anecdotal reports and field data highlight the seasonal abundance of non-native salmonids such as brown trout and the year-long use by high densities of introduced northern pike, particularly in slower backwater areas. Connectivity between the Clearwater and Blackfoot Rivers may be an important component of larger scale watershed native fish restoration efforts. Currently, hand-made rock dams and a large irrigation diversion may restrict upstream fish passage at low flows. 


\section{$\underline{\text { Land Ownership and Habitat Conditions }}$}

The Clearwater River Section I flows through a mix of publicly owned (State of Montana-DNRC) lands and privately owned lands (Figure 26). A large portion of this reach borders the Blackfoot-Clearwater Wildlife Management Area. Most of the privately owned parcels along this river were agricultural (grazing and timber), but are experiencing rapid subdivision and residential development. A significant portion of the Clearwater River waterfront on DNRC holdings is also leased for private residential use, particularly along Elbow Lake. Stream gradients are very low, ranging from $62 \mathrm{ft} / \mathrm{mile}(0.11 \%)$ below Salmon Lake to near $0.0 \%$ near the wide, wetland dominated portions referred to as "lakes".

Most of the Clearwater River Section I flows through moderately impacted riparian and terrestrial habitats. Channel alterations, removal of riparian vegetation, and water diversion exacerbate the effects of similar practices upstream. High levels of recreational use and annual manipulations to the shoreline and channel alter the natural integrity of the river corridor. For instance, riparian clearing, establishment of lawns adjacent to cabins, construction of artificial dams to enhance backwater areas for recreation, etc. are common. There is also a large irrigation diversion dam near the mouth they may partially impede upstream fish passage.

\section{$\underline{\text { Water Temperature Regime }}$}

The water temperature regime in the Clearwater River Section I is much above the optimal range of temperatures for salmonids (see Figure 27). Native salmonids require cold water in which to live and reproduce. Non-native species, such as rainbow trout, brook trout and brown trout, are generally capable of succeeding in warmer waters, but the surface discharge from Salmon Lake make this river reach excessively warm in July and August. Because of these high maximum water temperatures, use by salmonids is presumably seasonal. Fish movement is likely extensive and frequent in this reach. This highlights the importance of connectivity for aquatic organisms as they migrate or seek thermal refuge in lakes or near colder tributaries.

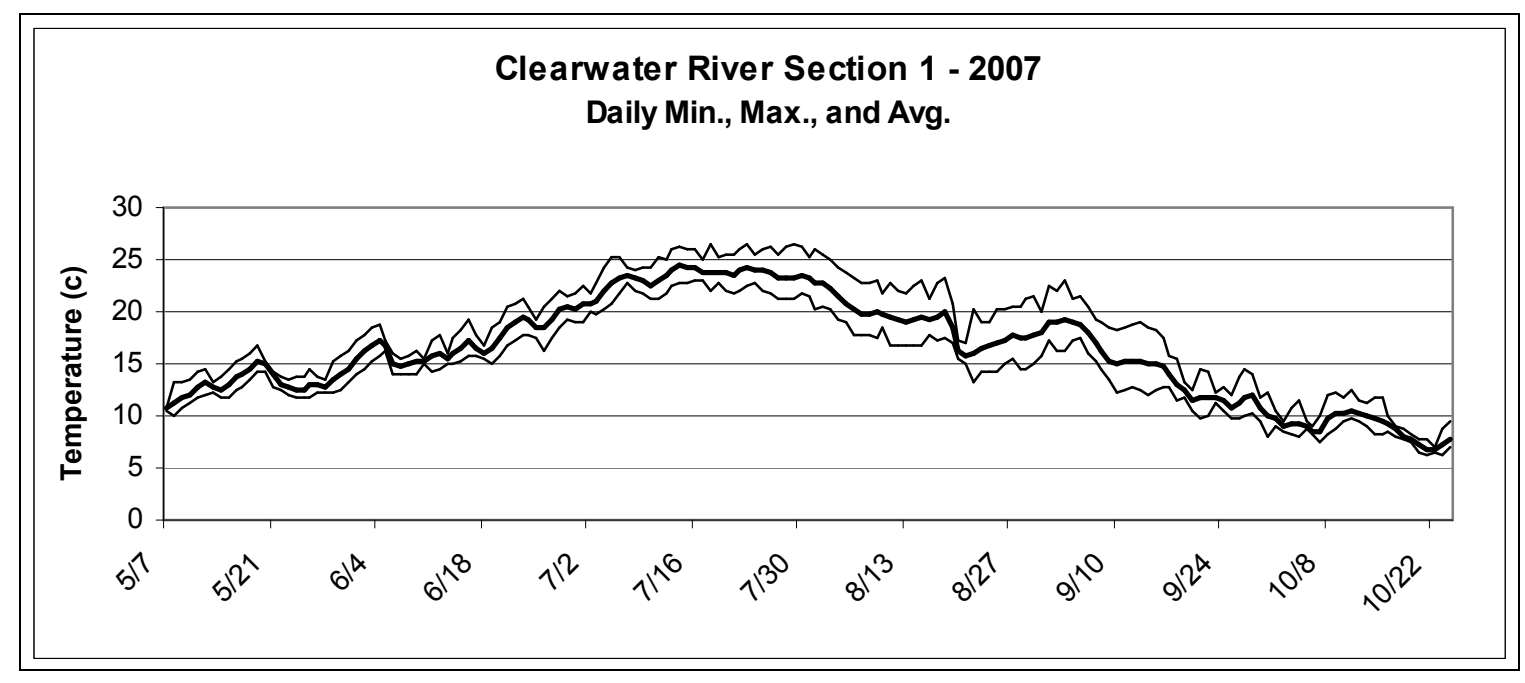

Figure 27. Temperature data from Clearwater River section I (stream mile 3.2), 2007. 
$\underline{\text { Fish Populations }}$

In 1995, four locations on the Clearwater River Section I were sampled to determine fish species composition (see Figure 28). These locations were at stream miles 0.1, 6.1, 9.0, and 9.6. These samples indicated that rainbow trout and brown trout were the dominant salmonid species during early summer. Overall, very little information on fish movement, composition or abundance is available for this reach. Efforts to collect these data will continue.

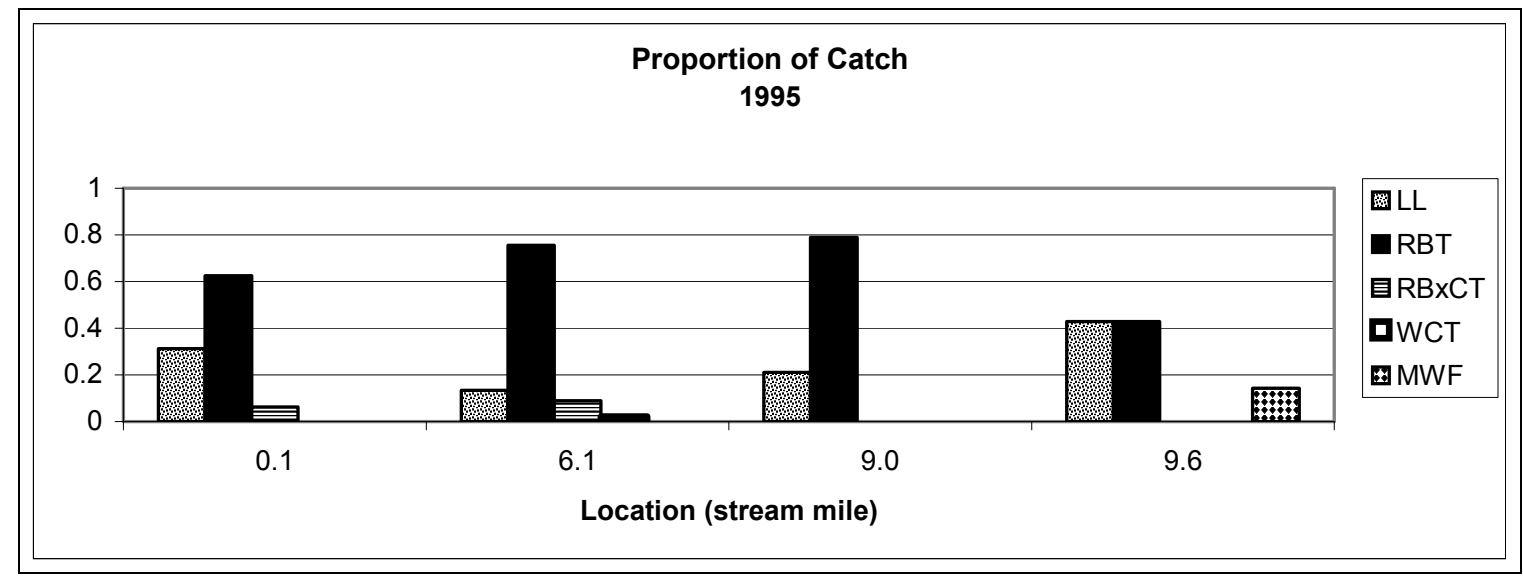

Figure 28. Proportion of catch for salmonids at four locations on the Clearwater River Section I in 1995.

\section{Clearwater River Section II}

(Salmon Lake to Seeley Lake)

Clearwater River Section II is the reach between the Seeley Lake outlet and the inlet of Salmon Lake. The actual outlet of Seeley Lake is often misrepresented, since the lake's outlet arm extends for more than 1.5 miles past the main lake body. The actual lake outlet (gradient break) occurs at Riverview Drive (T16N, R15W, section 3), just south of Seeley Lake. Clearwater River section II has two major tributaries: Owl Creek (outlet of Placid Lake) at stream mile 15.8 and Morrell Creek at stream mile 17.3. The

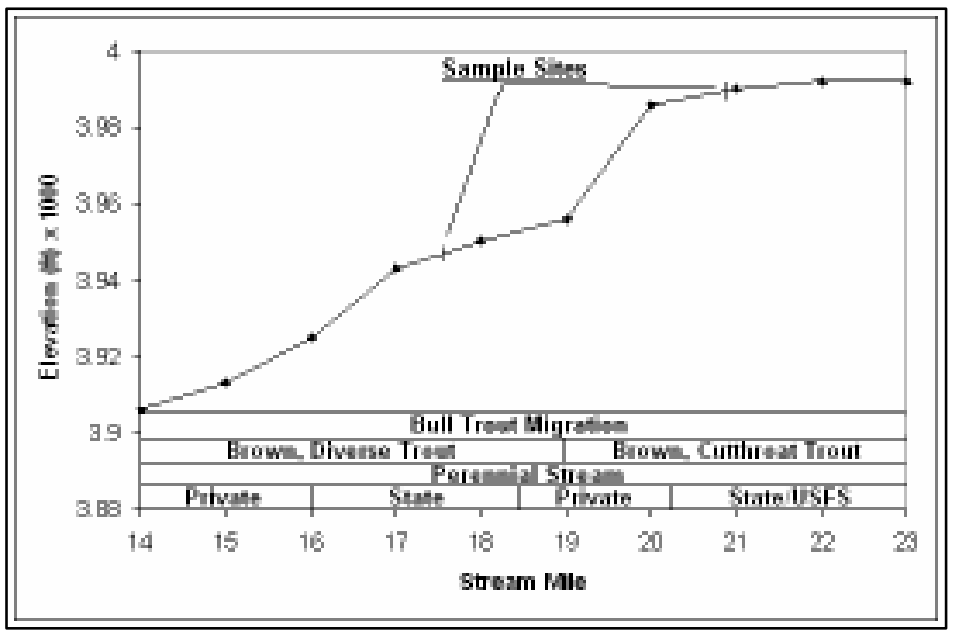

Figure 29. Longitudinal profile for Clearwater River Section II.

Morrell Creek drainage is extremely important for native trout spawning and rearing, and is 
described in an accompanying report section. Owl Creek is an intermittent stream reach due to Placid Lake management (dam at outlet) that connects the Placid Creek drainage with the Clearwater River. This stream does not appear to be utilized heavily by native fish, but does support a substantial kokanee migration from Salmon Lake. Owl Creek and other streams in the Placid Creek drainage will be described in a subsequent report (Boles Creek is described above).

The Clearwater River Section II is a vital stream segment for native salmonids in the Clearwater drainage, particularly migratory bull trout. High biological ranking and prioritization of this watershed relative to other Clearwater Drainage streams (see stream prioritization section) reflect high use by migrating adfluvial bull trout, relatively abundant migratory WSCT, and its location linking adfluvial trout populations with spawning and nursery habitats. Numerous adfluvial bull trout redds were also found in this section in 2006 and 2007.

Recent bull trout telemetry studies demonstrated that the Clearwater River Section II is vital as a migration corridor between Salmon Lake and Morrell Creek, and between Seeley Lake and Morrell Creek. Morrell Creek supports one of the two largest adfluvial bull trout populations in the upper Clark Fork Basin and represents one of four known adfluvial spawning populations in the Clearwater Drainage based on redd count data and juvenile distribution. Morrell Creek is particularly important for the viability and persistence of the Seeley Lake and Salmon Lake bull trout populations, as it is currently the only spawning stream readily accessible to these fish. Adfluvial westslope cutthroat and other fish species likely also use this river section extensively as they move between lakes and migrate at various life stages.

\section{$\underline{\text { Land Ownership and Habitat Conditions }}$}

The Clearwater River Section II is approximately an equal mix of privately owned and publicly owned lands (State of Montana-DNRC). However, portions of the DNRC land is leased to private parties as residential waterfront property. Stream gradients range from 30 $\mathrm{ft} /$ mile $(\sim 0.6 \%)$ near Seeley Lake to about $6 \mathrm{ft} / \mathrm{mile}(\sim 0.1 \%)$ near stream mile 19.

The majority of this Clearwater River section consists of slow moving stream habitat with associated wetlands. The riparian corridor is largely intact, although there are some lessees and landowners that have recently cleared and manipulated the stream corridor. Stream encroachment, removal of riparian vegetation, and illegal water diversion are common in this section. In low water years (e.g., 2006-2007) this reach of stream was completely dewatered in areas as illegal pumping, unauthorized dams and upstream water usage exacerbated already minimal instream flows and elevated water temperatures. In late summer and early fall, stream dewatering from Seeley Lake to Morrell Creek inhibits upstream and downstream movement of fish, which is particularly problematic for migrating adult bull trout attempting to reach spawning areas (based on 2006-2007 telemetry data).

\section{Water Temperature Regime}




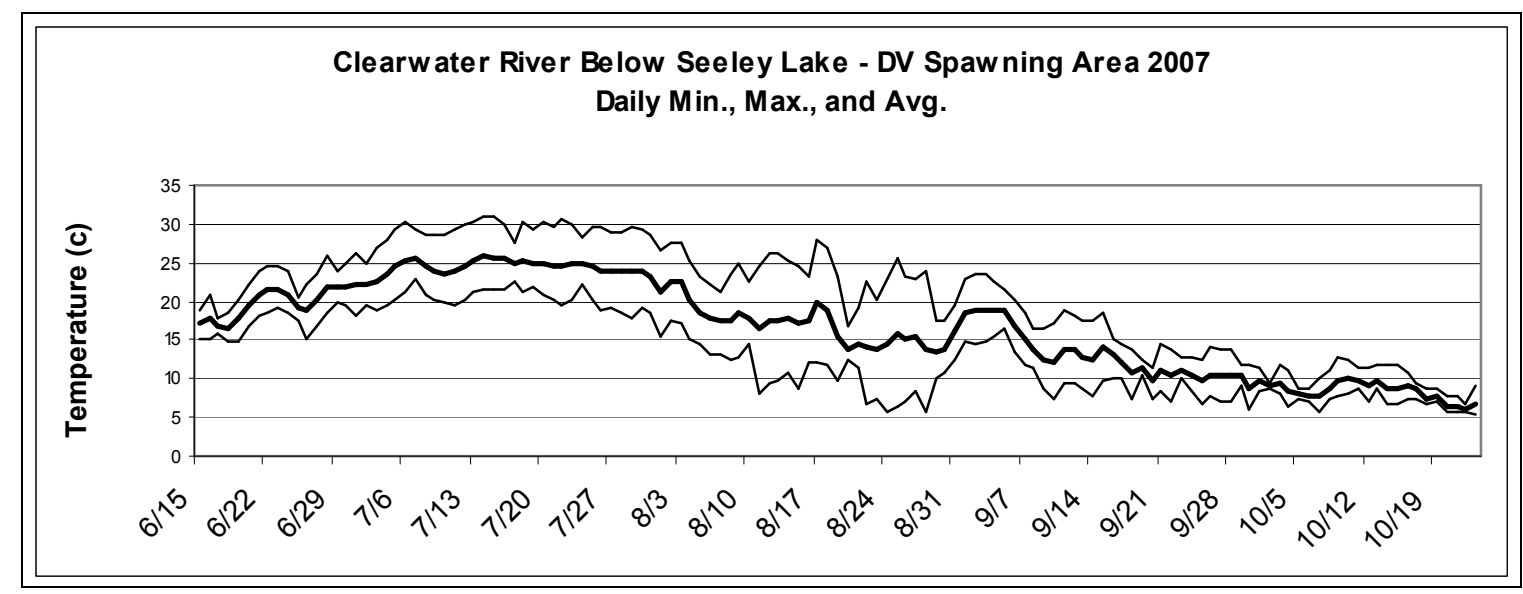

Figure 30. Temperature data from Clearwater River Section II (stream mile 19.2), 2007.

The water temperature regime in the Clearwater River Section II is much above the optimal range of temperatures for native trout populations and other salmonids from the end of June through early September in low water years (Figures $30 \& 31$ ). Because this reach naturally receives surface discharge from Seeley Lake, fish populations have adapted over time and use this river corridor seasonally. For example, adult bull trout inhabit and move through this section primarily in June and early September to reach Morrell Creek when water temperatures are favorable. During warmer summer periods, native trout are most abundant in the cooler waters of tributaries and at depth in lakes (due to lake thermal stratification). Fish movement is likely extensive and frequent in this reach. This highlights the importance of connectivity for aquatic organisms as they migrate or seek thermal refuge in lakes or near colder tributaries.

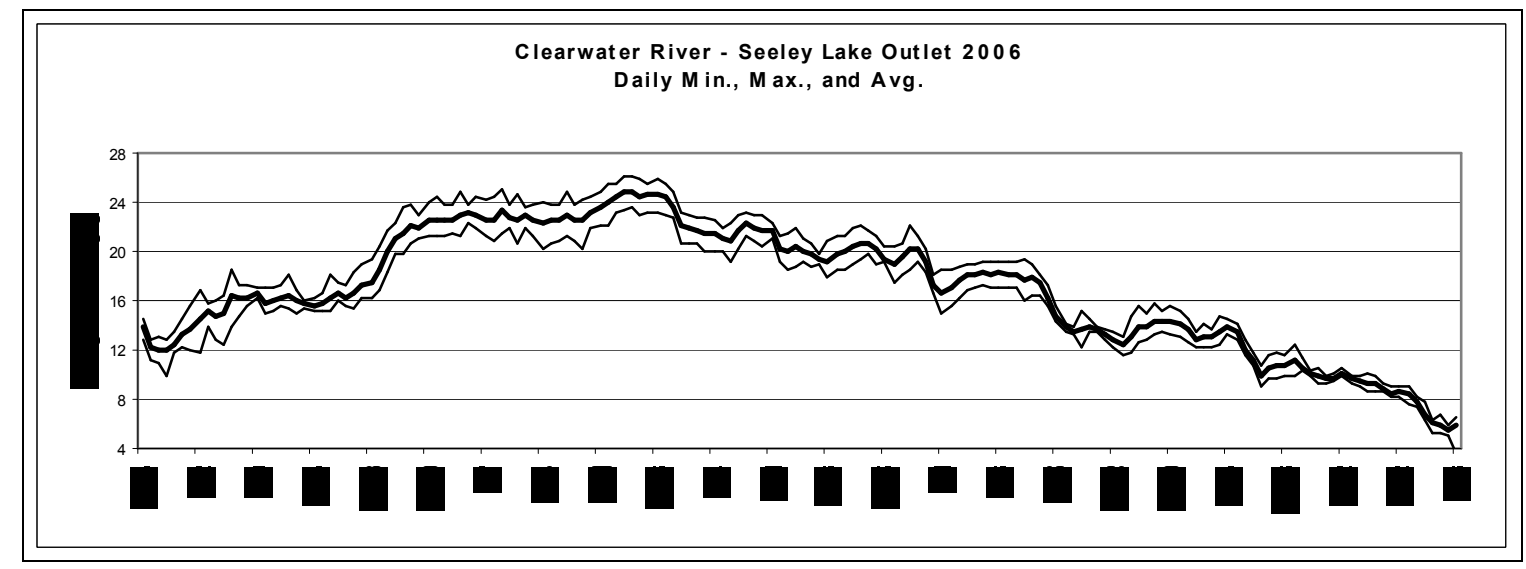

Figure 31. Temperature data from Clearwater River Section II (stream mile 22.9), 2006.

\section{$\underline{\text { Fish Populations }}$}

There is likely high variability in the way various fish species use this reach of the Clearwater River. As a result, species composition and relative abundance likely changes seasonally. As mentioned previously, this reach is a primary migratory corridor between 
Morrell Creek and Seeley/Salmon Lakes for migratory native trout. It also allows movement of many other species between lakes and throughout the lower Clearwater system. Sampling in 1995 at two locations (river mile 17.6 and 20.9) in late August indicated that brown trout and brook trout were common, along with documented mountain whitefish, sculpin and northern pikeminnow. Non-indigenous warm water fish introduced into Seeley Lake and Salmon Lake (e.g., yellow perch, northern pike, and largemouth bass) are likely also found in this section sporadically during warmer temperature periods. Expanded sampling efforts are planned for this reach during different temperature regimes to document fish community characteristics and the seasonal change in species composition.

Oncorhynchus spp. genetic testing has not been completed in this reach due to the history of rainbow trout stocking and current WSCT stocking in lakes. It is very unlikely that indigenous, non-introgressed WSCT make up a significant component of the fish community.

\section{Clearwater River Section III}

(Seeley Lake to Emily-A Dam)

Clearwater River Section III is the reach between the inlet to Seeley Lake and the constructed fish barrier (Emily-A Dam) located just downstream of the mouth of the West Fork Clearwater River and Lake Inez. The fish barrier was constructed by FWP in 1964 to prevent upstream colonization by introduced fishes. Since construction, all introduced species found in the lower system have also been introduced upstream of the barrier. The only species not found upstream are northern

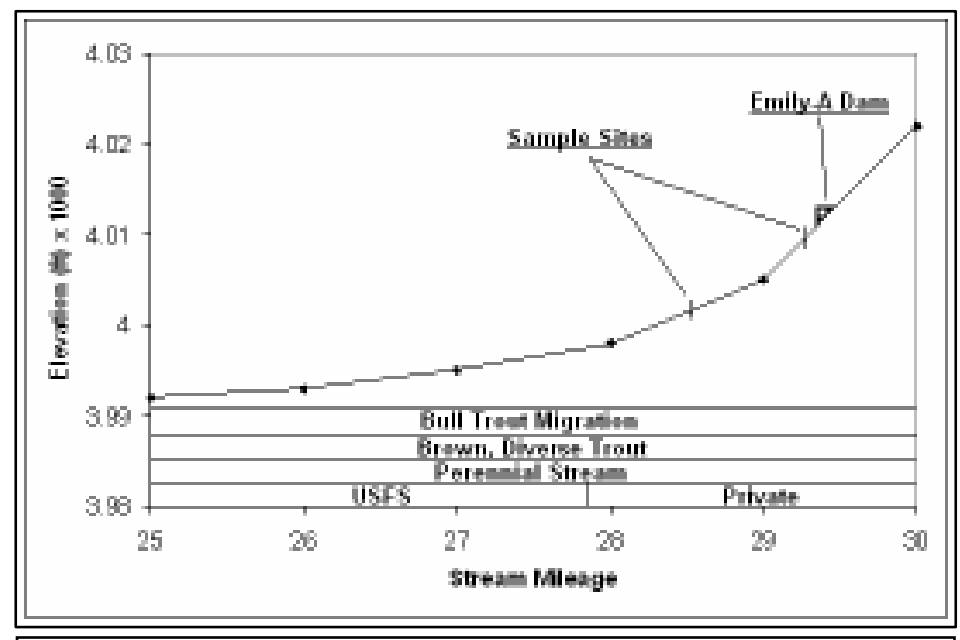

Figure 32. Longitudinal profile for Clearwater River Section III. pikeminnow and peamouth (both native fish). Restoring upstream fish passage at the dam is a restoration priority in the Clearwater Drainage as the dam continues to impede native fish. Clearwater River Section III has no major tributaries, although Benedict Creek enters just below the dam. Fisheries and aquatic information for this stream will be summarized in a subsequent report.

The Clearwater River Section II is a vital stream segment for native salmonids in the Clearwater drainage, particularly migratory bull trout. High biological ranking and prioritization of this watershed relative to other Clearwater Drainage streams (see stream prioritization section) reflect high use by migrating adfluvial bull trout, relatively abundant migratory WSCT, and its location linking adfluvial trout populations with spawning and nursery habitats in the West Fork Clearwater River (hereafter, West Fork).

Recent bull trout telemetry studies demonstrated that the Clearwater River Section III is vital as a migration corridor between Seeley Lake and the West Fork Clearwater River. The West Fork supports one of the two largest adfluvial bull trout populations in the upper Clark Fork Basin and represents one of four known adfluvial spawning populations in the Clearwater Drainage based on redd count data and juvenile distribution. The West Fork is 
particularly important for the viability and persistence of the Seeley Lake, Lake Inez, and Lake Alva bull trout populations. It is not known if emigrants from the West Fork also inhabit Salmon Lake. Adfluvial westslope cutthroat and other fish species likely also use this river section extensively as they attempt to move between lakes and migrate at various life stages.

\section{$\underline{\text { Land Ownership and Habitat Conditions }}$}

The Clearwater River Section III flows through public (USFS) and small private lands parallel to State Highway 83 (Figure 32). Stream gradients are very low, averaging just 6 $\mathrm{ft} / \mathrm{mile}(0.01 \%)$ in this reach. The majority of the Clearwater River Section III consists of functional, slightly degraded aquatic, riparian and terrestrial habitats. Along this main stem, there are limited examples of stream encroachment and removal of riparian vegetation. Most of the reach contains low gradient stream habitat with associated wetlands, debris jams and abundant beaver activity. The Emily-A dam, at the upstream boundary of the section, poses the greatest human disturbance and threat to river function and stream connectivity.

\section{$\underline{\text { Water Temperature Regime }}$}

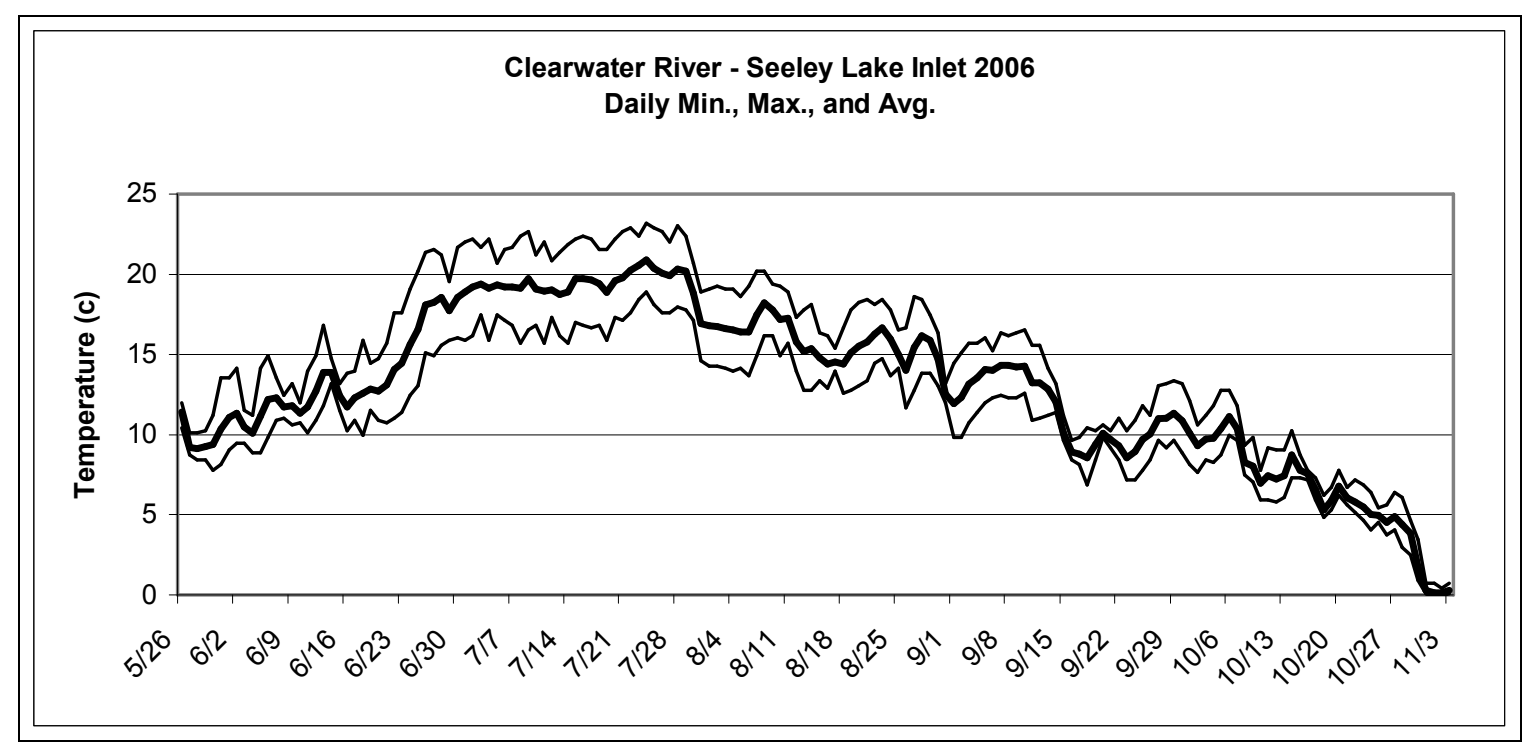

Figure 33. Temperature data from Clearwater River Section III upstream of Seeley Lake (stream mile 28.6), 2006. 


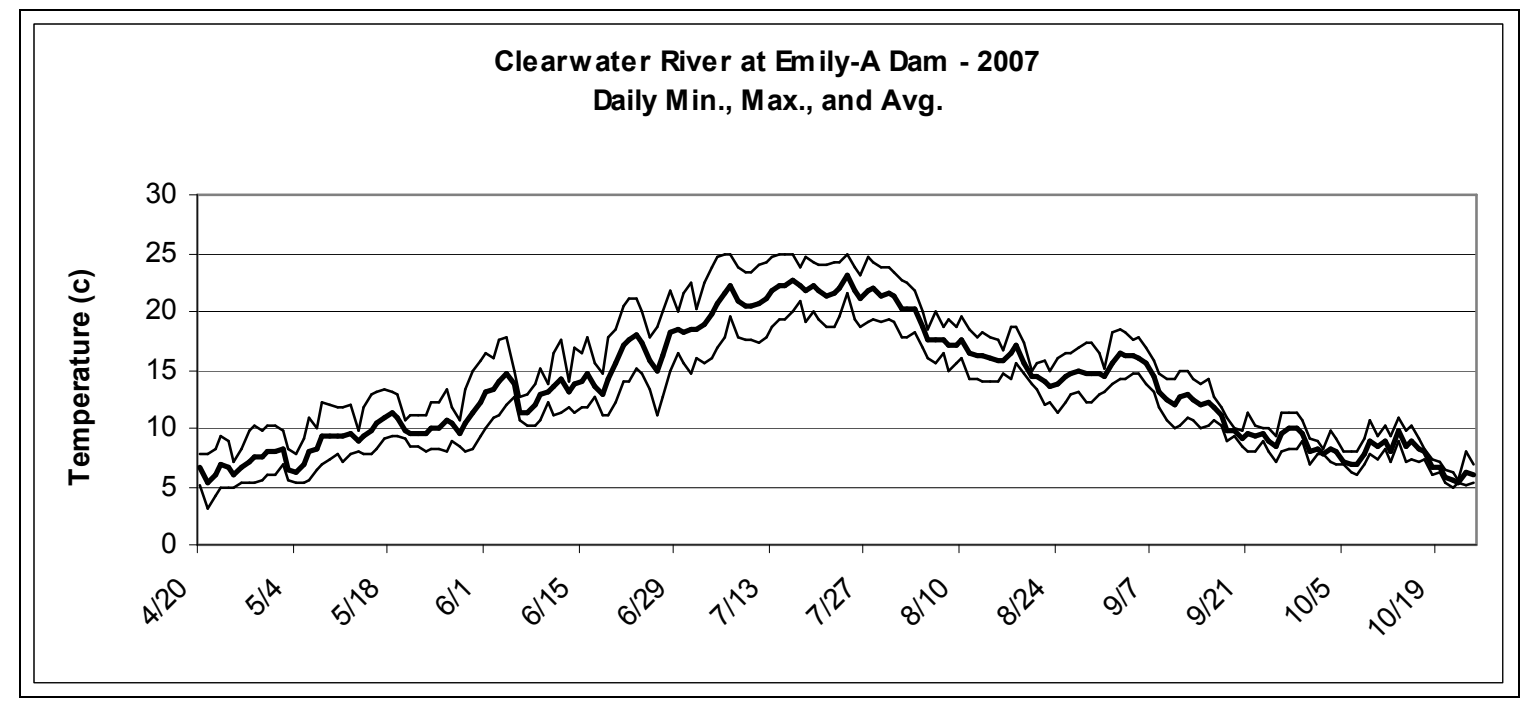

Figure 34. Temperature data from Clearwater River Section III at Emily-A Dam (stream mile 29.3), 2007.

The water temperature regime in the Clearwater River Section III is much above the optimal range of temperatures for salmonids during summer months, primarily due to surface discharge from Lake Inez (see Figures 33 and 34). As a result, fish species composition in the reach changes seasonally. This was observed through repeated sampling at Emily-A Dam in 2007. Bull trout and WSCT become stressed when subjected to maximum daily temperatures above $15-18^{\circ} \mathrm{C}$, which typically occurs in late June through August. During these months, salmonids must seek refuge in colder tributaries or lakes to escape lethal temperature extremes. Recent investigations have shown that adult adfluvial bull trout will use the Clearwater River Section III as a migration route, even when temperatures are above optimal. However, these behaviors may be unnatural as salmonid migrations are interrupted by the dam and fish remain in the section as they try to ascend past the obstruction.

\section{$\underline{\text { Road Crossings }}$}

The Clearwater River Section III has two road crossings. They are both bridges that do not inhibit upstream fish movement or natural stream function.

\section{$\underline{\text { Fish Populations }}$}




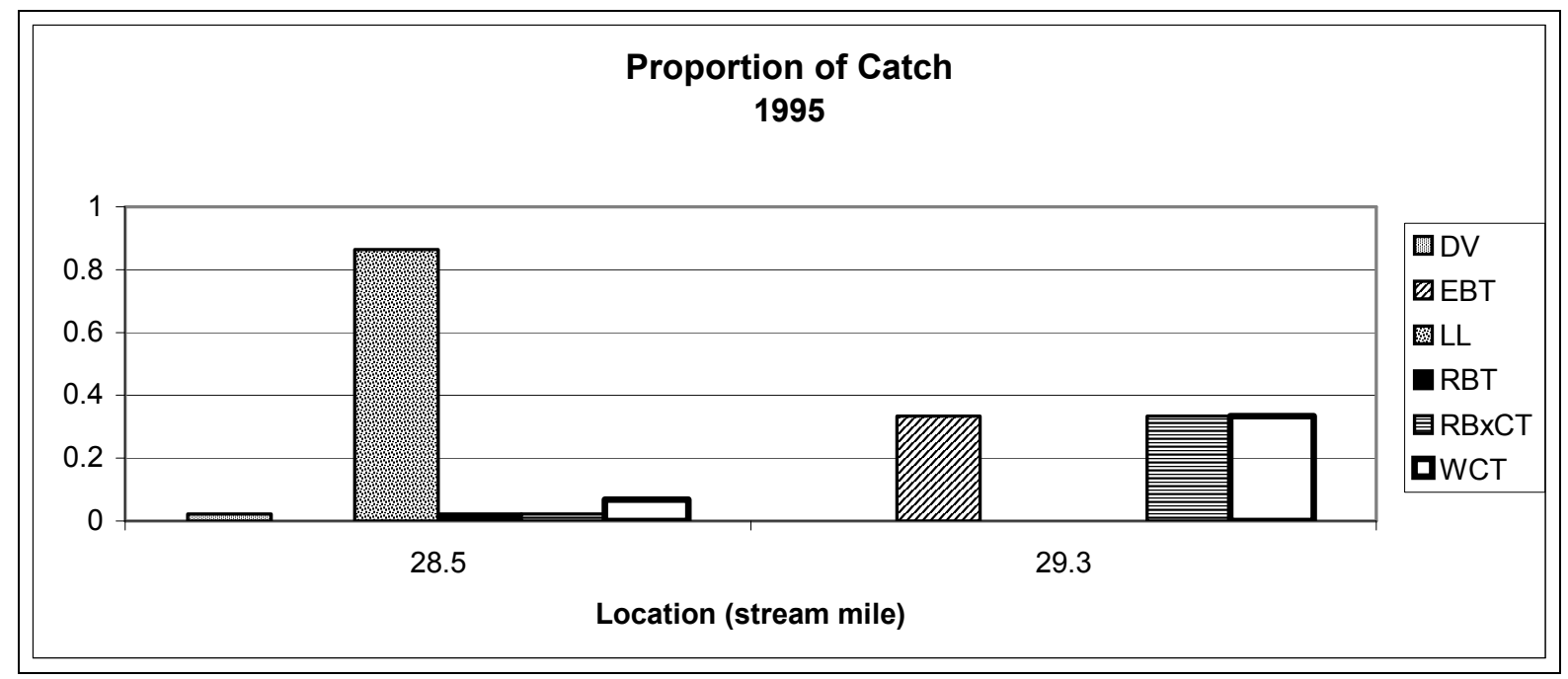

Figure 35. Proportion of catch for salmonids at two locations on Clearwater River Section III in 1995.

In 1995, two locations on the Clearwater River Section III were sampled at stream miles 28.5 and 29.3 in July to determine fish species composition (see Figure 35). These samples indicated that brown trout and brook trout comprised a large proportion of the salmonid composition in this section. Given the warm water temperatures in July and higher tolerance of introduced trout species, this is not unexpected. Multiple species of native, nonsalmonid fish were also documented including northern pikeminnow, redside shiner, peamouth, longnose sucker, etc. There is likely high variability in the way various fish species use this reach of the Clearwater River. As a result, species composition and relative abundance changes seasonally based on sampling in 2007 at Emily-A Dam. As mentioned previously, this reach would be a primary migratory corridor between the West Fork and Seeley/Salmon Lakes for migratory native trout. It would also allow movement of many other species between lakes and throughout the lower Clearwater system. This reach supports abundant spawning by kokanee migrating from Seeley Lake. Non-indigenous warm water fish introduced into Seeley Lake (e.g., yellow perch, northern pike, and largemouth bass) are likely also found in this section sporadically during warmer temperature periods. Expanded sampling efforts are planned for this reach during different temperature regimes to document fish community characteristics and the seasonal change in species composition.

\section{Clearwater River Section IV}

(Emily-A Dam to Rainy Lake outlet) 
Clearwater River Section IV is the reach between the Emily-A Dam and the Rainy Lake fish barrier just downstream of the Rainy Lake outlet. It encompasses both Lake Alva and Lake Inez. This river reach includes the mouths of the West Fork Clearwater River and Camp Creek, as well as several smaller tributaries including Colt, Uhler, and Richmond Creeks. The West Fork is described above, but other tributary attributes will be summarized in subsequent reports.

Clearwater River Section IV is a very important stream for native salmonids in the Clearwater drainage, particularly as a migration corridor for migratory life history forms. High biological ranking and prioritization of this watershed relative to other Clearwater Drainage streams (see Stream Prioritization section) reflect high use by migrating adfluvial bull trout, relatively abundant fluvial WSCT populations, and high habitat quality. This main stem reach is particularly important as a migration route for migratory native salmonids, as well as other sport fish populations.

Clearwater River Section IV is an important migration corridor between Lake Inez, Lake Alva, and the West Fork of the Clearwater River, a key adfluvial bull trout spawning stream as documented through radio telemetry studies in 2007-2008. The West Fork of the Clearwater River supports one of the two largest adfluvial bull trout populations in the upper Clark Fork Basin and represents one of four known adfluvial spawning

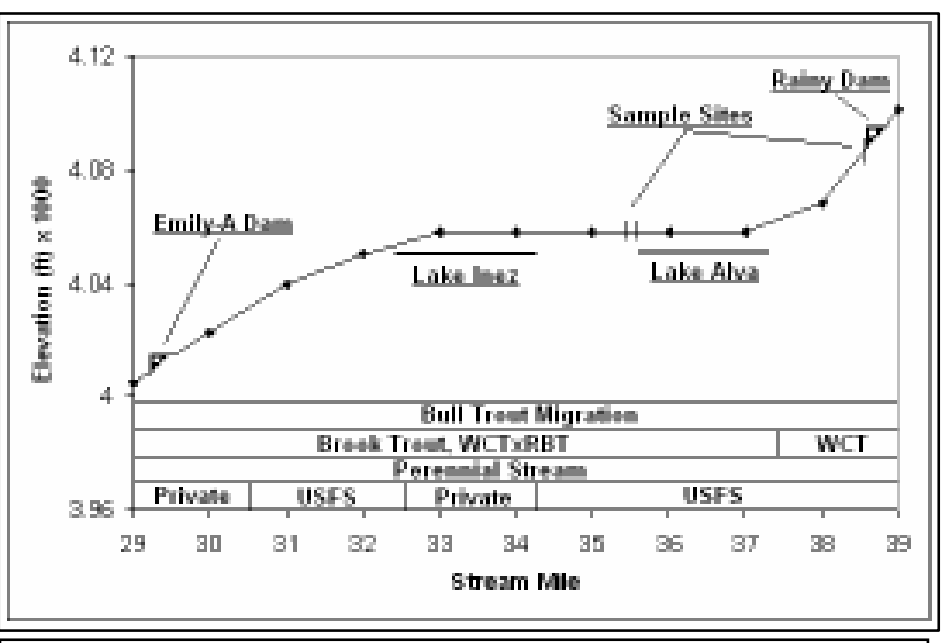

Figure 36. Longitudinal profile for Clearwater River Section IV. populations in the Clearwater Drainage. The West Fork of the Clearwater River is particularly important for the viability and persistence of the Lake Inez and Lake Alva bull trout populations, as it is currently the only spawning stream readily accessible to these fish. Recent studies have shown that some adult adfluvial bull trout from Rainy Lake also move downstream into this section of river. The Rainy Lake fish barrier prevents adult and juvenile fish from returning to Rainy Lake. Investigations are ongoing in order to determine the most prudent solution to this problem as the dam also prevents upstream colonization by several undesirable nonnative fish including northern pike and brook stickleback. A seasonal fish obstruction is also present at the outlet of Lake Inez as the lake is impounded each summer to enhance recreation. Installation of a fish ladder is planned for this site in 2008.

\section{$\underline{\text { Land Ownership and Habitat Conditions }}$}

The Clearwater River Section IV flows almost entirely through publicly owned (USFS) lands and a small amount of privately owned lands. Most of the privately owned land along this section of river is adjacent to Lake Inez or just downstream. Stream gradients are very low, ranging from $33 \mathrm{ft} / \mathrm{mile}(0.06 \%)$ near the Rainy Lake fish barrier to near $0 \mathrm{ft} / \mathrm{mile}$ $(0.0 \%)$ adjacent to the lakes. 
Nearly all of Clearwater River Section IV flows through functional, non-degraded riparian and terrestrial habitats. The channel is generally a low gradient corridor with associated wetlands and abundant beaver activity where wider floodplains exist.

\section{Water Temperature Regime}

The water temperature regime in this section is well above the optimal range of temperatures for native salmonids during July and August (see Figure 37). Native salmonids, particularly bull trout, require cold water in which to live and reproduce. Non-native species, such as brook trout, brown trout and other non-salmonids, are generally more tolerant of warmer temperatures. Bull trout become stressed when subjected to maximum daily temperatures $>15^{\circ} \mathrm{C}\left(\sim 18^{\circ} \mathrm{C}\right.$ for WSCT $)$, which occurs for a significant portion of most summers in this reach. During these months, native salmonids must seek refuge in colder tributaries in order to escape lethal temperature extremes. Recent investigations have shown that adfluvial bull trout will use the Clearwater River Section IV as a migration route, even when temperatures are above optimal. However, these fish attempt to minimize the time they spend in the warm river and spend the majority of their time in deep water in Lake Alva or Lake Inez.

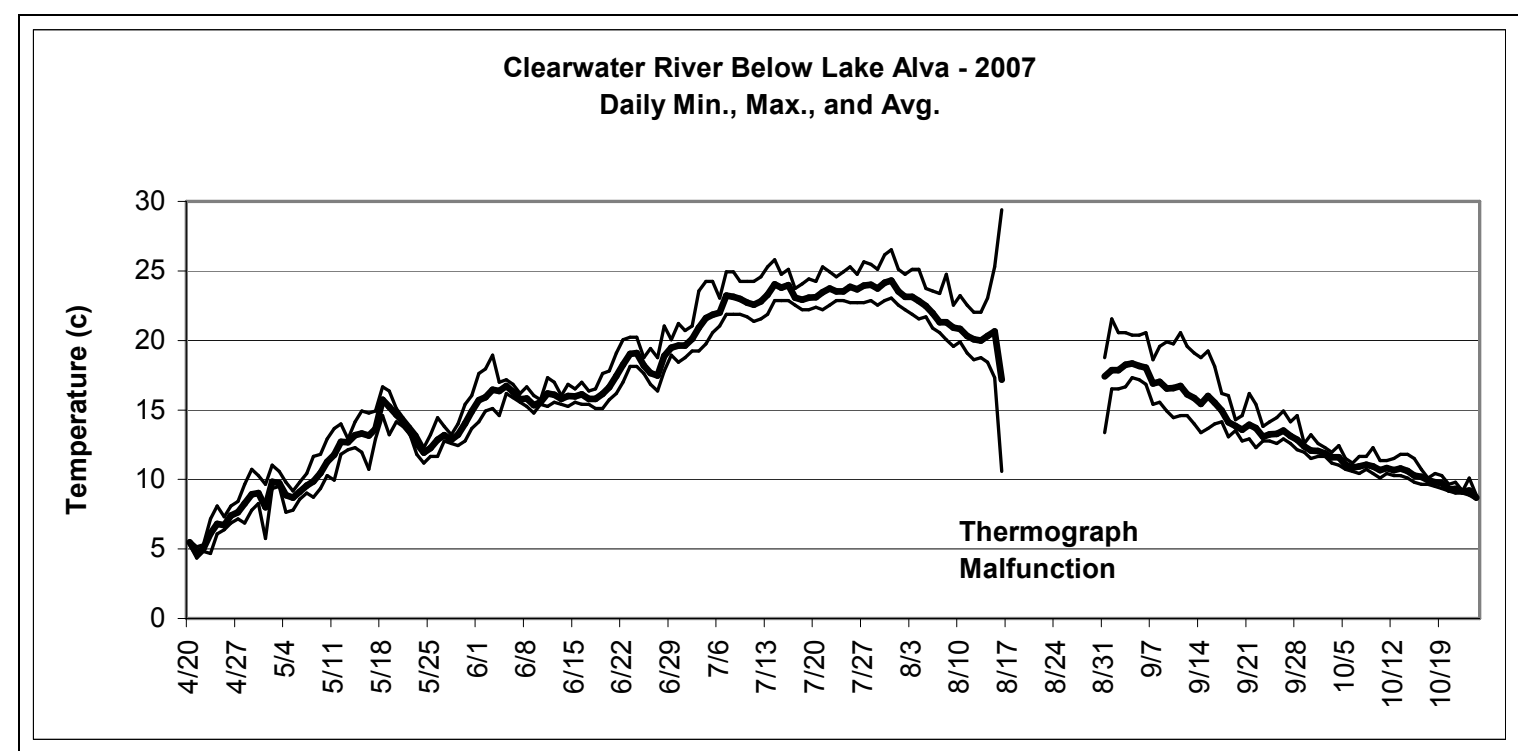

Figure 37. Temperature data from the Clearwater River Section 4 downstream of Lake Alva (stream mile 35.4), 2007.

\section{$\underline{\text { Road Crossings }}$}

Clearwater River Section IV has two road crossings. Both crossings are bridges that do not impede upstream fish passage or natural stream function.

\section{$\underline{\text { Fish Populations }}$}




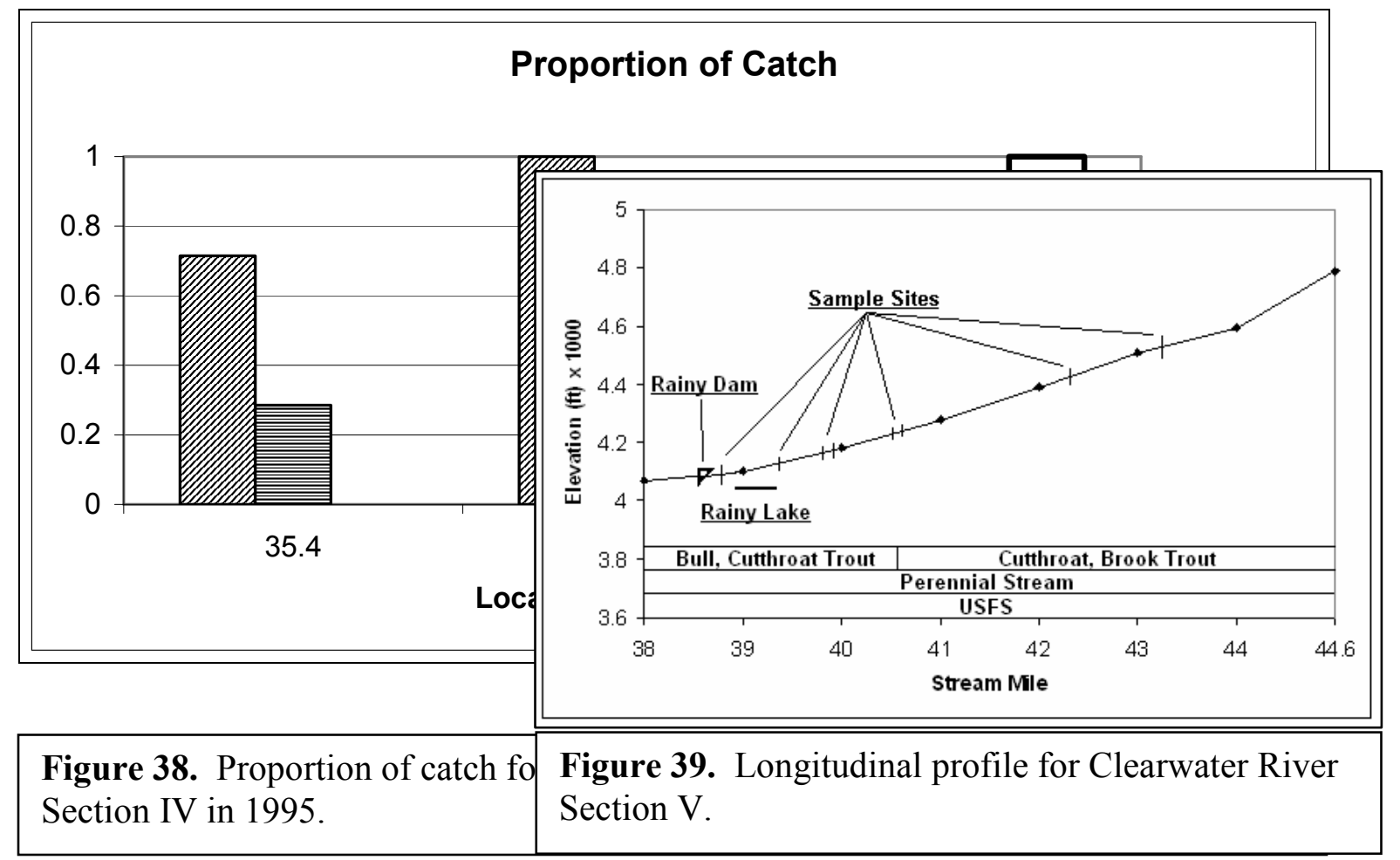

In July 1995, three locations at stream miles 35.4, 35.5, and 38.7 on Clearwater River Section IV were sampled to determine fish species composition (see Figure 38). These samples indicated that brook trout comprised a large majority of the fish in the portion of river below Lake Alva, while WSCT comprised a large majority of fish above Lake Inez. It is likely that a brook trout stronghold that exists in Uhler Creek, which enters the Clearwater River Section IV at stream mile 35.0 just downstream of Lake Alva, is contributing significantly to the brook trout population there. The few WSCT detected were not tested for genetic purity as hybridization is likely common (due to past rainbow trout stocking) and many of the non-introgressed fish were likely of hatchery origin (stocked in lakes). Presence of sculpins was not noted in the 1995 sampling, but long-nosed dace were common. The age of available data for the Clearwater River Section IV and the variable seasonal species composition in this reach necessitates additional sampling, which is planned for 2008.

\section{$\underline{\text { Amphibian Community }}$}

In 1995 sampling, no amphibians were noted. However, Columbia spotted frogs have been observed in these sections of the Clearwater River. More rigorous investigations are warranted.

\section{Clearwater River Section V}

(Rainy Lake to Clearwater Lake)

The upper Clearwater River is a third-order that extends from the outlet of Clearwater Lake to the Outlet of Rainy Lake, where a man-made dam prevents upstream fish passage. This reach generally flows south from its headwaters near Ptarmigan Mountain and the Swan 
River divide. Tributaries of this reach (described separately) include the East Fork of the Clearwater River (hereafter "East Fork") and Bertha Creek.

This section of the Clearwater River is a very important reach for native salmonids in the Clearwater drainage, particularly migratory life history forms. High biological ranking and prioritization of this watershed relative to other Clearwater Drainage streams (see stream prioritization section) reflect high use by migrating adfluvial bull trout, relatively abundant adfluvial WSCT populations, and high habitat quality.

The lower portion of the Clearwater River Section $\mathrm{V}$ is an important migration corridor between Rainy Lake and the East Fork, which is documented bull trout spawning habitat. The East Fork supports one of four known adfluvial spawning populations in the Clearwater Drainage and likely also supports a stream-resident population. The East Fork is particularly important for the viability and persistence of the Rainy Lake bull trout population, as it is likely the only spawning reach accessible to these fish. Recent radio-telemetry studies have shown that adult adfluvial bull trout from Rainy Lake move upstream into this section of river via the Clearwater River. These studies have also shown that adult adfluvial bull trout from Lake Alva (and likely from Lake Inez) occasionally attempt to migrate into the East Fork of the Clearwater River, but are hindered by the Rainy Lake fish barrier, immediately downstream of this section.

\section{$\underline{\text { Land Ownership and Habitat Conditions }}$}

The Clearwater River Section V flows entirely through publicly owned (USFS) lands (Figure 39). Stream gradients are very low, ranging from $126 \mathrm{ft} / \mathrm{mile}(2.4 \%)$ near Clearwater Lake to $80 \mathrm{ft} / \mathrm{mile}(1.5 \%)$ near Rainy Lake.

The Clearwater River Section V consists of functional, non-degraded aquatic, riparian and terrestrial habitats. The drainage is intact forest, with modest road densities and almost no logging. Riparian areas, water quality and channel morphology are largely intact, providing shade, instream habitat complexity, consistent recruitment of woody debris and adequate stream buffers along its length.

\section{$\underline{\text { Water Temperature Regime }}$}

The water temperature regime in the portion of the Clearwater River Section V that is below the mouth of the East Fork of the Clearwater River is lower than average for the Clearwater River drainage, likely remaining suitable year-round for salmonid species (see Figure 40 \& 41). However, upstream of the confluence with the East Fork, temperatures are frequently above optimal for native salmonids in July and August as this is the outlet of Clearwater Lake. Bull trout become stressed when subjected to maximum daily temperatures $>15^{\circ} \mathrm{C}\left(\sim 18^{\circ} \mathrm{C}\right.$ for WSCT $)$, which occurs for a significant portion of most summers. During these months, native salmonids must seek refuge in colder tributaries or lake environments in order to escape temperature extremes. Nonnative trout (i.e., brook trout in this reach) are more tolerant of warmer water temperatures. 


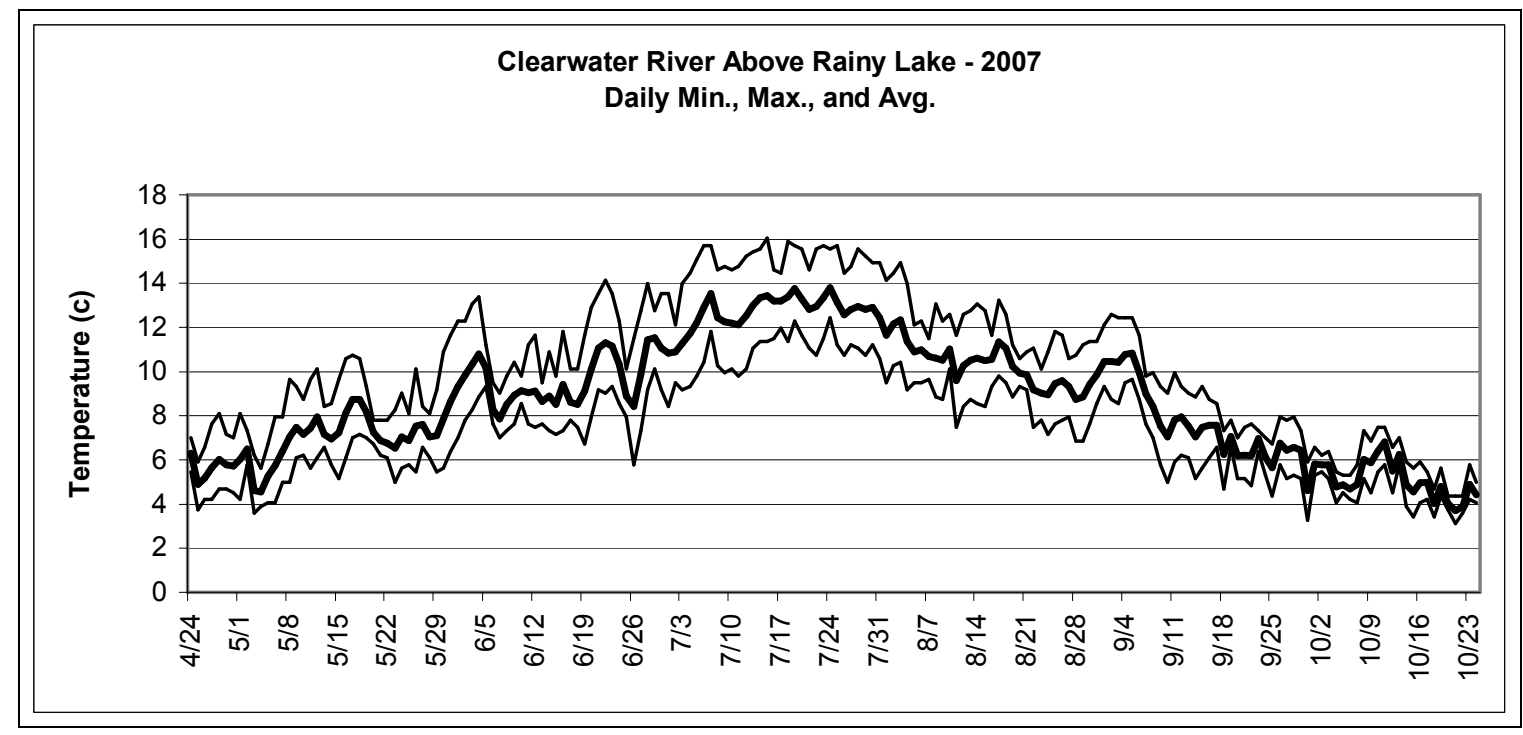

Figure 40. Temperature data from the Clearwater River section V, downstream of the East Fork of the Clearwater River, 2007.

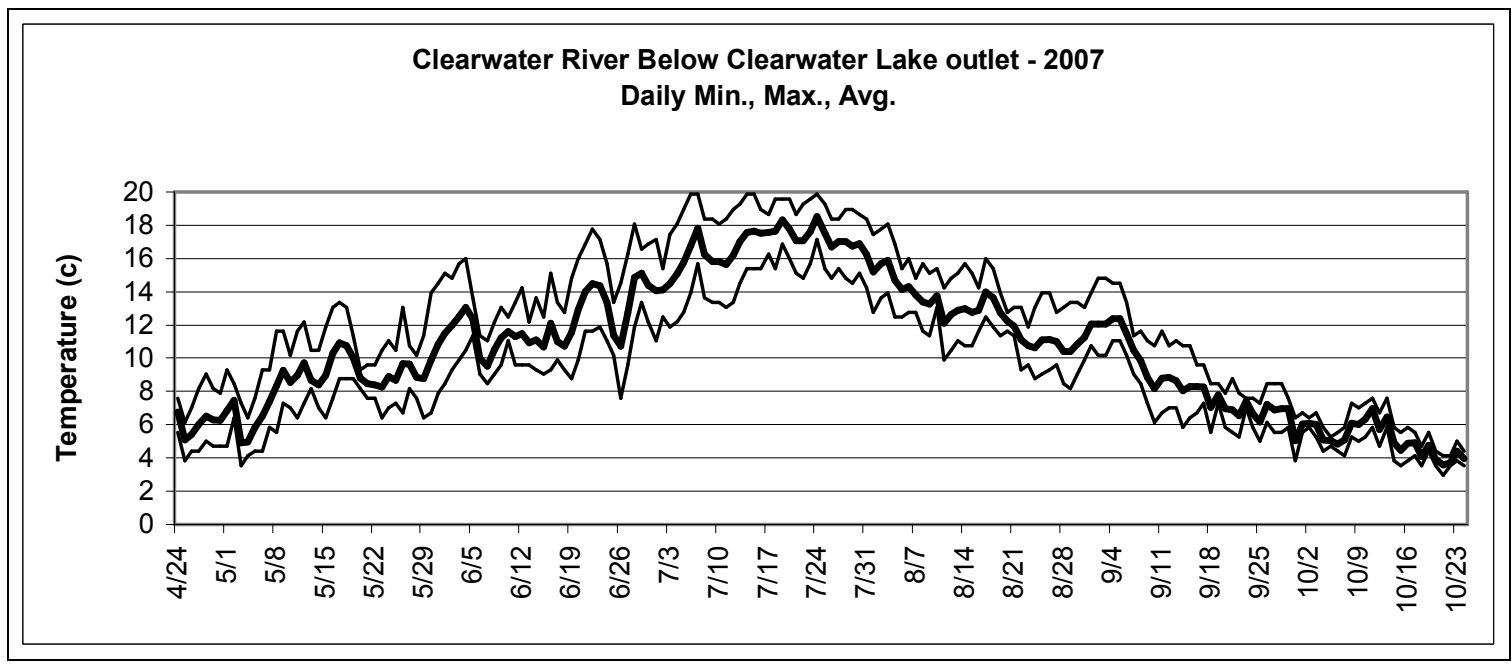

Figure 41. Temperature data from the Clearwater River section V, upstream of the East Fork of the Clearwater River, 2007.

\section{$\underline{\text { Road Crossings }}$}

The Clearwater River Section V has two road crossings. Both of these are bridges and likely do not impeded upstream fish movement or natural channel function.

$\underline{\text { Fish Populations }}$ 


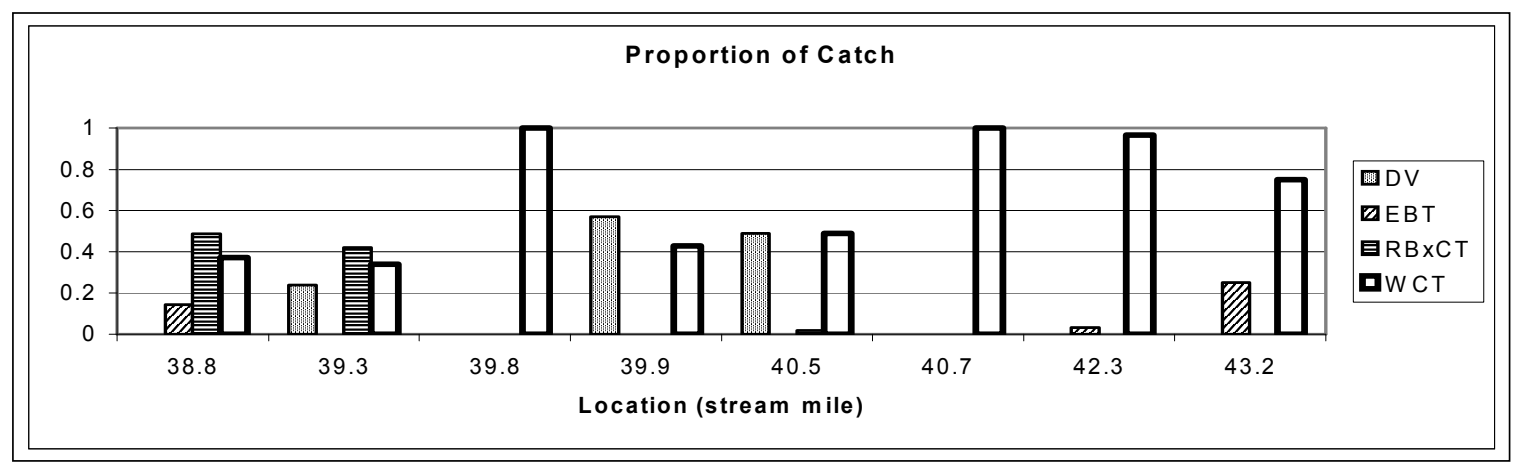

Figure 42. Proportion of catch for salmonids at eight locations on Clearwater River Section V, 1995-2007.

Since 1995, eight locations on the Clearwater River Section V have been sampled to determine fish species composition and Oncorhynchus genetic composition (see figure 4). These locations were at stream miles 38.8, 39.3, 39.8, 39.9, 40.5, 40.7, 42.3, and 43.2. These samples indicated WSCT and rainbow-westslope cutthroat hybrid trout dominate the section. The area near Rainy Lake appears to have the highest proportion of hybrid fish, likely as a result of past rainbow trout stocking. Bull trout were present downstream of and very near the mouth of the East Fork of the Clearwater River. It is likely that bull trout only use this habitat seasonally as high water temperatures may be limiting during summer. Brook trout have been found in the upper-most sites. This is the result of an illegally introduced population in Clearwater Lake. No sculpin have been noted in this section of the Clearwater River.

\section{$\underline{\text { Amphibian Community }}$}

Sampling conducted in 2006 indicated the presence of tailed frogs and Colombia spotted frogs in this section of river. 


\section{RESULTS PART V: Special Studies - Whirling Disease}

Results Part V is a whirling disease special study section with five related studies, all of which variously rely on sentinel exposures of fish (rainbow trout) in waters of the Blackfoot Basin. We begin with a brief introduction to the pathogen (worm and fish hosts) and summarize the current status of whirling disease within the Blackfoot Basin.

Individual studies then begin with a pilot-level investigations focusing on biotic relationships of the pathogen to "indicator" aquatic benthic organisms (e.g. stoneflies, caddis and mayflies). Our studies then expand to environmental predictors of disease as

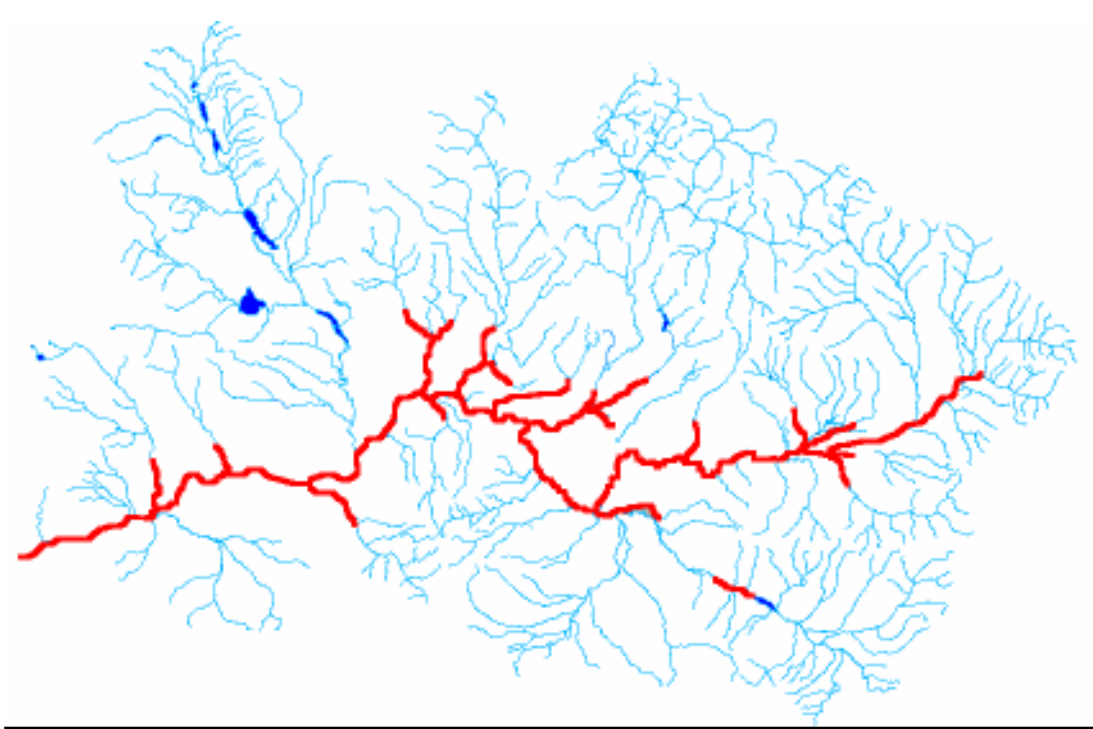

Figure 1. Generalized distribution of $M$. cerebralis infected waters in the Blackfoot Watershed as identified by sentinel cage exposures of RBT. measured by both biotic (benthic) and physical characteristics of basin-fed tributaries of the Blackfoot River. Lastly, we examine potential effects (and implications) of whirling disease of two susceptible species (rainbow trout and mountain whitefish) that inhabit the Blackfoot River.

\section{Introduction}

Whirling disease, caused by the exotic myxosporean parasite Myxobolus cerebralis, was first detected in the Blackfoot River in 1995 near Ovando. Since then, the disease has increased in both distribution severity (Figure 1). The disease is now present throughout the entire mainstem Blackfoot River and continues to expand in the lower reaches of some tributaries. Despite this expansion, sentinel exposures

\begin{tabular}{ccc}
\hline $\begin{array}{c}\text { Mean grade } \\
\text { category }\end{array}$ & $\begin{array}{c}\text { Infection Level } \\
\text { Description }\end{array}$ \\
\hline & $0.0-2.0$ & Low \\
ndo. & $2.01-2.74$ & Medium \\
ution & $2.75-3.7$ & High \\
& $3.71-5.0$ & Very High and \\
\hline
\end{tabular}

undertaken in 2006 and 2007 also suggest a recent reduction in severity of disease in the lower Blackfoot River (Table 3). The low-elevation distribution of the disease currently overlaps with the distribution of many salmonids.

Myxobolus cerebralis has a complex, twohost life-cycle involving a salmonid and the aquatic oligochaete worm, Tubifex tubifex. There are also two spore forms of the parasite; a fragile triactinomyxon (TAM) that is released by the worm and infects young trout and a hardy myxospore later released by infected fish and ingested by the worm host, where the myxospore is then converted back to the TAM stage. The development and severity of whirling disease in exposed salmonids is dependent on many factors involving: 1) the fish host (species, strain, age, size); 2) the worm host; 3) the environment

\begin{tabular}{lc}
\hline Com mon Name & Susceptibility \\
\hline \hline Rainbow Trout & 3 \\
Westslope Cutthroat & 2 \\
Brook Trout & 2 \\
Bull Trout & 1 \\
Brown Trout & 1 \\
Mountain Whitefish & $2 \mathrm{~S}$ \\
\hline
\end{tabular}

Table 2. Susceptibility to whirling disease among species of salmonids in the Blackfoot River. Scale of 0 to 3 or S: $0=$ resistant; $1=$ partial resistance; $2=$ susceptible; 3 = highly susceptible; $\mathrm{S}=$ susceptibility is unclear (conflicting reports). Adapted from MacConnell and Vincent (2002).
Table 1. Mean grade category descriptions (Baldwin et al. 2000). 
(water quality parameters, water temperature, flow rates); and 4) the overlap of contact with both spore types (overlap of TAM with susceptible fry species and myxospore being encountered by the worm). These variables all have potential to influence infection and severity among salmonids across the Blackfoot Basin.

As an indirect measure of TAM abundance and disease severity, sentinel cages were first deployed in the Blackfoot Watershed in 1998. Sentinel cage monitoring has continued through 2007 at established Blackfoot River sites and throughout tributaries in order to assess disease expansion. A mean grade infection is determined from histology results from sentinel fish exposed in each cage to determine disease severity at individual locations (Table 1).

Concurrent with the recent escalation of the disease was an increase in the clinical signs (cranial and skeletal deformities) through 2004, and modest population declines in rainbow trout in the middle Blackfoot River downstream of Monture Creek, a highly infected rainbow trout spawning stream.

Previous studies have classified salmonids based on susceptibility to the disease, which varies considerably by species (Table 2). All salmonids in the Blackfoot Watershed (WSCT, bull trout, rainbow trout, brown trout, brook trout and mountain whitefish) can be infected by the parasite. Rainbow trout are reported to be the most susceptible and brown trout and bull trout more resistant. The susceptibility of mountain whitefish is unclear but remains a concern and a focus of investigations in the Blackfoot Basin.

\begin{tabular}{lccccccccccc}
\multicolumn{1}{c}{ Waterbody } & \multicolumn{10}{c}{ Mean Grade Infection } \\
Blackfoot River & $\mathbf{1 9 9 8}$ & $\mathbf{1 9 9 9}$ & $\mathbf{2 0 0 0}$ & $\mathbf{2 0 0 1}$ & $\mathbf{2 0 0 2}$ & $\mathbf{2 0 0 3}$ & $\mathbf{2 0 0 4}$ & $\mathbf{2 0 0 5}$ & $\mathbf{2 0 0 6}$ & $\mathbf{2 0 0 7}$ \\
\hline Blackfoot River-Below Gold Cr & 0.22 & nd & 2.44 & nd & 0.59 & 2.42 & 2.2 & 2.06 & 0 & nd \\
Blackfoot River-Below Elk Cr & nd & nd & 2.3 & nd & 1.59 & nd & 2.3 & nd & 0.64 & 0.22 \\
Blackfoot River-above Clearwater & 1.1 & 0.22 & 3.11 & nd & 2.79 & 3.16 & 3.41 & 2.96 & 2.03 & 1.33 \\
Blackfoot River-Below North Fork & 0.25 & nd & nd & nd & nd & nd & 2.64 & 2.86 & 0.79 & nd \\
Blackfoot River-below Nevada Cr & 0 & 0 & 0.84 & nd & 0.9 & 2.12 & 3.93 & 3.28 & 0.1 & 0.31 \\
Blackfoot River-Below Lincoln & 0 & 0 & 0.6 & nd & 2.44 & nd & nd & 3.89 & 2.25 & nd \\
Blackfoot River-Headwaters & nd & nd & 0 & nd & 0.02 & 0.32 & nd & 0 & 0.07 & 0 \\
\hline
\end{tabular}

Basin-fed Streams

\begin{tabular}{|c|c|c|c|c|c|c|c|c|c|c|}
\hline Johnson Creek & nd & nd & nd & nd & nd & nd & nd & 0 & 0 & nd \\
\hline West Twin Creek & nd & nd & nd & nd & nd & nd & nd & 0 & 0 & 0 \\
\hline East Twin Creek & nd & nd & nd & nd & nd & nd & nd & 0 & 0 & nd \\
\hline Bear Creek & nd & nd & nd & nd & nd & nd & nd & na & 0 & nd \\
\hline Union Creek & nd & nd & nd & nd & nd & nd & 0 & nd & nd & nd \\
\hline Gold Creek & nd & 0.12 & 0 & nd & 0 & 0 & nd & 0 & 0 & 0 \\
\hline Belmont Creek & nd & nd & 0 & nd & 0.19 & 0.38 & 1.55 & 2.48 & 0.3 & 3.44 \\
\hline Elk Creek & nd & 0 & 0 & nd & 0 & 2.84 & 4.32 & 4.82 & nd & nd \\
\hline Clearwater River & nd & nd & nd & nd & nd & nd & 0 & nd & nd & nd \\
\hline CottonwoodCreek & 3.66 & 4.52 & nd & nd & 4.5 & nd & nd & 3.78 & 3.96 & 4.25 \\
\hline Chamberlain Creek & 0.16 & 2.71 & 3.88 & nd & 2.63 & nd & 4.33 & 3.78 & nd & 1.89 \\
\hline Monture Creek & 0 & 0 & 1.76 & nd & 3.22 & nd & nd & 4.81 & 4.57 & 4.26 \\
\hline Warren Creek & 0.21 & 2.1 & 1.72 & nd & nd & nd & nd & 0.0 & nd & nd \\
\hline North Fork Blackfoot River & 0 & nd & 0 & nd & 0.78 & nd & nd & 0.27 & nd & nd \\
\hline Arrastra Creek & nd & nd & nd & nd & nd & 0.34 & 1.23 & 0.02 & 0.14 & nd \\
\hline Beaver Creek & nd & nd & nd & nd & nd & nd & 0.45 & 0.85 & 0.3 & 0 \\
\hline Poorman Creek & nd & nd & nd & nd & nd & nd & 0.78 & ND & nd & 4.69 \\
\hline Landers Fork & nd & nd & nd & nd & nd & nd & 0.14 & 0 & 0 & 0 \\
\hline Upper Willow Creek & nd & nd & nd & nd & nd & nd & 0 & nd & nd & 0 \\
\hline Wasson Creek & nd & nd & nd & nd & nd & nd & nd & 0 & nd & 0 \\
\hline \multicolumn{11}{|l|}{ Spring Creeks } \\
\hline Jacobsen Spring Creek & nd & nd & nd & nd & nd & nd & 0.13 & nd & nd & nd \\
\hline Rock Creek & nd & 0 & 2.3 & 3.9 & nd & 3.38 & nd & nd & nd & nd \\
\hline Kleinschmidt Creek & 2.83 & 3.56 & 4.52 & 3.77 & nd & 4.9 & 4.7 & nd & nd & nd \\
\hline Nevada Spring Creek & nd & nd & nd & nd & 0 & nd & 3.66 & 2.22 & 1.94 & nd \\
\hline Grentier Spring Creek & nd & nd & nd & nd & nd & nd & 0.06 & 1 & nd & nd \\
\hline Lincoln Spring Creek & nd & nd & nd & nd & nd & nd & 5 & 4.7 & nd & nd \\
\hline
\end{tabular}

Table 3. Summary of histological results summarized as mean grade infections from sentinel cages placed in the Blackfoot River (top), the confluence areas of basin-fed tributaries (middle) and spring creeks (lower) for 1998-2007. 


\title{
Pilot assessment of the association between stonefly assemblages and the incidence and severity of whirling disease in tributaries of the Blackfoot River, Montana
}

\author{
Wease Bollman, Ron Pierce, and Lisa Eby
}

\section{Introduction}

This brief study was intended to investigate whether stonefly assemblages could be useful bellwethers of the presence or severity of whirling disease in tributary streams to the Blackfoot River. At least one previous study (Bollman 1998) demonstrated associations between stonefly richness and certain observational measures related to reach-scale habitat integrity; these measures included streambank stability, condition of the riparian zone, and stream channel morphological elements. Loss of streambank stability, riparian zone integrity, and natural channel morphology may contribute to instream conditions favoring the presence of Tubifex tubifex, the oligochaete intermediate host for the whirling disease organism (Myxobolus cerebralis). Thus, we hypothesize that metrics describing stonefly assemblages may be useful in predicting the presence and severity of whirling disease.

\section{Methods}

Benthic invertebrates were sampled on July 26-27, 2006 from single riffles in each of 13 tributary streams of the Blackfoot River. A D-frame net with 1000 micron mesh was used. Substrates were disturbed by kicking along transects; sampling effort was timed and distance approximated by stepping off. Table 1 lists sampling sites, the time expended for each sample, and the approximate distance over which substrates were disturbed. Samples were preserved in 95\% ethanol at streamside, and delivered to Rhithron Associates in Missoula for sorting and identification of organisms.

In the laboratory, samples were sorted under dissecting stereoscopes, using $10 \mathrm{x}-30 \mathrm{x}$ magnification. A random selection of 500 organisms was taken from each sample; stoneflies collected in these subsamples were separated from the remaining organisms and preserved. All stoneflies remaining in each sample were then collected, and these were preserved separately.

Stoneflies from both the random subsample and the total sample collection were identified using published keys; specimens were identified to the lowest taxonomic level possible considering the maturity of the animals and the availability of appropriate keys. Generally, at least genus level was achieved; in many cases, species could be determined. Earlyinstar capniids were left at family level. Two samples yielded a total of 6 extremely immature specimens. These were identified to family level, but were not considered in the subsequent analysis since it was not possible to determine whether they represented unique taxa or were early instars of taxa already included in the taxa lists.

No further analysis of the 500 organism random subsamples was performed, other than the inclusion of stoneflies from those subsamples in the present exploration. All sample fractions were preserved and retained at Rhithron for possible further analysis.

Physical and chemical data as well as data related to incidence (percent of reaches with infection $>3$ in 2005) and severity (mean MacConnell-Baldwin scale value in 2005) of whirling disease in each stream were collected and compiled by Montana Fish Wildlife and Parks personnel. Correlation matrices (Spearman rank R) were constructed using these data and stonefly data, and these matrices were examined for suggestive associations. In all, 18 metric expressions summarizing the stonefly data were analyzed for correlation with the 2 whirling disease measures. Data from Bear Creek was deleted from the data set, since the status of whirling disease in that stream in 2005 was not known at the time of this study. 


\section{Results}

Nineteen stonefly taxa in 7 families were present in the 13 samples. A total of 1348 stoneflies were identified.

Figures 1 and 2 illustrate correlation between stonefly taxa richness and 2 measures of whirling disease incidence and severity. Correlations were not significant, but Chamberlain Creek clearly presents as an outlier in these analyses. When Chamberlain Creek was removed from the dataset, correlation between stonefly taxa richness and measures of whirling disease severity and incidence were significant $(\mathrm{R}=-0.711143, p<0.05$ and $\mathrm{R}=-0.736352, p<0.05)$.

Three functional feeding groups were represented in the stonefly collection from the 13 samples: shredders were represented by 8 taxa, predators by 10 taxa, and collectors by 1 taxon. There was a significant association of predatory taxa richness with infection severity $(\mathrm{R}=$ $0.616833, p<0.05$ ), but not with infection incidence. This relationship is illustrated in Figure 3. Other significant correlative relationships were demonstrated between whirling disease severity and sensitive stonefly taxa richness and abundance, and between sensitive taxa richness and richness within the family Chloroperlidae and whirling disease incidence. However, neither sensitive taxa nor Chloroperlid taxa were well-distributed among these sites.

No other significant associations could be demonstrated between either measure of whirling disease and measures of richness, relative abundance, or absolute abundance of various stonefly families, functional groups, or tolerance characteristics.

Several taxa were collected only in streams with no incidence (i.e. $0 \%$ of reaches with $>3$ on the MacConnell-Baldwin scale) of whirling disease. These were the nemourids Visoka cataractae (collected from 2 sites) and Zapada oregonensis (one site), the perlid Calineuria californica (2 sites), the taeniopterygid Taeniopteryx sp. (one site), and perlodids Isoperla sp. (one site), Kogotus sp. (2 sites), and Megarcys sp. (4 sites). It should be noted that Kogotus sp. was collected from Arrasta Creek, which had a low mean severity rating (0.02). The low severity rating despite $0 \%$ of reaches severely infected suggests that whirling disease probably is present though not widespread in Arrasta Creek. Two taxa were collected only from streams with whirling disease infection: Pteronarcella badia (2 sites) and Claassenia sabulosa (2 sites). 
Tables and Figures

\begin{tabular}{|l|l|l|l|l|}
\hline Sampling date & Waterbody & $\begin{array}{l}\text { Time expended } \\
(\mathbf{m i n} \mathbf{s e c s})\end{array}$ & Distance & Description of effort \\
\hline $7 / 27 / 2006$ & Gold Creek & $6: 20$ & 36 feet & Single transect (riffle) \\
\hline $7 / 27 / 2006$ & Bear Creek & $6: 20$ & 36 feet & Single diagonal transect (riffle) \\
\hline $7 / 27 / 2006$ & W. Twin Creek & $6: 15$ & 36 feet & Triple diagonal transect (riffle) \\
\hline $7 / 27 / 2006$ & E. Twin Creek & $6: 20$ & 36 feet & Triple diagonal transect (riffle) \\
\hline $7 / 26 / 2006$ & Cottonwood Creek & $5: 00$ & 36 feet & Single diagonal transect riffle \\
\hline $7 / 26 / 2006$ & Monture Creek & $5: 30$ & 36 feet & Single transect (riffle) \\
\hline $7 / 26 / 2006$ & Chamberlain Creek & $8: 10$ & 36 feet & Triple transect (riffle) \\
\hline $7 / 26 / 2006$ & Arrastra Creek & $6: 40$ & 36 feet & Triple diagonal transect (riffle) \\
\hline $7 / 27 / 2006$ & Belmont Creek & $6: 04$ & 28 feet & Single transect (riffle) \\
\hline $7 / 26 / 2006$ & Blanchard Creek & $7: 15$ & 27 feet & Double transect (riffle) \\
\hline $7 / 26 / 2006$ & Landers Fork & $6: 20$ & 36 feet & Single transect (riffle) \\
\hline $7 / 27 / 2006$ & Johnson Creek & $6: 00$ & 36 feet & Double diagonal transect (riffle) \\
\hline $7 / 26 / 2006$ & Elk Creek & $6: 30$ & 36 feet & Triple diagonal transect (riffle) \\
\hline
\end{tabular}

Table 1. Summary of sampling events: July 2005.

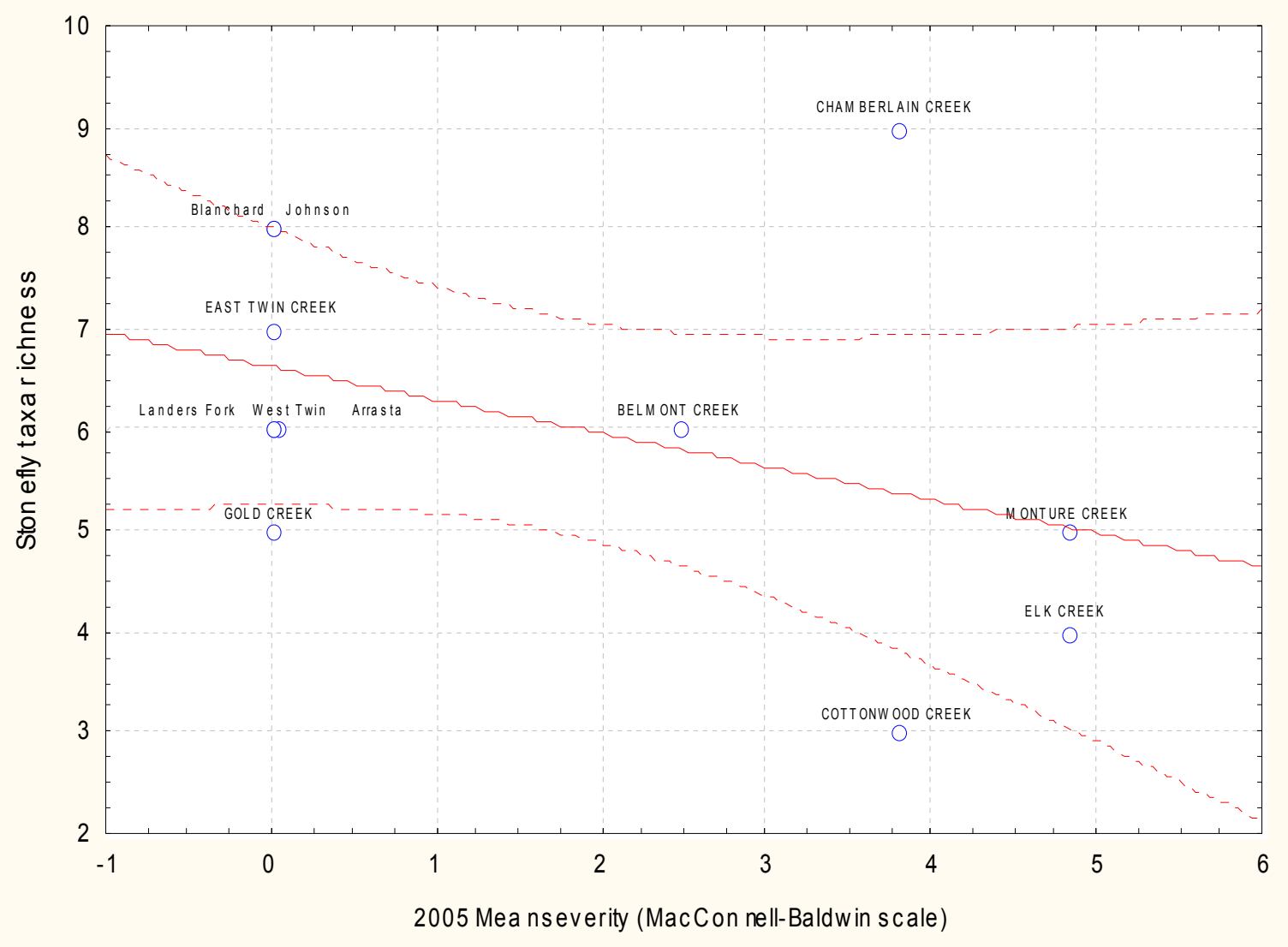

Figure 1. Association between stonefly taxa richness and severity of whirling disease $(\mathrm{R}=-0.46, p>0.05)$. 


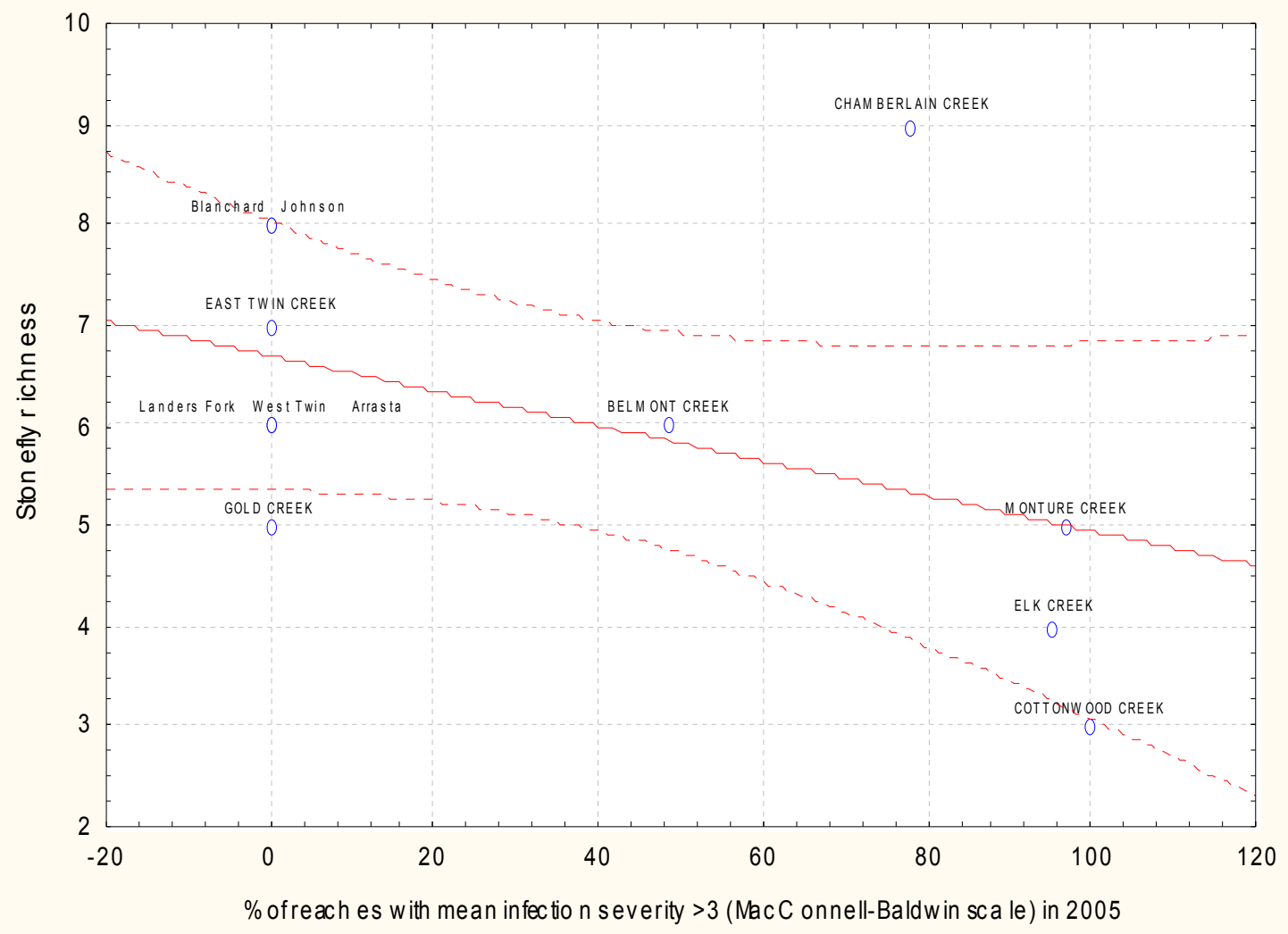

Figure 2. Association between stonefly taxa richness and incidence of whirling disease. ( $\mathrm{R}=-$ $0.51, p>0.05)$.

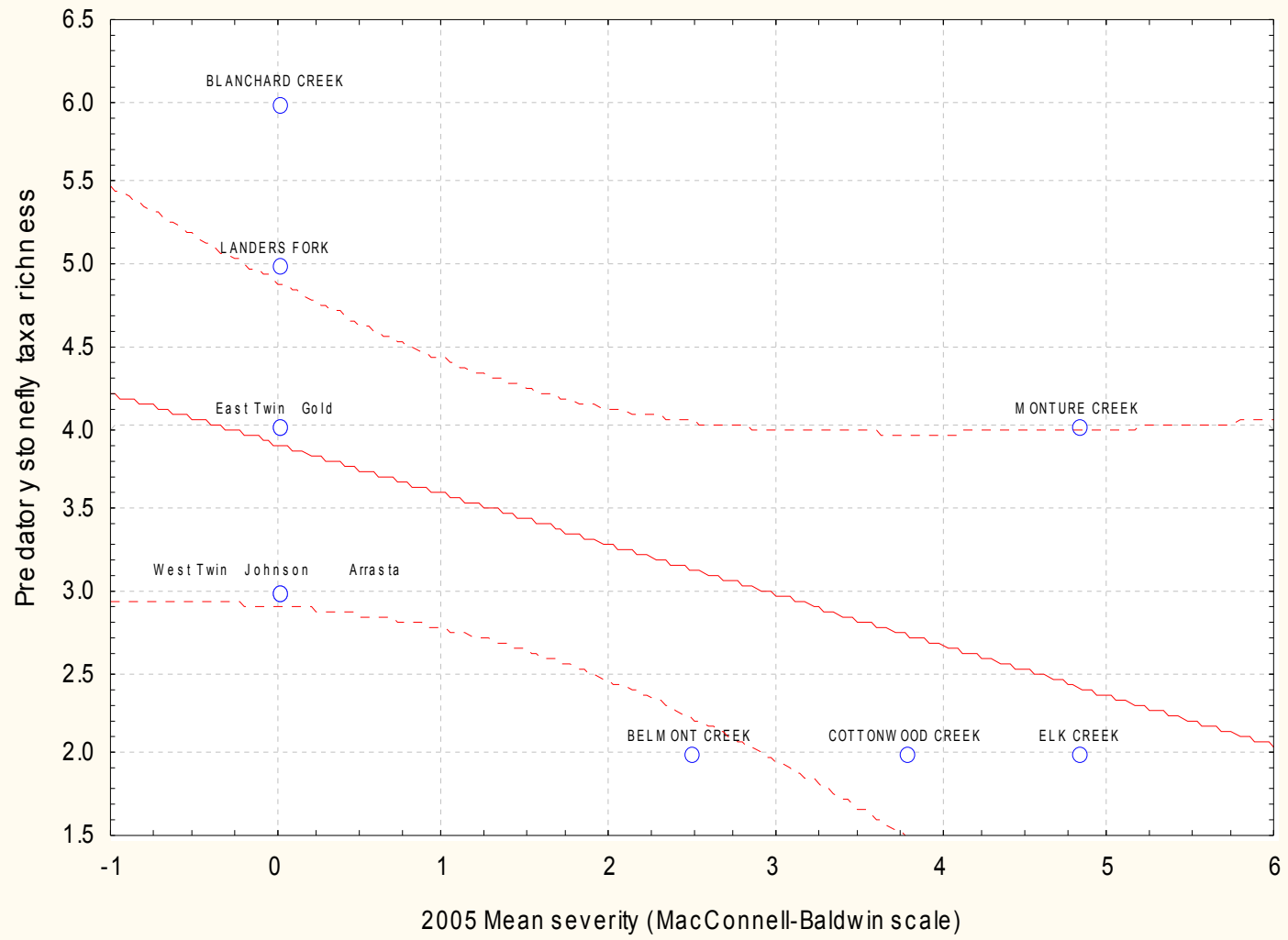

Figure 3. Association between predatory stonefly taxa richness and severity of whirling disease. $(\mathrm{R}=-0.51, p>0.05)$. Chamberlain Creek was not included in this analysis. 


\section{Discussion}

Although significant trends could be demonstrated, none of the correlative relationships explored in this study gave results definitive enough to support the hypothesis that characteristics of stonefly assemblages can predict the incidence or severity of whirling disease as measured here. In each analysis, there is considerable overlap of results between infected and uninfected streams.

It seemed justifiable to delete Chamberlain Creek from the correlation analyses, since there are some unique conditions in that watershed immediately upstream of the sampling location. As noted, this site presents as an outlier; despite high incidence of infection in this stream, the sample collected here yielded the highest stonefly taxa richness of any sample in this study. Historic reconstruction that reclaimed an altered channel may have resulted in ideal habitat conditions for stoneflies. Reconstructed reaches were located immediately upstream of the sampling location as well as two artificial upstream ponds that drain into Chamberlain Creek in the immediate upstream area. These ponds are thought to harbor t. tubifex "hotspot" conditions such as warmer water effluent and organic sediments used to line the ponds.

Since there were some taxa that may have been confined to uninfected streams, further investigation of potential indicator taxa in the family Perlodidae may be promising. Further, the taxa that were identified in this study as potential indicators will be relatively easy to identify streamside, if care is taken to sample at appropriate times of year. 


\section{Exploratory assessment of association between invertebrate "EPT" taxa and the incidence and severity of whirling disease in tributaries of the Blackfoot River}

Wease Bollman, Ron Pierce, and Lisa Eby

\section{Indroduction}

In an earlier pilot study, we investigated whether patterns in stonefly (Plecoptera) assemblages could suggest the presence of whirling disease in tributary streams to the Blackfoot River. In this study, we include 2 other aquatic insect orders, mayflies (Ephemeroptera) and caddisflies (Trichoptera). These 3 groups comprise the so-called "EPT" orders of aquatic insects, which are often considered to be general indicators of clean water and undisturbed habitat conditions.

\section{Methods}

Sampling methods and laboratory processing and identification protocols are described in the previous paper (Bollman et al. 2006), to which the reader is referred. Random subsamples of 500 organisms from all aquatic invertebrate groups were taken from whole samples, and these were identified. Physical and chemical data, as well as data related to the incidence (percent of reaches with infection $>3$ in 2005) and severity (mean McConnell-Baldwin scale value in 2005) of whirling disease in each stream were made available by Montana Fish Wildlife and Parks. Correlation matrices (Spearman rank R) were constructed using these data and the invertebrate data, and the matrices were examined for suggestive associations. In all, 22 metric expressions (listed in Table 1) summarizing the invertebrate data were analyzed for correlation with the 2 whirling disease measures. Ephemeroptera and Trichoptera taxa from both the random subsamples and the total sample collections were removed and identified, and these data were combined with the Plecoptera data generated for the earlier study. The relative abundance of each EPT taxon was examined for correlative association with whirling disease measures. As before, Bear Creek was not included in this analysis, since the status of whirling disease in that stream in 2005 was not known. The EPT fractions of the whole samples were further analyzed with an ordination study (nonmetric multidimensional scaling: McCune and Grace 2002). For this analysis, the Sorenson (Bray-Curtis) distance measure was used. The resulting plot was examined to see if groupings of invertebrate assemblages distinguished infected sites from uninfected sites. Bear Creek was included in this analysis.

\section{Results}

Sixty-seven EPT taxa were identified in the 13 samples. A total of 10,644 EPT individuals were present.

Significant correlation could be demonstrated between both measures of whirling disease and 4 metric expressions summarizing the invertebrate assemblages. Table 2 summarizes the correlation coefficients of these relationships. Figures 1-4 graph the results of each metric individually against the percentage of stream reaches with infection severity greater than 3 , as measured on the MacConnell-Baldwin scale.

Several taxa were collected only in streams with no incidence (i.e. $0 \%$ of reaches with $>3$ on the MacConnell-Baldwin scale) of whirling disease. A few taxa were only collected from streams with whirling disease infection. These data are summarized in Tables 3 and 4. Taxa that were collected at a single site were not included in the tables.

Figure 5 illustrates the ordination plot of the aquatic invertebrate assemblages collected at the 13 sites. Final stress for this analysis was 7.02, indicating a good fit of the ordination model to the data. 
Table 1. Metrics tested for association with incidence and severity of whirling disease.

Measures of habitus, physiology, or life history

Air Breather Richness

Burrower Richness

Clinger Richness

Cold Stenotherm Richness

Hemoglobin Bearer Richness

Semivoltine Richness

Swimmer Richness

Univoltine Richness

Tolerance measures

Hilsenhoff Biotic Index

Metals Tolerance Index

Pollution Sensitive Richness

Sediment Sensitive Richness

Sediment Tolerant Richness
Functional measures

Filterer Richness

Predator Richness

Taxonomic composition measures

Baetidae/Ephemeroptera

E Richness

EPT Richness

Hydropsychidae/Trichoptera

P Richness

T Richness

Taxa Richness

Table 2. Spearman rank order correlation coefficients (R) for associations between 2 measures of whirling disease and 4 metric expressions derived from invertebrate taxonomic data from 13 samples. Correlations are significant at $\mathrm{p}<.05000$.

\begin{tabular}{|l|l|l|}
\hline & $\mathbf{2 0 0 5}$ mean infection & $\begin{array}{l}\text { \% reaches > grade 3 } \\
\text { infected }\end{array}$ \\
\hline $\mathbf{2 0 0 5}$ mean infection & 1.000000 & 0.913293 \\
\hline \% reaches > grade 3 infected & 0.913293 & 1.000000 \\
\hline Cold Stenotherm Richness & -0.673981 & -0.710569 \\
\hline EPT Richness & -0.600712 & -0.608616 \\
\hline Metals Tolerance Index & 0.744218 & 0.842184 \\
\hline Pollution Sensitive Richness & -0.691541 & -0.745014 \\
\hline
\end{tabular}


Figure 1. Association between cold stenotherm taxa richness and incidence of whirling disease $(\mathrm{R}=-0.71, p<0.05)$. Dotted lines indicate $95 \%$ confidence intervals.

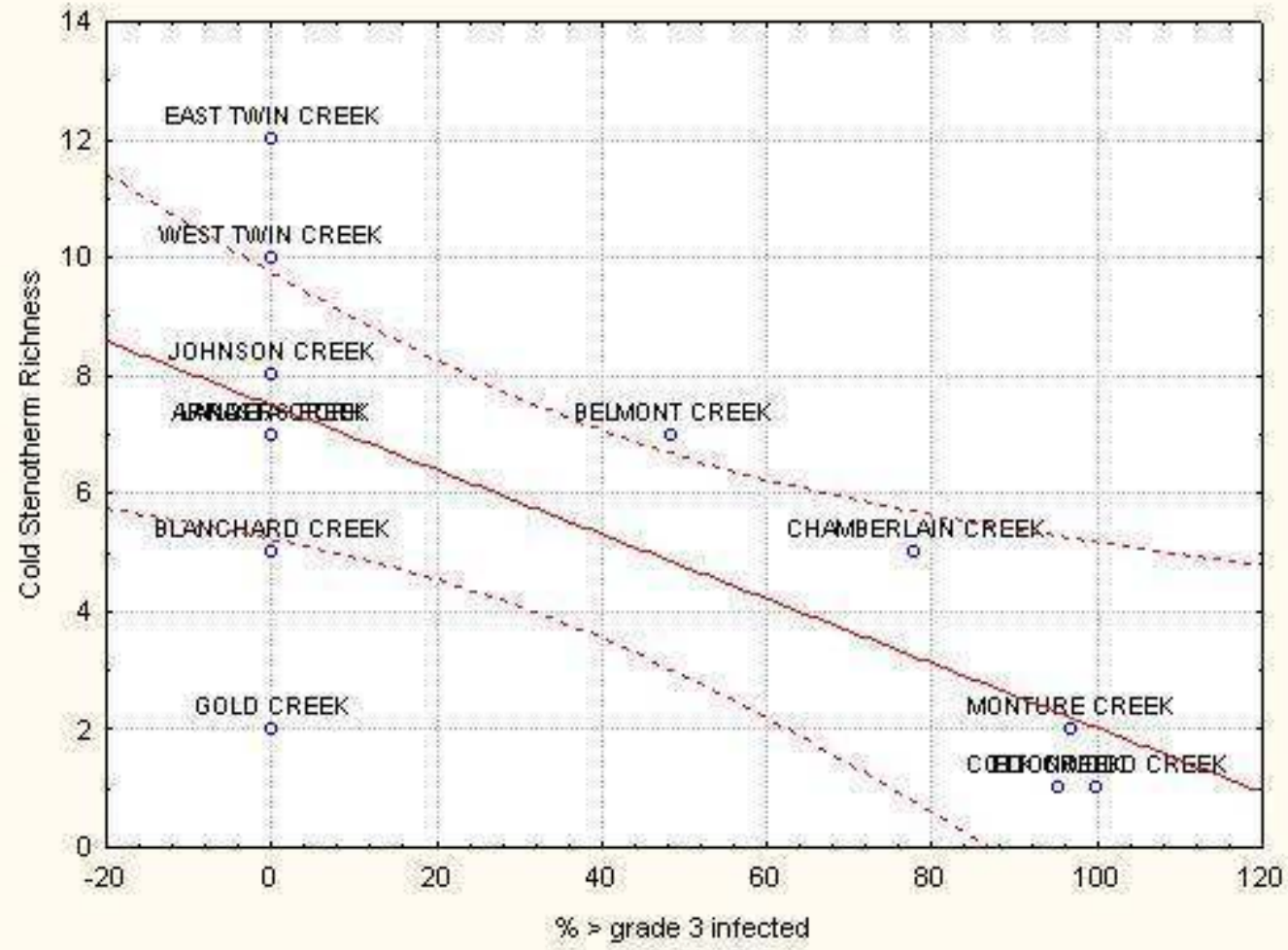

Figure 2. Association between EPT richness and incidence of whirling disease $(\mathrm{R}=-0.61, p<0.05)$. Dotted lines indicate $95 \%$ confidence intervals.

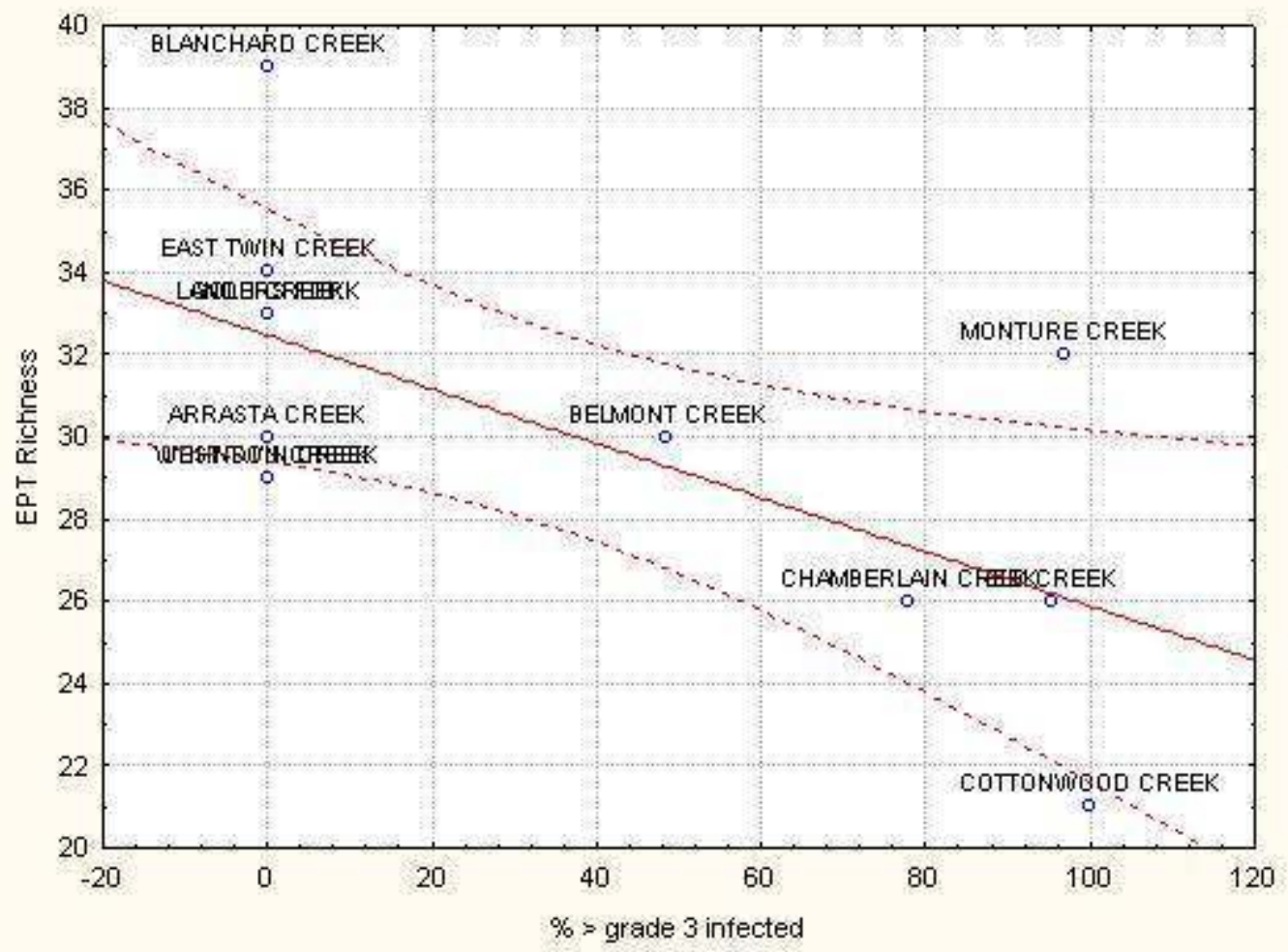


Figure 3. Association between the metals tolerance index and incidence of whirling disease $(\mathrm{R}=0.84, p<0.05)$. Dotted lines indicate $95 \%$ confidence intervals.

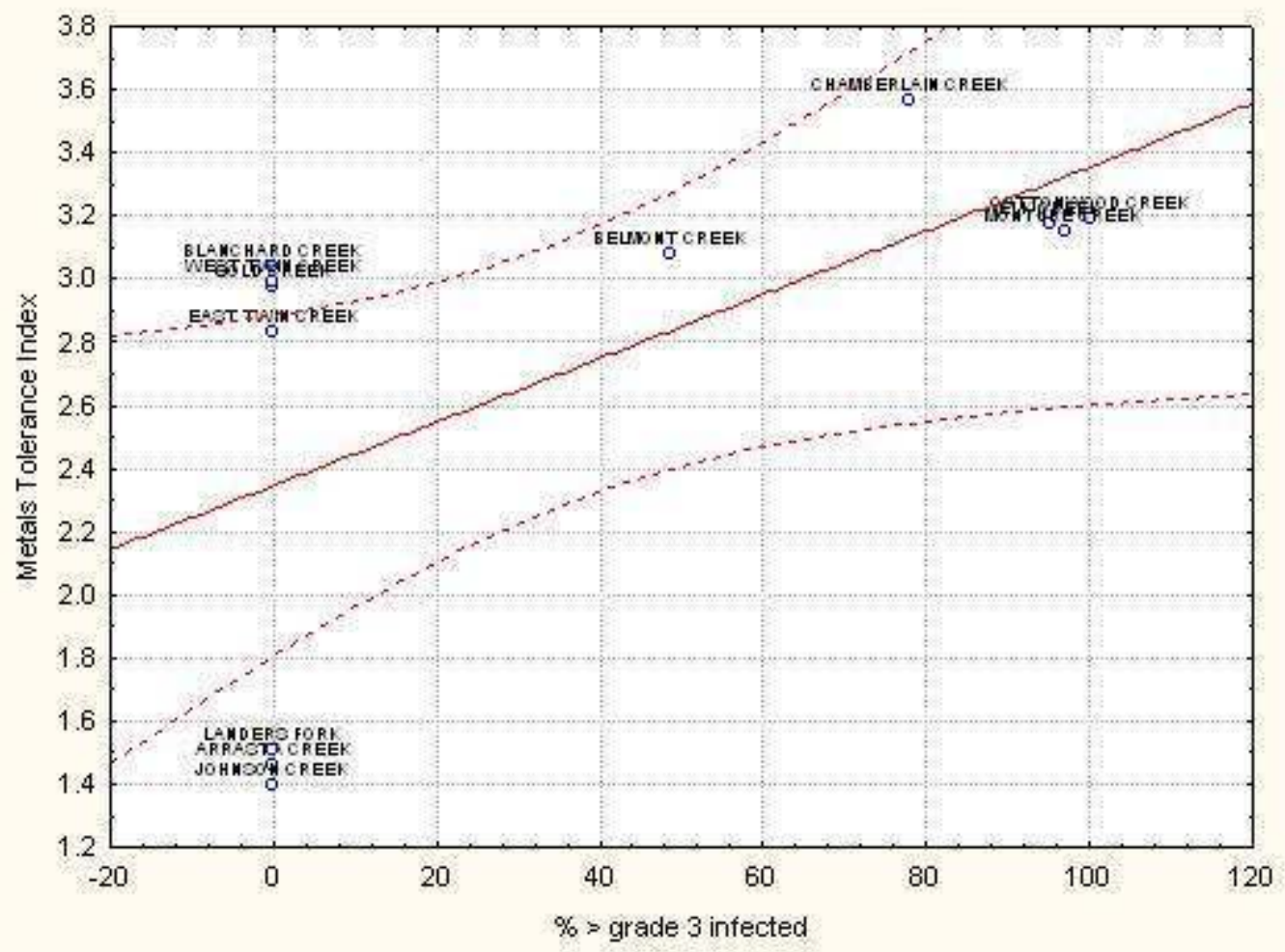

Figure 4. Association between pollution sensitive taxa richness and the incidence of whirling disease $(\mathrm{R}=-0.74, \mathrm{p}<0.05)$. Dotted lines indicate $95 \%$ confidence intervals.

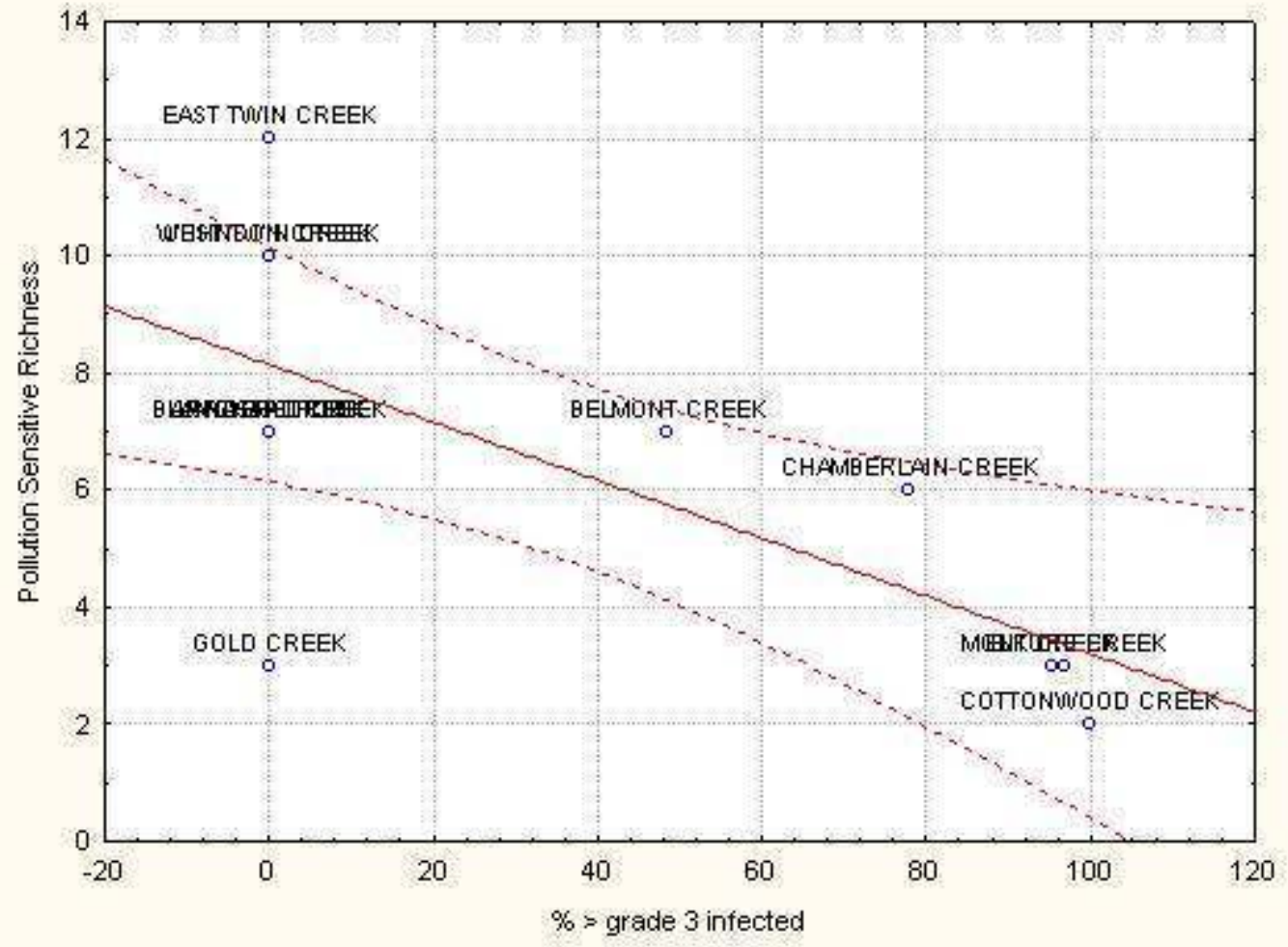


Table 3. Taxa collected only from streams without documented whirling disease infection. The number of sites where the taxon was collected is indicated in parentheses. Taxa collected at only a single site are not included in the table.

\begin{tabular}{lll}
\hline Ephemeroptera & Plecoptera & Trichoptera \\
& & \\
Drunella spinifera (2) & Visoka cataractae (2) & Parapsyche elsis (4) \\
Caudatella edmundsi (2) & Calineuria californica (2) & Agraylea sp. (2) \\
Epeorus deceptivus (2) & Megarcys signata (4) & Lepidostoma unicolor (4) \\
Epeorus longimanus (5) & & Rhyacophila alberta (3) \\
Rhithrogena sp. (4) & & \\
Ironodes sp. (2) & & \\
Baetis alius (2) & & \\
Baetis flavistriga (2) & & \\
\hline
\end{tabular}

Table 4. Taxa collected only from streams with documented whirling disease infection. The number of sites where the taxon was collected is indicated in parentheses. Taxa collected at only a single site are not included in the table.

\begin{tabular}{lll}
\hline Ephemeroptera & Plecoptera & Trichoptera \\
Timpanoga hecuba (3) & Pteronarcella badia (2) & Brachycentrus occidentalis (3) \\
& Claassenia sabulosa (2) & Hydropsyche oslari (2) \\
\hline
\end{tabular}

Figure 5. Ordination (nonmetric multidimensional scaling) of aquatic invertebrate assemblages from 13 stream sites in the Blackfoot drainage.

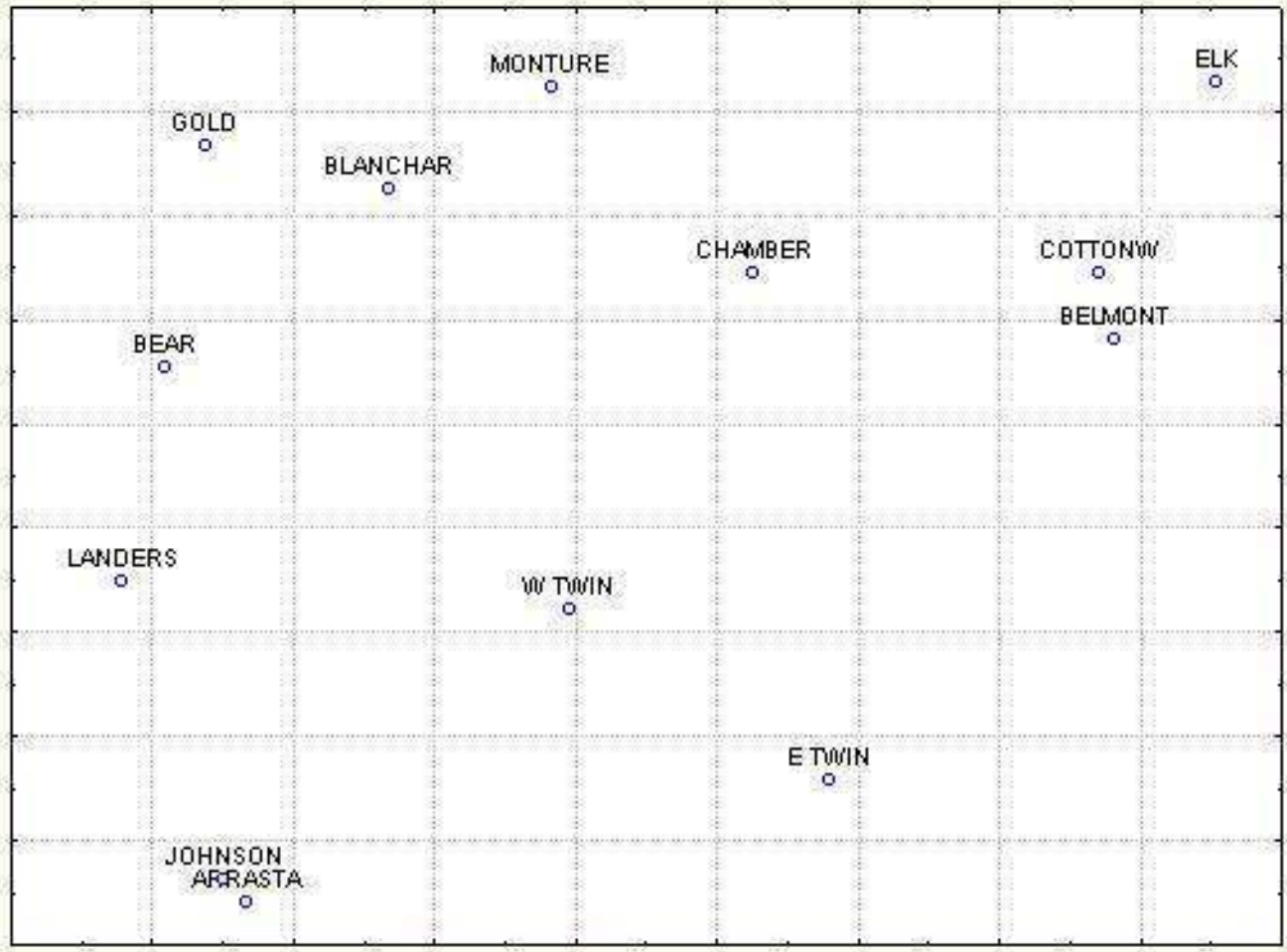

\section{Discussion}

The significant association of EPT taxa richness with whirling disease incidence and severity supports the finding reported by McGinnis and Kerans (undated report) for western Montana drainages. These investigators determined that the risk of whirling disease in watersheds increased as EPT richness diminished $\left(r^{2}=0.35, p=0.07\right)$. Neither E richness, $\mathrm{P}$ 
richness, nor $\mathrm{T}$ richness, when considered singly, produced significant correlation with the incidence of whirling disease, suggesting that different groups may have been advantaged in different environs. Although the association of EPT richness with whirling disease incidence was strong in our analysis, both Monture Creek and Belmont Creek supported relatively large numbers of EPT taxa despite the presence of whirling disease; EPT richness in samples collected in these drainages equaled or exceeded EPT richness in 3 drainages (Arrastra Creek, Johnson Creek, and West Twin Creek) that apparently did not harbor the infection. These findings suggest that it may be important to consider the presence or absence of individual taxa instead of metric summations of taxa richness.

Since both mean water temperature and July-August maximum water temperature were significantly associated with the incidence of whirling disease $(\mathrm{R}=0.621 p<0.05$ and $\mathrm{R}=0.799$ $p<0.05$ respectively), it was not surprising that the number of cold stenotherm taxa present in samples was also significantly correlated with whirling disease incidence. Pollution sensitive taxa are often cold stenothermic; the significant relationship between that metric and the whirling disease measures is predictable given the overlap between those 2 groups of aquatic invertebrates. However, similar to EPT richness, neither cold stenotherm richness nor pollution sensitive richness were perfect predictors of the presence of whirling disease.

These correlations suggest that the incidence and severity of whirling disease may be related to water temperature. Those taxa that were collected only in infected streams (Table 4) are generally tolerant of warmer thermal conditions, while those collected only in uninfected streams (Table 3) are generally cold stenotherms. A thermal association with whirling disease is also evident in the ordination. While no strong clustering of sites is apparent, the ordination suggests a sorting of assemblages with respect to temperature tolerances. There is a temperature gradient evident from the lower left corner of the plot to the upper right corner when July-August maximum temperature is considered. The plot suggests that sites with higher July-August maximum temperature tend to be infected with whirling disease. Other than Arrastra Creek, which demonstrated a low mean severity and $0 \%$ severely infected reaches, all infected sites plot in the upper right of the ordination space.

The significant association between whirling disease incidence and the metals tolerance index was an unexpected result. Among the group of sites studied, the incidence of whirling disease tended to be higher in streams where the invertebrate assemblage was more tolerant to metals contamination, when tolerance was measured by this index.

Curiously, sites in watersheds with a high percentage of reaches (48.5\% and greater) with whirling disease incidence have higher forest cover as a percentage of watershed area than uninfected watersheds $(\mathrm{R}=0.853 p<0.05)$. Forested area ranges from $73.4 \%$ to $87.3 \%$ in drainages without demonstrated whirling disease infection, and from $88.9 \%$ to $95.1 \%$ in infected drainages.

\section{References}

Bollman, W., R. Pierce and L. Eby. 2006. A pilot assessment of the association between stonefly assemblages and the incidence and severity of whirling disease in tributaries of the Blackfoot River, Montana. Unpublished report to Montana Fish Wildlife and Parks. Ron Pierce, project manager.

McGinnis, S. and B.L. Kerans. Undated report. A preliminary assessment of land use and aquatic invertebrates as indicators of whirling disease risk in Montana. MSU. 


\title{
Environmental conditions linked to Myxobolus cerebralis infection in basin-fed streams of the Blackfoot Watershed, Montana
}

\author{
Ron Pierce \\ Montana Fish, Wildlife and Parks \\ Lisa Eby \\ University of Montana \\ Wease Bollman \\ Rhithron Associates \\ Dick Vincent \\ Montana, Fish Wildlife and Parks
}

\begin{abstract}
The exotic parasite Myxobolus cerebralis, the infectious agent that ultimately causes whirling disease in salmonids, has successfully invaded many river systems throughout the interior West. Given the patchy distribution and variable effects of whirling disease, it is important to identify the physical and biological characteristics of watersheds that influence infection. In the Blackfoot Basin of western Montana, we investigated relationships between a group of five landscape-and four reach-scale environmental conditions and the presence of infection in hatchery rainbow trout (Onchorynchus mykiss) within basin-fed tributaries of the Blackfoot River in order to determine variables correlated with infection. Study results found that rainbow trout developed little to no infection in streams with higher gradients, lower levels of fines within the substrate and low summer temperatures despite the near proximity to higher infection rates in rainbow trout in adjacent waters. Infections were present in streams with summertime maximum water temperatures over $19^{\circ} \mathrm{C}$; a logistic regression model including maximum water temperatures, fine sediment $(<0.84 \mathrm{~mm})$ and channel gradient explained the presence of rainbow trout infection within our thirteen study streams. In our study area, rainbow trout infections were present and infection rates were high in meandering streams in broad valleys with gentle relief and warmer summer temperatures. We also examined the relationship between invertebrate taxa and our ability to detect infection. Species richness of stenohaline species was the single best indicator of infection; a logistic regression with stenohaline species, richness of Ephemeroptera, Plecoptera and Trichopera (EPT) species, and sediment sensitive species richness described was the best biotic model for describing the variation of infection in our dataset. In western Montana, environments with infected fish are often prone to the additive effects of habitat alterations that may increase sediment or temperature regimes. Such changes, whether natural or anthropogenic, may increase disease stressors in wild trout populations.
\end{abstract}

Key words: Blackfoot River Basin, Myxobolus cerebralis, infection, environmental characteristics, water temperature, macroinvertebrate assemblage, habitat 


\section{Introduction}

Whirling disease is a chronic disease caused by the invasive myxosporean parasite Myxobolus cerebralis (Hoffman 1990) that was introduced into North America in the 1950s (Bartholomew and Reno 2002). Myxobolus cerebralis has a complex, two-host life cycle involving the aquatic oligochaete worm Tubifex tubifex and most members of the salmonidae, the youngest of which (age-0 fry) have been shown to be the most susceptible to infection (Ryce 2004). High mortality and recruitment collapse has occurred in certain infected rainbow trout (Oncorhynchus mykiss) populations in Montana (MacConnell and Vincent 2002) and Colorado (Nehring and Walker 1996). First detected in Montana in 1994 in the Madison River, this disease has spread to salmonid-dominated river systems throughout western Montana; however, infection rates are geographically highly variable among and within watersheds despite the ubiquitous presence of the salmonid host. This high variation of infection across regions, within drainages and within streams has been observed throughout the West including Colorado, Idaho, Utah, California and Montana (Nehring and Walker 1996, Modin 1998, Hiner and Moffitt 2001, Sandell et al. 2001, de la Hoz Franco and Budy 2004, Krueger et al. 2006).

The extent of contact between vulnerable fry and the release of the infective triactinomyxon (TAM) stage of the parasite determine the degree of exposure for young fish and, ultimately, the magnitude of population-level effects. Thus, watershed characteristics and aspects of tributaries that influence $T$. tubifex availability and spore production can alter exposure rates. We can identify watershed characteristics governing whirling disease by examining distribution patterns of infection within the broader landscape.

Environmental factors play a critical role in determining the result of host and parasite interactions (MacConnell and Vincent 2002). Temperature influences the growth, reproduction and survival of T. tubifex (de la Hoz Franco and Budy 2004) as well as spore and infective TAM production (El-Matbouli et al. 1999). Water velocity may also influence TAM survival and concentrations (Kerans and Zale 2002, MacConnell and Vincent 2002). Substrate size and nutrients influence the distribution and abundance of T. tubifex (Sauter and Gude 1996, Arndt et al. 2002). Fewer studies examine how these factors interact in a field setting to help explain the distribution and prevalence in the environment (Hiner and Moffitt 2002, De la Hoz Franco and Budy 2004, Krueger et al. 2006). Linking these potentially limiting factors to patterns on the landscape in a variety of different system types and regions is useful as we attempt to separate the effects of correlated variables in the field, understand different limiting factors across different types of systems, and provide generalizations of vulnerability to disease. Response variables associated with infection (e.g., severity, spore production) increase with average water temperature (and variation in water temperature) in Idaho and Utah studies (Hiner and Moffitt 2002, de la Hoz Franco and Budy 2004), but decrease with water temperature in the tailwater section of Madison River MT (Krueger et al. 2006). Given that the temperature range observed in the Madison River study is similar to the other studies (range in study $10.1-13.6^{\circ} \mathrm{C}$ ), this effect could be due to the inverse correlation among fine sediment and temperature in the dataset or other factors related to flow alterations. Beyond temperature, the other variables that have a positive relationship with disease severity include water velocity (de la Hoz Franco and Budy 2004), fine sediments (Krueger et al. 2006), and density of oligochaetes and chironomids (Hiner and Moffitt 2002).

The distribution of $M$. cerebralis infected rainbow trout in basin-fed environments seems to adhere to a fairly predictable geographic pattern of increasing infection rates in the downstream direction (Smith 1998, Sandell et al. 2001, Hubert et al. 2002). Although the longitudinal relationships of infection has been described in some areas (Sandell et al. 2001, De la Hoz Franco and Budy 2004), the variables linked to infection (and severity) vary by geographic region and the specific physical characteristics influencing infection have not been quantitatively evaluated in western Montana tributaries. Improving our understanding to better predict infection in the field will require expanding our understanding of the environmental 
mechanisms that result in spatial overlap of fry with high concentrations of triactinomyxon (Downing et al. 2002, Kerans and Zale 2002). This would allow fisheries managers to better predict the species and streams in which high or low severity of whirling disease might be expected. If fisheries managers could link disease potential on the landscape (based on geomorphic and physiochemical predictors), they could forecast which species, life histories or stream-types are most vulnerable to whirling disease and better determine broad-scale (versus localized) population effects. In addition, depending on the factors determining exposure potential, managers may be able to offset disease effects in a particular tributary through habitat restoration or other management techniques.

Whirling disease, first identified in the Blackfoot Basin in 1995, is currently present throughout the mainstem Blackfoot River and lower reaches of many tributaries (Pierce et al 2006). Although not quantified, there tends to be a general inverse relationship between channel elevation, channel slope and infection rates, which appears to result from a lack of suitable habitat (slow water and fine substrate) to support T. tubifex (Smith 1998). Biotic predictors (e.g., sentinel exposures, T. tubifex or TAMs) are time consuming, expensive, and require specialized identification training and equipment. The ability to identify high disease risk areas potentially before severe infection levels occur is critical for practitioners to focus research and management effort.

This research investigates the $M$. cerebralis infection of rainbow trout with abiotic attributes of streams within a heterogeneous area of the Blackfoot Basin. In addition, riffle invertebrate assemblages were correlated with infection, as these data are routinely collected in environmental or water quality assessments. Our goals of this project are both to develop a model that identifies abiotic environmental conditions that explain the presence of infection, and to examine the relationship of the occurrence of infection with invertebrates to determine whether they may be a good indicator of infected environments.

Study area - The Blackfoot River, a $5^{\text {th }}$ order tributary (Strahler 1957) of the upper Columbia River, lies in west-central Montana and flows west $211 \mathrm{~km}$ from the Continental Divide to its confluence with the Clark Fork River in Bonner, Montana. The River drains a $3,728 \mathrm{~km}^{2}$ watershed through $3,040 \mathrm{~km}$ of perennial streams and generates a mean annual discharge of $45.2 \mathrm{~m}^{3} / \mathrm{s}$ (United States Geological Survey 2006). The geography of the watershed is a physically diverse, geo-structurally controlled glacial landscape with alpine and subalpine mountains at the upper elevations, montane forests at the mid-elevations and semi-arid glacial pothole and outwash topography on the valley floor. Many tributaries of the Blackfoot River begin in high cirque basins, flow through alluvial valleys with meandering streams in broad valleys with gentle relief, while others flow through confined steeper channels of non-glacial origin before entering the Blackfoot River. Lands in the upper Blackfoot Basin are mostly public $(65 \%)$ headwater areas with about 35 percent privately held lands consisting primarily of timbered foothills and agricultural bottomlands.

The Blackfoot River is a renowned trout river in Montana and contains diverse selfsustaining wild trout populations, most of which reproduce in tributaries (Pierce et al 2007, 2006). Salmonids of the Blackfoot watershed include brook trout (Salvelinus fontinalis), brown trout (Salmo trutta), bull trout (S. confluentus), mountain whitefish (Prosopium williamsoni), rainbow trout (Oncorhynchus mykiss), and westslope cutthroat trout (O. clarkii lewisi) all of which possess some level of whirling disease susceptibility (MacConnell and Vincent 2002). 


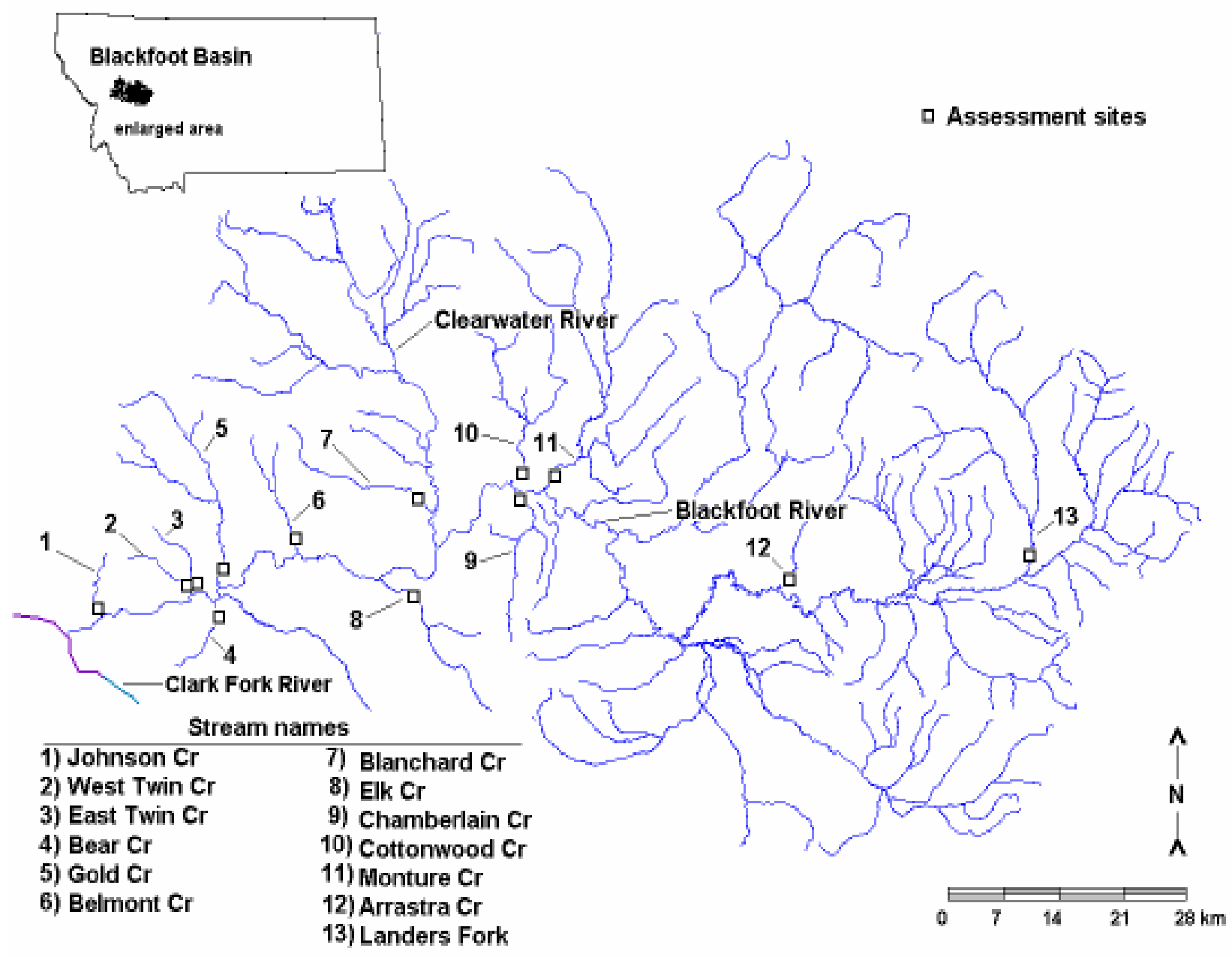

Figure 1. Study area: Blackfoot Basin including the names of study streams and locations of physical assessments and sentinel cage exposures. Whirling disease is present from the confluence of the Blackfoot and Clark Fork Rivers to upstream of the Landers Fork.

\section{Methods}

Tributary Selection - Infections of $M$. cerebralis in rainbow trout and the physical and benthic characteristics were examined among 13 basin-fed tributaries to the Blackfoot River (Figure 1). For this study, we selected spawning tributaries and avoided spring creeks due to more continuously high infections present within groundwater environments (Anderson 2004, Pierce and Podner 2006). All assessments were undertaken at or near proximity to fixed whirling disease monitoring sites in lower-most stream reaches of tributaries where histological tests had previously identified infection as either present (Belmont, Elk, Cottonwood, Chamberlain, Monture and Arrastra Creeks) or failed to detect infection (Johnson, East Twin, West Twin, Bear, Gold and Blanchard Creeks and Landers Fork) (Pierce et al 2006). These sites are located downstream of and directly connected to waters of the Blackfoot River where $M$. cerebralis infected fish are present, and salmonid spawning migrations from the Blackfoot River are known to occur. Thus, all tributary test sites had the potential for direct exposure to $M$. cerebralis.

Physical channel assessments - Physical assessments were then undertaken at both the reach and landscape-levels using the field survey methods and stream and valley classifications as described by Rosgen (1996). For each of the 13 sites, we began by measuring a representative 
and stable stream reach, where we surveyed 1) longitudinal profiles of channel bedforms along the thalweg as well as adjacent bankfull elevations over a distance of $~ 30$ bankfull widths, 2) valley cross-section extending from a stable riffle though the flood-prone area, and 3) meander geometry. At each riffle cross-section, we collected a 100 particle random Wohlman substrate sample from within the channels wetted-width. From each survey reach, we calculated bankfull width, bankfull depth, bankfull area, width/depth ratios at riffles, riffle substrate, percent channel slope entrenchment ratio and classified the reach by the channel and valley-types. Using topographic maps in Arcview GIS, we calculated sinuosity and percent valley slope for the contiguous valley-type and identified stream-order and percent forest cover for the basin.

Within each survey reach, we further examined channel substrate by extracting McNeil core samples from riffles using modified methods first describe by McNeil and Arhnel (1964). For this assessment, a hollow core sampler was pushed $10 \mathrm{~cm}$ into the streambed (six samples per stream) and the substrate extracted. The turbid water within the cone was sampled for sediment content utilizing an Imhoff cone as described in Shepard and Graham (1982) and Shepard et al (1984). The water in the McNeil core sampler was measured to the nearest half inch to calculate the intracore water volume and to assist in the conversion of the volume of the sediment captured in the Imhoff cone to dry weight. The substrata was removed from the core area and placed in bags for transport to a U. S. Forest Service lab. Streambed samples were oven dried and shaken through sieve series containing 76.2, 50.8, 25.4, 12.7, 6.3, 4.76, 2.38, 0.85, $0.074 \mathrm{~mm}$ mesh screens. The material retained within each sieve and the pan was weighed to the nearest hundredth of a gram. The estimated dry weight of the sediment within the Imhoff cone was added to the weight of material $<0.84 \mathrm{~mm}$. We calculated Fredle index, geometric mean and the weight of particle size classes of $<0.84,0.84-4.6$ and $<6.35 \mathrm{~mm}$. Substrate composition was reported as the percent of each size class by weight.

The remaining parameters of the physical channel assessment were also collected within the survey reach. These included basic water chemistry $(\mathrm{pH}$, conductivity, Total Dissolved Solids) and water temperatures logged at 48-minute intervals using Onset ${ }^{\mathrm{TM}}$ thermographs; both water chemistry and temperature were collected during mid-summer base flow periods (July and August 2006).

Invertebrate assessment - Benthic invertebrates were sampled on July 26-27, 2006 from single riffles within each of the physical channel assessment sites. The substrate was disturbed by kicking along transects and invertebrates were captured in D-frame net with 1,000-micron mesh. Samples were preserved in $95 \%$ ethanol at streamside and delivered to Rhithron Associates in Missoula for sorting and identification of organisms. In the laboratory the samples were sorted under dissecting stereoscopes, using 10x-30x magnification. Ephemeroptera, Trichoptera, and Plecoptera (EPT) were picked from the entire sample and identified to the lowest taxonomic level (genus or species) using published keys (Merritt et al. 2008, Thorp and Covich 2001). Several common water and habitat quality indicators including, cold stenotherm richness, burrower richness, clinger richness, sediment sensitive richness, sediment tolerant richness, filterer richness, predator richness, Plecoptera richness, and EPT richness were calculated.

Whirling disease exposures - Sentinel cage exposures of 50 hatchery (age-0) rainbow trout cohorts were used to detect infection within and among the 13 tributaries (Figure 1). Cages were placed in circulating water and exposures were completed in July 2006 within 9 weeks post-hatch to coincide with fry emergence in Blackfoot tributaries (Pierce et al. In review) and the known seasonal peak of TAM production within western Montana Rivers (Vincent 2000). The exposure period for each live cage was standardized at 10 days. At the end of that time, trout were transferred to Pony, MT, where they were held for an additional 80 days at a constant $10^{\circ} \mathrm{C}$ to ensure the infection, if present, would reach maximum intensity (Vincent 2000). At the end of the holding period, all surviving fish were sacrificed and sent to the Washington State University Animal Disease Diagnostic Laboratory at Pullman, WA. At the lab, the heads were 
histologically examined using the MacConnell-Baldwin histological grading scale, which ranks whirling disease infection from 0 (non-detect) to 5 (severe) (Baldwin et al. 2000). Severity was considered high if a majority (expressed as a percentage) of exposed RBT had histological (lesion) scores of $\geq 3$ on the MacConnell-Baldwin scale. As an index to severity, mean lesion scores of $>2.75$ have been associated with significant levels of mortality in wild rainbow trout populations (Vincent 2002).

Analyses - Scatterplots of the response variables (index of mean infection or percent of fish with infection grade $\geq 3$ ) indicted non-linear relationships with many of our predictor variables. Typically infections were either not-detected or infection rates were relatively high (majority $\geq$ grade 3 ) with very few intermediate values. In addition, streams with no or very low $(<0.05$ mean score) or relatively high histological scores $(\geq 3$ severity) have remained relatively consistent from year to year (Pierce et al. 2006). Given these considerations we decided to use infection presence and non-detect in our analyses. We used two approaches to link environmental conditions to infection. First, we used classification and regression trees (CART, Venables and Ripley 1997) to examine whether the groups (non-detect verses infected) reflect differences in any of the environmental predictor variables. Classification and regression trees attempt to partition a data set by recursively explaining subsets of the data using either continuous or categorical variables (Breiman et al. 1984). Because of the small data set (and only 5 streams with infection present), in Splus we set the minimum node size to be 3 but reduced the number of potential splits of the dataset ("pruned the tree") to prevent overfitting the data. In addition to CART analyses, we used logistic regression to identify the environmental variables that best explained the variation in non-detect/presence data. Logistic regressions were run with a backward elimination method (likelihood ratio) and performed in SPSS version 11.

\section{$\underline{\text { Results }}$}

Our first set of analyses examined which landscape-scale parameters best explained the presence of infection in tributaries. We included percent valley slope, percent forest cover, sinuosity, channel type, and stream order. Valley type and valley slope were not both used in this analysis because of the inherent relatedness of the factors (Table 1).

Next we used the same analytical techniques to examine which tributary characteristics best explained whether streams were vulnerable to infection. To remove correlated predictive variables, we first examined the relationships among the sediment measures. There were significant correlations among all of the McNeil coring measures, including the Fredle and geometric mean measures, as well as many of the Wolman pebble count measure (e.g., D50). To reduce correlated predictor variables and given the known relationship of T. tubifex with fine sediment, we used the percentage of substrate less than $0.84 \mathrm{~mm}$ to describe substrate composition in our analyses. This measure of substrate composition significantly correlated with several stream measures, including entrenchment and sinuosity. Conductivity was significantly correlated with $\mathrm{pH}$, Total Dissolved Solids, entrenchment, and reach slope. In addition, average temperature, maximum temperature, and reach slope were significantly correlated. Given the known importance of temperature to the biology of T. tubifex and spore production, we included temperature (versus slope) in the analyses. To examine what stream reach characteristics described the presence of infection, we excluded correlated predictor variables and included the following variables: (1) maximum summertime temperature, (2) substrate less than $0.84 \mathrm{~mm}$, (3) width/depth ratio, and (4) conductivity (Table 2). 


\begin{tabular}{lccccccccc}
\hline \multicolumn{1}{c}{ Stream } & $\begin{array}{c}\text { Mean } \\
\text { lesion } \\
\text { score }\end{array}$ & $\begin{array}{c}\text { Percent } \geq \\
\text { grade } 3 \\
\text { infected }\end{array}$ & $\begin{array}{c}\text { Presence/ } \\
\text { non-detect }\end{array}$ & Sinuosity & $\begin{array}{c}\text { Channel } \\
\text { type }\end{array}$ & $\begin{array}{c}\text { Percent } \\
\text { watershed } \\
\text { forested }\end{array}$ & $\begin{array}{c}\text { Percent } \\
\text { valley } \\
\text { slope }\end{array}$ & $\begin{array}{c}\text { Stream } \\
\text { order }\end{array}$ & $\begin{array}{c}\text { Valley } \\
\text { type }\end{array}$ \\
\hline Johnson & 0 & 0 & 0 & 1.1 & $\mathrm{~B} 4$ & 75.8 & 8.6 & 2 & II \\
E.Twin & 0 & 0 & 0 & 1.1 & $\mathrm{C} 4$ & 73.4 & 7.7 & 2 & II \\
W.Twin & 0 & 0 & 0 & 1.3 & $\mathrm{C} 4$ & 92.6 & 5 & 3 & II \\
Bear & 0 & 0 & 0 & 1.6 & $\mathrm{C} 4 \mathrm{~b}$ & 86.8 & 5.7 & 2 & VI \\
Gold & 0 & 0 & 0 & 1.4 & $\mathrm{C} 3$ & 90 & 1.4 & 3 & V \\
Belmont & 2.48 & 48.5 & 1 & 1.0 & $\mathrm{~B} 4$ & 95.1 & 1.3 & 3 & V \\
Elk & 4.82 & 95.3 & 1 & 1.8 & $\mathrm{E} 4$ & 83.1 & 0.4 & 3 & VIII \\
Blanchard & 0 & 0 & 0 & 1.3 & $\mathrm{C} 4$ & 88.9 & 3 & 2 & VI \\
Cottonwood & 3.78 & 100 & 1 & 1.1 & $\mathrm{C} 3$ & 77.4 & 0.7 & 3 & VIII \\
Monture & 4.81 & 96.9 & 1 & 1.5 & $\mathrm{C} 3$ & 74.6 & 0.7 & 4 & VIII \\
Arrastra & 0.02 & 0 & 0 & 1.3 & $\mathrm{C} 4$ & 86.4 & 1.2 & 2 & V \\
Chamberlain & 3.78 & 78 & 1 & 1.1 & $\mathrm{C} 4$ & 95 & 2.1 & 2 & VI \\
Landers & 0 & 0 & 0 & 1.2 & $\mathrm{C} 4$ & 87.3 & 0.9 & 4 & V \\
Fork & & & & & & & & & \\
\hline
\end{tabular}

Table 1. Variables used in the landscape scale analyses. Valley slope and valley type are correlated and were not included in the same analysis.

\begin{tabular}{|c|c|c|c|c|c|c|}
\hline Stream & $\begin{array}{c}\text { Presence/ } \\
\text { non-detect }\end{array}$ & $\begin{array}{l}\text { Width/Depth } \\
\text { ratio }\end{array}$ & $\begin{array}{l}\text { \% substrate } \\
<0.084 \mathrm{~mm}\end{array}$ & Conductivity & $\begin{array}{c}\text { Mean Temp }{ }^{\circ} \mathrm{C} \\
\text { (July/Aug) }\end{array}$ & $\begin{array}{c}\text { Max Temp }{ }^{\circ} \mathrm{C} \\
\text { (July/Aug) }\end{array}$ \\
\hline Johnson & 0 & 9.5 & 7.9 & 39 & 10.3 & 13.7 \\
\hline E. Twin & 0 & 11.5 & 5.9 & 18 & 11.8 & 14.8 \\
\hline W. Twin & 0 & 10.8 & 5.3 & 9 & 11.8 & 15.6 \\
\hline Bear & 0 & 14.4 & 5.9 & 82 & 11.2 & 17.5 \\
\hline Gold & 0 & 20.3 & 11 & 162 & 13.0 & 18.7 \\
\hline Belmont & 1 & 34.2 & 9.2 & 258 & 13.2 & 18.3 \\
\hline Elk & 1 & 11.2 & 29.1 & 230 & 13.9 & 20.6 \\
\hline Blanchard & 0 & 33.3 & 6.3 & 95 & 14.9 & 18.3 \\
\hline Cottonwood & 1 & 17.6 & 11.3 & 220 & 11.8 & 20.9 \\
\hline Monture & 1 & 48.0 & 12.1 & 135 & 14.7 & 20.6 \\
\hline Arrastra & 0 & 34.1 & 9.3 & 159 & 10.1 & 14.4 \\
\hline Chamberlain & 1 & 19.2 & 6.6 & 67 & 13.9 & 19.4 \\
\hline $\begin{array}{l}\text { Landers } \\
\text { Fork }\end{array}$ & 0 & 27.3 & 6.5 & 204 & 11.5 & 17.1 \\
\hline
\end{tabular}

Table 2. Variables used in the reach scale presence/non-detect analyses. 
Finally, we used similar analytical techniques to examine how much variation in whirling disease presence could be described by the invertebrate community indices. There are many potential indices to describe the invertebrate community; we focused on those that were linked to ecological mechanisms and we excluded highly correlated indices. We included cold stenotherm richness, EPT richness, sediment sensitive richness, and sediment tolerant richness in analyses to investigate how well invertebrate community indices describe variation in whirling disease.

When we examined the landscape predictors to the presence of infection (Table 1), the classification and regression tree analysis predicted infection

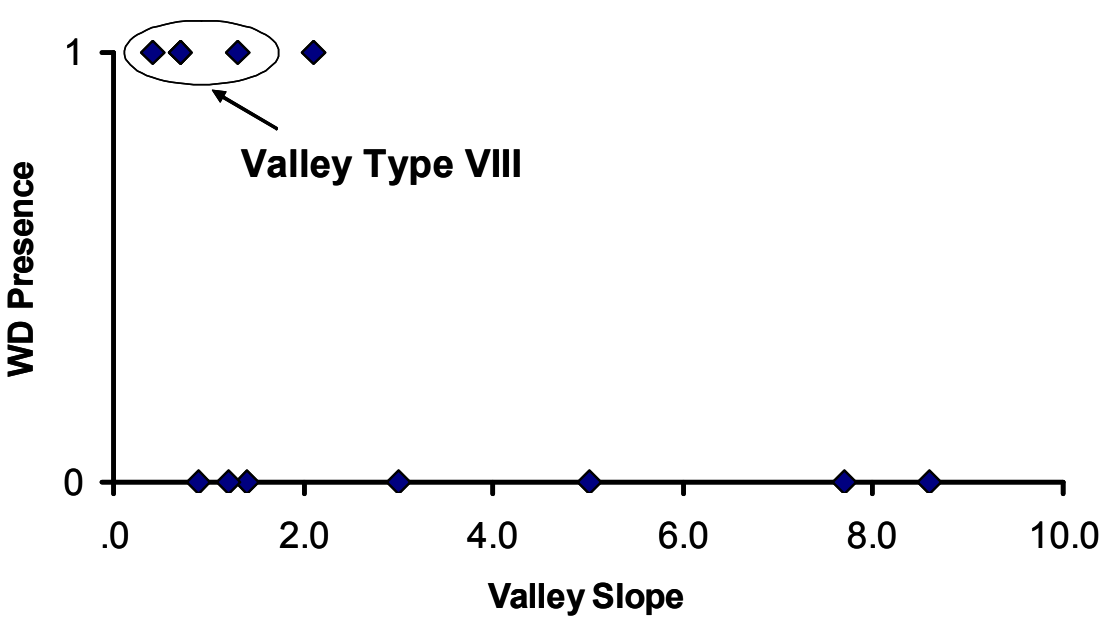

Figure 2. Plot of the whirling disease detection associated with valley slope and valley type.

presence based on percent valley slope (if valley slope is $<0.8$ present). In this Blackfoot River Basin dataset, if the valley slope is less that 0.8 then it is also a Valley type 8 (Rosgen classification). These valley types are characterized by wide, gentle valley slopes with welldeveloped floodplain adjacent to river or glacial terraces typically containing alluvial valley fill (Rosgen 2006). This analysis misclassified two tributaries, where there was a predicted nondetect when in fact infection was present. The misclassified tributaries were Chamberlain Creek (valley type 6, valley slope 2.1) and Belmont Creek (valley type 5, valley slope 1.3); although these two streams had higher slopes they did have warm summertime temperatures (max temp $>$ $18^{\circ} \mathrm{C}$ ). In this data set, valley type is significantly correlated with valley slope, channel slope, temperature, and percent of substrate less than $0.84 \mathrm{~mm}, \mathrm{pH}$, conductivity and Total Dissolved Solids. Results from the logistic regression were consistent with the CART analysis that valley slope was the only parameter not excluded from the final model (valley slope $p=0.022,67 \%$ misclassification, Figure 2).

In our analyses examining which reach level variables were linked to infection, the CART model predicted infection in streams with maximum summertime temperatures above $19.02^{\circ} \mathrm{C}$ and the only misclassified tributary was Belmont Creek (maximum temp $<19.02^{\circ} \mathrm{C}$ but infection present). Two different logistic regression models correctly classified all of the streams with two predictor variables: maximum temperature and conductivity or maximum temperature and width/depth ratio. The best individual predictor of disease presence was maximum summertime temperature (Figure 3). Not surprisingly, there was a significant correlation between our landscape level (valley slope) and several reach level variables (maximum temperature Pearson Correlation $\mathrm{R}=-0.74, \mathrm{p}=0.006$; fine sediment $<0.8 \mathrm{~mm} \mathrm{R}=0.585, \mathrm{p}=0.046$; and Total Dissolved Solids $\mathrm{R}=-0.806, \mathrm{p}=0.002$ ). 

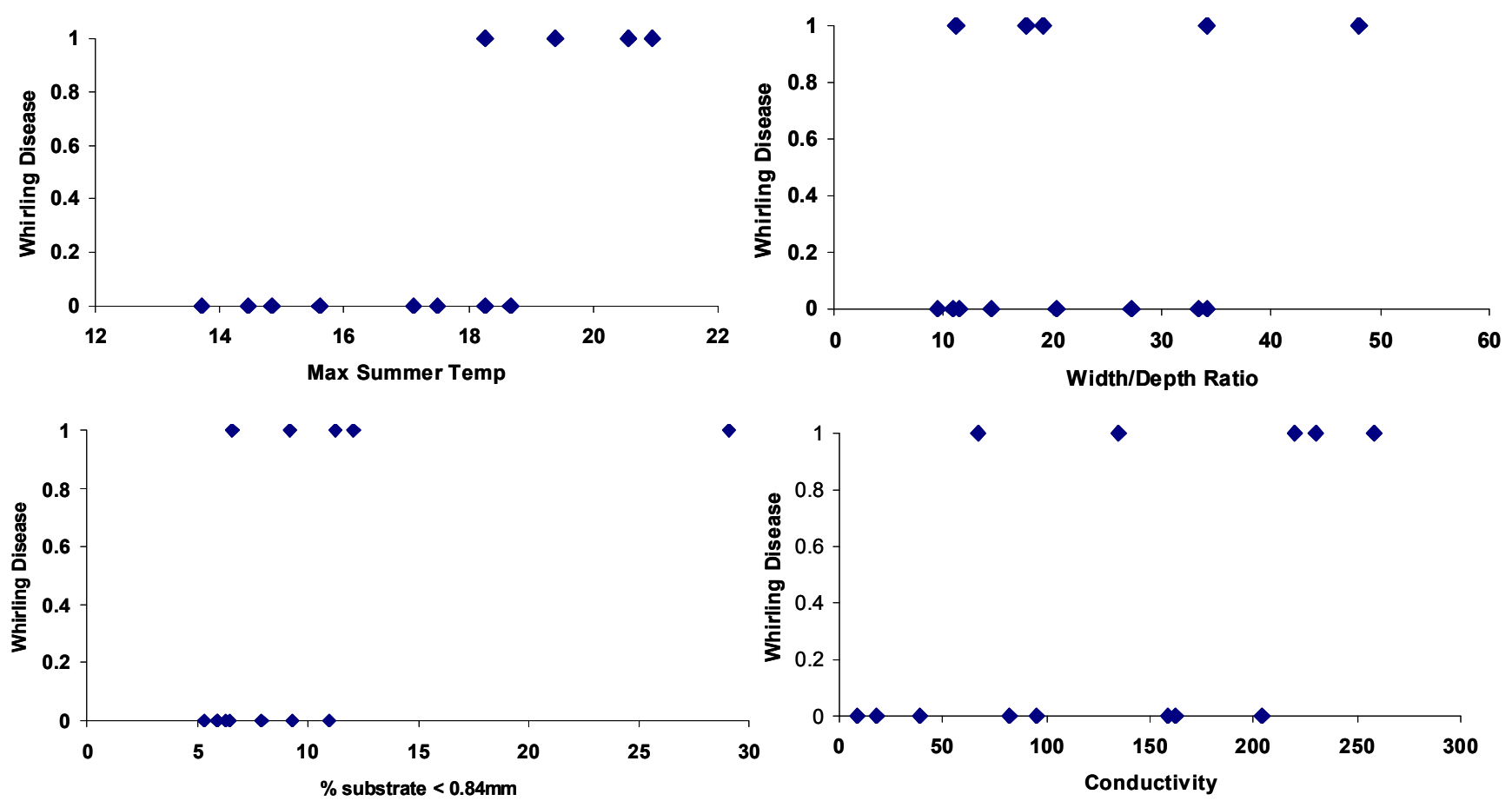

Figure 3. Scatterplots of the variables that were significant predictors of infection presence at the reach scale from the logistic regression analysis. A whirling disease score of 1.0 indicates detection and 0 indicates infection was not detected in the stream.

Sixty-seven EPT taxa were identified in the samples and a total of 10,644 EPT individuals were present. Several taxa were collected in more than one stream and exclusively in streams with no infection, including Drunella spinifera (2 sites), Caudatella edmundsi (2 sites), Epeorus longimanus (5 sites), Epeorus deceptivus (2 sites), Rhithrogena sp. (4 sites), Ironodes sp. (2 sites) Baetis alius (2 sites), Baetis flavistriga (2 sites), Visoka cataractae (2 sites), Calineuria californica (2), Megarcys signata (4 sites), Parapsyche elsis (4 sites), Agraylea sp. (2 sites), Lepidostoma unicolor (4 sites), Rhyacophila alberta (3 sites). The CART model predicted the presence of infection in streams with cold stenotherm richness of less than 6 species. This model misclassified 3 of the 13 streams, with Belmont incorrectly classified as a nondetect stream and Gold and Blanchard incorrectly classified as streams with infection. The logistic regression model indicated that we could correctly classify 12 of our 13 streams with two predictor variables: EPT species richness and cold stenotherm species richness. In this analysis, Belmont Creek was the only stream incorrectly classified (Figure 4).

\begin{tabular}{ccccc}
\hline Tributary & $\begin{array}{c}\text { Cold } \\
\text { Stenotherm } \\
\text { Richness }\end{array}$ & $\begin{array}{c}\text { Sediment } \\
\text { Sensitive } \\
\text { Richness }\end{array}$ & $\begin{array}{c}\text { EPT } \\
\text { Richness }\end{array}$ & $\begin{array}{c}\text { Sediment } \\
\text { Tolerant } \\
\text { Richness }\end{array}$ \\
\hline Arrasta & 7 & 3 & 30 & 0 \\
Belmont & 7 & 2 & 29 & 0 \\
Blanchard & 5 & 4 & 30 & 0 \\
Chamberlain & 5 & 4 & 39 & 2 \\
Cottonwood & 1 & 3 & 26 & 1 \\
East Twin & 12 & 4 & 21 & 0 \\
Elk & 1 & 4 & 34 & 2 \\
Gold & 2 & 2 & 26 & 1 \\
Johnson & 8 & 1 & 33 & 0 \\
Landers Fork & 7 & 3 & 29 & 2 \\
Monture & 2 & 2 & 33 & 0 \\
West Twin & 10 & 3 & 29 & 2 \\
\hline
\end{tabular}

Table 3. Indices developed from the invertebrate data and used in analyses 


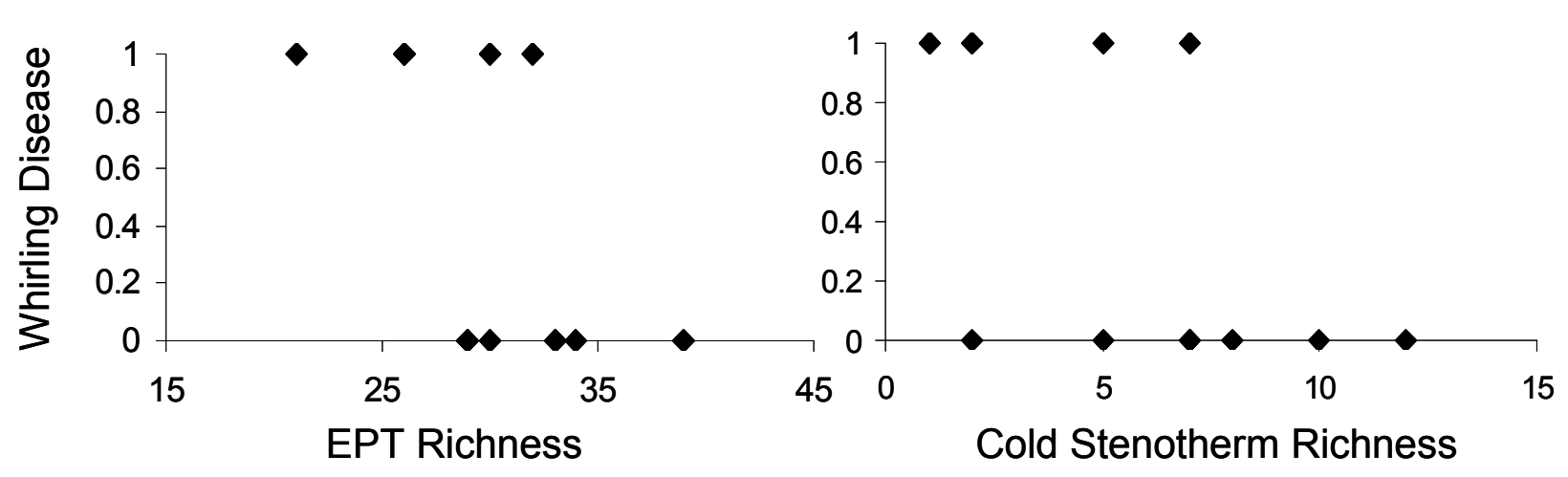

Figure 4. Scatterplots of the invertebrate variables that were significant predictors of infection presence from the logistic regression analysis. A score of 1.0 indicates infection present and 0 indicates infection was not detected or has a mean histological score of $<0.05$.

\section{Discussion}

Our study failed to detect infection of $M$. cerebralis in rainbow trout in colder high gradient streams but identified high infection rates in lower-gradient broader valley environments. These findings are consistent with down-valley morphological transitions of stream valleys and channel-types (Rosgen 1996) and a central tenet of stream ecology that abiotic conditions and biotic communities change predictably along longitudinal (upstreamdownstream) gradients (Vannote et al. 1980). In western Montana watersheds, channel features often transition in a predictable downstream path from steep cold streams to broader alluvial valleys. However due to basin heterogeneity, stream environments conducive to infection such as those in the Blackfoot Basin also vary substantially at a reach and sub-basin scales. In contrast to the lower Blackfoot Basin, the middle Blackfoot Basin includes many tributary environments suitable to T. tubifex, high TAM exposure and higher infection rates.

In our analysis of landscape variables, environments conducive to infection in fish were found in broad valleys with gentle, down-valley elevation relief (Valley type 8, Rosgen 1996). In the down-valley continuum of Rosgen channel-types, streams within these broad gentle valleys occupy are $\mathrm{C}$ and $\mathrm{E}$-type channels, which are slightly entrenched. In our study area, high infection rates were prevalent in meandering streams in broad valleys with gentle relief and warmer summer temperatures. Alluvial floodplains are the most predominant landforms, which can produce relatively high sediment supply. Soils are developed over alluvium, thus, streams in this valley are susceptible to accelerated bank erosion. In our study area, these streams are also prone to anthropogenic activities that elevate sediment and water temperature levels (Pierce et al 2006). By contrast, mountain streams of the lower Blackfoot Basin support lower temperatures, lower in-channel sediment levels within spawning areas, and low infection rates. These streams occupy steep forested valleys, narrow floodplains with moderate side-slopes formed primarily of colluvium.

At the reach scale, we had a strong positive correlation with infection and water temperature, similar to other studies (Hiner and Moffitt 2002, de la Hoz Franco and Budy 2004). This was expected given the entire life cycle of the parasite in both the fish and worm host is temperature dependant and natural outbreaks occur during temperatures optimal to the parasite (MacConnell and Vincent 2002). Summertime temperatures identify conditions favorably for spore TAM production and release, and thus the potential of a stream to support a high infection rates. Temperature also influence fish growth, development and immune response, all of which may influence the degree to which fish are susceptible to the development of the disease 
(MacConnell and Vincent 2002). Maximum annual water temperature also provides a simple and direct method of comparison to the other basins (De la Hoz Franco and Budy 2004).

Similar to other studies, we found a relationship with conductivity (in addition to temperature), the only water quality parameter correlated to disease severity in Oregon (Sandell et al. 2001). Although Sandell et al. (2001) provide a potential mechanistic explanation associated with conductivity influencing TAM recognition of living tissue, in our study conductivity is significantly correlated with Total Dissolved Solids, entrenchment, slope, and geometric mean sediment size. Therefore, high conductivity is indicative of stream reaches with low gradient channels, more fine sediments, greater entrenchment and higher Total Dissolved Solids. We did not find that stream size using bankfull area or stream-order as potential surrogates for discharge explained a significant amount of the variation in the occurrence of infection. But in a similar study, both water temperature and discharge were positively correlated with infection (de la Hoz Franco and Budy 2004). In the Blackfoot Basin, the variable geology influences the formation of large, cold-water bodies with very low incidence of infection. The results from analyses of our invertebrate indicators corroborate results from the analyses of abiotic factors. Cold stenotherm species richness classified infection fairly well in the CART analysis and EPT richness and cold stenotherm species richness predicting the presence of infection in the regression analyses.

Developments of high severity have been shown in areas of natural and man-made impoundments (Hiner and Moffit 2002), both of which are present in our study area and likely influence infection. Impoundments and can affect community structure of macroinvertebrates trap fine sediment and organic matter and increase warming and thus create optimal conditions for T. tubifex. These conditions can lead to the production and release of TAMs from infected worm populations. Both Belmont and Chamberlain Creeks have ponds (either man-made or beaver) upstream of the sentinel cage sites. Throughout this study Belmont was an outlier, a cold stream with whirling disease. The Belmont basin consists of $92 \%$ private industrial forest with 6.4-miles of logging roads per mile ${ }^{2}$, which once generated an estimated 200 tons/year of fine sediments from roads alone (Sugden, 1994). This combination of elevated sediment trapped in areas of increased recent beaver activity is likely creating this outlier "hot spot" condition for infection.

Management Implications - As we begin to better understand the environmental factors that influence infection, we can begin to predict areas that we expect to be naturally prone to having severe impacts of the disease. Reach scale variables imply that within certain watersheds we might manage the potential impacts of disease by protecting and restoring habitat in tributary spawning and rearing areas to minimize factors that favor habitat of $T$. tubifex (e.g. sediment) or otherwise increase whirling disease (e.g., temperature). In our study area, infections were identified in meandering streams in broad valleys with gentle relief and warmer summer temperatures. In western Montana, environments of this type are often prone to excessive grazing and other land-use activities that potentially elevate water temperatures and instream sediment levels. Zendt and Bergerson (2000) found the highest relative abundance of T. tubifex in areas where riparian zones were heavily disturbed.

Our study further suggests that anthropogenic warming or increases in sediment supply may increase infection (and severity) and shift disease distribution (and effects) in the upstream direction. For example, Monture Creek has been identified as the primary rainbow trout spawning tributary to the Blackfoot River. Water temperature monitoring beginning in 1993 has shown a $>1{ }^{\circ} \mathrm{C}$ increase in maximum annual temperatures. Relative influences of regional trends versus anthropogenic influences driving this temperature change are unclear as confounding factors such as habitat degradation of riparian areas is occurring within the watershed, which is likely influencing several environmental conditions conducive infection rates. If the exposure potential shifts upstream, so will the likely impacts of the disease on various species that 
typically spawn higher in the watershed. While there is little we can do within the Blackfoot Basin to affect climate, land-management related water temperature changes may be able to reduce disease severity. If we can predict which streams are likely to be sites with high disease severity because of habitat degradation, we can develop and/or implement existing stream restoration techniques to correct human-related factors in areas that may contribute to severity. Examining the potential for restoration to prevent and/or reverse trends in disease severity is needed. In addition, a priori predictions may allow managers to change fishing regulations to decrease other sources of mortality that would allow these populations to better handle the stress of extra juvenile mortality resulting from whirling disease. Hopefully, this information will help us maintain self-sustaining wild salmonid populations in parasite positive streams.

\section{Conclusions}

Determining the physical variables correlated with infection is critical to understanding the spatial characteristics of the whirling disease impacts on fish populations. This study improves our ability to better predict the aquatic environments prone to infection. Understanding the environmental and spatial relationships within the watershed allow more concise interpretation of the effects on susceptible species, when considered within a context of overlapping life-histories for vulnerable species. The role of anthropogenic habitat degradation must also be considered in terms of combined effects of multiple threats including disease. Based on our study, increased water temperature appears to be coupled with infection. Habitat degradation often increases temperature, in which cases we can generally predict a higher infection rates.

\section{Acknowledgments}

We would like to acknowledge the USFS for sifting samples, NRCS and Blackfoot Challenge for funding the McNeil core samples, Northwestern Energy for funding field technicians Ryen Aasheim Anderson, Mike Davidson and Craig Podner, and the Whirling Disease Foundation for contributing funds to help complete this project. We would also like to thank Eileen Ryce for her review of this manuscript. 


\section{References}

Anderson, R.A. 2004. Occurrence and seasonal dynamics of the whirling disease parasite, Myxobolus cerebralis, in Montana spring creeks. Masters Thesis Montana State University Bozeman, MT.

Arndt, R.E., E.J. Wagner, Q. Cannon, and M. Smith. 2002. Triactinomyxon production as related to rearing substrate and diel light cycle. Pages 87-91 in J.L. Bartholomew and J.C. Wilson, editors. Whirling disease: reviews and current topics. American Fisheries Society, Symposium 29, Bethesda, Maryland.

Baldwin, T. J., E. R. Vincent, R. M. Silflow, D. Stanek. 2000. Myxobolus cerebralis infection in rainbow trout (Oncorhynchus mykiss) and brown trout (Salmo trutta) exposed under natural stream conditions. Journal of Veterinary Diagnostic Investigations 12:312-321.

Bartholomew, J.L. and P.W. Reno. 2002. The history and dissemination of whirling disease. Pages 3-24. in J.L. Bartholomew and J.C. Wilson, editors. Whirling disease: reviews and current topics. American Fisheries Society, Symposium 29, Bethesda, Maryland.

Breiman, L., J.H. Friedman, R.A. Olshen, and C.J. Stone. 1984. Classification and regression trees. Chapman and Hall, New York.

De la Hoz, E, and P. Budy. 2004. Linking environmental heterogeneity to the distribution of prevalence of Myxobolus cerebralis: a comparison across sites in a northern Utah watershed. Transactions of the American Fisheries Society. 133:1176-1189.

Downing, D.C., T.E. McMahon, B.L. Kearns, and E.R. Vincent. 2002. Relation of spawning and rearing life history of rainbow trout and susceptibility to Myxobolus cerebralis infection in the Madison River, Montana. Journal of Aquatic Animal Health 14:191-203.

El-Matbouli, M., T.S. McDowell, D.B. Antonia, K.B. Andree, and R.P. Hendrick. 1999. Effect of water temperature on the development, release, and survival of triactinomyxon stage of Myxobolus cerebralis in its oligochaete host. International Journal for Parasitology 29:627641.

Hiner, M., and C.M. Moffitt. 2001. Variation in Myxobolus cerebralis infections in fieldexposed cutthroat and rainbow trout in Idaho. Journal of Aquatic Animal Health 13:124132.

Hiner, M. and C.M. Moffitt. 2002. Modeling Myxobolus cerebralis infections in trout: associations with habitat variables. Pages 167-179. in J.L. Bartholomew and J.C. Wilson, editors. Whirling disease: reviews and current topics. American Fisheries Society, Symposium 29, Bethesda, Maryland.

Hoffman, G.L. 1990. Myxobolus cerebralis, a worldwide cause of salmonid whirling disease. Journal of Aquatic Animal Health 2:30-37.

Hubert, W. A. and six coauthors. 2002. Whirling disease among Snake River cutthroat trout in two spring streams in Wyoming. Whirling disease: reviews and current topics. American Fisheries Society Symposium 29:181-193.

Kearns, B.L., and A.V. Zale. 2002. The ecology of Myxobolus cerebralis. Pages 145-166. in J.L. Bartholomew and J.C. Wilson, editors. Whirling disease: reviews and current topics. American Fisheries Society, Symposium 29, Bethesda, Maryland.

Krueger, R.C., B.L. Kearns, E.R. Vincent, and C. Rasmussen. 2006. Risk of Myxobolus cerebralis infection to rainbow trout in the Madison River, Montana, USA. Ecological Applications 16:770-783.

Landolt, P, and M, Sartori. 1997. Ephemeroptera and Plecoptera: biology-ecology-sytematics.

MacConnell, E. and E. R. Vincent 2002. Review: the effects of Myxobolus cerebralis on the salmonid host. Pages 95-108 in J. L. Bartholomew and J. C. Wilson, editors. Whirling disease: reviews and current topics. American Fisheries Society, Symposium 29, Bethesda Maryland. 
Merritt, R. W., K. W. Cummins and M. B. Berg, eds. 2008. An Introduction to the Aquatic Insects of North America, Fourth Edition. Kendall/Hunt Publishing Company. Dubuque, Iowa. $x i+1158 \mathrm{p}$.

Modin, J. 1998. Whirling disease in California: A review of its history, distribution, and impacts, 1965-1997. Journal of Aquatic Animal Health 10:132-142.

McNeil, W.J. and W.H Ahnell. 1964. Success of pink salmon spawning relative to size of spawning bed material. U.S. Fish and Wildlife Service Special Scientific Report Fisheries 469.

MWDTF (Montana Whirling Disease Task Force). 1996. Final report and action recommendations. Montana Whirling Disease Task Force, Helena, MT.

Nehring, B., and P. G. Walker. 1996. Whirling disease in the wild: the new reality in the intermountain west. Fisheries 21: 28-30.

Pierce., and R. Aasheim, and C. Podner 2005. An integrated stream restoration and native fish conservation strategy for the Big Blackfoot River Basin, Montana Fish, Wildlife and Parks, Missoula, MT.

Pierce, R., and C. Podner. 2006. The Big Blackfoot River Restoration Report for 2004 and 2005. Montana Fish, Wildlife and Parks. Missoula, MT.

Pierce, R., C. Podner, M. Davidson, and R. Vincent. In Review. Relationships of migratory (hybrid) rainbow trout spawning life histories to risk of Myxobolus cerebralis infection in the Blackfoot River Basin, Montana. In submission to Transactions of the American Fisheries Society.

Rosgen, D. 1996. Applied Fluvial Geomorphology. Wildlands Hydrology, Pagosa Springs Colorado.

Ryce, E. K. N, A. V. Zale and E. MacConnell. 2004. Effects of fish age and parasite dose on the development if whirling disease in rainbow trout. Diseases of Aquatic Organisms Vol. 59 (3):225-233.

Sandell, T. A., H. V. Lorz, D. G. Stevens, and J. L. Bartholomew. 2001. Dynamics of Myxobolus cerebralis in the Lostine River, Oregon: implications for resident and anadromous salmonids. Journal of Aquatic Animal Health 13:142-150.

Sauter, G., and H. Gude. 1996. Influence of grain size on the distribution of tubificid oligochaete species. Hydrobiologia 333:97-101.

Shepard, B. B., and P. J. Graham. 1982. Monitoring spawning gravel bed material used by bull trout on the glacier view district Flathead National Forest. Montana Fish Wildlife and Parks Completion Report.

Shepard, B., S. Leathe, T. Weaver, and M. Enk. 1984. Monitoring levels of fine sediments within tributaries to Flathead Lake and impacts of fine sediment to bull trout recruitment. Wild Trout III.

Smith, L. 1998. Study on the distribution and abundance of Tubifex tubifex within Cottonwood Creek in the Blackfoot drainage. Masters Thesis, University of Montana, Missoula, Montana.

Strahler, A.N. 1957. Quantitative analysis of watershed geomorphology. Transactions of the American Geophysical Union 38:913-920.

Sugden, B. 1996. Belmont Creek watershed analysis. Plum Creek Timber Company. Clearwater Unit, Missoula, MT.

Thorp, J. H. and A. P. Covich, eds. 2001. Ecology and classification of North American freshwater invertebrates (Second Edition). Academic Press. San Diego, California. xiii + $1056 \mathrm{p}$.

USGS. 2006. Gauging station 1234000 provisional unpublished data.

Vannote, R. L., G.W. Minshall, K.W. Cummins, JH. R. Sedell, and C.E. Cushing. 1980. The river continuum concept. Canadian Journal of Fisheries and Aquatic Sciences.; 37: 130-137. 
Venables, W.N. and B.D. Ripley. 1997. Modern applied statistics with S-PLUS (2 ${ }^{\text {nd }}$ edition). Springer, New York.

Vincent, E. R. 1996. Whirling disease and wild trout: the Montana experience. Fisheries 21 (6):32-33.

Vincent, E.R. 2000. Whirling disease report 1997-98. Montana, Fish, Wildlife and Parks. Project 3860. Helena, Montana.

Vincent, E. R. 2002. Relative susceptibility of various salmonids to whirling disease with emphasis on rainbow and cutthroat trout. Whirling disease: reviews and current topics. American Fisheries Society Symposium 29:109-115. Wolman, M. 1954. A method of sampling coarse river-bed material. Transactions of the American Geophysical Union 35:951-956.

Zendt, J. S. and E. P. Bergersen. 2000. Distribution and abundance of the aquatic oligochaete host Tubifex tubifex for the salmonid whirling disease parasite Myxobolus cerebralis in the upper Colorado River basin. North American Journal of Fisheries Management 20:502-512. 


\title{
Relationships of migratory (hybrid) rainbow trout spawning life histories to risk of Myxobolus cerebralis infection in the Blackfoot River Basin, Montana
}

\author{
Ron Pierce, Craig Podner, Michael Davidson and Richard Vincent, \\ Montana Fish, Wildlife and Parks
}

Abstract - The middle Blackfoot River Basin in western Montana is the site of a low-elevation whirling disease epizootic among rainbow trout (Oncorhynchus mykiss hybrids) caused by a recent invasion of the exotic parasite Myxobolus cerebralis. To assess exposure of Blackfoot River rainbow trout to the parasite, we investigated the spawning life histories of adult rainbow trout with respect to the distribution and severity of disease in spawning and rearing areas in two distinct reaches of the Blackfoot River. Radio-telemetry confirmed Blackfoot River rainbow trout migrate from wintering sites within the Blackfoot River to spawning tributaries. Over $90 \%$ of telemetered rainbow trout in the middle Blackfoot River spawned in a low-gradient, infected stream where fry emerged in early July during the vulnerable, highly infectious period. By contrast, spawning of lower Blackfoot River rainbow trout was dispersed among smaller, colder, higher gradient tributaries, most of which fell below disease detection levels. For fluvial rainbow trout risk of exposure varies at a sub-basin scale and relates to the geographical arrangement and properties of tributaries, including the longitudinal relationship of disease to spawning and early rearing areas. Prior to the invasion of M. cerebralis, the middle Blackfoot River was identified with recruitment-limitations caused by winter mortality and anthropogenic activities. Management implications suggest that riparian restoration and habitat enhancement with emphasis on migratory native fish within and upstream of infected waters may buffer effects of the disease.

Key words: Blackfoot River, rainbow trout, whirling disease, migration, movement patterns, tributary, and population risk

\section{Introduction}

Whirling disease (WD hereafter), a parasitic infection caused by the myxosporean Myxobolus cerebralis, has been associated with significant declines in wild rainbow trout (RBT hereafter) populations in certain streams in the western United States (Nehring and Walker 1996; Vincent 1996). WD was first detected in Montana in 1994 within the renowned Madison River following large and unexplained declines in RBT abundance. Soon thereafter, WD was described as one of the single greatest threats to wild trout (MWDTF 1996). Yet with time and the expansion of WD, it appears the influences of WD on interior populations of RBT are highly variable among watersheds (Nehring and Walker 1996, Modin 1998, Sandell et al. 2001). M. cerebralis has a complex, two-host life cycle involving the aquatic oligochaete worm Tubifex tubifex, and most salmonids, which include trout, whitefish and salmon. Susceptibility to disease depends on species (MacConnell and Vincent 2002), fish age and size (Ryce et al. 2005), and parasite dose at time of exposure (Vincent 2002). Young trout, particularly RBT, are most vulnerable when infected at less than nine weeks of age (Ryce et al. 2004). Coincidence between this vulnerable period and the release of the infective triactinomyxon (TAM) stage of the parasite largely determines the degree of exposure for young fish and, ultimately, the magnitude of population-level effects. High mortality and recruitment collapse can occur in highly exposed populations (Nehring and Walker 1996, but see Sandell et al. 2001).

Environmental conditions play an important role in the distribution of infection and level of severity within and among streams of the Blackfoot Basin. In Cottonwood Creek, a tributary to the middle Blackfoot River, Smith (1998) initially identified a longitudinal distribution with tubifex worms and WD absent from upper glacial valleys but abundant tubifex worms and a high severity of disease present in lower-valley stream reaches. More recently, 
water temperature, channel gradient and fine sediment were primary environmental predictors of WD presence within basin-fed streams of the Blackfoot Basin like Cottonwood Creek.

Although WD has resulted in very large population declines of RBT in certain Montana (Madison River - Vincent 1996, Baldwin et al. 1998) and Colorado Rivers (Nehring and Walker 1996), population effects are regionally variable. Previous studies of RBT vulnerability to WD in Montana have focused on the tailwater fishery of the Madison River where trout spawn in side-channels (Downing et al. 1999, Krueger et al 2006).

In western Montana, significant declines in RBT in Rock Creek, a large tributary to the upper Clark Fork River near Missoula, followed the introduction of WD (Montana Fish, Wildlife and Park, unpublished data). Likewise, RBT in lower Cottonwood Creek have declined 50\% from pre-WD estimates (Peters 1990, Smith 1998, Pierce et al. 2006). Both Rock Creek and lower Cottonwood Creek have experienced community-level shifts toward brown trout (Montana Fish, Wildlife and Parks, unpublished data), a species with partial WD resistant. These observations suggest some risk of population, or community-level, changes in the middle Blackfoot River where RBT declines are now being detected near infected RBT spawning tributaries. Predicting WD effects on RBT populations in western Montana requires assessing the juxtaposition of streams with high vulnerability to infection and the location of spawning and rearing sites.

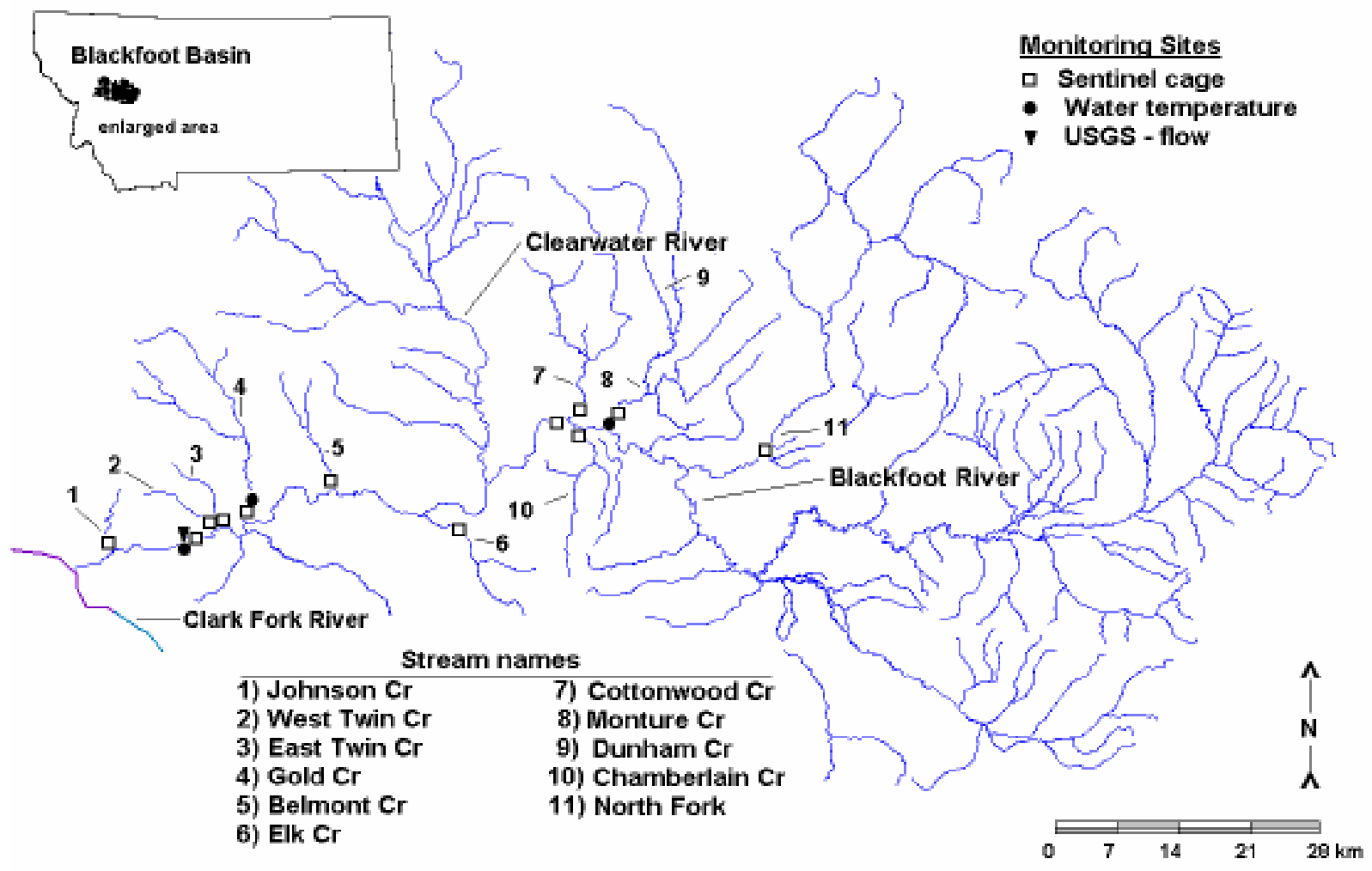

Figure 1. Study area: Blackfoot River Basin with sentinel cage, water temperature and Blackfoot River (USGS) discharge monitoring sites.

Previous studies identify Blackfoot River RBT reproduction within tributaries (Peters and Spoon 1989, FWP unpublished data); however, the relative importance of tributary stocks has not been evaluated, nor has the influence and spatial extent of possible WD effects upon fluvial RBT of the Blackfoot River. To investigate these questions, we assessed the overlap of 
fluvial RBT spawning sites with $M$. cerebralis infection in 10 spawning streams. Our study objectives were to: 1) identify the spawning life-histories of fluvial adult RBT of the Blackfoot River; 2) identify the relative use of spawning tributaries by fluvial stocks of the Blackfoot River; and 3) identify disease severity in spawning streams using sentinel exposures of age- 0 RBT. Our purpose is to assess disease risk for migratory RBT stocks for two reaches of the Blackfoot River, to gain a better understanding of fluvial RBT and to identify management measures that could buffer possible RBT declines within rivers of western Montana.

\section{Study Area}

The Blackfoot River, a $5^{\text {th }}$ order tributary (Strahler 1957) of the upper Columbia River, lies in west-central Montana and flows west $212 \mathrm{~km}$ from the Continental Divide to its confluence with the Clark Fork River in Bonner, Montana (Figure 1). The River drains a $5,998-\mathrm{km} 2$ heterogeneous watershed through $3,038 \mathrm{~km}$ of perennial streams and generates a mean annual discharge of $44.8 \mathrm{~m}^{3} \mathrm{~s}$ (United States Geological Survey 2006). The Blackfoot River flows freely to its confluence with the Clark Fork River where Milltown dam, a run-ofthe-river hydroelectric facility, has blocked upstream fish passage to the Blackfoot River since 1907. The physical geography of the watershed is geo-structurally controlled and regionally variable with subalpine forests dominating the high mountains, montane woodlands at the midelevations and semi-arid glacial (pothole and outwash) topography on the valley floor. Primary tributaries of the upper Blackfoot River (upstream of the Clearwater River) flow through a broad upper valley and alluvial bottomlands. Downstream of the Clearwater River, mountains constrict the Blackfoot River to a narrow canyon. With some exceptions, tributaries enter the lower Blackfoot River through a mountainous area with confined channels, steeper gradients and colder summer temperatures.

WD was first detected in the middle Blackfoot Watershed in 1995 in lower Cottonwood Creek. Since then, the disease has increased in distribution and severity. WD now infects the entire mainstem Blackfoot River and lower reaches of many tributaries (Pierce et al. 2006). Tributaries to the Blackfoot River provide spawning and rearing for migratory RBT, as well as other WD susceptible salmonids including bull trout (Salvelinus confluentus), westslope cutthroat trout (O. clarki lewisi), mountain whitefish (Prosopium williamsoni), brown trout (Salmo trutta) and brook trout (Salvelinus fontinalis) (Pierce et al. 2006).

Montana rivers are managed for a diversity of self-sustaining wild trout populations. Within the Blackfoot Basin, wild RBT are present at low-elevations, and population densities increase in the down-river direction (Pierce et al. 2006). Although RBT occupy only about $15 \%$ of the Blackfoot Basin, they comprise $\sim 70 \%$ of the trout community in the lower Blackfoot River. Below the mouth of the North Fork, RBT contribute to a high-value recreational fishery for the mainstem Blackfoot River supporting an estimated 26,817 anglers in 2005 (Montana Statewide Angling Pressure Estimates 2005).

For this study, we telemetered fluvial RBT from the Blackfoot River and examined life history and disease relationships up-and downstream of the mouth of the Clearwater River. The lower Clearwater River flows through a series of natural lakes causing high summer water temperatures $\left(>27^{\circ} \mathrm{C}\right)$, and seems to support very little, if any, RBT reproduction (Peters 1990, Pierce et al. 2002). This river demarcates the mid-point of rainbow trout distribution within the Blackfoot River RBT distribution, and separates the Blackfoot Basin into two general subbasins based on physical differences of tributaries. The lower reach of the Blackfoot River (R1 hereafter) extends from Clearwater River confluence $55.8 \mathrm{~km}$ downstream to the Blackfoot River confluence with the Clark Fork River. Except for the upper-most tributary to R1 (Elk Creek), RBT spawning tributaries originate in a mountainous region and tend toward smaller (second and third-order), higher gradient streams with colder summer temperatures. Conversely, Elk Creek, a low-gradient stream within an agricultural valley, supports elevated 
summer temperatures and high instream levels of fine sediment (Pierce et al. 2006). The Blackfoot River between the confluence of the Clearwater River and North Fork Blackfoot River (R2 hereafter) has RBT spawning tributaries that are fewer but generally larger (third and fourth-order), flow within wider channels, have broader floodplains with lower gradients and support warmer summer temperatures. An exception is the North Fork, a stream of wilderness origin that is larger and colder than all other R2 tributaries (Pierce et al. 2006).

\section{Methods}

Radio-telemetry - We assessed migration patterns, relative use of tributaries, timing of migration events and location of RBT spawning using radio-telemetry. Twenty-five RBT were captured in the lower Blackfoot River, phenotypically identified as RBT and implanted with continuous (12 hour on/off) Lotek ${ }^{\mathrm{TM}}$ radio transmitters on 8 March $2004(n=4)$, between 28 February - 8 March $2005(n=10)$ and $7-22$ March $2006(n=11)$ and tracked to spawning areas within tributaries. These fish ranged from 34.0 to $49.0 \mathrm{~cm}$ in total length (mean, 41.4) and from 408 to $1,270 \mathrm{~g}$ in weight (mean, 680). We selected larger "plump" female fish (based on absence of a kype) to increase the likelihood that telemetered fish were sexually mature, and to more accurately identify the timing and location of spawning events. Visual identification was later verified for the 21 of the 25 fish collected in 2005-06 through genetic analysis of fin clips using 17 fragments of nuclear DNA at the University of Montana, Trout and Wild Salmon Genetics Laboratory (Boecklen and Howard 1997).

Transmitters were evenly distributed among fish in the lower $35.4 \mathrm{~km}$ of R1 $(n=12)$; whereas telemetered fish were captured only in a 6.4-km section in R2 $(n=13)$ due to shelf ice and limited river access. Fish were captured prior to spawning migrations (by electro-fishing) in suspected wintering pools. Individually coded transmitters weighed $7.7 \mathrm{~g}$, had an estimated life of 450 days, emitted an individual coded signal, did not exceed 2 percent of fish weight (Winters 1997), and were implanted following standard surgical methods (Swanberg 1999).

Technicians located telemetered fish on foot using a hand held three-element Yagi antenna or by truck using an omni-directional whip antenna. We located fish weekly prior to migrations, 2-3 times per week during migrations and spawning, once per week following spawning and generally once per month thereafter.

We recorded upstream movements by river kilometer. We assumed fish spawned if they ascended a stream with suitable spawning habitats during the spring spawning period, and the upper-most location was the assumed spawning site. We estimated spawning dates as the median date between two contacts for a given event (i.e. spawning or migration) (Swanberg 1997). Peak spawning among spawners was identified as the median spawning date. We assumed the reach influenced by whirling disease extended from wintering locations to spawning sites.

Water temperature and flows - Water temperatures and flows were measured in the Blackfoot River to assess their influences on RBT migrations. Thermographs (Onset ${ }^{\mathrm{TM}}$ ) were placed (2005-06) at rkm 12.7 at the U.S. Geological Survey gauging station (guage number: 12345000). We used both mean daily discharge and temperature to examine potential relationships with RBT movements. Onset thermographs were placed in lower Gold (2005-06) and Monture creeks (2004-06) where mean daily temperatures were calculated to identify relationships of tributary movements and spawning. To predict the timing of fry emergence for Gold and Monture Creeks, we calculated the incubation period using a $350^{\circ} \mathrm{C}$ degree-day span (Piper 1982), beginning at the estimated spawning date for each individual fish that spawned in Gold and Monture Creeks, and emergence was estimated at three weeks posthatch. All thermographs recorded at 48-minute intervals. 
Analyses of life histories - To test the potential influence of introgression on movement patterns, we compared the start date of migration and the total pre-spawning migration distance between hybrids, and "pure" RBT using Mann-Whitney rank sum tests. For the total group, we used linear regressions to assess potential associations between the start date of migration and distance to spawning sites; the total duration (days) and total distance $(\mathrm{km})$ of migrations ; and the date spawners returned to the River and the total migration period (days). We used Kruskal-Wallis (ANOVA) on ranks to assess tributary size (i.e. stream-order) and the date of entry to a spawning stream and days spent within a tributary. For reach-stratified spawners, we used Mann Whitney rank sum tests to analyze the start of migration, dates RBT entered tributaries and the upstream distance to spawning sites upon entering a tributary, estimated spawning dates and dates RBT exited tributaries. All tests were evaluated at the $\alpha=0.05$ level of significance.

WD infection

and severity - We conducted sentinel exposures of 50 hatchery RBT fry (age-0 cohorts) at known RBT spawning sites in 10 streams to identify WD severity in individual streams and the spatial variation of $M$. cerebralis among tributaries (Figure 1). These fish were exposed at 98-103 days post-hatch at mean length of $36 \mathrm{~mm}$ in 2005 and $45 \mathrm{~mm}$ in 2006. Exposures were completed in July within 9 weeks of the estimate post-hatch period for wild fish. This timing coincides with high RBT susceptibility (Ryce et al. 2004), estimated emergence of wild RBT fry and the corresponding peak TAM production period within rivers of western Montana (Vincent 2000) including the Blackfoot Basin (Fish, Wildlife and Parks, unpublished data).
Flow $\left(M^{3} S\right)$

Temperature (C)

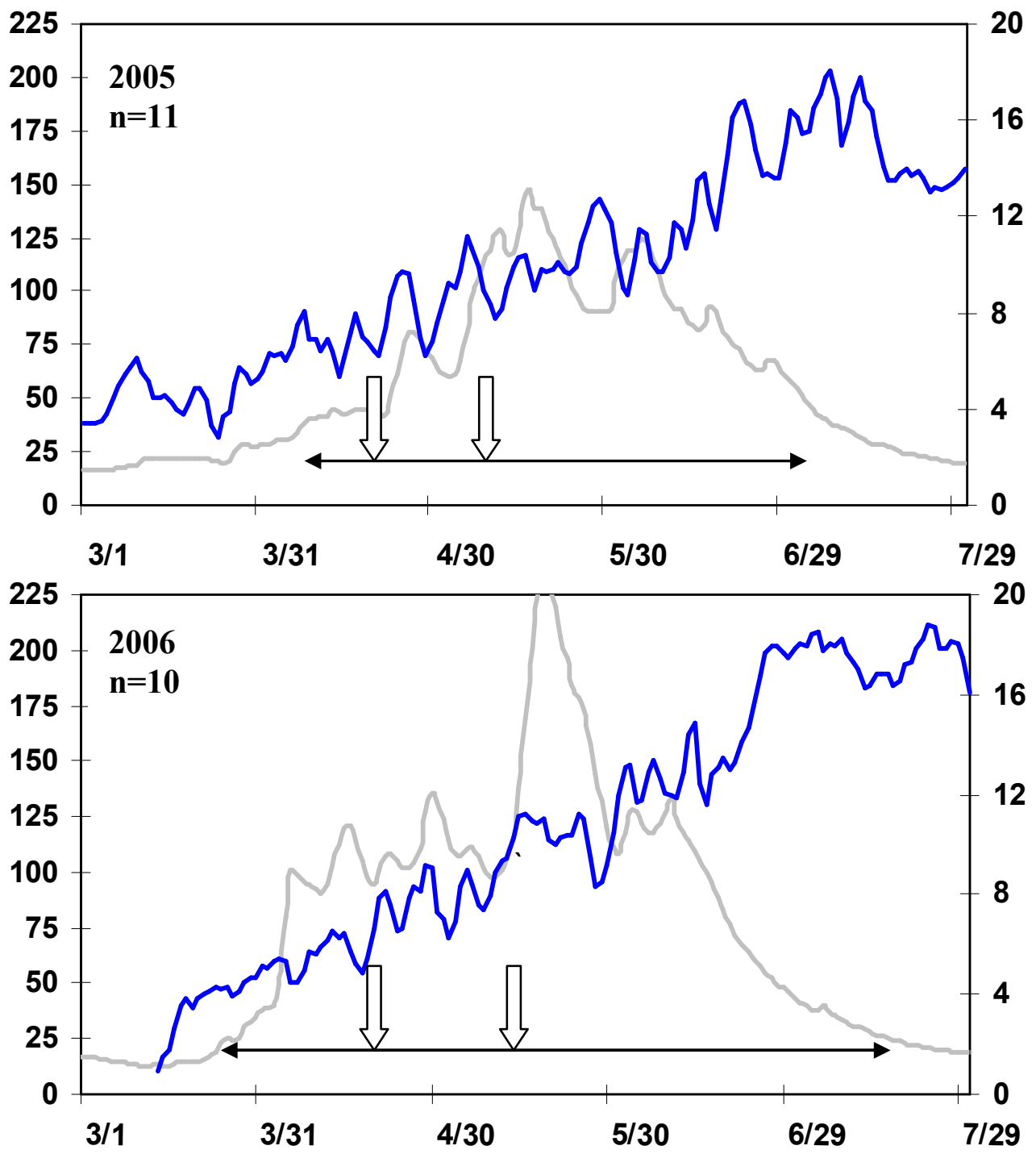

Figure 2. Blackfoot River: Mean daily flow (left axis - gray line) and mean daily water temperatures (right axis - dark line) during rainbow trout spawning migration. The total migration period is shown by the arrowed horizontal lines. The vertical arrows show median dates spawners entered and exited tributaries. 
The exposure period for each live cage was standardized at 10 days. At the end of that time, fry were transferred to Pony, MT, where they were held for an additional 80 days at a constant $10{ }^{\circ} \mathrm{C}$ to ensure that WD, if present, would reach maximum intensity (Vincent 2000). At the end of the holding period, all surviving fish were sacrificed and sent to the Washington State University Animal Disease Diagnostic Laboratory at Pullman, WA. At the lab, fish heads were examined histologically and scored using the MacConnell-Baldwin grading scale, which ranks whirling disease from 0 (absent) to 5 (severe) (Baldwin et al. 2000). Sentinel exposures were considered severe if a majority (\%) of exposed RBT had histological (lesion) scores of $\geq 3$ on the MacConnell-Baldwin scale. Lesion scores $\geq 3$ are determined by severe cartilage damage and a dispersed inflammatory response that occurs in infected fish (Baldwin et al. 1998).

\section{Results}

Migratory life histories and spawning - For 25 telemetered RBT, we made a total of 1,594 contacts with an average of 64 contacts (range: 12-129) per fish. All 25 RBT were successfully tracked to spawning tributaries from March 2004 to December 2006 (Table 1). Fourteen of twenty fish that underwent genetic analysis tested as post-F 1 RBT hybrids with westslope cutthroat trout having a predominant rainbow trout genetic contribution; the remaining six tested as genetically unaltered rainbow trout (Leary 2005, 2006). Four migrants captured in 2004 that later entered Monture Creek $(n=3)$ and the North Fork $(n=1)$ were untested. There were no significant differences between hybrid and "pure" RBT for either start (date) of migration (Mann Whitney, $\mathrm{P}=0.78$ ) or the total pre-spawning distance moved (Mann Whitney, $\mathrm{P}=0.56$ ).

River temperatures and flows incrementally increased during the (20042006) RBT pre-spawning migrations. In these years, migrations began between 19 March and 15 April on the rising limb of the

Temperature (C)
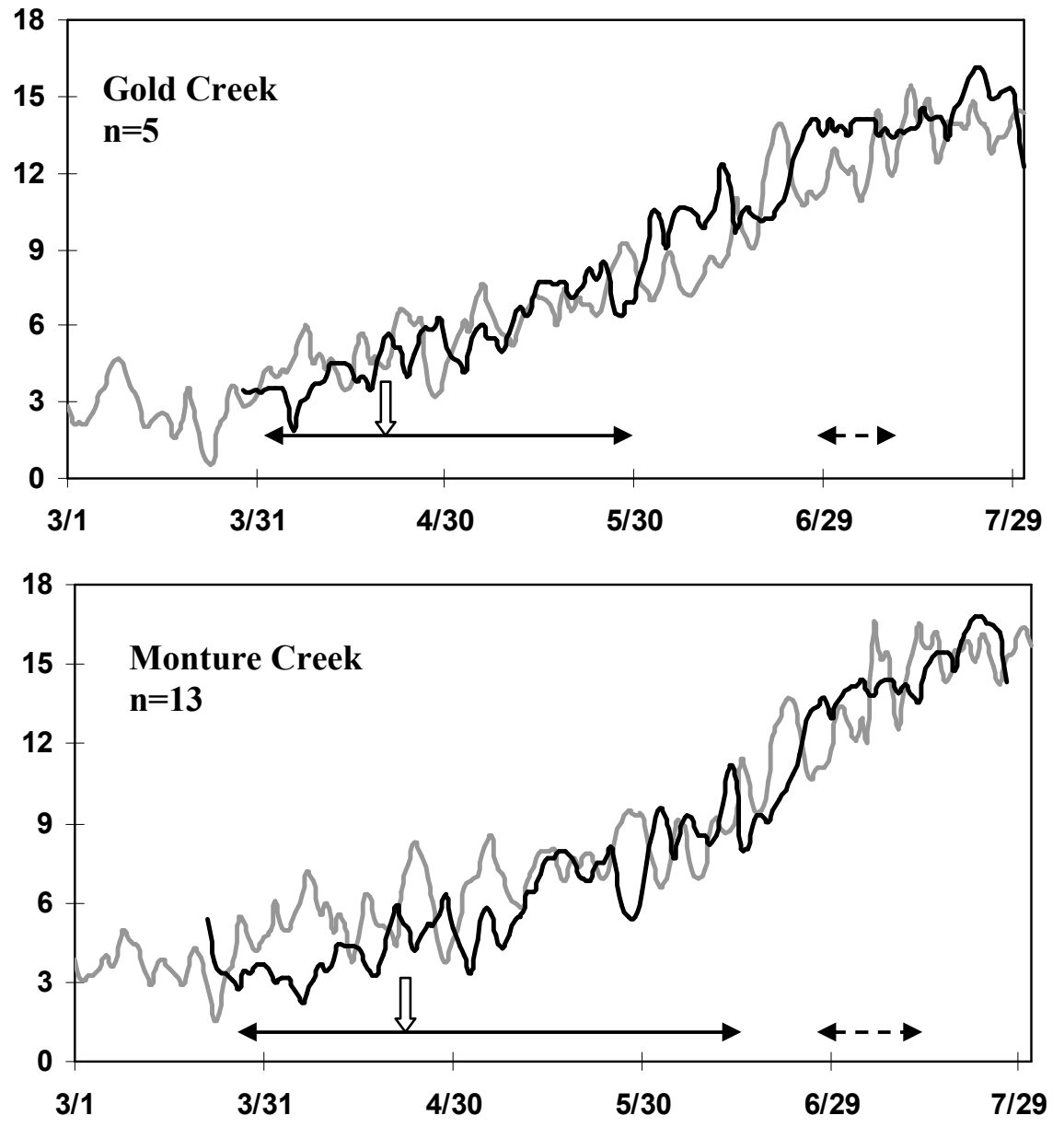

Figure 3. Water temperatures for Gold (top) and Monture Creeks in 2005 (gray) and 2006 (black). Duration within tributaries (2004-06) and the estimated emergence periods for 18 spawners are shown by arrowed left and right horizontal lines, respectively. The median spawning date for the tributary is shown by vertical arrows. hydrograph as mean daily temperatures approached $5^{\circ} \mathrm{C}$ (Figure 2). With the onset of 
migration, twenty-four RBT moved up-river and one moved down-river. In nine days telemetered RBT traveled a median of $6.8 \mathrm{rkm}$ to their respective spawning tributary. RBT from R1 moved a (median) distance of $10.0 \mathrm{rkm}$ (range $0.5-56.8$ ) compared to $6.6 \mathrm{rkm}$ (range 2.7-21.4) for R2.

For the total group, there was no relationship between the date migrations began and the total distance to spawning sites (linear regression, $\mathrm{R}^{2}=0.008, \mathrm{P}=0.89$ ). However, $\mathrm{RBT}$ with longer pre-spawning distance (start locations and spawning sites) underwent migrations of longer duration (linear regression, $\mathrm{R}^{2}=0.20, \mathrm{P}=0.04$ ), and $\mathrm{RBT}$ returned to the river later than fish exhibiting movements of shorter duration (linear regression, $\mathrm{R}^{2}=0.36, \mathrm{P}=0.003$ ).

Spawners spent an average of 17 days (range, 3-63) in tributaries and ascended a median of $3.0 \mathrm{~km}$ (range, $0.2-19.8$ ) to their spawning grounds where they held for an average of six (range 1-14) days before returning to the Blackfoot River. We observed that R2 fish migrated significantly farther up tributaries (median, 7.1 versus $1.0 \mathrm{~km}$ ) to spawning sites than $\mathrm{R} 1$ fish (Mann Whitney, $\mathrm{P}=0.005$ ). Based on the distance between winter pools and spawning sites, fish moved a (median) distance of $12.1 \mathrm{rkm}$ for the total group, and a median of 10.6 (range 1.1 - 63.2) rkm for R1 fish compared to 12.6 (range 6.0 - 27.5) for R2 fish.

Migration events began slightly earlier and ended later for R2 fish although these differences were not statistically significant. RBT from the R2 began their migrations eight days earlier (median, 9 April versus 17 April; Mann Whitney, $\mathrm{P}=0.17$ ), entered tributaries nine days earlier (median, 17 April versus 26 April; Mann Whitney, $\mathrm{P}=0.10$ ) and spawned six days earlier (median, 28 April versus 4 May; Mann Whitney, $\mathrm{P}=0.40$ ). However, the duration of tributary use was five days longer for R2 fish (median, 17 days versus 12 days), and fish exited

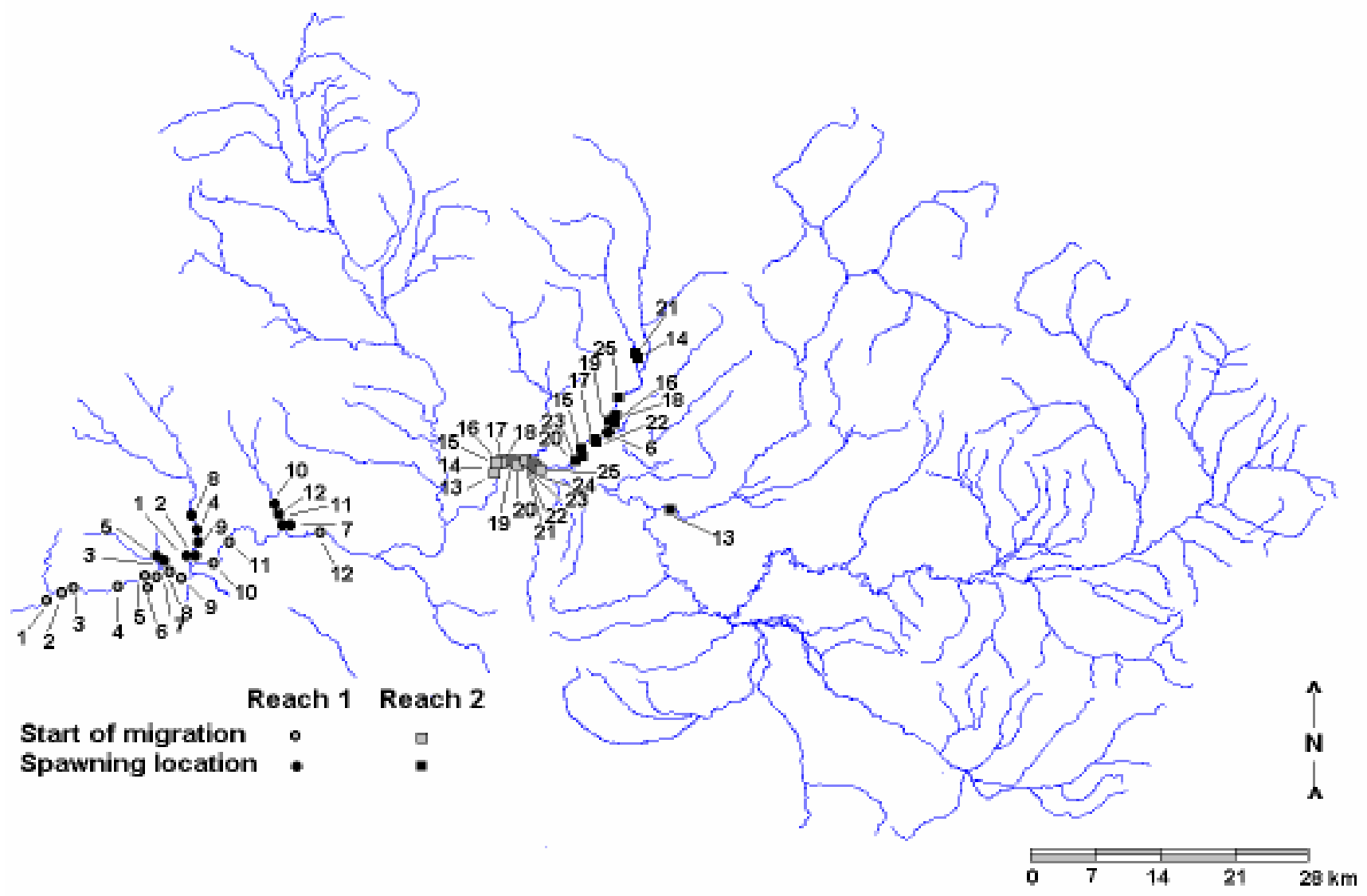

Figure 4. Start of migrations (open symbols) and upstream-most location (closed symbols) of spawning rainbow trout.

tributaries six days later (median, 15 May versus 9 May; Mann Whitney, $\mathrm{P}=0.24$ ) than $\mathrm{R} 1$ fish. 
RBT spawned in six tributaries ranging from $2^{\text {nd }}$ to $4^{\text {th }}$ order with the Monture Creek watershed and Gold Creek supporting the highest proportion of spawners $(n=12$ or $48 \%)$ and ( $n=5$ or $20 \%$ ) respectfully (Table 1). Fish from R1 spawned in four tributaries: Gold Creek $(n=5)$, Belmont Creek $(n=4)$, East Twin $(n=2)$ and Monture Creek $(n=1)$; whereas R2 fish spawned in Monture $(n=10)$ and its tributary Dunham Creek $(n=2)$, and only one spawning outside of the Monture Creek Basin, within the North Fork. Based on stream-order, spawners entered larger tributaries earlier than smaller tributaries (ANOVA, $\mathrm{P}=0.02$ ). However, there was no significant difference with stream-order and time spent in tributaries (ANOVA, $\mathrm{P}=0.20)$,

During the period of pre-spawning river migration (19 March to 15 April), mean water temperatures in the Blackfoot River were higher in $2005\left(5.6^{\circ} \mathrm{C}\right)$ than $2006\left(4.9^{\circ} \mathrm{C}\right)$. Thirteen RBT entered Monture Creek and five entered Gold Creek at mean water temperatures of 5.6 (range 3.6-8.1 ${ }^{\circ} \mathrm{C}$ ), and RBT spawned at mean temperatures of 5.2 (range 3.4-8.0 ${ }^{\circ} \mathrm{C}$ ) in these drainages.

After spawning, all fish with active radios $(n=24)$ exited the tributaries. Three of 24 (12\%) post-spawners (fish: 2, 9 and 25) moved downstream of Milltown Dam into the Clark Fork River during peak flow (May and July), including two spawners from Gold Creek and one that moved downriver $>74-\mathrm{km}$ after spawning in Monture Creek. However, the majority $(n=18$ or $76 \%)$ either returned to $(n=9)$, or were within $1.6 \mathrm{~km}(n=9)$ of their original start locations; three (12\%) moved downriver a mean of $14.0 \mathrm{~km}$ (range, 4.3-23.7) from their starting locations.

\begin{tabular}{|c|c|c|c|c|c|c|c|c|c|c|c|c|}
\hline \multirow{2}{*}{$\begin{array}{l}\text { Reach } \\
\text { and } \\
\text { fish \# }\end{array}$} & \multicolumn{2}{|c|}{$\begin{array}{c}\text { Start of river } \\
\text { migration }\end{array}$} & \multicolumn{2}{|c|}{$\begin{array}{l}\text { Pre-spawning } \\
\text { river migration }\end{array}$} & \multicolumn{5}{|c|}{ Tibutary spawning } & \multicolumn{3}{|c|}{ End of Migration } \\
\hline & $\mathrm{rkm}$ & start date & $\begin{array}{l}\text { Total } \\
\text { rkm }\end{array}$ & $\begin{array}{c}\text { Total } \\
\# \\
\text { days }\end{array}$ & $\begin{array}{c}\text { Tributary } \\
\text { name }\end{array}$ & $\begin{array}{c}\mathrm{km} \text { to } \\
\text { spawning } \\
\text { site }\end{array}$ & $\begin{array}{c}\text { Estimated } \\
\text { spawning } \\
\text { date }\end{array}$ & $\begin{array}{l}\text { Days } \\
\text { in trib. }\end{array}$ & $\begin{array}{c}\text { Date } \\
\text { exited }\end{array}$ & $\begin{array}{l}\text { Date } \\
\text { migration } \\
\text { ended }\end{array}$ & $\begin{array}{l}\text { Date returned to } \\
\text { migration } \\
\text { starting location }\end{array}$ & $\begin{array}{l}\text { River } \mathrm{km} \text { at } \\
\text { the end of } \\
\text { migration }\end{array}$ \\
\hline $1--1$ & 4.7 & $4 / 4 / 06$ & 17.5 & 5 & Gold Cr & 0.3 & $4 / 16 / 06$ & 14 & $4 / 23 / 06$ & $4 / 23 / 06$ & $4 / 23 / 06$ & 4.7 \\
\hline $1--2$ & 5.5 & $4 / 13 / 06$ & 16.7 & 11 & Gold Cr & 0.3 & $5 / 1 / 06$ & 12 & $5 / 6 / 06$ & & & \\
\hline $1--3$ & 6 & $4 / 22 / 06$ & 11.4 & 24 & East $\mathrm{Twin} \mathrm{Cr}$ & 0.2 & $5 / 18 / 06$ & 12 & $5 / 28 / 06$ & $6 / 17 / 06$ & & 6.8 \\
\hline $1--4$ & 14 & $4 / 27 / 06$ & 8.2 & 4 & Gold Cr & 1 & $5 / 15 / 06$ & 22 & $5 / 23 / 06$ & $6 / 17 / 06$ & $5 / 28 / 06$ & 22.7 \\
\hline $1--5$ & 16.9 & $5 / 2 / 05$ & 0.5 & 1 & East Twin Cr & 0.6 & $5 / 6 / 05$ & 6 & $5 / 9 / 05$ & $5 / 9 / 05$ & & 16.6 \\
\hline $1--6$ & 17.1 & $4 / 9 / 05$ & 56.8 & 14 & Monture $\mathrm{Cr}$ & 6.4 & $4 / 26 / 05$ & 63 & $6 / 25 / 05$ & 7/7/05 & 7/7/05 & 17.1 \\
\hline $1--7$ & 17.1 & $4 / 30 / 06$ & 18.2 & 20 & Belmont $\mathrm{Cr}$ & 0.2 & $5 / 23 / 06$ & 8 & $5 / 28 / 06$ & $7 / 23 / 06$ & & 19.6 \\
\hline $1--8$ & 17.7 & $4 / 2 / 06$ & 4.5 & 2 & Gold Cr & 3.1 & $4 / 18 / 06$ & 23 & $4 / 27 / 06$ & $4 / 29 / 06$ & $4 / 29 / 06$ & 17.4 \\
\hline $1--9$ & 19 & $4 / 7 / 05$ & 3 & 9 & Gold $\mathrm{Cr}$ & 0.5 & $4 / 18 / 05$ & 11 & $4 / 27 / 05$ & $5 / 4 / 05$ & & \\
\hline $1--10$ & 24 & $4 / 11 / 06$ & 11.3 & 16 & Belmont $\mathrm{Cr}$ & 3.4 & $5 / 15 / 06$ & 31 & $5 / 28 / 06$ & $5 / 28 / 06$ & $5 / 28 / 06$ & 23.8 \\
\hline $1--11$ & 26.6 & $5 / 15 / 06$ & 8.7 & 1 & Belmont $\mathrm{Cr}$ & 0.2 & $5 / 17 / 06$ & 5 & $5 / 20 / 06$ & $5 / 31 / 06$ & & 2.9 \\
\hline $1--12$ & 38.8 & $4 / 7 / 05$ & 3.4 & 17 & Belmont $\mathrm{Cr}$ & 1.5 & $4 / 26 / 05$ & 5 & $4 / 28 / 05$ & $5 / 7 / 05$ & $5 / 7 / 05$ & 38.8 \\
\hline $2--13$ & 65.5 & $4 / 7 / 04$ & 21.4 & 3 & NFBlkft & 1.9 & $4 / 13 / 04$ & 6 & $4 / 16 / 04$ & $4 / 23 / 04$ & & \\
\hline $2--14$ & 66 & $4 / 25 / 05$ & 7.9 & 10 & Dunham $\mathrm{Cr}$ & 19.6 & $5 / 20 / 05$ & 20 & $5 / 25 / 05$ & $6 / 26 / 05$ & $6 / 26 / 05$ & 66.0 \\
\hline $2--15$ & 66 & $4 / 7 / 05$ & 5.5 & 11 & Monture $\mathrm{Cr}$ & 3.2 & $4 / 29 / 05$ & 17 & $5 / 5 / 05$ & $5 / 6 / 05$ & $5 / 6 / 05$ & 66.0 \\
\hline $2--16$ & 66.8 & 3/19/04 & 7.1 & 5 & Monture $\mathrm{Cr}$ & 7.1 & $4 / 1 / 04$ & 13 & $4 / 6 / 04$ & $4 / 28 / 04$ & & 52.8 \\
\hline $2--17$ & 67.1 & $3 / 30 / 04$ & 6.8 & 6 & Monture $\mathrm{Cr}$ & 5.3 & & 11 & & & & \\
\hline 2--18 & 67.1 & $3 / 24 / 05$ & 6.8 & 10 & Monture $\mathrm{Cr}$ & 7.1 & $4 / 17 / 05$ & 20 & $4 / 23 / 04$ & $4 / 28 / 04$ & & 62.8 \\
\hline $2--19$ & 67.1 & $4 / 26 / 05$ & 6.8 & 7 & Monture $\mathrm{Cr}$ & 6.9 & $5 / 11 / 05$ & 11 & $5 / 14 / 05$ & $5 / 26 / 05$ & $5 / 26 / 05$ & 67.1 \\
\hline $2--20$ & 67.3 & $4 / 23 / 04$ & 6.6 & 4 & Monture $\mathrm{Cr}$ & 0.3 & $4 / 29 / 04$ & 3 & $4 / 30 / 04$ & $5 / 6 / 04$ & & 66.9 \\
\hline $2--21$ & 69 & $4 / 25 / 05$ & 4.8 & 10 & Dunham $\mathrm{Cr}$ & 19.8 & $5 / 16 / 05$ & 17 & $5 / 22 / 05$ & $6 / 12 / 05$ & $6 / 12 / 05$ & 69.0 \\
\hline $2--22$ & 70.3 & $3 / 25 / 06$ & 3.5 & 15 & Monture $\mathrm{Cr}$ & 5.6 & $4 / 23 / 06$ & 22 & $5 / 1 / 06$ & $5 / 15 / 06$ & & 72.9 \\
\hline $2--23$ & 70.3 & $4 / 10 / 06$ & 3.5 & 10 & Monture $\mathrm{Cr}$ & 2.4 & $4 / 28 / 06$ & 16 & $5 / 6 / 06$ & $5 / 6 / 06$ & $5 / 6 / 06$ & 70.3 \\
\hline $2--24$ & 70.3 & $4 / 8 / 06$ & 3.5 & 8 & Monture $\mathrm{Cr}$ & 7.2 & $5 / 7 / 06$ & 29 & $5 / 15 / 06$ & $6 / 17 / 06$ & & 55.0 \\
\hline $2--25$ & 71.1 & $4 / 8 / 05$ & 2.7 & 9 & Monture $\mathrm{Cr}$ & 9.8 & $4 / 28 / 05$ & 17 & $5 / 4 / 05$ & & & \\
\hline
\end{tabular}

Table 1. Summary of migration events including: start of river migration, migration time and distance, tributary spawning (dates and locations) and total migration distance for 25-telemetered RBT in two reaches of the Blackfoot River. Fish \# (1-25) relates to migration start and spawning locations on Figure 4

We monitored 17 fish at summering sites within the Blackfoot River. A majority of these $(n=11$ or $65 \%)$ showed either no movement $(n=5)$ or remained within $1.6 \mathrm{~km}(n=6)$ of starting locations; six (35\%) summered an average of $9.3 \mathrm{~km}$ (range, 2.6-23.7) from their 
original starting sites. Of 15 fish tracked into winter, all remained within $0.3 \mathrm{~km}$ of summering locations. We also observed a few rainbow trout moving laterally to the margins of the shoreline and into flooded vegetation during high spring runoff, an apparent refuge-seeking response to high river flows.

Emergence and WD severity - Estimated fry emergence was complete by July 11 (2005 and 2006) for both Gold and Monture Creeks. Sentinel exposures were completed for six tributaries in R1, four in R2 and both study reaches of the Blackfoot River. Histological examinations identified infection rates ranging from $0-100 \%$ and mean lesion scores ranging from 0-4.82 on the MacConnell-Baldwin scale (Table 2). Of the six RBT streams within R1, five streams recorded low severity (majority $<$ grade 3 ), and of those most $(n=4)$ detected no infection despite the near proximity (within $0.3 \mathrm{~km}$ ) to infected waters of the Blackfoot River (Table 2). Conversely, sentinel exposures in three of four spawning streams in R2 recorded high severity (majority $\geq$ grade 3 ) and identified only the North Fork with a low severity. The percent of Blackfoot River fish with high severity ( $\geq$ grade 3 ) was $43 \%$ in R1 compared with $66 \%$ in $\mathrm{R} 2$.

\section{Discussion}

A similar study east of the Continental Divide in Montana investigated RBT spawning life history and risk to juvenile survival within an infected "tailwater" section of the Madison River (Downing et al. 1999). By contrast, our study, undertaken west of the Continental Divide within a headwater basin of the upper Clark Fork drainage, examined fluvial life history within a "free-flowing" river system. Common to both areas are predictable migratory strategies involving pre-spawning migrants holding within wintering areas prior to upriver movement; the fidelity of most post-spawners to their initial tagging location; upstream migrations of similar distances (mean, 14.5 versus $18.7 \mathrm{~km}$ ) to spawning grounds; and fry emergence by early July during the vulnerable, highly infectious period (Downing et al. 1999, FWP unpublished data). Life history differences between the Madison and Blackfoot sites involve primarily mainstem spawning within the Madison River compared to tributary spawning within the Blackfoot Basin. Although WD has been shown to vary within the mainstem of the Madison River (Downing et al. 1999, Krueger et al 2006), our study identifies large differences in histological scores among spawning tributaries.

Like the Madison River, TAM production in the Blackfoot River express a seasonal peak in June and July, followed by declines by September (Downing et al. 1999, Montana Fish, Wildlife and Parks, unpublished data). This seasonal pattern of high TAM release overlaps with the emergence of wild RBT fry at the critical early life stage. In Blackfoot tributaries prone to high TAM production and high incidence of infection, the epizootic has been both rapid and severe. At category 3.0 severity, granulomatous lesions can be large and severely impact bone, causing distortion and breakage, which leaves the fish weak, less able to compete for food and habitat and ultimately increases chances of mortality. Mean lesion scores of $>2.75$ have been associated with significant levels of mortality in wild rainbow trout populations (Vincent 2002). Infections in Elk Creek increased from non-detectable to a mean lesion score of 2.8 within a single year (2002 to 2003) before increasing to 4.8 identified in this study. Likewise, infections in Monture Creek increased from non-detectable to a mean lesion score of 3.2 between 1999 and 2002 (Pierce et al 2006) before increasing to 4.8 in this study. M. Cerebralis infections to high severity in the middle Blackfoot River coincide with a temporal trend (1998-2004) of increased cranial deformities (a clinical sign of WD infection) and recent declines in RBT abundance in the Blackfoot River downstream of the Monture Creek confluence (Pierce et al 2006).

Similar to spatial variability of infected waters within a Utah watershed (Hoz Franco and Budy 2004), infections within the Blackfoot Basin vary geographically depending on the 
physical properties and arrangement of tributaries. For basin-fed tributaries within the Blackfoot Basin, conditions correlated with infection include wide alluvial valleys with warm water during summer, lower stream gradients and higher levels of fine sediments (Pierce et al. In review); all are conditions that favor habitat for T. tubifex or production of TAMs (Arndt et al. 2002, El-Matbouli et al. 1999).

For R1 fish, spawning was dispersed in lower reaches of three morphologically similar (cold, high-gradient) tributaries to the lower Blackfoot Basin. Within this group of similar streams are three additional tributaries (Johnson, East Twin and Bear Creeks), all of which support known (Peters and Spoon 1989, FWP unpublished data) but limited RBT spawning (based on our telemetry findings) and low to no measurable infection. From Belmont Creek (rkm 35.4) downriver, this concentrated group of relatively "clean" tributaries enters the Blackfoot River at a mean interval of one stream per $5.8 \mathrm{~km}$ of river. Of $11 \mathrm{RBT}$ tracked from wintering pools to tributaries within this area, ten expressed unidirectional (upstream) migration over a $9.2 \mathrm{~km}$ median distance to spawning areas including $8.7 \mathrm{~km}$ of the lower Blackfoot River. Unlike the upper reach, these movement patterns identify several overlapping spawning stocks, which cohabit this reach of the Blackfoot River. Sentinel exposures within this group of R1 tributaries consistently test at low levels ( $<$ grade 3 or non-detect) of severity compared to R2 tributaries where sentinel exposures consistently rank at high ( $\geq$ grade 3 ) severity (Pierce et al 2006). The RBT densities in the lower Blackfoot River remain stable (Pierce et al. 2006) despite an apparent annual loss of $\sim 15-20 \%$ of lower River RBT spawners over Milltown Dam identified in this study.

In contrast to this $\mathrm{R} 1$ river area, the $51.5-\mathrm{km}$ reach of the Blackfoot River between Belmont Creek and the North Fork (R2) contain fewer (five) RBT spawning streams - one per $10.3 \mathrm{~km}$ of river although most (four) enter within a $17.8-\mathrm{km}$ section of Blackfoot River between Cottonwood Creek (rkm 69.2) and the North Fork (rm 86.9). Consequently, RBT recruitment sources within the 33.8-km section of the Blackfoot River between Belmont and Cottonwood Creek are limited. Elk Creek enters this reach but this stream is water quality (sediment and temperature) impaired (Blackfoot Challenge 2006), supports high severity of WD, and has experienced RBT declines in recent years (Pierce et al 2004). Of the five RBT spawning streams upstream of Belmont Creek, only the North Fork supports a low severity of WD, yet it supports limited RBT reproduction (this study) and recruits relatively fewer age-0 RBT to the Blackfoot River than downstream tributaries (Peters and Spoon 1989).

Age-0 RBT abundance has been longitudinally evaluated in all RBT spawning streams during the early rearing mid-summer period (Peters and Spoon 1989, Peters 1990, Pierce et al. 2004, 2006). Juvenile inventories identify relatively high abundance of age- 0 RBT within and downstream of all central spawning grounds and concentrated densities extend to the Blackfoot River below the mouths of all spawning tributaries identified in this study (Peters and Spoon 1989), a pattern of rearing consistent with the Madison River (Downing et al. 2002). For the Blackfoot Basin, this pattern of limited early dispersal suggests a higher risk of disease exposure throughout the lower reaches of most R2 tributary and mainstem rearing areas, but conversely low risk in R1 tributaries (except Elk Creek) and those fry dispersing to the mainstem Blackfoot River during the summer period when WD severity ranked high.

Prior to the invasion of M. cerebralis, Peters and Spoon (1989) identified Monture Creek as a primary source of RBT recruitment, but considered the middle Blackfoot River as recruitment limited. Our study confirmed this spawning relationship with $>90 \%$ of telemetered R2 fish spawning within the lower Monture Basin with a central (median) spawning location of rkm 6.9 (range 0.3-19.8). Although the 2005 Monture Creek sentinel exposure identified a severe $(97 \% \geq$ grade 3$)$ exposure, the cage was located downstream (rkm 3.2) of the central spawning site. To clarify disease severity within the central spawning area, we further examined $M$. cerebralis exposures at rkm 7.4 and upstream of identified RBT spawning areas 
(rkm 20.8) with additional sentinel exposures in 2006. Exposure results confirmed the high severity at the central spawning areas $(95 \% \geq$ grade 3$)$, but detected no upstream infection. The combined 2005-06 exposure results confirm risk of severe exposure within and downstream of primary Monture Creek spawning areas, yet the upstream attenuation to no infection suggests an upper segment of the Monture RBT spawning site remains at a low level of risk.

The discrepancy between river migration distances in R1 an R2 (6.6 verses 10.0) raises concerns of disease-related recruitment losses in $\mathrm{R} 2$. In addition to a reduced level of river use, high lesion scores at the primary RBT spawning site (Monture Creek) indicate potential for a synergistic reduction in R2 recruits, including fish dispersing to downstream waters where trout populations are currently limited by the low number and poor quality of existing spawning streams (i.e. upstream of Belmont Creek).

Oncorhynchus resistance to pathogens such as whirling disease can take many forms such as inherent life history strategies that help avoid exposure of $M$. cerebralis at early life stages, or physiological resistance such as an innate immune response that limit the pathogen from infecting the host (MacConnell and Vincent 2002). Similar to nearby stocks within the Clark Fork Basin, a majority of fish identified as RBT in the Blackfoot Basin were found to be mildly introgressed with westslope cutthroat trout. Physiological resistance of RBT/ westslope cutthroat trout hybrids to WD is untested, but it is possible that $F_{1}$ hybrids may have an intermediate level of resistance between the low resistance of non-hybridized RBT and the "moderate" resistance of non-hybridized westslope cutthroat trout (MacConnell and Vincent 2002, Hendrick et al 1999). Within the Blackfoot watershed, the longitudinal distribution from pure westslope cutthroat trout predominant in the upper Blackfoot Basin to a more RBTdominated community downstream of the North Fork suggests an inter-specific reduction in WD susceptibility among the Oncorhynchus community, particularly when further considered within a context of migratory life histories and environmental factors that influence infection (and severity) along a longitudinal continuum (Smith 1998, see prediction paper)

Management Implications - Management implications vary by river reach and involve the potential for an additive loss of recruitment to the middle Blackfoot River, and the need to offset this loss by correcting anthropogenic degradation of spawning and rearing streams. The middle Blackfoot River (upstream of the Belmont Creek) was previously identified with trout recruitment problems brought on by drought and winter mortality, limited spawning areas and degradation of existing spawning and rearing areas caused by agricultural and other land uses. For the middle Blackfoot River, this study and other tributary assessments suggest abundant restoration opportunities even in tributaries that host high levels of disease.

Based on community-level changes in Rock Creek, brown trout clearly have potential for expansion under environments prone to WD. This naturally more resistant species has also shown significant population increases in highly infected spring creeks within the middle Blackfoot Basin once limiting factors related to physical habitat were corrected (Pierce et al. 2006). Like brown trout, native westslope cutthroat trout and bull trout could thrive within certain infected environments. While both westslope cutthroat trout and bull trout possess partial resistance to WD (MacConnell and Vincent 2002), both species also possess life history strategies that help avoid exposure of $M$. cerebralis at early life stages by spawning in headwaters of the Blackfoot Basin (including Monture Creek) where contact with $M$. cerebralis at critical stages (age-0) is reduced. Young cutthroat trout and bull trout migrate to infected waters at more disease-resistant (age-1 and older) stages. Both species migrate extensively within the Blackfoot Basin (Swanberg 1997, Schmetterling 2001, Pierce et al. 2007), including infected sections of the Blackfoot River prone to limited RBT recruitment (Pierce et al 2006). 
Even moderate levels of WD resistance for certain native species can temper population effects within waters that support severe WD. One example of this is Chamberlain Creek, a tributary supporting primarily westslope cutthroat trout. Following remediation of dewatering, ditch entrainment, riparian grazing and channel alterations, westslope cutthroat trout densities in lower Chamberlain Creek increased from two to 80 fish/100m by 1994 and remained stable thereafter (Pierce et al. 1997, 2006). After this recovery, telemetered adult fluvial cutthroat from the Blackfoot River identified Chamberlain Creek as an important westslope cutthroat trout spawning stream to the lower Blackfoot River (Schmetterling 2001). Densities of westslope cutthroat trout have remained stable in lower Chamberlain Creek despite a high severity of WD (range of mean lesion scores, 2.7 to 4.3) between 1999 and 2005. Population trends for fluvial westslope cutthroat trout in the lower and middle Blackfoot River have been stable despite being epizootic among rainbow trout.

Conclusions - Although future population (and community) effects are difficult to predict, our study clearly indicates disease risks to Blackfoot River RBT vary from the tributary to sub-basin scale. Our study suggests the middle Blackfoot River is at a higher risk of RBT recruitment loss through WD, perhaps at levels sufficient to affect angling success. Some highly infected valley-floor streams in the middle Blackfoot Valley seem predisposed to high WD because of their low gradient, high water temperatures and high sediment levels and synergistic effects of heavy grazing and other disturbances. By contrast, higher gradient mountain streams are less prone to infection. To offset potential RBT losses in disease prone waters of the middle Blackfoot Basin, stakeholders must 1) better manage riparian areas for channel stability, increased shade and erosion reduction, 2) promote native fish recovery and migratory life histories, and 3) restore (or enhance) habitats favoring salmonid life stages less affected by the WD pathogen.

\section{Acknowledgements}

Northwestern Energy, the Big Blackfoot Chapter of Trout Unlimited and U. S. Fish and Wildlife Service-Partners for Fish and Wildlife provided partial funding for this project. We also extend thanks to the landowners including the Two Creeks, Knob and Kettle, Paws Up and Heart-bar-Heart Ranches for allowing access to their lands. Pat Saffel and Robb Leary with Montana Fish, Wildlife and Parks and Ryen Aasheim with the Big Blackfoot Chapter of Trout Unlimited for their assistance with the project. Lisa Eby, Eileen Ryce and Pat Byorth reviewed and improved the quality of the manuscript.

\section{Literature Cited}

Anderson, R., A. 2004. Occurrence and seasonal dynamics of the whirling disease parasite, Myxobolus cerebralis, in Montana spring creeks. Master of Science thesis, Montana State University, Bozeman.

Arndt, R.E., E. J. Wagner, Q. Cannon, and M. Smith. 2002. Triactinomyxon production as related to rearing substrate and diel light cycle. Pages 87-91 in J.L. Bartholomew and J.C. Wilson, editors. Whirling disease: reviews and current topics. American Fisheries Society, Symposium 29, Bethesda, Maryland.

Baldwin, T. J., E. R. Vincent, R. M. Silflow, D. Stanek. 2000. Myxobolus cerebralis infection in RBT (Oncorhynchus mykiss) and brown trout (Salmo trutta) exposed under natural stream conditions. Journal of Veterinary Diagnostic Investigations 12:312-321.

Baldwin, T. J., J. E. Peterson, G. C. McGree, K.D. Staigmiller, E. S. Motteram, C. C. Downs and D. R. Stanek. 1998. Distribution of Myxobolus cerebralis in salmonid fishes of Montana. Journal of Aquatic Animal Health 10:361-371.

Blackfoot Challenge. 2005. A basin-wide restoration action plan for the Blackfoot Watershed.

Boecklen, W. J. and Howard, D. J. 1997. Genetic analysis of hybrid swarms: numbers of markers and power of resolution. Ecology 78 (8) pp. 2611-2616. 
Downing, D.C., T. E. McMahon, K.L. Kerans and E.R. Vincent. 2002. Relation of spawning and rearing of rainbow trout and susceptibility to Myxobolus cerebralis infection in the Madison River, Montana. Journal of Aquatic Animal Health 14:191-203.

El-Matbouli, M., T.S. McDowell, D.B. Antonia, K.B. Andree, and R.P. Hendrick. 1999. Effect of water temperature on the development, release, and survival of triactinomyxon stage of Myxobolus cerebralis in its oligochaete host. International Journal for Parasitology 29:627-641.

Goldberg, T. L., E. C. Grant, K. R. Inendino, T. W. Kassler, J. E. Claussen, D. P. Phillip. 2005. Increased infection disease susceptibility resulting from outbreeding depression. Conservation Biology 19: 455-462.

Hendrick, R. P., M. El-Matbouli, M. A. Adkinson, and E MacConnell. 1999. Susceptibility of selected inland salmonids to experimentally induced infections with Myxobolus Cerebralis, the causative agent of whirling disease. Journal of Aquatic Animal Health 11:330-376.

Leary R. 2005, 2006. Rainbow trout genetics lab reports. Wild Trout and Salmon Genetics Laboratory, Division of Biological Sciences, University of Montana, Missoula.

Kerans, B.L. and A.V. Zale. 2002. The ecology of Myxobolus cerebralis. Whirling disease: reviews and current topics. American Fisheries Society Symposium 29:145-166.

Krueger, R.C., B.L. Kearns, E.R.Vincent and C. Rasumussen. 2006. Risk of Myxobolus cerebralis infection to rainbow trout in the Madison River, Montana, USA. Ecological Applications, 16:770-783.

MacConnell, E. and E. R. Vincent 2002. Review: the effects of Myxobolus cerebralis on the salmonid host. Pages 95-108 in J. L. Bartholomew and J. C. Wilson, editors. WD: reviews and current topics. American Fisheries Society, Symposium 29, Bethesda Maryland.

Modin, J. 1998. Whirling disease in California: A review of its history, distribution, and impacts, 1965-1997. Journal of Aquatic Animal Health 10:132-142.

Montana Fish, Wildlife and Parks. 2006. Statewide angler pressure surveys for 2005.

MWDTF (Montana Whirling Disease Task Force). 1996. Final report and action recommendations. Montana WD Task Force, Helena, MT.

Nehring, B., and P. G. Walker. 1996. Whirling disease in the wild: the new reality in the intermountain west. Fisheries 21 (6): 28-30.

Peters, D.J. and R. Spoon. 1989. Preliminary inventory of the Big Blackfoot River. Montana Department of Fish, Wildlife and Parks, Missoula, Montana.

Peters, D. 1990. Inventory of fishery resources in the Blackfoot River and major tributaries to the Blackfoot River. Montana Department of Fish, Wildlife and Parks, Missoula, Montana.

Pierce R. and C. Podner. 2000. Blackfoot River fisheries inventory, monitoring and restoration report. Montana Fish, Wildlife and Parks, Missoula, Montana.

Pierce R., C. Podner and J. McFee. 2002. Blackfoot River fisheries Restoration progress report for 2001. Montana Fish, Wildlife and Parks, Missoula, Montana.

Pierce, R., R. Anderson and C. Podner. 2004. The Big Blackfoot River Restoration Progress Report for 2002 and 2003. Montana Fish Wildlife and Parks, Missoula Montana.

Pierce, R., R. Aasheim and C. Podner. 2005. An integrated stream restoration and native fish conservation strategy for the Big Blackfoot River basin. Montana Fish Wildlife and Parks, Missoula, Montana.

Pierce, R., R. Aasheim and C. Podner. 2007. Fluvial westslope cutthroat trout movements and restoration relationships in the upper Blackfoot Basin, Montana. Intermountain Journal of Sciences Vol. 13(2).

Piper, R. G. 1982. Fish Hatchery Management. USDI, United States Fish and Wildlife Service. Report 329-150. 
Ryce, E. K. N, A. V. Zale and E. MacConnell. 2004. Effects of fish age and parasite dose on the development if whirling disease in rainbow trout. Diseases of Aquatic Organisms Vol. 59 (3):225-233.

Ryce, E. K.N, A. V. Zale, E. MacConnell and M. Nelson. 2005. Effects of fish age versus size on the development of whirling disease in rainbow trout. Diseases of Aquatic Organisms, Vol. 63 (1): 69-76.

Sandell, T. A., H. V. Lorz, D. G. Stevens, and J. L. Bartholomew. 2001. Dynamics of Myxobolus cerebralis in the Lostine River, Oregon: implications for resident and anadromous salmonids. Journal of Aquatic Animal Health 13: 142-150.

Schmetterling, D. A. 2001. Seasonal movements of fluvial westslope cutthroat trout in the Blackfoot River drainage, Montana. North American Journal of Fisheries Management 21: 507-520.

Shepard, B. B., B.E. May and W. Urie. 2003. Status of westslope cutthroat trout (Onchorynchus clarki lewisi) in the United States: 2002. A report to the Westslope Cutthroat trout Interagency Conservation Team.

Smith, L. 1998. Study on the distribution and abundance of Tubifex tubifex within Cottonwood Creek in the Blackfoot drainage. Masters Thesis, University of Montana, Missoula, Montana.

Strahler, A.N. 1957. Quantitative analysis of watershed geomorphology. Transactions, American Geophysical Union 38:913-920.

Swanberg, T. R. 1997. Movements of and habitat use by fluvial bull trout in the Blackfoot River. Transactions of the American Fisheries Society 126: 735-746.

Swanberg, T. R., D. A. Schmetterling, and D. H. McEvoy. 1999. Comparison of surgical staples and silk sutures for closing incisions in RBT. North American Journal of Fisheries Management 19:215-218.

USGS 2006. Gauging station 1234000 provisional unpublished data.

Vincent, E. R. 1996. Whirling disease and wild trout: the Montana experience. Fisheries 21 (6):32-33.

Vincent, E. R. 2000. Whirling disease report 1997-98. Montana Fish, Wildlife and Parks. Project 3860. Helena, Montana.

Vincent, E. R. 2002. Relative susceptibility of various salmonids to WD with emphasis on rainbow and cutthroat trout. Whirling Disease: reviews and current topics. American Fisheries Society Symposium 29:109-115.

Winter, J. D. 1996. Advances in underwater biotelemetry. Pages 555-590 in B.R. Murphy and D. W. Willis, editors. Fisheries Techniques, $2^{\text {nd }}$ edition. American Fisheries Society, Bethesda, Maryland.

Zendt, J. S. and E. P. Bergersen. 2000. Distribution and abundance of the aquatic oligochaete host Tubifex tubifex for the salmonid WD parasite Myxobolus cerebralis in the upper Colorado River basin. North American Journal of Fisheries Management 20:502-512. 


\title{
Status review of Mountain Whitefish (Prosopium williamsoni) in the Blackfoot Basin: A pilot study to help identify risk of whirling disease
}

\author{
A report to the Whirling Disease Foundation
}

\section{Introduction}

Mountain whitefish - Prosopium williamsoni - (MWF) is a salmonid endemic to the Pacific Northwest of both the U.S and Canada. Native to western Montana, they are found primarily in cold, medium-to large rivers and in some lakes and reservoirs, and their distribution extends east and west of the Continental Divide. West of the Divide, they range throughout the upper Clark Fork and Flathead Basins. East of the Divide, their range extends throughout the headwaters of both the upper Missouri and Yellowstone Basins. Despite their generally ubiquitous presence in the river systems of western Montana, the life histories and population status of MWF have not been fully documented, nor has the vulnerability of MWF to whirling disease been fully investigated.

To help document the status of MWF and to begin to identify relationships of MWF to whirling disease in the Blackfoot Basin, Montana Fish, Wildlife and Parks (FWP) compiled all available historic fish population survey information within the Blackfoot Basin into a (GIS) database and began (in 2006) more targeted surveys of MWF within the Blackfoot River. This status review and related fieldwork are running concurrent with plans for controlled laboratory exposures of MWF fry to Myxobolus cerebralis followed by histological examination of infected fish. If successful, laboratory tests will help identify the age and size of susceptible fry and develop measures of disease severity. The testing of MWF using sentinel exposures in the field is expected in the near future.

Only one laboratory test has focused on the susceptibility of MWF to whirling disease (MacConnell et al. 2000). These researchers found when exposed within seven weeks of life to a high dose of TAMs, MWF experienced direct and rapid mortality. Other MWF exposed at lower doses survived but developed the clinical signs of whirling disease (blacktail, whirling behavior and skeletal (caudal) deformities). This study concluded that exposed MWF that were susceptible to infection by M. cerebralis, could develop whirling disease, and could serve as host for developing of $M$. cerebralis myxospores. This study observed that caudal lesions were prevalent in infected whitefish, and that these closely resembled lesions found in wild juvenile mountain whitefish collected from the Madison River in 1999. Certain aspects of the study were inconclusive because of an unrelated level of high MWF mortality during testing.

In addition to early lab results, field-based research and anecdotal reports likewise indicate MWF may have a high prevalence of $M$. cerebralis infection and could suffer population-level impacts. Whirling disease has been detected in MWF in the Salt River of Wyoming (Gelwicks and Zafft 2000). Barry Nehring of Colorado Division of Wildlife reported a $70 \%$ to $80 \%$ prevalence of $M$. cerebralis infection among wild MWF of the Roaring Fork River, Colorado. In Mission Creek, Montana, biologists from the Confederated Salish and Kootenai Tribes recently reported clinical signs of whirling and caudal deformities in MWF (Craig Barfoot, personal communication). Likewise, caudal deformities in juvenile MWF were recently detected within infected waters of the middle Blackfoot River of Montana. One local example of possible population declines within the Blackfoot Basin appears to be the recent loss of MWF from Hoyt Creek, a small spring creek tributary to Monture Creek. In 1992 prior to the introduction of whirling 
disease to waters of the Blackfoot Basin, juvenile MWF were identified as common in lower Hoyt Creek; however in 2006 following the local escalation of whirling disease, MWF were absent from the same Hoyt Creek sampling location. Infected spring creeks like Hoyt Creek have been shown to support continuously high TAM production during the early MWF rearing period (i.e., from winter through early summer; Anderson 2004, R. Pierce, unpublished data). Infected basin-fed tributaries however show variable infection levels during the early summer depending on the environmental properties (e.g. water temperature) of individual streams (Pierce et al., in review).

\section{MWF Status summary $M W F$}

Distribution and WD overlap

Understanding potential MWF disease relationships requires

understanding the distribution and basic life history of MWF with emphasis on the vulnerable juvenile life-stages. Fish population surveys conducted within the Blackfoot Basin between 19892006 identified the presence of MWF from the confluence of the Blackfoot River upstream $\sim 125$ river miles and present at the lower elevations with $\sim 25$ of the larger tributaries (Figure 1, Table 1). This distribution

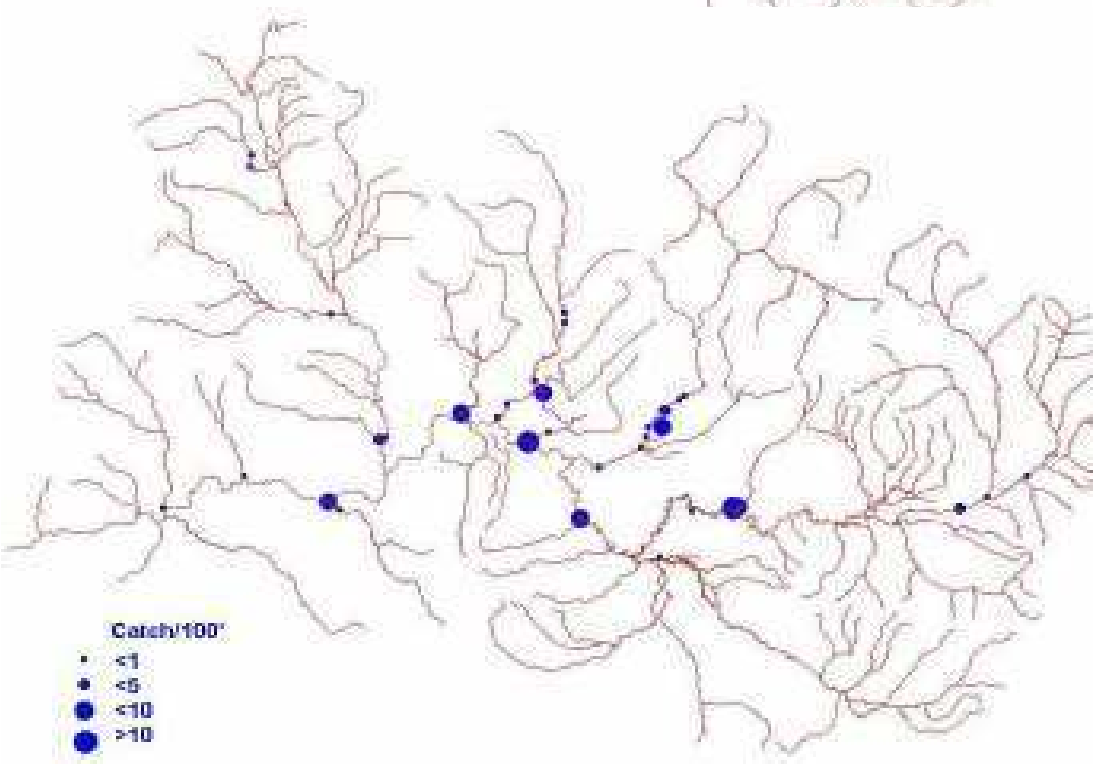

Figure 1 and 2. Fish populations survey sites (1989-2007) where the presence of MWF is documented (top) and YOY abundance classes (bottom). identified MWF mostly in the larger streams of basin-fed origin as well as the lower reaches of connected tributaries including several smaller spring creeks like Hoyt Creek, all of which are located in streams within the lower-valleys of the Blackfoot Basin. This distribution overlaps closely with high infection rates based on sentinel exposures.

Our review of the historic MWF information identifies at a basin scale primary YOY rearing areas within the middle Blackfoot Basin from Elk Creek to Arrastra Creek and within the lower reaches of nearby tributaries (Figure 2). This distribution pattern 
overlaps closely with the known distribution of whirling disease including a large degree of spatial overlap with high severity of disease with rainbow trout.

Basic life history - MWF are long-lived and possess some life history variation that often involves movement between habitats at multiple life stages. Spawning migration and spawning areas are highly variable between regions (Northcote and Ennis 1994). Although not well documented, spawning migrations often range from $10-30 \mathrm{~km}$ (Northcote and Ennis 1994), however, spawning migrations $>60 \mathrm{~km}$ have been identified (Davies and Thompson 1976). Migratory fish seem to undergo a complex sequence of seasonal movements beginning with passive dispersal of fry, followed by late summer movements to deeper water and higher velocity feeding habitats and autumn migrations to downriver over-wintering habitat. Spawning migrations of river populations are often in an upstream direction, although downstream spawning migrations from summer foraging areas to spawning locations in lower reaches of larger tributaries or into mainstem of rivers have also been documented (McPhail and Troffe 1998). MWF are longlived and usually reach sexually maturity by the age of six. Fecundity is a function of female body size, thus larger females produce more eggs than smaller females, ranging from 1,400 to 24,000 eggs in Montana females (Brown 1952). MWF seem to use a wide range of habitats for spawning, and no spawning site preparation (redd construction) occurs by females (McPhail and Troffe 1998). Instead, MWF often spawn in (small) groups and eggs are broadcast over the substrate in riffles or rapids in late fall or early winter. Egg collection in western Montana by FWP hatchery personnel in the fall of 2007 indicate November as a primary spawning period. Spawning occur at temperatures below $6{ }^{0} \mathrm{C}$, incubation requires $250-280\left({ }^{\mathrm{O}} \mathrm{C}\right)$ temperature units and emergent MWF fry were recently detected on March 15, 2008 in the upper Madison (Dick Vincent, FWP unpublished data).

According to Northcote and Ennis (1994), throughout their life MWF progressively move to faster and deeper waters as body size increases. Fry emergence occurs in spring at which time sac fry seek out side-channels or protected backwaters along stream margins (Brown 1952). Fry leave these habitats by early summer and passively disperse downstream to protected areas where fish school, before further dispersing to deeper sections of stream during summer. Consistent with this movement pattern, in summer 2006, FWP and Dr. Lisa Eby undertook a targeted YOY survey in a known spawning area in Rattlesnake Creek (a tributary of the Clark Fork River near Missoula) where they detected very low densities of YOY. However, YOY were observed nearby in relatively high abundance in riffles of a much larger river (the lower Blackfoot River), suggesting a run-off-related out-migration of YOY although high densities of YOY have been identified in the lower reaches of tributaries during summer as well (Figure 2). This general pattern of early downstream dispersal is consistent with trapping studies in tributaries to the Flathead River where YOY out-movements were identified during the runoff period (Craig Barfoot, personal communication). Older fish prefer pools but are often associated with runs (riffle breaks) and riffles for foraging areas slightly upstream of pools or in deeper depressions or quiet areas associated with the downstream side of woody debris.

\section{MWF survey in the Blackfoot River: Wales and Canyon Creek sections}

Based on past electro-fishing observations, MWF are identified as common throughout the mainstem Blackfoot River downstream of Lincoln (rm 108); however, as a non-target species, quantification of mainstem populations has not been a priority in the past. To assess MWF sampling techniques and develop a monitoring baseline for the Blackfoot River, MWF recently (in 2006) targeted two population surveys in the 
Blackfoot River under differing flow conditions. One survey was completed in May during the peak of runoff in the middle Blackfoot River (Wales Creek Section), and the other was completed in the upper Blackfoot River (Canyon Section) in September during base-flow conditions. Both surveys used mark-and-recapture and identical drift boat boom-mounted electrofishing methods. These surveys emphasized estimates of population densities and size structure metrics (length-weight and age-and-growth).

Survey Results - The spring survey in the Wales Creek section generated a very low capture efficiency and produced an unreliable estimate of population density. Conversely, the fall survey in the Canyon Section resulted in much higher capture efficiency and a more reliable density estimate. A comparison of these density estimates and related statistics for MWF over two years of age ( $\geq 8.0$ ") for both sections is located in Table 2.

Table 2. Comparison of mark-and-recapture survey results for MWF ( $\geq 8.0$ ") in two sections of the Blackfoot River. The Wales Creek is a spring estimate and the Canyon Section is a fall estimate.

\begin{tabular}{|c|c|c|c|c|c|c|c|c|c|c|c|}
\hline & River-mile & Date & Section & & Size Class & & & & Efficiency & & Estim/1000' \\
\hline Stream & mid-point & Sampled & Length $(\mathrm{ft})$ & Species & (in) & Marked & Captured & Recaptured & $(\mathbb{R C})$ & Total Estim $\pm \mathrm{Cl}$ & $\pm \mathrm{Cl}$ \\
\hline es Creek Sect & 63 & 20-May-02 & 7603 & MWF & $>8.0$ & 74 & 77 & 4 & 0.05 & $1169 \pm 923$ & $154 \pm 119$ \\
\hline Canyon Section & 95.3 & 20-Sep-06 & 5422 & MWF & $>8.0$ & 177 & 121 & 23 & 0.19 & $904 \pm 324$ & $167 \pm 59$ \\
\hline
\end{tabular}

Weight-length and age-size class assessment - Length frequency and weightlength scatter grams and condition factor plots for both sites are presented in Figures 3, 4 and 5, respectfully. The data indicates the upper Blackfoot River supports a "top-heavy" population, particularly in the upper river (Canyon Section). Condition factor (Wr) measurements (Anderson and Neuman 1996) showed a higher mean condition of 107 in the Wales Creek section compared to a mean of 96 in the Canyon Section.

Scales from $36 \mathrm{MWF}$ were also collected from the two sections on the Blackfoot River during sampling. Aging the scales from the Wales Creek section show little or no growth had occurred since winter annulus was formed; therefore the outer edge was considered the final annulus. Because the Canyon section scales were collected in September the ages were stated with a plus $(+)$, although little growth probably will occur after the September collection data. The fall age size groups are probably the same because growth after late September would not be significant; therefore 0+ mountain whitefish in the fall would be the same size as a yearling (age 1 fish) in the spring (Table $3)$. 
Table 3. Estimated size-groups for each age classes found in the Wales Creek and Canyon section of the Blackfoot River, 2006.

\begin{tabular}{|l|l|l|l|}
\multicolumn{2}{c}{ Wales Creek Section } & Canyon Section \\
\hline Age Class & Size Group (est.) & Age Class & Size Group (est.) \\
\hline 1 & $4-4.9$ inches & $0+$ & $4-4.9$ inches \\
\hline 2 & $5-7.9$ inches & $1+$ & $5-7.9$ inches \\
\hline 3 & $8-10.6$ inches & $2+$ & $8-10.6$ inches \\
\hline 4 & $10.7-11.8$ inches & $3+$ & $10.7-11.8$ inches \\
\hline $5+$ & $>11.9$ inches & $4+$ & $>11.9$ inches \\
\hline
\end{tabular}

Using the age structure comparisons for both survey sections, there is a noticeable lack of younger MWF in the Canyon section compared to the Wales Creek section (Figure 6). For the Canyon Section, all the year classes between 2005-2002 are either low or missing, however larger numbers of 2001 and older whitefish were collected. With exception of the low numbers of 2006year class (YOY) the year class distribution in the Wales Creek section looks much better.

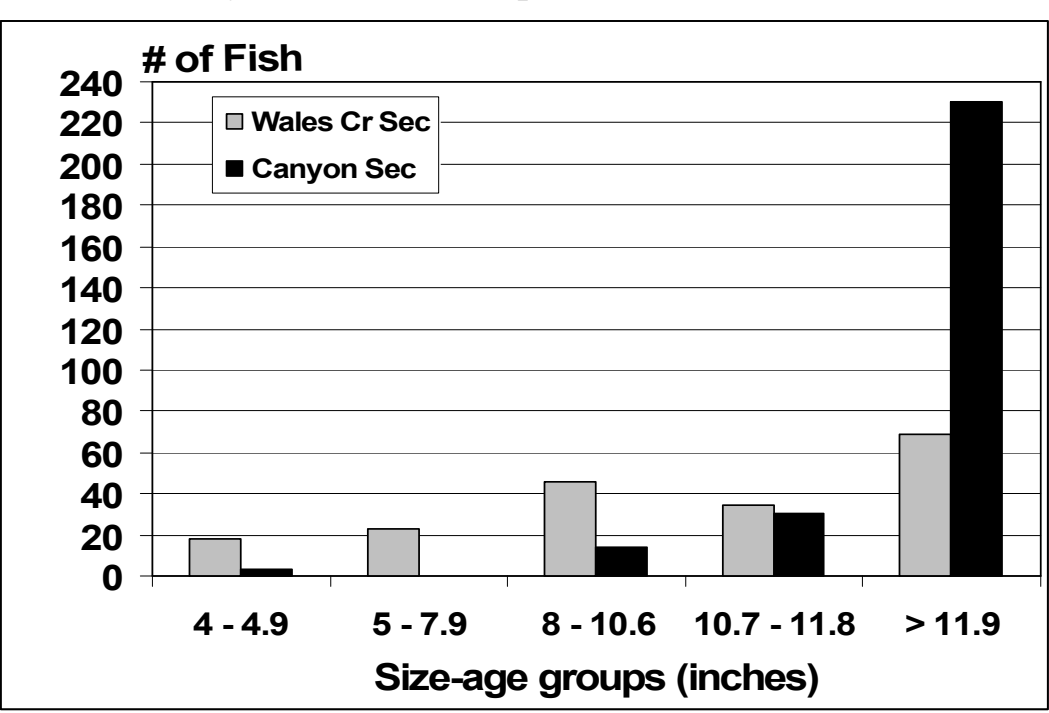

Figure 6. Comparisons of age structure between the Wales Creek section and Canyon section using size groups, 2006. Refer to Table 3 for ages. 


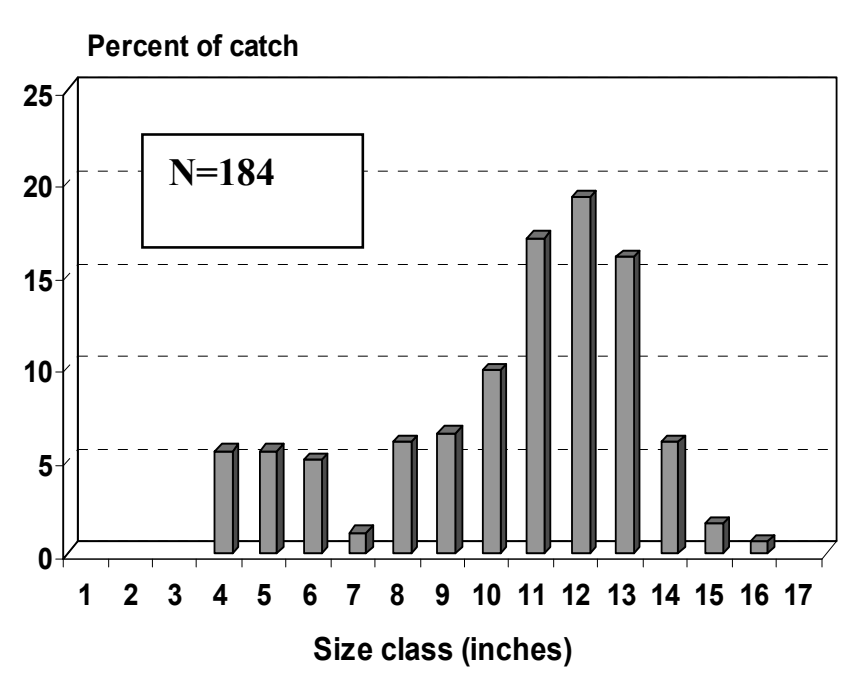

Percent of catch

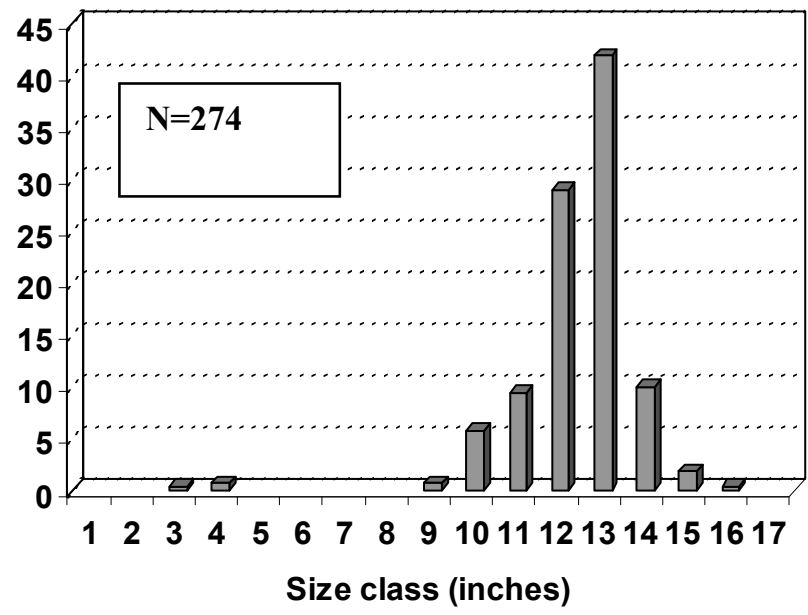

Figure 3. Length-frequency histograms for MWF in the Wales Creek (left) and Canyon Creeks (right) sections of the Blackfoot River, 2006
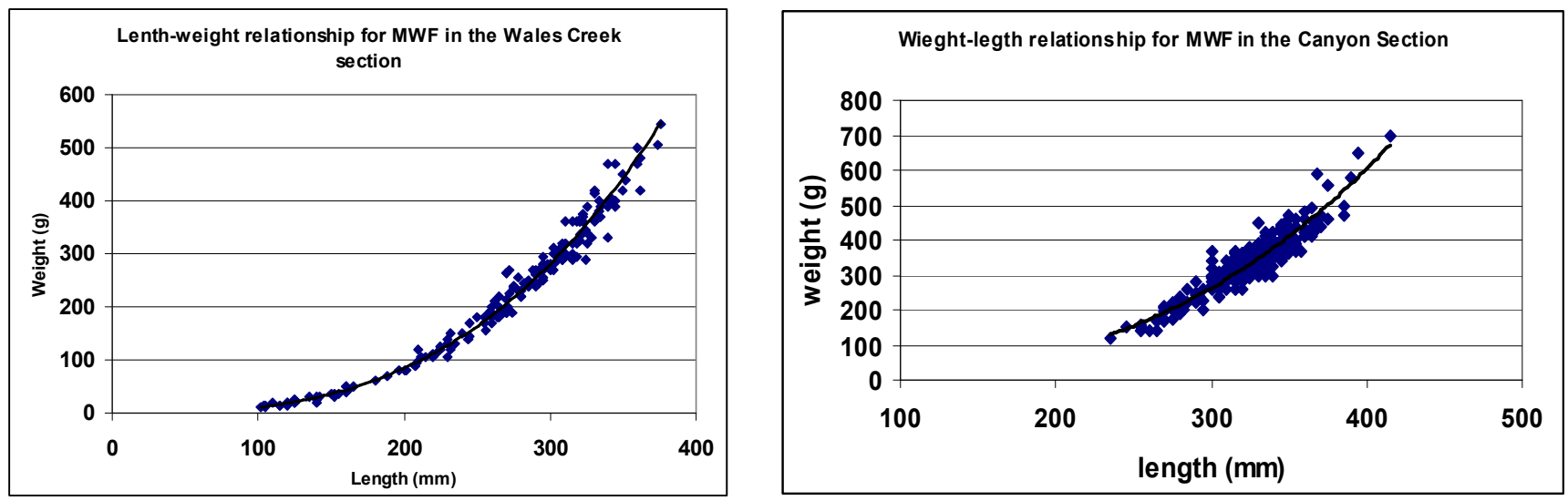

Figure 4. Scatter graphs showing length-weight relationships for MWF in the Wales Creek (left) and Canyon Creek sections of the Blackfoot River.
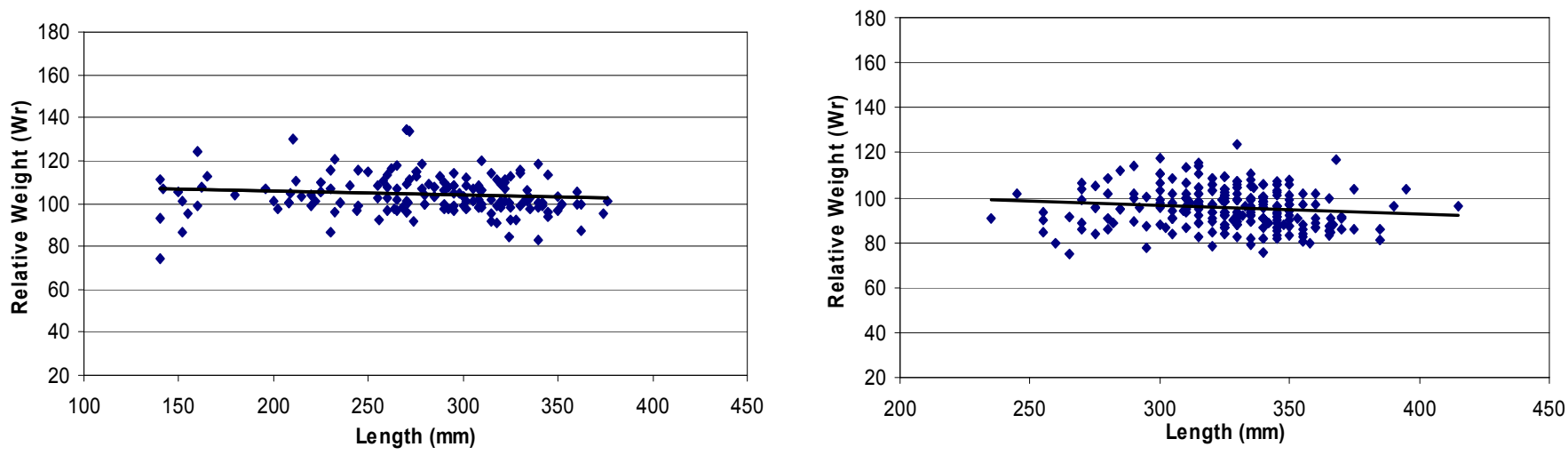

Figure 5. Relative weight for MWF in the Wales Creek (left) and Canyon Section (right) of the Blackfoot River. 


\section{Discussion}

Although not always appreciated by the common angler, the ecological importance of MWF is high, particularly for large salmonids like bull trout or other predatory game fish. If whirling disease were to reduce MWF populations, this could potentially impact not only the fish community, but also the overall food web including a myriad of terrestrial predators (and scavengers) that also rely on MWF as a key forage species

Although this review improves our understanding of MWF, still little is known about the local MWF life histories or the vulnerability of fry to whirling disease. What is known is that many streams in the middle Blackfoot Basin, identified as supporting high densities of juvenile MWF in the past, are now highly infected and the clinical signs of whirling are now being detected in MWF in certain western Montana waters, including the middle Blackfoot River. The recent absence of MWF from Hoyt Creek elevates disease concerns for MWF. The spatial overlap of MWF and M. cerebralis is a specific concern in the middle Blackfoot Basin where the high densities of YOY overlap with a high severity of disease in other species (e.g. rainbow trout). Until susceptibility is better identified and exposures of MWF are undertaken in the wild, it is difficult to interpret local population changes in places like Hoyt Creek or examine the extremely weak juvenile MWF numbers in highly infected waters of the upper Blackfoot River.

In the case of MWF in the upper Blackfoot River, it is interesting to further consider the "top-heavy" population within a context of potential disease implications. Although other factors (e.g. movement) could explain the very low abundance of juvenile fish (age 0 through age 3 ) in the Canyon section, weak juvenile year classes are consistent with recent increases in whirling disease to high levels of severity (i.e. prevalence of high severity $>3$ for rainbow trout on MacConnell-Baldwin scale) between 2003-2005. Unlike other susceptible salmonids such as rainbow trout, MWF is by comparison a long-lived fish with individuals approaching 30-years of age (Northcote and Ennis 1994). This longevity is important given the potential population effects resulting from whirling disease in waters like the Blackfoot River would not show up in adult populations for many years.

In summary, assessing potential disease effects on MWF in the wild requires an understanding of the movement and habitat use with emphasis on spawning sites, early rearing areas and related movement patterns. Once disease susceptibility is better identified, and if spawning and rearing sites of MWF can be better identified, the known temporal-spatial conditions associated with high (or low) whirling disease infection (and severity) in the Blackfoot Basin can be applied to MWF.

To aid in our understanding of local MWF life history, a pilot-level telemetry emphasizing movements and locations of spawning sites is planned for the Blackfoot River in 2008. If the timing and location of spawning can be identified, existing winter temperature information and environmental conditions conducive to infection could be used to identify incubation and hatching and better assess exposure risk of M. Cerebralis to fry at a more refined spatial scale. With a better understanding of MWF life history, habitats and susceptibility, the effects of whirling disease on MWF populations could be examined using sentinel cages as well as the continuation of population densities surveys and winter water temperature monitoring in suspected spawning and early rearing areas. This information will help in evaluating overlap between M. cerebralis and vulnerable fry. 


\section{Recommended future work}

- Complete lab exposures of MWF fry and identify the age and size and other factors related to susceptibility as follows: 1) expose MWF fry at TAM concentrations at 50, 100, 500, 1000, 2000 and 5000 TAMS/fish at three months of age; and 2) expose four month old fry to 1000,2000 and $5000 \mathrm{TAMS} /$ fish. There will be a control group of MWF for each of the two exposure experiments. The objective will be to determine at what TAM exposure intensity significant mortality will occur and then each of the exposure groups will have histology work at WADDL. Attempt total spore counts to determine how many myxospores potentially are added to the streams.

- Attempt sentinel exposures in the wild in areas where vulnerability and fry overlap.

- Repeat MWF sampling at pre-disease population survey sites in tributaries in order to detect possible disease-related MWF population changes.

- Identify adult spawning and early rearing life histories of MWF within the Blackfoot River Basin and various tributaries in order to determine specific MWF streams at risk.

- Continue to monitor the MWF population in the upper Blackfoot River Canyon Creek section.

- Identify a funding source to complete juvenile life-history work and develop a more refined study through a $\mathrm{U}$ of $\mathrm{M}$ graduate study

\section{Literature Cited}

Anderson, R. B. 2004. Occurrence and seasonal dynamics of the whirling disease parasite, Myxobolus cerebralis, in Montana spring creeks. Master of Science Thesis, Montana State University.

Anderson, R. O., and R. M. Neuman. 1996. Length, weight and associated structural indices, pages 447-482 in B. R. Murphy and D. W. Willis editors. Fisheries techniques, $2^{\text {nd }}$ edition. American Fisheries Society. Bethesda, Maryland.

Barfoot, Craig. Fisheries biologist with the Confederated Salish and Kootenai Tribe. Personal communication.

Brown, C. J. P. 1952. Spawning habits and early development of the mountain whitefish, Prosopim williamsoni, in Montana. Copeia. 2:109-113.

Davies, R. W. and G. W. Thompson 1976. Movements of mountain whitefish (Prosopium williamsoni) in the Sheep River watershed, Alberta. Journal of Fisheriers Research Board Canada. 33:2395-2401.

Gelwicks, K. and D. Zafft. 2000. Effects of Myxobolus cerebralis on salmonids in the mainstem Salt River, Wyoming. Whirling Disease Symposium: Solutions to Whirling Disease: Putting the Pieces Together. Pp 95-97. Coeur d' Alene, Idaho.

MacConnell, E., A.V. Zale and M. Quinn. 2000. Susceptibility of mountain whitefish, Prosopium williamsoni, to Myxobolus cerebralis. USFWS Fish Health Laboratory, unpublished report.

MacConnell, E. and E. R. Vincent. 2002. Review: The Effects of Myxobolus cerebralis on the Salmonid Host. Pp. 95-108 in J.L. Bartholomew and J.C. Wilson, editors, Whirling Disease: Reviews and Current Topics. American Fisheries Society, Symposium 29. Bethesda, Maryland. 
McPhail, J. D. and P. M. Troff. 1998. The mountain whitefish (Prosopium williamsoni): a potential indicator species for the Fraser System. Environmental Conservation Branch Aquatic and Atmospheric Sciences Divisions, Vancouver BC DOE FRAP 1998-16.

Northcote, T, G. and G. L. Ennis. 1994. Mountain whitefish biology and habitat use in relation to compensation and improvement possibilities. Review in Fisheries Science. 2(4):347-371.

Pierce R., L. Eby, W. Bollman and D. Vincent. In review. Prediction of whirling disease in basin-fed streams of the Blackfoot Watershed, Montana. Submitted to Transactions of the American Fisheries Society. 
Table 1 : Catch and size statistics for MWF in the Blackfoot Basin.

\begin{tabular}{|c|c|c|c|c|c|c|c|c|c|c|c|}
\hline Stream & River Mile & Date Sampled & \begin{tabular}{|c|} 
Section \\
Length (ft)
\end{tabular} & $\begin{array}{c}\text { MWF } \\
\text { abundance }\end{array}$ & $\begin{array}{c}\text { Total Number } \\
\text { Captured }\end{array}$ & $\begin{array}{c}\text { Number Captured 1st } \\
\text { Pass }\end{array}$ & \begin{tabular}{c|} 
MWF $\left(<4.0^{\prime \prime}\right)$ \\
Captured 1st Pass
\end{tabular} & $\begin{array}{l}\text { Range of } \\
\text { Lengths (in) }\end{array}$ & \begin{tabular}{|c|} 
Mean \\
Length (in)
\end{tabular} & $\begin{array}{c}\text { Total CPUE } \\
\left(\# / 100^{\prime}\right)\end{array}$ & $\begin{array}{l}\text { YOYCPUE } \\
\left(\# / 100^{\prime}\right)\end{array}$ \\
\hline \multirow[t]{4}{*}{ Arrastra Creek } & 0.3 & 15-Sept-99 & 360 & Present & 75 & 75 & 75 & $3.0-3.14$ & 3.1 & 20.8 & 20.8 \\
\hline & 0.5 & 23-Aug-89 & 360 & Present & & & & & & & \\
\hline & 0.7 & 26-Aug-96 & 440 & $\begin{array}{l}\text { Present } \\
\text {. }\end{array}$ & 18 & 12 & 12 & $2.9-3.5$ & 3.2 & 2.7 & 2.7 \\
\hline & & 15-Sep-99 & 450 & Present & 32 & 32 & 32 & $3.0-3.7$ & 3.7 & 7.1 & 7.1 \\
\hline Beaver Creek & 0.2 & 24-Aug-89 & 477 & Present & 3 & 3 & 0 & $10.2-12.2$ & 11.4 & 0.6 & 0.0 \\
\hline \multirow[t]{2}{*}{ Belmont Creek } & 0.1 & 25-Jul-89 & 365 & Present & 2 & 2 & 2 & $3.3-3.6$ & 3.5 & 0.5 & 0.5 \\
\hline & & 9-Aug-01 & 576 & Present & 2 & 2 & 2 & $3.3-3.6$ & 3.5 & 0.3 & 0.3 \\
\hline Blackfoot River-Johnrud & 13.5 & 30-May-06 & 17680 & Common & & & & & & & \\
\hline Scotty Brown & 43.9 & 25-May-06 & 20064 & Common & & & & & & & \\
\hline Raymond Bridge & 59.5 & 26-Aug-99 & 5745 & Common & & & & & & & \\
\hline Wales Creek Section & 64 & 24-May-06 & 7603 & Common & 190 & 84 & 0 & $4.0-15.4$ & 10.4 & & \\
\hline \multirow[t]{2}{*}{ H2-0 ditch } & 83.7 & 24-Jul-95 & 525 & Common & 7 & 7 & 0 & $2.7-3.2$ & 2.9 & 1.3 & 0.0 \\
\hline & & 31-Aug-04 & 1000 & Common & 12 & 12 & 10 & $2.7-3.7$ & 3.3 & 1.2 & 1.0 \\
\hline Pocha Ditch (trap) 5/19-7/15/05 & 86.5 & 19-May-05 & & Present & 31 & 31 & 3 & $3.7-7.7$ & 4.6 & & \\
\hline Canyon reach & 95.3 & 20-Sep-06 & 5422 & Common & 277 & 177 & 0 & $3.9-16.3$ & 12.8 & & \\
\hline Poorman/Dalton Section & 107.2 & 21-Sep-06 & 6800 & Common & 4 & 4 & 0 & $12.6-15.5$ & 14.1 & 0.1 & 0.0 \\
\hline \multirow[t]{2}{*}{ Hefner Ditch } & 114 & 25-Jul-00 & 570 & Common & 10 & 10 & 10 & 2.7 & 2.7 & 1.8 & 1.8 \\
\hline & & 8-Aug-01 & 1340 & Common & 4 & 4 & 4 & $2.6-2.8$ & 2.7 & 0.3 & 0.3 \\
\hline Hogum Section & 119.6 & 11-Sep-06 & 4000 & Common & 18 & 15 & 2 & $3.5-15.3$ & 12.2 & 0.4 & 0.1 \\
\hline \multirow[t]{5}{*}{ Blanchard Creek } & 0.1 & 15-Sept-94 & 350 & Present & 11 & 9 & 9 & $3.1-3.8$ & 3.9 & 2.6 & 2.6 \\
\hline & & 14-Sep-95 & 420 & Present & 7 & 7 & 6 & $3.3-4.3$ & 3.8 & 1.7 & 1.4 \\
\hline & & 12-Aug-97 & 550 & Present & 1 & 0 & 0 & 3.1 & 3.1 & & \\
\hline & & 23-Sep-98 & 425 & Present & 4 & 0 & 0 & $3.7-4.3$ & 4.1 & & \\
\hline & & 19-Sep-02 & 310 & Present & 1 & 1 & 0 & & & 0.3 & 0 \\
\hline \multirow[t]{2}{*}{ Chamberlain Creek } & 0.1 & 22-Sept-89 & 200 & Present & & & & & & & \\
\hline & & 17-Sep-98 & 430 & Present & 1 & 1 & 0 & 4.1 & 4.1 & 0.2 & 0.0 \\
\hline \multirow[t]{2}{*}{ Clearwater Ditch } & 0.1 & $2-$ Sep-03 & 4224 & Present & 2 & 2 & 1 & $3.7-4.3$ & 4.0 & 0.0 & 0.3 \\
\hline & & 22-Sep-05 & 567 & Present & & & & & & & \\
\hline \multirow[t]{5}{*}{ Clearwater River } & 8.8 & 8-Aug-95 & & Present & 1 & 1 & 0 & 10.7 & 10.7 & & \\
\hline & 17.2 & 29-Aug-95 & 10496 & Present & 1 & 1 & 0 & 10.4 & 10.4 & 0.0 & 0.0 \\
\hline & 37.5 & 17-Jul-95 & 492 & Present & 1 & 1 & 0 & 9.4 & 9.4 & 0.2 & 0.0 \\
\hline & & 23-Jun-06 & 66 & Present & 2 & 2 & 0 & $8.6-8.7$ & & 3.0 & 0.0 \\
\hline & & 11-Jul-06 & 66 & Present & 4 & 4 & 0 & $7.3-7.9$ & & 6.1 & 0.0 \\
\hline Copper Creek & 1.1 & 2-Sep-04 & 555 & Present & 1 & 1 & & 7.4 & 7.4 & 0.2 & 0.0 \\
\hline \multirow[t]{5}{*}{ Cottonwood Creek } & 0.1 & 29-Aug-00 & 465 & Present & 2 & 2 & 2 & $3.6-3.7$ & 3.7 & 0.4 & 0.4 \\
\hline & & 16-Sep-02 & 450 & Present & 30 & 30 & 30 & $3.1-3.8$ & 3.4 & 6.7 & 6.7 \\
\hline & & 1-Oct-03 & 465 & Present & 1 & 1 & 0 & 4 & 4 & 0.2 & 0.0 \\
\hline & 4.7 & 28-Jul-92 & 240 & Present & 1 & 1 & 0 & 2.7 & 2.7 & 0.4 & 0.0 \\
\hline & 5.0 & 7-Jul-92 & 225 & Present & 3 & 3 & 0 & $15.2-15.6$ & 15.5 & 1.3 & 0.0 \\
\hline \multirow[t]{3}{*}{ Dick Creek } & 0.1 & 6-May-92 & 420 & Present & 4 & 4 & 0 & $7.9-11.0$ & 9.4 & 1.0 & 0.0 \\
\hline & & 6-Sep-01 & 360 & Abundant & & & & & & & \\
\hline & 0.8 & 6-May-92 & 243 & Present & 2 & 2 & 0 & $7.5-7.9$ & 7.8 & 0.8 & 0.0 \\
\hline \multirow[t]{5}{*}{ Elk Creek } & 0.1 & 3-Oct-91 & 198 & Present & 1 & 1 & 0 & 3.7 & 3.7 & 0.5 & 0.0 \\
\hline & & 5-Sep-00 & 375 & Present & 6 & 4 & 4 & $3.2-4.3$ & 3.6 & 1.1 & 1.1 \\
\hline & & 22-Sep-03 & 430 & Present & 72 & 42 & 24 & $3.1-4.8$ & 3.9 & 9.8 & 5.6 \\
\hline & 1.1 & 5-Sep-00 & 354 & Present & 3 & 2 & 2 & $3.6-3.9$ & 3.8 & 0.6 & 0.6 \\
\hline & 3.0 & 3-Oct-91 & 108 & Present & 2 & 2 & 0 & $4.5-4.7$ & 4.6 & 1.9 & 0.0 \\
\hline \multirow[t]{5}{*}{ Gold Creek } & 0.2 & 17-Aug-00 & 490 & Present & 2 & 2 & 1 & $3.7-7.2$ & 5.4 & 0.4 & 0.2 \\
\hline & & 16-Aug-01 & 510 & Present & 2 & 1 & 0 & 7.1-7.7 & 7.4 & 0.2 & 0.0 \\
\hline & 1.9 & 10-Aug-98 & 400 & Present & 1 & 0 & 0 & 7.6 & 7.6 & 0.0 & 0.0 \\
\hline & & 21-Aug- 00 & 387 & Present & 1 & 0 & 0 & 4.1 & 4.1 & & \\
\hline & 2.6 & 6-Aug-96 & 569 & Present & 1 & 1 & 0 & 11.6 & 11.6 & 0.2 & 0.0 \\
\hline \multirow[t]{2}{*}{ Hogum Creek } & 0.1 & 10-Aug-95 & 108 & Present & 1 & 1 & 0 & 2.6 & 2.6 & 0.9 & 0.0 \\
\hline & 0.4 & 28-Jul-99 & 405 & Present & 1 & 1 & 0 & 5.1 & 5.1 & 0.2 & 0.0 \\
\hline Hoyt Creek & 0.2 & 8-Sep-92 & 200 & Present & 28 & 20 & 17 & $3.1-5.0$ & 3.6 & 10.0 & 8.5 \\
\hline Landers Fork & 0.1 & 13-Sept-89 & 781 & Present & 1 & 1 & 1 & 3.5 & 3.5 & 0.1 & 0.1 \\
\hline \multirow[t]{2}{*}{ Marshall Creek } & 2 & 29-Jun-95 & 443 & Present & 1 & 1 & 0 & 8.7 & 8.7 & 0.2 & 0.0 \\
\hline & 3.7 & 29-Jun-95 & 394 & Present & 1 & 1 & 0 & 7.3 & 7.3 & 0.3 & 0.0 \\
\hline
\end{tabular}


Table 1 (cont.): Catch and size statistics for MWF in the Blackfoot Basin.

\begin{tabular}{|c|c|c|c|c|c|c|c|c|c|c|c|}
\hline Stream & River Mile & Date Sampled & $\begin{array}{c}\text { Section } \\
\text { Length }(\mathrm{ft})\end{array}$ & $\begin{array}{c}\text { MWF } \\
\text { abundance }\end{array}$ & $\begin{array}{l}\text { Total Number } \\
\text { Captured }\end{array}$ & $\begin{array}{c}\text { Number Captured 1st } \\
\text { Pass }\end{array}$ & $\begin{array}{c}\text { MWF (<4.0") } \\
\text { Captured 1st Pass }\end{array}$ & $\begin{array}{l}\text { Range of } \\
\text { Lengths (in) }\end{array}$ & $\begin{array}{c}\text { Mean } \\
\text { Length (in) }\end{array}$ & $\begin{array}{c}\text { Total CPUE } \\
\left(\# / 100^{\prime}\right)\end{array}$ & $\begin{array}{c}\text { YOY CPUE } \\
\left(\# / 100^{\prime}\right)\end{array}$ \\
\hline \multirow[t]{8}{*}{ Monture Creek } & 0.4 & 9-Aug-89 & 480 & Present & 2 & 2 & 0 & $10.2-10.5$ & 10.3 & 0.3 & 0.0 \\
\hline & & 21-Aug-02 & 446 & Present & 1 & 1 & 1 & $2.4-3.2$ & 2.8 & 0.2 & 0.2 \\
\hline & 2.2 & 16-Aug-00 & 204 & Present & 1 & 1 & 1 & 3.7 & 3.7 & 0.5 & 0.5 \\
\hline & 5.4 & 16-Aug-00 & 456 & Present & & & & & & & \\
\hline & & 18-Aug-05 & 460 & Present & 1 & 1 & 1 & 2.5 & 2.5 & 0.2 & 0.2 \\
\hline & 8.6 & 14-Aug-02 & 680 & Present & & & & & & & \\
\hline & 12.9 & 25-Sep-68 & 400 & Present & 2 & 2 & 2 & $2.4-2.7$ & 2.5 & 0.4 & 0.4 \\
\hline & 13.9 & 25-Sep-68 & 400 & Present & 1 & 1 & 1 & 2.7 & 2.7 & 0.2 & 0.2 \\
\hline \multirow[t]{7}{*}{ Nevada Creek } & 0.3 & 14-Sep-00 & 465 & Present & 12 & 12 & 0 & 5.9 & 5.9 & 2.6 & 0.0 \\
\hline & 0.7 & 1-Nov-89 & 650 & Present & 2 & 2 & & $4.0-4.2$ & 4.1 & 0.3 & 0.0 \\
\hline & 5.1 & 29-Sep-05 & 6336 & Present & 60 & 60 & 3 & $3.3-8.8$ & 4.7 & 0.9 & 0.0 \\
\hline & 27 & 5-Jul-00 & 600 & Present & & & & & & & \\
\hline & 29.0 & 12-Apr-90 & 400 & Present & 2 & 2 & 0 & $11.6-12.8$ & 12.2 & 0.5 & 0.0 \\
\hline & & 9-Aug-94 & 430 & Present & 1 & 0 & 0 & 8.6 & 8.6 & 0.0 & 0.0 \\
\hline & & 27-Sep-00 & 522 & Abundant & & & & & & & \\
\hline \multirow[t]{4}{*}{ Nevada Spring Cr. } & 0.8 & 21-Sep-04 & 500 & Present & 1 & 0 & 0 & 5.2 & 5.2 & 0.0 & 0.0 \\
\hline & 1.1 & 15-Sep-05 & 500 & Present & 1 & 1 & 0 & 4.1 & 4.1 & 0.2 & 0.0 \\
\hline & 2.8 & 26-Sep-00 & 450 & Present & 1 & 1 & 0 & 4 & 4.0 & 0.2 & 0.0 \\
\hline & & 18-Sep-01 & 450 & Present & 1 & 1 & 0 & 4.4 & 4.4 & 0.2 & 0.0 \\
\hline North Fork snorkel survey & 1.2 & 19-Sep-85 & 12150 & Present & 17 & 17 & & & & 0.1 & \\
\hline \multirow[t]{3}{*}{ Blackfoot River } & 2.6 & 10-Aug-89 & 590 & Present & 4 & 4 & 0 & $6.4-11.7$ & 9.1 & 0.7 & 0.0 \\
\hline & & 10-Sep-98 & 770 & Present & 1 & 1 & 1 & 3.5 & 3.5 & 0.1 & 0.1 \\
\hline & & 22-Aug-02 & 660 & Present & & & & & & & \\
\hline \multirow[t]{5}{*}{ NF snorkel survey } & 4.0 & 17-Sep-85 & 20430 & Present & 305 & 305 & & & & 1.5 & \\
\hline & & 29-Aug-98 & 20430 & Abundant & & & & & & & \\
\hline & 7.6 & 29-Aug-02 & 850 & Present & 3 & 3 & 3 & $3.1-3.5$ & 3.3 & 0.4 & 0.4 \\
\hline & 7.9 & 16-Aug-89 & 735 & Present & 6 & 6 & 1 & $3.6-10.7$ & 8.2 & 0.8 & 0.1 \\
\hline & & 15-Aug-00 & 672 & Present & 1 & 1 & 1 & 2.6 & 2.6 & 0.1 & 0.1 \\
\hline \multirow[t]{3}{*}{ Weaver ditch at road xing } & 10.4 & 23-Sep-94 & 300 & Present & 2 & 2 & 1 & $3.1-4.0$ & 3.6 & 0.7 & 0.3 \\
\hline & & 28-Aug-96 & 375 & Present & 4 & 4 & 0 & - & - & 1.1 & 0.0 \\
\hline & & 13-Aug-02 & 450 & Present & 12 & 12 & 12 & $1.8-2.4$ & 2.1 & 2.7 & 2.7 \\
\hline Weaver ditch at road xing & & 22-Sep-94 & 210 & Present & 38 & 38 & 12 & $3.1-4.5$ & 4.1 & 18.1 & 5.7 \\
\hline Rangitch Ditch at N.F. mile 11.6 & 11.6 & 23-Aug-05 & 300 & Present & 1 & 1 & 1 & 2.8 & 2.8 & 0.3 & 0.3 \\
\hline Rowland Fish camp & 12 & 15-Aug-89 & 757 & Present & 1 & 1 & 1 & 2.7 & 2.7 & 0.2 & 0.2 \\
\hline NF snorkel survey & 15.5 & 19-Aug-85 & 18480 & Present & 77 & 77 & & & & 0.4 & \\
\hline Lund Ditch at N.F & 15.5 & 24-Aug-05 & 310 & Present & 8 & 8 & 8 & $2.3-2.9$ & 2.6 & 2.6 & 2.6 \\
\hline \multirow[t]{2}{*}{ Owl Creek } & 1.2 & 23-Aug-90 & 500 & Present & 1 & 1 & 1 & 3.2 & 3.2 & 0.2 & 0.2 \\
\hline & 4.2 & 19-Jul-95 & 50 & Present & 7 & 7 & 0 & $10.4-12.2$ & 11.7 & 14.0 & 0.0 \\
\hline Rock Creek & 0.0 & 2-Aug-94 & 385 & Present & 3 & 3 & 3 & $2.0-3.5$ & 2.6 & 0.8 & 0.8 \\
\hline \multirow[t]{2}{*}{ Wales Creek } & 0.1 & 8-Aug-00 & 396 & Present & 30 & 30 & 30 & 3.1 & 3.1 & 7.6 & 7.6 \\
\hline & & 6-Oct-03 & 391 & Present & 3 & 2 & 2 & $3.0-3.7$ & 3.2 & 0.5 & 0.5 \\
\hline \multirow[t]{6}{*}{ Warren Creek } & 0.1 & 11-Oct-91 & 186 & Present & 58 & 47 & 22 & $3.2-4.5$ & 3.9 & 25.3 & 11.8 \\
\hline & & 11-Sep-00 & 294 & Present & 6 & 4 & 3 & $3.0-4.1$ & 3.6 & 1.4 & 1.0 \\
\hline & 0.4 & 11-0ct-91 & 180 & Present & 13 & 10 & 1 & $3.8-4.7$ & 4.3 & 5.6 & 0.6 \\
\hline & 1.1 & 11-Sep-02 & 576 & Present & 1 & 0 & 0 & 3.2 & 3.2 & & \\
\hline & & 8-Sep-04 & 345 & Present & 1 & 0 & 1 & 3.7 & 3.7 & & \\
\hline & 2.1 & 12-Sep-00 & 333 & Present & 3 & 2 & 2 & $3.8-4.1$ & 4.0 & 0.6 & 0.6 \\
\hline \multirow[t]{2}{*}{ West Fork Clearwater River } & 2.3 & 22-Aug-06 & 492 & Present & 2 & 2 & 1 & $3.5-4.0$ & 3.7 & 0.4 & 0.2 \\
\hline & 3.3 & 23-Aug-06 & 492 & Present & 2 & 2 & 1 & $3.3-4.2$ & 3.7 & 0.4 & 0.2 \\
\hline
\end{tabular}




\title{
RESULTS PART VI: Other special studies
}

\section{Fluvial westslope cutthroat trout movements and restoration relationships in the upper Blackfoot Basin, Montana}

\author{
Ronald W. Pierce, Ryen B. Aasheim, Craig S. Podner, \\ Montana Fish, Wildlife and Parks, Missoula, Montana 59804
}

\begin{abstract}
We telemetered fluvial westslope cutthroat trout (Oncorhynchus clarki lewisi, WSCT) in order to relate migratory life history traits to restoration opportunities in the upper Blackfoot Basin (upstream of the North Fork confluence) of Montana. Telemetry confirmed life-history similarities to fish of the lower basin but also identified higher fidelity to spawning areas and mainstem pools as well as movements through intermittent channels to headwater spawning areas. Anthropogenic influences limit fluvial WSCT abundance and their ability of reproduce and place sensitive areas of the Blackfoot River environment at increased risk. Road crossings, riparian grazing and irrigation practices, primarily in tributaries of the Garnet Mountains, adversely influence fluvial WSCT from the tributary to sub-basin scales. Localized life history characteristics demonstrated in the upper Blackfoot River environment confirm the value of fisheries investigations at reach and regional scales. Understanding local life history strategies is vital when planning fluvial native fish recovery in watersheds of geo-spatial and anthropogenic variability. Telemetry results indicate that WSCT conservation and recovery in the upper Blackfoot basin will rely on restoration of tributaries, protection of intermittent channels, changes in grazing and timber harvest practices on alluvial stream channels and careful management of private ponds (to avoid hybridization). These assessments identified a fundamental need to work with private landowners for fluvial WSCT recovery at a metapopulation scale to be effective.
\end{abstract}

Key words: upper Blackfoot River, telemetry, movement, fluvial WSCT, tributary restoration, private land,

Pierce, R., R. Aasheim and C. Podner. 2007. Fluvial westslope cutthroat trout movements and restoration relationships in the upper Blackfoot Basin, Montana. Intermountain Journal of Sciences Volume 13 (2). 


\section{INTRODUCTION}

Concern over the declines in both abundance and distribution of westslope cutthroat trout (WSCT) throughout the subspecies range have prompted fisheries managers to attempt to identify the mechanisms responsible for declines and develop effective conservation and recovery programs (Behnke 1992, Shepard et al. 1997, 2003, Pierce et al. 2005). Historical accounts suggest WSCT were once abundant in river systems of western Montana (Lewis 1805, Behnke 1992, Shepard et al. 2005), where populations expressed a range of migratory (fluvial and adfluvial) and stream-resident life history traits (Behnke 2002, Shepard et al. 2003). Fluvial WSCT often occupy large home ranges, spawn in tributaries where the young rear for up to three years, migrate to a large river to mature and then return as adults to their natal tributaries to spawn (Schmetterling 2001, Behnke 2002). Fluvial WSCT have become increasingly rare as a result of habitat loss and degradation, competition with non-native fishes, genetic introgression and fish passage barriers (McIntyre and Reiman 1995, Shepard 2003), all of which are common in the Blackfoot watershed (Pierce et al. 2005).

Radio telemetry has recently been used to elucidate migratory life history traits of native trout species in the lower Blackfoot Basin (i.e. from the North Fork downstream; Swanberg 1997, Schmetterling 2001), such as extensive spawning migrations (>80 km) to natal tributaries by WSCT (Schmetterling 2001, 2003). Telemetered native trout have also helped to identify specific population recovery and protection actions at critical sites; validate restoration assumptions; and monitor fluvial use of completed restoration projects (Swanberg 1997, Schmetterling 2001, Pierce et al. 2004). Two examples of these applications include Dunham Creek and Chamberlain Creek, both recently restored tributaries to the lower Blackfoot River. Dunham Creek involved a bull trout (Salvelinus confluentus) tagged in the lower Blackfoot River, tracked to an unknown and severely altered (channelized) spawning site, and then entrained in an irrigation ditch during the out-migration (Swanberg 1997). This information, generated during the formative years of bull trout recovery planning, led to restoration of the channelized site and screening of the Dunham ditch (Pierce et al 2002), and contributed to the designation of Dunham Creek as proposed critical habitat for bull trout under the Endangered Species Act (USFWS 2002). The second example is Chamberlain Creek, a tributary to the lower Blackfoot river where, after chronic issues such as dewatering, entrainment, grazing and channel alterations were remediated (Pierce et al 1997), telemetered WSCT indicate that fluvial adults were beginning to use the tributary for spawning in greater numbers (Schmetterling 2001). And higher numbers (densities) of WSCT continue to persist in this stream, years after the restoration efforts (Pierce et al. 2006). The results from these and other telemetry-based investigations have been integrated into monitoring and restoration planning allowing these activities to be targeted more efficiently. However, these applications have focused primarily on the lower Blackfoot basin and other sub-basins within the Blackfoot watershed (Clearwater River Basin and upper Blackfoot River Basin) have not been emphasized.

Because of the successful interface between understanding life history traits through applied research and restoration planning and implementation in the lower Blackfoot Basin, we investigated fluvial adult WSCT movements and related our findings to anthropogenic impairments in upper Blackfoot basin where WSCT are present (Pierce et al. 2004). We hypothesized the physical and human environment of the upper Blackfoot basin would locally influence WSCT movement patterns, and areas with low densities of fluvial WSCT therein would reflect human disturbance of aquatic habitat. Study objectives were to 1) describe movement patterns of fluvial WSCT in 
the upper Blackfoot Basin following Schmetterling (2001), and 2) discuss restoration implications by comparing known upper basin impairments (Pierce et al 2004) with movement of adult WSCT as well as spawning, summering and wintering needs in the upper Blackfoot Basin. The purpose of this study is to characterize seasonal movements over a sub-basin scale so that specific recovery actions can be directed at important, but anthropogenically impaired habitat and movement corridors with the goal of conserving and restoring the fluvial WSCT life history in the upper Blackfoot Basin.

\section{STUDY AREA}

The Blackfoot River, a $5^{\text {th }}$ order tributary (Strahler 1957) of the upper Columbia River, lies in west-central Montana and flows west $211 \mathrm{~km}$ from the Continental Divide to its confluence with the Clark Fork River at Bonner, Montana (Figure 1). The Blackfoot River drains a $3,728 \mathrm{~km}^{2}$ watershed through $3,040 \mathrm{~km}$ of perennial streams, and discharges a mean annual flow of $45.2 \mathrm{~m}^{3} / \mathrm{s}$ (United States Geological Survey 2004). Higher elevation, glaciated mountains to the north and a lower relief, nonglaciated landscape to the south define the physical geography of the Blackfoot watershed. Northern tributary streams begin in high cirque basins and flow through alluviated glacial valleys, where sections of stream are often seasonally intermittent. The Garnet Mountains to the south of the Blackfoot River produce small streams that are naturally perennial to the Blackfoot River although most are anthropogenically degraded or dewatered during the irrigation season. Lands in the upper Blackfoot Basin are mostly public $(65 \%)$ headwater areas, with the private lands consisting primarily of timbered foothills and agricultural bottomland.

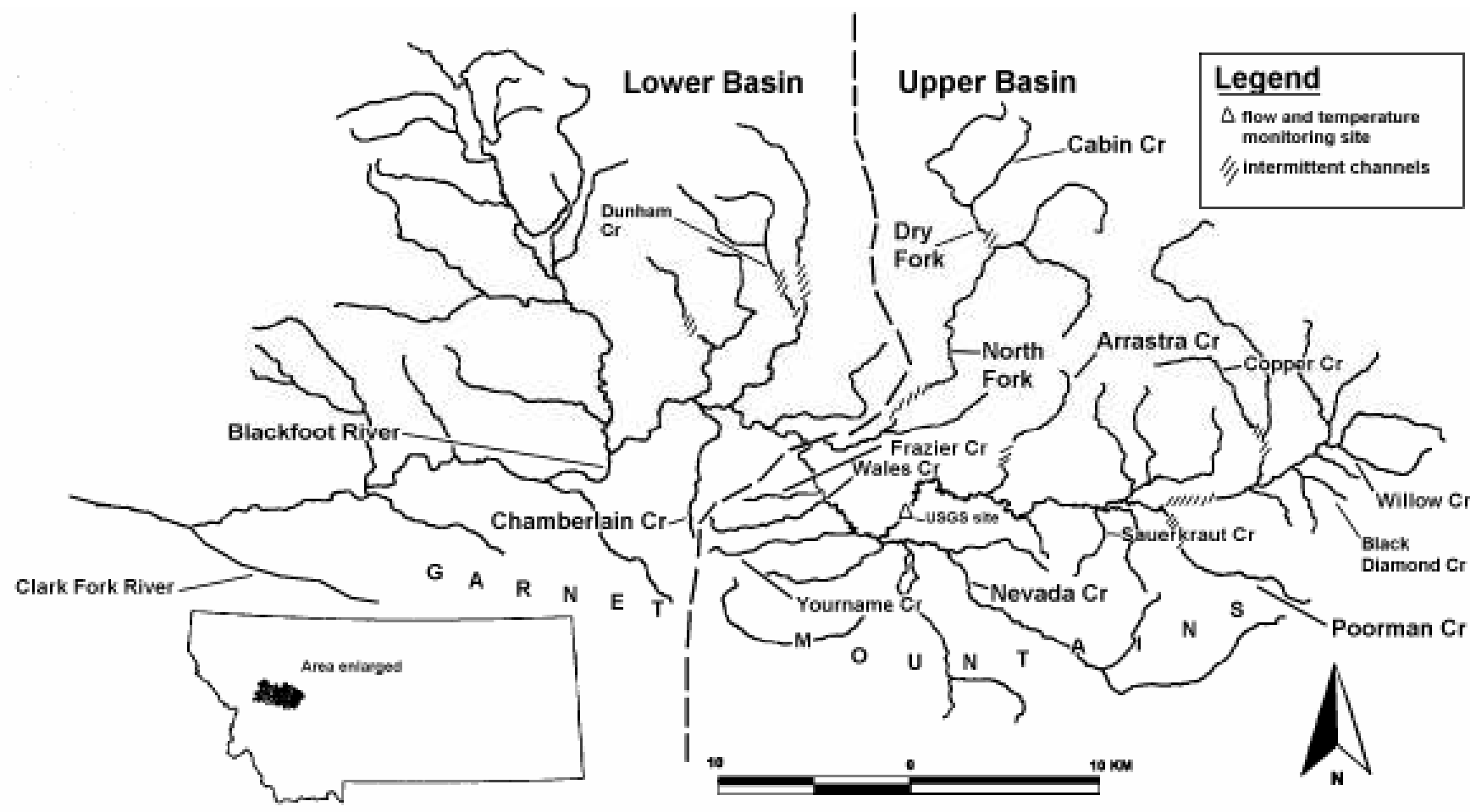

Figure 1. Study area: upper Blackfoot River Basin with water temperature and flow monitoring station and intermittent stream channels.

The regional (natural and human-induced) variability of the basin is further 
expressed within the valley of the Blackfoot River. The upper Blackfoot River occupies a lower gradient, alluvial channel with long segments without tributary input, and those tributaries that are present are often seasonally intermittent or degraded in lower reaches often as a result of agricultural activities. The upper river supports low instream (secondary) productivity and water quality impairment from non-point agricultural sources increases between Nevada Creek and the North Fork Blackfoot River (Ingman et al. 1990). At the junction of the North Fork, the divide between the upper and lower basins, the lower Blackfoot River receives a large influx of colder water, which reduces summer water temperature, improves water quality and approximately doubles the base flow of the lower Blackfoot River (Ingman et al. 1990, Pierce et al 2006, United States Geological Survey 2006). Contained by glacial boulders and bedrock, the lower river channel is steeper, geomorphically stable and bedrock controlled. The lower Blackfoot River has higher secondary productivity (Ingman et al. 1990) and much higher densities of WSCT than the upper Blackfoot River (Pierce et al. 2004). The density of adult WSCT in the upper mainstem Blackfoot River near Nevada Creek are as low as $4 / \mathrm{km}$ compared to $58 / \mathrm{km}$ in the lower Blackfoot River near Chamberlain Creek and few, if any, fluvial WSCT from the lower Blackfoot River migrate to the upper Blackfoot basin upstream of the North Fork confluence (Schmetterling 2001, 2003, Pierce et al. 2006).

Unlike the lower Blackfoot basin and despite no isolating mechanism, the upper Blackfoot Basin is absent of fluvial rainbow trout $(O$. mykiss) reproduction with the exception of Wales Creek (Shepard et al. 2003, Pierce et al. 2005). Here, WSCT occupy about 90 percent of headwater tributaries although population abundances usually decrease in the downstream direction due to tributary alterations (Pierce et al. 2004). The loss of spawning areas has been identified as a major reason for the decline and low abundance of WSCT within the upper Blackfoot River. Correcting anthropogenic impairments in the upper Blackfoot Basin is increasingly a restoration focus (Blackfoot Challenge 2005), but prior to this study no attempt has been made to identify problems specifically affecting fluvial WSCT.

Within the upper Blackfoot Basin, the first $88 \mathrm{~km}$ of upper mainstem Blackfoot River above the confluence of the North Fork Blackfoot River is naturally stratified into three (hereafter upper, middle and lower) reaches, among which anthropogenic impairments are spatially variable (Pierce et al 2004). The upper reach extends 33.4 river kilometers (rkm) from Poorman Creek (rkm 174.2) to Arrastra Creek (rkm 140.8) and is a densely wooded C4 alluvial channel-type (Rosgen 1996). This reach begins at the downstream end of an intermittent section of the mainstem where groundwater and spring creek inflows reenter the mainstem Blackfoot River. The middle reach, also a C4 channel-type, extends $32.5 \mathrm{~km}$ from Arrastra Creek downstream to Nevada Creek (rkm 108.3). This reach is less wooded and the channel loses slope, becomes highly sinuous, prone to bank erosion and deposition of fine sediment. Riparian livestock grazing is more common in downstream areas (Marler 1997, Confluence Consulting 2003) and the lower section of this reach is increasingly dewatered during the irrigation season (Pierce et al 2005). Other than at reach boundaries no tributaries enter the middle reach. The lower reach extends $22.3 \mathrm{~km}$ from Nevada Creek, a water quality (nitrate, phosphate, total suspended solids and temperature) impaired tributary, to the mouth of the North Fork (rkm 86) (Ingman et al. 1990, Pierce et al. 2006). Below Nevada Creek, the Blackfoot River transitions from a low gradient alluvial (C4) channel to a more confined, higher gradient geologically controlled (B3 and F3) channel (Rosgen 1996). Several small but degraded and dewatered tributaries enter this reach from the Garnet Mountains (Pierce et al. 2005). 


\section{METHODS}

\section{Radio telemetry}

WSCT were captured in the upper Blackfoot River, phenotypically identified, implanted with continuous radio Lotek ${ }^{\mathrm{TM}}$ transmitters (between 13 March - 18 April 2002 and 18 March - 13 April 2003) and tracked fish through one full spawning migration cycle. Visual identification was later verified through genetic analysis of fin clips using 17 fragments of nuclear DNA at the University of Montana, Trout and Wild Salmon Genetics Laboratory (Boecklen and Howard 1997). Transmitters were evenly distributed (10-11 per reach) within each of the three study reaches. Fish were captured prior to spring run off, presumably prior to spawning migrations (by angling or electrofishing) in suspected wintering pools. Individually coded transmitters weighed $7.7 \mathrm{~g}$, had an estimated life of 450 days, did not exceed 2 percent of fish weight (Winters 1997) were implanted following standard surgical methods (Swanberg 1997, Schmetterling 2001).

Fish were located from the ground, using either an omni-directional whip antenna mounted on a truck or a hand held three-element Yagi antenna when walking. When ground tracking failed to locate a fish, we relied on fixed wing aircraft flying approximately 100-200 meters above the river, equipped with a three-element Yagi antenna attached to the wing strut. Similar to Schmetterling (2001), fish were located at least three times per week immediately prior to and during spring migrations and spawning, once-per week while holding in tributaries or the Blackfoot River following spawning, and once per month thereafter. For each ground-based relocation within a habitat unit, we triangulated the fish's location to within an estimated $5 \mathrm{~m}$ and recorded with the location using GPS.

Within tributaries and the Blackfoot River, locations were expressed as the distance upstream from the mouth in river kilometers. Following Schmetterling (2001), fish were assumed to have spawned if they ascended a stream (or river reach) with suitable spawning habitats during a spring spawning period, and the upper-most location was the assumed spawning site. Because of high flows and poor instream visibility, we were unable to visually validate spawning at most assumed spawning areas. We therefore relied on the presence of juvenile (age 0 and I) WSCT within $<2$ $\mathrm{km}$ of all identified spawning areas (FWP unpublished data) to support spawning site assumptions. The mean date between two contacts surrounding an event, such as a migration start or spawning date was used to estimate the date of an event (Schmetterling 2001). We considered relocations from November through April to represent winter habitat use, while a spring spawning-migration period was delineated from May through 14 July and summer habitat use from 15 July through October.

Blackfoot River daily discharge data were obtained from U.S. Geological Survey (USGS) gauging station (No. 12335100) located in the middle reach at rkm 115.5 to examine potential relationships between discharge and fish movement. We also placed thermographs (Onset ${ }^{\mathrm{TM}}$ ) at the USGS guage to evaluate the effect of maximum daily water temperature on the onset of migration and spawning. We used the FWP "dewatered stream list" to identify naturally intermittent reaches (Pierce et al. 2005), and we compared the basin area above intermittent channels between the lower and upper Blackfoot subbasins. 
Because of small sample size, all first-year WSCT spawners from 2002 and 2003 were grouped by reach and reach differences were then tested by the dates migrations began and dates WSCT entered tributaries using a Kruskal-Wallis one way analysis of variance (ANOVA) on ranks. To explore between-year (2002 and 2003) differences influencing the onset of movement and spawning, we compared daily water temperatures for the May through 14 July spawning migration period using paired $t$ test. Mann-Whitney rank sum tests were then used to test between-year differences in the dates migrations began and the date first year WSCT spawners entered tributaries. Potential associations between date migrations began and total pre-spawning distance moved, and spawning tributary size (drainage area) and number of days WSCT spent in each of these tributaries was assessed with linear regressions. Second-year (repeat) spawners were tracked in 2003 but not included in our analyses because of the limited transmitter life during the second migration/spawning period. All results were tested at the alpha 0.05 level of significance.

\section{RESULTS}

Over the course of this study we tagged and tracked 31 WSCT to spawning sites, and those fish with active transmitters were then tracked to summering and wintering areas. These 31 fish were located each an average of 39 times (range: 17-88) between the March 2002 and December 2004 study period. Four spawners tagged in 2002 were tracked as repeat spawners in 2003 and these fish were used to identify spawning site fidelity. Twenty-nine $(94 \%)$ of the 31 fish tested genetically pure WSCT. Two fish (6\%) contained all WSCT genetic markers plus two of seven rainbow trout genetic markers and were classified as post-F1 generation hybrids (Martin 2004). Because of their visual WSCT features the low level of hybridization we included these fish in our analyses. Overall, twenty-eight (90\%) fish migrated to tributaries, while three migrated to spawning sites in the upper main stem Blackfoot River during the two-year study (Figure 2, Table 1).
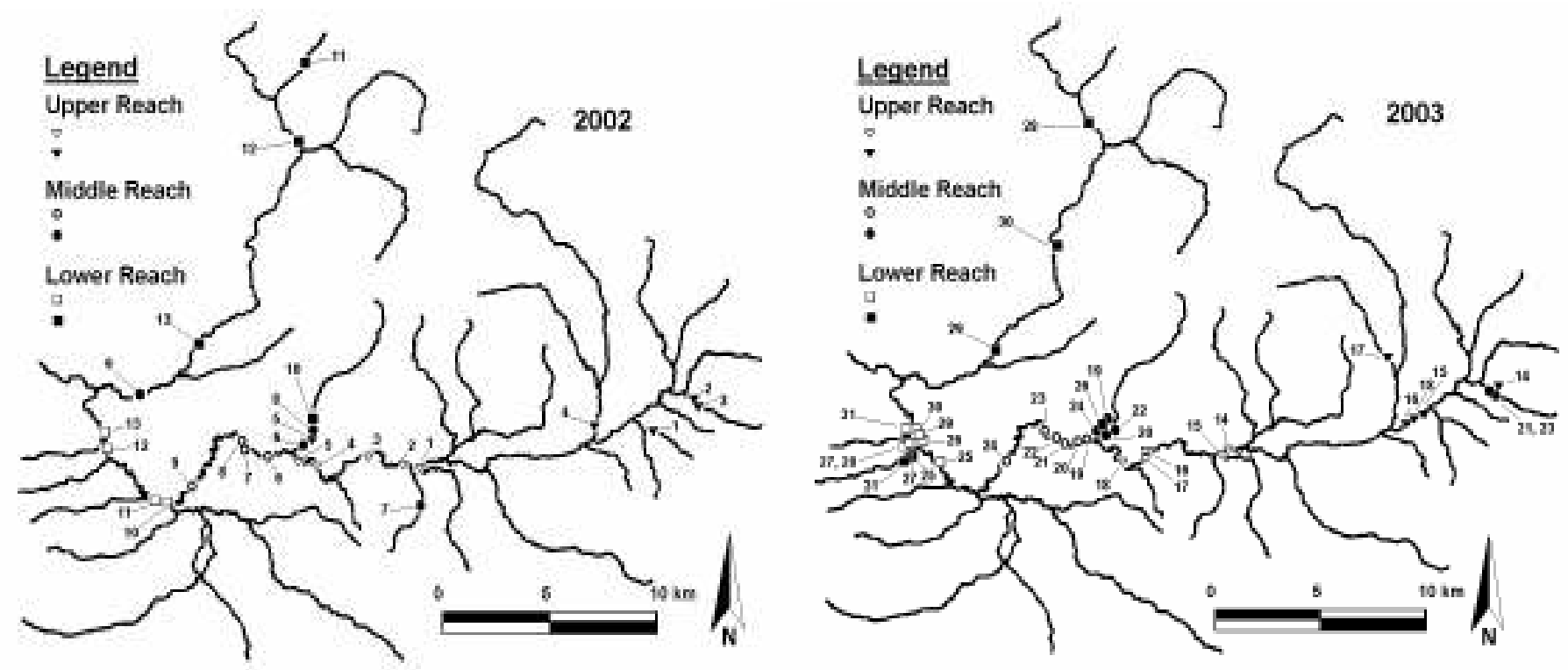

Figure 2. Capture locations (open symbols) and assumed spawning sites (closed symbols) of telemetered WSCT for 2002 (left) and 2003 (right). Numbers refer to individuals in Table 1.

During the migration and spawning periods, river temperatures were similar between 2002 and 2003 ( $\mathrm{P}=0.29)$, and WSCT migrations began on the rising limb of the hydrograph as temperatures approached $4{ }^{\circ} \mathrm{C}$ (Figure 3). Twenty-two WSCT 
migrated upstream, nine moved downstream and one repeat spawner (fish \# 8) moved upstream (in 2002) and downstream (in 2003) before ascending spawning streams. The period of migration in the Blackfoot River averaged 16 days and fish moved an average of 21 $\mathrm{km}$ in the Blackfoot River before reaching spawning tributaries or main stem spawning sites (Table Tributary spawners entered spawning streams at mean water temperatures of 6-7 ${ }^{\circ} \mathrm{C}$ and migrated another $8 \mathrm{~km}$ to spawning sites.

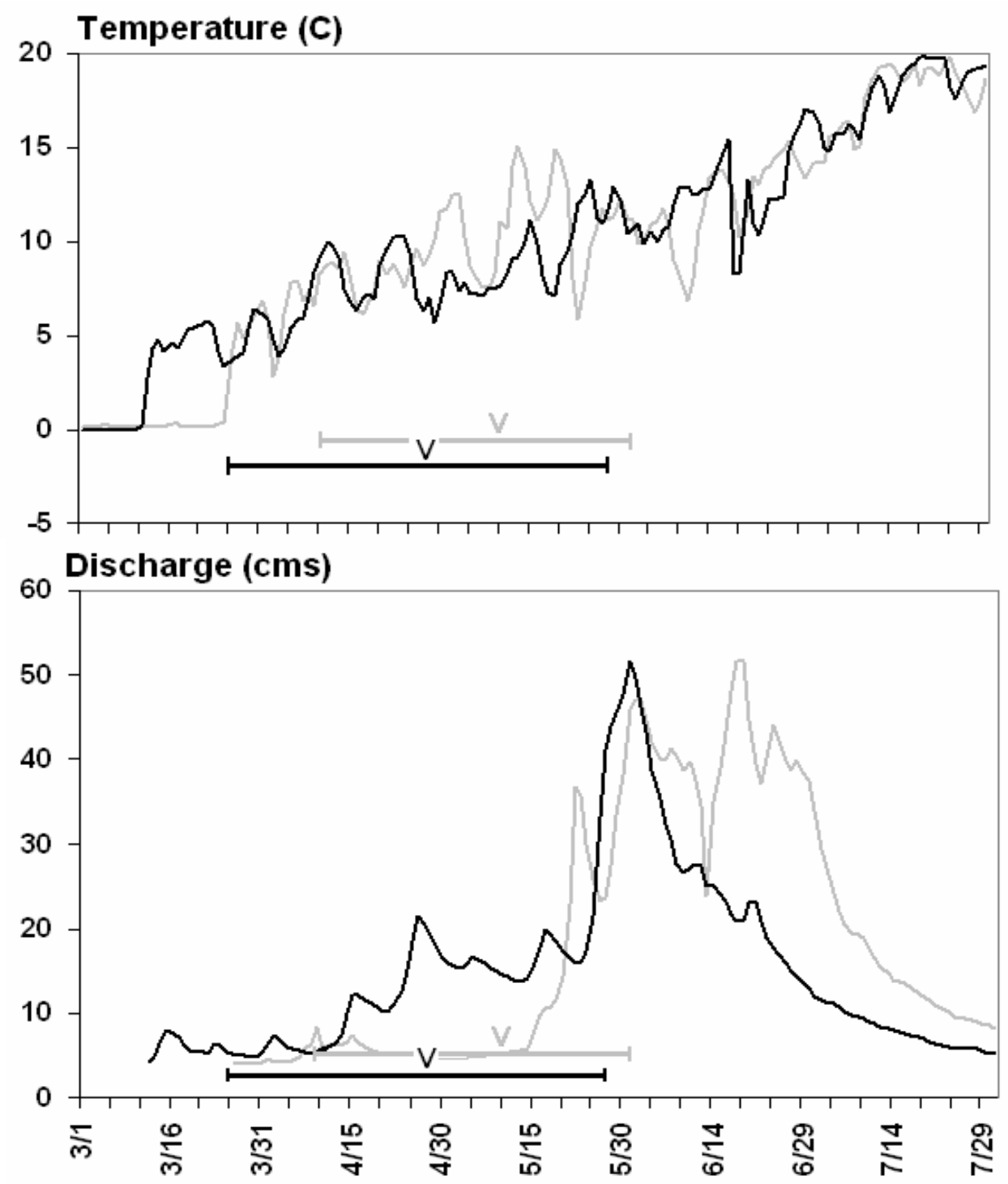

Figure 3. Relationships of water temperature (top) and discharge (bottom) to dates WSCT began migrations (range and median) in 2002 Among (grey) and 2003 (black). The range is shown by the horizontal bar and the three median migration start date by vertical arrows.

reaches, the start

of spawning migrations incrementally increased in the upstream direction from 29 April in the lower reach, to 1 May (middle reach) to 4 May in the upper reach, however differences were not significant (ANOVA, $\mathrm{P}=0.89$ ). Between years, WSCT began their spawning migrations 17 days later (13 April versus 26 March) in 2002 (range: 54 days) than in 2003 (range: 61 days). Although slight annual variation was detected (P $=0.085)$ differences were not significant. Likewise, the starting dates of WSCT migrations were not associated with the distance moved $\left(\mathrm{R}^{2}=0.08 \mathrm{P}=0.24\right)$.

Overall WSCT spawning occurred in nine tributaries varying from $1^{\text {st }}$ to $4^{\text {th }}$ order (see Table 1 and Figure 2 for locations). Arrastra Creek and Willow Creek supported the highest proportion of telemetered spawners ( 9 or $29 \%$ and 5 or $16 \%$ ) respectfully, and each of these tributaries also had at least one 2002 repeat spawner return in 2003. WSCT entered tributaries from mid-April through mid-June (mean date: May 16). There were no significant differences in the date WSCT entered 
spawning tributaries either among reaches (ANOVA, $\mathrm{P}=0.42)$ or between years $(\mathrm{P}=$ 0.17). WSCT spent an average 51 days in tributaries (range 4-402) and spent significantly different amounts of time in the seven different spawning tributaries $\left(\mathrm{R}^{2}=\right.$ $0.36, \mathrm{P}=0.002$ ), staying the longest in the largest tributary, the North Fork.

The majority of WSCT tagged in the lower river reach (6 of 11 or 55\%) migrated downriver to the lower reach boundary before ascending the North Fork for spawning $(n=3)$ or two tributaries to the upper North Fork (Dry Fork $(n=2)$ and Cabin Creek $(n=1))$. Three other lower reach fish entered Wales Creek $(n=3)$, a tributary adjacent to the lower reach; while two ascended the middle river reach to spawn in Arrastra Creek (located at the middle-upper reach boundary). Most ( 9 of 10 or $90 \%$ ) WSCT tagged in the middle river moved upriver to either Arrastra Creek $(n=6)$, Sauerkraut Creek (a tributary to the upper river reach, $n=1$ ), or through the upper reach to Willow Creek $(\mathrm{n}=2)$. Only one middle reach fish migrated downriver before ascending the North Fork. Similar to middle reach fish, most (9 of 10) WSCT originally in the upper river reach migrated upriver, however unlike the concentrated spawning of most middle reach fish, spawning of upper reach WSCT was dispersed

Table 1. Summary of capture locations, spawning movements sites and dates, time spent in tributaries and fate of post-spawning WSCT, 2002 and 2003; PM = post spawning mortality.

\begin{tabular}{|c|c|c|c|c|c|c|c|c|c|c|}
\hline \multirow{2}{*}{$\begin{array}{l}\text { Year } \\
\text { and } \\
\text { reach }\end{array}$} & \multirow[b]{2}{*}{$\begin{array}{l}\text { Fish } \\
\text { no. }\end{array}$} & \multirow[b]{2}{*}{$\begin{array}{l}\text { River capture } \\
\text { location (rkm) }\end{array}$} & \multirow[b]{2}{*}{$\begin{array}{c}\text { Prespawning } \\
\text { direction }\end{array}$} & \multicolumn{2}{|c|}{ Prespawning distance $(\mathrm{km})$} & \multirow[b]{2}{*}{$\begin{array}{c}\text { Spawning } \\
\text { stream }\end{array}$} & \multirow{2}{*}{$\begin{array}{c}\text { Use of } \\
\text { intermittent } \\
\text { reach }\end{array}$} & \multirow[b]{2}{*}{$\begin{array}{c}\text { Spawning } \\
\text { date }\end{array}$} & \multirow[b]{2}{*}{$\begin{array}{c}\text { Days in } \\
\text { trib. }\end{array}$} & \multirow[b]{2}{*}{ Fate } \\
\hline & & & & River & Tributaries & & & & & \\
\hline 2002 & 1 & 165.3 & upstream & 25.4 & 2.1 & Black Diamond & yes & 1-Jun-02 & 7 & radio expired \\
\hline \multirow[t]{4}{*}{ upper } & 2-rpt & 163.5 & upstream & 34.4 & 0.6 & Willow $\mathrm{Cr}$ & yes & 24-May-02 & 6 & radio expired \\
\hline & 3-rpt & 152.8 & upstream & 45.1 & 1.1 & Willow $\mathrm{Cr}$ & yes & 30-May-02 & 11 & radio expired \\
\hline & 4 & 148.3 & upstream & 37.5 & 1.3 & Landers Fork & yes & 23-Jun-02 & 12 & summer mort \\
\hline & 5-rpt & 142.4 & downstream & 0.3 & 3.4 & Arrastra $\mathrm{Cr}$ & no & 9-Jun-02 & 60 & radio expired \\
\hline \multirow[t]{4}{*}{ middle } & 6 & 139 & upstream & 3.5 & 1.1 & Arrastra $\mathrm{Cr}$ & no & 7-Jun-02 & 47 & radio expired \\
\hline & 7 & 132.3 & upstream & 31 & 3.7 & Sauerkraut $\mathrm{Cr}$ & no & 3-Jun-02 & & $\mathrm{PM}$ in trib \\
\hline & 8-rpt & 131.4 & upstream & 10.8 & 4.2 & Arrastra $\mathrm{Cr}$ & no & 29-Jun-02 & 153 & radio expired \\
\hline & 9 & 113.8 & downstream & 27.5 & 4.5 & North Fork & no & 11-Jul-02 & 142 & died in river \\
\hline \multirow[t]{4}{*}{ lower } & 10 & 103.5 & upstream & 38.6 & 5.4 & Arrastra $\mathrm{Cr}$ & no & 7-Jun-02 & 12 & radio expired \\
\hline & 11 & 103.5 & downstream & 14.3 & 50.4 & Cabin $\mathrm{Cr}$ & yes & 27-Jun-02 & 406 & radio expired \\
\hline & 12 & 95.8 & downstream & 11.1 & 41.9 & Dry Fork & yes & 23-Jun-02 & 93 & PM in trib-avian \\
\hline & 13 & 94.2 & downstream & 6.4 & 14.4 & North Fork & yes & 25-Jun-02 & 47 & $\mathrm{PM}$ in trib-avian \\
\hline 2003 & 14 & 165.8 & upstream & 32.2 & 1.4 & Willow $\mathrm{Cr}$ & yes & 14-May-03 & 7 & died in original pool \\
\hline \multirow[t]{4}{*}{ upper } & 15 & 165.6 & upstream & 22.6 & & Blackfoot River & yes & 1-Jun-03 & & unknown \\
\hline & 16 & 152.8 & upstream & 36.2 & & Blackfoot River & yes & 21-May-03 & & radio expired in trib \\
\hline & 17 & 152.8 & upstream & 33 & 7.7 & Copper $\mathrm{Cr}$ & yes & 21-May-03 & 5 & radio expired \\
\hline & 18 & 147.7 & upstream & 41.8 & & Blackfoot River & yes & 25-May-03 & & poached \\
\hline \multirow[t]{6}{*}{ middle } & 19 & 139.5 & upstream & 2.6 & 2.7 & Arrastra $\mathrm{Cr}$ & no & 17-May-03 & & PM in trib-avian \\
\hline & 20 & 139.5 & upstream & 2.6 & 1.1 & Arrastra $\mathrm{Cr}$ & no & 10-Jun-03 & 30 & died in original pool \\
\hline & 21 & 137.6 & upstream & 60.3 & 1.3 & Willow $\mathrm{Cr}$ & yes & 17-May-03 & 29 & radio expired \\
\hline & 22 & 134.6 & upstream & 7.2 & 1.6 & Arrastra $\mathrm{Cr}$ & no & 25-May-03 & 6 & radio expired \\
\hline & 23 & 131.4 & upstream & 66.9 & 1.3 & Willow $\mathrm{Cr}$ & yes & 4-Jun-03 & 4 & poached \\
\hline & 24 & 115.4 & upstream & 26.7 & 1 & Arrastra $\mathrm{Cr}$ & no & 19-May-03 & & $\mathrm{PM}$ in trib-avian \\
\hline \multirow[t]{7}{*}{ lower } & 25 & 101.4 & downstream & 13.8 & 0.3 & Wales $\mathrm{Cr}$ & $\overline{\text { no }}$ & 19-May-03 & & PM in trib-avian \\
\hline & 26 & 96.2 & upstream & 45.9 & 1 & Arrastra $\mathrm{Cr}$ & no & 29-May-03 & & $\mathrm{PM}$ in trib \\
\hline & 27-hyb & 96 & upstream & 2.9 & 0.6 & Wales $\mathrm{Cr}$ & no & 21-Apr-03 & 13 & $\mathrm{PM}$ in river \\
\hline & 28 & 96 & downstream & 10.9 & 43.2 & Dry Fork & yes & 19-Jun-03 & & $\mathrm{PM}$ in trib \\
\hline & 29 & 95.7 & downstream & 9.8 & 12.2 & North Fork & yes & 10-Jun-03 & 80 & $\mathrm{PM}$ in trib-avian \\
\hline & 30 & 95.2 & downstream & 9.3 & 28.5 & North Fork & yes & 19-Jun-03 & & radio expired in trib \\
\hline & 31-hyb & 94.2 & upstream & 2 & 1.1 & Wales $\mathrm{Cr}$ & no & 19-Jun-03 & & $\mathrm{PM}$ in trib \\
\hline
\end{tabular}

among several spawning sites including Copper Creek $(n=1)$, Landers Fork $(n=1)$ and Black Diamond Creek $(n=1)$, Willow Creek $(n=3)$ and the upper main stem of the Blackfoot River $(n=3)$. One upper reach fish moved downriver to Arrastra Creek.

Of the 31 WSCT that spawned in 2002 and 2003, $13(42 \%)$ died soon after spawning. Seven of the surviving eighteen WSCT (39\%) returned from tributaries to summer in their original capture pool locations within 1-55 days (mean: 22). Six others (33\%) (including two mainstem spawners) returned to summer within an average of 4.3 
$\mathrm{km}(1.1-11.4 \mathrm{~km})$ of their mainstem capture locations. Five $(28 \%)$ remained in their spawning tributaries during the summer.

Of the 18-tagged WSCT that survived into summer, we monitored eleven at wintering locations ( 1 November -30 April). Most (six) WSCT that summered at original captures remained there into winter and two additional fish that summered upstream moved downstream to (or within $<1.0 \mathrm{~km}$ ) of their original pool capture site, while two $(18 \%)$ over-wintered 11.2 and $25.1 \mathrm{~km}$ from their original capture sites. One WSCT originally captured in a pool in the Blackfoot River near rkm 103.5 in 2002 over-wintered in the North Fork (rkm 31.8) the following year, a distance of $51 \mathrm{rkm}$ between wintering sites. We observed a majority of wintering WSCT using large pools with complex wood associations and fish exhibited very little movement during the winter. The remaining seven WSCT either died or their transmitters expired prior to winter.

Ten WSCT (40\%) captured in 2002 were still alive with working transmitters in 2003. Four of these fish $(40 \%)$ were repeat spawners with three returning to spawn in the same stream they had used in 2002, and all within one km of the previous year's spawning location. The fourth fish returned to the mouth of the tributary (Willow Creek) it had used the previous year, within $1.1 \mathrm{~km}$ of the previous spawning site, at which point the transmitter expired and contact was lost.

\section{DISCUSSION}

\section{Movement patterns}

Fluvial WSCT of the upper Blackfoot River expressed migratory characteristics similar to those in the lower Blackfoot River (Schmetterling 2001). Spawning movements of fluvial WSCT began with increasing water temperatures just prior to the rising limb of the hydrograph, at which point adult spawners moved either up or down river before entering spawning tributaries near the peak of the hydrograph. Repeat spawning was common and spawners remained in larger tributaries significantly longer than smaller tributaries and post-spawning mortality was high. Telemetry failed to confirm mainstem spawning within the three study reaches, however spawning migrations to potential spawning sites in the upper-most Blackfoot River were observed. Unlike other studies that showed more discrete use of lower-order tributary streams (Magee et al. 1996), our results were similar to the lower Blackfoot River study as we identified spawning across $1^{\text {st }}$ through $4^{\text {th }}$ order tributary streams.

Despite many similarities to WSCT of the lower basin, we detected certain spawning site and mainstem habitat use differences compared to Schmetterling (2001). Adult WSCT fidelity to both spawning and main stem sites was higher in our study. Spawning site fidelity for WSCT has previously been documented (Magee et al. 1996), but was not apparent in the lower Blackfoot Basin where two repeat spawning migrants did not return to their previous year's spawning location (Schmetterling 2001). However, the small sample size of repeat spawners in the lower Blackfoot Basin limits the strength of this comparison. Nonetheless, all repeat spawners returned to or within $1.1 \mathrm{~km}$ of previous spawning sites, suggesting spawning sites may be more limiting in the upper Blackfoot Basin, prompting higher fidelity, a premise supported by lower WSCT densities in the upper Blackfoot River. We also found higher fidelity to wintering sites with $73 \%$ of post-spawning fish returning to their original pool capture locations compared with $11 \%$ in the lower basin study. These differences suggest a lower number of preferred wintering pools in the upper river compared with the lower Blackfoot River where pools are larger and geologically stable. In our study, we 
observed wintering in larger pools, a pattern of habitat use confirmed in similar studies (Brown and Mackay 1995, Schmetterling 2001, Dare and Hubert 2002).

A majority of WSCT (55\%) from the upper Blackfoot River ascended naturally intermittent reaches (i.e. channels dry during base flows) to access upstream spawning sites, compared with 4 percent in the lower river study (Schmetterling 2001). Including the North Fork basin, forty-eight percent of the upper basin lies upstream of naturally intermittent channels, compared to 10 percent of the lower basin. This use of natural intermittent channels likely reflects both a higher number of intermittent channels in the upper Blackfoot Basin and more suitable spawning sites found in smaller streams upstream of intermittent reaches. Interestingly, all telemetered WSCT migrating through naturally intermittent reaches from spawning sites returned prior to no flow periods with no related mortality.

WSCT spatial/temporal migration patterns were inconsistent among reaches and seem to reflect both natural and anthropogenic influences. As an example, upriver migrations for a majority of middle reach spawners to Arrastra Creek suggests a pattern influenced by the lack of natural tributaries downstream of there. Conversely, the lack of spawning at several tributaries in the area of Nevada Creek suggests the anthropogenic loss of natal connections influencing lower reach WSCT. Although not significantly different, lower reach WSCT began migrations earlier and these migrations were on average longer in both distance $(4.3 \mathrm{~km})$ and duration (8 days) compared to the combined upper reaches despite the near proximity to several tributaries. Unlike the upper two reaches, lower reach fish exhibited a downriver movement pattern, and spawners sustained a surprising high level of post-spawning mortality $(73 \%)$ compared with middle and upper reaches (combined total $=27 \%$ ). Similar to an evaluation with Yellowstone cutthroat trout (Clancy 1988), lower reach difference seem to be influenced by the loss of recruitment sources from adjacent Garnet Mountains tributaries and coincide with impaired water quality and very low densities of fluvial WSCT in the Blackfoot River near Nevada Creek (Pierce et al. 2004).

\section{Restoration Implications}

The upper Blackfoot River fluvial WSCT conservation strategy calls for metapopulation function and enhancing "core" populations of genetically "pure" WSCT (Shepard et al 2003). This strategy relies on access between mainstem habitats in the upper Blackfoot River and suitable spawning tributaries over a large area. The majority of perturbations to WSCT habitat in the Blackfoot Basin, including altered habitat and passage issues, occur in the lower reaches of most tributaries, primarily on private land (Pierce et al. 2004; 2005). These impairments include over-grazing in riparian areas (32 streams), road crossings (28 streams), irrigation structures (fish passage and entrainment) and irrigation-related flow problems (23 streams) and historical placer mining (12 streams) (Pierce et al. 2004, 2006). Although private lands in the upper Blackfoot Basin comprise only 35 percent of the land base, they contained the majority of WSCT spawning sites (64\%), migration corridors (69\%) and wintering areas $(80 \%)$ documented in this study. Thus successful application of the conservation strategy includes correcting human-caused impairments affecting WSCT on private land.

Compared to the lower Blackfoot Basin, the fidelity of fluvial upper River WSCT to pools and observations of cover associations suggests heightened preference to pool with instream wood, as identified in other studies (Brown and Mackay 1995). Using a census of large instream wood as an index to these habitat requirements, Pierce et al. (2004) measured a significant (89\%) decrease in amount of large instream wood between the upper and lower reaches. These findings identify a need to manage for the 
recruitment of large wood to the Blackfoot River channel between Arrastra Creek and the North Fork.

In a region where land use is dominated by traditional agriculture, tributary fish population inventories indicate a pattern of fewer WSCT in the lower reaches of 32 of 46 tributaries in the upper Blackfoot Basin (Pierce et al. 2005). Our telemetered fluvial WSCT entered only one tributary (Wales Creek) between the North Fork and Arrastra Creek, a distance of $55.5 \mathrm{rkm}$. Consistent with recent population trends that show very little WSCT use in lower reaches of other tributaries to the lower river reach (Pierce et al. 2004), we found no fluvial use of Nevada Creek (or its tributaries), Yourname Creek and Frazier Creek, a large contiguous area comprising $43 \%$ of the upper Blackfoot Basin upstream of the North Fork, despite stream-resident WSCT widely distributed throughout the headwaters of these streams. Between the mainstem Blackfoot River and resident WSCT populations in the upper tributaries, dewatering, habitat degradation (e.g. overgrazing) and low water quality are identified fisheries impairments (Ingman et al. 1990, Pierce et al. 2001, Blackfoot Challenge 2005), but correctable with alternative agricultural practices.

Between the North Fork and Arrastra Creek, only lower Wales Creek received limited spawning use by three WSCT, and this was downstream of an on-channel irrigation reservoir. Of these fish, two did not survive spawning potentially due to irrigation-induced low flows. Furthermore, Wales Creek, the lower-most spawning site identified in this study, is within the upper range of the rainbow trout in the watershed and contains private fishponds with rainbow trout. Both of the WSCT that showed rainbow trout hybridization in our study entered Wales Creek. With the exception of the North Fork, all other individual WSCT in our study spawned in tributaries supporting genetically unaltered WSCT stocks (Pierce et al. 2005). These findings confirm the risks of introducing hybridizing species into ponds and lakes within the range of WSCT in the upper Blackfoot Basin.

Arrastra Creek, the next identified upstream spawning stream, $45.4 \mathrm{~km}$ upstream of Wales Creek, received the highest spawning use of all streams, including WSCT from all reaches as well as the majority of WSCT tagged in the middle reach. However, these fish all spawned downstream from a set of impassable culverts. Compared to the concentrated spawning in Arrastra Creek, the majority of upper reach WSCT spawning was dispersed among headwater tributaries and the mainstem Blackfoot River upstream of an intermittent segment of the Blackfoot River. As important migration corridors intermittent reaches such as this should be managed within the context of migration and downriver recruitment. However, critical fisheries are not often associated with seasonally dry channels and Montana's stream protection laws do not offer intermittent streams the same legal protection as perennial streams without the consent of local conservation districts.

\section{CONCLUSIONS}

Variability within the physical and cultural landscape of the Blackfoot watershed influences the expression of fluvial life histories and habitat use at various spatial scales. Understanding this variability within a context of anthropogenic limiting factors is a vital step towards developing concise restoration actions for fluvial WSCT. We believe the links between human impairments and spawning limitations in the upper Blackfoot River are supported by: 1) reach-related low densities of WSCT in the River where adjacent spawning tributaries are no longer functional or accessible, 2) the concentrated use of the few available nearby tributary spawning sites between the North Fork and Arrastra Creek, and 3) movement differences and high mortality of the lower reach WSCT spawners. These links elucidate the value of the few existing 
spawning sites and a need to restore habitat and access at sites with high quality spawning and recruitment potential, particularly those near the lower and middle reaches. This study identifies a clear need to engage private landowners, county road departments and conservation districts in restoration work. Based on the proven ability of the stakeholders within the Blackfoot watershed to find solutions to identified fisheries problems, we expect this information will facilitate the development of specific fluvial WSCT restoration actions.

\section{ACKNOWLEDGEMENTS}

We thank Northwestern Energy, the Big Blackfoot Chapter of Trout Unlimited, Helena National Forest and U.S. Fish and Wildlife Service-Partners for Fish and Wildlife for project funding and other support. Fisheries technician responsible for data collections included Winston Morton and Sibley Ligas-Malee. Key volunteers included Jeff Everett and Don Peters. The H2-O Ranch and manager Kevin Ertle provided a field bunkhouse. We thank all the landowners that allowed access to streams. Finally, the comments of David Schmetterling, Brad Shepard, Pat Byorth and Carter Kruse and two anonymous reviewers improved the quality of this report.

\section{LITERATURE CITED}

Behnke, R. 1992. Native trout of western North America. American Fisheries Society monograph 6. American Fisheries Society. Bethesda, MD.

Behnke, R. 2002. Trout and salmon of North America. Chanticleer Press, New York.

Blackfoot Challenge. 2005. A basin-wide restoration action plan for the Blackfoot Watershed.

Boecklen, W. J. and Howard, D. J. 1997. Genetic analysis of hybrid swarms: numbers of markers and power of resolution. Ecology 78 (8) pp. 2611-2616.

Brown, R. S., and Mackay, W. C. 1995. Spawning ecology of cutthroat trout (Oncorynchus clarki) in the Ram River, Alberta. Canadian Journal of Fisheriesand Aquatic Sciences 52: 983-992.

Chapman, D. W., and E. Knutsen. 1980. Channelization and livestock impacts on salmonid habitat and biomass in western Washington. Transactions of the American Fisheries Society. 109 (4):357-363.

Clancy, C. G. 1988. Effects of dewatering on spawning by Yellowstone cutthroat trout in tributaries to the Yellowstone River, Montana. Pages 37-41 in R. R Gresswell, editor. Status and management of interior stocks of cutthroat trout. American Fisheries Society, Symposium 4, Bethesda, Maryland.

Confluence Consulting, 2003. Blackfoot headwaters planning area water quality and habitat restoration plan and TMDL for sediment. A draft report to the Blackfoot Challenge and Montana DEQ.

Dare, M. R. and W. A Hubert. 2002. Changes in habitat availability and habitat use and movements by two trout species in response to declining discharge in a regulated river during winter. North American Journal of Fisheries Management 22(3):917-928.

Ingman, G, L., M.A. Kerr and D.L. McGuire. 1990. Water quality investigations in the Blackfoot River drainage, Montana. Department of Health and Environmental Services, Helena, Montana.

Jakober, M, J., T. E. McMahon, R. F. Thurow and C. Clancy. 1998. Role of stream ice and fall and winter movement and habitat use by bull trout and cutthroat trout in Montana headwater streams. Transactions of the American Fisheries Society. 127(2):223-235.

Kanda, N., R. F. Leary, P. Spruell, and F. W. Allendorf. 2002. Molecular genetic 
markers identifying hybridization between Colorado River-greenback cutthroat trout complex and Yellowstone cutthroat trout or rainbow trout. Transactions of the American Fisheries Society 131:312-319.

Lewis, M. 1805. Lewis and Clark Expedition journal entry 13 June.

Magee, J. P., T. E. McMahon, and R. F. Thurow. 1996. Spatial variation in spawning habitat of cutthroat trout in a sediment-rich stream basin. Transactions of the American Fisheries Society 125(5):768-779.

Marler, M. 1997. Riparian health and inventory of the Blackfoot River between Nevada Creek and the North Fork Confluence: A GIS mapping project. Report to Montana Fish, Wildlife and Parks, Missoula, MT.

Martin, A. E. 2004. WSCT genetics lab report. Wild Trout and Salmon Genetics Laboratory, Division of Biological Sciences, University of Montana, Missoula.

Meehan, W. R., editor. 1991. Influence of forest and rangeland management on salmonid fishes and their habitats. American Fisheries Society Special Publication 19.

McIntyre, J. D., and B. E. Reiman, 1995. Westslope WSCT. Pages 1-15 in M. K. Young, editor. Conservation assessment for inland WSCT. U. S. Forest Service General Technical Report. RM-256.

Peters, D. 1990. Inventory of fishery resources in the Blackfoot River and major tributaries to the Blackfoot River. Montana Department of Fish, Wildlife and Parks, Missoula, Montana.

Pierce, R., D. Peters and T. Swanberg. 1997. Blackfoot River restoration progress report. Montana Fish Wildlife and Parks, Missoula, Montana.

Pierce et al 2002. The Blackfoot River Fisheries Inventory, Restoration and Monitoring Progress Report for 2001. Montana Fish Wildlife and Parks, Missoula Montana.

Pierce, R., R. Anderson and C. Podner. 2004. The Big Blackfoot River Restoration Progress Report for 2002 and 2003. Montana Fish Wildlife and Parks, Missoula Montana.

Pierce, R., R. Aasheim and C. Podner. 2005. An integrated stream restoration and native fish conservation strategy for the Big Blackfoot River basin. Montana Fish Wildlife and Parks, Missoula, Montana.

Pierce, R. and C. Podner. 2006. The Big Blackfoot River Restoration Progress Report for 2004 and 2005. Montana Fish Wildlife and Parks, Missoula Montana.

Rosgen, D. 1996. Applied Fluvial Geomorphology. Wildland Hydrology, Pagosa Springs Colorado.

Schmetterling, D. A. 2001. Seasonal movements of fluvial westslope cutthroat trout in the Blackfoot River drainage, Montana. North American Journal of Fisheries Management 21 (3):507-520.

Schmetterling, D. A. 2003. Reconnecting a fragmented river: movements of westslope cutthroat trout and bull trout after transport upstream of Milltown dam, Montana. North American Journal of Fisheries Management. 23 (3):721-731.

Shepard, B. B., B. E May and W. Urie. 2003. Status of westslope cutthroat trout (Onchorhunchs clarki lewisi) in the United States: 2002. A report to the Westslope Cutthroat Interagency Conservation Team.

Strahler, A.N. 1957. Quantitative analysis of watershed geomorphology. Transactions, American Geophysical Union 38:913-920.

Swanberg, T. R. 1997. Movements of and habitat use by fluvial bull trout in Blackfoot River. Transactions of the American Fisheries Society 126:735-746.

USFWS. 2002. Draft recovery plan for the bull trout and proposed critical habitat. U. S. Fish and Wildlife Service, Portland Oregon. 
USGS 2004, 2006. Gauging stations 12335100 and 12340000 provisional unpublished data.

Winters, J. D. 1996. Advances in underwater biotelemetry. Pages 555-590 in B.R. Murphy and D. W. Willis, editors. Fisheries Techniques, $2^{\text {nd }}$ edition. American Fisheries Society, Bethesda, Maryland. 


\section{An integrated stream restoration and native fish conservation strategy for 182 streams in the Blackfoot Basin, Montana}

\section{Introduction}

The Blackfoot River Fisheries Initiative continues to expand with restoration and conservation becoming more inclusive of native fish, water quality, instream flows and landscape protection. As such, the need for an inclusive clearly defined native fish conservation strategy for Blackfoot Basin has emerged. This need originates from 1) an expanded number (and scope) of watershed interest groups, 2) a cadre of federal, state and regional fisheries management directives, and 3) the recent development of drought, sub-basin and TMDL plans, NRCS fisheries-related EQIP projects and the recent development of Native Fish Habitat Conservation Plan (HCP) strategies.

To foster fisheries-related conservation endeavors, FWP recently developed an integrated stream restoration and native fish conservation strategy for 108 waterbodies of the Blackfoot Basin (Pierce et al. 2005). Although valuable to the broader restoration program, this planning document was also deficient because it failed to include large areas of the Blackfoot Basin where fisheries data was lacking. These areas include the Clearwater River Basin, the "backcountry" and heavily damaged streams in the upper Blackfoot Mining complex. With the recent initiation of native fish telemetry studies and the completion of fisheries data collections in these areas (Clearwater Basin (49 streams), the backcountry (19 streams), and mining areas (6 streams)), we are now able to generate a prioritization strategy for the entire Blackfoot River Basin.

The guiding purpose of this planning document is to develop a cohesive restoration and conservation strategy that directs stakeholder involvement to common priorities involving the needs of native fish. Native fisheries are indicators of ecosystem heath, and their recovery has become an FWP Fisheries Division priority. To this end, this plan provides a basin-wide, native fisheries-based, priority-driven template for restoration projects and expands upon the gains of the existing Blackfoot River Restoration Program. Our rationale for generating this report was that by integrating all fisheries-related restoration programs into a single guiding strategy, the Blackfoot Cooperators could better meet a common suite of conservation goals. For detailed review of restoration prioritization, we refer the reader to the original strategy (Pierce, Aasheim and Podner 2005).

Specific objectives of this report are to:

1. Provide a planning strategy to guide restoration activities of the Montana Fish, Wildlife and Parks (FWP), U.S. Fish and Wildlife Service, Blackfoot Challenge, The Nature Conservancy, Big Blackfoot Chapter of Trout Unlimited and other restoration partners.

2. Expand on an existing fisheries-based stream restoration prioritization ranking system (Pierce, Aasheim and Podner 2005) to include all inventories waters of the Blackfoot Basin

3. Re-prioritize all FWP currently inventoried streams to a hierarchical strategy that includes the Clearwater Basin. 


\section{Procedures}

We incorporated 74 additional tributaries inventoried since 2005 into the original matrix of 108 streams (Appendix K). The new matrix includes five reaches of the Clearwater River 1) mouth to the Salmon Lake outlet, 2) Salmon lake to Seeley Lake outlet, 3) Seeley lake to the outlet of Lake Inez (fish barrier), 4) Lake Inez to outlet of Rainy Lake (fish barrier), and, 4) Rainy lake to the headwaters. We then re-prioritized and ranked all inventoried waterbodies on a hierarchical point system that includes 1) native fish values (70 points), 2) total fisheries values (90 points), 3) total biological values (150 points), and finally 4) total values (200 possible points).

FWP fisheries personnel were given the job of assigning data input and corresponding point values to the matrix. Scoring of some criteria (primarily social and financial considerations) necessarily relied on past landowner interviews, direct knowledge of tributaries, along with professional expertise and judgment for inventoried non-project streams.

For the biological benefits section of the matrix, streams with documented bull trout use received scores of 10,20,30 or 40 points, depending on whether the stream supported spawning (20 points), rearing (10 points) or is a designated bull trout "core area" stream (10 points). Compared with other criteria, streams supporting bull trout received more points due to their: 1) "threatened" status under ESA along with State and Federal priorities for the recovery of this species; 2) high potential for improvement in the Blackfoot watershed; and 3) downstream and sympatric benefits to other species resulting from bull trout recovery efforts.

For streams supporting WSCT, an additional zero, 10 or 20 points were possible, depending on whether a stream supported no WSCT (zero points), resident WSCT (10 points) or fluvial WSCT use (20 points). Fluvial WSCT streams received a higher score than streams supporting resident fish due to 1) the precarious status of the fluvial life-history, 2) high sport fish value to the Blackfoot River, and 3) downstream and sympatric benefits to other species resulting from WSCT recovery efforts. Streams with fluvial WSCT status (20 points) were those identified through 1) telemetry studies, 2) direct observations of fluvial-sized fish by FWP fisheries personnel, or 3) direct tributaries to the Blackfoot River and biologically connected during high flows periods.

Streams received an additional zero, 10 or 20 points based on sport fishery value to the Blackfoot River. Streams with no sport fishery value (disjunct from the Blackfoot River) received zero points, single species sport fishery value (non-disjunct usually with WSCT) received 10 points, while non-disjunct streams that provide recruitment of multiple species (bull trout, WSCT, rainbow and brown trout) to the Blackfoot River received 20 points. We assumed connected streams supporting rainbow trout, brown trout and bull trout provided sport fishery value to the Blackfoot River. We assumed small non-direct and non-fluvial headwater tributaries to support primarily resident WSCT, and as such, these were not considered as providing sport fishery value to the Blackfoot River. We did not consider brook trout in this ranking due to their limited use of the Blackfoot River and adverse biological impacts to native species.

Stream restoration technical feasibility was also considered with zero points for not feasible and 20 points for streams considered technically feasible to restore. Large instream reservoirs (e.g. upper Nevada Creek, Frazier Creek, and Wales Creek), over-appropriated water rights (e.g. lower Nevada Creek), major highway problems (eg. Chimney Creek), and fully restored (e.g. Grantier Spring Creek) were considered not technically feasible to restore for the purposes of this report.

In addition to fisheries and feasibility criteria, streams with potential to increase instream flows (e.g. irrigation salvage potential) in the Blackfoot River were allotted 20 points. Finally, under the biological ranking section, streams with potential to improve downstream water quality by reducing 1) instream sediment (10 points), 2) water temperature (10 points), and 3) nutrient loading (10 points) could earn up to an additional 30 points. This water quality point 
system is based on FWP assessments and judgment based on field observations

For social and financial considerations, we used three criteria: 1) landowner and land manager cooperation (5, 10, 15 or 20 points) - a measure of perceived landowner cooperation; 2$)$ cost-effectiveness $(5,10$ or 20 points $)$ - an estimate of project cost $/ \mathrm{mile}$; and 3$)$ demonstration/educational value of potential projects (5 or 10 points) - a measure of project uniqueness, judgments of landowner interest and project access.

We transferred matrix values of all 182 streams to an EXCEL spreadsheet and then spatially converted the matrix to an Arcview GIS shape-file where priorities were classified and displayed. Streams were classified hierarchically first by: 1) native species score, 2) then by total fisheries score, 3) biological score, and finally 4) total score. All native species scores (7 classes) and total fisheries scores (9 classes) are presented. Biological scores and total scores were grouped by class values that approximated the 0-33, 34-66, and 67-100 cumulative percentiles, and these were assigned a respective high, moderate and low priority values.

\section{Prioritization shortcomings}

It is important to note that our ranking criteria does not consider many complex restoration-related issues, such as: 1) fisheries potential of sites, 2) potential contribution to connected systems, 3) severity of impacts, 4) population size, 5) native and non-native species interactions, 6) WSCT genetic composition, 6) numerical water quality standards and criteria, or 7) industrial-scale timber harvesting practices, public land or hard-rock mine drainage issues, or 8) other specific agency programs geared toward fisheries and water quality improvements. Rather, these issues should be considered at the project development phases. Our prioritization scheme attempts to guide the limited resources of the Blackfoot Cooperators to biologically important tributaries located primarily on private land. Although the prioritization is intended to guide restoration activities, as new information becomes available and as additional limiting factors are identified low priorities may be elevated potentially triggering restoration action. We recognize unique restoration opportunities may be presented, and that continued input from landowners and managers will help guide the Blackfoot River restoration initiative. 


\section{Restoration Priorities}

The hierarchy of the matrix is summarized below first by native fish priorities (Figure 1, Table 1) followed by total fisheries priorities (Figure 2, Table2) and biological score (Figure 3, Table 3 ) and finally by total restoration priority groupings (Figure 4, Table 4).

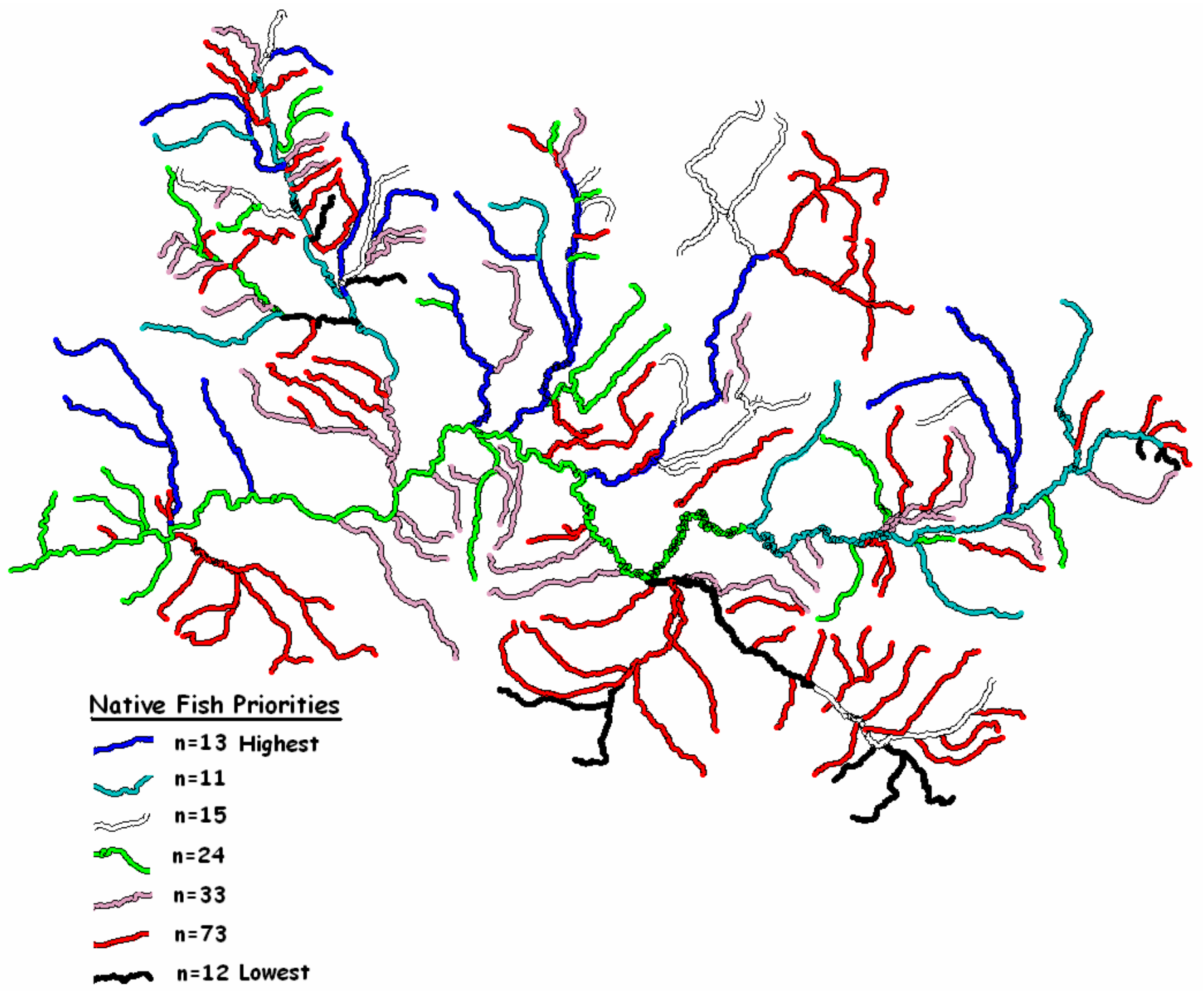

Figure 1. Native fish restoration priorities for the Blackfoot River Basin. Classes show the number of individual streams by priority grouping (Table 1). The highest scores are migratory bull trout and WSCT streams and the lowest scores possess little or no migratory native fish value to the Blackfoot River. 


\begin{tabular}{|c|c|c|c|c|c|c|c|}
\hline Stream Name & \begin{tabular}{|c|} 
Native \\
Species Total \\
Score
\end{tabular} & Stream Name & $\begin{array}{c}\text { Native } \\
\text { Species Total } \\
\text { Score }\end{array}$ & Stream Name & \begin{tabular}{|c|} 
Native \\
Species Total \\
Score
\end{tabular} & Stream Name & $\begin{array}{c}\text { Native } \\
\text { Species Total } \\
\text { Score }\end{array}$ \\
\hline Belmont Creek & 60 & East Twin Creek & 30 & Bear Gulch & 10 & Seeley Creek & 10 \\
\hline Clearwater Section 2 & 60 & Ender's Spring Creek & 30 & Bertha Creek & 10 & Shaue Gulch & 10 \\
\hline Clearwater Section 3 & 60 & Grantier Spring Cr. & 30 & Blanchard NF & 10 & Sheep Creek & 10 \\
\hline Clearwater Section 4 & 60 & Hogum Creek & 30 & Braziel Creek & 10 & Shingle Mill Creek & 10 \\
\hline Copper Creek & 60 & Inez Creek & 30 & Broadus Creek & 10 & Smith Creek & 10 \\
\hline Cottonwood Cr. (R.M.43) & 60 & Johnson Creek & 30 & Buffalo Gulch & 10 & Sourdough Creek & 10 \\
\hline Dunham Creek & 60 & McCabe Creek & 30 & Burnt Bridge Creek & 10 & Stonewall Creek & 10 \\
\hline E.F. Clearwater & 60 & Saurekraut Creek & 30 & California Gulch & 10 & Sucker Creek & 10 \\
\hline Gold Creek & 60 & Spring Cr.(Cottonwood) & 30 & Camas Creek & 10 & Swamp Creek & 10 \\
\hline Gold Creek, W,F & 60 & Trail Creek & 30 & Chicken Creek & 10 & Tamarack Creek & 10 \\
\hline Landers Fork & 60 & Unnamed tributary & 30 & Chimney Cr. (Douglas) & 10 & Theodore Creek & 10 \\
\hline Monture Creek below the Falls & 60 & West Twin Creek & 30 & Chimney Cr. (Nevada) & 10 & Uhler Creek & 10 \\
\hline Morrell Creek & 60 & Yellowjacket Creek & 30 & Clear Creek & 10 & Union Creek & 10 \\
\hline North Fork Blackfoot River below the Fa & 60 & Basin Spring Creek & 20 & Cold Brook Creek & 10 & Vaughn Creek & 10 \\
\hline W.F. Clearwater & 60 & Bear Creek trib. to N.F. & 20 & Colt Creek & 10 & Warm Springs Cr. & 10 \\
\hline Alice Creek & 50 & Bear Creek (R.M.37.5) & 20 & Cooney Creek & 10 & Warren Creek & 10 \\
\hline Arrastra Creek & 50 & Benedict Creek & 20 & Cottonwood Cr. (Nev.) & 10 & Warren Creek, Doney Lake trib & 10 \\
\hline Blackfoot River 1 & 50 & Blanchard Creek & 20 & Dobrota Creek & 10 & Washington Creek & 10 \\
\hline Blackfoot River 2 & 50 & Chamberlain EF & 20 & Douglas Creek & 10 & Washoe Creek & 10 \\
\hline Blind Canyon Creek & 50 & Chamberlain WF & 20 & East Fork of North Fork & 10 & Wedge Creek & 10 \\
\hline Boles Creek & 50 & Clearwater Section 1 & 20 & Finley Creek & 10 & Willow Cr. (lower) & 10 \\
\hline Lodgepole Creek & 50 & Elk Creek & 20 & First Creek & 10 & Wilson Creek & 10 \\
\hline Poorman Creek & 50 & Fawn Creek & 20 & Frazier Creek & 10 & Auggie Creek & 0 \\
\hline Cabin Creek & 40 & Findell Creek & 20 & Frazier Creek, NF & 10 & Bear Trap Creek & 0 \\
\hline Canyon Creek & 40 & Fish Creek & 20 & Gallagher Creek & 10 & Black Bear Creek & 0 \\
\hline Clearwater Section 5 & 40 & Keep Cool Creek & 20 & Game Creek & 10 & Buck Creek & 0 \\
\hline Dry Creek & 40 & Lincoln Spring Cr. & 20 & Gleason Creek & 10 & Drew Creek & 0 \\
\hline Dry Fork of the North Fork & 40 & Little Fish Creek & 20 & Grouse Creek & 10 & Finn Creek & 0 \\
\hline East Fork of Monture & 40 & Little Moose Creek & 20 & Hoyt Creek & 10 & Halfway Creek & 0 \\
\hline Hayden Creek & 40 & McDermott Creek & 20 & Humbug Creek & 10 & Horn Creek & 0 \\
\hline Kleinschmidt Cr. & 40 & Middle Fork of Monture Cree & 20 & Indian Creek & 10 & Mike Horse Creek & 0 \\
\hline Marshall Creek & 40 & Moose Creek & 20 & Jacobsen Spring Creek & 10 & Nevada Cr. (lower) & 0 \\
\hline Nevada Cr.(upper) & 40 & N.F. Placid Creek & 20 & Jefferson Creek & 10 & Owl Creek & 0 \\
\hline Rock Creek & 40 & Nevada Spring Cr. & 20 & Lost Horse Creek & 10 & Paymaster Creek & 0 \\
\hline Salmon Creek & 40 & Pearson Creek & 20 & Lost Pony Creek & 10 & Sheep Creek & 0 \\
\hline Snowbank Creek & 40 & Placid Creek & 20 & Lost Prairie Creek & 10 & Slippery John Creek & 0 \\
\hline Spring Creek (N.F.) & 40 & Seven up Pete Cr. & 20 & McElwain Creek & 10 & Strickland Creek & 0 \\
\hline Bear Creek (R.M.12.2) & 30 & Shanley Creek & 20 & Mitchell Creek & 10 & Sturgeon Creek & 0 \\
\hline Beaver Creek & 30 & Wales Creek & 20 & Mountain Creek & 10 & Ward Creek & 0 \\
\hline Blackfoot River 3 & 30 & Wales Spring Creek & 20 & Murphy Creek & 10 & & \\
\hline Blackfoot River 4 & 30 & Wasson Creek & 20 & Murray Creek & 10 & & \\
\hline Blackfoot River 5 & 30 & Willow Cr. (upper) & 20 & North Fork above the Falls & 10 & & \\
\hline Blackfoot River 6 & 30 & Yourname Creek & 20 & Pass Creek & 10 & & \\
\hline Burnt Cabin Creek & 30 & Anaconda Creek & 10 & Rice Creek & 10 & & \\
\hline Camp Creek & 30 & Archibald Creek & 10 & Richmond Creek & 10 & & \\
\hline Chamberlain Creek & 30 & Arkansas Creek & 10 & Sawyer Creek & 10 & & \\
\hline Deer Creek & 30 & Ashby Creek & 10 & Scotty Creek & 10 & & \\
\hline Dick Creek & 30 & Bartlett Creek & 10 & Second Creek & 10 & & \\
\hline
\end{tabular}

Table 1. Native fish restoration priority stream sorted alphabetically from high to low priority. 


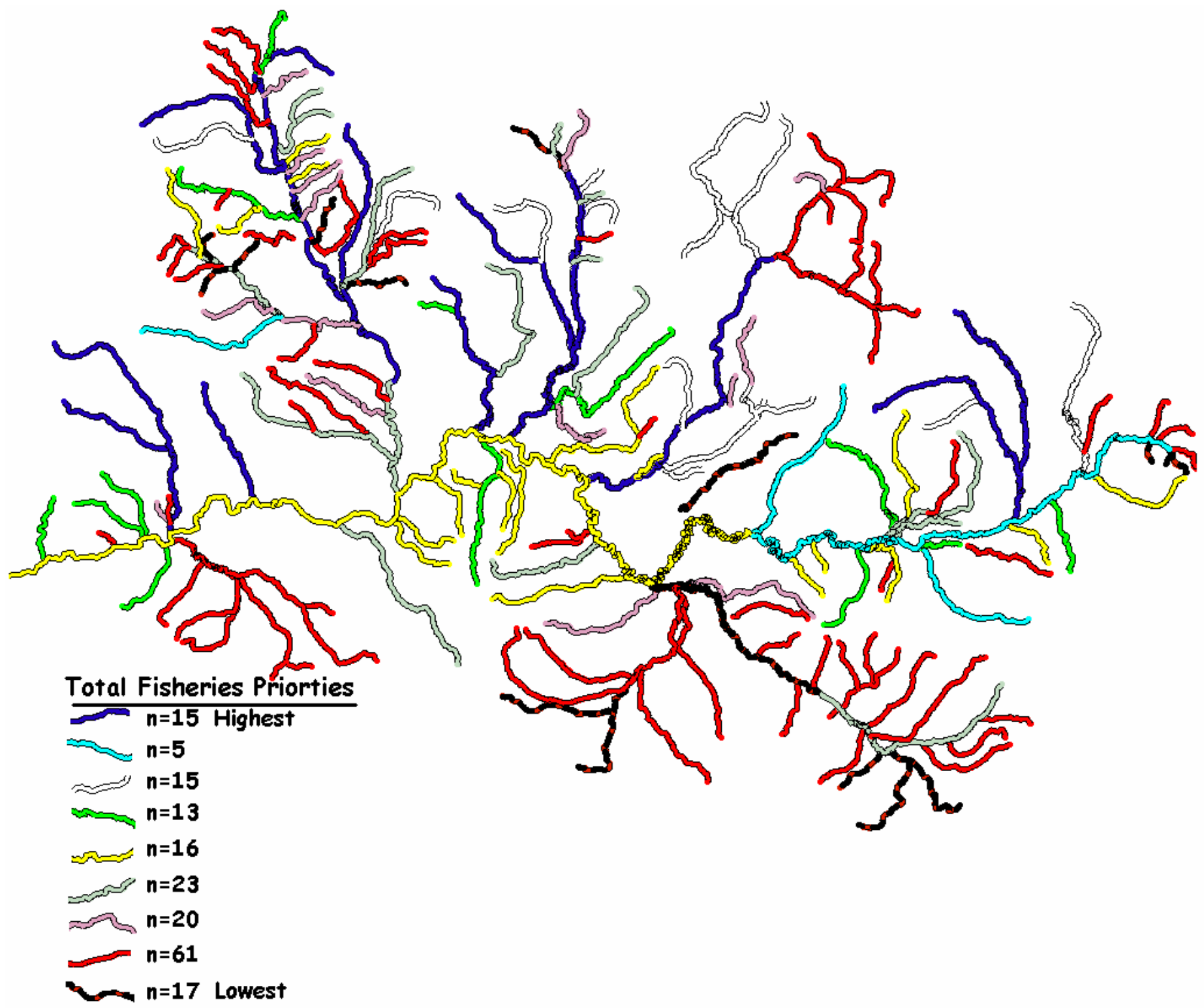

Figure 2. Total fisheries restoration priorities for the Blackfoot River Basin. High priority stream currently support migratory bull trout, WSCT and may recruit of game fish (rainbow and brown trout) to the Blackfoot River (Table 2). Streams near the bottom of the priority list provide very little or no native or recreational (recruitment) value to the Blackfoot River. 


\begin{tabular}{|c|c|c|c|c|c|c|c|}
\hline Stream Name & $\begin{array}{c}\text { Total } \\
\text { fisheries } \\
\text { score }\end{array}$ & Stream Name & $\begin{array}{c}\text { Total } \\
\text { fisheries } \\
\text { score }\end{array}$ & Stream Name & $\begin{array}{c}\text { Total } \\
\text { fisheries } \\
\text { score }\end{array}$ & Stream Name & $\begin{array}{c}\text { Total } \\
\text { fisheries } \\
\text { score }\end{array}$ \\
\hline Belmont Creek & 80 & Blanchard Creek & 40 & Murphy Creek & 20 & Scotty Creek & 10 \\
\hline Clearwater Section 2 & 80 & Burnt Cabin Creek & 40 & Nevada Spring Cr. & 20 & Second Creek & 10 \\
\hline Clearwater Section 3 & 80 & Camp Creek & 40 & Owl Creek & 20 & Seeley Creek & 10 \\
\hline Clearwater Section 4 & 80 & Clearwater Section 1 & 40 & Rice Creek & 20 & Shaue Gulch & 10 \\
\hline Copper Creek & 80 & Elk Creek & 40 & Richmond Creek & 20 & Sheep Creek & 10 \\
\hline Cottonwood Cr. (R.M.43) & 80 & Inez Creek & 40 & Sawyer Creek & 20 & Shingle Mill Creek & 10 \\
\hline Dunham Creek & 80 & Keep Cool Creek & 40 & Warm Springs Cr. & 20 & Smith Creek & 10 \\
\hline E.F. Clearwater & 80 & Lincoln Spring Cr. & 40 & Wasson Creek & 20 & Sourdough Creek & 10 \\
\hline Gold Creek & 80 & McCabe Creek & 40 & Anaconda Creek & 10 & Sucker Creek & 10 \\
\hline Gold Creek, W,F & 80 & Nevada Cr.(upper) & 40 & Archibald Creek & 10 & Swamp Creek & 10 \\
\hline Landers Fork & 80 & Placid Creek & 40 & Arkansas Creek & 10 & Tamarack Creek & 10 \\
\hline Monture Creek below the Falls & 80 & Shanley Creek & 40 & Ashby Creek & 10 & Theodore Creek & 10 \\
\hline Morrell Creek & 80 & Trail Creek & 40 & Bartlett Creek & 10 & Uhler Creek & 10 \\
\hline North Fork below the Falls & 80 & Unnamed tributary & 40 & Bear Gulch & 10 & Union Creek & 10 \\
\hline W.F. Clearwater & 80 & Wales Creek & 40 & Bertha Creek & 10 & Vaughn Creek & 10 \\
\hline Arrastra Creek & 70 & Wales Spring Creek & 40 & Blanchard NF & 10 & Warren Creek, Doney La & 10 \\
\hline Blackfoot River 1 & 70 & Yellowjacket Creek & 40 & Braziel Creek & 10 & \begin{tabular}{|l|} 
Washington Creek \\
\end{tabular} & 10 \\
\hline Blackfoot River 2 & 70 & Basin Spring Creek & 30 & Buffalo Gulch & 10 & Washoe Creek & 10 \\
\hline Boles Creek & 70 & Bear Creek (R.M.37.5) & 30 & Burnt Bridge Creek & 10 & Wedge Creek & 10 \\
\hline Poorman Creek & 70 & Benedict Creek & 30 & California Gulch & 10 & Wilson Creek & 10 \\
\hline Alice Creek & 60 & Blackfoot River 3 & 30 & Camas Creek & 10 & Auggie Creek & 0 \\
\hline Blind Canyon Creek & 60 & Blackfoot River 4 & 30 & Chicken Creek & 10 & Bear Trap Creek & 0 \\
\hline Cabin Creek & 60 & Blackfoot River 5 & 30 & Chimney Cr. (Douglas) & 10 & Black Bear Creek & 0 \\
\hline Canyon Creek & 60 & Blackfoot River 6 & 30 & Chimney Cr. (Nevada) & 10 & Buck Creek & 0 \\
\hline Dry Creek & 60 & Chamberlain EF & 30 & Clear Creek & 10 & Drew Creek & 0 \\
\hline Dry Fork of the North Fork & 60 & Chamberlain WF & 30 & Cold Brook Creek & 10 & Finn Creek & 0 \\
\hline East Fork of Monture & 60 & Fawn Creek & 30 & Colt Creek & 10 & Halfway Creek & 0 \\
\hline Hayden Creek & 60 & Findell Creek & 30 & Cooney Creek & 10 & Horn Creek & 0 \\
\hline Kleinschmidt $\mathrm{Cr}$. & 60 & Fish Creek & 30 & Cottonwood Cr. (Nev.) & 10 & Mike Horse Creek & 0 \\
\hline Lodgepole Creek & 60 & Jacobsen Spring Creek & 30 & Dobrota Creek & 10 & Nevada Cr. (lower) & 0 \\
\hline Marshall Creek & 60 & Little Fish Creek & 30 & Douglas Creek & 10 & Paymaster Creek & 0 \\
\hline Rock Creek & 60 & Little Moose Creek & 30 & East Fork of North Fork & 10 & Sheep Creek & 0 \\
\hline Salmon Creek & 60 & Moose Creek & 30 & First Creek & 10 & Slippery John Creek & 0 \\
\hline Snowbank Creek & 60 & N.F. Placid Creek & 30 & Frazier Creek & 10 & Strickland Creek & 0 \\
\hline Spring Creek (N.F.) & 60 & Pearson Creek & 30 & Frazier Creek, NF & 10 & Sturgeon Creek & 0 \\
\hline Bear Creek (R.M.12.2) & 50 & Seven up Pete Cr. & 30 & Gallagher Creek & 10 & Ward Creek & 0 \\
\hline Beaver Creek & 50 & Stonewall Creek & 30 & Game Creek & 10 & & \\
\hline Chamberlain Creek & 50 & Warren Creek & 30 & Gleason Creek & 10 & & \\
\hline Clearwater Section 5 & 50 & Willow Cr. (lower) & 30 & Grouse Creek & 10 & & \\
\hline Deer Creek & 50 & Willow Cr. (upper) & 30 & Humbug Creek & 10 & & \\
\hline Dick Creek & 50 & Yourname Creek & 30 & Indian Creek & 10 & & \\
\hline East Twin Creek & 50 & Bear Creek trib. to N.F. & 20 & Jefferson Creek & 10 & & \\
\hline Ender's Spring Creek & 50 & Broadus Creek & 20 & Lost Pony Creek & 10 & & \\
\hline Grantier Spring Cr. & 50 & Finley Creek & 20 & Lost Prairie Creek & 10 & & \\
\hline Hogum Creek & 50 & Hoyt Creek & 20 & Mitchell Creek & 10 & & \\
\hline Johnson Creek & 50 & Lost Horse Creek & 20 & Mountain Creek & 10 & & \\
\hline Saurekraut Creek & 50 & McDermott Creek & 20 & Murray Creek & 10 & & \\
\hline Spring Cr.(Cottonwood) & 50 & McElwain Creek & 20 & North Fork above the Falls & 10 & & \\
\hline West Twin Creek & 50 & Middle Fork of Monture Creet & 20 & Pass Creek & 10 & & \\
\hline
\end{tabular}

Table 2. Total fisheries scores for the Blackfoot River Basin. Streams are sorted alphabetically from high fisheries value to no current fisheries value to the Blackfoot River. 
Figure 3. Biologically scores ranked by high, moderate and low values. High priority streams support native and sport fish and most possess high restoration (i.e., flow and water quality) potential. Moderate priority streams possess often posses less valuable fish but high restoration potential (Table 3). Low values may possess restoration potential but provide little current fisheries value to the Blackfoot River. 


\begin{tabular}{|c|c|c|c|c|c|c|c|}
\hline Stream Name & Bio score & Stream Name & Bio score & Stream Name & Bio score & Stream Name & Bio score \\
\hline Alice Creek & High & Stonewall Creek & High & Pearson Creek & Moderate & McDermott Creek & Low \\
\hline Arrastra Creek & High & Wales Creek & High & Placid Creek & Moderate & Middle Fork of Monture Creek & Low \\
\hline Beaver Creek & High & Wales Spring Creek & High & Richmond Creek & Moderate & Mike Horse Creek & Low \\
\hline Belmont Creek & High & Wasson Creek & High & Seven up Pete Cr. & Moderate & Mitchell Creek & Low \\
\hline Blackfoot River 1 & High & Bear Creek (R.M.12.2) & Moderate & Sucker Creek & Moderate & North Fork above the Falls & Low \\
\hline Blackfoot River 2 & High & Ashby Creek & Moderate & Union Creek & Moderate & Pass Creek & Low \\
\hline Blackfoot River 3 & High & Basin Spring Creek & Moderate & Unnamed tributary & Moderate & Paymaster Creek & Low \\
\hline Blackfoot River 4 & High & Bear Gulch & Moderate & Warm Springs Cr. & Moderate & Rice Creek & Low \\
\hline Blanchard Creek & High & Benedict Creek & Moderate & Washington Creek & Moderate & Sawyer Creek & Low \\
\hline Blind Canyon Creek & High & Bertha Creek & Moderate & West Twin Creek & Moderate & Scotty Creek & Low \\
\hline Boles Creek & High & Blackfoot River 5 & Moderate & Willow Cr. (upper) & Moderate & Second Creek & Low \\
\hline Clearwater Section 2 & High & Braziel Creek & Moderate & Wilson Creek & Moderate & Seeley Creek & Low \\
\hline Clearwater Section 3 & High & Buffalo Gulch & Moderate & Yellowjacket Creek & Moderate & Shaue Gulch & Low \\
\hline Clearwater Section 4 & High & Burnt Cabin Creek & Moderate & Anaconda Creek & Low & Sheep Creek & Low \\
\hline Copper Creek & High & Cabin Creek & Moderate & Archibald Creek & Low & Sheep Creek & Low \\
\hline Cottonwood Cr. (R.M.43) & High & California Gulch & Moderate & Arkansas Creek & Low & Shingle Mill Creek & Low \\
\hline Deer Creek & High & Camas Creek & Moderate & Auggie Creek & Low & Slippery John Creek & Low \\
\hline Dick Creek & High & Camp Creek & Moderate & Bartlett Creek & Low & Smith Creek & Low \\
\hline Dry Creek & High & Canyon Creek & Moderate & Bear Creek trib. to N.F. & Low & Sourdough Creek & Low \\
\hline Dunham Creek & High & Chamberlain Creek & Moderate & Bear Creek (R.M.37.5) & Low & Strickland Creek & Low \\
\hline E.F. Clearwater & High & Chamberlain EF & Moderate & Bear Trap Creek & Low & Sturgeon Creek & Low \\
\hline Elk Creek & High & Chamberlain WF & Moderate & Black Bear Creek & Low & Swamp Creek & Low \\
\hline Ender's Spring Creek & High & Chicken Creek & Moderate & Blackfoot River 6 & Low & Tamarack Creek & Low \\
\hline Gold Creek & High & Chimney Cr. (Douglas) & Moderate & Blanchard NF & Low & Theodore Creek & Low \\
\hline Gold Creek, W,F & High & Clearwater Section 1 & Moderate & Broadus Creek & Low & Uhler Creek & Low \\
\hline Hoyt Creek & High & Clearwater Section 5 & Moderate & Buck Creek & Low & Vaughn Creek & Low \\
\hline Kleinschmidt Cr. & High & Cottonwood Cr. (Nev.) & Moderate & Burnt Bridge Creek & Low & Ward Creek & Low \\
\hline Landers Fork & High & Douglas Creek & Moderate & Chimney Cr. (Nevada) & Low & Warren Creek, Doney Lake trib & Low \\
\hline Lincoln Spring Cr. & High & Dry Fork of the North Fork & Moderate & Clear Creek & Low & Washoe Creek & Low \\
\hline Marshall Creek & High & East Fork of Monture & Moderate & Cold Brook Creek & Low & Wedge Creek & Low \\
\hline McCabe Creek & High & East Twin Creek & Moderate & Colt Creek & Low & & \\
\hline McElwain Creek & High & Fawn Creek & Moderate & Cooney Creek & Low & & \\
\hline Monture Creek below the Falls & High & Findell Creek & Moderate & Dobrota Creek & Low & & \\
\hline Morrell Creek & High & Finley Creek & Moderate & Drew Creek & Low & & \\
\hline N.F. Placid Creek & High & Fish Creek & Moderate & East Fork of North Fork & Low & & \\
\hline Nevada Spring Cr. & High & Hayden Creek & Moderate & Finn Creek & Low & & \\
\hline North Fork below the Falls & High & Hogum Creek & Moderate & First Creek & Low & & \\
\hline Owl Creek & High & Inez Creek & Moderate & Frazier Creek & Low & & \\
\hline Poorman Creek & High & Jacobsen Spring Creek & Moderate & Frazier Creek, NF & Low & & \\
\hline Rock Creek & High & Jefferson Creek & Moderate & Gallagher Creek & Low & & \\
\hline Salmon Creek & High & Johnson Creek & Moderate & Game Creek & Low & & \\
\hline Saurekraut Creek & High & Keep Cool Creek & Moderate & Gleason Creek & Low & & \\
\hline Shanley Creek & High & Little Fish Creek & Moderate & Grantier Spring Cr. & Low & & \\
\hline Snowbank Creek & High & Lodgepole Creek & Moderate & Grouse Creek & Low & & \\
\hline Spring Cr.(Cottonwood) & High & Lost Horse Creek & Moderate & Halfway Creek & Low & & \\
\hline Spring Creek (N.F.) & High & Moose Creek & Moderate & Horn Creek & Low & & \\
\hline Trail Creek & High & Mountain Creek & Moderate & Humbug Creek & Low & & \\
\hline W.F. Clearwater & High & Murphy Creek & Moderate & Indian Creek & Low & & \\
\hline Warren Creek & High & Murray Creek & Moderate & Little Moose Creek & Low & & \\
\hline Willow Cr. (lower) & High & Nevada Cr. (lower) & Moderate & Lost Pony Creek & Low & & \\
\hline Yourname Creek & High & Nevada Cr.(upper) & Moderate & Lost Prairie Creek & Low & & \\
\hline
\end{tabular}

Table 3. Streams arranged alphabetically and sorted by biological (high, moderate and low) classification groupings. 
Figure 4. Total restoration priorities. This map is classified by high, moderate and low scores. In addition to the biological scores, the social scores influence this classification (Table 4). 


\begin{tabular}{|c|c|c|c|c|c|c|c|}
\hline Stream Name & $\begin{array}{l}\text { Total } \\
\text { Score } \\
\end{array}$ & Stream Name & Total Score & Stream Name & Total Score & Stream Name & $\begin{array}{l}\text { Total } \\
\text { Score }\end{array}$ \\
\hline Alice Creek & High & Salmon Creek & High & Rice Creek & Moderate & Humbug Creek & Low \\
\hline Arrastra Creek & High & Saurekraut Creek & High & Richmond Creek & Moderate & Indian Creek & Low \\
\hline Bear Creek (R.M.12.2) & High & Snowbank Creek & High & Sawyer Creek & Moderate & Jefferson Creek & Low \\
\hline Beaver Creek & High & Spring Cr.(Cottonwood) & High & Seven up Pete Cr. & Moderate & Lost Horse Creek & Low \\
\hline Belmont Creek & High & Spring Creek (N.F.) & High & Shanley Creek & Moderate & Lost Pony Creek & Low \\
\hline Blackfoot River 1 & High & Trail Creek & High & Stonewall Creek & Moderate & Lost Prairie Creek & Low \\
\hline Blackfoot River 2 & High & W.F. Clearwater & High & Sucker Creek & Moderate & Mike Horse Creek & Low \\
\hline Blackfoot River 3 & High & West Twin Creek & High & Union Creek & Moderate & Nevada Cr. (lower) & Low \\
\hline Blackfoot River 4 & High & Ashby Creek & Moderate & Unnamed tributary & Moderate & North Fork above the Falls & Low \\
\hline Blackfoot River 5 & High & Basin Spring Creek & Moderate & Wales Creek & Moderate & Owl Creek & Low \\
\hline Blackfoot River 6 & High & Bear Creek trib. to N.F. & Moderate & Wales Spring Creek & Moderate & Pass Creek & Low \\
\hline Blind Canyon Creek & High & Bear Creek (R.M.37.5) & Moderate & Warm Springs Cr. & Moderate & Paymaster Creek & Low \\
\hline Boles Creek & High & Bear Gulch & Moderate & Warren Creek & Moderate & Scotty Creek & Low \\
\hline Cabin Creek & High & Benedict Creek & Moderate & Washoe Creek & Moderate & Second Creek & Low \\
\hline Camp Creek & High & Bertha Creek & Moderate & Wasson Creek & Moderate & Seeley Creek & Low \\
\hline Canyon Creek & High & Blanchard Creek & Moderate & Willow Cr. (lower) & Moderate & Shaue Gulch & Low \\
\hline Chamberlain Creek & High & Blanchard NF & Moderate & Willow Cr. (upper) & Moderate & Sheep Creek & Low \\
\hline Clearwater Section 2 & High & Braziel Creek & Moderate & Wilson Creek & Moderate & Sheep Creek & Low \\
\hline Clearwater Section 3 & High & Burnt Cabin Creek & Moderate & Yellowjacket Creek & Moderate & Shingle Mill Creek & Low \\
\hline Clearwater Section 4 & High & Camas Creek & Moderate & Yourname Creek & Moderate & Slippery John Creek & Low \\
\hline Clearwater Section 5 & High & Chamberlain EF & Moderate & Archibald Creek & Low & Smith Creek & Low \\
\hline Copper Creek & High & Chamberlain WF & Moderate & Anaconda Creek & Low & Sourdough Creek & Low \\
\hline Cottonwood Cr. (R.M.43) & High & Chicken Creek & Moderate & Arkansas Creek & Low & Strickland Creek & Low \\
\hline Deer Creek & High & Chimney Cr. (Douglas) & Moderate & Auggie Creek & Low & Sturgeon Creek & Low \\
\hline Dick Creek & High & Clearwater Section 1 & Moderate & Bartlett Creek & Low & Swamp Creek & Low \\
\hline Dry Creek & High & Douglas Creek & Moderate & Bear Trap Creek & Low & Tamarack Creek & Low \\
\hline Dry Fork of the North Fork & High & Elk Creek & Moderate & Black Bear Creek & Low & Theodore Creek & Low \\
\hline \begin{tabular}{|l} 
Dunham Creek \\
\end{tabular} & High & Fawn Creek & Moderate & Broadus Creek & Low & Uhler Creek & Low \\
\hline E.F. Clearwater & High & Findell Creek & Moderate & Buck Creek & Low & Vaughn Creek & Low \\
\hline East Fork of Monture & High & Finley Creek & Moderate & Buffalo Gulch & Low & Ward Creek & Low \\
\hline East Twin Creek & High & First Creek & Moderate & Burnt Bridge Creek & Low & Warren Creek, Doney Lake trib & Low \\
\hline Ender's Spring Creek & High & Fish Creek & Moderate & California Gulch & Low & Washington Creek & Low \\
\hline Gold Creek & High & Hoyt Creek & Moderate & Chimney Cr. (Nevada) & Low & Wedge Creek & Low \\
\hline Gold Creek, W,F & High & Jacobsen Spring Creek & Moderate & Clear Creek & Low & & \\
\hline Grantier Spring Cr. & High & Keep Cool Creek & Moderate & Cold Brook Creek & Low & & \\
\hline Hayden Creek & High & Lincoln Spring Cr. & Moderate & Colt Creek & Low & & \\
\hline Hogum Creek & High & Little Fish Creek & Moderate & Cooney Creek & Low & & \\
\hline Inez Creek & High & Little Moose Creek & Moderate & Cottonwood Cr. (Nev.) & Low & & \\
\hline Johnson Creek & High & McDermott Creek & Moderate & Dobrota Creek & Low & & \\
\hline Kleinschmidt Cr. & High & McElwain Creek & Moderate & Drew Creek & Low & & \\
\hline Landers Fork & High & Middle Fork of Monture Creek & Moderate & East Fork of North Fork & Low & & \\
\hline Lodgepole Creek & High & Mitchell Creek & Moderate & Finn Creek & Low & & \\
\hline Marshall Creek & High & Moose Creek & Moderate & Frazier Creek & Low & & \\
\hline McCabe Creek & High & Mountain Creek & Moderate & Frazier Creek, NF & Low & & \\
\hline Monture Creek below the Falls & High & Murphy Creek & Moderate & Gallagher Creek & Low & & \\
\hline Morrell Creek & High & Murray Creek & Moderate & Game Creek & Low & & \\
\hline Nevada Cr.(upper) & High & N.F. Placid Creek & Moderate & Gleason Creek & Low & & \\
\hline North Fork below the Falls & High & Nevada Spring Cr. & Moderate & Grouse Creek & Low & & \\
\hline Poorman Creek & High & Pearson Creek & Moderate & Halfway Creek & Low & & \\
\hline Rock Creek & High & Placid Creek & Moderate & Horn Creek & Low & & \\
\hline
\end{tabular}

Table 4. Total restoration classification organized alphabetically by high, moderate and low scores. 


\section{RESULTS PART VII: Backcountry fisheries investigations}

\section{Introduction}

Beginning in 2004, FWP fisheries crews performed a series of fisheries-based aquatic resource inventories in the "backcountry" (e.g. roadless and wilderness areas) streams of the Blackfoot Basin. Fisheries surveys initially focused on the Dry Fork Basin (Pierce et al. 2006), and in 2006-07 surveys expanded to the headwaters of upper Monture Creek and upper North Fork of the Blackfoot River. These surveys represent the first comprehensive fisheries inventory within this backcountry area of the Blackfoot Basin. We initiated this work in order to identify headwater fisheries (and related resources) and to supplement information related to native fish (bull trout and WSCT) within and downstream of the backcountry region. Additional stream surveys are planned for the summer of 2008 .

\section{Study area}

Fisheries inventories emphasized the headwaters of Monture Creek and the North Fork. This area falls within a high glacial landscape in the northernmost portion of the Blackfoot Basin (Figure 1). This northern mountain region represents the southern extension of a large contiguous wilderness complex that extends from Glacier National Park south through the Bob Marshall and Scapegoat wildernesses and adjacent "roadless" areas. A majority of the North Fork study area burned in the 1988 Canyon Creek wildfire. Within the study

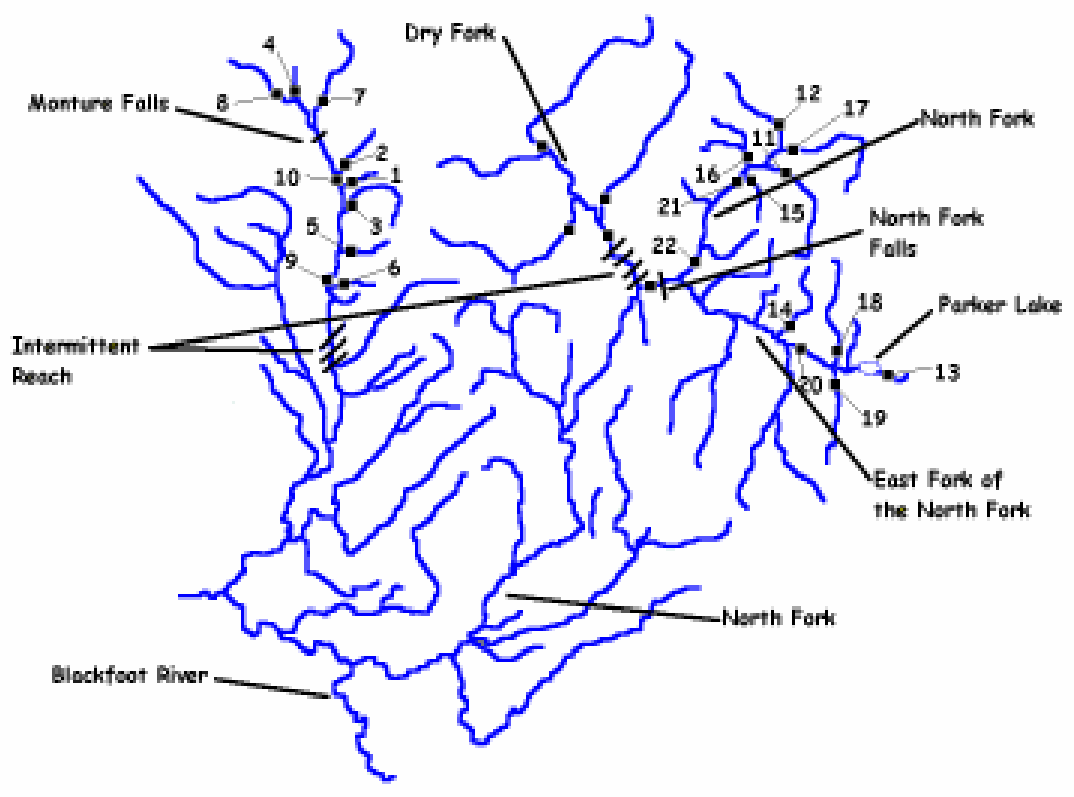
area, streams originate in glacial cirques, drain adjoining hill slopes and lead southerly through glacial trough valleys before exiting the mountains as larger, colder tributaries of the Blackfoot River. These stream systems are the headwaters to critical native fish-bearing tributaries of the Blackfoot River. Both Monture Creek and the North Fork Blackfoot River are classified as "proposed critical habitat" and "core areas" for the recovery of bull trout and both basins support Blackfoot River fluvial and stream-resident WSCT.

Within this area, we established 22 fish population-sampling locations on 19 streams (Figure 1). We conducted surveys at 12 sites upstream of the North Fork Falls (located at streammile 26.9), one site in Canyon Creek (downstream of the North Fork Falls) and at 10 sites in the upper Monture Creek drainage. Seven surveys within Monture Creek drainage were undertaken between a naturally intermittent channel (stream-mile 12.5 and 15.0) and Monture Falls at streammile 25.0, and the remaining three surveys were taken upstream of Monture Falls (Figure 1). 


\section{Results/Discussion}

Summary fish population survey results for streams are located in Table 1. More detailed tributary descriptions of all the aquatic resource assessments follow the Discussion section.

Table 1. Catch and size statistics and genetic sample results for 22 fish population survey sites, 2006-07.

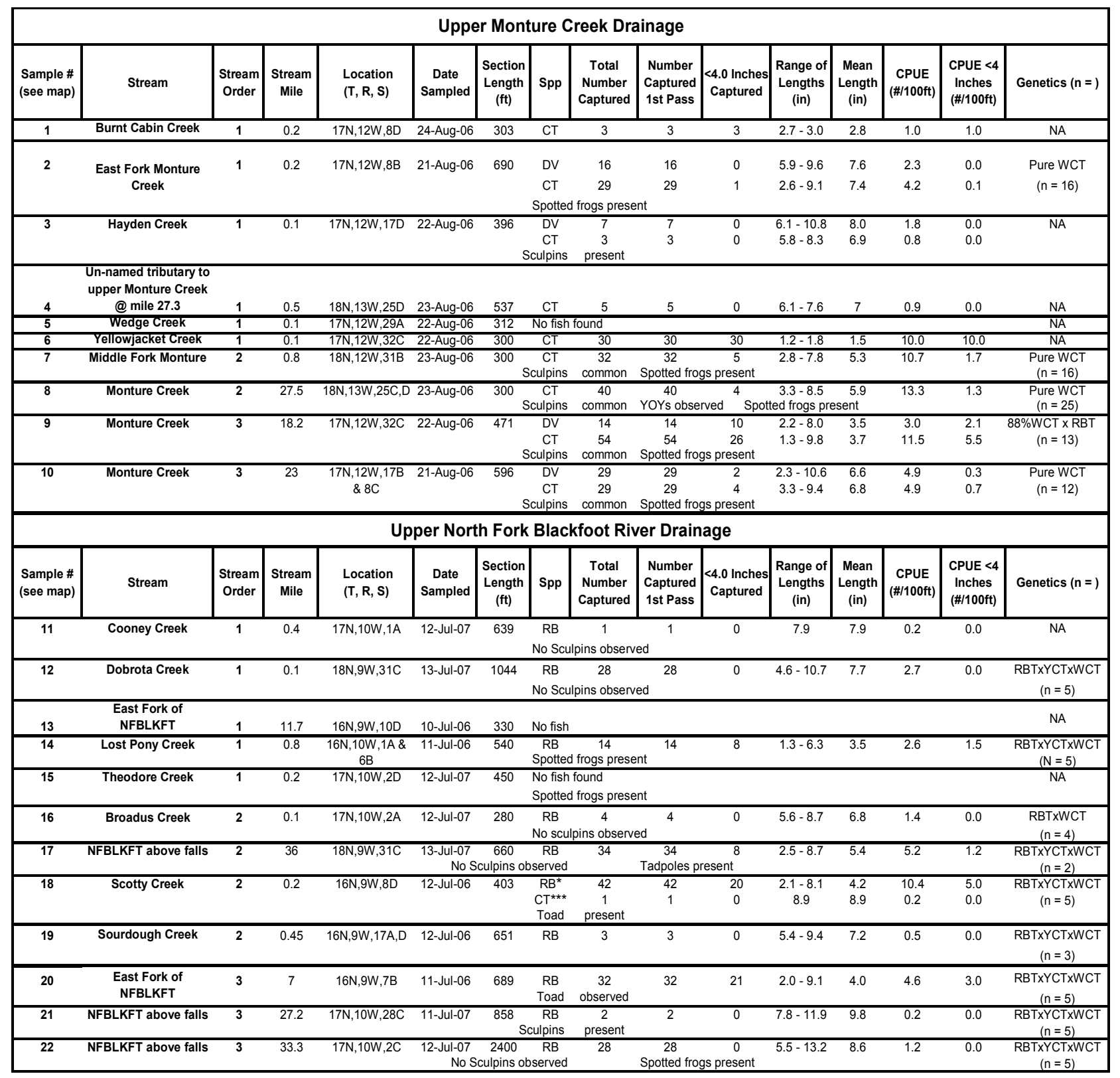

\section{Discussion}

Both Monture and the upper North Fork are geoclimatically similar, and both contain geologic barriers (waterfalls) that limit upstream fish passage. Despite environmental similarities, our surveys identify large differences between fisheries of upper Monture Creek and the upper North Fork, and certain differences extent to geologically isolated areas upstream of natural barriers.

Between the intermittent reach and Monture Falls, upper Monture Creek supports both bull trout and WSCT. In this area, bull trout are dispersed throughout the mainstem of Monture Creek (and lower tributaries) downstream of Monture Falls; however, bull trout are absent upstream of 
Monture Falls. Genetics testing identified WSCT as mildly introgressed (with rainbow trout) at the lower-most sampling site (mile 18.2) but identified no introgression in upstream samples. We found no brook trout in the study area upstream of the intermittent reach, which contrasts with the common presence of brook trout downstream of the intermittent reach. Genetic analyses upstream of Monture Fall found only genetically "pure" WSCT and no other fish species upstream of this geologic barrier. Upstream of Monture Creek Falls, only one lake supports fish and these were phenotypically identified as WSCT.

Similar to Monture Creek, previous North Fork surveys identified bull trout below the North Fork Falls and the absence of brook trout. By contrast, stream surveys upstream of North Fork Falls identified predominately rainbow trout or rainbow introgressed with Yellowstone and WSCT. We failed to identify a westslope population upstream of the North Fork Falls and observations of native fish upstream of the North Fork Falls were limited to a single sculpin. It remains unclear whether WSCT were ever present upstream of the North Fork Falls; however, the observation of a sculpin may indicate the historic presence of native fish

We grouped the electrofishing catch by $1^{\text {st }}, 2^{\text {nd }}$ and $3^{\text {rd }}$ stream-order streams to help identify an observable pattern in which non-native fish in the upper North Fork streams are present in much lower abundance compared to native fish within the upper Monture Basin (Figure 2). These differences suggest non-native species are poorly suited to this headwater ecosystem compared to species native to the region. At least two fish-bearing lakes upstream of the North Fork Falls (Parker and Lower Twin Lakes) were historically stocked with WSCT, Yellowstone cutthroat trout and rainbow trout. Both lakes are directly connected to the

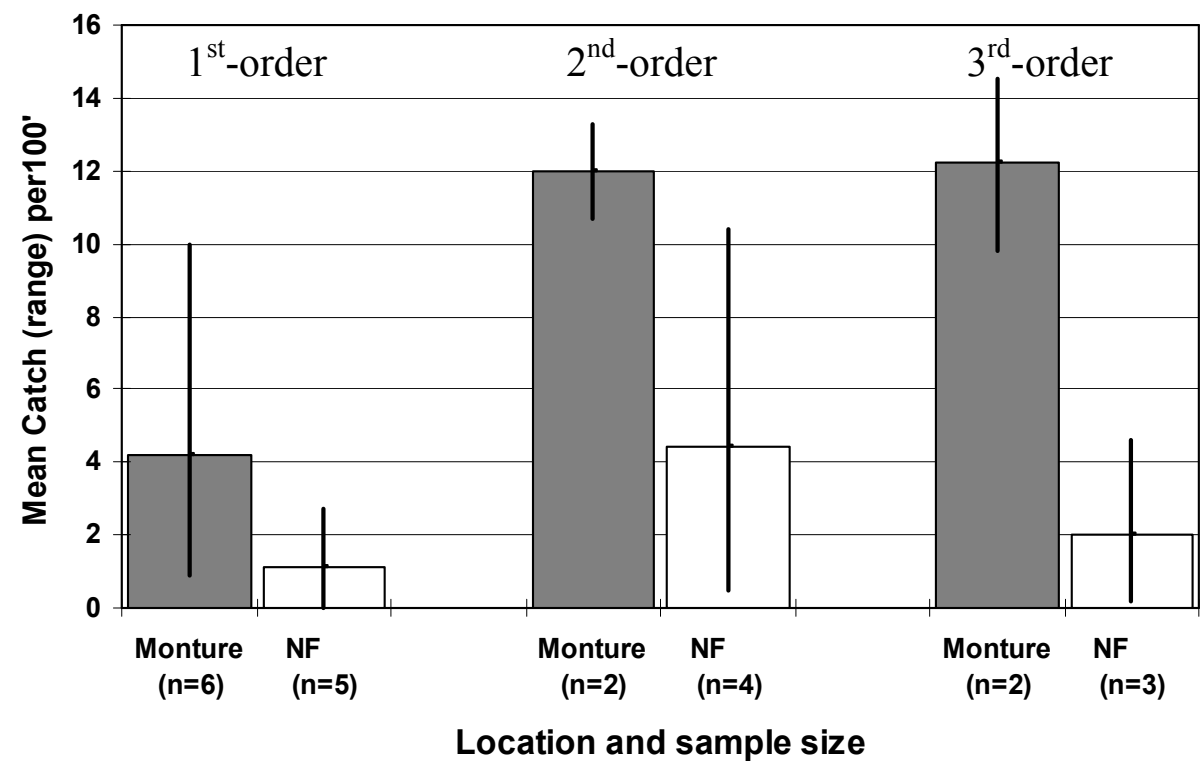

Figure 2. Electrofishing catch comparison by stream-order between the upper Monture and upper North Fork Basins.

tributary system. High densities of hybrids in Parker Lake further identify it as an upstream source to the tributary system upstream of the North Fork Falls.

The upstream presence of these non-native Onchoynchus place WSCT in connected downstream waters at risk of hybridization, including tributaries of the Dry Fork. Genetic tests conducted in Cabin Creek identified mild introgression between WSCT and rainbow trout at this time. This suggests that intermittent channels in the lower Dry Fork may be slowing, but most likely not preventing the introgression to the tributary populations found downstream of the North Fork Falls. 


\section{Results: Tributary descriptions}

\section{Monture Creek}

\section{Description}

Monture Creek, a large $4^{\text {th }}$ order tributary to the middle Blackfoot River, is a primary spawning and rearing tributary for fluvial bull trout and fluvial WSCT (WSCT). Monture Creek also serves as thermal refugia for fluvial bull trout during periods of Blackfoot River warming. Reproduction of WSCT and bull trout occurs primarily in the midto-upper basin. Fluvial rainbow trout and brown trout inhabit the lower portions of the drainage. Brook trout are found throughout the lower portions of the drainage; however, in upper Monture Creek, brook trout have not been identified as present.

Upper Monture Creek, upstream from the Monture Creek trailhead (at stream-mile 13), is fed by at least 18 perennial streams and drains an area of $\sim 65$ miles $^{2}$. Above the Monture Trailhead, upper Monture Creek lies entirely in Lolo National Forest land and this area is managed for wilderness values.

In 2006, we conducted fish population surveys at three locations on upper Monture Creek (miles 18.2, 23.0 and 27.5) and seven of its headwater tributaries. Riparian vegetation is primarily of alder, willow and rocky mountain maple, ferns and grasses beneath an over-story of Douglas fir, spruce, lodgepole pine and black cottonwood. The majority of the habitat features (stream-miles 18.2 and 23.0) consist of deep pools within bedrock and large boulders, overhanging vegetation and under-cut banks. Large woody debris recruitment at the two lower sites is light; however at stream-mile 27.5, LWD recruitment is high. Instream wood augments large, bouldery substrates and overhanging vegetation and creates high quality fish habitat.

Fish populations and other monitoring activities

Fish population surveys at three upper Monture Creek sampling sites found native salmonids (WSCT and bull trout) only. Sculpins were common and spotted frogs were present at all three locations. Sampling recorded a WSCT CPUE ranging from 4.9 to 13.3 . Bull trout were identified downstream of Monture Falls (CPUE range, 3.0 - 4.9); however, bull trout were absent upstream of Monture Falls (Figure 4). Water chemistry readings at all three locations recorded an average $\mathrm{pH}$ of 7.8 ,

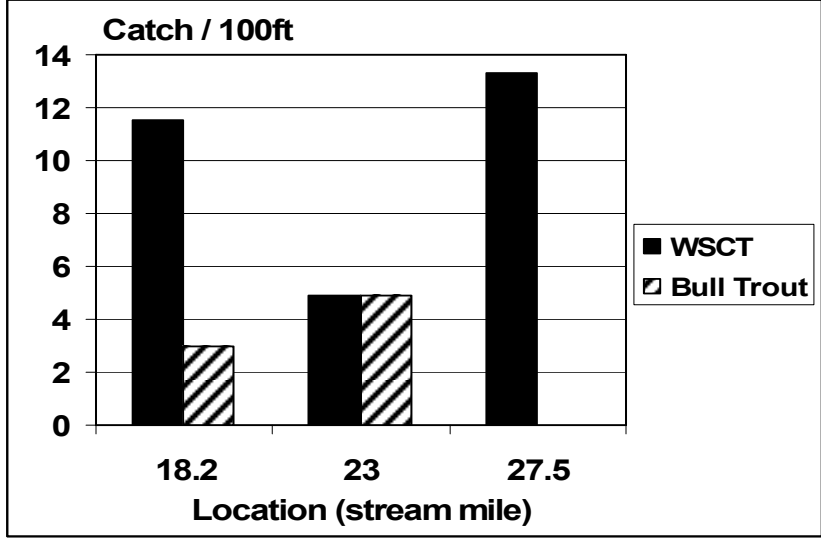

Figure 4. CPUE for WSCT and Bull trout at 3 locations on Upper Monture Creek, 2006. 
conductivity of $55.7 \mathrm{uS}$ and TDS at $27 \mathrm{ppm}$. Genetic samples suggest mild introgression with RBT downstream of Monture Falls. However, genetic analyses upstream of Monture Falls $(n=25)$ identified only genetically pure WSCT.

\section{Middle Fork of Monture Creek}

Description

The Middle Fork of Monture Creek is a small $2^{\text {nd }}$ order tributary stream that drains three small cirque lakes each averaging about 6-acres in size. The Monture Lakes lie at elevations between 7,217 and 7,702', and they drain the southern slopes of Moser Mountain (see lake survey section). Also fed by a small unnamed tributary stream draining the western slopes of Foolhen Mountain, the Middle Fork drains a $\sim 7$ mile $^{2}$ basin just south of the Bob Marshall Wilderness Area. This area is located on Lolo National Forest and is managed for wilderness values.

This Middle Fork is 3.6miles in length and generates an estimated base-flow of 4-6cfs.

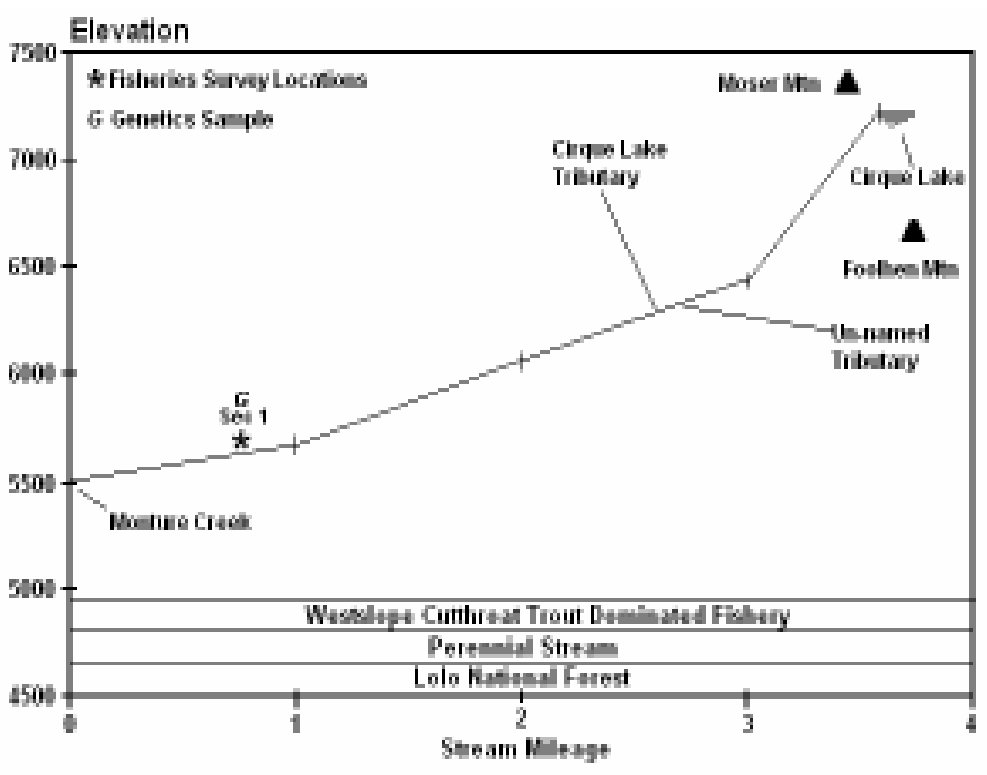

Figure 5. Longitudinal profile for Middle Fork Monture Creek. Gradient is relatively steep near the headwaters descending $\sim 788^{\prime}$ the first 0.6 -miles decreasing to an average of $377^{\prime} /$ mile between miles one and three and decreasing to $169 \%$ mile in the lower mile. The Middle Fork enters Monture Creek at stream-mile 25.9, which is $\sim 0.2$ miles upstream of Monture Creek Falls.

Much of the riparian under-story vegetation at the survey section (mile 0.8) on Middle Fork Monture Creek is dense alder mixed with willow and rocky mountain maple, ferns and various grasses beneath a canopy of Douglas fir, Englemann spruce, lodgepole pine and black cottonwood stands. The channel supports pool and riffle sequences with a predominately cobble and boulder substrate, overhanging vegetation and under-cut banks. Large woody debris recruitment to the stream channel at the survey location is light.

Fish populations and other monitoring activities

Our fish population survey on the Middle Fork Monture Creek in 2006 at stream-mile 0.8, found only WSCT. Sampling recorded a CPUE of 10.7. We identified sculpins as common and spotted frogs as present. Water chemistry readings recorded a $\mathrm{pH}$ level of 7.63 , low conductivity of $42 \mathrm{uS}$ and TDS $20 \mathrm{ppm}$. Genetic analyses $(n=16)$ identified no introgression.

\section{East Fork of Monture Creek}

Description

The East Fork of Monture Creek drains the western slopes of Limestone Pass and the eastern slopes of Monahan Mountain. The East Fork is a small $1^{\text {st }}$ order stream 3.2 miles in length, and it enters upper Monture Creek at stream-mile 23.9, about 1.9-miles downstream of Monture Creek Falls (Figure 3). The East Fork drains a small (3.0 miles $\left.{ }^{2}\right)$ basin, has an average stream gradient of 533\% mile and generates an estimated base-flow of 4-6cfs. The East Fork lies against 
the southern boundary of the Bob Marshall Wilderness (Lolo National Forest) and this basin is managed for wilderness values.

The riparian under-story vegetation along the lower portion of the survey section (mile 0.2 ) consists of a dense mix community of alder, willow, rocky mountain maple and young conifers, ferns and grasses beneath a canopy of Douglas fir, Englemann spruce, lodgepole pine and black cottonwood. In the upstream direction the bedrock walls constrict the channel. The channel classifies as a "Rosgen Aa" channeltype consisting of plunge-pools composed of bedrock, boulder and cobble substrate with overhanging vegetation serving as habitat features. Large woody debris recruitment to the stream channel at the survey location is light.

Fish populations and other monitoring activities

We conducted only one fish population survey on the East Fork Monture Creek at streammile 0.2. Sampling recorded low numbers of bull trout and WSCT (CPUE $=2.3$ and 4.2, respectively). No sculpins were observed, and spotted frogs were present. Water chemistry readings recorded a $\mathrm{pH} 7.92$ and a low conductivity of $43 \mathrm{uS}$ and low TDS at 21ppm. Genetic analyses $(n=28)$ identify the East Fork as supporting genetically pure WSCT.

\section{Burnt Cabin Creek}

\section{Description}

A small $1^{\text {st }}$ order perennial tributary stream, Burnt Cabin Creek flows west 1.1-miles to its confluence with Monture Creek at stream-mile 23.0. Burnt Cabin Creek has a stream gradient of 1,213 ' / mile and generates an estimate base flow of $0.2-0.5 \mathrm{cfs}$ from a small $\sim 0.7$ mile $^{2}$ basin (Figure 7).

The riparian under-story is relatively dense with primarily rocky mountain maple, alder, ferns and bear grass beneath a mature canopy of lodgepole pine and Douglas fir and Englemann spruce. Large woody debris recruitment to the stream channel is moderate. Stream channel substrate is predominately cobble and boulders with gravel and small woody detritus near the mouth. The stream transitions to a more boulder and bedrock dominated channel as gradient increases in the upstream direction.

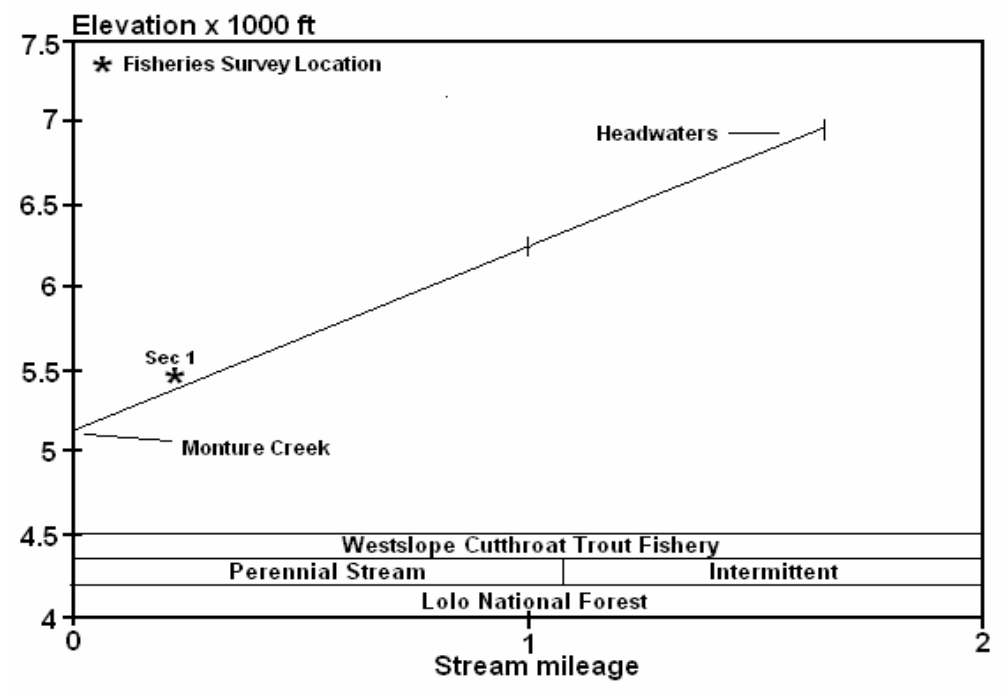

Figure 7. Longitudinal profile for Burnt Cabin Creek. 
Fish Populations and other monitoring activities

We surveyed fisheries at stream-mile 0.1 and recorded moderated densities of YOY WSCT $(\mathrm{CPUE}=10)$. No adult fish or amphibians were sampled or observed. Water chemistry readings were $8.23 \mathrm{pH}$, conductivity of $113 \mathrm{uS}$ and TDS at $57 \mathrm{ppm}$.

\section{Hayden Creek}

\section{Description}

A small $1^{\text {st }}$ order tributary stream that flows into upper Monture Creek at stream-mile 22.3, Hayden Creek has an average gradient of $495^{\prime}$ / mile over its 4.1 mile length. It generates an estimated base-flow of 2 - $4 \mathrm{cfs}$ from a 4.0 mile $^{2}$ basin which drains the northern slopes of Fenn Mountain. It lies within Lolo National Forest near the southern boundary of the Bob Marshall Wilderness and is managed for wilderness values.

Hayden Creek is classified as a steep "Rosgen Aal" channel-type with cascading bedrock and boulder step-pool features. The riparian over-story vegetation is a dense forest of Douglas fir, larch and lodgepole pine above a mixed understory of rocky mountain maple, alder,

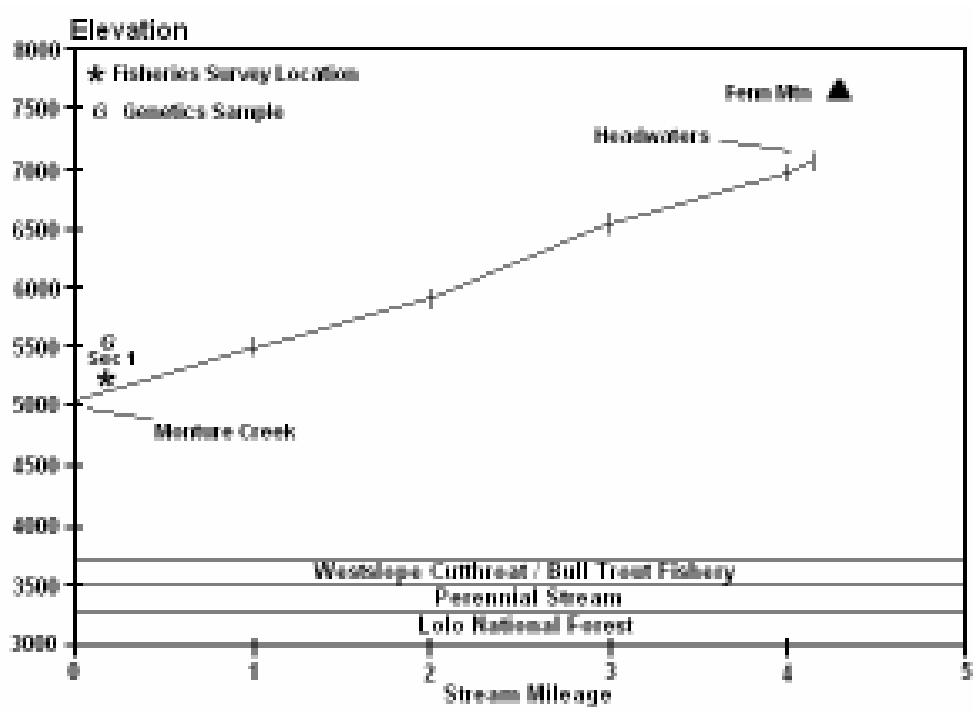

Figure 8. Longitudinal profile for Hayden Creek. young conifers, and grasses growing among confined bedrock.

Fish Population and other monitoring activities

We surveyed fisheries at stream-mile 0.1 and identified low numbers of bull trout and WSCT (CPUE $=1.8$ and 0.8, respectively). Sculpins were present, but no amphibians were observed. Water Chemistry readings identified a $\mathrm{pH}$ of 7.62 , very low conductivity of $44 \mathrm{uS}$ and very low TDS reading TDS of $21 \mathrm{ppm}$.

\section{Un-named Creek near Hahn Creek Pass}

Description

We sampled an unnamed tributary that enters Monture Creek at stream-mile 27.2 and drains a small basin (1.8 mile $\left.{ }^{2}\right)$ near Hahn Creek Pass. It lies entirely on the Lolo National Forest adjacent to the southern boundary of the Bob Marshall Wilderness. Approximately 2.2 stream-miles in length, only the

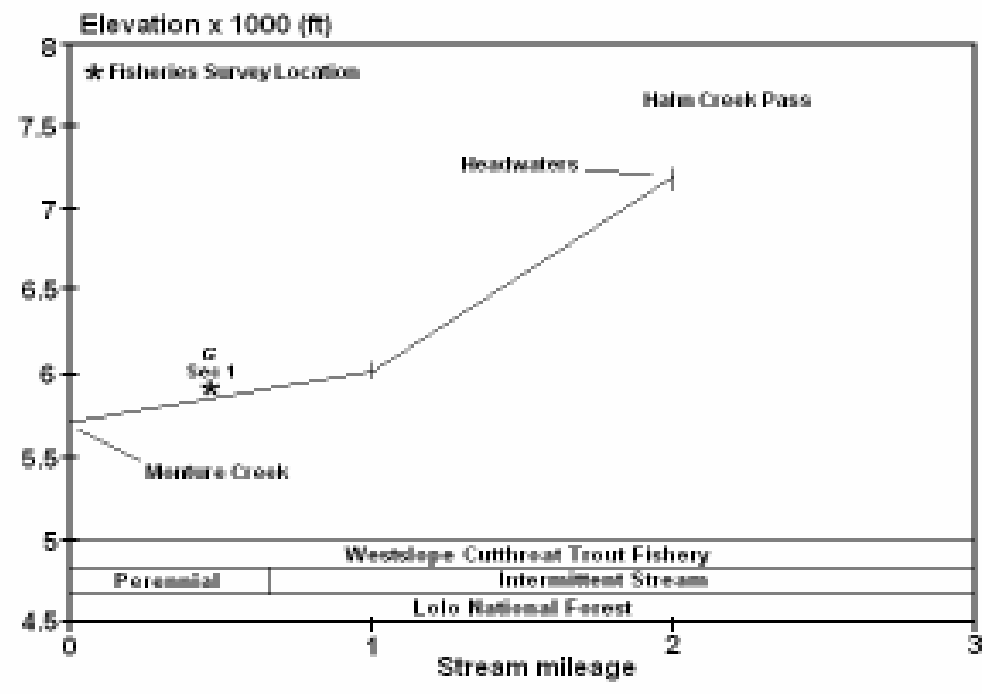

Figure 9. Longitudinal profile for Un-named Creek. 
lower 0.7-mile of stream is perennial. Stream gradient is $325^{\prime}$ in the lower mile, but increases significantly to 1200' / mile in the upper reaches (Figure 9). Base flow discharge was estimated at $0.5-1.0 \mathrm{cfs}$.

The riparian under-story vegetation is primarily alder, rocky mountain maple and young conifers above a ground-cover of mixed with horsetail, forbs and various grasses beneath a canopy of lodgepole pine. Stream channel substrate is primarily boulder, bedrock and cobble with gravel and detritus. Large woody debris recruitment to the stream channel is moderate creating small plunge pools and cover for fish habitat.

Fish population and other monitoring activities

In 2006, we conducted a fish population survey at stream-mile 0.5. Sampling recorded low numbers of WSCT at a CPUE of 0.9 fish and these fish averaged 7 inches in length. No fish were found upstream of a bedrock nick point observed $\sim 450$ ' upstream of the survey section. No other fish species or amphibians were sampled or observed. Water chemistry data was collected recording: $\mathrm{pH}$ of 8.0, low conductivity of $48 \mathrm{uS}$ and low TDS of $24 \mathrm{ppm}$.

\section{Wedge Creek}

\section{Description}

Wedge Creek is a high-gradient stream (mean gradient $\left.=1,030^{\prime} / \mathrm{mile}\right), 2.1$-mile length and drains a small 1.9 mile $^{2}$ basin on the southern slopes of Fenn Mountain. It lies within the Lolo National Forest just south of the Bob Marshall Wilderness. Wedge Creek is a $1^{\text {st }}$ order tributary stream that enters Monture Creek at stream-mile 20.3 with an estimated base-flow of 0.5-1.0cfs. Wedge Creek is classified as a "Rosgen A1" channel-type, and it is characterized by high-gradient stream channels with cascading step pools created by bedrock and boulders.

The riparian over-story vegetation is dense and predominately a Douglas fir, larch and lodgepole pine forest above a thin under-story of rocky mountain maple, young conifers, snowberry, ferns and grasses.

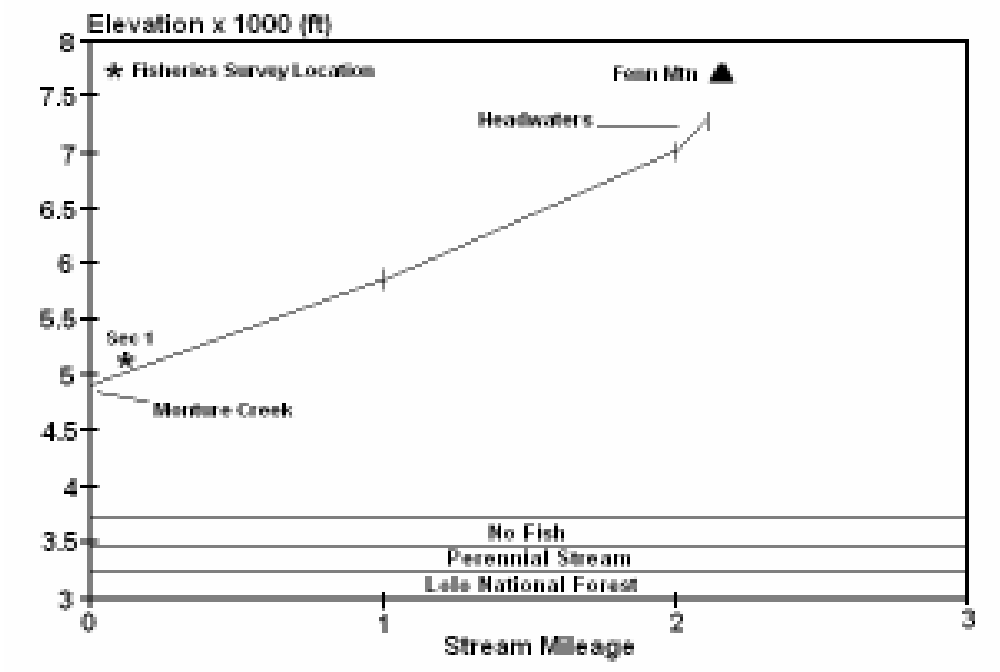

Figure 10. Longitudinal profile for Wedge Creek.

Fish population and other monitoring activities

In 2006, we conducted a fish population survey at stream mile 0.1 on Wedge Creek. No fish or amphibians were sampled or observed. Water chemistry reading identified a $\mathrm{pH}$ of 8.43, conductivity of $135 \mathrm{uS}$ and low TDS of $67 \mathrm{ppm}$.

\section{Yellowjacket Creek}

\section{Description}

Yellowjacket Creek is a small $1^{\text {st }}$ order stream that flows west 1.9 stream-miles to its confluence with Monture Creek at stream-mile 18.4. It drains $\sim 0.9$ mile $^{2}$ of Lolo National Forest 
land with an average stream gradient of $1,205^{\prime}$ / mile and generates an estimated base-flow of $0.2-0.5 \mathrm{cfs}$.

The riparian under-story is relatively dense, primarily rocky mountain maple and alder, ferns and beargrass beneath an over-story of lodgepole pine and Douglas fir mixed with Englemann spruce. Large woody debris recruitment to the stream channel is moderate. Stream channel substrate is predominately cobble and boulders with gravel. The stream becomes boulder and bedrock dominated as gradient increases in the upstream direction.

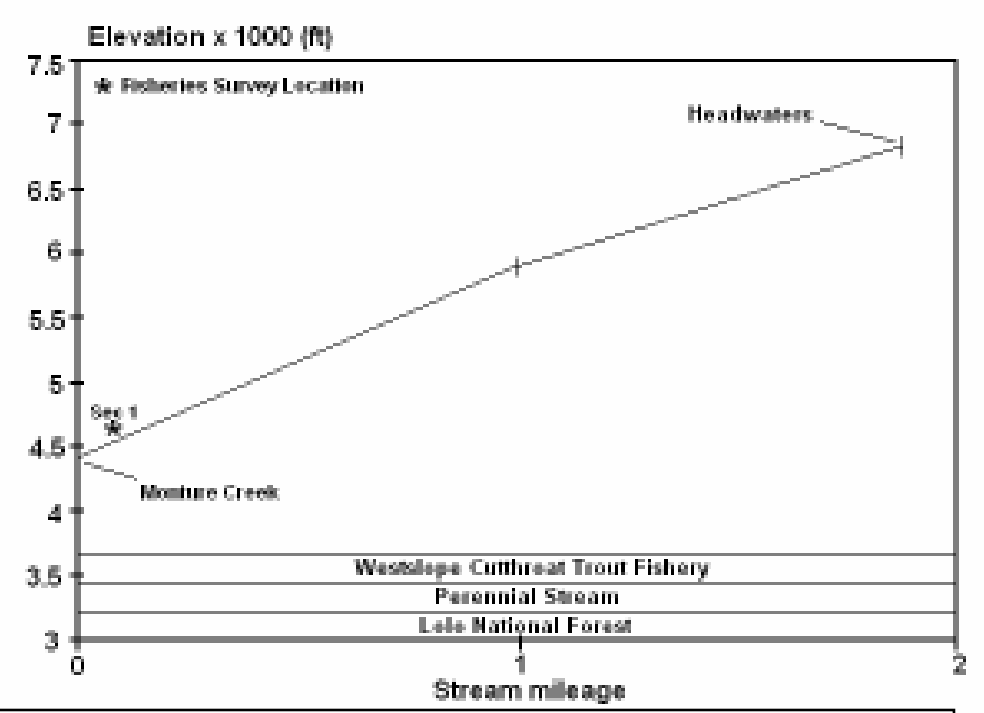

Figure 11. Longitudinal profile for Yellowjacket Creek.

$\underline{\text { Fish populations and other monitoring activities }}$

We conducted a fish population survey section at stream-mile 0.1 where we found only YOY WSCT at a CPUE of 10. No adult fish, other species or amphibians were observed. Water chemistry readings identified a $\mathrm{pH}$ of 8.23 , conductivity of $113 \mathrm{uS}$ and TDS of $57 \mathrm{ppm}$.

\section{North Fork of the Blackfoot River}

Description

The North Fork of the Blackfoot River is the largest tributary to the Blackfoot River. Beginning on the Continental Divide, the headwaters of the North Fork drain a glaciated region of the Scapegoat Wilderness. The North Fork flows west and southwest a total of 41.5-miles. At stream-mile 22, the North Fork exits the Wilderness and then enters Kleinschmidt Flats, a large glacial outwash plain, near stream-mile 12.0. The North Fork enters the middle Blackfoot River at river-mile 54.

Below the North Fork Falls

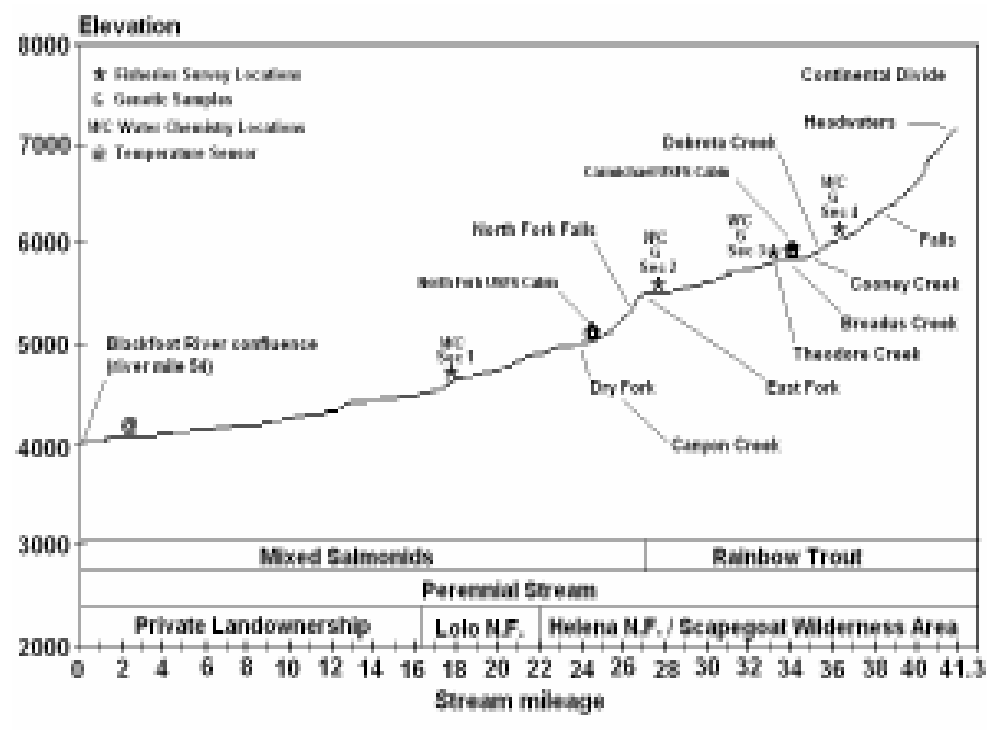

Figure 12. Longitudinal profile for upper North Fork Blackfoot River.

(at mile 26.7) the lower North Fork variably supports fluvial bull trout and WSCT, brown trout, rainbow trout and very low densities of brook trout depending on the specific stream reach.

In 2006-07, we conducted a series of fish population surveys above the North Fork Falls. These included three sites (stream-miles 27.2, 33.3 and 36) on the mainstem North Fork, two sites on the East Fork of the North Fork and seven smaller tributaries (Broadus, Cooney, Dobrota and Theodore, Pony, Scotty and Sourdough Creeks). We also surveyed Canyon Creek - a tributary to Dry Fork, which is located downstream of the North Fork Falls (Figure 12). 
The upper North Fork is a relatively confined, geologically controlled channel with a moderate meander pattern and an average gradient change of $120 \%$ mile. Substrates at the three survey locations are primarily cobble and gravel among erratic glacial boulders and large areas of exposed bedrock. In 1988, the Canyon Creek wildfire swept through the upper North Fork watershed. Among the existing deadfall, the young riparian community consists of lodgepole pine, Douglas fir, Englemann spruce and black cottonwood, as well as a dense willow layer along the immediate shoreline. Over-hanging

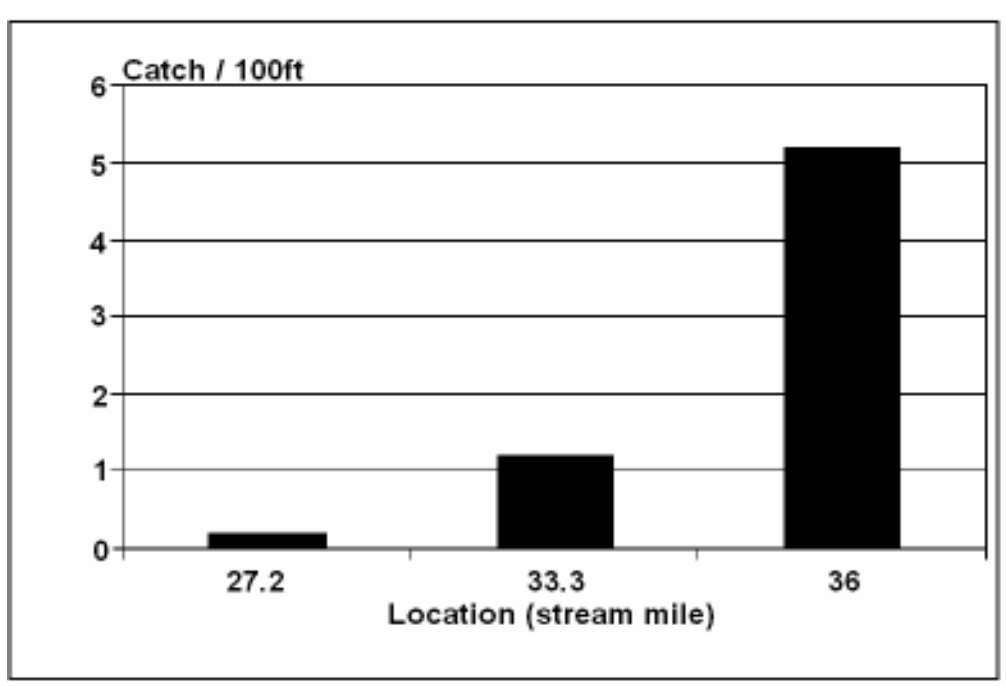

Figure 13. CPUE for rainbow trout at three survey locations on upper North Fork Blackfoot River, 2007. willow, large boulders and log-jams create instream habitat features. LWD retention in the North Fork channel is very high.

Fish Populations and other monitoring activities

Fish population surveys conducted on the upper North Fork Blackfoot River (miles 27.2, 33.3 and 36) recorded low numbers of rainbow trout (CPUE $=0.2,1.2$ and 5.2, respectively; (Figure 13). Genetic analysis at all three North Fork sample location showed introgression of WSCT and RBT. Water chemistry readings at these three survey locations show conductivity and TDS decreasing in the upstream direction from 177 to $109 \mathrm{uS}$, and from 89 to 55ppm, respectively.

\section{East Fork of North Fork of the Blackfoot River}

\section{Description}

The East Fork of the North Fork is a $3^{\text {rd }}$ order stream that originates $\sim 1.5$ stream-miles upstream of Parker Lake. From Parker Lake, the East Fork flows northwest $\sim 13$ miles to its confluence with the North Fork at stream-mile 27. The East Fork drains eight tributary streams over a $\sim 67$ mile $^{2}$ basin, which includes the Helena and Lolo National Forest portions of the Scapegoat Wilderness (Figure 14).

In 2006, we established two fish population surveys sections (stream miles 7.0 and 11.7) on the East Fork. The lower survey site falls within the 1988 Canyon Creek burn area, and it contained significant amounts of LWD within the channel. A dense forest of lodgepole pine has become established in the riparian zone along with a corridor of

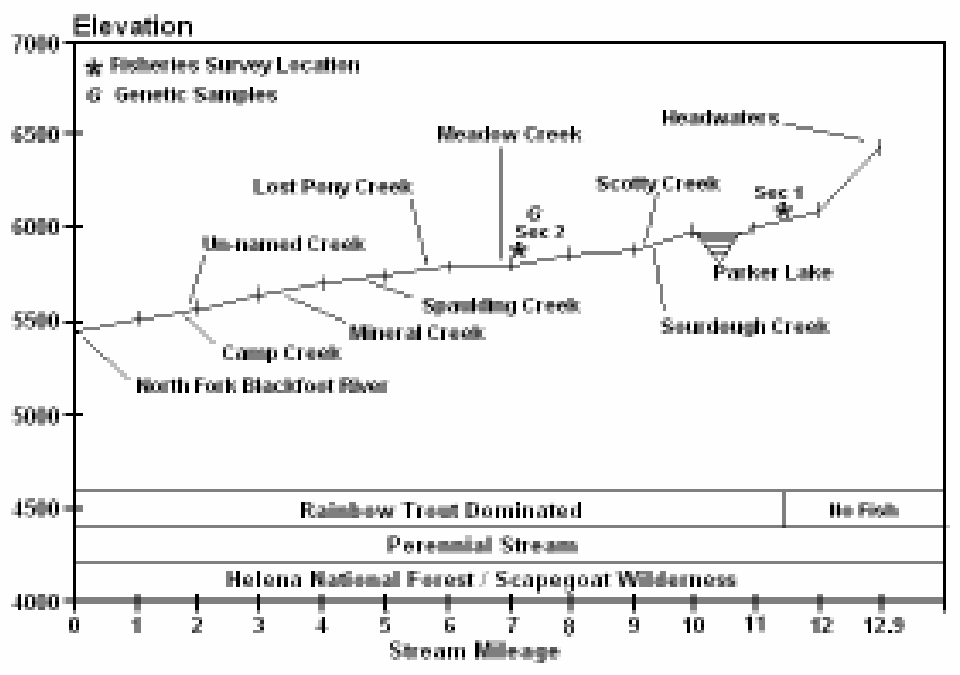

Figure 14. Longitudinal profile for East Fork of North Fork Blackfoot River. 
willow and alder, forbs and various grasses.

Outside of the burn area, the upper survey site (at stream- mile 11.7, above Parker Lake) of the stream is lined with a dense under-story of alder and other shrubs, snowberry and various grasses beneath a over-story of mature lodgepole pine.

Fish populations and other monitoring activities

Although the East Fork was historically stocked with "undifferentiated" cutthroat trout during the 1940s and 1950s (FWP historic files), our 2006 sampling identified only low numbers of rainbow trout hybrids $($ CPUE $=4.6)$ at mile 7.0. Western toads were also observed. We found no fish or amphibians at stream-mile 11.7 above Parker Lake despite the high abundance of Oncorhynchus hybrids in Parker Lake. The presence of rainbow trout hybrids below Parker Lake (at stream-mile 11.7) identify it and perhaps other nearby lakes (Meadow and West Twin Lakes) as source areas. Genetic analyses identified East Fork rainbow trout were introgressed with both Yellowstone cutthroat trout and WSCT (Appendix I).

\section{Broadus Creek}

\section{Description}

Broadus Creek is a $2^{\text {nd }}$ order tributary to the North Fork Blackfoot River. Located on Lolo National Forest land within the Scapegoat Wilderness, Broadus Creek drains a small (3.4 mile ${ }^{2}$ in conjunction with Eagle Creek) on the eastern slopes of Evans Peak. Broadus Creek flows east and south $\sim 2.5$ miles to its confluence with the North Fork at stream-mile 34. Eagle Creek, a $1^{\text {st }}$ order perennial stream, enters Broadus Creek at stream-mile 0.75. The upper mile of Broadus Creek is intermittent and has a gradient of 1,200 ' / mile while the lower 1.5 miles of stream is perennial and descends $430 \%$ mile (Figure 15)

Broadus Creek is a "Rosgen Aa2" type-channel. This high gradient stream has a mix of boulder-bedrock substrates. LWD is recruited from burned snags off the

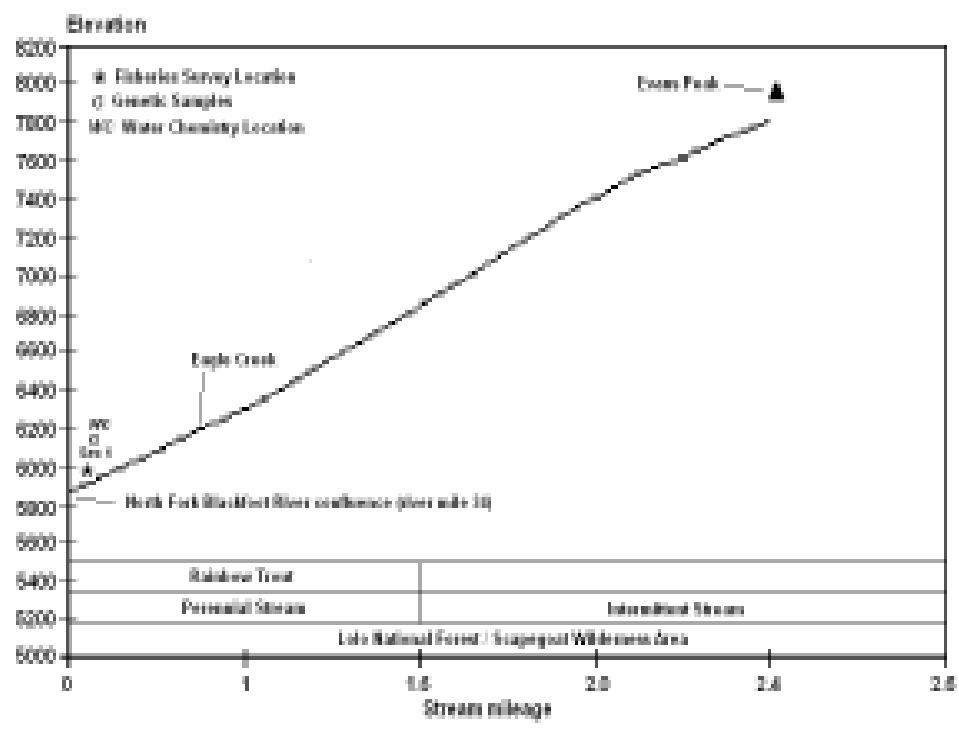

Figure 15. Longitudinal profile for Broadus Creek. steep surrounding cliffs. The banks are stable due to bedrock, but where allowed alder and a mixed community of grasses and forbs have taken hold. The young riparian forest is composed of lodgepole pine and spruce. Fish habitat is primarily in plunge and pockets pools. About 0.1 miles upstream of the mouth is a 12 -foot high waterfall which appears to be a fish passage barrier.

Fish populations and other monitoring activities

In 2007, we surveyed up and downstream of waterfalls at mile 0.1 . The survey identified rainbow trout in low abundance (CPUE $=1.4$ ) below the falls but the stream was absent of fish upstream of the falls. Genetics samples confirmed these fish as hybrid RBT. Water chemistry data was collected recording: moderate-high conductivity of $197 \mathrm{uS}$ and moderate TDS of 98ppm and a water temperature of $50.5^{0} \mathrm{~F}$. 


\section{Cooney Creek}

Description

Cooney Creek is a $1^{\text {st }}$ order tributary stream to the upper North Fork. Located on Lolo National Forest land within the Scapegoat Wilderness, Cooney Creek drains a small headwater basin $\left(9.3\right.$ mile $\left.^{2}\right)$ on northern slopes of Olson Peak and Galusha Peak. Cooney Creek flows northerly for about 5.5 miles to its confluence with the North Fork at stream-mile 34.9 near the Carmichael Guard Station. Stream gradient ranges from $91 \%$ mile near the mouth to $617^{\prime} /$ mile in upper reaches (Figure 16). Numerous small un-named perennial and ephemeral streams enter Cooney Creek throughout its entire length.

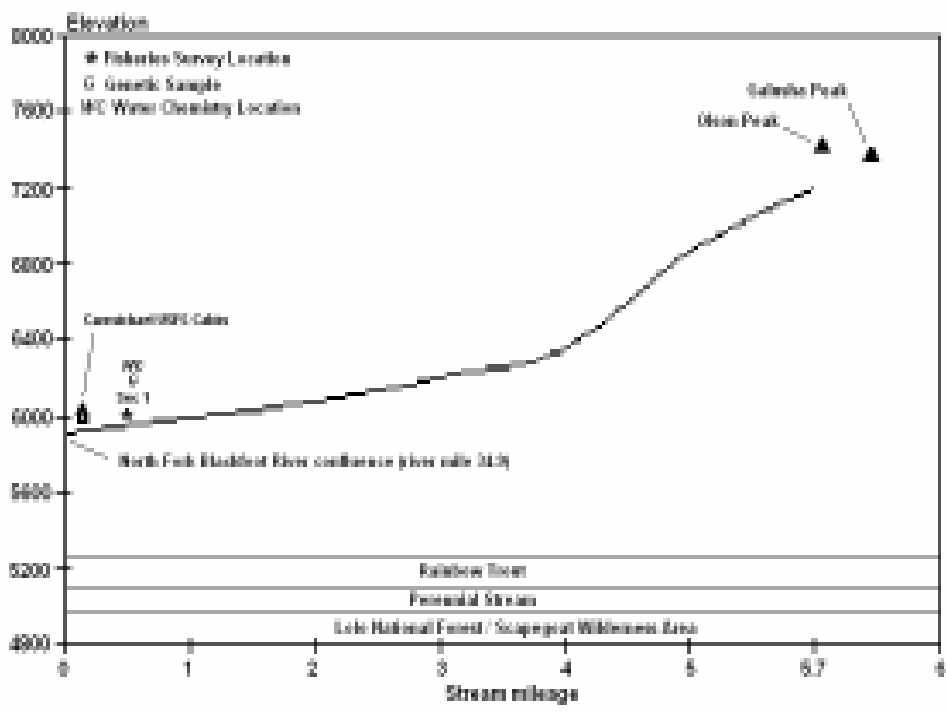

Figure 16. Longitudinal profile for Cooney Creek.

Cooney Creek classifies as a "Rosgen B3" type-channel with cobble and boulder and bedrock substrate. Shrubs (Alder and willow), forbs and grasses line the stream banks beneath a dense riparian forest composed of Englemann spruce and lodgepole pine. The surrounding slopes of Cooney Creek burned in the 1988 Canyon Creek fire. Currently, LWD recruitment is extremely high due to avalanche activity.

Fish populations and other monitoring activities

A fisheries survey at stream-mile 0.4 recorded low numbers of rainbow trout $(\mathrm{CPUE}=$ 0.2 ), and no other fish species were present. Water chemistry readings identified moderate conductivity of $160 \mathrm{uS}$, low TDS of $80 \mathrm{ppm}$ and a water temperature of $56.3^{\circ} \mathrm{F}$ during the survey.

\section{Dobrota Creek}

\section{Description}

Dobrota Creek is a $1^{\text {st }}$ order tributary to the North Fork, located on Lolo National Forest and within the Scapegoat Wilderness. Dobrota Creek drains a small basin $\left(\sim 6.1 \mathrm{mile}^{2}\right)$ on the southern slopes of Scapegoat Mountain. Dobrota Creek flows in a southerly direction for about 4.0 miles to its confluence with the North Fork at stream-mile 35.9 near the Carmichael Guard Station. The lower 2.0 miles of Dobrota Creek has an average gradient of 192 ' / mile, compared to $1,434 \%$ mile in the upper 2.0 miles of stream

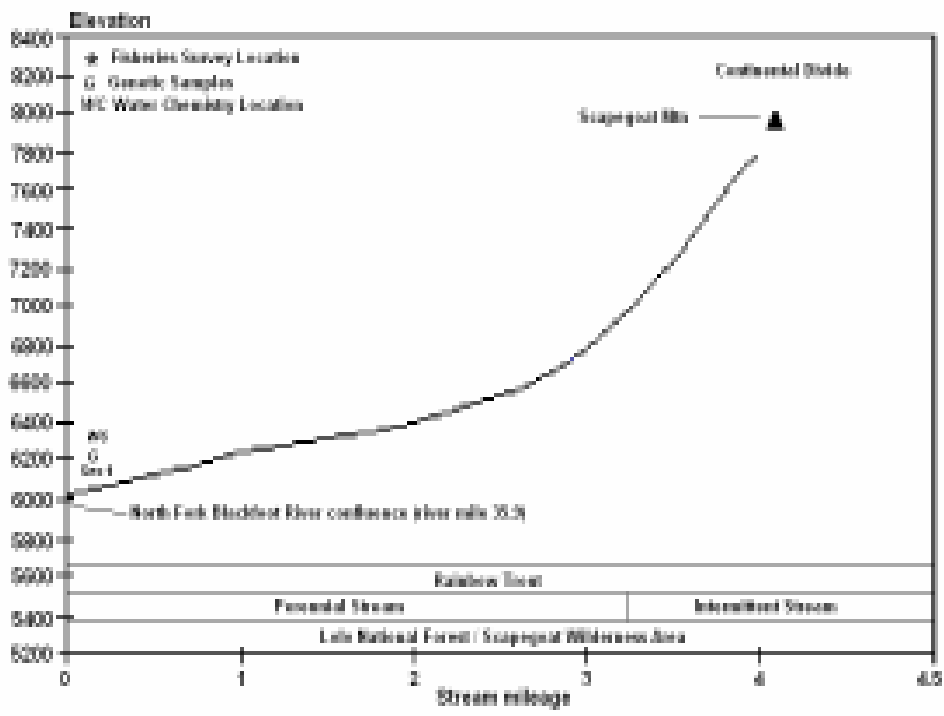

Figure 17 . Longitudinal profile for Dobrota Creek. 
(Figure 17).

The Canyon Creek fire burned this area intensely in 1988, resulting in a stand-replacement of lodgepole pine forest. High rates of erosion are occurring in areas against steep hillsides where plant re-growth is slow. This erosion process, however, is recruiting high amounts of LWD from standing snags. The riparian plant communities are composed of willow, alder, young lodgepole pine and a robust mixture of grasses and forbs that contributes to bank stability. Dobrota Creek classifies as a "Rosgen B3" with cobble-dominated substrate along with gravel, boulders mix with large areas of bedrock. Because of the lack of overhanging vegetation, fish habitat is primarily localized to LWD plunge and scour pools and boulder pocket water.

Fish populations and other monitoring activities

A survey of fish populations at stream-mile 0.1 found low numbers of rainbow trout $(\mathrm{CPUE}=2.7)$ and no other fish species were found. Genetic samples were analyzed and confirmed introgression of RBT with WSCT and Yellowstone cutthroat trout. Water chemistry recorded conductivity at $148 \mathrm{uS}$, TDS of $74 \mathrm{ppm}$ and a water temperature of $52.9^{0} \mathrm{~F}$ during the survey.

\section{Lost Pony Creek}

\section{Description}

Lost Pony Creek is a $1^{\text {st }}$ order perennial tributary to the middle reaches of the East Fork. Located in Helena National Forest and Scapegoat Wilderness, Lost Pony Creek drains a small basin $\left(\sim 3.6\right.$ mile $\left.^{2}\right)$ on the southern slopes of Galusha Peak. Lost Pony Creek flows in a southerly direction 3.8 miles to its confluence with the East Fork at stream-mile 6.1. Stream gradients range from 208 ' / mile near the mouth to 750 ' / mile in the upper reaches. At stream-mile 0.85 the outlet stream from West Twin Lake enters with $\sim 0.2-0.4 \mathrm{cfs}$. Below this junction Lost Pony Creek has an estimated base-flow of $0.5 \mathrm{cfs}$.

The stream banks are stable as a result of very dense riparian shoreline vegetation composed of shrubs, sedges and grasses. Over hanging vegetation, LWD, alder roots and under-cut banks provide

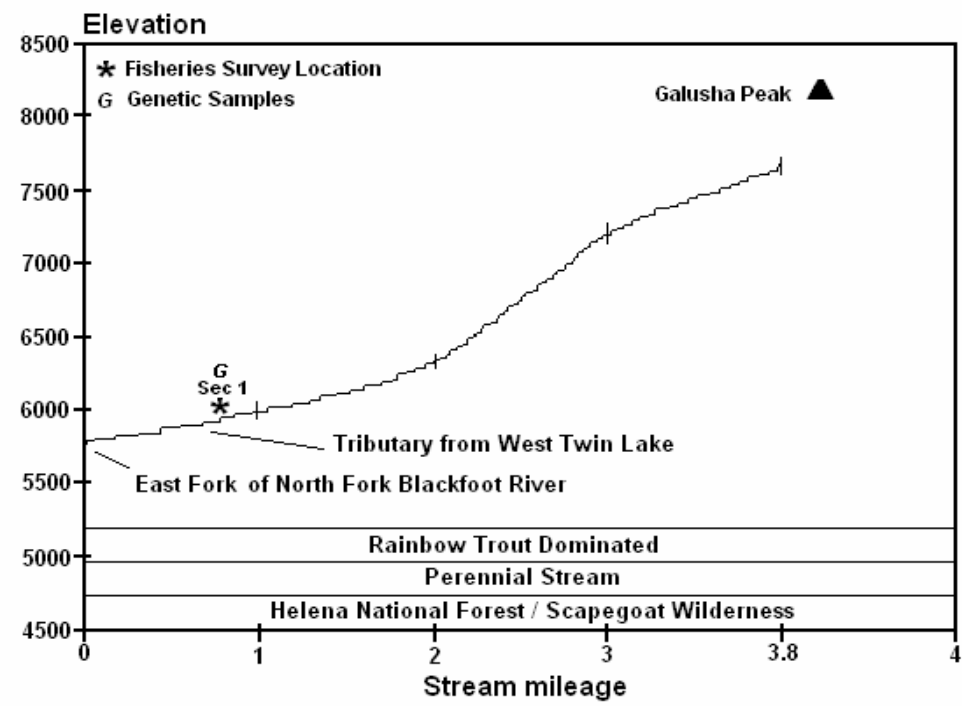

Figure 18. Longitudinal profile for Lost Pony Creek. high quality fish habitat. The Lost Pony Creek drainage was intensely burned in the 1988 Canyon Creek fire, resulting in the dense regeneration of the surrounding lodgepole pine forest.

Fish Populations and other monitoring activities

We surveyed fish population at stream-mile 0.8 and found low numbers of hybrid rainbow trout (CPUE = 2.6). No other fish species were found, but numerous spotted frogs were observed. Genetic analyses identify sampled fish as rainbow trout introgressed with Yellowstone cutthroat trout and WSCT with a predominant rainbow trout genetic contribution. 


\section{Scotty Creek}

Description

Scotty Creek is a $2^{\text {nd }}$

order tributary flowing south $\sim 4.8$ miles through Helena National Forest land to its confluence with the East Fork at stream-mile 9.3. The small watershed ( 4.4 mile $\left.^{2}\right)$ drains a small cirque lake and the slopes of Olson and Pyramid Peaks that lie along Red Ridge within the Scapegoat Wilderness Area. Stream gradients range from 710' / mile near the headwaters to $220 \%$ mile near the mouth (Figure 19).

Riparian vegetation is

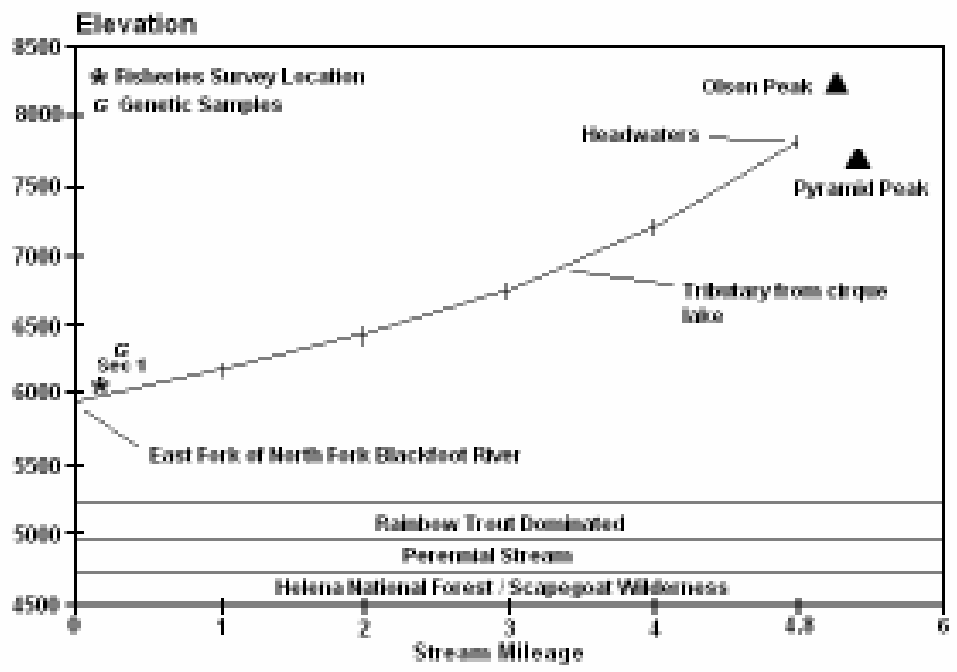

Figure 19. Longitudinal profile for Scotty Creek.

very dense and consists of willows and grasses within a regenerating lodgepole pine forest. The forest was severely burned during the 1988 Canyon Creek fire and is now recruiting high concentrations of LWD to the stream channel.

Fish Populations and other monitoring activities

A fish population survey at stream-mile 0.2 identified hybrid rainbow trout at low densities $(\mathrm{CPUE}=0.4)$. One "cutthroat trout" was identified $(\mathrm{CPUE}=0.2)$ in the field and numerous western toads were observed. Genetic analyses identify rainbow trout hybridized with Yellowstone cutthroat trout and minor genetic contribution of WSCT.

\section{Sourdough Creek}

$\underline{\text { Description }}$

Sourdough Creek, a $2^{\text {nd }}$ order tributary, drains a small $\left(\sim 5.1\right.$ mile $\left.^{2}\right)$ basin on the western slopes of Red Mountain, as well as a series of small cirque lakes before flowing north $\sim 3.4$ miles and joining the East Fork at stream-mile 9.4. Sourdough Creek lies entirely in Helen National Forest and Scapegoat Wilderness. Stream gradients average $185^{\prime} /$ mile in the lower 2.0 miles of stream, and then increase to 1,060' / mile between stream-mile 2.0 and 3.0 before decreasing in the very headwaters (Figure 20).

The riparian under-story vegetation is a dense shrub community (willow, alder and red-osier dogwood) and various forbs and grasses. Only the lower 0.1-mile of Sourdough Creek was affected by the 1988

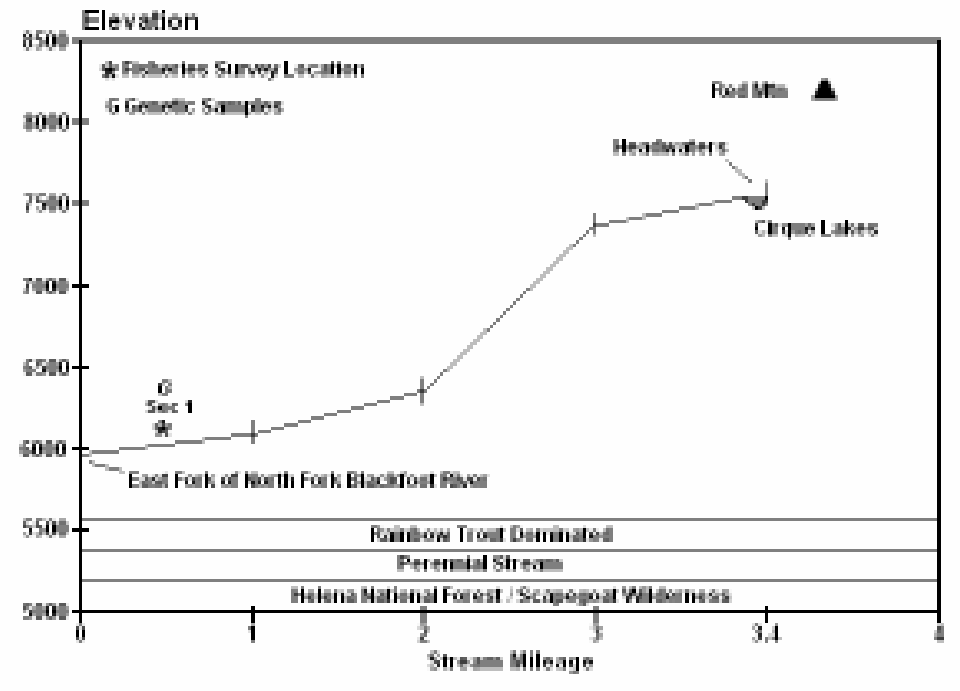

Figure 20. Longitudinal profile for Sourdough Creek. 
Canyon Creek fire; thus, the drainage supports a mature lodgepole pine and subalpine fir forest. Fish habitat consists of overhanging vegetation, under-cut banks and large boulder substrates. Larger woody debris recruitment in the majority of the stream channel is low compared to the nearby burn area.

Fish Populations and other monitoring activities

A fish population survey conducted at stream-mile 0.45 recorded very low numbers of rainbow trout $(\mathrm{CPUE}=0.5)$ and fish averaged 7.2 inches in length. No other fish species or amphibians were observed. Only three genetic samples were collected and these fish were identified as rainbow trout introgressed with Yellowstone cutthroat trout and WSCT.

\section{Theodore Creek}

\section{Description}

A small $1^{\text {st }}$ order perennial tributary, Theodore Creek flows northerly $\sim 2.4$ miles through Lolo

National Forest (Scapegoat Wilderness) before entering the upper North Fork at stream-mile 33.6. This high-gradient stream (mean gradient 530\% $/$ mile) drains as small basin $\left(1.6\right.$ mile $\left.^{2}\right)$ on the northeastern slopes of Galusha Peak and generates an estimate base-flow of 0.5-1.0cfs (Figure 21).

The 1988 Canyon Creek fire burned the riparian plant community along Theodore Creek, which now consists of dense communities of young Englemann spruce, black cottonwood and lodgepole pine, along

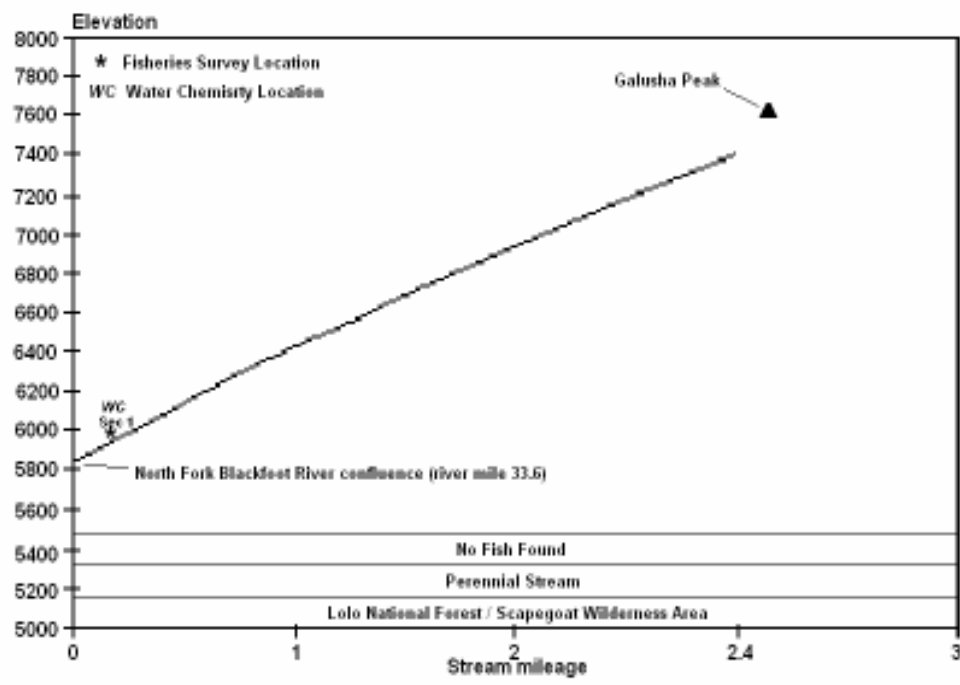

Figure 21. Longitudinal profile for Theodore Creek. with willow, forbs and grasses at the stream margin. LWD recruitment to the channel is high and over-hanging shrubs contribute extensively to instream habitat features. The survey location on lower Theodore Creek falls into a "Rosgen C4" type-channel with a predominately gravel substrate.

Fish population and other monitoring activities

A fish population survey at stream-mile 0.2 found no fish. Spotted frogs were observed. Water chemistry measurements recorded conductivity at $166 \mathrm{uS}$, TDS at $83 \mathrm{ppm}$ and a water temperature at $56.8^{0} \mathrm{~F}$ during the survey.

\section{Canyon Creek}

$\underline{\text { Description }}$

Canyon Creek is a tributary to the Dry Fork of the North Fork. The Dry Fork is a large glaciated basin that enters the North Fork downstream of the North Fork Falls. The headwaters of Canyon Creek begin in a marsh within a cirque basin upstream of Canyon Lake. The upper Canyon Creek basin is proposed wilderness and the lower basin falls within the Scapegoat Wilderness area of the Lolo National Forest. The Canyon Lake outlet stream joins with Conger Creek, a small tributary stream draining the slopes of Omar Mountain and Canyon Point, and 
together they form a $2^{\text {nd }}$-order stream that enters the Dry Fork of the North Fork Blackfoot River near rm 5.0. Approximately 5.6-miles in length, stream gradient decreases from 165 ' / mile at the headwaters to $40^{\prime} /$ mile in the middle reaches before increasing to 184 ' / mile near the mouth (Figure 22). Canyon Creek flows northerly and contributes an estimated base-flow of $\sim 5$ to $10 \mathrm{cfs}$ to Dry Creek.

The 1988 Canyon Creek forest fire burned the lower basin. A strong regeneration of lodgepole pine and high concentrations of LWD recruitment to the stream channel is now occurring. The middle to upper reaches of the drainage were unaffected by the fire, the stream banks are stable supporting dense

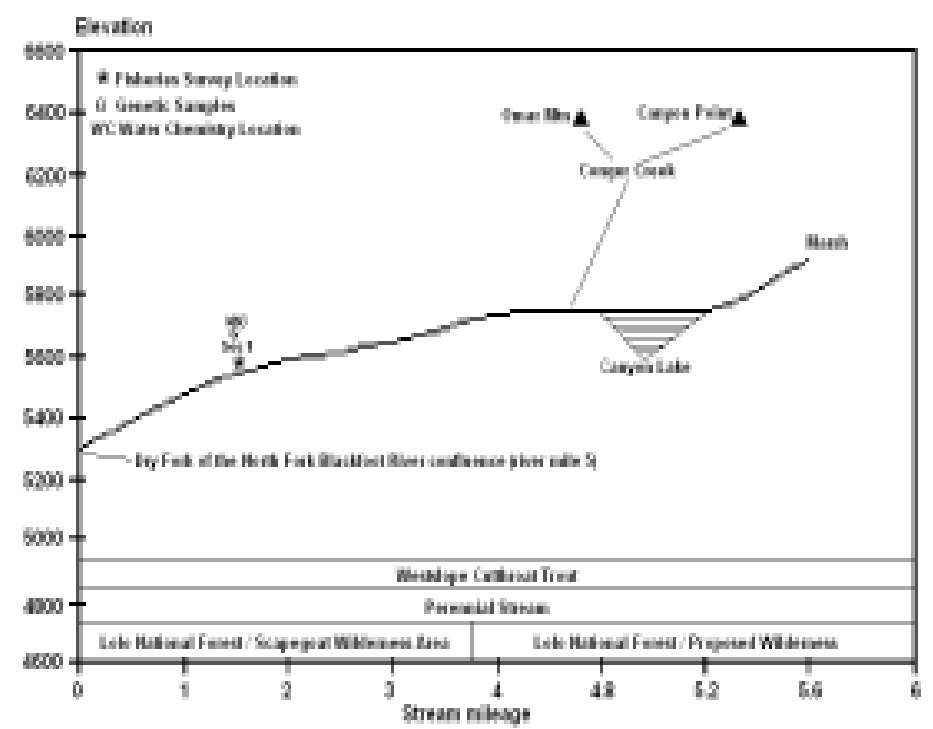

Figure 22. Longitudinal profile for Canyon Creek. over-story populations of lodgepole pine, Douglas fir, Englemann spruce above an under-story of willows, alders, rocky mountain maple, forbs, shrubs and various grasses. Large woody debris recruitment to the stream channel is moderate occurring at its natural pace. Stream channel classification at the survey location is predominately a "Rosgen B3" type channel with a substrate of cobble / gravel mixed with boulders. Log scour pools, overhanging vegetation, undercut banks and boulder pocket pools are primary habitat features.

Fish Population and other monitoring

We conducted a fish population survey on Canyon Creek at sm 1.5 in 2007. Fish sampling recorded a WSCT CPUE of 8.1. We failed to detect bull trout or other fish species. Bull trout were present in Canyon Lake in past surveys. Genetic analysis showed this population to be pure WSCT. Frog tadpoles were present but no adults were observed. Water chemistry readings were: conductivity at $118 \mathrm{uS}$, TDS at $60 \mathrm{ppm}$ and a water temperature at $57.7^{0} \mathrm{~F}$ during the survey. 


\section{Lake surveys in the Blackfoot Basin}

\section{Introduction and study area}

During the field season of 2006 and 2007, fisheries crews surveyed both the high mountain lakes in the "backcountry" areas (i.e. roadless and wilderness areas) as well as several lowelevation lakes located on the floor of the Blackfoot valley (Figure 23). The backcountry lakes were last surveyed more than 20 years ago and many of these were historically stocked with rainbow trout and "undifferentiated" cutthroat trout. Our survey objectives were to describe physical and biological attributes of lakes and evaluate accessibility and relative levels of recreational use. Surveys included fish population assessments, amphibian searches, bathymetric mapping, water chemistry measurements and a description of recreation sites and trail networks. We surveyed a total of 15 backcountry lakes, including three in the upper Monture Basin, seven in the North Fork Basin and five in the Landers Fork Basin. In addition to the backcountry lakes, we also surveyed Nevada Reservoir and eight additional lower-elevation natural lakes that possess some level of public access. All surveyed lakes are also included in Figure 23. Additional lake surveys are planned for the summer of 2008.

$x$

Figure 23. Lake survey sites: The lakes identified in black are the backcountry lakes and lakes identified in brown are lower-elevation lakes.

\section{Procedures}

Backcountry lakes - Using pack stock, fisheries crews established a series of remote base camps near all known fish-bearing and a few fishless backcountry lakes. Descriptive information (e.g., elevation, surface area, specific location, etc.) was approximated from USGS topographic maps and existing GIS data.

Fish sampling was conducted using overnight sets of sinking experimental gill nets. We used standardized net dimensions and mesh size (125'x 4'; 5 panels; 0.75 ', 1.00", 1.25", 1.5", and 2.0" bar) specified for alpine lake sampling in Montana. Nets were set for a single sampling period (minimum 10 hrs) usually beginning between 18:00 and 20:00. Nets were typically anchored to a $\log$ or rock on the shoreline (small mesh end) near a point or prominent feature with 
gradual depth contour. We used an inflatable boat to stretch and set the remainder of the net (maximum depth rarely exceeded $30 \mathrm{ft}$ ). Small lakes $(<10$ acres) were sampled for one netting period. On larger lakes and in instances where fish abundance was obviously low, we set two nets concurrently at widely spaced locations. For comparative purposes, all gill net catch results were standardized by species as number of fish per net-hr. Nets were located at previous sampling locations where possible.

Fish caught in gill nets were sacrificed and processed on shore. We weighed and measured each individual, assessed sex and maturity, and recorded a qualitative description of stomach contents. Scales were removed from a sub-sample for subsequent age and growth analyses. In most instances where Oncorhynchus Clarkii lewisi were suspected, we preserved 25 fin clips in individual vials filled with 95\% ethanol. Amphibian surveys were conducted during lakeperimeter surveys. All amphibians were identified to species and life stage. Total observed abundance of each species and life stage was approximated for each lake.

Basic water chemistry measurements were collected at shoreline and mid-lake locations using a hand-held electronic meter. Measurements included surface water temperature, $\mathrm{pH}$, conductivity $(\mathrm{uS} / \mathrm{cm})$, and total dissolved solids (TDS; ppm). Water clarity was also measured from an inflatable boat with a Secchi disk between 10:00 and 17:00 while wearing polarized sunglasses. The Secchi depth reported was the mean of two replicates by independent observers. In some cases, the maximum observable Secchi depth was estimated because it exceeded the maximum depth of the lake.

Lake bathymetric maps were created using field location and depth measurements at a series of points that characterized each lake. Although the total number of points varied based on lake size and depth variability, the protocol always included locations along the entire lake perimeter and at least five transects across the water body. At each transect point, latitude and longitude measurements were collected from an inflatable boat using a hand held GPS unit. Water depth was measured with a hand held electronic depth-finder. The total number of points collected per lake generally ranged from 150-300.

Field data were transferred to spreadsheet files in the office and shipped to the FWP Information Services Unit. Once formatted, point data were processed by TIN (triangulated integrated network) mapping software to produce bathymetric maps with 2-10 ft contours. The program also calculated surface area and lake volume. Features of interest such as trails, inlet streams, outlet streams and campsite/fire ring locations were later plotted on each map.

\section{Results}

Summary results of all lake surveys are located in Table 2. More detailed individual descriptions of all surveyed lakes are identified below. 
Table 2. Summary of lake survey information collected in 2005-2007.

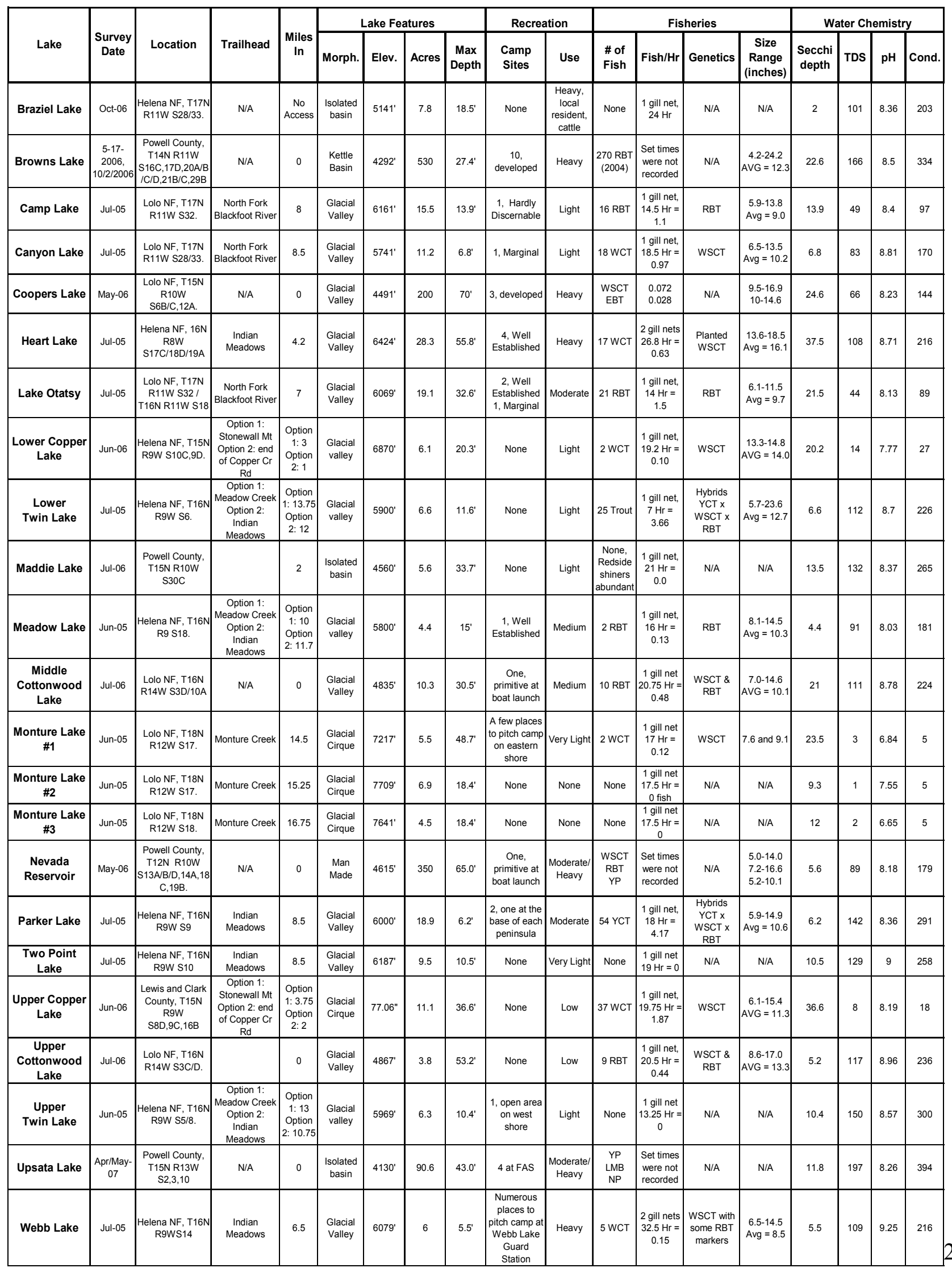




\section{Braziel Lake}
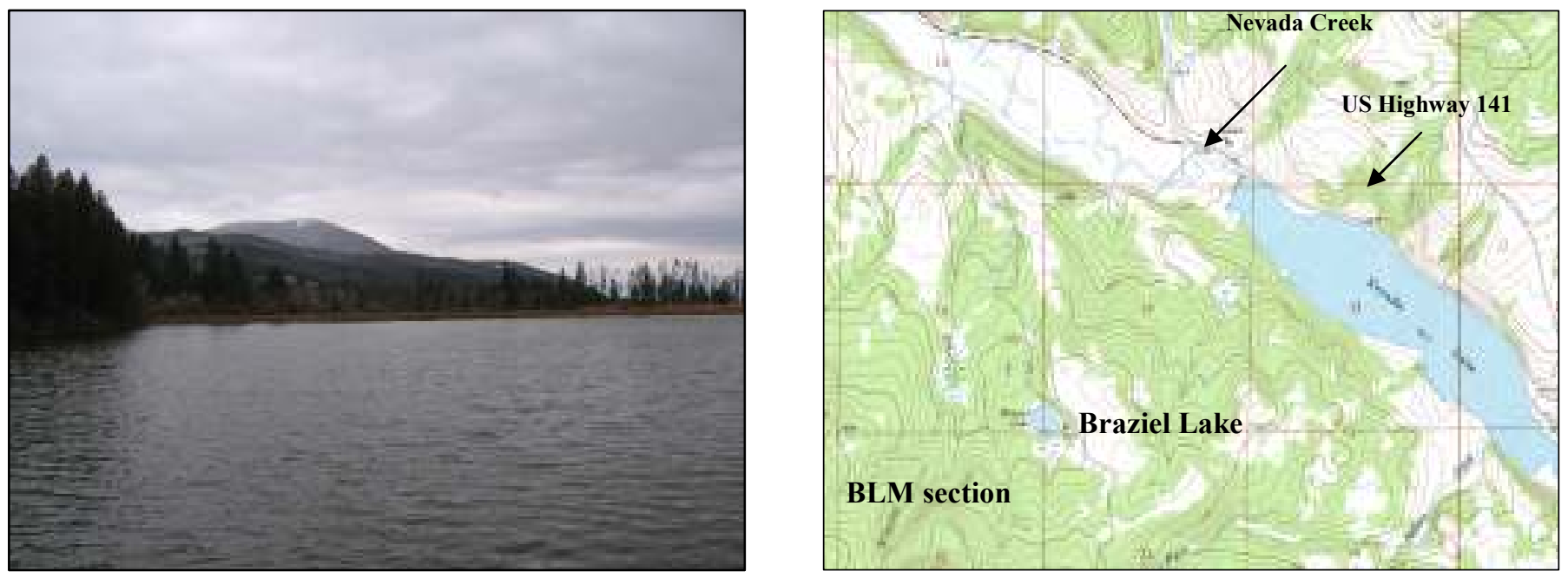

Description: In the upper Braziel Creek drainage, Braziel Lake is a small ( 7.4 acres) kettle lake (elevation of $5,141^{\prime}$ ) and is located 3.2 miles due east of Hoodoo Mountain and 1.2 miles southwest of Nevada Lake (Reservoir) in the eastern Garnet Mountain Range (see above map). Private ranch surrounds the lake except for the very westsouthwest side of the lake (section 22), which is Bureau of Land Management land (BLM).

Location: T12N, R10W, Sections 14, 15, 22 and 23; Latitude N47.78848 ${ }^{\circ}$, Longitude W112.83057 ${ }^{\circ}$; Nearest Town: Helmville.

Pubic Access: The very corner of section 22 of BLM land touches Braziel Lake (see above map), which appears to limit public access to this single site. "Corner-crossing" at section lines is not recommended. Recreationists are advised to obtain permission from the adjacent landowners to reduce conflict and ensure compliance with applicable access laws and rules.

Camp Sites and Use: Because the majority of lake's perimeter is privately owned land, there are no camping areas on Braziel Lake.

Angling Opportunity: Our 2006 gill net survey found no fish in Braziel Lake. However, the lake was recently planted by adjacent private landowner. Many areas of the immediate shoreline are marshy with cattails, sedges and rushes.

Stocking History: The lake has been periodically stocked by private landowners, most recently in 2007

Angling Pressure: Unknown.

Other Nearby Lakes: Nevada Lake (Reservoir) is only other lake in the immediate vicinity of Braziel Lake. Nevada Reservoir can be access from Highway 141 approximately 10.6 miles southeast of Helmville or 20.2 miles northwest of Avon. 
Date Sampled: 10/18-19/2006

Game Fish Present: WSCT

Other Fish Species Present: None

Size Captured: NA

Trout Condition (Wr): NA
Water Code: None

Sampling Methods: Sinking Gill Net

Gill Net Catch Rate: NA

Natural Recruitment: NA

Amphibians Observed: None

Management Objectives: Explore opportunities to improve public access to the lake. Consider stocking program that provides for limited public recreation.

Currently Stocked: Yes (by private landowner) Last Stocked: 2007 (private landowners) Species: Westslope Cutthroat Trout Recommended Stocking Frequency: NA Water Chemistry: pH: 8.36 TDS: 101 ppm Conductivity: $203 \mathrm{uS}$ Secchi Depth: $2.0 \mathrm{ft}$

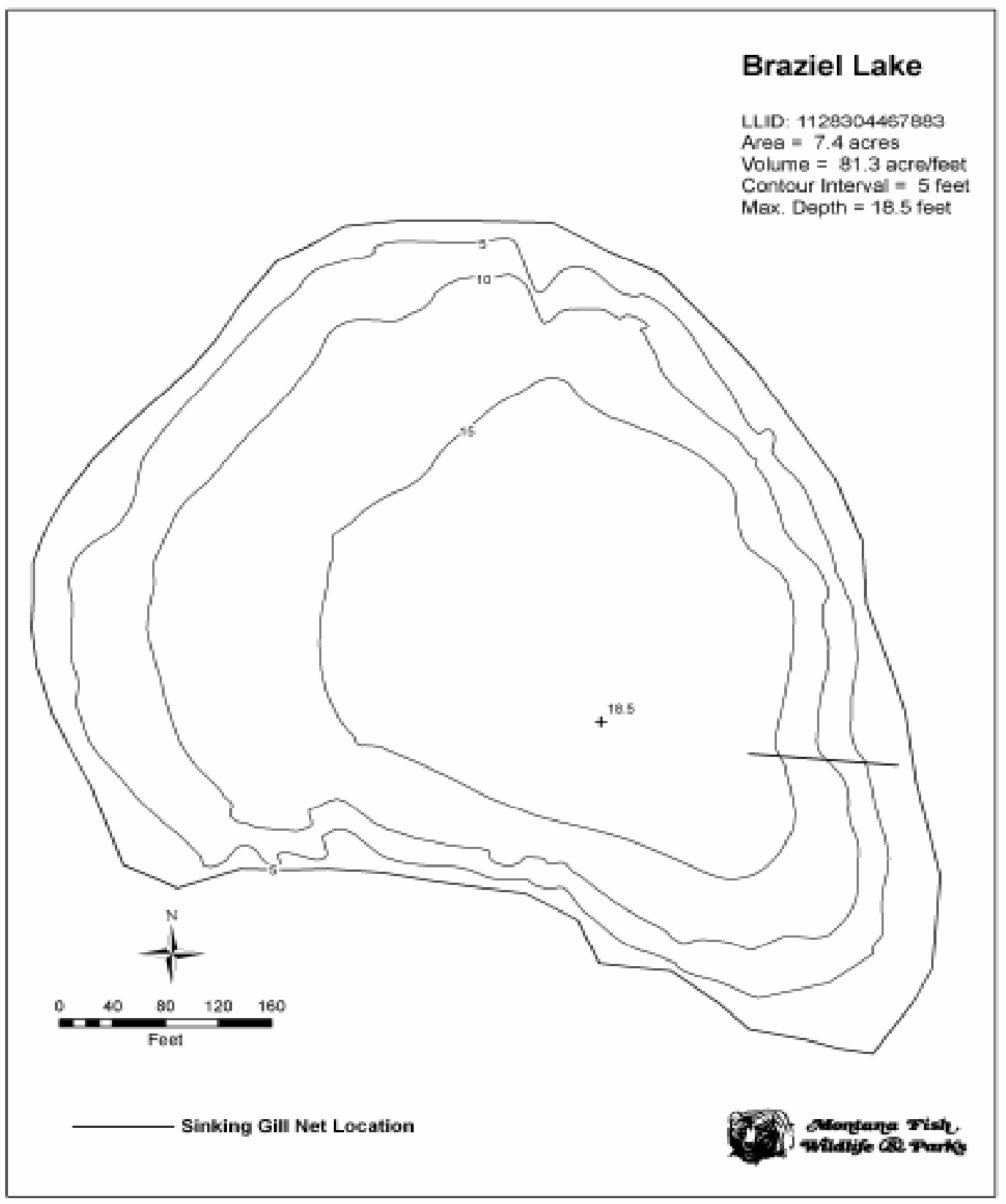




\section{Browns Lake}
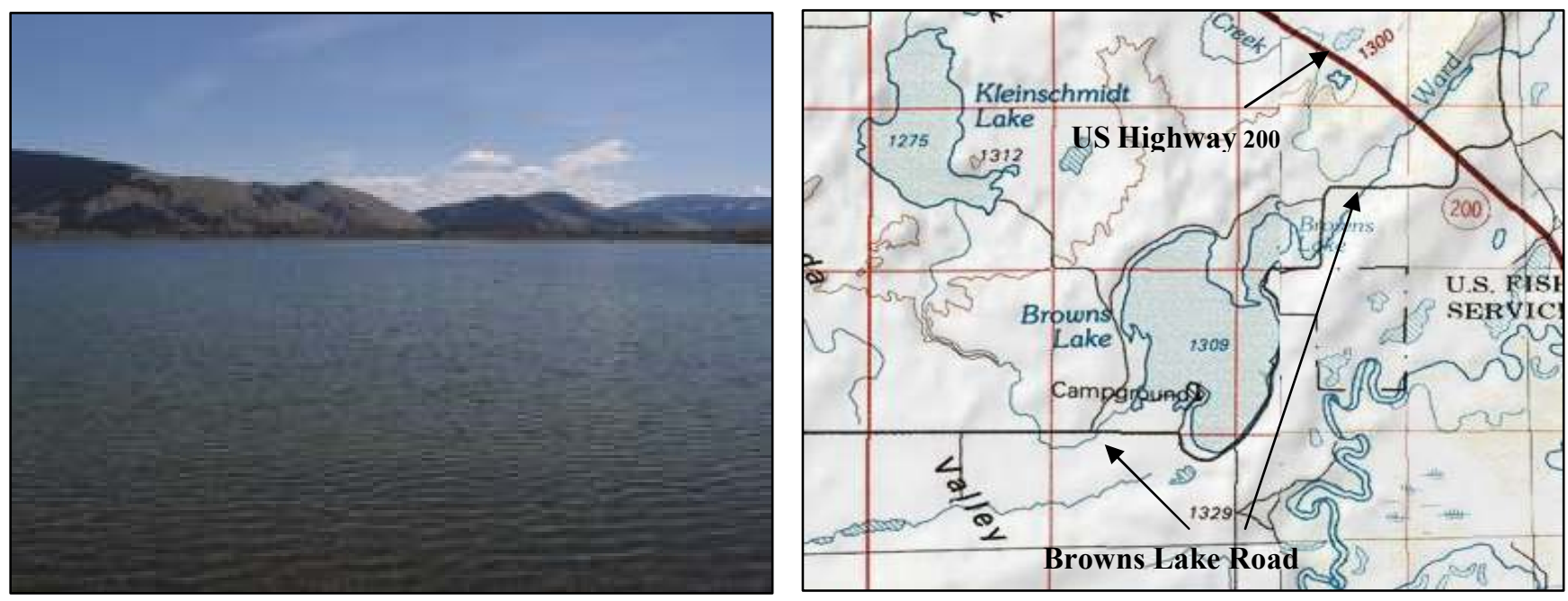

Description: Browns Lake is a large (549.9-acre) "pothole" lake located in the "knob and kettle" topography of Kleinschmidt Flats near the middle Blackfoot River watershed. The lake sits at an elevation of 4,294' and is bordered primarily by private ranchlands except for about 80 -acres of state land on the northeast corner of the lake. Portions of the eastern shoreline are owned by USFW for waterfowl production. Ward Creek enters at the northeast corner and exits at the southwest corner of the Browns Lake with estimated flows ranging from 0.5-5cfs.

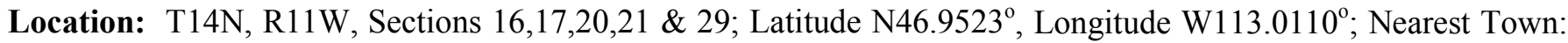
Ovando.

Public Access: Access to Browns Lake can be reached from Ovando or Helmville by using the Ovando-Helmville Road then turning east for 4 miles on the Browns Lake Road. Access can be obtained from US Highway 200 by turning south for 3 miles on the Browns Lake Road. Browns Lake is signed from Ovando and Highway 200.

Camp Sites and Use: Browns Lake has an established campground under lease and maintained by Montana Fish, Wildlife and Parks. This "fee" area has 15 camp sites with fire rings, two boat ramps and toilets. There are numerous other undeveloped (primitive) camp sites on the eastern shore of the lake along Browns Lake Road.

Angling Opportunity: Browns Lake is a productive "put-and-take" rainbow trout fishery. The lake also supports an abundant number of longnose suckers. Primary means of fishing is done from a boat or through the ice. Shoreline topography lends well to shoreline angling from most of the lake's perimeter.

Stocking History: From 1953 through 2006, annual stocking has occurred with primarily rainbow trout augmented with periodic stockings of westslope cutthroat trout in 1959, 1989, 1994 and 1998 and Coho salmon between 195355, and 1968-69. Currently Browns Lake is stocked annually with $\sim 50,000$ rainbow trout.

Angling Pressure: From March 2005 to February 2006, estimated angling pressure for Browns Lake supported 10,078 angler-days.

Other Nearby Lakes: Kleinschmidt Lake (a fishless lake surrounded by private land), approximately one mile to the northwest is the only other lake in the immediate vicinity of Browns Lake. 


\section{Browns Lake: Biological \& Physical Information}

Date Sampled: 9/9-10/2007, 5/10, 16, 17 \& 10/2/2006, $9 / 8-11 / 2004$

Game Fish Present: Rainbow trout

Other Fish Present: Longnose sucker, redside shiner

Size Captured: Mean 14.8 inches (range $6.2-22.8$ inches)

Trout Condition Factor (Wr): Mean $113 \pm 16.1$ (range $42-157$ )

Amphibians Observed: Spotted frogs (adults \& larvae), painted turtles
Water Code: 04-6210

Sampling Methods: Floating and Sinking Gill Nets

Gill Net Catch Rate: 0.9/trout/net/hr Natural Recruitment: NA

Management Objectives: Continue existing annual stocking fishery and investigate alternative strains and timing of rainbow trout plants.

Currently Stocked: Yes Last Stocked: Stocked annually Species: RBT Recommended Frequency: Annually

Water Chemistry: pH: 8.50 TDS: 166 ppm Conductivity: $334 \mathrm{uS}$ Secchi Depth: $22.6 \mathrm{ft}$

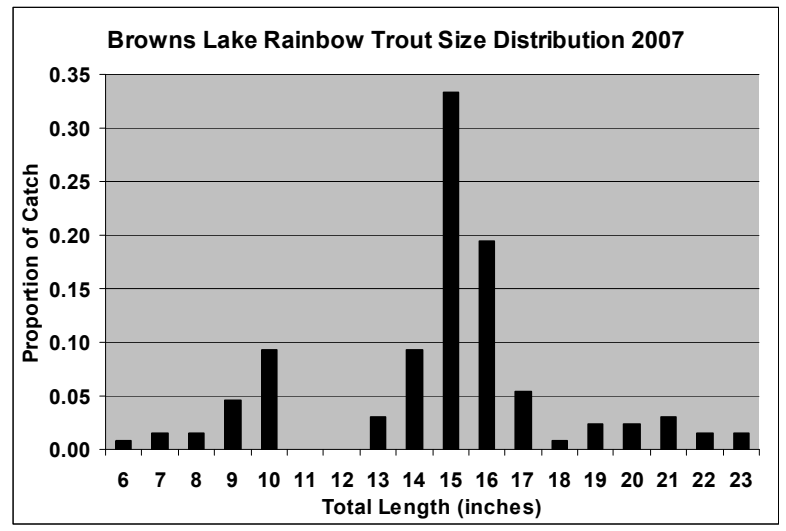

Stocking History

\begin{tabular}{|c|c|c|}
\hline Year & Species & \# Stocked \\
\hline $\begin{array}{c}\text { 2006-1932 } \\
\text { periodically }\end{array}$ & RBT & $\mathbf{2 , 7 7 9 , 0 8 3}$ \\
\hline $\begin{array}{c}\text { 1998 -1959 } \\
\text { periodically }\end{array}$ & WSCT & 72,856 \\
\hline $\begin{array}{c}\text { 1969-1940 } \\
\text { periodically }\end{array}$ & Coho & $\mathbf{3 2 7 , 5 9 0}$ \\
\hline 1937 & Kokanee & $\mathbf{6 3 , 2 0 0}$ \\
\hline 1931,1928 & Chinook & $\mathbf{7 3 , 0 0 0}$ \\
\hline
\end{tabular}




\section{Browns Lake}

\section{LLID: 1130104469583}

Area $=549.9$ acres

Volume $=6023.9$ acre/feet

Contour Interval $=5$ feet

Max. Depth $=27.4$

\section{et}
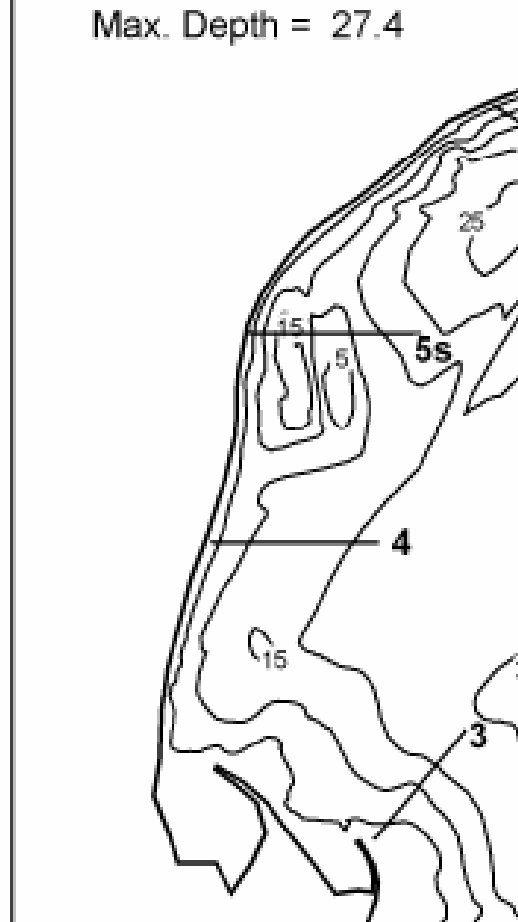

Fluating Gill Net Locations

s Sinking Gill Net Locations 


\section{Camp Lake}
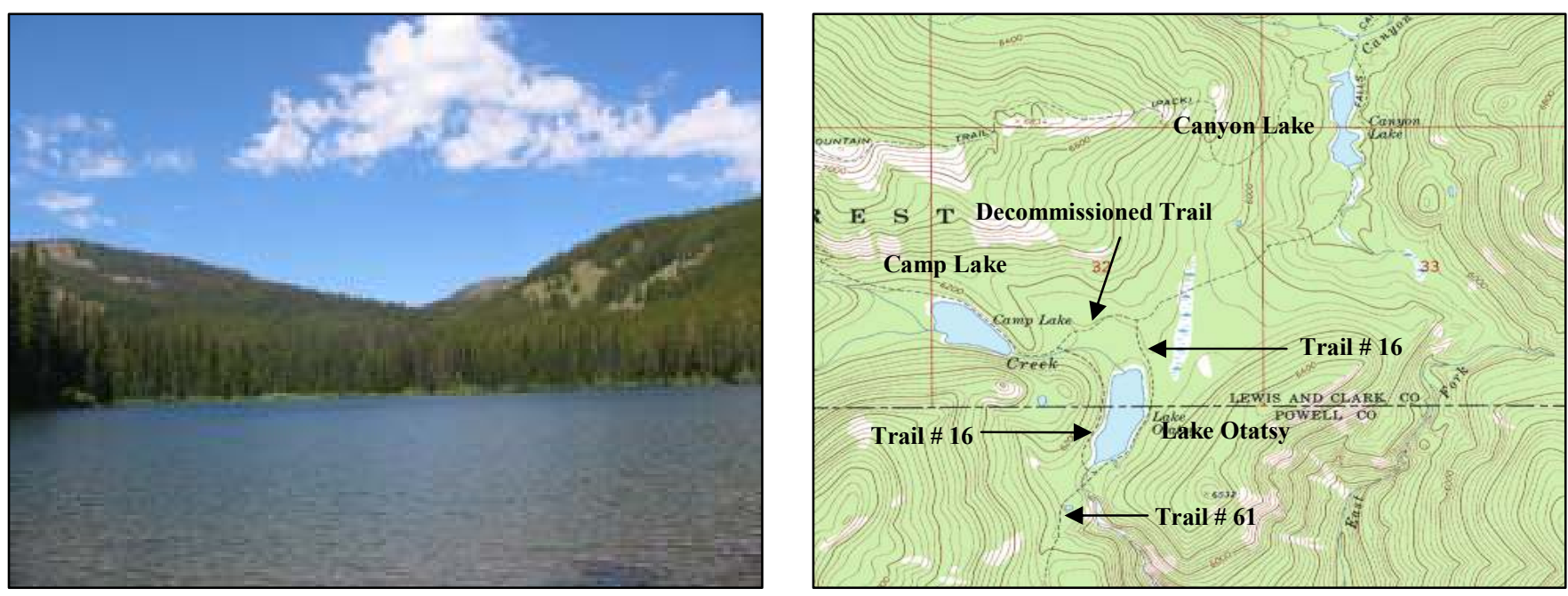

Description: Camp Lake is a small (17.8 acres) glacial valley trough lake located approximately 1.5 miles north of East Spread Mountain near the southwestern boundary of the Scapegoat Wilderness. The lake lies within the Lolo National Forest in a proposed wilderness area at 6,161' in North Fork Blackfoot River drainage.

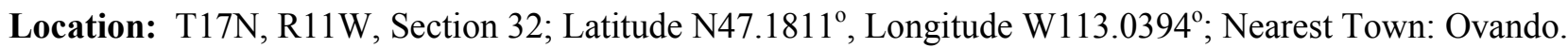

Pubic Access: Access to Camp Lake can be obtained by taking Highway 200 from Ovando 19 miles to the McCabe-Lake Creek Trail at North Fork Blackfoot River Trailhead. From the trailhead either hike or pack in on horses following USFS Trail \#61 (McCabe-Lake Creek Trail) to its intersection with USFS Trail \#1404, approximately 4.0 miles from the trailhead. The USFS Trail \#61 changes its name to Lake Otatsy Trail and continues north to the southern end of Lake Otatsy where it intersects with USFS Trail \#16 which splits and follows both sides of Lake Otatsy. The trail on the west side of Lake Otatsy continues on for another 0.7 miles to Camp Lake. The Camp Lake route is approximately 7.7 miles distance, with a moderate difficultly.

Camp Sites and Use: Camp Lake lies in a remote setting that receives very light recreational use. One primitive camp site was observed near the Lake Creek inlet on the western side of the lake. "Leave no trace" camping and recreating is essential in this area as it is proposed wilderness. Camping is available nearby at Lake Otatsy.

Angling Opportunity: Camp Lake supports a wild rainbow trout population through natural reproduction. Shoreline topography is brushy and may hinder shoreline angling in most areas.

Stocking History: Historically planted with rainbow trout, Camp Lake now supports a self-sustaining rainbow population.

Angling Pressure: From March 2005 to February 2006, estimated angling pressure for Camp Lake supported 50 angler-days.

Other Nearby Lakes: There are two other lakes in the general vicinity of Camp Lake that lies in the North Fork Blackfoot River drainage. Lake Otatsy is approximately 0.4 miles southeast of Camp Lake and is passed on USFS Trail \#16 on the way to Camp Lake. USFS Trail \#16 splits at the southern end of Lake Otatsy. The trail on the eastern side of Lake Otatsy leads to Canyon Lake, approximately 1.5 miles northeast of Camp Lake. 


\section{Camp Lake: Biological \& Physical Information}

Date Sampled: 7/12-13/2005

Game Fish Present: Rainbow trout Other Fish Present: None

Size Captured: Mean 9 inches (range 5.9-13.8 inches)

Trout Condition (Wr): Mean $86 \pm 17.7$ (range 71-147)
Water Code: 04-6240

Sampling Methods: Sinking Gill Net

Gill Net Catch Rate: 1.1 trout $/$ net $/ \mathrm{hr}$

Natural Recruitment: Present (limited)

Amphibians Observed: Spotted Frogs (adults)

Management Objectives: Continue as a self-sustaining rainbow trout fishery.

Currently Stocked: No Last Stocked: Unknown Species: RB Recommended Frequency: NA

Water Chemistry: pH: 8.4 TDS: 49ppm Conductivity: $97 \mathrm{uS}$ Secchi Depth: $13.9 \mathrm{ft}$
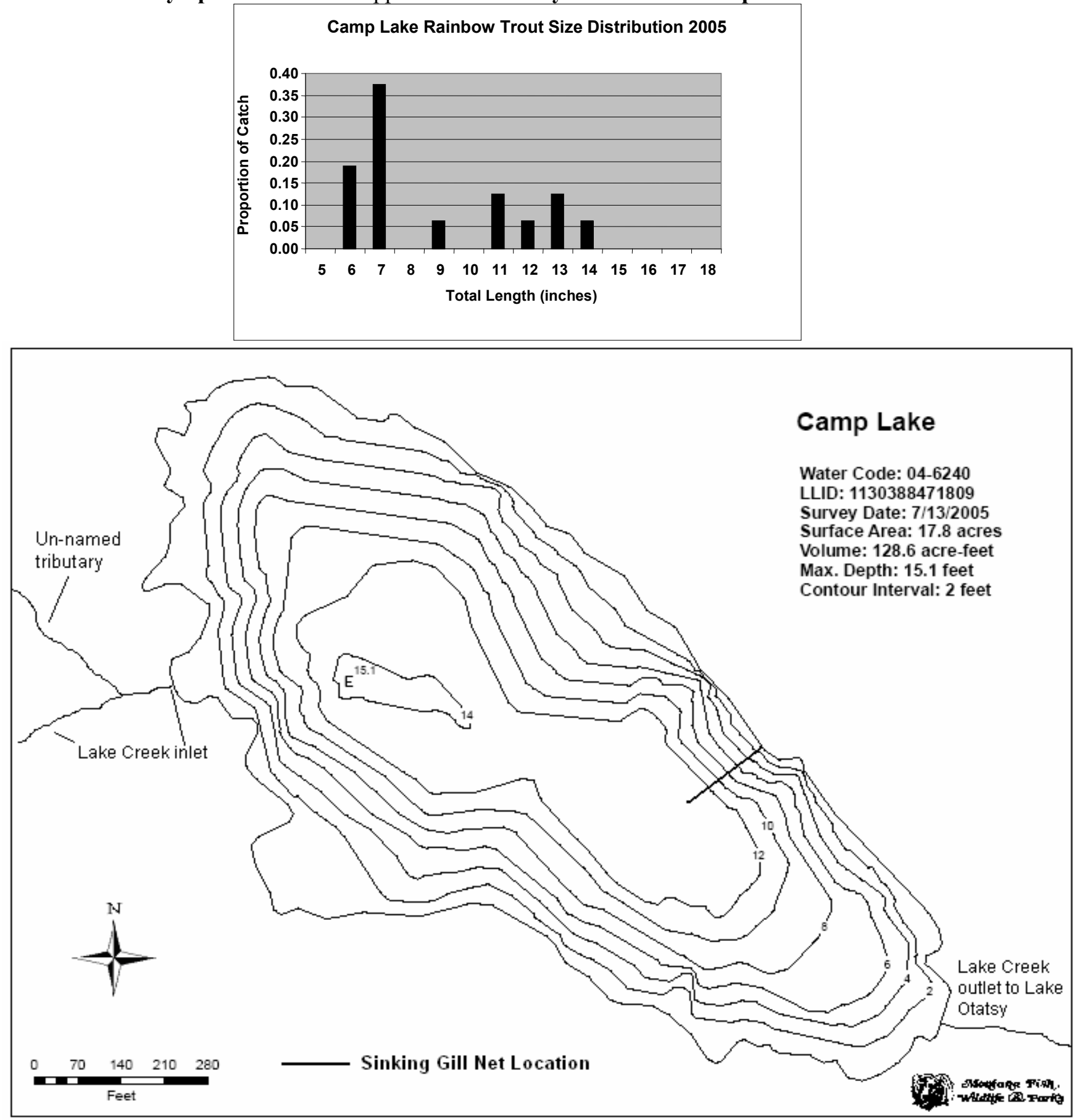


\section{Canyon Lake}
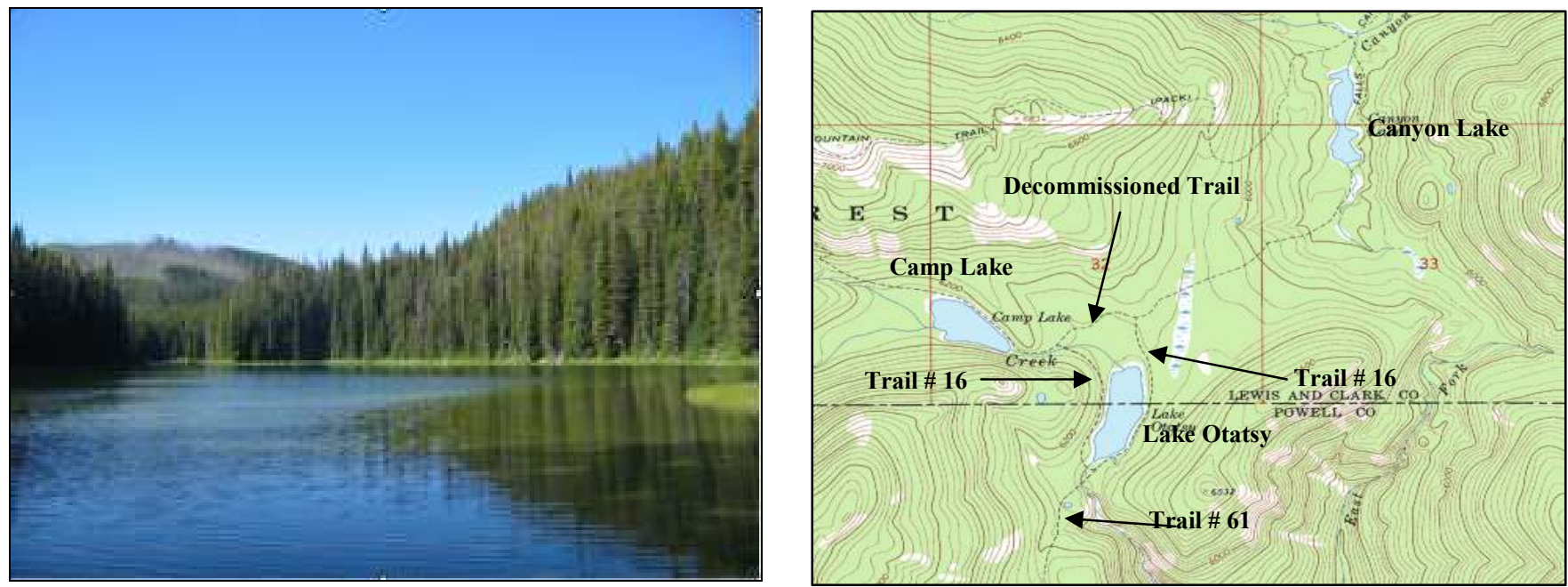

Description: Canyon Lake is a shallow 11.5 acres glacial valley lake located approximately 2.7 miles northeast of East Spread Mountain near the southwestern boundary of the Scapegoat Wilderness. The lake lies within the Lolo National Forest in a proposed wilderness area at an elevation of 5,741 ft, within the Dry Fork drainage of the North Fork Blackfoot River watershed.

Location: T17N, R11W, Section 28, 33; Latitude N47.19213º Longitude W113.01548 ${ }^{\circ}$; Nearest Town: Ovando.

Pubic Access: Access to Canyon Lake can be obtained by taking Highway 200 from Ovando approximately 19 miles to the North Fork Blackfoot River Trailhead. From the trailhead, either hike or pack in on horses along USFS Trail \#61 (McCabe-Lake Creek Trail) to its intersection with USFS Trail \#1404, about 4.0 miles from trailhead. USFS Trail \#1404 retains the McCabe-Lake Creek Trail name. The USFS Trail \#61 changes its name to Lake Otatsy Trail and continues north to the southern end of Lake Otatsy where it intersects with USFS Trail \#16 (FallsCanyon Trail) . USFS Trail \#16 (Falls-Canyon Trail) loops around the southern end of Lake Otatsy following both shores. The trail on the west side of Lake Otatsy leads north to Camp Lake ( $\sim 0.7$ miles). The trail on the east side of Lake Otatsy continues on in a northeasterly direction for another 1.7 miles to Canyon Lake. The Canyon Lake route is approximately 8.5 miles distance from the North Fork trailhead, with a moderate difficultly.

Camp Sites and Use: Canyon Lake lies in a remote setting and appears to support light recreational use, except during hunting season during which time the Canyon Lake area serves hunting camps. The USFS Trail \#16 (Lake Otatsy Trail) is a well established trail that skirts the eastern side of the lake. Numerous primitive camp sites are located around the lake; one near the inlet on the northern end of the lake, a second site near a small inlet on the southeast corner of the lake and a couple near the outlet. "Leave no trace" camping and recreating is essential in this area as it is a proposed wilderness.

Angling Opportunity: Canyon Lake supports a small population of westslope cutthroat trout through natural reproduction from Canyon Creek. Genetic testing suggests a potentially pure strain of westslope cutthroat trout in the lake. Shoreline topography is steep and brushy in areas and may hinder shoreline angling.

\section{Stocking History: NA}

\section{Angling Pressure: NA}

Other Nearby Lakes: There are two other lakes in the general vicinity of Canyon Lake. Lake Otatsy is approximately 1.7 miles southwest along USFS Trail \#16 on the way to Canyon Lake. Camp Lake is about 2.5 mile southwest of Canyon Lake along USFS Trail \#16 following the trail along the western side of Lake Otatsy. A short trail of approximately 0.3 miles in length north of Lake Otatsy that connected Camp and Canyon Lakes has been decommissioned (see map). 
Date Sampled: 7/13-14/2005

Game Fish Present: Westslope Cutthroat Trout

Other Fish Present: None, although bull trout were historically present

Size Captured: Mean 10.3 inches (range 6.5 - 13.5inches)

Trout Condition (Wr): Mean $103 \pm 9.5$ (range 85 - 122)
Water Code: 04-6270

Sampling Methods: Sinking Gill Net

Gill Net Catch Rate: 0.97 trout $/$ net/hr

Natural Recruitment: Present (limited)

Amphibians Observed: Western Toad (adult)

Management Objectives: Continue to manage as native population of pure westslope cutthroat trout Currently Stocked: No Last Stocked: NA Species: NA Recommended Frequency: None

Water Chemistry: pH: 8.81 TDS: $83 \mathrm{ppm}$ Conductivity: $170 \mathrm{uS}$ Secchi Depth: 6.8 feet
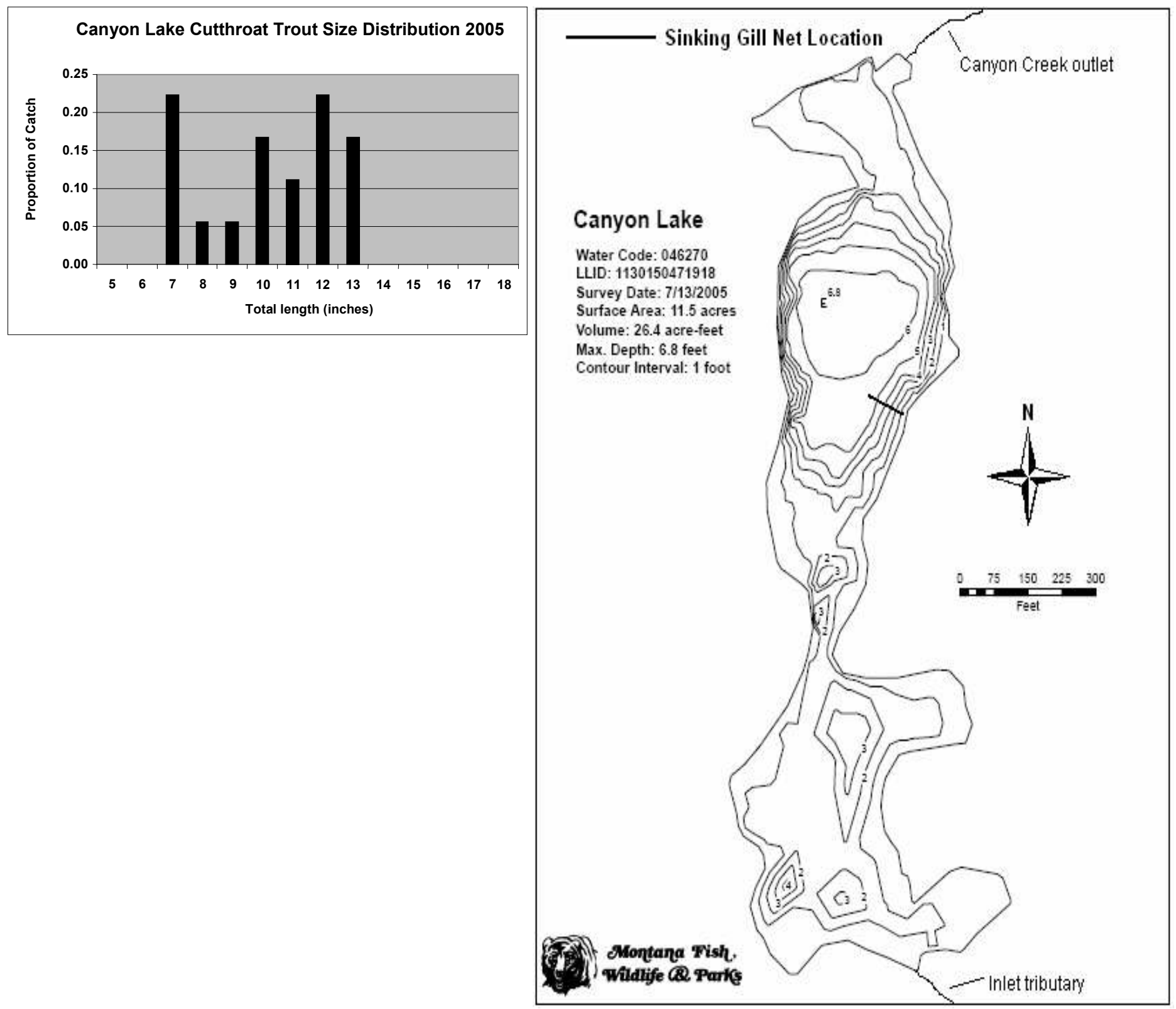


\section{Coopers Lake}
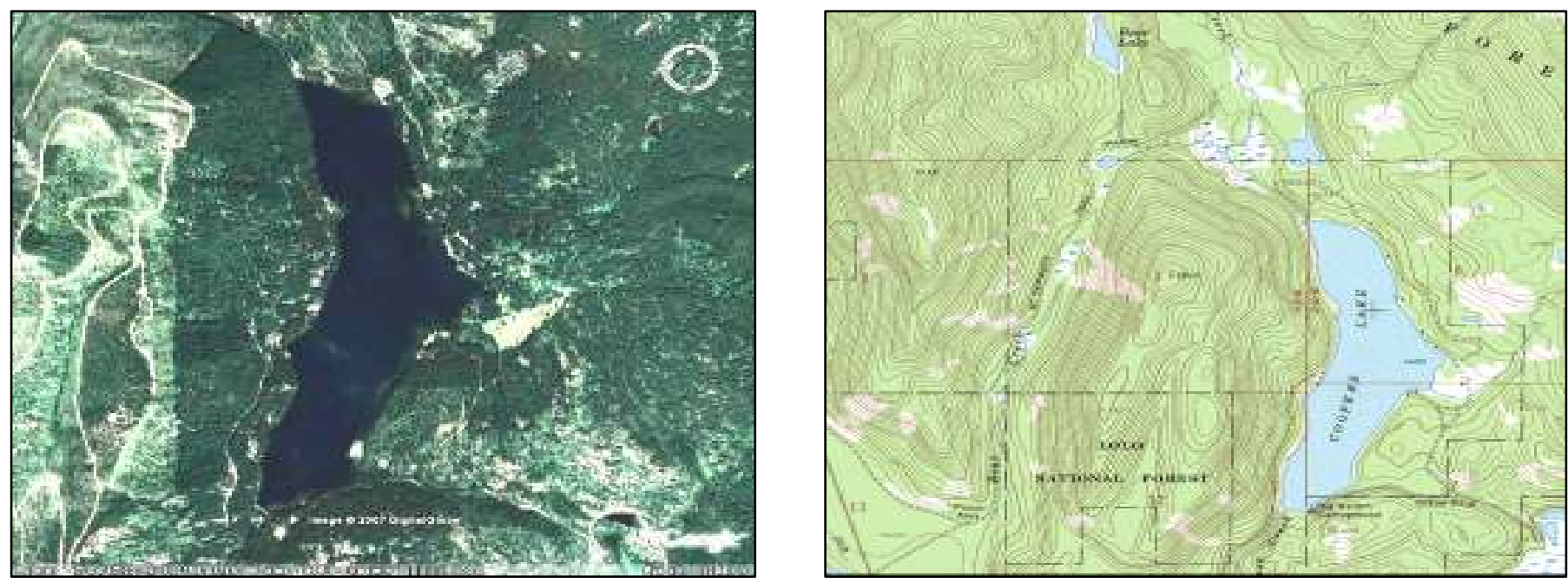

Description: Coopers Lake is a 215.5 acres glacial trough lake located northeast of Kleinschmidt Flat at an elevation of 4,491'. The lake is bordered primarily by privately owned land on all side with the exception of approximately 10 acres on the south end of the lake that lies within the Lolo National Forest (Seeley Lake Ranger District). McDermott Creek enters the northern end of the lake and contributes approximately 10-15cfs. On the eastern side of the lake an un-named tributary and numerous small feeder springs contribute approximately $2-5 \mathrm{cfs}$. Coopers Lake's outlet stream forms Salmon Creek, which flows south to its junction with Dry Creek and form Rock Creek, a tributary to North Fork Blackfoot River.

Location: T15N, R10\&11W, Sections 1, 6, 7 \&12; Latitude N47.07762º Longitude W112.91864 ${ }^{\circ}$ Nearest Town: Ovando.

Pubic Access: Coopers Lake can be accessed from Ovando by traveling east on Highway 200 approximately 6.2 miles, then turning north on North Fork Blackfoot River Trailhead road for 2.2 miles. At the crossroads turn east and continue approximately 3.0 miles to the intersection with Dry Creek road, turn north and continue 6.5 miles to the lake. An alternate route is to travel east along US highway 200 to the Dry Creek road (approximately 8.3 miles east of Ovando) turn north and continue approximately 11.4 miles to the lake. The route to Coopers Lake is signed from both directions.

Camp Sites and Use: USFS Big Nelson Campground on the south end of the lake offers three basic campsites with a restroom facility near a boat ramp. The lake experiences light use.

Angling Opportunity: Coopers Lake contains primarily hatchery westslope cutthroat trout, along with brook trout, northern pikeminnow and longnose sucker. Primary means of fishing is done from a boat or through the ice. Because the majority of the land adjacent to the lake is privately owned, shoreline angling is limited to USFS land unless landowner permission is granted. The surrounding topography is heavily timbered, rocky, steep and very brushy that may hinder shoreline angling.

Stocking History: From 1936 through 1953, Coopers Lake was annually stocked with cutthroat and rainbow trout followed by only cutthroat trout in 1955 and 1956. The lake was again stocked periodically from 1969 to 2005 with westslope cutthroat trout. Currently Coopers Lake receives and annual plant of 4,000 WSCT greater than 6 inches.

Angling Pressure: From March 2005 through February 2006, the estimated angling pressure for Coopers Lake was 756 angler-days.

Other Nearby Lakes: Bear Lake is approximately 1.0 mile to the northwest and is the only other lake in the immediate vicinity of Coopers Lake. Access to Bear Lake can be obtained from a small trailhead along an unmarked dirt road that spurs off from the North Fork Blackfoot River Trailhead road in section 11. The 
McDermott Creek Trail \#17 crosses Bear Creek outlet stream approximately 2.0 miles from the trailhead and then requires bushwhacking upstream along the outlet stream 0.4 miles to the lake (see map).

\section{Coopers Lake: Biological \& Physical Information}

Date Sampled: 5/23-25/2006

Water Code: 046330

Game Fish Present: Westslope Cutthroat \& Eastern Brook Trout

Sampling Methods: Sinking \& Floating Other Fish Present: Northern pikeminnow, longnose sucker and redside shiner Gill Nets

WSCT Size Captured: Mean 12.8 inches (range 9.5-16.9 inches)

Gill Net Catch Rate: 0.072/WSCT/net/hr

WSCT Condition Factor (Wr): Mean 103 (range 92-115)

Natural Recruitment: Present (limited)

EBT Size Captured: Mean 12.2inches (range10-14.6inches)

EBT Condition Factor (Wr): Mean 111 (range 100-121)

Amphibians Observed: None observed

Gill Net Catch Rate: $0.028 / \mathrm{EBT} / \mathrm{net} / \mathrm{hr}$

Natural Recruitment: Present (limited)

Management Objectives: Continue annual stocking and evaluate stocking program.

Currently Stocked: Yes Last Stocked: 2005 Species: WSCT Recommended Frequency: Annually

Water Chemistry: pH: 8.23 TDS: 66ppm Conductivity: $144 \mathrm{uS}$ Secchi Depth: $24.6 \mathrm{ft}$

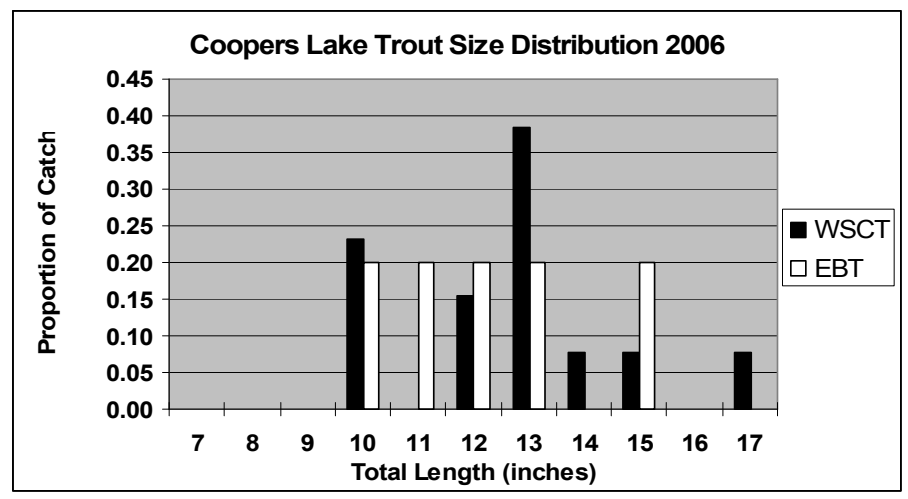

\begin{tabular}{|c|c|c|}
\hline \multicolumn{3}{|c|}{ Stocking History } \\
\hline Year & Species & \# Stocked \\
\hline 2005-1969 & WSCT & 284,866 \\
\hline $\begin{array}{l}1969-1936 \\
\text { periodically }\end{array}$ & CT & 234,138 \\
\hline $\begin{array}{l}1953-1937 \\
\text { periodically }\end{array}$ & RBT & 152,704 \\
\hline
\end{tabular}




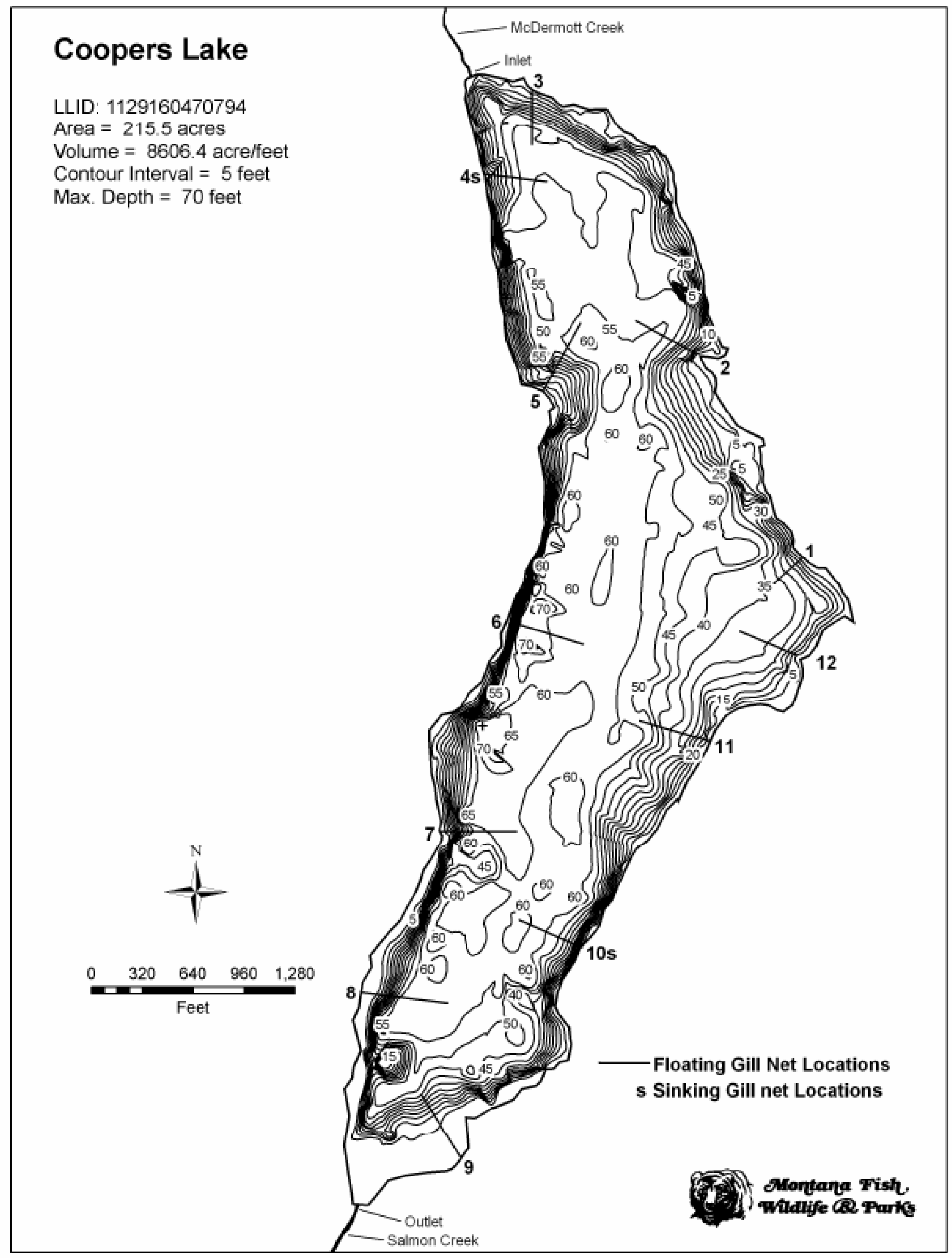




\section{Heart Lake}
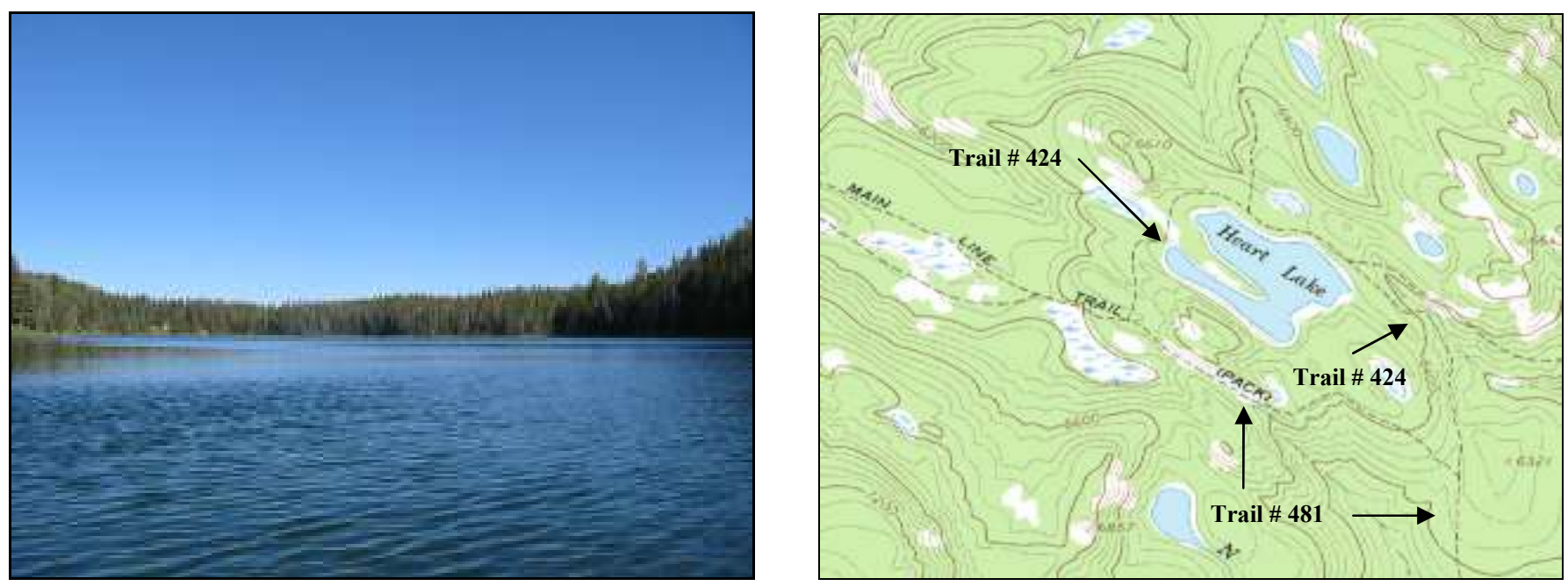

Description: Heart Lake is a moderate sized (31.6 acres) glacial valley lake located approximately 4.2 miles northeast of Red Mountain and 5.0 miles west of the Continental Divide. The lake lies within the Scapegoat Wilderness, Helena National Forest (Lincoln Ranger District) at 6,424ft elevation in Landers Fork of the Blackfoot River drainage.

Location: T16N, R8W, Sections 17, 18 \&19; Latitude N47.13774 ${ }^{\circ}$, Longitude W112.65070 ${ }^{\circ}$; Nearest Town: Lincoln.

Pubic Access: Access to Heart Lake can be obtained by taking Highway 200 east from Lincoln approximately 6.2 miles to the Copper Creek Road. Follow the Copper Creek road approximately 10.2 miles to the Indian Meadows Trailhead. From the trailhead either hike or pack in on horses along USFS Trail \#481 (Main Line Pack Trail) 4.1 miles to its intersection with USFS Trail \#424 (Heart Lake Trail) and follow Trail \#424 the final 0.7 miles into Heart Lake (see map). The Heart Lake route is approximately 4.8 miles distance, with moderate difficultly.

Camp Sites and Use: Because of Heart Lake's relatively short distance within the Scapegoat Wilderness boundary on a well maintained trail system, it receives moderate-to-heavy recreational use. Two campsites were observed along the southeast shoreline, one site along northeast shoreline and one along the north-northwest shoreline. All four campsites show heavy use. Pack stock is not allowed within 200 feet of the shore. "Leave no trace" camping and recreating is essential in this wilderness area.

Angling Opportunity: Heart Lake is managed as a "put-and-take" Arctic grayling and westslope cutthroat trout fishery. Areas of the shoreline topography are brushy, heavily timbered and moderately steep; however, there are many areas that lend well to shoreline angling.

Stocking History: Heart Lake has a long history of Arctic grayling stocking, and more recently it was stocked in 1996 with grayling and in 2001 the plant was converted with westslope cutthroat trout due to shortages of available Arctic grayling. In 2006, both westslope cutthroat trout and Arctic grayling were planted in Heart Lake.

\section{Angling Pressure: Moderate}

Other Nearby Lakes: There are numerous small un-named pot-hole lakes averaging approximately 2.5 acres in size in the near vicinity of Heart Lake. Webb Lake is about 2.3 miles northwest of Heart Lake. To access Webb Lake, follow the Heart Lake Trail \#424 back to and continue west-northwest along the Main Line Pack Trail \#481(see map) access to Parker and Two Point Lakes are also west- northwest along Main Line Pack Trail \#481. Two Point Lake is about 4.3 miles then right on Trail \#479 for additional 0.4 miles and Parker Lake is $~ 5.0$ miles from Heart Lake along the Main Line Pack Trail \#481. Travel is moderately difficult to these other lakes. 


\section{Heart Lake: Biological \& Physical Information}

Date Sampled: 7/18-19/2005

Fish Species Present: Westslope Cutthroat Trout

Other Fish Present: Arctic Grayling

Size Captured: Mean 16.1 inches (range13.6-18.5 inches)

Trout Condition (Wr): Mean $110 \pm 13.5$ (range 94-143)

Amphibians Observed: Spotted Frogs (adults)
Water Code: $04-6690$

Sampling Methods: Sinking Gill Net Gill Net Catch Rate: 0.64 trout $/$ net/hr Natural Recruitment: NA

Management Objectives: Continue as a "put and take" fishery for WSCT and Arctic grayling and periodically evaluate planting program.

Currently Stocked: Yes Last Stocked: 2006 Species: WSCT and Arctic grayling

Recommended Frequency: 4-6 years for WSCT and 10 years for Arctic grayling

Water Chemistry: pH 8.71 TDS: 108ppm Conductivity: 216uS Secchi Depth: $37.5 \mathrm{ft}$

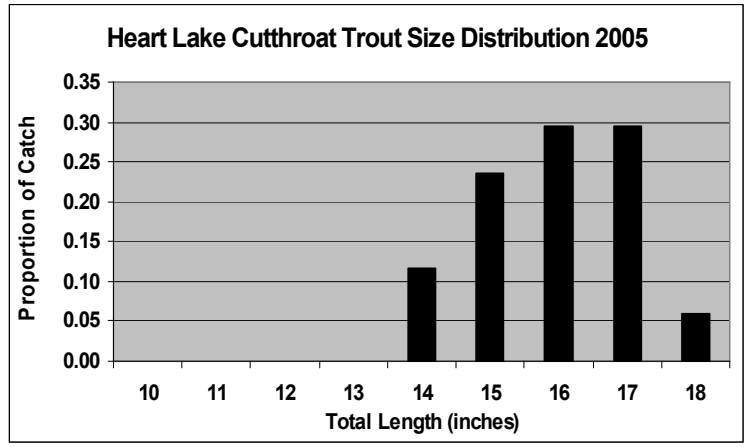

Stocking History
\begin{tabular}{|c|c|c|}
\hline Year & Species & \# Stocked \\
\hline $\begin{array}{c}\mathbf{2 0 0 1 - 1 9 8 8} \\
\text { periodically }\end{array}$ & WSCT & 11,587 \\
\hline $\begin{array}{c}\text { 1989-1932 } \\
\text { periodically }\end{array}$ & GR & $\mathbf{8 8 4 , 5 0 0}$ \\
\hline $\begin{array}{c}1952-1942 \\
\text { periodically }\end{array}$ & CT & 48,704 \\
\hline 1937 & RBT & 10,000 \\
\hline
\end{tabular}

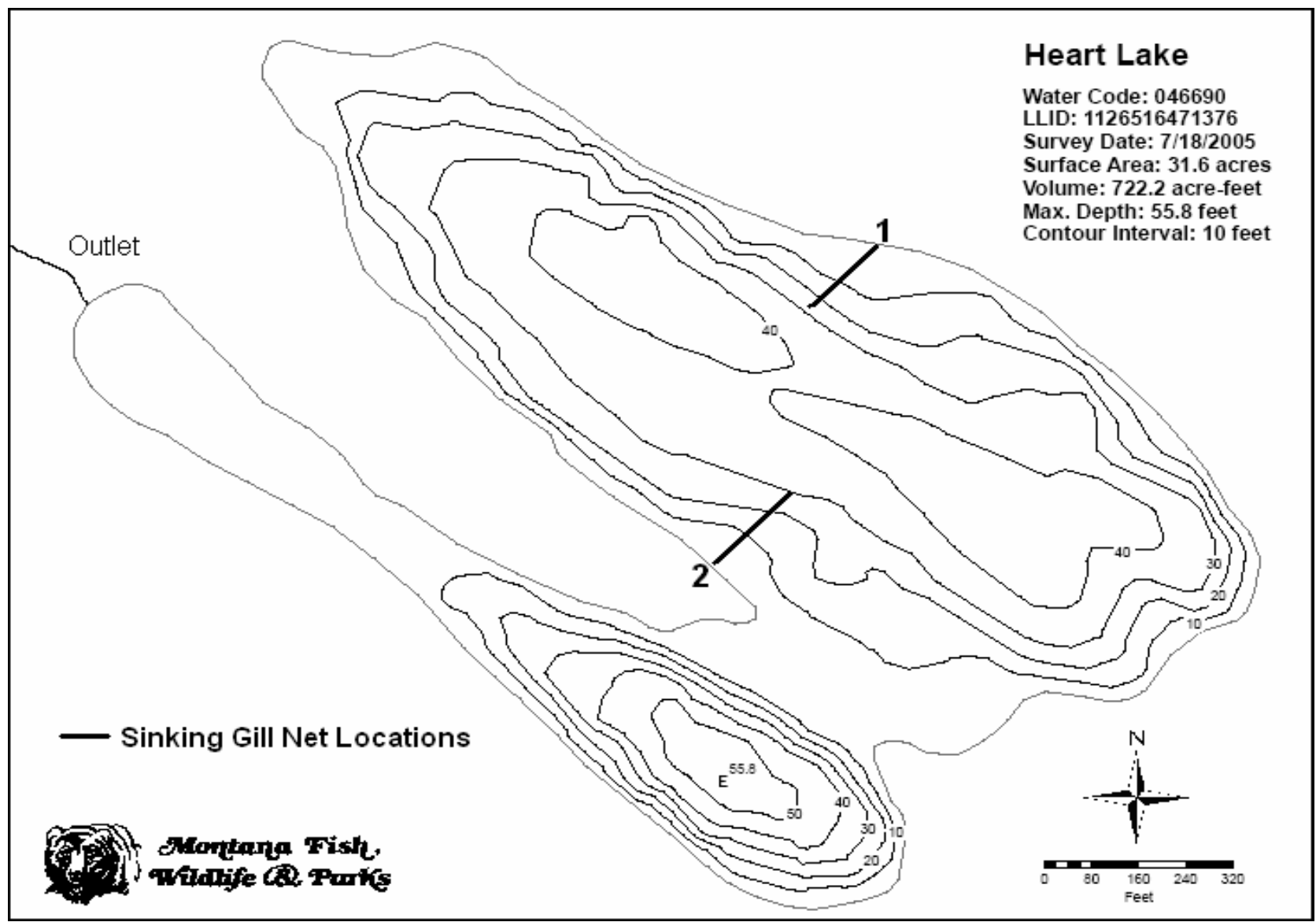




\section{Lake Otatsy}
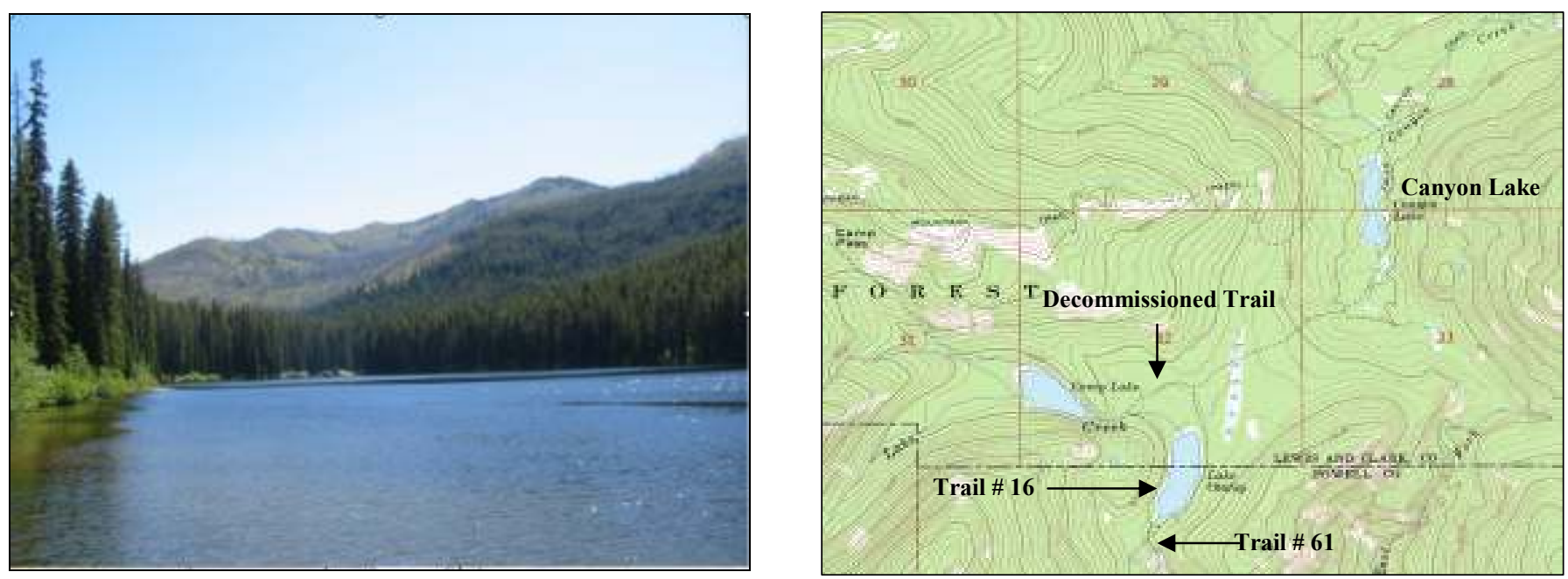

Description: A small glacial valley trough lake, Lake Otatsy is 22.3 acres in size and located approximately 1.5 miles northeast of East Spread Mountain near the southwestern boundary of the Scapegoat Wilderness. The lake lies within the Lolo National Forest (Seeley Lake Ranger District) on a proposed wilderness area at 6,069' elevation in the North Fork Blackfoot River drainage.

Location: T16N, R11W, Section 6; T17N, R11W, Section 32; Latitude N47.17626 ${ }^{\circ}$, Longitude W113.02958 Nearest Town: Ovando.

Public Access: Access to Lake Otatsy can be obtained by taking Highway 200 from Ovando northeast 19 miles to the North Fork Blackfoot River Trailhead. From the trailhead, travel along USFS Trail \#61 (McCabe-Lake Creek Trail) to its intersection with USFS Trail \#1404, about 4.0 miles. The USFS Trail \#61 changes its name to Lake Otatsy Trail and continues north 3.0 miles to the southern end of Lake Otatsy where it intersects with USFS Trail \#16 (Falls-Canyon Trail), which divides and follows both sides of Lake Otatsy. The Lake Otatsy route is 7.0 miles distance from the North Fork Blackfoot River Trailhead, with a moderate degree of difficultly.

Camp Sites and Use: Lake Otatsy lies in a remote setting that receives light recreational use. The USFS Trail \#16 (Falls-Canyon Trail) follows both sides of the lake. Three primitive camp sites were observed with light to moderate use. One site was located near the Lake Creek outlet on the east-southeastern end of the lake. A second site was located on the east-northeastern end of the lake and a third site near the middle of the lake on the western shore. "Leave no trace" camping and recreating is essential in this area as it is a proposed wilderness.

Angling Opportunity: Lake Otatsy supports "wild" rainbow trout through natural reproduction. The shoreline topography lends well to shoreline angling for most of the lake perimeter.

Stocking History: Lake Otatsy was historically planted with rainbow trout and is now a self-sustaining population in high abundance.

\section{Angling Pressure: Light}

Other Nearby Lakes: There are two other lakes in the vicinity of Lake Otatsy that lie in the North Fork Blackfoot River drainage. Camp Lake is northwest of Lake Otatsy 0.7 miles from the intersection of USFS Trail \#61 (Lake Otatsy Trail) and USFS Trail \#16 (Falls-Canyon Trail) at the southern of Lake Otatsy. Canyon Lake is approximately 1.7 miles northeast of Lake Otatsy following USFS Trail \#16 (Falls-Canyon Trail) along the eastern shore of Lake Otatsy. 
Date Sampled: 7/12-13/2005

Game Fish Present: Rainbow Trout

Other Fish Present: None

Size Captured: Mean 9.7 inches (range 6.1-11.5 inches)

Trout Condition Factor (Wr): Mean $81 \pm 12.25$ (range 61-125)

Amphibians Observed: Spotted Frogs (adults \& tadpoles), Western Toads (adult)

Management Objectives: Status Quo

Currently Stocked: No Last Stocked: Unknown Species: RBT Recommended Frequency: NA

Water Chemistry: pH: 8.13 TDS: 44 ppm Conductivity: 89 uS Secchi Depth: $21.5 \mathrm{ft}$
Water Code: 04-7050

Sampling Methods: Sinking Gill Net Gill Net Catch Rate: 1.5 trout $/$ net $/ \mathrm{hr}$ Natural Recruitment: Present
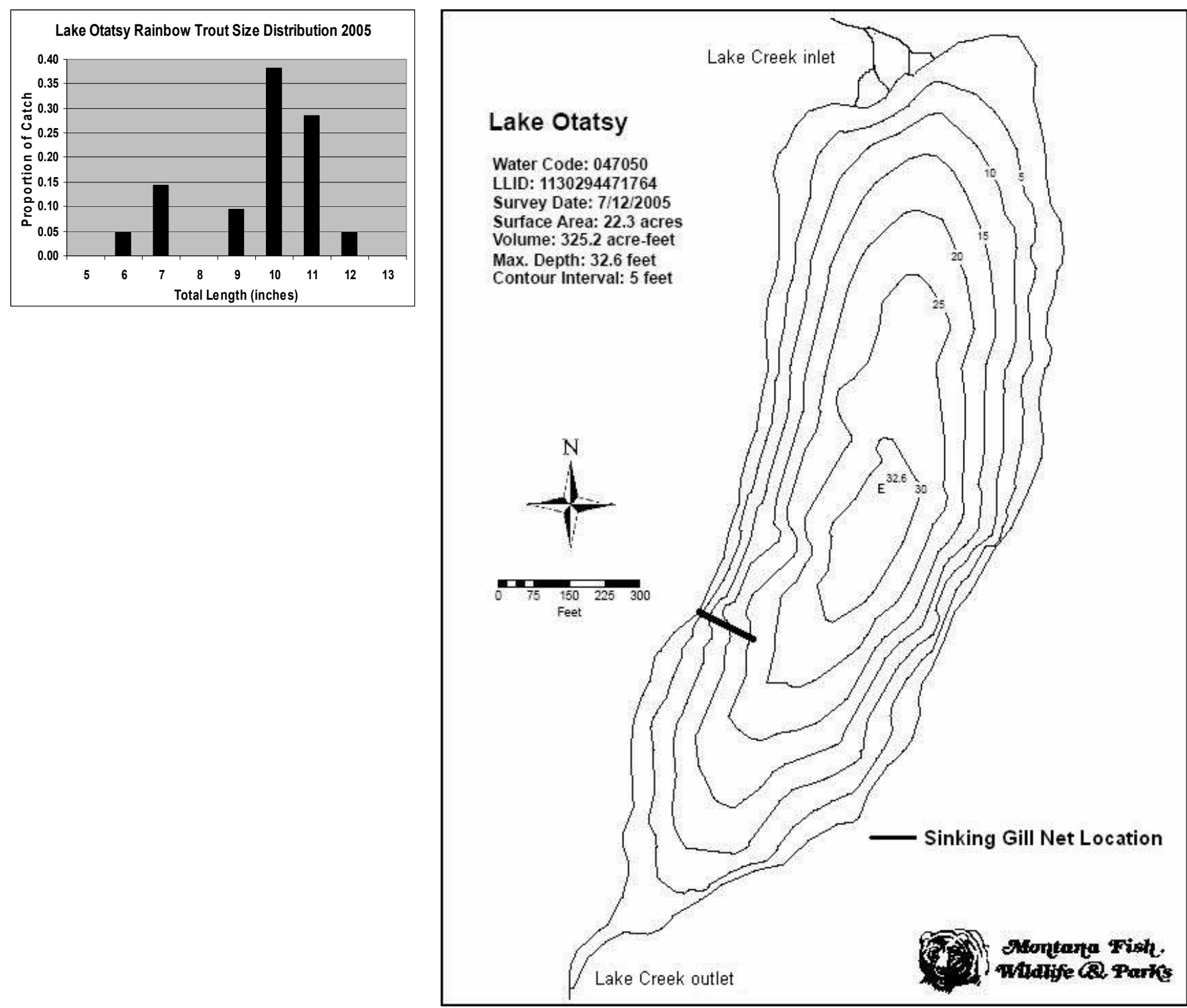


\section{Lower Copper Lake}
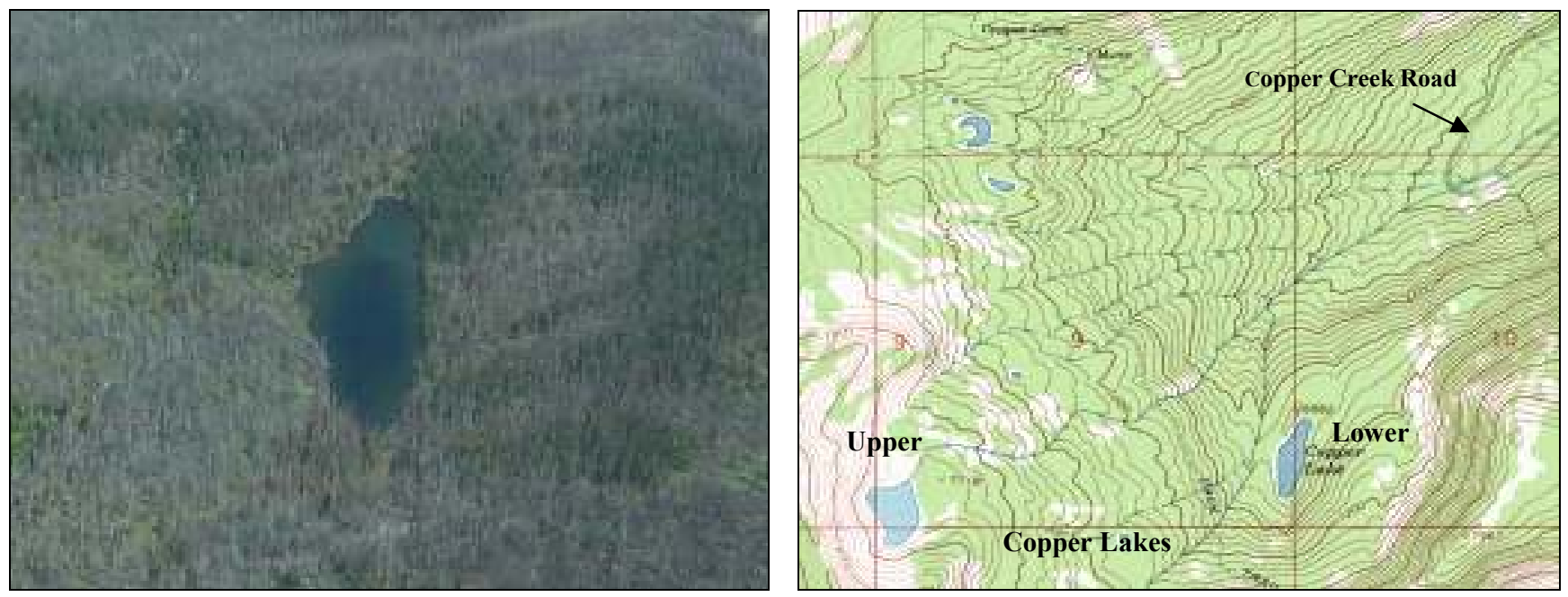

Description: Lower Copper Lake is a small (5.9 acres) glacial cirque lake located about 1.8 miles west-northwest of Stonewall Mountain and 3.6 miles south-southeast of Red Mountain. The lake lies within the Helena National Forest (Lincoln Ranger District) at 6,700' elevation. Its outlet flow combined with the outlet flow from Upper Copper Lake form the headwaters to Copper Creek, in the Landers Fork drainage, a major tributary of the upper Blackfoot River.

Location: T15N, R9W, Sections 9\&10; Latitude N47.06284 ${ }^{\circ}$ Longitude W112.73242º ; Nearest Town: Lincoln.

Public Access: Access to Lower Copper Lake can be obtained by taking Highway 200 east from Lincoln $~ 6.2$ miles to the USFS Road 330 (Copper Creek Road). Follow the USFS Road 330 for 12 miles to the end of the road (USFS gate). At the end of the road there is small trailhead information board and parking for 3 vehicles. Not shown on maps, the trail is an unmarked primitive trail that ascends following the effluent streams from the lakes that form Copper Creek. Lower Copper Lake is about 1.0 mile up the trail with an elevation gain of 600'. The trail is very brushy.

Camp Sites and Use: No camping areas were observed around Lower Copper Lake.

Angling Opportunity: Historically supplemented with hatchery westslope cutthroat trout, Lower Copper Lake now supports a very small population of self-sustaining westslope cutthroat trout. The immediate shoreline topography is relatively flat, brushy, with thick areas of alder and timbered with sub-alpine fir and spruce, but is easily accessible on foot and lends well to shoreline angling.

Stocking History: According to Lower Copper Lake fish planting records, only westslope cutthroat trout have been planted in this lake. It was first planted in 1969 then again in 1975 and 1978. The lake was last stocked in 1979.

\section{Angling Pressure: Very light}

Other Nearby Lakes: Upper Copper Lake is the only lake in the near vicinity of Lower Copper Lake. Upper Copper Lake sits at a higher elevation of 7,706'. To access Upper Copper Lake requires bushwhacking an additional mile past Lower Copper Lake with an elevation gain of approximately $800 \mathrm{ft}$. Because of the lack of an established trail between the lakes, travel is steep and difficult. An easier, but longer, alternate route to Upper Copper Lake is traveling $\sim 3.0$ miles up the closed jeep road (behind the USFS gate at the trailhead) by foot to the old mining site and intercepting the northern end of USFS Trail \#485. USFS Trail \#485 runs south and stays relatively level while skirting the slopes of the Upper Copper Creek basin (elevation 7,100 ') and intercepts the outlet stream from the upper lake. An ascent of 0.7 miles along the outlet stream, with an elevation gain of $600 \mathrm{ft}$, 
will terminate at the lake. Caution: a large area between the upper and lower lakes burned in 2003 and is dangerous due to falling trees during windy conditions.

\section{Lower Copper Lake: Biological \& Physical Information}

Date Sampled: 6/26-27/2006

Game Fish Present: Westslope Cutthroat Trout

Other Fish Present: None

Size Captured: Mean 14.0 inches (2 fish, 13.3 and 14.8 inches)

Trout Condition Factor (Wr): NA (scale malfunction)
Water Code: 04-6360

Sampling Methods: Sinking Gill Net Gill Net Catch Rate: 0.1 trout $/$ net $/ \mathrm{hr}$ Natural Recruitment: Present (limited) Amphibians Observed: None observed

Management Objectives: Continue to manage as a self-sustaining westslope cutthroat trout population. Currently Stocked: No Last Stocked: 1979 Species: WSCT Recommended Frequency: NA

Water Chemistry: pH: 7.77 TDS: 14 ppm Conductivity: 27 uS Secchi Depth: $20.3 \mathrm{ft}$

Stocking History

\begin{tabular}{|c|c|c|}
\hline Year & Species & \# Stocked \\
\hline 1969 & WSCT & 2,541 \\
\hline 1975 & WSCT & 2,400 \\
\hline 1978 & WSCT & 3,000 \\
\hline 1979 & WSCT & 1,000 \\
\hline
\end{tabular}

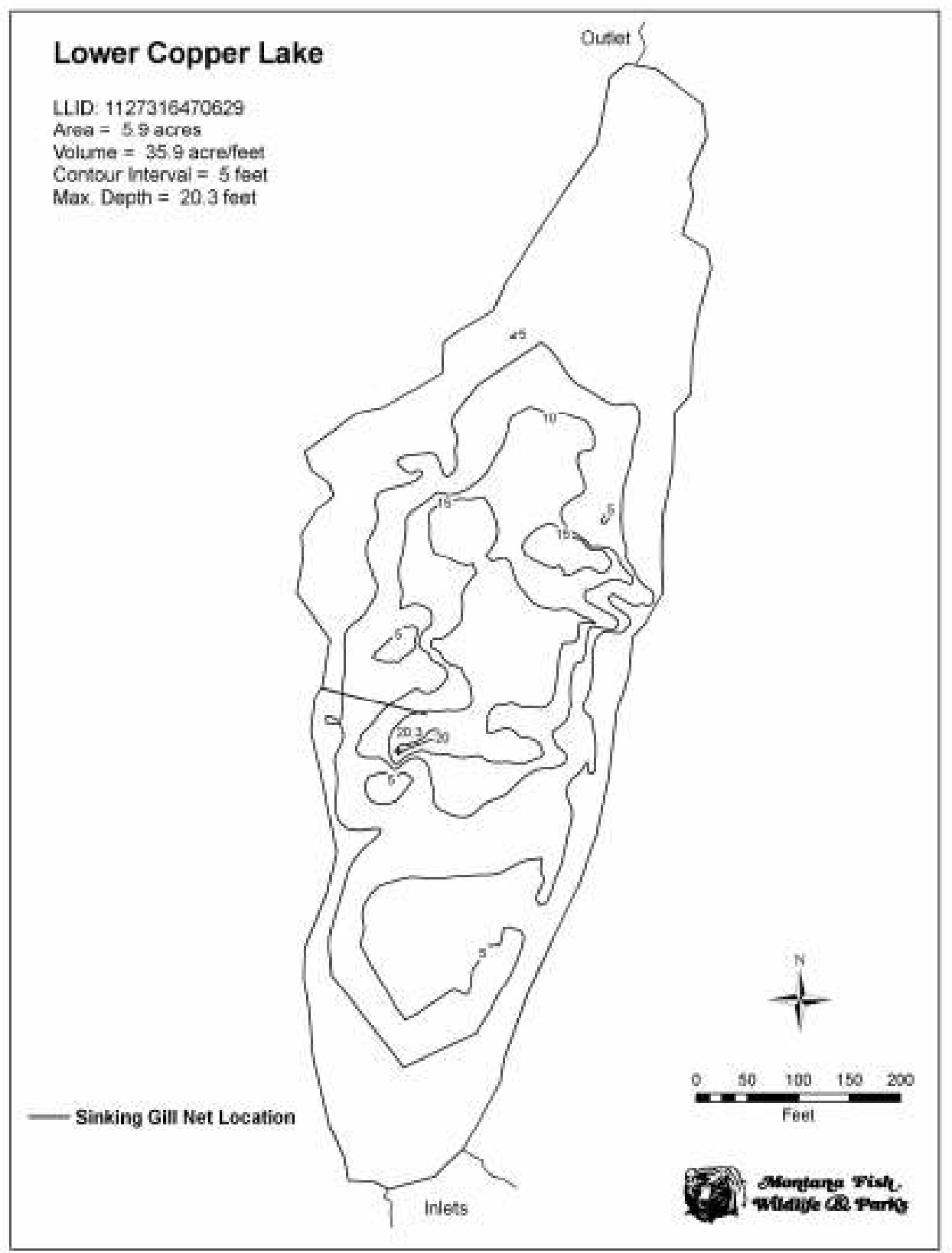




\section{Lower Twin Lake}
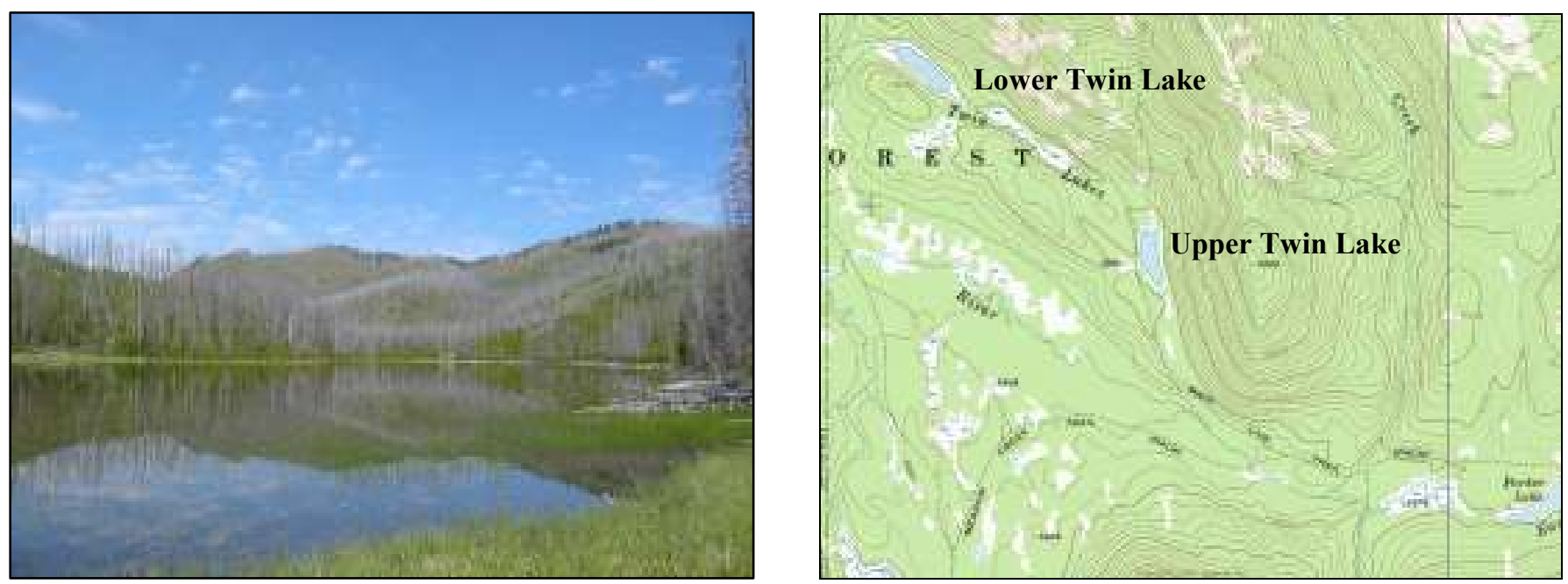

Description: Lower Twin Lake is a small ( 8.6 acres) glacial lake located $\sim 2.4$ miles north-northeast of Bugle Mountain and 2.7 miles west-southwest of Pyramid Peak within the Scapegoat Wilderness. The lake lies on the Helena National Forest (Lincoln Ranger District) at 5,900' in East Fork of the North Fork Blackfoot River drainage. Lower Twin Lake's outlet feeds Lost Pony Creek.

Location: T16N, R9W, Sections 6; Latitude N47.17288, Longitude W112.78843º; Nearest Town: Lincoln.

Public Access: There are two options to access Lower Twin Lake. Option 1: Meadow Creek Trailhead, near the northeast corner of the Kleinschmidt Flats east of Ovando take USFS Trail \#483 (Meadow Creek Trail) 12 miles to its intersection with USFS Trail \#481 (Main Line Pack Trail) then travel 0.25 miles northwest to the Twin Lakes Trail \#425 and follow it 1.5 miles passed Upper Twin Lake to Lower Twin Lake. Option 2: Indian Meadows Trailhead, east of Lincoln in the Landers Fork and Copper Creek drainage, take the USFS Trail \#481 (Main Line Pack Trail) northwest about 10.5 miles to the USFS Trail \#425 (Twin Lakes Trail) and follow it another 1.5 miles to the lake. Both trails leading to Lower Twin Lake have a moderate degree of difficultly.

Camp Sites and Use: No campsites were observed on Lower Twin Lake. "Leave no trace" camping and recreating is essential in this wilderness area.

Angling Opportunity: Lower Twin Lake currently supports self-sustaining hybridized population of westslope cutthroat, Yellowstone cutthroat and rainbow trout. Areas of the shoreline topography are lined with sedges, dense brush and lodgepole pine; however, there are some areas that lend well to shoreline angling.

Stocking History: Fish planting records show Lower Twin Lake was planted once in 1950 and twice in 1952 with undesignated cutthroat trout. Genetics analyses confirm rainbow trout were also introduced at some point.

\section{Angling Pressure: Very light}

Other Nearby Lakes: Upper Twin Lake is in the very near vicinity of Lower Twin Lake, 0.9 miles southeast along Twins Lakes Trail (USFS Trail \#425) on the way into Lower Twin Lake. If you accessed Lower Twin Lake using the Main Line Pack Trail (USFS Trail \#481) from Indian Meadows Trailhead, you can back-track 2.9 miles southeast to Parker Lake. Meadow Lake is 4.0 miles south-southwest of Lower Twin Lake. To access Meadow Lake will require you to back-track to the Main Line Pack Trail (USFS Trail \#481) before continuing on Meadow Creek Trail (USFS Trail \# 483). 
Date Sampled: 6/21/2005

Game Fish Present: Hybridized Cutthroat-Rainbow Trout Other Fish Present: None

Size Captured: Mean 12.3 inches (range 5.7 - 23.6 inches)
Water Code: 04-6900

Sampling Methods: Sinking Gill Net Gill Net Catch Rate: 3.6trout $/ \mathrm{net} / \mathrm{hr}$ Natural Recruitment: Present

Trout Condition (Wr): Mean $82 \pm 21.78$ (range $25-111$ )

Genetics: All fish possessed genetic markers for Yellowstone and westslope cutthroat trout and rainbow trout. Genetic analyses identify two somewhat reproductively isolated populations of hybrid rainbow trout and hybrid Yellowstone cutthroat trout

Amphibians Observed: Spotted frogs (adults), tadpoles and eggs present, western toad (adult)

Management Objectives: Identify opportunities to convert to WSCT

Currently Stocked: No Last Stocked: 1952 Species: CT Recommended Frequency: NA

Water Chemistry: pH: 8.70 TDS: 112 ppm Conductivity: 226 uS Secchi Depth: NA

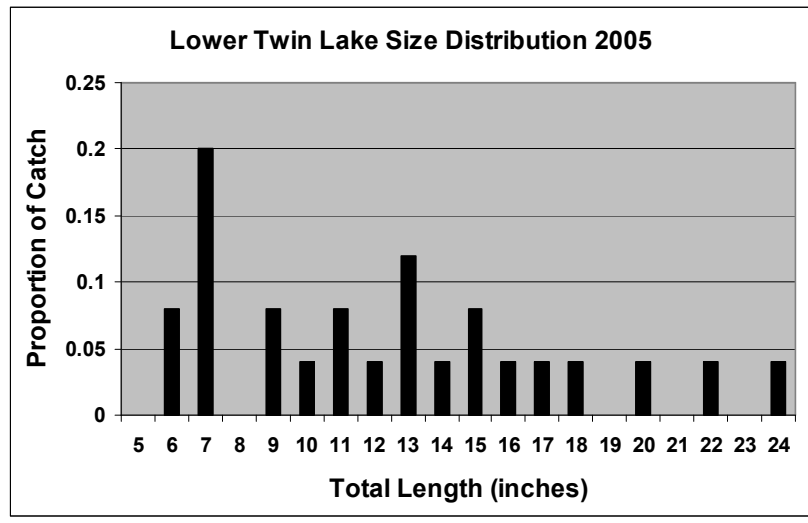

Stocking History

\begin{tabular}{|c|c|c|}
\hline Year & Species & \# Stocked \\
\hline 1952 & CT & 3,120 \\
\hline 1952 & CT & 6,864 \\
\hline 1950 & CT & 3,600 \\
\hline
\end{tabular}

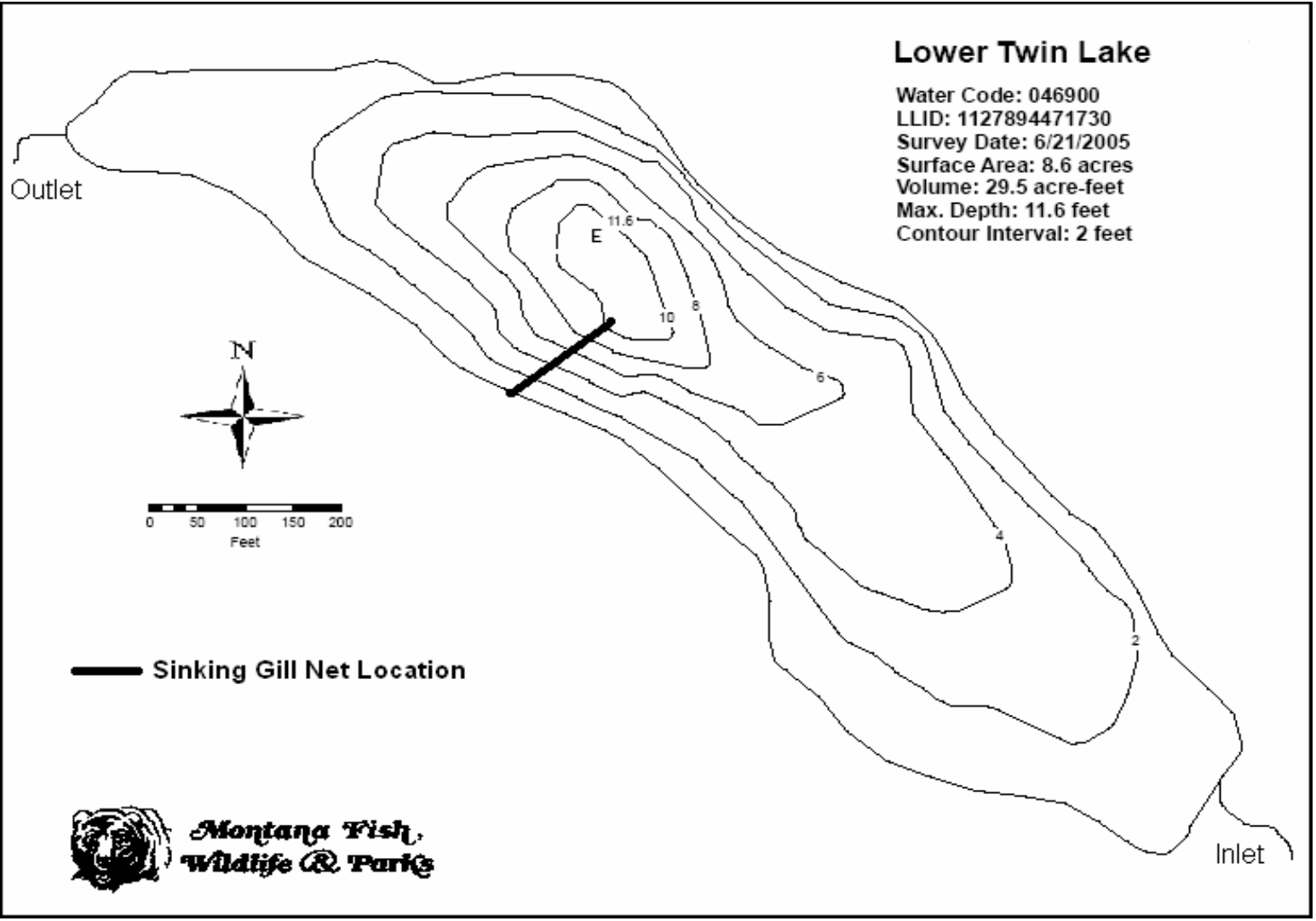




\section{Maddie Lake}
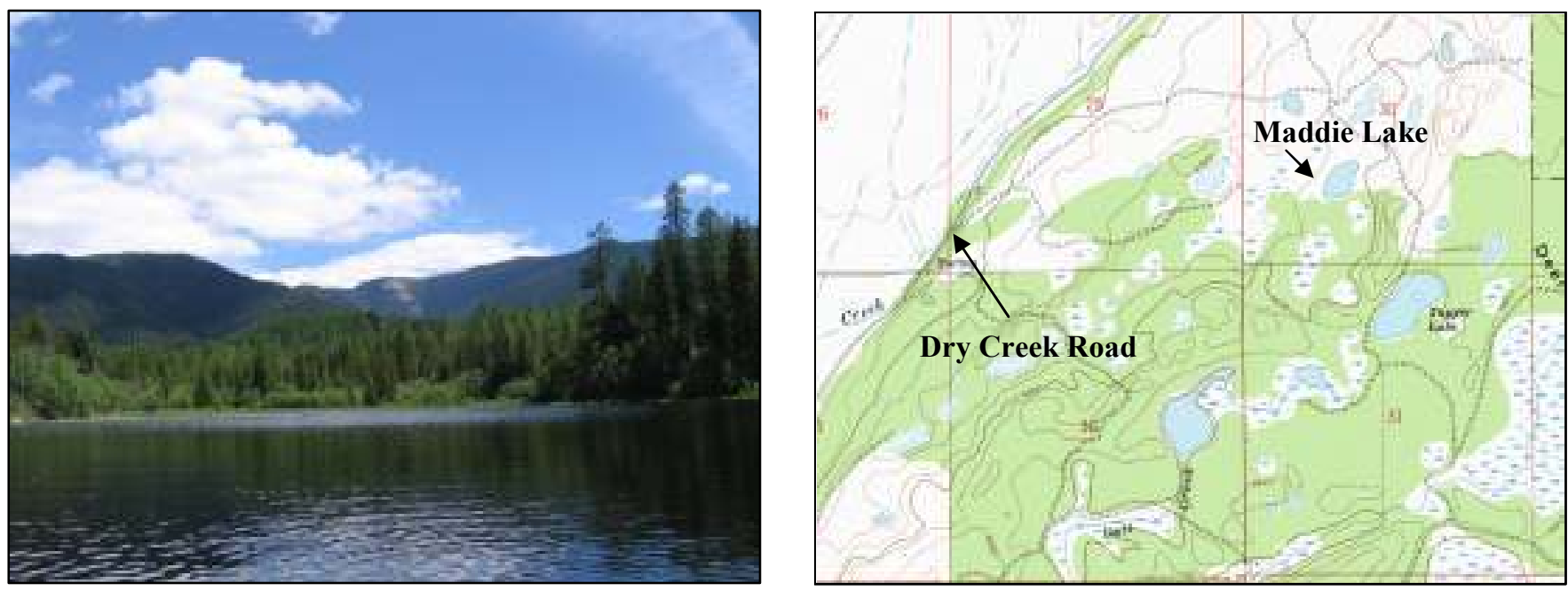

Description: Maddie Lake is a small (5.7 acres) kettle lake located 4.1 miles north-northeast of Marcum Mountain. The lake is part of The Nature Conservancy land holdings, located about 1.1 miles east of Kleinschmidt Flats off the Dry Creek Road. It lies at 4,560' in the Rock Creek drainage, a tributary to the North Fork Blackfoot River.

Location: T15N, R10W, Sections 30; Latitude N47.02429 ${ }^{\circ}$ Longitude W113.91551 ${ }^{\circ}$; Nearest Town: Ovando.

Public Access: Approximately 8.3 miles east of Ovando along Highway 200, follow the Dry Creek Road north 6.5 miles to a Nature Conservancy gate, walk in area only. The lake is 1.0 mile from the gate and requires bushwhacking from a second Nature Conservancy gate off the main road into the lake. The lake is on Nature Conservancy land.

Camp Sites and Use: No camping areas were observed around Maddie Lake. Because of its size, relative remote location and lack of sport fishing opportunities, the lake experiences light use.

Angling Opportunity: The 2006 gill net survey found no game fish within Maddie Lake although red-side shiners are present in abundance. The immediate shoreline is marshy with floating vegetation mats and overgrown with alder and red-osier dogwood. The surrounding topography is a mixture of aspen and coniferous forest with an alder, willow and dogwood under-story.

Stocking History: NA

Angling Pressure: NA

Other Nearby Lakes: There are a series of small kettle lakes in the immediate vicinity of Maddie Lake. Most are grown in with sedges and rushes. Tupper Lake lies 0.3 miles to the southeast and lies entirely on private land with no access. Coppers Lake is located $\sim 7.0$ road miles north of Maddie Lake on the Dry Creek Road. 


\section{Maddie Lake: Biological \& Physical Information}

Date Sampled: 6/7-8/2006

Game Fish Present: None

Other Fish Present: Redside shiners

Size Captured: NA

Trout Condition Factor (Wr): NA
Water Code: 04-6950

Sampling Methods: Sinking Gill Net Gill Net Catch Rate: NA

Natural Recruitment: NA

Amphibians Observed: Painted turtles

Management Objectives: Consider future WSCT stocking if public access is secured.

Currently Stocked: No Last Stocked: None known Species: NA Recommended Frequency: NA

Water Chemistry: pH: 8.37 TDS: 132 ppm Conductivity: 265 uS Secchi Depth: $13.5 \mathrm{ft}$

\section{Maddie Lake}
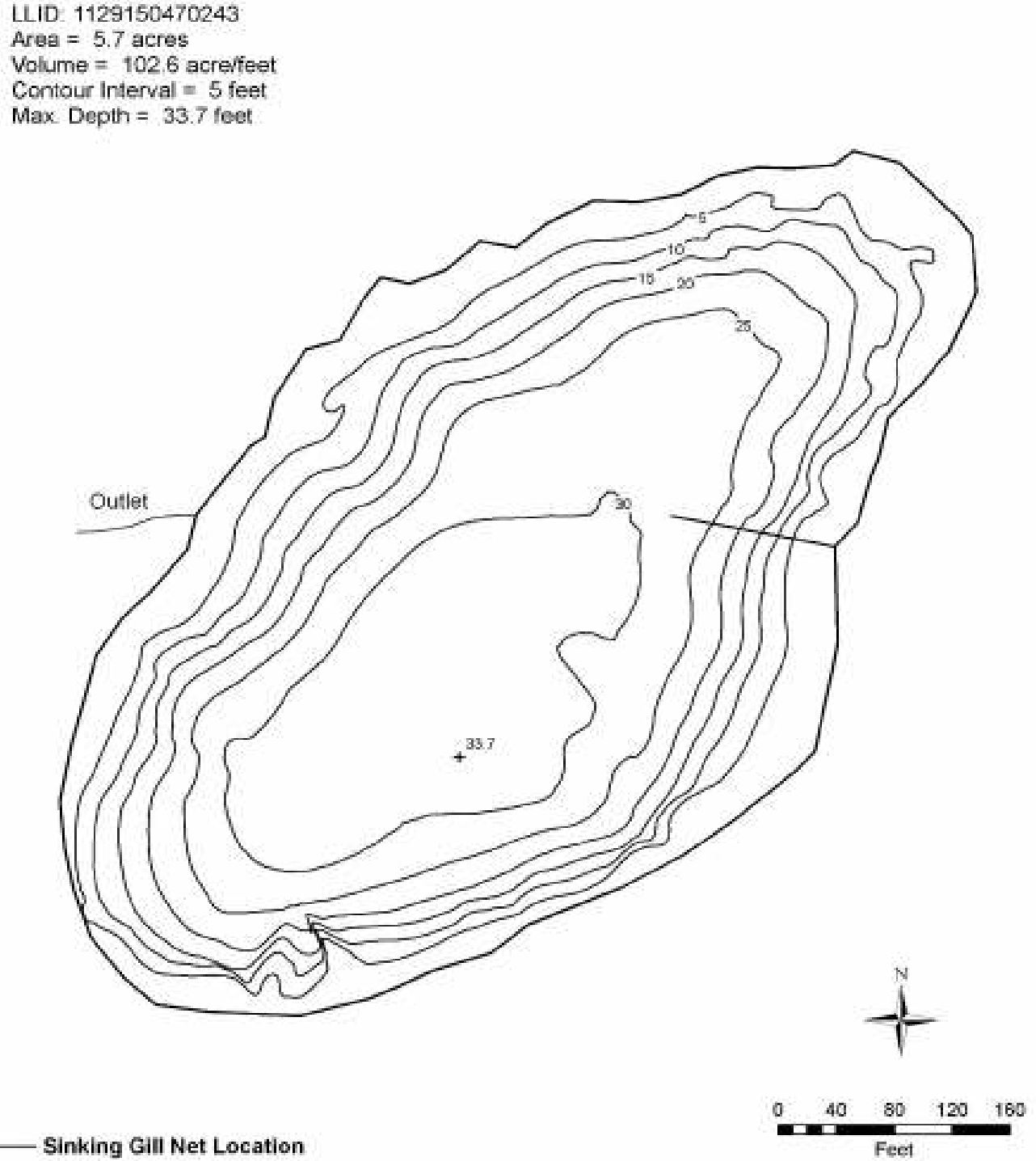


\section{Meadow Lake}
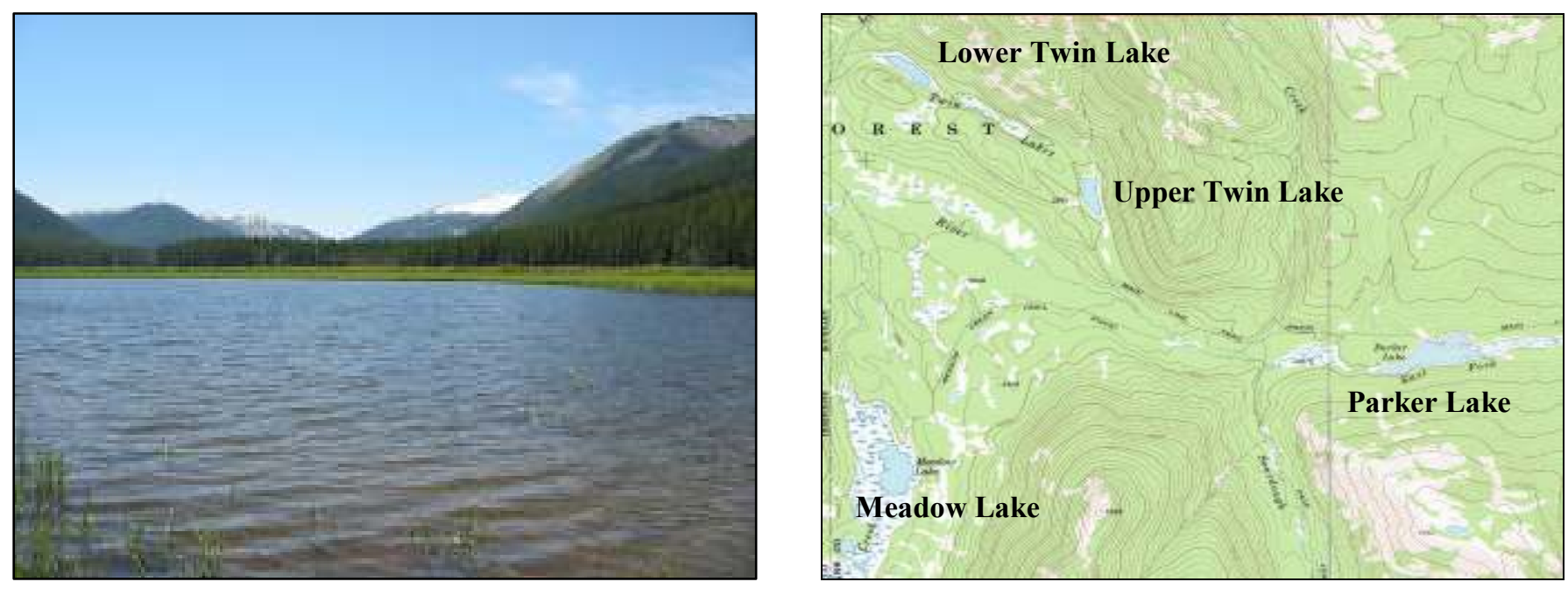

Description: Meadow Lake is a shallow and small ( 8.5 acres) glacial valley trough lake. Meadow Lake is located 1.4 miles east of Bugle Mountain and 3.0 miles north-northwest of Red Mountain. The lake lies within the Scapegoat Wilderness, Helena National Forest (Lincoln Ranger District), at 5,800' in the Meadow Creek watershed. Meadow Creek is a tributary to East Fork of the North Fork Blackfoot River drainage.

Location: T16N, R9W, Sections 18; Latitude N47.14495 , Longitude W112.78987º ${ }^{\circ}$ Nearest Town: Lincoln.

Public Access: There are three options to access Meadow Lake: Option 1: From Meadow Creek Trailhead near the northeast corner of the Kleinschmidt Flats, east of Ovando, take USFS Trail \#483 (Meadow Creek Trail) about 11.5 miles to the lake. Option 2: From the Arrastra Creek Trailhead, accessed on USFS Road \#4106, take USFS Trail \#482 (Arrastra Creek Pack Trail) north 8.0 miles to its intersection with USFS Trail \#483 (Meadow Creek Trail). From there, travel another 2.6 miles to the lake. Option 3: From the Indian Meadows Trailhead, east of Lincoln, in the Landers Fork and Copper Creek drainage, take the USFS Trail \#481 (Main Line Pack Trail) northwest $\sim 10$ miles to USFS Trail \#483 (Meadow Creek Trail) and follow it 1.8 miles to the lake. Travel on USFS Trail \# 483 and Trail \#481 has a moderate degree of difficultly. USFS Trail \#482 has a higher degree difficultly.

Camp Sites and Use: Only one moderately used campsite was observed on the northeast side of the lake. "Leave no trace" camping and recreating is essential in this wilderness area.

Angling Opportunity: Meadow Lake supports rainbow trout at low densities. The surrounding topography is heavily timbered, rocky and steep. Shoreline topography is flat and marshy with sedges and rushes encroaching well out into the lake. Shoreline angling is limited to a few small areas. Wade fishing is difficult because of the high level of silt.

Stocking History: Historically planted with RBT

Angling Pressure: Very light

Other Nearby Lakes: There are three lakes in the general vicinity of Meadow Lake. Access to Upper Twin and Lower Twin Lakes is easily obtained by following the Meadow Creek Trail (USFS Trail \#483) northeast 1.8 miles to its intersection with Main Pack Trail (USFS Trail \#481) then northwest for 0.4 miles to Twin Lakes Trail (USFS Trail \#425). Once on the Twin Lake Trail, both lakes are within 1.5 miles distance. Turning southeast on to the Main Line Pack Trail from the Meadow Creek Trail will take you to Parker Lake, a total distance of 3.0 miles from Meadow Lake. All routes are relatively easy traveling with a moderate degree of difficultly. 
Date Sampled: 6/21-22/2005

Game Fish Present: Rainbow Trout

Other Fish Present: None

Size Captured: Mean 10.3 inches (range $8.1-14.5$ inches)

Trout Condition Factor (Wr): Mean $83 \pm 13.67$ (range $71-98$ )
Water Code: 04-6960

Sampling Methods: Sinking Gill Net

Gill Net Catch Rate: 0.12trout/net/hr

Natural Recruitment: Present (Limited)

Amphibians Observed: Spotted Frogs

(adults)

Management Objectives: The lake is naturally limited by its very shallow depth - recommend no changes at this time.

Currently Stocked: No Last Stocked: unknown Species: RBT Recommended Frequency: NA

Water Chemistry: pH: 8.03 TDS: 91 ppm Conductivity: $181 \mathrm{uS}$ Secchi Depth: $3.5 \mathrm{ft}$

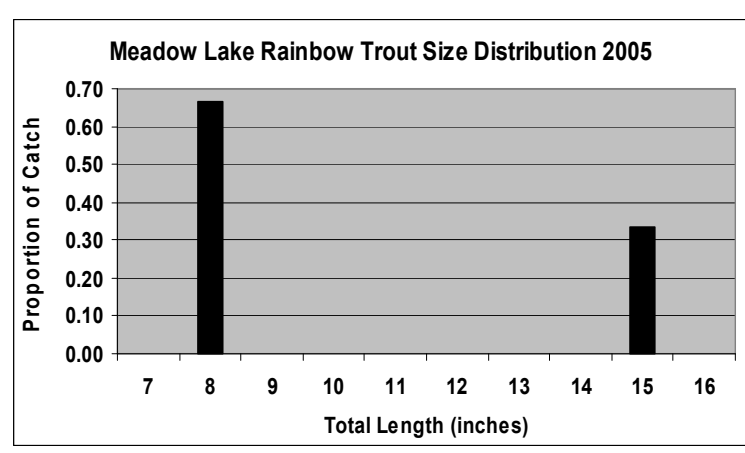

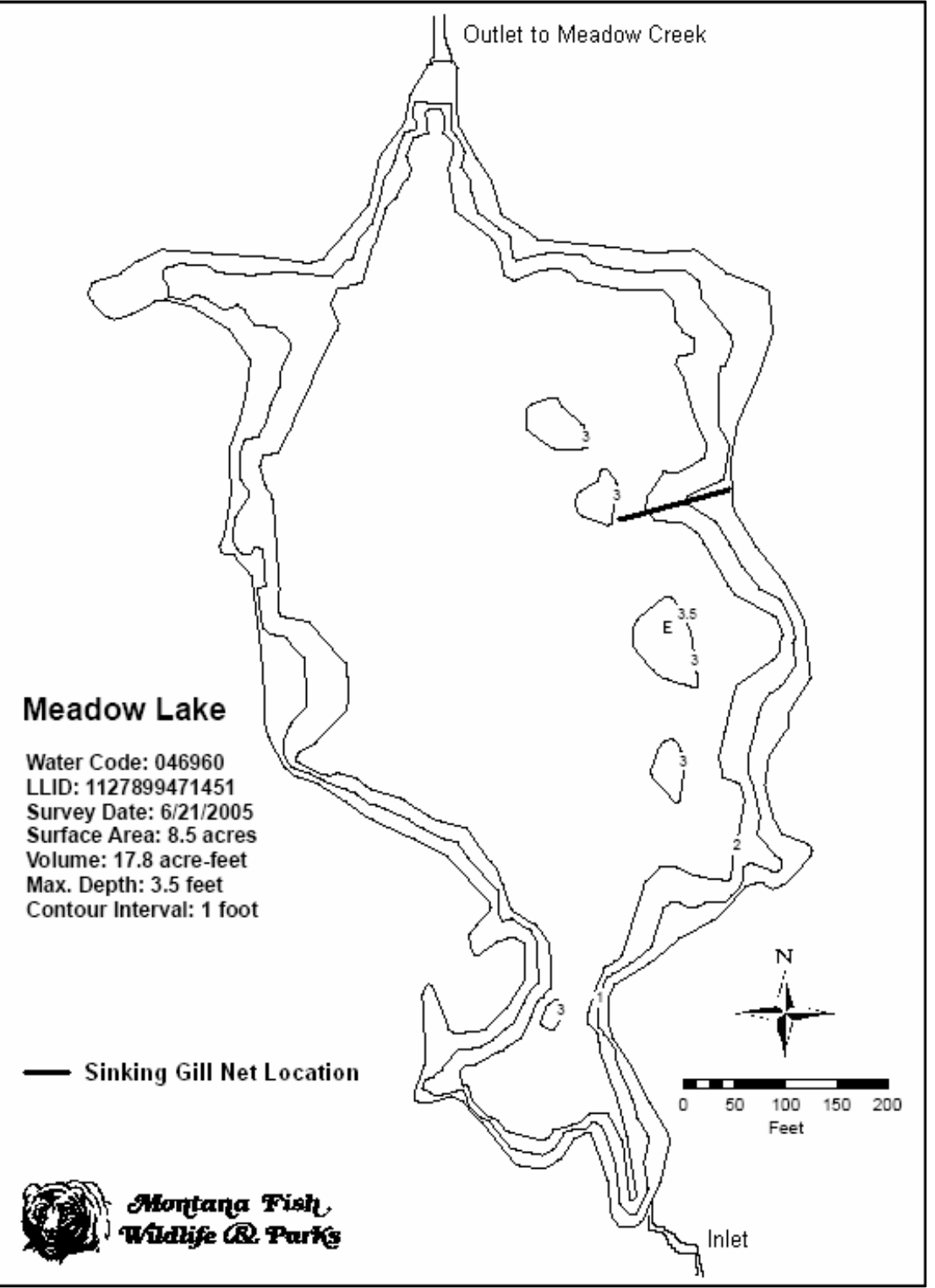




\section{Middle Cottonwood Lake}
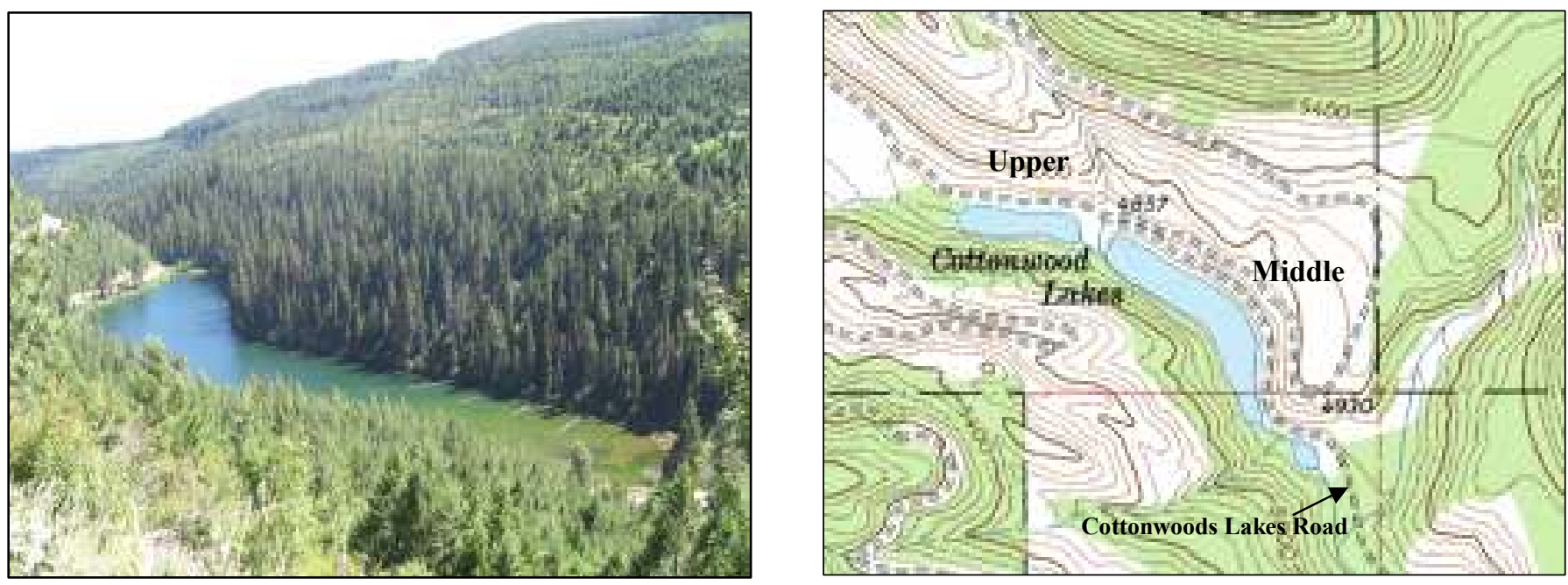

Description: Middle Cottonwood Lake is a moderate-sized (12.0 acres) glacial valley trough lake located 1.5 miles south-southwest of Morrell Mountain and $~ 8.3$ miles east-southeast of Seeley Lake. The lake lies within the Lolo National Forest (Seeley Lake Ranger District) at $4,835^{\prime}$ in Cottonwood Creek drainage, a tributary to the middle Blackfoot River.

Location: T16N, R14W, Sections 3 \& 10; Latitude N47.16637º, Longitude W113.35097º Nearest Town: Seeley Lake.

Public Access: Middle Cottonwood Lake lies along USFS Road 477 (Cottonwood Lakes Road) providing easy access to the lake. From Highway 83 in Seeley Lake, take USFS Road 477 (primary road) east 8.3 miles to the lake. From US Highway 200, take Woodworth Road northwest 9.0, then right (north) on USFS Road 9976 for 3.6 miles and then left (west) on USFS Road 447 for 2.2 miles to the lake.

Camp Sites and Use: Only one campsite / boat launch on the northwest corner of the lake along USFS Road 477 was observed. The site experiences heavy use.

Angling Opportunity: Middle Cottonwood Lake supports a self-sustaining population of rainbow trout. From 2001 through 2005, the lake was on a yearly stocking schedule of westslope cutthroat trout; however these fish did not show up in recent lake surveys. The northwest corner of the lake has a boat launch. Most areas of the north shoreline topography are very brushy with alder and red osier dogwood, but there are areas that lend well to shoreline angling. The southern shoreline is steep, very brushy with alder and heavily timbered.

Stocking History: According to fish planting records, from 1974 through 2000 the lake was planted with rainbow trout on a yearly schedule. From 2001 through 2005, the lake was switched to annual stocking of westslope cutthroat trout.

Angling Pressure: From March 2005 to February 2006, angling pressure was estimated at 155 angler-days.

Other Nearby Lakes: Upper Cottonwood Lake also lies along USFS Road 477 (Cottonwood Lakes Road) immediately west, within 0.1 mile of Middle Cottonwood Lake. Immediately east, within 0.1 mile of Middle Cottonwood Lake, is a small un-named lake. All three lakes are connected by a small first-order tributary stream that feeds Cottonwood Creek. High water events allow fish passage between the lakes. 
Date Sampled: 7/18-19/2006

Game Fish Present: Rainbow Trout

Other Fish Present: Redside shiners

Size Captured: Mean 10.1 inches (range 7.0 - 14.6 inches)

Trout Condition Factor (Wr): Mean $100 \pm 10.1$ (range $85-121$ )
Water Code: 04-6390

Sampling Methods: Sinking Gill Net Gill Net Catch Rate: 0.48trout/net/hr Natural Recruitment: Present (limited) Amphibians Observed: Spotted Frogs (adults)

Management Objectives: Stop WSCT plan and evaluate potential to convert to WSCT due to downstream hybridization risk to pure WSCT in Cottonwood Creek.

Currently Stocked: No Last Stocked: 2005 Species: WSCT Recommended Frequency: NA

Water Chemistry: pH: 8.78 TDS: 111 ppm Conductivity: 224 uS Secchi Depth: $21 \mathrm{ft}$
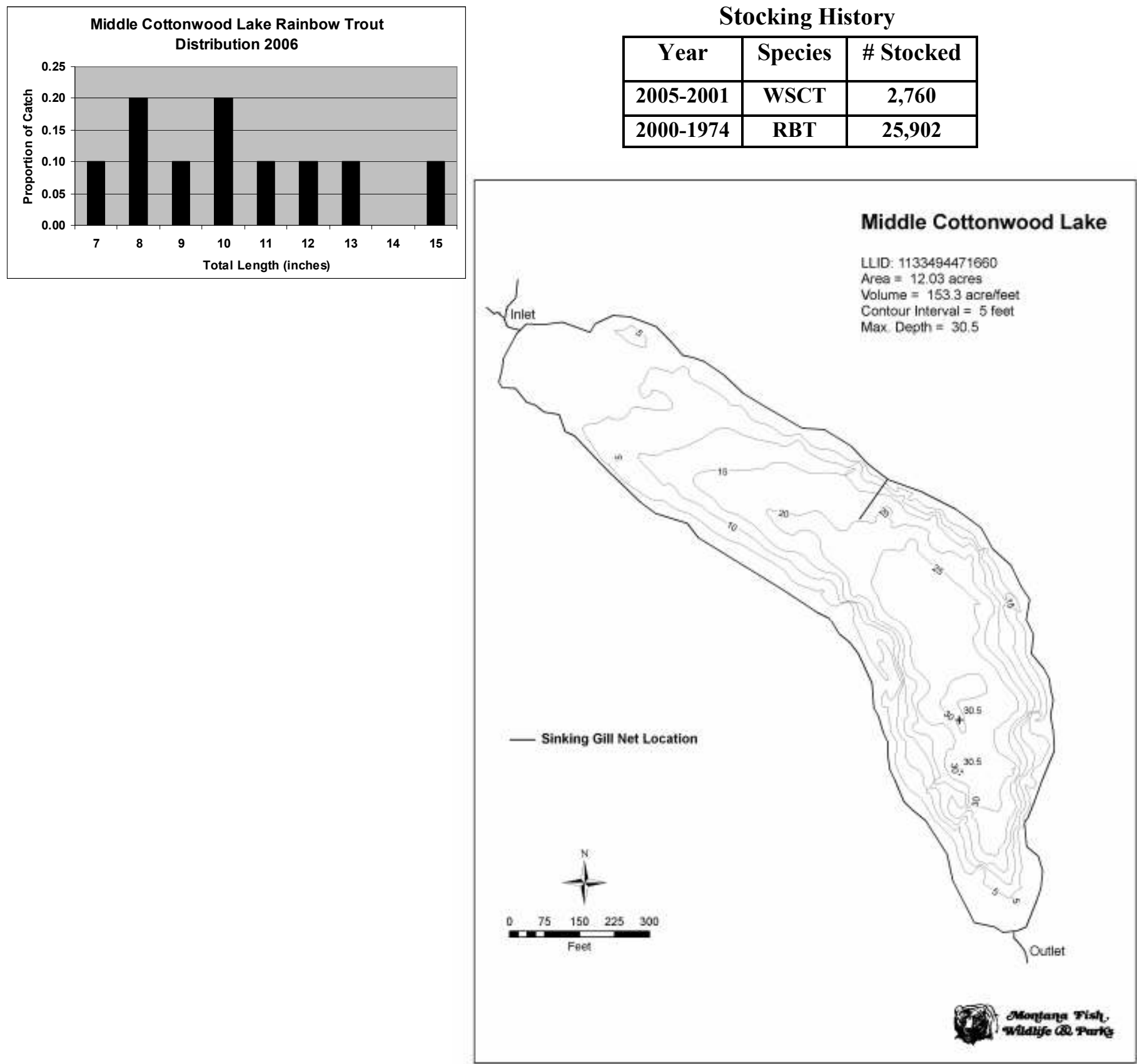


\section{Monture Lake \#1}
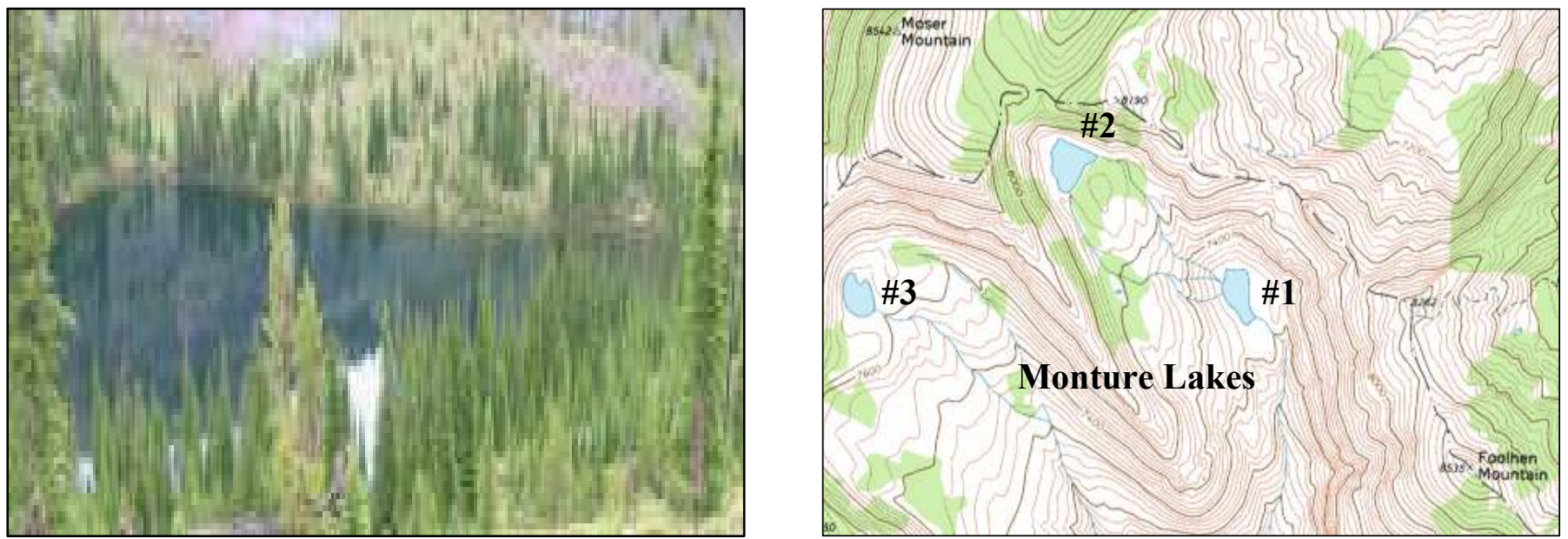

Description: One of a cluster of three un-named lakes, Monture Lake \#1 is a small high elevation (7,217') glacial cirque lake geographically located on the Lolo National Forest (Seeley Lake Ranger District) along the flanks of Foolhen Mountain, the southern border of the Bob Marshall Wilderness. Only 5.8 acres in size, its outlet stream forms the headwaters of Middle Fork Monture Creek in the upper Monture Creek drainage, a major tributary to the middle Blackfoot River.

Location: T18N, R12W, Sections 17; Latitude N47.31398 ${ }^{\circ}$, Longitude W113.15554 ${ }^{\circ}$; Nearest Town: Ovando.

Public Access: Access to Monture Lake \#1 can be obtained by traveling north 8.0 miles from Highway 200 at Ovando, on USFS Road 89 to the Monture Creek Campground / Trailhead. From the trailhead, travel along USFS Trail \#25, which changes to USFS Trail \#27 (Monture-Hahn Pack Trail) at trail mile 1.6 near Falls Creek. Continue north along USFS Trail \#27 for 12.6 miles or 1.1 mile above the Monture Creek Falls to USFS Trail \#371W. Follow Trail \#371W northeast up the Middle Fork Monture Creek drainage to the lake, a distance of 23.7 miles. The total distance from the trailhead to Monture Lake \#1 is roughly 16.3 miles. USFS Trails \#25 \& 27 are categorized as mainline (primary) trails in good condition with moderate ascent and difficultly. Trail $\# 371 \mathrm{~W}$ is categorized as a primitive trail with areas of steep ascents and more difficult traveling.

Camp Sites and Use: Three small primitive camp fire-rings with a few small tent sites were observed along the eastern side of the lake. Pack stock is not allowed within 200" of the shore. "Leave no trace" camping and recreating is essential in this proposed wilderness area.

Angling Opportunity: Monture Lake \#1 supports an abundant population of small (stunted) westslope cutthroat trout through natural reproduction. The immediate shoreline on the eastern and southern sides of the lake is relatively flat and brushy with sporadic stands of subalpine fir and spruce. The north and west sides of the lake are rugged, steep, and rocky with scattered timber. The eastern shoreline lends itself more to shoreline anglers.

Stocking History: According to fish plant records, Monture Lake \#1 was stocked once with westslope cutthroat trout in 1968.

\section{Angling Pressure: Light}

Other Nearby Lakes: There are two other cirque lakes in the general vicinity of Monture Lake \#1. Monture Lake \#2 lies $\sim 0.5$ miles northwest at an elevation of 7,700' on the southeastern slope of Moser Mountain. To reach Monture Lake \#2 involves a 500' ascent up from Monture Lake \#1. Monture Lake \#3 lies at an elevation of 7,623' about 1.1 miles directly west of lake \#1 on the southwestern slope of Moser Mountain. Access requires an ascent of 644' up then over a finger ridge of Moser Mountain, then a decent of 255' to the lake. There are no established 
trails between the three lakes and only the one primitive trail leading into Monture Lake \#1. Travel is difficult and strenuous, over rocky terrain, to these other lakes and requires good physical health.

\section{Monture Lake \#1: Biological \& Physical Information}

Date Sampled: 6/28-29/2005

Water Code: 04-6985

Game Fish Present: Westslope Cutthroat Trout

Sampling Methods: Sinking Gill Net

Other Fish Present: None

Gill Net Catch Rate: 0.12trout/net/hr

Size Captured: Mean 8.3 inches (range $7.6-9.0$ inches)

Natural Recruitment: Present

Trout Condition Factor (Wr): Mean $100 \pm 2.9$ (range 96-103)

Amphibians Observed: Spotted Frogs (adults, larvae, eggs)

Management Objectives: No change

Currently Stocked: No Last Stocked: 1968 Species: WSCT Recommended Frequency: NA

Water Chemistry: pH: 6.84 TDS: 3 ppm Conductivity: 5 uS Secchi Depth: $23.5 \mathrm{ft}$

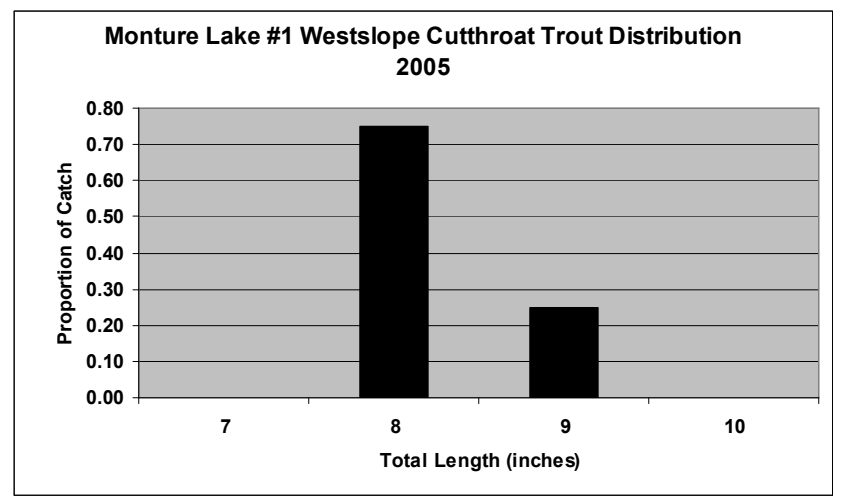

\begin{tabular}{|c|c|c|}
\hline Year & Species & \# Stocked \\
\hline 1968 & WSCT & $\mathbf{2 , 2 7 2}$ \\
\hline
\end{tabular}

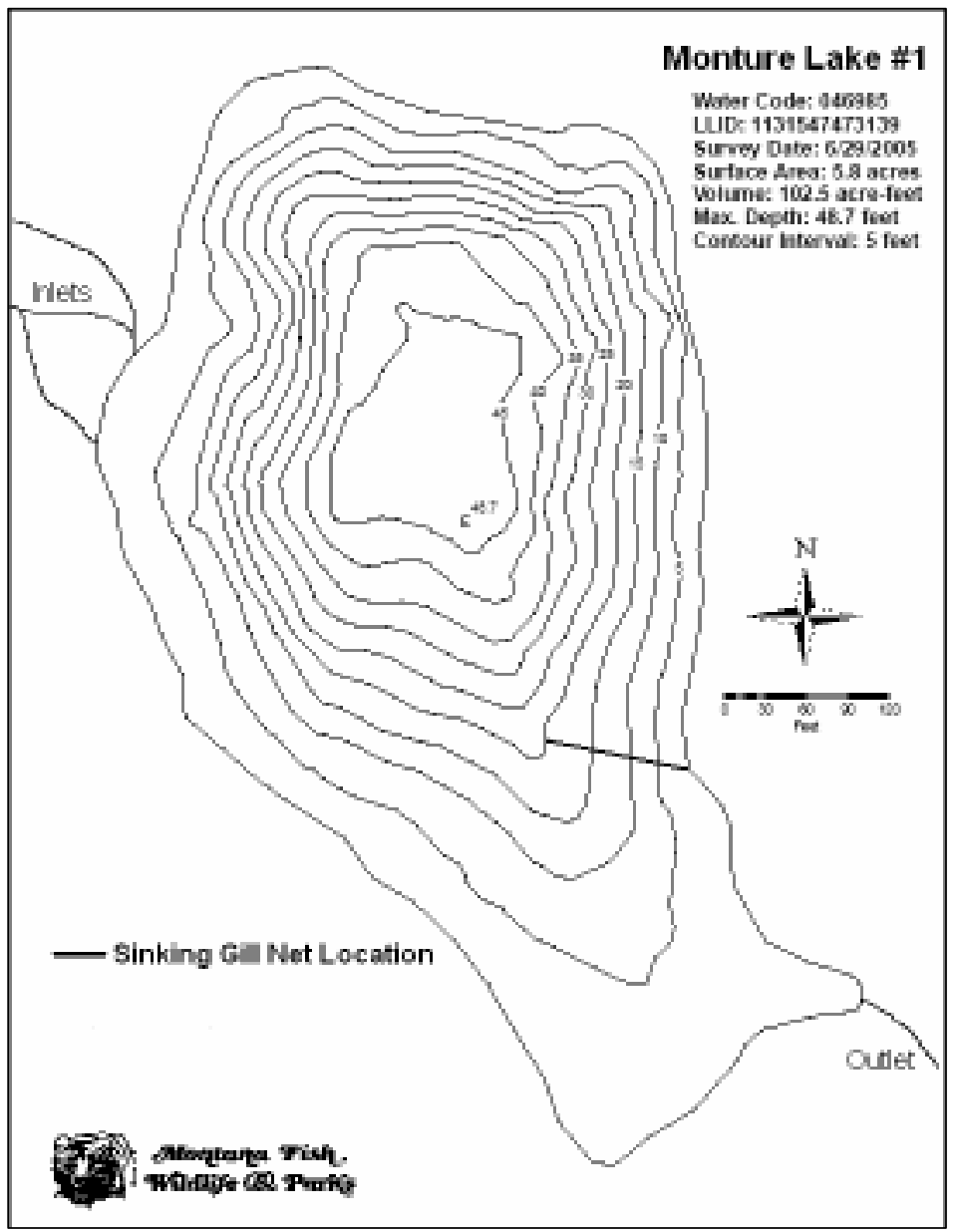




\section{Monture Lake \#2}
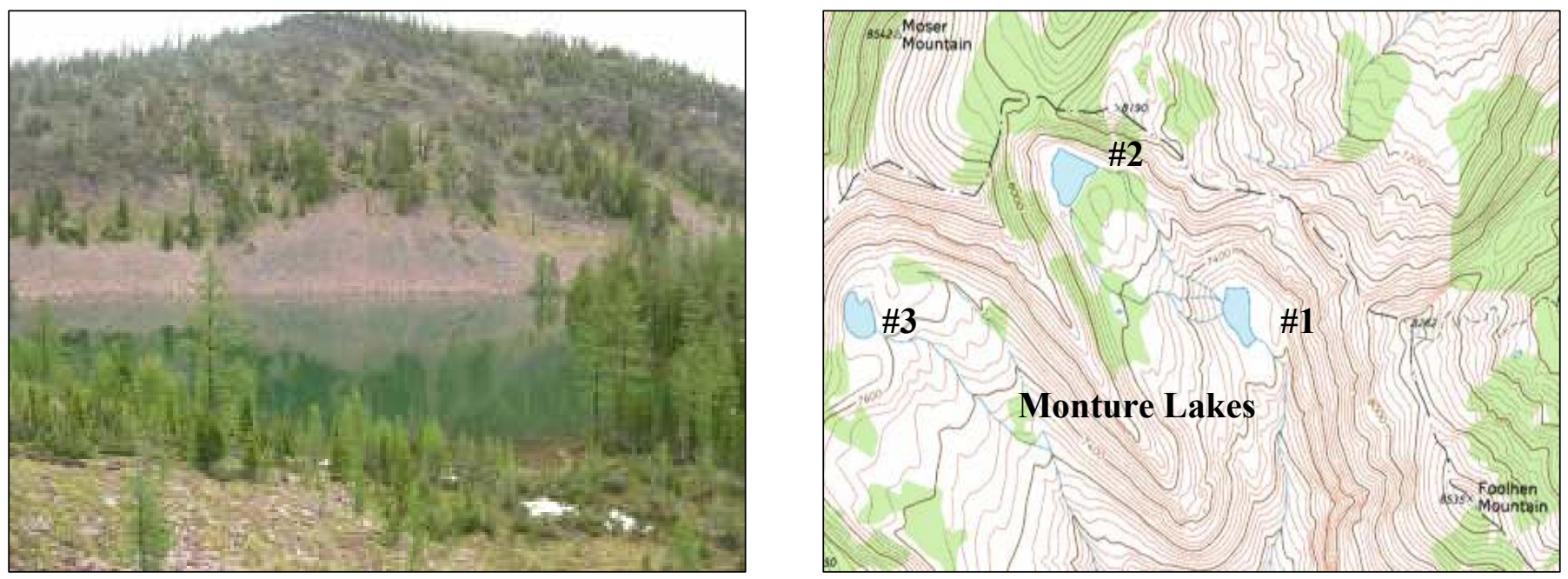

Description: One of a cluster of three un-named lakes, Monture Lake \#2 is a small (7.2 acre) high elevation (7,700') glacial cirque lake geographically located on the Lolo National Forest (Seeley Lake Ranger District) on the southeastern slope of Moser Mountain, just south of the Bob Marshall Wilderness. The lakes outlet flows into Monture Lake \#1, which forms the headwaters of the Middle Fork Monture Creek in the upper Monture drainage. Monture Creek is a major tributary to the middle Blackfoot River.

Location: T18N, R12W, Sections 17 \& 18; Latitude N47.31854 ${ }^{\circ}$, Longitude W113.16580' Nearest Town: Ovando.

Public Access: Access to Monture Lake \#2 can be obtained by traveling north 8.0 miles from Highway 200 at Ovando on USFS Road 89 to the Monture Creek Campground / Trailhead. From the trailhead, travel along USFS Trail \#25, which changes to USFS Trail \#27 (Monture-Hahn Pack Trail) at trail mile 1.6 near Falls Creek. Continue north along USFS Trail \#27 for 12.6 miles, 1.1 miles above the Monture Creek Falls, to USFS Trail \#371W. Follow USFS Trail \#371W northeast up the Middle Fork of Monture Creek to Monture Lake \#1, a distance of $\sim 3.7$ miles. From Monture Lake \#1 it is an ascent of approximately 500' over a distance of 4,000' to reach Monture Lake \#2. There are no established trails between the lakes. The total distance from trailhead to Monture Lake \#2 is $~ 17.1$ miles. Trails \#25 and \#27 are categorized as mainline (primary) trails, and these are well maintained with a moderate ascent and difficultly. Trail $\# 371 \mathrm{~W}$ is categorized as a primitive trail with areas of steep ascents.

Camp Sites and Use: No camping areas were observed around Monture Lake \#2.

Angling Opportunity: Our 2005 gill net survey found no fish in Monture Lake \#2. The immediate shoreline on the southeastern side of the lake is relatively flat, brushy and timbered with sub-alpine firs. The remaining shoreline surrounding the lake is rugged, steep, rocky talus slopes and lightly timbered.

Stocking History: No record of historical fish plants

Angling Pressure: NA

Other Nearby Lakes: There are two other cirque lakes in the vicinity of Monture Lake \#2. Monture Lake \#1 lies at an elevation 500' lower than Monture Lake \#2 (7,217'), about 0.5 miles southeast on the western slope of Foolhen Mountain and accessed from the USFS Trail \#371W that leads to lake. Monture Lake \#3 is about 1.1 miles west-southwest of Monture Lake \#2 on the southwestern slope of Moser Mountain and it lies at an elevation of 7,623'. Access requires an ascent up and over a finger ridge of Moser Mountain that separates the two cirque lakes. There are no established trails between the three lakes and only the one primitive trail leading into Monture Lake \#1. Travel is difficult and strenuous, over rocky terrain, to these other lakes and requires good physical health. 
Date Sampled: 6/28/2005

Game Fish Present: None

Other Fish Present: None

Size Captured: NA

Trout Condition (Wr): NA
Water Code: 04-6986

Sampling Methods: Sinking Gill Net Gill Net Catch Rate: NA

Natural Recruitment: NA

Amphibians Observed: None

Management Objectives: Potential to convert from fishless to WSCT in the future if desired. Currently Stocked: No Last Stocked: NA Species: NA Recommended Frequency: NA

Water Chemistry: pH: 7.55 TDS: 1 ppm Conductivity: 5 uS Secchi Depth: $9.3 \mathrm{ft}$

\section{Monture Lake \#2}

Water Code: 046986

LLID: 1131649473188

Survey Date: 6/28/2005

Surface Area: 7.2 acres

Volume: 82.3 acre-feet

Max. Depth: 18.4 feet

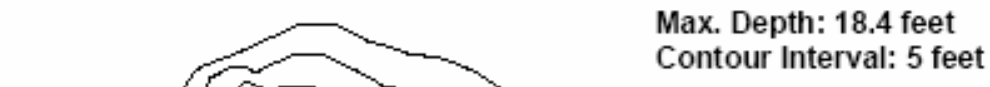

Contour Interval: 5 feet

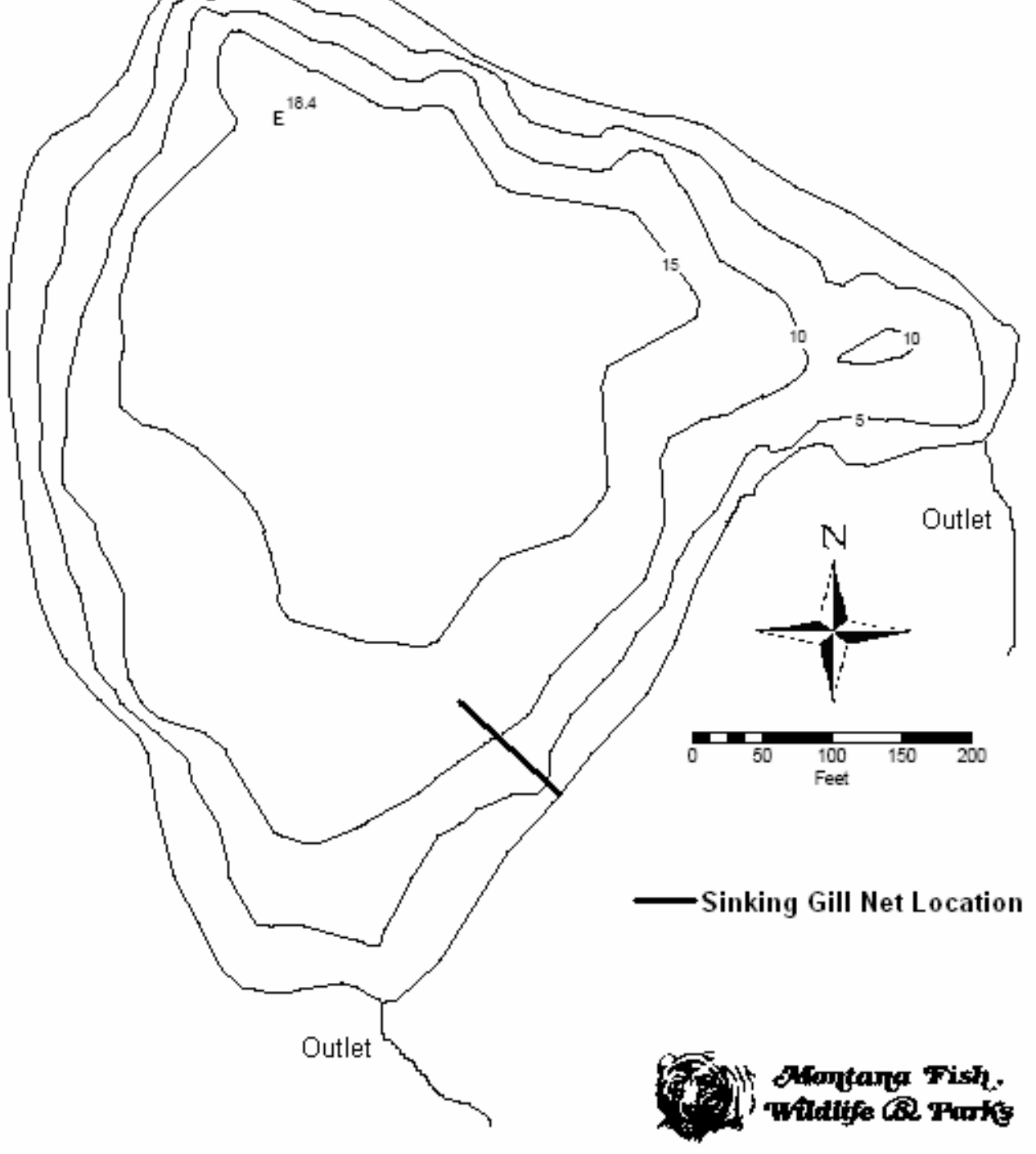




\section{Monture Lake \#3}
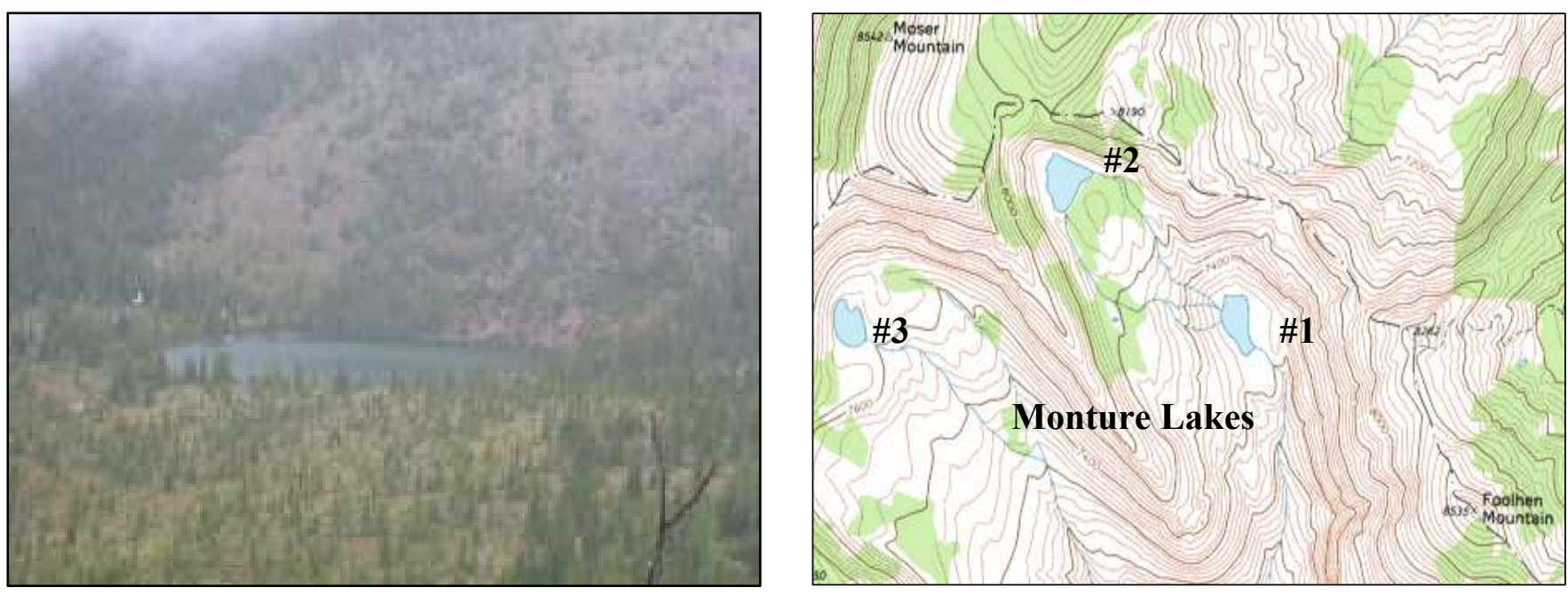

Description: One of a cluster of three un-named lakes, Monture Lake \#3 is a small (6.0 acre) high elevation (7,641 ft) glacial cirque lake located on the Lolo National Forest (Seeley Lake Ranger District) on the south-southwestern slope of Moser Mountain, just south of the Bob Marshall Wilderness. The outlet stream, together with that from Monture Lake \#1, forms the headwaters of Middle Fork Monture Creek in the upper Monture Creek drainage. Monture Creek is a major tributary to the middle reach of the Blackfoot River.

Location: T18N, R12W, Sections 18; Latitude N47.31356 ${ }^{\circ}$, Longitude W113.17903우 Nearest Town: Ovando.

Access: Access to Monture Lake \#3 can be obtained by traveling north 8.0 miles from Highway 200 at Ovando on USFS Road 89 to the Monture Creek Campground/Trailhead. From the trailhead, travel along USFS Trail \#25 which changes to USFS Trail \#27 (Monture-Hahn Pack Trail) at trail mile 1.6 near Falls Creek. Continue north along USFS Trail \#27 for 12.6 miles and 1.1 mile above the Monture Creek Falls to USFS Trail \#371W. Follow USFS Trail \#371W northeast up the Middle Fork of Monture Creek about 2.5 miles to the first tributary stream flowing down from the northwest. Follow this small tributary upstream 2.0 miles to the lake. There is no established trail leading to the lake. An alternate route is to continue following USFS Trail \#371W to Monture Lake \#1, a distance of 3.7 miles from the USFS Trail \#27. From Monture Lake \#1, an ascent up and over a fingerridge of Moser Mountain that separates the two cirque lake basins is required. Depending on the route followed, the average distance from trailhead to Monture Lake \#3 is approximately 17.3 miles. Trails \#25 and \#27 are categorized as mainline (primary) trails and are well maintained with moderate ascents and difficultly. Trail \#371W is a primitive trail with areas of steep ascents and more difficult travel.

Camp Sites and Use: No camping areas were observed around Monture Lake \#3.

Angling Opportunity: Our 2005 gill net survey identified Monture Lake \#3 as fishless. The shoreline on the southern side of the lake is relatively flat, brushy and timbered with sub-alpine firs. The remaining shoreline surrounding the lake is rugged, steep, rocky talus slopes and lightly timbered.

Stocking History: No history of fish plants.

Angling Pressure: NA

Other Nearby Lakes: There are two other cirque lakes in the vicinity of Monture Lake \#3. Monture Lake \#1 is 425 ' lower in elevation than lake \#3 (7,217ft), and it is found about 1.4 miles east on the western slope of Foolhen Mountain and is accessed from the USFS Trail $371 \mathrm{~W}$ that leads up to the lake. Monture Lake \#2 is 1.3 miles northeast of Monture Lake \#3 on the southeastern slope of Moser Mountain (elevation of 7,700') and access to it requires an ascent from Monture Creek Lake \#1. There are no established trails between the three lakes and only 
the one primitive trail leads to Monture Lake \#1. Travel between the lakes is difficult and requires good physical health.

\section{Monture Lake \#3: Biological \& Physical Information}

Date Sampled: 6/28/2005

Game Fish Present: None

Other Fish Present: None

Size Captured: NA

Trout Condition Factor (Wr): NA

Amphibians Observed: Spotted Frogs (adults, eggs), Long-toed Salamander

Management Objectives: No change - manage as fishless.

Currently Stocked: No Last Stocked: NA Species: NA Recommended Frequency: NA

Water Chemistry: pH: 6.65 TDS: 2 ppm Conductivity: 5 uS Secchi Depth: $12.0 \mathrm{ft}$
Water Code: 04-6987

Sampling Methods: Sinking Gill Net Gill Net Catch Rate: NA

Natural Recruitment: NA

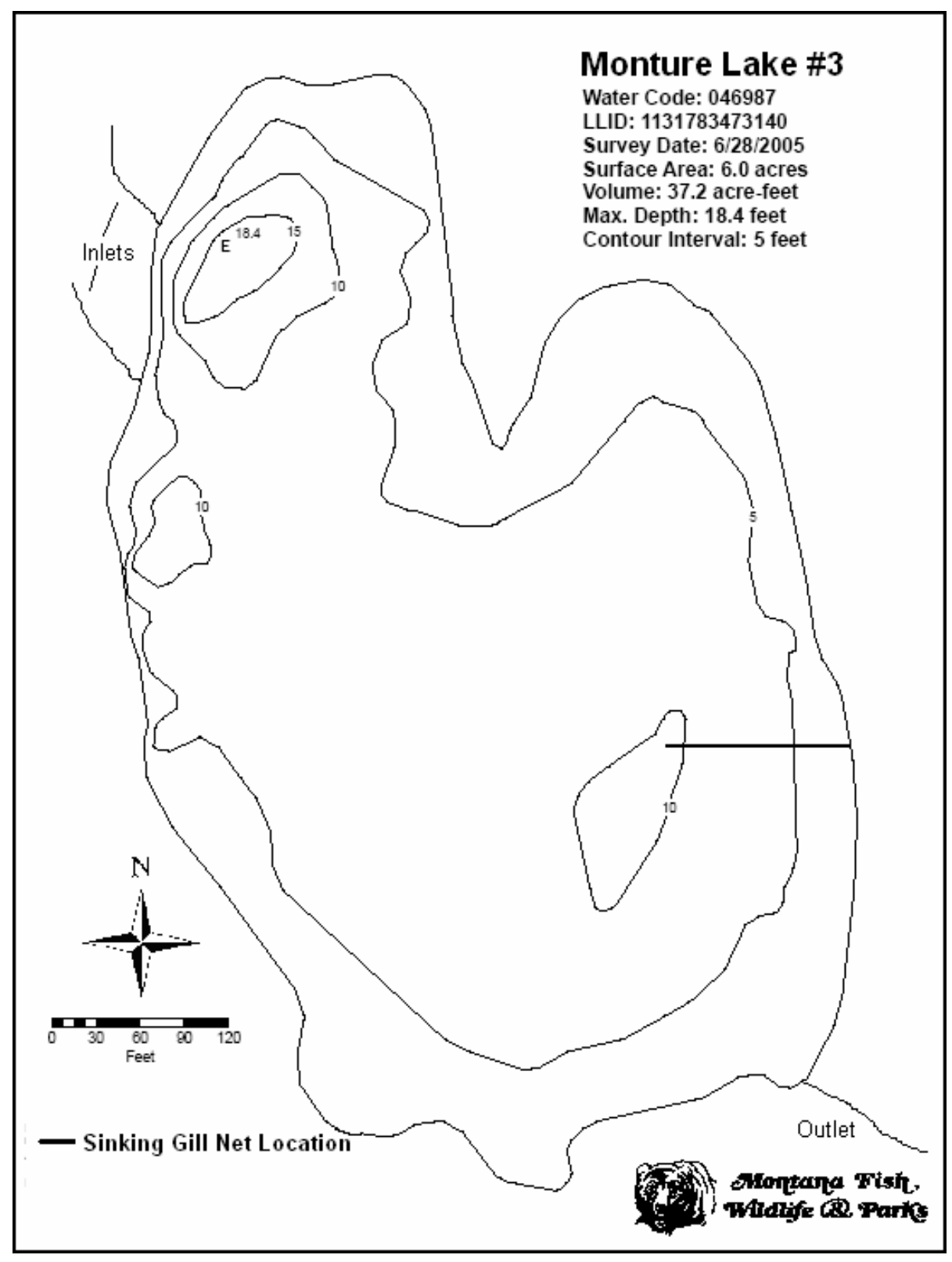




\section{Nevada Lake Reservoir}
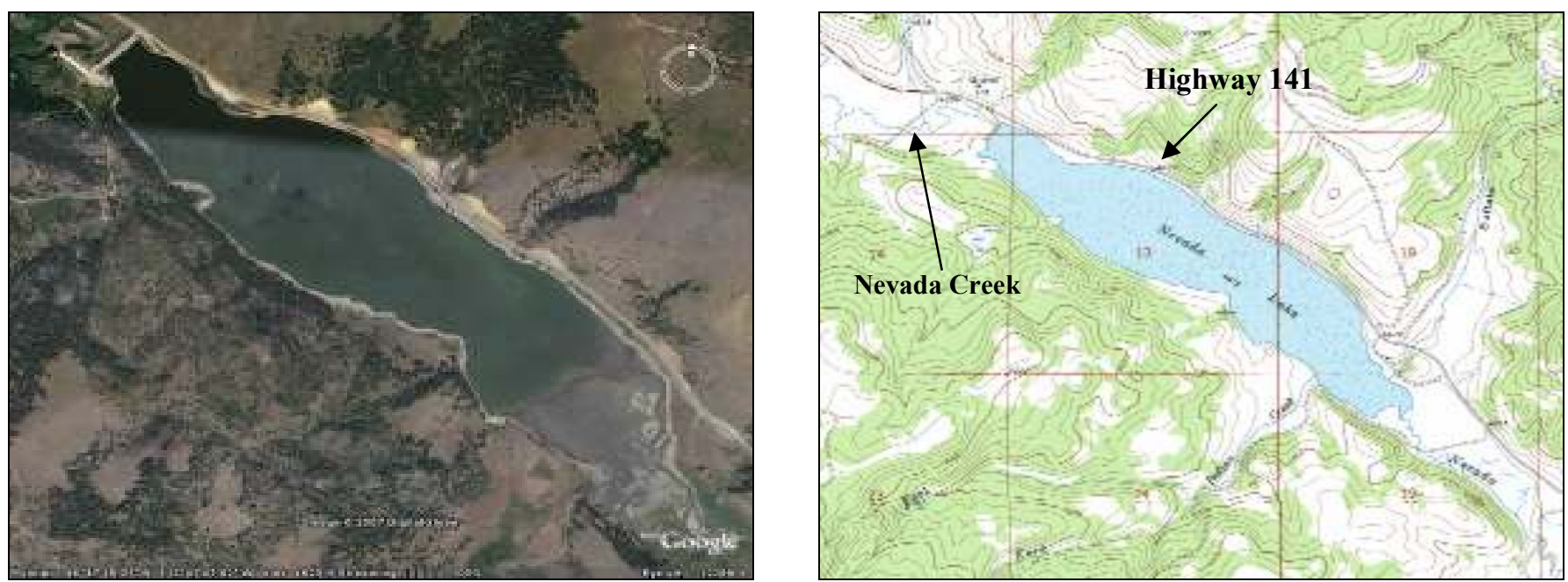

Description: Nevada Lake Reservoir is an instream (366.6 acre) reservoir (elevation of 4,615') in the upper Nevada Creek watershed, a tributary to the middle Blackfoot River. It is located $\sim 4.3$ miles east-northeast of Hoodoo Mountain and 10.4 road miles southeast of Helmville. The reservoir was created in 1939 by damming Nevada Creek to provide irrigation water to the Nevada Creek valley ranchlands and for recreational benefits. The lake is bordered by private ranch land on all side except the northeastern third, which is State land.

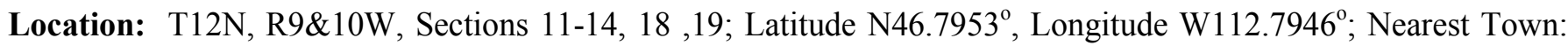
Helmville.

Public Access: Nevada Lake Reservoir lies adjacent to Highway 141, located 10.4 miles southeast of Helmville and 20.2 miles northwest of Avon.

Camp Sites and Use: The reservoir offers no camping facilities, but does have a boat ramp access off of Highway 141. The lake experiences moderate angling use.

Angling Opportunity: Nevada Lake Reservoir supports a stocked rainbow and westslope cutthroat trout fishery. The lake also supports a population of yellow perch, which were illegally introduced. Angling is primarily from a boat, shoreline and through the ice. Only the northeast third, along Highway 141, is easily accessible to shoreline angling.

Stocking History: From 1939 to 2001, Nevada Lake Reservoir was periodically stocked with rainbow trout and in 1948 and 1951 with Coho salmon. In 2002, stocking was switched to an annual plant of westslope cutthroat trout.

Angling Pressure: From March 2005 to February 2006, angling pressure was estimated at 1,264 angler-days.

Other Nearby Lakes: Browns Lake and Braziel Lake are the only two lakes in the area of Nevada Reservoir. Access to Browns Lake can be reached from Ovando or Helmville by using the Ovando-Helmville Road. From Ovando, follow the Ovando-Helmville Road south to Browns Lake Road then turn east for 4 miles to the lake or from Highway 141 and then follow County Road 271 to the Ovando-Helmville Road (1.8 miles), then northwest for 8.6 miles to the Browns Lake Road. The intersection of Browns Lake Road and Highway 200 is 8.3 miles east of Ovando, turn south and continue 3 miles to the lake. Braziel Lake is accessed by taking USFS Road 117 located 0.3 miles below Nevada Lake Reservoirs. Braziel Lake is a walk-in lake and a map is required since most of the land adjacent to the lake is private. 
Game Fish Present: Westslope Cutthroat \& Rainbow Trout, Yellow Perch

Other Fish Present: Largescale suckers and redside shiners

Sampling Methods: Sinking \& Floating Gill Net

WSCT Size Captured: Mean 8.4 inches (range 5.0-14.0 inches)

WSCT Condition Factor (Wr): Mean $121 \pm 62$ (range 81-429)

RBT Size Captured: Mean 13.2 inches (range 7.2-16.6 inches)

RBT Condition Factor (Wr): $85 \pm 8.7$ (range 69-132)

YP Size Captured: Mean 6.7 inches (range 5.2-10.1 inches)

YP Condition Factor (Wr): $104 \pm 15.8$ (range 60-163)
Gill Net Catch Rate: $0.13 \mathrm{WSCT} / \mathrm{net} / \mathrm{hr}$

Natural Recruitment: Present

Gill Net Catch Rate: $0.37 / \mathrm{RBT} / \mathrm{net} / \mathrm{hr}$

Natural Recruitment: Present

Gill Net Catch Rate: $0.96 \mathrm{YP} / \mathrm{net} / \mathrm{hr}$

Natural Recruitment: Present

Amphibians Observed: None observed

Management Objectives: Manage as a put-and-take WSCT fishery until such a time as natural reproduction can be sustained. This will involve substantial restoration activities in upper Nevada Creek.

Currently Stocked: Yes Last Stocked: 2006 Species: WSCT Recommended Frequency: Annually

Water Chemistry: pH: 8.18 TDS: 89 ppm Conductivity: 179 uS Sechi Depth: $5.6 \mathrm{ft}$

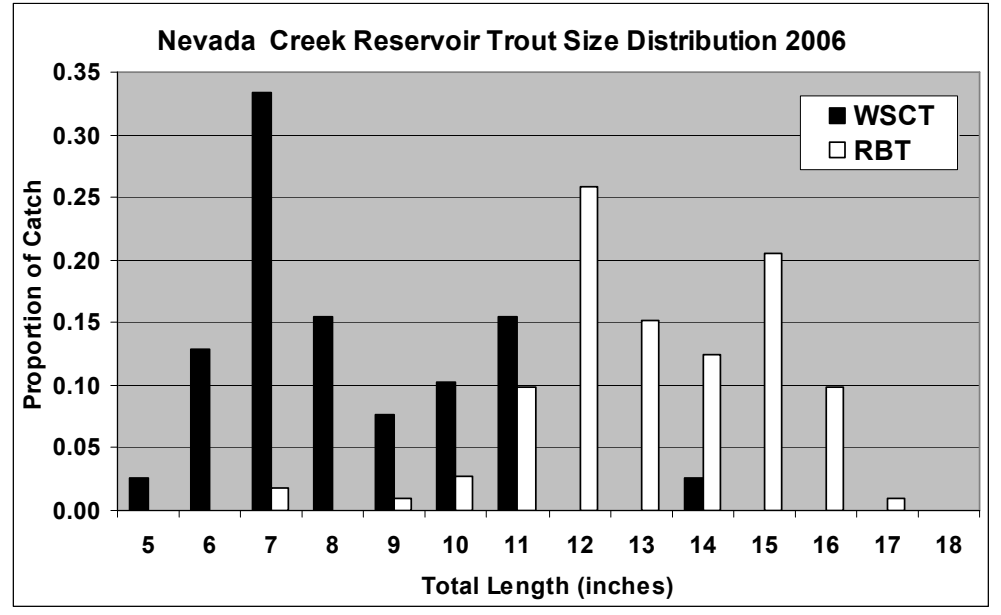

\begin{tabular}{|c|c|c|}
\hline \multicolumn{3}{|c|}{ Stocking History } \\
\hline Year & Species & \# Stocked \\
\hline 2006-2002 & WSCT & 10,000 \\
\hline 2001-1989 & RBT & 28,613 \\
\hline 1969-1967 & RBT & 16,785 \\
\hline 1954-1951 & RBT & 48,810 \\
\hline 1951 & Coho & 10,850 \\
\hline 1950-1949 & RBT & 16,890 \\
\hline 1948 & Coho & 4,845 \\
\hline 1947-1939 & RBT & 302,860 \\
\hline
\end{tabular}




\title{
Nevada Lake Reservoir
}

\author{
LLID: 1127946467953 \\ Area $=366.65$ acres \\ Volume $=10416$ acre/feet \\ Contour Interval $=5$ feet \\ Max. Depth $=65$ feet
}

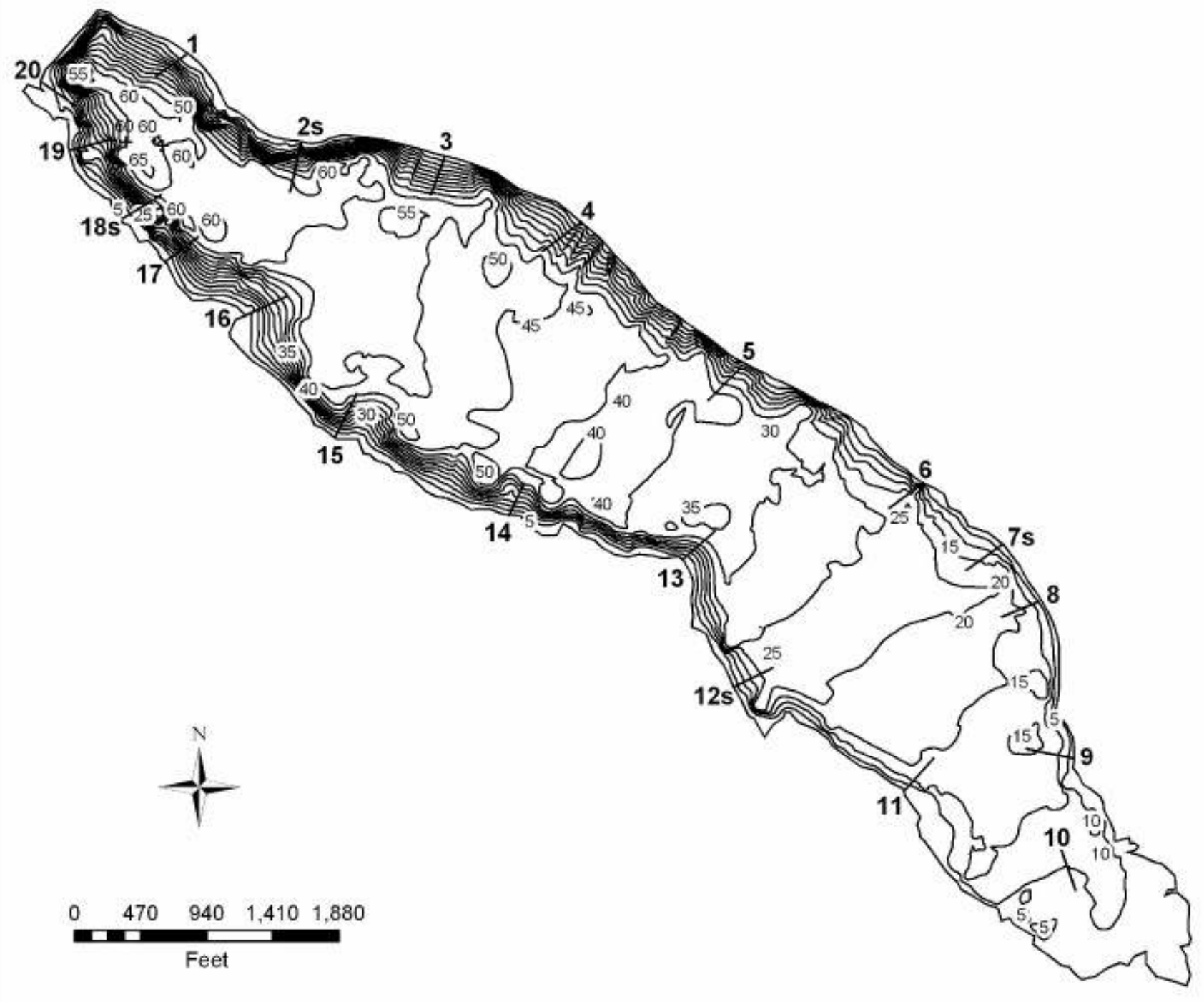

_ Floating Gill Net Locations

\#s — Sinking Gill Net Locations 


\section{Parker Lake}
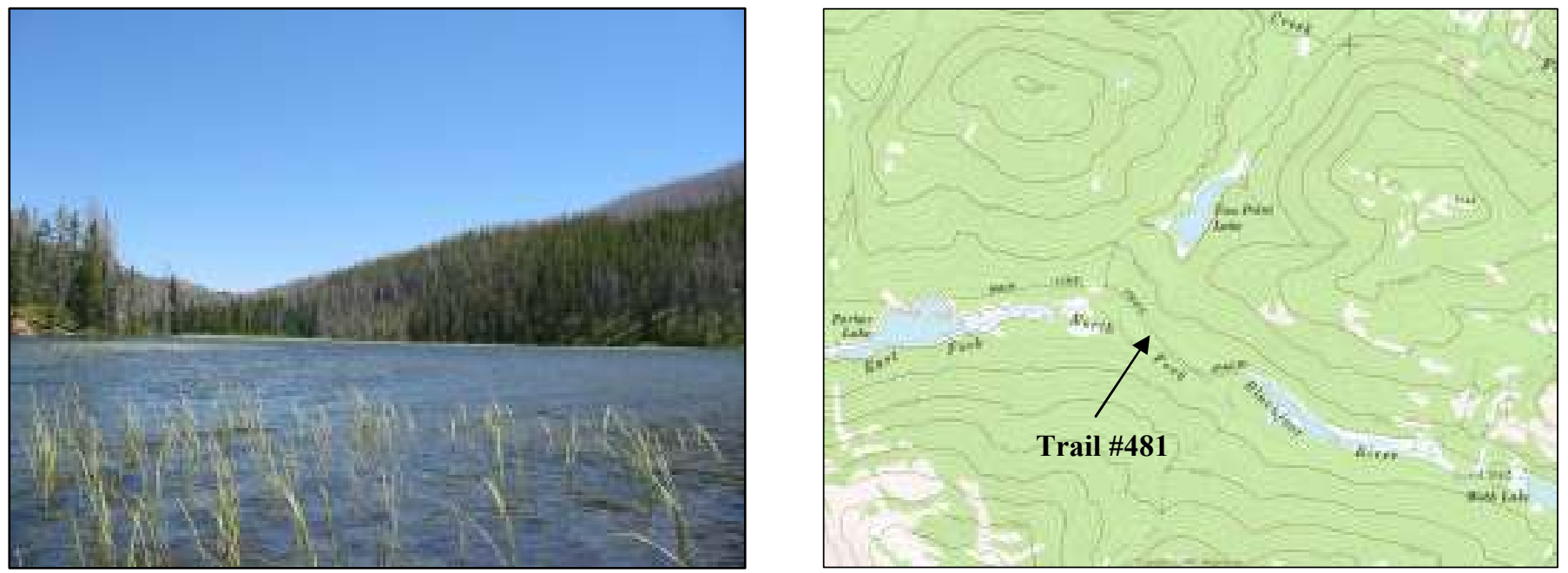

Description: Parker Lake is a moderate sized (24.7 acres) glacial valley trough lake $\sim 2.5$ miles north-northwest of Red Mountain. The lake lies with in the Scapegoat Wilderness, Helena National Forest (Lincoln Ranger District) at $6,000^{`}$ elevation in the East Fork of the North Fork Blackfoot River drainage.

Location: T16N, R9W, Sections 9; Latitude N47.15331 ${ }^{\circ}$, Longitude W112.74102 ${ }^{\circ}$; Nearest Town: Lincoln.

Public Access: Access to Parker Lake can be obtained by taking Highway 200 east from Lincoln 6.2 miles to the Copper Creek Road. Follow the Copper Creek Road 10.2 miles to the Indian Meadows Trailhead. From the trailhead, travel along USFS Trail \#481 (Main Line Pack Trail) 9.5 miles to the Parker Lake. The trail is in good condition with moderate difficultly.

Camp Sites and Use: Parker Lake receives moderate recreational use because of its relatively short distance within the Scapegoat Wilderness boundary on a well-maintained trail system. Two primitive campsites that are offset from the shoreline were observed. One campsite was located at the base of the peninsula at northeast corner near the inlet stream to the lake. A second campsite was observed at the base of the adjacent peninsula near the northnorthwestern shoreline of the lake. Both campsites show heavy use. Camping is not allowed on the peninsulas. Pack stock is not allowed within 200 feet of the shore. "Leave no trace" camping and recreating is essential in this wilderness area.

Angling Opportunity: Parker Lake currently supports hybrid cutthroat trout (Yellowstone and westslope) as well as hybridized rainbow trout, all of which are currently sustained through natural reproduction. Most areas of the shoreline topography are brushy, heavily timbered and moderately steep; however, there are areas that lend well to shoreline angling.

Stocking History: Fish planting records show that Parker Lake has been stocked with cutthroat trout. It was first planted in 1942 and 1943 then every two years through 1952 when the last stocking of the lake occurred. Genetics samples confirm that at some point rainbow trout were also introduced, but no records are known of this stocking.

\section{Angling Pressure: Moderate}

Other Nearby Lakes: In the vicinity of Parker Lake are five other lakes. Approximately 7.0 miles from the Indian Meadows Trailhead, Webb Lake lies next to the Main Line Pack Trail (USFS Trail \#481) 2.3 miles east of Parker Lake. Continuing northwest along USFS Trail \#481, Two Point Lake is accessed by USFS Trail \#479 that intersects the Main Line Pack Trail 0.5 miles east of Parker Lake, a total distance of 0.9 miles from Parker Lake. Unlike Parker Lake, both Webb and Two Point Lakes lie in the Landers Fork drainage. Both Upper and Lower Twin Lakes can be accessed by continuing northwest along USFS Trail \#481 past Parker Lake, 1.7 miles, to Twin Lakes Trail (USFS Trail \#425), then another 0.4 miles to Upper Twin Lake or 1.5 miles to Lower Twin Lake. 
Before reaching the Twin Lakes Trail, Meadow Creek Trail (USFS Trail \#483) branches off to the west from the Main Line Pack Trail 1.2 miles past Parker Lake and continues for another 1.8 miles to Meadow Lake. Travel is moderately difficult to these other lakes.

\section{Parker Lake: Biological \& Physical Information}

Date Sampled: 7/20/2005

Game Fish Present: Hybrid Cutthroat-Rainbow Trout Other Fish Present: None

Size Captured: Mean 10.6 inches (range 5.9 - 14.9 inches)

Trout Condition Factor (Wr): Mean $95 \pm 11.1$ (range $63-120$ )

Genetics: All fish possessed genetic markers for Yellowstone and westslope cutthroat trout and rainbow trout. Genetic analyses suggest that there maybe two somewhat reproductively isolated populations, both of which are hybridized.

Amphibians Observed: Spotted Frogs (adults and tadpoles), Western Toads (adults and tadpoles)

Management Objectives: To be determined.

Currently Stocked: No Last Stocked: 1952 Species: CT and RBT Recommended Frequency: NA

Water Chemistry: pH: 8.36 TDS: 142 ppm Conductivity: $291 \mathrm{uS}$ Secchi Depth: $6.2 \mathrm{ft}$

Stocking History

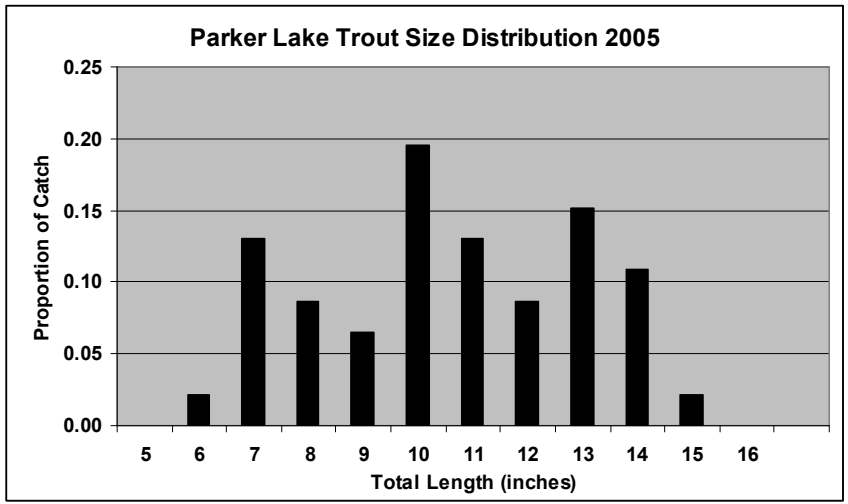

\begin{tabular}{|c|c|c|}
\hline Year & Species & \# Stocked \\
\hline $1942-1943$ & CT & 16,000 \\
\hline 1946 & CT & 7,333 \\
\hline 1948 & CT & 10,000 \\
\hline 1950 & CT & 3,600 \\
\hline 1952 & CT & 16,164 \\
\hline
\end{tabular}

\section{Parker Lake}

Water Code: 047080

LLID: 1127422471532

Survey Date: $7 / 20 / 2005$

Surface Area: 24.7 acres

Volume: 68.9 acre-feet

Max. Depth: 6.2 feet

Contour Interval: $\mathbf{2}$ feet

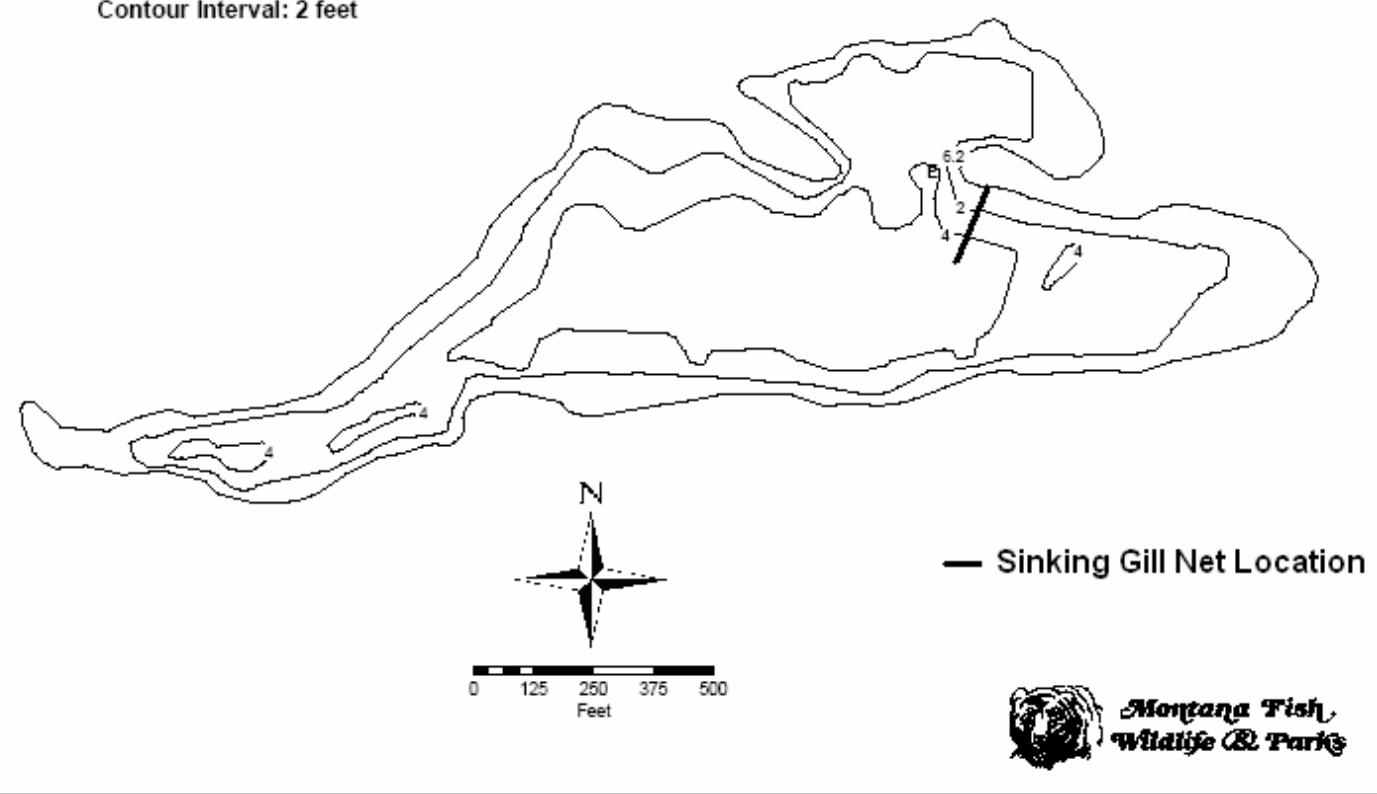




\section{Two Point Lake}
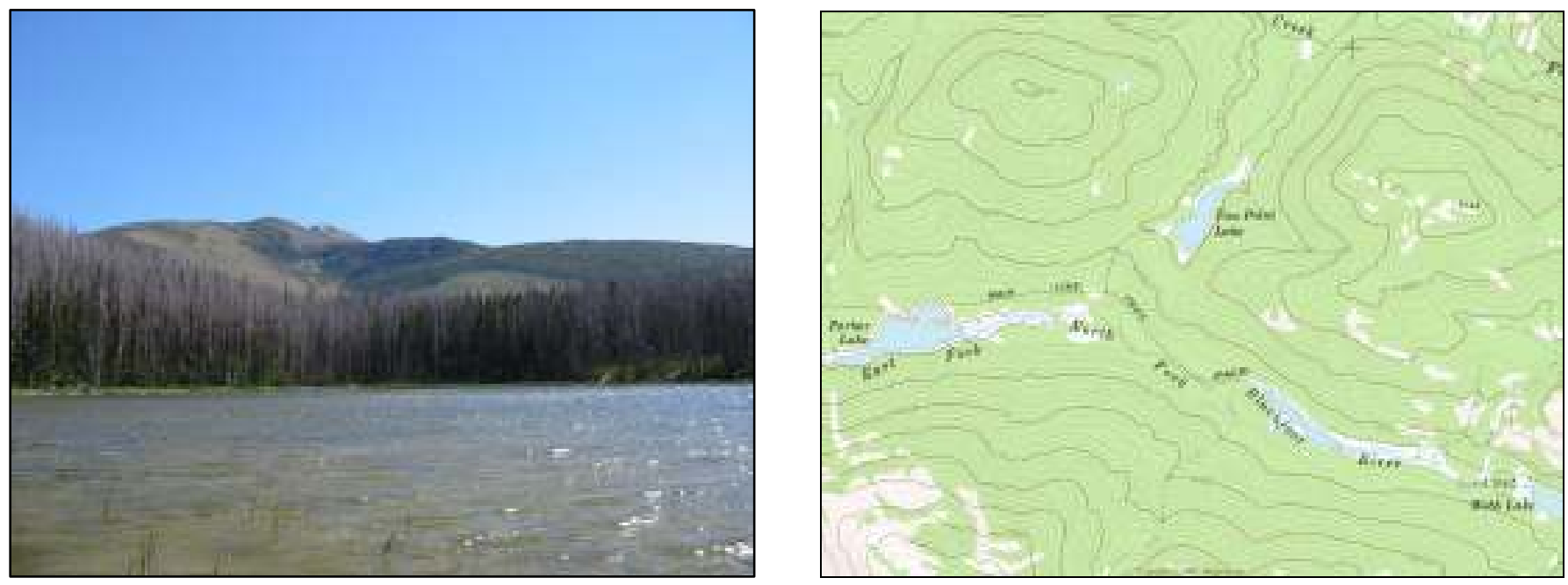

Description: Two Point Lake is a small ( 8.3 acres) glacial valley trough lake located $\sim 2.9$ miles north-northeast of Red Mountain. The lake lies within the Scapegoat Wilderness, Helena National Forest (Lincoln Ranger District) at 6,187'. Its outlet stream flows into Maryann Creek, a tributary to the Landers Fork - an Upper Blackfoot River tributary.

Location: T16N, R9W, Sections 10; Latitude N47.15861 ${ }^{\circ}$, Longitude W112.72011 ${ }^{\circ}$; Nearest Town: Lincoln.

Public Access: Access to Two Point Lake can be obtained by taking Highway 200 east from Lincoln 6.2 miles to the Copper Creek Road. Follow the Copper Creek Road 10.2 miles to the Indian Meadows Trailhead. From the trailhead travel along USFS Trail \#481 (Main Line Pack Trail) passed Webb Lake USFS Guard Station to USFS Trail \#479, a total distance of 8.5 miles, then northeast on USFS Trail \#479 for 0.5 mile to the lake. The trail is in very good condition with a moderate ascent and difficultly.

Camp Sites and Use: No camping areas were observed around Two Point Lake. Pack animals are not allowed within 200 feet of the shore. "Leave no trace" camping and recreating is essential in this wilderness area.

Angling Opportunity: Our 2005 gill-net survey identified Two Point Lake as fishless. Much of the shoreline is marshy with sedges and rush extending out into the lake. The surrounding topography is heavily timbered moderately steep slopes.

Stocking History: None

Angling Pressure: NA

Other Nearby Lakes: There are three other lakes in the vicinity of Two Point Lake. Approximately 4.8 miles from the Indian Meadows Trailhead, Heart Lake lies along USFS Trail \#424 that branches off the Main Line Pack Trail (USFS Trail \#481) at about trail mile 3.9, which eventually reconnects back into the Main Line Pack Trail northwest of Heart Lake. Webb Lake lies along the Main Line Pack Trail 7.0 miles from Indian Meadow Trailhead and roughly 1.5 miles before reaching the Trail \#479 turnoff. Continuing northwest along USFS Trail \#481, 2.3 miles passed Webb Lake and 0.6 miles passed the USFS Trail \#479 turnoff to Two Point Lake, is Parker Lake. Travel is moderately difficult to these other lakes. 
Date Sampled: 7/20/2005

Game Fish Present: None

Other Fish Present: None

Size Captured: NA

Trout Condition Factor (Wr): NA

Amphibians Observed: Spotted Frogs (adults, tadpoles), Western Toad (tadpoles)

Management Objectives: This lake likely will not sustain fish and should managed as fishless.

Currently Stocked: No Last Stocked: NA Species: NA Recommended Frequency: NA

Water Chemistry: pH: 9.00 TDS: 129 ppm Conductivity: 258 uS Secchi Depth: $10.5 \mathrm{ft}$

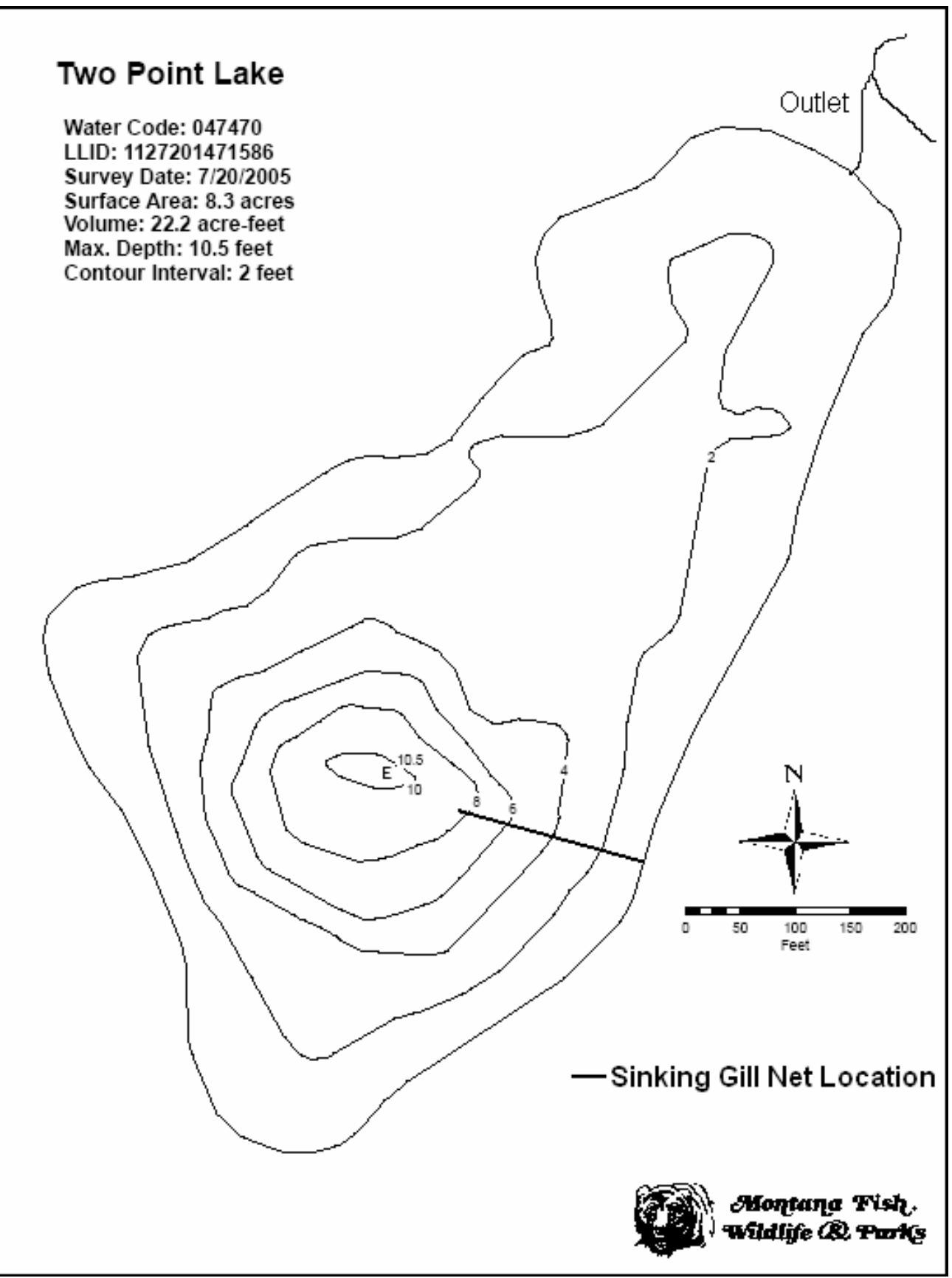




\section{Upper Copper Lake}
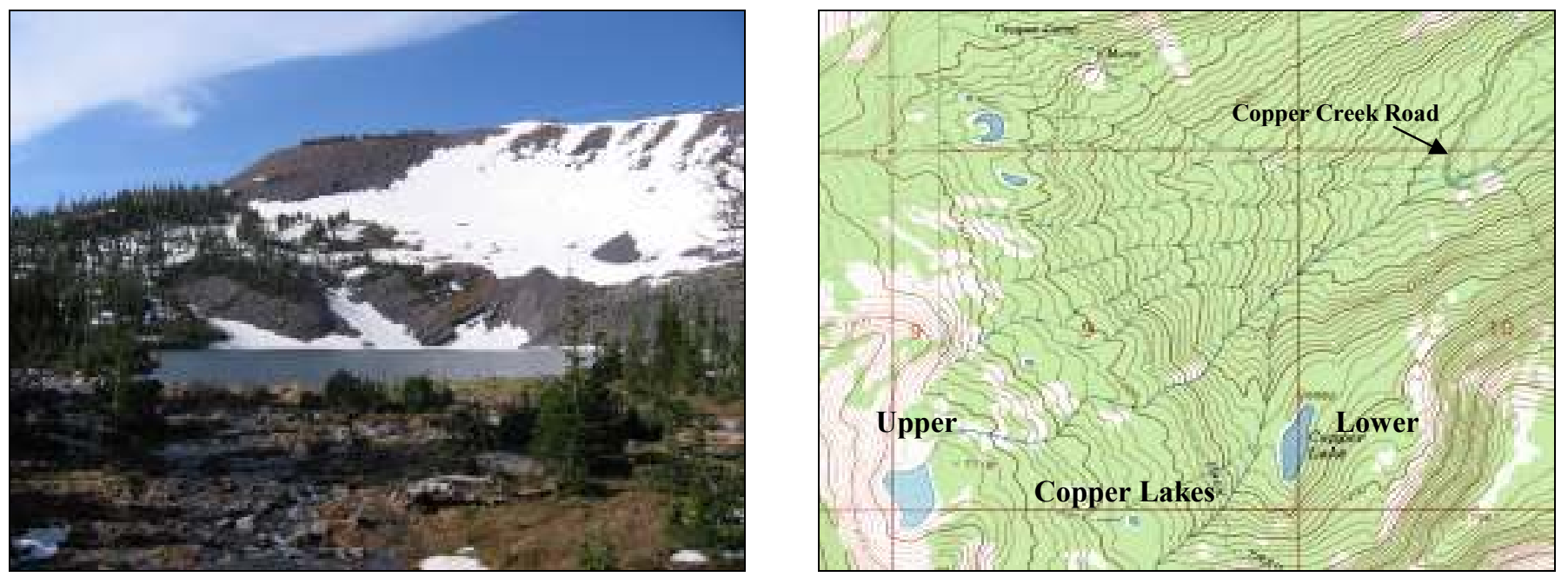

Description: Upper Copper Lake is a small (9.44 acres) glacial cirque lake located $\sim 2.5$ miles west-northwest of Stonewall Mountain and 3.8 miles south-southwest of Red Mountain. The lake lies within the Helena National Forest (Lincoln Ranger District) at 7,706'. Its outlet forms the headwaters to Copper Creek, in the Landers Fork drainage, a major tributary of the upper Blackfoot River.

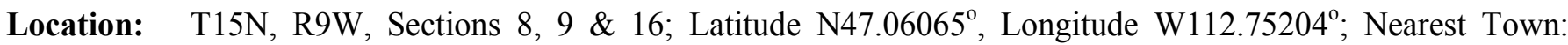
Lincoln.

Public Access: To access upper Copper Lake, take Highway 200 east from Lincoln 6.2 miles to the USFS Road 330 (Copper Creek Road). Follow USFS Road 33012 miles to the end of the road (USFS gate). At the end of the road there is a small trailhead information board and parking for 3 vehicles. Not shown on maps, the trail is an unmarked primitive trail that ascends following the outlet streams from the lakes that form Copper Creek. Lower Copper Lake is one mile up the trail with an elevation gain of 600'. The trail is very brushy with alder and downed trees. Reaching Upper Copper Lake requires an additional mile hike, with no trail, through a "burn" area and an elevation gain 800 '. There is a total elevation gain of 1,400' from the trailhead. An alternate route to Upper Copper Lake is by traveling 3 miles up the closed jeep road (behind USFS gate at the trailhead) by foot to the abandoned mining site and intercepting the northern end of USFS Trail \#485. USFS Trail \#485 runs south and stays relatively level while skirting the slopes of the upper Copper Creek basin (elevation 7,100') and intercepts the outlet stream from the upper lake. An ascent of 0.7 miles along the outlet stream, with an elevation gain of 600', will terminate at the lake. Caution: a large area between the two lakes burned in 2003 making it hard to distinguish the trail in many areas and dangerous due to falling trees during windy conditions.

Camp Sites and Use: No camping areas were observed around Upper Copper Lake.

Angling Opportunity: Upper Copper Lake supports a small population of native westslope cutthroat trout. The topography on the eastern side of the lake is relatively flat; however, the western side of the lake is steep, rocky and prone to avalanches and rockslides, but is easily accessible by foot lending itself to shoreline angling.

\section{Stocking History: None}

Angling Pressure: Very light

Other Nearby Lakes: Lower Copper Lake is the only lake in the near vicinity of Upper Copper Lake. Lower Copper Lake sits at a lower elevation of 6,858' and is passed while accessing Upper Copper Lake along the unmarked trail from the trailhead along USFS Road \#330, or it can be accessed from USFS Trail \#485, above the lake, by descending $245^{\prime}$ to the lake. Because of the lack of an established trail between the lakes, traveling is steep and difficult. 


\section{Upper Copper Lake: Biological \& Physical Information}

Date Sampled: 6/26-27/2006

Game Fish Present: Westslope Cutthroat Trout Other Fish Present: None

Size Captured: Mean 11.3 inches (range 6.1-15.4 inches)

Trout Condition Factor (Wr): No data

Amphibians Observed: Long-toed salamander
Water Code: $04-6363$

Sampling Methods: Sinking Gill Net Gill Net Catch Rate: 1.87 trout $/$ net/hr Natural Recruitment: Present

Genetics: $100 \%$ pure westslope cutthroat trout

Management Objectives: Status Quo

Currently Stocked: No Last Stocked: NA Species: NA Recommended Frequency: NA

Water Chemistry: pH: 8.19 TDS: 8 ppm Conductivity: 18 uS Secchi Depth: $36.8 \mathrm{ft}$
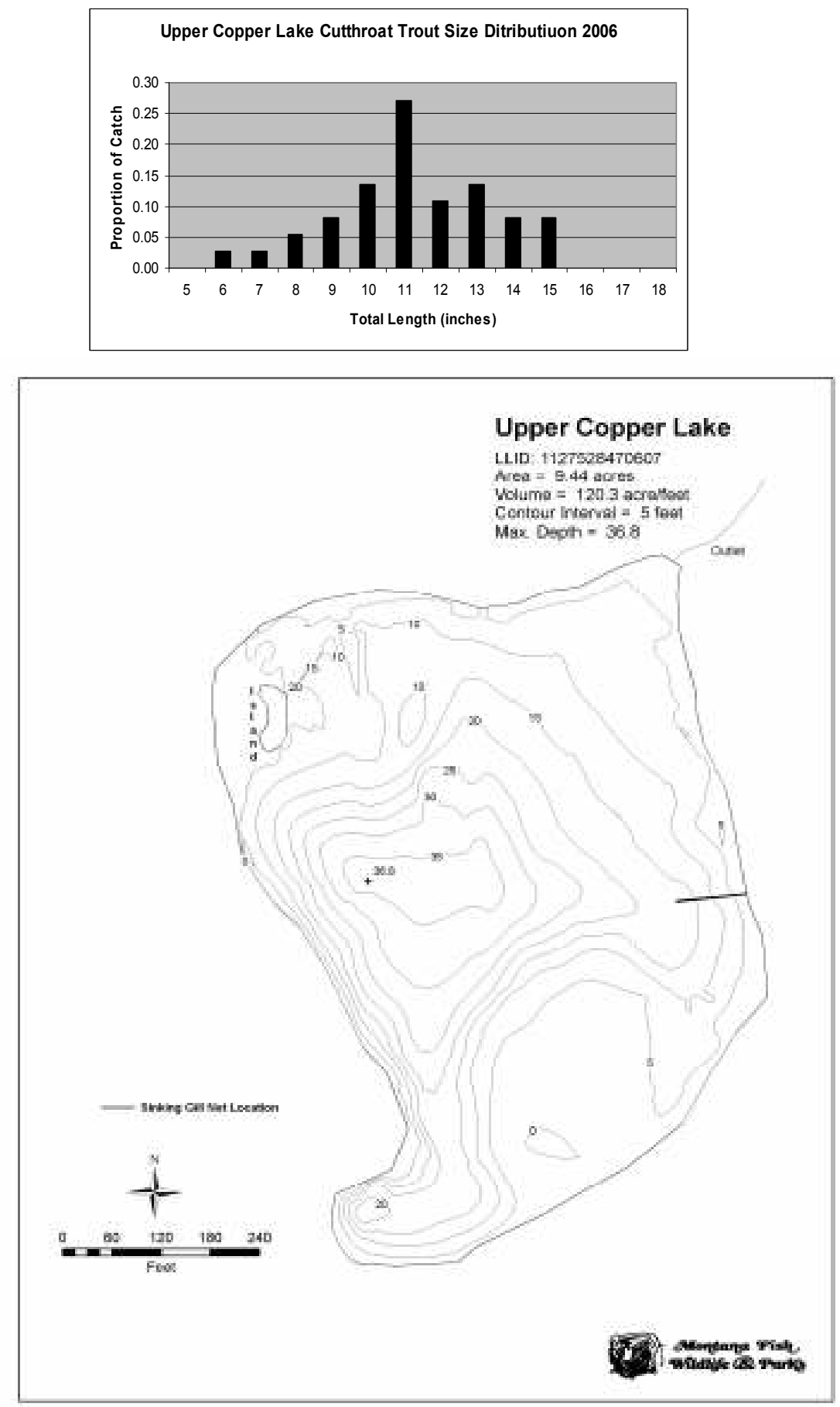


\section{Upper Cottonwood Lake}
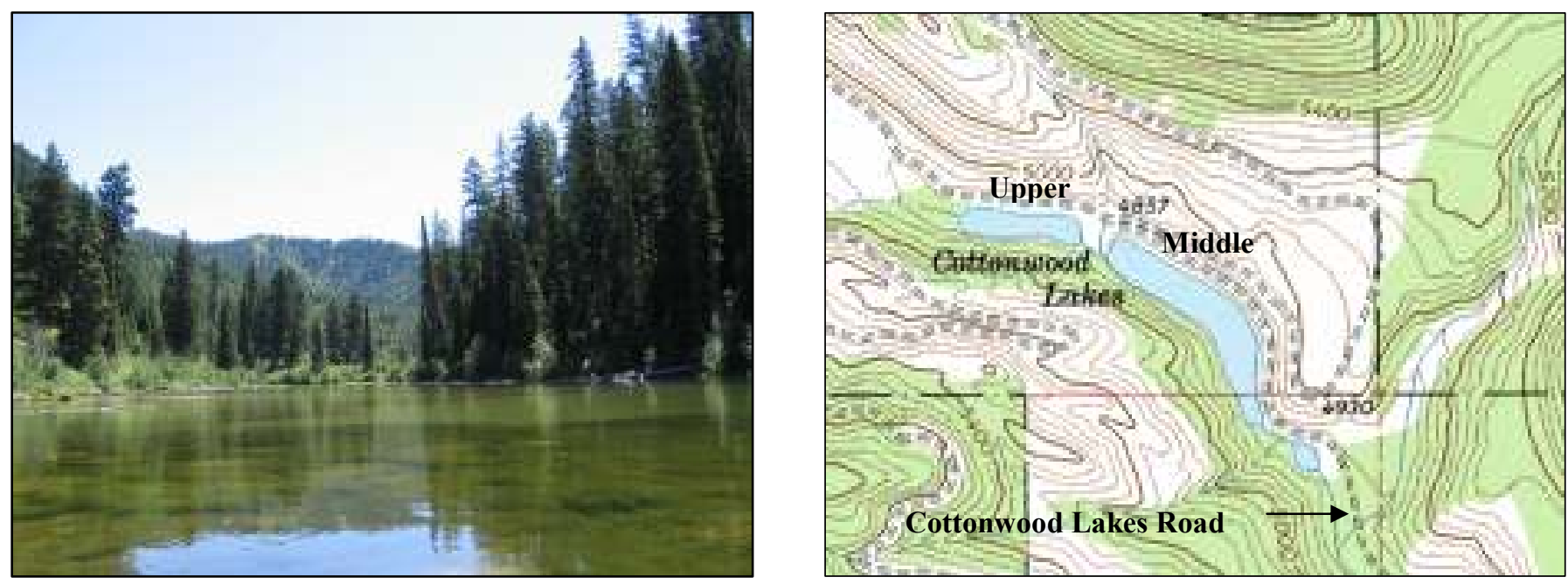

Description: Upper Cottonwood Lake is a shallow and small (4.15 acres) glacial valley trough lake located $\sim 1.5$ miles south-southwest of Morrell Mountain and 8.3 miles east-southeast of Seeley Lake. The lake lies within Lolo National Forest (Seeley Lake Ranger District) at 4,867' in the upper Cottonwood Creek drainage. Cottonwood Creek is a tributary to the middle Blackfoot River.

Location: T16N, R14W, Sections 3; Latitude N47.16783², Longitude W113.35612º ${ }^{\circ}$ earest Town: Seeley Lake.

Public Access: Upper Cottonwood Lake lies along USFS Road 477 (Cottonwood Lakes Road), which provides easy access to the lake. From Highway 83 in Seeley Lake, take USFS Road 477 (primary road) east 8.3 miles to the lake. From Highway 200, take Woodworth Road northwest 9.0 miles, then turn right (north) on USFS Road 9976 for 3.6 miles and then left (west) on USFS Road 4472.2 miles to the lake.

Camp Sites and Use: No camping areas were observed around Upper Cottonwood Lake. Because of the absence of a boat launch combined with a very brushy shoreline, the lake experiences light to moderate use.

Angling Opportunity: Upper Cottonwood Lake supports a small self-sustaining population of rainbow trout. The lake has also been planted with westslope cutthroat trout; however none were sampled during 2006 surveys. The majority of the north shoreline topography along USFS Road 477 is very brushy with alder and red osier dogwood. There are a few small areas that allow shoreline angling. The southern shoreline is steep, very brushy with alder and heavily timbered.

Stocking History: According to past fish planting records, rainbow trout were stocked only once in 1954. However, Upper Cottonwood Lake is connected to Middle Cottonwood Lake, which has been on the fish plant program.

Angling Pressure: From March 2005 to February 2006, angling pressure was estimated at 163 angler-days.

Other Nearby Lakes: Middle Cottonwood Lake also lies along USFS Road 477 (Cottonwood Lakes Road) immediately east, within 0.1 mile of Upper Cottonwood Lake. A half a mile east of Upper Cottonwood Lake is a small un-named lake. These three lakes are connected by a small first-order tributary stream, which then enters Cottonwood Creek. High water allows fish passage between the lakes. 
Date Sampled: 7/18-19/2006

Game Fish Present: Rainbow Trout

Other Fish Present: Redside shiners

Size Captured: Mean 13.3 inches (range $8.6-17.0$ inches)

Trout Condition Factor (Wr): Mean $96 \pm 6.6$ (range $87-108$ )

Amphibians Observed: Spotted Frogs (ẩults \& larvae), Painted Turtles

Management Objectives: Stop the WSCT plant and evaluate potential to convert to WSCT due to downstream hybridization risk to pure WSCT in Cottonwood Creek.

Currently Stocked: No Last Stocked: 2005 Species: WSCT Recommended Frequency: NA

Water Chemistry: pH: 8.96 TDS: 117 ppm Conductivity: $236 \mathrm{uS}$ Secchi Depth: $5.2 \mathrm{ft}$
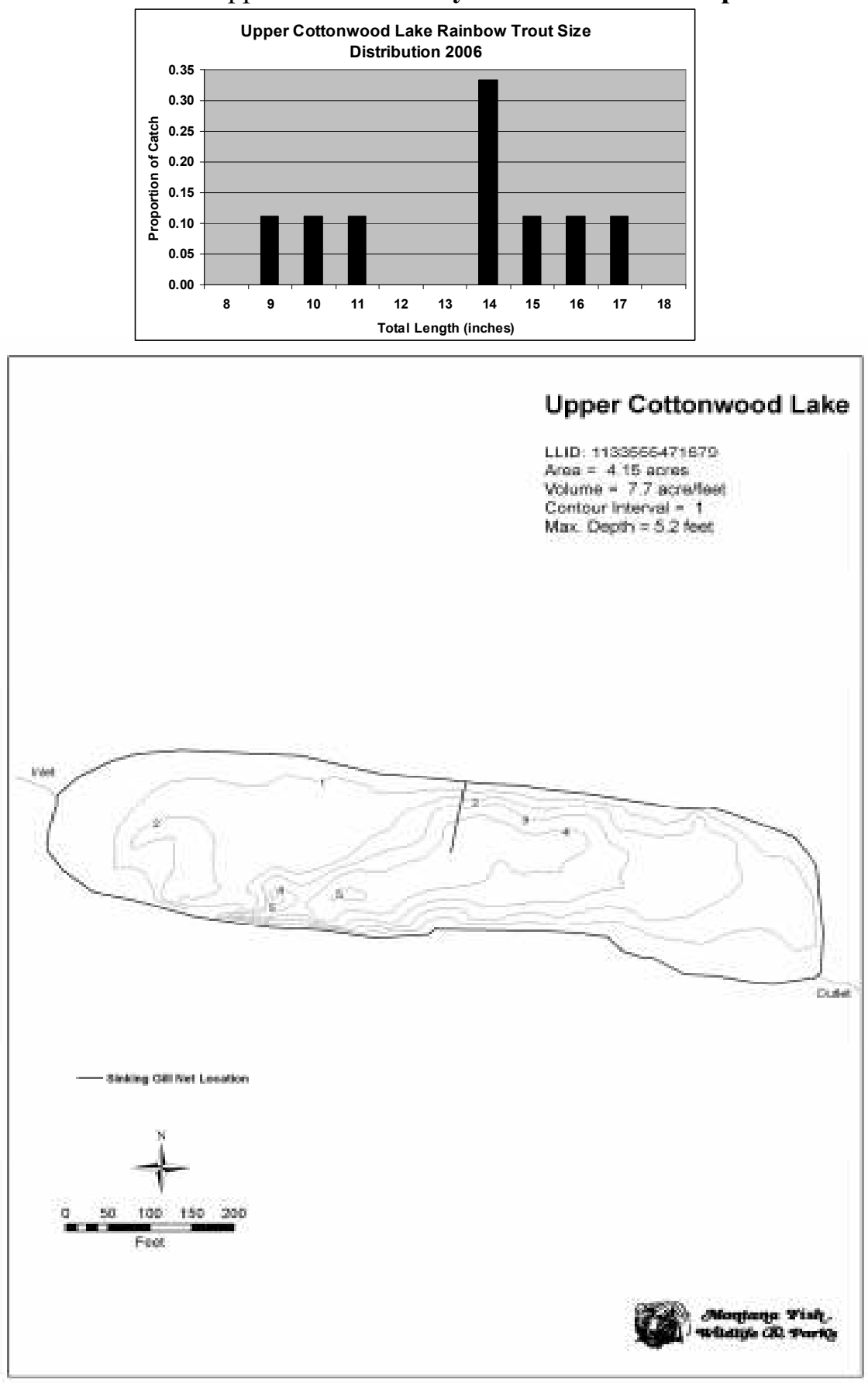


\section{Upper Twin Lake}
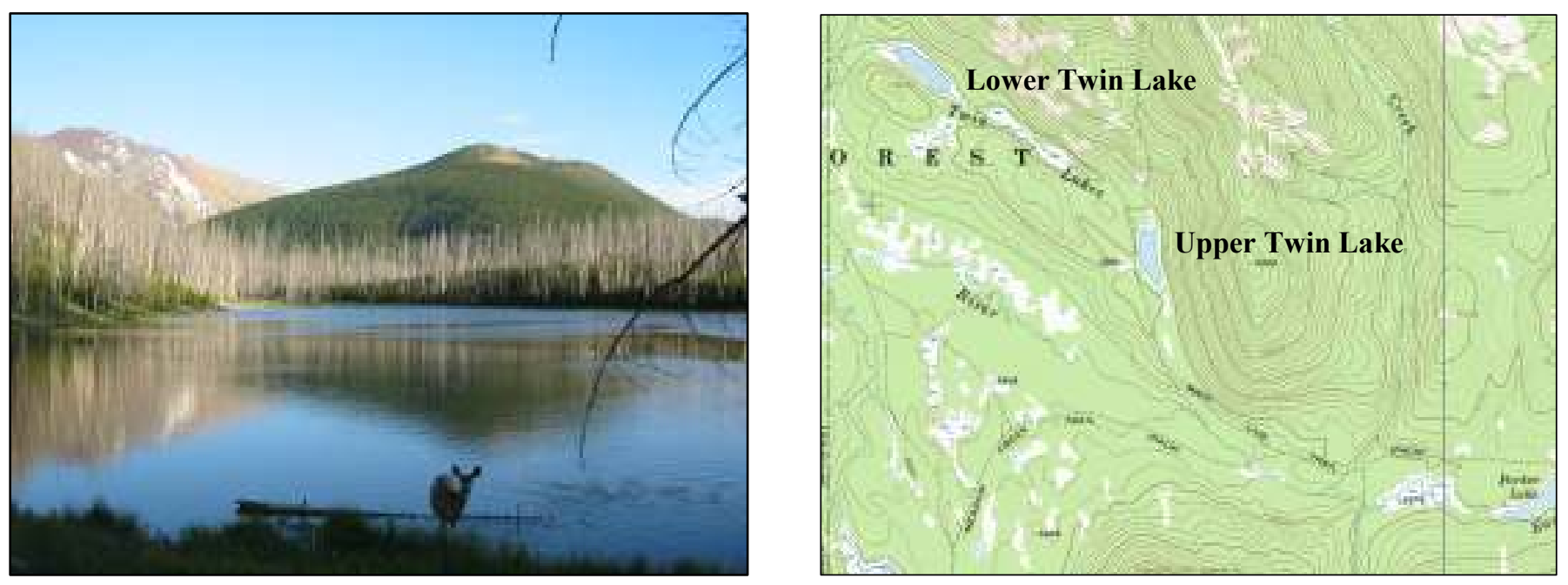

Description: Upper Twin Lake is a small (6.3 acres) glacial lake located $\sim 2.6$ miles east-northeast of Bugle Mountain and 2.5 miles south-southwest of Pyramid Peak within the Scapegoat Wilderness. The lake lies on the Helena National Forest (Lincoln Ranger District) at 5,967' in the East Fork of the North Fork Blackfoot River drainage.

Location: T16N, R9W, Sections 5 \& 8; Latitude N47.16432 , Longitude W112.77245º Nearest Town: Lincoln.

Public Access: There are two options to access to Upper Twin Lake: Option 1: From Meadow Creek Trailhead, east of Ovando, take USFS Trail \#483 (Meadow Creek Trail) 12 miles to its intersection with USFS Trail \#481 (Main Line Pack Trail) then travel $\sim 0.25$ miles northwest to the Twin Lakes Trail \#425 and follow it 0.6 miles to the lake. Option 2: From the Indian Meadows Trailhead, east of Lincoln in the Landers Fork and Copper Creek drainage, take the USFS Trail \#481 (Main Line Pack Trail) northwest 10.5 miles to the USFS Trail \#425 (Twin Lakes Trail) and follow it 0.6 miles to the lake. Both trails leading to Upper Twin Lake have a moderate degree of difficultly.

Camp Sites and Use: One primitive campsite was observed at Upper Twin Lake on the northern end of the lake near the small inlet stream. "Leave no trace" camping and recreating is essential in this wilderness area.

Angling Opportunity: Gill net surveys identified Upper Twin Lake as fishless.

Stocking History: Fish planting records show that Upper Twin Lake was stocked four times, beginning in 1943 with unspecified cutthroat trout. In 1969 and 1971, Yellowstone cutthroat were also planted. The most recent stocking occurred 1988 with westslope cutthroat trout.

\section{Angling Pressure: NA}

Other Nearby Lakes: In the vicinity of Upper Twin Lake is Lower Twin Lake located $\sim 0.9$ miles northwest along the Twin Lakes Trail \#425. If you accessed upper Twin Lake via the Main Line Pack Trail (USFS trail \#481) from the Indian Meadows Trailhead, you can retrace it back approximately 2.0 miles southeast to Parker Lake. If you accessed Upper Twin Lake area using the Meadow Creek Trailhead (USFS Trail \#483), Meadow Lake is 2.9 miles southwest of Upper Twin Lake on the return trip to the trailhead. 
Date Sampled: 6/20/2005

Game Fish Present: None

Other Fish Present: None

Size Captured: NA

Trout Condition Factor (Wr): NA
Water Code: $04-7530$

Sampling Methods: Sinking Gill Net

Gill Net Catch Rate: NA

Natural Recruitment: NA

Amphibians Observed: Spotted frogs (adults)

Management Objectives: The lake can not sustain natural reproduction and appears marginal from the perspective of winter survival. Recommend the lake remain fishless.

Currently Stocked: No Last Stocked: 1988 Species: WSCT Recommended Frequency: NA

Water Chemistry: pH: 8.57 TDS: 150 ppm Conductivity: $300 \mathrm{uS}$ Secchi Depth: $10.4 \mathrm{ft}$

Stocking History

\begin{tabular}{|c|c|c|}
\hline Year & Species & \# Stocked \\
\hline 1988 & WSCT & 3,990 \\
\hline 1971 & YCT & 1,035 \\
\hline 1969 & YCT & 990 \\
\hline 1943 & CT & 4,000 \\
\hline
\end{tabular}

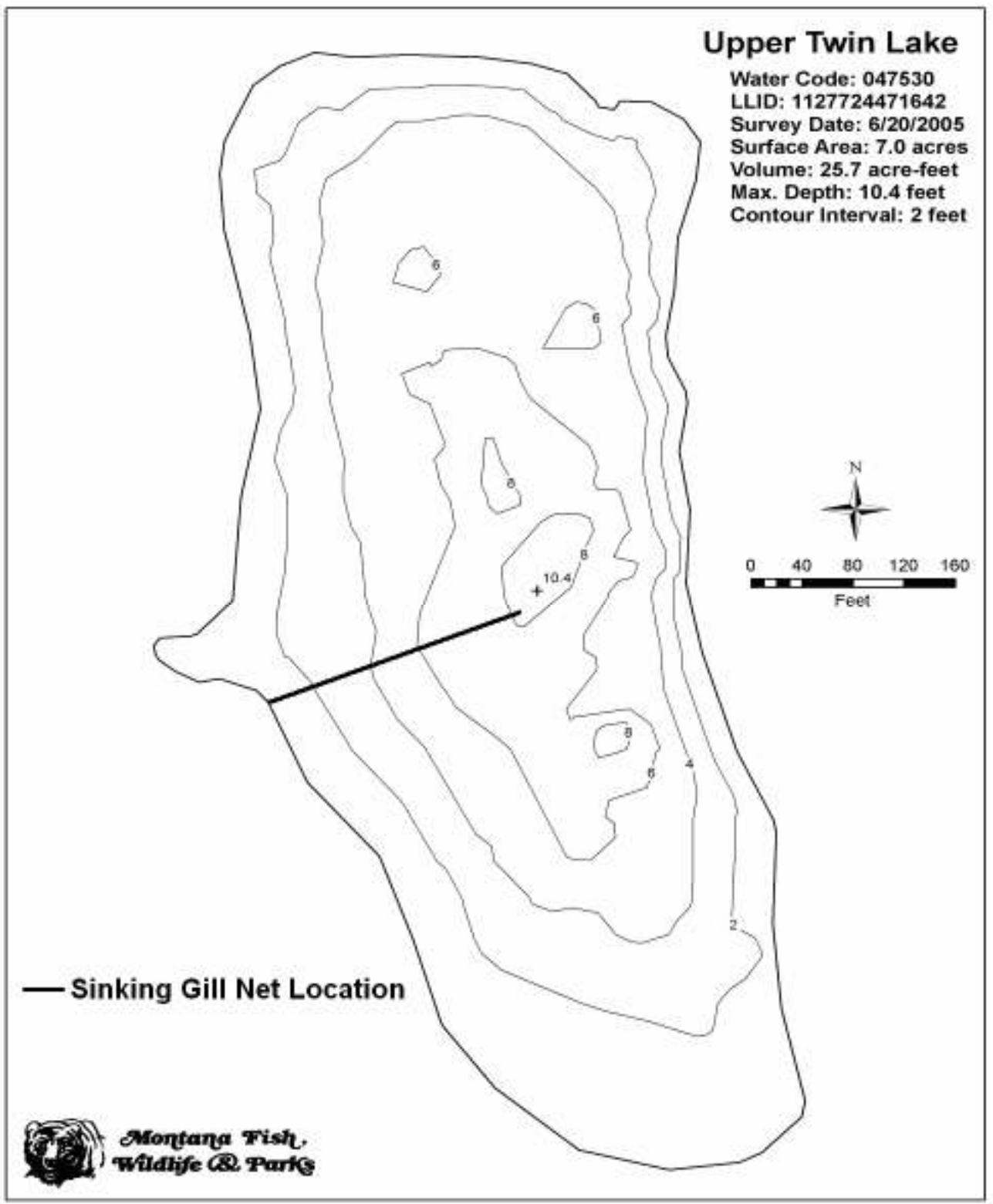




\section{Upsata Lake}
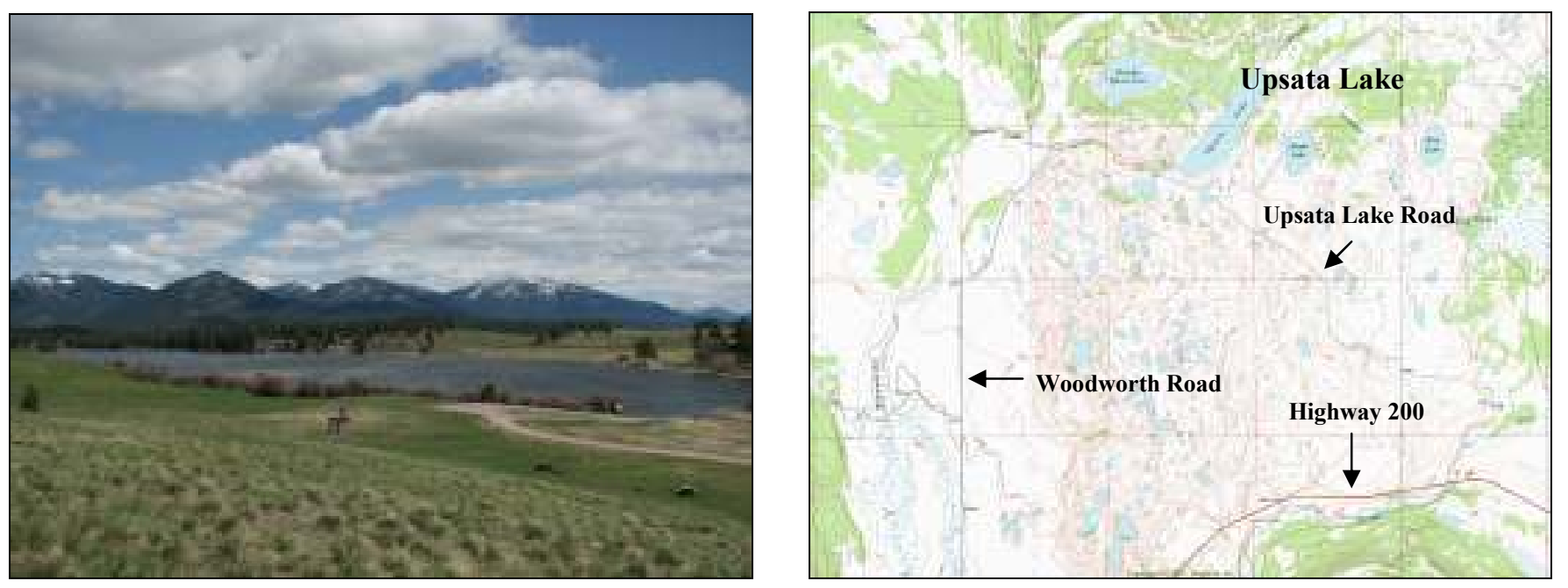

Description: Upsata Lake is a 90.6 acre glacial "pothole" lake (elevation of 4,130') located in the "knob-kettle" topography of the middle Blackfoot River watershed. Upsata Lake is 6.1 miles south of Dunham Point and $~ 11.2$ miles east-northeast of Ovando.

Location: T15N, R13W, Sections 2, 3 \& 10; Latitude N47.07795 ${ }^{\circ}$, Longitude W113.22162 ${ }^{\circ}$; Nearest Town: Ovando.

Public Access: Upsata Lake lies along Upsata Lake Road, which is easily accessed from the Woodworth Road. From Highway 200, take Woodworth Road northwest 3.3 miles, then turn right (east) on Upsata Lake Road for 0.9 miles to the Upsata Lake Fishing Access Site.

Camp Sites and Use: Four campsites and a boat launch are located at the Upsata Lake Fishing Access Site. These camp sites receive moderate to heavy use.

Angling Opportunity: Upsata Lake supports an abundant population of "stunted" yellow perch and low numbers of largemouth bass and northern pike. Upsata Lake is surrounded by private property with the exception of the Fishing Access Site at the southwest end of the lake.

Stocking History: From 1959 to 1992, Upsata Lake was on a yearly stocking schedule of rainbow trout. Starting in the early 1990's, largemouth bass were also stocked annually to curb rising populations of yellow perch that were illegally introduced. Upsata Lake is now periodically supplemented with adult largemouth bass.

Angling Pressure: From March 2005 to February 2006 angling pressure estimated at 770 angler-days per year.

Other Nearby Lakes: The Cottonwood Lakes lie along USFS Road 477 (Cottonwood Lakes Road) to the northwest of Upsata Lake approximately 12.0 miles. Browns Lake is southeast of Upsata Lake 18.2 miles and can be accessed from Highway 200, east of Ovando, or from the Ovando-Helmville Road, south of Ovando. 
Date Sampled: 8/7/2006, 4/24/2007 and 5/2/2007

Game Fish Present: Yellow Perch, Largemouth Bass and Northern Pike Other Fish Present: Redside shiners

Size Captured: NA

Trout Condition (Wr): NA

Amphibians Observed: Spotted Frogs (adults) and Painted Turtles
Water Code: 04-7560

Sampling Methods: NA

Gill Net Catch Rate: NA

Natural Recruitment: Present

Management Objectives: Status quo

Currently Stocked: No Last Stocked: 1992 Species: LMB Recommended Frequency: NA

Water Chemistry: pH: 8.26 TDS: 197 ppm Conductivity: 394 uS Secchi Depth: $11.8 \mathrm{ft}$ Stocking History

Histogram: No Data

\begin{tabular}{|c|c|c|}
\hline Year & Species & \# Stocked \\
\hline $1988-1991$ & LMB & 3,613 \\
\hline $1959-1992$ & RBT & 371,921 \\
\hline
\end{tabular}

\section{Lake Upsata}

LLID: 1128304467883

Area $=90.6$ acres

Volume $=1,185$ acre/feet

Contour Interval $=5$ feet

Max. Depth $=43$ feet
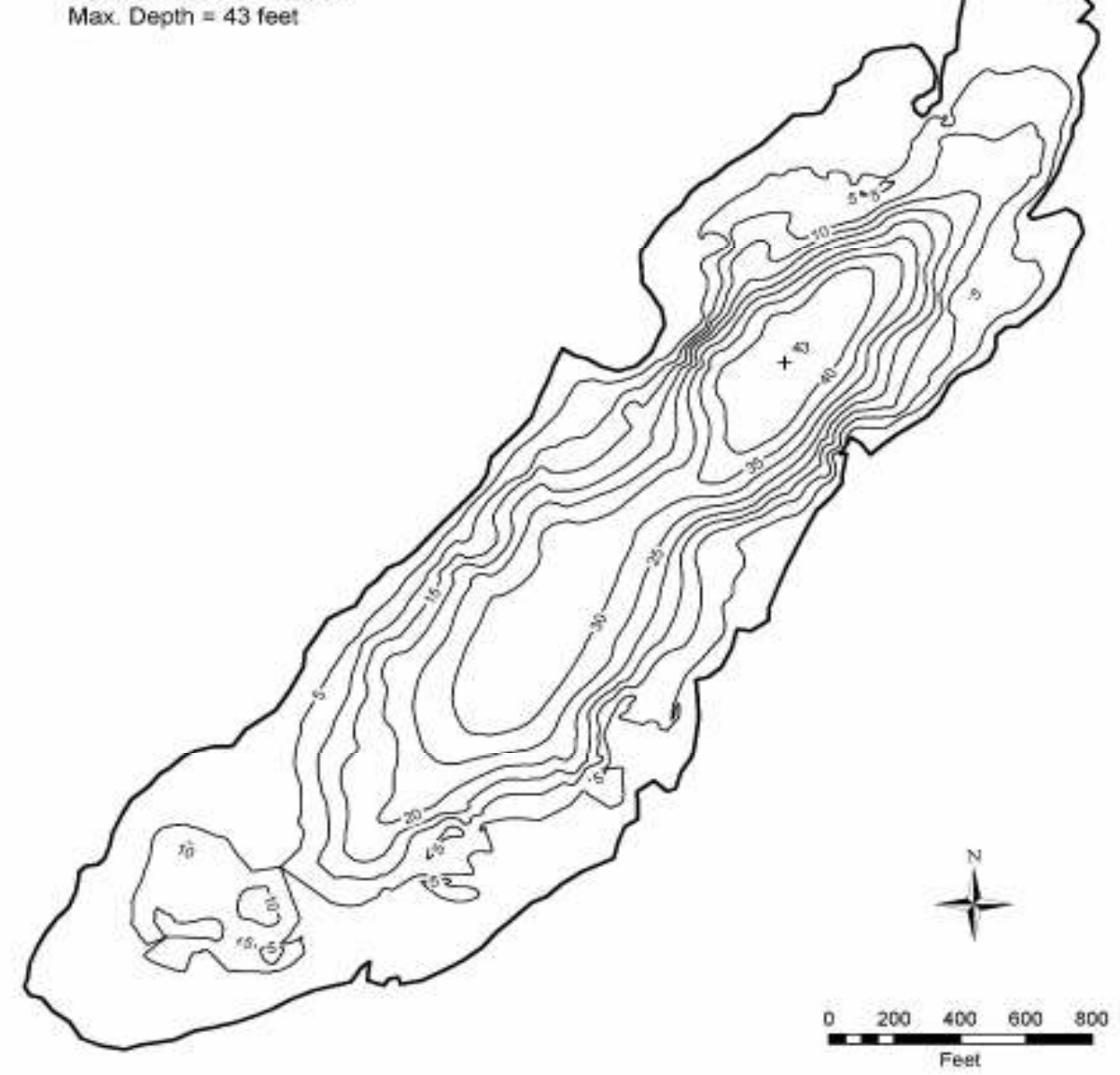


\section{Webb Lake}
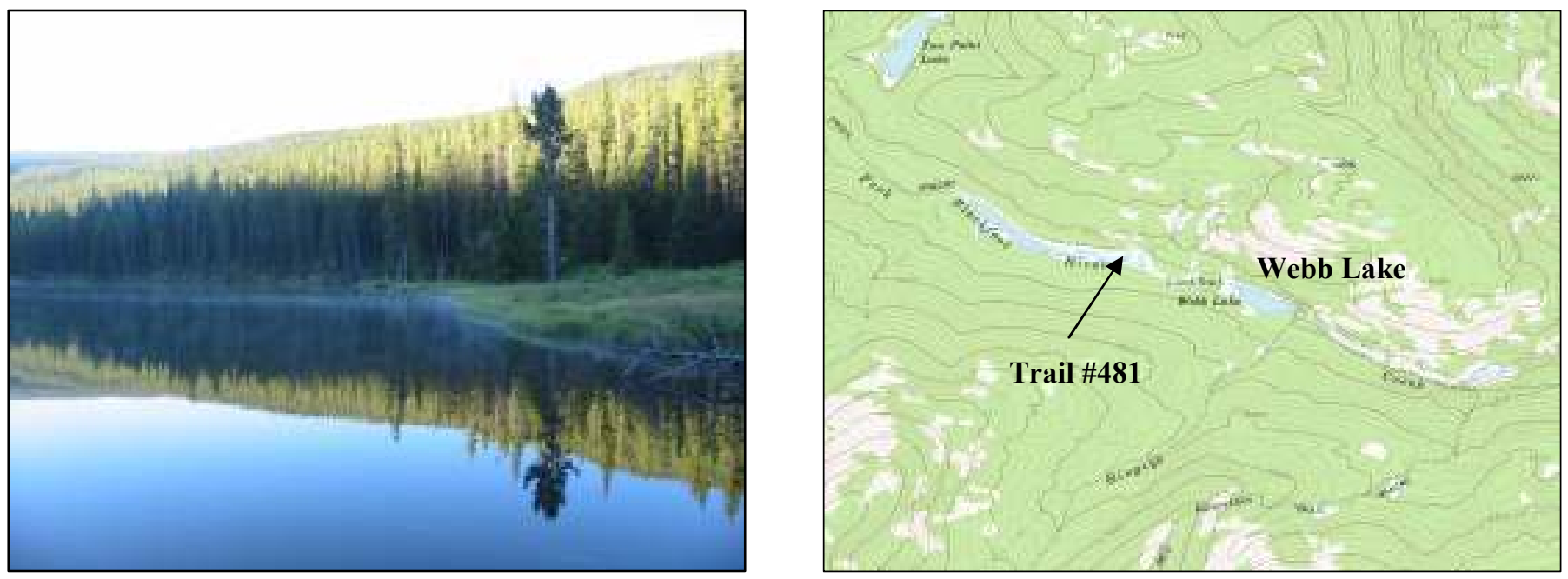

Description: Webb Lake is a shallow (24.7 acres) glacial valley trough lake located $\sim 2.8$ miles northeast of Red Mountain at an elevation of 6,079'. The lake lies within the Scapegoat Wilderness, Helena National Forest (Lincoln Ranger District). Its outlet flows into Ringeye Creek, a tributary to the Landers Fork of the Blackfoot River.

Location: T16N, R9W, Sections 14; Latitude N47.14522 ${ }^{\circ}$ Longitude W112.69466 ${ }^{\circ}$; Nearest Town: Lincoln.

Public Access: Access to Webb Lake can be obtained by taking Highway 200 east from Lincoln 6.2 miles to the Copper Creek Road. Follow the Copper Creek Road 10.2 miles to the Indian Meadows Trailhead. From the trailhead follow USFS Trail \#481 (Main Line Pack Trail) 6.5 miles to Webb Lake. The trail is in very good condition with moderate difficultly.

Camp Sites and Use: Because of its relatively short distance within the Scapegoat Wilderness boundary on a well maintained trail system, Webb Lake receives relatively heavy recreational use. Camping opportunities exist in the vicinity of the inlet (near USFS Webb Lake Guard Station) located at the northwest end of the lake. Pack stock is not allowed within $200 \mathrm{ft}$ of the shore except on the trail. "Leave no trace" camping and recreating is essential in this wilderness area.

Angling Opportunity: Webb Lake supports a small hybrid cutthroat trout population through natural reproduction. Many areas of the shoreline topography are brushy with sedges and rushes extending out into the lake. The adjacent topography is heavily timbered with moderately steep slopes; however, there are areas that lend well to shoreline angling.

Stocking History: Webb Lake was stocked with undifferentiated cutthroat trout between 1940 and 1952.

Angling Pressure: Moderate

Other Nearby Lakes: In the vicinity of Webb Lake are three other lakes. Approximately 4.8 miles from the Indian Meadows Trailhead, Heart Lake lies along a short spur trail (USFS Trail \#424) that branches off the Main Line Pack Trail (USFS Trail \#481) at trail mile 3.9 then reconnects back into the Main Line Pack Trail at mile 4.8, 2.1 trail miles to the southeast of Webb Lake. Continuing northwest along USFS Trail \#481 west of Webb Lake, but 0.6 miles before Parker Lake, Two Point Lake is 0.5 miles north of the Main Line Pack Trail along USFS Trail \#479. Parker Lake lies 2.3 miles west of Webb Lake along USFS Trail \#481, or 7.0 miles from Indian Meadows Trailhead. Travel is moderately difficult to these other lakes. 


\section{Webb Lake: Biological \& Physical Information}

Date Sampled: 7/19/2005

Game Fish Present: Hybridized Westslope Cutthroat Trout

Other Fish Present: None

Size Captured: Mean 8.5 inches (range $6.4-14.5$ inches)

Trout Condition Factor (Wr): Mean $90 \pm 14.6$ (range $67-106$ )

Genetics: Westslope cutthroat trout hybridized with rainbow trout.
Water Code: $04-7590$

Sampling Methods: Sinking Gill Net Gill Net Catch Rate: 0.15 trout $/$ net $/ \mathrm{hr}$ Natural Recruitment: Present (limited) Amphibians Observed: Spotted Frogs

Management Objectives: Recommend no change

Currently Stocked: No Last Stocked: 1952 Species: CT Recommended Frequency: NA

Water Chemistry: pH: 9.25 TDS: 109 ppm Conductivity: $216 \mathrm{uS}$ Secchi Depth: $5.4 \mathrm{ft}$

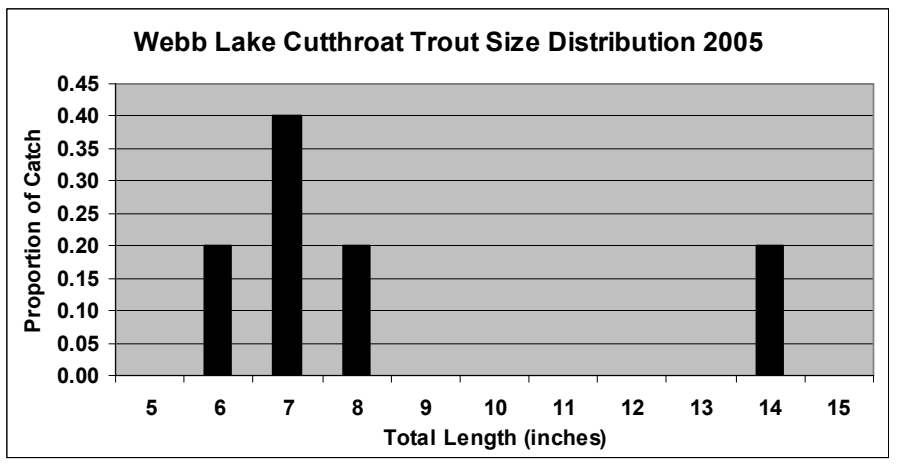

Stocking History

\begin{tabular}{|c|c|c|}
\hline Year & Species & \# Stocked \\
\hline $\mathbf{1 9 4 0 - 1 9 5 2}$ & CT & $\mathbf{3 4 , 4 8 5}$ \\
\hline
\end{tabular}

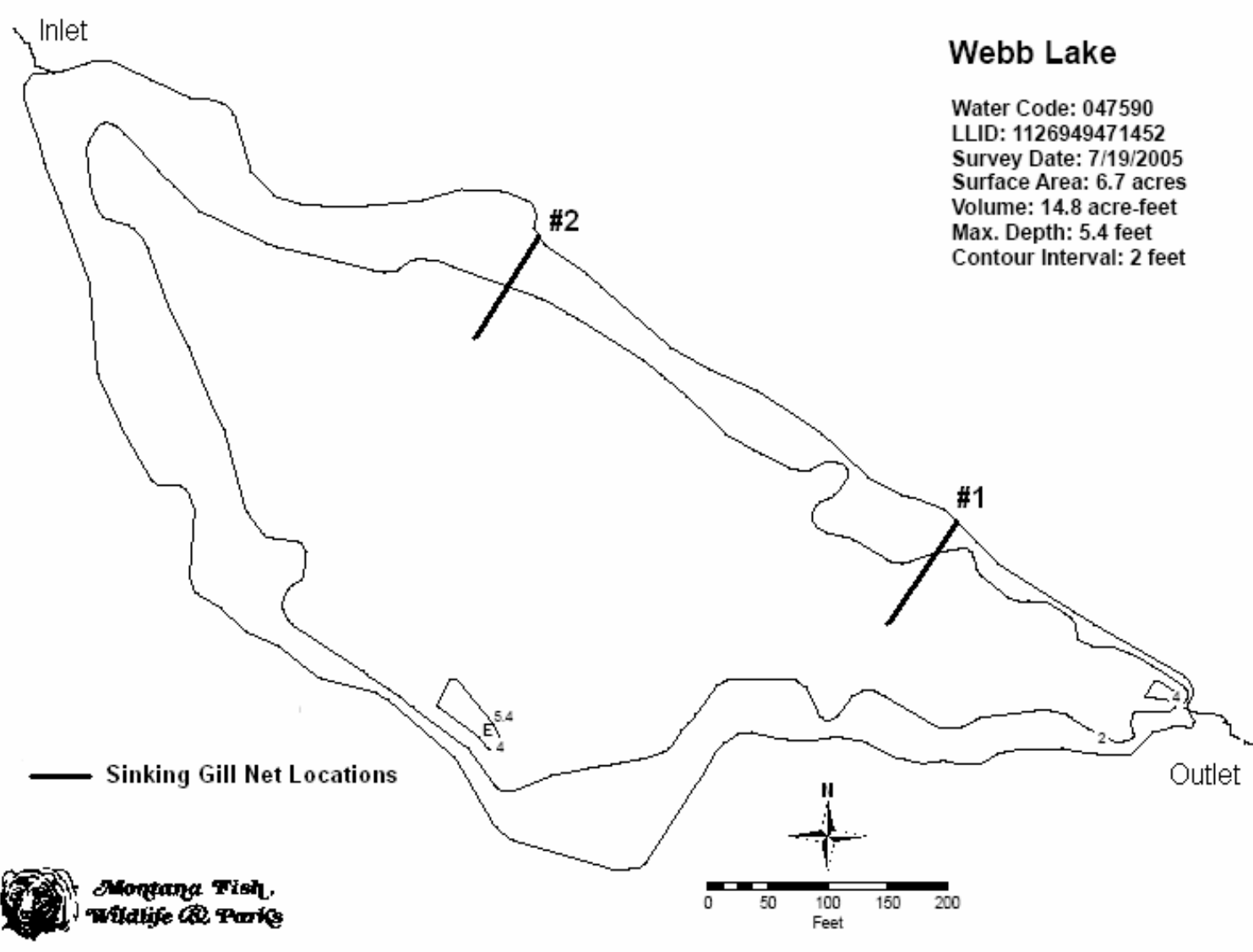




\section{RECOMMENDATIONS}

- Identify a sustainable fisheries technician-funding source in order to continue the current FWP fisheries restoration program at the level outlined in this report. The need stems from the loss of the Milltown Mitigation Funds in 2009.

- Encourage watershed groups and resource agencies that promote and develop fisheries restoration and grazing plans to implement a grazing monitoring plan to better ensure fisheries restoration projects are successful.

- Expand on the ground restoration to the Clearwater River Basin with support provided through watershed groups including the Blackfoot Challenge, Big Blackfoot Chapter of Trout Unlimited, Clearwater Resource Council as well as other supporting agencies and organizations.

- Complete restoration projects in all bull trout "core areas" and current restoration streams. Expand restoration to the upper Blackfoot and Clearwater Basin with emphasis placed on native fish priority streams.

- Continue to monitor the spread and impacts of whirling disease and the results of restoration on infection rates. Examine the susceptibility of whirling disease on mountain whitefish. Incorporate pertinent results into the restoration program.

- Increase landscape protection on critical fish and wildlife habitat in cooperation with the Montana Land Reliance, Nature Conservancy, US Fish and Wildlife Service, Montana Fish, Wildlife and Parks, Blackfoot Challenge and Plum Creek Timber Company and extend protective measures to critical waters in the Clearwater River Basin.

- Continue fish populations monitoring at the Johnsrud and Scotty Brown Bridge section of the Blackfoot River, and major tributary restoration projects as funding allows.

- Examine methods of converting rainbow trout above the North Fork Falls to WSCT.

- Increase FWP enforcement efforts in bull trout spawning and staging areas. Initiate additional bull trout regulation protection measures as necessary

- Complete the cleanup of the Mike Horse mine in a manner that allows the recolonization of WSCT, and develop a post-project monitoring program that measures metal uptake in aquatic biota. 


\section{ACKNOWLEDGEMENTS}

The 2006-07 fisheries fieldwork was made possible through a Northwestern Energy (Milltown Mitigation) grant, for which we especially thank Sam Milodragovich and the Milltown Technical Advisory Committee. We extend our thanks to the Backcountry Horsemen (Randy Kappas and Kirk Sybrant) and the U.S. Forest Service (Helena and Lolo National Forests) for assisting with the backcountry work. The whirling disease work was made possible with the help of Dr. Lisa Eby (University of Montana), Wease Bollman (Rhrithron Associates), Dick Vincent (FWP) and David Kumlien (the Whirling Disease Foundation). The Big Blackfoot Chapter of Trout Unlimited helped fund the writing of this report. Both Ryen Aasheim (BBCTU) and Linneae Schroeer-Smith (FWP) helped improve the quality of this report. We extend a special thanks to all the landowners that cooperated with data collections, restoration projects and allowed us access to streams during the 2006 and 2007 field seasons. 


\section{LITERATURE CITED}

Anderson, R. A. 2004. Occurrence and seasonal dynamics of the whirling disease parasite, Myxobolus cerebralis, in Montana spring creeks. Master of Science thesis, Montana State University, Bozeman.

Baldwin, T. J., E. R. Vincent, R. M. Silflow, D. Stanek. 2000. Myxobolus cerebralis infection in RBT (Oncorhynchus mykiss) and brown trout (Salmo trutta) exposed under natural stream conditions. Journal of Veterinary Diagnostic Investigations 12:312-321.

Brown, C., G. Decker, R. Pierce and T. Brant. 2001. Applying natural channel design philosophy to the restoration of instating native fish habitat. Practical approaches to conserving inland native fish, Western Division AFS Symposium, Missoula, Montana.

Dunne, T., and L. B. Leopold. 1978. Water in Environmental Planning. Freeman and Co. New York.

Fish Analysis Plus (FA+) Montana Fish, Wildlife and Parks fisheries software.

Fitzgerald G. 1997. Analysis and inventory of riparian vegetation along Nevada and Monture Creeks using ADAR imagery. MS. Thesis University of Montana, Missoula.

Fredenberg, F. 1992. Evaluation of electrofishing-induced spinal injuries resulting from field electrofishing surveys in Montana. Montana Department of Fish, Wildlife and Parks, Bozeman, Montana.

Leathe, S. 1983. Inter-office memo of the two-pass depletion estimator. Montana Fish, Wildlife and Parks, Helena.

Lewis, M. 1805. Lewis and Clark Expedition journal entry 13 June.

Lockwood R.N. and J. C. Schneider. 2000. Stream fish population estimates by mark-and-recapture and depletion methods. Chapter 7 in Schneider, James C. (ed.) 2000. Manual of fisheries survey methods II: with periodic updates. Michigan Department of Natural Resources, Fisheries Special Report 25, Ann Arbor.

McIntyre, J. D., and B. E. Reiman. 1995. Westslope WSCT. Pages 1-15 in M. K. Young, editor. Conservation assessment for inland WSCT. U. S. Forest Service General Technical Report. RM-256.

Nehring, R. B., and J. P. Goettl Jr. 1974. Acute toxicity of a zinc-polluted stream to four species of salmonids. Bulletin of Environmental Contamination and Toxicology 12(4):464-469.

Peters, D. J. and R. Spoon. 1989. Preliminary inventory of the Big Blackfoot River. Montana Department of Fish, Wildlife and Parks, Missoula, Montana.

Peters, D. J. 1990. Inventory of fishery resources in the Blackfoot River and major tributaries of the Blackfoot River. Montana Fish Wildlife and Parks, Missoula, Montana.

Pierce R. and D. J. Peters. 1991. Aquatic investigation in the middle Blackfoot River, Nevada Creek and Nevada Spring Creek corridor. Montana Department of Fish, Wildlife and Parks, Bozeman, Montana.

Pierce, R. 1991. A stream habitat and fisheries analysis for six tributaries to the Blackfoot River. Montana Department of Fish, Wildlife and Parks, Missoula, Montana.

Pierce, R., D. Peters and T. Swanberg. 1997. Blackfoot River restoration progress report. Montana Fish Wildlife and Parks, Missoula, Montana.

Pierce, R., and D.A. Schmetterling. 1999. Blackfoot River restoration project progress report, 1997-1998. Montana Fish, Wildlife and Parks, Missoula, Montana.

Pierce, R. and C. Podner. 2000. Blackfoot River fisheries inventory, monitoring and restoration report. Montana Fish, Wildlife and Parks, Missoula, Montana.

Pierce, R. C. Podner and J. McFee. 2001. Blackfoot River fisheries inventory, monitoring and restoration report. Montana Fish, Wildlife and Parks, Missoula, Montana.

Pierce, R., C. Podner and J. McFee. 2002. The Blackfoot River fisheries inventory, restoration and monitoring progress report for 2001. Montana Fish, Wildlife and Parks, Missoula, Montana.

Pierce, R., R. Anderson and C. Podner. 2004. The Big Blackfoot River Restoration Progress Report for 2002 and 2003. Montana Fish Wildlife and Parks, Missoula Montana.

Pierce, R., R. Aasheim and C. Podner. 2005. An integrated stream restoration and native fish conservation strategy for the Big Blackfoot River basin. Montana Fish Wildlife and Parks, Missoula, Montana.

Pierce, R and C. Podner. 2006. The Big Blackfoot River Fisheries Restoration Report for 2004 and 2005. Montana Fish, Wildlife and Parks, Missoula, Montana.

Pierce, R., R. Aasheim and C. Podner. 2007. Fluvial westslope cutthroat trout movements and restoration relationships in the upper Blackfoot Basin, Montana. Intermountain Journal of Sciences Vol. 13(2). 
Reiman. B., E, and D. Isaak, S. Adams, D. Horan, D. Nagel, C. Luce and D. Myers. 2007. Anticipated climate warming effects on bull trout habitats and populations across the interior Columbia River basin. Transactions of the American Fisheries Society, 13:1552-565.

Ricker, W. E. 1975. Computation and interpretation of biological statistics of fish populations. Bulletin of the Fisheries Research Board of Canada, Bulletin 191. Ottawa, Canada.

Rosgen, D. 1994. A classification of natural rivers. Catena 22:169-199.

Rosgen, D. 1996. Applied Fluvial Geomorphology. Wildland Hydrology, Pagosa Springs Colorado.

Schmetterling, D.A. 2003. Reconnecting a fragmented river: movements of westslope cutthroat trout and bull trout after transport upstream of Milltown Dam, Montana. North American Journal of Fisheries Management 23:721-731.

Schmetterling, D. A. 2001. Seasonal movements of fluvial westslope cutthroat trout in the Blackfoot River drainage, Montana. North American Journal of Fisheries Management 21: 507-520.

Shepard, B. B., B. E May and W. Urie. 2003. Status of westslope cutthroat trout (Onchorhunchs clarki lewisi) in the United States: 2002. A report to the Westslope Cutthroat Interagency Conservation Team.

Shepard, B. B., B. E May and W. Urie. 2005. Status and conservation of westslope cutthroat trout within the Western United States. North American Journal of Fisheries Management 25:1426-1440.

Spence, L. E. 1975. Upper Blackfoot River study: A premining inventory of aquatic and wildlife resources. Montana Department of Fish and Game \& the Anaconda Mining Company. $86 \mathrm{pp}+$ appendices.

Stratus Consulting. 2007. Preliminary evaluation of injuries and damages: Upper Blackfoot Mining Complex, Lewis and Clark County, Montana, A report to the Natural Resources Damage Claim, Montana Department of Justice, Helena, MT.

Swanberg, T. R. 1997. Movement of and Habitat Use by Fluvial Bull Trout in the Blackfoot River, Montana. Transactions of the American Fisheries Society 126:735-746.

Vincent, E. R. 2000. Whirling disease report 1997-98. Montana Fish, Wildlife and Parks. Project 3860. Helena, Montana.

Vincent, E. R. 2002. Relative susceptibility of various salmonids to WD with emphasis on rainbow and cutthroat trout. WD: reviews and current topics. American Fisheries Society Symposium 29:109-115. 


\section{APPENDICES}

Appendix A: Summary of catch and size statistics for Blackfoot tributaries, 2006-07.

Appendix B: Summary of two-pass estimates for Blackfoot tributaries, 2006-07.

Appendix C: Mark and recapture estimates for the Blackfoot River, 2006.

Appendix D: Summary of stream discharge measurements for 2006-07.

Appendix E: Restoration streams and table of activities through 2007.

Appendix F: Potential restoration projects in the Blackfoot drainage through 2007.

Appendix G: Restoration streams and cooperators through 2007.

Appendix H: Summary of water temperature in the Blackfoot drainage, 2006-07.

Appendix I: Summary of water chemistry readings for 2006 and 2007.

Appendix J: Westslope cutthroat trout genetic sampling sites and results, 2006-07

Appendix K: Blackfoot Basin restoration prioritization scorecard though 2007 
Appendix A : Catch and size statistics for tributaries to the Blackfoot River excluding the Clearwater Basin, 2006-2007.

\begin{tabular}{|c|c|c|c|c|c|c|c|c|c|c|c|c|}
\hline Stream & $\begin{array}{l}\text { River } \\
\text { Mile }\end{array}$ & Location $(T, R, S)$ & $\begin{array}{c}\text { Date } \\
\text { Sampled }\end{array}$ & $\begin{array}{l}\text { Section } \\
\text { Length (ft) }\end{array}$ & Species & $\begin{array}{l}\text { Total Number } \\
\text { Captured }\end{array}$ & $\begin{array}{c}\text { Number } \\
\text { Captured 1st } \\
\text { Pass }\end{array}$ & $\begin{array}{c}\text { YOY(<4.0") } \\
\text { Captured 1st } \\
\text { Pass }\end{array}$ & $\begin{array}{c}\text { Range of } \\
\text { Lengths (in) }\end{array}$ & $\begin{array}{c}\text { Mean } \\
\text { Length (in) }\end{array}$ & $\begin{array}{c}\text { CPUE (\#/100') } \\
\text { in 1st Pass }\end{array}$ & $\begin{array}{l}\text { YOY CPUE } \\
\left(\# / 100^{\prime}\right) \text { in 1st } \\
\text { Pass }\end{array}$ \\
\hline \multirow[t]{3}{*}{ Anaconda Creek } & 0.1 & $15 \mathrm{~N}, 6 \mathrm{~W}, 27 \mathrm{~B}$ & 25-Jul-06 & 330 & $\mathrm{CT}$ & 4 & 4 & 0 & 5.2 & $4.9-5.8$ & 1.2 & 0.0 \\
\hline & & & & & $\mathrm{EB}$ & 1 & 1 & 0 & 5.5 & 5.5 & 0.3 & 0.0 \\
\hline & 0.5 & $15 \mathrm{~N}, 6 \mathrm{~W}, 22 \mathrm{C}$ & 25-Jul-06 & 346 & $\mathrm{CT}$ & 46 & 46 & 26 & 3.8 & $2.0-8.8$ & 13.3 & 7.5 \\
\hline \multirow[t]{10}{*}{ Ashby Creek } & 2 & $13 \mathrm{~N}, 16 \mathrm{~W}, 26 \mathrm{~A}$ & 9-Aug-07 & 390 & No fish & found & & & & & & \\
\hline & 3 & $13 \mathrm{~N}, 16 \mathrm{~W}, 35 \mathrm{~B}$ & 31-Jul-06 & 300 & $\mathrm{CT}$ & 75 & 59 & 34 & $1.5-8.4$ & 3.1 & 19.7 & 11.3 \\
\hline & & & & & EB & 1 & 1 & 0 & 5.1 & 5.1 & 0.3 & 0.0 \\
\hline & & & & & Sculpins & present & Spotted frogs & present & & & & \\
\hline & & & 9-Aug-07 & 351 & No fish & found & Observed & Spotted frogs & & & & \\
\hline & 4 & $12 \mathrm{~N}, 16 \mathrm{~W}, 3 \mathrm{~A}$ & 31-Jul-06 & 300 & CT & 79 & 62 & 30 & $1.4-7.5$ & 4.1 & 20.7 & 10.0 \\
\hline & & & & & $\mathrm{EB}$ & 2 & 2 & 0 & $2.0-2.1$ & 2.1 & 0.7 & 0.0 \\
\hline & & & & & Sculpins & present & Spotted frogs & present & & & & \\
\hline & & & 9-Aug-07 & 300 & $\mathrm{CT}$ & 122 & 97 & 49 & $1.4-7.6$ & 4 & 32.3 & 16.3 \\
\hline & & & & & $\begin{array}{c}\text { EB } \\
\text { Sculpins }\end{array}$ & $\begin{array}{c}27 \\
\text { present }\end{array}$ & $\begin{array}{c}22 \\
\text { Spotted frogs }\end{array}$ & $\begin{array}{c}21 \\
\text { present }\end{array}$ & $2.0-5.6$ & 2.6 & 7.3 & 7.0 \\
\hline Bear Creek & 1.1 & $13 \mathrm{~N}, 16 \mathrm{~W}, 18 \mathrm{~B}$ & 2-Aug-06 & 374 & $\mathrm{RB}$ & 241 & 180 & 141 & $1.0-7.5$ & 2.5 & 48.1 & 37.7 \\
\hline \multirow[t]{7}{*}{ lower river trib. } & & $13 \mathrm{~N}, 16 \mathrm{~W}, 7 \mathrm{C}$ & & & СT & 2 & 2 & 0 & $4.3-6.0$ & 5.1 & 0.5 & 0.0 \\
\hline & & & & & LL & 15 & 13 & 5 & $1.9-9.8$ & 5.2 & 3.5 & 1.3 \\
\hline & & & & & $\mathrm{EB}$ & 16 & 15 & 7 & $2.2-7.5$ & 3.8 & 4.0 & 1.9 \\
\hline & & & & & Sculpins & abundant & & & & & & \\
\hline & & & 8-Aug-07 & 374 & $\mathrm{RB}$ & 254 & 201 & 118 & $1.5-9.0$ & 3.2 & 53.7 & 31.6 \\
\hline & & & & & $\mathrm{LL}$ & 59 & 46 & 32 & $2.3-12.0$ & 3.5 & 12.3 & 8.6 \\
\hline & & & & & $\begin{array}{c}\text { EB } \\
\text { Sculpins }\end{array}$ & $\begin{array}{c}14 \\
\text { abundant }\end{array}$ & 14 & 4 & $2.4-7.0$ & 4.6 & 3.7 & 1.1 \\
\hline \multirow[t]{4}{*}{ Bear Gulch } & 0.1 & $13 \mathrm{~N}, 9 \mathrm{~W}, 34 \mathrm{~A}$ & 3-Aug-06 & 250 & No fish & Spotted frogs & present & & & & & \\
\hline & 0.6 & $13 \mathrm{~N}, 9 \mathrm{~W}, 34 \mathrm{~A}$ & 3-Aug-06 & 250 & $\begin{array}{c}\text { CT } \\
\text { Spotted frogs }\end{array}$ & $\begin{array}{c}19 \\
\text { present } \\
\end{array}$ & 19 & 9 & $3.0-6.0$ & 4.1 & 7.6 & 3.6 \\
\hline & 0.7 & $13 \mathrm{~N}, 9 \mathrm{~W}, 34 \mathrm{AB}$ & $20-J u l-06$ & 450 & $\mathrm{CT}$ & 36 & 36 & 27 & $1.3-6.4$ & 3.1 & 8.0 & 6.0 \\
\hline & 1.2 & $13 \mathrm{~N}, 9 \mathrm{~W}, 3 \mathrm{~B}$ & $20-J u l-06$ & 480 & CT & 85 & 85 & 60 & $2.4-7.1$ & 3.6 & 17.7 & 12.5 \\
\hline \multirow[t]{2}{*}{ Beartrap Cr } & 0.2 & $15 \mathrm{~N}, 6 \mathrm{~W}, 27 \mathrm{~B}$ & 25-Jul-06 & 400 & No fish & & & & & & & \\
\hline & 1.2 & $15 \mathrm{~N}, 6 \mathrm{~W}, 27 \mathrm{C}$ & 25-Jul-06 & 325 & No fish & & & & & & & \\
\hline Blackfoot River & 119.6 & $14 \mathrm{~N}, 7 \mathrm{~W}, 5 \mathrm{D}$ & 11-Sep-06 & 4000 & DV & 1 & 1 & 0 & 15.3 & 15.3 & 0.0 & 0.0 \\
\hline \multirow[t]{5}{*}{ (above Hogum Cr Rd) } & & & & & СT & 64 & 48 & 28 & $1.8-16.9$ & 4.5 & 1.2 & 0.7 \\
\hline & & & & & $\mathrm{LL}$ & 22 & 15 & 9 & $2.6-18.3$ & 6.8 & 0.4 & 0.2 \\
\hline & & & & & $\mathrm{EB}$ & 18 & 13 & 5 & $2.7-11.8$ & 5.4 & 0.3 & 0.1 \\
\hline & & & & & MWF & 18 & 15 & 2 & $3.5-15.3$ & 12.2 & 0.4 & 0.1 \\
\hline & & & & & Sculpins & abuundant & Western toads & present & & & & \\
\hline \multirow[t]{6}{*}{ (above Flesher Pass Rd) } & 124.3 & $15 \mathrm{~N}, 7 \mathrm{~W}, 35 \mathrm{~B} \& 26 \mathrm{C}$ & 5-Sep-06 & 2457 & DV & 1 & 1 & 0 & 12.4 & 12.4 & 0.0 & 0.0 \\
\hline & & & & & CT & 93 & 75 & 63 & $1.9-9.9$ & 2.9 & 3.1 & 2.6 \\
\hline & & & & & LL & 1 & 1 & 0 & 2.9 & 2.9 & 0.0 & 0.0 \\
\hline & & & & & $\mathrm{EB}$ & 117 & 91 & 64 & $2.1-10.3$ & 4.0 & 3.7 & 2.6 \\
\hline & & & & & LNS & 4 & 3 & 1 & $3.2-6.5$ & 5.2 & 0.1 & 0.0 \\
\hline & & & & & Sculpins & abuundant & Spotted frogs & common & & & & \\
\hline (above Pass Cr) & 130.5 & $15 \mathrm{~N}, 6 \mathrm{~W}, 20 \mathrm{~A}$ & 26-Jul-06 & 725 & $\begin{array}{c}\text { EB } \\
\text { Sculpins }\end{array}$ & $\begin{array}{c}19 \\
\text { present }\end{array}$ & $\begin{array}{c}19 \\
\text { Spotted frogs }\end{array}$ & $\begin{array}{c}6 \\
\text { present }\end{array}$ & $\begin{array}{l}4.2 \\
\text { LNS }\end{array}$ & $\begin{array}{l}1.9-7.0 \\
\text { present }\end{array}$ & 2.6 & 0.8 \\
\hline (above Shave Cr) & 131.8 & $15 \mathrm{~N}, 6 \mathrm{~W}, 21 \mathrm{D}$ & 26-Jul-06 & 540 & $\begin{array}{c}\mathrm{CT} \\
\text { Spotted frogs }\end{array}$ & $\begin{array}{c}1 \\
\text { present }\end{array}$ & 1 & 1 & 2 & 2.0 & 0.2 & 0.2 \\
\hline
\end{tabular}


Appendix A : Catch and size statistics for tributaries to the Blackfoot River excluding the Clearwater Basin, 2006-2007 (cont'd).

\begin{tabular}{|c|c|c|c|c|c|c|c|c|c|c|c|c|}
\hline Stream & $\begin{array}{c}\text { River } \\
\text { Mile }\end{array}$ & Location (T,R,S) & $\begin{array}{c}\text { Date } \\
\text { Sampled }\end{array}$ & $\begin{array}{c}\text { Section } \\
\text { Length (ft) }\end{array}$ & Species & $\begin{array}{c}\text { Total Number } \\
\text { Captured }\end{array}$ & $\begin{array}{l}\text { Number } \\
\text { Captured 1st } \\
\text { Pass }\end{array}$ & $\begin{array}{l}\text { YOY(<4.0") } \\
\text { Captured 1st } \\
\text { Pass }\end{array}$ & $\begin{array}{c}\text { Range of } \\
\text { Lengths (in) }\end{array}$ & $\begin{array}{c}\text { Mean } \\
\text { Length (in) }\end{array}$ & $\begin{array}{c}\text { CPUE (\#/100') } \\
\text { in 1st Pass }\end{array}$ & $\begin{array}{l}\text { YOY CPUE } \\
\left(\# / 100^{\prime}\right) \text { in } 1 \mathrm{st} \\
\text { Pass }\end{array}$ \\
\hline \multirow[t]{6}{*}{ Blanchard Creek } & 3.3 & $15 \mathrm{~N}, 15 \mathrm{~W}, 36 \mathrm{AB}$ & 15-Jun-06 & 492 & $\mathrm{CT}^{*}$ & 3 & 3 & 1 & $3.7-7.3$ & 5.2 & 0.6 & 0.2 \\
\hline & & & & & $\mathrm{RB}^{*}$ & 21 & 21 & 7 & $3.5-8.2$ & 5.0 & 4.3 & 1.4 \\
\hline & & & & & Spotted & frogs & present & & & & & \\
\hline & 5.6 & $15 \mathrm{~N}, 15 \mathrm{~W}, 34 \mathrm{~B}$ & 15-Jun-06 & 492 & $\mathrm{CT}$ & 27 & 27 & 19 & $2.7-7.4$ & 4.1 & 5.5 & 3.9 \\
\hline & & & & & Spotted & frogs \& & Western & toads & present & & & \\
\hline & 9.4 & $15 \mathrm{~N}, 16 \mathrm{~W}, 25 \mathrm{D}$ & 19-Jun-06 & 410 & $\mathrm{CT}$ & 39 & 39 & 26 & $2.2-7.2$ & 3.7 & 9.5 & 6.3 \\
\hline \multirow[t]{9}{*}{ N.F.Blanchard Creek } & 0.15 & $15 \mathrm{~N}, 14 \mathrm{~W}, 31 \mathrm{~B}$ & 15-Jun-06 & 492 & $\mathrm{RB}^{*}$ & 4 & 4 & 3 & $2.4-4.3$ & 3.4 & 0.8 & 0.6 \\
\hline & & & & & $\mathrm{EB}$ & 13 & 13 & 11 & $1.3-4.9$ & 2.2 & 2.6 & 2.2 \\
\hline & & & & & SCUL & present & Spotted & frogs & present & & & \\
\hline & 2 & $15 \mathrm{~N}, 15 \mathrm{~W}, 26 \mathrm{~A}$ & 19-Jun-06 & 492 & $\mathrm{CT}^{*}$ & 10 & 10 & 5 & $3.2-5.5$ & 4.1 & 2.0 & 1.0 \\
\hline & & & & & $\mathrm{RB}^{*}$ & 10 & 10 & 7 & $2.7-6.0$ & 3.9 & 2.0 & 1.4 \\
\hline & & & & & $\mathrm{EB}$ & 11 & 11 & 4 & $3.3-7.0$ & 4.7 & 2.2 & 0.8 \\
\hline & & & & & SCUL & present & & & & & & \\
\hline & 6.3 & $15 \mathrm{~N}, 15 \mathrm{~W}, 17 \mathrm{~A}$ & 19-Jun-06 & 492 & $\mathrm{CT}$ & 7 & 7 & 3 & $1.9-6.1$ & 4.1 & 1.4 & 0.6 \\
\hline & & & & & $\mathrm{EB}$ & 7 & 7 & 1 & $3.9-6.0$ & 4.8 & 1.4 & 0.2 \\
\hline Braziel Creek & 0.7 & $12 \mathrm{~N}, 10 \mathrm{~W}, 15 \mathrm{~A}$ & 19-Oct-06 & 309 & $\mathrm{CT}$ & 57 & 57 & 50 & $1.6-6.1$ & 2.4 & 18.4 & 16.2 \\
\hline YOY based on <3.0" & & & & & Sculpins & abundant & & & & & & \\
\hline YOY based on <3.0" & 1.4 & $12 \mathrm{~N}, 10 \mathrm{~W}, 15 \mathrm{D}$ & 19-Oct-06 & 325 & $\begin{array}{c}C T \\
\text { No sculpins }\end{array}$ & $\begin{array}{c}130 \\
\text { observed }\end{array}$ & $\begin{array}{c}130 \\
\text { Spotted frogs }\end{array}$ & $\begin{array}{c}91 \\
\text { present }\end{array}$ & $1.4-7.2$ & 2.6 & 42.1 & 29.4 \\
\hline Broadus Creek & 0.1 & $17 \mathrm{~N}, 10 \mathrm{~W}, 2 \mathrm{~A}$ & 12-Jul-07 & 280 & $\mathrm{RB}$ & 4 & 4 & 0 & $5.6-8.7$ & 6.8 & 1.4 & 0.0 \\
\hline & & & & & No sculpins & observed & & & & & & \\
\hline Burnt Cabin Creek & 0.2 & $17 \mathrm{~N}, 12 \mathrm{~W}, 8 \mathrm{D}$ & 24-Aug-06 & 303 & $\mathrm{CT}$ & 3 & 3 & 3 & $2.7-3.0$ & 2.8 & 1.0 & 1.0 \\
\hline \multirow[t]{2}{*}{ Canyon Creek } & 1.5 & $17 \mathrm{~N}, 11 \mathrm{~W}, 14 \mathrm{C}$ & 14-Jul-07 & 393 & $\mathrm{CT}$ & 32 & 32 & 0 & $4.2-9.1$ & 6.4 & 8.1 & 0.0 \\
\hline & & & & & No sculpins & observed & Spotted frogs & present & & & & \\
\hline \multirow[t]{7}{*}{ Chamberlain Creek } & 0.1 & $15 \mathrm{~N}, 13 \mathrm{~W}, 32 \mathrm{~A}$ & 12-Sep-06 & 300 & $\mathrm{CT}$ & 163 & 144 & 111 & $2.0-7.5$ & 3.2 & 48.0 & 37.0 \\
\hline & & & & & LL & 21 & 21 & 13 & $2.8-5.9$ & 4.1 & 7.0 & 4.3 \\
\hline & & & & & Sculpins & abundant & LNS present & Spotted & frogs & present & & \\
\hline & & & 10-Sep-07 & 300 & CT & 234 & 184 & 144 & $1.7-8.5$ & 3.0 & 61.3 & 48.0 \\
\hline & & & & & LL & 36 & 27 & 20 & $2.9-6.5$ & 4.0 & 9.0 & 6.7 \\
\hline & & & & & MWF & 1 & 1 & 1 & 3.7 & 3.7 & 0.3 & 0.3 \\
\hline & & & & & Sculpins & abundant & RSS \& LNS & present & Spotted & frogs & present & \\
\hline $\begin{array}{l}\text { Cold Brook Creek } \\
\text { trib to Blanchard } \mathrm{Cr}\end{array}$ & 1.1 & $15 \mathrm{~N}, 15 \mathrm{~W}, 28 \mathrm{~B}$ & 15-Jun-06 & 410 & CT & 11 & 11 & 8 & $2.3-5.8$ & 3.6 & 2.7 & 2.0 \\
\hline Cooney Creek & 0.4 & $17 \mathrm{~N}, 10 \mathrm{~W}, 1 \mathrm{~A}$ & 12-Jul-07 & 639 & $\begin{array}{c}\text { RB } \\
\text { No Sculpins }\end{array}$ & $\begin{array}{c}1 \\
\text { observed }\end{array}$ & 1 & 0 & 7.9 & 7.9 & 0.2 & 0.0 \\
\hline
\end{tabular}


Appendix A : Catch and size statistics for tributaries to the Blackfoot River excluding the Clearwater Basin, 2006-2007 (cont'd).

\begin{tabular}{|c|c|c|c|c|c|c|c|c|c|c|c|c|}
\hline Stream & $\begin{array}{l}\text { River } \\
\text { Mile }\end{array}$ & Location $(\mathrm{T}, \mathrm{R}, \mathrm{S})$ & $\begin{array}{c}\text { Date } \\
\text { Sampled }\end{array}$ & $\begin{array}{c}\text { Section } \\
\text { Length (ft) }\end{array}$ & Species & $\begin{array}{l}\text { Total Number } \\
\text { Captured }\end{array}$ & $\begin{array}{c}\text { Number } \\
\text { Captured 1st } \\
\text { Pass }\end{array}$ & $\begin{array}{c}\text { YOY }(<4.0 ") \\
\text { Captured 1st } \\
\text { Pass }\end{array}$ & $\begin{array}{l}\text { Range of } \\
\text { Lengths (in) }\end{array}$ & $\begin{array}{c}\text { Mean } \\
\text { Length (in) }\end{array}$ & $\begin{array}{l}\text { CPUE (\#/100') } \\
\text { in 1st Pass }\end{array}$ & $\begin{array}{l}\text { YOY CPUE } \\
\left(\# / 100^{\prime}\right) \text { in } 1 \text { st } \\
\text { Pass }\end{array}$ \\
\hline \multirow[t]{2}{*}{ Copper Creek } & 6.2 & $15 \mathrm{~N}, 8 \mathrm{~W}, 9 \mathrm{~A}$ & 2-Aug-07 & 512 & DV & 67 & 67 & 53 & $1.9-12.2$ & 2.9 & 13.1 & 10.4 \\
\hline & & & & & $\begin{array}{c}\text { CT } \\
\text { Sculpins } \\
\end{array}$ & $\begin{array}{c}179 \\
\text { abundant }\end{array}$ & $\begin{array}{c}179 \\
\text { Spotted frogs }\end{array}$ & $\begin{array}{c}127 \\
\text { present }\end{array}$ & $\begin{array}{l}0.9-12.9 \\
\text { Western }\end{array}$ & $\begin{array}{l}2.9 \\
\text { toad }\end{array}$ & $\begin{array}{c}35.0 \\
\text { observed }\end{array}$ & 24.8 \\
\hline \multirow[t]{7}{*}{ Cottonwood Creek } & 7.5 & $15 \mathrm{~N}, 13 \mathrm{~W}, 5 \mathrm{C}$ & 27-Aug-07 & 300 & CT & 1 & 1 & 0 & 8.7 & 8.7 & 0.3 & 0.0 \\
\hline & & & & & $\begin{array}{c}\text { EB } \\
\text { Sculpins } \\
\end{array}$ & $\begin{array}{c}23 \\
\text { present } \\
\end{array}$ & 23 & 14 & $2.4-10.6$ & 5.0 & 7.7 & 4.7 \\
\hline & 12.0 & $16 \mathrm{~N}, 14 \mathrm{~W}, 24 \mathrm{D}$ & 19-Sep-06 & 515 & $\mathrm{DV}^{* \pi}$ & 8 & 8 & 4 & 5.6 & $2.5-10$ & 1.6 & 0.8 \\
\hline & & & & & $\begin{array}{c}C T \\
E B\end{array}$ & $\begin{array}{c}120 \\
11\end{array}$ & $\begin{array}{l}34 \\
10\end{array}$ & $\begin{array}{c}59 \\
8\end{array}$ & $\begin{array}{c}3.1 \\
4\end{array}$ & $\begin{array}{l}1.2-10 \\
2.5-8.5\end{array}$ & $\begin{array}{l}6.6 \\
1.9\end{array}$ & $\begin{array}{c}11.5 \\
1.6\end{array}$ \\
\hline & & & & & Sculpins & abundant & Spotted frogs & present & & & & \\
\hline & & & 18-Sep-07 & 515 & $\mathrm{DV}^{* \pi}$ & 4 & 3 & 0 & $2.3-5.3$ & 4.1 & 0.6 & 0.0 \\
\hline & & & & & $\begin{array}{c}C T \\
\text { EB ** } \\
\text { Sculpins } \\
\end{array}$ & $\begin{array}{c}144 \\
7 \\
\text { abundant } \\
\end{array}$ & $\begin{array}{c}45 \\
5\end{array}$ & $\begin{array}{c}63 \\
4\end{array}$ & $\begin{array}{l}1.3-8.9 \\
2.7-7.1\end{array}$ & $\begin{array}{l}3.2 \\
4.0\end{array}$ & $\begin{array}{l}8.7 \\
1.0\end{array}$ & $\begin{array}{c}12.2 \\
0.8\end{array}$ \\
\hline \multicolumn{13}{|c|}{ Spring Creek tributaries to Cottonwood Creek } \\
\hline Eastern "Big" Spring Creek & 0.2 & $15 N, 13 W, 5 D$ & 27-Aug-07 & 300 & EB & 56 & 56 & 51 & $2.2-7.5$ & 3.1 & 18.7 & 17.0 \\
\hline "Blackfoot-Clearwater Game & & & & & $\begin{array}{c}\text { LL } \\
\text { Sculpins } \\
\end{array}$ & $\begin{array}{c}1 \\
\text { present }\end{array}$ & 1 & 1 & 2.5 & 2.5 & 0.3 & 0.3 \\
\hline Range (BCGR)" & 0.65 & $15 \mathrm{~N}, 13 \mathrm{~W}, 5 \mathrm{~A}$ & 27-Aug-07 & 360 & $\begin{array}{c}\text { EB } \\
\text { Sculpins } \\
\end{array}$ & $\begin{array}{c}45 \\
\text { abundant } \\
\end{array}$ & $\begin{array}{c}45 \\
\text { Spotted frogs } \\
\end{array}$ & $\begin{array}{c}45 \\
\text { present }\end{array}$ & $2.1-3.7$ & 2.7 & 12.5 & 12.5 \\
\hline $\begin{array}{l}\text { East Fork of Eastern "Big" Spring } \\
\text { Creek "BCGR" }\end{array}$ & 0.1 & $15 \mathrm{~N}, 13 \mathrm{~W}, 5 \mathrm{~A}$ & 28-Aug-07 & 405 & $\begin{array}{c}\text { EB } \\
\text { Sculpins } \\
\end{array}$ & $\begin{array}{c}32 \\
\text { common }\end{array}$ & 32 & 30 & $2.2-5.7$ & 3.2 & 7.9 & 7.4 \\
\hline $\begin{array}{l}\text { Middle Spring Creek } \\
\text { "BCGR" }\end{array}$ & 0.2 & $15 \mathrm{~N}, 13 \mathrm{~W}, 5 \mathrm{D}$ & 26-Aug-07 & 333 & $\begin{array}{c}\text { EB } \\
\text { Sculpins \& }\end{array}$ & $\begin{array}{c}51 \\
\text { Spotted frogs }\end{array}$ & $\begin{array}{c}51 \\
\text { present }\end{array}$ & 50 & $2.2-6.7$ & 2.8 & 15.3 & 15.0 \\
\hline $\begin{array}{l}\text { Western Spring Cr } \\
\text { "BCGR" }\end{array}$ & 0.1 & $15 \mathrm{~N}, 13 \mathrm{~W}, 5 \mathrm{C}$ & 27-Aug-07 & 420 & $\begin{array}{c}\text { EB } \\
\text { Sculpins }\end{array}$ & $\begin{array}{c}7 \\
\text { present }\end{array}$ & 7 & 7 & $2.2-3.4$ & 2.7 & 1.7 & 1.7 \\
\hline Dobrota Creek & 0.1 & $18 \mathrm{~N}, 9 \mathrm{~W}, 31 \mathrm{C}$ & 13-Jul-07 & 1044 & $\begin{array}{c}\text { RB } \\
\text { No Sculpins } \\
\end{array}$ & $\begin{array}{c}28 \\
\text { observed } \\
\end{array}$ & 28 & 0 & $4.6-10.7$ & 7.7 & 2.7 & 0.0 \\
\hline \multirow[t]{2}{*}{ East Fork of NFBLKFT } & 7 & $16 \mathrm{~N}, 9 \mathrm{~W}, 7 \mathrm{~B}$ & 11-Jul-06 & 689 & $\begin{array}{c}\text { RB } \\
\text { Toad } \\
\end{array}$ & $\begin{array}{c}32 \\
\text { observed } \\
\end{array}$ & 32 & 21 & $2.0-9.1$ & 4.0 & 4.6 & 3.0 \\
\hline & 11.7 & $16 \mathrm{~N}, 9 \mathrm{~W}, 10 \mathrm{D}$ & 10-Jul-06 & 330 & No fish & & & & & & & \\
\hline \multirow[t]{2}{*}{ East Fork Monture Creek } & 0.2 & $17 \mathrm{~N}, 12 \mathrm{~W}, 8 \mathrm{~B}$ & 21-Aug-06 & 690 & DV & 16 & 16 & 0 & $5.9-9.6$ & 7.6 & 2.3 & 0.0 \\
\hline & & & & & $\begin{array}{c}\text { CT } \\
\text { Spotted frogs } \\
\end{array}$ & $\begin{array}{c}29 \\
\text { present } \\
\end{array}$ & 29 & 1 & $2.6-9.1$ & 7.4 & 4.2 & 0.1 \\
\hline Enders Spring Creek & 0.5 & $14 \mathrm{~N}, 11 \mathrm{~W}, 31 \mathrm{C}$ & 24-Aug-06 & 300 & DV & 2 & 1 & 0 & $5.6-9.1$ & 7.3 & 0.3 & 0.0 \\
\hline \multirow[t]{4}{*}{ trib to NFBLKFT } & & & & & EB & 60 & 58 & 53 & $2.0-6.0$ & 3.1 & 19.3 & 17.7 \\
\hline & & & 15-Aug-07 & 300 & EB & 110 & 78 & 59 & $1.5-7.4$ & 2.9 & 26.0 & 19.7 \\
\hline & & & & & LL & 2 & 2 & 0 & $5.8-7.8$ & 6.8 & 0.7 & 0.0 \\
\hline & & & & & $\begin{array}{c}\text { MWF } \\
\text { Sculpins }\end{array}$ & $\begin{array}{c}2 \\
\text { common }\end{array}$ & $\begin{array}{c}2 \\
\text { Spotted Frogs }\end{array}$ & $\begin{array}{c}2 \\
\text { present }\end{array}$ & $3.3-3.5$ & 3.4 & 0.7 & 0.7 \\
\hline
\end{tabular}


Appendix A : Catch and size statistics for tributaries to the Blackfoot River excluding the Clearwater Basin, 2006-2007 (cont'd).

\begin{tabular}{|c|c|c|c|c|c|c|c|c|c|c|c|c|}
\hline Stream & $\begin{array}{c}\text { River } \\
\text { Mile }\end{array}$ & Location $(\mathrm{T}, \mathrm{R}, \mathrm{S})$ & $\begin{array}{c}\text { Date } \\
\text { Sampled }\end{array}$ & $\begin{array}{c}\text { Section } \\
\text { Length (ft) }\end{array}$ & Species & $\begin{array}{l}\text { Total Number } \\
\text { Captured }\end{array}$ & $\begin{array}{c}\text { Number } \\
\text { Captured 1st } \\
\text { Pass }\end{array}$ & $\begin{array}{c}\text { YOY }(<4.0 ") \\
\text { Captured 1st } \\
\text { Pass }\end{array}$ & $\begin{array}{c}\text { Range of } \\
\text { Lengths (in) }\end{array}$ & $\begin{array}{c}\text { Mean } \\
\text { Length (in) }\end{array}$ & $\begin{array}{c}\text { CPUE (\#/100') } \\
\text { in 1st Pass }\end{array}$ & $\begin{array}{l}\text { YOY CPUE } \\
\left(\# / 100^{\prime}\right) \text { in } 1 \mathrm{st} \\
\text { Pass }\end{array}$ \\
\hline \multirow{18}{*}{ Gold Creek } & 1.9 & $14 \mathrm{~N}, 16 \mathrm{~W}, 30 \mathrm{D}$ & 14-Sep-06 & 400 & CT & 2 & 2 & 0 & 11.1 & $104-11.9$ & 0.5 & 0.0 \\
\hline & & & & & $\mathrm{RB}^{*}$ & 98 & 70 & 32 & 4.5 & $1.9-10.1$ & 17.5 & 8.0 \\
\hline & & & & & LL & 45 & 37 & 8 & 6.2 & $2.4-14.9$ & 9.3 & 2.0 \\
\hline & & & & & Sculpins & abundant & YOY's & abundant & & & & \\
\hline & 5.7 & $14 \mathrm{~N}, 16 \mathrm{~W}, 7 \mathrm{C}$ & 21-Aug-07 & 300 & DV & 2 & 2 & 0 & $4.4-4.7$ & 4.6 & 0.7 & 0.0 \\
\hline & & & & & CT & 6 & 6 & 0 & $5.2-8.7$ & 7.4 & 2.0 & 0.0 \\
\hline & & & & & RB & 64 & 64 & 21 & $2.0-12.2$ & 4.8 & 21.3 & 7.0 \\
\hline & & & & & $E B$ & 9 & 9 & 4 & $2.4-6.2$ & 4.1 & 3.0 & 1.3 \\
\hline & & & & & LL & 180 & 180 & 88 & $1.9-13$ & 5.0 & 60.0 & 29.3 \\
\hline & & & & & $\begin{array}{c}\text { ONC } \\
\text { Sculpins }\end{array}$ & $\begin{array}{c}21 \\
\text { present }\end{array}$ & 21 & 21 & $1.5-2.1$ & 1.8 & 7.0 & 7.0 \\
\hline & 5.9 & $14 \mathrm{~N}, 16 \mathrm{~W}, 7 \mathrm{~B}$ & 23-Aug-07 & 300 & DV & 3 & 3 & 0 & $4.7-5.1$ & 4.9 & 1.0 & 0.0 \\
\hline & & & & & $\mathrm{RB}$ & 73 & 73 & 55 & $1.7-8.5$ & 3.0 & 24.3 & 60.0 \\
\hline & & & & & LL & 54 & 54 & 22 & $2.2-11.9$ & 5.4 & 18.0 & 7.3 \\
\hline & & & & & $\begin{array}{c}\text { EB } \\
\text { Sculpins }\end{array}$ & $\begin{array}{c}3 \\
\text { present }\end{array}$ & 3 & 0 & $5.2-6.2$ & 5.5 & 1.0 & 0.0 \\
\hline & 6.2 & $14 \mathrm{~N}, 16 \& 17 \mathrm{~W}, 7 \mathrm{~B} \&$ & 23-Aug-07 & 270 & CT & 1 & 1 & 0 & 6.8 & 6.8 & 0.4 & 0.0 \\
\hline & & $12 A$ & & & RB & 17 & 17 & 13 & $1.9-10.6$ & 3.3 & 6.3 & 4.8 \\
\hline & & & & & LL & 46 & 46 & 22 & $2.2-11.8$ & 5.0 & 17.0 & 8.1 \\
\hline & & & & & $\begin{array}{c}\text { EB } \\
\text { Spotted frogs }\end{array}$ & $\begin{array}{c}33 \\
\text { present }\end{array}$ & 33 & 11 & $2.4-10.5$ & 4.9 & 12.2 & 4.1 \\
\hline \multirow[t]{2}{*}{ Hayden Creek } & 0.1 & $17 \mathrm{~N}, 12 \mathrm{~W}, 17 \mathrm{D}$ & 22-Aug-06 & 396 & DV & 7 & 7 & 0 & $6.1-10.8$ & 8.0 & 1.8 & 0.0 \\
\hline & & & & & $\begin{array}{c}\text { CT } \\
\text { Sculpins }\end{array}$ & $\begin{array}{c}3 \\
\text { present }\end{array}$ & 3 & 0 & $5.8-8.3$ & 6.9 & 0.8 & 0.0 \\
\hline \multirow[t]{7}{*}{ Hoyt Creek } & 0.2 & $15 \mathrm{~N}, 12 \mathrm{~W}, 19 \mathrm{~B}$ & 12-Sep-06 & 300 & $\begin{array}{c}\text { EB } \\
\text { Sculpins }\end{array}$ & $\begin{array}{c}4 \\
\text { common }\end{array}$ & $\begin{array}{c}3 \\
\text { Spotted frogs }\end{array}$ & $\begin{array}{c}1 \\
\text { present }\end{array}$ & $4.0-8.3$ & 6.7 & 1.0 & 0.3 \\
\hline & 1.2 & $15 \mathrm{~N}, 12 \mathrm{~W}, 19 \mathrm{C}$ & 12-Sep-06 & 300 & $\mathrm{~EB}$ & 6 & 6 & 2 & $3.8-6.3$ & 4.8 & 2.0 & 0.7 \\
\hline & & & & & $\begin{array}{c}\text { LL } \\
\text { Sculpins } \\
\end{array}$ & $\begin{array}{c}1 \\
\text { common }\end{array}$ & $\begin{array}{c}1 \\
\text { LND present, }\end{array}$ & 0 & 7.4 & 7.4 & 0.3 & 0.0 \\
\hline & & & 4-Sep-07 & 375 & No fish found & & & & & & & \\
\hline & 2.7 & $15 \mathrm{~N}, 12 \mathrm{~W}, 29 \mathrm{C}$ & 4-Sep-07 & 300 & $\begin{array}{c}\text { EB } \\
\text { Sculpins } \\
\end{array}$ & $\begin{array}{c}2 \\
\text { present }\end{array}$ & 2 & 1 & $3.7-7.5$ & 5.6 & 0.7 & 0.3 \\
\hline & 4.3 & $15 \mathrm{~N}, 12 \mathrm{~W}, 28 \mathrm{C}$ & 12-Sep-06 & 300 & $\begin{array}{c}\text { EB } \\
\text { Sculpins } \\
\end{array}$ & $\begin{array}{c}15 \\
\text { common } \\
\end{array}$ & $\begin{array}{c}11 \\
\text { Spotted frogs } \\
\end{array}$ & $\begin{array}{c}9 \\
\text { present }\end{array}$ & $2.9-5.2$ & 3.4 & 3.7 & 3.0 \\
\hline & & & 4-Sep-07 & 300 & $\begin{array}{c}\text { EB } \\
\text { Sculpins }\end{array}$ & $\begin{array}{c}10 \\
\text { common }\end{array}$ & $\begin{array}{c}9 \\
\text { Spotted frogs } \\
\end{array}$ & $\begin{array}{c}4 \\
\text { present }\end{array}$ & $3.4-4.6$ & 4.1 & 3.0 & 1.3 \\
\hline \multirow[t]{6}{*}{ Jacobson Spring Creek } & 0.6 & $14 \mathrm{~N}, 12 \mathrm{~W}, 1 \mathrm{CD}$ & 24-Aug-06 & 525 & $\mathrm{LL}$ & 11 & 10 & 2 & $3.0-6.1$ & 5.0 & 1.9 & 0.4 \\
\hline & & & & & $\begin{array}{c}\text { EB } \\
\text { Sculpins } \\
\end{array}$ & $\begin{array}{c}40 \\
\text { common }\end{array}$ & 36 & 23 & $2.4-9.3$ & 4.1 & 6.9 & 4.4 \\
\hline & & & 13-Aug-07 & 525 & $\mathrm{LL}$ & 21 & 17 & 6 & $2.7-8.7$ & 5.0 & 3.2 & 1.1 \\
\hline & & & & & $\mathrm{RB}$ & 3 & 2 & 1 & $1.3-4.9$ & 3.4 & 0.4 & 0.2 \\
\hline & & & & & $E B$ & 69 & 59 & 44 & $1.3-8.8$ & 3.3 & 11.2 & 8.4 \\
\hline & & & & & $\begin{array}{l}\text { MWF } \\
\text { Sculpins }\end{array}$ & $\begin{array}{c}9 \\
\text { common }\end{array}$ & $\begin{array}{c}6 \\
\text { Spotted frogs }\end{array}$ & $\begin{array}{c}6 \\
\text { present }\end{array}$ & $2.8-3.9$ & 3.2 & 1.1 & 1.1 \\
\hline
\end{tabular}


Appendix A : Catch and size statistics for tributaries to the Blackfoot River excluding the Clearwater Basin, 2006-2007 (cont'd).

\begin{tabular}{|c|c|c|c|c|c|c|c|c|c|c|c|c|}
\hline Stream & $\begin{array}{c}\text { River } \\
\text { Mile }\end{array}$ & Location $(\mathrm{T}, \mathrm{R}, \mathrm{S})$ & $\begin{array}{c}\text { Date } \\
\text { Sampled }\end{array}$ & $\begin{array}{l}\text { Section } \\
\text { Length (ft) }\end{array}$ & Species & $\begin{array}{c}\text { Total Number } \\
\text { Captured }\end{array}$ & $\begin{array}{c}\text { Number } \\
\text { Captured 1st } \\
\text { Pass }\end{array}$ & $\begin{array}{l}\text { YOY }(<4.0 ") \\
\text { Captured 1st } \\
\text { Pass }\end{array}$ & $\begin{array}{l}\text { Range of } \\
\text { Lengths (in) }\end{array}$ & $\begin{array}{c}\text { Mean } \\
\text { Length (in) }\end{array}$ & $\begin{array}{l}\text { CPUE (\#/100') } \\
\text { in 1st Pass }\end{array}$ & $\begin{array}{l}\text { YOY CPUE } \\
\left(\# / 100^{\prime}\right) \text { in 1st } \\
\text { Pass }\end{array}$ \\
\hline \multirow[t]{10}{*}{ Kleinschmidt Creek } & 0.5 & $14 \mathrm{~N}, 11 \mathrm{~W}, 5 \mathrm{C}$ & 16-Aug-06 & 500 & LL & 165 & 120 & 93 & $1.9-20.3$ & 3.9 & 24.0 & 18.6 \\
\hline & & & & & $\begin{array}{c}\text { EB } \\
\text { Sculpins }\end{array}$ & $\begin{array}{c}3 \\
\text { abundant }\end{array}$ & 2 & 1 & $3.3-6.8$ & 5.2 & 0.4 & 0.2 \\
\hline & & & 22-Aug-07 & 500 & $\mathrm{LL}$ & 106 & 79 & 52 & $2.1-14.8$ & 4.5 & 15.8 & 10.4 \\
\hline & & & & & $\begin{array}{c}\text { EB } \\
\text { Sculpins }\end{array}$ & $\begin{array}{c}3 \\
\text { abundant }\end{array}$ & 2 & 2 & $2.8-3.5$ & 3.2 & 0.4 & 0.4 \\
\hline & 0.8 & $14 \mathrm{~N}, 11 \mathrm{~W}, 5 \mathrm{C}$ & 16-Aug-06 & 500 & $\mathrm{LL}$ & 219 & 152 & 120 & $2.4-14.0$ & 4.0 & 30.4 & 24.0 \\
\hline & & & & & $\begin{array}{c}\text { EB } \\
\text { Sculpins }\end{array}$ & $\begin{array}{c}14 \\
\text { abundant }\end{array}$ & 3 & 3 & $2.8-9.2$ & 2.8 & 0.6 & 0.6 \\
\hline & & & 22-Aug-07 & 500 & CT & 1 & 1 & 1 & 1.8 & 1.8 & 0.2 & 0.2 \\
\hline & & & & & DV & 1 & 0 & 0 & 7.1 & 7.1 & 0.0 & 0.0 \\
\hline & & & & & LL & 157 & 127 & 78 & $2.3-10.6$ & 5.1 & 25.4 & 15.6 \\
\hline & & & & & $\begin{array}{c}\text { EB } \\
\text { Sculpins }\end{array}$ & $\begin{array}{c}16 \\
\text { abundant }\end{array}$ & 12 & 8 & $3.0-8.5$ & 4.8 & 2.4 & 1.6 \\
\hline \multirow[t]{2}{*}{ Lincoln Spring Creek } & 2.8 & $14 \mathrm{~N}, 9 \mathrm{~W}, 13 \mathrm{D}$ & 21-Aug-07 & 321 & $\mathrm{LL}$ & 18 & 13 & 0 & $4.2-8.9$ & 6.3 & 4.0 & 0.0 \\
\hline & & & & & $\begin{array}{c}\text { EB } \\
\text { Sculpins }\end{array}$ & $\begin{array}{c}196 \\
\text { common }\end{array}$ & 145 & 117 & $2.0-11.2$ & 3.7 & 45.2 & 36.4 \\
\hline Lost Pony Creek & 0.8 & $16 \mathrm{~N}, 10 \mathrm{~W}, 1 \mathrm{~A} \& 6 \mathrm{~B}$ & 11-Jul-06 & 540 & $\begin{array}{c}\text { RB } \\
\text { Spotted frogs }\end{array}$ & $\begin{array}{c}14 \\
\text { present }\end{array}$ & 14 & 8 & $1.3-6.3$ & 3.5 & 2.6 & 1.5 \\
\hline \multirow[t]{2}{*}{ McCabe Creek } & 2.2 & $15 \mathrm{~N}, 12 \mathrm{~W}, 5 \mathrm{C}$ & 20-Aug-07 & 340 & CT & 168 & 151 & 113 & $1.6-9.9$ & 3.2 & 44.4 & 33.2 \\
\hline & & & & & $\begin{array}{c}\text { EB } \\
\text { Sculpins }\end{array}$ & $\begin{array}{c}50 \\
\text { abundant }\end{array}$ & 45 & 25 & $1.9-7.6$ & 3.9 & 13.2 & 7.4 \\
\hline Middle Fork Monture Creek & 0.8 & $18 \mathrm{~N}, 12 \mathrm{~W}, 31 \mathrm{~B}$ & 23-Aug-06 & 300 & $\begin{array}{c}\text { CT } \\
\text { Sculpins }\end{array}$ & $\begin{array}{c}32 \\
\text { common }\end{array}$ & $\begin{array}{c}32 \\
\text { Spotted frogs }\end{array}$ & $\begin{array}{c}5 \\
\text { present }\end{array}$ & $2.8-7.8$ & 5.3 & 10.7 & 1.7 \\
\hline \multirow[t]{2}{*}{ Mike Horse Creek } & 0.1 & $15 \mathrm{~N}, 6 \mathrm{~W}, 27 \mathrm{~B}$ & 25-Jul-06 & 300 & No fish & & & & & & & \\
\hline & 0.4 & $15 \mathrm{~N}, 6 \mathrm{~W}, 28 \mathrm{D}$ & 25-Jul-06 & 345 & No fish & & & & & & & \\
\hline \multirow[t]{8}{*}{ Monture Creek } & 12.9 & $16 \mathrm{~N}, 12 \mathrm{~W}, 29 \mathrm{~B}$ & 6-Aug-07 & 480 & DV & 31 & 31 & 23 & $2.4-7.8$ & 3.6 & 6.5 & 4.8 \\
\hline & & & & & CT & 14 & 14 & 10 & $2.2-9.2$ & 4.0 & 2.9 & 2.1 \\
\hline & & & & & $\begin{array}{c}\text { EB } \\
\text { Sculpins }\end{array}$ & $\begin{array}{c}79 \\
\text { abundant }\end{array}$ & $\begin{array}{c}79 \\
\text { Spotted frogs }\end{array}$ & $\begin{array}{c}52 \\
\text { present }\end{array}$ & $1.8-9.6$ & 3.6 & 16.5 & 10.8 \\
\hline & 18.2 & $17 \mathrm{~N}, 12 \mathrm{~W}, 32 \mathrm{C}$ & 22-Aug-06 & 471 & DV & 14 & 14 & 10 & $2.2-8.0$ & 3.5 & 3.0 & 2.1 \\
\hline & & & & & $\begin{array}{c}\text { CT } \\
\text { Sculpins }\end{array}$ & $\begin{array}{c}54 \\
\text { common }\end{array}$ & $\begin{array}{c}54 \\
\text { Spotted frogs }\end{array}$ & $\begin{array}{c}26 \\
\text { present }\end{array}$ & $1.3-9.8$ & 3.7 & 11.5 & 5.5 \\
\hline & 23 & $17 \mathrm{~N}, 12 \mathrm{~W}, 17 \mathrm{~B} \& 8 \mathrm{C}$ & 21-Aug-06 & 596 & DV & 29 & 29 & 2 & $2.3-10.6$ & 6.6 & 4.9 & 0.3 \\
\hline & & & & & $\begin{array}{c}\text { CT } \\
\text { Sculpins }\end{array}$ & $\begin{array}{c}29 \\
\text { common }\end{array}$ & $\begin{array}{c}29 \\
\text { Spotted frogs }\end{array}$ & 4 & $3.3-9.4$ & 6.8 & 4.9 & 0.7 \\
\hline & 27.5 & $18 \mathrm{~N}, 13 \mathrm{~W}, 25 \mathrm{C}, \mathrm{D}$ & 23-Aug-06 & 300 & $\begin{array}{c}\text { CT } \\
\text { Sculpins }\end{array}$ & $\begin{array}{c}40 \\
\text { common }\end{array}$ & $\begin{array}{c}40 \\
\text { YOYs observed }\end{array}$ & $\begin{array}{c}4 \\
\text { Spotted frogs }\end{array}$ & $\begin{array}{l}3.3-8.5 \\
\text { present }\end{array}$ & 5.9 & 13.3 & 1.3 \\
\hline $\begin{array}{l}\text { Un-named tributary to } \\
\text { upper Monture Cr } \\
\text { entering @ mile } 27.3\end{array}$ & 0.5 & $18 \mathrm{~N}, 13 \mathrm{~W}, 25 \mathrm{D}$ & 23-Aug-06 & 537 & $\mathrm{CT}$ & 5 & 5 & 0 & $6.1-7.6$ & 7 & 0.9 & 0.0 \\
\hline
\end{tabular}


Appendix A : Catch and size statistics for tributaries to the Blackfoot River excluding the Clearwater Basin, 2006-2007 (cont'd).

\begin{tabular}{|c|c|c|c|c|c|c|c|c|c|c|c|c|}
\hline Stream & $\begin{array}{l}\text { River } \\
\text { Mile }\end{array}$ & Location $(\mathrm{T}, \mathrm{R}, \mathrm{S})$ & $\begin{array}{c}\text { Date } \\
\text { Sampled }\end{array}$ & $\begin{array}{c}\text { Section } \\
\text { Length (ft) }\end{array}$ & Species & $\begin{array}{l}\text { Total Number } \\
\text { Captured }\end{array}$ & $\begin{array}{c}\text { Number } \\
\text { Captured 1st } \\
\text { Pass }\end{array}$ & $\begin{array}{c}\text { YOY(<4.0") } \\
\text { Captured 1st } \\
\text { Pass }\end{array}$ & $\begin{array}{l}\text { Range of } \\
\text { Lengths (in) }\end{array}$ & $\begin{array}{c}\text { Mean } \\
\text { Length (in) }\end{array}$ & $\begin{array}{c}\text { CPUE (\#/100') } \\
\text { in 1st Pass }\end{array}$ & $\begin{array}{l}\text { YOY CPUE } \\
\left(\# / 100^{\prime}\right) \text { in 1st } \\
\text { Pass }\end{array}$ \\
\hline Murphy Spring Creek & 0.6 & $15 \mathrm{~N}, 11 \mathrm{~W}, 21 \mathrm{~B}$ & 14-Sep-06 & 385 & DV & 4 & 4 & 2 & 4.2 & $2.8-6.9$ & 1.0 & 0.5 \\
\hline trib. to NFBLKFT & & & & & CT & 104 & 76 & 61 & 2.5 & $1.4-6.9$ & 19.7 & 15.8 \\
\hline \multirow[t]{4}{*}{ above culvert } & & & & & $\begin{array}{c}\text { EB } \\
\text { Sculpins }\end{array}$ & $\begin{array}{c}22 \\
\text { common }\end{array}$ & 15 & 11 & 3.4 & $1.8-6.7$ & 3.9 & 2.9 \\
\hline & & & 6-Sep-07 & 385 & DV & 2 & 2 & 0 & $5.3-7.9$ & 6.6 & 0.5 & 0.0 \\
\hline & & & & & $\mathrm{CT}$ & 91 & 73 & 56 & $1.2-6.0$ & 2.7 & 19.0 & 14.5 \\
\hline & & & & & $\begin{array}{c}\text { EB } \\
\text { Sculpins }\end{array}$ & $\begin{array}{c}30 \\
\text { abundant }\end{array}$ & 25 & 19 & $1.5-7.1$ & 2.8 & 6.5 & 4.9 \\
\hline \multirow[t]{18}{*}{ Nevada Spring Creek } & 0.8 & $13 \mathrm{~N}, 11 \mathrm{~W}, 10 \mathrm{C}$ & 13-Sep-06 & 500 & CT & 5 & 5 & 0 & $10.2-13.3$ & 11.3 & 1.0 & 0.0 \\
\hline & & & & & LL & 22 & 17 & 0 & $4.1-14.6$ & 9.2 & 3.4 & 0.0 \\
\hline & & & & & RB & 1 & 1 & 0 & 11.4 & 11.4 & 0.2 & 0.0 \\
\hline & & & & & NPM & 35 & 30 & 3 & $2.4-4.44$ & 3.2 & 6.0 & 0.6 \\
\hline & & & & & RSS & 38 & 22 & 15 & $2.4-4.4$ & 3.2 & 4.4 & 3.0 \\
\hline & & & & & Sucker & 1 & 1 & 1 & 2.7 & 2.7 & 0.2 & 0.2 \\
\hline & & & 12-Sep-07 & 500 & CT & 13 & 12 & 0 & $5.4-8.3$ & 7.2 & 2.4 & 0.0 \\
\hline & & & & & LL & 4 & 3 & 0 & $5.6-10.3$ & 8.8 & 0.6 & 0.0 \\
\hline & & & & & RSS & 16 & 10 & 10 & $2.2-3.9$ & 3.5 & 2.0 & 2.0 \\
\hline & & & & & NPM & 44 & 18 & 1 & $3.6-9.1$ & 4.8 & 3.6 & 0.2 \\
\hline & & & & & Suckers & 3 & 2 & 0 & $4.4-6.8$ & 5.6 & 0.4 & 0.0 \\
\hline & 3.5 & $13 \mathrm{~N}, 11 \mathrm{~W}, 11 \mathrm{D}$ & 13-Sep-06 & 470 & CT & 2 & 1 & 0 & $10.1-11.0$ & 10.6 & 0.2 & 0.0 \\
\hline & & & & & LL & 39 & 41 & 5 & $3.1-17.1$ & 8.6 & 8.7 & 1.1 \\
\hline & & & & & RSS & 4 & 2 & 1 & $2.8-4.1$ & 3.2 & 0.4 & 0.2 \\
\hline & & & 12-Sep-07 & 470 & CT & 26 & 24 & 0 & $4.8-12.4$ & 6.9 & 5.1 & 0.0 \\
\hline & & & & & $\mathrm{LL}$ & 26 & 21 & 0 & $2.6-15$ & 8.4 & 4.5 & 0.0 \\
\hline & & & & & RSS & 3 & 1 & 0 & $3.4-4.1$ & 3.7 & 0.2 & 0.0 \\
\hline & & & & & Suckers & 1 & 1 & 0 & 6 & 6.0 & 0.2 & 0.0 \\
\hline North Fork Blackfoot River & 17.2 & $16 \mathrm{~N}, 11 \mathrm{~W}, 35 \mathrm{~B}$ & 6-Aug-07 & 250 & DV & 19 & 19 & 14 & $2.2-6.4$ & 3.4 & 7.6 & 5.6 \\
\hline \multirow[t]{4}{*}{ below USFS bridge } & & & & & $\begin{array}{c}\text { CT } \\
\text { Sculpins }\end{array}$ & $\begin{array}{c}2 \\
\text { common }\end{array}$ & 2 & 1 & $3.7-8.6$ & 6.2 & 0.8 & 0.4 \\
\hline & 27.2 & $17 \mathrm{~N}, 10 \mathrm{~W}, 28 \mathrm{C}$ & 11-Jul-07 & 858 & $\begin{array}{c}\mathrm{RB} \\
\text { Sculpins } \\
\end{array}$ & $\begin{array}{c}2 \\
\text { present }\end{array}$ & 2 & 0 & $7.8-11.9$ & 9.8 & 0.2 & 0.0 \\
\hline & 33.3 & $17 \mathrm{~N}, 10 \mathrm{~W}, 2 \mathrm{C}$ & 12-Jul-07 & 2400 & $\begin{array}{c}\text { RB } \\
\text { No Sculpins } \\
\end{array}$ & $\begin{array}{c}28 \\
\text { observed }\end{array}$ & $\begin{array}{c}28 \\
\text { Spotted frogs } \\
\end{array}$ & $\begin{array}{c}0 \\
\text { present }\end{array}$ & $5.5-13.2$ & 8.6 & 1.2 & 0.0 \\
\hline & 36 & $18 \mathrm{~N}, 9 \mathrm{~W}, 31 \mathrm{C}$ & 13-Jul-07 & 660 & $\begin{array}{c}R B \\
\text { No Sculpins }\end{array}$ & $\begin{array}{c}34 \\
\text { observed }\end{array}$ & $\begin{array}{c}34 \\
\text { Tadpoles }\end{array}$ & $\begin{array}{c}8 \\
\text { present }\end{array}$ & $2.5-8.7$ & 5.4 & 5.2 & 1.2 \\
\hline \multirow[t]{4}{*}{ Pass Creek } & 0.5 & $15 \mathrm{~N}, 6 \mathrm{~W}, 17 \mathrm{D}$ & 24-Jul-06 & 315 & $\mathrm{CT}$ & 10 & 10 & 2 & 4.8 & $3.3-6.4$ & 3.2 & 0.6 \\
\hline & & & & & $\begin{array}{c}\text { EB } \\
\text { Sculpins } \\
\end{array}$ & $\begin{array}{c}60 \\
\text { common } \\
\end{array}$ & $\begin{array}{c}60 \\
\text { Spotted frogs } \\
\end{array}$ & $\begin{array}{c}18 \\
\text { present }\end{array}$ & 4.4 & $1.7-6.9$ & 19.0 & 5.7 \\
\hline & 1.5 & $15 \mathrm{~N}, 6 \mathrm{~W}, 9 \mathrm{C}$ & 24-Jul-06 & 325 & CT & 2 & 2 & 1 & 4.1 & $3.3-4.8$ & 0.6 & 0.3 \\
\hline & & & & & EB & 10 & 10 & 1 & 4.6 & $3.7-6.2$ & 3.1 & 0.3 \\
\hline \multirow[t]{3}{*}{ Paymaster $\mathrm{Cr}$} & 0.4 & $15 \mathrm{~N}, 6 \mathrm{~W}, 20 \mathrm{D}$ & 24-Jul-06 & 321 & No fish & & & & & & & \\
\hline & 0.65 & $15 \mathrm{~N}, 6 \mathrm{~W}, 29 \mathrm{~A}$ & 24-Jul-06 & 300 & No fish & & & & & & & \\
\hline & 1.2 & $15 \mathrm{~N}, 6 \mathrm{~W}, 29 \mathrm{D}$ & 24-Jul-06 & 300 & No fish & & & & & & & \\
\hline
\end{tabular}


Appendix A : Catch and size statistics for tributaries to the Blackfoot River excluding the Clearwater Basin, 2006-2007 (cont'd).

\begin{tabular}{|c|c|c|c|c|c|c|c|c|c|c|c|c|}
\hline Stream & $\begin{array}{c}\text { River } \\
\text { Mile }\end{array}$ & Location $(\mathrm{T}, \mathrm{R}, \mathrm{S})$ & $\begin{array}{c}\text { Date } \\
\text { Sampled }\end{array}$ & $\begin{array}{l}\text { Section } \\
\text { Length (ft) }\end{array}$ & Species & $\begin{array}{l}\text { Total Number } \\
\text { Captured }\end{array}$ & $\begin{array}{c}\text { Number } \\
\text { Captured 1st } \\
\text { Pass }\end{array}$ & $\begin{array}{l}\text { YOY(<4.0") } \\
\text { Captured 1st } \\
\text { Pass }\end{array}$ & $\begin{array}{l}\text { Range of } \\
\text { Lengths (in) }\end{array}$ & $\begin{array}{c}\text { Mean } \\
\text { Length (in) }\end{array}$ & $\begin{array}{l}\text { CPUE }\left(\# / 100^{\prime}\right) \\
\text { in 1st Pass }\end{array}$ & $\begin{array}{l}\text { YOY CPUE } \\
\left(\# / 100^{\circ}\right) \text { in 1st } \\
\text { Pass }\end{array}$ \\
\hline Pearson Creek & 0.5 & $15 \mathrm{~N}, 13 \mathrm{~W}, 33 \mathrm{D}$ & 18-Sep-06 & 300 & CT & 11 & 8 & 0 & $5.3-6.7$ & 6.0 & 2.7 & 0.0 \\
\hline \multirow[t]{4}{*}{ CPUE based on year class } & & & & & Spotted frogs & present & & & & & & \\
\hline & & & 11-Sep-07 & 300 & $\mathrm{CT}$ & 12 & 10 & 0 & $4.7-7.1$ & 5.8 & 3.3 & 0.0 \\
\hline & 1.1 & $14 \mathrm{~N}, 13 \mathrm{~W}, 3 \mathrm{~B}$ & 18-Sep-06 & 405 & CT & 96 & 74 & 6 & $2.5-8.1$ & 4.4 & 18.3 & 1.5 \\
\hline & & & & & $\begin{array}{c}\text { EB } \\
\text { Spotted frogs }\end{array}$ & $\begin{array}{c}1 \\
\text { present }\end{array}$ & 1 & 1 & 3.7 & 3.7 & 0.2 & 0.2 \\
\hline \multirow[t]{3}{*}{ CPUE based on year class } & & & 11-Sep-07 & 405 & $\mathrm{CT}$ & 93 & 83 & 4 & $3.1-8.4$ & 4.2 & 20.5 & 1.0 \\
\hline & & & & & EB & 4 & 4 & 2 & $3.0-6.3$ & 4.6 & 1.0 & 0.5 \\
\hline & & & & & $\begin{array}{c}\text { LNS } \\
\text { Spotted frogs }\end{array}$ & $\begin{array}{c}16 \\
\text { present }\end{array}$ & 16 & 15 & $3.0-4.5$ & 3.7 & 4.0 & 3.7 \\
\hline \multirow[t]{3}{*}{$\begin{array}{l}\text { Poorman Creek } \\
\text { Below lower ditch }\end{array}$} & 1.3 & $14 \mathrm{~N}, 9 \mathrm{~W}, 36 \mathrm{~A}$ & 10-Aug-06 & 490 & $\begin{array}{c}\mathrm{LL} \\
\text { Sculpins }\end{array}$ & $\begin{array}{c}88 \\
\text { present }\end{array}$ & 70 & 65 & $1.9-4.3$ & 3.1 & 14.3 & 13.3 \\
\hline & & & 16-Aug-07 & 490 & $\mathrm{LL}$ & 226 & 178 & 172 & $2.2-5.7$ & 2.9 & 36.3 & 35.1 \\
\hline & & & & & $\begin{array}{c}\text { Onc } \\
\text { Sculpins }\end{array}$ & $\begin{array}{c}87 \\
\text { present }\end{array}$ & 70 & 70 & $1.5-2.1$ & 1.8 & 14.3 & 14.3 \\
\hline \multirow[t]{4}{*}{ Above upper ditch } & 1.5 & $14 \mathrm{~N}, 9 \mathrm{~W}, 36 \mathrm{~A}$ & 10-Aug-06 & 290 & LL & 97 & 79 & 71 & $1.7-13.6$ & 3.5 & 27.2 & 24.5 \\
\hline & & & & & $\begin{array}{c}\text { EB } \\
\text { Sculpins }\end{array}$ & $\begin{array}{c}4 \\
\text { present }\end{array}$ & $\begin{array}{c}4 \\
\text { Western toad }\end{array}$ & $\begin{array}{c}3 \\
\text { observed }\end{array}$ & $2.1-5.8$ & 3.6 & 1.4 & 1.0 \\
\hline & & & 16-Aug-07 & 270 & $\mathrm{CT}$ & 89 & 76 & 76 & $1.6-2.2$ & 1.8 & 28.1 & 28.1 \\
\hline & & & & & $\begin{array}{c}\text { LL } \\
\text { Sculpins }\end{array}$ & $\begin{array}{c}261 \\
\text { present }\end{array}$ & $\begin{array}{c}221 \\
\text { Spotted frogs }\end{array}$ & $\begin{array}{c}190 \\
\text { present }\end{array}$ & $2.3-10.6$ & 3.2 & 81.9 & 70.4 \\
\hline Rock Creek & 1.6 & $14 \mathrm{~N}, 11 \mathrm{~W}, 5 \mathrm{~A}$ & 6-Sep-06 & 510 & DV & 1 & 1 & 0 & 11.1 & 11.1 & 0.2 & 0.0 \\
\hline \multirow{17}{*}{ Below forks } & & & & & LL & 52 & 40 & 24 & $2.0-15.1$ & 4.6 & 7.8 & 4.7 \\
\hline & & & & & $\begin{array}{c}\text { EB } \\
\text { Sculpins }\end{array}$ & $\begin{array}{c}46 \\
\text { abundant }\end{array}$ & 41 & 35 & $1.7-10.5$ & 3.5 & 8.0 & 6.9 \\
\hline & & & 15-Aug-07 & 510 & LL & 63 & 50 & 31 & $1.8-10.4$ & 4.1 & 9.8 & 6.1 \\
\hline & & & & & $\mathrm{EB}$ & 31 & 21 & 16 & $2.6-8.7$ & 3.8 & 4.1 & 3.1 \\
\hline & & & & & $\begin{array}{l}\text { Onc } \\
\text { Sculpins }\end{array}$ & $\begin{array}{c}2 \\
\text { abundant }\end{array}$ & 0 & 2 & 1.7 & 1.7 & 0.0 & 0.4 \\
\hline & 3.9 & $15 \mathrm{~N}, 11 \mathrm{~W}, 35 \mathrm{~B}$ & 13-Aug-07 & 405 & CT & 1 & 1 & 0 & 7.7 & 7.7 & 0.2 & 0.0 \\
\hline & & & & & $\mathrm{LL}$ & 7 & 7 & 0 & $4.1-8.4$ & 6.3 & 1.7 & 0.0 \\
\hline & & & & & EB & 18 & 16 & 1 & $3.6-8.3$ & 6.6 & 4.0 & 0.2 \\
\hline & & & & & $\mathrm{RB}$ & 1 & 0 & 0 & 8.4 & 8.4 & 0.0 & 0.0 \\
\hline & & & & & RSS & 5 & 3 & 3 & $2.1-3.9$ & 3.2 & 0.7 & 0.7 \\
\hline & & & & & LNS & 1 & 1 & 1 & 2.6 & 2.6 & 0.2 & 0.2 \\
\hline & & & & & Sculpins & present & & & & & & \\
\hline & 6.4 & $15 \mathrm{~N}, 11 \mathrm{~W}, 24 \mathrm{D}$ & 13-Aug-07 & 525 & CT & 3 & 3 & 0 & $5.6-7.1$ & 6.4 & 0.6 & 0.0 \\
\hline & & & & & $\mathrm{LL}$ & 1 & 1 & 0 & 4.3 & 4.3 & 0.2 & 0.0 \\
\hline & & & & & EB & 42 & 35 & 4 & $2.1-7.9$ & 5.8 & 6.7 & 0.8 \\
\hline & & & & & Onc & 13 & 11 & 11 & $1.6-2.1$ & 1.9 & 2.1 & 2.1 \\
\hline & & & & & $\begin{array}{l}\text { LND } \\
\text { Sculpins }\end{array}$ & $\begin{array}{c}1 \\
\text { Present }\end{array}$ & 1 & 1 & 2.3 & 2.3 & 0.2 & 0.2 \\
\hline
\end{tabular}


Appendix A : Catch and size statistics for tributaries to the Blackfoot River excluding the Clearwater Basin, 2006-2007 (cont'd).

\begin{tabular}{|c|c|c|c|c|c|c|c|c|c|c|c|c|}
\hline Stream & $\begin{array}{l}\text { River } \\
\text { Mile }\end{array}$ & Location $(\mathrm{T}, \mathrm{R}, \mathrm{S})$ & $\begin{array}{c}\text { Date } \\
\text { Sampled }\end{array}$ & $\begin{array}{l}\text { Section } \\
\text { Length (ft) }\end{array}$ & Species & $\begin{array}{l}\text { Total Number } \\
\text { Captured }\end{array}$ & $\begin{array}{c}\text { Number } \\
\text { Captured 1st } \\
\text { Pass }\end{array}$ & $\begin{array}{l}\text { YOY(<4.0") } \\
\text { Captured 1st } \\
\text { Pass }\end{array}$ & $\begin{array}{l}\text { Range of } \\
\text { Lengths (in) }\end{array}$ & $\begin{array}{c}\text { Mean } \\
\text { Length (in) }\end{array}$ & $\begin{array}{c}\text { CPUE (\#/100') } \\
\text { in 1st Pass }\end{array}$ & $\begin{array}{l}\text { YOY CPUE } \\
\left(\# / 100^{\prime}\right) \text { in } 1 \text { st } \\
\text { Pass }\end{array}$ \\
\hline \multirow[t]{6}{*}{ Rock Creek (cont'd) } & 7.5 & $15 \mathrm{~N}, 10 \mathrm{~W}, 19 \mathrm{~B}$ & 15-Aug-07 & 435 & CT & 14 & 12 & 9 & $1.6-5.8$ & 3.1 & 2.8 & 2.1 \\
\hline & & & & & LL & 1 & 1 & 0 & 7.2 & 7.2 & 0.2 & 0.0 \\
\hline & & & & & EB & 128 & 100 & 65 & $2.2-13.4$ & 4.4 & 23.0 & 14.9 \\
\hline & & & & & LND & 5 & 5 & 5 & $2.6-3.2$ & 2.9 & 1.1 & 1.1 \\
\hline & & & & & Sucker & 1 & 1 & 0 & 5.6 & 5.6 & 0.2 & 0.0 \\
\hline & & & & & Sculpins & abundant & RSS present & Spotted frogs & present & & & \\
\hline \multirow[t]{12}{*}{ Sauerkraut Creek } & 0.2 & $14 \mathrm{~N}, 9 \mathrm{~W}, 29 \mathrm{C}$ & 30-Jul-07 & 755 & DV & 1 & 1 & 0 & 7.2 & 7.2 & 0.1 & 0.0 \\
\hline & & & & & CT & 83 & 65 & 29 & $1.4-9.9$ & 4.3 & 8.6 & 3.8 \\
\hline & & & & & LL & 57 & 49 & 40 & $2.1-8.7$ & 3.5 & 6.5 & 5.3 \\
\hline & & & & & $\mathrm{EB}$ & 134 & 97 & 39 & $1.9-9.9$ & 4.6 & 12.8 & 5.2 \\
\hline & & & & & Sculpins & abundant & Spotted frogs & common & & & & \\
\hline & 2.7 & $13 \mathrm{~N}, 9 \mathrm{~W}, 5 \mathrm{D}$ & 26-Jul-07 & 630 & $C T$ & 11 & 11 & 11 & $1.2-3.6$ & 2.3 & 1.7 & 1.7 \\
\hline & & & & & $\mathrm{EB}$ & 8 & 7 & 5 & $1.8-8.0$ & 3.3 & 1.1 & 0.8 \\
\hline & & & & & Sculpins & present & Spotted frogs & present & & & & \\
\hline & 3.2 & $13 \mathrm{~N}, 9 \mathrm{~W}, 8 \mathrm{~A}$ & 2-Aug-07 & 360 & DV & 1 & 1 & 0 & 6.8 & 6.8 & 0.3 & 0.0 \\
\hline & & & & & $\mathrm{CT}$ & 90 & 76 & 54 & $1.3-7.2$ & 3.5 & 21.1 & 15.0 \\
\hline & & & & & $E B$ & 4 & 4 & 1 & $3.7-8.7$ & 6.8 & 1.1 & 0.3 \\
\hline & & & & & Sculpins & abundant & & & & & & \\
\hline \multirow[t]{3}{*}{ Scotty Creek } & 0.2 & $16 \mathrm{~N}, 9 \mathrm{~W}, 8 \mathrm{D}$ & 12-Jul-06 & 403 & $\mathrm{RB}^{*}$ & 42 & 42 & 20 & $2.1-8.1$ & 4.2 & 10.4 & 5.0 \\
\hline & & & & & CT *** & 1 & 1 & 0 & 8.9 & 8.9 & 0.2 & 0.0 \\
\hline & & & & & Western toad & present & & & & & & \\
\hline \multirow[t]{11}{*}{ Shanley Creek } & 0.2 & $15 \mathrm{~N}, 13 \mathrm{~W}, 9 \mathrm{~B}$ & 14-Aug-06 & 360 & $\mathrm{CT}$ & 1 & 1 & 0 & 7.2 & 7.2 & 0.3 & 0.0 \\
\hline & & & & & LL & 32 & 28 & 3 & $2.2-10.1$ & 6.2 & 7.8 & 0.8 \\
\hline & & & & & EB & 11 & 9 & 5 & $2.3-8.0$ & 4.2 & 2.5 & 1.4 \\
\hline & & & & & Sculpins & common & Spotted & present & & & & \\
\hline & 1.4 & $15 \mathrm{~N}, 13 \mathrm{~W}, 3 \mathrm{~B}$ & 14-Aug-06 & 261 & $\mathrm{CT}$ & 24 & 19 & 1 & $1.7-6.2$ & 4.7 & 7.3 & 0.4 \\
\hline & & & & & $\begin{array}{c}\text { EB } \\
\text { Spotted frogs }\end{array}$ & $\begin{array}{c}16 \\
\text { common }\end{array}$ & 15 & 7 & $1.7-6.9$ & 4.0 & 5.7 & 2.7 \\
\hline & 1.6 & $15 \mathrm{~N}, 13 \mathrm{~W}, 3 \mathrm{~B}$ & 6-Sep-06 & 466 & $\mathrm{CT}$ & 53 & 43 & 16 & $1.2-10$ & 4.2 & 9.2 & 3.4 \\
\hline & & & & & $\mathrm{EB}$ & 16 & 13 & 7 & $1.9-7.1$ & 3.4 & 2.8 & 1.5 \\
\hline & & & & & Sculpins & abundant & Spotted frogs & abundant & & & & \\
\hline & 2 & $15 \mathrm{~N}, 13 \mathrm{~W}, 3 \mathrm{~A}$ & 14-Aug-06 & 285 & CT & 57 & 44 & 14 & $1.5-7.5$ & 4.3 & 15.4 & 4.9 \\
\hline & & & & & $\begin{array}{c}\text { EB } \\
\text { Sculpins }\end{array}$ & $\begin{array}{c}34 \\
\text { common }\end{array}$ & $\begin{array}{c}28 \\
\text { Spotted frogs }\end{array}$ & $\begin{array}{c}16 \\
\text { common }\end{array}$ & $2.0-7.7$ & 3.9 & 9.8 & 5.6 \\
\hline \multirow[t]{4}{*}{ Shave Creek } & 0.4 & $15 \mathrm{~N}, 6 \mathrm{~W}, 21 \mathrm{~B}$ & 24-Jul-06 & 300 & $\mathrm{CT}$ & 66 & 66 & 36 & 3.7 & $1.8-7.0$ & 22.0 & 12.0 \\
\hline & & & & & EB & 6 & 6 & 5 & 2.5 & $1.6-5.6$ & 2.0 & 1.7 \\
\hline & & & & & Sculpins & abundant & Spotted frogs & present & & & & \\
\hline & 0.9 & 15N,6W,21A \&16D & 24-Jul-06 & 345 & $\begin{array}{c}\text { CT } \\
\text { Sculpins }\end{array}$ & $\begin{array}{c}81 \\
\text { common }\end{array}$ & 81 & 35 & 4.4 & $1.9-7.2$ & 23.5 & 10.1 \\
\hline
\end{tabular}

*** Genetics testing pending 
Appendix A : Catch and size statistics for tributaries to the Blackfoot River excluding the Clearwater Basin, 2006-2007 (cont'd).

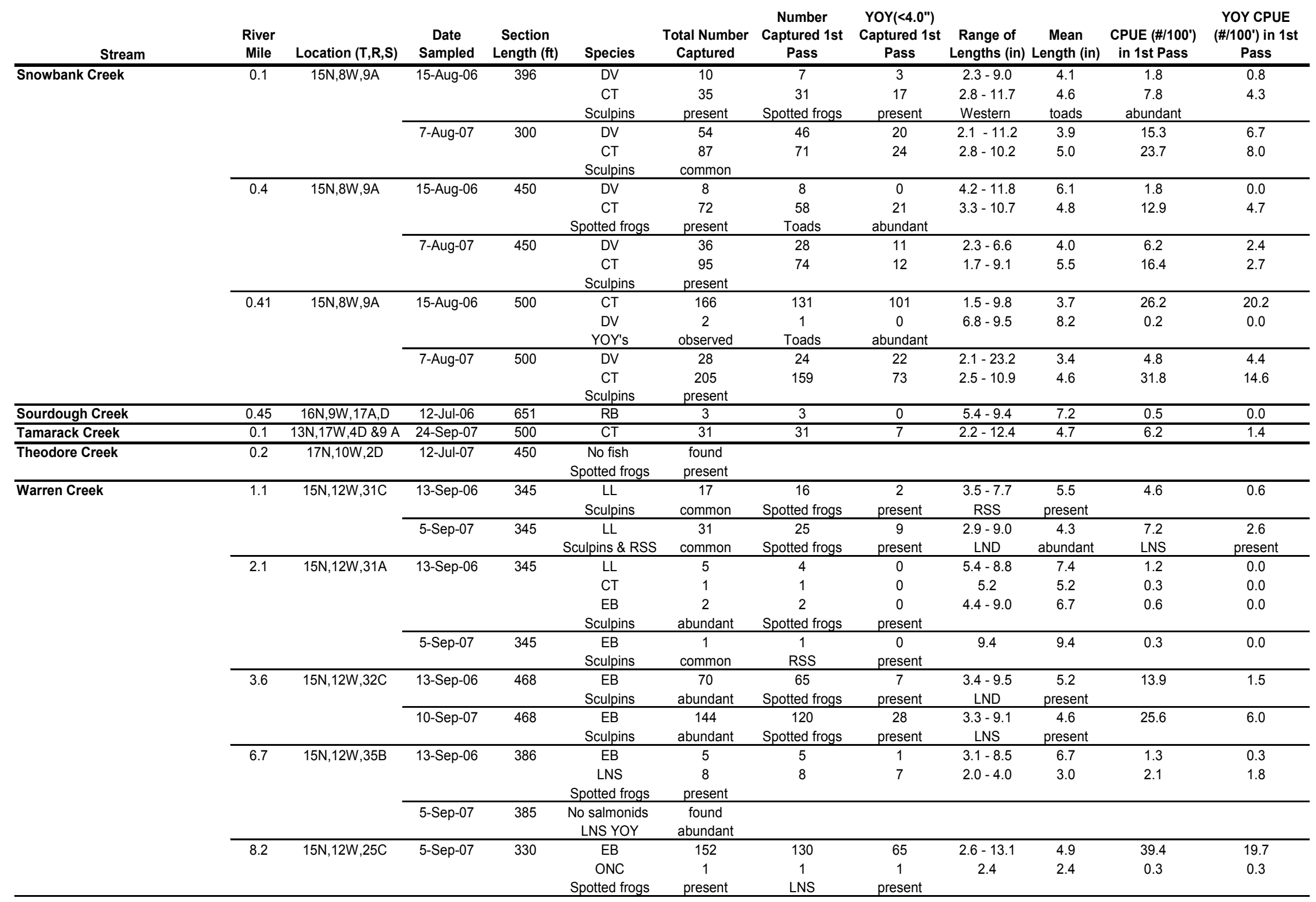


Appendix A : Catch and size statistics for tributaries to the Blackfoot River excluding the Clearwater Basin, 2006-2007 (cont'd).

\begin{tabular}{|c|c|c|c|c|c|c|c|c|c|c|c|c|}
\hline Stream & $\begin{array}{l}\text { River } \\
\text { Mile }\end{array}$ & Location $(\mathrm{T}, \mathrm{R}, \mathrm{S})$ & $\begin{array}{c}\text { Date } \\
\text { Sampled }\end{array}$ & $\begin{array}{l}\text { Section } \\
\text { Length (ft) }\end{array}$ & Species & $\begin{array}{l}\text { Total Number } \\
\text { Captured }\end{array}$ & $\begin{array}{c}\text { Number } \\
\text { Captured 1st } \\
\text { Pass }\end{array}$ & $\begin{array}{l}\text { YOY }(<4.0 ") \\
\text { Captured 1st } \\
\text { Pass }\end{array}$ & $\begin{array}{l}\text { Range of } \\
\text { Lengths (in) }\end{array}$ & $\begin{array}{c}\text { Mean } \\
\text { Length (in) }\end{array}$ & $\begin{array}{l}\text { CPUE (\#/100') } \\
\text { in 1st Pass }\end{array}$ & $\begin{array}{l}\text { YOY CPUE } \\
\left(\# / 100^{\prime}\right) \text { in 1st } \\
\text { Pass }\end{array}$ \\
\hline \multirow[t]{7}{*}{ Wasson Creek } & 0.1 & 13N,11W,11D & 17-Aug-06 & 300 & CT & 8 & 6 & 0 & $7.1-9.8$ & 8.5 & 2.0 & 0.0 \\
\hline & & & & & LL & 15 & 12 & 1 & $3.8-12.6$ & 6.8 & 4.0 & 0.3 \\
\hline & & & & & LNS & 2 & 2 & 0 & 5.7 & 5.7 & 0.7 & 0.0 \\
\hline & & & 14-Aug-07 & 300 & CT & 32 & 21 & 0 & $4.4-7.3$ & 5.5 & 7.0 & 0.0 \\
\hline & & & & & LL & 4 & 4 & 1 & $3.6-8.7$ & 6.9 & 1.3 & 0.3 \\
\hline & & & & & LNS & 2 & 2 & 0 & $4.3-5.2$ & 4.8 & 0.7 & 0.0 \\
\hline & & & & & RSS & 2 & 0 & 0 & $3.9-4.5$ & 4.2 & 0.0 & 0.0 \\
\hline \multirow[t]{2}{*}{ Below lower ditch } & 2.8 & $13 \mathrm{~N}, 10 \mathrm{~W}, 7 \mathrm{C}$ & 17-Aug-06 & 312 & $\mathrm{CT}$ & 23 & 19 & 4 & $1.9-7.0$ & 4.7 & 6.1 & 1.3 \\
\hline & & & 14-Aug-07 & 312 & CT & 52 & 45 & 13 & $1.4-8.1$ & 4.5 & 14.4 & 4.2 \\
\hline \multirow[t]{2}{*}{ Above upper ditch } & 3 & $13 \mathrm{~N}, 10 \mathrm{~W}, 7 \mathrm{C}$ & 17-Aug-06 & 300 & CT & 71 & 64 & 25 & $1.6-7.5$ & 4.4 & 21.3 & 8.3 \\
\hline & & & 14-Aug-07 & 300 & $\mathrm{CT}$ & 100 & 85 & 61 & $1.4-7.7$ & 3.6 & 28.3 & 20.3 \\
\hline Wedge Creek & 0.1 & $17 \mathrm{~N}, 12 \mathrm{~W}, 29 \mathrm{~A}$ & 22-Aug-06 & 312 & No fish found & & & & & & & \\
\hline Willow Creek & 1.7 & $14 \mathrm{~N}, 9 \mathrm{~W}, 28 \mathrm{~A}$ & 24-Jul-07 & 510 & LNS & 9 & 9 & 2 & $3.6-11.7$ & 6.0 & 1.8 & 0.4 \\
\hline \multirow[t]{9}{*}{ below Lincoln } & & & & & Sculpins & RSS \& LND & abundant, & & & & & \\
\hline & 3.6 & $14 \mathrm{~N}, 9 \mathrm{~W}, 34 \mathrm{~A}$ & 25-Jul-07 & 371 & No salmonids & found & Sculpins & common & Spotted & frogs & present & \\
\hline & 4.7 & $14 \mathrm{~N}, 9 \mathrm{~W}, 34 \mathrm{D}$ & 25-Jul-07 & 560 & $\mathrm{CT}$ & 19 & 17 & 6 & $1.5-7.2$ & 4.0 & 3.0 & 1.1 \\
\hline & & & & & EB & 23 & 21 & 9 & $2.0-7.5$ & 4.0 & 3.8 & 1.6 \\
\hline & & & & & Sculpins & abundant & Stopped frogs & present & LNS & present & & \\
\hline & 5.2 & $13 \mathrm{~N}, 9 \mathrm{~W}, 3 \mathrm{~A}$ & 24-Jul-07 & 300 & CT & 28 & 26 & 4 & $1.7-8.4$ & 4.5 & 8.7 & 1.3 \\
\hline & & & & & $\begin{array}{c}\text { EB } \\
\text { Sculpins }\end{array}$ & $\begin{array}{c}29 \\
\text { abundant }\end{array}$ & $\begin{array}{c}24 \\
\text { Spotted frogs }\end{array}$ & $\begin{array}{c}9 \\
\text { present }\end{array}$ & $2.0-7.4$ & 4.4 & 8.0 & 3.0 \\
\hline & 5.7 & $13 \mathrm{~N}, 9 \mathrm{~W}, 3 \mathrm{C}$ & 23-Jul-07 & 395 & CT & 73 & 60 & 28 & $1.3-8.5$ & 4.0 & 15.2 & 7.1 \\
\hline & & & & & $\begin{array}{c}\text { EB } \\
\text { Sculpins }\end{array}$ & $\begin{array}{c}42 \\
\text { abundant }\end{array}$ & $\begin{array}{c}35 \\
\text { Spotted frogs }\end{array}$ & $\begin{array}{l}15 \\
\text { present }\end{array}$ & $1.7-8.0$ & 4.3 & 8.9 & 3.8 \\
\hline Yellowjacket Creek & 0.1 & $17 \mathrm{~N}, 12 \mathrm{~W}, 32 \mathrm{C}$ & 22-Aug-06 & 300 & CT & 30 & 30 & 30 & $1.2-1.8$ & 1.5 & 10.0 & 10.0 \\
\hline
\end{tabular}

* Sample may include rainbow trout/ cutthroat trout hybrids

** Sample may include bull trout / brook trout hybrids

*** Genetics testing pending

$\mathrm{CT}=$ Cutthroat trout

DV = Bull trout (Dolly Varden)

$\mathrm{LL}=$ Brown trout (Loch Leven)

$\mathrm{RB}=$ Rainbow trout

$\mathrm{EB}=$ Eastern brook trout

MWF $=$ Monutain whitefis

LNS = Longnose sucker

LSS $=$ Largescale sucker

$\mathrm{LND}=$ Longnose dace

RSS $=$ Redside shiner

ONC = Oncorhynchus (undifferentiated) 
Appendix B: Two-pass depletion estimates for tributaries to the Blackfoot River excluding Clearwater Basin, 2006-2007.

\begin{tabular}{|c|c|c|c|c|c|c|c|c|c|c|c|c|}
\hline Stream & $\begin{array}{l}\text { River } \\
\text { Mile }\end{array}$ & Location $(T, R, S)$ & $\begin{array}{c}\text { Date } \\
\text { Sampled }\end{array}$ & $\begin{array}{c}\text { Section } \\
\text { Length ( } \mathrm{ft} \text { ) }\end{array}$ & Species & $\begin{array}{l}\text { Size Class } \\
\text { (inches) }\end{array}$ & 1st Pass & $\begin{array}{l}\text { 2nd } \\
\text { Pass }\end{array}$ & $\begin{array}{l}\text { 3rd } \\
\text { Pass }\end{array}$ & $\begin{array}{c}\text { Probability of } \\
\text { Capture }\end{array}$ & $\begin{array}{l}\text { Total Estimate } \pm \\
\mathrm{Cl}\end{array}$ & Estim/100 $\pm \mathrm{Cl}$ \\
\hline \multirow[t]{15}{*}{ Ashby Creek } & \multirow[t]{5}{*}{3} & \multirow[t]{5}{*}{$12 \mathrm{~N}, 16 \mathrm{~W}, 35 \mathrm{~B}$} & \multirow[t]{5}{*}{ 31-Jul-06 } & \multirow[t]{5}{*}{300} & \multirow[t]{2}{*}{ CT } & $<4.0$ & 34 & 15 & & 0.56 & $60.8 \pm 19.4$ & $20.3 \pm 6.5$ \\
\hline & & & & & & $>4.0$ & 25 & 1 & & 0.96 & $26 \pm 0.4$ & $8.7 \pm 0.1$ \\
\hline & & & & & $E B$ & $>4.0$ & 1 & 0 & & 1.00 & $1.0 \pm 0.0$ & $0.3 \pm 0.0$ \\
\hline & & & & & \multirow[t]{2}{*}{ All } & $<4.0$ & 34 & 15 & & 0.56 & $60.8 \pm 19.4$ & $20.3 \pm 6.5$ \\
\hline & & & & & & $>4.0$ & 26 & 1 & & 0.96 & $27 \pm 0.4$ & $9.0 \pm 0.1$ \\
\hline & \multirow[t]{10}{*}{4} & \multirow[t]{10}{*}{$12 \mathrm{~N}, 16 \mathrm{~W}, 3 \mathrm{~A}$} & \multirow[t]{5}{*}{ 31-Jul-06 } & \multirow[t]{5}{*}{300} & \multirow[t]{2}{*}{ CT } & $<4.0$ & 30 & 8 & & 0.73 & $40.8 \pm 6.0$ & $13.6 \pm 2.0$ \\
\hline & & & & & & $>4.0$ & 32 & 9 & & 0.72 & $44.5 \pm 6.8$ & $14.8+2.3$ \\
\hline & & & & & EB & $<4.0$ & 2 & 0 & & 1.00 & $2.0 \pm 0.0$ & $0.7 \pm 0.0$ \\
\hline & & & & & \multirow[t]{2}{*}{ All } & $<4.0$ & 32 & 8 & & 0.75 & $42.7 \pm 5.5$ & $14.2 \pm 1.8$ \\
\hline & & & & & & $>4.0$ & 32 & 9 & & 0.72 & $44.5 \pm 6.8$ & $14.8 \pm 2.3$ \\
\hline & & & \multirow[t]{5}{*}{ 9-Aug-07 } & \multirow[t]{5}{*}{300} & \multirow[t]{2}{*}{ CT } & $<4.0$ & 49 & 17 & & 0.65 & $75.0 \pm 13$ & $25.0 \pm 4.3$ \\
\hline & & & & & & $>4.0$ & 48 & 8 & & 0.83 & $57.6 \pm 3.5$ & $19.2 \pm 1.2$ \\
\hline & & & & & $E B$ & $<4.0$ & 21 & 4 & & 0.81 & $25.9+2.8$ & $8.6 \pm 0.9$ \\
\hline & & & & & \multirow[t]{2}{*}{ All } & $<4.0$ & 70 & 21 & & 0.70 & $100 \pm 11.4$ & $33.3 \pm 3.8$ \\
\hline & & & & & & $>4.0$ & 49 & 9 & & 0.82 & $60 \pm 4.1$ & $20 \pm 1.4$ \\
\hline Bear Creek & 1.1 & $13 \mathrm{~N}, 16 \mathrm{~W}, 18 \mathrm{~B}, 7 \mathrm{C}$ & 2-Aug-06 & 374 & RB & YOY $(<2.5)$ & 113 & 42 & & 0.63 & $179.9 \pm 23.0$ & $48.1 \pm 6.1$ \\
\hline & & & & & & Age $1+(>2.5)$ & 67 & 19 & & 0.72 & $93.5 \pm 10.0$ & $25.0 \pm 2.7$ \\
\hline & & & & & $\mathrm{LL}$ & YOY $(<3.0)$ & 4 & 1 & & 0.75 & $5.3 \pm 1.9$ & $1.4 \pm 0.5$ \\
\hline & & & & & & Age $1+(>3.0)$ & 9 & 1 & & 0.89 & $10.1 \pm 0.9$ & $2.7 \pm 0.2$ \\
\hline & & & & & $\mathrm{EB}$ & YOY $(<4.0)$ & 7 & 1 & & 0.86 & $8.2 \pm 1.1$ & $2.2 \pm 0.3$ \\
\hline & & & & & & Age $1+(>4.0)$ & 8 & 0 & & 1.00 & $8.0 \pm 0.0$ & $2.1 \pm 0.0$ \\
\hline & & & & & All & YOY & 11 & 2 & & 0.82 & $13.4 \pm 1.9$ & $3.6 \pm 0.5$ \\
\hline & & & & & & Age 1+ & 84 & 20 & & 0.76 & $110.3 \pm 8.2$ & $29.5 \pm 2.2$ \\
\hline & & & 8-Aug-07 & 374 & RB & YOY $(<3.0)$ & 101 & 32 & & 0.68 & $147.8 \pm 15.3$ & $39.5 \pm 4.1$ \\
\hline & & & & & & Age $1+(>3.0)$ & 100 & 21 & & 0.79 & $126.6 \pm 7.3$ & $33.8 \pm 1.9$ \\
\hline & & & & & LL & YOY $(<4.0)$ & 32 & 12 & & 0.63 & $51.2 \pm 12.5$ & $13.7 \pm 3.3$ \\
\hline & & & & & & Age $1+(>4.0)$ & 14 & 1 & & 0.93 & $15.08 \pm 0.6$ & $4.0 \pm 0.2$ \\
\hline & & & & & EB & YOY $(<4.0)$ & 4 & 0 & & 1.00 & $4.0 \pm 0.0$ & $1.1 \pm 0.0$ \\
\hline & & & & & & Age $1+(>4.0)$ & 10 & 0 & & 1.00 & $10.0 \pm 0.0$ & $2.7 \pm 0.0$ \\
\hline & & & & & All & YOY & 137 & 44 & & 0.68 & $201.8 \pm 18.4$ & $54.0 \pm 4.9$ \\
\hline & & & & & & Age $1+$ & 124 & 22 & & 0.82 & $150.8+6.2$ & $40.3+1.7$ \\
\hline Blackfoot River & 119.6 & $14 \mathrm{~N}, 7 \mathrm{~W}, 5 \mathrm{D}$ & 11-Sep-06 & 4000 & DV & $>4.0$ & 1 & 0 & & 1.00 & $1.0 \pm 0.0$ & $0.0 \pm 0.0$ \\
\hline (above Hogum $\mathrm{Cr}$ Rd) & & & & & CT & $<4.0$ & 28 & 12 & & 0.57 & $49 \pm 16.3$ & $1.2 \pm 0.4$ \\
\hline & & & & & & $>4.0$ & 20 & 4 & & 0.80 & $25 \pm 3.0$ & $0.6 \pm 0.1$ \\
\hline & & & & & LL & $<4.0$ & 9 & 5 & & 0.44 & $20.5 \pm 20.6$ & $0.5 \pm 0.5$ \\
\hline & & & & & & $>4.0$ & 6 & 2 & & 0.67 & $9.0 \pm 4.2$ & $0.2 \pm 0.1$ \\
\hline & & & & & EB & $<4.0$ & 5 & 4 & & 0.20 & $25 \pm 11.7 .6$ & $0.6 \pm 2.9$ \\
\hline & & & & & & $>4.0$ & 8 & 1 & & 0.88 & $9 . \overline{4} \pm 1.0$ & $0.2 \pm 0.0$ \\
\hline & & & & & MWF & $<4.0$ & 2 & 0 & & 1.00 & $2.0 \pm 0.0$ & $0.1 \pm 0.0$ \\
\hline & & & & & & $>4.0$ & 13 & 3 & & 0.77 & $16.9 \pm 3.1$ & $0.4 \pm 0.1$ \\
\hline & & & & & All & $<4.0$ & 44 & 21 & & 0.52 & $84.2 \pm 27.6$ & $2.1 \pm 0.7$ \\
\hline & & & & & & $>4.0$ & 47 & 10 & & 0.79 & $59.7 \pm 5.1$ & $1.5 \pm 0.1$ \\
\hline Blackfoot River & 124.3 & $15 \mathrm{~N}, 7 \mathrm{~W}, 35 \mathrm{~B}, 26 \mathrm{C}$ & 5-Sep-06 & 2457 & CT & $<4.0$ & 63 & 13 & & 0.79 & $79.4 \pm 5.6$ & $3.2 \pm 0.2$ \\
\hline (above Flesher Pass Rd) & & & & & & $>4.0$ & 12 & 5 & & 0.58 & $20.6 \pm 9.9$ & $0.8 \pm 0.4$ \\
\hline & & & & & $\mathrm{LL}$ & $>4.0$ & 1 & 0 & & 1.00 & $1.0 \pm 0.0$ & $0.0 \pm 0.0$ \\
\hline & & & & & EB & $<4.0$ & 64 & 17 & & 0.73 & $87.1 \pm 8.7$ & $3.5 \pm 0.4$ \\
\hline & & & & & & $>4.0$ & 27 & 9 & & 0.67 & $4.05 \pm 8.8$ & $1.6 \pm 0.4$ \\
\hline & & & & & LNS & $<4.0$ & 1 & 0 & & 1.00 & $1.0 \pm 0.0$ & $0.0 \pm 0.0$ \\
\hline & & & & & & $>4.0$ & 2 & 1 & & 0.50 & $4.0 \pm 6.8$ & $0.2 \pm 0.3$ \\
\hline & & & & & All & $<4.0$ & 128 & 30 & & 0.77 & $167.2 \pm 9.9$ & $6.8 \pm 0.4$ \\
\hline & & & & & & $>4.0$ & 42 & 15 & & 0.64 & $65.3+12.8$ & $2.7 \pm 0.5$ \\
\hline
\end{tabular}


Appendix B: Two-pass depletion estimates for tributaries to the Blackfoot River excluding Clearwater Basin, $2006-2007$ (cont'd).

\begin{tabular}{|c|c|c|c|c|c|c|c|c|c|c|c|c|}
\hline Stream & $\begin{array}{l}\text { River } \\
\text { Mile }\end{array}$ & Location (T,R,S) & $\begin{array}{c}\text { Date } \\
\text { Sampled }\end{array}$ & $\begin{array}{c}\text { Section } \\
\text { Length (ft) }\end{array}$ & Species & $\begin{array}{l}\text { Size Class } \\
\text { (inches) }\end{array}$ & 1st Pass & $\begin{array}{l}\text { 2nd } \\
\text { Pass }\end{array}$ & $\begin{array}{l}\text { 3rd } \\
\text { Pass }\end{array}$ & $\begin{array}{l}\text { Probability of } \\
\text { Capture }\end{array}$ & $\begin{array}{l}\text { Total Estimate } \pm \\
\qquad \mathrm{Cl}\end{array}$ & Estim/100' $\pm \mathrm{Cl}$ \\
\hline \multirow[t]{13}{*}{ Chamberlain Creek } & 0.1 & $15 \mathrm{~N}, 13 \mathrm{~W}, 32 \mathrm{~A}$ & 12-Sep-06 & 300 & CT & $<4.0$ & 111 & 14 & & 0.87 & $127 \pm 3.6$ & $42.3 \pm 1.2$ \\
\hline & & & & & & $>4.0$ & 33 & 5 & & 0.85 & $38.9 \pm 2.5$ & $13 \pm 0.8$ \\
\hline & & & & & LL & $<4.0$ & 13 & 0 & & 1.00 & $13 \pm 0.0$ & $4.3 \pm 0.0$ \\
\hline & & & & & & $>4.0$ & 8 & 0 & & 1.00 & $8.0 \pm 0.0$ & $2.7 \pm 0.0$ \\
\hline & & & & & All & $<4.0$ & 124 & 14 & & 0.89 & $139.8 \pm 3.3$ & $46.6 \pm 1.1$ \\
\hline & & & & & & $>4.0$ & 41 & 5 & & 0.88 & $46.7 \pm 2.1$ & $15.6 \pm 0.7$ \\
\hline & & & 10-Sep-07 & 300 & CT & $<4.0$ & 144 & 41 & & 0.72 & $201.3 \pm 14.8$ & $67.1 \pm 4.9$ \\
\hline & & & & & & $>4.0$ & 40 & 9 & & 0.78 & $51.6 \pm 5.1$ & $17.2 \pm 1.7$ \\
\hline & & & & & LL & $<4.0$ & 20 & 7 & & 0.65 & $30.8 \pm 8.4$ & $10.3 \pm 2.8$ \\
\hline & & & & & & $>4.0$ & 7 & 2 & & 0.71 & $9.8 \pm 3.3$ & $3.3 \pm 1.1$ \\
\hline & & & & & MWF & $<4.0$ & 1 & 0 & & 1.00 & $1.0 \pm 0.0$ & $0.3 \pm 0.0$ \\
\hline & & & & & All & $<4.0$ & 165 & 48 & & 0.71 & $232.7 \pm 16.6$ & $77.6 \pm 5.5$ \\
\hline & & & & & & $>4.0$ & 47 & 11 & & 0.77 & $61.4 \pm 6.0$ & $20.5 \pm 2.0$ \\
\hline \multirow[t]{16}{*}{ Cottonwood Creek } & 12.0 & $16 \mathrm{~N}, 14 \mathrm{~W}, 24 \mathrm{D}$ & 19-Sep-06 & 515 & CT & YOY $(<3.0)$ & 59 & 16 & & 0.73 & $81 \pm 8.7$ & $15.7 \pm 1.7$ \\
\hline & & & & & & Age $1+(>3.0)$ & 34 & 11 & & 0.68 & $50.3 \pm 9.3$ & $9.8 \pm 1.8$ \\
\hline & & & & & $\mathrm{DV}^{\pi \times}$ & YOY $(<4.0)$ & 4 & 0 & & 1.00 & $4.0 \pm 0.0$ & $0.8 \pm 0.0$ \\
\hline & & & & & & Age $1+(>4.0)$ & 4 & 0 & & 1.00 & $4.0 \pm 0.0$ & $0.8 \pm 0.0$ \\
\hline & & & & & $E B^{\pi \pi}$ & $<4.0$ & 8 & 0 & & 1.00 & $8.0 \pm 0.0$ & $1.6 \pm 0.0$ \\
\hline & & & & & & $>4.0$ & 2 & 1 & & 0.50 & $4.0 \pm 6.8$ & $0.8+1.3$ \\
\hline & & & & & All & $<4.0$ & 12 & 0 & & 1.00 & $12 \pm 0.0$ & $2.3 \pm 0.0$ \\
\hline & & & & & & $>4.0$ & 6 & 1 & & 0.83 & $7.2 \pm 1.2$ & $1.4 \pm 0.2$ \\
\hline & & & 18-Sep-07 & 515 & CT & YOY $(<3.0)$ & 63 & 18 & & 0.71 & $88.2 \pm 9.9$ & $17.1 \pm 1.9$ \\
\hline & & & & & & Age1+ $+(>3.0)$ & 45 & 18 & & 0.60 & $75 \pm 17.3$ & $14.6 \pm 3.4$ \\
\hline & & & & & DV & YOY $(<4.0)$ & 0 & 1 & & & & \\
\hline & & & & & & Age $1+(>4.0)$ & 3 & 0 & & 1.00 & $3.0 \pm 0.0$ & $0.6 \pm 0.0$ \\
\hline & & & & & $E B$ & $<4.0$ & 4 & 1 & & 0.75 & $5.3 \pm 1.9$ & $1.0 \pm 0.4$ \\
\hline & & & & & & $>4.0$ & 1 & 1 & & 0.00 & & \\
\hline & & & & & All & $<4.0$ & 4 & 2 & & 0.50 & $8.0 \pm 9.6$ & $1.6 \pm 1.9$ \\
\hline & & & & & & $>4.0$ & 4 & 1 & & 0.75 & $5.3 \pm 1.9$ & $1.0 \pm 0.4$ \\
\hline \multirow{7}{*}{$\begin{array}{l}\text { Enders Spring Creek } \\
\text { (trib to NFBLKFT) }\end{array}$} & 0.5 & $14 \mathrm{~N}, 11 \mathrm{~W}, 31 \mathrm{C}$ & 24-Aug-06 & 300 & DV & $>4.0$ & 1 & 1 & & 0.00 & & \\
\hline & & & & & EB & $<4.0$ & 53 & 0 & & 1.00 & $53.0 \pm 0.0$ & $17.7 \pm 0.0$ \\
\hline & & & & & & $>4.0$ & 5 & 2 & & 0.60 & $8.3 \pm 5.8$ & $2.8+1.9$ \\
\hline & & & 15-Aug-07 & 300 & EB & $<4.0$ & 59 & 26 & & 0.56 & $105.5 \pm 25.5$ & $35.2 \pm 8.5$ \\
\hline & & & & & & $>4.0$ & 19 & 6 & & 0.68 & $27.8 \pm 6.6$ & $9.3 \pm 2.2$ \\
\hline & & & & & $\mathrm{LL}$ & $>4.0$ & 2 & 0 & & 1.00 & $2.0 \pm 0.0$ & $0.7 \pm 0.0$ \\
\hline & & & & & MWF & $<4.0$ & 2 & 0 & & 1.00 & $2.0 \pm 0.0$ & $0.7 \pm 0.0$ \\
\hline \multirow[t]{7}{*}{ Gold Creek } & 1.9 & $14 \mathrm{~N}, 16 \mathrm{~W}, 30 \mathrm{D}$ & 14-Sep-06 & 400 & $\mathrm{RB}^{*}$ & $<4.0$ & 32 & 6 & & 0.81 & $39.4 \pm 3.4$ & $9.8 \pm 0.9$ \\
\hline & & & & & & $>4.0$ & 38 & 22 & & 0.42 & $90.2 \pm 49.6$ & $22.6 \pm 12.4$ \\
\hline & & & & & CT & $>4.0$ & 2 & 0 & & 1.00 & $2.0 \pm 0.0$ & $0.5 \pm 0.0$ \\
\hline & & & & & $\mathrm{LL}$ & $<4.0$ & 8 & 2 & & 0.75 & $10.7 \pm 2.8$ & $2.7 \pm 0.7$ \\
\hline & & & & & & $>4.0$ & 29 & 6 & & 0.79 & $36.6 \pm 3.8$ & $9.1 \pm 1.0$ \\
\hline & & & & & All & $<4.0$ & 40 & 8 & & 0.80 & $50 \pm 4.2$ & $12.5 \pm 1.1$ \\
\hline & & & & & & $>4.0$ & 69 & 28 & & 0.59 & $116.1 \pm 22.2$ & $29.0 \pm 5.5$ \\
\hline
\end{tabular}

** Sample may include bull trout / brook trout hybrids 
Appendix B: Two-pass depletion estimates for tributaries to the Blackfoot River excluding Clearwater Basin, 2006-2007 (cont'd).

\begin{tabular}{|c|c|c|c|c|c|c|c|c|c|c|c|c|}
\hline Stream & $\begin{array}{l}\text { River } \\
\text { Mile }\end{array}$ & Location $(\mathrm{T}, \mathrm{R}, \mathrm{S})$ & $\begin{array}{c}\text { Date } \\
\text { Sampled }\end{array}$ & $\begin{array}{c}\text { Section } \\
\text { Length (ft) }\end{array}$ & Species & $\begin{array}{c}\text { Size Class } \\
\text { (inches) }\end{array}$ & 1st Pass & $\begin{array}{l}\text { 2nd } \\
\text { Pass }\end{array}$ & $\begin{array}{l}\text { 3rd } \\
\text { Pass }\end{array}$ & $\begin{array}{c}\text { Probability of } \\
\text { Capture }\end{array}$ & $\begin{array}{l}\text { Total Estimate } \pm \\
\mathrm{Cl}\end{array}$ & Estim/100 $\pm \mathrm{Cl}$ \\
\hline \multirow[t]{5}{*}{ Hoyt Creek } & 0.2 & $15 \mathrm{~N}, 12 \mathrm{~W}, 19 \mathrm{~B}$ & 12-Sep-06 & 300 & $\mathrm{~EB}$ & $<4.0$ & 1 & 0 & & 1.00 & $1.0 \pm 0.0$ & $0.3 \pm 0.0$ \\
\hline & & & & & & $>4.0$ & 2 & 1 & & 0.50 & $4.0 \pm 6.8$ & $1.3 \pm 2.3$ \\
\hline & 1.2 & $15 \mathrm{~N}, 12 \mathrm{~W}, 19 \mathrm{C}$ & 12-Sep-06 & 300 & EB & $<4.0$ & 1 & 0 & & 1.00 & $1.0 \pm 0.0$ & $0.3 \pm 0.0$ \\
\hline & & & & & & $>4.0$ & 5 & 0 & & 1.00 & $5.0 \pm 0.0$ & $1.7 \pm 0.0$ \\
\hline & & & & & $\mathrm{LL}$ & $>4.0$ & 1 & 0 & & 1.00 & $1.0 \pm 0.0$ & $0.3 \pm 0.0$ \\
\hline \multirow{6}{*}{$\begin{array}{l}\text { New post restoration } \\
\text { section } 2007\end{array}$} & 2.7 & $15 \mathrm{~N}, 12 \mathrm{~W}, 29 \mathrm{C}$ & $4-S e p-07$ & 300 & EB & $<4.0$ & 1 & 0 & & 1.00 & $1.0 \pm 0.0$ & $0.3 \pm 0.0$ \\
\hline & & & & & & $>4.0$ & 1 & 0 & & 1.00 & $1.0 \pm 0.0$ & $0.3 \pm 0.0$ \\
\hline & 4.3 & $15 \mathrm{~N}, 12 \mathrm{~W}, 28 \mathrm{C}$ & 12-Sep-06 & 300 & $E B$ & $<4.0$ & 9 & 4 & & 0.56 & $16.2 \pm 10.2$ & $5.4 \pm 3.4$ \\
\hline & & & & & & $>4.0$ & 2 & 0 & & 1.00 & $2.0 \pm 0.0$ & $0.7 \pm 0.0$ \\
\hline & & & 4-Sep-07 & 300 & $E B$ & $<4.0$ & 4 & 0 & & 1.00 & $4.0 \pm 0.0$ & $1.3 \pm 0.0$ \\
\hline & & & & & & $>4.0$ & 5 & 1 & & 0.80 & $6.3 \pm 1.5$ & $2.1 \pm 0.5$ \\
\hline \multirow[t]{16}{*}{ Jacobson Spring Creek } & 0.6 & $14 \mathrm{~N}, 12 \mathrm{~W}, 1 \mathrm{CD}$ & 24-Aug-06 & 525 & $\overline{\mathrm{LL}}$ & $<4.0$ & 2 & 0 & & 1.00 & $2.0 \pm 0.0$ & $0.4 \pm 0.0$ \\
\hline & & & & & & $>4.0$ & 8 & 1 & & 0.88 & $9.1 \pm 1.0$ & $1.7 \pm 0.2$ \\
\hline & & & & & EB & $<4.0$ & 23 & 0 & & 1.00 & $23.0 \pm 0.0$ & $4.4 \pm 0.0$ \\
\hline & & & & & & $>4.0$ & 13 & 4 & & 0.69 & $18.8+5.2$ & $3.6 \pm 1.0$ \\
\hline & & & & & All & $<4.0$ & 25 & 0 & & 1.00 & $25.0 \pm 0.0$ & $4.8 \pm 0.0$ \\
\hline & & & & & & $>4.0$ & 21 & 5 & & 0.76 & $27.6 \pm 4.1$ & $5.3 \pm 0.8$ \\
\hline & & & 13-Aug-07 & 525 & LL & $<4.0$ & 6 & 2 & & 0.67 & $9.0 \pm 4.2$ & $1.7 \pm 0.8$ \\
\hline & & & & & & $>4.0$ & 11 & 2 & & 0.82 & $13.4 \pm 1.9$ & $2.6 \pm 0.4$ \\
\hline & & & & & RB & $<4.0$ & 1 & 0 & & 1.00 & $1.0 \pm 0.0$ & $0.2 \pm 0.0$ \\
\hline & & & & & & $>4.0$ & 1 & 1 & & 0.00 & & \\
\hline & & & & & EB & $<4.0$ & 44 & 8 & & 0.82 & $53.8 \pm 3.8$ & $10.2 \pm 0.7$ \\
\hline & & & & & & $>4.0$ & 15 & 2 & & 0.87 & $17.3 \pm 1.4$ & $3.3 \pm 0.3$ \\
\hline & & & & & All & $<4.0$ & 51 & 10 & & 0.80 & $63.4 \pm 4.6$ & $12.1 \pm 0.9$ \\
\hline & & & & & & $>4.0$ & 27 & 5 & & 0.81 & $33.1 \pm 3.1$ & $6.3 \pm 0.6$ \\
\hline & & & & & MWF & $<4.0$ & 6 & 2 & & 0.67 & $9.0 \pm 4.2$ & $1.7 \pm 0.8$ \\
\hline & & & & & & $>4.0$ & 0 & 1 & & & & \\
\hline \multirow[t]{2}{*}{ Kleinschmidt Creek } & 0.5 & $14 \mathrm{~N}, 11 \mathrm{~W}, 6 \mathrm{D}, 5 \mathrm{C}$ & 16-Aug-06 & 500 & $\mathrm{LL}$ & {$[<4.3]$} & 93 & 33 & & 0.65 & $144.2 \pm 18.8$ & $28.8 \pm 3.8$ \\
\hline & & & & & & {$[>4.3]$} & 27 & 12 & & 0.56 & $48.6 \pm 17.6$ & $9.7 \pm 3.5$ \\
\hline Post 2001 reconstruction & & & & & EB & {$[<4.3]$} & 1 & 0 & & 1.00 & $1.0 \pm 0.0$ & $0.2 \pm 0.0$ \\
\hline \multirow[t]{9}{*}{ E channel "woodless" section } & & & & & & {$[>4.3]$} & 1 & 1 & & 0.00 & & \\
\hline & & & & & All & {$[<4.3]$} & 94 & 33 & & 0.65 & $144.9 \pm 18.4$ & $29.0 \pm 3.7$ \\
\hline & & & & & & {$[>4.3]$} & 28 & 13 & & 0.54 & $52.3 \pm 20.3$ & $10.5 \pm 4.1$ \\
\hline & & & 22-Aug-07 & 500 & $\overline{\mathrm{LL}}$ & {$[<4.3]$} & 52 & 14 & & 0.73 & $71.2 \pm 8.0$ & $14.2 \pm 1.6$ \\
\hline & & & & & & {$[>4.3]$} & 27 & 13 & & 0.52 & $52.1 \pm 22.2$ & $10.4 \pm 4.4$ \\
\hline & & & & & EB & {$[<4.3$} & 2 & 1 & & 0.50 & $4.0+6.8$ & $0.8 \pm 1.4$ \\
\hline & & & & & All & {$[<4.3]$} & 54 & 15 & & 0.72 & $74.8 \pm 8.7$ & $15.0 \pm 1.7$ \\
\hline & & & & & & {$[>4.3]$} & 27 & 13 & & 0.52 & $52.1 \pm 22.2$ & $10.4 \pm 4.4$ \\
\hline & 0.8 & $14 \mathrm{~N}, 11 \mathrm{~W}, 5 \mathrm{C}$ & 16-Aug-06 & 500 & $\mathrm{LL}$ & {$[<4.3]$} & 120 & 40 & & 0.67 & $180 \pm 18.6$ & $36 \pm 3.7$ \\
\hline Post-2001 reconstruction & & based on 3 pass est & & & & {$[>4.3]$} & 32 & 20 & 7 & 0.54 & $64 \pm 7.0$ & $12.8+3.1$ \\
\hline \multirow{12}{*}{ E channel "woody"section } & & & & & $\mathrm{EB}$ & {$[<4.3]$} & 3 & 3 & & 0.00 & & \\
\hline & & & & & & {$[>4.3]$} & 3 & 5 & & & & \\
\hline & & & & & All & {$[<4.3]$} & 123 & 43 & & 0.65 & $189.1 \pm 20.9$ & $37.8 \pm 4.2$ \\
\hline & & based on 3 pass est & & & & {$[>4.3]$} & 35 & 25 & 7 & 0.53 & $73.2 \pm 7.9$ & $14.6+3.5$ \\
\hline & & & 22-Aug-07 & 500 & CT & {$[<4.3]$} & 1 & 0 & & 1.00 & $1.0 \pm 0.0$ & $0.2 \pm 0.0$ \\
\hline & & & & & DV & {$[>4.3]$} & 0 & 1 & & & & \\
\hline & & & & & $\mathrm{LL}$ & {$[<4.3]$} & 78 & 14 & & 0.82 & $95.06 \pm 5.0$ & $19.0 \pm 1.0$ \\
\hline & & & & & & {$[>4.3]$} & 49 & 16 & & 0.67 & $72.8+11.4$ & $14.6+2.3$ \\
\hline & & & & & EB & {$[<4.3[$} & 8 & 2 & & 0.75 & $10.7 \pm 2.8$ & $2.1 \pm 0.6$ \\
\hline & & & & & & {$[>4.3]$} & 4 & 2 & & 0.50 & $8.0 \pm 9.6$ & $1.6 \pm 1.9$ \\
\hline & & & & & All & {$[<4.3]$} & 87 & 16 & & 0.82 & $106.6 \pm 5.5$ & $21.3 \pm 1.1$ \\
\hline & & & & & & {$[>4.3]$} & 53 & 19 & & 0.64 & $82.6 \pm 14.5$ & $16.5 \pm 2.9283$ \\
\hline
\end{tabular}


Appendix B: Two-pass depletion estimates for tributaries to the Blackfoot River excluding Clearwater Basin, 2006-2007 (cont'd).

\begin{tabular}{|c|c|c|c|c|c|c|c|c|c|c|c|c|}
\hline Stream & $\begin{array}{l}\text { River } \\
\text { Mile }\end{array}$ & Location $(T, R, S)$ & $\begin{array}{c}\text { Date } \\
\text { Sampled }\end{array}$ & $\begin{array}{c}\text { Section } \\
\text { Length (ft) }\end{array}$ & Species & $\begin{array}{c}\text { Size Class } \\
\text { (inches) }\end{array}$ & 1st Pass & $\begin{array}{l}\text { 2nd } \\
\text { Pass }\end{array}$ & $\begin{array}{l}\text { 3rd } \\
\text { Pass }\end{array}$ & $\begin{array}{c}\text { Probability of } \\
\text { Capture }\end{array}$ & $\begin{array}{c}\text { Total Estimate } \pm \\
\mathrm{Cl}\end{array}$ & Estim/100' $\pm \mathrm{Cl}$ \\
\hline \multirow[t]{2}{*}{ Lincoln Spring Creek } & 3.8 & $14 \mathrm{~N}, 9 \mathrm{~W}, 13 \mathrm{D}$ & 21-Aug-07 & 321 & $\mathrm{LL}$ & $>4.0$ & 13 & 5 & & 0.62 & $21.1 \pm 8.4$ & $6.6 \pm 2.6$ \\
\hline & & & & & EB & $<4.0$ & 117 & 43 & & 0.63 & $185.0 \pm 22.8$ & $57.6 \pm 7.1$ \\
\hline \multirow[t]{3}{*}{ Pre-restoration } & & & & & & $>4.0$ & 20 & 8 & & 0.60 & $33.3 \pm 11.5$ & $10.4 \pm 3.6$ \\
\hline & & & & & All & $<4.0$ & 117 & 43 & & 0.63 & $185.0 \pm 22.8$ & $57.6 \pm 7.1$ \\
\hline & & & & & & $>4.0$ & 33 & 13 & & 0.61 & $54.5 \pm 14.3$ & $17.0 \pm 4.4$ \\
\hline \multirow[t]{6}{*}{ McCabe Creek } & 2.2 & $15 \mathrm{~N}, 12 \mathrm{~W}, 5 \mathrm{C}$ & 20-Aug-07 & 340 & CT & $\mathrm{YOY}(<3.0)$ & 97 & 7 & & 0.93 & $104.5 \pm 1.7$ & $31 \pm 0.5$ \\
\hline & & & & & & Age $1+(>3.0)$ & 54 & 10 & & 0.81 & $66.3 \pm 4.4$ & $19.5 \pm 1.3$ \\
\hline & & & & & $\mathrm{EB}$ & YOY $(<3.0)$ & 23 & 3 & & 0.87 & $26.5 \pm 1.7$ & $7.8 \pm 0.5$ \\
\hline & & & & & & Age $1+(>3.0)$ & 22 & 2 & & 0.91 & $24.2 \pm 1.1$ & $7.1 \pm 0.3$ \\
\hline & & & & & All & YOY $(<3.0)$ & 120 & 10 & & 0.92 & $130.9 \pm 2.2$ & $38.5 \pm 0.7$ \\
\hline & & & & & & Age $1+(>3.0)$ & 76 & 12 & & 0.84 & $90.3 \pm 4.1$ & $26.5 \pm 1.2$ \\
\hline \multirow[t]{2}{*}{ Nevada Spring Creek } & $0.8(1.1)$ & $13 \mathrm{~N}, 11 \mathrm{~W}, 10 \mathrm{C}$ & 13-Sep-06 & 500 & CT & $>4.0$ & 5 & 0 & & 1.00 & $5.0 \pm 0.0$ & $1.0 \pm 0.0$ \\
\hline & & & & & $\overline{\mathrm{LL}}$ & $>4.0$ & 17 & 5 & & 0.71 & $24.1 \pm 5.4$ & $4.8 \pm 1.1$ \\
\hline Old stream mile was 0.8 & & & & & $\mathrm{RB}$ & $>4.0$ & 1 & 0 & & 1.00 & $1.0 \pm 0.0$ & $0.2 \pm 0.0$ \\
\hline \multirow[t]{9}{*}{ Post restoration stream mile ( ) } & & & & & NPM & $<4.0$ & 3 & 0 & & 1.00 & $3.0 \pm 0.0$ & $0.6 \pm 0.0$ \\
\hline & & & & & & $>4.0$ & 27 & 5 & & 0.81 & $33.1 \pm 3.1$ & $6.6 \pm 0.6$ \\
\hline & & & & & RSS & $<4.0$ & 15 & 15 & & 0.00 & & \\
\hline & & & & & & $>4.0$ & 7 & 1 & & 0.86 & $8.2 \pm 1.1$ & $1.6 \pm 0.2$ \\
\hline & & & & & Sucker & $<4.0$ & 1 & 0 & & 1.00 & $1.0 \pm 0.0$ & $0.2 \pm 0.0$ \\
\hline & & & & & All & $<4.0$ & 19 & 15 & & 0.21 & $90.3 \pm 203.6$ & $18.1 \pm 40.7$ \\
\hline & & & & & & $>4.0$ & 57 & 11 & & 0.81 & $70.6 \pm 4.8$ & $14.1+1.0$ \\
\hline & & & 12-Sep-07 & 500 & $\mathrm{CT}$ & $>4.0$ & 12 & 1 & & 0.92 & $13.1 \pm 0.7$ & $2.6+0.1$ \\
\hline & & & & & $\mathrm{LL}$ & $>4.0$ & 3 & 1 & & 0.67 & $4.5+2.9$ & $0.9+0.6$ \\
\hline Old stream mile was 3.0 & $3(3.5)$ & $13 \mathrm{~N}, 11 \mathrm{~W}, 11 \mathrm{D}$ & 13-Sep-06 & 470 & $\mathrm{CT}$ & $>4.0$ & 1 & 1 & & 0.00 & & \\
\hline \multirow[t]{8}{*}{ Post restoration stream mile ( ) } & & & & & $\overline{\mathrm{LL}}$ & $<4.0$ & 5 & 2 & & 0.60 & $8.3 \pm 5.8$ & $1.8 \pm 1.2$ \\
\hline & & & & & & $>4.0$ & 26 & 6 & & 0.77 & $33.8+4.3$ & $7.2 \pm 0.9$ \\
\hline & & & & & RSS & $<4.0$ & 1 & 2 & & & & \\
\hline & & & & & & $>4.0$ & 1 & 0 & & 1.00 & $1.0 \pm 0.0$ & $0.2 \pm 0.0$ \\
\hline & & & 12-Sep-07 & 470 & CT & $>4.0$ & 24 & 2 & & 0.92 & $26.2+1.0$ & $5.6+0.2$ \\
\hline & & & & & $\mathrm{LL}$ & $<4.0$ & 0 & 1 & & & & \\
\hline & & & & & & $>4.0$ & 21 & 4 & & 0.81 & $25.9+2.8$ & $5.5 \pm 0.6$ \\
\hline & & & & & All & $>4.0$ & 45 & 6 & & 0.87 & $51.9 \pm 2.5$ & $11.0 \pm 0.5$ \\
\hline \multirow[t]{11}{*}{ Pearson Creek } & 0.5 & $15 N, 13 W, 33 D$ & 18-Sep-06 & 300 & $\overline{C T Y O Y}$ & $<3.2$ & 0 & 0 & & & & \\
\hline & & & & & age $1+$ & $>3.2$ & 8 & 3 & & 0.63 & $12.8+6.2$ & $4.3+2.1$ \\
\hline & & & 11-Sep-07 & 300 & CTYOY & $<3.2$ & 0 & 0 & & & & \\
\hline & & & & & age $1+$ & $>3.2$ & 10 & 2 & & 0.80 & $12.5 \pm 2.1$ & $4.2 \pm 0.7$ \\
\hline & 1.1 & $14 \mathrm{~N}, 13 \mathrm{~W}, 3 \mathrm{~B}$ & 18-Sep-06 & 405 & CT YOY & $<3.2$ & 6 & 3 & & 0.50 & $12 \pm 11.8$ & $3.0 \pm 2.9$ \\
\hline & & & & & age $1+$ & $>3.2$ & 68 & 19 & & 0.72 & $94 . \overline{4}+9.8$ & $23.3 \pm 2.4$ \\
\hline & & & & & EB & $<4.0$ & 1 & 0 & & 1.00 & $1.0 \pm 0.0$ & $0.2 \pm 0.0$ \\
\hline & & & 11-Sep-07 & 405 & CT YOY & $<3.2$ & 4 & 0 & & 1.00 & $4.0 \pm 0.0$ & $1.0 \pm 0.0$ \\
\hline & & & & & age $1+$ & $>3.2$ & 79 & 10 & & 0.87 & $90.5 \pm 3.1$ & $22.3 \pm 0.8$ \\
\hline & & & & & EB & $<4.0$ & 2 & 0 & & 1.00 & $2.0 \pm 0.0$ & $0.5 \pm 0.0284$ \\
\hline & & & & & & $>4.0$ & 2 & 0 & & 1.00 & $2.0 \pm 0.0$ & $0.5 \pm 0.0284$ \\
\hline
\end{tabular}


Appendix B: Two-pass depletion estimates for tributaries to the Blackfoot River excluding Clearwater Basin, 2006-2007 (cont'd).

\begin{tabular}{|c|c|c|c|c|c|c|c|c|c|c|c|c|}
\hline Stream & $\begin{array}{l}\text { River } \\
\text { Mile }\end{array}$ & Location $(T, R, S)$ & $\begin{array}{c}\text { Date } \\
\text { Sampled }\end{array}$ & $\begin{array}{l}\text { Section } \\
\text { Length (ft) }\end{array}$ & Species & $\begin{array}{c}\text { Size Class } \\
\text { (inches) }\end{array}$ & 1st Pass & $\begin{array}{l}\text { 2nd } \\
\text { Pass }\end{array}$ & $\begin{array}{c}\text { 3rd } \\
\text { Pass }\end{array}$ & $\begin{array}{c}\text { Probability of } \\
\text { Capture }\end{array}$ & $\begin{array}{c}\text { Total Estimate } \pm \\
\mathrm{Cl}\end{array}$ & Estim/100 $\pm \mathrm{Cl}$ \\
\hline \multirow[t]{2}{*}{ Poorman Creek } & 1.3 & $14 \mathrm{~N}, 9 \mathrm{~W}, 36 \mathrm{~A}$ & 10-Aug-06 & 490 & $\mathrm{LL}$ & $<4.0$ & 65 & 16 & & 0.75 & $86.2 \pm 7.6$ & $17.6 \pm 1.6$ \\
\hline & & & & & & $>4.0$ & 5 & 2 & & 0.60 & $8.3+5.8$ & $1.7+1.2$ \\
\hline \multirow[t]{6}{*}{ (Downstream of lowest Diversion) } & & & 16-Aug-07 & 490 & $\overline{\mathrm{LL}}$ & $<4.0$ & 172 & 48 & & 0.72 & $238.6 \pm 15.6$ & $48.7 \pm 3.2$ \\
\hline & & & & & & $>4.0$ & 6 & 0 & & 1.00 & $6.0+0.0$ & $1.2 \pm 0.0$ \\
\hline & & & & & $\mathrm{CT}$ & $<4.0$ & 70 & 17 & & 0.76 & $92.5 \pm 7.7$ & $18.9 \pm 1.6$ \\
\hline & & & & & All & $<4.0$ & 242 & 65 & & 0.73 & $330.9 \pm 17.2$ & $67.5 \pm 3.5$ \\
\hline & & & & & & $>4.0$ & 6 & 0 & & 1.00 & $6.0 \pm 0.0$ & $1.2 \pm 0.0$ \\
\hline & 1.5 & $14 \mathrm{~N}, 9 \mathrm{~W}, 36 \mathrm{~A}$ & 10-Aug-06 & 270 & LL & $<4.0$ & 71 & 14 & & 0.80 & $88.4+5.5$ & $30.5 \pm 1.9$ \\
\hline \multirow[t]{10}{*}{ (Upstream of upper diversion) } & & & & & & $>4.0$ & 8 & 4 & & 0.50 & $16.0+13.6$ & $5.5+4.7$ \\
\hline & & & & & $\mathrm{EB}$ & $<4.0$ & 3 & 0 & & 1.00 & $3.0 \pm 0.0$ & $1.0 \pm 0.0$ \\
\hline & & & & & & $>4.0$ & 1 & 0 & & 1.00 & $1.0 \pm 0.0$ & $0.3+0.0$ \\
\hline & & & & & All & $<4.0$ & 74 & 14 & & 0.81 & $91.3 \pm 5.3$ & $31.5 \pm 1.8$ \\
\hline & & & & & & $>4.0$ & 9 & 4 & & 0.56 & $16.2 \pm 10.2$ & $5.6+3.5$ \\
\hline & & & 16-Aug-07 & 270 & CT & $<4.0$ & 76 & 13 & & 0.83 & $91.7 \pm 4.6$ & $34.0 \pm 1.7$ \\
\hline & & & & & LL & $<4.0$ & 190 & 33 & & 0.83 & $230.0 \pm 7.4$ & $85.2 \pm 2.8$ \\
\hline & & & & & & $>4.0$ & 31 & 7 & & 0.77 & $40.04+4.6$ & $14.8+1.7$ \\
\hline & & & & & All & $<4.0$ & 266 & 46 & & 0.83 & $321.6 \pm 8.8$ & $119.1 \pm 3.2$ \\
\hline & & & & & & $>4.0$ & 31 & 7 & & 0.77 & $40.04+4.6$ & $14.8+1.7$ \\
\hline \multirow[t]{42}{*}{ Rock Creek } & 1.6 & $14 \mathrm{~N}, 11 \mathrm{~W}, 5 \mathrm{~A}$ & 6-Sep-06 & 510 & DV & $<4.0$ & 0 & 0 & & & & \\
\hline & & & & & & $>4.0$ & 1 & 0 & & 1.00 & $1.0 \pm 0.0$ & $0.2 \pm 0.0$ \\
\hline & & & & & $\mathrm{LL}$ & $<4.0$ & 24 & 7 & & 0.71 & $33.9 \pm 6.3$ & $6.6 \pm 1.2$ \\
\hline & & & & & & $>4.0$ & 16 & 5 & & 0.69 & $23.3 \pm 5.9$ & $4.6 \pm 1.2$ \\
\hline & & & & & EB & $<4.0$ & 35 & $\frac{5}{3}$ & & 0.91 & $38.3 \pm 1.2$ & $7.5 \pm 0.2$ \\
\hline & & & & & & $>4.0$ & 6 & 2 & & 0.67 & $9.0+4.2$ & $1.8+0.8$ \\
\hline & & & & & All & $<4.0$ & 59 & 10 & & 0.83 & $71 \pm 4.0$ & $13.9 \pm 0.8$ \\
\hline & & & & & & $>4.0$ & 23 & 7 & & $\begin{array}{l}0.03 \\
0.70\end{array}$ & $33.1 \pm 6.8$ & $6.5 \pm 1.3$ \\
\hline & & & 15-Aug-07 & 510 & $\mathrm{LL}$ & $<4.0$ & 31 & 9 & & 0.71 & $43.7 \pm 7.1$ & $8.6 \pm 1.4$ \\
\hline & & & & & & $>4.0$ & 19 & 4 & & 0.79 & $24.1 \pm 3.2$ & $4.7 \pm 0.6$ \\
\hline & & & & & EB & $<4.0$ & 16 & 8 & & 0.50 & $32.0 \pm 19.2$ & $6.3 \pm 3.8$ \\
\hline & & & & & & $>4.0$ & 5 & 2 & & 0.60 & $8.3+5.8$ & $1.6+1.1$ \\
\hline & & & & & Onc & $<4.0$ & 0 & 2 & & & & \\
\hline & & & & & All & $<4.0$ & 47 & $\frac{2}{19}$ & & 0.60 & $78.9 \pm 18.1$ & $15.5 \pm 3.6$ \\
\hline & & & & & & $>4.0$ & 24 & 6 & & 0.75 & $32.0+4.8$ & $6.3 \pm 0.9$ \\
\hline & 3.9 & $15 \mathrm{~N}, 11 \mathrm{~W}, 35 \mathrm{~B}$ & 13-Aug-07 & 405 & $\mathrm{LL}$ & $>4.0$ & 7 & 0 & & 1.00 & $7.0 \pm 0.0$ & $1.7 \pm 0.0$ \\
\hline & & & & & $\mathrm{CT}$ & $>4.0$ & 1 & 0 & & 1.00 & $1.0 \pm 0.0$ & $0.2 \pm 0.0$ \\
\hline & & & & & $\mathrm{RB}$ & $>4.0$ & 0 & 1 & & & & \\
\hline & & & & & $\mathrm{EB}$ & $<4.0$ & 1 & 1 & & 0.00 & & \\
\hline & & & & & & $>4.0$ & 15 & 1 & & 0.93 & $16.1 \pm 0.6$ & $4.0 \pm 0.1$ \\
\hline & & & & & All & $<4.0$ & 1 & 1 & & 0.00 & & \\
\hline & & & & & & $>4.0$ & 23 & 2 & & 0.91 & $25.2 \pm 1.0$ & $6.2 \pm 0.3$ \\
\hline & & & & & RSS & $<4.0$ & 3 & 1 & & 0.67 & $4.5 \pm 2.9$ & $1.1 \pm 0.7$ \\
\hline & & & & & & $>4.0$ & 0 & 1 & & & & \\
\hline & & & & & LNS & $<4.0$ & 1 & 0 & & 1.00 & $1.0 \pm 0.0$ & $0.2 \pm 0.0$ \\
\hline & 6.4 & $15 \mathrm{~N}, 11 \mathrm{~W}, 24 \mathrm{D}$ & 13-Aug-07 & 525 & CT & $>4.0$ & 3 & 0 & & 1.00 & $3.0 \pm 0.0$ & $0.6 \pm 0.0$ \\
\hline & & & & & $\mathrm{LL}$ & $>4.0$ & 1 & 0 & & 1.00 & $1.0 \pm 0.0$ & $0.2 \pm 0.0$ \\
\hline & & & & & $\mathrm{EB}$ & $<4.0$ & 4 & 1 & & 0.75 & $5.3 \pm 1.9$ & $1.0 \pm 0.4$ \\
\hline & & & & & & $>4.0$ & 31 & 6 & & 0.81 & $38.4+3.5$ & $7.3+0.7$ \\
\hline & & & & & Onc & $<4.0$ & 11 & 2 & & 0.82 & $13.4+1.9$ & $2.6+0.4$ \\
\hline & & & & & All & $<4.0$ & 15 & $\frac{2}{3}$ & & 0.02 & $18.8 \pm 2.6$ & $3.6 \pm 0.5$ \\
\hline & & & & & & $>4.0$ & 35 & 6 & & 0.83 & $42.2 \pm 3.1$ & $8.0 \pm 0.6$ \\
\hline & & & & & LND & $<4.0$ & $\frac{0}{1}$ & 0 & & 1.00 & $1.0 \pm 0.0$ & $0.2+0.0$ \\
\hline & 7.5 & $15 \mathrm{~N}, 10 \mathrm{~W}, 9 \mathrm{~B}$ & 15-Aug-07 & 435 & CT & $<4.0$ & 9 & 1 & & 0.89 & $10.1 \pm 0.9$ & $2.3 \pm 0.2$ \\
\hline & & & & & & $>4.0$ & 3 & 1 & & 0.67 & $4.5+2.9$ & $1.0+0.7$ \\
\hline & & & & & $\mathrm{LL}$ & $>4.0$ & $\frac{4}{1}$ & $\frac{1}{0}$ & & 1.00 & $1.0+0.0$ & $0.2+0.0$ \\
\hline & & & & & $\mathrm{EB}$ & $<4.0$ & 65 & 22 & & 0.66 & $98.3 \pm 14.1$ & $22.6 \pm 3.3$ \\
\hline & & & & & & $>4.0$ & 35 & 6 & & 0.83 & $42.2 \pm 3.1$ & $9.7 \pm 0.7$ \\
\hline & & & & & All & $<4.0$ & 74 & 23 & & 0.69 & $107.4 \pm 12.6$ & $24.7 \pm 2.9$ \\
\hline & & & & & & $>4.0$ & 39 & 7 & & 0.82 & $47.5+3.5$ & $10.9 \pm 0.8$ \\
\hline & & & & & LND & $<4.0$ & 5 & 0 & & 1.00 & $5.0 \pm 0.0$ & $1.1 \pm 0.0$ \\
\hline & & & & & Sucker & $>4.0$ & 1 & 0 & & 1.00 & $1.0+0.0$ & $0.2+0.0$ \\
\hline
\end{tabular}


Appendix B: Two-pass depletion estimates for tributaries to the Blackfoot River excluding Clearwater Basin, 2006-2007 (cont'd).

\begin{tabular}{|c|c|c|c|c|c|c|c|c|c|c|c|c|}
\hline Stream & $\begin{array}{c}\text { River } \\
\text { Mile }\end{array}$ & Location $(\mathrm{T}, \mathrm{R}, \mathrm{S})$ & $\begin{array}{c}\text { Date } \\
\text { Sampled }\end{array}$ & $\begin{array}{c}\text { Section } \\
\text { Length (ft) }\end{array}$ & Species & $\begin{array}{l}\text { Size Class } \\
\text { (inches) }\end{array}$ & 1st Pass & $\begin{array}{l}\text { 2nd } \\
\text { Pass }\end{array}$ & $\begin{array}{l}\text { 3rd } \\
\text { Pass }\end{array}$ & $\begin{array}{c}\text { Probability of } \\
\text { Capture }\end{array}$ & $\begin{array}{c}\text { Total Estimate } \pm \\
\mathrm{Cl}\end{array}$ & Estim $/ 100^{\prime} \pm \mathrm{Cl}$ \\
\hline \multirow[t]{21}{*}{ Sauerkraut Creek } & 0.2 & $14 \mathrm{~N}, 9 \mathrm{~W}, 29 \mathrm{C}$ & 30-Jul-07 & 755 & DV & $>4.0$ & 1 & 0 & & 1.00 & $1.0 \pm 0.0$ & $0.1 \pm 0.0$ \\
\hline & & & & & CT & $<4.0$ & 29 & 15 & & 0.48 & $60.1 \pm 28.9$ & $8.0 \pm 3.8$ \\
\hline & & & & & & $>4.0$ & 36 & 3 & & 0.92 & $39.3 \pm 1.2$ & $5.2 \pm 0.2$ \\
\hline & & & & & $\mathrm{LL}$ & $<4.0$ & 40 & 5 & & 0.88 & $45.7 \pm 2.1$ & $6.1 \pm 0.3$ \\
\hline & & & & & & $>4.0$ & 9 & 3 & & 0.67 & $13.5+5.1$ & $1.8 \pm 0.7$ \\
\hline & & & & & $\mathrm{EB}$ & $<4.0$ & 39 & 25 & & 0.36 & $108.6 \pm 78.0$ & $14.4 \pm 10.3$ \\
\hline & & & & & & $>4.0$ & 58 & 12 & & 0.79 & $73.1 \pm 5.4$ & $9.7 \pm 0.7$ \\
\hline & & & & & All & $<4.0$ & 108 & 45 & & 0.58 & $185.1 \pm 29.7$ & $24.5 \pm 3.9$ \\
\hline & & & & & & $>4.0$ & 104 & 18 & & 0.83 & $125.8+5.5$ & $16.7 \pm 0.7$ \\
\hline & 2.7 & $13 \mathrm{~N}, 9 \mathrm{~W}, 4 \mathrm{D}$ & 26-Jul-07 & 630 & CT & $<4.0$ & 11 & 0 & & 1.00 & $11.0 \pm 0.0$ & $1.7 \pm 0.0$ \\
\hline & & & & & $\mathrm{EB}$ & $<4.0$ & 5 & 1 & & 0.80 & $6.3 \pm 1.5$ & $1.0 \pm 0.2$ \\
\hline & & & & & & $>4.0$ & 2 & 0 & & 1.00 & $2.0 \pm 0.0$ & $0.3 \pm 0.0$ \\
\hline & & & & & All & $<4.0$ & 16 & 1 & & 0.94 & $17.1 \pm 0.6$ & $2.7 \pm 0.1$ \\
\hline & & & & & & $>4.0$ & 2 & 0 & & 1.00 & $2.0 \pm 0.0$ & $0.3+0.0$ \\
\hline & 3.2 & $13 \mathrm{~N}, 9 \mathrm{~W}, 8 \mathrm{~A}$ & 2-Aug-07 & 360 & DV & $>4.0$ & 1 & 0 & & 1.00 & $1.0 \pm 0.0$ & $0.3 \pm 0.0$ \\
\hline & & & & & CT & $<4.0$ & 54 & 12 & & 0.78 & $69.4 \pm 5.8$ & $19.3 \pm 1.6$ \\
\hline & & & & & & $>4.0$ & 22 & 2 & & 0.91 & $24.2+1.1$ & $6.7 \pm 0.3$ \\
\hline & & & & & $E B$ & $<4.0$ & 1 & 0 & & 1.00 & $1.0 \pm 0.0$ & $0.3 \pm 0.0$ \\
\hline & & & & & & $>4.0$ & 3 & 0 & & 1.00 & $3.0 \pm 0.0$ & $0.8 \pm 0.0$ \\
\hline & & & & & All & $<4.0$ & 55 & 12 & & 0.78 & $70.4 \pm 5.7$ & $19.5 \pm 1.6$ \\
\hline & & & & & & $>4.0$ & 26 & 2 & & 0.92 & $28.2 \pm 0.9$ & $7.8 \pm 0.3$ \\
\hline \multirow[t]{25}{*}{ Shanley Creek } & 0.2 & $15 \mathrm{~N}, 13 \mathrm{~W}, 9 \mathrm{~B}$ & 14-Aug-06 & 360 & CT & Age $1+(>4.0)$ & 1 & 0 & & 1.00 & $1.0 \pm 0.0$ & $0.3 \pm 0.0$ \\
\hline & & & & & $\mathrm{LL}$ & YOY $(<3.0)$ & 3 & 1 & & 0.67 & $4.5 \pm 2.9$ & $1.3 \pm 0.8$ \\
\hline & & & & & & Age $1+(>3.0)$ & 25 & 3 & & 0.88 & $28.4+1.6$ & $7.9 \pm 0.4$ \\
\hline & & & & & $E B$ & YOY $(<4.0)$ & 5 & 2 & & 0.60 & $8.3 \pm 5.8$ & $2.3 \pm 1.6$ \\
\hline & & & & & & Age $1+(>4.0)$ & 4 & 0 & & 1.00 & $4.0 \pm 0.0$ & $1.1 \pm 0.0$ \\
\hline & & & & & All & YOY & 8 & 3 & & 0.63 & $12.8 \pm 6.2$ & $3.6 \pm 1.7$ \\
\hline & & & & & & Age 1+ & 30 & 3 & & 0.90 & $33.3 \pm 1.4$ & $9.3 \pm 0.4$ \\
\hline & 1.4 & $15 \mathrm{~N}, 13 \mathrm{~W}, 3 \mathrm{~B}$ & 14-Aug-06 & 261 & CT & YOY $(<3.0)$ & 1 & 0 & & 1.00 & $1.0 \pm 0.0$ & $0.4 \pm 0.0$ \\
\hline & & & & & & Age $1+(>3.0)$ & 17 & 5 & & 0.71 & $24.1+5.4$ & $9.2+2.1$ \\
\hline & & & & & $\mathrm{EB}$ & YOY $(<3.0)$ & 6 & 1 & & 0.83 & $7.2 \pm 1.2$ & $2.8 \pm 0.5$ \\
\hline & & & & & & Age $1+(>3.0)$ & 9 & 0 & & 1.00 & $9.0 \pm 0.0$ & $3.4+0.0$ \\
\hline & & & & & All & YOY $(<3.0)$ & 7 & 1 & & 0.86 & $8.2 \pm 1.1$ & $3.1 \pm 0.4$ \\
\hline & & & & & & Age $1+(>3.0)$ & 26 & 5 & & 0.81 & $32.2+3.2$ & $12.3+1.2$ \\
\hline & 1.6 & $15 \mathrm{~N}, 13 \mathrm{~W}, 3 \mathrm{~B}$ & 6-Sep-06 & 466 & $\overline{C T}$ & YOY $(<3.0)$ & 13 & 3 & & 0.77 & $16.9 \pm 3.1$ & $3.6 \pm 0.7$ \\
\hline & & & & & & Age $1+(>3.0)$ & 30 & 7 & & 0.77 & $39.1 \pm 4.7$ & $8.4 \pm 1.0$ \\
\hline & & & & & $E B$ & YOY $(<3.0)$ & 7 & 3 & & 0.57 & $12.2 \pm 8.1$ & $2.6 \pm 1.7$ \\
\hline & & & & & & Age $1+(>3.0)$ & 6 & 0 & & 1.00 & $6.0 \pm 0.0$ & $1.3 \pm 0.0$ \\
\hline & & & & & All & YOY $(<3.0)$ & 20 & 6 & & 0.70 & $28.6 \pm 6.1$ & $6.1 \pm 1.3$ \\
\hline & & & & & & Age $1+(>3.0)$ & 36 & 7 & & 0.81 & $44.7 \pm 3.9$ & $9.6 \pm 0.8$ \\
\hline & 2 & $15 \mathrm{~N}, 13 \mathrm{~W}, 3 \mathrm{~A}$ & 14-Aug-06 & 285 & CT & YOY $(<3.0)$ & 12 & 2 & & 0.83 & $14.4 \pm 1.8$ & $5.1 \pm 0.6$ \\
\hline & & & & & & Age $1+(>3.0)$ & 32 & 11 & & 0.66 & $48.8+10.3$ & $17.1+3.6$ \\
\hline & & & & & $E B$ & YOY $(<3.0)$ & 14 & 3 & & 0.79 & $17.8 \pm 2.8$ & $6.3 \pm 1.0$ \\
\hline & & & & & & Age $1+(>3.0)$ & 14 & 3 & & 0.79 & $17.8+2.8$ & $6.3 \pm 1.0$ \\
\hline & & & & & All & YOY $(<3.0)$ & 26 & 5 & & 0.81 & $32.2 \pm 3.2$ & $11.3 \pm 1.1$ \\
\hline & & & & & & Age $1+(>3.0)$ & 46 & 14 & & 0.70 & $66.1+9.5$ & $23.2+3.4$ \\
\hline
\end{tabular}


Appendix B: Two-pass depletion estimates for tributaries to the Blackfoot River excluding Clearwater Basin, 2006-2007 (cont'd).

\begin{tabular}{|c|c|c|c|c|c|c|c|c|c|c|c|c|}
\hline Stream & $\begin{array}{l}\text { River } \\
\text { Mile }\end{array}$ & Location $(\mathrm{T}, \mathrm{R}, \mathrm{S})$ & $\begin{array}{c}\text { Date } \\
\text { Sampled }\end{array}$ & $\begin{array}{l}\text { Section } \\
\text { Length (ft) }\end{array}$ & Species & $\begin{array}{l}\text { Size Class } \\
\text { (inches) }\end{array}$ & 1st Pass & $\begin{array}{l}\text { 2nd } \\
\text { Pass }\end{array}$ & $\begin{array}{l}\text { 3rd } \\
\text { Pass }\end{array}$ & $\begin{array}{l}\text { Probability of } \\
\text { Capture }\end{array}$ & $\begin{array}{l}\text { Total Estimate } \pm \\
\mathrm{Cl}\end{array}$ & Estim/100' $\pm \mathrm{Cl}$ \\
\hline \multirow[t]{12}{*}{ Snowbank Creek } & \multirow[t]{12}{*}{0.1} & \multirow[t]{12}{*}{$15 \mathrm{~N}, 8 \mathrm{~W}, 9 \mathrm{~A}$} & \multirow[t]{6}{*}{ 15-Aug-06 } & \multirow[t]{6}{*}{396} & \multirow[t]{2}{*}{ DV } & $<4.0$ & 3 & 2 & & 0.33 & $9.0 \pm 26.3$ & $2.3 \pm 6.6$ \\
\hline & & & & & & $>4.0$ & 4 & 1 & & 0.75 & $5.3 \pm 1.9$ & $1.3 \pm 0.5$ \\
\hline & & & & & \multirow[t]{2}{*}{ CT } & $<4.0$ & 17 & 2 & & 0.88 & $19.3 \pm 1.3$ & $4.9 \pm 0.3$ \\
\hline & & & & & & $>4.0$ & 14 & 2 & & 0.86 & $16.3 \pm 1.5$ & $4.1 \pm 0.4$ \\
\hline & & & & & \multirow[t]{2}{*}{ All } & $<4.0$ & 20 & 4 & & 0.80 & $25 \pm 3.0$ & $6.3 \pm 0.8$ \\
\hline & & & & & & $>4.0$ & 18 & 3 & & 0.83 & $21.6 \pm 2.2$ & $5.5 \pm 0.5$ \\
\hline & & & \multirow[t]{6}{*}{ 7-Aug-07 } & \multirow[t]{6}{*}{300} & \multirow[t]{2}{*}{ DV } & $<4.0$ & 20 & 3 & & 0.85 & $23.5 \pm 2.0$ & $7.8 \pm 0.7$ \\
\hline & & & & & & $>4.0$ & 26 & 5 & & 0.81 & $32.2 \pm 3.2$ & $10.7 \pm 1.1$ \\
\hline & & & & & \multirow[t]{2}{*}{ CT } & $<4.0$ & 24 & 2 & & 0.92 & $26.2 \pm 1.0$ & $8.7 \pm 0.3$ \\
\hline & & & & & & $>4.0$ & 47 & 14 & & 0.70 & $66.9 \pm 9.2$ & $22.3 \pm 3.1$ \\
\hline & & & & & \multirow[t]{2}{*}{ All } & $<4.0$ & 44 & 5 & & 0.89 & $49.6 \pm 2.0$ & $16.5 \pm 0.7$ \\
\hline & & & & & & $>4.0$ & 73 & 19 & & 0.74 & $98.7 \pm 8.9$ & $32.9 \pm 3.0$ \\
\hline \multirow[t]{12}{*}{ below diversion } & \multirow[t]{12}{*}{0.4} & \multirow[t]{12}{*}{$15 \mathrm{~N}, 8 \mathrm{~W}, 9 \mathrm{~A}$} & \multirow[t]{6}{*}{ 15-Aug-06 } & 450 & DV & $<4.0$ & 0 & 0 & & & & \\
\hline & & & & & & $>4.0$ & 8 & 4 & & 0.50 & $16 \pm 13.6$ & $3.6 \pm 3.0$ \\
\hline & & & & & CT & $<4.0$ & 21 & 7 & & 0.67 & $31.5 \pm 7.8$ & $7.0 \pm 1.7$ \\
\hline & & & & & & $>4.0$ & 37 & 7 & & 0.81 & $45.6+3.7$ & $10.1 \pm 0.8$ \\
\hline & & & & & All & $<4.0$ & 21 & 7 & & 0.67 & $31.5 \pm 7.8$ & $7.0 \pm 1.7$ \\
\hline & & & & & & $>4.0$ & 45 & 11 & & 0.76 & $59.6 \pm 6.3$ & $13.2 \pm 1.4$ \\
\hline & & & 7-Aug-07 & 450 & DV & $<4.0$ & 11 & 2 & & 0.82 & $13.4 \pm 1.9$ & $3.0 \pm 0.4$ \\
\hline & & & & & & $>4.0$ & 17 & 6 & & 0.65 & $26.3 \pm 7.9$ & $5.8 \pm 1.8$ \\
\hline & & & & & CT & $<4.0$ & 12 & 3 & & 0.75 & $16.0 \pm 3.4$ & $3.6 \pm 0.7$ \\
\hline & & & & & & $>4.0$ & 62 & 18 & & 0.71 & $87.4 \pm 10.1$ & $19.4 \pm 2.2$ \\
\hline & & & & & All & $<4.0$ & 23 & 5 & & 0.78 & $29.4 \pm 3.7$ & $6.5 \pm 0.8$ \\
\hline & & & & & & $>4.0$ & 79 & 24 & & 0.70 & $113.5 \pm 12.5$ & $25.2 \pm 2.8$ \\
\hline above diversion & 0.41 & $15 \mathrm{~N}, 8 \mathrm{~W}, 9 \mathrm{~A}$ & 15-Aug-06 & 500 & DV & $<4.0$ & 0 & 0 & & & & \\
\hline & & & & & & $>4.0$ & 1 & 1 & & 0.00 & & \\
\hline & & & & & CT & $<4.0$ & 101 & 27 & & 0.73 & $137.8+11$ & $27.6+2.2$ \\
\hline & & & & & & $>4.0$ & 30 & 8 & & 0.73 & $40.9 \pm 6.0$ & $8.2 \pm 1.2$ \\
\hline & & & & & All & $<4.0$ & 101 & 27 & & 0.73 & $137.8 \pm 11$ & $27.6 \pm 2.2$ \\
\hline & & & & & & $>4.0$ & 31 & 9 & & 0.71 & $43.7 \pm 7.1$ & $8.7 \pm 1.4$ \\
\hline & & & 7-Aug-07 & 500 & DV & $<4.0$ & 22 & 4 & & 0.82 & $26.9 \pm 2.7$ & $5.4 \pm 0.5$ \\
\hline & & & & & & $>4.0$ & 2 & 0 & & 1.00 & $2.0 \pm 0.0$ & $0.4 \pm 0.0$ \\
\hline & & & & & CT & $<4.0$ & 73 & 24 & & 0.67 & $108.8 \pm 14.1$ & $21.8 \pm 2.8$ \\
\hline & & & & & & $>4.0$ & 86 & 22 & & 0.74 & $115.6 \pm 9.4$ & $23.1 \pm 1.9$ \\
\hline & & & & & All & $<4.0$ & 95 & 28 & & 0.71 & $134.7 \pm 12.9$ & $26.9 \pm 2.6$ \\
\hline & & & & & & $>4.0$ & 88 & 22 & & 0.75 & $117.3 \pm 9.1$ & $23.5 \pm 1.8$ \\
\hline Spring Creek, & 0.6 & $15 \mathrm{~N}, 11 \mathrm{~W}, 21 \mathrm{~B}$ & 14-Sep-06 & 385 & DV & $<4.0$ & 2 & 0 & & 1.00 & $2.0 \pm 0.0$ & $0.5 \pm 0.0$ \\
\hline trib to NFBLKFT & & & & & & $>4.0$ & 2 & 0 & & 1.00 & $2.0 \pm 0.0$ & $0.5 \pm 0.0$ \\
\hline (Murphy's Spring Cr) & & & & & CT & $<4.0$ & 61 & 26 & & 0.57 & $106.3 \pm 23.7$ & $27.6 \pm 6.1$ \\
\hline & & & & & & $>4.0$ & 15 & 2 & & 0.87 & $17.3 \pm 1.4$ & $4.5 \pm 0.4$ \\
\hline & & & & & EB & $<4.0$ & 11 & 5 & & 0.55 & $20.2 \pm 12$ & $5.2 \pm 3.1$ \\
\hline & & & & & & $>4.0$ & 4 & 2 & & 0.50 & $8.0 \pm 9.6$ & $2.1 \pm 2.5$ \\
\hline & & & & & All & $<4.0$ & 74 & 31 & & 0.58 & $127.3 \pm 24.9$ & $33.1 \pm 6.5$ \\
\hline & & & & & & $>4.0$ & 21 & 4 & & 0.81 & $25.9 \pm 2.8$ & $6.7 \pm 0.7$ \\
\hline & & & 6-Sep-07 & 385 & DV & $>4.0$ & 2 & 0 & & 1.00 & $2.0 \pm 0.0$ & $0.5 \pm 0.0$ \\
\hline & & & & & CT & $<4.0$ & 56 & 16 & & 0.71 & $78.4 \pm 9.3$ & $20.4 \pm 2.4$ \\
\hline & & & & & & $>4.0$ & 17 & 2 & & 0.88 & $19.3 \pm 1.3$ & $5.0 \pm 0.3$ \\
\hline & & & & & EB & $<4.0$ & 19 & 5 & & 0.74 & $25.8 \pm 4.7$ & $6.7 \pm 1.2$ \\
\hline & & & & & & $>4.0$ & 6 & 0 & & 1.00 & $6.0 \pm 0.0$ & $1.6 \pm 0.0$ \\
\hline & & & & & All & $<4.0$ & 75 & 21 & & 0.72 & $104.2 \pm 10.4$ & $27.1 \pm 2.7$ \\
\hline & & & & & & $>4.0$ & 25 & 2 & & 0.92 & $27.2 \pm 1.0$ & $7.1 \pm 0.3$ \\
\hline
\end{tabular}


Appendix B: Two-pass depletion estimates for tributaries to the Blackfoot River excluding Clearwater Basin, 2006-2007 (cont'd).

\begin{tabular}{|c|c|c|c|c|c|c|c|c|c|c|c|c|}
\hline Stream & $\begin{array}{l}\text { River } \\
\text { Mile }\end{array}$ & Location $(\mathrm{T}, \mathrm{R}, \mathrm{S})$ & $\begin{array}{c}\text { Date } \\
\text { Sampled }\end{array}$ & $\begin{array}{c}\text { Section } \\
\text { Length (ft) }\end{array}$ & Species & $\begin{array}{c}\text { Size Class } \\
\text { (inches) }\end{array}$ & 1st Pass & $\begin{array}{l}\text { 2nd } \\
\text { Pass }\end{array}$ & $\begin{array}{l}\text { 3rd } \\
\text { Pass }\end{array}$ & $\begin{array}{c}\begin{array}{c}\text { Probability of } \\
\text { Capture }\end{array} \\
\end{array}$ & $\begin{array}{c}\text { Total Estimate } \pm \\
\mathrm{Cl}\end{array}$ & Estim/100' $\pm \mathrm{Cl}$ \\
\hline \multirow[t]{22}{*}{ Warren Creek } & \multirow[t]{4}{*}{1.1} & \multirow[t]{4}{*}{$15 \mathrm{~N}, 12 \mathrm{~W}, 31 \mathrm{C}$} & \multirow[t]{2}{*}{ 13-Sep-06 } & \multirow[t]{2}{*}{345} & \multirow[t]{2}{*}{$\mathrm{LL}$} & $<4.0$ & 2 & 0 & & 1.00 & $2.0 \pm 0.0$ & $0.6 \pm 0.0$ \\
\hline & & & & & & $>4.0$ & 14 & 1 & & 0.93 & $15.8 \pm 0.6$ & $4.4 \pm 0.2$ \\
\hline & & & \multirow[t]{2}{*}{ 5-Sep-07 } & \multirow[t]{2}{*}{345} & \multirow[t]{2}{*}{ LL } & $<4.0$ & 9 & 5 & & 0.44 & $20.3 \pm 20.6$ & $5.9 \pm 6.0$ \\
\hline & & & & & & $>4.0$ & 16 & 1 & & 0.94 & $17.1 \pm 0.6$ & $4.9 \pm 0.2$ \\
\hline & \multirow[t]{8}{*}{2.1} & \multirow[t]{8}{*}{$15 \mathrm{~N}, 12 \mathrm{~W}, 31 \mathrm{~A}$} & \multirow[t]{7}{*}{ 13-Sep-06 } & \multirow[t]{7}{*}{345} & \multirow[t]{2}{*}{ LL } & $<4.0$ & 0 & 0 & & & & \\
\hline & & & & & & $>4.0$ & 4 & 1 & & 0.75 & $5.3 \pm 1.9$ & $1.5 \pm 0.6$ \\
\hline & & & & & \multirow[t]{2}{*}{ CT } & $<4.0$ & 0 & 0 & & & & \\
\hline & & & & & & $>4.0$ & 1 & 0 & & 1.00 & $1.0 \pm 0.0$ & $0.3 \pm 0.0$ \\
\hline & & & & & \multirow[t]{2}{*}{ EB } & $<4.0$ & 0 & 0 & & & & \\
\hline & & & & & & $>4.0$ & 2 & 0 & & 1.00 & $2.0 \pm 0.0$ & $0.6 \pm 0.0$ \\
\hline & & & & & All & $>4.0$ & 7 & 1 & & 0.86 & $8.2 \pm 1.1$ & $2.4 \pm 0.3$ \\
\hline & & & 5-Sep-07 & 345 & $E B$ & $>4.0$ & 1 & 0 & & 1.00 & $1.0 \pm 0.0$ & $0.3 \pm 0.0$ \\
\hline & \multirow[t]{4}{*}{3.6} & $15 \mathrm{~N}, 12 \mathrm{~W}, 32 \mathrm{C}$ & 13-Sep-06 & 468 & EB & $<4.0$ & 7 & 1 & & 0.86 & $8.2 \pm 1.1$ & $1.7 \pm 0.2$ \\
\hline & & & & & & $>4.0$ & 58 & 4 & & 0.93 & $62.3 \pm 1.2$ & $13.3 \pm 0.3$ \\
\hline & & & 10-Sep-07 & 468 & $\mathrm{~EB}$ & $<4.0$ & 28 & 6 & & 0.79 & $35.6 \pm 4.0$ & $7.6 \pm 0.8$ \\
\hline & & & & & & $>4.0$ & 92 & 18 & & 0.80 & $114.4 \pm 6.2$ & $24.4 \pm 1.3$ \\
\hline & 6.7 & $15 \mathrm{~N}, 12 \mathrm{~W}, 35 \mathrm{~B}$ & 13-Sep-06 & 386 & EB & $<4.0$ & 1 & 0 & & 1.00 & $1.0 \pm 0.0$ & $0.3 \pm 0.0$ \\
\hline & & & & & & $>4.0$ & 4 & 0 & & 1.00 & $4.0 \pm 0.0$ & $1.0 \pm 0.0$ \\
\hline & & & 5-Sep-07 & 385 & & No salomnids & present & & & & & \\
\hline & 8.2 & $15 \mathrm{~N}, 12 \mathrm{~W}, 25 \mathrm{C}$ & 5-Sep-07 & 330 & $\mathrm{~EB}$ & $<4.0$ & 65 & 16 & & 0.75 & $86.2 \pm 7.6$ & $26.1 \pm 2.3$ \\
\hline & & & & & & $>4.0$ & 65 & 6 & & 0.91 & $71.6 \pm 1.9$ & $21.7 \pm 0.6$ \\
\hline & & & & & Onc. & $<4.0$ & 1 & 0 & & 1.00 & $1.0 \pm 0.0$ & $0.3 \pm 0.0$ \\
\hline Wasson Creek & 0.1 & $13 \mathrm{~N}, 11 \mathrm{~W}, 11 \mathrm{D}$ & 17-Aug-06 & 300 & $\mathrm{CT}$ & $<4.0$ & 0 & 0 & & & & \\
\hline & & & & & & $>4.0$ & 6 & 2 & & 0.67 & $9.0 \pm 4.2$ & $3.0 \pm 1.4$ \\
\hline & & & & & LL & $<4.0$ & 1 & 1 & & 0.00 & & \\
\hline & & & & & & $>4.0$ & 11 & 2 & & 0.82 & $13.4 \pm 1.9$ & $4.5 \pm 0.6$ \\
\hline & & & & & LNS & $>4.0$ & 0 & 0 & & & & \\
\hline & & & & & & $>4.0$ & 2 & 0 & & 1.00 & $2.0 \pm 0.0$ & $0.7 \pm 0.0$ \\
\hline & & & & & All & $<4.0$ & 1 & 1 & & 0.00 & & \\
\hline & & & & & & $>4.0$ & 19 & 4 & & 0.79 & $24.1 \pm 3.2$ & $8.0 \pm 1.1$ \\
\hline & & & 14-Aug-07 & 300 & $\mathrm{CT}$ & $>4.0$ & 21 & 11 & & 0.48 & $44.1 \pm 25.6$ & $14.7 \pm 8.5$ \\
\hline & & & & & LL & $<4.0$ & 1 & 0 & & 1.00 & $1.0 \pm 0.0$ & $0.3 \pm 0.0$ \\
\hline & & & & & & $>4.0$ & 3 & 0 & & 1.00 & $3.0 \pm 0.0$ & $1.0 \pm 0.0$ \\
\hline & & & & & ALL & $<4.0$ & 1 & 0 & & 1.00 & $1.0 \pm 0.0$ & $0.3 \pm 0.0$ \\
\hline & & & & & & $>4.0$ & 24 & 11 & & 0.54 & $44.3 \pm 18.1$ & $14.8 \pm 6.0$ \\
\hline & & & & & LNS & $>4.0$ & 2 & 0 & & 1.00 & $2.0 \pm 0.0$ & $0.7 \pm 0.0$ \\
\hline & & & & & RSS & $>4.0$ & 0 & 2 & & & & \\
\hline Old stream mile was 0.6 & $0.6(1)$ & $13 \mathrm{~N}, 11 \mathrm{~W}, 13 \mathrm{~B}$ & 29-Aug-06 & 300 & $\mathrm{CT}$ & $<4.0$ & 0 & 0 & & & & \\
\hline Post restoration stream mile ( ) & & Based on 3 pass est & & & & $>4.0$ & 13 & 7 & 1 & 0.69 & $21.1 \pm 0.5$ & $7.0 \pm 0.3$ \\
\hline & & & & & LNS & $>4.0$ & 1 & 0 & & 1.00 & & \\
\hline & & & 14-Aug-07 & 300 & CT & $<4.0$ & 1 & 0 & & 1.00 & $1.0 \pm 0.0$ & $0.3 \pm 0.0$ \\
\hline & & & & & & $>4.0$ & 6 & 4 & & 0.33 & $18.0 \pm 37.2$ & $6.0 \pm 12.4$ \\
\hline & & & & & RSS & $<4.0$ & 0 & 2 & & & & \\
\hline Old stream mile was 2.4 & $2.4(2.8)$ & $13 \mathrm{~N}, 10 \mathrm{~W}, 7 \mathrm{C}$ & 17-Aug-06 & 312 & CT & $<4.0$ & 4 & 1 & & 0.75 & $5.3 \pm 1.9$ & $1.7 \pm 0.6$ \\
\hline Post restoration stream mile ( ) & & & & & & $>4.0$ & 15 & 3 & & 0.80 & $18.7 \pm 2.6$ & $6.0 \pm 0.8$ \\
\hline & & & 14-Aug-07 & 312 & CT & $<4.0$ & 13 & 3 & & 0.77 & $16.9 \pm 3.1$ & $5.4 \pm 1.0$ \\
\hline & & & & & & $>4.0$ & 32 & 4 & & 0.88 & $36.6 \pm 1.9$ & $11.7 \pm 0.6$ \\
\hline Old stream mile was 2.6 & $2.6(3)$ & $13 \mathrm{~N}, 10 \mathrm{~W}, 7 \mathrm{C}$ & 17-Aug-06 & 300 & CT & $<4.0$ & 25 & 2 & & 0.92 & $27.2 \pm 1.0$ & $9.1 \pm 0.3$ \\
\hline Post restoration stream mile ( ) & & & & & & $>4.0$ & 39 & 5 & & 0.87 & $44.7 \pm 2.2$ & $14.9 \pm 0.7$ \\
\hline & & & 14-Aug-07 & 300 & CT & $<4.0$ & 61 & 9 & & 0.85 & $71.6 \pm 3.3$ & $23.9 \pm 1.1$ \\
\hline & & & & & & $>4.0$ & 24 & 6 & & 0.75 & $32.0 \pm 4.8$ & $10.7 \pm 1.6$ \\
\hline
\end{tabular}


Appendix B: Two-pass depletion estimates for tributaries to the Blackfoot River excluding Clearwater Basin, 2006-2007 (cont'd).

\begin{tabular}{|c|c|c|c|c|c|c|c|c|c|c|c|c|}
\hline Stream & $\begin{array}{l}\text { River } \\
\text { Mile }\end{array}$ & Location (T,R,S) & $\begin{array}{l}\text { Date } \\
\text { Sampled }\end{array}$ & $\begin{array}{l}\text { Section } \\
\text { Length (ft) }\end{array}$ & Species & $\begin{array}{c}\text { Size Class } \\
\text { (inches) }\end{array}$ & 1st Pass & $\begin{array}{l}\text { 2nd } \\
\text { Pass }\end{array}$ & $\begin{array}{c}\text { 3rd } \\
\text { Pass }\end{array}$ & $\begin{array}{c}\text { Probability of } \\
\text { Capture }\end{array}$ & $\begin{array}{c}\text { Total Estimate } \pm \\
\mathrm{Cl}\end{array}$ & Estim $/ 100^{\prime} \pm \mathrm{Cl}$ \\
\hline Willow Creek & 1.7 & $14 \mathrm{~N}, 9 \mathrm{~W}, 28 \mathrm{D}$ & 24-Jul-07 & 510 & LNS & $<4.0$ & 2 & 0 & & 1.00 & $2.0 \pm 0.0$ & $0.4 \pm 0.0$ \\
\hline \multirow[t]{20}{*}{ below Lincoln } & & & & & & $>4.0$ & 7 & 0 & & 1.00 & $7.0 \pm 0.0$ & $1.4 \pm 0.0$ \\
\hline & 3.6 & $14 \mathrm{~N}, 9 \mathrm{~W}, 34 \mathrm{~A}$ & 25-Jul-07 & 371 & No fish & found & & & & & & \\
\hline & 4.7 & $13 \mathrm{~N}, 9 \mathrm{~W}, 34 \mathrm{D}$ & 25-Jul-07 & 560 & CT & $<4.0$ & 6 & 1 & & 0.83 & $7.2 \pm 1.2$ & $1.3 \pm 0.2$ \\
\hline & & & & & & $>4.0$ & 11 & 1 & & 0.91 & $12.1 \pm 0.7$ & $2.2 \pm 0.1$ \\
\hline & & & & & EB & $<4.0$ & 9 & 2 & & 0.78 & $11.6 \pm 2.4$ & $2.1 \pm 0.4$ \\
\hline & & & & & & $>4.0$ & 12 & 0 & & 1.00 & $12.0 \pm 0.0$ & $2.1 \pm 0.0$ \\
\hline & & & & & All & $<4.0$ & 15 & 3 & & 0.80 & $18.8 \pm 2.6$ & $3.3 \pm 0.5$ \\
\hline & & & & & & $>4.0$ & 23 & 1 & & 0.96 & $24.1 \pm 0.5$ & $4.3 \pm 0.1$ \\
\hline & 5.2 & $13 \mathrm{~N}, 9 \mathrm{~W}, 3 \mathrm{~A}$ & 24-Jul-07 & 300 & CT & $<4.0$ & 4 & 2 & & 0.50 & $8.0 \pm 9.6$ & $2.7 \pm 3.2$ \\
\hline & & & & & & $>4.0$ & 22 & 0 & & 1.00 & $22.0 \pm 0.0$ & $7.3 \pm 0.0$ \\
\hline & & & & & EB & $<4.0$ & 9 & 5 & & 0.44 & $20.3 \pm 20.6$ & $6.8 \pm 6.9$ \\
\hline & & & & & & $>4.0$ & 15 & 0 & & 1.00 & $15.0 \pm 0.0$ & $5.0 \pm 0.0$ \\
\hline & & & & & All & $<4.0$ & 13 & 7 & & 0.46 & $28.2 \pm 22.2$ & $9.4 \pm 7.4$ \\
\hline & & & & & & $>4.0$ & 37 & 0 & & 1.00 & $37.0 \pm 0.0$ & $12.3 \pm 0.0$ \\
\hline & 5.7 & $13 \mathrm{~N}, 9 \mathrm{~W}, 3 \mathrm{C}$ & 23-Jul-07 & 395 & CT & $<4.0$ & 28 & 8 & & 0.71 & $39.2 \pm 6.6$ & $9.9 \pm 1.7$ \\
\hline & & & & & & $>4.0$ & 32 & 5 & & 0.84 & $37.9 \pm 2.6$ & $9.6 \pm 0.7$ \\
\hline & & & & & EB & $<4.0$ & 15 & 5 & & 0.67 & $22.5 \pm 6.6$ & $5.7 \pm 1.7$ \\
\hline & & & & & & $>4.0$ & 20 & 2 & & 0.90 & $22.2+1.1$ & $5.6 \pm 0.3$ \\
\hline & & & & & All & $<4.0$ & 43 & 13 & & 0.70 & $61.6 \pm 9.1$ & $15.6 \pm 2.3$ \\
\hline & & & & & & $>4.0$ & 52 & 7 & & 0.87 & $60.1+2.7$ & $15.2+0.7$ \\
\hline
\end{tabular}

"Sample may include rainbow trout / cutthroat trout hybrids

Sample may include bull trout / brook trout hybrids

*** Genetics testing pending

$\mathrm{CT}=$ Cutthroat trout

DV = Bull trout (Dolly Varden)

$\mathrm{LL}=$ Brown trout (Loch Leven)

$\mathrm{RB}=$ Rainbow trout

$\mathrm{EB}=$ Eastern brook trout

$\mathrm{MWF}=$ Monutain whitefish

LNS = Longnose sucker

LSS $=$ Largescale sucke

LND = Longnose dace

RSS $=$ Redside shine

$\mathrm{ONC}=$ Oncorhynchus (undifferentiated) 
Appendix C: Mark and recapture and biomass estimates for the Blackfoot River, 2006.

\begin{tabular}{|c|c|c|c|c|c|c|c|c|c|c|c|c|c|c|}
\hline Stream & $\begin{array}{l}\text { River } \\
\text { Mile Mid- } \\
\text { point }\end{array}$ & $\begin{array}{l}\text { Date } \\
\text { Sampled }\end{array}$ & $\begin{array}{l}\text { Section } \\
\text { Length } \\
\text { (ft) }\end{array}$ & Species & $\begin{array}{l}\text { Size Class } \\
\text { (inches) }\end{array}$ & $\mathbf{M}$ & c & $\mathbf{R}$ & $(\mathrm{R} / \mathrm{C})$ & $\begin{array}{c}\text { Total Estimate } \pm \\
95 \% \mathrm{Cl}\end{array}$ & $\begin{array}{c}\text { Total } \\
\text { Biomass } \\
\text { (Ib/section) }\end{array}$ & $\begin{array}{l}\text { Estimate/1000 } \\
\quad \pm 95 \% \mathrm{Cl}\end{array}$ & $\begin{array}{l}\text { Biomass } \\
\text { (lb/1000') }\end{array}$ & $\begin{array}{l}\text { Condition } \\
\text { Factor } \\
\text { /1000 }\end{array}$ \\
\hline \multirow[t]{11}{*}{$\begin{array}{l}\text { Blackfoot River, } \\
\text { Johnsrud Section }\end{array}$} & \multirow[t]{11}{*}{13.5} & \multirow[t]{11}{*}{ 30-May-06 } & \multirow[t]{11}{*}{17680} & \multirow[t]{3}{*}{$\mathrm{RB}$} & $\begin{array}{c}5-9.9 \\
10-11.9\end{array}$ & $\begin{array}{c}355 \\
45\end{array}$ & $\begin{array}{l}319 \\
28\end{array}$ & $\begin{array}{c}46 \\
4\end{array}$ & $\begin{array}{l}0.14 \\
0.14\end{array}$ & $\begin{array}{c}2422.8+590.1 \\
265.8+183.4\end{array}$ & $\begin{array}{l}381.43 \\
130.73\end{array}$ & $\begin{array}{c}137.04+33.4 \\
15+10.4\end{array}$ & $\begin{array}{l}21.57 \\
7.39\end{array}$ & $\begin{array}{l}40.60 \\
36.77\end{array}$ \\
\hline & & & & & $>12$ & 77 & 70 & 14 & 0.20 & $368.2+144.4$ & 363.80 & $20.8+8.2$ & 20.58 & 33.75 \\
\hline & & & & & $\mathrm{RB}>6$ & 424 & 359 & 61 & 0.17 & $2466.7+512.4$ & 874.48 & $139.5+29$ & 49.46 & 38.36 \\
\hline & & & & \multirow[t]{3}{*}{$\overline{\mathrm{LL}}$} & $6-11.9$ & 78 & 54 & 13 & 0.24 & $309.4+123.01$ & 74.55 & $17.5+6.96$ & 4.22 & 41.65 \\
\hline & & & & & $>12$ & 44 & 29 & 12 & 0.41 & $102.9+34$ & 274.27 & $5.8+1.95$ & 15.51 & 39.74 \\
\hline & & & & & $\mathrm{LL}>6$ & 122 & 83 & 25 & 0.30 & $396.4+110.6$ & 161.64 & $22.42+6.26$ & 9.14 & 36.01 \\
\hline & & & & \multirow[t]{3}{*}{ CT } & $6-11.9$ & 63 & 47 & 6 & 0.13 & $437.9+265.3$ & 143.47 & $24.8+15$ & 8.12 & 43.09 \\
\hline & & & & & $>12$ & 19 & 11 & 5 & 0.45 & $39.0+17.5$ & 36.40 & $2.21+1.0$ & 2.06 & 34.91 \\
\hline & & & & & $\mathrm{CT}>6$ & 82 & 58 & 11 & 0.19 & $407.1 \pm 183.1$ & 181.16 & $23.03+10.36$ & 10.25 & 41.50 \\
\hline & & & & DV & $>6^{* *}$ & 13 & 8 & 1 & 0.13 & & & & & \\
\hline & & & & All & $>6$ & $\frac{13}{641}$ & 508 & $\frac{1}{98}$ & 0.19 & $3300 \pm 534$ & 1500.58 & $186.6 \pm 30.20$ & 84.87 & 38.92 \\
\hline \multirow{12}{*}{$\begin{array}{l}\text { Blackfoot River, } \\
\text { Scotty Brown Bridge }\end{array}$} & \multirow[t]{12}{*}{43.9} & \multirow[t]{12}{*}{ 25-May-06 } & \multirow[t]{12}{*}{20064} & \multirow[t]{4}{*}{$\mathrm{RB}$} & $4-10.9$ & 38 & 47 & 6 & 0.13 & $266.4+155.1$ & 59.80 & $13.3+7.7$ & 2.98 & 40.59 \\
\hline & & & & & $11-13.9$ & 22 & 24 & 4 & 0.17 & $114+72.8$ & 84.17 & $5.68+3.6$ & 4.19 & 39.01 \\
\hline & & & & & $>14$ & 30 & 33 & 9 & 0.27 & $104.4+43.1$ & 162.87 & $5.2+2.1$ & 8.12 & 34.24 \\
\hline & & & & & $\mathrm{RB}>6$ & 86 & 98 & 18 & 0.18 & $452.3+157.9$ & 360.70 & $22.54+7.9$ & 17.98 & 37.88 \\
\hline & & & & \multirow[t]{3}{*}{ LL } & $6-11.9$ & 46 & 55 & 12 & 0.22 & $201.5+79$ & 62.80 & $10.4+3.9$ & 3.13 & 38.92 \\
\hline & & & & & $>12$ & 39 & 41 & 13 & 0.32 & $119+40$ & 175.93 & $5.93+2.0$ & 8.77 & 36.01 \\
\hline & & & & & $\mathrm{LL}>6$ & 85 & 96 & 25 & 0.26 & $319.9+86.5$ & 259.96 & $15.9+4.3$ & 12.96 & 37.67 \\
\hline & & & & \multirow[t]{3}{*}{$\mathrm{CT}$} & $6-11.9$ & 44 & 67 & 10 & 0.15 & $277.2+125.3$ & 95.45 & $13.8+6.2$ & 4.76 & 38.21 \\
\hline & & & & & $>12$ & 46 & 45 & 16 & 0.36 & $126.2+37.3$ & 139.33 & $6.29+1.86$ & 6.94 & 37.29 \\
\hline & & & & & $\mathrm{CT}>6$ & 90 & 112 & 26 & 0.23 & $379.9+103.2$ & 253.81 & $18.9+5.1$ & 12.65 & 37.82 \\
\hline & & & & DV & $>6$ & 19 & 26 & 5 & 0.19 & $89.00+49.2$ & 168.21 & $4.44+2.5$ & 8.38 & 33.64 \\
\hline & & & & All & $>6$ & 280 & 332 & 74 & 0.22 & $1246.6+211.4$ & 1048.23 & $62.1+10.5$ & 52.24 & 37.48 \\
\hline \multirow{8}{*}{$\begin{array}{l}\text { Wales Creek } \\
\text { Section }\end{array}$} & \multirow[t]{7}{*}{63} & \multirow[t]{7}{*}{ 24-May-06 } & \multirow[t]{7}{*}{31635} & $\mathrm{RB}$ & $>6^{* *}$ & 6 & 3 & 0 & 0.00 & & & & & \\
\hline & & & & \multirow{3}{*}{$\frac{\mathrm{RB}}{\mathrm{LL}}$} & $6-11.9$ & 20 & 18 & 6 & 0.33 & $56+25.63$ & 23.22 & $1.77+0.81$ & 0.73 & 38.08 \\
\hline & & & & & $>12$ & 49 & 46 & 10 & 0.22 & $212.6+93.4$ & 299.56 & $6.72+2.95$ & 9.47 & 34.21 \\
\hline & & & & & $\mathrm{LL}>6$ & 69 & 64 & 16 & 0.25 & $266.7+92.5$ & 303.14 & $8.43+2.92$ & 9.58 & 35.27 \\
\hline & & & & CT & $\frac{L L}{>6^{* *}}$ & 3 & $\frac{44}{2}$ & 0 & 0.00 & & & & & \\
\hline & & & & DV & $>6^{* *}$ & 2 & 1 & 0 & 0.00 & & & & & \\
\hline & & & & All & $>6$ & 80 & 70 & 16 & 0.23 & $337.3+121$ & 371.08 & $10.7+3.8$ & 11.73 & 35.34 \\
\hline & 65 & 24-May-06 & 7603 & MWF & $>6$ & 70 & 85 & 4 & 0.05 & $1220+914$ & 706.84 & $160+120$ & 92.97 & 37.71 \\
\hline Canyon Section & 95.3 & $20-$ Sep-06 & 5422 & $\mathrm{CT}$ & $>6^{* *}$ & 4 & 6 & $\frac{4}{2}$ & 0.33 & $10.7+5.5$ & 11.17 & $2.0+1.0$ & 2.06 & 36.59 \\
\hline & & & & LL Age 1+ & $>4.5$ & 22 & 14 & 4 & 0.29 & $68.0+39.9$ & 59.12 & $12.5+7.4$ & 10.90 & 36.71 \\
\hline & & & & LL Age 2+ & $>8.5 * *$ & 15 & 9 & 3 & 0.33 & $39.0+23.5$ & 48.92 & $7.2 \pm 4.3$ & 4.90 & 37.29 \\
\hline & & & & & $\mathrm{LL}>6^{* *}$ & 21 & 13 & 3 & 0.23 & $76+52$ & 68.00 & $14+9.5$ & 12.54 & 36.49 \\
\hline & & & & All & $>6$ & 25 & 19 & 5 & 0.26 & $85.7+47.1$ & 79.33 & $15.8+8.7$ & 14.63 & 36.51 \\
\hline & & & & MWF & $6-11.9^{* *}$ & 28 & 19 & 3 & 0.16 & $144+105.6$ & 70.87 & $26.6+19.5$ & 13.07 & 36 \\
\hline & & & & & $>12$ & 149 & 102 & 21 & 0.21 & $701.3+235.1$ & 563.31 & $129.3+43.4$ & 103.89 & 34.78 \\
\hline & & & & & $M W F>6$ & $\frac{149}{177}$ & $\frac{102}{121}$ & $\frac{21}{24}$ & 0.20 & $\frac{1.3+23.1}{867.6+276}$ & $\frac{503.31}{653.60}$ & $160+51$ & 120.55 & $\frac{34.10}{34.97}$ \\
\hline$\overline{\text { Poorman - Dalton }}$ & 107.2 & 21-Sep-06 & 6800 & DV & $>6^{* *}$ & 2 & 0 & $\frac{1-1}{0}$ & & & & & & \\
\hline Section & & & & CT Age 1+ & $>3.0^{* *}$ & 12 & 5 & 1 & 0.20 & & & & & \\
\hline & & & & LL Age 1+ & $>4.5$ & 123 & 116 & 39 & 0.34 & $361.7+74.1$ & 192.2 & $53.2+10.9$ & 28.3 & 38.5 \\
\hline & & & & EB Age 1+ & $4.5-11.9^{* \star}$ & 0 & 1 & 0 & 0.00 & & & & & \\
\hline & & & & All Age 1+ & & 135 & $\frac{1}{122}$ & 40 & 0.33 & $407.0 \pm 84.2$ & 216.5 & $59.9 \pm 12.4$ & 31.8 & 39.6 \\
\hline & & & & All & $>6$ & 133 & 114 & 39 & 0.34 & $384.3 \pm 79.8$ & 217.2 & $56.5 \pm 11.7$ & 31.9 & 38.33 \\
\hline
\end{tabular}

** These estimates did not meet the minimal number of recaptures for a valid estimate and should be used with caution.

CT $=$ Cutthroat trout

$\mathrm{DV}=$ Cutthroat trout
$\mathrm{DV}=$ Bull trout (Dolly Varden)

$\mathrm{LL}=$ Brown trout (Loch Leve

$\mathrm{RB}=$ Rainbow trout
$\mathrm{MWF}$ = Mountain whitefish 
Appendix D: Summary of stream discharge measurements for 2006 and 2007.

\begin{tabular}{|c|c|c|c|c|c|c|c|}
\hline Stream name & $\begin{array}{c}\text { Legal } \\
\text { Description }\end{array}$ & $\begin{array}{c}\text { Stream } \\
\text { Mile }\end{array}$ & Date & $\begin{array}{l}\text { Discharge } \\
\text { (cfs) }\end{array}$ & Lat & Long & Location / Comments \\
\hline Bear Gulch & T14N,R9W,34D & 0.7 & 23-Jul-07 & 0.011 & N46.92245 & W112.71989 & $\sim 150$ ft upstream of Dalton Mtn Rd. \\
\hline Bear Gulch & T13N,R9W,3B & 1.2 & 24-Jul-07 & 0.026 & $\mathrm{~N} 46.91521$ & W112.72527 & \\
\hline Blanchard Creek & T14N,R14W,5B & 1 & 25-Sep-06 & 1.503 & N47.00349 & W113.40356 & Upstream of Richards diversion \\
\hline Cottonwood Lake & T16N,R14W,10A & & 26-Apr-07 & 0.026 & N47.16371 & W113.34865 & $\begin{array}{l}\text { Stream connecting upper and middle } \\
\text { Cottonwood Lakes }\end{array}$ \\
\hline Cottonwood Lake & T16N,R14W,3D & & 26-Apr-07 & 0.067 & N47.16725 & W113.35423 & $\begin{array}{l}\text { Stream connecting middle and lower } \\
\text { Cottonwood Lakes }\end{array}$ \\
\hline Douglas Creek & T12N,R11W,6B & 7.6 & 3-May-07 & 34.17 & $\mathrm{~N} 46.82523$ & W113.03197 & BLM land downstream of Huff Ranch \\
\hline Enders Spring Creek & T14N,R11W,6B & 0.2 & 30-May-07 & 6.553 & N47.00186 & W113.04422 & Discharge part of a pool-frequency survey \\
\hline Frazier Creek & T14N,R12W,28D & 0.2 & 22-May-07 & 0.739 & $\mathrm{~N} 46.93903$ & W113.12330 & $\begin{array}{l}\text { Downstream of lower Mannix irrigation ditch } \\
\# 1 \text {. Normal base flow from middle Frazier } \mathrm{Cr} \\
\text { reservoir. Ditch \# } 1 \text { open and ditch \#2 open. }\end{array}$ \\
\hline Frazier Creek & T14N,R12W,28D & 0.2 & 23-May-07 & 2.38 & N46.93903 & W113.12330 & $\begin{array}{l}\text { Downstream of lower Mannix irrigation ditch } \\
\text { \#1. Normal base flow from middle Frazier } \mathrm{Cr} \\
\text { reservoir. Ditch \# } 1 \text { \& } 2 \text { closed. }\end{array}$ \\
\hline Frazier Creek & T14N,R12W,28D & 0.3 & 23-May-07 & 3.323 & N46.93861 & W113.12386 & $\begin{array}{l}\text { Upstream of lower Mannix irrigation ditch \# } 1 . \\
\text { Normal base flow from middle Frazier } \mathrm{Cr} \\
\text { reservoir. Ditch \#1open \& ditch \#2 closed. }\end{array}$ \\
\hline Frazier Creek & T14N,R12W,28D & 0.2 & 31-May-07 & 7.325 & N46.93903 & W113.12330 & $\begin{array}{l}\text { Rating curve - Headgate on middle Frazier } \mathrm{Cr} \\
\text { reservoir opened } \sim 5 " \text {, lower Mannix irrigation } \\
\text { ditches \#1 \&\# } 2 \text { closed. } \\
\end{array}$ \\
\hline Frazier Creek & T14N,R12W,28D & 0.2 & 31-May-07 & 2.006 & N46.93903 & W113.12330 & $\begin{array}{c}\text { Rating curve - Headgate on middle Frazier } \mathrm{Cr} \\
\text { reservoir at normal setting, lower Mannix } \\
\text { irrigation ditches \#1 \& \#2 closed } \\
\end{array}$ \\
\hline Frazier Creek & $\mathrm{T} 14 \mathrm{~N}, \mathrm{R} 12 \mathrm{~W}, 28 \mathrm{D}$ & 0.2 & 31-May-07 & 1.392 & N46.93903 & W113.12330 & $\begin{array}{c}\text { Rating curve - Headgate on middle Frazier } \mathrm{Cr} \\
\text { reservoir at normal setting, Mannix irrigation } \\
\text { ditch \#1open, ditch \# } 2 \text { closed. } \\
\end{array}$ \\
\hline Frazier Creek & T14N,R12W,28D & 0.2 & 31-May-07 & 0.075 & N46.93903 & W113.12330 & $\begin{array}{l}\text { Rating curve - Headgate on middle Frazier } \mathrm{Cr} \\
\text { reservoir closed, Mannix irrigation ditches \#1 } \\
\& \# 2 \text { open.Tarp placed in stream channel to } \\
\text { divert water down ditch \#1 to obtain low flow } \\
\text { reading. }\end{array}$ \\
\hline $\begin{array}{l}\text { Upper irrigation ditch } \\
\text { from North Fork } \\
\text { Frazier Creek }\end{array}$ & T14N,R12W,28C & & 23-May-07 & 0.608 & N46.93967 & W113.13268 & $\begin{array}{l}\text { Measurement on Upper Mannix irrigation ditch } \\
\text { from North Fork Frazier Cr to upper pasture. }\end{array}$ \\
\hline Nevada Creek & T12N,R9W,34A & 32.5 & 3-May-07 & 57.46 & $\mathrm{~N} 46.75418$ & W112.71109 & Quiggley Ranch \\
\hline Sauerkraut $\mathrm{Cr}$ & T14N,R9W,29C & 0.15 & 26-Jul-07 & 1.756 & N46.93233 & W112.76775 & Lower Sauerkraut $\mathrm{Cr}$ above beaver complex \\
\hline Sauerkraut $\mathrm{Cr}$ & TT13N,R9W,5D & 2.7 & 26-Jul-07 & 0.506 & N46.90537 & W112.75443 & mainstem Sauerkraut $\mathrm{Cr}$ in old mining area \\
\hline Sauerkraut $\mathrm{Cr}$ & T13N,R9W,5D & 2.7 & 2-Aug-07 & 0.067 & N46.90675 & W112.75371 & $\begin{array}{l}\text { Split channel in old mining area, channel flows } \\
\text { east side of valley into upper beaver complex }\end{array}$ \\
\hline Sauerkraut $\mathrm{Cr}$ & T13N,R9W,8A & 3 & 26-Jul-07 & 0.93 & N46.90111 & W112.75749 & $\begin{array}{l}\text { Above old mining area on Helena National } \\
\text { Forest land }\end{array}$ \\
\hline Tamarack Creek & T13N,R17W,9A & 0.1 & 19-Sep-07 & 0.376 & $\mathrm{~N} 46.90673$ & W113.74987 & Lockwood property 0.1 upstream of lake \\
\hline Willow Creek & T14N,R9W,28A & 1.7 & 24-Jul-07 & 0.856 & N46.93544 & W112.73946 & lower Willow Creek \\
\hline Willow Creek & T14N,R9W,34A & 4.1 & 24-Jul-07 & 0.574 & N46.92444 & W112.71313 & Sunny Slope Grazing Assoc.land \\
\hline $\begin{array}{l}\text { Irrigation Ditch at } \\
\text { Willow Cr mile } 4.1\end{array}$ & T14N,R9W,34A & 4.1 & 24-Jul-07 & 0.321 & N46.92464 & W112.71288 & Sunny Slope Grazing Assoc.land \\
\hline $\begin{array}{l}\text { Irrigation Ditch at } \\
\text { Willow Cr mile } 4.3\end{array}$ & T14N,R9W,34A & 4.3 & 24-Jul-07 & 0.509 & N46.92299 & W112.71372 & Sunny Slope Grazing Assoc.land \\
\hline $\begin{array}{l}\text { Willow Creek (east } \\
\text { channel) }\end{array}$ & T14N,R9W,34D & 4.7 & 25-Jul-07 & 1.775 & N46.91635 & W112.71190 & Sunny Slope Grazing Assoc.land \\
\hline $\begin{array}{l}\text { Willow Creek (west } \\
\text { channel) }\end{array}$ & T14N,R9W,34D & 4.7 & 25-Jul-07 & 0.719 & N46.91595 & W112.71220 & Sunny Slope Grazing Assoc.land \\
\hline Willow Creek & T13N,R9W,3A & 5.2 & 24-Jul-07 & 1.411 & N46.90910 & W112.71300 & Gerald Biresch land \\
\hline Willow Creek & T13N,R9W,3C & 5.7 & 23-Jul-07 & 1.259 & N46.90171 & W112.72139 & $\begin{array}{l}\text { Plum Creek Timber Co. land above Sunny } \\
\text { Slope Grazing Assoc. land }\end{array}$ \\
\hline
\end{tabular}


Appendix E: Restoration Streams and Table of Activities.

\begin{tabular}{|c|c|c|c|c|c|c|c|c|c|c|c|c|}
\hline \multicolumn{13}{|c|}{ Blackfoot River Basin } \\
\hline Stream Name & $\begin{array}{l}\text { Fish passage } \\
\text { improvement }\end{array}$ & $\begin{array}{c}\text { Prevent } \\
\text { Irrigation } \\
\text { ditch losses }\end{array}$ & $\begin{array}{l}\text { Spawning } \\
\text { habitat } \\
\text { protection }\end{array}$ & $\begin{array}{l}\text { Channel } \\
\text { restoration }\end{array}$ & $\begin{array}{l}\text { Fish habitat } \\
\text { improvement }\end{array}$ & $\begin{array}{c}\text { Riparian } \\
\text { vegetation } \\
\text { improvement }\end{array}$ & $\begin{array}{l}\text { Improve } \\
\text { instream } \\
\text { flows }\end{array}$ & $\begin{array}{l}\text { Improve } \\
\text { wetlands }\end{array}$ & $\begin{array}{c}\text { Improve } \\
\text { range/ } \\
\text { riparian } \\
\text { habitat }\end{array}$ & $\begin{array}{l}\text { Improve } \\
\text { irrigation }\end{array}$ & $\begin{array}{c}\text { Conservation } \\
\text { easements }\end{array}$ & $\begin{array}{c}\text { Remove } \\
\text { streamside } \\
\text { feedlots }\end{array}$ \\
\hline \multicolumn{13}{|l|}{ Alice Creek } \\
\hline \multicolumn{13}{|l|}{ Arkansas Creek } \\
\hline Arrastra Creek & $\mathbf{X}$ & & & & & & & & & & & \\
\hline Ashby Creek & $\mathbf{X}$ & $\mathbf{X}$ & & $\mathbf{X}$ & $\mathbf{X}$ & $\mathbf{X}$ & $\mathbf{X}$ & $\mathrm{X}$ & $\mathbf{X}$ & $\mathrm{X}$ & $\mathrm{X}$ & \\
\hline \multicolumn{13}{|l|}{ Bartlett Creek } \\
\hline Basin Spring Creek & & & & $\mathrm{X}$ & $\mathbf{X}$ & $\mathrm{X}$ & $\mathbf{X}$ & $\mathbf{X}$ & $\mathbf{X}$ & $\mathrm{X}$ & $\mathrm{X}$ & $\mathrm{X}$ \\
\hline Bear Creek (Blackfoot trib. At R.M. 12.2) & $\mathrm{X}$ & & & $\mathrm{X}$ & $\mathbf{X}$ & $\mathbf{X}$ & $\mathbf{X}$ & & $\mathbf{X}$ & $\mathbf{X}$ & & $\mathbf{X}$ \\
\hline \multicolumn{13}{|l|}{ Bear Creek (Blackfoot trib.at R.M. 37.5) } \\
\hline \multicolumn{13}{|l|}{ Bear Creek (North Fork drainage) } \\
\hline \multicolumn{13}{|l|}{ Bear Gulch } \\
\hline Beaver Creek & $\mathrm{X}$ & $\mathrm{X}$ & & & & & & $\mathrm{X}$ & & $\mathrm{X}$ & $\mathrm{X}$ & \\
\hline Belmont Creek & $\mathrm{X}$ & & $\mathbf{X}$ & & & & & & $\mathbf{X}$ & & & \\
\hline \multicolumn{13}{|l|}{ Black Bear Creek } \\
\hline Blackfoot River (mouth to Clearwater) & & & & & & & $\mathbf{X}$ & & & & $\mathrm{X}$ & \\
\hline Blackfoot River (Clearwater to N.F.) & & & & & & & $\mathbf{X}$ & & $\mathbf{X}$ & & $\mathbf{X}$ & \\
\hline Blackfoot River (N.F. to Nevada Creek) & & & & & & & & $\mathbf{X}$ & $\bar{X}$ & & $\mathrm{X}$ & \\
\hline Blackfoot River (Nevada Cr. to Arrastra Cr.) & & & & & & & & $\mathbf{X}$ & $\mathbf{X}$ & $\mathbf{X}$ & $\mathbf{X}$ & $\mathrm{X}$ \\
\hline \multicolumn{13}{|l|}{ Blackfoot River (Arrastra Cr. to Lincoln, MT) } \\
\hline \multicolumn{13}{|l|}{ Blackfoot River (Lincoln, MT to Headwaters) } \\
\hline \multicolumn{13}{|l|}{ Braziel Creek } \\
\hline \multicolumn{13}{|l|}{ Buffalo Gulch } \\
\hline \multicolumn{13}{|l|}{ Burnt Bridge Creek } \\
\hline \multicolumn{13}{|l|}{ California Gulch } \\
\hline \multicolumn{13}{|l|}{ Camas Creek } \\
\hline Chamberlain Creek & $\mathrm{X}$ & $\mathbf{X}$ & $\mathbf{X}$ & $\mathrm{X}$ & $\mathrm{X}$ & $\mathbf{X}$ & $\mathbf{X}$ & $\mathrm{X}$ & $\mathbf{X}$ & $\mathbf{X}$ & $\mathrm{X}$ & $\mathbf{X}$ \\
\hline \multicolumn{13}{|l|}{ Chamberlain Creek, East Fork } \\
\hline Chamberlain Creek, West Fork & & & & & & & & & $\mathrm{X}$ & & & \\
\hline \multicolumn{13}{|l|}{ Chicken Creek } \\
\hline \multicolumn{13}{|l|}{ Chimney Creek (Douglas Cr tributary) } \\
\hline \multicolumn{13}{|l|}{ Chimney Creek (Nevada Cr tributary) } \\
\hline \multicolumn{13}{|l|}{ Clear Creek } \\
\hline \multicolumn{13}{|l|}{ Copper Creek } \\
\hline Cottonwood Creek (Blackfoot trib.at R.M. 43) & $\mathbf{X}$ & $\mathbf{X}$ & & & & $\mathbf{X}$ & $\mathbf{X}$ & $\mathbf{X}$ & $\mathbf{X}$ & $\mathbf{X}$ & $\mathbf{X}$ & $\mathbf{X}$ \\
\hline
\end{tabular}


Appendix E: Restoration Streams and Table of Activities (cont'd).

\begin{tabular}{|c|c|c|c|c|c|c|c|c|c|c|c|c|}
\hline \multicolumn{13}{|c|}{ Blackfoot River Basin (cont'd) } \\
\hline Stream Name & $\begin{array}{l}\text { Fish passage } \\
\text { improvement }\end{array}$ & $\begin{array}{c}\text { Prevent } \\
\text { Irrigation } \\
\text { ditch losses }\end{array}$ & $\begin{array}{c}\text { Spawning } \\
\text { habitat } \\
\text { protection }\end{array}$ & $\begin{array}{l}\text { Channel } \\
\text { restoration }\end{array}$ & $\begin{array}{l}\text { Fish habitat } \\
\text { improvement }\end{array}$ & $\begin{array}{c}\text { Riparian } \\
\text { vegetation } \\
\text { improvement }\end{array}$ & $\begin{array}{l}\text { Improve } \\
\text { instream } \\
\text { flows }\end{array}$ & $\begin{array}{l}\text { Improve } \\
\text { wetlands }\end{array}$ & $\begin{array}{c}\text { Improve } \\
\text { range/ } \\
\text { riparian } \\
\text { habitat }\end{array}$ & $\begin{array}{l}\text { Improve } \\
\text { irrigation }\end{array}$ & $\begin{array}{c}\text { Conservation } \\
\text { easements }\end{array}$ & $\begin{array}{l}\text { Remove } \\
\text { streamside } \\
\text { feedlots }\end{array}$ \\
\hline Cottonwood Creek (Nevada Cr tributary) & $\mathbf{X}$ & & & $\mathbf{X}$ & & $\mathbf{X}$ & & & $\mathbf{X}$ & $\mathbf{X}$ & & $\mathbf{X}$ \\
\hline Dick Creek & $\mathbf{X}$ & $\mathrm{X}$ & & $\mathrm{X}$ & $\mathrm{X}$ & $\mathbf{X}$ & $\mathbf{X}$ & $\mathbf{X}$ & $\bar{X}$ & $\mathbf{X}$ & $\mathbf{X}$ & $\mathbf{X}$ \\
\hline Douglas Creek & $\mathbf{X}$ & & & & & $\mathbf{X}$ & & & & & & \\
\hline Dry Creek & & & & & & $\mathrm{X}$ & & & $\mathbf{X}$ & & $\mathbf{X}$ & \\
\hline Dunham Creek & & $\mathbf{X}$ & & $\mathbf{X}$ & $\mathbf{X}$ & $\mathbf{X}$ & & & & $\mathbf{X}$ & $\mathbf{X}$ & \\
\hline East Twin Creek & $X$ & & & & & & & & & & & \\
\hline \multicolumn{13}{|l|}{ Elk Creek } \\
\hline Enders Spring Creek & & & & $\mathbf{X}$ & $\mathbf{X}$ & & & & $\mathbf{X}$ & & & \\
\hline \multicolumn{13}{|l|}{ Finn Creek } \\
\hline \multicolumn{13}{|l|}{ Fish Creek } \\
\hline \multicolumn{13}{|l|}{ Frazier Creek } \\
\hline \multicolumn{13}{|l|}{ Frazier Creek, North Fork } \\
\hline \multicolumn{13}{|l|}{ Gallagher Creek } \\
\hline \multicolumn{13}{|l|}{ Game Creek } \\
\hline \multicolumn{13}{|l|}{ Gleason Creek } \\
\hline Gold Creek & & & & & $\mathbf{X}$ & & & & & & & \\
\hline \multicolumn{13}{|l|}{ Gold Creek, West Fork } \\
\hline Grantier Spring Creek & $\mathbf{X}$ & & $\mathbf{X}$ & $\mathbf{X}$ & $\mathbf{X}$ & $\mathbf{X}$ & & $\bar{X}$ & $\bar{X}$ & & & \\
\hline \multicolumn{13}{|l|}{ Halfway Creek } \\
\hline \multicolumn{13}{|l|}{ Hogum Creek } \\
\hline Hoyt Creek & $\mathbf{X}$ & & & $\mathbf{X}$ & $\mathbf{X}$ & $\mathbf{X}$ & $\mathbf{X}$ & $X$ & $\mathbf{X}$ & $X$ & $X$ & \\
\hline \multicolumn{13}{|l|}{ Humbug Creek } \\
\hline \multicolumn{13}{|l|}{ Indian Creek } \\
\hline Jacobsen Spring Creek & & & & $\bar{X}$ & $\bar{x}$ & $\bar{X}$ & $\bar{X}$ & $\bar{X}$ & $\bar{X}$ & $\bar{X}$ & $\bar{X}$ & \\
\hline \multicolumn{13}{|l|}{\begin{tabular}{|l|} 
Jefferson Creek \\
\end{tabular}} \\
\hline Johnson Creek & $\mathbf{X}$ & & & & & & & & & & & \\
\hline Keep Cool Creek & & & & & & $\mathbf{X}$ & & & & & & \\
\hline Kleinschmidt Creek & $\bar{X}$ & & $\bar{X}$ & $\bar{X}$ & $\bar{X}$ & $\bar{X}$ & & $\bar{X}$ & $\bar{X}$ & & $\bar{X}$ & \\
\hline \multicolumn{13}{|l|}{\begin{tabular}{|l} 
Landers Fork \\
\end{tabular}} \\
\hline Lincoln Spring Creek & & $\mathbf{X}$ & $X$ & $\mathrm{X}$ & $\mathrm{X}$ & $\mathrm{X}$ & & & $\bar{X}$ & & & \\
\hline \multicolumn{13}{|l|}{ Little Fish Creek } \\
\hline \multicolumn{13}{|l|}{ Little Moose Creek } \\
\hline Lodgepole Creek & & & & & & & & & & & & \\
\hline
\end{tabular}


Appendix E: Restoration Streams and Table of Activities (cont'd).

\begin{tabular}{|c|c|c|c|c|c|c|c|c|c|c|c|c|}
\hline \multicolumn{13}{|c|}{ Blackfoot River Basin (cont'd) } \\
\hline Stream Name & $\begin{array}{l}\text { Fish passage } \\
\text { improvement }\end{array}$ & $\begin{array}{c}\text { Prevent } \\
\text { Irrigation } \\
\text { ditch losses }\end{array}$ & $\begin{array}{l}\text { Spawning } \\
\text { habitat } \\
\text { protection }\end{array}$ & $\begin{array}{l}\text { Channel } \\
\text { restoration }\end{array}$ & $\begin{array}{l}\text { Fish habitat } \\
\text { improvement }\end{array}$ & $\begin{array}{c}\text { Riparian } \\
\text { vegetation } \\
\text { improvement }\end{array}$ & $\begin{array}{l}\text { Improve } \\
\text { instream } \\
\text { flows }\end{array}$ & $\begin{array}{l}\text { Improve } \\
\text { wetlands }\end{array}$ & $\begin{array}{c}\text { Improve } \\
\text { range/ } \\
\text { riparian } \\
\text { habitat }\end{array}$ & $\begin{array}{l}\text { Improve } \\
\text { irrigation }\end{array}$ & $\begin{array}{c}\text { Conservation } \\
\text { easements }\end{array}$ & $\begin{array}{c}\text { Remove } \\
\text { streamside } \\
\text { feedlots }\end{array}$ \\
\hline McCabe Creek & $\mathbf{X}$ & $\mathbf{X}$ & & $\bar{X}$ & $\mathbf{X}$ & $\bar{X}$ & $\bar{X}$ & & $\bar{X}$ & $\bar{X}$ & & \\
\hline McDermott Creek & & & & & & & & & & & & \\
\hline McElwain Creek & & & & & & $\mathbf{X}$ & & & $\bar{X}$ & & & \\
\hline Mitchell Creek & & & & & & & & & & & & \\
\hline Monture Creek & & & $\mathbf{X}$ & $\mathbf{X}$ & $\mathbf{X}$ & $\mathbf{X}$ & $\bar{x}$ & $\mathbf{X}$ & $\bar{X}$ & $\bar{X}$ & $\mathbf{X}$ & \\
\hline Moose Creek & & & & & & & & & & & & \\
\hline Murphys Spring Creek & $\mathbf{X}$ & $\mathrm{X}$ & & & & $\mathbf{x}$ & 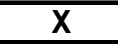 & & $\bar{x}$ & $\mathrm{X}$ & $X$ & \\
\hline Murray Creek & & & & & & & & & & & & \\
\hline Nevada Creek (lower) & $\bar{x}$ & & & $\bar{x}$ & $\mathbf{X}$ & $\bar{x}$ & $\bar{x}$ & $\mathbf{X}$ & $\bar{X}$ & $\mathbf{X}$ & $\bar{x}$ & \\
\hline Nevada Creek (upper) & & & & $\bar{x}$ & & & & & & & & \\
\hline \begin{tabular}{|l|} 
Nevada Spring Creek \\
\end{tabular} & $\bar{X}$ & & $\bar{X}$ & $\bar{x}$ & $\bar{x}$ & $\bar{x}$ & $\bar{x}$ & $\mathbf{X}$ & $\bar{x}$ & $\mathrm{X}$ & $\mathrm{X}$ & $\bar{x}$ \\
\hline North Fork Blackfoot River & & $\mathbf{X}$ & & $\mathbf{X}$ & $\mathbf{X}$ & $\mathbf{X}$ & $\mathbf{x}$ & & $\mathbf{x}$ & $\mathbf{X}$ & $\mathbf{X}$ & \\
\hline Pearson Creek & $\mathbf{X}$ & $\mathrm{X}$ & $\mathbf{X}$ & $\bar{X}$ & $\bar{x}$ & $\bar{X}$ & $\bar{X}$ & $X$ & $\bar{X}$ & $\bar{X}$ & $\bar{x}$ & $\mathbf{x}$ \\
\hline Poorman Creek & $\bar{X}$ & $\mathrm{X}$ & & & $\bar{X}$ & $\bar{X}$ & $\bar{x}$ & & $\bar{X}$ & $\mathbf{X}$ & & \\
\hline Rock Creek & $\mathbf{X}$ & $\mathrm{X}$ & & $\mathbf{x}$ & $\mathbf{X}$ & $\mathbf{x}$ & $\mathbf{x}$ & $\mathbf{X}$ & $\mathbf{X}$ & $\mathrm{X}$ & $\mathbf{X}$ & $x$ \\
\hline Salmon Creek & $\bar{x}$ & $\mathrm{X}$ & $\bar{x}$ & $\mathbf{x}$ & $\bar{X}$ & $\bar{X}$ & $\bar{X}$ & $\mathbf{X}$ & $\bar{X}$ & $\mathbf{X}$ & $\mathbf{X}$ & $\bar{X}$ \\
\hline Sauerkraut Creek & & & & & & & & & & & & \\
\hline Seven Up Pete Creek & & & & & & & & & & & & \\
\hline Shanley Creek & & $\mathbf{X}$ & & & & $\mathbf{X}$ & $\mathbf{x}$ & & $\mathbf{X}$ & $\mathbf{X}$ & $\mathbf{X}$ & \\
\hline Sheep Creek & & & & & & & & & & & & \\
\hline Shingle Mill Creek & & & & & & & & & & & & \\
\hline Smith Creek & & & & & & & & & & & & \\
\hline Snowbank Creek & $\mathbf{X}$ & $\mathbf{X}$ & & & & & $\mathbf{X}$ & & & & & \\
\hline Spring Creek (Cottonwood Cr tributary) & & & & & & & & & & & & \\
\hline Stonewall Creek & & & & & & & & & & & & \\
\hline Strickland Creek & & & & & & & & & & & & \\
\hline Sturgeon Creek & & & & & & & & & & & & \\
\hline Sucker Creek & & & & & & & & & & & & \\
\hline Tamarack Creek & & & & & & & & & & & & \\
\hline Union Creek & & & & & & & & & & & & \\
\hline Wales Creek & & & & & & & & & $\mathbf{X}$ & & & \\
\hline Wales Spring Creek & & & & & & & & & & & & \\
\hline Ward Creek & & & & & & & & & & & & \\
\hline Warm Springs Creek & & & & & & & & & & & & \\
\hline Warren Creek & $\bar{X}$ & & $\bar{X}$ & $\mathbf{X}$ & $\mathbf{X}$ & $\mathbf{X}$ & $\bar{X}$ & $\mathbf{X}$ & $\mathbf{X}$ & $\bar{X}$ & $\mathbf{X}$ & $\mathbf{X}$ \\
\hline
\end{tabular}


Appendix E: Restoration Streams and Table of Activities (cont'd).

\begin{tabular}{|c|c|c|c|c|c|c|c|c|c|c|c|c|}
\hline \multicolumn{13}{|c|}{ Blackfoot River Basin (cont'd) } \\
\hline Stream Name & $\begin{array}{l}\text { Fish passage } \\
\text { improvement }\end{array}$ & $\begin{array}{c}\text { Prevent } \\
\text { Irrigation } \\
\text { ditch losses }\end{array}$ & $\begin{array}{l}\text { Spawning } \\
\text { habitat } \\
\text { protection }\end{array}$ & $\begin{array}{l}\text { Channel } \\
\text { restoration }\end{array}$ & $\begin{array}{l}\text { Fish habitat } \\
\text { improvement }\end{array}$ & $\begin{array}{c}\text { Riparian } \\
\text { vegetation } \\
\text { improvement }\end{array}$ & $\begin{array}{l}\text { Improve } \\
\text { instream } \\
\text { flows }\end{array}$ & $\begin{array}{l}\text { Improve } \\
\text { wetlands }\end{array}$ & $\begin{array}{c}\text { Improve } \\
\text { range/ } \\
\text { riparian } \\
\text { habitat }\end{array}$ & $\begin{array}{l}\text { Improve } \\
\text { irrigation }\end{array}$ & $\begin{array}{c}\text { Conservation } \\
\text { easements }\end{array}$ & $\begin{array}{c}\text { Remove } \\
\text { streamside } \\
\text { feedlots }\end{array}$ \\
\hline \multicolumn{13}{|c|}{ Warren Creek (Doney lake trib.) } \\
\hline \multicolumn{13}{|l|}{ Washington Creek } \\
\hline \multicolumn{13}{|l|}{ Washoe Creek } \\
\hline Wasson Creek & $\mathbf{X}$ & $\mathbf{X}$ & $\mathbf{X}$ & $\mathbf{X}$ & $\mathbf{X}$ & $\mathbf{X}$ & $\mathbf{X}$ & $\mathbf{X}$ & $\mathbf{X}$ & $\mathbf{X}$ & $\mathbf{X}$ & $\mathbf{X}$ \\
\hline West Twin Creek & $\mathbf{X}$ & & & & & & & & & & & \\
\hline \multicolumn{13}{|c|}{ Willow Creek (above Lincoln, MT) } \\
\hline \multicolumn{13}{|c|}{ Willow Creek (below Lincoln, MT) } \\
\hline \multicolumn{13}{|c|}{ Wilson Creek } \\
\hline \multicolumn{13}{|l|}{ Yourname Creek } \\
\hline \multicolumn{13}{|c|}{ Clearwater River Basin } \\
\hline Auggie Creek & $\mathbf{X}$ & & & & & & & & & & & \\
\hline Benedict Creek & $\mathbf{X}$ & & & & & & & & & & & \\
\hline \multicolumn{13}{|l|}{ Bertha Creek } \\
\hline Blanchard Creek & $\mathbf{X}$ & & & & & $\mathbf{X}$ & & & $\mathbf{X}$ & $\mathbf{X}$ & & \\
\hline \multicolumn{13}{|l|}{ Blanchard Creek, North Fork } \\
\hline \multicolumn{13}{|l|}{ Blind Canyon Creek } \\
\hline \multicolumn{13}{|l|}{ Boles Creek } \\
\hline \multicolumn{13}{|l|}{ Buck Creek } \\
\hline \multicolumn{13}{|l|}{ Camp Creek } \\
\hline Clearwater River Section 1 & $\mathbf{X}$ & & & & & & & & & & & \\
\hline \multicolumn{13}{|l|}{ Clearwater River Section 2} \\
\hline \multicolumn{13}{|l|}{ Clearwater River Section 3} \\
\hline \multicolumn{13}{|l|}{ Clearwater River Section 4} \\
\hline \multicolumn{13}{|l|}{ Clearwater River Section 5} \\
\hline Clearwater River, East Fork & $\mathbf{X}$ & & & & & & & & & & & \\
\hline \multicolumn{13}{|l|}{ Clearwater River, West Fork } \\
\hline \multicolumn{13}{|l|}{ Cold Brook Creek } \\
\hline \multicolumn{13}{|l|}{ Colt Creek } \\
\hline \multicolumn{13}{|l|}{ Deer Creek } \\
\hline \multicolumn{13}{|l|}{ Drew Creek } \\
\hline \multicolumn{13}{|l|}{ Fawn Creek } \\
\hline Findell Creek & & & & & & & & & & & & \\
\hline
\end{tabular}


Appendix E: Restoration Streams and Table of Activities (cont'd).

\begin{tabular}{|c|c|c|c|c|c|c|c|c|c|c|c|c|}
\hline \multicolumn{13}{|c|}{ Clearwater River Basin (cont'd) } \\
\hline Stream Name & $\begin{array}{l}\text { Fish passage } \\
\text { improvement }\end{array}$ & $\begin{array}{c}\text { Prevent } \\
\text { Irrigation } \\
\text { ditch losses }\end{array}$ & $\begin{array}{c}\text { Spawning } \\
\text { habitat } \\
\text { protection }\end{array}$ & $\begin{array}{l}\text { Channel } \\
\text { restoration }\end{array}$ & $\begin{array}{l}\text { Fish habitat } \\
\text { improvement }\end{array}$ & $\begin{array}{c}\text { Riparian } \\
\text { vegetation } \\
\text { improvement }\end{array}$ & $\begin{array}{c}\text { Improve } \\
\text { instream } \\
\text { flows }\end{array}$ & $\begin{array}{l}\text { Improve } \\
\text { wetlands }\end{array}$ & $\begin{array}{c}\text { Improve } \\
\text { range/ } \\
\text { riparian } \\
\text { habitat }\end{array}$ & $\begin{array}{l}\text { Improve } \\
\text { irrigation }\end{array}$ & $\begin{array}{c}\text { Conservation } \\
\text { easements }\end{array}$ & $\begin{array}{c}\text { Remove } \\
\text { streamside } \\
\text { feedlots }\end{array}$ \\
\hline \multicolumn{13}{|l|}{ Finley Creek } \\
\hline \multicolumn{13}{|l|}{ First Creek } \\
\hline \multicolumn{13}{|l|}{ Grouse Creek } \\
\hline \multicolumn{13}{|l|}{ Horn Creek } \\
\hline \multicolumn{13}{|l|}{ Inez Creek } \\
\hline \multicolumn{13}{|l|}{ Lost Horse Creek } \\
\hline \multicolumn{13}{|l|}{ Lost Prairie Creek } \\
\hline \multicolumn{13}{|l|}{ Marshall Creek } \\
\hline Morrell Creek & & $\mathrm{X}$ & & & & & & & & & & \\
\hline Mountain Creek & & $X$ & & & & & & & & & & \\
\hline \multicolumn{13}{|l|}{ Murphy Creek } \\
\hline \multicolumn{13}{|l|}{ Owl Creek } \\
\hline \multicolumn{13}{|l|}{ Placid Creek } \\
\hline \multicolumn{13}{|c|}{ Placid Creek, North Fork } \\
\hline Rice Creek & & $\mathbf{X}$ & & & & & & & & & & \\
\hline \multicolumn{13}{|l|}{ Richmond Creek } \\
\hline \multicolumn{13}{|l|}{ Sawyer Creek } \\
\hline \multicolumn{13}{|l|}{ Second Creek } \\
\hline \multicolumn{13}{|l|}{ Seeley Creek } \\
\hline \multicolumn{13}{|l|}{ Sheep Creek } \\
\hline \multicolumn{13}{|l|}{ Slippery John Creek } \\
\hline \multicolumn{13}{|l|}{ Swamp Creek } \\
\hline Trail Creek & & $\mathrm{X}$ & & & & & & & & $\mathrm{X}$ & & \\
\hline \multicolumn{13}{|l|}{ Uhler Creek } \\
\hline Vaughn Creek & & & & & & & & & & & & \\
\hline
\end{tabular}


Appendix F: Table of Potential Restoration Projects

\begin{tabular}{|c|c|c|c|c|c|c|c|c|c|c|c|c|}
\hline \multicolumn{13}{|c|}{ Blackfoot River Basin } \\
\hline Stream Name & $\begin{array}{c}\text { Road } \\
\text { Crossings }\end{array}$ & $\begin{array}{l}\text { Irrigation } \\
\text { Impacts }\end{array}$ & $\begin{array}{c}\text { Channel } \\
\text { Alterations }\end{array}$ & $\begin{array}{c}\text { Lacks } \\
\text { Complexity }\end{array}$ & $\begin{array}{c}\text { Riparian } \\
\text { Vegetation }\end{array}$ & $\begin{array}{l}\text { Instream } \\
\text { Flow }\end{array}$ & $\begin{array}{c}\text { Road } \\
\text { Drainage }\end{array}$ & $\begin{array}{c}\text { Feedlots, } \\
\text { Grazing }\end{array}$ & $\begin{array}{l}\text { Recreation } \\
\text { Impacts }\end{array}$ & $\begin{array}{l}\text { Whirling } \\
\text { Disease }\end{array}$ & Mining & Residential \\
\hline Alice Creek & & & & $\mathbf{X}$ & $\mathbf{X}$ & & & & $\mathbf{X}$ & & & \\
\hline Arkansas Creek & & & & & & & $\mathbf{X}$ & $\mathbf{X}$ & & & & \\
\hline Arrastra Creek & $\mathbf{X}$ & & & & & & $\mathbf{X}$ & & $\mathbf{X}$ & $\mathbf{X}$ & & \\
\hline Ashby Creek & $\mathbf{X}$ & $\mathbf{X}$ & $\mathbf{X}$ & $\mathbf{X}$ & $\mathbf{X}$ & $\mathbf{X}$ & $\mathbf{X}$ & $\mathbf{X}$ & & & & \\
\hline Bartlett Creek & & & & & $\mathbf{X}$ & & & & $\mathbf{X}$ & & & \\
\hline \multicolumn{13}{|l|}{ Basin Spring Creek } \\
\hline Bear Creek (Blackfoot trib. at R.M. 12.2) & & & & & $\mathbf{X}$ & & $\mathbf{X}$ & & & & & \\
\hline Bear Creek (Blackfoot trib. at R.M. 37.5) & $\mathbf{X}$ & & & & & & & & & & & \\
\hline Bear Creek (North Fork drainage) & & $\mathbf{X}$ & & & & $\mathbf{X}$ & & & & & & \\
\hline Bear Gulch & $\mathbf{X}$ & $\mathbf{X}$ & $\mathbf{X}$ & $\mathbf{X}$ & $\mathbf{X}$ & $\mathbf{X}$ & $\mathbf{X}$ & $\mathbf{X}$ & & & & \\
\hline Beaver Creek & & $\mathbf{X}$ & & & $\mathbf{X}$ & $\mathbf{X}$ & & $\mathbf{X}$ & & $\mathbf{X}$ & & \\
\hline Belmont Creek & & & & & & & $\mathbf{X}$ & & $\mathbf{X}$ & $\mathbf{X}$ & & \\
\hline Black Bear Creek & $\mathbf{X}$ & & & & & $\mathbf{X}$ & & $\mathbf{X}$ & & & & \\
\hline Blackfoot River (mouth to Clearwater) & & & $\mathbf{X}$ & $\mathbf{X}$ & & & $\mathbf{X}$ & $\mathbf{X}$ & $\mathbf{X}$ & $\mathbf{X}$ & & \\
\hline Blackfoot River (Clearwater to N.F) & & & $\mathbf{X}$ & & $\mathbf{X}$ & & & $\mathbf{X}$ & $\mathbf{X}$ & $\mathbf{X}$ & & \\
\hline Blackfoot River (N.F. to Nevada Creek) & & & & & & $\mathbf{X}$ & & $\mathbf{X}$ & & $\mathbf{X}$ & & \\
\hline Blackfoot River (Nevada Cr. to Arrastra Cr.) & & $\mathbf{X}$ & & $\mathbf{X}$ & $\mathbf{X}$ & $\mathbf{X}$ & & $\mathbf{X}$ & & $\mathbf{X}$ & & \\
\hline Blackfoot River (Arrastra Cr. to Lincoln, MT) & & $\mathbf{X}$ & $\mathbf{X}$ & $\mathbf{X}$ & $\mathbf{X}$ & $\mathbf{X}$ & & $\mathbf{X}$ & $\mathbf{X}$ & $\mathbf{X}$ & & \\
\hline Blackfoot River (Lincoln to Headwaters) & & $\mathbf{X}$ & $\mathbf{X}$ & $\mathbf{X}$ & & $\mathbf{X}$ & & & $\mathbf{X}$ & $\mathbf{X}$ & $\mathbf{X}$ & \\
\hline Braziel Creek & $\mathbf{X}$ & & $\mathbf{X}$ & $\mathbf{X}$ & $\mathbf{X}$ & $\mathbf{X}$ & $\mathbf{X}$ & $\mathbf{X}$ & & & & \\
\hline Buffalo Gulch & $\mathbf{X}$ & & & $\mathbf{X}$ & $\mathbf{X}$ & & & $\mathbf{X}$ & & & $\mathbf{X}$ & \\
\hline Burnt Bridge Creek & $\mathbf{X}$ & $\mathbf{X}$ & $\mathbf{X}$ & & $\mathbf{X}$ & $\mathbf{X}$ & $\mathbf{X}$ & & & & & \\
\hline California Gulch & $\mathbf{X}$ & & & $\mathbf{X}$ & $\mathbf{X}$ & & & $\mathbf{X}$ & & & & \\
\hline Camas Creek & & & $\mathbf{X}$ & $\mathbf{X}$ & & & & $\mathbf{X}$ & & & & \\
\hline Chamberlain Creek & & & & $\mathbf{X}$ & $\mathbf{X}$ & & $\mathbf{X}$ & & & $\mathbf{X}$ & & \\
\hline Chamberlain Creek, East Fork & & & & & & & $\mathbf{X}$ & & & & & \\
\hline Chamberlain Creek, West Fork & & & & & & & $\mathbf{X}$ & & & & & \\
\hline Chicken Creek & $\mathbf{X}$ & & $\mathbf{X}$ & $\mathbf{X}$ & $\mathbf{X}$ & & & $\mathbf{X}$ & & & & \\
\hline Chimney Creek (Douglas Cr tributary) & & $\mathbf{X}$ & $\mathbf{X}$ & $\mathbf{X}$ & $\mathbf{X}$ & & & $\mathbf{X}$ & & & & \\
\hline Chimney Creek (Nevada Cr tributary) & $\mathbf{X}$ & $\mathbf{X}$ & $\mathbf{X}$ & & & $\mathbf{X}$ & & $\mathbf{X}$ & & & & \\
\hline Clear Creek & $\mathbf{X}$ & & $\mathbf{X}$ & & $\mathbf{X}$ & & & $\mathbf{X}$ & & & & $\mathbf{X}$ \\
\hline Copper Creek & $\mathbf{X}$ & & & & & & & & $\mathbf{X}$ & & & \\
\hline Cottonwood Creek (Blackfoot trib. at R.M. 43) & $\mathbf{X}$ & & $\mathbf{X}$ & $\mathbf{X}$ & $\mathbf{X}$ & $\mathbf{X}$ & $\mathbf{X}$ & $\mathbf{X}$ & & $\mathbf{X}$ & & \\
\hline Cottonwood Creek (Nevada Cr tributary) & $\mathbf{X}$ & $\mathbf{X}$ & $\mathbf{X}$ & $\mathbf{X}$ & $\mathbf{X}$ & $\mathbf{X}$ & & $\mathbf{X}$ & & & & $\mathbf{X}$ \\
\hline
\end{tabular}


Appendix F: Table of Potential Restoration Projects (cont'd).

\begin{tabular}{|c|c|c|c|c|c|c|c|c|c|c|c|c|}
\hline \multicolumn{13}{|c|}{ Blackfoot River Basin (cont'd) } \\
\hline Stream Name & $\begin{array}{c}\text { Road } \\
\text { Crossings }\end{array}$ & $\begin{array}{l}\text { Irrigation } \\
\text { Impacts }\end{array}$ & $\begin{array}{c}\text { Channel } \\
\text { Alterations }\end{array}$ & $\begin{array}{c}\text { Lacks } \\
\text { Complexity }\end{array}$ & $\begin{array}{c}\text { Riparian } \\
\text { Vegetation }\end{array}$ & $\begin{array}{l}\text { Instream } \\
\text { Flow }\end{array}$ & $\begin{array}{c}\text { Road } \\
\text { Drainage }\end{array}$ & $\begin{array}{l}\text { Feedlots, } \\
\text { Grazing }\end{array}$ & $\begin{array}{c}\text { Recreation } \\
\text { Impacts }\end{array}$ & $\begin{array}{l}\text { Whirling } \\
\text { Disease }\end{array}$ & Mining & Residentia \\
\hline Dick Creek & $\mathbf{X}$ & $\mathbf{X}$ & $\mathrm{X}$ & $\mathbf{X}$ & $\mathbf{X}$ & $x$ & & $\mathbf{X}$ & & & & \\
\hline Douglas Creek & & $\mathbf{X}$ & $\mathbf{X}$ & $\mathbf{X}$ & $\mathbf{X}$ & $\mathbf{X}$ & $\mathbf{X}$ & $\mathbf{X}$ & & & & \\
\hline Dry Creek & & & & $\mathbf{X}$ & $\mathbf{X}$ & & & $\mathbf{X}$ & & & & \\
\hline Dunham Creek & & & & & $\mathrm{X}$ & $\mathrm{X}$ & & & & & & \\
\hline \multicolumn{13}{|l|}{ East Twin Creek } \\
\hline Elk Creek & $\mathrm{X}$ & $\mathrm{X}$ & $\mathrm{X}$ & $\mathbf{X}$ & $\mathrm{X}$ & $\mathrm{X}$ & $\mathrm{X}$ & $\mathrm{X}$ & & $\mathbf{X}$ & $\mathbf{x}$ & \\
\hline Enders Spring Creek & & & & $\mathbf{X}$ & $\mathrm{X}$ & & & & & & & \\
\hline Finn Creek & & $\mathrm{X}$ & & $\mathbf{X}$ & & $\mathrm{X}$ & & $\mathrm{X}$ & & & & \\
\hline Fish Creek & & $\mathrm{X}$ & $\mathrm{X}$ & & & & & & & & & \\
\hline Frazier Creek & $\mathbf{X}$ & $\bar{X}$ & $\mathbf{X}$ & $\mathbf{x}$ & $\mathbf{x}$ & $\mathbf{X}$ & $\mathbf{X}$ & $\bar{X}$ & & & & \\
\hline Frazier Creek, North fork & & $\mathbf{X}$ & $\mathbf{X}$ & & $\mathbf{X}$ & $\mathbf{X}$ & & $\mathbf{X}$ & & & & \\
\hline Gallagher Creek & $\mathbf{X}$ & & & & & & & $\mathbf{X}$ & & & & \\
\hline Game Creek & $\mathbf{X}$ & & & & & & & $\bar{X}$ & & & & \\
\hline Gleason Creek & $\mathbf{X}$ & & & & & & & & & & $\mathbf{X}$ & \\
\hline Gold Creek & & & & & & & & & $\mathbf{X}$ & $\mathbf{X}$ & & \\
\hline \multicolumn{13}{|l|}{ Gold Creek, West Fork } \\
\hline \multicolumn{13}{|l|}{ Grantier Spring Creek } \\
\hline \begin{tabular}{|l|l|} 
Halfway Creek \\
\end{tabular} & & & & $\mathbf{X}$ & $\mathbf{X}$ & & & $\mathbf{X}$ & & & & \\
\hline Hogum Creek & $\mathbf{X}$ & & & & $\bar{X}$ & & & $\mathbf{X}$ & & & & \\
\hline Hoyt Creek & & $\mathbf{X}$ & $\mathbf{X}$ & $\mathbf{X}$ & $\mathbf{X}$ & $\mathbf{X}$ & & $\bar{X}$ & & $\mathbf{X}$ & & \\
\hline Humbug Creek & & $\bar{X}$ & $\bar{X}$ & & $\bar{X}$ & $\bar{X}$ & & $\bar{X}$ & & & $\mathrm{X}$ & \\
\hline Indian Creek & & & & $\mathbf{X}$ & & & & & & & & \\
\hline Jacobsen Spring Creek & & & & & & & & & & $\mathbf{X}$ & & \\
\hline Jefferson Creek & $\mathbf{X}$ & & $\mathbf{X}$ & $\mathbf{X}$ & & $\mathbf{x}$ & & & & & $\mathbf{X}$ & \\
\hline \multicolumn{13}{|l|}{ 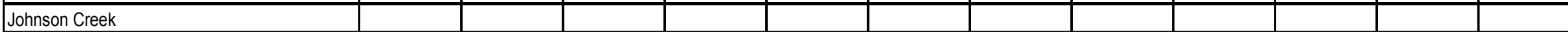 } \\
\hline Keep Cool Creek & $\mathbf{X}$ & $\mathbf{X}$ & $\mathbf{X}$ & & $\mathbf{X}$ & $\mathbf{X}$ & & $\mathbf{X}$ & & & $\mathbf{X}$ & \\
\hline Kleinschmidt Creek & & & & & & & & $\bar{x}$ & & $\mathbf{X}$ & & \\
\hline \begin{tabular}{|l} 
Landers Fork \\
\end{tabular} & & & $\mathbf{X}$ & $\mathbf{X}$ & $\mathbf{X}$ & $\mathbf{X}$ & & & $\mathbf{X}$ & & & \\
\hline Lincoln Spring Creek & $\mathbf{X}$ & $\mathbf{X}$ & $\mathrm{X}$ & $\mathbf{X}$ & $\bar{X}$ & & & $\mathbf{X}$ & & $\mathrm{X}$ & & $\mathrm{X}$ \\
\hline Little Fish Creek & $\mathbf{X}$ & & & & $\bar{X}$ & & $\mathbf{X}$ & $\mathbf{X}$ & & & & \\
\hline \multicolumn{13}{|l|}{ Little Moose Creek } \\
\hline \multicolumn{13}{|l|}{ Lodgepole Creek } \\
\hline McCabe Creek & $\mathbf{X}$ & & & & $\mathbf{X}$ & & & & & & & \\
\hline
\end{tabular}


Appendix F: Table of Potential Restoration Projects (cont'd).

\begin{tabular}{|c|c|c|c|c|c|c|c|c|c|c|c|c|}
\hline \multicolumn{13}{|c|}{ Blackfoot River Basin (cont'd) } \\
\hline Stream Name & $\begin{array}{c}\text { Road } \\
\text { Crossings }\end{array}$ & $\begin{array}{l}\text { Irrigation } \\
\text { Impacts }\end{array}$ & $\begin{array}{c}\text { Channel } \\
\text { Alterations }\end{array}$ & $\begin{array}{c}\text { Lacks } \\
\text { Complexity }\end{array}$ & $\begin{array}{c}\text { Riparian } \\
\text { Vegetation }\end{array}$ & $\begin{array}{c}\text { Instream } \\
\text { Flow }\end{array}$ & $\begin{array}{c}\text { Road } \\
\text { Drainage }\end{array}$ & $\begin{array}{l}\text { Feedlots, } \\
\text { Grazing }\end{array}$ & $\begin{array}{c}\text { Recreation } \\
\text { Impacts }\end{array}$ & $\begin{array}{l}\text { Whirling } \\
\text { Disease }\end{array}$ & Mining & Residential \\
\hline \multicolumn{13}{|l|}{ McDermott Creek } \\
\hline McElwain Creek & $\mathbf{X}$ & $\mathbf{X}$ & & & $\mathbf{X}$ & $\mathbf{X}$ & $\mathbf{X}$ & $\mathbf{X}$ & & & & \\
\hline Mitchell Creek & $\bar{X}$ & & & $\mathbf{X}$ & & & & $\bar{X}$ & & & & \\
\hline Monture Creek & $\bar{X}$ & & $\mathbf{X}$ & $\bar{X}$ & $\mathbf{X}$ & & & $\bar{X}$ & $\mathrm{X}$ & $\mathbf{X}$ & & $\mathbf{X}$ \\
\hline Moose Creek & $\bar{X}$ & & & & & & & & & & $\mathbf{X}$ & \\
\hline \begin{tabular}{|l|} 
Murphys Spring Creek \\
\end{tabular} & & $\mathbf{X}$ & & & & $\mathbf{X}$ & & & & & & \\
\hline Murray Creek & $\mathbf{X}$ & $\mathbf{X}$ & & $\bar{X}$ & $\mathbf{X}$ & $\mathbf{X}$ & $\mathbf{X}$ & $\mathbf{X}$ & & & & \\
\hline Nevada Creek (lower) & & $\mathbf{X}$ & $\mathbf{X}$ & $\mathbf{X}$ & $\mathbf{X}$ & $\mathbf{X}$ & & $\mathbf{X}$ & & & & \\
\hline Nevada Creek (upper) & $\mathbf{X}$ & $\mathbf{X}$ & & & $\mathbf{X}$ & & $\mathbf{X}$ & $\mathbf{X}$ & & & $\mathbf{X}$ & \\
\hline Nevada Spring Creek & & & $\mathrm{X}$ & & & & & & & $\mathbf{X}$ & & \\
\hline North Fork Blackfoot River & & & $\mathbf{X}$ & $\mathbf{X}$ & $\mathbf{X}$ & $\mathbf{X}$ & & & $\mathbf{X}$ & $\mathbf{X}$ & & \\
\hline Pearson Creek & & & & & $\mathbf{X}$ & & $\mathbf{X}$ & & & & & \\
\hline Poorman Creek & $\mathbf{X}$ & & $\mathbf{X}$ & $\mathbf{X}$ & $\mathbf{X}$ & & $\mathbf{X}$ & $\mathbf{X}$ & & & $\mathbf{X}$ & \\
\hline Rock Creek & $\mathbf{X}$ & $\mathbf{X}$ & & $\mathbf{X}$ & $\mathbf{X}$ & $\mathbf{X}$ & & & & $\mathbf{X}$ & & $\mathbf{X}$ \\
\hline Salmon Creek & & $\mathbf{X}$ & & $\mathbf{X}$ & & $\mathbf{X}$ & & & & & & \\
\hline Sauerkraut Creek & $\mathbf{X}$ & & $\mathbf{X}$ & $\bar{X}$ & $\mathbf{X}$ & $\bar{X}$ & $\mathbf{X}$ & $\mathbf{X}$ & & & $\mathbf{X}$ & \\
\hline Seven up Pete Creek & $\bar{X}$ & & & & & & & & $\mathbf{X}$ & & $\mathbf{X}$ & \\
\hline Shanley Creek & & $\mathbf{X}$ & & $\bar{X}$ & $\mathbf{X}$ & $\mathbf{X}$ & & $\mathbf{X}$ & & $\mathbf{X}$ & & \\
\hline Sheep Creek & & & & & & $\mathbf{X}$ & & $\mathbf{X}$ & & & & \\
\hline Shingle Mill Creek & & $\mathbf{X}$ & & & & & & $\bar{X}$ & & & & \\
\hline Smith Creek & $\mathbf{X}$ & & & & $\mathbf{X}$ & & & $\bar{X}$ & & & & \\
\hline Snowbank Creek & $\mathbf{X}$ & $\mathbf{X}$ & $\mathbf{X}$ & & & & & & & & & \\
\hline Spring Creek (Cottonwood Cr tributary) & & $\mathbf{X}$ & $\mathbf{X}$ & & $\mathbf{X}$ & $\mathbf{X}$ & & & & & & \\
\hline Stonewall Creek & $\mathbf{X}$ & $\mathbf{X}$ & $\mathbf{X}$ & & & $\mathbf{X}$ & & $\mathbf{X}$ & & & $\mathbf{X}$ & \\
\hline Strickland Creek & & & & $\mathbf{X}$ & $\mathbf{X}$ & & & $\mathbf{X}$ & & & & \\
\hline Sturgeon Creek & & & $\mathbf{X}$ & & $\mathbf{X}$ & $\mathbf{X}$ & & $\mathbf{X}$ & & & & \\
\hline Sucker Creek & $\mathbf{X}$ & $\mathbf{X}$ & $\mathbf{X}$ & $\mathbf{X}$ & $\mathbf{X}$ & $\mathbf{X}$ & & $\mathbf{X}$ & & & & \\
\hline Tamarack Creek & $\mathbf{X}$ & $\mathbf{X}$ & $\mathbf{X}$ & $\mathbf{X}$ & $\mathbf{X}$ & $\mathbf{X}$ & $\mathbf{X}$ & & & & & $\mathbf{X}$ \\
\hline Union Creek & $\mathbf{X}$ & $\mathbf{X}$ & & $\mathbf{X}$ & $\mathbf{X}$ & $\mathbf{X}$ & & $\mathbf{X}$ & & & & \\
\hline Wales Creek & & $\mathbf{X}$ & $\mathbf{X}$ & & $\mathbf{X}$ & $\bar{X}$ & & $\mathbf{X}$ & & & & \\
\hline Wales Spring Creek & & & $\mathbf{X}$ & & $\bar{X}$ & & & $\bar{X}$ & & & & \\
\hline Ward Creek & $\mathbf{X}$ & $\mathbf{X}$ & $\mathbf{X}$ & $\mathbf{X}$ & $\mathbf{X}$ & $\mathbf{X}$ & & $\mathbf{X}$ & & & & \\
\hline Warm Springs Creek & $\bar{X}$ & $\bar{X}$ & & & & $\bar{X}$ & $\mathbf{X}$ & & & & & \\
\hline
\end{tabular}


Appendix F: Table of Potential Restoration Projects (cont'd).

\begin{tabular}{|c|c|c|c|c|c|c|c|c|c|c|c|c|}
\hline \multicolumn{13}{|c|}{ Blackfoot River Basin (cont'd) } \\
\hline Stream Name & $\begin{array}{c}\text { Road } \\
\text { Crossings }\end{array}$ & $\begin{array}{l}\text { Irrigation } \\
\text { Impacts }\end{array}$ & $\begin{array}{c}\text { Channel } \\
\text { Alterations }\end{array}$ & $\begin{array}{c}\text { Lacks } \\
\text { Complexity }\end{array}$ & $\begin{array}{l}\text { Riparian } \\
\text { Vegetation }\end{array}$ & $\begin{array}{l}\text { Instream } \\
\text { Flow }\end{array}$ & $\begin{array}{c}\text { Road } \\
\text { Drainage }\end{array}$ & $\begin{array}{c}\text { Feedlots, } \\
\text { Grazing }\end{array}$ & $\begin{array}{l}\text { Recreation } \\
\text { Impacts }\end{array}$ & $\begin{array}{l}\text { Whirling } \\
\text { Disease }\end{array}$ & Mining & Residential \\
\hline Warren Creek & $\mathbf{X}$ & $\mathbf{X}$ & $\mathbf{X}$ & $\mathbf{X}$ & $\mathrm{X}$ & $\mathrm{X}$ & & $\mathbf{X}$ & & $\mathbf{X}$ & & \\
\hline \multicolumn{13}{|l|}{ Warren Creek (Doney Lake trib.) } \\
\hline Washington Creek & $\mathbf{X}$ & $\mathbf{X}$ & $\mathrm{X}$ & $\mathrm{X}$ & & & & $\mathrm{X}$ & & & $\mathbf{X}$ & \\
\hline Washoe Creek & & & & $\mathrm{X}$ & & & & $\mathrm{X}$ & & & & \\
\hline Wasson Creek & & & & & $X$ & $\mathbf{X}$ & & $\mathbf{X}$ & & & & \\
\hline \multicolumn{13}{|l|}{ West Twin Creek } \\
\hline Willow Creek (above Lincoln) & & & & & $\mathbf{X}$ & & & $\mathbf{X}$ & & & & \\
\hline Willow Creek (below Lincoln) & $X$ & $\mathbf{X}$ & $X$ & $\mathrm{X}$ & $X$ & $\mathbf{X}$ & $\mathbf{X}$ & $\mathbf{X}$ & & & $\mathrm{X}$ & \\
\hline Wilson Creek & $\mathbf{X}$ & $\mathbf{X}$ & & & & $\mathbf{X}$ & & & & & & \\
\hline Yourname Creek & & $\mathrm{X}$ & $\mathrm{X}$ & $\mathbf{X}$ & $\mathrm{X}$ & $\mathrm{X}$ & & $\mathrm{X}$ & & & & \\
\hline \multicolumn{13}{|c|}{ Clearwater River Basin } \\
\hline Stream Name & $\begin{array}{c}\text { Road } \\
\text { Crossings }\end{array}$ & $\begin{array}{l}\text { Irrigation } \\
\text { Impacts }\end{array}$ & $\begin{array}{c}\text { Channel } \\
\text { Alterations }\end{array}$ & $\begin{array}{c}\text { Lacks } \\
\text { Complexity }\end{array}$ & $\begin{array}{c}\text { Riparian } \\
\text { Vegetation }\end{array}$ & $\begin{array}{l}\text { Instream } \\
\text { Flow }\end{array}$ & $\begin{array}{c}\text { Road } \\
\text { Drainage }\end{array}$ & $\begin{array}{c}\text { Feedlots, } \\
\text { Grazing }\end{array}$ & $\begin{array}{l}\text { Recreation } \\
\text { Impacts }\end{array}$ & $\begin{array}{l}\text { Whirling } \\
\text { Disease }\end{array}$ & Mining & Residential \\
\hline Auggie Creek & $\mathbf{X}$ & & & & & $\mathbf{X}$ & $\mathbf{X}$ & & & & & \\
\hline Benedict Creek & $\mathbf{X}$ & & & & $X$ & & & & & & & \\
\hline \multicolumn{13}{|l|}{\begin{tabular}{|l} 
Bertha Creek \\
\end{tabular}} \\
\hline Blanchard Creek & $\mathbf{X}$ & $X$ & $\mathbf{X}$ & $\mathrm{X}$ & $\mathrm{X}$ & $\mathbf{X}$ & $X$ & $\mathbf{X}$ & & & & \\
\hline \multicolumn{13}{|l|}{ Blanchard Creek, North Fork } \\
\hline \begin{tabular}{|l|} 
Blind Canyon Creek \\
\end{tabular} & & & & & & & $\mathbf{X}$ & & & & & \\
\hline Boles Creek & & & & & $\mathrm{X}$ & & $\mathrm{X}$ & & & & & \\
\hline Buck Creek & $\mathbf{X}$ & & & & $\mathrm{X}$ & $\mathrm{X}$ & & & & & & \\
\hline Camp Creek & $X$ & & & & $X$ & $\mathbf{X}$ & $\mathrm{X}$ & & & & & \\
\hline Clearwater River Section 1 & & $\mathrm{X}$ & $\mathrm{X}$ & & $\mathrm{X}$ & $\mathrm{X}$ & & & $\mathrm{X}$ & & & $\mathbf{X}$ \\
\hline Clearwater River Section 2 & & & $\bar{X}$ & & $\mathrm{X}$ & $\mathrm{X}$ & & & $\mathrm{X}$ & & & $\mathrm{X}$ \\
\hline Clearwater River Section 3 & & & & & $X$ & $\mathrm{X}$ & & $\mathrm{X}$ & & & & \\
\hline Clearwater River Section 4 & & & $\mathbf{X}$ & & & $\mathrm{X}$ & & & $\mathrm{X}$ & & & \\
\hline Clearwater RiverSection 5 & $\mathbf{X}$ & & & & & & & & & & & \\
\hline Clearwater River, East Fork & & & & & & & $\mathrm{X}$ & & & & & \\
\hline Clearwater River, West Fork & & & & & $\mathrm{X}$ & $\mathrm{X}$ & $\mathrm{X}$ & & & & & \\
\hline \multicolumn{13}{|l|}{ Cold Brook Creek } \\
\hline Colt Creek & $\mathbf{X}$ & & $\mathrm{X}$ & & $\mathrm{X}$ & $\mathbf{X}$ & $\mathrm{X}$ & & & & & \\
\hline Deer Creek & $\mathbf{X}$ & & & & $\mathrm{X}$ & & $\mathrm{X}$ & & & & & \\
\hline Drew Creek & $\mathbf{X}$ & $\mathrm{X}$ & $\mathrm{X}$ & $\mathrm{X}$ & $X$ & & $\mathbf{X}$ & & & & & $\mathbf{X}$ \\
\hline
\end{tabular}


Appendix F: Table of Potential Restoration Projects (cont'd).

\begin{tabular}{|c|c|c|c|c|c|c|c|c|c|c|c|c|}
\hline \multicolumn{13}{|c|}{ Clearwater River Basin (cont'd) } \\
\hline Stream Name & $\begin{array}{c}\text { Road } \\
\text { Crossings }\end{array}$ & $\begin{array}{l}\text { Irrigation } \\
\text { Impacts }\end{array}$ & $\begin{array}{l}\text { Channel } \\
\text { Alterations }\end{array}$ & $\begin{array}{c}\text { Lacks } \\
\text { Complexity }\end{array}$ & $\begin{array}{l}\text { Riparian } \\
\text { Vegetation }\end{array}$ & $\begin{array}{l}\text { Instream } \\
\text { Flow }\end{array}$ & $\begin{array}{c}\text { Road } \\
\text { Drainage }\end{array}$ & $\begin{array}{c}\text { Feedlots, } \\
\text { Grazing }\end{array}$ & $\begin{array}{l}\text { Recreation } \\
\text { Impacts }\end{array}$ & $\begin{array}{l}\text { Whirling } \\
\text { Disease }\end{array}$ & Mining & Residential \\
\hline Fawn Creek & $\mathbf{X}$ & & & & & $\mathbf{X}$ & $\mathbf{X}$ & & & & & \\
\hline Findell Creek & $\mathbf{X}$ & & & & $X$ & & $\mathbf{X}$ & & & & & \\
\hline Finley Creek & $\mathrm{X}$ & & & & $\mathrm{X}$ & & $\mathrm{X}$ & & & & & \\
\hline First Creek & $\mathbf{X}$ & & & & $\mathbf{X}$ & & $\mathbf{X}$ & & & & & \\
\hline Grouse Creek & $X$ & & & & & & $X$ & & & & & \\
\hline Horn Creek & & & & & & $X$ & $\mathbf{X}$ & & & & & \\
\hline Inez Creek & $X$ & & & & $X$ & & $\mathbf{X}$ & & & & & \\
\hline Lost Horse Creek & $\mathrm{X}$ & & & $X$ & $\mathrm{X}$ & & $\mathrm{X}$ & & & & & \\
\hline Lost Prairie Creek & & & & & & $\mathbf{X}$ & $\mathrm{X}$ & & & & & \\
\hline Marshall Creek & & & & & $\mathbf{X}$ & & $X$ & & & & & \\
\hline Morrell Creek & & $X$ & $\mathbf{X}$ & $X$ & $\mathbf{X}$ & $X$ & $\mathbf{X}$ & & $\mathbf{X}$ & & & $\mathbf{X}$ \\
\hline Mountain Creek & $X$ & $X$ & & & $X$ & $X$ & $X$ & & & & & $X$ \\
\hline Murphy Creek & $\mathbf{X}$ & & & & $\mathbf{X}$ & & $X$ & & & & & \\
\hline Owl Creek & & & & $X$ & $\mathbf{X}$ & $\mathrm{X}$ & $\mathrm{X}$ & & $X$ & & & \\
\hline Placid Creek & $X$ & & & $\mathrm{X}$ & & & $\mathrm{X}$ & & & & & \\
\hline Placid Creek, North Fork & $\mathbf{X}$ & $\mathbf{X}$ & & & & & $\mathbf{X}$ & & & & & \\
\hline Rice Creek & & $\mathrm{X}$ & & & & & $X$ & & & & & \\
\hline Richmond Creek & $\mathbf{X}$ & & & & $X$ & & $\mathbf{X}$ & & & & & \\
\hline Sawyer Creek & $\mathbf{X}$ & & & & & & $\mathrm{X}$ & & & & & \\
\hline Second Creek & & & & & & & $\mathrm{X}$ & & & & & \\
\hline Seeley Creek & & $\mathbf{X}$ & & & & & $X$ & & & & & $\mathbf{X}$ \\
\hline Sheep Creek & $\mathbf{X}$ & & & & & $\mathbf{X}$ & $X$ & & & & & \\
\hline Slippery John Creek & $\mathbf{X}$ & & & & & $\mathbf{X}$ & & & & & & \\
\hline Swamp Creek & $\mathbf{X}$ & & $x$ & $X$ & $X$ & $\mathrm{X}$ & $X$ & & & & & $X$ \\
\hline Trail Creek & $\mathbf{X}$ & $\mathbf{X}$ & $X$ & $X$ & $X$ & & $\mathbf{X}$ & & & & & $\mathbf{X}$ \\
\hline Uhler Creek & $\mathrm{X}$ & & & & $X$ & $\mathrm{X}$ & $\mathrm{X}$ & & & & & \\
\hline Vaughn Creek & & & & & & & $X$ & & & & & \\
\hline
\end{tabular}


Appendix G : Table of Restoration Streams and Cooperators.

\begin{tabular}{|c|c|c|c|c|c|c|c|c|c|c|c|c|c|c|c|c|c|}
\hline \multirow[b]{2}{*}{ Stream Name } & \multicolumn{5}{|c|}{ State } & \multicolumn{5}{|c|}{ Federal } & \multicolumn{7}{|c|}{ Private } \\
\hline & FWP & MDT & NPCD & DEQ & DNRC & USFWS & BLM & NRCS & BOR & USFS & BC & TU & PL & CF & NFWF & NWE & PCT \\
\hline \multicolumn{18}{|l|}{ Alice Creek } \\
\hline \multicolumn{18}{|l|}{ Arkansas Creek } \\
\hline Arrastra Creek & $\mathrm{X}$ & & & $\mathrm{X}$ & & & & & $\mathrm{X}$ & & $\mathrm{X}$ & $\mathrm{X}$ & & & & $\mathrm{X}$ & \\
\hline Ashby Creek & $\bar{X}$ & & & & & $X$ & $\mathrm{X}$ & $\mathrm{X}$ & & & $\bar{X}$ & $\bar{x}$ & $X$ & $X$ & & $\mathrm{X}$ & \\
\hline \multicolumn{18}{|l|}{ Bartlett Creek } \\
\hline Basin Spring Creek & $X$ & & & & & $\mathrm{X}$ & & & & & & $\mathrm{X}$ & $X$ & & & & \\
\hline Bear Creek (Blackfoot trib. at R.M. 12.2) & $\bar{X}$ & & & & $\mathrm{X}$ & $\bar{X}$ & & $\mathrm{X}$ & & & & $\bar{X}$ & $\bar{X}$ & & & $X$ & $\bar{X}$ \\
\hline \multicolumn{18}{|l|}{ Bear Creek (Blackfoot trib.at R.M. 37.5) } \\
\hline \multicolumn{18}{|l|}{ Bear Creek (North Fork drainage) } \\
\hline \multicolumn{18}{|l|}{ Bear Gulch } \\
\hline Beaver Creek & & & & & & $\mathrm{X}$ & & & & & & $\mathrm{X}$ & $\mathrm{X}$ & & & & \\
\hline Belmont Creek & $\mathrm{X}$ & & & & & & $\mathrm{X}$ & & & & & $\underline{X}$ & & & & & $\mathrm{X}$ \\
\hline \multicolumn{18}{|l|}{ Black Bear Creek } \\
\hline Blackfoot River (mouth to Clearwater) & $\mathrm{X}$ & & $\mathrm{X}$ & & & & $\mathrm{X}$ & & & & & $\mathrm{X}$ & $\mathrm{X}$ & $\mathrm{X}$ & & & $\mathrm{X}$ \\
\hline Blackfoot River (Clearwater to N.F.) & $\mathrm{X}$ & & & & & $\mathrm{X}$ & & & & & & $\mathrm{X}$ & $\mathrm{X}$ & & & & \\
\hline Blackfoot River (N.F. to Nevada) & & & & & & & & & & & & & $\bar{X}$ & & & & \\
\hline Blackfoot River (Nevada to Arrastra) & $\mathrm{X}$ & & & & & $\mathrm{X}$ & & & & & & $\bar{x}$ & $\mathrm{X}$ & & & & \\
\hline \multicolumn{18}{|l|}{ Blackfoot River (Arrastra to Lincoln) } \\
\hline \multicolumn{18}{|l|}{ Blackfoot River (Lincoln to Headwaters) } \\
\hline \multicolumn{18}{|l|}{ Braziel Creek } \\
\hline \multicolumn{18}{|l|}{ Buffalo Gulch } \\
\hline \multicolumn{18}{|l|}{ Burnt Bridge Creek } \\
\hline \multicolumn{18}{|l|}{ California Gulch } \\
\hline \multicolumn{18}{|l|}{ Camas Creek } \\
\hline Chamberlain Creek & $\mathrm{X}$ & & & & & $\mathrm{X}$ & $\mathrm{X}$ & & & & & $\mathrm{X}$ & $\mathrm{X}$ & & $\mathrm{X}$ & & $\mathrm{X}$ \\
\hline Chamberlain Creek, East Fork & $\mathrm{X}$ & & & & & $\mathrm{X}$ & $\mathrm{X}$ & & & & & & & & & & $\mathrm{X}$ \\
\hline Chamberlain Creek, West Fork & & & & & & & $\mathrm{X}$ & & & & & & & & & & $\mathrm{X}$ \\
\hline \multicolumn{18}{|l|}{ Chicken Creek } \\
\hline \multicolumn{18}{|l|}{ Chimney Creek (Douglas Cr tributary) } \\
\hline \multicolumn{18}{|l|}{ Chimney Creek (Nevada Cr tributary) } \\
\hline \multicolumn{18}{|l|}{ Clear Creek } \\
\hline \multicolumn{18}{|l|}{ Copper Creek } \\
\hline Cottonwood Creek (Blackfoot trib.at R.M. 43) & $\mathrm{X}$ & & & & $\mathrm{X}$ & $\mathrm{X}$ & $\bar{X}$ & & $\mathrm{X}$ & $\mathrm{X}$ & $\mathrm{X}$ & $\mathrm{x}$ & $\mathrm{X}$ & $\bar{X}$ & & $\bar{X}$ & \\
\hline
\end{tabular}


Appendix G : Table of Restoration Streams and Cooperators (cont'd).

\begin{tabular}{|c|c|c|c|c|c|c|c|c|c|c|c|c|c|c|c|c|c|}
\hline \multirow[b]{2}{*}{ Stream Name } & \multicolumn{5}{|c|}{ State } & \multicolumn{5}{|c|}{ Federal } & \multicolumn{7}{|c|}{ Private } \\
\hline & FWP & MDT & NPCD & DEQ & DNRC & USFWS & BLM & NRCS & BOR & USFS & $B C$ & TU & PL & CF & NFWF & NWE & PCT \\
\hline Cottonwood Creek (Nevada Cr tributary) & & & & & & $\mathrm{X}$ & & & & & & & & & & & \\
\hline Dick Creek & $X$ & & & & & $\mathrm{X}$ & & $\mathrm{X}$ & & & & $X$ & $\mathrm{X}$ & & & & $\mathrm{X}$ \\
\hline Douglas Creek & $\bar{X}$ & & $\mathrm{X}$ & & & $\bar{X}$ & & $\bar{X}$ & $\mathrm{X}$ & & $X$ & $\bar{X}$ & $\bar{X}$ & & & & \\
\hline \multicolumn{18}{|l|}{ Dry Creek } \\
\hline Dunham Creek & $X$ & & & & & $X$ & & & & $X$ & $X$ & $X$ & $\mathrm{X}$ & $X$ & & $\mathrm{X}$ & \\
\hline East Twin Creek & $\bar{X}$ & $\mathrm{X}$ & & & & & & & & & & & & & & & \\
\hline Elk Creek & $\bar{X}$ & & & & & $\mathrm{X}$ & $\mathrm{X}$ & & $\mathrm{X}$ & & $\mathrm{X}$ & $\mathrm{X}$ & $\mathrm{X}$ & & $\mathrm{X}$ & $\mathrm{X}$ & \\
\hline Enders Spring Creek & $\mathrm{X}$ & & & & & $\mathrm{X}$ & & & & & & $\mathrm{X}$ & & $\mathrm{X}$ & & & \\
\hline \multicolumn{18}{|l|}{ Finn Creek } \\
\hline \multicolumn{18}{|l|}{ Fish Creek } \\
\hline \multicolumn{18}{|l|}{ Frazier Creek } \\
\hline \multicolumn{18}{|l|}{ Frazier Creek, North Fork } \\
\hline \multicolumn{18}{|l|}{ Gallagher Creek } \\
\hline \multicolumn{18}{|l|}{ Game Creek } \\
\hline \multicolumn{18}{|l|}{ Gleason Creek } \\
\hline Gold Creek & $\mathrm{X}$ & & & & $\mathrm{X}$ & $\mathrm{X}$ & $\mathrm{X}$ & & & & & $X$ & $\mathrm{X}$ & & & $X$ & $X$ \\
\hline \multicolumn{18}{|l|}{ Gold Creek, West Fork } \\
\hline Grantier Spring Creek & $\mathrm{X}$ & & & & & $\bar{X}$ & & & & & & $X$ & $\mathrm{X}$ & & & & \\
\hline \multicolumn{18}{|l|}{ Halfway Creek } \\
\hline \multicolumn{18}{|l|}{ Hogum Creek } \\
\hline Hoyt Creek & $\mathrm{X}$ & & & $\mathrm{X}$ & & $\mathrm{X}$ & & $\mathrm{X}$ & $\mathrm{X}$ & & $\mathrm{X}$ & $\mathrm{X}$ & $\mathrm{X}$ & $\mathrm{X}$ & & & \\
\hline \multicolumn{18}{|l|}{ Humbug Creek } \\
\hline \multicolumn{18}{|l|}{ Indian Creek } \\
\hline Jacobsen Spring Creek & $\mathrm{X}$ & & & & & $\mathrm{X}$ & & $\mathrm{X}$ & $\mathrm{X}$ & & $\mathrm{X}$ & $X$ & $\mathrm{X}$ & $\mathrm{X}$ & & & \\
\hline \multicolumn{18}{|l|}{ Jefferson Creek } \\
\hline Johnson Creek & $\mathrm{X}$ & & & & & $\mathrm{X}$ & & & & & & $\mathrm{X}$ & $\mathrm{X}$ & & & $\mathrm{X}$ & \\
\hline Keep Cool Creek & $X$ & & $\mathrm{X}$ & & & $\bar{x}$ & & $X$ & $X$ & & $X$ & $\bar{X}$ & $\bar{X}$ & $\mathrm{X}$ & & & \\
\hline Kleinschmidt Creek & $X$ & $\mathrm{X}$ & $\mathrm{X}$ & $\mathrm{X}$ & & $\mathrm{X}$ & & $\mathrm{X}$ & & & $X$ & $X$ & $\mathrm{X}$ & $\mathrm{X}$ & $\mathrm{X}$ & $X$ & \\
\hline \multicolumn{18}{|l|}{ Landers Fork } \\
\hline Lincoln Spring Creek & $X$ & & & & & $\mathrm{X}$ & & $\mathrm{X}$ & $X$ & & & $X$ & $\mathrm{X}$ & $X$ & & & \\
\hline \multicolumn{18}{|l|}{ Little Fish Creek } \\
\hline \multicolumn{18}{|l|}{ Little Moose Creek } \\
\hline Lodgepole Creek & & & & & & & & & & & & & & & & & \\
\hline
\end{tabular}


Appendix G : Table of Restoration Streams and Cooperators (cont'd).

\begin{tabular}{|c|c|c|c|c|c|c|c|c|c|c|c|c|c|c|c|c|c|}
\hline \multirow[b]{2}{*}{ Stream Name } & \multicolumn{5}{|c|}{ State } & \multicolumn{5}{|c|}{ Federal } & \multicolumn{7}{|c|}{ Private } \\
\hline & FWP & MDT & NPCD & $\mathrm{DEQ}$ & DNRC & USFWS & BLM & NRCS & BOR & USFS & $\mathrm{BC}$ & TU & $\mathrm{PL}$ & CF & NFWF & NWE & PCT \\
\hline McCabe Creek & $\mathrm{X}$ & & & & & $\mathrm{X}$ & & $X$ & & $X$ & $X$ & $\bar{X}$ & $\bar{X}$ & & & $\mathrm{X}$ & \\
\hline \multicolumn{18}{|l|}{ McDermott Creek } \\
\hline McElwain Creek & $\mathrm{X}$ & & & & & $\mathrm{X}$ & & & & & & $\mathrm{X}$ & $\mathrm{X}$ & & & & \\
\hline \multicolumn{18}{|l|}{ Mitchell Creek } \\
\hline Monture Creek & $\mathrm{X}$ & & & & & $\mathrm{X}$ & & $X$ & & $\mathrm{X}$ & & $\mathrm{X}$ & $\mathrm{X}$ & & $X$ & & \\
\hline Moose Creek & & & & & & & & & & $\mathrm{X}$ & & $\bar{X}$ & & $\bar{X}$ & & & \\
\hline Murphys Spring Creek & $\mathrm{X}$ & & & & $\mathrm{X}$ & $\bar{X}$ & & $\mathrm{X}$ & & & $\mathrm{X}$ & $\bar{X}$ & $X$ & & & & $\mathrm{X}$ \\
\hline \multicolumn{18}{|l|}{ Murray Creek } \\
\hline Nevada Creek (lower) & $\mathrm{X}$ & & $\mathrm{X}$ & & & & $\mathrm{X}$ & $\mathrm{X}$ & & & & $\bar{X}$ & $\bar{X}$ & & & & \\
\hline Nevada Creek (upper) & $\bar{X}$ & & $\bar{X}$ & & & $\bar{X}$ & & $\bar{X}$ & & & $\bar{X}$ & & $\bar{X}$ & & $\bar{X}$ & & \\
\hline Nevada Spring Creek & $\bar{X}$ & & $\bar{X}$ & & & $\bar{X}$ & & $\bar{X}$ & $\bar{X}$ & & $\bar{X}$ & $\mathrm{X}$ & $\bar{X}$ & $\mathrm{X}$ & & $\bar{X}$ & \\
\hline North Fork Blackfoot River & $\bar{X}$ & & & & $\mathrm{X}$ & $\bar{X}$ & & & & & $\bar{X}$ & $\bar{X}$ & $\mathrm{X}$ & $\mathrm{X}$ & $\mathrm{X}$ & $\bar{X}$ & $\mathrm{X}$ \\
\hline Pearson Creek & $\bar{X}$ & & $\bar{X}$ & & & $\bar{X}$ & $\mathrm{X}$ & $\mathrm{X}$ & & & $\bar{X}$ & $\bar{X}$ & $\bar{X}$ & & & $\bar{X}$ & $\bar{X}$ \\
\hline Poorman Creek & $\bar{X}$ & $\mathrm{X}$ & & $X$ & $\bar{X}$ & $\bar{X}$ & & $\bar{X}$ & & $X$ & $\bar{X}$ & $\bar{X}$ & $\bar{X}$ & $X$ & & $\bar{X}$ & \\
\hline Rock Creek & $\bar{X}$ & $\bar{X}$ & $X$ & $\bar{X}$ & $\bar{X}$ & $\bar{X}$ & & $\bar{X}$ & & & $\bar{X}$ & $\bar{X}$ & $\bar{X}$ & $\bar{X}$ & $\mathrm{X}$ & $\bar{X}$ & \\
\hline Salmon Creek & $\bar{X}$ & & & & & $\bar{X}$ & & & & & & $\bar{X}$ & $\bar{X}$ & $\bar{X}$ & $\bar{X}$ & & \\
\hline \multicolumn{18}{|l|}{ Sauerkraut Creek } \\
\hline \multicolumn{18}{|l|}{ Seven Up Pete Creek } \\
\hline Shanley Creek & $\mathrm{X}$ & & & & & $\mathrm{X}$ & & & & & & $X$ & $X$ & & & & \\
\hline \multicolumn{18}{|l|}{ Sheep Creek } \\
\hline \multicolumn{18}{|l|}{ Shingle Mill Creek } \\
\hline \multicolumn{18}{|l|}{ Smith Creek } \\
\hline \multicolumn{18}{|l|}{ Snowbank Creek } \\
\hline \multicolumn{18}{|c|}{ Spring Creek (Cottonwood Cr tributary) } \\
\hline \multicolumn{18}{|c|}{ Stonewall Creek } \\
\hline \multicolumn{18}{|l|}{ Strickland Creek } \\
\hline \multicolumn{18}{|l|}{ Sturgeon Creek } \\
\hline \multicolumn{18}{|l|}{ Sucker Creek } \\
\hline \multicolumn{18}{|l|}{ Tamarack Creek } \\
\hline \multicolumn{18}{|l|}{ Union Creek } \\
\hline Wales Creek & $\mathbf{X}$ & & & & & & & & & & $\mathbf{X}$ & & $\mathrm{X}$ & & & $\mathbf{X}$ & \\
\hline \multicolumn{18}{|l|}{ Wales Spring Creek } \\
\hline Ward Creek & & & $\bar{X}$ & $\bar{X}$ & & $\mathrm{X}$ & & & & & $\bar{X}$ & $\bar{X}$ & $\bar{X}$ & $\bar{X}$ & & & \\
\hline \multicolumn{18}{|l|}{ Warm Springs Creek } \\
\hline Warren Creek & $\bar{X}$ & & $\bar{X}$ & $\bar{X}$ & & $\mathbf{X}$ & & $\mathrm{X}$ & $\mathrm{X}$ & & $\bar{X}$ & $\bar{X}$ & $\bar{X}$ & $\bar{X}$ & & & $\mathrm{X}$ \\
\hline
\end{tabular}


Appendix G : Table of Restoration Streams and Cooperators (cont'd).

\begin{tabular}{|c|c|c|c|c|c|c|c|c|c|c|c|c|c|c|c|c|c|}
\hline \multirow[b]{2}{*}{ Stream Name } & \multicolumn{5}{|c|}{ State } & \multicolumn{5}{|c|}{ Federal } & \multicolumn{7}{|c|}{ Private } \\
\hline & FWP & MDT & NPCD & DEQ & DNRC & USFWS & BLM & NRCS & BOR & USFS & $B C$ & TU & PL & $\mathrm{CF}$ & NFWF & NWE & PCT \\
\hline \multicolumn{18}{|l|}{ Warren Creek (Doney lake trib.) } \\
\hline \multicolumn{18}{|l|}{ Washington Creek } \\
\hline \multicolumn{18}{|l|}{ Washoe Creek } \\
\hline Wasson Creek & $\bar{X}$ & & $\bar{X}$ & $\bar{X}$ & & $\bar{X}$ & & $\bar{X}$ & $\bar{X}$ & & $\bar{X}$ & $\bar{X}$ & $\bar{X}$ & & & $\bar{X}$ & \\
\hline West Twin Creek & $\bar{X}$ & $X$ & & & & & & & & & & & & & & & \\
\hline \multicolumn{18}{|l|}{ Willow Creek (above Lincoln, MT) } \\
\hline \multicolumn{18}{|l|}{ Willow Creek (below Lincoln, MT) } \\
\hline \multicolumn{18}{|l|}{ Wilson Creek } \\
\hline Yourname Creek & & & & & & & & & & & & & & & & & \\
\hline
\end{tabular}

\begin{tabular}{|c|c|c|c|c|c|c|c|c|c|c|c|c|c|c|c|}
\hline \multirow{2}{*}{\multicolumn{16}{|c|}{ Auggie Creek }} \\
\hline & & & & & & & & & & & & & & & \\
\hline \multicolumn{16}{|l|}{ Bertha Creek } \\
\hline Blanchard Cre & $X$ & & & $X$ & $\mathrm{X}$ & $X$ & & & & & $\mathrm{X}$ & $X$ & & & \\
\hline \multicolumn{16}{|c|}{ Blanchard Creek, North Fork } \\
\hline \multicolumn{16}{|c|}{ Blind Canyon Creek } \\
\hline \multicolumn{16}{|l|}{ Boles Creek } \\
\hline \multicolumn{16}{|l|}{ Buck Creek } \\
\hline \multicolumn{16}{|c|}{ Camp Creek } \\
\hline \multicolumn{16}{|c|}{ Clearwater River Section 1} \\
\hline \multicolumn{16}{|c|}{ Clearwater River Section 2} \\
\hline \multicolumn{16}{|c|}{ Clearwater River Section 3} \\
\hline \multicolumn{16}{|c|}{ Clearwater River Section 4} \\
\hline \multicolumn{16}{|c|}{ Clearwater River Section 5} \\
\hline \multicolumn{16}{|c|}{ Clearwater River, East Fork } \\
\hline \multicolumn{16}{|c|}{ Clearwater River, West Fork } \\
\hline \multicolumn{16}{|c|}{ Cold Brook Creek } \\
\hline \multicolumn{16}{|c|}{ Colt Creek } \\
\hline \multicolumn{16}{|l|}{ Deer Creek } \\
\hline \multicolumn{16}{|l|}{ Drew Creek } \\
\hline \multicolumn{16}{|l|}{ Fawn Creek } \\
\hline Findell Creek & & & & & & & & & & & & & & & \\
\hline
\end{tabular}


Appendix G : Table of Restoration Streams and Cooperators (cont'd).

\begin{tabular}{|c|c|c|c|c|c|c|c|c|c|c|c|c|c|c|c|c|c|}
\hline \multirow[b]{2}{*}{ Stream Name } & \multicolumn{5}{|c|}{ State } & \multicolumn{5}{|c|}{ Federal } & \multicolumn{7}{|c|}{ Private } \\
\hline & FWP & MDT & NPCD & DEQ & DNRC & USFWS & BLM & NRCS & BOR & USFS & $\mathrm{BC}$ & TU & $\mathrm{PL}$ & $\mathrm{CF}$ & NFWF & NWE & PCT \\
\hline \multicolumn{18}{|l|}{ Finley Creek } \\
\hline \multicolumn{18}{|l|}{ First Creek } \\
\hline \multicolumn{18}{|l|}{ Grouse Creek } \\
\hline \multicolumn{18}{|l|}{ Horn Creek } \\
\hline \multicolumn{18}{|l|}{ Inez Creek } \\
\hline \multicolumn{18}{|l|}{ Lost Horse Creek } \\
\hline \multicolumn{18}{|l|}{ Lost Prairie Creek } \\
\hline \multicolumn{18}{|l|}{ Marshall Creek } \\
\hline Morrell Creek & $\mathrm{X}$ & & & & & $\bar{X}$ & & & & & & $\bar{X}$ & & & & $\bar{X}$ & \\
\hline \multicolumn{18}{|l|}{ Mountain Creek } \\
\hline \multicolumn{18}{|l|}{ Murphy Creek } \\
\hline \multicolumn{18}{|l|}{ Owl Creek } \\
\hline \multicolumn{18}{|l|}{ Placid Creek } \\
\hline \multicolumn{18}{|l|}{ Placid Creek, North Fork } \\
\hline \multicolumn{18}{|l|}{ Rice Creek } \\
\hline \multicolumn{18}{|l|}{ Richmond Creek } \\
\hline \multicolumn{18}{|l|}{ Sawyer Creek } \\
\hline \multicolumn{18}{|l|}{ Second Creek } \\
\hline \multicolumn{18}{|l|}{ Seeley Creek } \\
\hline \multicolumn{18}{|l|}{ Sheep Creek } \\
\hline \multicolumn{18}{|l|}{ Slippery John Creek } \\
\hline \multicolumn{18}{|l|}{ Swamp Creek } \\
\hline \multicolumn{18}{|l|}{ Trail Creek } \\
\hline \multicolumn{18}{|l|}{\begin{tabular}{|l|} 
Uhler Creek \\
\end{tabular}} \\
\hline Vaughn Creek & & & & & & & & & & & & & & & & & \\
\hline
\end{tabular}

FWP-Montana Fish, Wildlife and Parks

MDT-Montana Department of Transportation

NPCD-North Powell Conservation District

DEQ-Department of Environment Quality

DNRC-Dept. of Natural Resources and Conservation

USFWS-U.S.Fish and Wildlife Service

BLM-Bureau of Land Management

USFS-U.S. Forest Service

BC-Blackfoot Challenge

TU-Trout Unlimited

PL-Private Landowners

CF-Chutney Foundation

NFWF-National Fish and Wildlife Foundation

NWE-Northwestern Energy

PCT-Plum Creek Timber Company 
Appendix H: Temperatures sensor locations in the Blackfoot drainage, 2006

\begin{tabular}{|c|c|c|c|c|c|}
\hline Stream Name & $\begin{array}{c}\text { Location } \\
\text { (stream } \\
\text { mile) }\end{array}$ & $\begin{array}{c}\text { Legal } \\
\text { Description }\end{array}$ & Duration & $\begin{array}{c}\text { Sensor } \\
\text { Type }\end{array}$ & $\begin{array}{c}\text { Recording } \\
\text { Interval }\end{array}$ \\
\hline Belmont Creek @ mouth & 0.1 & $14 \mathrm{~N}, 16 \mathrm{~W}, 24 \mathrm{C}$ & $6 / 29 / 06-10 / 4 / 06$ & Tidbit & $50 \mathrm{~min}$. \\
\hline Blackfoot River above Belmont Creek & 21.8 & $14 \mathrm{~N}, 16 \mathrm{~W}, 24 \mathrm{C}$ & $6 / 29 / 06-10 / 4 / 06$ & Tidbit & $50 \mathrm{~min}$. \\
\hline Blackfoot River @ Cuttoff Rd Bridge & 72.2 & $14 \mathrm{~N}, 11 \mathrm{~W}, 32 \mathrm{D}$ & $6 / 29 / 06-10 / 4 / 06$ & Tidbit & $50 \mathrm{~min}$. \\
\hline Blackfoot River @ Dalton Mtn Rd Bridge & 104.5 & $14 \mathrm{~N}, 9 \mathrm{~W}, 28 \mathrm{~B}$ & $6 / 29 / 06-10 / 4 / 06$ & Tidbit & $50 \mathrm{~min}$. \\
\hline Blackfoot River @ Raymond Bridge & 60 & $14 \mathrm{~N}, 12 \mathrm{~W}, 28 \mathrm{D}$ & $6 / 29 / 06-10 / 3 / 06$ & Tidbit & $50 \mathrm{~min}$. \\
\hline Blackfoot River @ Scotty Brown Bridge & 46.1 & $15 \mathrm{~N}, 13 \mathrm{~W}, 33 \mathrm{~A}$ & $3 / 21 / 06-10 / 3 / 06$ & Tidbit & $50 \mathrm{~min}$. \\
\hline Blackfoot River @ USGS Gage Station & 7.9 & $13 \mathrm{~N}, 17 \mathrm{~W}, 9 \mathrm{~B}$ & $3 / 14 / 06-10 / 4 / 06$ & Tidbit & $50 \mathrm{~min}$. \\
\hline Copper Creek @ Sucker Creek Rd Bridge & 1.1 & $15 \mathrm{~N}, 8 \mathrm{~W}, 25 \mathrm{C}$ & $6 / 29 / 06-10 / 4 / 06$ & Tidbit & $50 \mathrm{~min}$. \\
\hline Cottonwood Creek @ Hwy 200 & 1 & $15 \mathrm{~N}, 13 \mathrm{~W}, 29 \mathrm{~B}$ & $6 / 29 / 06-10 / 3 / 06$ & Tidbit & $50 \mathrm{~min}$. \\
\hline Gold Creek & 1.6 & $14 \mathrm{~N}, 16 \mathrm{~W}, 30 \mathrm{C}$ & $3 / 29 / 06-10 / 4 / 06$ & Tidbit & $50 \mathrm{~min}$. \\
\hline Jacobsen Spring Creek @ mouth & 0.1 & $14 \mathrm{~N}, 12 \mathrm{~W}, 1 \mathrm{C}$ & $6 / 29 / 06-10 / 4 / 06$ & Hobo & $72 \mathrm{~min}$ \\
\hline Landers Fork @ Hwy 200 & 1 & $14 \mathrm{~N}, 8 \mathrm{~W}, 12 \mathrm{C}$ & $6 / 29 / 06-10 / 4 / 06$ & Hobo & $72 \mathrm{~min}$ \\
\hline Monture Creek @ mouth & 0.1 & $15 \mathrm{~N}, 13 \mathrm{~W}, 27 \mathrm{D}$ & $3 / 22 / 06-7 / 27 / 06$ & Tidbit & $50 \mathrm{~min}$. \\
\hline Nevada Creek above Nevada Spr Creek & 5.5 & $13 \mathrm{~N}, 11 \mathrm{~W}, 9 \mathrm{C}$ & $6 / 29 / 06-10 / 3 / 06$ & Hobo & $72 \mathrm{~min}$ \\
\hline Nevada Creek below Nevada Spr Creek & 4.5 & $13 \mathrm{~N}, 11 \mathrm{~W}, 8 \mathrm{D}$ & $6 / 29 / 06-10 / 3 / 06$ & Hobo & $72 \mathrm{~min}$ \\
\hline Nevada Spring Creek @ mouth & 0.1 & $13 \mathrm{~N}, 11 \mathrm{~W}, 9 \mathrm{C}$ & $6 / 29 / 06-10 / 3 / 06$ & Hobo & $72 \mathrm{~min}$ \\
\hline Nevada Spring Creek @ lower bridge & 1.1 & $13 \mathrm{~N}, 11 \mathrm{~W}, 10 \mathrm{~B}$ & $6 / 29 / 06-10 / 3 / 06$ & Hobo & $72 \mathrm{~min}$ \\
\hline Nevada Spring Creek @ upper fenceline & 3.5 & $13 \mathrm{~N}, 11 \mathrm{~W}, 11 \mathrm{C}$ & $6 / 29 / 06-10 / 3 / 06$ & Hobo & $72 \mathrm{~min}$ \\
\hline North Fork Blackfoot River & 2.6 & $14 \mathrm{~N}, 12 \mathrm{~W}, 10 \mathrm{D}$ & $6 / 29 / 06-10 / 3 / 06$ & Tidbit & $50 \mathrm{~min}$. \\
\hline Wasson Creek @ mouth & 0.1 & $13 \mathrm{~N}, 11 \mathrm{~W}, 11 \mathrm{D}$ & $6 / 29 / 06-10 / 3 / 06$ & Hobo & $72 \mathrm{~min}$ \\
\hline
\end{tabular}

Temperatures sensor locations in the Blackfoot drainage, 2007.

\begin{tabular}{|c|c|c|c|c|c|}
\hline Beaver Creek @ Hwy 200 & 0.2 & 14N9W22B & 6/14/07-9/13/07 & Tidbit & 50min. \\
\hline Belmont Creek @ mouth & 0.1 & $14 \mathrm{~N}, 16 \mathrm{~W}, 24 \mathrm{C}$ & $4 / 18 / 07-9 / 11 / 07$ & Tidbit & 50min. \\
\hline Blackfoot River above Belmont Creek & 21.8 & 14N16W24C & 1/1/07-present & Tidbit & $50 \mathrm{~min}$. \\
\hline Blackfoot River @ Cutoff Bridge & 72.4 & $14 \mathrm{~N}, 11 \mathrm{~W}, 32 \mathrm{D}$ & $4 / 18 / 07-9 / 12 / 07$ & Tidbit & 50min. \\
\hline Blackfoot River @ Dalton Mtn Rd & 104.5 & 14N9W28B & 1/1/07-present & Tidbit & 50min. \\
\hline Blackfoot River @ Raymond Bridge & 60 & $14 \mathrm{~N}, 12 \mathrm{~W}, 28 \mathrm{D}$ & $4 / 18 / 07-9 / 17 / 07$ & Tidbit & $50 \mathrm{~min}$. \\
\hline Blackfoot River @ Scotty Brown Bridge & 46.1 & $15 \mathrm{~N}, 13 \mathrm{~W}, 33 \mathrm{~A}$ & $4 / 18 / 07-9 / 11 / 07$ & Tidbit & 50min. \\
\hline Blackfoot River @ USGS Gage Station & 7.9 & $13 \mathrm{~N}, 17 \mathrm{~W}, 9 \mathrm{~B}$ & 1/1/07-present & Tidbit & 50min. \\
\hline Chamberlain Creek @ mouth & 0.1 & $15 \mathrm{~N}, 13 \mathrm{~W}, 32 \mathrm{~A}$ & $4 / 18 / 07-9 / 10 / 07$ & Hobo & $72 \mathrm{~min}$. \\
\hline Chamberlain Creek above Brach Diversion & 0.7 & $15 \mathrm{~N}, 13 \mathrm{~W}, 32 \mathrm{D}$ & $4 / 18 / 07-9 / 10 / 07$ & Hobo & $72 \mathrm{~min}$. \\
\hline Chamberlain Creek below West Fork & 3.7 & $14 \mathrm{~N}, 13 \mathrm{~W}, 8 \mathrm{D}$ & $4 / 18 / 07-9 / 10 / 07$ & Hobo & $72 \mathrm{~min}$. \\
\hline Copper Creek @ Sucker Creek Rd Bridge & 1.1 & $15 \mathrm{~N} 8 \mathrm{~W} 25 \mathrm{C}$ & $4 / 18 / 07-9 / 12 / 07$ & Tidbit & 50min. \\
\hline Cottonwood Creek @ Hwy 200 & 1 & $15 \mathrm{~N}, 13 \mathrm{~W}, 29 \mathrm{~B}$ & 1/1/07-present & Tidbit & 50min. \\
\hline Cottonwood Creek @ Woodworth Rd & 9.5 & $16 \mathrm{~N}, 13 \mathrm{~W}, 31 \mathrm{~B}$ & 7/3/07-9/11/07 & Tidbit & 50min. \\
\hline Ender's Spring Creek & 0.1 & $14 \mathrm{~N}, 11 \mathrm{~W}, 6 \mathrm{~B}$ & $5 / 31 / 07-9 / 11 / 07$ & Hobo & $72 \mathrm{~min}$. \\
\hline Frazier Cr abv Upper Frazier Cr Reservoir & 1.2 & $14 \mathrm{~N}, 12 \mathrm{~W}, 32 \mathrm{~A}$ & $5 / 22 / 07-9 / 17 / 07$ & Hobo & 72min. \\
\hline Frazier Creek @ mouth & 0.1 & $14 \mathrm{~N}, 12 \mathrm{~W}, 28 \mathrm{D}$ & $5 / 22 / 07-9 / 17 / 07$ & Hobo & $72 \mathrm{~min}$. \\
\hline Frazier Cr below Middle Frazier Cr Reservoir & 0.4 & $14 \mathrm{~N}, 12 \mathrm{~W}, 28 \mathrm{C}$ & $5 / 22 / 07-9 / 17 / 07$ & Hobo & $72 \min$. \\
\hline Frazier Cr trib. between Mannix Reservoirs & 0.25 & $14 \mathrm{~N}, 12 \mathrm{~W}, 28 \mathrm{D}$ & $5 / 22 / 07-9 / 17 / 07$ & Hobo & $72 \mathrm{~min}$. \\
\hline $\begin{array}{ll}\text { Frazier Creek (North Fork) } \\
\end{array}$ & 0.1 & $14 \mathrm{~N}, 12 \mathrm{~W}, 32 \mathrm{~A}$ & $5 / 22 / 07-9 / 17 / 07$ & Hobo & $72 \mathrm{~min}$. \\
\hline Gold Creek@ lower bridge & 1.6 & $14 \mathrm{~N}, 16 \mathrm{~W}, 30 \mathrm{C}$ & $4 / 18 / 07-9 / 12 / 07$ & Tidbit & 50min. \\
\hline Hoyt Creek & 1.3 & $15 \mathrm{~N}, 12 \mathrm{~W}, 19 \mathrm{C}$ & 6/18/07-9/11/07 & Hobo & $72 \mathrm{~min}$. \\
\hline Hoyt Creek & 4.3 & $15 \mathrm{~N}, 12 \mathrm{~W}, 28 \mathrm{C}$ & $6 / 28 / 07-9 / 11 / 07$ & Hobo & $72 \mathrm{~min}$. \\
\hline Landers Fork @ Hwy 200 & 1 & $14 \mathrm{~N}, 8 \mathrm{~W}, 12 \mathrm{C}$ & 6/14/07-9/12/07 & Tidbit & 50min. \\
\hline Monture Creek @ FAS & 1.8 & 15N13W22D & 6/14/07-9/11/07 & Tidbit & 50min. \\
\hline Monture Creek @ USFS Bridge & 13.1 & 16N12W29C & 6/18/07-9/11/07 & Tidbit & 50min. \\
\hline Nevada Creek below Nevada Spring Creek & 4.5 & $13 \mathrm{~N}, 11 \mathrm{~W}, 8 \mathrm{D}$ & 6/14/04-9/12/07 & Hobo & $72 \mathrm{~min}$. \\
\hline Nevada Spring Creek @ mouth & 0.1 & $13 \mathrm{~N}, 11 \mathrm{~W}, 9 \mathrm{C}$ & 6/14/04-911/07 & Hobo & $72 \mathrm{~min}$. \\
\hline North Fork Blackfoot River & 2.6 & $14 \mathrm{~N}, 12 \mathrm{~W}, 10 \mathrm{D}$ & 1/1/07-present & Tidbit & $50 \mathrm{~min}$. \\
\hline North Fork Blackfoot River @ USFS Bridge & 17.5 & $16 \mathrm{~N}, 11 \mathrm{~W}, 35 \mathrm{~B}$ & 6/18/07-9/12/07 & Tidbit & 50min. \\
\hline Poorman Creek & 2.2 & $14 \mathrm{~N}, 9 \mathrm{~W}, 36 \mathrm{D}$ & 6/14/07-9/12/07 & Hobo & 72min. \\
\hline Rock Creek @ County Rd X-ing & 1.6 & $14 \mathrm{~N}, 9 \mathrm{~W}, 36 \mathrm{D}$ & $6 / 18 / 07-9 / 12 / 07$ & Tidbit & $50 \mathrm{~min}$. \\
\hline Saurerkraut Creek & 0.5 & $14 \mathrm{~N}, 9 \mathrm{~W}, 36 \mathrm{D}$ & 6/14/07-9/17/07 & Tidbit & 50min. \\
\hline Shanley Creek@ @oodworth Rd & 0.4 & $14 \mathrm{~N}, 9 \mathrm{~W}, 36 \mathrm{D}$ & $6 / 14 / 07-9 / 11 / 07$ & Tidbit & 50min. \\
\hline Upper Willow Creek & 0.7 & $15 \mathrm{~N}, 7 \mathrm{~W}, 35 \mathrm{C}$ & $6 / 14 / 07-9 / 12 / 07$ & Hobo & $72 \mathrm{~min}$. \\
\hline Warren Creek @ lower bridge & 1.1 & $15 \mathrm{~N}, 12 \mathrm{~W}, 31 \mathrm{C}$ & 6/18/07-9/10/07 & Tidbit & 50min. \\
\hline Wasson Creek @ Hwy 141 & 1 & $13 \mathrm{~N}, 11 \mathrm{~W}, 11 \mathrm{D}$ & $7 / 3 / 07-9 / 12 / 07$ & Tidbit & 50min. \\
\hline Wasson Creek@ mouth & 0.1 & $13 \mathrm{~N}, 11 \mathrm{~W}, 11 \mathrm{D}$ & $6 / 14 / 07-9 / 12 / 07$ & Hobo & $72 \mathrm{~min}$. \\
\hline West Twin Creek & 0.1 & $13 \mathrm{~N}, 17 \mathrm{~W}, 2 \mathrm{D}$ & $6 / 18 / 07-9 / 11 / 07$ & Tidbit & $50 \mathrm{~min}$. \\
\hline Willow Creek @ Dalton Mtn Rd & 1.6 & $14 \mathrm{~N}, 9 \mathrm{~W}, 28 \mathrm{D}$ & $6 / 14 / 07-9 / 12 / 07$ & Hobo & $72 \mathrm{~min}$. \\
\hline $\begin{array}{l}\text { Willow Creek } \\
\end{array}$ & 3.7 & $14 \mathrm{~N}, 9 \mathrm{~W}, 34 \mathrm{D}$ & 6/14/07-9/12/07 & Hobo & 72min. \\
\hline Willow Creek & 5.4 & $14 \mathrm{~N}, 9 \mathrm{~W}, 10 \mathrm{~B}$ & 6/14/07-9/12/07 & Hobo & 72min. \\
\hline
\end{tabular}



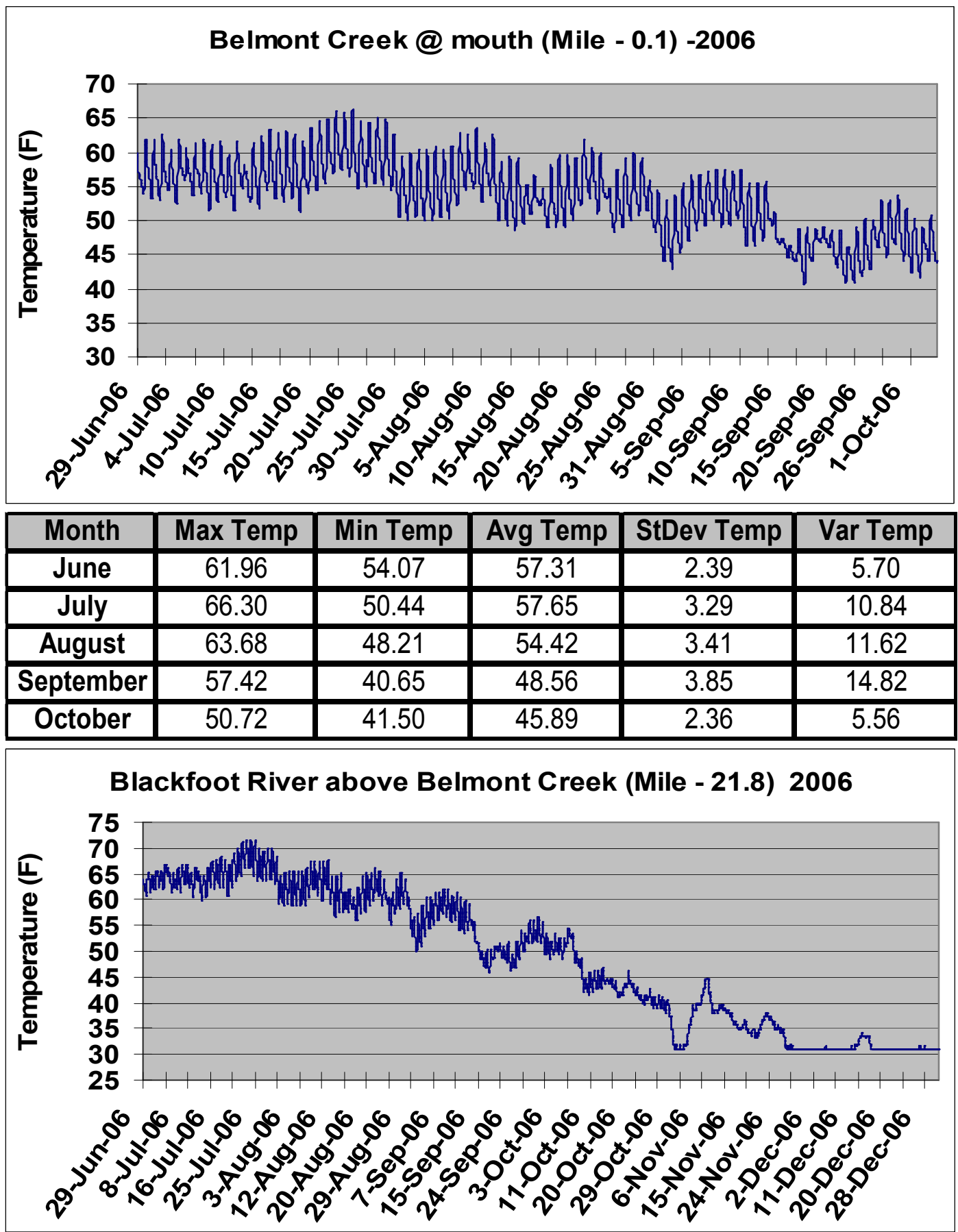

\begin{tabular}{|c|c|c|c|c|c|}
\hline Month & Max Temp & Min Temp & Avg Temp & StDev temp & Var Temp \\
\hline June & 65.1 & 60.82 & 63.00 & 1.41 & 1.98 \\
\hline July & 71.67 & 59.24 & 65.26 & 2.47 & 6.09 \\
\hline August & 67.8 & 52.99 & 61.26 & 2.82 & 7.97 \\
\hline September & 61.88 & 45.74 & 53.54 & 4.06 & 16.49 \\
\hline October & 53.51 & 48.34 & 50.74 & 1.26 & 1.58 \\
\hline November & 44.7 & 30.97 & 35.77 & 3.48 & 12.09 \\
\hline December & 34.19 & 30.97 & 31.23 & 0.74 & 0.54 \\
\hline
\end{tabular}



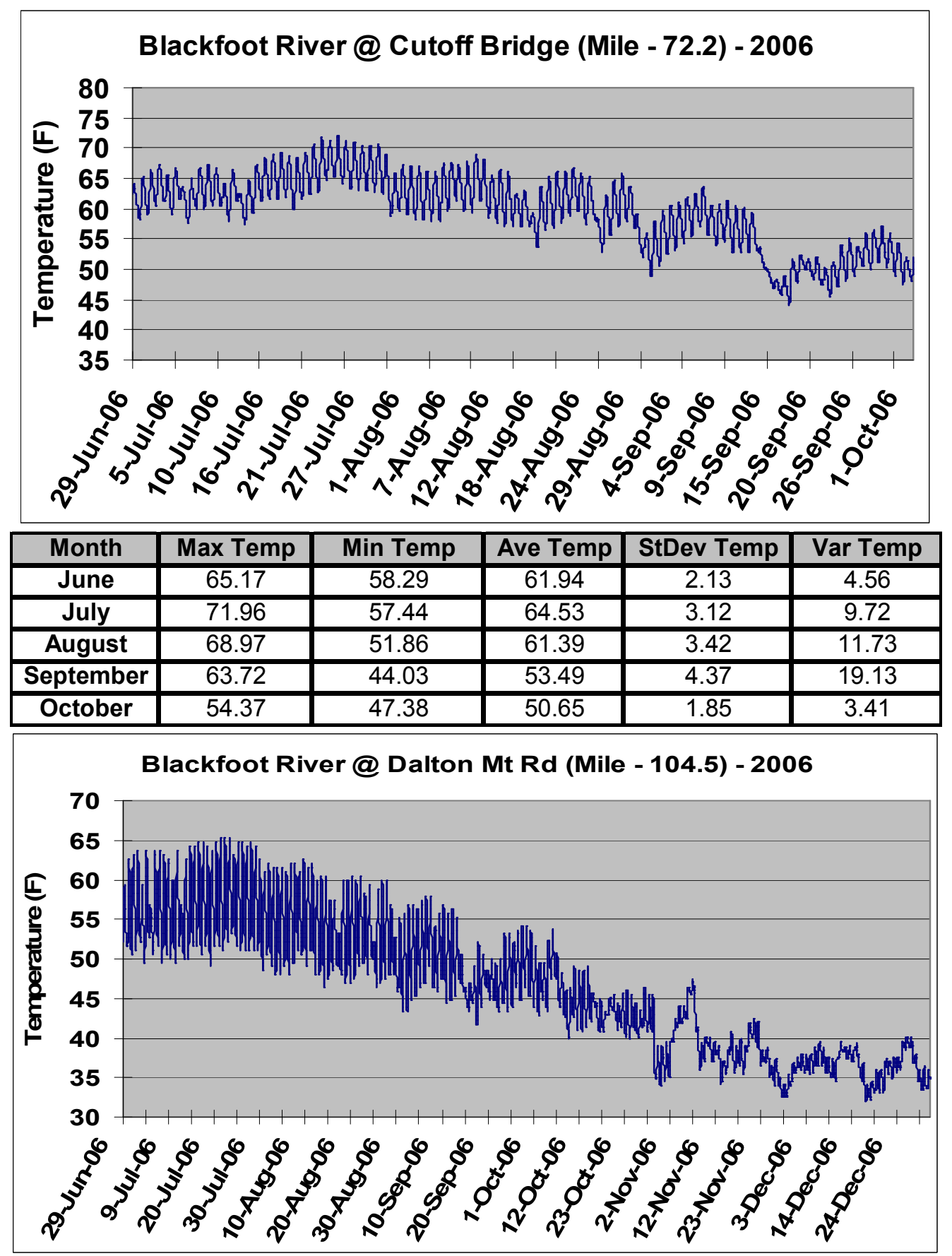

\begin{tabular}{|c|c|c|c|c|c|}
\hline Month & Max Temp & Min Temp & Ave Temp & StDev Temp & Var Temp \\
\hline June & 62.60 & 51.61 & 56.16 & 3.59 & 12.90 \\
\hline July & 65.28 & 48.51 & 56.78 & 4.43 & 19.66 \\
\hline August & 62.60 & 45.90 & 53.65 & 4.22 & 17.8 \\
\hline September & 57.85 & 41.75 & 48.98 & 3.62 & 13.09 \\
\hline October & 53.83 & 33.93 & 43.94 & 3.44 & 11.83 \\
\hline November & 47.43 & 32.49 & 38.52 & 3.19 & 10.17 \\
\hline December & 40.17 & 31.91 & 36.5 & 1.8 & 3.24 \\
\hline
\end{tabular}




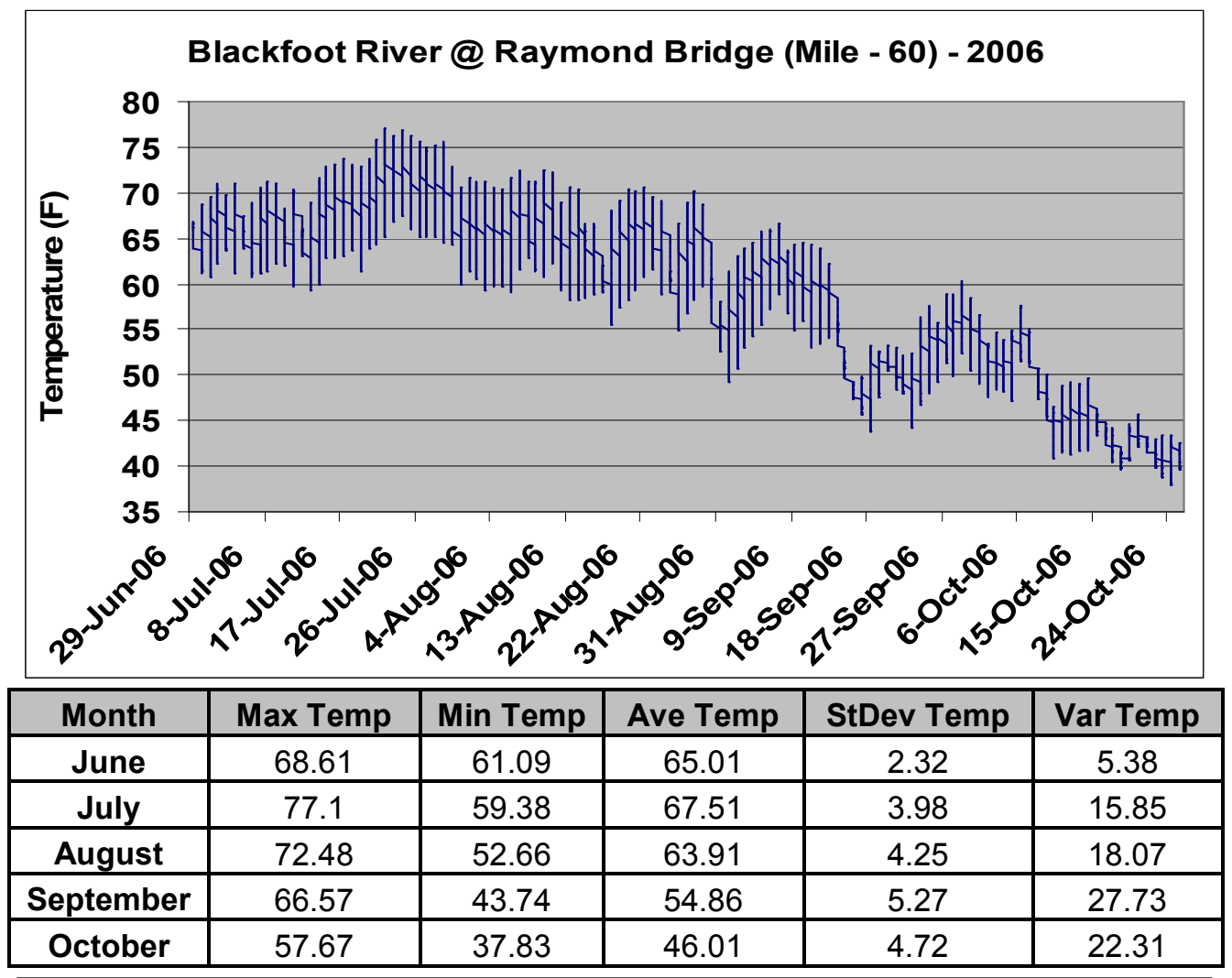

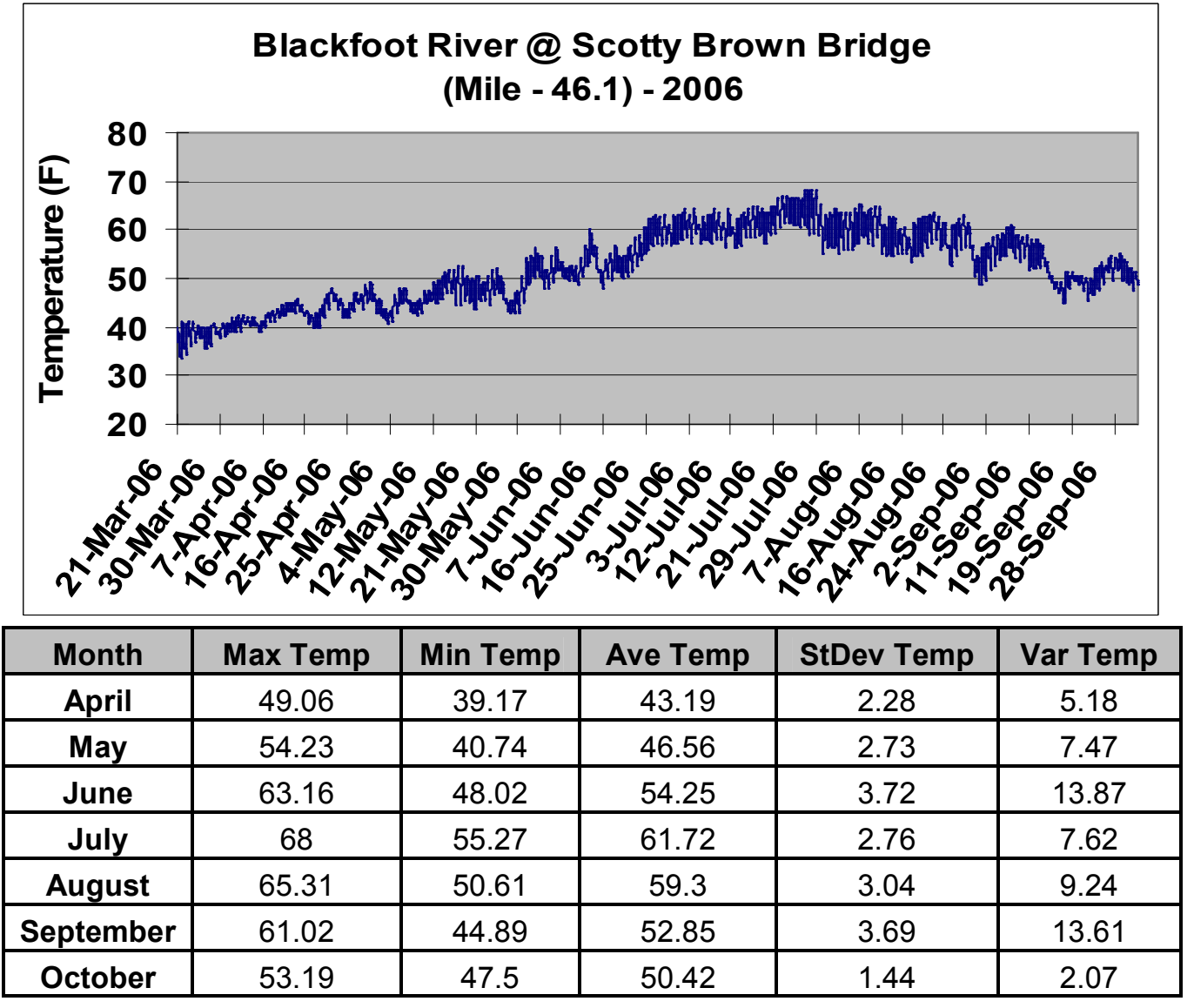




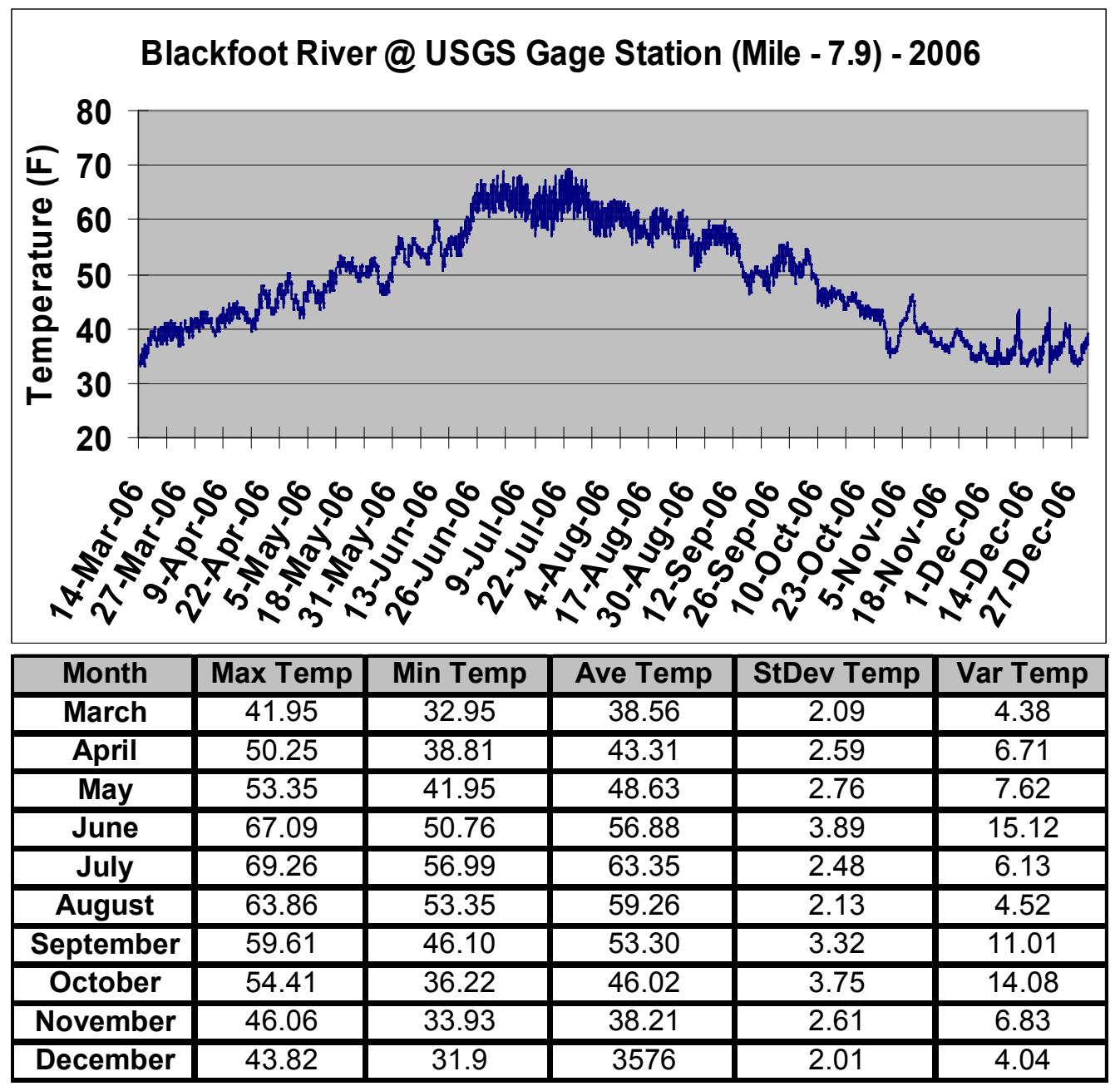




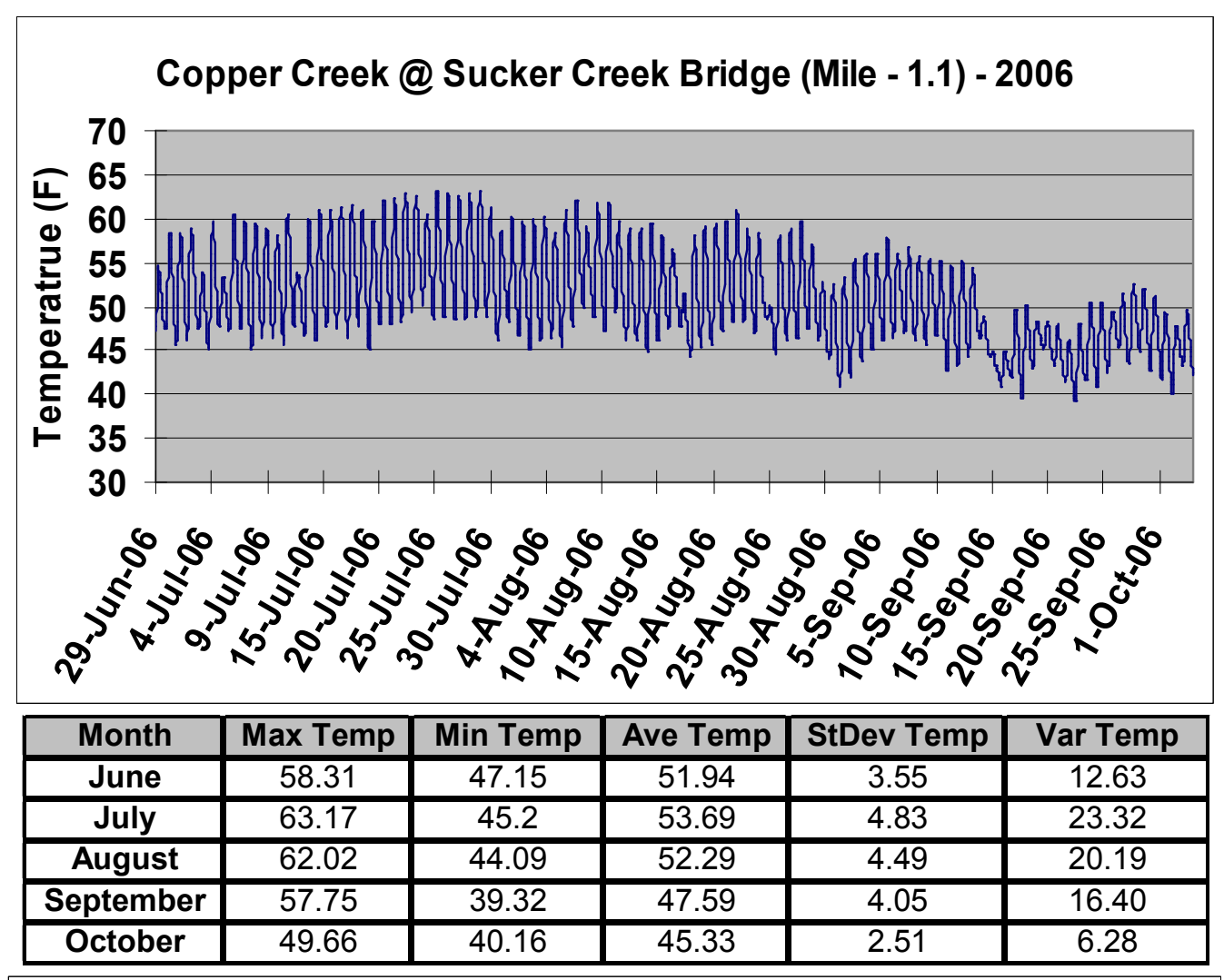

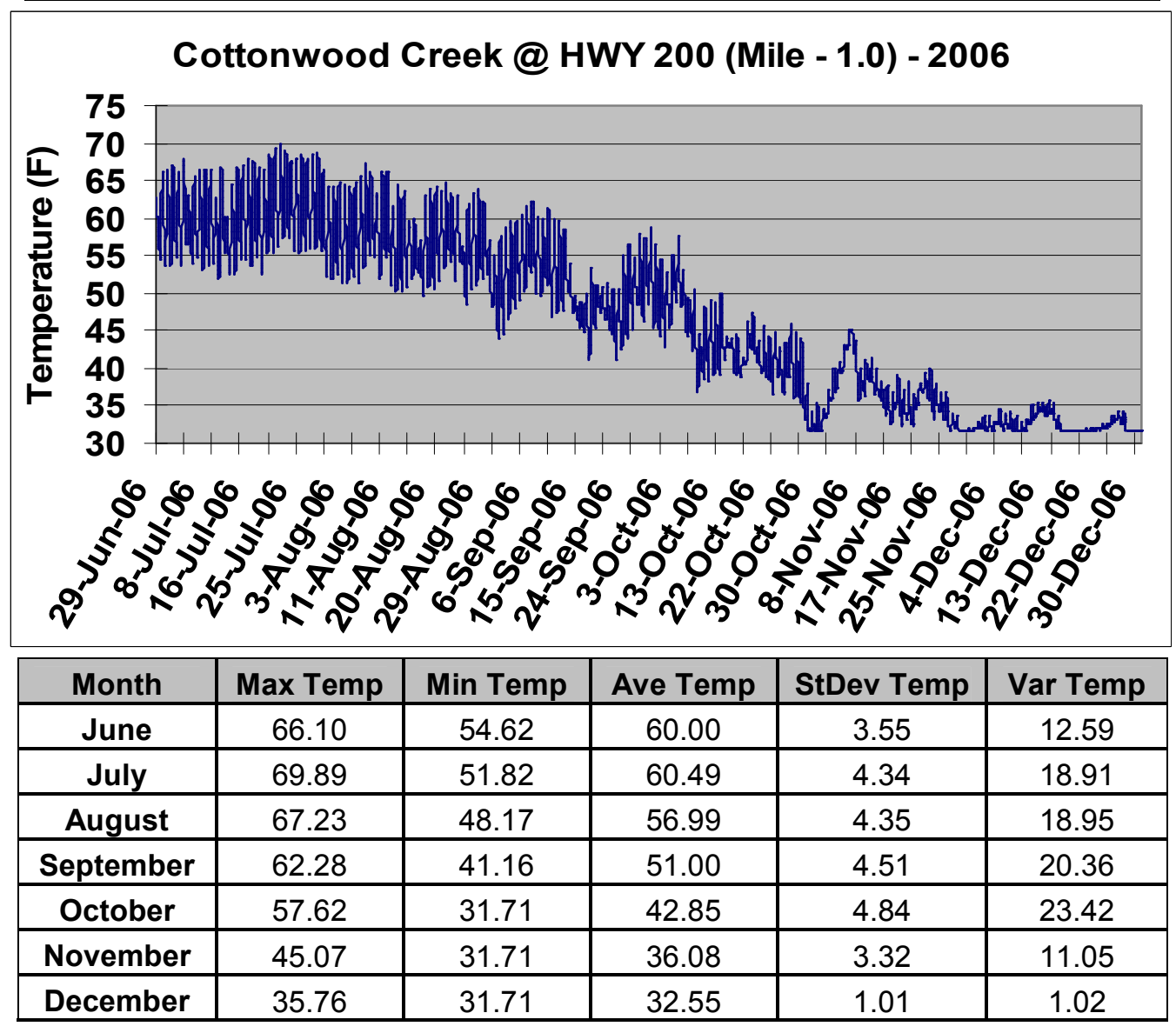



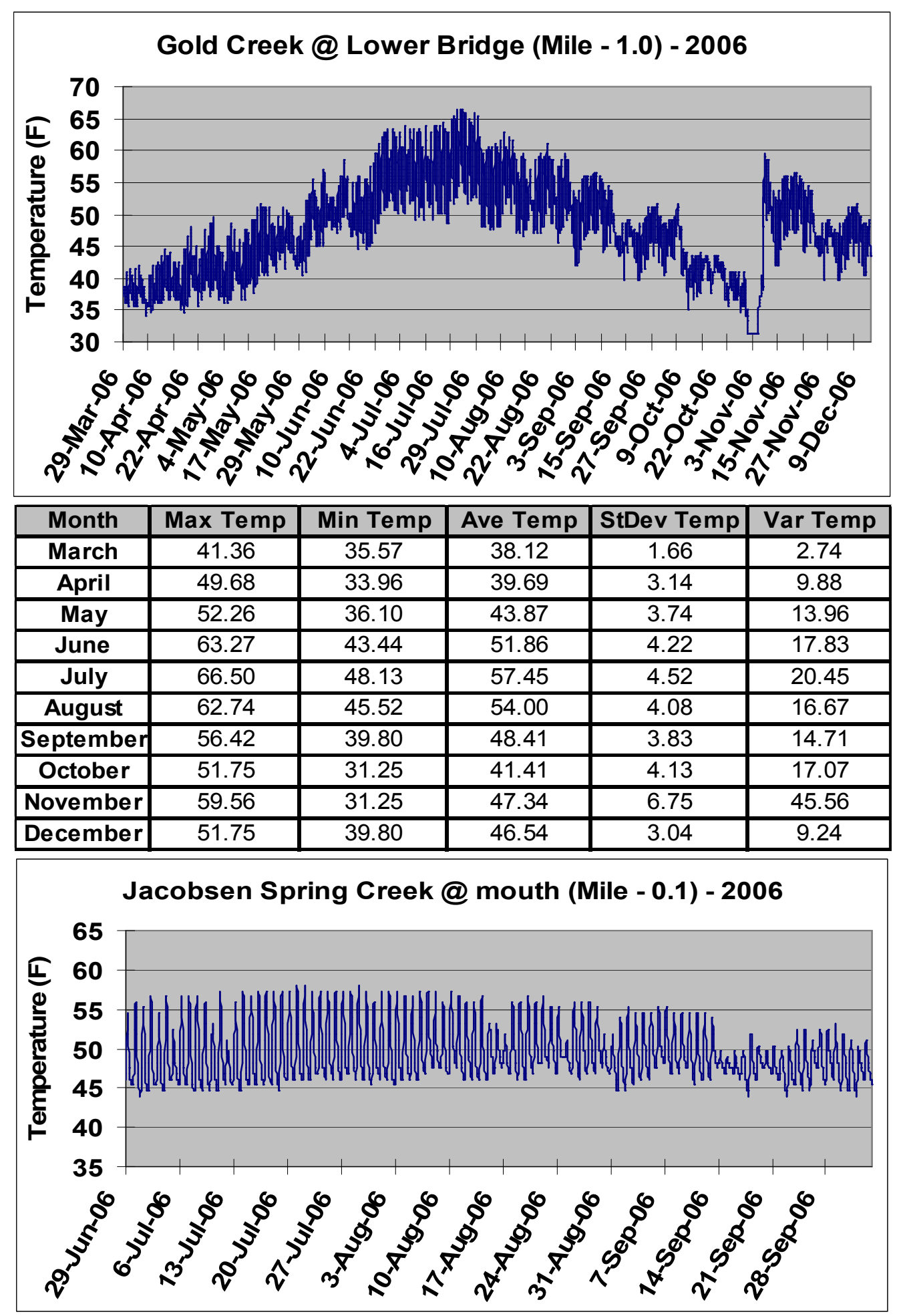

\begin{tabular}{|c|c|c|c|c|c|}
\hline Month & Max Temp & Min Temp & Ave Temp & StDev Temp & Var Temp \\
\hline June & 55.97 & 45.38 & 48.91 & 3.56 & 12.66 \\
\hline July & 58.04 & 43.92 & 49.54 & 3.98 & 15.84 \\
\hline August & 57.35 & 45.38 & 50.10 & 3.17 & 10.04 \\
\hline September & 55.28 & 43.92 & 48.74 & 2.49 & 6.23 \\
\hline October & 51.08 & 43.92 & 47.51 & 1.93 & 3.74 \\
\hline
\end{tabular}




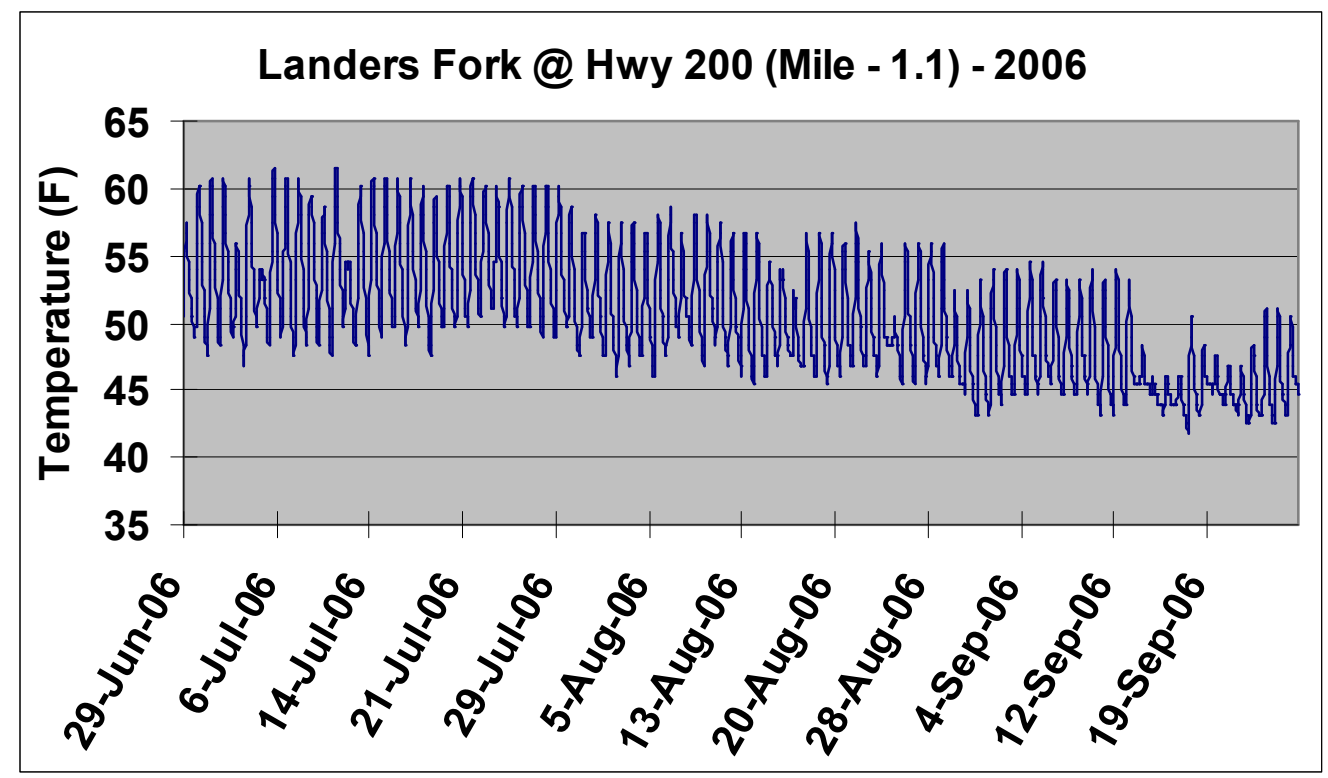

\begin{tabular}{|c|c|c|c|c|c|}
\hline Month & Max Temp & Min Temp & Ave Temp & StDev Temp & Var Temp \\
\hline June & 60.10 & 49.00 & 53.97 & 3.46 & 11.98 \\
\hline July & 61.50 & 46.80 & 53.95 & 3.82 & 14.58 \\
\hline August & 58.70 & 44.70 & 50.62 & 3.43 & 11.76 \\
\hline September & 54.60 & 41.70 & 46.59 & 2.96 & 8.74 \\
\hline
\end{tabular}

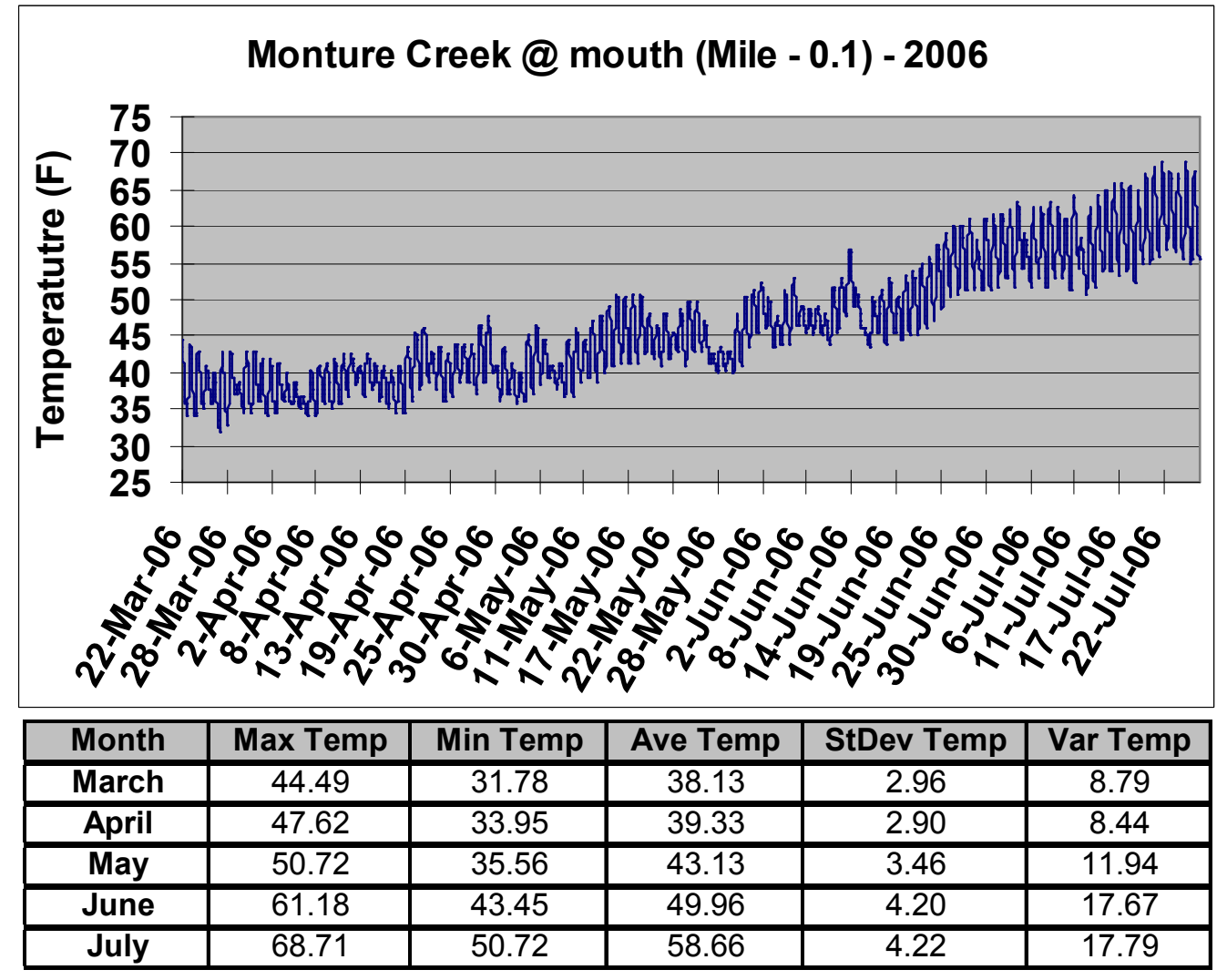




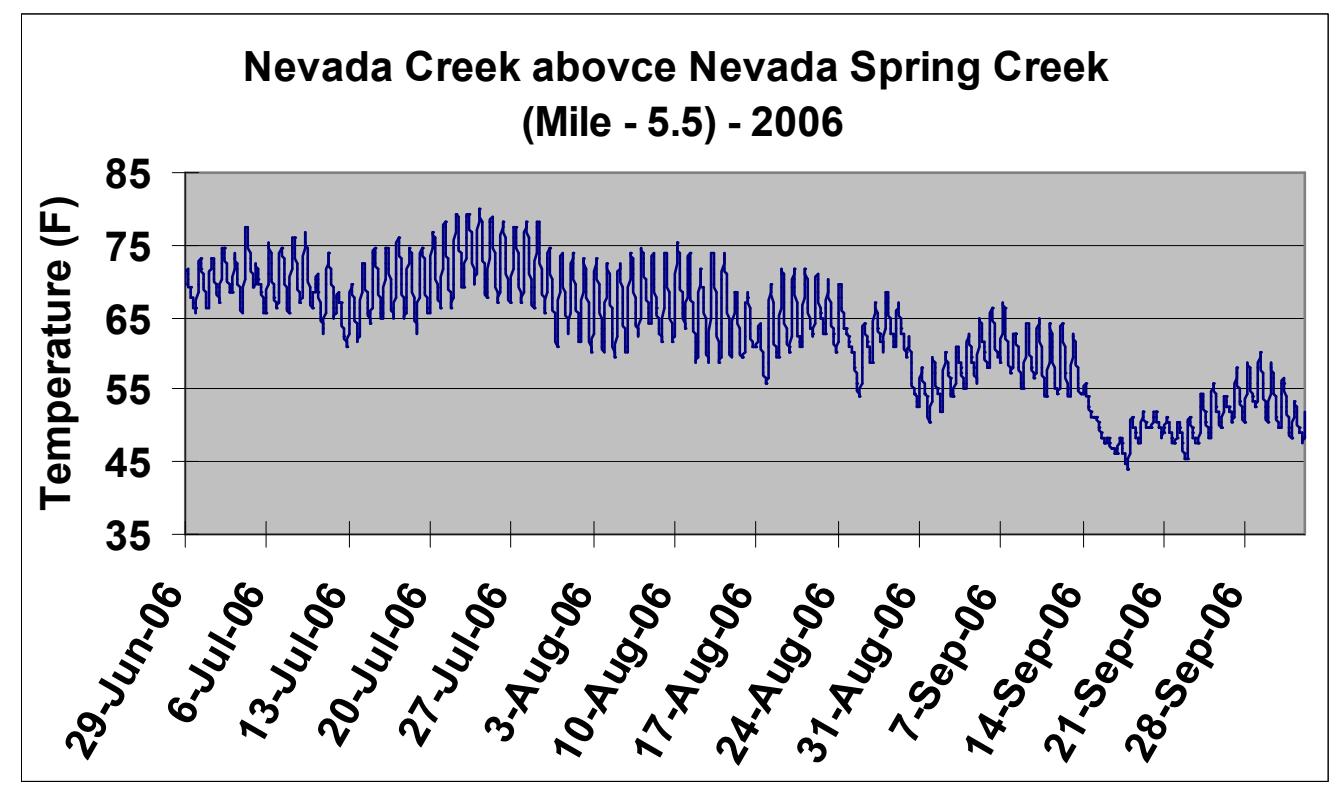

\begin{tabular}{|c|c|c|c|c|c|}
\hline Month & Max Temp & Min Temp & Ave Temp & StDev Temp & Var Temp \\
\hline June & 73.15 & 65.59 & 69.38 & 2.33 & 5.43 \\
\hline July & 80.12 & 60.8 & 70.42 & 4.04 & 16.31 \\
\hline August & 75.22 & 52.49 & 64.71 & 4.71 & 22.17 \\
\hline September & 66.96 & 43.92 & 54.36 & 5.17 & 26.75 \\
\hline October & 56.66 & 47.53 & 51.11 & 2.35 & 5.54 \\
\hline
\end{tabular}

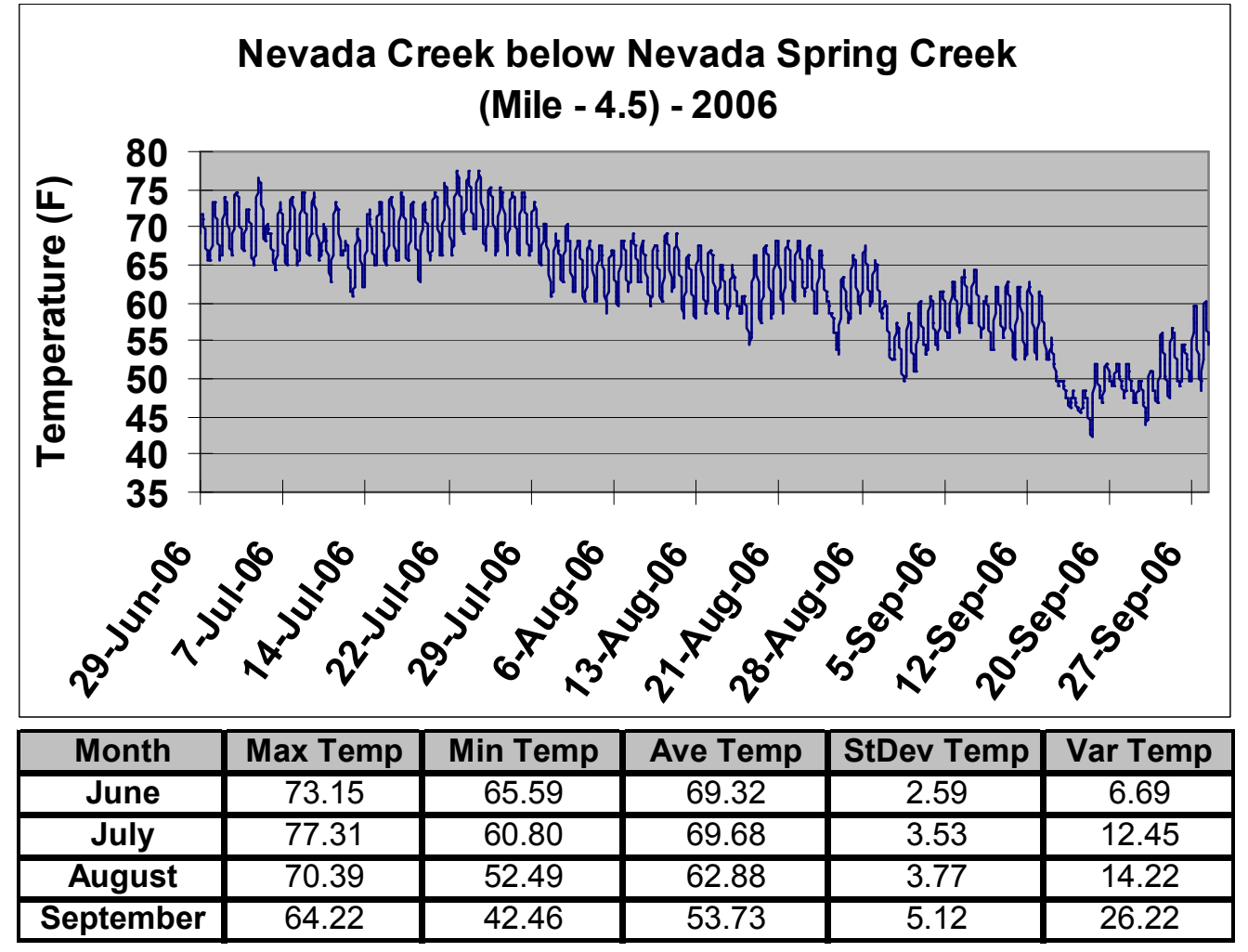




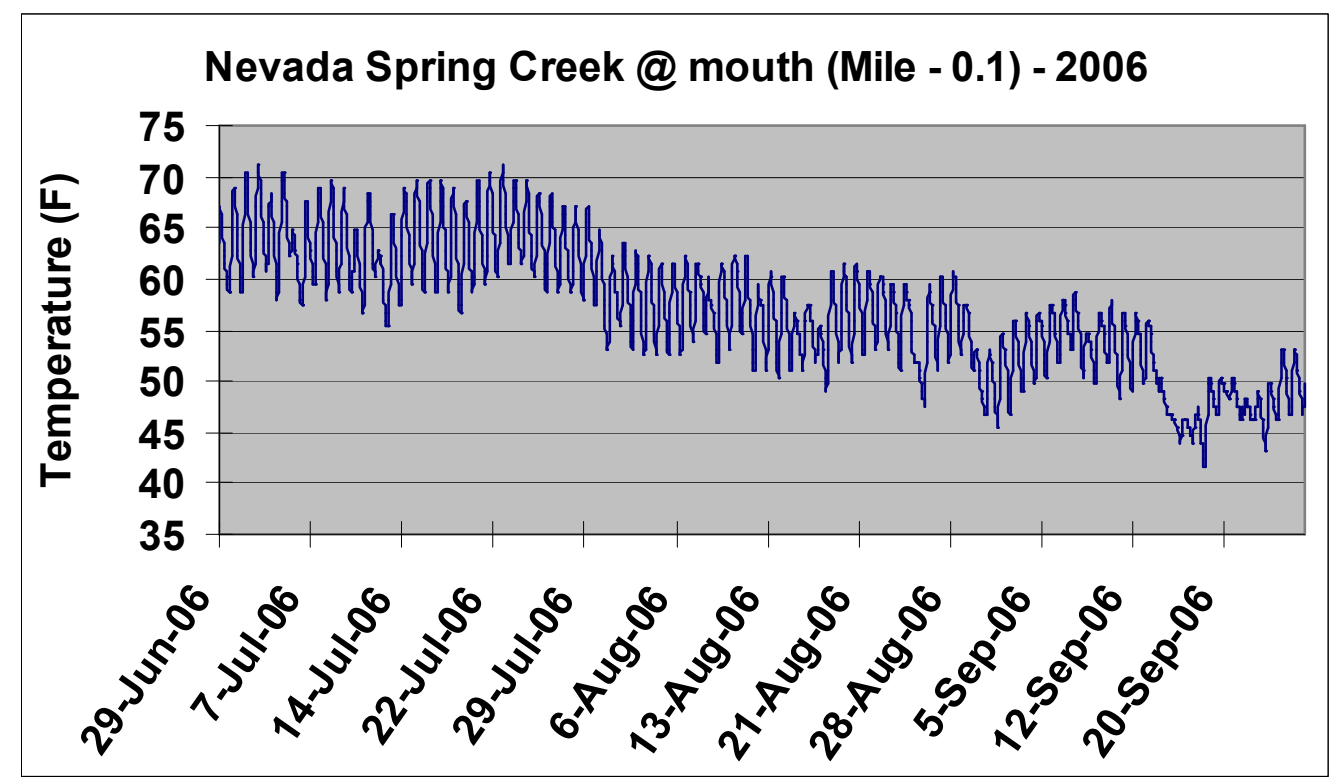

\begin{tabular}{|c|c|c|c|c|c|}
\hline Month & Max Temp & Min Temp & Ave Temp & StDev Temp & Var Temp \\
\hline June & 69.00 & 58.70 & 63.67 & 3.37 & 11.34 \\
\hline July & 71.10 & 53.20 & 63.38 & 3.75 & 14.08 \\
\hline August & 63.50 & 46.80 & 56.16 & 3.47 & 12.01 \\
\hline September & 58.70 & 41.70 & 50.65 & 3.85 & 14.86 \\
\hline
\end{tabular}

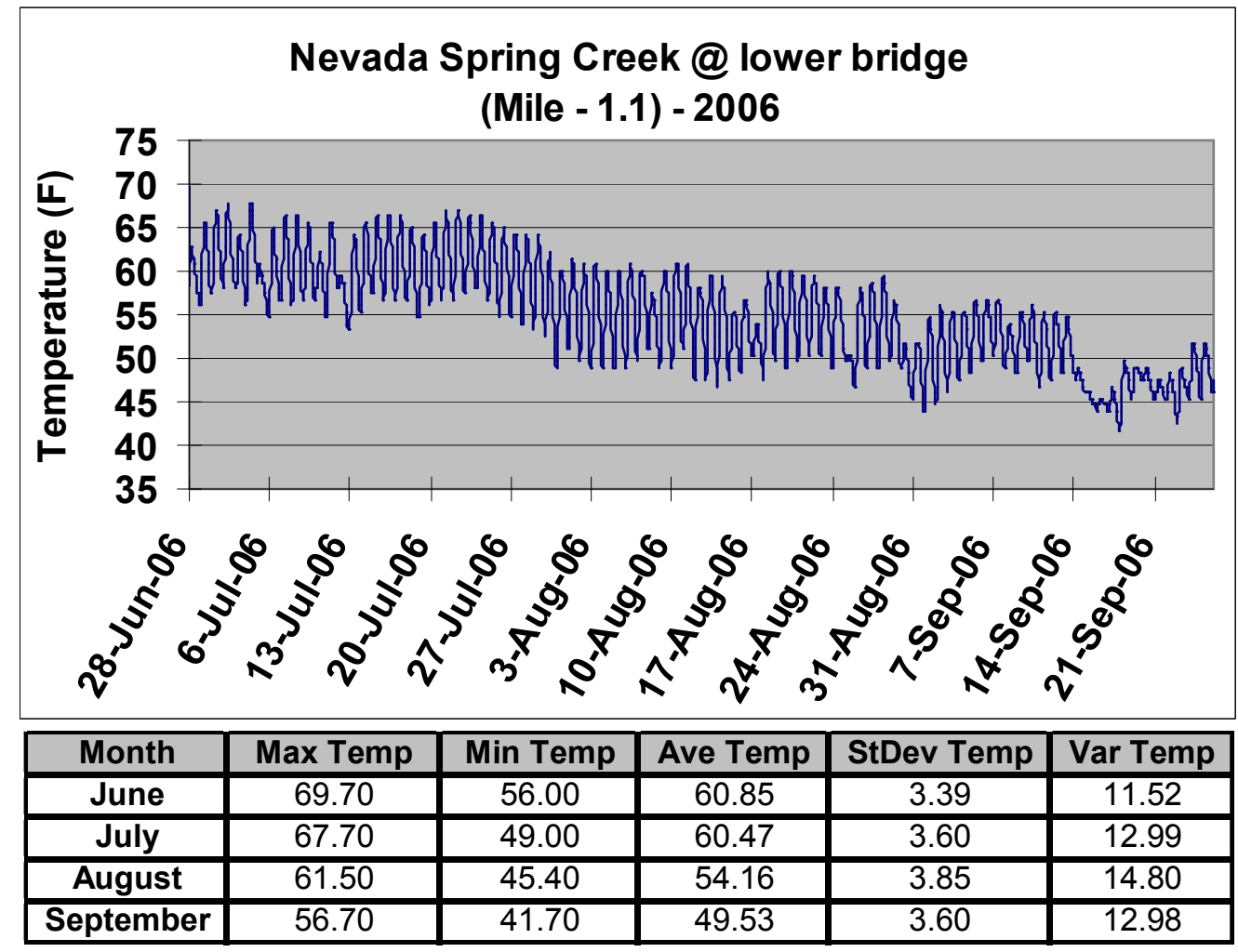




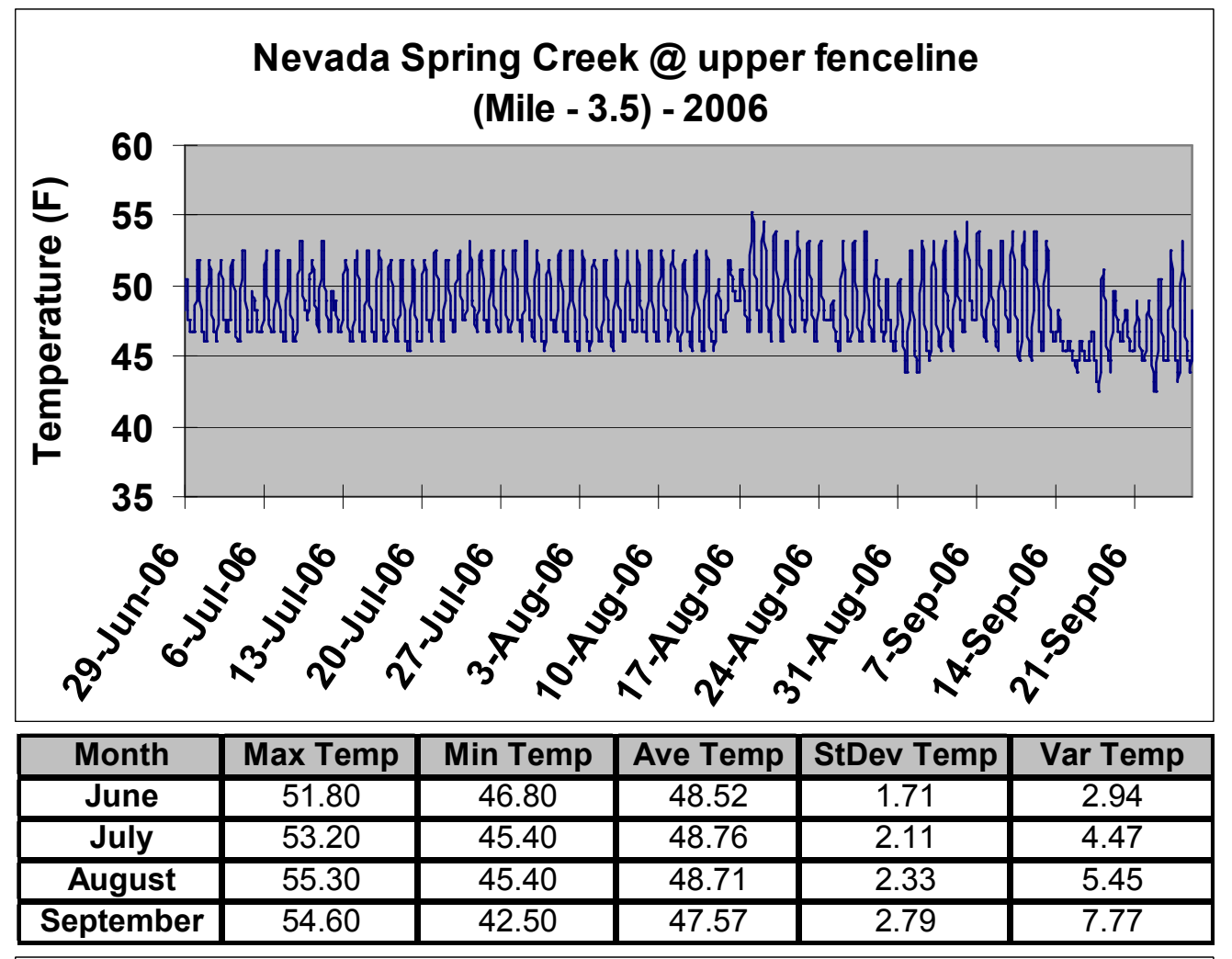

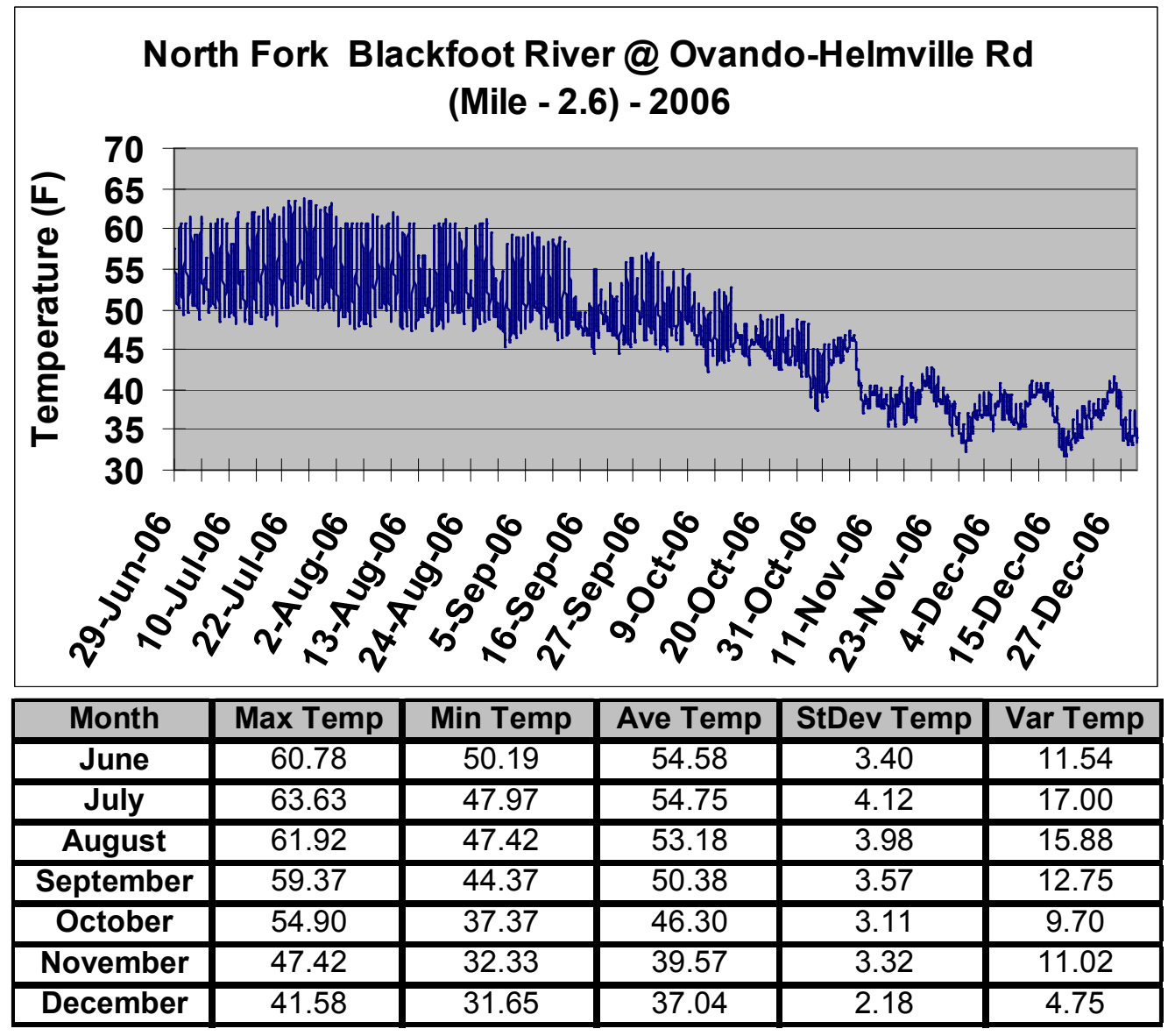




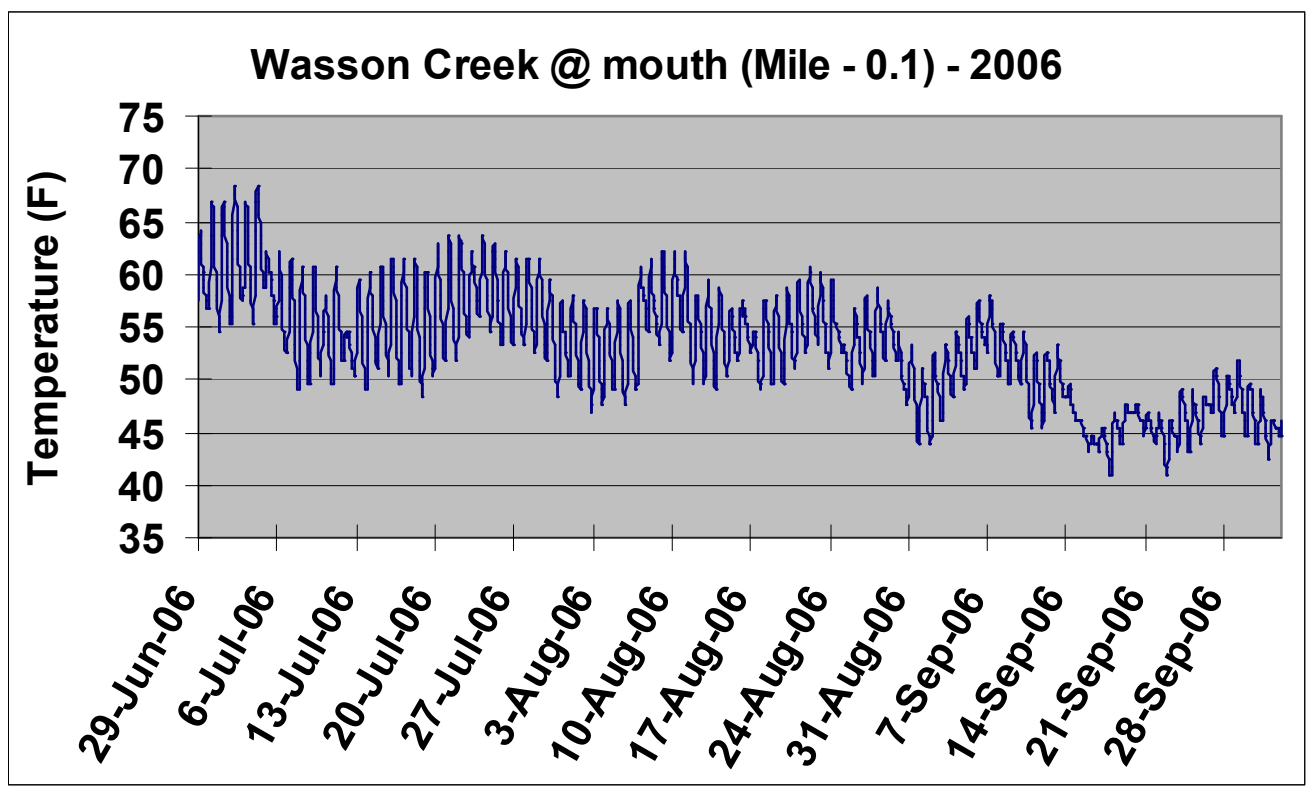

\begin{tabular}{|c|c|c|c|c|c|}
\hline Month & Max Temp & Min Temp & Ave Temp & StDev Temp & Var Temp \\
\hline June & 66.96 & 56.66 & 60.99 & 3.30 & 10.89 \\
\hline July & 68.33 & 48.25 & 56.76 & 4.17 & 17.40 \\
\hline August & 62.17 & 46.82 & 54.13 & 3.18 & 10.14 \\
\hline September & 58.04 & 40.97 & 48.28 & 3.50 & 12.25 \\
\hline October & 48.96 & 42.46 & 45.49 & 1.44 & 2.08 \\
\hline
\end{tabular}



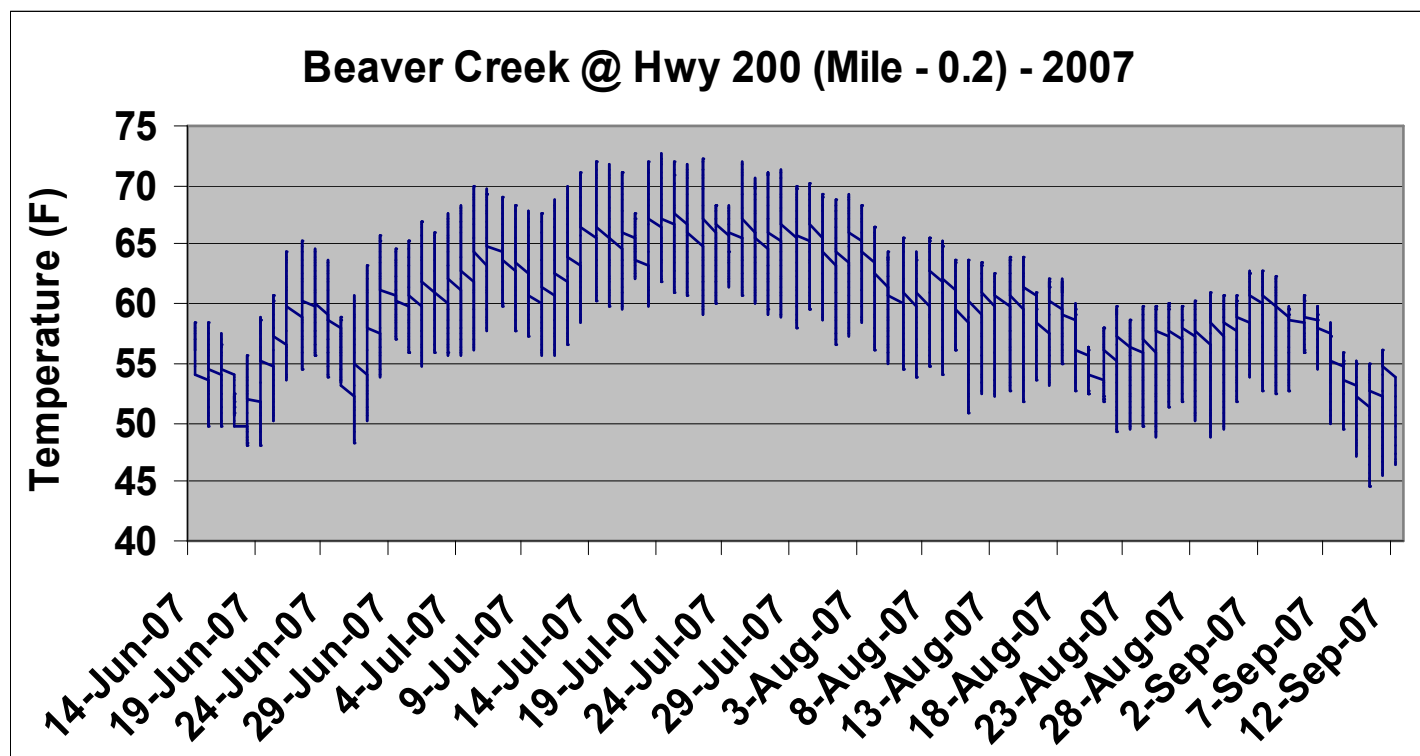

\begin{tabular}{|c|c|c|c|c|c|}
\hline Month & Max Temp & Min Temp & Avg Temp & StDev Temp & Var Temp \\
\hline June & 65.81 & 48 & 56.43 & 4.55 & 20.7 \\
\hline July & 72.62 & 54.71 & 64.1 & 4.35 & 18.93 \\
\hline August & 69.31 & 48.83 & 57.92 & 4.44 & 19.73 \\
\hline September & 62.91 & 44.67 & 55.04 & 4.3 & 18.53 \\
\hline
\end{tabular}

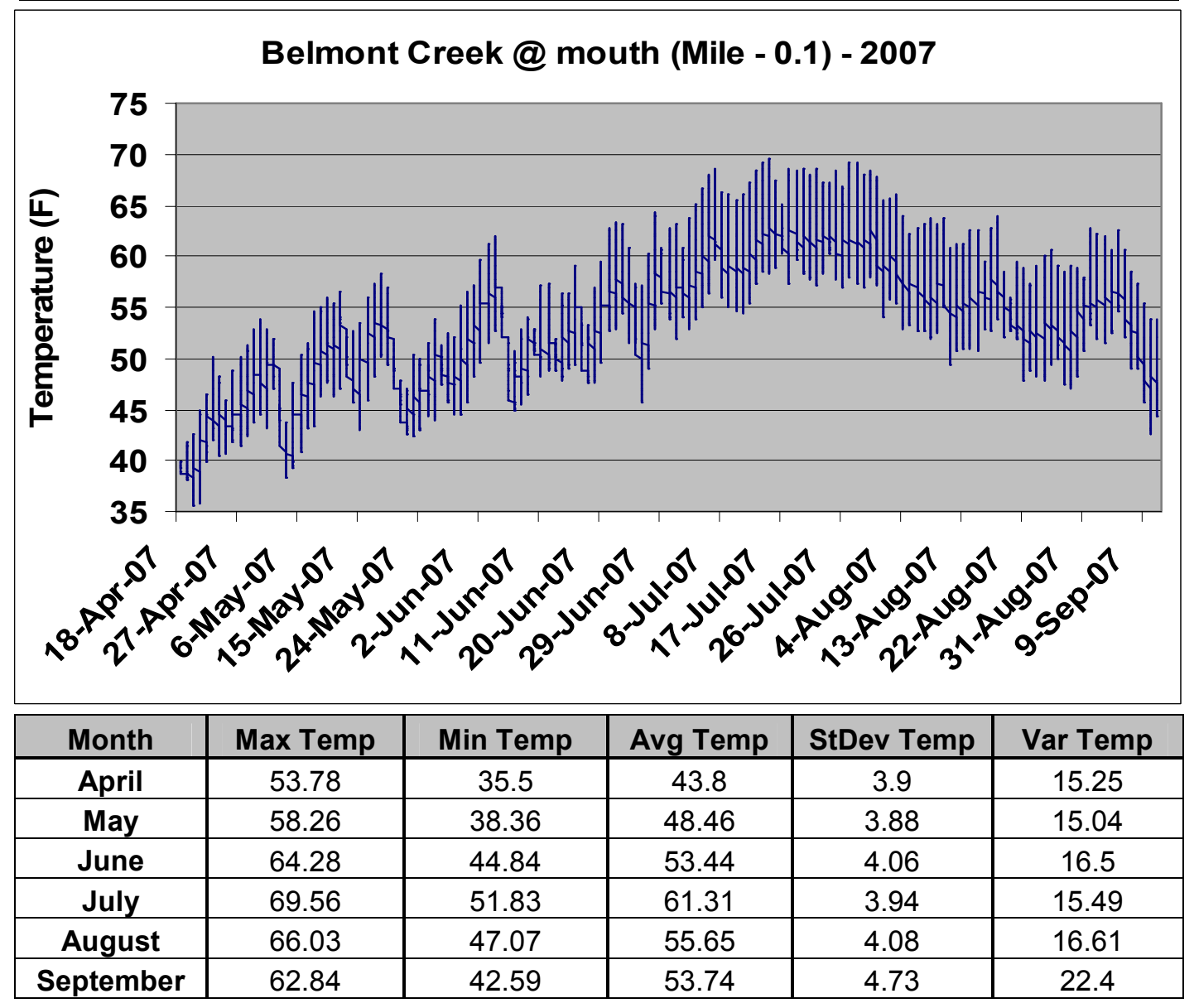




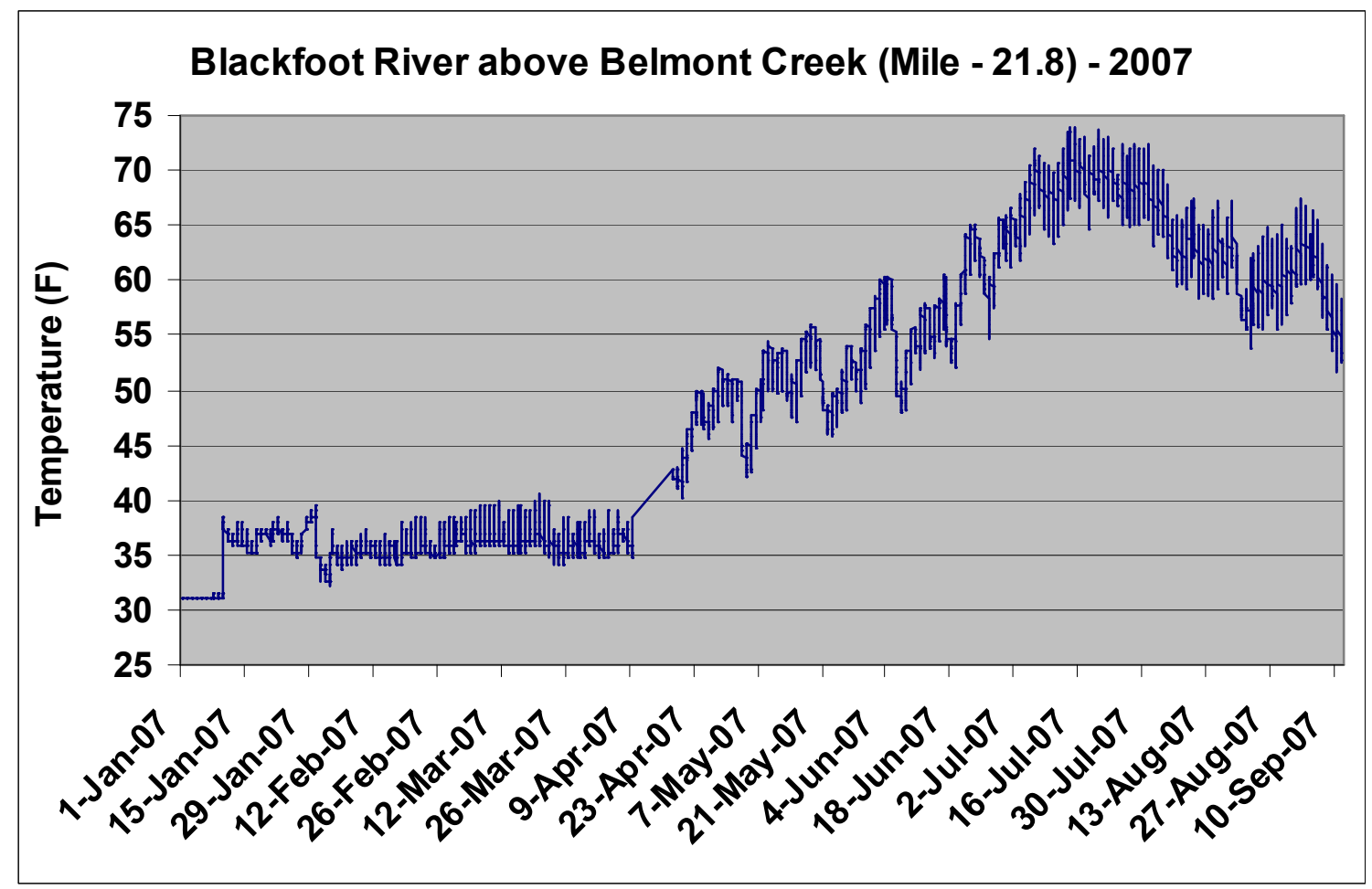

\begin{tabular}{|c|c|c|c|c|c|}
\hline Month & Max Temp & Min Temp & Avg Temp & StDev Temp & Var Temp \\
\hline January & 39.5 & 30.97 & 34.95 & 2.73 & 7.45 \\
\hline February & 38.45 & 32.05 & 35.36 & 1.06 & 1.11 \\
\hline March & 40.55 & 32.05 & 35.36 & 1.06 & 1.11 \\
\hline April & 52.16 & 40.19 & 46.85 & 3.06 & 9.37 \\
\hline May & 57.44 & 42.15 & 50.34 & 2.97 & 8.84 \\
\hline June & 66.01 & 47.98 & 57.47 & 4.23 & 17.98 \\
\hline July & 74 & 61.12 & 68.17 & 2.47 & 6.12 \\
\hline August & 70.39 & 53.82 & 61.63 & 3.36 & 11.26 \\
\hline September & 67.46 & 51.6 & 59.88 & 3.64 & 13.28 \\
\hline
\end{tabular}




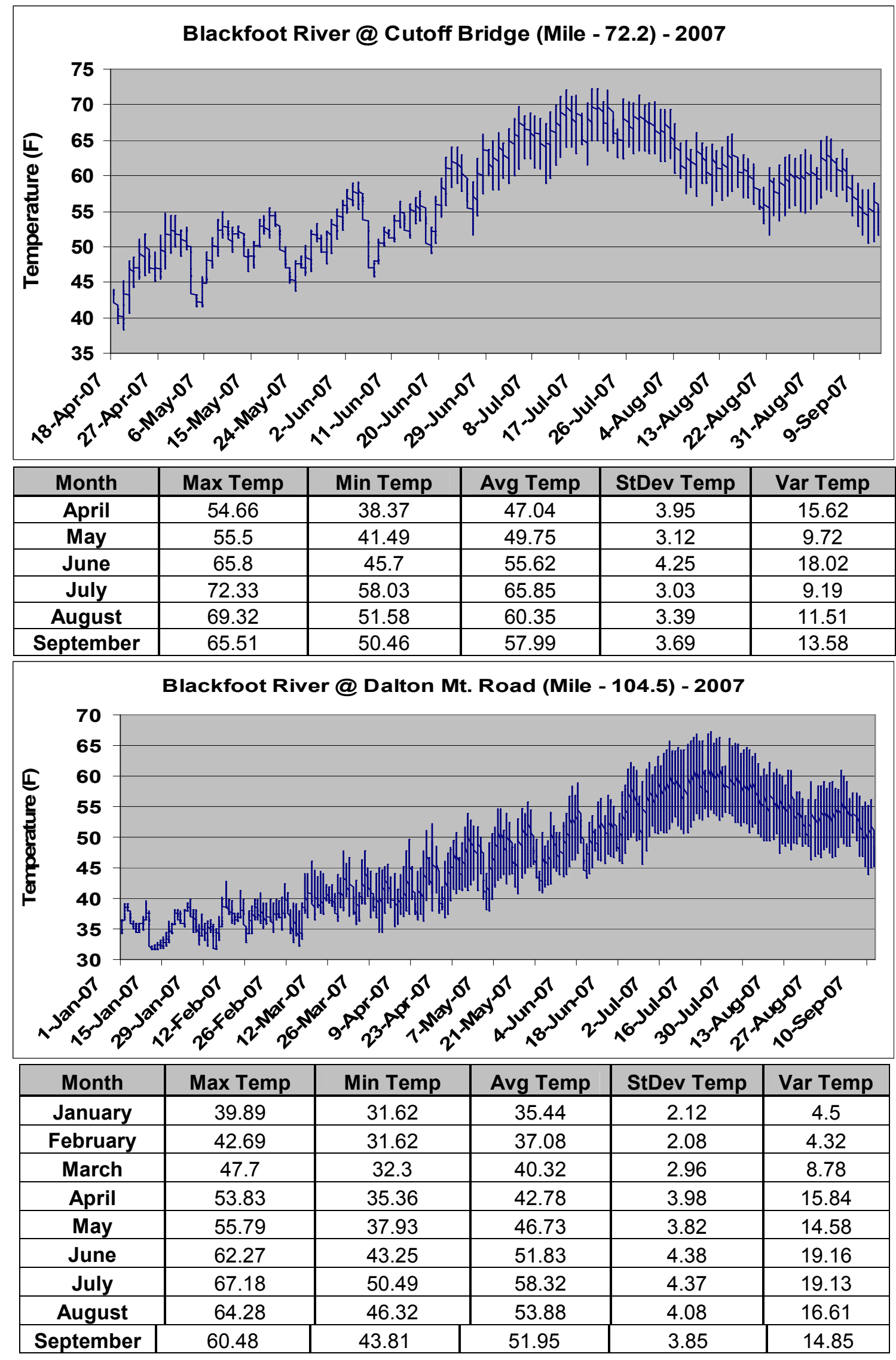



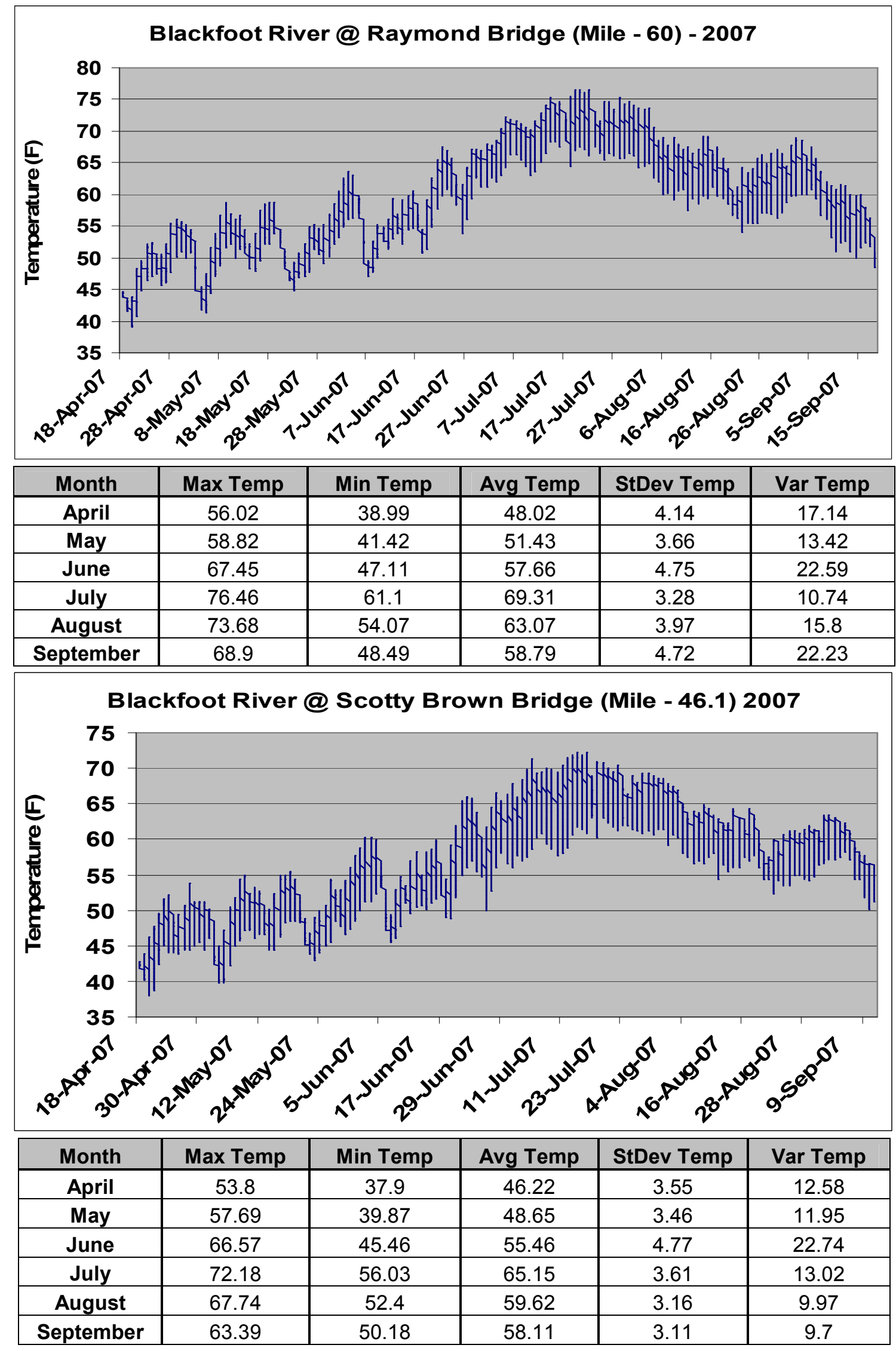

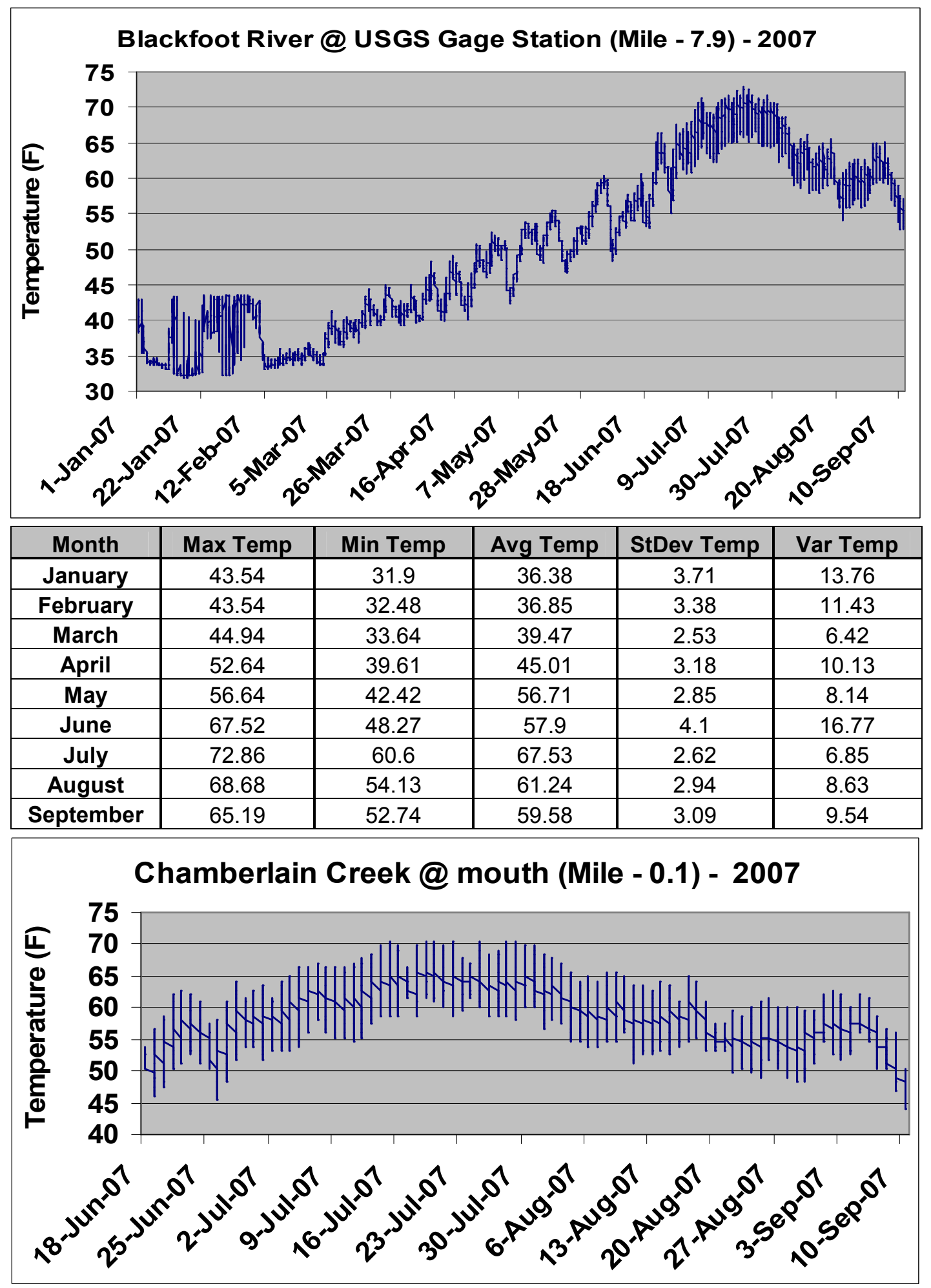

\begin{tabular}{|c|c|c|c|c|c|}
\hline Month & Max Temp & Min Temp & Avg Temp & StDev Temp & Var Temp \\
\hline June & 64.2 & 45.4 & 55.05 & 4.38 & 19.18 \\
\hline July & 70.4 & 51.8 & 62.4 & 4.18 & 17.49 \\
\hline August & 68.4 & 48.3 & 57.3 & 4.17 & 17.37 \\
\hline September & 62.8 & 43.9 & 55.03 & 4.17 & 17.41 \\
\hline
\end{tabular}



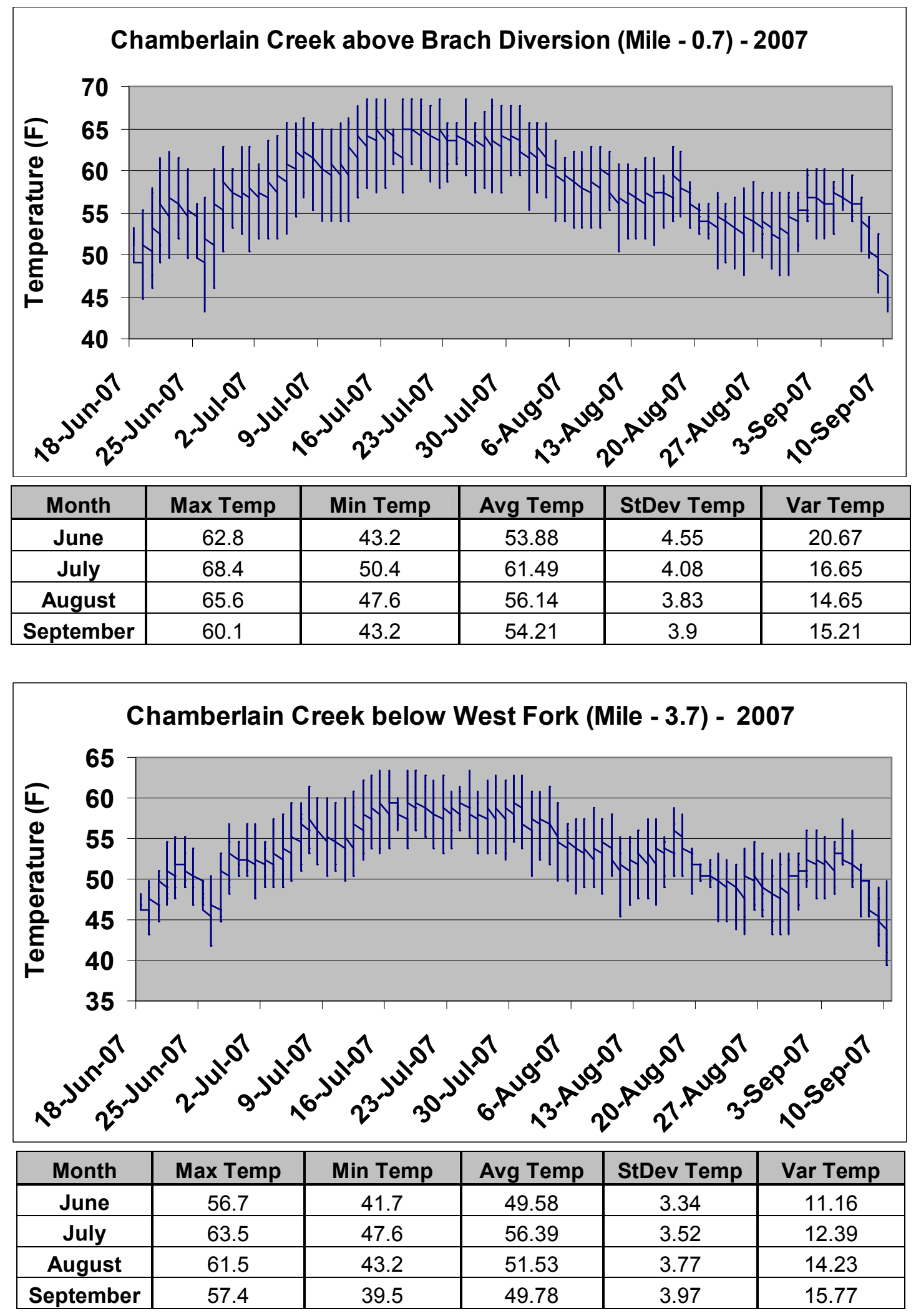


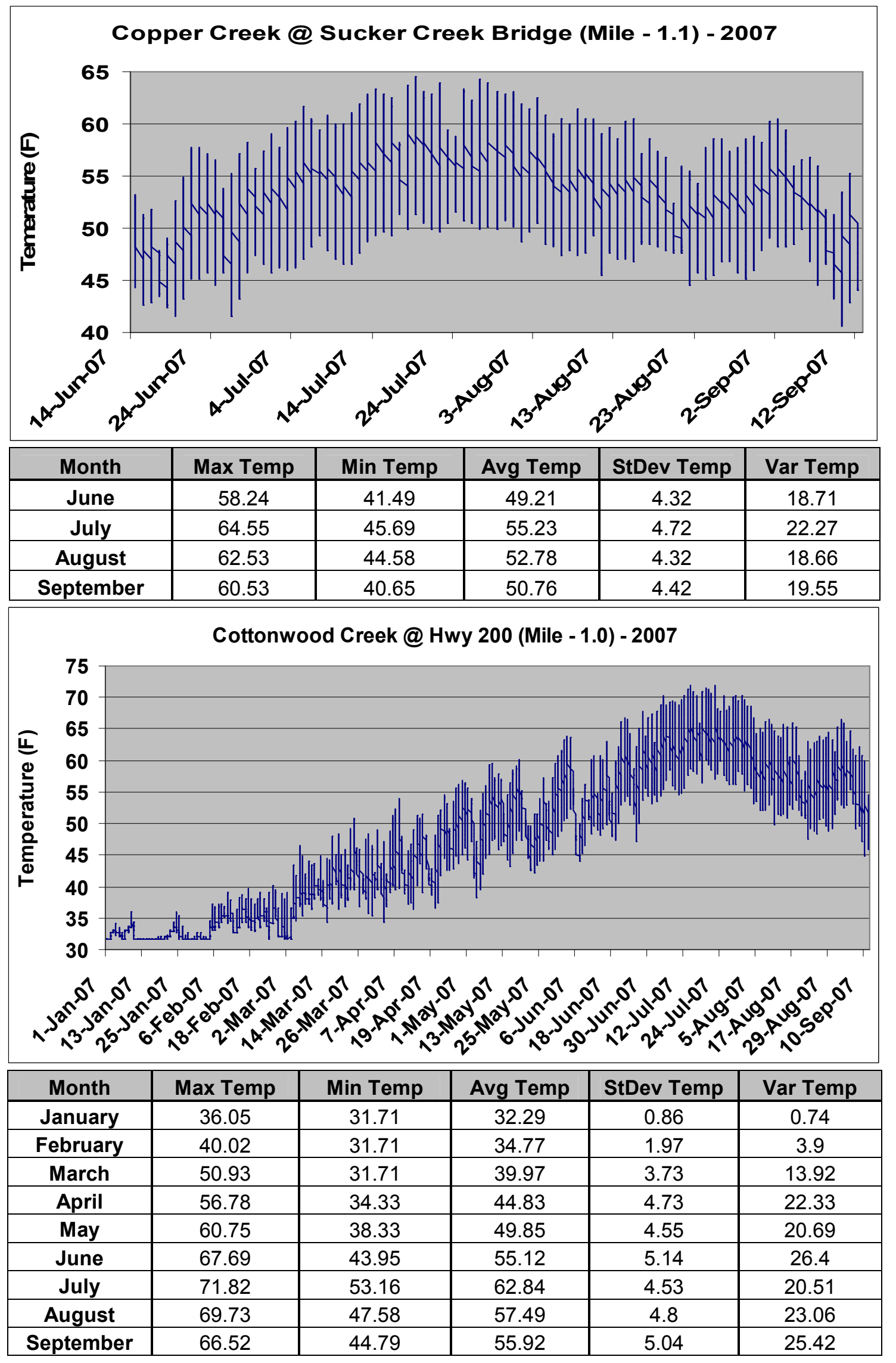



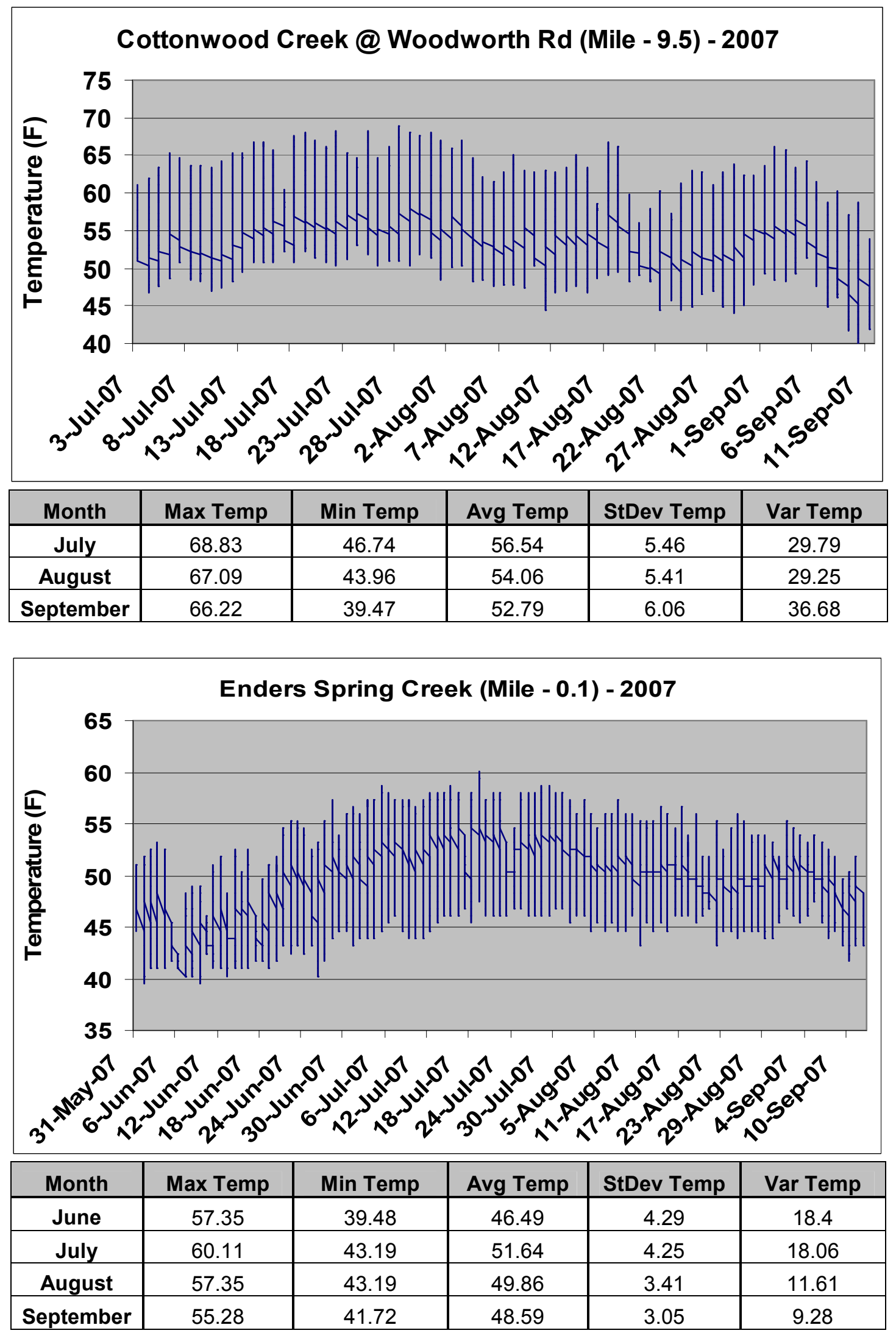

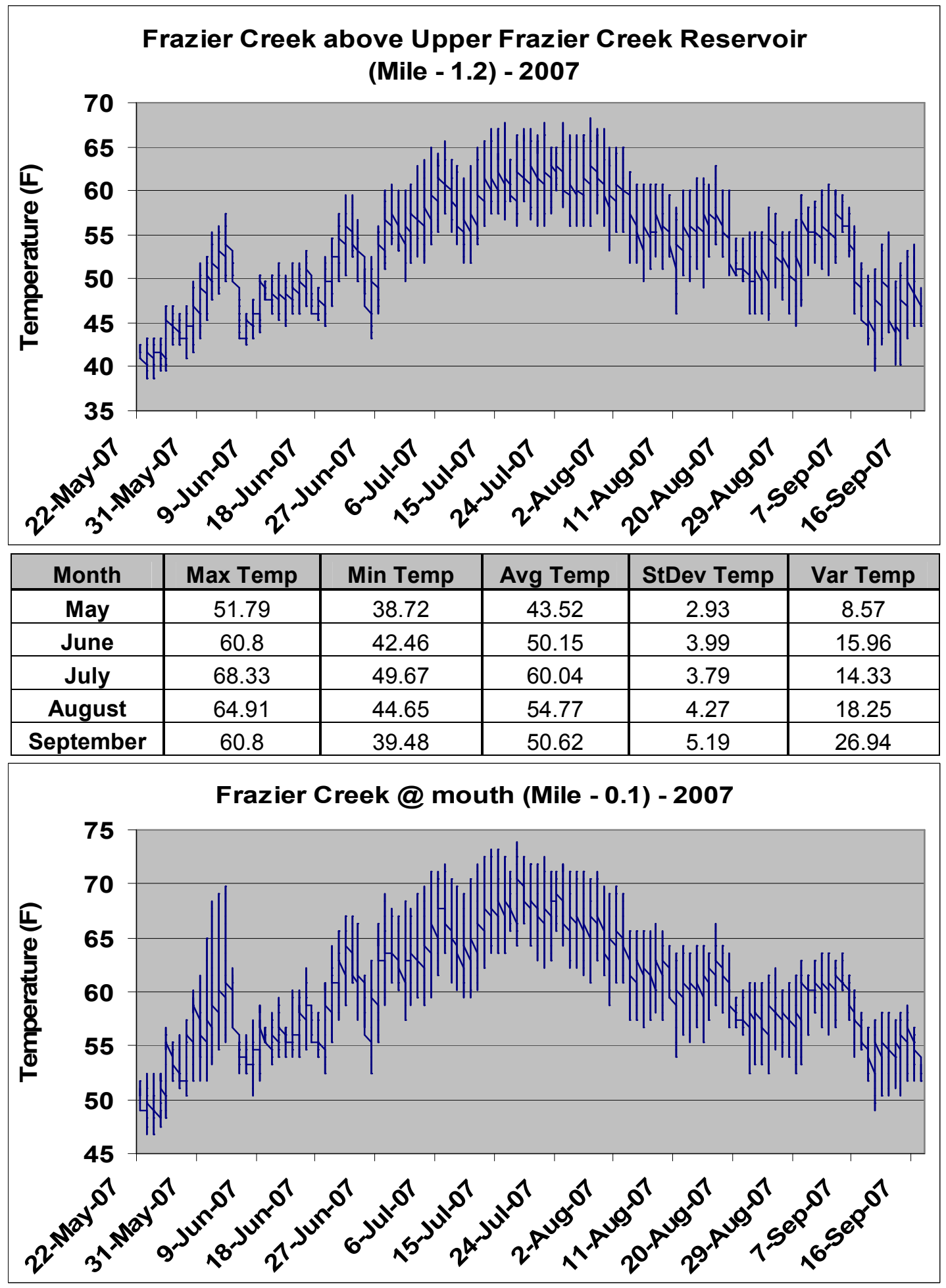

\begin{tabular}{|c|c|c|c|c|c|}
\hline Month & Max Temp & Min Temp & Avg Temp & StDev Temp & Var Temp \\
\hline May & 61.48 & 46.82 & 52.68 & 3.28 & 10.78 \\
\hline June & 69.71 & 50.38 & 58.77 & 4.24 & 17.95 \\
\hline July & 73.84 & 57.35 & 66.54 & 3.53 & 12.46 \\
\hline August & 69.71 & 52.49 & 60.17 & 3.54 & 12.55 \\
\hline September & 63.54 & 48.96 & 56.88 & 3.57 & 12.75 \\
\hline
\end{tabular}



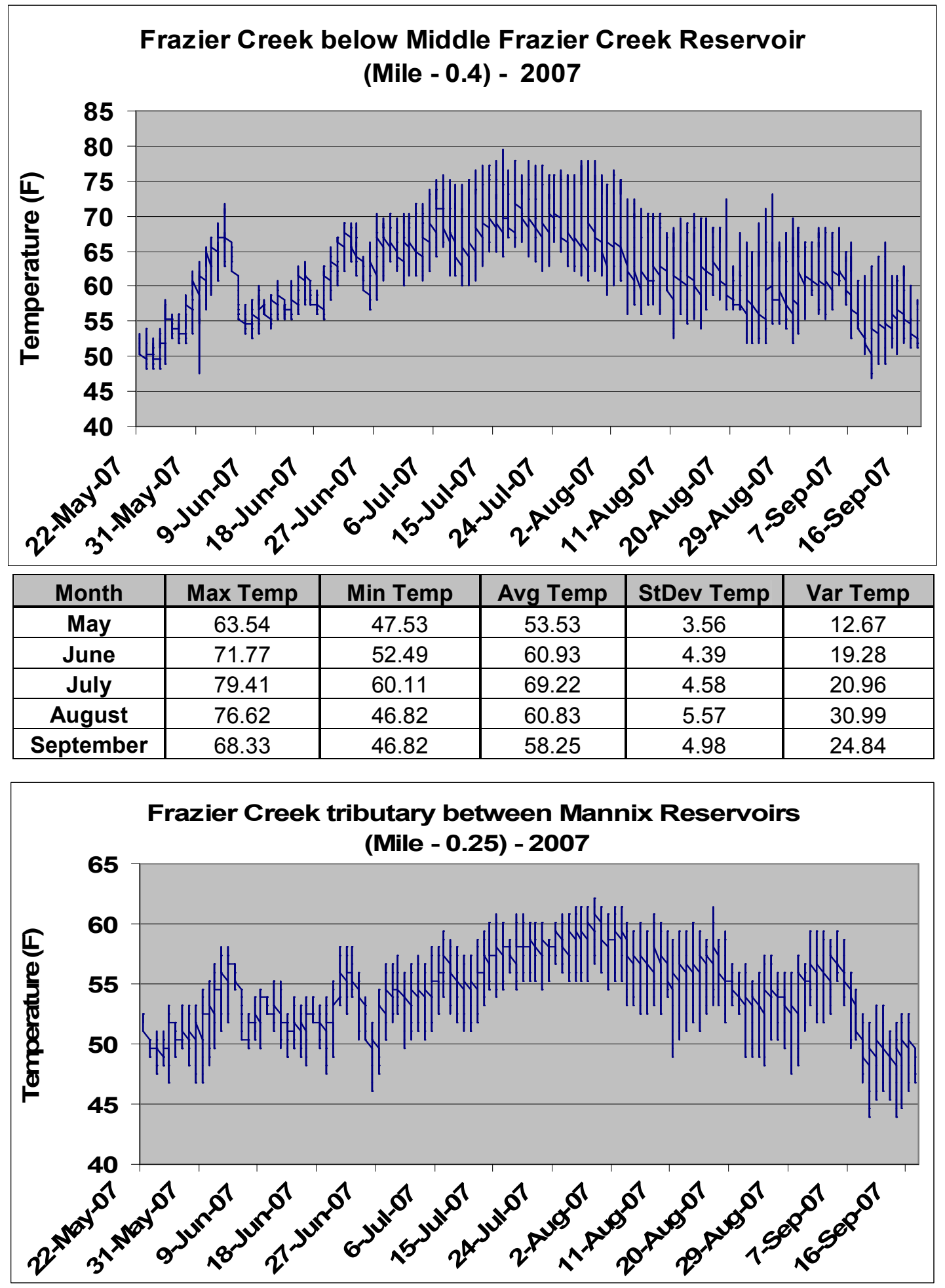

\begin{tabular}{|c|c|c|c|c|c|}
\hline Month & Max Temp & Min Temp & Avg Temp & StDev Temp & Var Temp \\
\hline May & 54.58 & 46.82 & 50.21 & 1.93 & 3.71 \\
\hline June & 58.04 & 46.18 & 52.71 & 2.48 & 6.13 \\
\hline July & 62.17 & 49.67 & 56.57 & 2.72 & 7.41 \\
\hline August & 61.48 & 47.53 & 55.16 & 3.15 & 9.93 \\
\hline September & 59.42 & 43.92 & 51.91 & 4.1 & 16.82 \\
\hline
\end{tabular}



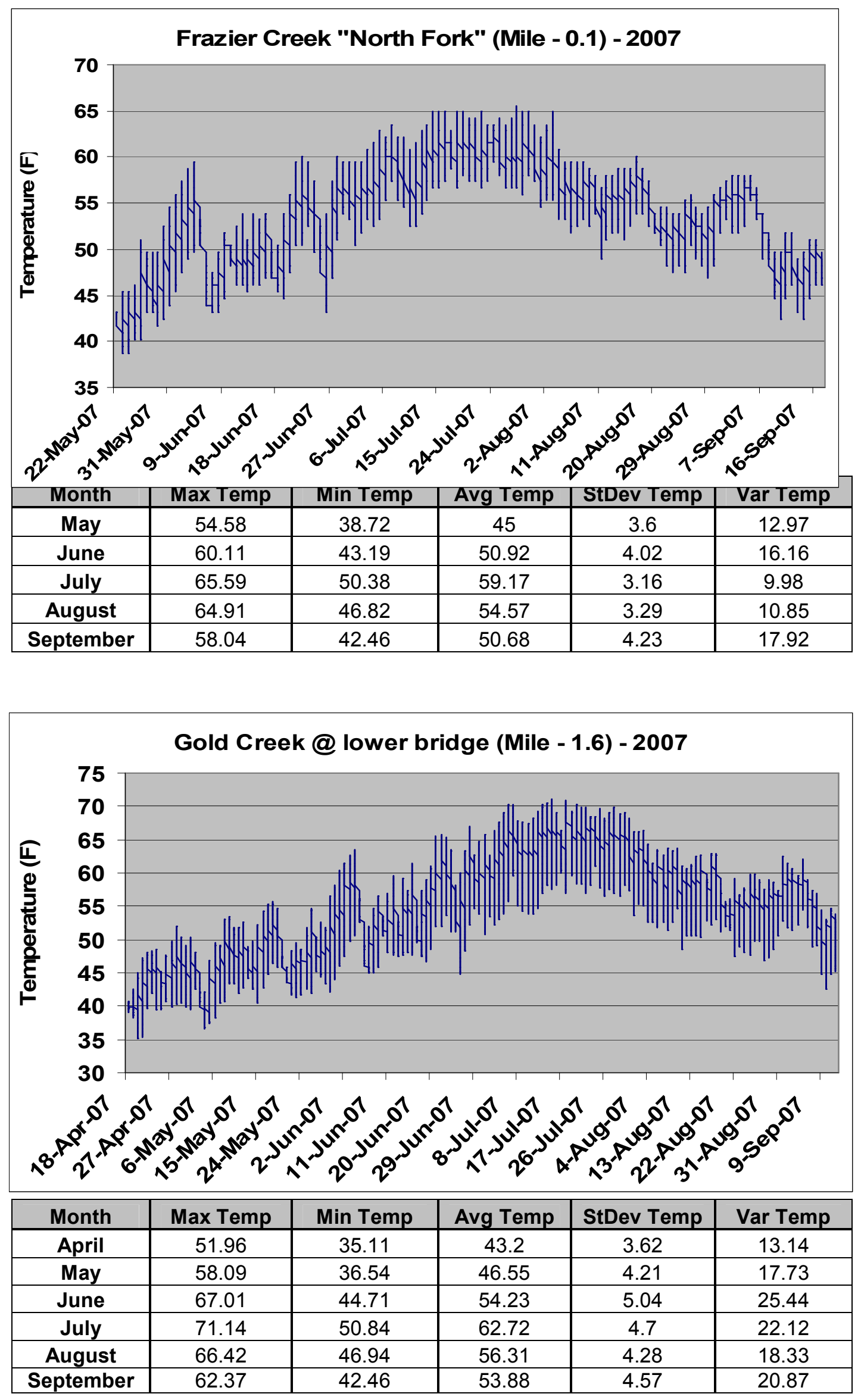

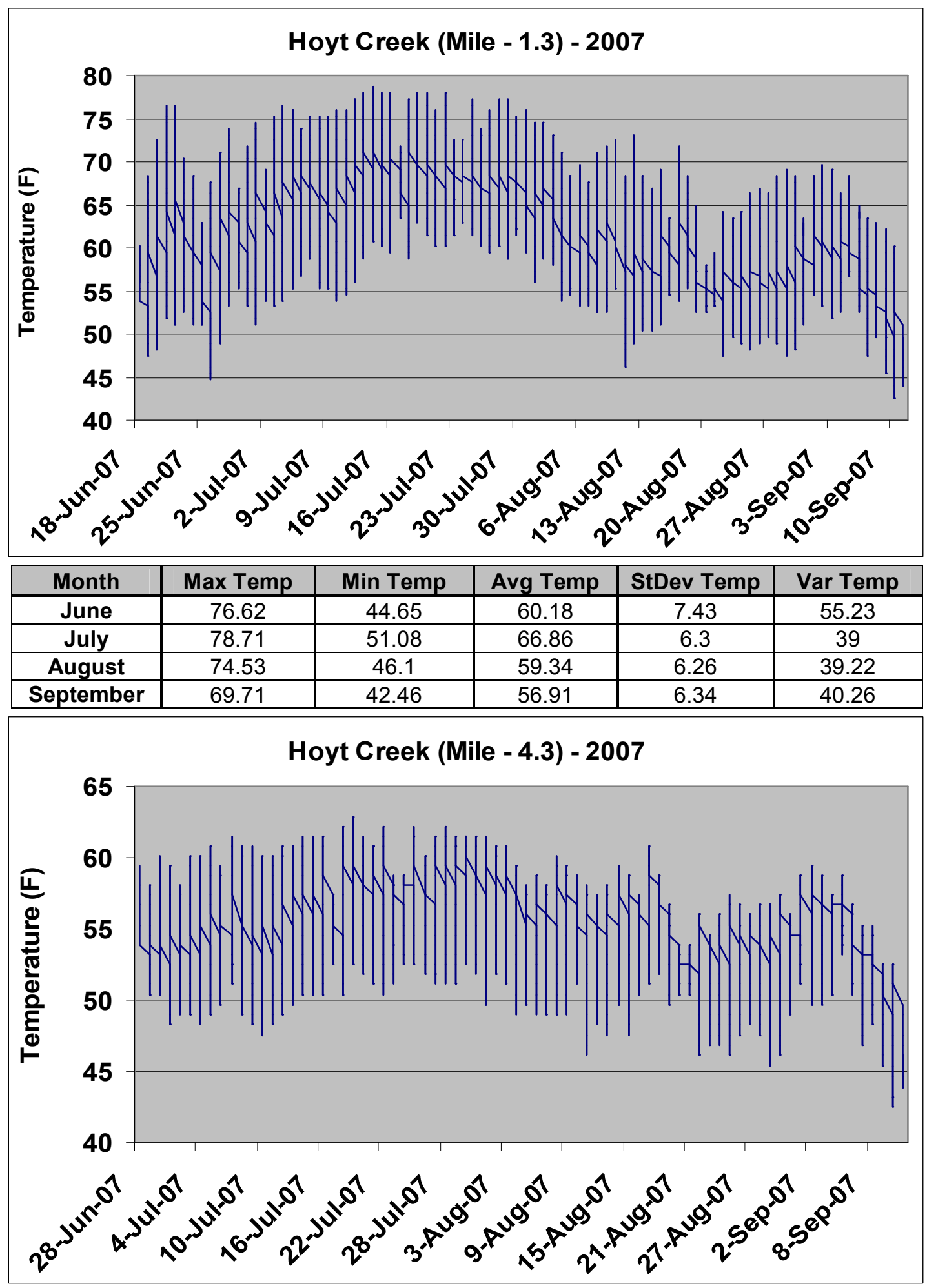

\begin{tabular}{|c|c|c|c|c|c|}
\hline Month & Max Temp & Min Temp & Avg Temp & StDev Temp & Var Temp \\
\hline June & 60.11 & 50.38 & 54.44 & 3.08 & 9.5 \\
\hline July & 62.85 & 47.53 & 55.44 & 3.92 & 15.34 \\
\hline August & 61.48 & 45.38 & 53.59 & 3.63 & 13.15 \\
\hline September & 59.42 & 42.46 & 52.51 & 4 & 16.04 \\
\hline
\end{tabular}



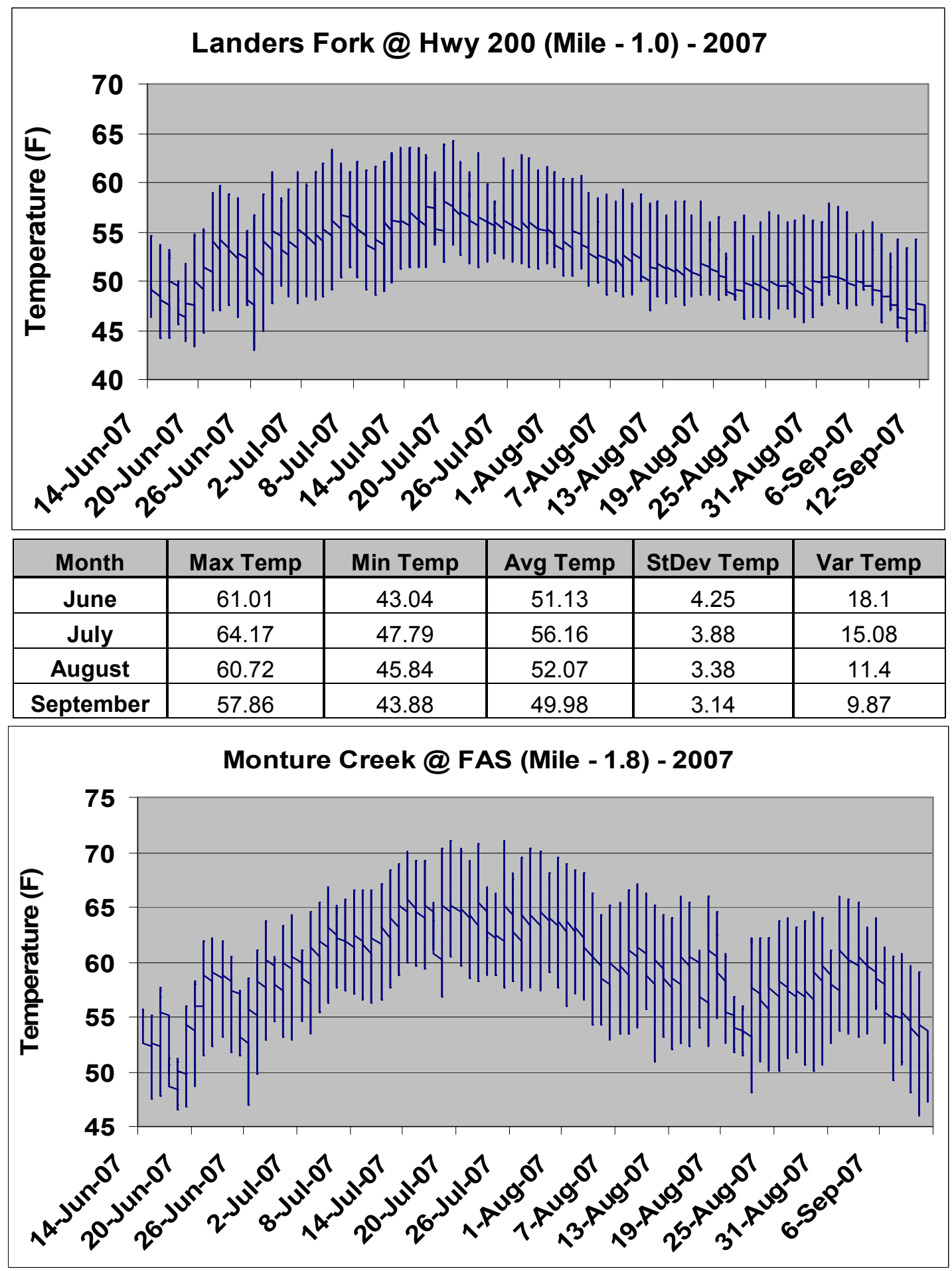

\begin{tabular}{|c|c|c|c|c|c|}
\hline Month & Max Temp & Min Temp & Avg Temp & StDev Temp & Var Temp \\
\hline June & 63.67 & 46.49 & 54.81 & 4.16 & 17.33 \\
\hline July & 71.02 & 52.91 & 62.67 & 3.91 & 15.3 \\
\hline August & 68.93 & 48.16 & 58.34 & 4.51 & 20.36 \\
\hline September & 66 & 45.93 & 56.61 & 4.61 & 21.29 \\
\hline
\end{tabular}




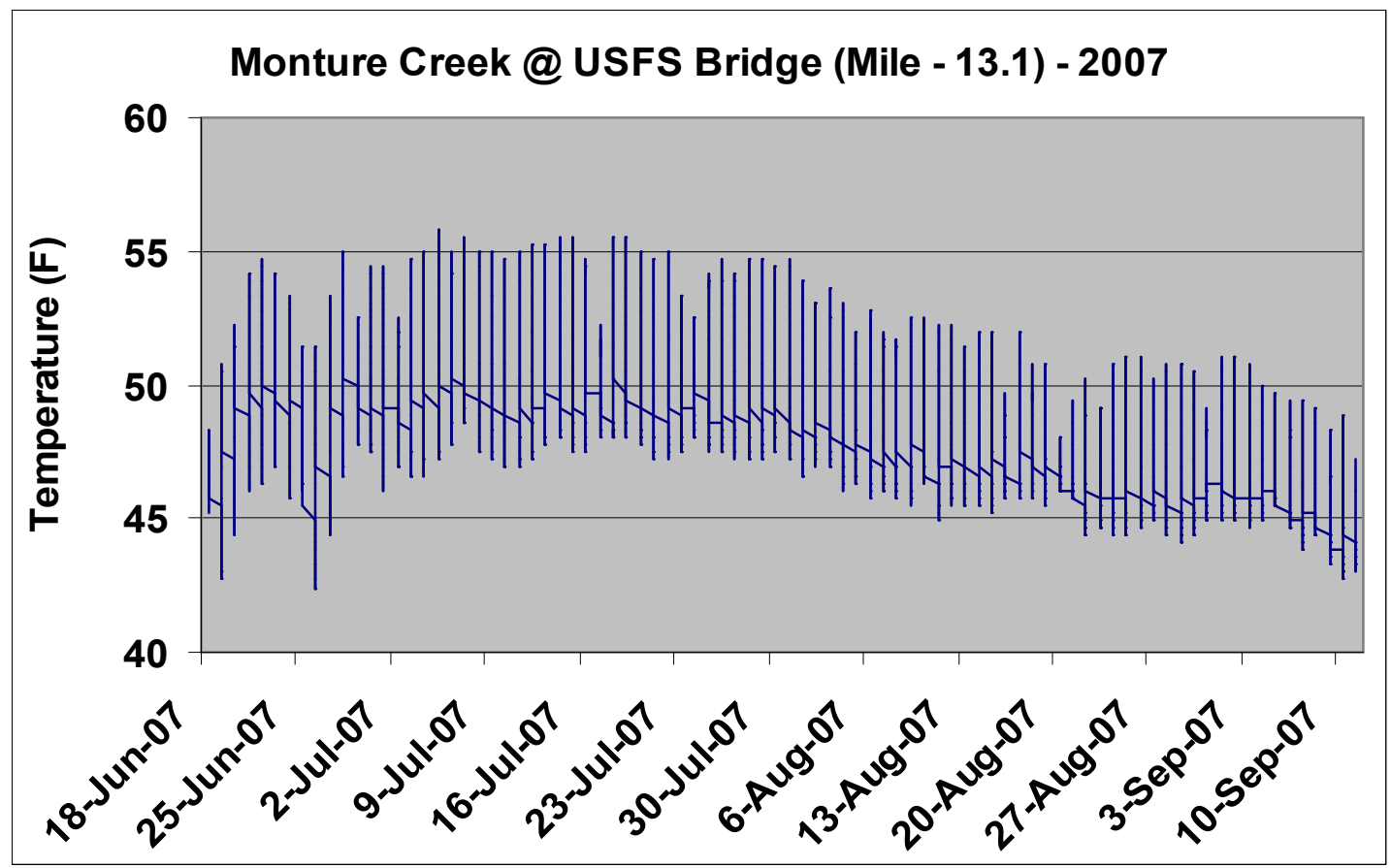

\begin{tabular}{|c|c|c|c|c|c|}
\hline Month & Max Temp & Min Temp & Avg Temp & StDev Temp & Var Temp \\
\hline June & 55 & 42.41 & 48.82 & 2.88 & 8.3 \\
\hline July & 55.84 & 46.06 & 50.3 & 2.5 & 6.25 \\
\hline August & 53.88 & 44.1 & 47.73 & 2.2 & 4.85 \\
\hline September & 51.09 & 42.7 & 46.21 & 1.96 & 3.85 \\
\hline
\end{tabular}

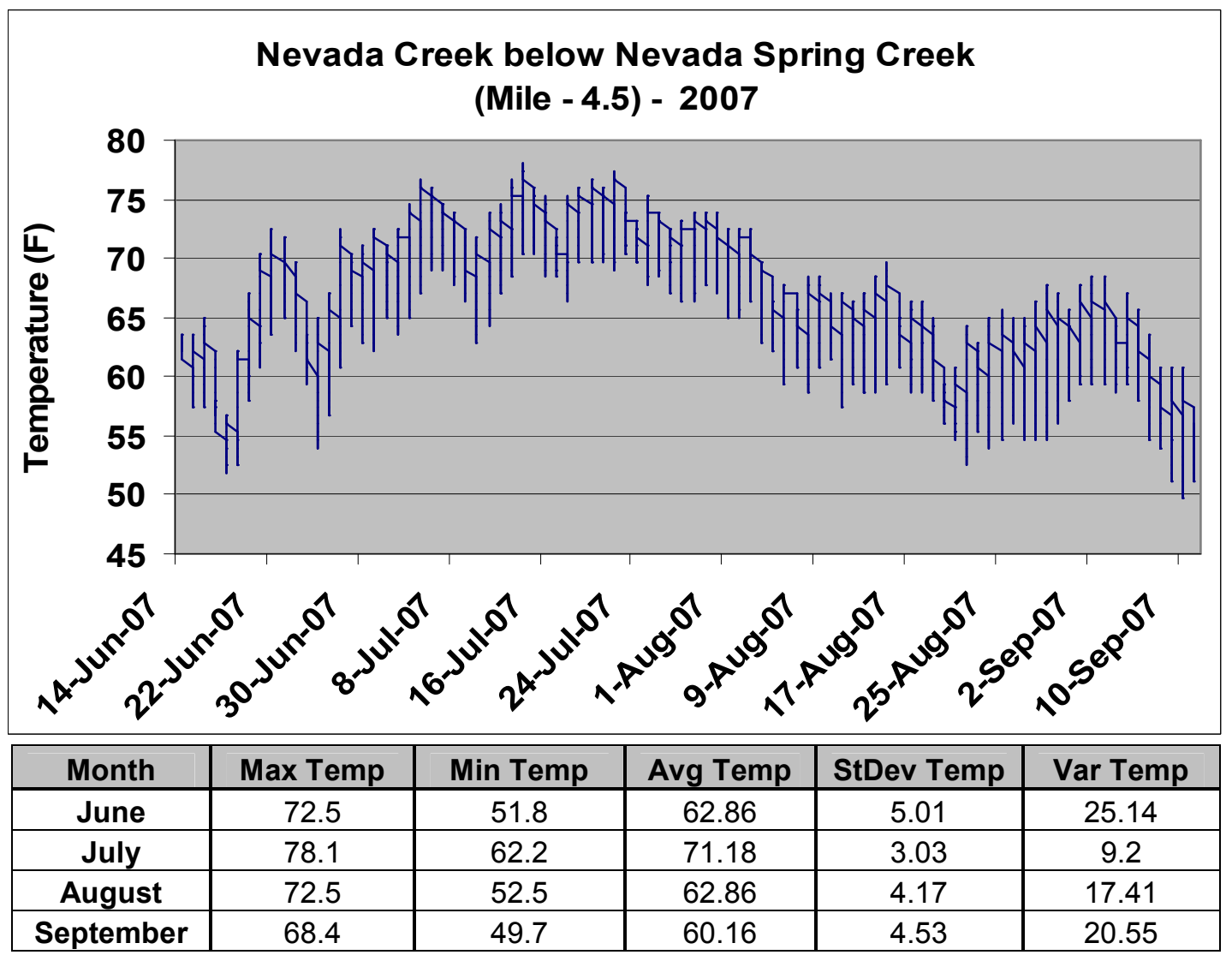



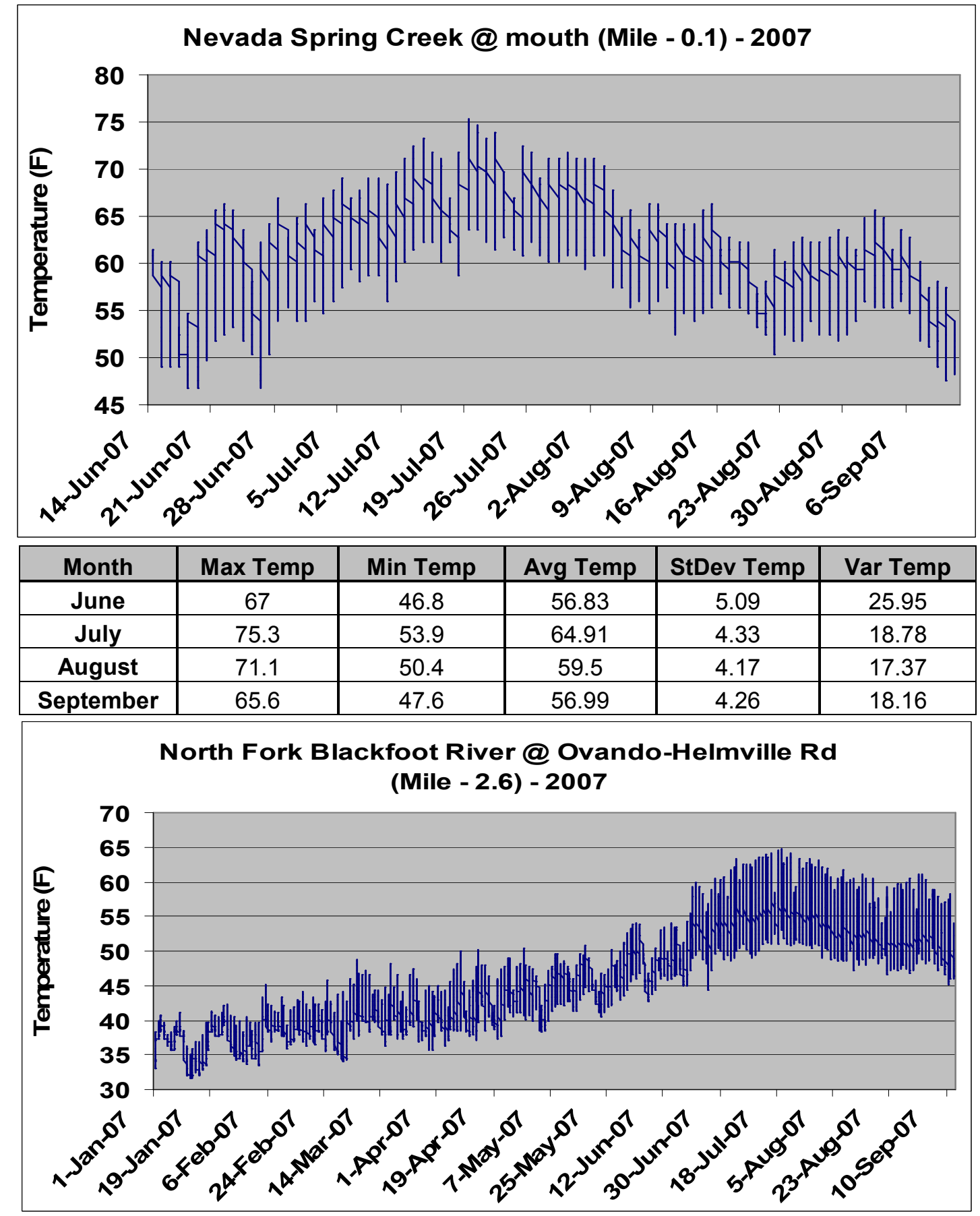

\begin{tabular}{|c|c|c|c|c|c|}
\hline Month & Max Temp & Min Temp & Avg Temp & StDev Temp & Var Temp \\
\hline January & 42.42 & 31.65 & 36.99 & 2.42 & 5.85 \\
\hline February & 45.76 & 33.37 & 39.02 & 2.18 & 4.75 \\
\hline March & 48.8 & 33.96 & 40.58 & 2.83 & 7.99 \\
\hline April & 50.47 & 36.24 & 42.37 & 3.07 & 9.44 \\
\hline May & 52.69 & 38.22 & 44.81 & 2.75 & 7.61 \\
\hline June & 60.4 & 42.69 & 50.15 & 3.79 & 14.34 \\
\hline July & 64.78 & 48.52 & 55.84 & 4.12 & 16.98 \\
\hline August & 62.2 & 46.59 & 53.02 & 3.86 & 14.89 \\
\hline September & 61.07 & 45.2 & 51.94 & 3.92 & 15.35 \\
\hline
\end{tabular}



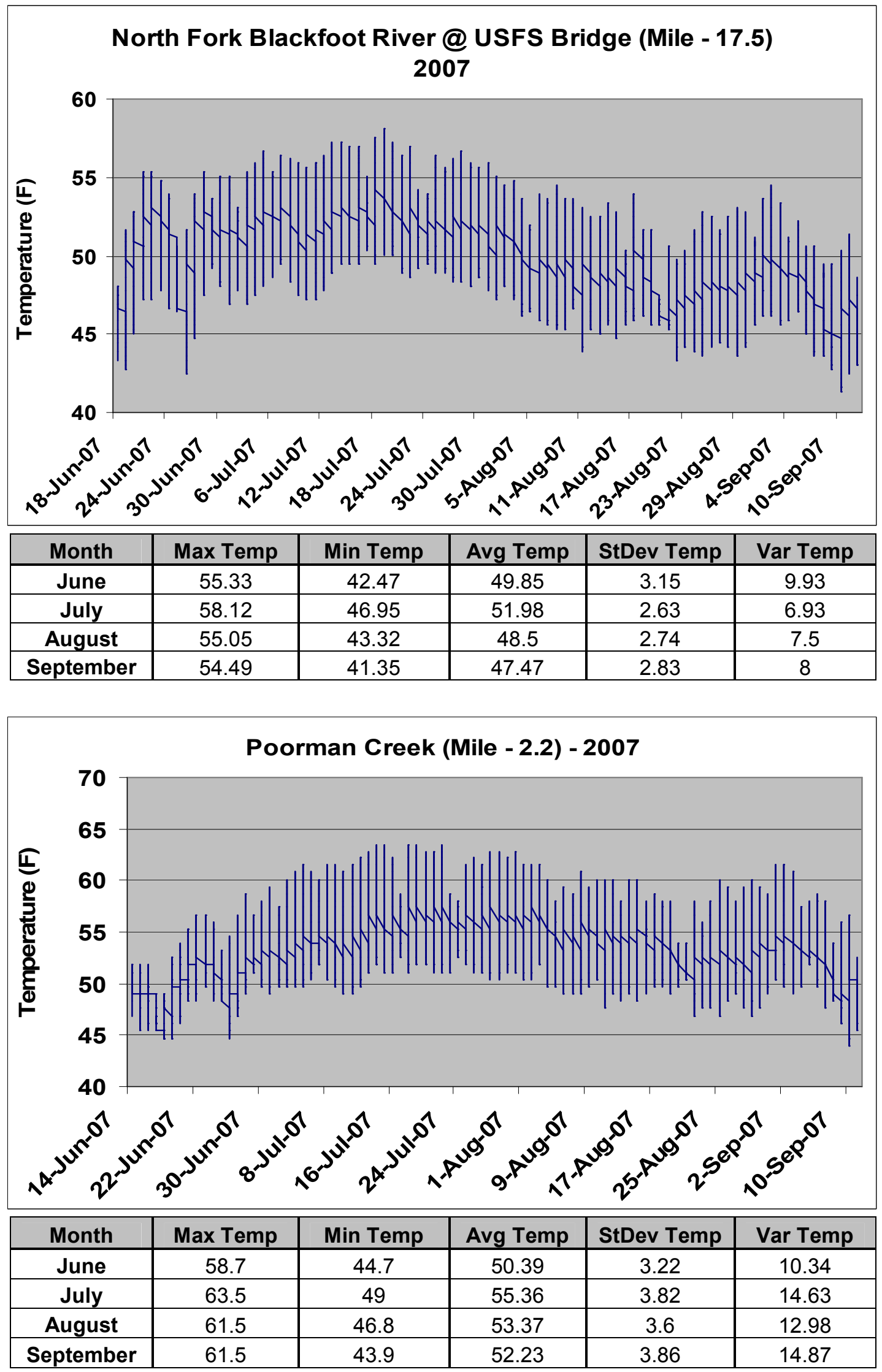

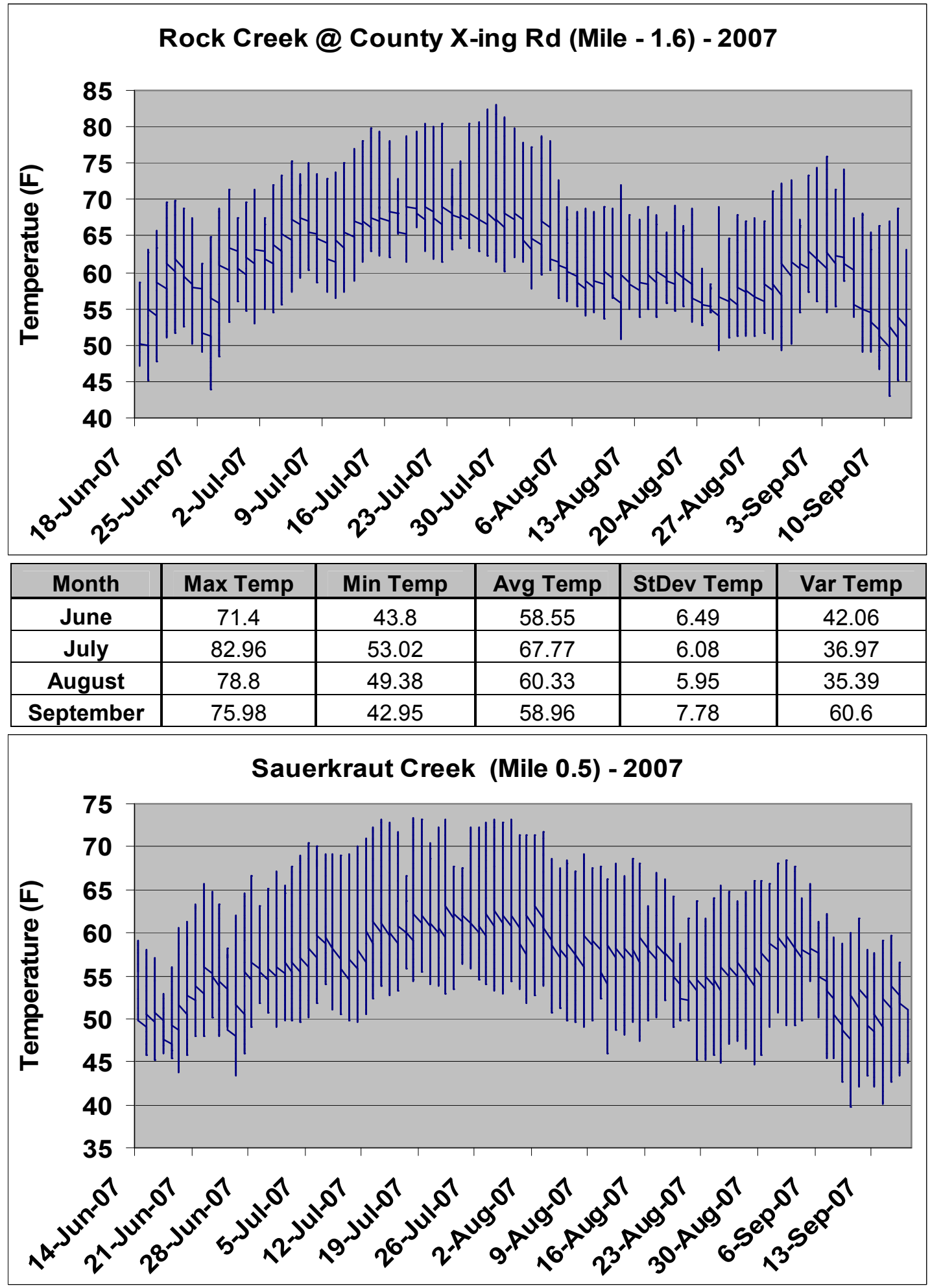

\begin{tabular}{|c|c|c|c|c|c|}
\hline Month & Max Temp & Min Temp & Avg Temp & StDev Temp & Var Temp \\
\hline June & 66.61 & 43.47 & 53.66 & 5.59 & 31.22 \\
\hline July & 73.44 & 49.04 & 60.78 & 6.46 & 41.7 \\
\hline August & 71.63 & 44.59 & 57.01 & 6.46 & 41.7 \\
\hline September & 68.36 & 39.81 & 53.1 & 6.62 & 43.84 \\
\hline
\end{tabular}




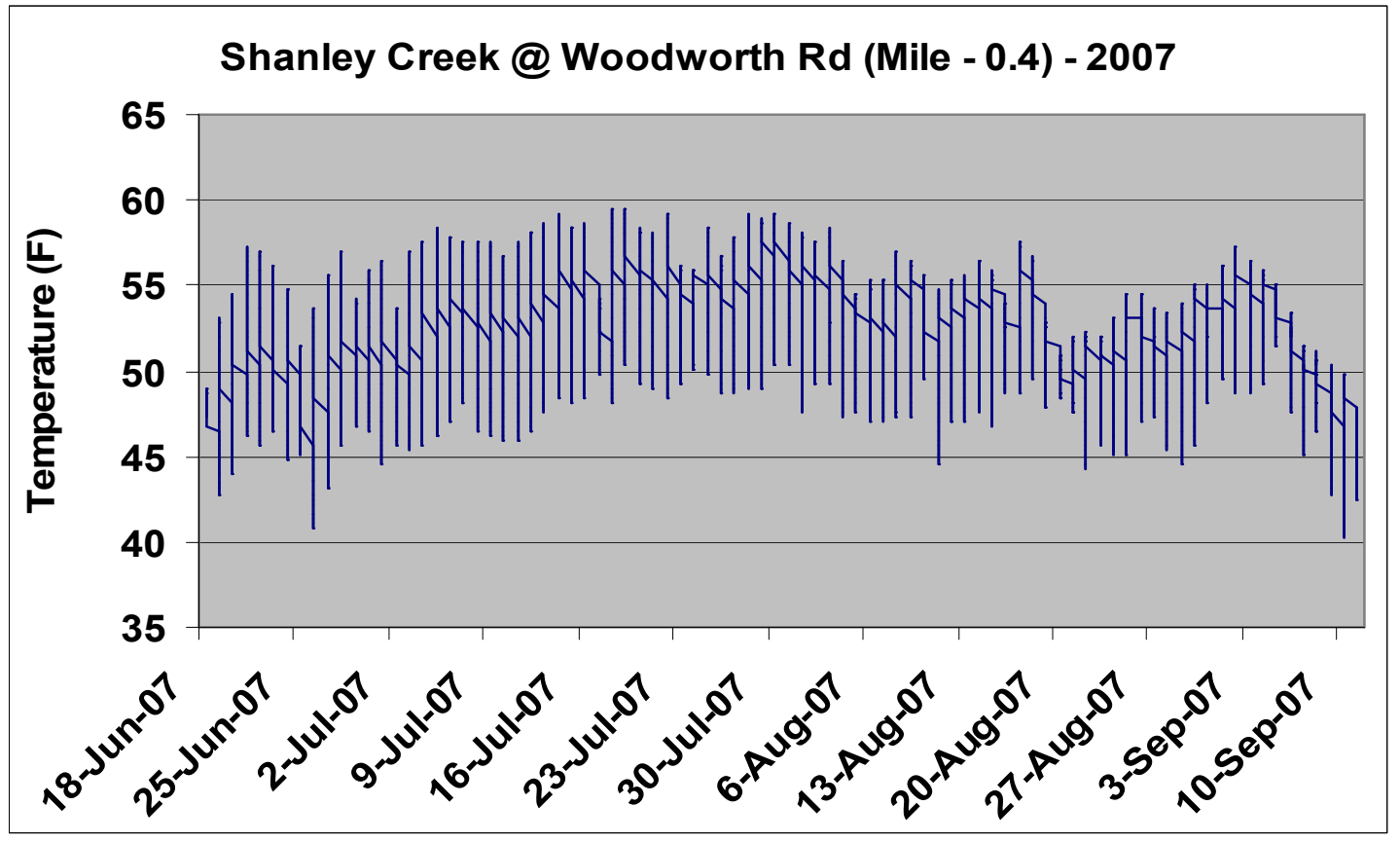

\begin{tabular}{|c|c|c|c|c|c|}
\hline Month & Max Temp & Min Temp & Avg Temp & StDev Temp & Var Temp \\
\hline June & 57.27 & 40.85 & 49.49 & 3.85 & 14.83 \\
\hline July & 59.53 & 44.48 & 52.74 & 3.75 & 14.09 \\
\hline August & 58.39 & 44.2 & 51.4 & 3.11 & 9.69 \\
\hline September & 57.27 & 40.28 & 50.4 & 3.8 & 14.48 \\
\hline
\end{tabular}
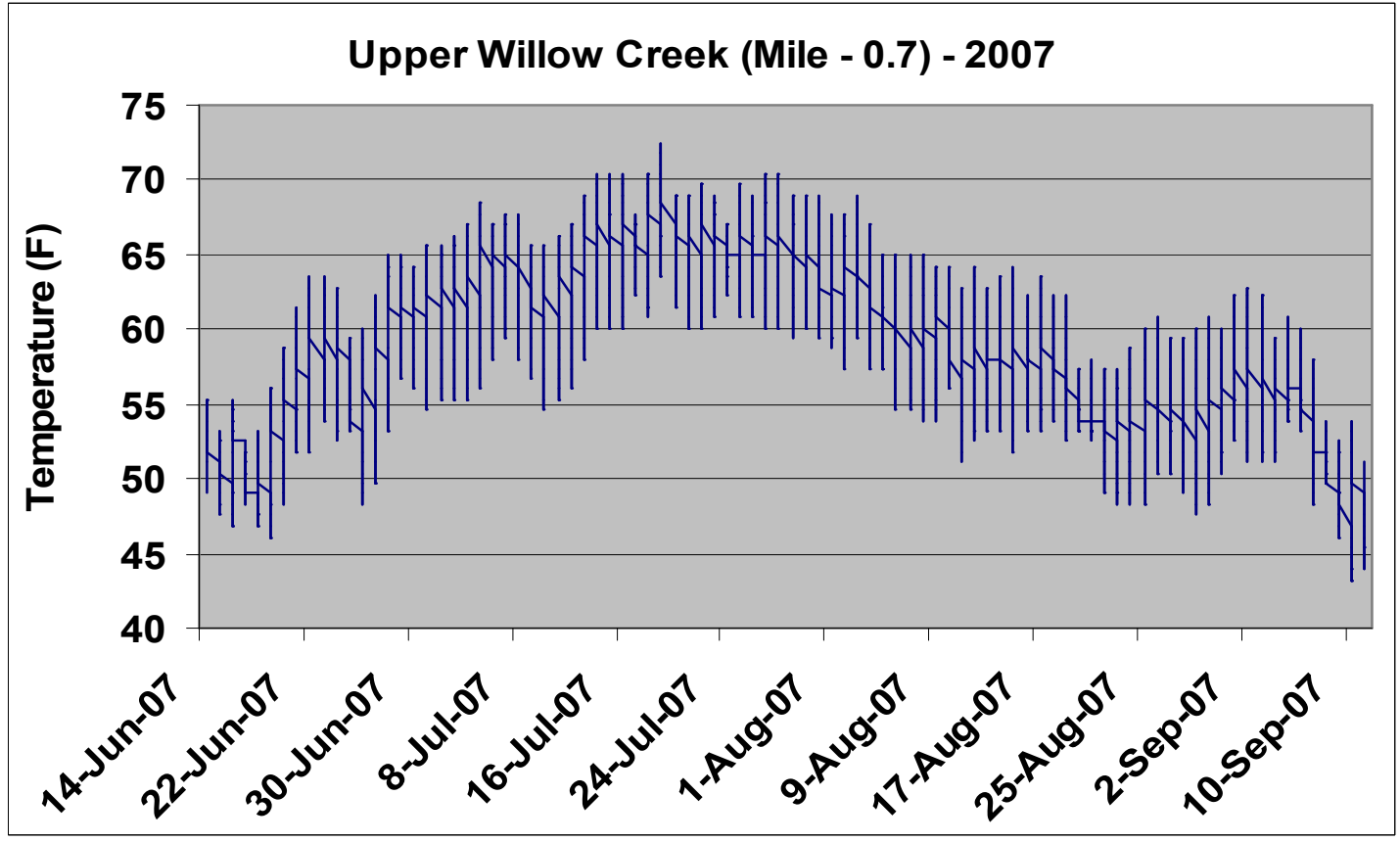

\begin{tabular}{|c|c|c|c|c|c|}
\hline Month & Max Temp & Min Temp & Avg Temp & StDev Temp & Var Temp \\
\hline June & 64.9 & 46.1 & 55 & 4.84 & 23.42 \\
\hline July & 72.5 & 54.6 & 63.78 & 3.85 & 14.86 \\
\hline August & 69 & 47.6 & 57.28 & 4.47 & 20.01 \\
\hline September & 62.8 & 43.2 & 53.44 & 4.56 & 20.83 \\
\hline
\end{tabular}




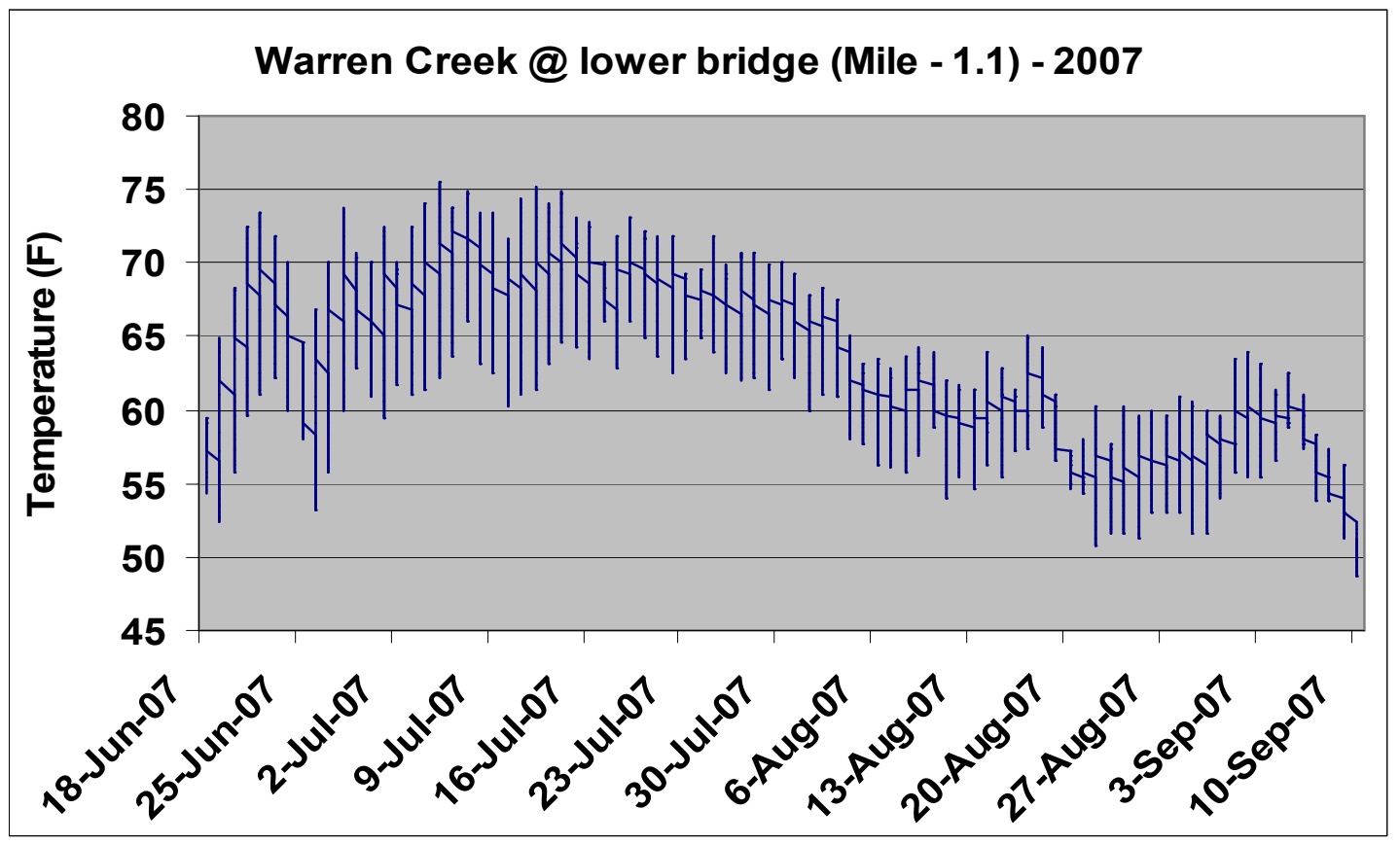

\begin{tabular}{|c|c|c|c|c|c|}
\hline Month & Max Temp & Min Temp & Avg Temp & StDev Temp & Var Temp \\
\hline June & 73.71 & 52.39 & 63.9 & 5.05 & 25.51 \\
\hline July & 75.56 & 59.4 & 67.72 & 3.47 & 12.07 \\
\hline August & 68.35 & 50.72 & 58.9 & 3.61 & 13.01 \\
\hline September & 63.97 & 48.77 & 57.51 & 3.36 & 11.27 \\
\hline
\end{tabular}

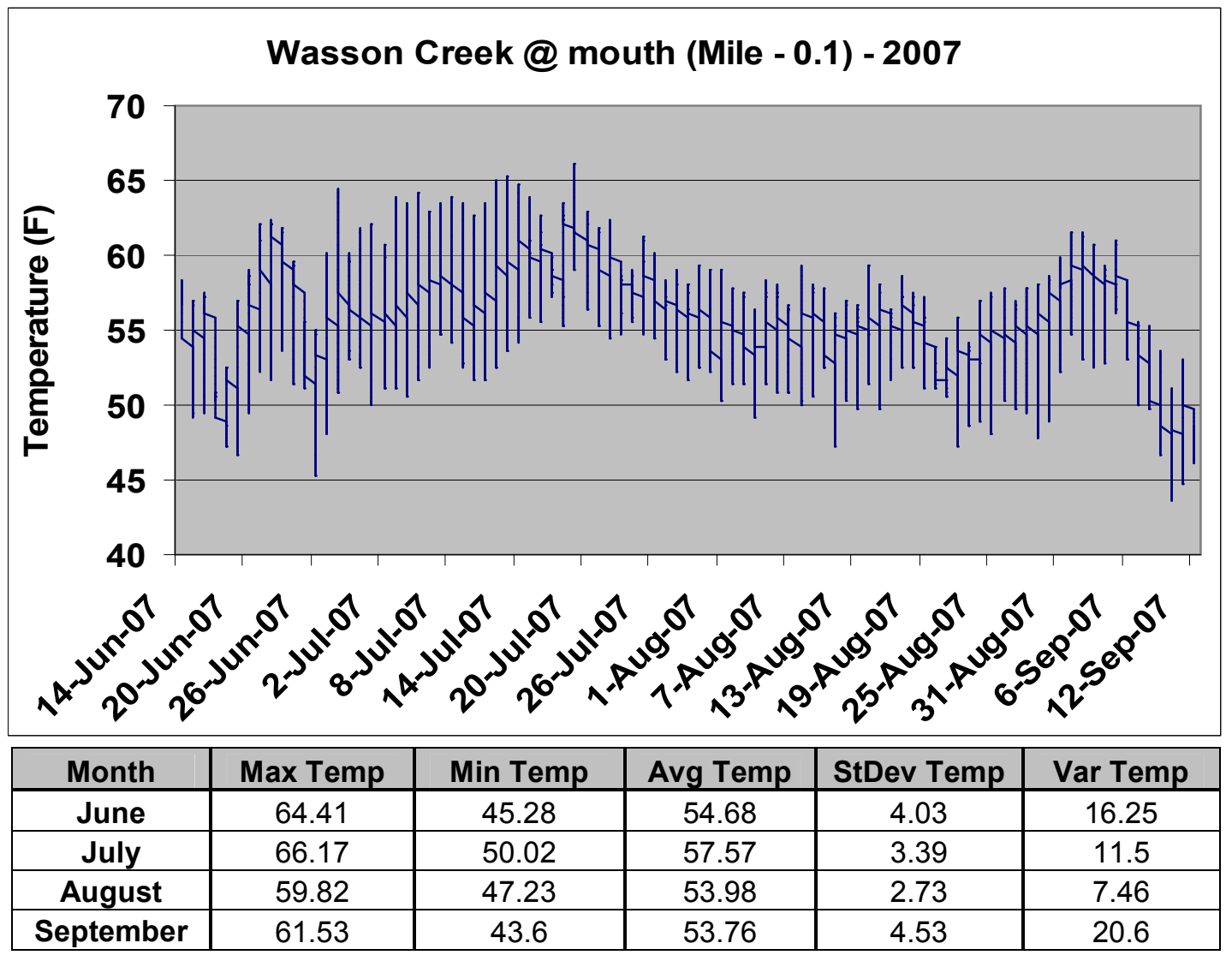



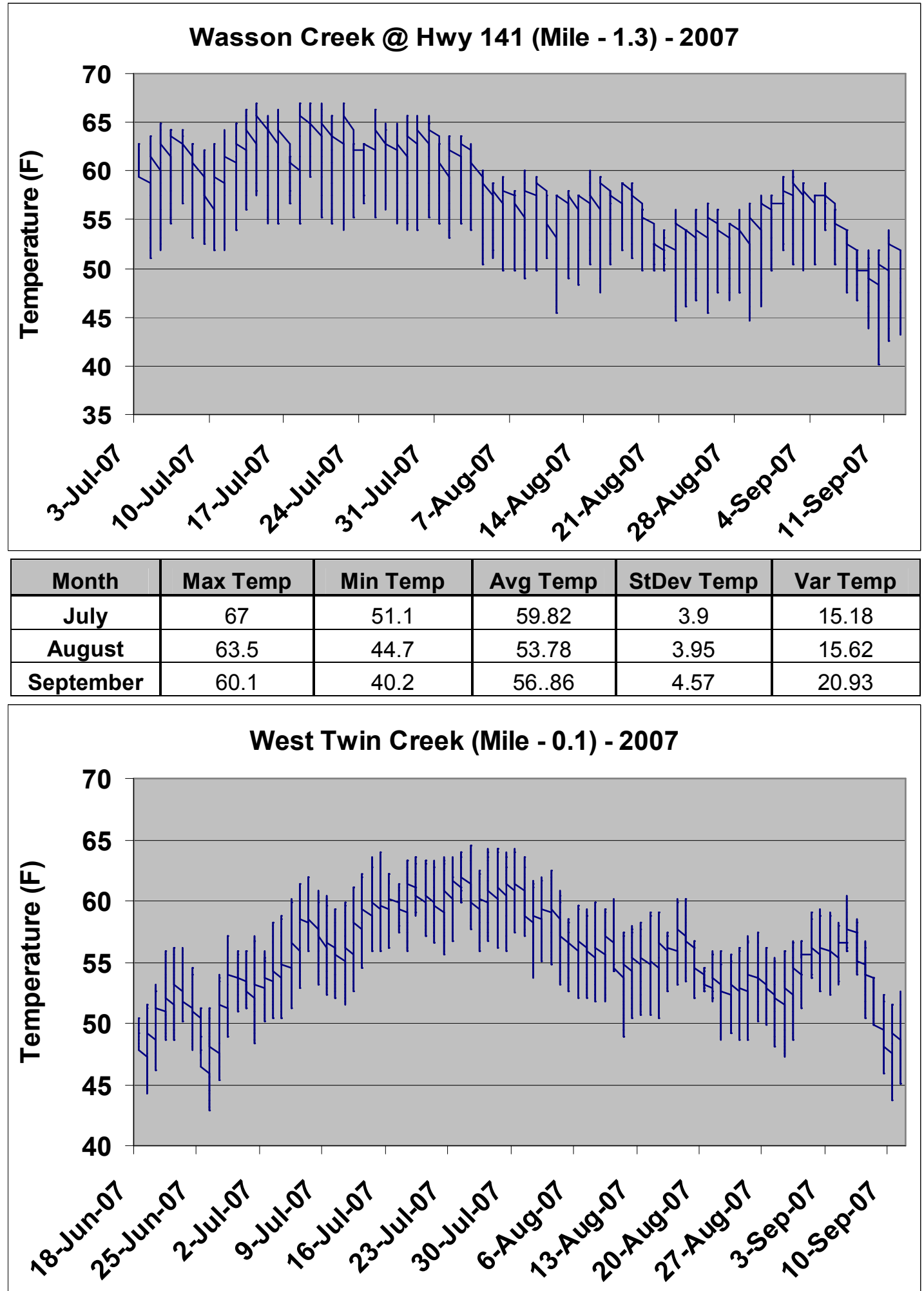

\begin{tabular}{|c|c|c|c|c|c|}
\hline Month & Max Temp & Min Temp & Avg Temp & StDev Temp & Var Temp \\
\hline June & 57.06 & 42.83 & 50.9 & 3.2 & 10.25 \\
\hline July & 64.49 & 48.4 & 58.28 & 3.53 & 12.46 \\
\hline August & 62.47 & 47.29 & 54.78 & 3.1 & 9.6 \\
\hline September & 60.47 & 43.67 & 53.57 & 3.97 & 15.76 \\
\hline
\end{tabular}




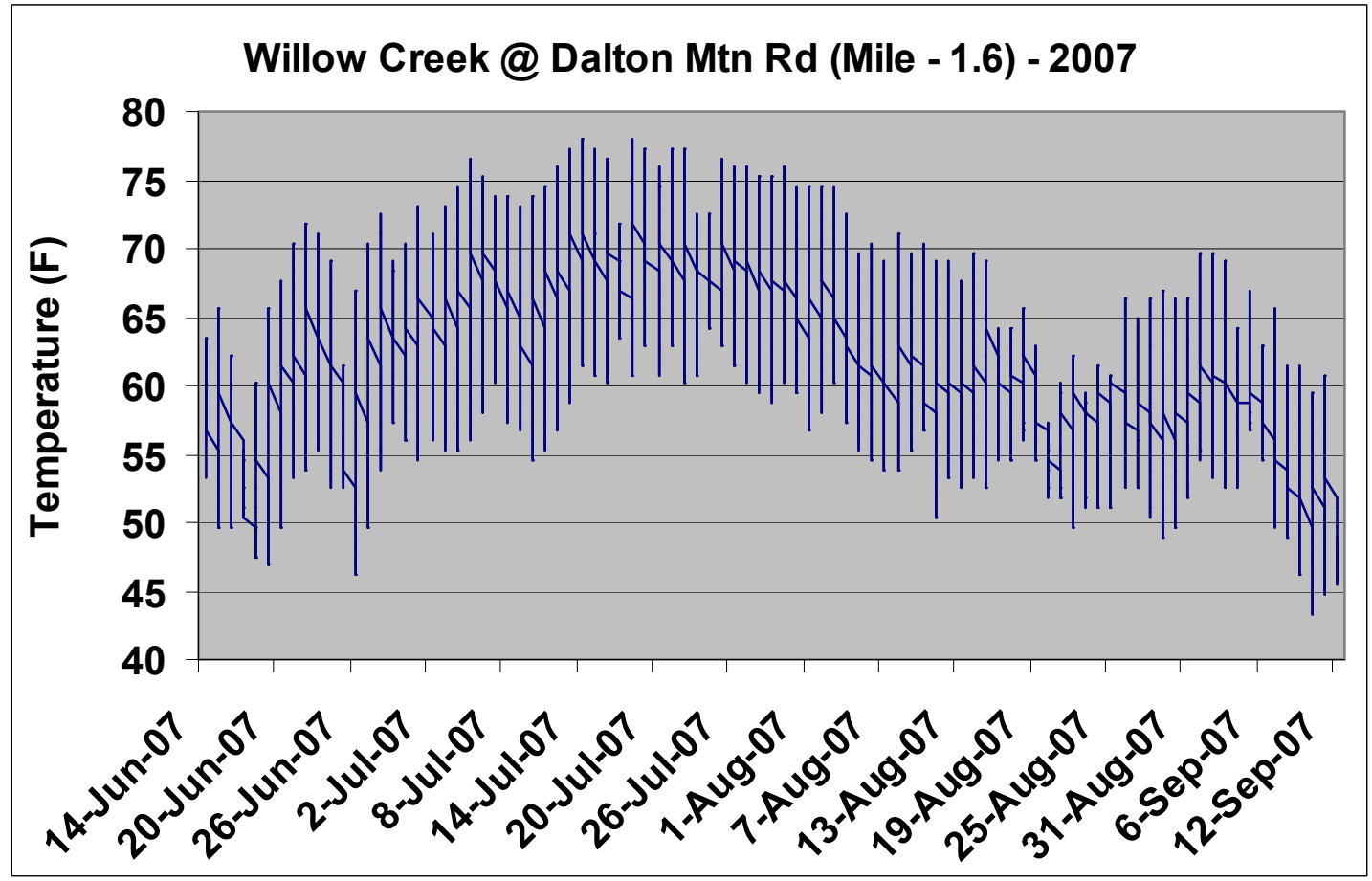

\begin{tabular}{|c|c|c|c|c|c|}
\hline Month & Max Temp & Min Temp & Avg Temp & StDev Temp & Var Temp \\
\hline June & 72.46 & 46.1 & 59.05 & 6.46 & 41.75 \\
\hline July & 78.01 & 54.58 & 67.12 & 5.78 & 33.38 \\
\hline August & 74.53 & 48.96 & 59.72 & 5.65 & 31.89 \\
\hline September & 69.71 & 43.19 & 56.64 & 6.13 & 37.6 \\
\hline
\end{tabular}

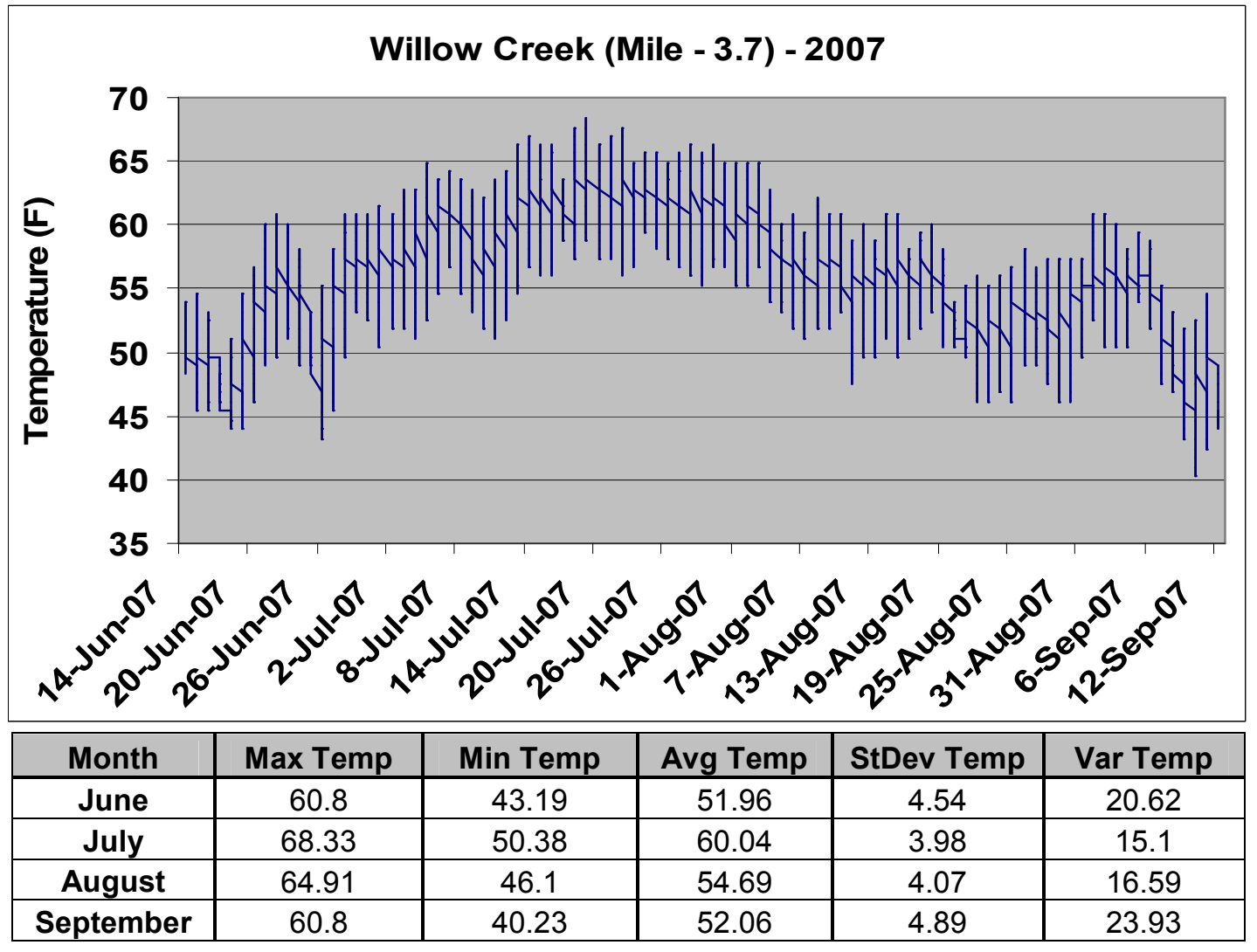




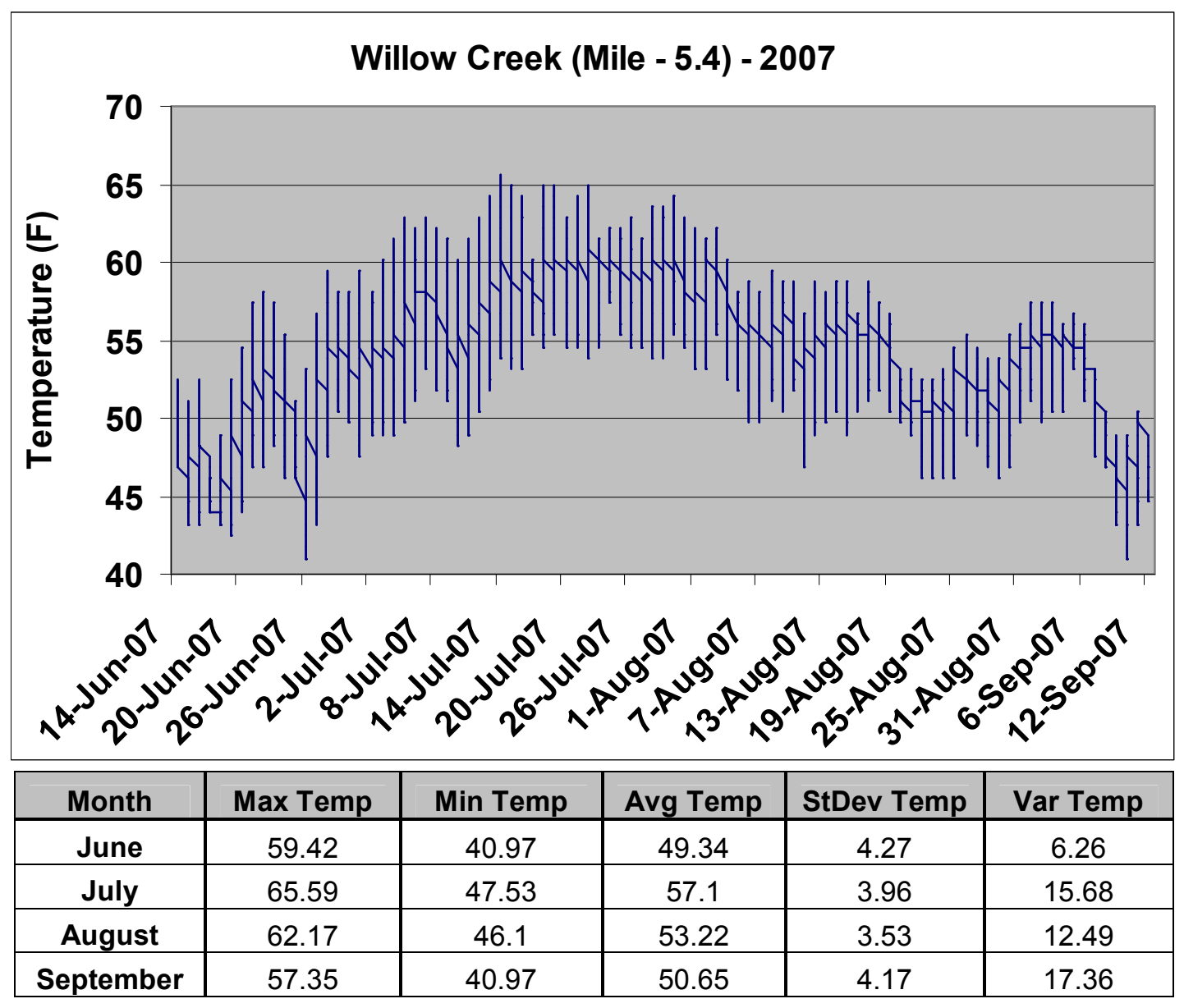


Appendix I : Summary of water chemistry readings for 2006.

\begin{tabular}{|c|c|c|c|c|c|c|c|c|c|}
\hline Stream name & Date & $\begin{array}{c}\text { River } \\
\text { Mile }\end{array}$ & $\mathrm{pH}$ & $\begin{array}{c}\text { Conductivity } \\
\text { (uS) }\end{array}$ & $\begin{array}{l}\text { TDS } \\
\text { (ppm) }\end{array}$ & $\begin{array}{l}\text { Tem } \\
p^{\circ} F\end{array}$ & Lat & Long & TRS \\
\hline Anaconda $\mathrm{Cr} @$ mile 0.1 & 25-Jul-06 & 0.1 & 8.12 & 160 & 80 & 50.2 & N47.03485 & W112.35775 & $15 \mathrm{~N}, 6 \mathrm{~W}, 27 \mathrm{~B}$ \\
\hline Anaconda Cr @ mile 0.5 & 25-Jul-06 & 0.5 & 8.14 & 161 & 80 & 49.8 & N47.03524 & W112.35125 & $15 \mathrm{~N}, 6 \mathrm{~W}, 22 \mathrm{C}$ \\
\hline Beartrap Cr @ mile 0.2 & 25-Jul-06 & 0.2 & 8.27 & 296 & 147 & 58.6 & N47.03397 & W112.35729 & $15 \mathrm{~N}, 6 \mathrm{~W}, 27 \mathrm{~B}$ \\
\hline Beartrap Cr @ mile 1.2 & 25-Jul-06 & 1.2 & 8.22 & 183 & 90 & 62.6 & N47.02128 & W112.34695 & $15 \mathrm{~N}, 6 \mathrm{~W}, 27 \mathrm{C}$ \\
\hline $\begin{array}{l}\text { Blackfoot River (Poorman - Dalton } \\
\text { Section) }\end{array}$ & 21-Sep-06 & 107.2 & 8.59 & 283 & 141 & 50.7 & N46.93578 & W112.69184 & 14N,9W,27A\&26A,B \\
\hline Blackfoot River (above Hogum $\mathrm{Cr}$ Rd) & 11-Sep-06 & 119.6 & 8.48 & 226 & 110 & 62.8 & N46.99214 & W112.50309 & $14 \mathrm{~N}, 7 \mathrm{~W}, 5 \mathrm{D}$ \\
\hline $\begin{array}{l}\text { Blackfoot River (above Flesher Pass } \\
\text { Rd) }\end{array}$ & 5-Sep-06 & 124.3 & 8.21 & 219 & 110 & 55.9 & N47.01344 & W112.45405 & $15 \mathrm{~N}, 7 \mathrm{~W}, 35 \mathrm{~B} \& 26 \mathrm{C}$ \\
\hline Blackfoot River (above Pass Cr) & 26-Jul-06 & 130.5 & 7.84 & 241 & 112 & 56.1 & $\mathrm{~N} 47.04295$ & W112.38473 & $15 \mathrm{~N}, 6 \mathrm{~W}, 20 \mathrm{~A}$ \\
\hline Blackfoot River (above Shave Cr) & 26-Jul-06 & 131.5 & 8.06 & 323 & 160 & 54.9 & N47.03933 & W112.37019 & $15 \mathrm{~N}, 6 \mathrm{~W}, 21 \mathrm{D}$ \\
\hline Braziel Creek & 19-0ct-06 & 0.7 & 8.24 & 140 & 70 & 42.6 & N46.80259 & W112.83766 & $12 \mathrm{~N}, 10 \mathrm{~W}, 15 \mathrm{~A}$ \\
\hline Braziel Creek & 19-Oct-06 & 1.4 & 8.17 & 106 & 53 & 41.9 & N46.79295 & W112.83982 & $12 \mathrm{~N}, 10 \mathrm{~W}, 15 \mathrm{D}$ \\
\hline Burnt Cabin Cr & 24-Aug-06 & 0.2 & 7.68 & 37 & 17 & 48.9 & N47.23796 & W113.15359 & $17 \mathrm{~N}, 12 \mathrm{~W}, 8 \mathrm{D}$ \\
\hline Chamberlain $\mathrm{Cr}$ & 12-Sep-06 & 0.1 & 8.07 & 146 & 72 & 60.8 & N47.01408 & W113.26819 & $15 \mathrm{~N}, 13 \mathrm{~W}, 32 \mathrm{~A}$ \\
\hline CottonwoodCr@ Dyer Diversion & 19-Sep-06 & 12 & 8.34 & 157 & 79 & 47.7 & N47.12273 & W113.30516 & $16 \mathrm{~N}, 14 \mathrm{~W}, 24 \mathrm{D}$ \\
\hline East Fork Monture $\mathrm{Cr}$ & 21-Aug-06 & 0.2 & 7.92 & 43 & 21 & 51.9 & $\mathrm{~N} 47.24512$ & W113.15814 & $17 \mathrm{~N}, 12 \mathrm{~W}, 8 \mathrm{~B}$ \\
\hline Gold $\mathrm{Cr}$ & 14-Sep-06 & 1.9 & 8.84 & 216 & 108 & 50.9 & N46.93928 & W113.66877 & $14 \mathrm{~N}, 16 \mathrm{~W}, 30 \mathrm{D}$ \\
\hline Hayden $\mathrm{Cr}$ & 22-Aug-06 & 0.1 & 7.62 & 44 & 21 & 54.7 & N47.22443 & W113.15319 & $17 \mathrm{~N}, 12 \mathrm{~W}, 17 \mathrm{D}$ \\
\hline Hoyt $\mathrm{Cr} @$ lower fenceline & 12-Sep-06 & 0.2 & 8.38 & 444 & 222 & 48.4 & N47.04867 & $\mathrm{N} 113.17111$ & $15 \mathrm{~N}, 12 \mathrm{~W}, 19 \mathrm{~B}$ \\
\hline $\begin{array}{l}\text { Hoyt Cr below Jim Stone's at Hwy } \\
200\end{array}$ & 12-Sep-06 & 1.2 & 8.6 & 427 & 216 & 50.5 & N47.03936 & W113.17001 & $15 \mathrm{~N}, 12 \mathrm{~W}, 19 \mathrm{C}$ \\
\hline $\begin{array}{l}\text { Hoyt Cr above Jim Stone's at Hwy } \\
200\end{array}$ & 12-Sep-06 & 4.3 & 8.68 & 364 & 178 & 48.9 & N47.02496 & W113.1328 & $15 \mathrm{~N}, 12 \mathrm{~W}, 28 \mathrm{C}$ \\
\hline Middle Fork Monture $\mathrm{Cr}$ & 23-Aug-06 & 0.8 & 7.63 & 42 & 20 & 52.9 & N47.27666 & W113.18103 & $18 \mathrm{~N}, 12 \mathrm{~W}, 31 \mathrm{~B}$ \\
\hline Mike Horse Cr @ mile 0.1 & 25-Jul-06 & 0.1 & 8.12 & 286 & 143 & 62.2 & N47.0272 & W112.3588 & $15 \mathrm{~N}, 6 \mathrm{~W}, 27 \mathrm{~B}$ \\
\hline Mike Horse Cr @ mile 0.4 & 25-Jul-06 & 0.4 & 8.18 & 254 & 127 & 53.4 & N47.02496 & W112.36166 & $15 \mathrm{~N}, 6 \mathrm{~W} 28 \mathrm{D}$ \\
\hline Mike Horse Cr @ mile 0.45 & 25-Jul-06 & 0.45 & 7.65 & 243 & 122 & 50.9 & N47.02425 & W112.36208 & $15 \mathrm{~N}, 6 \mathrm{~W}, 28 \mathrm{D}$ \\
\hline Mike Horse Cr @ mile 0.5 & 25-Jul-06 & 0.5 & 7.91 & 204 & 100 & 53.8 & N47.02361 & W112.36229 & $15 \mathrm{~N}, 6 \mathrm{~W}, 28 \mathrm{D}$ \\
\hline Mike Horse Reservoir & 25-Jul-06 & & 8.51 & 190 & 95 & 77 & N47.02766 & W112.35482 & $15 \mathrm{~N}, 6 \mathrm{~W}, 27 \mathrm{~B}$ \\
\hline Monture $\mathrm{Cr} @$ mile 18.2 & 22-Aug-06 & 18.2 & 7.98 & 62 & 29 & 53.6 & N47.17976 & W113.15949 & $17 \mathrm{~N}, 12 \mathrm{~W}, 32 \mathrm{C}$ \\
\hline Monture $\mathrm{Cr} @$ mile 23 & 21-Aug-06 & 23 & 7.55 & 44 & 22 & 53.9 & N47.23606 & W113.15628 & $17 \mathrm{~N}, 12 \mathrm{~W}, 17 \mathrm{~B} \& 8 \mathrm{C}$ \\
\hline Monture Cr @ mile 27.5 & 23-Aug-06 & 27.5 & 7.91 & 61 & 30 & 55.6 & N47.28197 & W113.19702 & $18 \mathrm{~N}, 13 \mathrm{~W}, 25 \mathrm{C}, \mathrm{D}$ \\
\hline Murphy's Spring Cr & 14-Sep-06 & 0.6 & 8.38 & 172 & 86 & 48.2 & N47.04345 & W113.00662 & $15 \mathrm{~N}, 11 \mathrm{~W}, 21 \mathrm{~B}$ \\
\hline Pass Cr @ mile 0.5 & 24-Jul-06 & 0.5 & 7.78 & 166 & 82 & 54.3 & N47.04818 & W112.38132 & $15 \mathrm{~N}, 6 \mathrm{~W}, 17 \mathrm{D}$ \\
\hline Pass Cr @ mile 1.5 & 24-Jul-06 & 1.5 & 7.77 & 158 & 79 & 52.3 & N47.06443 & W112.37402 & $15 \mathrm{~N}, 6 \mathrm{~W}, 9 \mathrm{C}$ \\
\hline Paymaster @ mile 0.4 & 24-Jul-06 & 0.4 & 3.96 & 196 & 97 & 66.6 & N47.03944 & W112.38505 & $15 \mathrm{~N}, 6 \mathrm{~W}, 20 \mathrm{D}$ \\
\hline Paymaster @ mile 0.65 & 24-Jul-06 & 0.65 & 4.07 & 109 & 54 & 60.6 & N47.03447 & W112.38683 & $15 \mathrm{~N}, 6 \mathrm{~W}, 29 \mathrm{~A}$ \\
\hline Paymaster @ mile 1.2 & 24-Jul-06 & 1.2 & 6.02 & 45 & 24 & 55.8 & N47.02796 & W112.38531 & $15 \mathrm{~N}, 6 \mathrm{~W}, 29 \mathrm{D}$ \\
\hline Rock Cr & 6-Sep-06 & $\overline{1.6}$ & 8.2 & 227 & 114 & 53.4 & N47.00011 & W113.01624 & $14 \mathrm{~N}, 11 \mathrm{~W}, 5 \mathrm{~A}$ \\
\hline Shanley Cr @ mile 1.6 & 6-Sep-06 & 1.6 & 8.56 & 175 & 85 & 54 & N47.0883 & W113.23401 & $15 \mathrm{~N}, 13 \mathrm{~W}, 3 \mathrm{~B}$ \\
\hline Shave Cr @ mile 0.4 & 24-Jul-06 & 0.4 & 7.04 & 97 & 50 & 61.9 & $\mathrm{~N} 47.0444$ & W112.37148 & $15 \mathrm{~N}, 6 \mathrm{~W}, 21 \mathrm{~B}$ \\
\hline Shave Cr @ mile 0.9 & 24-Jul-06 & 0.9 & 7.65 & 103 & 52 & 61 & N47.04938 & W112.36385 & $15 \mathrm{~N}, 6 \mathrm{~W}, 21 \mathrm{~A} \& 16 \mathrm{D}$ \\
\hline Un-named trib to upper Monture $\mathrm{Cr}$ & 23-Aug-06 & 0.4 & 8 & 48 & 24 & 50.5 & $\mathrm{~N} 47.2869$ & W113.19562 & $18 \mathrm{~N}, 13 \mathrm{~W}, 25 \mathrm{D}$ \\
\hline Warren Cr @ lower bridge & 13-Sep-06 & 1.1 & 8.13 & 413 & 206 & 49.8 & N47.00557 & W113.17481 & $15 \mathrm{~N}, 12 \mathrm{~W}, 31 \mathrm{C}$ \\
\hline Warren Cr @ 2nd bridge & 13-Sep-06 & 2.1 & 8.13 & 405 & 203 & 48.4 & N47.01221 & W113.161 & $15 \mathrm{~N}, 12 \mathrm{~W}, 31 \mathrm{~A}$ \\
\hline Warren Cr @ step pool section & 13-Sep-06 & 3.6 & 8.38 & 384 & 190 & 53.6 & N47.01715 & W113.13747 & $15 \mathrm{~N}, 12 \mathrm{~W}, 32 \mathrm{C}$ \\
\hline $\begin{array}{l}\text { Warren Cr dwnstn Murphy's } \\
\text { diversion }\end{array}$ & 13-Sep-06 & 6.7 & 8.76 & 166 & 82 & 59.9 & N47.01417 & W113.00279 & $15 \mathrm{~N}, 12 \mathrm{~W}, 35 \mathrm{~B}$ \\
\hline Wasson Cr@ mouth & 17-Aug-06 & 0.1 & 8.23 & 274 & 137 & 54 & N46.89363 & W112.94875 & $13 \mathrm{~N}, 11 \mathrm{~W}, 11 \mathrm{D}$ \\
\hline Wasson Cr @ hayshed & 17-Aug-06 & 1 & 8.41 & 242 & 124 & 57.4 & N46.88357 & W112.9411 & $13 \mathrm{~N}, 11 \mathrm{~W}, 13 \mathrm{~B}$ \\
\hline Wasson $\mathrm{Cr}$ below lower diversion & 17-Aug-06 & 2.8 & 8.43 & 218 & 113 & 51.8 & N46.89074 & W112.91902 & $13 \mathrm{~N}, 10 \mathrm{~W}, 7 \mathrm{C}$ \\
\hline Wasson $\mathrm{Cr}$ above upper diversion & 17-Aug-06 & 3 & 8.54 & 228 & 113 & 53 & N46.89009 & W112.91066 & $13 \mathrm{~N}, 10 \mathrm{~W}, 7 \mathrm{C}$ \\
\hline Wedge $\mathrm{Cr}$ & 22-Aug-06 & 0.1 & 8.43 & 135 & 67 & 50.2 & N47.20433 & W113.15273 & $17 \mathrm{~N}, 12 \mathrm{~W}, 29 \mathrm{~A}$ \\
\hline Yellowjacket Creek & 22-Aug-06 & 0.1 & 8.23 & 113 & 57 & 55 & N47.18246 & W113.16131 & $17 \mathrm{~N}, 12 \mathrm{~W}, 32 \mathrm{C}$ \\
\hline
\end{tabular}


Appendix I : Summary of water chemistry readings for 2007.

\begin{tabular}{|c|c|c|c|c|c|c|c|c|c|}
\hline Stream name & Date & $\begin{array}{l}\text { River } \\
\text { Mile }\end{array}$ & $\mathrm{pH}$ & $\begin{array}{l}\text { Conductivity } \\
\text { (uS) }\end{array}$ & $\begin{array}{c}\text { TDS } \\
(\mathrm{ppm})\end{array}$ & $\begin{array}{l}\text { Tem } \\
\mathrm{p}^{\circ} \mathrm{F}\end{array}$ & Lat & Long & TRS \\
\hline Ashby Creek & 9-Aug-07 & $\sim 2.0$ & 8.85 & 394 & 199 & 52 & N46.85582 & W113.57534 & $13 \mathrm{~N}, 16 \mathrm{~W}, 35 \mathrm{~B}$ \\
\hline Ashby Creek & 9-Aug-07 & $\sim 3.0$ & 8.85 & 395 & 202 & 50.9 & $\mathrm{~N} 46.84720$ & W113.58944 & $12 \mathrm{~N}, 16 \mathrm{~W}, 35 \mathrm{~B}$ \\
\hline Ashby Creek & 9-Aug-07 & 4.0 & 9.06 & 389 & 198 & 51.4 & $\mathrm{~N} 46.83152$ & W113.59586 & $12 \mathrm{~N}, 16 \mathrm{~W}, 3 \mathrm{~A}$ \\
\hline Bear Creek & 8-Aug-07 & 1.1 & 8.49 & 108 & 56 & 52.7 & N46.89785 & W113.68035 & $13 \mathrm{~N}, 16 \mathrm{~W}, 18 \mathrm{~B} \& 7 \mathrm{C}$ \\
\hline Beaver Creek & 3-Jul-07 & 0.2 & 8.06 & 192 & 95 & 63 & N46.95388 & W112.72346 & $14 \mathrm{~N}, 9 \mathrm{~W}, 22 \mathrm{~B}$ \\
\hline \multicolumn{10}{|l|}{$\begin{array}{l}\text { Blackfoot-Clearwater Game Range " } \\
\text { Dryer Ranch" }\end{array}$} \\
\hline Fen in southwestern pasture & 11-Jun-07 & & 7.17 & 293 & 145 & 59.4 & N47.08427 & W113.28160 & $15 \mathrm{~N}, 13 \mathrm{~W}, 6 \mathrm{D}$ \\
\hline $\begin{array}{l}\text { Fen dunping into Western Spr Cr } \\
\text { headwaters }\end{array}$ & 11-Jun-07 & & 7.51 & 286 & 138 & 56.1 & N47.08259 & W113.27947 & $15 \mathrm{~N}, 13 \mathrm{~W}, 5 \mathrm{C}$ \\
\hline Western Spr Cr upstream ditch & 11-Jun-07 & & 7.42 & 195 & 100 & 47.1 & $\mathrm{~N} 47.08229$ & W113.27782 & $15 \mathrm{~N}, 13 \mathrm{~W}, 5 \mathrm{C}$ \\
\hline $\begin{array}{l}\text { Ditch entering Western Sr Cr from } \\
\text { north }\end{array}$ & 11-Jun-07 & & 7.7 & 464 & 233 & 64.6 & N47.08227 & W113.27781 & $15 \mathrm{~N}, 13 \mathrm{~W}, 5 \mathrm{C}$ \\
\hline Western Spr Cr at mouth & 11-Jun-07 & & 7.68 & 219 & 106 & 51.8 & N47.08255 & W113.27229 & $15 \mathrm{~N}, 13 \mathrm{~W}, 5 \mathrm{C}$ \\
\hline $\begin{array}{l}\text { Tributary entering eastern fork of } \\
\text { East } \mathrm{Spr} \mathrm{Cr}\end{array}$ & 12-Jun-07 & & 8.32 & 244 & 122 & 59.7 & N47.08708 & W113.26319 & $15 \mathrm{~N}, 13 \mathrm{~W}, 5 \mathrm{~A}$ \\
\hline Eastern Fork of East Spr Cr abv trib & 12-Jun-07 & & 8.04 & 299 & 150 & 54.7 & N47.08701 & W113.26385 & $15 \mathrm{~N}, 13 \mathrm{~W}, 5 \mathrm{~A}$ \\
\hline East Spr Cr abv eastern fork & 12-Jun-07 & & 8.21 & 230 & 113 & 52.9 & N47.08590 & W113.26443 & $15 \mathrm{~N}, 13 \mathrm{~W}, 5 \mathrm{~A}$ \\
\hline East $\mathrm{Spr} \mathrm{Cr}$ at lower culvert & 12-Jun-07 & & 8.3 & 239 & 120 & 58.5 & N47.08368 & W113.26350 & $15 \mathrm{~N}, 13 \mathrm{~W}, 5 \mathrm{D}$ \\
\hline Middle Spr Cr at ford xing & 12-Jun-07 & & 8.27 & 216 & 109 & 53.9 & $\mathrm{~N} 47.08448$ & W113.26773 & $15 \mathrm{~N}, 13 \mathrm{~W}, 5 \mathrm{D}$ \\
\hline Boyd/Portman Spr & 12-Jun-07 & & 5.00 & 215 & 107 & 54.7 & N47.07957 & W113.25984 & $15 \mathrm{~N}, 13 \mathrm{~W}, 5 \mathrm{C}$ \\
\hline Boyd Log Home Spr & 12-Jun-07 & & 7.47 & 252 & 152 & 54.1 & N47.07972 & W113.26019 & $15 \mathrm{~N}, 13 \mathrm{~W}, 5 \mathrm{C}$ \\
\hline East Tributary & 12-Jun-07 & & 8.28 & 253 & 125 & 57.7 & $\mathrm{~N} 47.08737$ & W113.26121 & $15 \mathrm{~N}, 13 \mathrm{~W}, 5 \mathrm{~A}$ \\
\hline Bog @ head of East Tributary & 12-Jun-07 & & 9.12 & 238 & 121 & 66.4 & N47.10031 & W113.25580 & $16 \mathrm{~N}, 13 \mathrm{~W}, 33 \mathrm{C}$ \\
\hline Canyon Creek & 14-Jul-07 & & & 118 & 60 & 57.7 & N47.21952 & W112.97434 & $17 \mathrm{~N}, 11 \mathrm{~W}, 14 \mathrm{C}$ \\
\hline Chamberlain Creek & 17-Jul-07 & 3.7 & 10.89 & 96 & 48 & 68.2 & N46.97886 & W113.26221 & $14 \mathrm{~N}, 13 \mathrm{~W}, 9 \mathrm{~A}$ \\
\hline Cooney Creek & 12-Jul-07 & 0.4 & & 160 & 80 & 56.3 & N47.25727 & W112.81068 & $17 \mathrm{~N}, 10 \mathrm{~W}, 1 \mathrm{~A}$ \\
\hline Copper Creek & 2-Aug-07 & 6.2 & & 225 & 113 & 55.9 & $\mathrm{~N} 47.07256$ & W112.61203 & $15 \mathrm{~N}, 8 \mathrm{~W}, 9 \mathrm{~A}$ \\
\hline $\begin{array}{l}\text { Cottonwood Cr below Dryer } \\
\text { diversion }\end{array}$ & 3-Jul-07 & 12 & 8.08 & 128 & 64 & 57.6 & N47.12143 & W113.30473 & $16 \mathrm{~N}, 13 \mathrm{~W}, 24 \mathrm{D}$ \\
\hline Cottonwood Cr below Hwy 200 & 5-Jul-07 & 0.5 & 9.02 & 224 & 111 & 68.5 & N47.02865 & W113.2744 & $15 \mathrm{~N}, 13 \mathrm{~W}, 29 \mathrm{~B}$ \\
\hline Dobrota Creek & 13-Jul-07 & 0.1 & & 148 & 74 & 52.9 & N47.26928 & W112.80687 & $18 \mathrm{~N}, 9 \mathrm{~W}, 31 \mathrm{C}$ \\
\hline Enders Spring $\mathrm{Cr}$ & 15-Aug-07 & 0.5 & & 233 & 118 & 60.1 & $\mathrm{~N} 47.00493$ & W113.04479 & $14 \mathrm{~N}, 11 \mathrm{~W}, 31 \mathrm{C}$ \\
\hline Gold Creek & 5-Jul-07 & 0.4 & 8.59 & 189 & 95 & 61.2 & N46.92126 & W113.67853 & $14 \mathrm{~N}, 16 \mathrm{~W}, 31 \mathrm{C}$ \\
\hline Gold Creek & 21-Aug-07 & 5.6 & & 218 & 111 & 56.1 & N46.98415 & W113.67762 & $14 \mathrm{~N}, 16 \mathrm{~W}, 7 \mathrm{C}$ \\
\hline Gold Creek & 23-Aug-07 & 5.9 & & 226 & 117 & 49.1 & N46.98821 & W113.67851 & $14 \mathrm{~N}, 16 \mathrm{~W}, 7 \mathrm{~B}$ \\
\hline Gold Creek & 23-Aug-07 & 6.2 & & 225 & 114 & 51.4 & N46.98887 & W113.68191 & $\begin{array}{l}14 \mathrm{~N}, 16 \mathrm{~W}, 7 \mathrm{~B} \\
14 \mathrm{~N}, 17 \mathrm{~W}, 12 \mathrm{~A}\end{array}$ \\
\hline Jacobsen Spring Cr & 13-Aug-07 & & 8.55 & 281 & 143 & 51.4 & $\mathrm{~N} 46.99433$ & W113.05995 & $14 \mathrm{~N}, 12 \mathrm{~W}, 14 \mathrm{D}$ \\
\hline Landers Fork & 2-Jul-07 & 0.9 & 8.12 & 203 & 102 & 58.5 & N46.97353 & W112.55975 & $14 \mathrm{~N}, 8 \mathrm{~W}, 12 \mathrm{C}$ \\
\hline Lincoln Spring Cr & 21-Aug-07 & 2.8 & & 310 & 157 & 53.4 & N46.96457 & W112.67493 & $14 \mathrm{~N}, 9 \mathrm{~W}, 13 \mathrm{D}$ \\
\hline McCabe Creek & 20-Aug-07 & 2.2 & & 279 & 141 & 50 & N47.07834 & W113.15115 & $15 \mathrm{~N}, 12 \mathrm{~W}, 5 \mathrm{C}$ \\
\hline Monture Creek at USFS bridge & $31-\mathrm{Jul}-07$ & 12.5 & & 122 & 61 & 52.7 & $\mathrm{~N} 47.11708$ & W113.14788 & $16 \mathrm{~N}, 12 \mathrm{~W}, 29 \mathrm{~B}$ \\
\hline Monture Creek & 6-Aug-07 & 12.9 & 7.8 & 129 & 63 & 54.9 & N47.11838 & W113.14677 & $16 \mathrm{~N}, 12 \mathrm{~W}, 29 \mathrm{~B}$ \\
\hline North Fork Blackfoot River & 6-Aug-07 & 17.2 & 8.54 & 197 & 99 & 51.1 & N47.10293 & W112.96053 & $16 \mathrm{~N}, 11 \mathrm{~W}, 35 \mathrm{~B}$ \\
\hline North Fork Blackfoot River & 19-Jul-07 & 17.5 & & 187 & 94 & 57.2 & N47.10251 & W112.96134 & $16 \mathrm{~N}, 11 \mathrm{~W}, 35 \mathrm{~B}$ \\
\hline North Fork Blackfoot River & 11-Jul-07 & 27.2 & 8.85 & 177 & 89 & 66.4 & N47.19729 & W113.88304 & $17 \mathrm{~N}, 10 \mathrm{~W}, 28 \mathrm{C}$ \\
\hline North Fork Blackfoot River & 12-Jul-07 & 33.3 & & 157 & 78 & 59.9 & N47.24827 & W112.84164 & $17 \mathrm{~N}, 10 \mathrm{~W}, 2 \mathrm{C}$ \\
\hline North Fork Blackfoot River & 13-Jul-07 & 36 & & 109 & 55 & 56.7 & $\mathrm{~N} 47.26750$ & W112.80538 & $18 \mathrm{~N}, 9 \mathrm{~W}, 31 \mathrm{C}$ \\
\hline Poorman Creek & 3-Jul-07 & 6.7 & 8.56 & 239 & 120 & 50.5 & N46.878 & W112.61797 & $13 \mathrm{~N}, 8 \mathrm{~W}, 16 \mathrm{D}$ \\
\hline Rock Creek & 15-Aug-07 & 1.6 & & 220 & 110 & 54.9 & $\mathrm{~N} 47.00073$ & W113.01580 & $14 \mathrm{~N}, 11 \mathrm{~W}, 5 \mathrm{~A}$ \\
\hline Rock Creek & 13-Aug-07 & 3.9 & & 158 & 74 & 64.9 & N47.01230 & W112.96450 & $15 \mathrm{~N}, 11 \mathrm{~W}, 35 \mathrm{~B}$ \\
\hline Rock Creek & 13-Aug-07 & 6.4 & & 162 & 83 & 69.1 & N47.03470 & W112.92714 & $15 \mathrm{~N}, 11 \mathrm{~W}, 24 \mathrm{D}$ \\
\hline Rock Creek & 15-Aug-07 & 7.5 & & 152 & 79 & 70.5 & N47.04581 & W112.91270 & $15 \mathrm{~N}, 10 \mathrm{~W}, 19 \mathrm{~B}$ \\
\hline Sauerkraut Creek & 26-Jul-07 & 2.7 & & 80 & 40 & 71.6 & N46.90688 & W112.75397 & $13 \mathrm{~N}, 9 \mathrm{~W}, 4 \mathrm{D}$ \\
\hline Sauerkraut Creek & 2-Aug-07 & 3.2 & & 82 & 41 & 55.6 & N46.89977 & W112.75828 & $13 \mathrm{~N}, 9 \mathrm{~W}, 8 \mathrm{~A}$ \\
\hline Shanley Creek & 19-Jul-07 & 0.2 & & 168 & 84 & 63.1 & $\mathrm{~N} 47.07782$ & W113.25658 & $15 \mathrm{~N}, 7 \mathrm{~W}, 35 \mathrm{C}$ \\
\hline Snowbank Creek & 7 -Aug-07 & 0.1 & 8.4 & 168 & 81 & 52.7 & $\mathrm{~N} 47.07047$ & W112.61097 & $15 \mathrm{~N}, 8 \mathrm{~W}, 9 \mathrm{~A}$ \\
\hline Snowbank Creek & 7-Aug-07 & 0.4 & 8.25 & 162 & 82 & 58.1 & $\mathrm{~N} 47.07223$ & W112.61669 & $15 \mathrm{~N}, 8 \mathrm{~W}, 9 \mathrm{~A}$ \\
\hline Snowbank Creek & 7-Aug-07 & 0.41 & 8.36 & 169 & 85 & 59.9 & N47.07178 & W112.61810 & $15 \mathrm{~N}, 8 \mathrm{~W}, 9 \mathrm{~A}$ \\
\hline Spring Cr to NFBLKFT & 6-Sep-07 & 0.6 & 8.15 & 179 & 91 & 52.7 & N47.04341 & W113.00666 & $15 \mathrm{~N}, 11 \mathrm{~W}, 21 \mathrm{~B}$ \\
\hline Theodore Creek & 12-Jul-07 & 0.2 & & 166 & 83 & 56.8 & N47.25377 & W112.83523 & $17 \mathrm{~N}, 10 \mathrm{~W}, 2 \mathrm{D}$ \\
\hline Wasson Creek @ hayshed & 14-Aug-07 & 1 & 9.02 & 275 & 142 & 56.8 & $\mathrm{~N} 46.88330$ & W112.94076 & $13 \mathrm{~N}, 11 \mathrm{~W}, 13 \mathrm{~B}$ \\
\hline Wasson $\mathrm{Cr}$ below lower diversion & 19-Jul-07 & 2.8 & & 222 & 110 & 60.8 & $\mathrm{~N} 46.89074$ & W112.91902 & $13 \mathrm{~N}, 10 \mathrm{~W}, 7 \mathrm{C}$ \\
\hline Wasson $\mathrm{Cr}$ above upper diversion & 14-Aug-07 & 3 & 9.41 & 247 & 126 & 65.7 & N46.89009 & W112.91066 & $13 \mathrm{~N}, 10 \mathrm{~W}, 7 \mathrm{C}$ \\
\hline Willow Creek behind Lincoln,MT. & 24-Jul-07 & 1.7 & & 176 & 74 & 67.6 & $\mathrm{~N} 46.93544$ & W112.73946 & $14 \mathrm{~N}, 9 \mathrm{~W}, 28 \mathrm{D}$ \\
\hline Willow Creek behind Lincoln,MT. & 25-Jul-07 & 3.6 & & 83 & 42 & 66.4 & N46.92873 & W112.71545 & $14 \mathrm{~N}, 9 \mathrm{~W}, 34 \mathrm{~A}$ \\
\hline Willow Creek behind Lincoln,MT. & 24-Jul-07 & 5.2 & & 85 & 42 & 61.5 & N46.90910 & W112.71300 & $13 \mathrm{~N}, 9 \mathrm{~W}, 3 \mathrm{~A}$ \\
\hline Willow Creek behind Lincoln,MT. & 23-Jul-07 & 5.7 & 8.96 & 72 & 37 & 62.2 & N46.90171 & W112.72139 & $13 \mathrm{~N}, 9 \mathrm{~W}, 3 \mathrm{C}$ \\
\hline Upper Willow Creek & 2-Jul-07 & 0.6 & 7.93 & 129 & 63 & 57.9 & N47.00549 & W112.45051 & $15 \mathrm{~N}, 7 \mathrm{~W}, 35 \mathrm{C}$ \\
\hline
\end{tabular}




\section{Appendix: J. Westslope cutthroat trout genetic sampling sites and results, 2006-07}

\section{University of Montana Conservation Genetics Laboratory \\ Division of Biological Sciences, University of Montana, Missoula, Montana 59812 (406) 243-6749 Fax (406) 243-4184}

June 3, 2006

Ladd Knotek

Genetics Contact, Region 2

Mt. Dept. of Fish, Wildlife, and Parks

3201 Spurgin Rd

Missoula, MT 59801

Ladd:

The paired interspersed nuclear DNA elements (PINE) technique has been used to analyze DNA from the following trout samples:

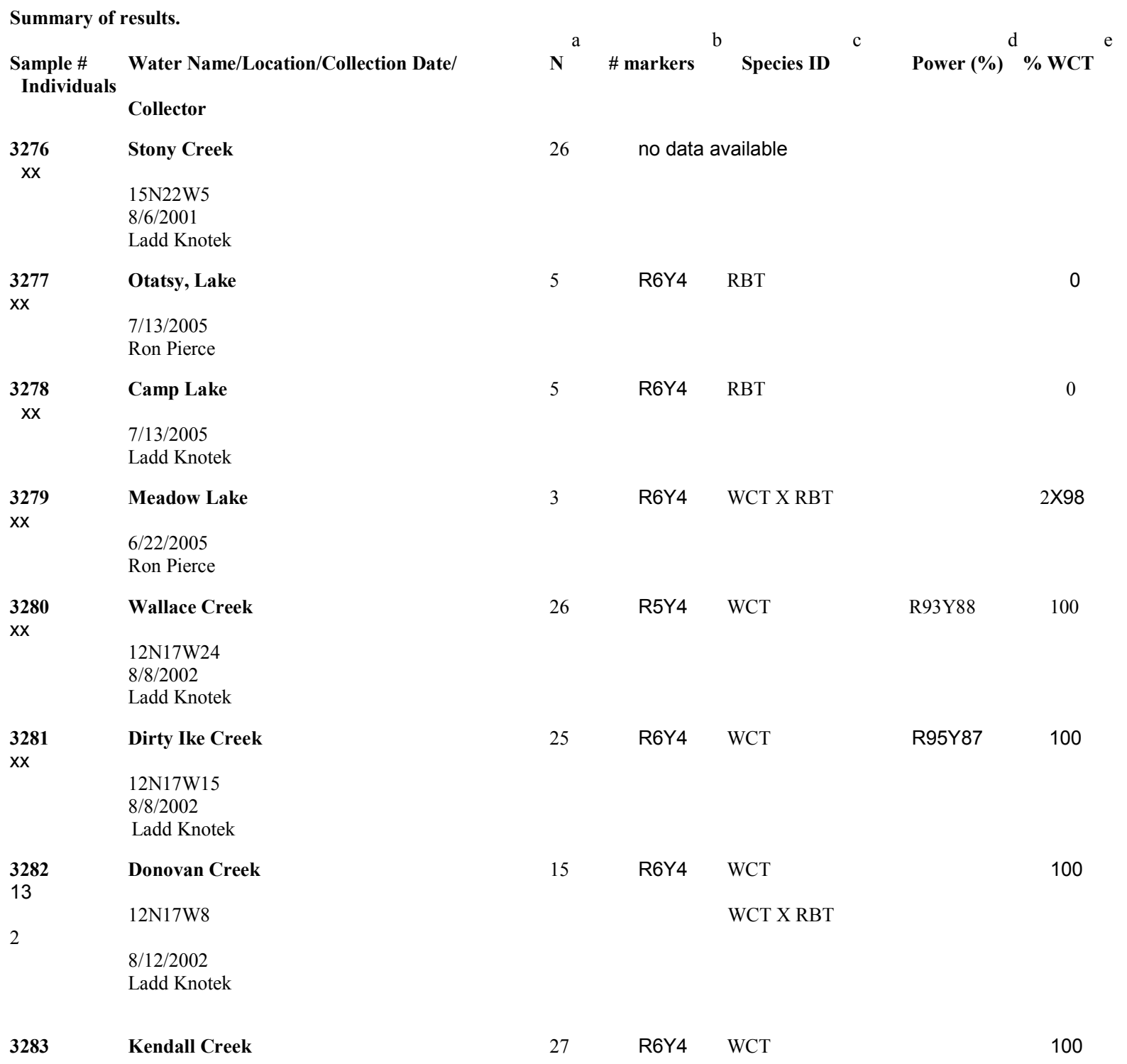


13N18W36

$5 / 19 / 1999$

Ladd Knotek

\begin{tabular}{|c|c|c|c|c|c|c|}
\hline & & $\mathrm{a}$ & & & & \\
\hline $\begin{array}{l}\text { Sample \# } \\
\text { Individuals }\end{array}$ & $\begin{array}{l}\text { Water Name/Location/Collection Date/ } \\
\text { Collector }\end{array}$ & $\mathbf{N}$ & \# markers & Species ID & Power (\%) & $\%$ WCT \\
\hline $\begin{array}{l}3286 \\
x x\end{array}$ & $\begin{array}{l}\text { Straight Creek above falls } \\
\text { 13N26W9 } \\
\text { 8/31/2004 } \\
\text { Ladd Knotek }\end{array}$ & $8(25)$ & R6Y4 & WCT & R96Y88 & 100 \\
\hline $\begin{array}{l}3287 \\
x x\end{array}$ & $\begin{array}{l}\text { Crow Creek near mouth } \\
\text { 17N8W19NE1/4 } \\
\text { 7/30/2002 } \\
\text { Laura Burns }\end{array}$ & 25 & R6Y4 & WCT & R95Y87 & 100 \\
\hline $\begin{array}{l}3288 \\
x x\end{array}$ & $\begin{array}{l}\text { Maryann Creek } \\
\text { 16N09W02 } \\
7 / 30 / 2002 \\
\text { Laura Burns }\end{array}$ & 25 & R6Y4 & WCT & R95Y87 & 100 \\
\hline $\begin{array}{l}3289 \\
x x\end{array}$ & $\begin{array}{l}\text { Lookout Creek } \\
\text { 16N08W16 } \\
7 / 31 / 2002 \\
\text { Laura Burns }\end{array}$ & 25 & R6Y4 & WCT & R95Y87 & 100 \\
\hline $\begin{array}{l}3290 \\
x x\end{array}$ & $\begin{array}{l}\text { Rock Creek } \\
\text { 16N22W34 } \\
\text { 6/30/2005 } \\
\text { Ladd Knotek }\end{array}$ & 25 & R6Y4 & WCT & R95Y87 & 100 \\
\hline $\begin{array}{l}3292 \\
x x\end{array}$ & $\begin{array}{l}\text { Donovan Creek site } 2 \\
\text { 12N17W08 } \\
\text { 8/12/2002 } \\
\text { Ladd Knotek }\end{array}$ & 12 & R6Y4 & WCT X RBT & & $97 \times 3$ \\
\hline
\end{tabular}

${ }^{\text {a }}$ Number of fish successfully analyzed. If combined with a previous sample, the number in parentheses indicates the combined sample size

${ }^{\mathrm{b}}$ Number of markers analyzed that are diagnostic for the non-native species $(\mathrm{R}=$ rainbow trout, $\mathrm{W}=$ westslope cutthroat trout, $\mathrm{Y}=$ Yellowstone cutthroat trout).

${ }^{\mathrm{c}}$ Codes: $\mathrm{WCT}=$ westslope cutthroat trout (Oncorhynchus clarki lewisi); $\mathrm{RBT}=$ rainbow trout $($ O. mykiss); YCT $=$ Yellowstone cutthroat trout $(O$. clarki bouvieri). Only one species code is listed when the entire sample possessed alleles from that species only. However, it must be noted that we cannot definitively rule out the possibility that some or all of the individuals are hybrids. We may not have detected any non-native alleles at the loci examined because of sampling error (see Power \%). Species codes separated by " $\mathrm{x}$ " indicate hybridization between those species.

${ }^{\mathrm{d}}$ Number corresponds to the percent chance we have to detect $1 \%$ hybridization given the number of individuals successfully analyzed and the number of diagnostic markers used. For example, 25 individuals are required to yield a $95 \%$ chance to detect as little as $1 \%$ hybridization with rainbow or an $87 \%$ chance to detect as little as $1 \%$ hybridization with Yellowstone cutthroat trout into what once was a westslope cutthroat trout population. Not reported when hybridization is detected.

${ }^{\mathrm{e}}$ Indicates the genetic contribution of the hybridizing taxa in the order listed under $\mathrm{c}$ to the sample assuming Hardy-Weinburg proportions. This number is reported if the sample appears to have come from a hybrid swarm. That is, a random mating population in which species markers are randomly distributed among individuals.

Indicates number of individuals with genetic characteristics corresponding to the species code column when the sample can be analyzed on the individual level. This occurs when marker alleles are not randomly distributed among individuals and 
hybridization appears to be recent and/or if the sample appears to consist of a mixture of populations and hybrids and non-hybrids can be reliably distinguished.

\section{Methods and Data Analysis}

The PINE technique uses short synthetically made segments of DNA called primers, in pairs, to search for relatively small segments of organismal DNA flanked by particular, often viral, DNA inserts. During the polymerase chain reaction (PCR), the primers bind to the ends of the inserts and many copies of the organismal DNA between the primers are made. While the DNA from some organisms may have two appropriately spaced inserts to which the primers can attach, the DNA from other organisms may have only one or none of the appropriately spaced inserts in particular regions. During PCR we will fail to copy DNA in the latter two cases. Thus, the PINE technique coupled with PCR is used to search for evidence of genetic variation based on the presence or absence of particular DNA fragments. The fragments are labeled by the primers used to produce them and their length in terms of the number of nucleotides in the fragment.

The fragments are made using dye labeled nucleotides and after PCR are separated from each other via electrophoresis in polyacrylamide gels. Smaller fragments move through the gels at a faster rate than larger fragments. The use of dye labeled nucleotides allows one to visualize the position of the fragments in the gels after electrophoresis using a spectrophotometer and the size of the fragments is determined by comparison to the position of synthetic fragments of known size that were also migrated into the gel.

When DNA from westslope cutthroat trout, Oncorhynchus clarki lewisi, and rainbow trout, $O$. mykiss, is compared with PINE analysis and three different pairs of primers seven fragments are usually characteristic of westslope cutthroat trout and six fragments are usually characteristic of rainbow trout (Table 1). Likewise, when DNA from westslope and Yellowstone cutthroat trout, O.c. bouvieri, is compared using the same procedure two fragments are usually characteristic of westslope cutthroat trout and four fragments are usually characteristic of Yellowstone cutthroat trout (Table 1).

Fragments produced from the DNA of one taxon and not another are commonly termed diagnostic or marker loci because they can be used to help determine whether a sample came from a nonhybridized population of one of the taxa or a population in which hybridization between them has or is occurring. Individuals from a non-hybridized population will possess fragments characteristic of only that taxon. In contrast, since half the DNA of first generation hybrids comes from each of the parental taxa the DNA from such individuals will yield all the fragments characteristic of the two parental taxa. In later generation hybrids, the amount and particular regions of DNA acquired from the parental taxa will vary among individuals. Thus, DNA from later generation hybrid individuals will yield only a subset of the parental fragments and the particular subset will vary among individuals.

In a sample from a random mating hybrid swarm, that is a population in which the genetic material (i.e. fragments) of the parental taxa is randomly distributed among individuals such that essentially all of them are of hybrid origin, the frequency of the fragment producing allele from the non-native taxon is expected to be nearly equal among the diagnostic loci since their presence can all be traced to a common origin or origins. Thus, if a sample contains substantial variation at only a single marker locus where the presence of the fragment is usually characteristic of a non-native taxon and lacks such fragments at all other markers this is probably not indicative of hybridization. Rather, it much more likely represents the existence of genetic variation for the presence or absence of the fragment within this particular population of the native taxon.

An important aspect of PINE marker loci is that individuals homozygous for the presence allele ( $p p)$ or heterozygous $(p a)$ will both yield the fragment. That is, $p$ is dominant to $a$. Thus, in order to estimate the genetic contribution of the native taxon to a hybrid swarm we concentrate on the marker 
loci at which the $p$ allele is characteristic of the non-native taxon. Furthermore, we must assume that genotypic distributions in the population reasonably conform to expected random mating proportions. Under this assumption the frequency of the native $a$ allele is approximately the square root of the frequency of individuals in the population lacking the fragment (aa). The frequency of the non-native allele then is one minus this value. We focus on the $p$ alleles characteristic of the nonnative taxon because with low levels of hybridization it is the presence of these alleles that are likely to provide evidence of hybridization. With low levels of hybridization, it is likely all individuals in the sample will genotypically be $p p$ or $p a$ where the $p$ allele is characteristic of the native taxon. Thus, like in non-hybridized populations all individuals in the sample will yield the fragment providing no evidence of hybridization.

Failure to detect evidence of hybridization in a sample does not necessarily mean the population is non-hybridized because there is always the possibility that we would not detect evidence of hybridization because of sampling error. In order to assess the likelihood the population is nonhybridized, we determine the chances of not detecting as little as a one percent genetic contribution of a non-native taxon to a hybrid swarm. This is simply $0.99^{2 \mathrm{NX}}$ where $\mathrm{N}$ is the number of fish in the sample and $\mathrm{X}$ is the number of marker loci where the $p$ allele is characteristic of the non-native taxon.

In samples showing evidence of hybridization, that is; fragments characteristic of a non-native taxon were detected at two or more marker loci, we used two approaches to determine if the population appeared to be a hybrid swarm. First, contingency table chi-square analysis was used to test for heterogeneity of allele frequencies among the marker loci. Next, we computed a hybrid index for each individual in the sample. Each diagnostic locus at which an individual possessed a PINE fragment characteristic of the non-native taxon was given a value of one. Each diagnostic locus at which an individual did not possess a PINE fragment characteristic of the non-native taxon was given a value of zero. These values summed over all diagnostic loci represent an individual's hybrid index. The observed distribution of hybrid index scores was then statistically compared to the expected random binomial distribution based on the estimated native and non-native genetic contributions to the sample. If the allele frequencies were statistically homogeneous among the diagnostic loci and the observed distribution of hybrid indices statistically conformed to the expected random binomial distribution, then the sample was considered to have come from a hybrid swarm.

Heterogeneity of allele frequencies among marker loci can arise in very old hybrid swarms as the frequencies over time diverge from each other due to genetic drift. In this case, however, the nonnative fragments will still be randomly distributed among individuals. Thus, samples with these characteristics were also considered to have come from hybrid swarms.

There are two likely reasons why a non-random distribution of non-native fragments may be observed among individuals in a sample. It may contain individuals from genetically divergent populations with different amounts of hybridization or hybridization may have only recently occurred in the population. Based on PINE data alone, these two situations will generally be difficult to distinguish from each other. Regardless of the explanation, when the non-native fragments are not randomly distributed among individuals in a sample estimating a mean level of hybridization has little, if any, biological meaning and, therefore, is often not estimated.

\section{Results and Discussion:}

\section{Stony Creek 3276}

We were only able to obtain poor quality DNA from the individuals in this sample. Thus, the PCR reactions completely failed to copy the DNA and unfortunately no data could be obtained 
from the sample.

\section{Otatsy Lake 3277}

All five individuals in the sample possessed PINE fragments usually characteristic of rainbow trout at all six diagnostic loci analyzed that distinguish rainbow from westslope cutthroat trout. At one of the seven diagnostic loci analyzed that usually distinguish westslope cutthroat trout from rainbow trout, three fish in the sample possessed a PINE fragment characteristic of westslope cutthroat trout. This could indicate a small amount of hybridization with westslope cutthroat trout or it could simply be rainbow trout genetic variation that is electrophoretically indistinguishable from that usually characteristic of westslope cutthroat trout. In this situation, we favor the latter interpretation because the allele frequencies at the westslope cutthroat trout diagnostic loci are statistically heterogeneous (Contingency table chi-square, $\mathrm{P}<0.05$ ).

Furthermore, the same westslope cutthroat trout diagnostic locus that was variable in the Otatsy Lake sample was also the only westslope cutthroat trout diagnostic locus that was genetically variable in the Camp Lake sample (\#3278). Thus, we conclude Otatsy Lake contains an introduced, non-hybridized rainbow trout population.

\section{Camp Lake 3278}

All five individuals in the sample possessed PINE fragments usually characteristic of rainbow trout at all six diagnostic loci analyzed that distinguish rainbow from westslope cutthroat trout. At one of the seven diagnostic loci analyzed that usually distinguish westslope cutthroat trout from rainbow trout, one fish in the sample possessed a PINE fragment characteristic of westslope cutthroat trout. This could indicate a small amount of hybridization with westslope cutthroat trout or it could simply be rainbow trout genetic variation that is electrophoretically indistinguishable from that usually characteristic of westslope cutthroat trout. In this situation, we favor the latter interpretation as the same westslope cutthroat trout diagnostic locus that was variable in the Camp Lake sample was also the only westslope cutthroat trout diagnostic locus that was genetically variable in the Otatsy Lake sample (\#3278). Thus, we conclude Camp Lake contains an introduced, non-hybridized rainbow trout population.

\section{Meadow Lake 3279}

All three individuals in the sample possessed PINE fragments usually characteristic of rainbow trout at all six diagnostic loci analyzed that usually distinguish rainbow from westslope cutthroat trout. At two of the seven diagnostic loci analyzed that usually distinguish westslope cutthroat trout from rainbow trout, one fish in the sample possessed a PINE fragments characteristic of westslope cutthroat trout. This fish, therefore, was almost certainly a later than first generation hybrid between rainbow and westslope cutthroat trout. Because of the small sample size, it is not possible for us to reliably determine whether or not the Meadow Lake population appears to be a hybrid swarm between westslope cutthroat and rainbow trout. Regardless of this statistical problem, the population clearly is not native westslope cutthroat trout and from a management perspective it should be considered to be hybridized with a predominant (98\%) rainbow trout genetic contribution.

\section{Wallace Creek 3280}


Individuals were collected from two locations in Wallace Creek: site $2(\mathrm{~N}=15)$ and site $4(\mathrm{~N}=11)$. There was no evidence of genetic differences between the fish collected from the two sites so they were combined into one for further analysis.

PINE fragments usually characteristic of rainbow trout were detected at one of the six diagnostic loci analyzed in the sample that distinguish rainbow from westslope cutthroat trout. The rainbow trout fragment was detected in only two fish (\#3 and 21) in the sample. Because of its low frequency (0.04), we can not ascertain from the available data whether the presence of this fragment more likely represents a small amount of hybridization with rainbow trout or is simply westslope cutthroat trout genetic variation that is electrophoretically indistinguishable from that characteristic of rainbow trout. With this uncertainty, the conservative approach would be to consider the Wallace Creek population to be non-hybridized westslope cutthroat trout unless further data indicate otherwise

\section{Dirty Ike Creek 3281}

Fish were collected from two locations in Dirty Ike Creek: site $1(\mathrm{~N}=14)$ and site $2(\mathrm{~N}=11)$. There was no evidence of genetic differences between the fish collected from the two sites so they were combined into one for further analysis.

PINE fragments characteristic of only westslope cutthroat trout were detected in the sample. With the sample size of 25 , we have a $95 \%$ chance of detecting as little as a one percent rainbow trout and an $87 \%$ chance of detecting as little as a one percent Yellowstone cutthroat trout genetic contribution to a hybrid swarm. The Dirty Ike Creek population, therefore, is very likely non-hybridized westslope cutthroat trout

\section{Donovan Creek 3282 (site 1) and 3292 (site 2)}

Fish were collected from two locations in Donovan Creek: site $1(\mathrm{~N}=15)$ and site $2(\mathrm{~N}=12)$. There were genetic differences between the fish collected from the two sites so they were treated separately for further analysis.

In site 1, PINE fragments usually characteristic of rainbow trout were detected at all six diagnostic loci analyzed in the sample that distinguish rainbow from westslope cutthroat trout. The rainbow trout fragments were not randomly distributed (Poisson distribution, $\mathrm{P}<0.001$ ) among the fish in the sample. Rather they were detected in only two fish. One of these fish (\#6) possessed PINE fragments characteristic of rainbow trout at all six diagnostic loci analyzed for this fish and possessed PINE fragments characteristic of westslope cutthroat trout at all seven diagnostic loci analyzed for this fish. This individual, therefore, appears to be a first generation hybrid between rainbow and westslope cutthroat trout. Another fish (\#13) possessed PINE fragments characteristic of rainbow trout at four of the six diagnostic loci for this fish that were analyzed and possessed PINE fragments characteristic of westslope cutthroat trout at all seven diagnostic loci analyzed for this fish. Thus, this fish definitely was a later than first generation hybrid between rainbow and westslope cutthroat trout. The other 13 fish in the sample possessed PINE fragments characteristic of only westslope cutthroat trout. Overall, the data suggest that when this reach of Donovan Creek was sampled it contained a mixture of non-hybridized westslope cutthroat trout and hybrids between rainbow and westslope cutthroat trout with a substantial rainbow trout genetic contribution. Because the hybrids have a high rainbow trout genetic contribution, in this situation on an individual basis they can reliably be distinguished from the non-hybridized westslope cutthroat trout. From a management perspective, therefore, this reach of Donovan Creek should be considered to contain a mixture of westslope cutthroat X 
rainbow trout hybrids and non-hybridized westslope cutthroat trout.

In site 2, PINE fragments usually characteristic of rainbow trout were detected at two of the six diagnostic loci that were analyzed in the sample that distinguish rainbow from westslope cutthroat trout. The rainbow trout fragments appeared to be randomly distributed (Poisson distribution, $\mathrm{P}>0.05$ ) among the fish in the sample. Thus, when this reach of Donovan Creek was sampled it appears to have possessed a hybrid swarm between westslope cutthroat and rainbow trout with a predominant $(97 \%)$ westslope cutthroat trout genetic contribution.

\section{Kendall Creek 3283}

Individuals were collected from two locations in Kendall Creek: site $1(\mathrm{~N}=15)$ and site $2(\mathrm{~N}=12)$. There was no evidence of genetic differences between the fish collected from the two sites so they were combined into one for further analysis.

PINE fragments usually characteristic of rainbow trout were detected at all six diagnostic loci analyzed in the sample that distinguish rainbow from westslope cutthroat trout. The rainbow trout fragments were not randomly distributed (Poisson distribution, $\mathrm{P}<0.001$ ) among the fish in the sample. In contrast, they were detected in only two fish. One of these (\#27) possessed PINE fragments characteristic of only rainbow trout suggesting it to be a non-hybridized rainbow trout. Another fish (\#1) possessed PINE fragments characteristic of rainbow trout at all six diagnostic loci analyzed for this fish and possessed PINE fragments characteristic of westslope cutthroat trout at all seven diagnostic loci analyzed for this fish. This individual, therefore, appears to be a first generation hybrid between rainbow and westslope cutthroat trout. The remaining 25 fish in the sample possessed PINE fragments characteristic of only westslope cutthroat trout suggesting them to be non-hybridized westslope cutthroat trout. When Kendall Creek was sampled, therefore, it appears to have contained a mixture of non-hybridized westslope cutthroat trout, non-hybridized rainbow trout, and first generation hybrids between these fishes.

\section{Tura Creek 3284}

Fish were collected from two locations in Tura Creek: site $1(\mathrm{~N}=10)$ and site $2(\mathrm{~N}=5)$. Unfortunately, only poor quality DNA was obtainable from the fish collected from site 1 so no data are available from this collection.

In the site 2 sample, PINE fragments characteristic of only westslope cutthroat trout were detected. With the sample size of five, we have only a $43 \%$ chance of detecting as little as a one percent rainbow trout and a $33 \%$ chance of detecting as little as a one percent Yellowstone cutthroat trout genetic contribution to a hybrid swarm. Thus, we can not reasonably exclude the possibility that the Tura Creek population may be slightly hybridized with rainbow trout, westslope cutthroat trout, or both of these fishes. Although the status of this population is uncertain, conservatively it should be considered to be non-hybridized westslope cutthroat trout unless further data indicate otherwise. 
PINE fragments characteristic of only westslope cutthroat trout were detected in the sample. A previous PINE analysis of fish collected from Straight Creek above the falls (sample \# 1961, $\mathrm{N}=18$ ) also detected fragments characteristic of only westslope cutthroat trout. With the combined sample size of 26 , we have a $96 \%$ chance of detecting as little as a one percent rainbow trout and an $88 \%$ chance of detecting as little as a one percent Yellowstone cutthroat trout genetic contribution to a hybrid swarm. Straight Creek above the falls, therefore, very likely contains a non-hybridized westslope cutthroat trout population.

\section{Crow Creek near mouth 3287}

PINE fragments characteristic of only westslope cutthroat trout were detected in the sample. With the sample size of 25 , we have a $95 \%$ chance of detecting as little as a one percent rainbow trout and an $87 \%$ chance of detecting as little as a one percent Yellowstone cutthroat trout genetic contribution to a hybrid swarm. Crow Creek, therefore, very likely contains a nonhybridized westslope cutthroat trout population.

\section{Maryann Creek 3288}

PINE fragments characteristic of only westslope cutthroat trout were detected in the sample. With the sample size of 25 , we have a $95 \%$ chance of detecting as little as a one percent rainbow trout and an $87 \%$ chance of detecting as little as a one percent Yellowstone cutthroat trout genetic contribution to a hybrid swarm. Maryann Creek, therefore, very likely contains a nonhybridized westslope cutthroat trout population.

\section{Lookout Creek 3289}

PINE fragments characteristic of only westslope cutthroat trout were detected in the sample. With the sample size of 25 , we have a $95 \%$ chance of detecting as little as a one percent rainbow trout and an $87 \%$ chance of detecting as little as a one percent Yellowstone cutthroat trout genetic contribution to a hybrid swarm. Lookout Creek, therefore, very likely contains a nonhybridized westslope cutthroat trout population.

\section{Rock Creek 3290}

PINE fragments characteristic of only westslope cutthroat trout were detected in the sample. With the sample size of 25 , we have a $95 \%$ chance of detecting as little as a one percent rainbow trout and an $87 \%$ chance of detecting as little as a one percent Yellowstone cutthroat trout genetic contribution to a hybrid swarm. Rock Creek, therefore, very likely contains a nonhybridized westslope cutthroat trout population.

\section{Robb Leary}

Ben Wright 


\section{TABLE 1}

Diagnostic PINE markers for westslope cutthroat, Yellowstone cutthroat, and rainbow trout. $\mathbf{X}$ indicates the fragment is present in the particular taxon.

\begin{tabular}{|c|c|c|c|}
\hline Markers & Yellowstone & Westslope & Rainbow \\
\hline \multicolumn{4}{|c|}{ Hpa1 5'/Hpa1 3' } \\
\hline 232 & $x$ & & \\
\hline 153 & & $x$ & \\
\hline 72 & $x$ & $x$ & \\
\hline 70 & & & $x$ \\
\hline 69 & $x$ & $\mathrm{x}$ & \\
\hline 66 & & & $x$ \\
\hline \multicolumn{4}{|c|}{ Fok1 5'/Tc1 } \\
\hline 369 & & & $\mathrm{x}$ \\
\hline 366 & $x$ & $x$ & \\
\hline 230 & & & $x$ \\
\hline 159 & $x$ & & \\
\hline 138 & $x$ & & \\
\hline 110 & & $x$ & \\
\hline \multicolumn{4}{|c|}{ Hpa1 5'/33.6+2 } \\
\hline 395 & & & $x$ \\
\hline 388 & $\mathrm{x}$ & $x$ & \\
\hline 266 & & & $x$ \\
\hline 248 & $x$ & & \\
\hline 148 & $x$ & $\mathrm{x}$ & \\
\hline
\end{tabular}




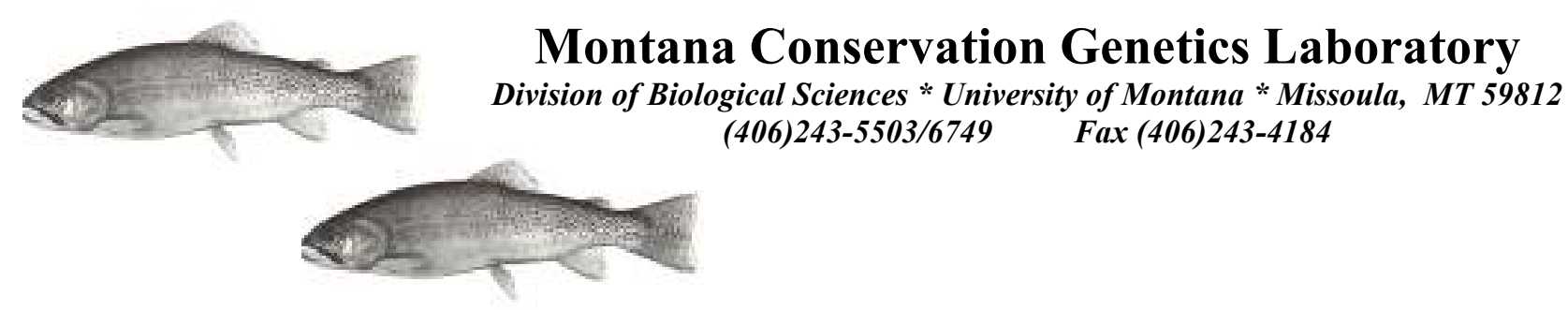

July 11, 2006

\section{Ron Pierce}

Genetics Contact, Region 2

Mt. Dept. of Fish, Wildlife, and Parks

3201 Spurgin Road

Missoula, MT 59801

Ron:

The paired interspersed nuclear DNA elements (PINE) technique has been used to analyze DNA from the following trout samples:

Summary of results.

$\begin{array}{ll}\begin{array}{c}\text { Sample \# } \\ \text { Individuals }\end{array} & \text { Water Name/Location/Collection Date/ } \\ & \text { Collector }\end{array}$

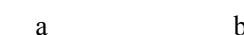

N \# markers

b c

Power (\%) ${ }^{d} \%$ WCT

R7Y4

RBTXWCT

10

3/22/2006

RBT?

10

Ron Pierce

${ }^{a}$ Number of fish successfully analyzed. If combined with a previous sample, the number in parentheses indicates the combined sample size

${ }^{\mathrm{b}}$ Number of markers analyzed that are diagnostic for the non-native species $(\mathrm{R}=$ rainbow trout, $\mathrm{W}=$ westslope cutthroat trout, $\mathrm{Y}=$ Yellowstone cutthroat trout).

${ }^{\mathrm{c}}$ Codes: $\mathrm{WCT}=$ westslope cutthroat trout (Oncorhynchus clarki lewisi); RBT = rainbow trout $($ O. mykiss); YCT = Yellowstone cutthroat trout $(O$. clarki bouvieri). Only one species code is listed when the entire sample possessed alleles from that species only. However, it must be noted that we cannot definitively rule out the possibility that some or all of the individuals are hybrids. We may not have detected any non-native alleles at the loci examined because of sampling error (see Power \%). Species codes separated by " $\mathrm{x}$ " indicate hybridization between those species.

${ }^{\mathrm{d}}$ Number corresponds to the percent chance we have to detect $1 \%$ hybridization given the number of individuals successfully analyzed and the number of diagnostic markers used. For example, 25 individuals are required to yield a $95 \%$ chance to detect as little as $1 \%$ hybridization with rainbow or an $87 \%$ chance to detect as little as $1 \%$ hybridization with Yellowstone cutthroat trout into what once was a westslope cutthroat trout population. Not reported when hybridization is detected.

${ }^{\mathrm{e}}$ Indicates the genetic contribution of the hybridizing taxa in the order listed under $\mathrm{c}$ to the sample assuming Hardy-Weinburg proportions. This number is reported if the sample appears to have come from a hybrid swarm. That is, a random mating population in which species markers are randomly distributed among individuals.

${ }^{\mathrm{f}}$ Indicates number of individuals with genetic characteristics corresponding to the species code column when the sample can be analyzed on the individual level. This occurs when marker alleles are not randomly distributed among individuals and hybridization appears to be recent and/or if the sample appears to consist of a mixture of populations and hybrids and non-hybrids can be reliably distinguished.

\section{Methods and Data Analysis}

The PINE technique uses short synthetically made segments of DNA called primers, in pairs, to search for relatively small segments of organismal DNA flanked by particular, often viral, DNA inserts. During the polymerase chain reaction (PCR), the primers bind to the ends of the inserts and 
many copies of the organismal DNA between the primers are made. While the DNA from some organisms may have two appropriately spaced inserts to which the primers can attach, the DNA from other organisms may have only one or none of the appropriately spaced inserts in particular regions. During PCR we will fail to copy DNA in the latter two cases. Thus, the PINE technique coupled with PCR is used to search for evidence of genetic variation based on the presence or absence of particular DNA fragments. The fragments are labeled by the primers used to produce them and their length in terms of the number of nucleotides in the fragment.

The fragments are made using dye labeled nucleotides and after PCR are separated from each other via electrophoresis in polyacrylamide gels. Smaller fragments move through the gels at a faster rate than larger fragments. The use of dye labeled nucleotides allows one to visualize the position of the fragments in the gels after electrophoresis using a spectrophotometer and the size of the fragments is determined by comparison to the position of synthetic fragments of known size that were also migrated into the gel.

When DNA from westslope cutthroat trout, Oncorhynchus clarki lewisi, and rainbow trout, $O$. mykiss, is compared with PINE analysis and three different pairs of primers seven fragments are usually characteristic of westslope cutthroat trout and seven fragments are usually characteristic of rainbow trout (Table 1). Likewise, when DNA from westslope and Yellowstone cutthroat trout, O. $c$. bouvieri, is compared using the same procedure two fragments are usually characteristic of westslope cutthroat trout and four fragments are usually characteristic of Yellowstone cutthroat trout (Table 1).

Fragments produced from the DNA of one taxon and not another are commonly termed diagnostic or marker loci because they can be used to help determine whether a sample came from a nonhybridized population of one of the taxa or a population in which hybridization between them has or is occurring. Individuals from a non-hybridized population will possess fragments characteristic of only that taxon. In contrast, since half the DNA of first generation hybrids comes from each of the parental taxa the DNA from such individuals will yield all the fragments characteristic of the two parental taxa. In later generation hybrids, the amount and particular regions of DNA acquired from the parental taxa will vary among individuals. Thus, DNA from later generation hybrid individuals will yield only a subset of the parental fragments and the particular subset will vary among individuals.

In a sample from a random mating hybrid swarm, that is a population in which the genetic material (i.e. fragments) of the parental taxa is randomly distributed among individuals such that essentially all of them are of hybrid origin, the frequency of the fragment producing allele from the non-native taxon is expected to be nearly equal among the diagnostic loci since their presence can all be traced to a common origin or origins. Thus, if a sample contains substantial variation at only a single marker locus where the presence of the fragment is usually characteristic of a non-native taxon and lacks such fragments at all other markers this is probably not indicative of hybridization. Rather, it much more likely represents the existence of genetic variation for the presence or absence of the fragment within this particular population of the native taxon.

An important aspect of PINE marker loci is that individuals homozygous for the presence allele ( $p p)$ or heterozygous $(p a)$ will both yield the fragment. That is, $p$ is dominant to $a$. Thus, in order to estimate the genetic contribution of the native taxon to a hybrid swarm we concentrate on the marker loci at which the $p$ allele is characteristic of the non-native taxon. Furthermore, we must assume that genotypic distributions in the population reasonably conform to expected random mating proportions. Under this assumption the frequency of the native $a$ allele is approximately the square root of the frequency of individuals in the population lacking the fragment $(a a)$. The frequency of the non-native allele then is one minus this value. We focus on the $p$ alleles characteristic of the nonnative taxon because with low levels of hybridization it is the presence of these alleles that are likely to provide evidence of hybridization. With low levels of hybridization, it is likely all individuals in 
the sample will genotypically be $p p$ or $p a$ where the $p$ allele is characteristic of the native taxon. Thus, like in non-hybridized populations all individuals in the sample will yield the fragment providing no evidence of hybridization.

Failure to detect evidence of hybridization in a sample does not necessarily mean the population is non-hybridized because there is always the possibility that we would not detect evidence of hybridization because of sampling error. In order to assess the likelihood the population is nonhybridized, we determine the chances of not detecting as little as a one percent genetic contribution of a non-native taxon to a hybrid swarm. This is simply $0.99^{2 \mathrm{NX}}$ where $\mathrm{N}$ is the number of fish in the sample and $\mathrm{X}$ is the number of marker loci where the $p$ allele is characteristic of the non-native taxon.

In samples showing evidence of hybridization, that is; fragments characteristic of a non-native taxon were detected at two or more marker loci, we used two approaches to determine if the population appeared to be a hybrid swarm. First, contingency table chi-square analysis was used to test for heterogeneity of allele frequencies among the marker loci. Next, we computed a hybrid index for each individual in the sample. Each diagnostic locus at which an individual possessed a PINE fragment characteristic of the non-native taxon was given a value of one. Each diagnostic locus at which an individual did not possess a PINE fragment characteristic of the non-native taxon was given a value of zero. These values summed over all diagnostic loci represent an individual's hybrid index. The observed distribution of hybrid index scores was then statistically compared to the expected random binomial distribution based on the estimated native and non-native genetic contributions to the sample. If the allele frequencies were statistically homogeneous among the diagnostic loci and the observed distribution of hybrid indices statistically conformed to the expected random binomial distribution, then the sample was considered to have come from a hybrid swarm.

Heterogeneity of allele frequencies among marker loci can arise in very old hybrid swarms as the frequencies over time diverge from each other due to genetic drift. In this case, however, the nonnative fragments will still be randomly distributed among individuals. Thus, samples with these characteristics were also considered to have come from hybrid swarms.

There are two likely reasons why a non-random distribution of non-native fragments may be observed among individuals in a sample. It may contain individuals from genetically divergent populations with different amounts of hybridization or hybridization may have only recently occurred in the population. Based on PINE data alone, these two situations will generally be difficult to distinguish from each other. Regardless of the explanation, when the non-native fragments are not randomly distributed among individuals in a sample estimating a mean level of hybridization has little, if any, biological meaning and, therefore, is often not estimated.

\section{Results and Discussion:}

\section{Blackfoot River 3299}

All of the fish in the sample contained PINE fragments usually characteristic of rainbow trout at six or seven of the diagnostic loci analyzed that distinguish rainbow from westslope cutthroat trout. PINE fragments usually characteristic of westslope cutthroat trout were also detected at two of the seven diagnostic loci analyzed that distinguish westslope cutthroat from rainbow trout. The frequencies of the westslope cutthroat trout PINE fragments were statistically heterogeneous $\left(X_{6}^{2}=32.925, \mathrm{P}<0.001\right)$ among the diagnostic loci and, they were not randomly distributed (Poisson distribution, $X_{I}^{2}=288.478, \mathrm{P}<0.001$ ) among the fish in the sample. In contrast, significantly fewer individuals possessed no PINE fragments characteristic of westslope 
cutthroat trout and significantly more possessed PINE fragments characteristic of westslope cutthroat trout at one or two loci than expected by chance (Fig. 1). Overall, these results suggest that the sample contained individuals from two or more genetically different populations.

On an individual basis, ten fish in the sample (\#'s 1751, 1752, 1754, 1755, 1757, 1858, $1862,1863,1967$, and 1969) possessed PINE fragments characteristic of both rainbow and westslope cutthroat trout definitely indicating that they were post first generation hybrids between these fishes with a predominant rainbow trout genetic contribution. The remaining ten fish in the sample possessed PINE fragments characteristic of only rainbow trout suggesting that they may be non-hybridized rainbow trout. We cannot exclude the possibility, however, that some or all of these latter individuals may be slightly hybridized with westslope cutthroat trout but, evidence of this was not detected because of sampling error.

Robb Leary

John Powell 
Table 1: Diagnostic PINE markers for westslope cutthroat, Yellowstone cutthroat, and rainbow trout. $\mathbf{X}$ indicates the fragment is present in the particular taxon.

Markers Yellowstone Westslope Rainbow Hpa1 5'/Hpa1 3'

$232 \quad \mathrm{x}$

153

$\mathrm{X}$

110.5

72

70

$69 \quad \mathrm{x}$

$\mathrm{X}$

66

Fok1 5'/Tc1

X

230

159

138

110

X

\section{X}

X

$\mathrm{X}$

$\mathrm{X}$

X

\begin{tabular}{rrrr}
159 & $\mathrm{X}$ & & \\
138 & $\mathrm{X}$ & $\mathrm{X}$ & \\
110 & & & \\
\hline Hpa1 $55^{\prime} / 33.6+2$ & & & \\
\hline 395 & & $\mathrm{X}$ & \\
388 & $\mathrm{X}$ & & $\mathrm{X}$ \\
266 & & & \\
248 & $\mathrm{X}$ & $\mathrm{X}$ & \\
148 & $\mathrm{X}$ & &
\end{tabular}




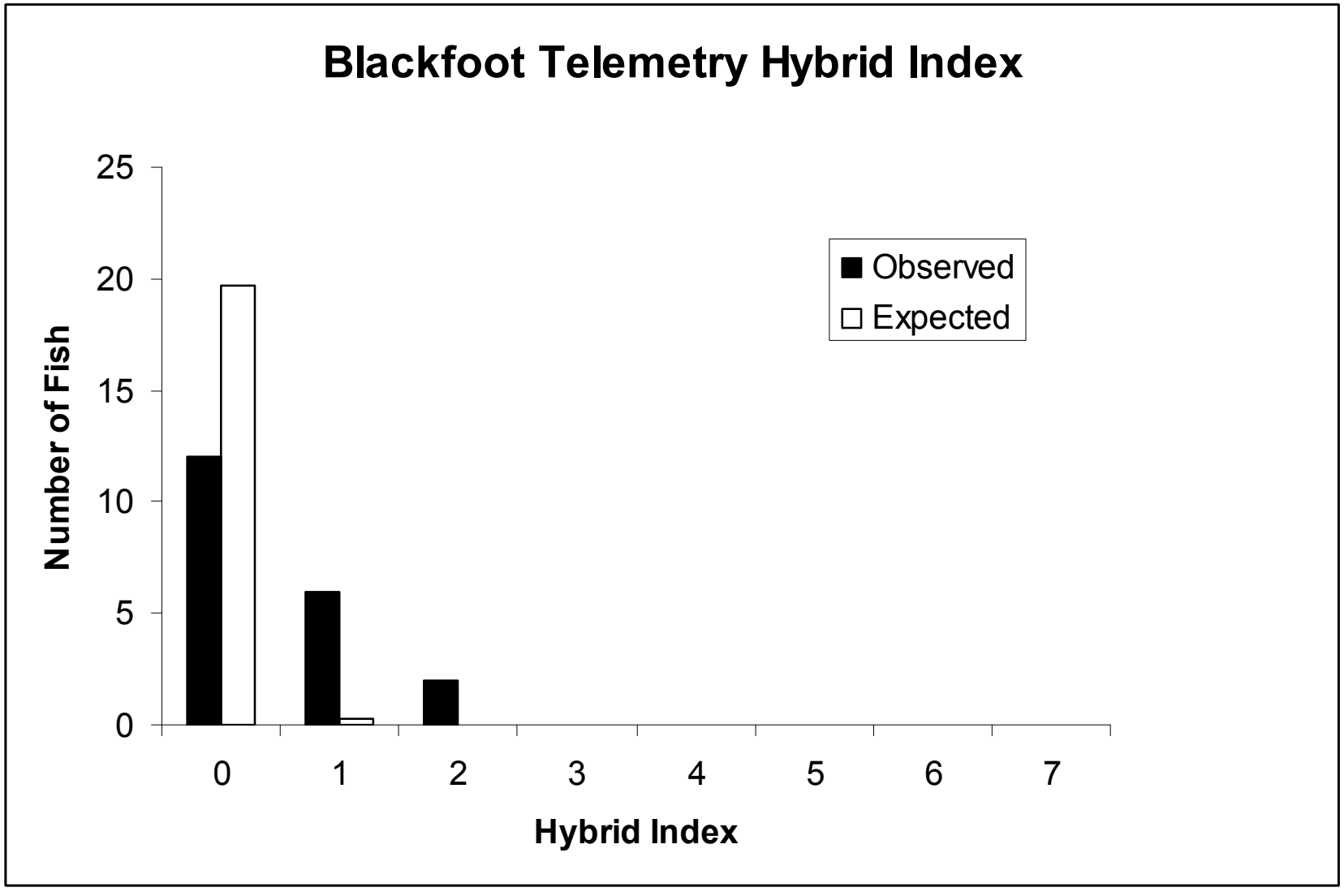

Figure 1. Number of diagnostic loci at which fish collected from the Blackfoot River and implanted with radio telemeters possessed PINE fragments characteristic of westslope cutthroat trout (hybrid index). Observed is the observed number of fish and expected is the expected number of fish if the westslope cutthroat trout PINE fragments were randomly distributed among the individuals in the sample. 


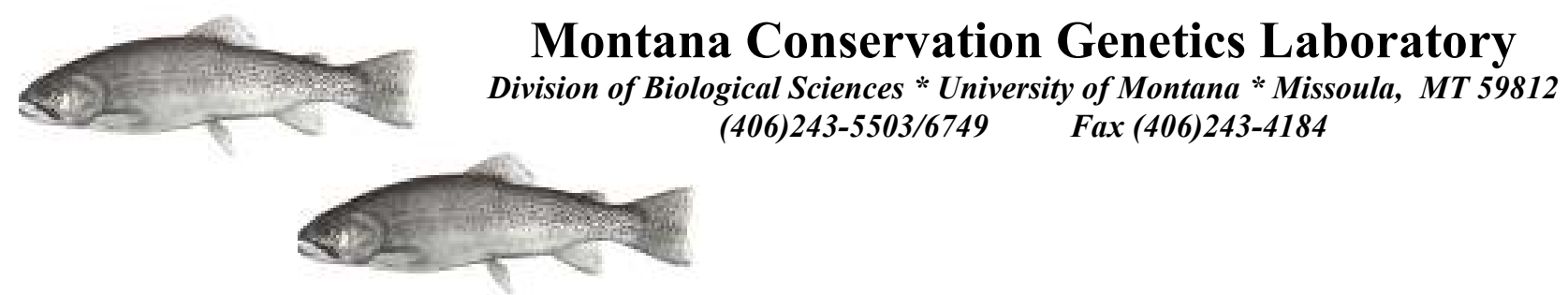

April 21, 2007

Ladd Knotek

Genetics Contact, Region 2

Montana Fish, Wildlife, \& Parks

3201 Spurgin Road

Missoula, Montana 59801

Ladd:

In order to determine if there is evidence of hybridization, we used a combination of insertion/deletion events (indel loci) and microsatellite loci to analyze DNA extracted from fin clips taken from trout sampled from the following populations:

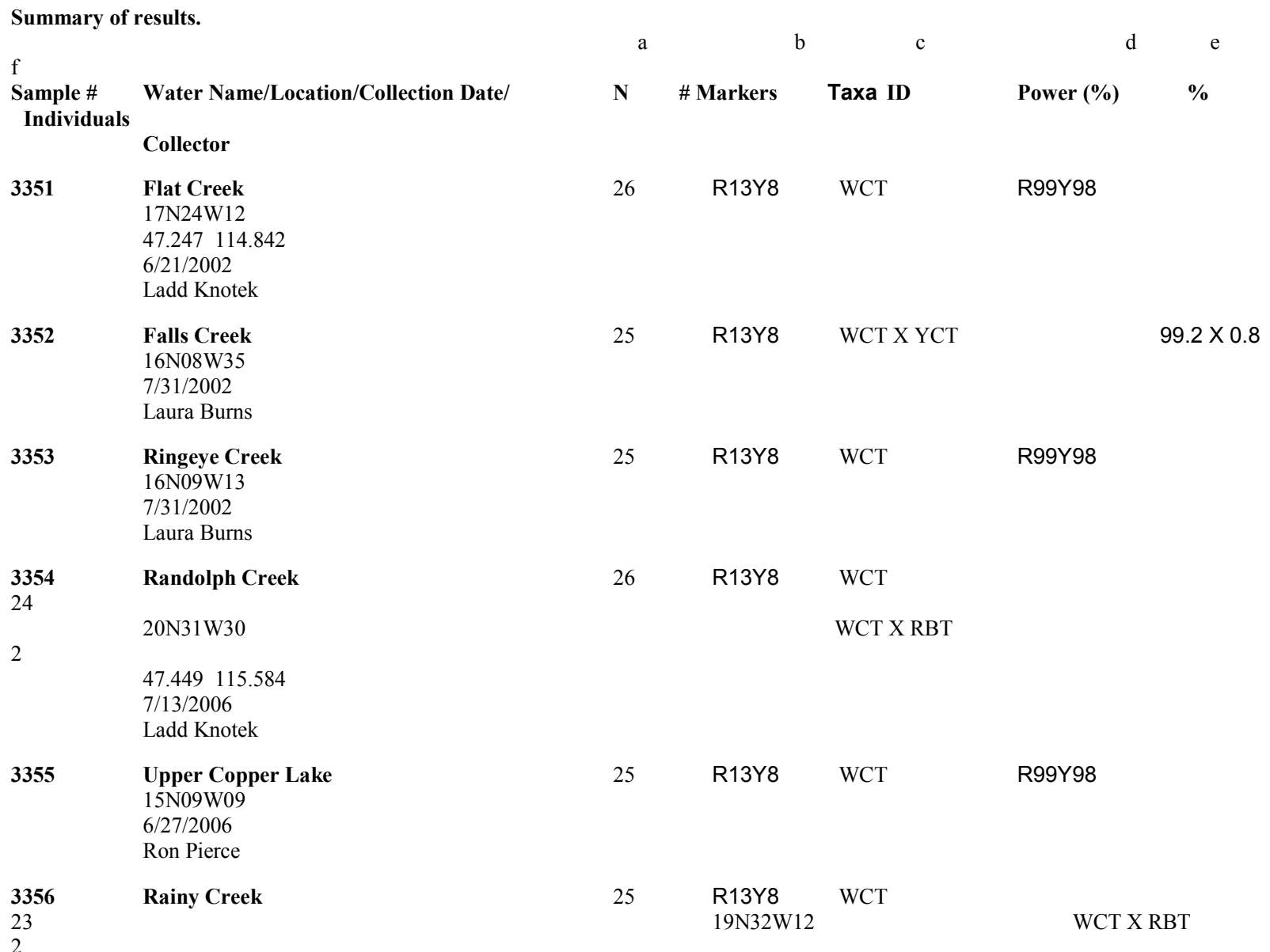




\begin{tabular}{|c|c|c|c|c|c|c|}
\hline & $\begin{array}{l}\text { 8/16/2002 } \\
\text { Ladd Knotek }\end{array}$ & & & & & \\
\hline 3357 & $\begin{array}{l}\text { East Fork Twin Creek } \\
19 \mathrm{~N} 29 \mathrm{~W} 18 \\
8 / 22 / 2002 \\
\text { Ladd Knotek }\end{array}$ & 26 & R13Y8 & WCT & R99Y98 & \\
\hline f & & $\mathrm{a}$ & & $\mathrm{b}$ & & $\mathrm{e}$ \\
\hline $\begin{array}{l}\text { Sample \# } \\
\text { Individuals }\end{array}$ & $\begin{array}{l}\text { Water Name/Location/Collection Date/ } \\
\text { Collector }\end{array}$ & $\mathbf{N}$ & \# Markers & Taxa ID & Power (\%) & $\%$ \\
\hline $\begin{array}{c}\mathbf{3 3 8 0} \\
14\end{array}$ & East Fork Big Creek & 16 & R6Y4 & WCT & & \\
\hline 2 & $\begin{array}{l}\text { 18N30W09 } \\
8 / 15 / 2002 \\
\text { Ladd Knotek }\end{array}$ & & & WCT X RBT & & \\
\hline $\begin{array}{c}3375 \\
12\end{array}$ & Middle Fork Big Creek & 16 & R6Y4 & WCT & & \\
\hline 2 & $\begin{array}{l}18 \text { N30W13 } \\
8 / 15 / 2002 \\
\text { Ladd Knotek }\end{array}$ & & & WCT X RBT & & \\
\hline 3359 & $\begin{array}{l}\text { Dominion Creek } \\
\text { 19N31W19 } \\
7 / 13 / 2006 \\
\text { Ladd Knotek }\end{array}$ & 12 & R13Y8 & WCT X RBT & & \\
\hline 3360 & $\begin{array}{l}\text { East Fork North Fork Blackfoot River } \\
\text { 16N09W07 } \\
47.164112 .795 \\
7 / 11 / 2006 \\
\text { Ron Pierce }\end{array}$ & 5 & R13Y8 & WCT X YCT X RBT & & \\
\hline 3361 & $\begin{array}{l}\text { Sourdough Creek } \\
\text { 16N09W17 } \\
47.147112 .756 \\
7 / 12 / 2006 \\
\text { Ron Pierce }\end{array}$ & 3 & $\mathrm{R} 13 \mathrm{Y} 8$ & WCT X YCT X RBT & & \\
\hline 3362 & $\begin{array}{l}\text { Scotty Creek } \\
16 \text { N09W08 } \\
47.155112 .757 \\
7 / 12 / 2006 \\
\text { Ron Pierce }\end{array}$ & 5 & R13Y8 & WCT X YCT X RBT & & \\
\hline 3363 & $\begin{array}{l}\text { Lost Pony Creek } \\
\text { 16N10W01 } \\
47.173112 .796 \\
7 / 11 / 2006 \\
\text { Ron Pierce }\end{array}$ & 5 & $\mathrm{R} 13 \mathrm{Y} 8$ & RBT X YCT X WCT & & $83.9 \times 10.0 \times 6.1$ \\
\hline 3364 & $\begin{array}{l}\text { Rye Creek } \\
03 \mathrm{~N} 20 \mathrm{~W} 25 \\
8 / 10 / 2006 \\
\text { Chris Clancy }\end{array}$ & 28 & R13Y8 & WCT? & R99Y99 & \\
\hline $\begin{array}{l}3365 \\
1.8\end{array}$ & $\begin{array}{l}\text { East Fork Clearwater River } \\
\text { 19N15W32NE1/4 } \\
\text { 9/12/2002 } \\
\text { Ladd Knotek }\end{array}$ & 26 & R13Y8 & WCT X YCT X RBT & & $96.7 \times 1.5 \times$ \\
\hline 3366 & $\begin{array}{l}\text { Clearwater River (above Rainy Lake) } \\
\text { 19N16W01NW1/4 } \\
\text { 7/19/2006 } \\
\text { Ladd Knotek }\end{array}$ & 25 & R13Y8 & WCT X RBT & & $99.4 \times 0.6$ \\
\hline 3367 & $\begin{array}{l}\text { Bertha Creek } \\
\text { 19N16W28NW1/4 } \\
7 / 19 / 2006 \\
\text { Ladd Knotek }\end{array}$ & 8 & R13Y8 & WCT? & R88Y72 & \\
\hline
\end{tabular}


46.999113 .84

$8 / 9 / 2006$

Ladd Knotek

f Sample \# Water Name/Location/Collection Date/ Individuals

Collector

$3369 \quad$ Morrell Creek (upper)

17N15W01NE1/4

9/11/2002

Ladd Knotek

337

Morrell Creek (middle)

17N15W24NE1/4

$8 / 8 / 2006$

Ladd Knotek

$3381 \quad$ Morrell Creek (lower)

$17 \mathrm{~N} 15 \mathrm{~W} 25 \mathrm{SW} 1 / 4$

$8 / 8 / 2006$

Ladd Knotek

3371+3382 Savenac Creek

$19 \mathrm{~N} 29 \mathrm{~W} 10+20 \mathrm{~N} 29 \mathrm{~W} 26$

$8 / 28 / 2002+7 / 31 / 06$

Ladd Knotek

Monture Creek below falls (lower)

17N12W32

2

47.18113 .16

$8 / 22 / 2006$

Ron Pierce

3374 Monture Creek below falls (upper)

47.236113 .156

$8 / 21 / 2006$

Ron Pierce

$3383 \quad$ Monture Creek above falls

$18 \mathrm{~N} 13 \mathrm{~W} 25$

47.28113 .20

$8 / 23 / 06$

Ron Pierce

3384 East Fork Monture Creek

17N12W08

$47.245 \quad 113.158$

$8 / 21 / 2006$

Ron Pierce

$3385 \quad$ Middle Fork Monture Creek

$18 \mathrm{~N} 12 \mathrm{~W} 31$

47.277113 .181

$8 / 23 / 2006$

Ron Pierce

$3376 \quad$ Windlass Gulch

7/27/2006

Dave Schmetterling

$3377 \quad$ Scotchman Gulch

8/7/2006

Dave Schmetterling

$3378 \quad$ Sluice Gulch

8/2/2006

Dave Schmetterling

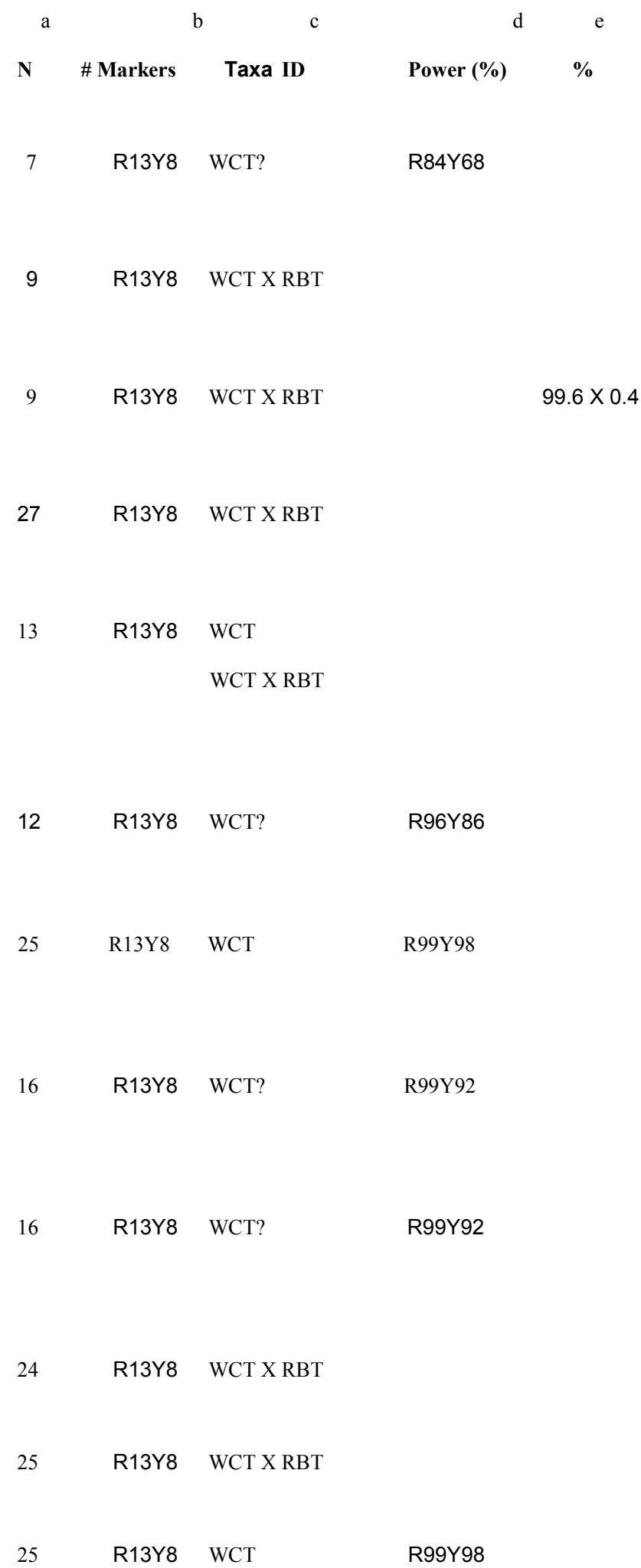

R13Y8 WCT?

R99Y92

16

R13Y8 WCT?

R99Y92

24

R13Y8 WCT X RBT

25

R13Y8 WCT X RBT

25

R13Y8 WCT

R99Y98 


\begin{abstract}
${ }^{a}$ Number of fish successfully analyzed. If combined with a previous sample, the number in parentheses indicates the combined sample size.

${ }^{\mathrm{b}}$ Number of diagnostic loci analyzed for the non-native taxa ( $\mathrm{R}=$ rainbow trout Oncorhynchus mykiss, $\mathrm{W}=$ westslope cutthroat trout

O. clarki lewisii, Y=Yellowstone cutthroat trout O. c. bouvieri).

${ }^{\mathrm{c}}$ Codes: $\mathrm{WCT}=$ westslope cutthroat trout; RBT = rainbow trout; YCT = Yellowstone cutthroat trout . Only one taxon code is listed when the entire sample possessed alleles from that taxon only. It must be noted, however, that we cannot definitively rule out the possibility that some or all of the individuals are hybrids. We may not have detected any non-native alleles at the loci examined because of sampling error (see Power \%). Taxa codes separated by "x" indicate hybridization between those taxa. ${ }^{d}$ Number corresponds to the percent chance we have to detect $1 \%$ hybridization given the number of individuals successfully analyzed and the number of diagnostic markers used. For example, with 25 individuals we have better than a $99 \%$ chance to detect as little as $1 \%$ hybridization with rainbow trout or a $98 \%$ chance to detect as little as $1 \%$ hybridization with Yellowstone cutthroat trout in a hybrid swarm (a random mating population in which taxa markers are randomly distributed among individuals such that essentially all of them in the population are of hybrid origin) that once was a westslope cutthroat trout population. Likewise, with 25 individuals we have better than a $99 \%$ chance to detect as little as a $1 \%$ rainbow trout genetic contribution in a hybrid swarm that once was a Yellowstone cutthroat trout population. Not reported when hybridization is detected. Taxa as in b.

${ }^{\mathrm{e}}$ Indicates the genetic contribution of the hybridizing taxa in the order listed under c. This number is usually reported only if the sample appears to have come from a hybrid swarm.

${ }^{\mathrm{f}}$ Indicates number of individuals with genetic characteristics corresponding to the taxa ID code column when the sample can be analyzed at the individual level. This occurs when marker alleles are not randomly distributed among individuals and hybrids and non-hybrids can be reliably distinguished.
\end{abstract}

\title{
Methods and Data Analysis
}

The indel technique (Ostberg and Rodriguez 2004) uses short synthetically made segments of DNA called primers, in pairs, to detect areas of DNA in trout that have undergone insertion or deletion (indel) events. During the polymerase chain reaction (PCR), the primers bind to specific areas of the organismal DNA and many copies of the DNA between the primers are made using dye labeled nucleotides. The indel events have resulted in length differences (alleles) in the region of DNA copied between the primers that characterize different trout taxa. These differences have been found to be useful for analysis of hybridization (e.g. Ostberg et al. 2004; Ostberg and Rodriguez 2006). After PCR, the alleles are separated from each other using capillary electrophoresis and visualized using an applied Biosystems 3130x1 genetic analyzer. The alleles are labeled by the primers used to produce them and the number of nucleotides in the sequence. After electrophoresis, the alleles detected in an individual are determined by comparison to synthetic fragments of DNA of known length and alleles from previously analyzed individuals.

Microsatellite loci are segments of DNA in which small nucleotide sequences (usually two to five nucleotides) are consecutively repeated numerous times. By using PCR amplification methods similar to those used for indel loci, specific microsatellite loci can be analyzed for differences in the number of repeat units. These differences result in size differences among alleles which are detected using the procedure used to detect indel alleles.

We obtained data from seven indel loci and seven microsatellite loci. At 13 of these loci, westslope cutthroat trout, Oncorhynchus clarki lewisii, and rainbow trout, O. mykiss, rarely, if ever, share alleles in common (Table 1). This situation also pertains to a comparison of westslope and Yellowstone cutthroat trout, O. c. bouvieri, at eight loci and Yellowstone cutthroat and rainbow trout at 14 loci (Table 1). Finally, seven loci usually distinguish all three taxa from each other (Table 1).

Loci at which taxa rarely, if ever, share alleles in common are often termed diagnostic or marker loci because the alleles detected at them can be used to help determine if a sample came from a nonhybridized population or a population in which hybridization between two or more taxa has or is 
occurring. Individuals from a non-hybridized population will possess alleles at all diagnostic loci analyzed characteristic of only that taxon. In contrast, since half the DNA from first generation hybrids $\left(\mathrm{F}_{1}\right)$ comes from each of the parental taxa $\mathrm{F}_{1}$ individuals will possess alleles characteristic of both the hybridizing taxa at all diagnostic loci analyzed. In later generation hybrids (post $F_{1}$ ), the amount and particular regions of DNA acquired from the parental taxa will vary among individuals. Thus, the particular alleles detected in post $\mathrm{F}_{1}$ hybrids will be highly variable at the diagnostic loci analyzed within and among individuals.

An important aspect of both indel and microsatellite alleles is that they demonstrate a codominant mode of inheritance. That is, all genotypes are readily distinguishable from each other. Thus, at diagnostic loci the genotype of individuals in a sample can directly be determined. From these data, the proportion of alleles from different taxa in the population sampled can be directly estimated at each diagnostic locus analyzed. These values averaged over all diagnostic loci yields an estimate of the proportion of alleles in the population that can be attributed to one or more taxa (proportion of admixture).

When evidence of hybridization is detected, the first issue to address is whether or not the sample appears to have come from a hybrid swarm. That is, a random mating population in which the alleles of the hybridizing taxa are randomly distributed among individuals such that essentially all of them are of hybrid origin.

A common attribute of hybrid swarms is that allele frequencies at diagnostic loci are usually similar among them because their presence can all be traced to a common origin or origins. Thus, one criterion we used for the assessment of whether or not a sample appeared to have come from a hybrid swarm was whether or not the allele frequencies among diagnostic loci reasonably conformed to homogeneity using contingency table chi-square.

In order to determine whether or not alleles at the diagnostic loci were randomly distributed among the fish in a sample showing evidence of hybridization, we calculated a hybrid index for each fish in the sample. The hybrid index for an individual was calculated as follows. At each diagnostic locus, an allele characteristic of the native taxon was given a value of zero and an allele characteristic of the non-native taxon a value of one. Thus, at a single diagnostic locus the hybrid index for an individual could have a value of zero (only native alleles present), one (both native and non-native alleles present), or two (only non-native alleles present). These values summed over all diagnostic loci analyzed yields an individual's hybrid index. Considering westslope cutthroat and rainbow trout, therefore, non-hybridized westslope cutthroat trout would have a hybrid index of zero, nonhybridized rainbow trout a hybrid index of $26, \mathrm{~F}_{1}$ hybrids a hybrid index of 13 , and post $\mathrm{F}_{1}$ hybrids could have values ranging from zero to 26 . The distribution of hybrid indices among fish in a sample was statistically compared to the expected random binomial distribution based on the proportion of admixture detected estimated from the allele frequencies at the diagnostic loci. If the allele frequencies appeared to be statistically homogeneous among diagnostic loci and the observed distribution of hybrid indices reasonably conformed to the expected random distribution, then the sample was considered to have come from a hybrid swarm.

In very old hybrid swarms, allele frequencies at diagnostic loci can randomly diverge from homogeneity over time because of genetic drift. In this case, however, the observed distribution of hybrid indices is still expected to reasonably conform to the expected random distribution. Thus, if the allele frequencies were statistically heterogeneous among the diagnostic loci in a sample, but the observed distribution of hybrid indices reasonably conformed to the expected random distribution the sample was also considered to have come from a hybrid swarm.

The strongest evidence that a sample showing evidence of hybridization did not come from a hybrid swarm is failure of the observed distribution of hybrid indices to reasonably conform to the expected 
random distribution. The most likely reasons for this are that the population has only recently become hybridized or the sample contains individuals from two or more populations with different proportions of admixture. At times, the distribution of genotypes at diagnostic loci and the observed distribution of hybrid indices can provide insight into which of these two factors appears mainly responsible for the non-random distribution of the alleles from the hybridizing taxa among individuals in the population. At other times, the distribution of genotypes at diagnostic loci and the observed distribution of hybrid indices may provide little or no insight into the cause of the nonrandom distribution of alleles among individuals. The latter situation is expected to be fairly common as the two factors usually responsible for the non-random distribution of alleles are not necessarily mutually exclusive. Regardless of the cause, when alleles at the diagnostic loci do not appear to be randomly distributed among individuals in a sample, estimating the proportion of admixture has little if any biological meaning and, therefore, is generally not estimated and reported.

Failure to detect evidence of hybridization in a sample does not necessarily mean the population is non-hybridized because there is always the possibility that we would not detect evidence of hybridization because of sampling error. When no evidence of hybridization was detected in a sample, we assessed the likelihood the population is non-hybridized by determining the chances of not detecting as little as a one percent genetic contribution of a non-native taxon to a hybrid swarm. This is simply $0.99^{2 \mathrm{NX}}$ where $\mathrm{N}$ is the number of fish in the sample and $\mathrm{X}$ is the number of diagnostic loci analyzed.

\section{Results and Discussion:}

\section{Flat Creek 3351}

Alleles characteristic of only westslope cutthroat trout were detected at all the loci analyzed in the sample from Flat Creek (Table 2). With the sample size of 26, we have better than a $99 \%$ chance of detecting as little as a one percent rainbow trout and better than a $98 \%$ chance of detecting as little as a one percent Yellowstone cutthroat trout genetic contribution to a hybrid swarm with westslope cutthroat trout. The Flat Creek population, therefore, strongly appears to be non-hybridized westslope cutthroat trout.

\section{Falls Creek 3352}

Alleles characteristic of both westslope and Yellowstone cutthroat trout were detected at two of the eight diagnostic loci between these fishes that were analyzed in the sample from Falls Creek (Table 3). The allele frequencies were statistically homogeneous among the diagnostic loci $\left(X^{2}{ }_{T}=10.201 ; \mathrm{P}>0.10\right)$ and the Yellowstone cutthroat trout alleles appeared to be randomly distributed $\left(X_{1}^{2}=0.180 ; \mathrm{P}>0.50\right)$ among the individuals in the sample. Thus, unlike a previous allozyme analysis (sample \#492, collected 7/1/91, $\mathrm{N}=10$ ) that provided no evidence of hybridization in the Falls Creek population this sample clearly indicates the population to be a hybrid swarm between westslope and Yellowstone cutthroat trout with a predominant (0.992) westslope cutthroat trout genetic contribution. We feel the discrepancy between the two samples more likely reflects sampling error rather than the situation in which the Falls Creek population has only recently become hybridized because with only ten fish in the first sample there is about a $15 \%$ chance we would not detect a one percent Yellowstone cutthroat trout genetic contribution to a hybrid swarm.

\section{Ringeye Creek 3353}

Alleles characteristic of only westslope cutthroat trout were detected at all the loci analyzed in the sample from Ringeye Creek (Table 2). With a sample size of 25, we have better than a 99\% chance of detecting as little as a one percent rainbow trout and a $98 \%$ chance of detecting as little as a one percent 
Yellowstone cutthroat trout genetic contribution to a hybrid swarm with westslope cutthroat trout. The Ringeye Creek sample, therefore, strongly appears to have come from a non-hybridized westslope cutthroat trout population.

\section{Randolph Creek 3354}

Alleles characteristic of both westslope cutthroat and rainbow trout were detected at five of the 13 diagnostic loci between these fishes that were analyzed in the Randolph Creek sample (Table 4). Although the allele frequencies are statistically homogeneous $\left(X^{2}{ }_{12}=11.454 ; \mathrm{P}>0.10\right)$ among the diagnostic loci, the rainbow trout alleles do not appear to be randomly distributed $\left(X^{2}=21.820 ; \mathrm{P}<0.001\right)$ among the fish in the sample. Rather, there are significantly more fish with a hybrid index of zero or greater than one than expected by chance (Figure 1). Furthermore, the hybrid indices in the sample divide the fish into discrete categories with individuals having a hybrid index of zero or greater than one. The Randolph Creek sample, therefore, appears to have contained a mixture of non-hybridized westslope cutthroat trout and hybrids between westslope cutthroat and rainbow trout with a predominant westslope cutthroat trout genetic contribution.

\section{Upper Copper Lake 3355}

Alleles characteristic of only westslope cutthroat trout were detected at all the loci analyzed in the sample from Upper Copper Lake (Table 2). With a sample size of 25 , we have better than a $99 \%$ chance of detecting as little as a one percent rainbow trout and a 98\% chance of detecting as little as a one percent Yellowstone cutthroat trout genetic contribution to a hybrid swarm with westslope cutthroat trout. The Upper Copper Lake population, therefore, very likely is non-hybridized westslope cutthroat trout.

\section{Rainy Creek 3356}

Alleles characteristic of both westslope cutthroat and rainbow trout were detected at seven of the 13 diagnostic loci between these fishes that were analyzed in the sample from Rainy Creek (Table 4). Although the allele frequencies are statistically homogeneous $\left(X_{12}^{2}=6.048 ; \mathrm{P}>0.50\right)$ among the diagnostic loci in the sample, the rainbow trout alleles are not randomly distributed $\left(X^{2}{ }_{2}=59.548 ; \mathrm{P}<0.001\right)$ among the fish in the sample. In contrast, there are significantly more individuals with a hybrid index of zero or greater than two and significantly fewer with a hybrid index of one than expected by chance (Figure 2). Furthermore, the hybrid indices divide the fish in the sample into two distinct groups one of which appears to be non-hybridized westslope cutthroat trout and the other definitely hybrids between westslope cutthroat and rainbow trout. This sample, therefore, appears to have been a mixture of non-hybridized westslope cutthroat trout and hybrids.

At $O m y 1001^{*}$, we detected a single copy of the 266 allele in the sample which is usually characteristic of Yellowstone cutthroat trout (Table 1). This could indicate a small amount of hybridization with Yellowstone cutthroat trout or it could simply be westslope cutthroat trout genetic variation that is indistinguishable from that usually characteristic of Yellowstone cutthroat trout. Because of the very low frequency of $O m y 1001 * 266$, we cannot reasonably begin to distinguish between these possibilities but, there is a reasonable chance this allele is simply westslope cutthroat trout genetic variation as we have previously detected it in some non-hybridized westslope cutthroat trout populations (Table1). Regardless of whether or not the presence of Omy1001*266 represents evidence of hybridization with Yellowstone cutthroat trout, the sample clearly contained hybrids between westslope cutthroat and rainbow trout and Rainy Creek should be considered to contain a mixture of non-hybridized westslope cutthroat trout and hybrids. 


\section{East Fork Twin Creek 3357}

Alleles characteristic of only westslope cutthroat trout were detected at all the loci analyzed in the sample from the East Fork of Twin Creek (Table 2). With a sample size of 26 , we have better than a $99 \%$ chance of detecting as little as a one percent rainbow trout and better than a $98 \%$ chance of detecting as little as a one percent Yellowstone cutthroat trout

genetic contribution to a hybrid swarm with westslope cutthroat trout. The East Fork of Twin Creek sample, therefore, very likely came from a non-hybridized westslope cutthroat trout population.

\section{Big Creek Drainage}

Samples were collected from the Big Creek drainage from two locations in the East Fork and two locations in the Middle Fork. Thus, the first issue to address is whether there is any evidence of genetic differences between the two samples collected from the same stream. If so, then it would not be appropriate to combine the samples from the same stream into one for further analysis.

In the two East Fork Big Creek samples, evidence of genetic variation was detected at all 14 loci analyzed (data not presented). Contingency table chi-square analysis indicates that the allele frequencies are statistically heterogeneous $(\mathrm{P}<0.05)$ between the samples at two of these loci. This could indicate that genetic differences exist between the samples or these significant differences could represent chance departures from homogeneity due to the number of comparisons performed. In order to distinguish between these possibilities, we compared the chi-square statistic at the two loci showing significant differences to the modified level of significance proposed by Rice (1989). These differences are not significant at the modified level suggesting they most likely represent chance departures from homogeneity. Thus, there is no compelling evidence of genetic differences between the two East Fork Big Creek samples. The two samples, therefore, were combined into one for subsequent analysis.

Evidence of genetic variation was detected at 13 of the 14 loci analyzed in the two Middle Fork Big Creek samples (data not presented). The allele frequencies were statistically heterogeneous at three of these loci. These differences, however, are not significant at the modified level suggesting they most likely represent chance departures from homogeneity rather than true genetic differences between the samples. Thus, the two Middle Fork Big Creek samples were combined into one for further analysis.

When the East and Middle Fork Big Creek samples are compared, the allele frequencies are statistically heterogeneous between them at one of the 14 loci analyzed. This difference remains significant at the modified level indicating that genetic differences exist between the fish in the East and Middle Fork of Big Creek. These samples, therefore, were treated separately in subsequent analyses.

\section{East Fork Big Creek 3380}

Alleles characteristic of both westslope cutthroat and rainbow trout were detected at all 13 of the diagnostic loci between these fishes that were analyzed in the East Fork Big Creek sample (Table 4). Although the allele frequencies are statistically homogeneous $\left(X^{2}{ }_{12}=7.515 ; \mathrm{P}>0.50\right)$ among the diagnostic loci, the rainbow trout alleles are not randomly distributed $\left(X^{2}=379.188 ; \mathrm{P}<0.001\right)$ among the fish in the sample. In contrast, there were significantly more individuals in the sample with a hybrid index of zero or greater than seven and significantly fewer individuals with a hybrid index of one through six than expected by chance (Figure 3). The hybrid indices also divide the individuals into two distinct categories one of which appears to be non-hybridized westslope cutthroat trout and the other hybrids between westslope cutthroat and rainbow trout. The East Fork Big Creek sample, therefore, appears to be a mixture of non-hybridized westslope cutthroat trout and hybrids. 
Alleles characteristic of both westslope cutthroat and rainbow trout were detected at 11 of the 13 diagnostic loci between these fishes that were analyzed in the sample from Middle Fork Big Creek (Table 4). Although the allele frequencies are statistically homogeneous $\left(X_{12}^{2}=14.864 ; \mathrm{P}>0.10\right)$ among the diagnostic loci, the rainbow trout alleles are not randomly distributed $\left(X^{2}{ }_{5}=135.111 ; \mathrm{P}<0.001\right)$ among the fish in the sample. Rather, there were significantly more individuals in the sample with a hybrid index of zero or greater than four and significantly fewer individuals with a hybrid index of one through four than expected by chance (Figure 4). The hybrid indices also divide the individuals into two distinct categories one of which appears to be non-hybridized westslope cutthroat trout and the other hybrids between westslope cutthroat and rainbow trout. The Middle Fork Big Creek sample, therefore, appears to be a mixture of non-hybridized westslope cutthroat trout and hybrids.

\section{Dominion Creek 3359}

Alleles characteristic of both westslope cutthroat and rainbow trout were detected at 11 of the 13 diagnostic loci between these fishes that were analyzed in the sample from Dominion Creek (Table 4). The allele frequencies are statistically homogeneous $\left(X_{12}^{2}=7.369 ; \mathrm{P}>0.50\right)$ among the diagnostic loci but, the rainbow trout alleles are not randomly distributed $\left(X^{2}{ }_{4}=46.811 ; \mathrm{P}<0.001\right)$ among the fish in the sample. The hybrid indices divide the individuals into two distinct categories one of which is composed of individuals with values of zero or one and the other with values of five or more (Figure 5). This distribution suggests the sample mainly contained individuals from a hybrid swarm between westslope cutthroat and rainbow trout with a predominant westslope cutthroat trout genetic contribution (the former group) and a couple of migrants into Dominion Creek from a hybridized population that has a substantial rainbow trout genetic contribution (the latter group). This population, therefore, should simply be considered to be hybridized between westslope cutthroat and rainbow trout.

The above results somewhat contradict those obtained from a previous PINE analysis of fish collected from Dominion Creek (sample \#3080; col. 8/16/02; N=13 and 14). The sample collected from above a culvert showed no evidence of hybridization but, the sample collected from below the culvert indicated it came from a hybrid swarm between westslope cutthroat and rainbow trout with a predominant (0.98) westslope cutthroat trout genetic contribution. The present sample was also collected from above the culvert but, it clearly shows evidence of hybridization. The simplest explanation for the discrepancy between the two samples collected from above the culvert is that evidence of hybridization was not detected in the first sample because of sampling error. With the 14 fish in the sample and six diagnostic PINE loci, we had about a $20 \%$ chance of not detecting a one percent rainbow trout genetic contribution to a hybrid swarm with westslope cutthroat trout.

\section{East Fork North Fork Blackfoot River 3360}

Alleles characteristic of both rainbow and Yellowstone cutthroat trout were detected at ten of the 14 diagnostic loci between these fishes that were analyzed in the sample from the East Fork of the North Fork Blackfoot River (Table 5). The allele frequencies were statistically homogeneous $\left(X^{2}{ }_{13}=15.396\right.$; $\mathrm{P}>0.10)$ among the diagnostic loci but, the Yellowstone cutthroat trout alleles were not randomly distributed $\left(X^{2}{ }_{9}=18.940 ; \mathrm{P}<0.05\right)$ among the fish in the sample. All of the fish in the sample, however, were definitely of hybrid origin between rainbow and Yellowstone cutthroat trout (Figure 6).

At $O m m 1037-1^{*}$, a single copy of the 147 allele was detected in the sample. This allele is usually characteristic of westslope cutthroat trout and its presence, therefore, suggests that at least some of the fish in the East Fork of the North Fork Blackfoot River may have a minor westslope cutthroat trout genetic contribution. Thus, considering all the data the East Fork of the North Fork Blackfoot River should be considered to contain hybridized fish with a predominant rainbow trout genetic contribution, a moderate Yellowstone cutthroat trout genetic contribution, and a minor contribution from westslope 
cutthroat trout.

These results are highly concordant with those obtained from a previous allozyme analysis of fish collected from the East Fork of the North Fork Blackfoot River (sample \#1203; col. 8/1/96; N=9). The previous results also indicated the population to contain hybrids among rainbow, Yellowstone cutthroat, and westslope cutthroat trout with a predominant rainbow trout genetic contribution.

\section{Sourdough Creek 3361}

Alleles characteristic of both rainbow and Yellowstone cutthroat trout were detected at 13 of the 14 diagnostic loci between these fishes that were analyzed in the sample from Sourdough Creek (Table 5). The allele frequencies were statistically homogeneous $\left(X_{13}^{2}=10.628 ; \mathrm{P}>0.50\right)$ among the diagnostic loci but, the Yellowstone cutthroat trout alleles were not randomly distributed $\left(X^{2}{ }_{12}=346.963 ; \mathrm{P}<0.001\right)$ among the fish in the sample. All of the fish in the sample, however, were definitely of hybrid origin between rainbow and Yellowstone cutthroat trout (Figure 7).

At Omy0004*, two copies of the 77 allele were detected in the sample. This allele is usually characteristic of westslope cutthroat trout and its presence, therefore, suggests that at least some of the fish in Sourdough Creek may have a minor westslope cutthroat trout genetic contribution. Thus, considering all the data Sourdough Creek should be considered to contain hybridized fish with a substantial rainbow and Yellowstone cutthroat trout genetic contribution and a minor contribution from westslope cutthroat trout.

\section{Scotty Creek 3362}

Alleles characteristic of both rainbow and Yellowstone cutthroat trout were detected at all 14 diagnostic loci between these fishes that were analyzed in the sample from Scotty Creek (Table 5). Although the allele frequencies were statistically homogeneous $\left(X^{2}{ }_{13}=10.202 ; \mathrm{P}>0.50\right)$ among the diagnostic loci, the Yellowstone cutthroat trout alleles were not randomly distributed $\left(X^{2}{ }_{12}=346.963 ; \mathrm{P}<0.001\right)$ among the fish in the sample. All of the fish in the sample except one, however, were definitely of hybrid origin between rainbow and Yellowstone cutthroat trout (Figure 8). The exception was one individual that may have been a non-hybridized rainbow trout (Figure 8). The conclusion that this individual was a nonhybridized rainbow trout is tentative because the small sample size precludes a reliable assessment of this likelihood.

At Oki10*, a single copy of the 145 allele was detected in the sample. A single copy of the 77 allele was also detected at Omy0004*. These alleles are usually characteristic of westslope cutthroat trout and their presence indicates that at least some of the fish in Scotty Creek may have a minor westslope cutthroat trout genetic contribution. Thus, considering all the data Scotty Creek should be considered to contain hybridized fish with a substantial rainbow and Yellowstone cutthroat trout genetic contribution and a minor contribution from westslope cutthroat trout.

\section{Lost Pony Creek 3363}

Alleles characteristic of both rainbow and Yellowstone cutthroat trout were detected at eight of the 14 diagnostic loci between these fishes that were analyzed in the sample from Lost Pony Creek (Table 5). The allele frequencies were statistically heterogeneous $\left(X^{2}{ }_{13}=36.252 ; \mathrm{P}<0.001\right)$ among the diagnostic loci but, the Yellowstone cutthroat trout alleles appeared to be randomly distributed $\left(X^{2}{ }_{7}=3.228 ; \mathrm{P}>0.50\right)$ among the fish in the sample.

At $\mathrm{Ssa}_{408 *}$ and $\mathrm{Omm} 1037-\mathrm{I}^{*}$, alleles characteristic of westslope cutthroat trout were detected in the 
sample (Table 4). Although the allele frequencies were statistically heterogeneous $\left(X^{2}{ }_{12}=77.509\right.$; $\mathrm{P}<0.001)$ among the diagnostic loci, the westslope cutthroat trout alleles appeared to be randomly distributed $\left(X_{3}^{2}=2.486 ; \mathrm{P}>0.10\right)$ among the fish in the sample. Considering all the data, therefore, Lost Pony Creek appears to contain a hybrid swarm among rainbow, Yellowstone cutthroat, and westslope cutthroat trout with a predominant $(0.839)$ rainbow trout genetic contribution.

\section{Rye Creek 3364}

With the exception of $S \mathrm{sa} 408^{*}$, alleles characteristic of only westslope cutthroat trout were detected in the Rye Creek sample. At Ssa408*, a single copy of the 282 allele was detected. This allele is usually characteristic of rainbow trout. Its presence, therefore, could indicate a small amount of hybridization with rainbow trout or it could simply be westslope cutthroat trout genetic variation that is indistinguishable from that usually characteristic of rainbow trout. The low frequency of the allele precludes us from reliably distinguishing between these possibilities but, the failure of two previous allozyme analyses (sample \#130; col. 9/12/84; $\mathrm{N}=26$ and sample \#898; col. 4/27/94; $\mathrm{N}=10$ ) to detect evidence of hybridization lends some support to the latter interpretation. The conclusion that $S s a 408 * 282$ simply represents westslope cutthroat trout genetic variation, however, is tentative. Thus, we conclude the status of the Rye Creek population is presently uncertain. With this uncertainty we suggest the conservative approach is to consider the Rye Creek population to be non-hybridized westslope cutthroat trout unless further data indicate otherwise.

\section{East Fork Clearwater River 3365}

Samples were collected from two locations in the lower East Fork Clearwater River in 2002 and two locations from the upper river in 2006. The first issue to address, therefore, is whether there is any evidence of genetic differences between the two 2002 and the two 2006 samples. Contingency table chisquare analysis indicated the allele frequencies at the loci showing evidence of genetic variation (data not presented) were statistically homogeneous ( $\mathrm{P}>0.05)$ between the two 2002 and two 2006 samples. Thus, there was no evidence of genetic differences between the samples collected within a year so they were combined for subsequent analysis.

The next issue to address is whether there is any evidence of genetic differences between the fish collected from the lower and upper East Fork Clearwater River. At the 11 loci showing evidence of genetic variation between the two samples (data not presented), the allele frequencies were statistically heterogeneous at one locus. This difference, however, is not significant at the modified level suggesting it most likely represents a chance departure from homogeneity rather than the existence of genetic differences between the samples. Thus, there is no compelling evidence of genetic differences between the samples so they were combined into a single East Fork Clearwater River sample for subsequent analysis.

Alleles characteristic of both westslope cutthroat and rainbow trout were detected at five of the thirteen diagnostic loci between these fishes that were analyzed in the East Fork Clearwater River sample (Table 4). The allele frequencies were statistically heterogeneous $\left(X^{2}{ }_{12}=26.866 ; \mathrm{P}<0.01\right)$ among the diagnostic loci but, the rainbow trout alleles appeared to be randomly distributed $\left(X_{3}^{2}=2.830 ; \mathrm{P}>0.10\right)$ among the fish in the sample.

Alleles characteristic of both westslope and Yellowstone cutthroat trout were detected at three of the eight diagnostic loci between these fishes that were analyzed in the sample (Table 3 ). The allele frequencies were statistically homogeneous $\left(X_{T}^{2}=12.892 ; \mathrm{P}>0.05\right)$ among the diagnostic loci in the sample and the Yellowstone cutthroat trout alleles appeared to be randomly distributed $\left(X_{2}^{2}=0.998 ; \mathrm{P}>0.10\right)$ among the fish in the sample. Considering all the data, therefore, the East Fork Clearwater River appears to contain a hybrid swarm among westslope cutthroat, rainbow, and Yellowstone cutthroat trout with a predominant 
(0.967) westslope cutthroat trout genetic contribution.

This sample also contained five bull trout.

\section{Clearwater River (above Rainy Lake) 3366}

Samples were collected from three areas in the Clearwater River above Rainy Lake. The allele frequencies were statistically homogeneous among the samples at all six loci showing evidence of genetic variation (data not presented). Thus, there was no evidence of genetic differences among the samples and they were combined into one for further analysis.

Alleles characteristic of both westslope cutthroat and rainbow trout were detected at three of the 13 diagnostic loci between these fishes that were analyzed in the sample (Table 4). The allele frequencies were statistically homogeneous $\left(X_{12}^{2}=15.479 ; \mathrm{P}>0.10\right)$ among the diagnostic loci and the rainbow trout alleles appeared to be randomly distributed $\left(X_{I}^{2}=0.397 ; \mathrm{P}>0.50\right)$ among the fish in the sample. The Clearwater River above Rainy Lake, therefore, contains a hybrid swarm between westslope cutthroat and rainbow trout with a predominant (0.994) westslope cutthroat trout genetic contribution.

At $O m m 1037-1^{*}$, a single copy of the 127 allele was detected in the sample. This allele is usually characteristic of Yellowstone cutthroat trout. Its presence, therefore, could indicate a small amount of hybridization with Yellowstone cutthroat trout or it could simply be westslope cutthroat trout genetic variation that is indistinguishable from that usually characteristic of Yellowstone cutthroat trout. Because of the low frequency of $0 m m 1037-1 * 127$, we cannot reasonably distinguish between these possibilities. Regardless of whether or not the presence of Omm1037-1*127 indicates hybridization with Yellowstone cutthroat trout, the population is clearly a hybrid swarm between westslope cutthroat and rainbow trout and should simply be considered to be hybridized.

\section{Bertha Creek 3367}

Alleles characteristic of only westslope cutthroat trout were detected in the sample from Bertha Creek (Table 2). With the sample size of eight, we have only an $88 \%$ chance of detecting as little as a one percent rainbow trout and a $72 \%$ chance of detecting as little as a one percent Yellowstone cutthroat trout genetic contribution to a hybrid swarm with westslope cutthroat trout. Although no evidence of hybridization was detected, we, therefore, cannot reasonably exclude the possibility that the Bertha Creek population may be slightly hybridized with rainbow trout, Yellowstone cutthroat trout, or both and that evidence of this was not detected because of sampling error. With this uncertainty, we suggest the conservative approach is to consider the Bertha Creek population to be non-hybridized westslope cutthroat trout unless further data indicate otherwise.

\section{Rattlesnake Creek 3368}

A single copy of an allele characteristic of Yellowstone cutthroat trout was detected at two loci in the sample from Rattlesnake Creek (Table 3). Although the allele frequencies are statistically homogeneous $\left(X^{2}{ }_{7}=6.027 ; \mathrm{P}>0.50\right)$ among the diagnostic loci, the Yellowstone cutthroat trout alleles were not randomly distributed $\left(X_{I}^{2}=12.556 ; \mathrm{P}<0.001\right)$ among the individuals in the sample. In contrast, they were detected in only one fish providing clear evidence of hybridization with Yellowstone cutthroat trout but, also indicating the sample did not come from a hybrid swarm between westslope and Yellowstone cutthroat trout. 
Alleles characteristic of both westslope cutthroat and rainbow trout were detected at nine of the 13 diagnostic loci between these fishes that were analyzed in the sample (Table 4). The allele frequencies were statistically homogeneous $\left(X_{12}^{2}=7.571 ; \mathrm{P}>0.50\right)$ among the diagnostic loci but, the rainbow trout alleles do not appear to be randomly distributed $\left(X_{2}^{2}=11.317 ; \mathrm{P}<0.01\right)$ among the fish in the sample. Rather, there are significantly more individuals with a hybrid index of zero or greater than two and significantly fewer individuals with a hybrid index of one than expected by chance (Figure 9). This sample, therefore, does not appear to have come from a hybrid swarm between westslope cutthroat and rainbow trout and may contain some non-hybridized westslope cutthroat trout. Since the hybrid indices do not clearly separate the fish definitely of hybrid origin and those possibly being non-hybridized into distinct groups, from a management perspective Rattlesnake Creek should simply be considered to contain hybrids among westslope cutthroat, Yellowstone cutthroat, and rainbow trout.

The above results are quite consistent with those obtained from previous allozyme (sample \#150; col. 10/4/85; N=32 and sample \# 188; col. 10/3/86; N=30) and PINE analyses (sample \# 2271; col. 7/31/02; $\mathrm{N}=24$ and sample \#'s $3090 \mathrm{~N}=10,3091 \mathrm{~N}=16$ and $3092 \mathrm{~N}=16$ all col. 5/1/04) of fish collected from Rattlesnake Creek. All the samples provided clear evidence of hybridization with rainbow trout and the first allozyme analysis also clearly provided evidence of hybridization with Yellowstone cutthroat trout.

\section{Morrell Creek drainage}

Samples were collected from three areas of Morrell Creek. The allele frequencies were statistically heterogeneous $(\mathrm{P}<0.001$; data not presented) among the samples at one of the seven loci at which evidence of genetic variation was detected and, this difference remains significant at the modified level. Since genetic differences exist among the samples, they were treated separately in subsequent analyses.

\section{Morrell Creek (upper) 3369}

Alleles characteristic of only westslope cutthroat trout were detected in the sample from upper Morrell Creek (Table 2). With the sample size of seven, we have only an $84 \%$ chance of detecting as little as a one percent rainbow trout and a $68 \%$ chance of detecting as little as a one percent Yellowstone cutthroat trout genetic contribution to a hybrid swarm with westslope cutthroat trout. Although no evidence of hybridization was detected, we, therefore, cannot reasonably exclude the possibility that the upper Morrell Creek population may be slightly hybridized with rainbow trout, Yellowstone cutthroat trout, or both and that evidence of this was not detected because of sampling error. With this uncertainty, we suggest the conservative approach is to consider the upper Morrell Creek population to be non-hybridized westslope cutthroat trout unless further data indicate otherwise.

\section{Morrell Creek (middle) 3370}

Alleles characteristic of both westslope cutthroat and rainbow trout were detected at three of the 13 diagnostic loci between these fishes that were analyzed in the sample from middle Morrell Creek (Table 4). The allele frequencies were statistically homogeneous $\left(X_{12}^{2}=10.163 ; \mathrm{P}>0.50\right)$ among the diagnostic loci but, the rainbow trout alleles do not appear to be randomly distributed $\left(X^{2}{ }_{2}=0.25 .382 ; \mathrm{P}<0.001\right)$ among the fish in the sample. In contrast, they were detected in only one fish (Figure 10). Furthermore, the distribution of hybrid indices clearly divides the fish in the sample into a group that appears to be nonhybridized westslope cutthroat trout and the one individual definitely of hybrid origin. At the time of sampling, therefore, middle Morrell Creek appears to have contained a mixture of non-hybridized westslope cutthroat trout and a relatively small percentage of hybrids between westslope cutthroat and rainbow trout.

\section{Morrell Creek (lower) 3381}

Alleles characteristic of both westslope cutthroat and rainbow trout were detected at only one of the 13 
diagnostic loci between these fishes that were analyzed in the sample (Table 4). This could indicate a small amount of hybridization with rainbow trout or it could simply be westslope cutthroat trout genetic variation that is indistinguishable from that usually characteristic of rainbow trout. In this situation we tend to favor the former interpretation because fish definitely of hybrid origin between westslope cutthroat and rainbow trout have been detected further up the drainage.

Assuming $O c c 38 * 150$ represents hybridization with rainbow trout, the allele frequencies were statistically homogeneous $\left(X_{12}^{2}=11.591 ; \mathrm{P}>0.10\right)$ among the diagnostic loci and the rainbow trout alleles appeared to be randomly distributed $\left(X_{I}^{2}=0.073 ; \mathrm{P}>0.50\right)$ among the fish in the sample. Lower Morrell Creek, therefore, appears to contain a hybrid swarm between westslope cutthroat and rainbow trout with a predominant (0.996) westslope cutthroat trout genetic contribution.

\section{Savenac Creek 3371 and 3382}

Samples were collected from Savenac Creek from two areas in 2002 and two different areas in 2006. The allele frequencies were statistically heterogeneous $(\mathrm{P}<0.05)$ between the two 2002 samples at two of the six loci showing evidence of genetic variation (data not presented). These differences, however, are not significant at the modified level suggesting they more likely represent chance departures from homogeneity due to the number of comparisons performed rather than the existence of genetic differences between the samples. These samples, therefore, were combined into one for further analysis.

The allele frequencies were statistically homogeneous ( $\mathrm{P}>0.05$; data not presented) between the two 2006 samples at all seven loci showing evidence of genetic variation. These two samples, therefore, were also combined into one for subsequent analysis.

Finally, the allele frequencies were statistically homogeneous ( $\mathrm{P}>0.05$; data not presented) between the 2002 and 2006 samples at all seven loci showing evidence of genetic variation. Thus, all the samples from Savenac Creek were combined into one for further analysis.

Alleles characteristic of both westslope cutthroat and rainbow trout were detected at two of the 13 diagnostic loci between these fishes that were analyzed in the Savenac Creek sample (Table 4). The allele frequencies were statistically homogeneous $\left(X^{2}{ }_{12}=16.887 ; \mathrm{P}>0.10\right)$ among the diagnostic loci but, the rainbow trout alleles do not appear to be randomly distributed $\left(X^{2}=6.661 ; \mathrm{P}<0.01\right.$; Figure 11) among the fish in the sample. At the time of sampling, therefore, Savenac Creek appears to have contained a mixture of non-hybridized westslope cutthroat trout and hybrids between westslope cutthroat and rainbow trout. The hybrid indices, however, do not separate what may be non-hybridized westslope cutthroat trout and hybrids into discrete categories. Thus, reliably identifying non-hybridized westslope cutthroat trout in Savenac Creek on an individual basis will be problematic and from a management perspective the creek should simply be considered to contain hybrids between westslope cutthroat and rainbow trout.

\section{Monture Creek drainage}

Samples were collected from five areas in the Monture Creek drainage: two areas below the falls, one above the falls, one in East Fork Monture Creek, and one in Middle Fork Monture Creek. The allele frequencies were statistically heterogeneous $(\mathrm{P}<0.01)$ among the five samples at three of the 12 loci showing evidence of genetic variation (data not presented). These differences remain significant at the modified level indicating that genetic differences exist among the samples.

Most of the above genetic divergence appeared to be due to the sample collected from the lower reaches of Monture Creek below the falls. Thus, we excluded this sample and re-analyzed the data using only the remaining four samples. The allele frequencies were statistically heterogeneous $(\mathrm{P}<0.001)$ among these four samples at two of the four loci showing evidence of genetic variation. These differences remain 
significant at the modified level indicating that genetic differences exist among these samples. All five samples, therefore, were treated separately in subsequent analyses.

\section{Monture Creek below falls (lower) 3373}

Alleles characteristic of both westslope cutthroat and rainbow trout were detected at eight of the 13 diagnostic loci between these fishes that were analyzed in the sample collected from the lower reach of Monture Creek below the falls (Table 4). The allele frequencies were statistically homogeneous $\left(X_{12}^{2}=9.356\right.$; $\left.\mathrm{P}>0.50\right)$ among the diagnostic loci but, the rainbow trout alleles do not appear to be randomly distributed $\left(X_{4}^{2}=219.797 ; \mathrm{P}<0.001\right)$ among the fish in the sample. In contrast, eleven fish in the sample appear to be non-hybridized westslope cutthroat trout and two were definitely hybrids between westslope cutthroat and rainbow trout (Figure 12). Since the hybrid indices clearly separate the nonhybridized and hybridized fish into discrete classes, this portion of Monture Creek should be considered to contain a mixture of non-hybridized westslope cutthroat trout and hybrids between westslope cutthroat and rainbow trout.

The above results are highly concordant with those obtained from a previous PINE analysis of fish collected from lower Monture Creek (sample \#2891; col. 9/15/03; N=27). This sample contained 23 fish appearing to be non-hybridized westslope cutthroat trout and four hybrids between westslope cutthroat and rainbow trout.

\section{Monture Creek below falls (upper) 3374}

Alleles characteristic of only westslope cutthroat trout were detected in the sample from the upper reach of Monture Creek below the falls (Table 2). With the sample size of 12 , we have a $96 \%$ chance of detecting as little as a one percent rainbow trout but, only an $86 \%$ chance of detecting as little as a one percent Yellowstone cutthroat trout genetic contribution to a hybrid swarm with westslope cutthroat trout. We, therefore, cannot reasonably exclude the possibility that the fish in Monture Creek in the upper reach below the falls may be slightly hybridized with Yellowstone cutthroat trout and that evidence of this was not detected because of sampling error. With this uncertainty, we suggest the conservative approach is to consider the fish in the upper reach of Monture Creek below the falls to be non-hybridized westslope cutthroat trout unless further data indicate otherwise.

\section{Monture Creek above falls 3383}

Alleles characteristic of only westslope cutthroat trout were detected in the sample from Monture Creek collected above the falls (Table 2). With the sample size of 25 , we have a $99 \%$ chance of detecting as little as a one percent rainbow trout and a $98 \%$ chance of detecting as little as a one percent Yellowstone cutthroat trout genetic contribution to a hybrid swarm with westslope cutthroat trout. Monture Creek above the falls, therefore, very likely contains a non-hybridized westslope cutthroat trout population.

\section{East Fork Monture Creek 3384}

Alleles characteristic of only westslope cutthroat trout were detected in the sample from the East Fork Monture Creek (Table 2). With the sample size of 16, we have a 99\% chance of detecting as little as a one percent rainbow trout but, only a $92 \%$ chance of detecting as little as a one percent Yellowstone cutthroat trout genetic contribution to a hybrid swarm with westslope cutthroat trout. We, therefore, cannot reasonably exclude the possibility that the fish in East Fork Monture Creek may be slightly hybridized with Yellowstone cutthroat trout and that evidence of this was not detected because of 
sampling error. With this uncertainty, we suggest the conservative approach is to consider the fish in East Fork Monture Creek to be non-hybridized westslope cutthroat trout unless further data indicate otherwise.

\section{Middle Fork Monture Creek 3385}

Alleles characteristic of only westslope cutthroat trout were detected in the sample from the Middle Fork Monture Creek (Table 2). With the sample size of 16, we have a $99 \%$ chance of detecting as little as a one percent rainbow trout but, only a $92 \%$ chance of detecting as little as a one percent Yellowstone cutthroat trout genetic contribution to a hybrid swarm with westslope cutthroat trout. Thus, we cannot reasonably exclude the possibility that the fish in Middle Fork Monture Creek may be slightly hybridized with Yellowstone cutthroat trout but, evidence of this was not detected because of sampling error. With this uncertainty, we suggest the conservative approach is to consider the fish in Middle Fork Monture Creek to be non-hybridized westslope cutthroat trout unless further data indicate otherwise.

\section{Windlass Gulch 3376}

Alleles characteristic of both westslope cutthroat and rainbow trout were detected at all 13 diagnostic loci between these fishes that were analyzed in the sample collected from Windlass Gulch (Table 4). Although the allele frequencies were statistically homogeneous $\left(X^{2}{ }_{12}=4.682 ; \mathrm{P}>0.50\right)$ among the diagnostic loci, the rainbow trout alleles do not appear to be randomly distributed $\left(X_{8}^{2}=152.294\right.$; $\mathrm{P}<0.001)$ among the fish in the sample. Rather, the sample appears to have been a mixture of nonhybridized westslope cutthroat trout, possibly one non-hybridized rainbow trout, and hybrids between westslope cutthroat and rainbow trout (Figure 13). Because the value of the hybrid indices is highly variable among the fish definitely of hybrid origin and some fish have relatively low values, this makes reliably identifying the non-hybridized westslope cutthroat trout on an individual basis problematic. From a management perspective, therefore, Windlass Gulch should simply be considered to contain hybrids between westslope cutthroat and rainbow trout.

At $O m y 1001^{*}$, a single copy of the 212 allele was detected in the sample. This allele is usually characteristic of Yellowstone cutthroat trout. Its presence, therefore, could indicate a small amount of hybridization with Yellowstone cutthroat trout or it could simply be westslope cutthroat trout genetic variation that is indistinguishable from that usually characteristic of Yellowstone cutthroat trout. Because of the low frequency of Omy $1001 * 212$, we cannot reasonably distinguish between these possibilities. Regardless of whether or not the presence of $O m y 1001 * 212$ indicates hybridization with Yellowstone cutthroat trout, the population clearly contains hybrids between westslope cutthroat and rainbow trout and should simply be considered to be hybridized.

\section{Scotchman Gulch 3377}

Alleles characteristic of both westslope cutthroat and rainbow trout were detected at 11 of the 13 diagnostic loci between these fishes that were analyzed in the sample collected from Scotchman Gulch (Table 4). Although the allele frequencies were statistically homogeneous $\left(X^{2}{ }_{12}=11.736 ; \mathrm{P}>0.10\right)$ among the diagnostic loci, the rainbow trout alleles do not appear to be randomly distributed $\left(X_{4}^{2}=146.963\right.$; $\mathrm{P}<0.001)$ among the fish in the sample. In contrast, the sample appears to have been a mixture of nonhybridized westslope cutthroat trout and hybrids between westslope cutthroat and rainbow trout (Figure 14). Because the hybrid indices do not divide the non-hybridized westslope cutthroat trout and hybrids into discrete categories, we cannot at the individual level reliably identify non-hybridized westslope cutthroat trout. From a management perspective, therefore, Scotchman Gulch should simply be 
considered to contain hybrids between westslope cutthroat and rainbow trout.

\section{Sluice Gulch 3378}

Alleles characteristic of only westslope cutthroat trout were detected in the sample collected from Sluice Gulch (Table 2). With the sample size of 25 , we have a $99 \%$ chance of detecting as little as a one percent rainbow trout and a $98 \%$ chance

of detecting as little as a one percent Yellowstone cutthroat trout genetic contribution to a hybrid swarm with westslope cutthroat trout. Sluice Gulch, therefore, very likely contains a non-hybridized westslope cutthroat trout population.

\section{Robb Leary}

John Powell

\section{Literature Cited}

Ostberg, C. O., and R. J. Rodriguez. 2004. Bi-parentally inherited species-specific markers identify hybridization between rainbow trout and cutthroat trout subspecies. Molecular Ecology 4:26-29.

Ostberg, C. O., and R. J. Rodriguez. 2006. Hybridization and cytonuclear associations among native

westslope cutthroat trout, introduced rainbow trout, and their hybrids within the Stehekin River drainage, North Cascades National Park. Tranactions of the American Fisheries Society 135:924-942.

Ostberg, C. O., S. L. Slatton, and R. J. Rodriquez. 2004. Spatial partitioning and asymmetric hybridization among sympatric coastal steelhead (Oncorhynchus mykiss irideus), coastal cutthroat trout $(O$.

clarki clarki) and interspecific hybrids. Molecular Ecology 13:2773-2788.

Rice, W. R. 1989. Analyzing tables of statistical tests. Evolution 43:223-225. 
Table 1

Alleles at the diagnostic indel and microsatellite loci that usually differentiate among westslope cutthroat, Yellowstone cutthroat, and rainbow trout. Alleles in bold are occassionally shared between or among taxa.

\begin{tabular}{|c|c|c|c|}
\hline Locus & Westslope & $\frac{\text { Taxa and alleles }}{\text { Yellowstone }}$ & Rainbow \\
\hline \multicolumn{4}{|l|}{ Indels } \\
\hline Occ34 & 225 & 225 & 215 \\
\hline Occ35 & 230 & 230 & 200 \\
\hline Occ36 & $\begin{array}{l}325 \\
324\end{array}$ & $\begin{array}{l}325 \\
275\end{array}$ & $\begin{array}{l}275 \\
285\end{array}$ \\
\hline Occ37 & 270 & 270 & 260 \\
\hline Occ38 & 175 & 175 & 150 \\
\hline Occ42 & $\begin{array}{l}190 \\
160\end{array}$ & 190 & 160 \\
\hline Om55 & $\begin{array}{l}220 \\
221\end{array}$ & 180 & $\begin{array}{l}199 \\
200\end{array}$ \\
\hline \multicolumn{4}{|c|}{ Microsatellites } \\
\hline Ssa408 & $\begin{array}{l}183 \\
195 \\
\mathbf{2 2 6} \\
\mathbf{2 8 2}\end{array}$ & 199 & $\begin{array}{l}170 \\
174 \\
178 \\
182 \\
183 \\
186 \\
190 \\
194 \\
198 \\
202 \\
206 \\
210 \\
214 \\
218 \\
222 \\
226 \\
230 \\
234 \\
238 \\
246 \\
250 \\
254 \\
262 \\
282\end{array}$ \\
\hline
\end{tabular}


Table 1-continued

\begin{tabular}{|c|c|c|c|}
\hline \multirow[b]{2}{*}{ Locus } & \multicolumn{3}{|c|}{ Taxa and alleles } \\
\hline & Westslope & Yellowstone & Rainbow \\
\hline \multicolumn{4}{|c|}{ Microsatellites } \\
\hline \multirow[t]{18}{*}{ Oki10 } & 93 & 141 & 99 \\
\hline & 99 & 149 & 101 \\
\hline & 97 & 153 & 103 \\
\hline & 101 & 157 & 105 \\
\hline & 103 & 161 & 109 \\
\hline & 105 & 165 & 113 \\
\hline & 109 & 169 & 117 \\
\hline & 113 & 173 & 121 \\
\hline & 117 & & 125 \\
\hline & 121 & & 129 \\
\hline & 125 & & 133 \\
\hline & 129 & & 137 \\
\hline & 133 & & 153 \\
\hline & 137 & & \\
\hline & 141 & & \\
\hline & 145 & & \\
\hline & 149 & & \\
\hline & 153 & & \\
\hline \multirow[t]{12}{*}{ Omm1037-1 } & 127 & 127 & 159 \\
\hline & 131 & & 163 \\
\hline & 135 & & 167 \\
\hline & 139 & & 171 \\
\hline & 143 & & 175 \\
\hline & 147 & & 179 \\
\hline & 151 & & 183 \\
\hline & 155 & & 187 \\
\hline & & & 191 \\
\hline & & & 195 \\
\hline & & & 199 \\
\hline & & & 203 \\
\hline \multirow[t]{2}{*}{ Omm1037-2 } & 104 & 106 & 100 \\
\hline & 106 & & 102 \\
\hline
\end{tabular}


Table 1-continued

\begin{tabular}{|c|c|c|c|}
\hline Locus & Westslope & $\frac{\text { Taxa and alleles }}{\text { Yellowstone }}$ & Rainbow \\
\hline \multicolumn{4}{|c|}{ Microsatellites } \\
\hline Omm1050 & $\begin{array}{l}226 \\
227 \\
230 \\
231 \\
234 \\
235 \\
236\end{array}$ & 235 & $\begin{array}{l}238 \\
240 \\
244 \\
246 \\
250 \\
254 \\
256 \\
258 \\
260 \\
262 \\
266 \\
269 \\
270 \\
271 \\
272 \\
274 \\
276 \\
278 \\
280 \\
281 \\
282 \\
284 \\
285 \\
286 \\
289 \\
291 \\
292 \\
293 \\
296 \\
300 \\
302 \\
304 \\
306 \\
308 \\
310 \\
312 \\
322 \\
324 \\
325 \\
326 \\
328 \\
330 \\
335 \\
338 \\
340 \\
365\end{array}$ \\
\hline
\end{tabular}


Table 1-continued

\begin{tabular}{|c|c|c|c|}
\hline Locus & Westslope & $\frac{\text { Taxa and alleles }}{\text { Yellowstone }}$ & Rainbow \\
\hline \multicolumn{4}{|c|}{ Microsatellites } \\
\hline Omy0004 & $\begin{array}{c}77 \\
183\end{array}$ & $\begin{array}{l}173 \\
178 \\
181 \\
183 \\
189 \\
191 \\
193 \\
195 \\
197 \\
199 \\
239 \\
241 \\
245\end{array}$ & $\begin{array}{c}99 \\
101 \\
103 \\
105 \\
109 \\
113 \\
117 \\
121 \\
125 \\
129 \\
131 \\
133 \\
135 \\
137 \\
139 \\
141 \\
145 \\
149 \\
151 \\
153 \\
157 \\
159\end{array}$ \\
\hline Omy1001 & $\begin{array}{l}228 \\
232 \\
236 \\
240 \\
242 \\
244 \\
248 \\
252 \\
254 \\
256 \\
258 \\
260 \\
262 \\
264 \\
266 \\
268 \\
270 \\
272 \\
276 \\
280 \\
284\end{array}$ & $\begin{array}{l}212 \\
216 \\
220 \\
224 \\
242 \\
258 \\
262 \\
266 \\
270 \\
274 \\
278 \\
282 \\
286 \\
290 \\
294 \\
298 \\
306 \\
310 \\
318\end{array}$ & $\begin{array}{l}159 \\
174 \\
176 \\
178 \\
182 \\
184 \\
186 \\
190 \\
192 \\
194 \\
196 \\
198 \\
200 \\
202 \\
204 \\
206 \\
208 \\
210 \\
214 \\
218 \\
222 \\
226 \\
230\end{array}$ \\
\hline
\end{tabular}


Table 2

Allele frequencies at the loci showing evidence of genetic variation in samples from what appear to be non-hybridized westslope cutthroat trout collected from Bertha Creek, East Fork Monture Creek, East Fork Twin Creek, Flat Creek, Middle Fork Monture Creek, Monture Creek above the falls, Monture Creek below the falls, upper Morrell Creek, Ringeye Creek, Rye Creek, Sluice Gulch, and Upper Copper Lake.

\begin{tabular}{|c|c|c|c|c|c|c|c|c|}
\hline \multirow[b]{2}{*}{ Locus } & \multirow[b]{2}{*}{ Alleles } & \multicolumn{7}{|c|}{ Sample and allele frequencies } \\
\hline & & Bertha & $\begin{array}{c}\text { E.F. } \\
\text { Monture }\end{array}$ & E. F. Twin & Flat & $\begin{array}{c}\text { M. F. } \\
\text { Monture }\end{array}$ & $\begin{array}{r}\text { Monture } \\
\text { (above) }\end{array}$ & $\begin{array}{r}\text { Monture } \\
\text { (below) }\end{array}$ \\
\hline \multirow[t]{2}{*}{ Occ36* } & 324 & 0.188 & & 0.423 & 0.192 & & & \\
\hline & 325 & 0.812 & 1.000 & 0.577 & 0.808 & 1.000 & 1.000 & 1.000 \\
\hline \multirow[t]{2}{*}{ Om55* } & 220 & 1.000 & 1.000 & 0.904 & 0.673 & 1.000 & 1.000 & 1.000 \\
\hline & 221 & & & 0.096 & 0.327 & & & \\
\hline \multirow[t]{2}{*}{ Ssa408* } & 195 & 1.000 & 1.000 & 1.000 & 1.000 & 1.000 & 1.000 & 1.000 \\
\hline & 282 & & & & & & & \\
\hline \multirow[t]{11}{*}{ Oki10* } & 101 & 0.250 & & & & & & \\
\hline & 105 & & 0.343 & 0.300 & 0.125 & 0.281 & 0.220 & 0.208 \\
\hline & 109 & 0.438 & & & 0.479 & 0.156 & 0.120 & 0.083 \\
\hline & 113 & 0.313 & 0.375 & 0.140 & 0.104 & 0.469 & 0.360 & 0.458 \\
\hline & 117 & & 0.063 & 0.040 & & 0.031 & 0.120 & 0.042 \\
\hline & 121 & & & & & & & \\
\hline & 125 & & & 0.180 & 0.042 & & & \\
\hline & 129 & & 0.094 & 0.240 & 0.250 & 0.031 & 0.140 & 0.125 \\
\hline & 133 & & 0.125 & 0.100 & & 0.031 & 0.040 & 0.083 \\
\hline & 137 & & & & & & & \\
\hline & 141 & & & & & & & \\
\hline \multirow[t]{3}{*}{ Omm1037-1* } & 139 & 0.438 & 0.281 & 0.440 & 0.846 & 0.688 & 0.740 & 0.458 \\
\hline & 147 & & & & & & & \\
\hline & 151 & 0.562 & 0.719 & 0.560 & 0.154 & 0.312 & 0.260 & 0.542 \\
\hline \multirow[t]{4}{*}{ Omm1050* } & 226 & & & & & 0.094 & 0.020 & \\
\hline & 230 & & & & & & 0.060 & \\
\hline & 234 & 1.000 & 1.000 & 0.840 & 0.096 & 0.906 & 0.920 & 1.000 \\
\hline & 236 & & & 0.160 & 0.904 & & & \\
\hline
\end{tabular}


Table 2-continued

\begin{tabular}{|c|c|c|c|c|c|c|c|c|}
\hline & & \multicolumn{7}{|c|}{ Sample and allele frequencies } \\
\hline & & & E.F. & & & M. F. & Monture & Monture \\
\hline Locus & Alleles & Bertha & Monture & E. F. Twin & Flat & Monture & (above) & (below) \\
\hline \multirow[t]{14}{*}{ Omy1001* } & 228 & 0.188 & & 0.160 & & & & \\
\hline & 232 & & & 0.260 & 0.077 & & 0.020 & \\
\hline & 236 & 0.438 & & 0.420 & 0.403 & 0.094 & & 0.042 \\
\hline & 240 & 0.125 & 0.406 & & 0.058 & 0.188 & 0.260 & 0.250 \\
\hline & 244 & & & 0.140 & & & 0.080 & \\
\hline & 248 & & & 0.020 & 0.019 & & & \\
\hline & 252 & & & & 0.038 & 0.031 & & 0.208 \\
\hline & 256 & 0.125 & & & 0.385 & & & 0.042 \\
\hline & 260 & 0.063 & 0.094 & & & 0.094 & 0.140 & 0.042 \\
\hline & 264 & & & & 0.019 & 0.094 & 0.100 & 0.083 \\
\hline & 268 & 0.063 & 0.281 & & & 0.406 & 0.220 & 0.333 \\
\hline & 272 & & 0.188 & & & 0.063 & 0.160 & \\
\hline & 276 & & 0.031 & & & 0.031 & 0.020 & \\
\hline & 280 & & & & & & & \\
\hline & & & & & & & & \\
\hline
\end{tabular}


Table 2-continued

\begin{tabular}{|c|c|c|c|c|c|c|}
\hline \multirow[b]{2}{*}{ Locus } & \multirow[b]{2}{*}{ Alleles } & \multicolumn{5}{|c|}{ Sample and allele frequencies } \\
\hline & & Morrell & Ringeye & Rye & Sluice & $\begin{array}{l}\text { Upper } \\
\text { Copper }\end{array}$ \\
\hline \multirow[t]{2}{*}{$0 \operatorname{0c} 36^{*}$} & 324 & 0.143 & & 0.054 & & \\
\hline & 325 & 0.857 & 1.000 & 0.946 & 1.000 & 1.000 \\
\hline \multirow[t]{2}{*}{ Om55* } & 220 & 1.000 & 1.000 & 1.000 & 1.000 & 1.000 \\
\hline & 221 & & & & & \\
\hline \multirow[t]{2}{*}{ Ssa 408* } & 195 & 1.000 & 1.000 & 0.982 & 1.000 & 1.000 \\
\hline & 282 & & & 0.018 & & \\
\hline \multirow[t]{11}{*}{ Oki10* } & 101 & 0.500 & 0.188 & & 0.220 & \\
\hline & 105 & & 0.208 & 0.148 & & 0.083 \\
\hline & 109 & 0.071 & 0.021 & 0.074 & 0.720 & 0.188 \\
\hline & 113 & 0.357 & 0.167 & 0.259 & & 0.479 \\
\hline & 117 & 0.071 & & 0.204 & 0.060 & 0.104 \\
\hline & 121 & & 0.021 & & & \\
\hline & 125 & & 0.292 & & & \\
\hline & 129 & & & 0.111 & & 0.021 \\
\hline & 133 & & 0.042 & 0.130 & & 0.125 \\
\hline & 137 & & 0.063 & & & \\
\hline & 141 & & & 0.074 & & \\
\hline \multirow[t]{3}{*}{ Omm1037-1* } & 139 & 0.500 & 0.375 & 0.500 & 0.020 & 0.458 \\
\hline & 147 & & 0.021 & & & \\
\hline & 151 & 0.500 & 0.604 & 0.500 & 0.980 & 0.542 \\
\hline \multirow[t]{4}{*}{ Omm1050* } & 226 & & & & & \\
\hline & 230 & & 0.042 & & 0.040 & 0.292 \\
\hline & 234 & 1.000 & 0.958 & 0.946 & 0.860 & 0.708 \\
\hline & 236 & & & 0.054 & 0.100 & \\
\hline
\end{tabular}


Table 2-continued

\begin{tabular}{|c|c|c|c|c|c|c|}
\hline \multirow[b]{2}{*}{ Locus } & \multirow[b]{2}{*}{ Alleles } & \multicolumn{5}{|c|}{ Sample and allele frequrncies } \\
\hline & & Morrell & Ringeye & Rye & Sluice & $\begin{array}{l}\text { Upper } \\
\text { Copper }\end{array}$ \\
\hline Omy1001* & $\begin{array}{l}228 \\
232 \\
236 \\
240 \\
244 \\
248 \\
252 \\
256 \\
260 \\
264 \\
268 \\
272 \\
276 \\
280\end{array}$ & $\begin{array}{l}0.071 \\
0.214 \\
0.071 \\
0.143\end{array}$ & $\begin{array}{l}0.271 \\
0.146 \\
0.375 \\
0.021\end{array}$ & $\begin{array}{l}0.019 \\
0.093 \\
0.185 \\
0.019 \\
0.296 \\
0.037 \\
0.093 \\
0.056 \\
0.093 \\
\\
0.056 \\
0.037 \\
0.019\end{array}$ & $\begin{array}{l}0.180 \\
0.080 \\
\\
0.160 \\
0.300 \\
0.220\end{array}$ & $\begin{array}{l}0.021 \\
0.458 \\
0.021 \\
0.104\end{array}$ \\
\hline
\end{tabular}


Allele frequencies at the diagnostic loci between westslope and Yellowstone cutthroat trout in samples showing evidence of hybridization between these fishes collected from the East Fork Clearwater River, Falls Creek, and Rattlesnake Creek. Alleles in bold are characteristic of Yellowstone cutthroat trout. Means are reported only if the sample appears to have come from a hybrid swarm. Allele frequencies and means may not sum to one in some samples because they also contained a rainbow trout genetic contribution (see Table 4).

\begin{tabular}{|c|c|c|c|c|}
\hline \multirow[b]{2}{*}{ Locus } & \multirow[b]{2}{*}{ Alleles } & \multicolumn{3}{|c|}{ Sample and allele frequencies } \\
\hline & & E. F. Clearwater & Falls & Rattlesnake \\
\hline \multirow[t]{2}{*}{ Om55* } & 220 & 0.738 & 1.000 & 0.964 \\
\hline & 221 & 0.167 & & 0.018 \\
\hline \multirow[t]{2}{*}{ Ssa408* } & 195 & 0.929 & 1.000 & 0.946 \\
\hline & 199 & 0.071 & & 0.018 \\
\hline \multirow[t]{9}{*}{ Oki10* } & 97 & 0.024 & 0.020 & \\
\hline & 101 & 0.024 & 0.360 & \\
\hline & 105 & 0.119 & 0.120 & 0.250 \\
\hline & 109 & 0.357 & 0.020 & 0.196 \\
\hline & 113 & 0.357 & 0.120 & 0.375 \\
\hline & 117 & 0.048 & & 0.143 \\
\hline & 125 & & 0.340 & 0.036 \\
\hline & 129 & 0.071 & & \\
\hline & 157 & & 0.020 & \\
\hline \multirow[t]{3}{*}{ Omm1037-1* } & 139 & 0.429 & 0.380 & 0.321 \\
\hline & 147 & & 0.020 & \\
\hline & 151 & 0.571 & 0.600 & 0.642 \\
\hline \multirow[t]{2}{*}{ Omm1037-2* } & 104 & 0.952 & 1.000 & 1.000 \\
\hline & 106 & 0.024 & & \\
\hline \multirow[t]{5}{*}{ Omm1050* } & 226 & & & 0.018 \\
\hline & 230 & 0.143 & 0.100 & 0.036 \\
\hline & 234 & 0.786 & 0.860 & 0.892 \\
\hline & 235 & & 0.040 & \\
\hline & 236 & 0.071 & & 0.018 \\
\hline \multirow[t]{3}{*}{ Omy0004* } & 77 & 0.976 & 1.000 & 0.964 \\
\hline & 181 & 0.024 & & \\
\hline & 191 & & & 0.018 \\
\hline
\end{tabular}


Table 3-continued

\begin{tabular}{|c|c|c|c|c|}
\hline \multirow[b]{2}{*}{ Locus } & \multirow[b]{2}{*}{ Alleles } & \multicolumn{3}{|c|}{ Sample and allele frequencies } \\
\hline & & E. F. Clearwater & Falls & Rattlesnake \\
\hline \multirow[t]{13}{*}{ Omy1001* } & 228 & 0.310 & & \\
\hline & 232 & 0.071 & 0.200 & \\
\hline & 236 & 0.024 & 0.240 & 0.036 \\
\hline & 240 & 0.167 & 0.340 & 0.250 \\
\hline & 244 & & & 0.161 \\
\hline & 248 & 0.048 & 0.040 & \\
\hline & 252 & 0.024 & & \\
\hline & 256 & 0.167 & & 0.143 \\
\hline & 260 & & 0.020 & 0.054 \\
\hline & 264 & 0.071 & 0.160 & 0.089 \\
\hline & 268 & 0.119 & & 0.161 \\
\hline & 272 & & & 0.018 \\
\hline & 276 & & & 0.071 \\
\hline Mean Westslope & & 0.967 & 0.992 & \\
\hline Mean Yellowstone & & 0.015 & 0.008 & \\
\hline
\end{tabular}


Allele frequencies at the diagnostic loci between westslope cutthroat and rainbow trout in samples showing evidence of hybridization between these fishes collected from the Clearwater River (Clear.), Dominion Creek, East Fork Big Creek, East Fork Clearwater River (E. F. Clear.), East Fork North Fork Blackfoot River (E. F. Black), Lost Pony Creek, Middle Fork Big Creek, Monture Creek below the falls, lower Morrell Creek, middle Morrell Creek, Rainy Creek, Randolph Creek, Rattlesnake Creek (Rattle.), Savenac Creek, Scothman Gulch (Scotch.), Scotty Creek, Sourdough Creek (Sour.), and Windlass Gulch. Alleles in bold are characteristic of rainbow trout. Means are provided only if the sample appears to have come from a hybrid swarm. Allele frequencies and means in some samples may not sum to one because they also contained a genetic contribution from Yellowstone cutthroat trout (see Tables 3 and 5).

\begin{tabular}{|c|c|c|c|c|c|c|c|c|}
\hline \multirow[b]{2}{*}{ Locus } & \multirow[b]{2}{*}{ Alleles } & \multicolumn{7}{|c|}{ Sample and allele frequencies } \\
\hline & & Clear. & Dominion & $\begin{array}{c}\text { E. F. } \\
\text { Big }\end{array}$ & $\begin{array}{l}\text { E. F. } \\
\text { Clear }\end{array}$ & $\begin{array}{l}\text { E. F. } \\
\text { Black. }\end{array}$ & $\begin{array}{l}\text { Lost } \\
\text { Pony }\end{array}$ & $\begin{array}{r}\text { M. F. } \\
\text { Big }\end{array}$ \\
\hline \multirow[t]{2}{*}{ Occ34* } & 215 & & 0.041 & 0.156 & 0.024 & 0.900 & 0.900 & 0.094 \\
\hline & 225 & 1.000 & 0.959 & 0.844 & 0.976 & & & 0.906 \\
\hline \multirow[t]{2}{*}{ Occ35* } & 200 & & 0.083 & 0.064 & & 0.900 & 0.900 & \\
\hline & 230 & 1.000 & 0.917 & 0.936 & 1.000 & & & 1.000 \\
\hline \multirow[t]{3}{*}{ Occ36* } & 275 & 0.020 & 0.041 & 0.094 & 0.024 & 1.000 & 1.000 & 0.125 \\
\hline & 324 & 0.120 & 0.041 & 0.064 & 0.095 & & & 0.063 \\
\hline & 325 & 0.860 & 0.918 & 0.844 & 0.881 & & & 0.813 \\
\hline \multirow[t]{2}{*}{$0 \operatorname{cc} 37^{*}$} & 260 & 1.000 & 0.083 & 0.064 & & 1.000 & 1.000 & 0.031 \\
\hline & 270 & & 0.917 & 0.936 & 1.000 & & & 0.969 \\
\hline \multirow[t]{2}{*}{ Occ38* } & 150 & 0.020 & 0.041 & 0.064 & 0.071 & 0.900 & 1.000 & 0.063 \\
\hline & 175 & 0.980 & 0.959 & 0.936 & 0.929 & & & 0.937 \\
\hline \multirow[t]{2}{*}{ Occ42* } & 160 & & & 0.064 & & 0.800 & 1.000 & 0.063 \\
\hline & 190 & 1.000 & 1.000 & 0.936 & 1.000 & & & 0.937 \\
\hline \multirow[t]{4}{*}{ Om55* } & 199 & & & 0.064 & & 0.700 & 0.400 & \\
\hline & 200 & & 0.083 & & 0.095 & 0.100 & 0.600 & \\
\hline & 220 & 0.860 & 0.542 & 0.656 & 0.738 & & & 0.781 \\
\hline & 221 & 0.140 & 0.375 & 0.281 & 0.167 & & & 0.219 \\
\hline
\end{tabular}




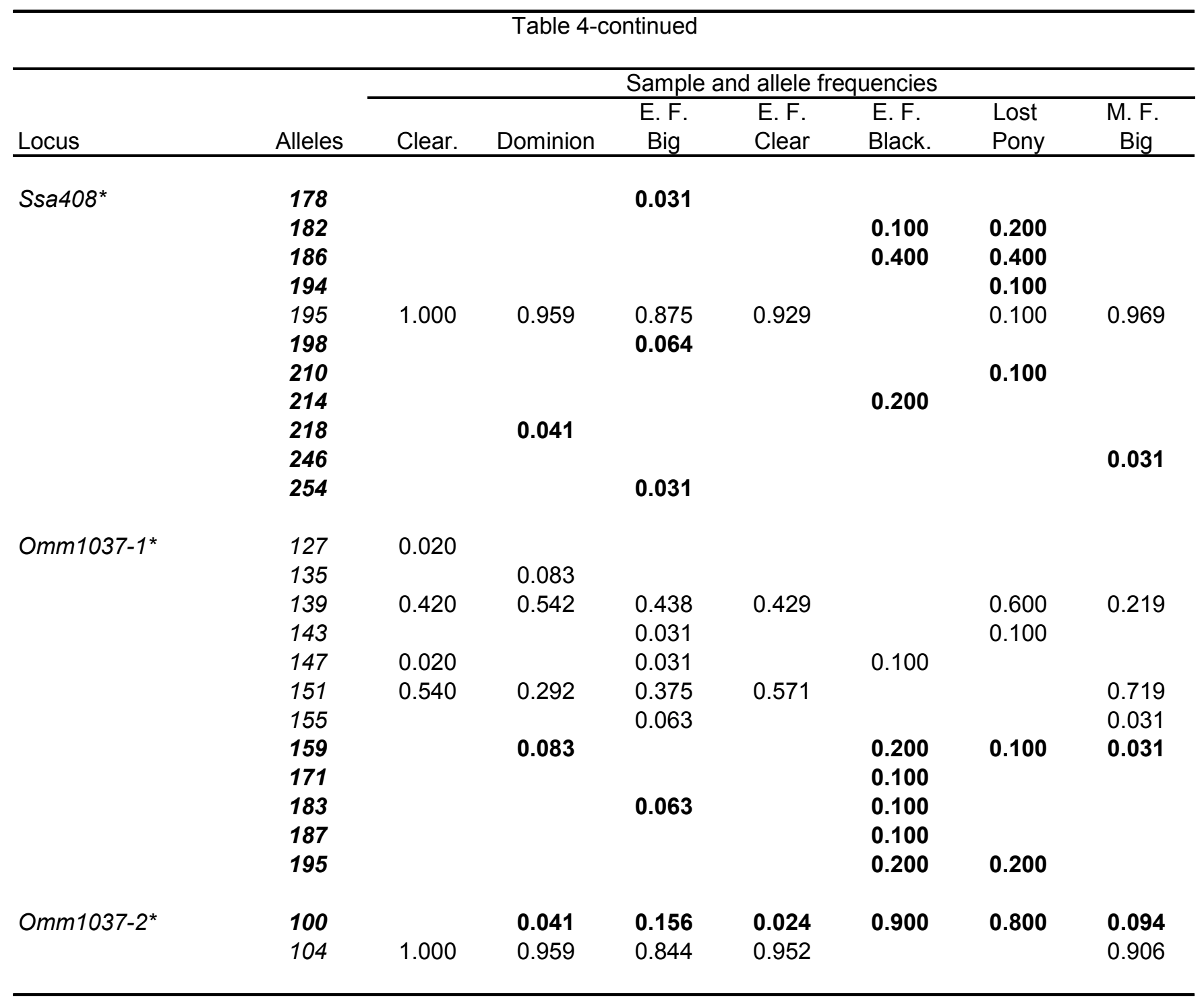


Table 4-continued

\begin{tabular}{|c|c|c|c|c|c|c|c|c|}
\hline \multirow[b]{2}{*}{ Locus } & \multirow[b]{2}{*}{ Alleles } & \multicolumn{7}{|c|}{ Sample and allele frequencies } \\
\hline & & Clear. & Dominion & $\begin{array}{c}\text { E. F. } \\
\text { Big }\end{array}$ & $\begin{array}{l}\text { E. F. } \\
\text { Clear }\end{array}$ & $\begin{array}{l}\text { E. F. } \\
\text { Black. }\end{array}$ & $\begin{array}{l}\text { Lost } \\
\text { Pony }\end{array}$ & $\begin{array}{r}\text { M. F. } \\
\text { Big }\end{array}$ \\
\hline \multirow[t]{14}{*}{ Omm1050* } & 230 & 0.200 & & & 0.143 & & & \\
\hline & 234 & 0.800 & 0.833 & 0.750 & 0.786 & & & 0.781 \\
\hline & 236 & & 0.041 & 0.125 & 0.071 & & & 0.063 \\
\hline & 238 & & 0.041 & & & & & 0.031 \\
\hline & 260 & & & & & & & 0.062 \\
\hline & 270 & & & & & 0.100 & & \\
\hline & 272 & & & & & 0.100 & 0.100 & 0.031 \\
\hline & 276 & & & & & & 0.100 & \\
\hline & 278 & & & & & 0.100 & & \\
\hline & 280 & & 0.041 & 0.063 & & 0.100 & & \\
\hline & 296 & & & & & 0.200 & 0.200 & \\
\hline & 300 & & 0.041 & 0.031 & & & 0.200 & \\
\hline & 308 & & & & & 0.100 & 0.100 & \\
\hline & 335 & & & 0.031 & & & & 0.031 \\
\hline \multirow[t]{7}{*}{ Omy0004* } & 77 & 1.000 & 1.000 & 0.844 & 0.976 & & & 0.969 \\
\hline & 131 & & & 0.063 & & 0.200 & 0.300 & \\
\hline & 137 & & & & & 0.600 & 0.400 & \\
\hline & 139 & & & 0.094 & & & & \\
\hline & 141 & & & & & 0.100 & 0.100 & \\
\hline & 151 & & & & & & & 0.031 \\
\hline & 159 & & & & & 0.100 & & \\
\hline
\end{tabular}


Table 4-continued

\begin{tabular}{|c|c|c|c|c|c|c|c|c|}
\hline \multirow[b]{2}{*}{ Locus } & \multirow[b]{2}{*}{ Alleles } & \multicolumn{7}{|c|}{ Sample and allele frequencies } \\
\hline & & Clear. & Dominion & $\begin{array}{c}\text { E. F. } \\
\text { Big }\end{array}$ & $\begin{array}{l}\text { E. F. } \\
\text { Clear }\end{array}$ & $\begin{array}{l}\text { E. F. } \\
\text { Black. }\end{array}$ & $\begin{array}{l}\text { Lost } \\
\text { Pony }\end{array}$ & $\begin{array}{r}\text { M. F. } \\
\text { Big }\end{array}$ \\
\hline \multirow[t]{25}{*}{ Omy1001* } & 172 & & & & & & 0.200 & \\
\hline & 178 & & & & & 0.125 & & \\
\hline & 186 & & & 0.031 & & & & \\
\hline & 190 & & & & & & 0.100 & 0.033 \\
\hline & 194 & & & & & & & 0.033 \\
\hline & 200 & & & & & 0.125 & & \\
\hline & 202 & & & 0.031 & & 0.250 & 0.100 & \\
\hline & 214 & & & & & & 0.300 & \\
\hline & 218 & & 0.041 & & & & & \\
\hline & 222 & 0.040 & & & 0.143 & & & \\
\hline & 228 & 0.360 & & 0.031 & 0.167 & & & 0.100 \\
\hline & 232 & 0.040 & 0.292 & 0.406 & 0.071 & & & 0.033 \\
\hline & 236 & 0.060 & 0.583 & 0.188 & 0.024 & & & 0.133 \\
\hline & 240 & 0.100 & 0.083 & 0.094 & 0.167 & & & 0.533 \\
\hline & 244 & 0.040 & & 0.063 & & & & 0.033 \\
\hline & 248 & & & & 0.048 & & & \\
\hline & 252 & 0.040 & & & 0.024 & & & 0.033 \\
\hline & 256 & 0.040 & & 0.063 & 0.167 & & & \\
\hline & 258 & & & 0.031 & & & & \\
\hline & 260 & 0.020 & & & & & & \\
\hline & 262 & & & & & & & 0.033 \\
\hline & 264 & 0.120 & & & 0.071 & & & 0.033 \\
\hline & 268 & 0.060 & & 0.063 & 0.119 & & & \\
\hline & 270 & 0.020 & & & & & & \\
\hline & 272 & 0.020 & & & & & & \\
\hline Mean Westslope & & 0.994 & & & 0.967 & & 0.061 & \\
\hline Mean Rainbow & & 0.006 & & & 0.018 & & 0.839 & \\
\hline
\end{tabular}


Table 4-continued

\begin{tabular}{|c|c|c|c|c|c|c|c|c|}
\hline \multirow[b]{2}{*}{ Locus } & \multirow[b]{2}{*}{ Alleles } & \multicolumn{7}{|c|}{ Sample and allele frequencies } \\
\hline & & Monture & $\begin{array}{l}\text { lower } \\
\text { Morrell }\end{array}$ & $\begin{array}{l}\text { middle } \\
\text { Morrell }\end{array}$ & Rainy & Randolph & Rattle. & Savenac \\
\hline \multirow[t]{2}{*}{ Occ34* } & 215 & 0.039 & & & & & & \\
\hline & 225 & 0.961 & 1.000 & 1.000 & 1.000 & 1.000 & 1.000 & 1.000 \\
\hline \multirow[t]{2}{*}{ Occ35* } & 200 & & & & 0.020 & 0.019 & 0.018 & \\
\hline & 230 & 1.000 & 1.000 & 1.000 & 0.980 & 0.989 & 0.982 & 1.000 \\
\hline \multirow[t]{3}{*}{$0 \operatorname{cc36} 6^{*}$} & 275 & & & 0.055 & & & & \\
\hline & 324 & 0.423 & 0.111 & 0.222 & 0.160 & 0.058 & 0.179 & 0.093 \\
\hline & 325 & 0.577 & 0.889 & 0.722 & 0.840 & 0.942 & 0.821 & 0.907 \\
\hline \multirow[t]{2}{*}{ Occ37* } & 260 & 0.039 & & 0.055 & & & 0.018 & 0.018 \\
\hline & 270 & 0.961 & 1.000 & 0.945 & 1.000 & 1.000 & 0.982 & 0.982 \\
\hline \multirow[t]{2}{*}{ Occ38* } & 150 & 0.077 & 0.055 & 0.055 & 0.020 & 0.019 & & \\
\hline & 175 & 0.923 & 0.945 & 0.945 & 0.980 & 0.989 & 1.000 & \\
\hline \multirow[t]{2}{*}{ Occ42* } & 160 & 0.039 & & & 0.020 & & 0.018 & \\
\hline & 190 & 0.961 & 1.000 & 1.000 & 0.980 & 1.000 & 0.982 & 1.000 \\
\hline \multirow[t]{4}{*}{ Om55* } & 199 & & & & 0.020 & & & \\
\hline & 200 & 0.039 & & & & 0.058 & 0.018 & \\
\hline & 220 & 0.961 & 1.000 & 1.000 & 0.700 & 0.558 & 0.964 & 0.574 \\
\hline & 221 & & & & 0.280 & 0.404 & 0.018 & 0.426 \\
\hline \multirow[t]{2}{*}{ Ssa408* } & 182 & & & & & & 0.018 & \\
\hline & 195 & 1.000 & 1.000 & 1.000 & 1.000 & 1.000 & 0.946 & 1.000 \\
\hline
\end{tabular}


Table 4-continued

\begin{tabular}{|c|c|c|c|c|c|c|c|c|}
\hline \multirow[b]{2}{*}{ Locus } & \multirow[b]{2}{*}{ Alleles } & \multicolumn{7}{|c|}{ Sample and allele frequencies } \\
\hline & & Monture & $\begin{array}{l}\text { lower } \\
\text { Morrell }\end{array}$ & $\begin{array}{l}\text { middle } \\
\text { Morrell }\end{array}$ & Rainy & Randolph & Rattle. & Savenac \\
\hline \multirow[t]{8}{*}{ Omm1037-1* } & 139 & 0.231 & 0.500 & 0.556 & 0.700 & 0.780 & 0.321 & 0.759 \\
\hline & 143 & & & & 0.020 & 0.020 & & \\
\hline & 147 & & & 0.055 & & & & \\
\hline & 151 & 0.538 & 0.500 & 0.389 & 0.260 & 0.200 & 0.642 & 0.241 \\
\hline & 155 & 0.192 & & & & & & \\
\hline & 159 & 0.039 & & & & & & \\
\hline & 179 & & & & 0.020 & & 0.018 & \\
\hline & 183 & & & & & & 0.018 & \\
\hline Omm1037-2* & 104 & 1.000 & 1.000 & 1.000 & 1.000 & 1.000 & 1.000 & 1.000 \\
\hline \multirow[t]{9}{*}{ Omm1050* } & 226 & & & & & & 0.018 & \\
\hline & 230 & & 0.055 & & 0.020 & 0.058 & 0.036 & 0.018 \\
\hline & 234 & 0.923 & 0.945 & 1.000 & 0.760 & 0.731 & 0.892 & 0.889 \\
\hline & 236 & & & & 0.220 & 0.212 & 0.018 & 0.056 \\
\hline & 238 & & & & & & 0.018 & 0.018 \\
\hline & 240 & 0.077 & & & & & & \\
\hline & 272 & & & & & & 0.018 & \\
\hline & 300 & & & & & 0.019 & & \\
\hline & 335 & & & & & & & 0.018 \\
\hline
\end{tabular}


Table 4-continued

\begin{tabular}{|c|c|c|c|c|c|c|c|c|}
\hline \multirow[b]{2}{*}{ Locus } & \multirow[b]{2}{*}{ Alleles } & \multicolumn{7}{|c|}{ Sample and allele frequencies } \\
\hline & & Monture & $\begin{array}{l}\text { lower } \\
\text { Morrell }\end{array}$ & $\begin{array}{l}\text { middle } \\
\text { Morrell }\end{array}$ & Rainy & Randolph & Rattle. & Savenac \\
\hline \multirow[t]{3}{*}{ Omy0004* } & 77 & 0.923 & 1.000 & 1.000 & 0.980 & 0.989 & 0.964 & 1.000 \\
\hline & 137 & 0.039 & & & & 0.019 & & \\
\hline & 141 & 0.039 & & & 0.020 & & 0.018 & \\
\hline \multirow[t]{19}{*}{ Omy1001* } & 178 & & & & & & 0.018 & \\
\hline & 182 & & & & 0.020 & & & \\
\hline & 228 & & & & 0.100 & 0.096 & & 0.204 \\
\hline & 232 & 0.039 & & & 0.360 & 0.269 & & 0.204 \\
\hline & 236 & & 0.333 & 0.556 & 0.320 & 0.365 & 0.036 & 0.370 \\
\hline & 240 & & & 0.111 & 0.060 & 0.096 & 0.250 & 0.093 \\
\hline & 244 & 0.077 & 0.111 & & & & 0.161 & \\
\hline & 248 & 0.077 & & 0.055 & 0.020 & 0.038 & & 0.037 \\
\hline & 252 & 0.039 & & & & 0.038 & & 0.018 \\
\hline & 254 & & & & 0.080 & & & \\
\hline & 256 & 0.192 & 0.167 & 0.055 & & & 0.143 & \\
\hline & 258 & & & & & & & 0.056 \\
\hline & 260 & 0.077 & 0.055 & 0.111 & 0.020 & 0.019 & 0.054 & \\
\hline & 262 & & & & & & & 0.018 \\
\hline & 264 & 0.231 & & & & 0.019 & 0.089 & \\
\hline & 266 & & & & 0.020 & & & \\
\hline & 268 & 0.154 & 0.287 & 0.111 & & & 0.161 & \\
\hline & 272 & 0.115 & 0.055 & & & 0.058 & 0.018 & \\
\hline & 276 & & & & & & 0.071 & \\
\hline Mean Westslope & & & 0.996 & & & & & \\
\hline Mean Rainbow & & & 0.004 & & & & & \\
\hline
\end{tabular}




\section{Table 4-continued}

\begin{tabular}{|c|c|c|c|c|c|}
\hline \multirow[b]{2}{*}{ Locus } & \multirow[b]{2}{*}{ Alleles } & \multicolumn{4}{|c|}{ Sample and allele frequencies } \\
\hline & & Scotch. & Scotty & Sour. & Windlass \\
\hline \multirow[t]{2}{*}{ Occ34* } & 215 & 0.020 & 0.800 & 1.000 & 0.354 \\
\hline & 225 & 0.980 & & & 0.646 \\
\hline \multirow[t]{2}{*}{ Occ35* } & 200 & 0.020 & 0.800 & 0.500 & 0.354 \\
\hline & 230 & 0.980 & & & 0.646 \\
\hline \multirow[t]{4}{*}{ Occ36* } & 275 & 0.040 & 0.700 & 0.833 & 0.229 \\
\hline & 285 & & 0.100 & & \\
\hline & 324 & & & & 0.083 \\
\hline & 325 & 0.960 & & & 0.688 \\
\hline \multirow[t]{2}{*}{$0 \operatorname{cc} 37^{*}$} & 260 & 0.040 & 0.700 & 0.667 & 0.292 \\
\hline & 270 & 0.960 & & & 0.708 \\
\hline \multirow[t]{2}{*}{ Occ38* } & 150 & 0.040 & 0.800 & 0.500 & 0.313 \\
\hline & 175 & 0.960 & & & 0.688 \\
\hline \multirow[t]{2}{*}{ Occ42* } & 160 & 0.020 & 0.800 & 0.667 & 0.292 \\
\hline & 190 & 0.980 & & & 0.708 \\
\hline \multirow[t]{4}{*}{ Om55* } & 199 & & 0.200 & 0.333 & 0.229 \\
\hline & 200 & 0.020 & 0.600 & & 0.104 \\
\hline & 220 & 0.980 & & & 0.604 \\
\hline & 221 & & & & 0.063 \\
\hline \multirow[t]{9}{*}{ Ssa408* } & 170 & & 0.100 & & \\
\hline & 182 & & 0.100 & & 0.063 \\
\hline & 186 & & & 0.167 & 0.104 \\
\hline & 190 & & 0.100 & & 0.042 \\
\hline & 195 & 1.000 & & & 0.708 \\
\hline & 198 & & 0.200 & & \\
\hline & 210 & & & & 0.063 \\
\hline & 214 & & & & 0.021 \\
\hline & 222 & & & 0.167 & \\
\hline
\end{tabular}




\section{Table 4-continued}

\begin{tabular}{|c|c|c|c|c|c|}
\hline \multirow[b]{2}{*}{ Locus } & \multirow[b]{2}{*}{ Alleles } & \multicolumn{4}{|c|}{ Sample and allele frequencies } \\
\hline & & Scotch. & Scotty & Sour. & Windlass \\
\hline \multirow[t]{8}{*}{ Omm1037-1* } & 139 & 0.260 & & & 0.341 \\
\hline & 151 & 0.660 & & & 0.432 \\
\hline & 159 & 0.040 & 0.400 & & 0.068 \\
\hline & 163 & 0.020 & & & 0.091 \\
\hline & 167 & 0.020 & & & \\
\hline & 171 & & 0.100 & 0.500 & 0.045 \\
\hline & 183 & & & 0.167 & \\
\hline & 199 & & & & 0.023 \\
\hline \multirow[t]{2}{*}{ Omm1037-2* } & 100 & & 0.700 & 0.833 & 0.227 \\
\hline & 104 & 1.000 & & & 0.773 \\
\hline \multirow[t]{18}{*}{ Omm1050* } & 230 & 0.120 & & & 0.045 \\
\hline & 234 & 0.820 & & & 0.477 \\
\hline & 236 & & & & 0.159 \\
\hline & 238 & & & & 0.023 \\
\hline & 240 & & 0.200 & & \\
\hline & 256 & & 0.100 & & \\
\hline & 273 & 0.020 & & & 0.045 \\
\hline & 280 & & & 0.167 & \\
\hline & 284 & & & & 0.023 \\
\hline & 285 & 0.020 & & & 0.023 \\
\hline & 286 & & & & 0.023 \\
\hline & 296 & & 0.100 & & \\
\hline & 304 & & & & 0.023 \\
\hline & 308 & 0.020 & 0.100 & 0.167 & \\
\hline & 312 & & & 0.167 & 0.068 \\
\hline & 325 & & & & 0.023 \\
\hline & 341 & & & & 0.045 \\
\hline & 348 & & & & 0.023 \\
\hline
\end{tabular}


Table 4-continued

\begin{tabular}{|c|c|c|c|c|c|}
\hline \multirow[b]{2}{*}{ Locus } & \multirow[b]{2}{*}{ Alleles } & \multicolumn{4}{|c|}{ Sample and allele frequencies } \\
\hline & & Scotch. & Scotty & Sour. & Windlass \\
\hline \multirow[t]{9}{*}{ Omy0004* } & 77 & 0.980 & 0.100 & 0.333 & 0.750 \\
\hline & 131 & & 0.100 & & \\
\hline & 135 & & 0.100 & & \\
\hline & 137 & & 0.300 & 0.333 & 0.023 \\
\hline & 139 & & & & 0.023 \\
\hline & 145 & & & & 0.023 \\
\hline & 153 & 0.020 & 0.100 & & 0.045 \\
\hline & 157 & & & & 0.068 \\
\hline & 163 & & & & 0.068 \\
\hline \multirow[t]{20}{*}{ Omy1001* } & 176 & 0.020 & & & \\
\hline & 182 & & 0.300 & & 0.023 \\
\hline & 186 & & & & 0.045 \\
\hline & 190 & & & & 0.045 \\
\hline & 192 & & & 0.167 & \\
\hline & 198 & & 0.100 & 0.167 & \\
\hline & 200 & 0.020 & 0.100 & & 0.091 \\
\hline & 202 & 0.020 & & & \\
\hline & 212 & & & & 0.023 \\
\hline & 214 & & & 0.167 & \\
\hline & 218 & & & & 0.023 \\
\hline & 226 & & & & 0.045 \\
\hline & 232 & & & & 0.136 \\
\hline & 236 & 0.100 & & & 0.068 \\
\hline & 240 & 0.060 & & & 0.068 \\
\hline & 244 & 0.420 & & & 0.182 \\
\hline & 248 & 0.200 & & & 0.114 \\
\hline & 256 & 0.080 & & & \\
\hline & 260 & 0.080 & & & \\
\hline & 264 & & & & 0.136 \\
\hline \multicolumn{6}{|c|}{ Mean Westslope } \\
\hline Mean Rainb & & & & & \\
\hline
\end{tabular}


Allele frequencies at the diagnostic loci between rainbow and Yellowstone cutthroat trout in samples showing evidence of hybridization between these fishes collected from East Fork North Fork Blackfoot River (E. F. Black.), Lost Pony Creek, Scotty Creek, and Sourdough Creek (Sour.) Alleles in bold are characteristic of Yellowstone cutthroat trout. Mean rainbow and Yellowstone cutthroat trout allele frequencies are reported only when a sample appears to have come from a hybrid swarm. In some samples, means and allele frequencies may not sum to one because they also contained a westslope cutthroat trout genetic contribution (see Table 4).

\begin{tabular}{|c|c|c|c|c|c|}
\hline \multirow[b]{2}{*}{ Locus } & \multirow[b]{2}{*}{ Alleles } & \multicolumn{4}{|c|}{ Sample and allele frequencies } \\
\hline & & $\begin{array}{l}\text { E. F. } \\
\text { Black. }\end{array}$ & $\begin{array}{l}\text { Lost } \\
\text { Pony }\end{array}$ & Scotty & Sour. \\
\hline Occ34* & $\begin{array}{l}215 \\
225\end{array}$ & $\begin{array}{l}0.900 \\
\mathbf{0 . 1 0 0}\end{array}$ & $\begin{array}{l}0.900 \\
0.100\end{array}$ & $\begin{array}{l}0.800 \\
\mathbf{0 . 2 0 0}\end{array}$ & 1.000 \\
\hline Occ35* & $\begin{array}{l}200 \\
230\end{array}$ & 0.901 & $\begin{array}{l}0.900 \\
\mathbf{0 . 1 0 0}\end{array}$ & $\begin{array}{l}0.800 \\
\mathbf{0 . 2 0 0}\end{array}$ & $\begin{array}{l}0.500 \\
\mathbf{0 . 5 0 0}\end{array}$ \\
\hline Occ36* & $\begin{array}{l}275 \\
285 \\
\mathbf{3 2 5}\end{array}$ & 1.000 & 1.000 & $\begin{array}{l}0.700 \\
0.100 \\
\mathbf{0 . 2 0 0}\end{array}$ & $\begin{array}{l}0.833 \\
\mathbf{0 . 1 6 7}\end{array}$ \\
\hline $0 \operatorname{ccs} 37^{*}$ & $\begin{array}{l}260 \\
270\end{array}$ & 1.000 & 1.000 & $\begin{array}{l}0.700 \\
\mathbf{0 . 3 0 0}\end{array}$ & $\begin{array}{l}0.667 \\
\mathbf{0 . 3 3 3}\end{array}$ \\
\hline $0 \operatorname{cc} 38^{*}$ & $\begin{array}{l}150 \\
175\end{array}$ & $\begin{array}{l}0.900 \\
\mathbf{0 . 1 0 0}\end{array}$ & 1.000 & $\begin{array}{l}0.800 \\
0.200\end{array}$ & $\begin{array}{l}0.500 \\
\mathbf{0 . 5 0 0}\end{array}$ \\
\hline Occ42* & $\begin{array}{l}160 \\
190\end{array}$ & $\begin{array}{l}0.800 \\
0.200\end{array}$ & 1.000 & $\begin{array}{l}0.800 \\
0.200\end{array}$ & $\begin{array}{l}0.667 \\
\mathbf{0 . 3 3 3}\end{array}$ \\
\hline Om55* & $\begin{array}{l}180 \\
199 \\
200\end{array}$ & $\begin{array}{l}\mathbf{0 . 2 0 0} \\
0.700 \\
0.100\end{array}$ & $\begin{array}{l}0.400 \\
0.600\end{array}$ & $\begin{array}{l}0.200 \\
0.200 \\
0.600\end{array}$ & $\begin{array}{l}\mathbf{0 . 6 6 7} \\
0.333\end{array}$ \\
\hline Ssa 408* & $\begin{array}{l}170 \\
182 \\
186 \\
190 \\
194 \\
198 \\
199 \\
210 \\
214 \\
222\end{array}$ & $\begin{array}{l}\mathbf{0 . 3 0 0} \\
0.200\end{array}$ & $\begin{array}{l}0.200 \\
0.400 \\
0.100\end{array}$ & $\begin{array}{l}0.100 \\
0.100 \\
0.100 \\
0.200 \\
\mathbf{0 . 5 0 0}\end{array}$ & 0.167 \\
\hline
\end{tabular}


Table 5- continued

\begin{tabular}{|c|c|c|c|c|c|}
\hline \multirow[b]{2}{*}{ Locus } & \multirow[b]{2}{*}{ Alleles } & \multicolumn{4}{|c|}{ Sample and allele frequencies } \\
\hline & & $\begin{array}{l}\text { E. F. } \\
\text { Black. }\end{array}$ & $\begin{array}{l}\text { Lost } \\
\text { Pony }\end{array}$ & Scotty & Sour. \\
\hline \multirow[t]{9}{*}{ Oki10* } & 99 & 0.200 & 0.100 & & \\
\hline & 101 & 0.100 & 0.100 & 0.300 & 0.333 \\
\hline & 109 & 0.600 & 0.300 & & \\
\hline & 117 & & 0.100 & & 0.167 \\
\hline & 125 & & & 0.100 & \\
\hline & 137 & & 0.100 & & \\
\hline & 153 & & & 0.100 & \\
\hline & 157 & & 0.100 & 0.300 & \\
\hline & 161 & 0.100 & & 0.100 & 0.500 \\
\hline \multirow[t]{6}{*}{ Omm1037-1* } & 127 & 0.200 & & 0.500 & 0.333 \\
\hline & 159 & 0.200 & 0.100 & 0.400 & \\
\hline & 171 & 0.100 & & 0.100 & 0.500 \\
\hline & 183 & 0.100 & & & 0.167 \\
\hline & 187 & 0.100 & & & \\
\hline & 195 & 0.200 & 0.200 & & \\
\hline \multirow[t]{2}{*}{ Omm1037-2* } & 100 & 0.900 & 0.800 & 0.700 & 0.833 \\
\hline & 106 & 0.100 & 0.200 & 0.300 & 0.167 \\
\hline \multirow[t]{12}{*}{ Omm1050* } & 235 & 0.300 & 0.300 & 0.500 & 0.500 \\
\hline & 240 & & & 0.200 & \\
\hline & 256 & & & 0.100 & \\
\hline & 270 & 0.100 & & & \\
\hline & 272 & 0.100 & 0.100 & & \\
\hline & 276 & & 0.100 & & \\
\hline & 278 & 0.100 & & & \\
\hline & 280 & 0.100 & & & 0.167 \\
\hline & 296 & 0.200 & 0.200 & 0.100 & \\
\hline & 300 & & 0.200 & & \\
\hline & 308 & 0.100 & 0.100 & 0.100 & 0.167 \\
\hline & 312 & & & & 0.167 \\
\hline \multirow[t]{11}{*}{ Omy0004* } & 131 & 0.200 & 0.300 & 0.100 & \\
\hline & 135 & & & 0.100 & \\
\hline & 137 & 0.600 & 0.400 & 0.300 & 0.333 \\
\hline & 141 & 0.100 & 0.100 & & \\
\hline & 153 & & & 0.100 & \\
\hline & 159 & 0.100 & & & \\
\hline & 189 & & & & 0.167 \\
\hline & 191 & & & 0.100 & \\
\hline & 195 & & 0.200 & & \\
\hline & 197 & & & 0.100 & \\
\hline & 239 & & & 0.100 & 0.167 \\
\hline
\end{tabular}




\section{Table 5- continued}

\begin{tabular}{|c|c|c|c|c|c|}
\hline \multirow[b]{2}{*}{ Locus } & \multirow[b]{2}{*}{ Alleles } & \multicolumn{4}{|c|}{ Sample and allele frequencies } \\
\hline & & $\begin{array}{l}\text { E. F. } \\
\text { Black. }\end{array}$ & $\begin{array}{l}\text { Lost } \\
\text { Pony }\end{array}$ & Scotty & Sour. \\
\hline \multirow[t]{15}{*}{ Omy1001* } & 172 & & 0.200 & & \\
\hline & 178 & 0.125 & & 0.300 & \\
\hline & 182 & & & & \\
\hline & 190 & & 0.100 & & \\
\hline & 192 & & & & 0.167 \\
\hline & 198 & & & 0.100 & 0.167 \\
\hline & 200 & 0.125 & & 0.100 & \\
\hline & 202 & 0.250 & 0.100 & & \\
\hline & 214 & & 0.300 & & 0.167 \\
\hline & 270 & 0.250 & 0.200 & & \\
\hline & 274 & & & 0.200 & 0.167 \\
\hline & 290 & 0.125 & & & \\
\hline & 294 & & & 0.100 & \\
\hline & 298 & 0.125 & 0.100 & 0.100 & 0.167 \\
\hline & 318 & & & 0.100 & 0.167 \\
\hline Mean Rainbow & & & 0.839 & & \\
\hline Mean Yellowstone & & & 0.100 & & \\
\hline
\end{tabular}




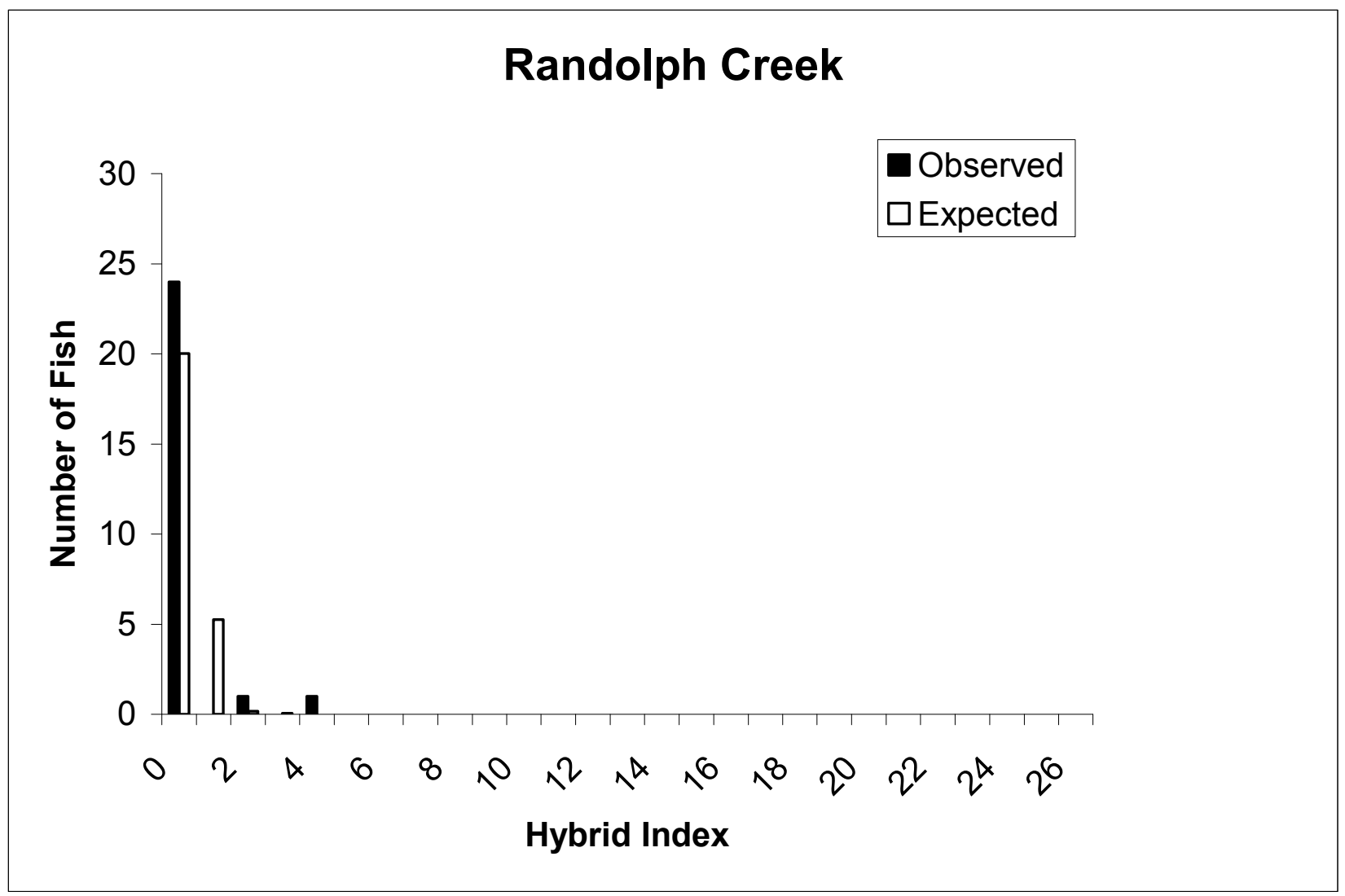

Figure 1.- Observed and expected random distribution of hybrid index values between westslope cutthroat and

rainbow trout in a sample showing evidence of hybridization between these fishes collected from Randolph

Creek. Note the observed distribution does not statistically conform $(\mathrm{P}<0.05)$ with the expected random

distribution. 


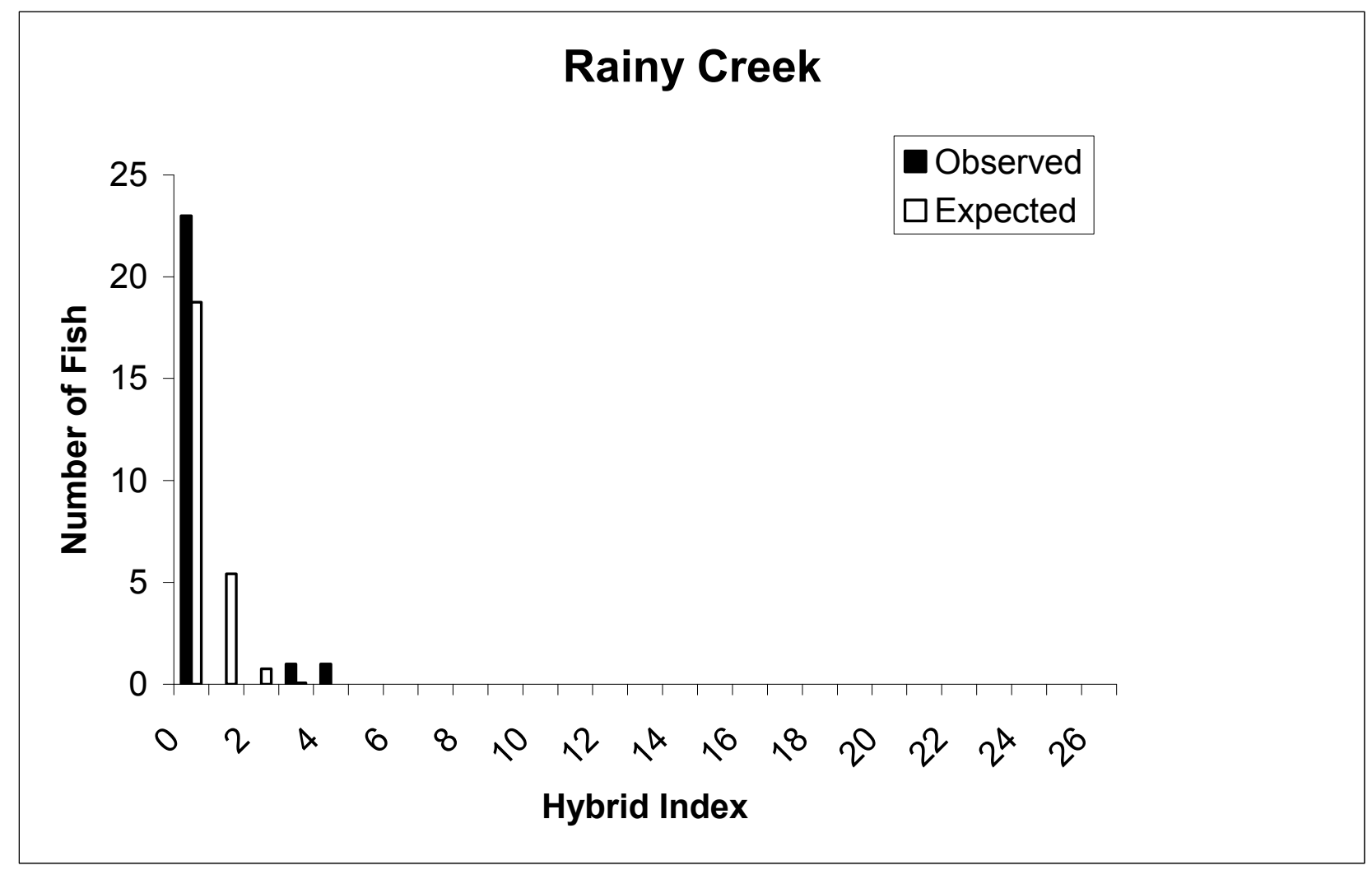

Figure 2.- Observed and expected random distribution of hybrid index values between westslope cutthroat and

rainbow trout in a sample showing evidence of hybridization between these fishes collected from Rainy

Creek. Note the observed distribution does not statistically conform $(\mathrm{P}<0.05)$ with the expected random

distribution. 


\section{East Fork Big Creek}

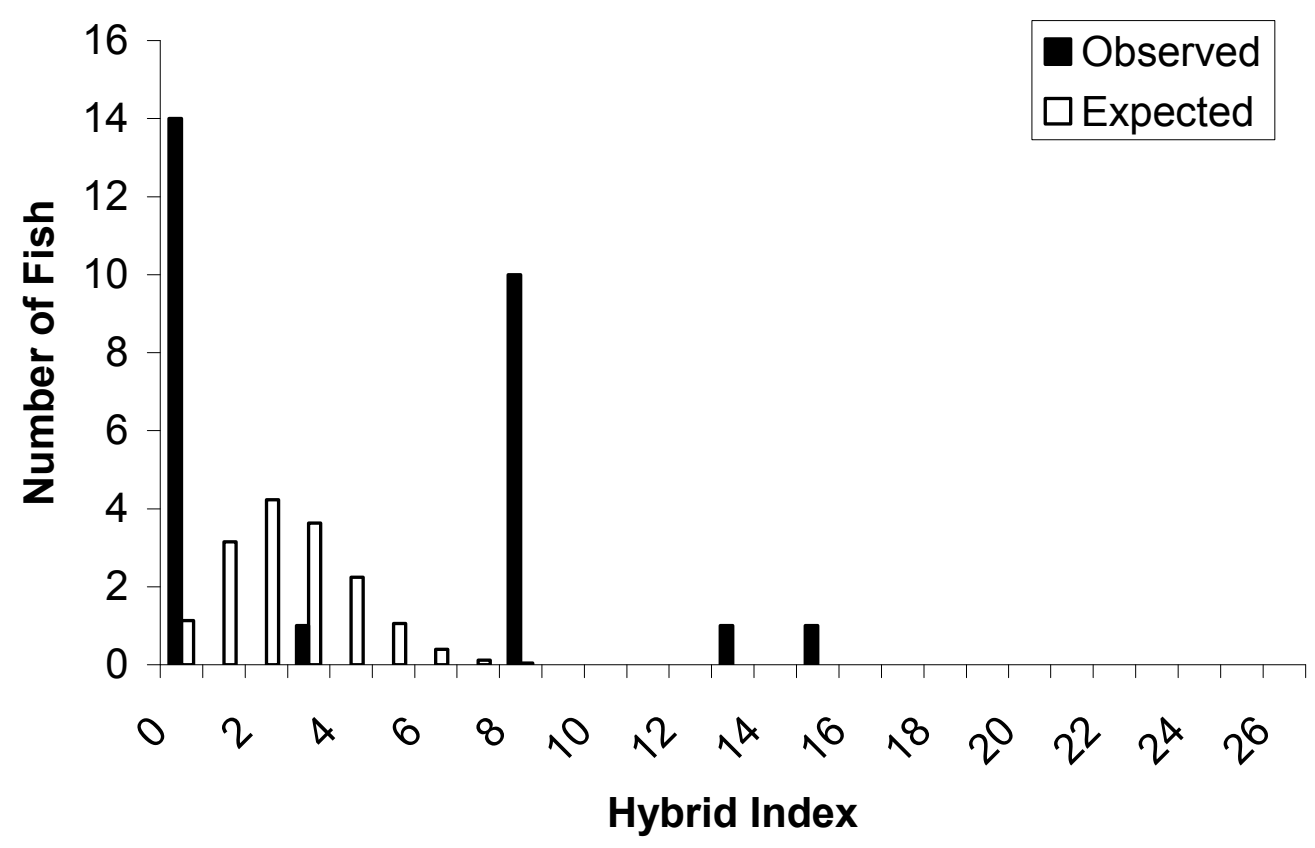

Figure 3.- Observed and expected random distribution of hybrid index values between westslope cutthroat and

rainbow trout in a sample showing evidence of hybridization between these fishes collected from East Fork

Big Creek. Note the observed distribution does not statistically conform $(\mathrm{P}<0.05)$ with the expected

random distribution. 


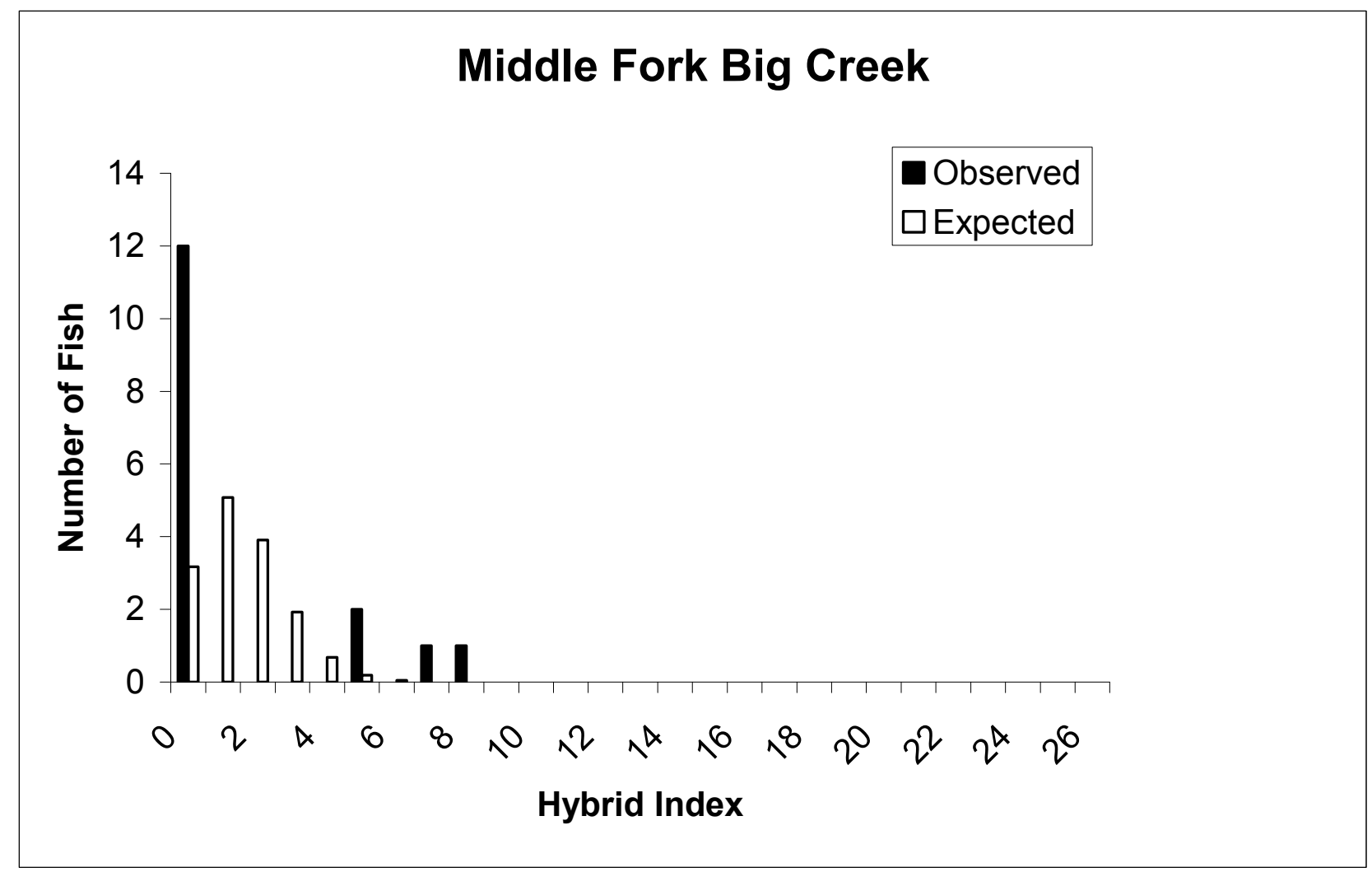

Figure 4.- Observed and expected random distribution of hybrid index values between westslope cutthroat and

rainbow trout in a sample showing evidence of hybridization between these fishes collected from Middle

Fork Big Creek. Note the observed distribution does not statistically conform $(\mathrm{P}<0.05)$ with the expected random distribution. 


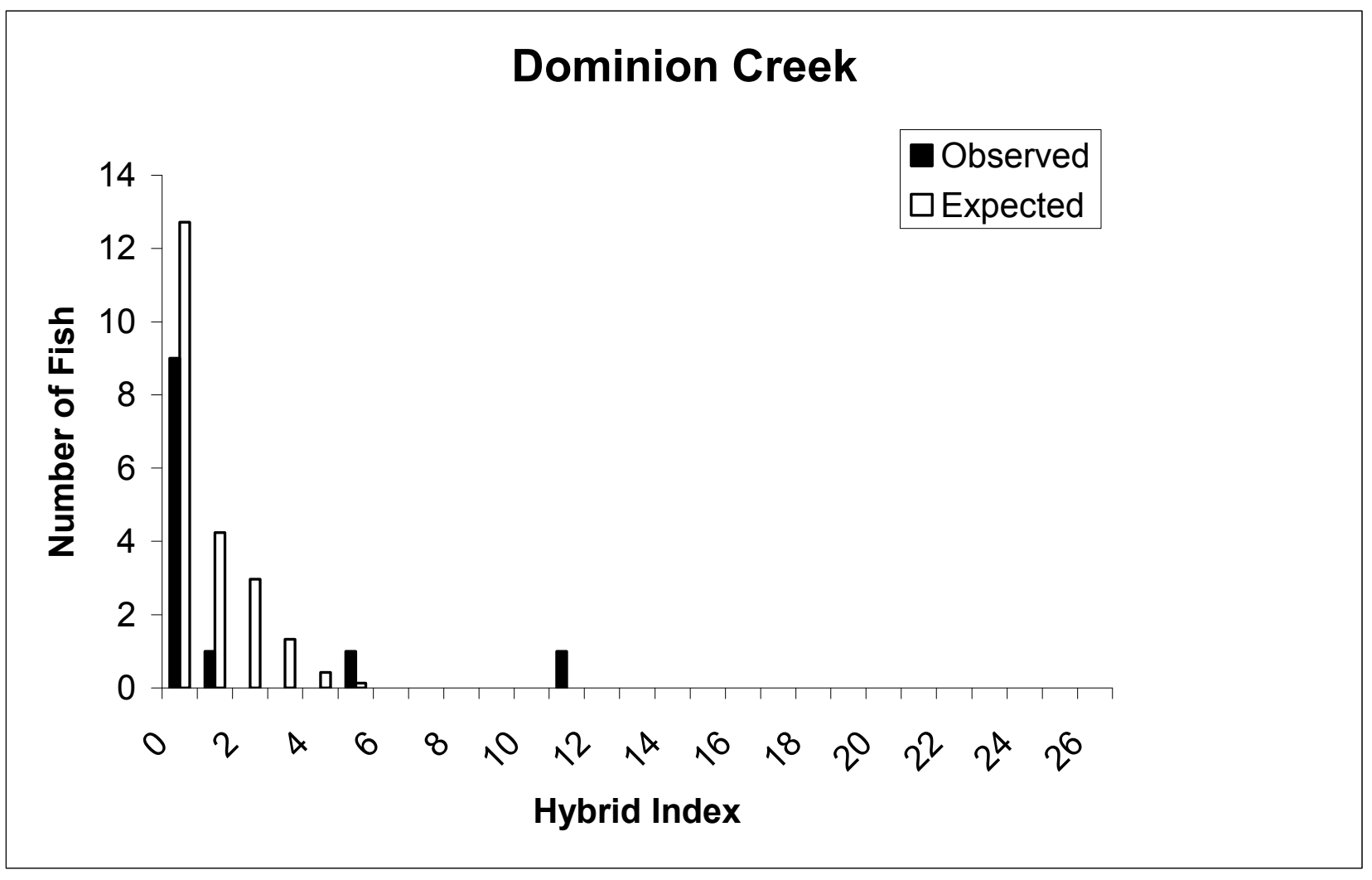

Figure 5.- Observed and expected random distribution of hybrid index values between westslope cutthroat and

rainbow trout in a sample showing evidence of hybridization between these fishes collected from Dominion

Creek. Note the observed distribution does not statistically conform $(\mathrm{P}<0.05)$ with the expected random

distribution. 


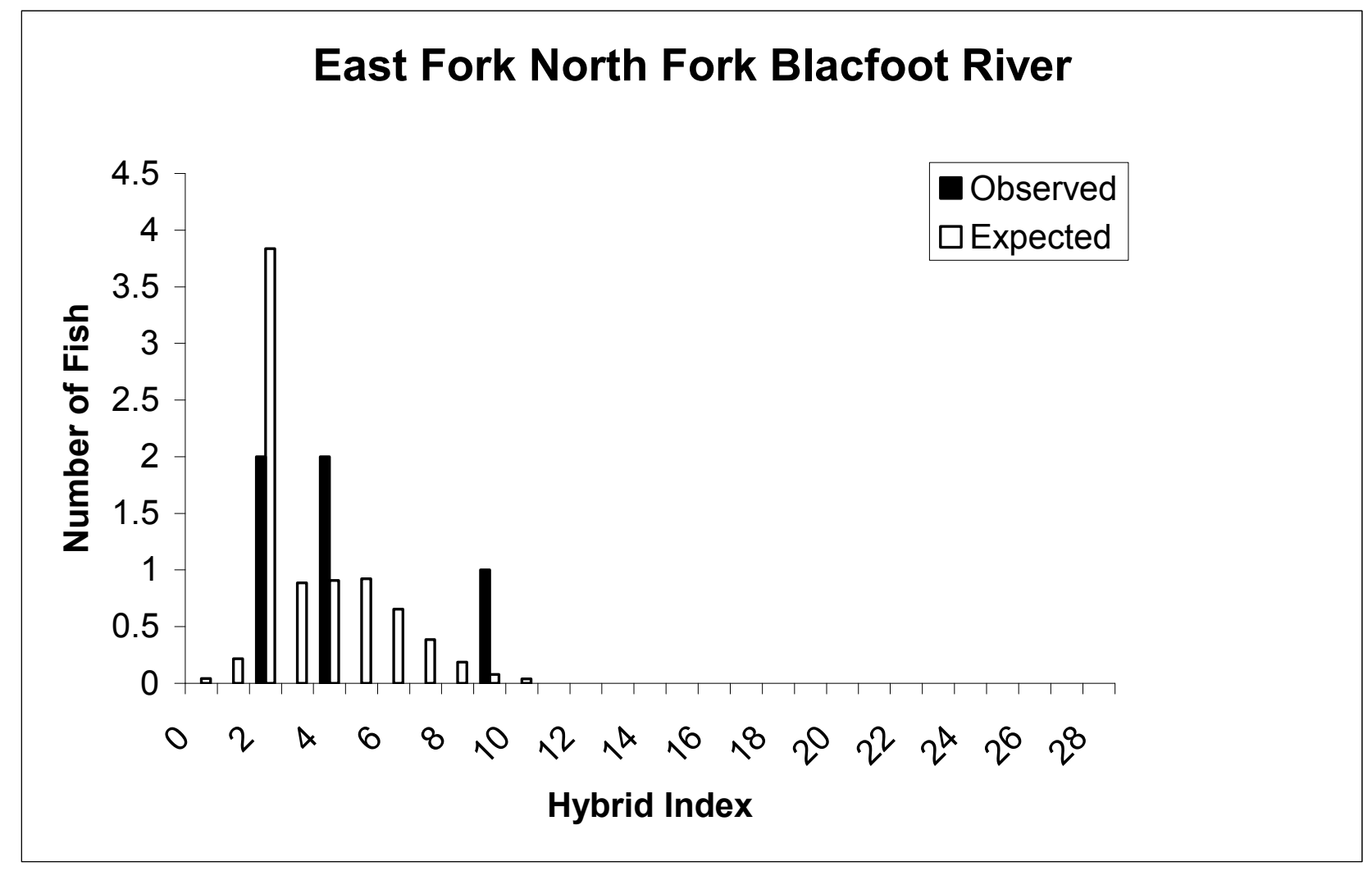

Figure 6.- Observed and expected random distribution of hybrid index values between rainbow and

Yellowstone cutthroat trout in a sample showing evidence of hybridization between these fishes collected

from East Fork North Fork Blackfoot River. Note the observed distribution does not statistically conform

$(\mathrm{P}<0.05)$ with the expected random distribution. A hybrid index of zero is characteristic of rainbow trout

and a hybrid index of 28 is characteristic of Yellowstone cutthroat trout. 


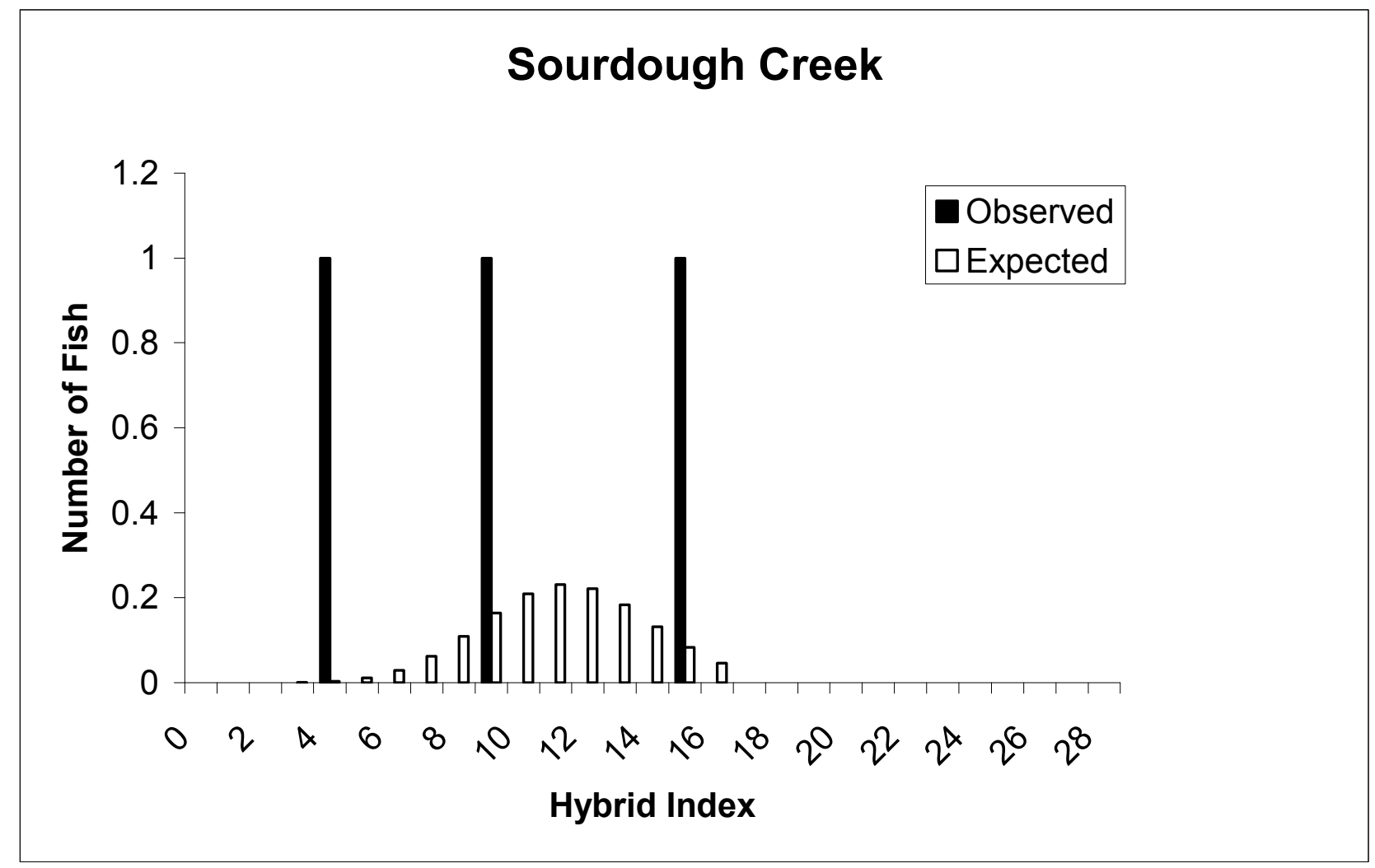

Figure 7.- Observed and expected random distribution of hybrid index values between rainbow and

Yellowstone cutthroat trout in a sample showing evidence of hybridization between these fishes collected

from Sourdough Creek. Note the observed distribution does not statistically conform

$(\mathrm{P}<0.05)$ with the

expected random distribution. A hybrid index of zero is characteristic of rainbow trout and a hybrid index of 28 is characteristic of Yellowstone cutthroat trout. 


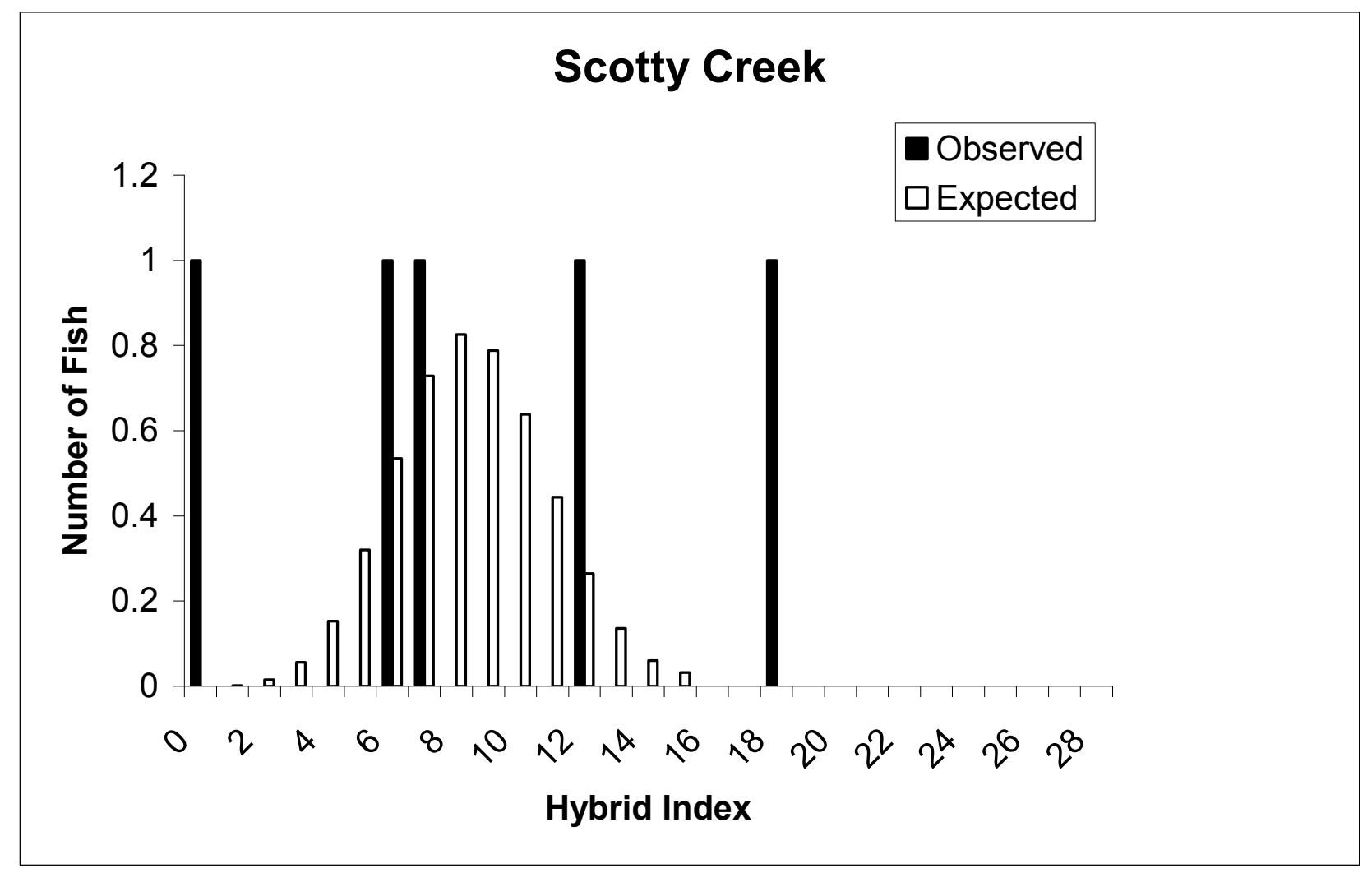

Figure 8.- Observed and expected random distribution of hybrid index values between rainbow and

Yellowstone cutthroat trout in a sample showing evidence of hybridization between these fishes collected

from Scotty Creek. Note the observed distribution does not statistically conform $(\mathrm{P}<0.05)$

with the

expected random distribution. A hybrid index of zero is characteristic of rainbow trout and a hybrid index of 28 is characteristic of Yellowstone cutthroat trout. 


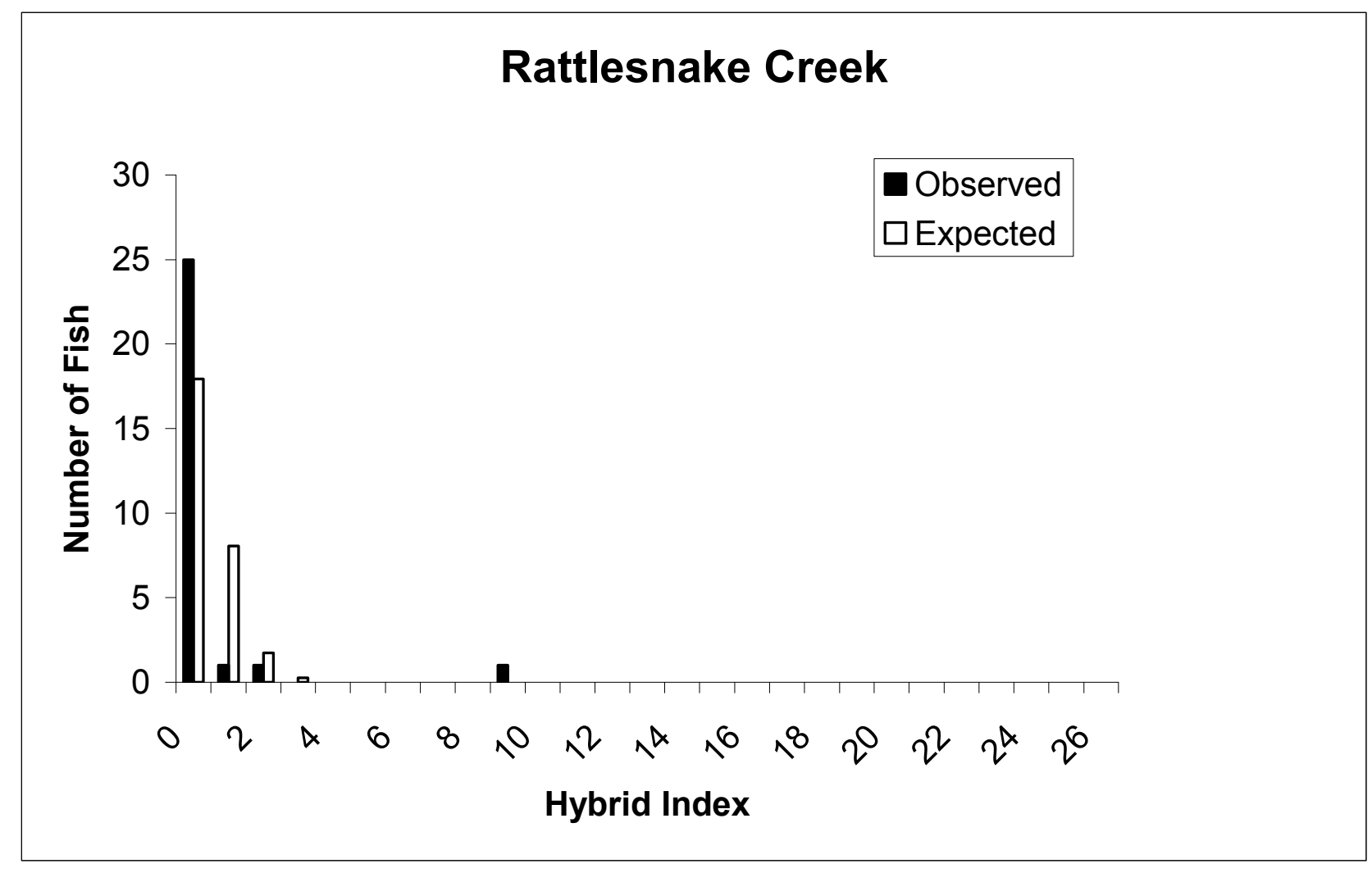

Figure 9.- Observed and expected random distribution of hybrid index values between westslope cutthroat and

rainbow trout in a sample showing evidence of hybridization between these fishes collected from

Rattlesnake Creek. Note the observed distribution does not statistically conform $(\mathrm{P}<0.05)$ with the expected

random distribution. 


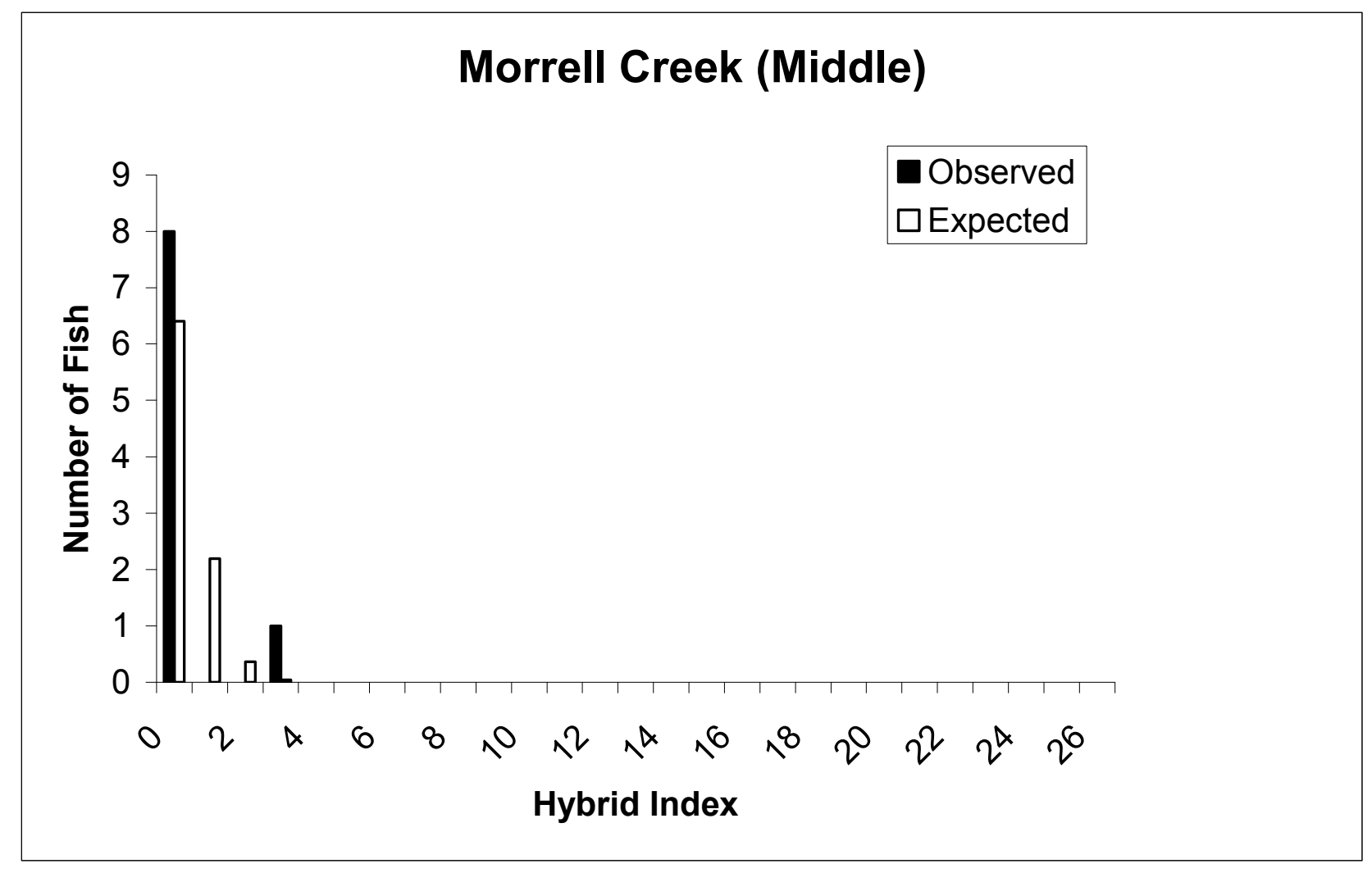

Figure 10.- Observed and expected random distribution of hybrid index values between westslope cutthroat and

rainbow trout in a sample showing evidence of hybridization between these fishes collected from middle

Morrell Creek. Note the observed distribution does not statistically conform $(\mathrm{P}<0.05)$ with the expected

random distribution. 


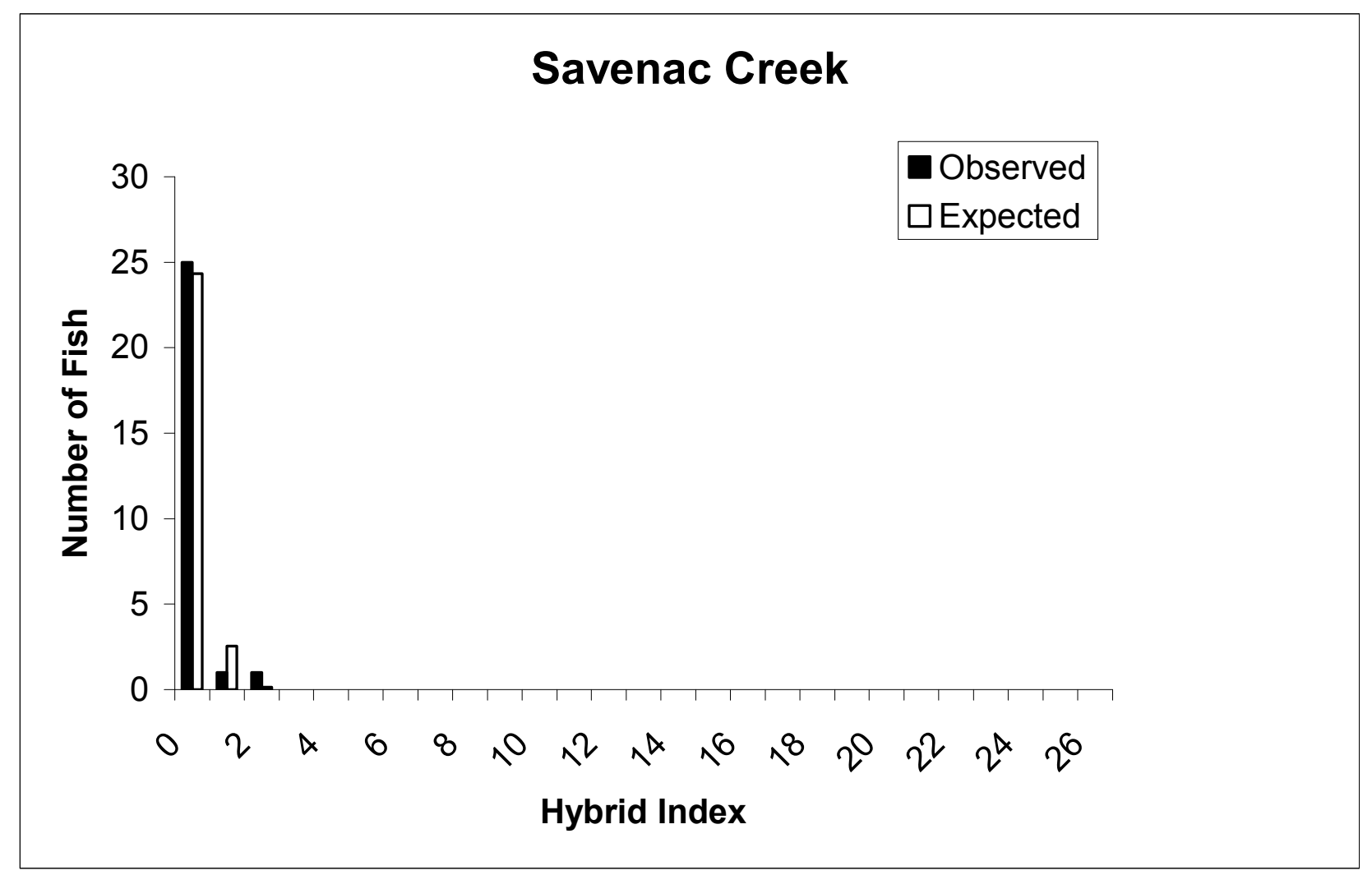

Figure 11.- Observed and expected random distribution of hybrid index values between westslope cutthroat and

rainbow trout in a sample showing evidence of hybridization between these fishes collected from Savenac

Creek. Note the observed distribution does not statistically conform $(\mathrm{P}<0.05)$ with the expected random

distribution. 


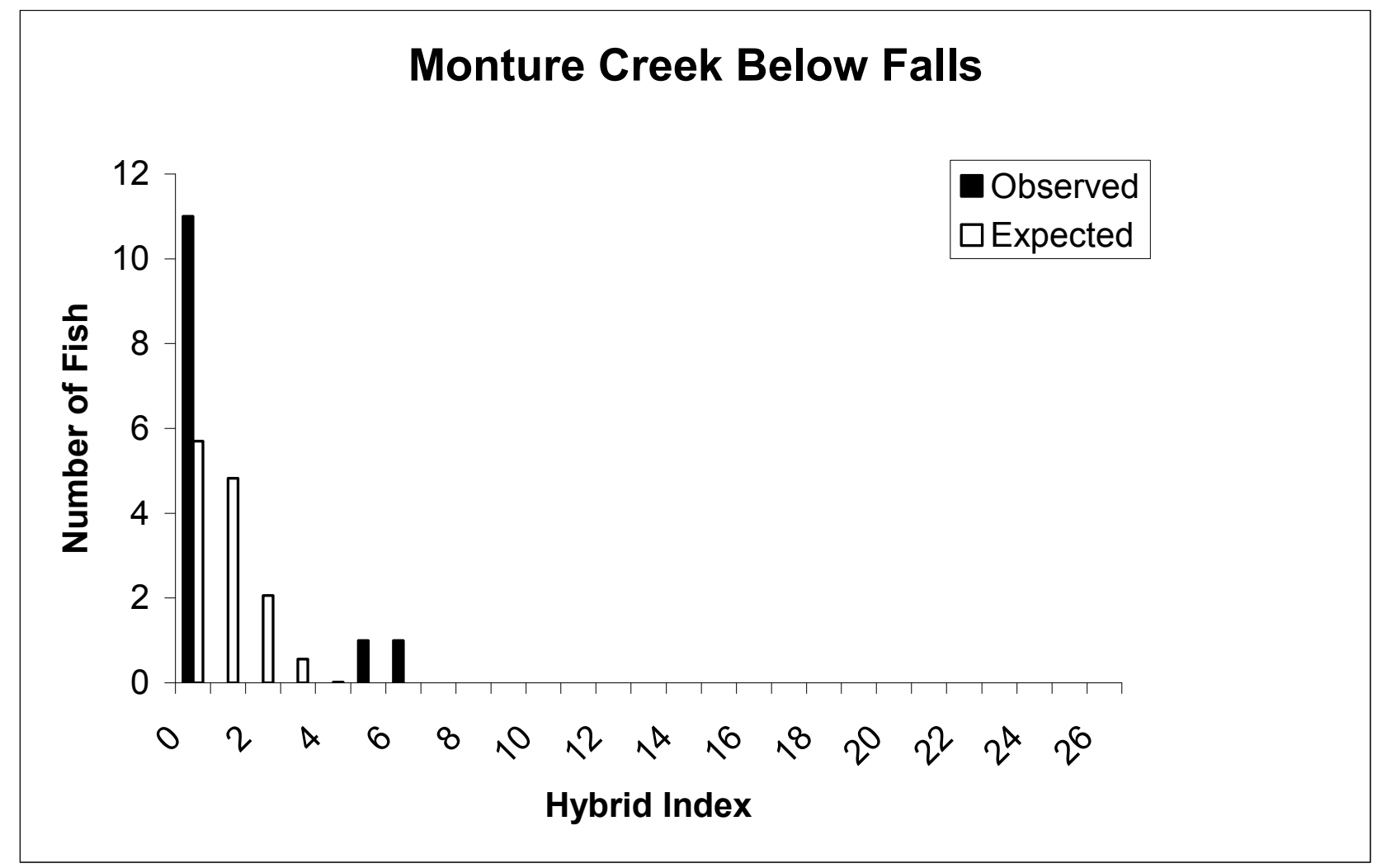

Figure 12.- Observed and expected random distribution of hybrid index values between westslope cutthroat and

rainbow trout in a sample showing evidence of hybridization between these fishes collected from Monture

Creek below the falls. Note the observed distribution does not statistically conform $(\mathrm{P}<0.05)$ with the

expected random distribution. 


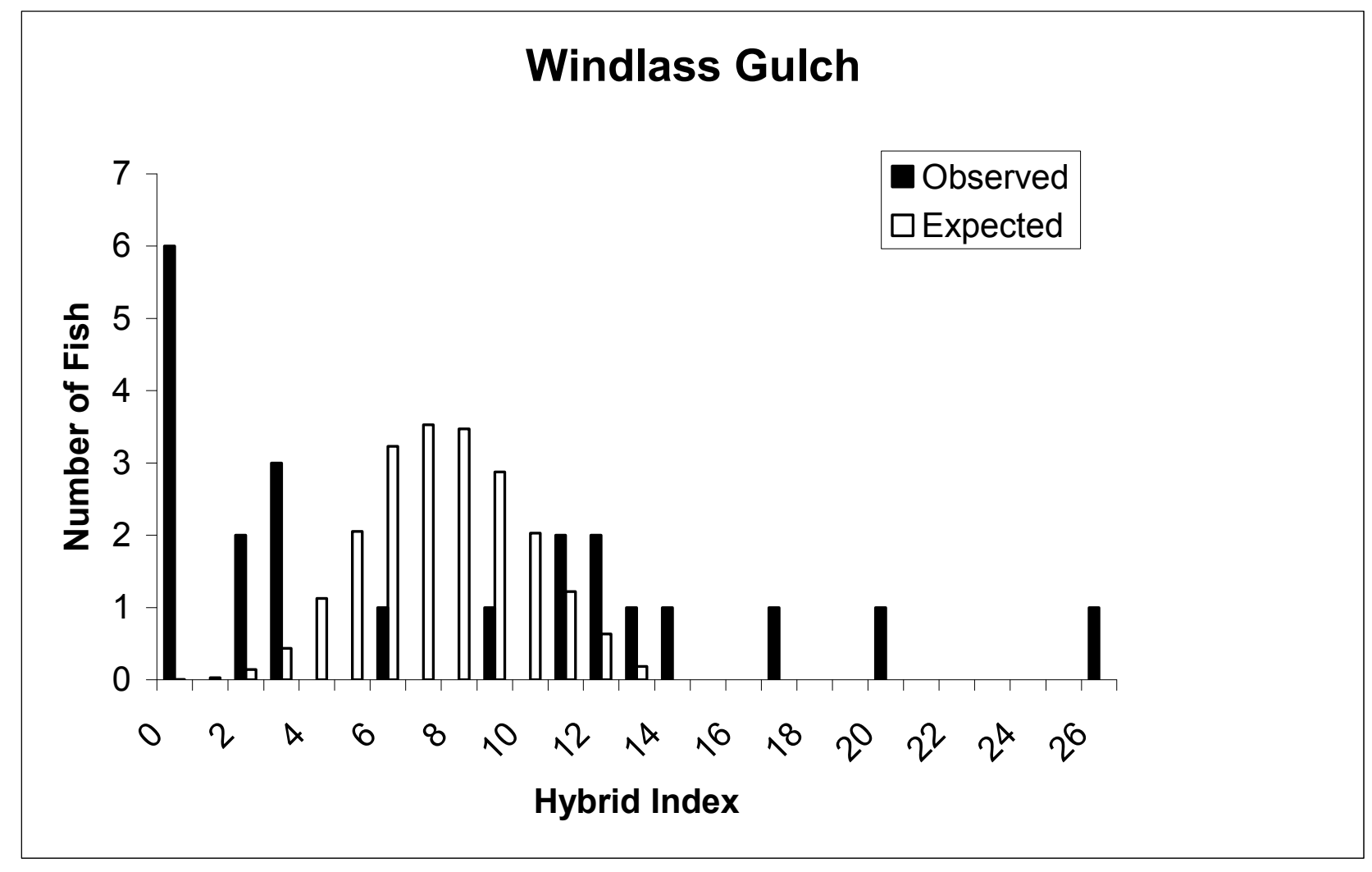

Figure 13.- Observed and expected random distribution of hybrid index values between westslope cutthroat and

rainbow trout in a sample showing evidence of hybridization between these fishes collected from Windlass

Gulch. Note the observed distribution does not statistically conform $(\mathrm{P}<0.05)$ with the expected random

distribution. 


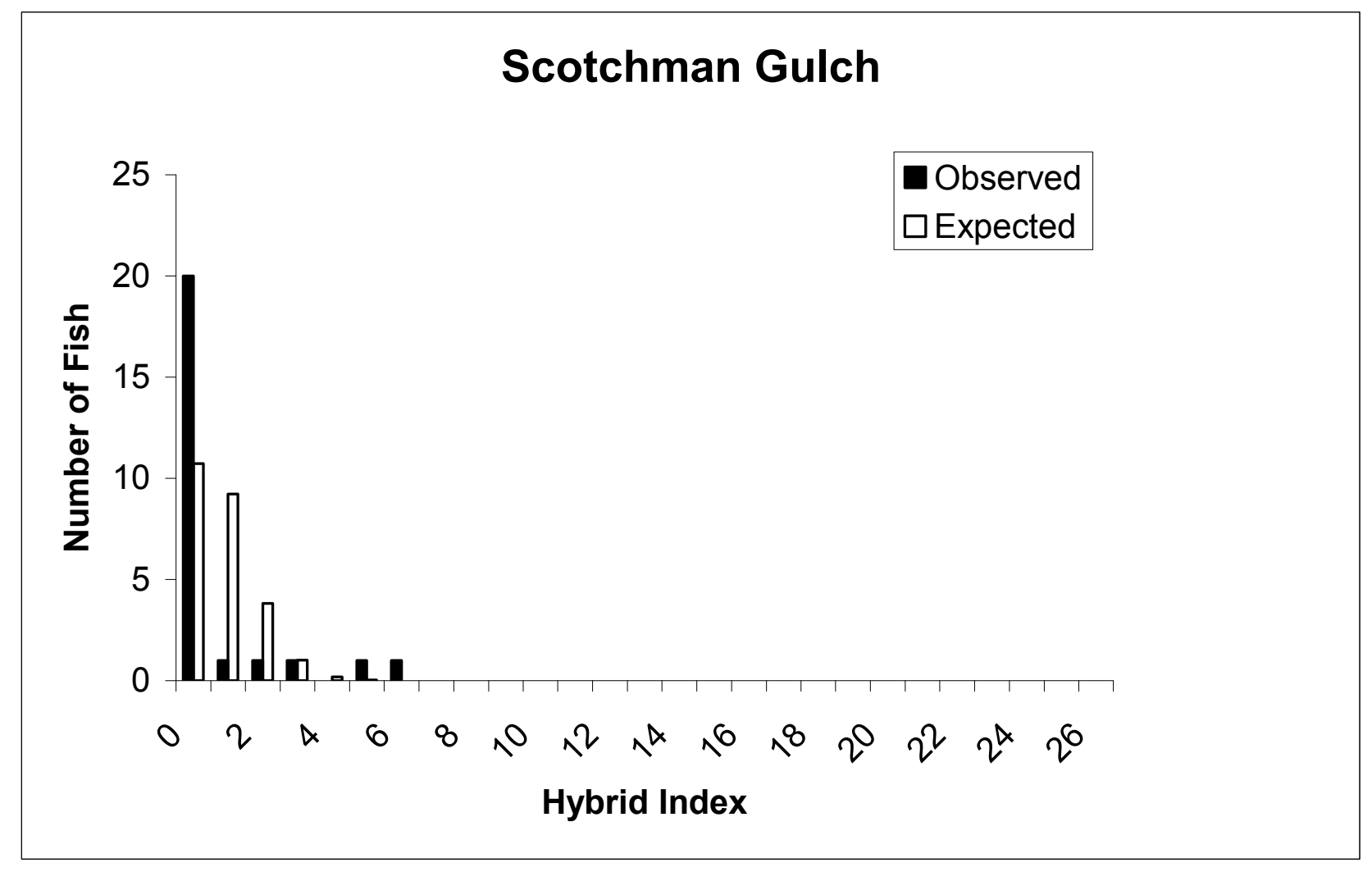

Figure 14.- Observed and expected random distribution of hybrid index values between westslope cutthroat and

rainbow trout in a sample showing evidence of hybridization between these fishes collected from

Scotchman Gulch . Note the observed distribution does not statistically conform $(\mathrm{P}<0.05)$ with the expected

random distribution. 


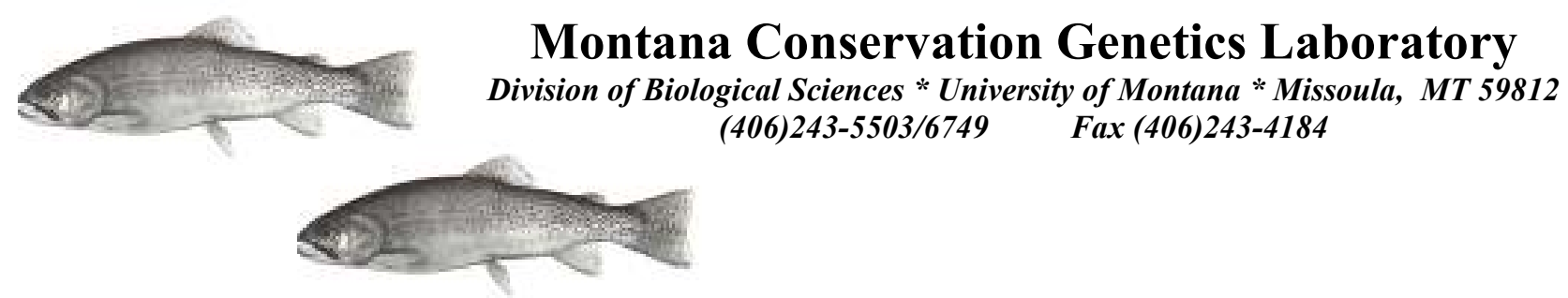

March 7, 2008

Ladd Knotek

Montana Fish, Wildlife, \& Parks

3201 Spurgin Road

Missoula, Montana 59801

Ladd:

In order to determine if there is evidence of hybridization, we used a combination of insertion/deletion events (indel loci) and microsatellite loci to analyze DNA extracted from fin clips taken from trout sampled from the following populations:

Summary of results.

$\mathrm{f}$

Sample \# Water Name/Location/Collection Date/ Individuals

Collector

3499 Devils Creek

$17 \mathrm{~N} 25 \mathrm{~W} 14$

$8 / 1 / 2001$

Ladd Knotek

R13Y8 WCT X RBT

W96.2XR3.8

3500

Eustache Creek

$17 \mathrm{~N} 25 \mathrm{~W} 12$

$8 / 1 / 2001$

Ladd Knotek

$3501 \quad$ Ninemile Creek

$17 \mathrm{~N} 24 \mathrm{~W} 18$

$8 / 1 / 2001$

Ladd Knotek

3502 Bertha Creek

19N16W28

$7 / 24 / 2007$

Ladd Knotek

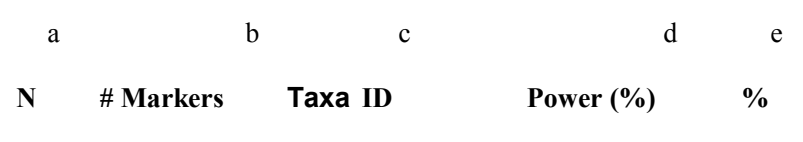

R13Y8

$10 \quad$ R13Y8 WCT X RBT

W93.4XR6.6

$3503 \quad$ Blind Canyon Creek

$17 \mathrm{~N} 14 \mathrm{~W} 16$

$47.208 \quad 113.42$

6/26/2007

Ladd Knotek

18 (26) R13Y8 WCT X RBT

W99.1XR0.9 
7/6/2006

Ladd Knotek

f

Sample \# Water Name/Location/Collection Date/

Individuals

Collector

3505

Broadus Creek

47.258112 .83

$7 / 12 / 2007$

Ron Pierce

3506

Butler Creek

16 N22W20

$9 / 3 / 2002$

Ladd Knotek

3507

Camp Creek

$18 \mathrm{~N} 15 \mathrm{~W} 29$

47.333113 .53

6/19/2007

Ladd Knotek

3508 Canyon Creek

47.220112 .97

$7 / 14 / 2007$

Ron Pierce

3509 Colt Creek

47.323113 .60

$7 / 31 / 2007$

Ladd Knotek

3510

Cooney Creek

47.258112 .81

$7 / 12 / 2007$

Ron Pierce

3511 Deborta Creek

47.269112 .81

$7 / 13 / 2007$

Ron Pierce

3512

Findell Creek

17N05W32

$7 / 24 / 2007$

Ladd Knotek

3513 Lower Holloman Creek

$11 \mathrm{~N} 18 \mathrm{~W} 17$

8/8/2007

Ladd Knotek

$3514 \quad$ Upper Holloman Creek

$11 \mathrm{~N} 18 \mathrm{~W} 16$

8/8/2007

Ladd Knotek

3515 Lower Inez Creek

17N15W32

6/20/2006

Ladd Knotek

$\begin{array}{lrrrrr} & & \text { b } & \text { c } & \text { d } & \text { e } \\ \text { N } & \text { \# markers } & \text { Taxa ID } & \text { Power (\%) } & \text { \% WCT } \\ & & & \\ 4 & \text { R13Y8 } & \text { WCT X RBT } & \text { W6.7XR93.3 }\end{array}$

$\mathrm{R} 12 \mathrm{Y} 8$

WCT?

R99Y98

12

R13Y8 WCT X RBT

25

R13Y8

WCT

R99Y98

25

R13Y8 WCT X RBT

W99.4XR0.6

W9.4XR0.6

1 R13Y8 WCT?

5 R13Y8 WCT X YCT X RBT

$\begin{array}{llll}22 & \text { R12Y8 } & \text { WCT? } & \text { R99Y97 }\end{array}$

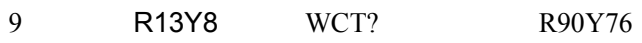

10 R13Y8 WCT X RBT

$8 \quad$ R13Y8 WCT??

WCT X RBT 


$$
\text { f }
$$$$
\text { Sample \# Water Name/Location/Collection Date/ }
$$

$\begin{array}{rrrrrr} & \text { b } & \text { c } & \text { d } & \text { e } \\ \text { N } & \text { \# Markers } & \text { Taxa ID } & \text { Power (\%) } & \%\end{array}$

R13Y8 WCT X RBT

W98.5XR1.5
R13Y8

WCT?

R97Y88

8

R13Y8

WCT?

R88Y72

11

R13Y8 WCT X YCT X RBT

1

$11 \quad \mathrm{R} 13 \mathrm{Y} 8$

WCT?

R94Y83 


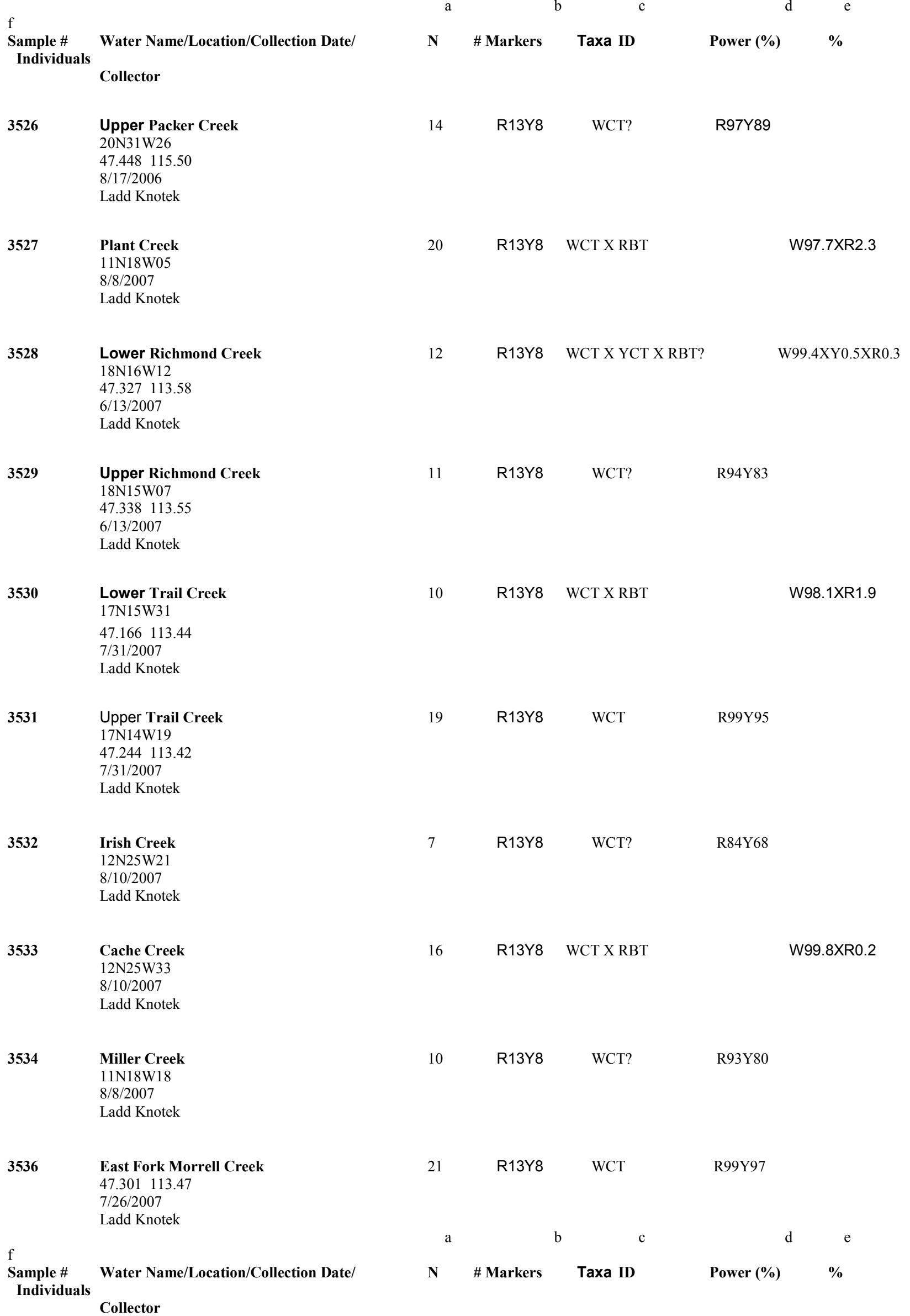




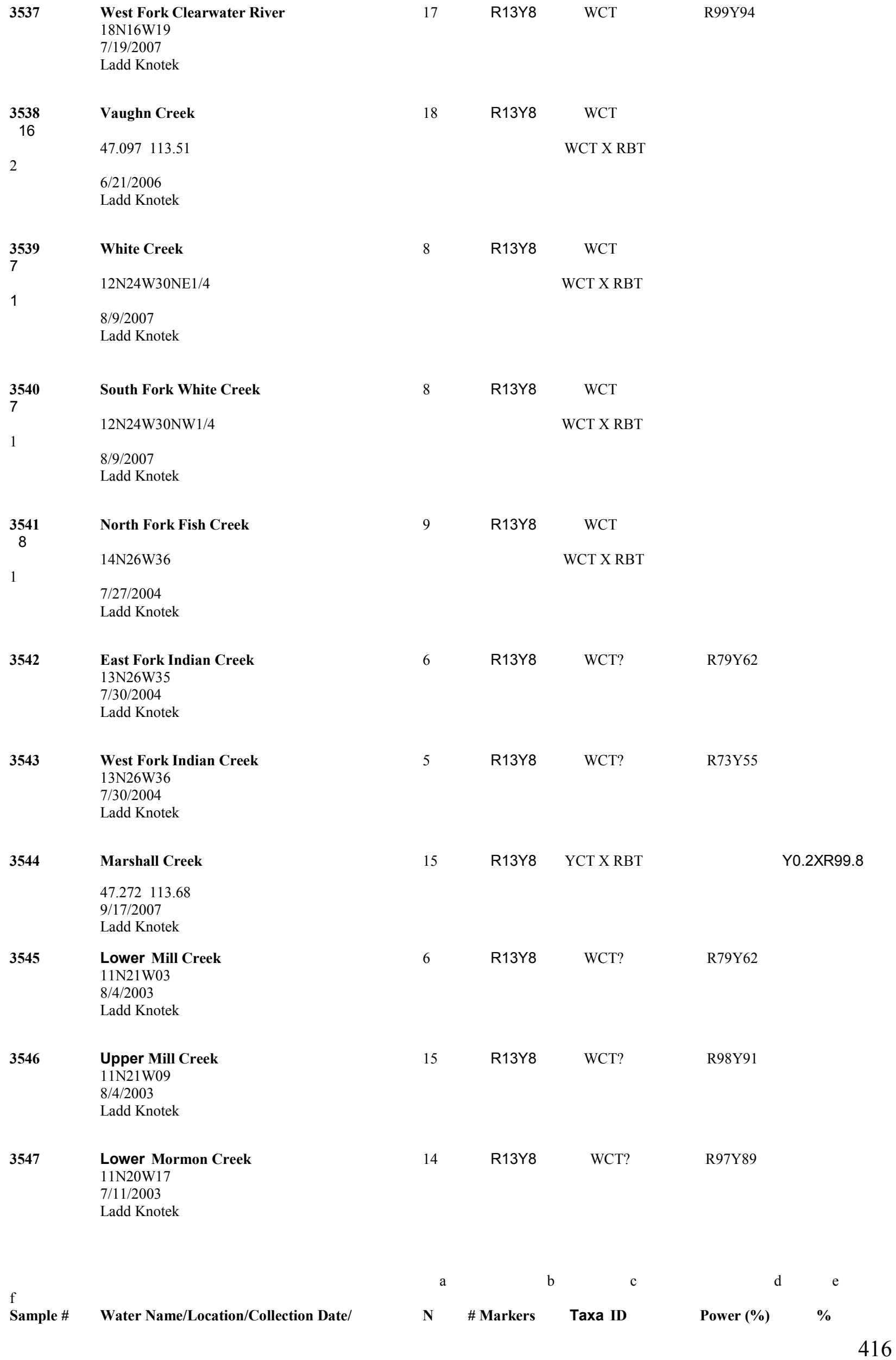




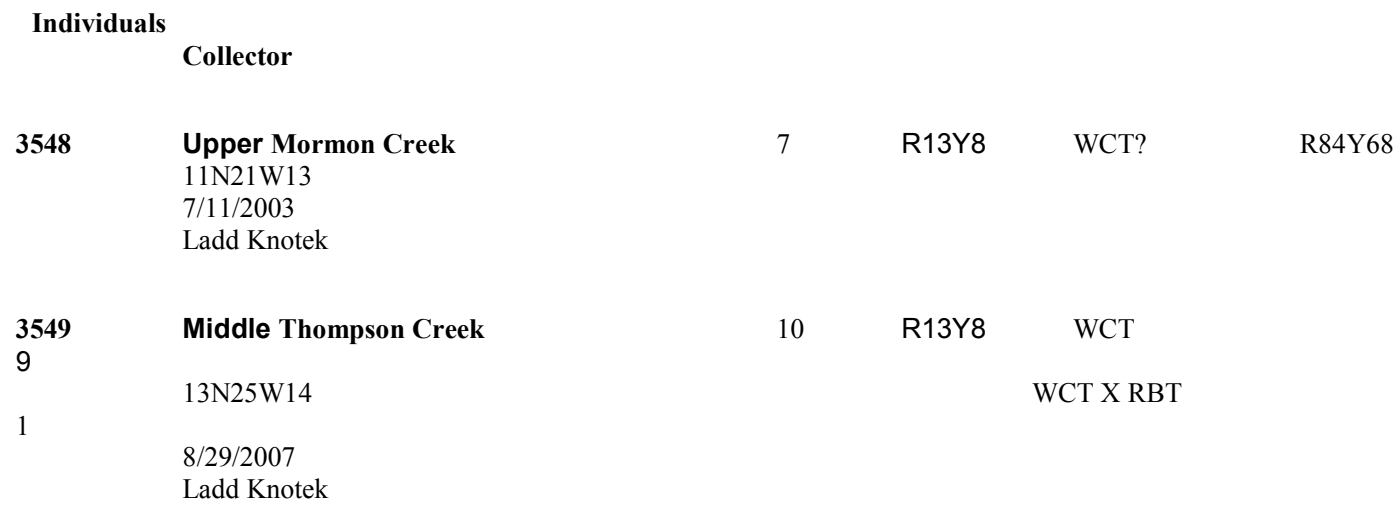

\begin{abstract}
${ }^{a}$ Number of fish successfully analyzed. If combined with a previous sample, the number in parentheses indicates the combined sample size.

${ }^{\mathrm{b}}$ Number of diagnostic loci analyzed for the non-native taxa ( $\mathrm{R}=$ rainbow trout Oncorhynchus mykiss, $\mathrm{W}=$ westslope cutthroat trout

O. clarki lewisii, $\mathrm{Y}=$ Yellowstone cutthroat trout $O$. c. bouvieri).

${ }^{\mathrm{c}}$ Codes: $\mathrm{WCT}=$ westslope cutthroat trout; $\mathrm{RBT}=$ rainbow trout; $\mathrm{YCT}=$ Yellowstone cutthroat trout. Only one taxon code is listed when the entire sample possessed alleles from that taxon only. It must be noted, however, that we cannot definitely rule out the possibility that some or all of the individuals are hybrids. We may not have detected any non-native alleles at the loci examined because of sampling error (see Power \%). Taxa codes separated by "x" indicate hybridization between those taxa. ${ }^{\mathrm{d}}$ Number corresponds to the percent chance we have to detect $1 \%$ hybridization given the number of individuals successfully analyzed and the number of diagnostic markers used. For example, with 25 individuals we have better than a $99 \%$ chance to detect as little as $1 \%$ hybridization with rainbow trout or a $98 \%$ chance to detect as little as $1 \%$ hybridization with Yellowstone cutthroat trout in a hybrid swarm (a random mating population in which taxa markers are randomly distributed among individuals such that essentially all of them in the population are of hybrid origin) that once was a westslope cutthroat trout population. Likewise, with 25 individuals we have better than a $99 \%$ chance to detect as little as a $1 \%$ rainbow trout genetic contribution in a hybrid swarm that once was a Yellowstone cutthroat trout population. Not reported when hybridization is detected. Taxa as in b.

${ }^{\mathrm{e}}$ Indicates the genetic contribution of the hybridizing taxa in the order listed under c. This number is usually reported only if the sample appears to have come from a hybrid swarm.

${ }^{\mathrm{f}}$ Indicates number of individuals with genetic characteristics corresponding to the taxa ID code column when the sample can be analyzed at the individual level. This occurs when marker alleles are not randomly distributed among individuals and hybrids and non-hybrids can be reliably distinguished.
\end{abstract}

\title{
Methods and Data Analysis
}

The indel technique (Ostberg and Rodriguez 2004) uses short synthetically made segments of DNA called primers, in pairs, to detect areas of DNA in trout that have undergone insertion or deletion (indel) events. During the polymerase chain reaction (PCR), the primers bind to specific areas of the organismal DNA and many copies of the DNA between the primers are made using dye labeled nucleotides. The indel events have resulted in length differences (alleles) in the region of DNA copied between the primers that characterize different trout taxa. These differences have been found to be useful for analysis of hybridization (e.g. Ostberg et al. 2004; Ostberg and Rodriguez 2006). After PCR, the alleles are separated from each other using capillary electrophoresis and visualized using an applied Biosystems 3130x1 genetic analyzer. The alleles are labeled by the primers used to produce them and the number of nucleotides in the sequence. After electrophoresis, the alleles detected in an individual are determined by comparison to synthetic fragments of DNA of known length and alleles from previously analyzed individuals.

Microsatellite loci are segments of DNA in which small nucleotide sequences (usually two to five nucleotides) are consecutively repeated numerous times. By using PCR amplification methods similar to those used for indel loci, specific microsatellite loci can be analyzed for differences in the number of repeat units. These differences result in size differences among alleles which are detected using the procedure used to detect indel alleles.

We obtained data from seven indel loci and seven microsatellite loci. At 13 of these loci, westslope cutthroat trout, Oncorhynchus clarki lewisii, and rainbow trout, O. mykiss, rarely share alleles in 
common (Table 1). This situation also pertains to a comparison of westslope and Yellowstone cutthroat trout, O. c. bouvieri, at eight loci and Yellowstone cutthroat and rainbow trout at 14 loci (Table 1). Finally, seven loci usually distinguish all three taxa from each other (Table 1).

Loci at which taxa rarely share alleles in common are often termed diagnostic or marker loci because the alleles detected at them can be used to help determine if a sample came from a non-hybridized population or a population in which hybridization between two or more taxa has or is occurring. Individuals from a non-hybridized population will possess alleles at all diagnostic loci analyzed characteristic of only that taxon. In contrast, since half the DNA from first generation hybrids $\left(\mathrm{F}_{1}\right)$ comes from each of the parental taxa $\mathrm{F}_{1}$ individuals will possess alleles characteristic of both the hybridizing taxa at all diagnostic loci analyzed. In later generation hybrids (post $\mathrm{F}_{1}$ ), the amount and particular regions of DNA acquired from the parental taxa will vary among individuals. Thus, the particular alleles detected in post $\mathrm{F}_{1}$ hybrids will be highly variable at the diagnostic loci analyzed within and among individuals.

An important aspect of both indel and microsatellite alleles is that they demonstrate a codominant mode of inheritance. That is, all genotypes are readily distinguishable from each other. Thus, at diagnostic loci the genotype of individuals in a sample can directly be determined. From these data, the proportion of alleles from different taxa in the population sampled can be directly estimated at each diagnostic locus analyzed. These values averaged over all diagnostic loci yields an estimate of the proportion of alleles in the population that can be attributed to one or more taxa (proportion of admixture).

When evidence of hybridization is detected, the next issue to address is whether or not the sample appears to have come from a hybrid swarm. That is, a random mating population in which the alleles of the hybridizing taxa are randomly distributed among individuals such that essentially all of them are of hybrid origin.

A common attribute of hybrid swarms is that allele frequencies at diagnostic loci are usually similar among them because their presence can all be traced to a common origin or origins. Thus, one criterion we used for the assessment of whether or not a sample appeared to have come from a hybrid swarm was whether or not the allele frequencies among diagnostic loci reasonably conformed to homogeneity using contingency table chi-square.

In order to determine whether or not alleles at the diagnostic loci were randomly distributed among the fish in a sample showing evidence of hybridization, we calculated a hybrid index for each fish in the sample. The hybrid index for an individual was calculated as follows. At each diagnostic locus, an allele characteristic of the native taxon was given a value of zero and an allele characteristic of the non-native taxon a value of one. Thus, at a single diagnostic locus the hybrid index for an individual could have a value of zero (only native alleles present), one (both native and non-native alleles present), or two (only non-native alleles present). These values summed over all diagnostic loci analyzed yields an individual's hybrid index. Considering westslope cutthroat and rainbow trout, therefore, non-hybridized westslope cutthroat trout would have a hybrid index of zero, nonhybridized rainbow trout a hybrid index of $26, \mathrm{~F}_{1}$ hybrids a hybrid index of 13 , and post $\mathrm{F}_{1}$ hybrids could have values ranging from zero to 26 . The distribution of hybrid indices among the fish in a sample was statistically compared to the expected random binomial distribution based on the proportion of admixture detected estimated from the allele frequencies at the diagnostic loci. If the allele frequencies appeared to be statistically homogeneous among the diagnostic loci and the observed distribution of hybrid indices reasonably conformed to the expected random distribution, then the sample was considered to have come from a hybrid swarm.

In very old hybrid swarms, allele frequencies at diagnostic loci can randomly diverge from homogeneity over time because of genetic drift. In this case, however, the observed distribution of 
hybrid indices is still expected to reasonably conform to the expected random distribution. Thus, if the allele frequencies were statistically heterogeneous among the diagnostic loci in a sample, but the observed distribution of hybrid indices reasonably conformed to the expected random distribution the sample was also considered to have come from a hybrid swarm.

The strongest evidence that a sample showing evidence of hybridization did not come from a hybrid swarm is failure of the observed distribution of hybrid indices to reasonably conform to the expected random distribution. The most likely reasons for this are that the population has only recently become hybridized or the sample contains individuals from two or more populations with different proportions of admixture. At times, the distribution of genotypes at diagnostic loci and the observed distribution of hybrid indices can provide insight into which of these two factors appears mainly responsible for the nonrandom distribution of the alleles from the hybridizing taxa among individuals in the population. At other times, the distribution of genotypes at diagnostic loci and the observed distribution of hybrid indices may provide little or no insight into the cause of the nonrandom distribution of alleles among individuals. The latter situation is expected to be fairly common as the two factors usually responsible for the nonrandom distribution of alleles are not necessarily mutually exclusive. Regardless of the cause, when alleles at the diagnostic loci do not appear to be randomly distributed among individuals in a sample, estimating the proportion of admixture has little if any biological meaning and, therefore, is generally not estimated and reported.

Failure to detect evidence of hybridization in a sample does not necessarily mean the population is non-hybridized because there is always the possibility that we would not detect evidence of hybridization because of sampling error. When no evidence of hybridization was detected in a sample, we assessed the likelihood the population is non-hybridized by determining the chances of not detecting as little as a one percent genetic contribution of a non-native taxon to a hybrid swarm. This is simply $0.99^{2 \mathrm{NX}}$ where $\mathrm{N}$ is the number of fish in the sample and $\mathrm{X}$ is the number of diagnostic loci analyzed.

\section{Results and Discussion:}

\section{Devils Creek 3499}

Alleles characteristic of both westslope cutthroat and rainbow trout were detected at five of the 13 diagnostic loci between these species that were analyzed in the sample from Devils Creek (Table 2). The allele frequencies were statistically homogeneous $\left(X^{2}{ }_{12}=15.232 ; \mathrm{P}>0.10\right)$ among the diagnostic loci and the rainbow trout alleles appeared to be randomly distributed $\left(X^{2}{ }_{3}=0.886\right.$; $\mathrm{P}>0.50$ ) among the fish in the sample. This sample, therefore, appears to have come from a hybrid swarm between westslope cutthroat and rainbow trout with a predominant $(0.96)$ westslope cutthroat trout genetic contribution.

\section{Eustache Creek 3500}

At eight of the 13 diagnostic loci between westslope cutthroat and rainbow trout that were analyzed in the sample from Eustache Creek, alleles characteristic of both fishes were detected (Table 2). Although the allele frequencies were statistically heterogeneous $\left(X^{2}{ }_{12}=25.908\right.$; $\mathrm{P}<0.05)$ among the diagnostic loci in the sample, the rainbow trout alleles appeared to be randomly distributed among the fish $\left(X^{2}{ }_{2}=5.518 ; \mathrm{P}>0.05\right)$. Thus, Eustache Creek appears to contain a hybrid swarm between westslope cutthroat and rainbow trout with a predominant (0.93) westslope cutthroat trout genetic contribution.

\section{Ninemile Creek 3501}


Because of poor DNA quality, we were not able to obtain the genotype of all individuals at all the loci analyzed in the Ninemile Creek sample. At nine of the 13 diagnostic loci between westslope cutthroat and rainbow trout that were analyzed, however, alleles characteristic of both fishes were detected in the sample (Table 3). The allele frequencies were statistically homogeneous $\left(X^{2}{ }_{12}=14.296 ; \mathrm{P}>0.10\right)$ among the diagnostic loci. Because of missing genotypes we were not able to obtain hybrid indices for all the fish and statistically determine whether or not the sample appeared to have come from a hybrid swarm. Of the seven fish in the sample, however, five were definitely of hybrid origin suggesting that the majority or all of the fish in this reach of Ninemile Creek were hybrids. Thus, from a management perspective this section of Ninemile Creek should simply be considered to contain hybrids between westslope cutthroat and rainbow trout.

\section{Bertha Creek (combined) 3502}

This reach of Bertha Creek was previously sampled July 19, 2006 (sample \#3367; N=8). Between the two samples, evidence of genetic variation was detected at five loci. The allele frequencies were statistically homogeneous between the samples at all these loci. Thus, there was no evidence of genetic differences between the samples so they were combined into one for further analysis.

In the combined sample, alleles characteristic of both westslope cutthroat and rainbow trout were detected at two of the 13 diagnostic loci between these species that were analyzed (Table 2). The allele frequencies were statistically homogeneous $\left(X^{2}{ }_{12}=10.627 ; \mathrm{P}>0.50\right)$ among the diagnostic loci and the rainbow trout alleles were randomly distributed $\left(X^{2}{ }_{1}=0.078 ; \mathrm{P}>0.50\right)$ among the fish in the sample. This sample, therefore, appears to have come from a hybrid swarm between westslope cutthroat and rainbow trout with a predominant $(>0.99)$ westslope cutthroat trout genetic contribution. Furthermore, these results suggest the population has been hybridized for many generations suggesting that the failure to detect evidence of hybridization in the first sample was simply due to sampling error. With the first sample size of eight and the estimated proportion of rainbow trout alleles in the population, we had a $15 \%$ chance of detecting no evidence of hybridization.

\section{Blind Canyon Creek 3503}

Fish were collected from three reaches of Blind Canyon Creek. Among these samples, evidence of genetic variation was detected at seven loci. The allele frequencies were statistically heterogeneous among the samples only at $O m y 1001^{*}\left(X^{2}{ }_{20}=31.604 ; \mathrm{P}<0.05\right)$. This could indicate that genetic differences exist among the samples or it could simply be a chance departure from homogeneity due to the number of comparisons performed. In order to distinguish between these possibilities, we compared the chi-square statistic at $0 m y 1001 *$ to the modified level of significance proposed by Rice (1989). At the modified level, this difference is not significant. Thus, it most likely represents a chance departure from homogeneity and there is no compelling evidence of genetic differences among the samples. The samples, therefore, were combined into a single Bertha Creek sample for further analysis.

At two of the 13 diagnostic loci between westslope cutthroat and rainbow trout that were analyzed, alleles characteristic of both fishes were detected in the combined sample (Table 2). The allele frequencies were statistically homogeneous $\left(X^{2}{ }_{12}=11.319 ; \mathrm{P}>0.10\right)$ among the diagnostic loci in the sample and the rainbow trout alleles appeared to be randomly distributed among the fish $\left(X^{2}=0.101 ; \mathrm{P}>0.50\right)$. Thus, Blind Canyon Creek appears to contain a hybrid 
swarm between westslope cutthroat and rainbow trout with a predominant $(>0.99)$ westslope cutthroat trout genetic contribution.

\section{Boles Creek 3504}

Fish were sampled from three areas of Boles Creek. Evidence of genetic variation was detected at nine loci among the samples. At all of these loci, the allele frequencies were statistically homogeneous among the samples. Thus, they were combined into one for further analysis.

Alleles characteristic of both westslope cutthroat and rainbow trout were detected at six of the 13 diagnostic loci between these species that were analyzed in the combined sample (Table 2). Although the allele frequencies were statistically heterogeneous $\left(X^{2}{ }_{12}=37.904 ; \mathrm{P}<0.001\right)$ among the diagnostic loci, the rainbow trout alleles appeared to be randomly distributed $\left(X_{2}^{2}=3.379\right.$; $\mathrm{P}>0.10$ ) among the fish in the sample. This sample, therefore, appears to have come from a hybrid swarm between westslope cutthroat and rainbow trout with a predominant $(0.98)$ westslope cutthroat trout genetic contribution.

\section{Broadus Creek 3505}

Alleles characteristic of both westslope cutthroat and rainbow trout were detected at seven of the 13 diagnostic loci between these species that were analyzed in the sample from Broadus Creek (Table 2). The allele frequencies were statistically homogeneous $\left(X_{12}^{2}=7.448 ; \mathrm{P}>0.05\right)$ among the diagnostic loci and the rainbow trout alleles appeared to be randomly distributed $\left(X^{2}{ }_{3}=2.879\right.$; $\mathrm{P}>0.10$ ) among the fish in the sample. This sample, therefore, appears to have come from a hybrid swarm between westslope cutthroat and rainbow trout with a predominant $(0.93)$ rainbow trout genetic contribution.

\section{Butler Creek 3506}

Samples were collected from above and below the dam in Butler Creek. Between the two samples, evidence of genetic variation was detected at five loci. The allele frequencies were statistically homogeneous between the samples at all these loci. The two samples, therefore, were combined into a single Butler Creek sample for subsequent analysis.

With the exception of Ssa408*, alleles characteristic of only westslope cutthroat trout were detected in the combined sample (Table 5). At $S s a 408^{*}$, one fish collected from below the dam possessed a single copy of the $282^{*}$ allele. This allele is usually characteristic of rainbow trout (Table 1). Its presence in the sample, therefore, could indicate a small amount of hybridization with rainbow trout or it could be westslope cutthroat trout genetic variation that is indistinguishable from that usually characteristic of rainbow trout. In this situation, we can not distinguish between these possibilities. With this uncertainty and a lack of conclusive evidence for hybridization, the conservative approach would be to consider Butler Creek as containing a non-hybridized westslope cutthroat trout population unless future data indicate otherwise.

\section{Camp Creek 3507}

At seven of the 13 diagnostic loci between westslope cutthroat and rainbow trout that were analyzed, alleles characteristic of both fishes were detected in the Camp Creek sample (Table 3). 
Although the allele frequencies were statistically homogeneous $\left(X_{12}^{2}=10.101 ; \mathrm{P}>0.50\right)$ among the diagnostic loci in the sample, the rainbow trout alleles were not randomly distributed among the fish $\left(X_{2}^{2}=9.013 ; \mathrm{P}<0.05\right)$. In contrast, significantly more fish had a hybrid index of three and significantly fewer fish a hybrid index of one than expected by chance (Figure 1). This sample, therefore, probably contained a mixture of hybridized and non-hybridized westslope cutthroat trout. The potentially non-hybridized westslope cutthroat trout and hybrids, however, do not fall into distinct groups. Thus, it will not be possible on an individual basis to reliably separate the non-hybridized fish from hybrids. From a management perspective, therefore, Camp Creek should simply be considered to contain hybrids between westslope cutthroat and rainbow trout with a predominant westslope cutthroat trout genetic component.

\section{Canyon Creek 3508}

Alleles characteristic of only westslope cutthroat trout were detected at all the loci analyzed in the sample from Canyon Creek (Table 5). With the sample size of 25, we have better than a 99\% chance of detecting as little as a one percent rainbow trout and better than a $98 \%$ chance of detecting as little as a one percent Yellowstone cutthroat trout genetic contribution to a hybrid swarm that once was non-hybridized westslope cutthroat trout. Canyon Creek, therefore, very likely contains a non-hybridized westslope cutthroat trout population.

\section{Colt Creek 3509}

Samples were collected from three reaches of Colt Creek. Among these samples, evidence of genetic variation was detected at seven loci. The allele frequencies were statistically homogeneous among the samples at all these loci. Thus, the samples were combined into a single Colt Creek sample for subsequent analysis.

Alleles characteristic of both westslope cutthroat and rainbow trout were detected at two of the 13 diagnostic loci between these species that were analyzed in the combined sample (Table 2). Although the allele frequencies were statistically heterogeneous $\left(X^{2}{ }_{12}=28.463 ; \mathrm{P}<0.01\right)$ among the diagnostic loci, the rainbow trout alleles were randomly distributed $\left(X^{2}{ }_{1}=0.389 ; \mathrm{P}>0.50\right)$ among the fish in the sample. Fish definitely of hybrid origin were detected in both the middle and upper reaches of the creek that were sampled. Colt Creek, therefore, appears to contain a hybrid swarm between westslope cutthroat and rainbow trout with a predominant $(0.99)$ westslope cutthroat trout genetic contribution.

\section{Cooney Creek 3510}

A single fish believed to be a rainbow trout was collected from Cooney Creek. In contrast to the expectation, alleles characteristic of only westslope cutthroat trout were detected at all the loci analyzed in this fish. This fish, therefore, was undoubtedly not a rainbow trout and in fact may possibly have been a non-hybridized westslope cutthroat trout.

\section{Deborta Creek 3511}

Alleles characteristic of rainbow, Yellowstone cutthroat, and westslope cutthroat trout were detected in the sample collected from Deborta Creek (Table 4). The westslope cutthroat $\left(X_{6}^{2}=19.027 ; \mathrm{P}<0.01\right)$ and Yellowstone cutthroat trout $\left(X^{2}{ }_{7}=23.563 ; \mathrm{P}<0.01\right)$ allele frequencies were statistically heterogeneous among the diagnostic loci and they were not randomly distributed $\left(X_{11}^{2}=123.008 ; \mathrm{P}<0.001\right)$ among the fish in the sample (Figure 2). Although Deborta Creek does not appear to contain a hybrid swarm, all the fish in the sample were definitely of 
hybrid origin. From a management perspective, therefore, Deborta Creek should simply be considered to contain hybrids among westslope cutthroat, Yellowstone cutthroat, and rainbow trout with a predominant rainbow trout genetic contribution.

\section{Findell Creek 3512}

Samples were collected from two reaches of Findell Creek. Between the two samples, evidence of genetic variation was detected at six loci. The allele frequencies were statistically heterogeneous between the samples only at $O \operatorname{mm~1050*}\left(X_{1}^{2}=4.400 ; \mathrm{P}<0.05\right)$. This difference, however, is not significant at the modified level suggesting it most likely represents a chance departure from homogeneity. Since there was no compelling evidence of genetic differences between the samples, they were combined into a single Findell Creek sample for subsequent analysis.

With the exception of $\mathrm{Om} 55^{*}$, alleles characteristic of only westslope cutthroat trout were detected in the combined sample (Table 5). At $\mathrm{Om} 55^{*}$, one fish collected from the upper reach possessed a single copy of the $199 *$ allele. This allele is usually characteristic of rainbow trout (Table 1). Its presence in the sample, therefore, could indicate a small amount of hybridization with rainbow trout or it could simply be westslope cutthroat trout genetic variation that is indistinguishable from that usually characteristic of rainbow trout. In this situation, we can not distinguish between these possibilities. With this uncertainty and a lack of conclusive evidence for hybridization, the conservative approach would be to consider Findell Creek as containing a non-hybridized westslope cutthroat trout population unless future data indicate otherwise.

\section{Holloman Creek}

Samples were collected from two reaches of Holloman Creek. Between the two samples, evidence of genetic variation was detected at all 14 loci analyzed. The allele frequencies were statistically heterogeneous between the samples at ten of these loci. These differences remain significant at the modified level indicating that genetic differences exist between the samples. The lower and upper Holloman Creek samples, therefore, were treated separately for further analysis.

\section{Lower Holloman Creek 3513}

Alleles characteristic of only westslope cutthroat trout were detected at all the loci analyzed in the sample from lower Holloman Creek (Table 5). With the sample size of nine, however, we have only a $90 \%$ chance of detecting as little as a one percent rainbow trout and only a $76 \%$ chance of detecting as little as a one percent Yellowstone cutthroat trout genetic contribution to a hybrid swarm that once was non-hybridized westslope cutthroat trout. Thus, we can not reasonably exclude the possibility that the fish in lower Holloman Creek may be slightly hybridized with rainbow trout, Yellowstone cutthroat trout, or both fishes but evidence of this was not detected because of sampling error. Since the status of the trout in lower Holloman Creek is uncertain and there was no evidence of hybridization, the conservative approach would be to consider this reach of the creek to contain non-hybridized westslope cutthroat trout unless further data indicate otherwise.

\section{Upper Holloman Creek 3514}

Alleles characteristic of both westslope cutthroat and rainbow trout were detected at all 13 of the diagnostic loci between these species that were analyzed in the sample from upper Holloman 
Creek (Table 3). Although the allele frequencies were statistically homogeneous $\left(X^{2}{ }_{12}=10.258\right.$; $\mathrm{P}>0.50$ ) among the diagnostic loci, the rainbow trout alleles were not randomly distributed $\left(X^{2}{ }_{11}=923.089 ; \mathrm{P}<0.001\right)$ among the fish in the sample. In contrast, significantly more fish had a hybrid index of zero and greater than five than expected by chance (Figure 3). Upper Holloman Creek, therefore, appears to have contained a mixture of non-hybridized westslope cutthroat trout and hybrids between westslope cutthroat and rainbow trout when it was sampled. Since some of the definite hybrids had relatively low hybrid indices, reliably distinguishing the non-hybridized fish on an individual basis from the hybrids will be problematic. Thus, from a management perspective, upper Holloman Creek should simply be considered to contain hybrids between westslope cutthroat and rainbow trout.

\section{Inez Creek}

Samples were collected from four reaches of Inez Creek. Among the four samples, evidence of genetic variation was detected at nine of the loci analyzed. The allele frequencies were statistically heterogeneous among the samples at two of these loci. These differences remain significant at the modified level indicating that genetic differences exist among the samples. Much of this divergence was due to differences between the two lower samples and the two upper ones. When only the data from the two upper samples were analyzed, there was no evidence of genetic differences between them at the six loci showing evidence of genetic variation. These two samples, therefore, were combined into a single upper Inez Creek sample for subsequent analysis. When only the two lower most samples were compared, the allele frequencies were statistically heterogeneous between them at one of the eight loci showing evidence of genetic variation. This difference remains significant at the modified level so these were treated as separate lower and middle Inez Creek samples for further analysis.

\section{Lower Inez Creek 3515}

At three of the 13 diagnostic loci between westslope cutthroat and rainbow trout that were analyzed, alleles characteristic of both fishes were detected in the lower Inez Creek sample (Table 3). Although the allele frequencies were statistically homogeneous $\left(X^{2}{ }_{12}=18.601\right.$; $\mathrm{P}>0.05)$ among the diagnostic loci in the sample, the rainbow trout alleles were not randomly distributed among the fish $\left(X^{2}{ }_{3}=25.172 ; \mathrm{P}<0.001\right)$. In contrast, they were detected in only one fish (Figure 4). This sample, therefore, did not come from a hybrid swarm. Since the middle Inez Creek sample appears to have come from a hybrid swarm with a slight rainbow trout genetic contribution (see sample \#3516), we can not conclude with any certainty that the fish in the lower sample with hybrid indices of zero are non-hybridized westslope cutthroat trout. With the estimated frequency of rainbow trout alleles being 0.015 in the middle sample, there is a six percent chance that the apparent non-hybridized fish in the lower sample actually may possess this level of hybridization but it was not detected because of sampling error. Regardless of the status of the fish in the lower sample with hybrid indices of zero, the fish definitely of hybrid origin in the sample clearly appears to be a recent migrant.

\section{Middle Inez Creek 3516}

Alleles characteristic of both westslope cutthroat and rainbow trout were detected at two of the 13 diagnostic loci between these species that were analyzed in the sample from middle Inez Creek (Table 2). The allele frequencies were statistically homogeneous $\left(X^{2}{ }_{12}=10.752 ; \mathrm{P}>0.50\right)$ among the diagnostic loci and the rainbow trout alleles appeared to be randomly distributed $\left(X^{2}{ }_{1}=0.472 ; \mathrm{P}>0.10\right)$ among the fish in the sample. Middle Inez Creek, therefore, appears to 
have contained a hybrid swarm between westslope cutthroat and rainbow trout with a predominant (0.99) westslope cutthroat trout genetic contribution.

\section{Upper Inez Creek 3517}

Alleles characteristic of only westslope cutthroat trout were detected at all the loci analyzed in the sample from upper Inez Creek (Table 5). With the sample size of 13, we have about a 97\% chance of detecting as little as a one percent and considering the middle sample better than a $99 \%$ chance of detecting a $1.5 \%$ rainbow trout genetic contribution to a hybrid swarm. Thus, this sample very likely did not come from a population hybridized with rainbow trout. In contrast, we have only about an $88 \%$ chance of detecting as little as a one percent Yellowstone cutthroat trout genetic contribution to a hybrid swarm that once was non-hybridized westslope cutthroat trout. We, therefore, can not reasonably exclude the possibility that the fish in upper Inez Creek may be slightly hybridized with Yellowstone cutthroat trout but evidence of this was not detected because of sampling error.

\section{Inez Creek compared to previous samples}

The results from the present Inez Creek samples are somewhat similar to those obtained from samples collected in 2002 and 2006 (sample \#3498). The previous samples indicated a slight amount of hybridization with rainbow (0.002) and Yellowstone cutthroat trout (0.007). Thus, the major differences between the two sets of data are the presence of a recent hybrid migrant in the present lower sample, the absence of evidence of hybridization with Yellowstone cutthroat trout in all the most recent samples, and the absence of any evidence of hybridization in the recent upper sample. The lack of evidence of hybridization with Yellowstone cutthroat trout in the recent samples may simply reflect sampling error as with the estimated proportion of Yellowstone cutthroat trout alleles in the previous samples we had a $41 \%$ chance of not detecting any in the lower sample, a $57 \%$ chance of not detecting any in the middle sample, and a $23 \%$ chance of not detecting any in the upper sample. Considering all the data, therefore, with the exception of the very upper reaches possibly containing non-hybridized westslope cutthroat trout the fish in middle Inez Creek and downstream should probably be treated as being slightly hybridized with rainbow and Yellowstone cutthroat trout.

\section{Montana Creek 3518}

Alleles characteristic of only westslope cutthroat trout were detected at all the loci analyzed in the sample from Montana Creek (Table 5). With the sample size of eight, however, we have only about an $88 \%$ chance of detecting as little as a one percent rainbow trout and only about a $72 \%$ chance of detecting as little as a one percent Yellowstone cutthroat trout genetic contribution to a hybrid swarm that once was non-hybridized westslope cutthroat trout. Thus, we can not reasonably exclude the possibility that the fish in this sample from Montana Creek may be slightly hybridized with rainbow trout, Yellowstone cutthroat trout, or both fishes but evidence of this was not detected because of sampling error. This possibility, however, seems slight as previous samples of trout collected above (sample \#3459) and below (sample \#3460) the location of the present sample also showed no evidence of hybridization (we could not combine any of the samples as genetic differences clearly existed among all of them). Overall, therefore, Montana Creek should be considered to contain multiple populations of nonhybridized westslope cutthroat trout. 


\section{Murphy Creek}

Samples were collected from two areas in Murphy Creek. Among the two samples, evidence of genetic variation was detected at five of the loci analyzed. The allele frequencies were statistically heterogeneous between the samples at three of these loci. These differences remain significant at the modified level indicating that genetic differences exist between the samples. The lower and upper Murphy Creek samples, therefore, were treated separately for further analysis.

\section{Lower Murphy Creek 3519}

At two of the eight diagnostic loci between westslope and Yellowstone cutthroat trout that were analyzed, alleles characteristic of both fishes were detected in the sample from lower Murphy Creek (Table 4). Likewise, alleles characteristic of both westslope cutthroat and rainbow trout were detected at one of the 13 diagnostic loci between these fishes that were analyzed. The rainbow $\left(X^{2}{ }_{6}=6.203 ; \mathrm{P}>0.10\right)$ and Yellowstone cutthroat trout $\left(X^{2}{ }_{7}=10.505 ; \mathrm{P}>0.10\right)$ allele frequencies were statistically homogeneous among the diagnostic loci and they appeared to be randomly distributed $\left(X_{2}^{2}=2.318 ; \mathrm{P}>0.10\right)$ among the fish in the sample. Thus, lower Murphy Creek appears to contain a hybrid swarm among westslope cutthroat, Yellowstone cutthroat, and rainbow trout with a predominant $(0.97)$ westslope cutthroat trout genetic component.

\section{Upper Murphy Creek 3520}

Alleles characteristic of only westslope cutthroat trout were detected at all the loci analyzed in the sample from upper Murphy Creek (Table 5). With the sample size of 11, however, we have only about a $94 \%$ chance of detecting as little as a one percent rainbow trout and only about an $83 \%$ chance of detecting as little as a one percent Yellowstone cutthroat trout genetic contribution to a hybrid swarm that once was non-hybridized westslope cutthroat trout. Thus, we can not reasonably exclude the possibility that the fish in the sample from upper Murphy Creek may be slightly hybridized with rainbow trout, Yellowstone cutthroat trout, or both fishes but evidence of this was not detected because of sampling error. With this uncertainty and a lack of evidence for hybridization, the conservative approach would be to consider upper Murphy Creek to contain non-hybridized westslope cutthroat trout unless additional data indicate otherwise.

\section{North Fork Blackfoot River above Deborta 3521}

Alleles characteristic of rainbow, Yellowstone cutthroat, and westslope cutthroat trout were detected in the sample collected from the North Fork Blackfoot River above Deborta Creek (Table 4). The westslope cutthroat $\left(X_{6}^{2}=8.805 ; \mathrm{P}>0.10\right)$ and Yellowstone cutthroat trout $\left(X^{2}{ }_{7}=10.051 ; \mathrm{P}>0.10\right)$ allele frequencies were statistically homogeneous among the diagnostic loci but the alleles did not appear to be randomly distributed $\left(X^{2}{ }_{5}=9.327 ; \mathrm{P}<0.05\right)$ among the fish in the sample. Thus, this sample clearly contained hybrids among rainbow, westslope cutthroat, and Yellowstone cutthroat trout with a predominant rainbow trout genetic contribution but it does not appear to have come from a hybrid swarm.

\section{North Fork Blackfoot River below South 3522}

This sample also contained alleles characteristic of rainbow, Yellowstone cutthroat, and westslope cutthroat trout (Table 4). The westslope cutthroat $\left(X_{6}^{2}=5.897 ; \mathrm{P}>0.10\right)$ and Yellowstone cutthroat trout $\left(X^{2}{ }_{7}=6.731 ; \mathrm{P}>0.10\right)$ allele frequencies were statistically homogeneous among the diagnostic loci but the alleles did not appear to be randomly distributed 
$\left(X^{2}{ }_{l}=4.564 ; \mathrm{P}<0.05\right)$ among the fish in the sample. Thus, this sample also clearly contained hybrids among rainbow, westslope cutthroat, and Yellowstone cutthroat trout with a predominant rainbow trout genetic contribution but it does not appear to have come from a hybrid swarm.

\section{North Fork Blackfoot River below Theodore 3523}

This sample also contained alleles characteristic of rainbow, Yellowstone cutthroat, and westslope cutthroat trout (Table 4). In this sample, the westslope cutthroat trout $\left(X^{2}{ }_{6}=28.561\right.$; $\mathrm{P}<0.001)$ alleles were not statistically homogeneous among the diagnostic loci but, the Yellowstone cutthroat trout allele frequencies were $\left(X^{2}{ }_{7}=12.276 ; \mathrm{P}>0.05\right)$. Also, the westslope and Yellowstone cutthroat trout alleles did not appear to be randomly distributed $\left(X^{2}{ }_{6}=19.020\right.$; $\mathrm{P}<0.01$ ) among the fish in the sample. Thus, this sample also clearly contained hybrids among rainbow, westslope cutthroat, and Yellowstone cutthroat trout with a predominant rainbow trout genetic contribution but it does not appear to have come from a hybrid swarm.

\section{North Fork Blackfoot River combined}

The average rainbow, westslope cutthroat, and Yellowstone cutthroat trout allele frequencies did not statistically differ among the three North Fork Blackfoot River samples. Thus, they were combined into a single sample for further analysis.

In the combined sample, the westslope cutthroat trout $\left(X^{2}{ }_{6}=35.289 ; \mathrm{P}<0.001\right)$ alleles were not statistically homogeneous among the diagnostic loci but, the Yellowstone cutthroat trout allele frequencies were $\left(X^{2}=12.740 ; \mathrm{P}>0.05\right)$. Given the previous results, not surprisingly the westslope and Yellowstone cutthroat trout alleles did not appear to be randomly distributed $\left(X_{6}^{2}=14.062 ; \mathrm{P}<0.05\right)$ among the fish in the combined sample (Figure 5). A likely explanation for the heterogeneity of allele frequencies at some of the diagnostic loci and the nonrandom distribution of the westslope and Yellowstone cutthroat trout alleles among the fish is that when this reach of the North Fork Blackfoot River was sampled it contained fish from two or more hybridized populations of rainbow, westslope cutthroat, and Yellowstone cutthroat trout with different amounts of hybridization.

\section{West Fork Packer Creek 3524}

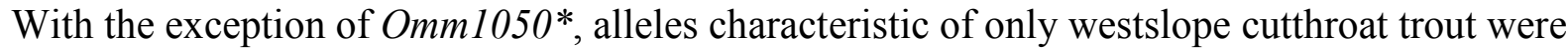
detected in the sample from West Fork Packer Creek. At Omm1050*, two copies of the 300* allele were detected (Table 2). This allele is usually characteristic of rainbow trout (Table 1). Normally we would be uncertain whether its presence in the sample indicated a small amount of hybridization with rainbow trout or simply represented westslope cutthroat trout genetic variation that is indistinguishable from that usually characteristic of rainbow trout. In this situation, however, we strongly favor the former interpretation because a sample collected from Packer Creek near the confluence with the West Fork Packer Creek (sample \#3525) clearly contained hybrids between westslope cutthroat and rainbow trout.

Although the allele frequencies were statistically heterogeneous $\left(X^{2}{ }_{11}=24.833 ; \mathrm{P}<0.05\right)$ among the diagnostic loci, the rainbow trout alleles appeared to be randomly distributed $\left(X^{2}{ }_{I}=1.466\right.$; $\mathrm{P}>0.10$ ) among the fish in the sample. West Fork Packer Creek, therefore, appears to contain a hybrid swarm between westslope cutthroat and rainbow trout with a predominant (0.99) westslope cutthroat trout genetic contribution. 


\section{Packer Creek}

Samples were collected from three reaches of Packer Creek. Among the samples, evidence of genetic variation was detected at 12 of the loci analyzed. Although the allele frequencies were statistically homogeneous among the samples at all of these loci the frequency of alleles characteristic of rainbow trout was statistically higher in the lower sample than in the other two $\left(X_{2}^{2}=24.540 ; \mathrm{P}<0.001\right)$. Thus, the lower sample was treated separately and the middle and upper samples were combined for subsequent analysis.

\section{Lower Packer Creek 3525}

At ten of the 13 diagnostic loci between westslope cutthroat and rainbow trout that were analyzed, alleles characteristic of both fishes were detected in the sample from lower Packer Creek (Table 3). Although the frequency of rainbow trout alleles was statistically homogeneous $\left(X^{2}{ }_{12}=8.615 ; \mathrm{P}>0.50\right)$ among the diagnostic loci, the rainbow trout alleles did not appear to be randomly distributed $\left(X^{2}{ }_{5}=29.885 ; \mathrm{P}<0.001\right)$ among the fish in the sample. Rather, significantly more fish had a hybrid index of zero and greater than three than expected by chance (Figure 6). Thus, lower Packer Creek may contain some non-hybridized westslope cutthroat trout. The hybrid indices, however, do not divide the potentially non-hybridized fish and hybrids into distinct classes. Thus, reliably identifying non-hybridized fish on an individual basis will be problematic and from a management perspective lower Packer Creek should simply be considered to contain hybrids between westslope cutthroat and rainbow trout with a major westslope cutthroat trout genetic component.

\section{Upper Packer Creek 3526}

Alleles characteristic of only westslope cutthroat trout were detected at all the loci analyzed in the sample from upper Packer Creek (Table 5). With the sample size of 14, we have about a $97 \%$ chance of detecting as little as a one percent rainbow trout but only about an $89 \%$ chance of detecting as little as a one percent Yellowstone cutthroat trout genetic contribution to a hybrid swarm that once was non-hybridized westslope cutthroat trout. Thus, we can not reasonably exclude the possibility that the fish in upper Packer Creek may be slightly hybridized with Yellowstone cutthroat trout but evidence of this was not detected because of sampling error. Although the status of the trout in upper Packer Creek is somewhat uncertain, with the absence of evidence for hybridization the conservative approach would be to consider this reach of the creek to contain non-hybridized westslope cutthroat trout unless further data indicate otherwise.

\section{Plant Creek 3527}

Samples were collected from two reaches of Plant Creek. Between the samples, evidence of genetic variation was detected at eight of the loci analyzed. The allele frequencies were statistically heterogeneous between the samples only at $O \operatorname{Cc} 36^{*}\left(X^{2}{ }_{1}=4.328 ; \mathrm{P}<0.05\right)$ but, this difference is not significant at the modified level. Since there was no conclusive evidence of genetic differences between the samples, they were combined into one for subsequent analysis.

Alleles characteristic of both westslope cutthroat and rainbow trout were detected at six of the 13 diagnostic loci between these species that were analyzed in the sample from Plant Creek (Table

$2)$. The allele frequencies were statistically homogeneous $\left(X_{12}^{2}=16.602 ; \mathrm{P}>0.10\right)$ among the diagnostic loci and the rainbow trout alleles appeared to be randomly distributed $\left(X^{2}{ }_{1}=3.407\right.$; $\mathrm{P}>0.10$ ) among the fish in the sample. Plant Creek, therefore, appears to have contained a hybrid 
swarm between westslope cutthroat and rainbow trout with a predominant $(0.98)$ westslope cutthroat trout genetic contribution.

\section{Richmond Creek}

Samples were collected from two reaches of Richmond Creek. Between the samples, evidence of genetic variation was detected at six of the loci analyzed. The allele frequencies were statistically heterogeneous between the samples only at $O m y 1001 *\left(X^{2}{ }_{7}=25.565 ; \mathrm{P}<0.001\right)$. This difference is significant at the modified level so the samples were treated separately for further analysis.

\section{Lower Richmond Creek 3528}

Alleles characteristic of only westslope cutthroat trout were detected in the sample collected from lower Richmond Creek except at $O m 55^{*}$ and $O c c 36^{*}$ (Table 4). At Occ36*, one individual possessed a single copy of the $285^{*}$ allele and at $O m 55^{*}$ another individual contained a single copy of the $180^{*}$ allele. The former allele is usually characteristic of rainbow trout and the latter is usually characteristic of Yellowstone cutthroat trout. The presence of these alleles in the sample, therefore, could indicate a small amount of hybridization with rainbow trout, Yellowstone cutthroat trout, or both fishes. Alternatively, these alleles could represent westslope cutthroat trout genetic variation that is indistinguishable from that usually characteristic of rainbow or Yellowstone cutthroat trout. Unfortunately, we can not distinguish between these possibilities in this situation but, we suspect the former interpretation is the most likely. Adhering to the latter interpretation requires postulating that this population contains two different rare variants at diagnostic loci which would be an unusual situation. Thus, tentatively we suggest that lower Richmond Creek be considered to contain a hybrid swarm among westslope cutthroat, Yellowstone cutthroat, and rainbow trout with a major (0.99) westslope cutthroat trout genetic component.

\section{Upper Richmond Creek 3529}

Alleles characteristic of only westslope cutthroat trout were detected at all the loci analyzed in the sample from upper Richmond Creek (Table 5). With the sample size of 11, we have only about a $94 \%$ chance of detecting as little as a one percent rainbow trout and only about an $83 \%$ chance of detecting as little as a one percent Yellowstone cutthroat trout genetic contribution to a hybrid swarm that once was non-hybridized westslope cutthroat trout. Thus, we can not reasonably exclude the possibility that the fish in upper Richmond Creek may be slightly hybridized with rainbow trout, Yellowstone cutthroat trout, or both but evidence of this was not detected because of sampling error. Since the status of the trout in upper Richmond Creek is somewhat uncertain, in the absence of evidence for hybridization the conservative approach would be to consider this reach of the creek to contain non-hybridized westslope cutthroat trout unless further data indicate otherwise.

\section{Trail Creek}

Samples were collected from four reaches of Trail Creek. Among the four samples, evidence of genetic variation was detected at seven of the loci analyzed. The allele frequencies were statistically heterogeneous among the samples at five of these loci. These differences remain significant at the modified level indicating that genetic differences exist among the samples. 
Much of this divergence was due to differences between the two lower samples and the two upper ones. When only the data from the two upper samples were analyzed, there was no evidence of genetic differences between them at the six loci showing evidence of genetic variation. These two samples, therefore, were combined into a single upper Trail Creek sample for subsequent analysis. When only the two lower most samples were compared, there was no evidence of genetic differences between them at the seven loci showing evidence of genetic variation. These two samples, therefore, were also combined into a single lower Trail Creek sample for further analysis.

\section{Lower Trial Creek 3530}

At three of the 13 diagnostic loci between westslope cutthroat and rainbow trout that were analyzed, alleles characteristic of both fishes were detected in the sample from lower Trail Creek (Table 2). Although the frequency of rainbow trout alleles was not statistically homogeneous $\left(X_{12}^{2}=24.350 ; \mathrm{P}<0.05\right)$ among the diagnostic loci, the rainbow trout alleles appeared to be randomly distributed $\left(X_{1}^{2}=2.289 ; \mathrm{P}>0.10\right)$ among the fish in the sample. Thus, lower Trail Creek appears to contain a hybrid swarm between westslope cutthroat and rainbow trout with a predominant (0.98) westslope cutthroat trout genetic contribution.

\section{Upper Trail Creek 3531}

Alleles characteristic of only westslope cutthroat trout were detected at all the loci analyzed in the sample from upper Trail Creek (Table 5). With the sample size of 19, we have better than a $99 \%$ chance of detecting as little as a one percent rainbow trout and about a $95 \%$ chance of detecting as little as a one percent Yellowstone cutthroat trout genetic contribution to a hybrid swarm that once was non-hybridized westslope cutthroat trout. Upper Trail Creek, therefore, very likely contains a non-hybridized westslope cutthroat trout population.

\section{Irish Creek 3532}

Alleles characteristic of only westslope cutthroat trout were detected at all the loci analyzed in the sample from Irish Creek (Table 5). With the sample size of seven, however, we have only about an $84 \%$ chance of detecting as little as a one percent rainbow trout and only about a $68 \%$ chance of detecting as little as a one percent Yellowstone cutthroat trout genetic contribution to a hybrid swarm that once was non-hybridized westslope cutthroat trout. Thus, we can not reasonably exclude the possibility that the fish in Irish Creek may be slightly hybridized with rainbow trout, Yellowstone cutthroat trout, or both but evidence of this was not detected because of sampling error. Since the status of the trout in Irish Creek is somewhat uncertain, in the absence of evidence of hybridization the conservative approach would be to consider this reach of the creek to contain non-hybridized westslope cutthroat trout unless further data indicate otherwise.

\section{Cache Creek 3533}

Samples were collected from two reaches of Cache Creek. Between the samples, evidence of genetic variation was detected at six of the loci analyzed. The allele frequencies were statistically heterogeneous between the samples only at $O m m 1037-1^{*}\left(X^{2}=4.571 ; \mathrm{P}<0.05\right)$. This difference, however, is not significant at the modified level so the samples were combined for further analysis. 
At all of the loci analyzed except $\mathrm{Om} 55^{*}$, alleles characteristic of only westslope cutthroat trout were detected in the Cache Creek sample (Table 2). At $O m 55^{*}$, a single copy of the $199^{*}$ allele was detected. This allele is usually characteristic of rainbow trout. Thus, normally we would be uncertain as to whether or not the presence of this allele represented a small amount of hybridization with rainbow trout. In this case, however, we strongly favor the hybridization interpretation as a previous allozyme (sample \#588) and indel analysis (sample \#3462) of fish collected from Cache Creek lower in the drainage clearly provided evidence of hybridization with rainbow trout. Upper Cache Creek, therefore, appears to contain a hybrid swarm between westslope cutthroat and rainbow trout with a predominant $(>0.99)$ westslope cutthroat trout genetic contribution.

\section{Miller Creek above Holloman 3534}

Alleles characteristic of only westslope cutthroat trout were detected at all the loci analyzed in the sample from Miller Creek (Table 5). With the sample size of ten, however, we have only about a $93 \%$ chance of detecting as little as a one percent rainbow trout and only about an $80 \%$ chance of detecting as little as a one percent Yellowstone cutthroat trout genetic contribution to a hybrid swarm that once was non-hybridized westslope cutthroat trout. Thus, we can not reasonably exclude the possibility that the fish in Miller Creek may be slightly hybridized with rainbow trout, Yellowstone cutthroat trout, or both but evidence of this was not detected because of sampling error. Since the status of the trout in Miller Creek is somewhat uncertain, in the absence of evidence of hybridization the conservative approach would be to consider this reach of the creek to contain non-hybridized westslope cutthroat trout unless additional data indicate otherwise.

\section{East Fork Morrell Creek 3536}

Samples were collected from three reaches of East Fork Morrell Creek. Among the samples, evidence of genetic variation was detected at five loci. The allele frequencies were statistically homogeneous among the samples at all these loci. The three samples, therefore, were combined into one for subsequent analysis.

Alleles characteristic of only westslope cutthroat trout were detected at all the loci analyzed in the sample from East Fork Morrell Creek (Table 5). With the sample size of 21, we have better than a $99 \%$ chance of detecting as little as a one percent rainbow trout and about a $97 \%$ chance of detecting as little as a one percent Yellowstone cutthroat trout genetic contribution to a hybrid swarm that once was non-hybridized westslope cutthroat trout. East Fork Morrell Creek, therefore, very likely contains a non-hybridized westslope cutthroat trout population.

The above results are very similar to those obtained from an indel analysis of fish collected in Morrell Creek just below the confluence of the East Fork (sample \#3369). These fish also appeared to be non-hybridized westslope cutthroat trout. In contrast to these results, indel analysis of fish collected from Morrell Creek further downstream (samples \#3370 and \#3381) clearly provided evidence of hybridization with rainbow trout. Thus, it appears that only the very upper portion of the Morrell Creek drainage still contains non-hybridized westslope cutthroat trout.

\section{West Fork Clearwater River 3537}

Samples were collected from two areas of the West Fork Clearwater River. Between the samples, evidence of genetic variation was detected at five loci. The allele frequencies were 
statistically homogeneous between the samples at all of these loci so they were combined into one for subsequent analysis.

Alleles characteristic of only westslope cutthroat trout were detected at all the loci analyzed in the sample from the West Fork Clearwater River (Table 5). With the sample size of 17, we have about a $99 \%$ chance of detecting as little as a one percent rainbow trout and about a $94 \%$ chance of detecting as little as a one percent Yellowstone cutthroat trout genetic contribution to a hybrid swarm that once was non-hybridized westslope cutthroat trout. The West Fork Clearwater River, therefore, very likely contains a non-hybridized westslope cutthroat trout population.

The above results differ from those obtained from previous PINE (sample \#2002) and indel (sample \#3492) analyses of fish collected from the West Fork Clearwater River drainage further downstream. The PINE results suggested the sample was a mixture of 24 non-hybridized westslope cutthroat trout and one hybrid between westslope cutthroat and rainbow trout. The indel results suggested this sample came from a hybrid swarm among westslope cutthroat, Yellowstone cutthroat, and rainbow trout with a predominant (0.99) westslope cutthroat trout genetic contribution. Considering all the results, therefore, it appears that now exclusively nonhybridized westslope cutthroat trout in the West Fork Clearwater River drainage are mainly, if not solely, confined to the upper portion of the drainage.

\section{Vaughn Creek 3538}

Samples were collected from two areas of Vaughn Creek. Considering both samples, evidence of genetic variation was detected at eight loci. The allele frequencies at these loci were all statistically homogeneous between the two samples so they were combined into one for further analysis.

At six of the 13 diagnostic loci between westslope cutthroat and rainbow trout that were analyzed, alleles characteristic of both fishes were detected in the sample from Vaughn Creek (Table 3). Although the frequency of rainbow trout alleles was statistically homogeneous $\left(X_{12}^{2}=9.834 ; \mathrm{P}>0.50\right)$ among the diagnostic loci, the rainbow trout alleles did not appear to be randomly distributed $\left(X_{2}^{2}=36.403 ; \mathrm{P}<0.001\right)$ among the fish in the sample. In contrast, they were detected in only two fish with one being in the lower and the other the upper sampling locations (Figure 7). Thus, this sample appeared to contain a mixture of non-hybridized westslope cutthroat trout and hybrids between westslope cutthroat and rainbow trout. The hybrid indices clearly separate the fish into these two groups so from a management perspective it would not be inappropriate to consider Vaughn Creek to still contain non-hybridized westslope cutthroat trout and a relatively small proportion of hybrid migrants.

\section{White Creek above South Fork 3539}

Alleles characteristic of both westslope cutthroat and rainbow trout were detected at five of the 13 diagnostic loci between these fishes that were analyzed in the sample from White Creek collected above the South Fork (Table 3). Although the frequency of rainbow trout alleles was statistically homogeneous $\left(X_{12}^{2}=9.106 ; \mathrm{P}>0.50\right)$ among the diagnostic loci, the rainbow trout alleles were not randomly distributed $\left(X_{2}^{2}=10.321 ; \mathrm{P}<0.01\right)$ among the fish in the sample. Rather, they were detected in only one fish (Figure 8). Thus, this sample appeared to contain a mixture of non-hybridized westslope cutthroat trout and hybrids between westslope cutthroat and rainbow trout. The hybrid indices clearly separate the fish into these two groups so from a management perspective it would not be inappropriate to consider this reach of White Creek to 
still contain non-hybridized westslope cutthroat trout and a relatively small proportion of hybrid migrants.

The above results are different from those obtained from a previous indel analysis of fish collected from White Creek (sample \#3461). In this sample of nine fish collected further downstream than the present one, alleles characteristic of only westslope cutthroat trout were detected. Because of the small sample size we were not sure whether or not this indicated an absence of hybridization in the drainage. The present results and those obtained from a sample in the South Fork (sample \#3540) clearly indicate that hybrids between westslope cutthroat and rainbow trout exist in the White Creek drainage. The majority of the fish in the drainage, however, still appear to be non-hybridized westslope cutthroat trout.

\section{South Fork White Creek 3540}

At two of the 13 diagnostic loci between westslope cutthroat and rainbow trout that were analyzed, alleles characteristic of both fishes were detected in the sample from South Fork White Creek (Table 3). Although the frequency of rainbow trout alleles was statistically homogeneous $\left(X^{2}{ }_{12}=10.687 ; \mathrm{P}>0.50\right)$ among the diagnostic loci, the rainbow trout alleles were not randomly distributed $\left(X^{2}{ }_{1}=4.500 ; \mathrm{P}<0.05\right)$ among the fish in the sample. In contrast, they were detected in only one fish (Figure 9). Thus, this sample appeared to contain a mixture of non-hybridized westslope cutthroat trout and hybrids between westslope cutthroat and rainbow trout. The hybrid indices tend to separate the fish into these two groups so from a management perspective it would not be inappropriate to consider South Fork White Creek to still contain non-hybridized westslope cutthroat trout and a relatively small proportion of hybrid migrants.

\section{North Fork Fish Creek 3541}

Alleles characteristic of both westslope cutthroat and rainbow trout were detected at four of the 13 diagnostic loci between these fishes that were analyzed in the sample from North Fork Fish Creek (Table 3). Although the frequency of rainbow trout alleles was statistically homogeneous $\left(X_{12}^{2}=9.106 ; \mathrm{P}>0.50\right)$ among the diagnostic loci, the rainbow trout alleles were not randomly distributed $\left(X_{2}^{2}=12.690 ; \mathrm{P}<0.01\right)$ among the fish in the sample. Rather, they were detected in only one fish (Figure 10). Thus, this sample appeared to contain a mixture of non-hybridized westslope cutthroat trout and hybrids between westslope cutthroat and rainbow trout.

Indel analysis of two previous samples (\# 3480 and \#3481) collected from North Fork Fish Creek upstream from the present sample detected no evidence of hybridization. Likewise, indel analysis of fish collected from Fletcher Gulch (\#3482) and Greenwood Creek (\#3484), tributaries to North Fork Fish Creek above the present sample, detected alleles characteristic of only westslope cutthroat trout. In contrast to these results, indel analysis of fish collected from French Creek (\#3483), another North Fork tributary above the present sample, appeared to be a mixture of non-hybridized westslope cutthroat trout and hybrids between westslope cutthroat and rainbow trout. Considering all the data, therefore, it appears that the North Fork Fish Creek drainage mainly contains non-hybridized westslope cutthroat trout and a small proportion of hybrids between westslope cutthroat and rainbow trout. It is also likely that the hybrids may be fairly widely distributed throughout the drainage and failure to detect them in some locations may be a result of sampling error rather than their actual absence.

\section{East Fork Indian Creek 3542}


Alleles characteristic of only westslope cutthroat trout were detected at all the loci analyzed in the sample from East Fork Indian Creek (Table 5). With the sample size of six, we have only about a $79 \%$ chance of detecting as little as a one percent rainbow trout and only about a $62 \%$ chance of detecting as little as a one percent Yellowstone cutthroat trout genetic contribution to a hybrid swarm that once was non-hybridized westslope cutthroat trout. Thus, we can not reasonably exclude the possibility that the fish in East Fork Indian Creek may be slightly hybridized with rainbow trout, Yellowstone cutthroat trout, or both but evidence of this was not detected because of sampling error. Since the status of the trout in East Fork Indian Creek is somewhat uncertain, in the absence of evidence of hybridization the conservative approach would be to consider this reach of the creek to contain non-hybridized westslope cutthroat trout unless further data indicate otherwise.

\section{West Fork Indian Creek 3543}

Alleles characteristic of only westslope cutthroat trout were detected at all the loci analyzed in the sample from West Fork Indian Creek (Table 5). With the sample size of five, we have only about a $73 \%$ chance of detecting as little as a one percent rainbow trout and only about a 55\% chance of detecting as little as a one percent Yellowstone cutthroat trout genetic contribution to a hybrid swarm that once was non-hybridized westslope cutthroat trout. Thus, we can not reasonably exclude the possibility that the fish in West Fork Indian Creek may be slightly hybridized with rainbow trout, Yellowstone cutthroat trout, or both but evidence of this was not detected because of sampling error. Since the status of the trout in West Fork Indian Creek is somewhat uncertain, in the absence of evidence of hybridization the conservative approach would be to consider this reach of the creek to contain non-hybridized westslope cutthroat trout unless future data indicate otherwise.

\section{Upper Indian Creek drainage}

Samples have now been analyzed from the East Fork, Middle Fork (\#3497), and West Fork of Indian Creek and Indian Creek below the forks. In all the samples, alleles characteristic of only westslope cutthroat trout were detected. Thus, it appears that the Indian Creek drainage in the West Fork Fish Creek drainage mainly, if not solely, contains non-hybridized westslope cutthroat trout. We can not, however, completely rule out the possibility that this portion of the West Fork Fish Creek drainage may contain a small proportion of hybrids between westslope cutthroat and rainbow trout but they were not detected because of sampling error. This is a possibility as hybrids between these fishes have been detected in other portions of the West Fork Fish Creek drainage (e.g. see samples \#3483 and 3541).

\section{Upper Marshall Creek 3544}

With the exception of $S s a 408^{*}$, alleles characteristic of only rainbow trout were detected in the sample from upper Marshall Creek. At $S s a 408^{*}$, a single copy of the $199^{*}$ allele, which is usually characteristic of Yellowstone cutthroat trout, was detected. Thus, this sample may have come from a hybrid swarm between rainbow and Yellowstone cutthroat trout with a predominant rainbow trout $(>0.99)$ genetic contribution. Alternatively, this could be a non-hybridized rainbow trout population with an unusual Ssa408* variant.

Regardless of the case, this is certainly an introduced non-native trout population.

Indel analysis of two previous samples from Marshall Creek collected downstream from the present one found no evidence of hybridization in one location (\#3490) but hybrids between westslope cutthroat and rainbow trout were definitely present in the lower most sample (\#3491). 
Considering all the data, we now suspect that the absence of evidence for hybridization in the middle sample (\#3490) was probably more likely due to sampling error than the actual absence of hybridization. From a management perspective, therefore, Marshall Creek should simply be considered to contain non-native trout.

\section{Mill Creek}

Samples were collected from three reaches of Mill Creek. Among the samples, evidence of genetic variation was detected at four loci. The allele frequencies were statistically heterogeneous among the samples only at $\operatorname{Omm} 1037-1 *\left(X_{2}^{2}=8.452 ; \mathrm{P}<0.05\right)$. This difference remains significant at the modified level indicating that genetic differences exist among the samples. Much of this divergence was due to differences between the lower sample and the other two. When only the data from the two upper samples were analyzed, there was no evidence of genetic differences between them at the three loci showing evidence of genetic variation. These two samples, therefore, were combined into a single upper Mill Creek sample for subsequent analysis and the lower sample was treated separately.

\section{Lower Mill Creek 3545}

Alleles characteristic of only westslope cutthroat trout were detected at all the loci analyzed in the sample from lower Mill Creek (Table 5). With the sample size of six, we have only about a $79 \%$ chance of detecting as little as a one percent rainbow trout and only about a $62 \%$ chance of detecting as little as a one percent Yellowstone cutthroat trout genetic contribution to a hybrid swarm that once was non-hybridized westslope cutthroat trout. Thus, we can not reasonably exclude the possibility that the fish in lower Mill Creek may be slightly hybridized with rainbow trout, Yellowstone cutthroat trout, or both but evidence of this was not detected because of sampling error. Since the status of the trout in lower Mill Creek is somewhat uncertain, in the absence of evidence of hybridization the conservative approach would be to consider this reach of the creek to contain non-hybridized westslope cutthroat trout unless further data indicate otherwise.

\section{Upper Mill Creek 3546}

Alleles characteristic of only westslope cutthroat trout were detected at all the loci analyzed in the sample from upper Mill Creek (Table 5). With the sample size of 15, we have about a 98\% chance of detecting as little as a one percent rainbow trout and about a 91\% chance of detecting as little as a one percent Yellowstone cutthroat trout genetic contribution to a hybrid swarm that once was non-hybridized westslope cutthroat trout. Thus, the fish in upper Mill Creek very likely are non-hybridized westslope cutthroat trout.

\section{Mormon Creek}

Samples were collected from three areas of Mormon Creek. Among the samples, evidence of genetic variation was detected at six loci. The allele frequencies were statistically heterogeneous among the samples at two of these loci. These differences remain significant at the modified level indicating that genetic differences exist among the samples. Much of this divergence was due to differences between the upper sample and the other two. When only the data from the two lower samples were analyzed, there was no evidence of genetic differences between them at the six loci showing evidence of genetic variation. These two samples, therefore, were combined into a single lower Mormon Creek sample for subsequent analysis and the upper sample was treated separately. 


\section{Lower Mormon Creek 3547}

Alleles characteristic of only westslope cutthroat trout were detected at all the loci analyzed in the sample from lower Mormon Creek (Table 5). With the sample size of 14, we have about a $97 \%$ chance of detecting as little as a one percent rainbow trout but only about an $89 \%$ chance of detecting as little as a one percent Yellowstone cutthroat trout genetic contribution to a hybrid swarm that once was non-hybridized westslope cutthroat trout. Thus, we can not reasonably exclude the possibility that the trout in lower Mormon Creek may be slightly hybridized with Yellowstone cutthroat trout but evidence of this was not detected because of sampling error. Since the status of the trout in lower Mormon Creek is somewhat uncertain, in the absence of evidence of hybridization the conservative approach would be to consider this reach of the creek to contain non-hybridized westslope cutthroat trout unless additional data indicate otherwise.

\section{Upper Mormon Creek 3548}

Alleles characteristic of only westslope cutthroat trout were detected at all the loci analyzed in the sample from upper Mormon Creek (Table 5). With the sample size of seven, we have only about an $84 \%$ chance of detecting as little as a one percent rainbow trout and only about a $68 \%$ chance of detecting as little as a one percent Yellowstone cutthroat trout genetic contribution to a hybrid swarm that once was non-hybridized westslope cutthroat trout. Thus, we can not reasonably exclude the possibility that the fish in upper Mormon Creek may be slightly hybridized with rainbow trout, Yellowstone cutthroat trout, or both but evidence of this was not detected because of sampling error. Since the status of the trout in upper Mormon Creek is somewhat uncertain, in the absence of evidence of hybridization the conservative approach would be to consider this reach of the creek to contain non-hybridized westslope cutthroat trout unless further data indicate otherwise.

\section{Middle Thompson Creek \#3549}

This sample was collected from the middle reach of Thompson Creek above a supposed barrier. Although a previous indel analysis of trout collected from this reach (\#3488) provided no evidence of hybridization, in the present sample alleles characteristic of both westslope cutthroat and rainbow trout were detected at seven of the 13 diagnostic loci between these fishes that were analyzed (Table 3). Although the frequency of rainbow trout alleles was statistically homogeneous $\left(X^{2}{ }_{12}=7.189 ; \mathrm{P}>0.50\right)$ among the diagnostic loci, the rainbow trout alleles did not appear to be randomly distributed $\left(X^{2}{ }_{2}=9.401 ; \mathrm{P}<0.01\right)$ among the fish in the sample. Rather, they were detected in only one fish (Figure 11). Thus, the present sample appeared to contain a mixture of non-hybridized westslope cutthroat trout and hybrids between westslope cutthroat and rainbow trout.

There are two possible explanations for the difference between the past and present sample. Hybrids were actually present in this reach when it was first sampled in 1999 and they were not detected because of sampling error or hybrids have only fairly recently invaded this portion of the stream. If the latter is the case, then it is possible that the hybrids came from downstream as a previous indel analysis of fish collected from below the supposed barrier (\#3487) definitely contained hybrids between westslope cutthroat and rainbow trout. If this is the case, then the supposed barrier is not absolute.

Robb Leary 
Steve Amish

\section{Literature Cited}

Ostberg, C. O., and R. J. Rodriguez. 2004. Bi-parentally inherited species-specific markers identify hybridization between rainbow trout and cutthroat trout subspecies. Molecular Ecology 4:26-29.

Ostberg, C. O., and R. J. Rodriguez. 2006. Hybridization and cytonuclear associations among native

westslope cutthroat trout, introduced rainbow trout, and their hybrids within the Stehekin River drainage, North Cascades National Park. Transactions of the American Fisheries Society 135:924-942.

Ostberg, C. O., S. L. Slatton, and R. J. Rodriquez. 2004. Spatial partitioning and asymmetric hybridization

among sympatric coastal steelhead (Oncorhynchus mykiss irideus), coastal cutthroat trout $(O$.

clarki clarki) and interspecific hybrids. Molecular Ecology 13:2773-2788.

Rice, W. R. 1989. Analyzing tables of statistical tests. Evolution 43:223-225. 
Table 1

Alleles at the diagnostic indel and microsatellite loci that usually differentiate among westslope cutthroat, Yellowstone cutthroat, and rainbow trout. Alleles in bold are occassionally shared between or among taxa.

\begin{tabular}{|c|c|c|c|}
\hline Locus & Westslope & $\frac{\text { Taxa and alleles }}{\text { Yellowstone }}$ & Rainbow \\
\hline \multicolumn{4}{|l|}{ Indels } \\
\hline Occ34 & 225 & 225 & 215 \\
\hline Occ35 & 230 & 230 & 200 \\
\hline Occ36 & $\begin{array}{l}324 \\
325\end{array}$ & $\begin{array}{l}325 \\
275\end{array}$ & $\begin{array}{l}275 \\
285\end{array}$ \\
\hline Occ37 & $\begin{array}{l}268 \\
270\end{array}$ & 270 & 260 \\
\hline Occ38 & 175 & 175 & 150 \\
\hline Occ42 & $\begin{array}{l}160 \\
190\end{array}$ & 190 & 160 \\
\hline Om55 & $\begin{array}{l}220 \\
221\end{array}$ & 180 & $\begin{array}{l}199 \\
200\end{array}$ \\
\hline Microsa & & & \\
\hline Ssa408 & $\begin{array}{l}\mathbf{1 8 3} \\
195 \\
\mathbf{2 2 6} \\
\mathbf{2 8 2}\end{array}$ & 199 & $\begin{array}{l}170 \\
174 \\
178 \\
182 \\
183 \\
186 \\
190 \\
194 \\
198 \\
202 \\
206 \\
210 \\
214 \\
218 \\
222 \\
226 \\
230 \\
234 \\
238 \\
246 \\
250 \\
254 \\
262 \\
266 \\
282\end{array}$ \\
\hline
\end{tabular}


Table 1-continued

\begin{tabular}{|c|c|c|c|}
\hline Locus & Westslope & $\frac{\text { Taxa and alleles }}{\text { Yellowstone }}$ & Rainbow \\
\hline \multicolumn{4}{|c|}{ Microsatellites } \\
\hline Oki10 & $\begin{array}{c}93 \\
99 \\
97 \\
101 \\
103 \\
105 \\
109 \\
113 \\
117 \\
121 \\
125 \\
129 \\
133 \\
137 \\
141 \\
145 \\
149 \\
153 \\
157\end{array}$ & $\begin{array}{l}\mathbf{1 4 1} \\
\mathbf{1 4 9} \\
\mathbf{1 5 3} \\
157 \\
\mathbf{1 6 1} \\
165 \\
169 \\
173\end{array}$ & $\begin{array}{c}99 \\
101 \\
103 \\
105 \\
109 \\
113 \\
117 \\
121 \\
125 \\
129 \\
133 \\
137 \\
153 \\
161\end{array}$ \\
\hline Omm1037-1 & $\begin{array}{l}\mathbf{1 2 7} \\
131 \\
135 \\
\mathbf{1 3 9} \\
\mathbf{1 4 3} \\
147 \\
151 \\
155 \\
163\end{array}$ & 127 & $\begin{array}{l}\mathbf{1 3 9} \\
\mathbf{1 4 3} \\
159 \\
163 \\
167 \\
171 \\
175 \\
179 \\
183 \\
187 \\
191 \\
195 \\
199 \\
203\end{array}$ \\
\hline Omm1037-2 & $\begin{array}{l}104 \\
106\end{array}$ & 106 & $\begin{array}{c}98 \\
100 \\
102\end{array}$ \\
\hline
\end{tabular}


Table 1-continued

\begin{tabular}{|c|c|c|c|}
\hline Locus & Westslope & $\frac{\text { Taxa and alleles }}{\text { Yellowstone }}$ & Rainbow \\
\hline \multicolumn{4}{|c|}{ Microsatellites } \\
\hline Omm1050 & $\begin{array}{l}226 \\
227 \\
230 \\
231 \\
234 \\
235 \\
236 \\
238\end{array}$ & 235 & $\begin{array}{l}238 \\
240 \\
244 \\
246 \\
250 \\
254 \\
256 \\
258 \\
260 \\
262 \\
266 \\
268 \\
269 \\
270 \\
271 \\
272 \\
273 \\
274 \\
276 \\
278 \\
280 \\
281 \\
282 \\
284 \\
285 \\
286 \\
289 \\
291 \\
292 \\
293 \\
296 \\
300 \\
302 \\
304 \\
306 \\
308 \\
310 \\
312 \\
316 \\
322 \\
324 \\
325 \\
326 \\
328 \\
330 \\
331 \\
335 \\
338 \\
340 \\
347 \\
348 \\
265\end{array}$ \\
\hline
\end{tabular}


Table 1-continued

\begin{tabular}{|c|c|c|c|}
\hline Locus & Westslope & $\frac{\text { Taxa and alleles }}{\text { Yellowstone }}$ & Rainbow \\
\hline \multicolumn{4}{|c|}{ Microsatellites } \\
\hline Omy0004 & $\begin{array}{c}77 \\
183\end{array}$ & $\begin{array}{l}173 \\
178 \\
181 \\
183 \\
189 \\
191 \\
193 \\
195 \\
197 \\
199 \\
201 \\
205 \\
225 \\
227 \\
229 \\
231 \\
233 \\
235 \\
239 \\
241 \\
245 \\
249\end{array}$ & $\begin{array}{c}99 \\
101 \\
103 \\
105 \\
109 \\
113 \\
117 \\
121 \\
125 \\
129 \\
131 \\
133 \\
135 \\
137 \\
139 \\
141 \\
142 \\
143 \\
145 \\
149 \\
151 \\
153 \\
155 \\
157 \\
159 \\
165\end{array}$ \\
\hline Omy1001 & $\begin{array}{l}219 \\
228 \\
232 \\
236 \\
240 \\
242 \\
244 \\
248 \\
252 \\
254 \\
256 \\
258 \\
260 \\
262 \\
264 \\
266 \\
268 \\
270 \\
272 \\
276 \\
280 \\
284\end{array}$ & $\begin{array}{l}212 \\
216 \\
220 \\
224 \\
\mathbf{2 4 2} \\
\mathbf{2 5 8} \\
\mathbf{2 6 2} \\
\mathbf{2 6 6} \\
\mathbf{2 7 0} \\
274 \\
278 \\
282 \\
286 \\
290 \\
294 \\
298 \\
306 \\
310 \\
318\end{array}$ & $\begin{array}{l}159 \\
174 \\
176 \\
178 \\
182 \\
184 \\
186 \\
190 \\
192 \\
194 \\
196 \\
198 \\
200 \\
202 \\
204 \\
206 \\
208 \\
210 \\
214 \\
218 \\
222 \\
226 \\
230\end{array}$ \\
\hline
\end{tabular}


Table 2

Allele frequencies at the diagnostic loci between westslope cutthroat and rainbow trout in samples from what appear to be hybrid swarms between these fishes collected from Bertha Creek, Blind Canyon Creek, Boles Creek, Broadus Creek, Cache Creek, Colt Creek, Devils Creek, Eustache Creek, middle Inez Creek, Plant Creek, lower Trail Creek, and West Fork Packer Creek. Alleles in bold are characteristic of rainbow trout.

\begin{tabular}{|c|c|c|c|c|c|c|c|}
\hline \multirow[b]{2}{*}{ Locus } & \multirow[b]{2}{*}{ Alleles } & \multicolumn{6}{|c|}{ Sample and allele frequencies } \\
\hline & & Bertha & Blind & Boles & Broadus & Cache & Colt \\
\hline \multirow[t]{2}{*}{ Occ34* } & 215 & & & & 1.000 & & 0.020 \\
\hline & 225 & 1.000 & 1.000 & 1.000 & & 1.000 & 0.980 \\
\hline \multirow[t]{2}{*}{ Occ35* } & 200 & & & & 0.875 & & \\
\hline & 230 & 1.000 & 1.000 & 1.000 & 0.125 & 1.000 & 1.000 \\
\hline \multirow[t]{4}{*}{$0 \operatorname{0c} 36^{*}$} & 275 & & & 0.019 & 0.875 & & \\
\hline & 285 & & & 0.096 & & & 0.060 \\
\hline & 324 & 0.139 & 0.146 & 0.154 & & 0.300 & 0.020 \\
\hline & 325 & 0.861 & 0.854 & 0.731 & 0.125 & 0.700 & 0.920 \\
\hline \multirow[t]{2}{*}{$0 \operatorname{cc} 37^{*}$} & 260 & & & 0.019 & 1.000 & & \\
\hline & 270 & 1.000 & 1.000 & 0.981 & & 1.000 & 1.000 \\
\hline \multirow[t]{2}{*}{ Occ38* } & 150 & & 0.021 & 0.019 & 1.000 & & \\
\hline & 175 & 1.000 & 0.979 & 0.981 & & 1.000 & 1.000 \\
\hline \multirow[t]{2}{*}{ Occ42* } & 160 & & & & 0.875 & & \\
\hline & 190 & 1.000 & 1.000 & 1.000 & 0.125 & 1.000 & 1.000 \\
\hline \multirow[t]{4}{*}{ Om55* } & 199 & & & & 0.500 & 0.031 & \\
\hline & 200 & & & 0.019 & 0.500 & & \\
\hline & 220 & 1.000 & 0.917 & 0.654 & & 0.938 & 0.960 \\
\hline & 221 & & 0.083 & 0.327 & & 0.031 & 0.040 \\
\hline \multirow[t]{10}{*}{ Ssa408* } & 178 & & & & 0.125 & & \\
\hline & 182 & & & & & & \\
\hline & 186 & & & & & & \\
\hline & 195 & 0.917 & 1.000 & 1.000 & & 1.000 & 1.000 \\
\hline & 199 & 0.056 & & & & & \\
\hline & 210 & & & & 0.125 & & \\
\hline & 218 & & & & 0.250 & & \\
\hline & 234 & & & & 0.250 & & \\
\hline & 250 & & & & 0.250 & & \\
\hline & 282 & 0.028 & & & & & \\
\hline
\end{tabular}


Table 2-continued

\begin{tabular}{|c|c|c|c|c|c|c|c|}
\hline \multirow[b]{2}{*}{ Locus } & \multirow[b]{2}{*}{ Alleles } & \multicolumn{6}{|c|}{ Sample and allele frequencies } \\
\hline & & Bertha & Blind & Boles & Broadus & Cache & Colt \\
\hline \multirow[t]{7}{*}{ Omm1037-1* } & 139 & 0.250 & 0.375 & 0.442 & 0.125 & 0.438 & 0.380 \\
\hline & 147 & & 0.042 & & & & \\
\hline & 151 & 0.750 & 0.583 & 0.462 & & 0.563 & 0.620 \\
\hline & 155 & & & 0.096 & & & \\
\hline & 159 & & & & & & \\
\hline & 171 & & & & 0.625 & & \\
\hline & 187 & & & & 0.250 & & \\
\hline \multirow[t]{3}{*}{ Omm1037-2* } & 100 & & & & 0.875 & & \\
\hline & 104 & 1.000 & 1.000 & 1.000 & & 1.000 & 1.000 \\
\hline & 106 & & & & 0.125 & & \\
\hline \multirow[t]{11}{*}{ Omm1050* } & 230 & & 0.167 & 0.038 & & 0.031 & 0.160 \\
\hline & 234 & 1.000 & 0.833 & 0.942 & & 0.875 & 0.800 \\
\hline & 236 & & & & & 0.094 & 0.040 \\
\hline & 238 & & & & & & \\
\hline & 270 & & & & 0.125 & & \\
\hline & 273 & & & 0.019 & & & \\
\hline & 281 & & & & 0.125 & & \\
\hline & 292 & & & & & & \\
\hline & 300 & & & & & & \\
\hline & 304 & & & & 0.250 & & \\
\hline & 308 & & & & 0.500 & & \\
\hline \multirow[t]{6}{*}{ Omy0004* } & 77 & 1.000 & 1.000 & 0.981 & 0.125 & 1.000 & 1.000 \\
\hline & 131 & & & & 0.125 & & \\
\hline & 137 & & & 0.019 & 0.500 & & \\
\hline & 139 & & & & & & \\
\hline & 141 & & & & 0.125 & & \\
\hline & 159 & & & & 0.125 & & \\
\hline
\end{tabular}


Table 2-continued

\begin{tabular}{|c|c|c|c|c|c|c|c|}
\hline \multirow[b]{2}{*}{ Locus } & \multirow[b]{2}{*}{ Alleles } & \multicolumn{6}{|c|}{ Sample and allele frequencies } \\
\hline & & Bertha & Blind & Boles & Broadus & Cache & Colt \\
\hline \multirow[t]{20}{*}{ Omy1001* } & 186 & & & & 0.125 & & \\
\hline & 190 & & & & & & \\
\hline & 192 & & & & 0.125 & & \\
\hline & 202 & & & & 0.500 & & \\
\hline & 206 & & & & 0.125 & & \\
\hline & 222 & 0.028 & 0.021 & & & & \\
\hline & 228 & 0.056 & 0.042 & & & 0.031 & 0.020 \\
\hline & 232 & & 0.021 & 0.019 & & 0.094 & 0.020 \\
\hline & 236 & 0.639 & 0.333 & 0.346 & & 0.031 & 0.140 \\
\hline & 240 & 0.083 & & 0.019 & & 0.125 & 0.220 \\
\hline & 244 & & & & & 0.219 & 0.040 \\
\hline & 248 & & 0.063 & & & & 0.040 \\
\hline & 252 & & 0.083 & 0.058 & & & 0.040 \\
\hline & 254 & & & & 0.125 & & \\
\hline & 256 & 0.028 & 0.083 & 0.250 & & 0.188 & 0.100 \\
\hline & 260 & & 0.146 & 0.192 & & 0.094 & 0.080 \\
\hline & 264 & 0.056 & 0.063 & 0.096 & & 0.219 & 0.180 \\
\hline & 268 & 0.111 & 0.125 & 0.019 & & & 0.060 \\
\hline & 272 & & 0.021 & & & & 0.040 \\
\hline & 276 & & & & & & 0.020 \\
\hline Average Westslope & & 0.991 & 0.997 & 0.984 & 0.067 & 0.998 & 0.994 \\
\hline Average Rainbow & & 0.009 & 0.003 & 0.016 & 0.933 & 0.002 & 0.006 \\
\hline
\end{tabular}


Table 2-continued

\begin{tabular}{|c|c|c|c|c|c|c|c|}
\hline \multirow[b]{2}{*}{ Locus } & \multirow[b]{2}{*}{ Alleles } & \multicolumn{6}{|c|}{ Sample and allele frequencies } \\
\hline & & Devils & Eustache & Inez & Packer & Plant & Trail \\
\hline \multirow[t]{2}{*}{ Occ34* } & 215 & 0.062 & & & & 0.075 & 0.150 \\
\hline & 225 & 0.938 & 1.000 & 1.000 & 1.000 & 0.925 & 0.850 \\
\hline \multirow{2}{*}{ Occ35* } & 200 & & & & & & \\
\hline & 230 & 1.000 & 1.000 & 1.000 & 1.000 & 1.000 & 1.000 \\
\hline \multirow[t]{4}{*}{ Occ36* } & 275 & 0.062 & 0.071 & & & & \\
\hline & 285 & & & & & & \\
\hline & 324 & 0.750 & & 0.100 & & 0.175 & 0.050 \\
\hline & 325 & 0.188 & 0.929 & 0.900 & 1.000 & 0.825 & 0.950 \\
\hline \multirow[t]{2}{*}{$0 \operatorname{cc} 37^{*}$} & 260 & & 0.062 & & & & \\
\hline & 270 & 1.000 & 0.938 & 1.000 & 1.000 & 1.000 & 1.000 \\
\hline \multirow[t]{2}{*}{ Occ $38^{*}$} & 150 & & 0.062 & & & & \\
\hline & 175 & 1.000 & 0.938 & 1.000 & 1.000 & 1.000 & 1.000 \\
\hline \multirow[t]{2}{*}{$0 \operatorname{cc} 42^{*}$} & 160 & & 0.062 & & & & \\
\hline & 190 & 1.000 & 0.938 & 1.000 & 1.000 & 1.000 & 1.000 \\
\hline \multirow[t]{4}{*}{ Om55* } & 199 & & & & & 0.025 & \\
\hline & 200 & & 0.062 & & & 0.025 & \\
\hline & 220 & 1.000 & 0.875 & 0.900 & 0.714 & 0.925 & 0.850 \\
\hline & 221 & & 0.062 & 0.100 & 0.286 & 0.025 & 0.150 \\
\hline \multirow[t]{10}{*}{ Ssa408* } & 178 & & & & & & \\
\hline & 182 & 0.062 & & & & & \\
\hline & 186 & 0.062 & & & & & \\
\hline & 195 & 0.875 & 1.000 & 0.900 & 1.000 & 1.000 & 1.000 \\
\hline & 199 & & & 0.100 & & & \\
\hline & 210 & & & & & & \\
\hline & 218 & & & & & & \\
\hline & 234 & & & & & & \\
\hline & 250 & & & & & & \\
\hline & 282 & & & & & & \\
\hline \multirow[t]{7}{*}{ Omm1037-1* } & 139 & 0.438 & 0.750 & 0.400 & 0.929 & 0.350 & 0.800 \\
\hline & 147 & & & & & 0.025 & \\
\hline & 151 & 0.562 & 0.250 & 0.500 & 0.071 & 0.575 & 0.150 \\
\hline & 155 & & & & & & \\
\hline & 159 & & & & & & 0.050 \\
\hline & 171 & & & 0.100 & & 0.050 & \\
\hline & 187 & & & & & & \\
\hline
\end{tabular}


Table 2-continued

\begin{tabular}{|c|c|c|c|c|c|c|c|}
\hline \multirow[b]{2}{*}{ Locus } & \multirow[b]{2}{*}{ Alleles } & \multicolumn{6}{|c|}{ Sample and allele frequencies } \\
\hline & & Devils & Eustache & Inez & Packer & Plant & Trail \\
\hline \multirow[t]{2}{*}{ Omm1037-2* } & 100 & & 0.062 & & & 0.050 & \\
\hline & $\begin{array}{l}104 \\
106\end{array}$ & 1.000 & 0.938 & 1.000 & 1.000 & 0.950 & 1.000 \\
\hline \multirow[t]{11}{*}{ Omm1050* } & 230 & & & & & 0.150 & 0.050 \\
\hline & 234 & 0.875 & 0.500 & 1.000 & 0.786 & 0.750 & 0.900 \\
\hline & 236 & & & & 0.071 & 0.050 & \\
\hline & 238 & & 0.500 & & & & \\
\hline & 270 & & & & & & \\
\hline & 273 & & & & & & \\
\hline & 281 & & & & & & 0.050 \\
\hline & 292 & 0.062 & & & & & \\
\hline & 300 & 0.062 & & & 0.143 & 0.050 & \\
\hline & 304 & & & & & & \\
\hline & 308 & & & & & & \\
\hline \multirow[t]{6}{*}{ Omy0004* } & 77 & 1.000 & 0.875 & 1.000 & 1.000 & 1.000 & 1.000 \\
\hline & 131 & & & & & & \\
\hline & 137 & & & & & & \\
\hline & 139 & & 0.125 & & & & \\
\hline & 141 & & & & & & \\
\hline & 159 & & & & & & \\
\hline
\end{tabular}


Table 2-continued

\begin{tabular}{|c|c|c|c|c|c|c|c|}
\hline \multirow[b]{2}{*}{ Locus } & \multirow[b]{2}{*}{ Alleles } & \multicolumn{6}{|c|}{ Sample and allele frequencies } \\
\hline & & Devils & Eustache & Inez & Packer & Plant & Trail \\
\hline \multirow[t]{20}{*}{ Omy1001* } & 186 & & 0.214 & & & & \\
\hline & 190 & 0.125 & & & & & \\
\hline & 192 & & 0.143 & & & 0.025 & \\
\hline & 202 & & & & & & \\
\hline & 206 & & & & & & \\
\hline & 222 & & & & & & \\
\hline & 228 & & & & 0.071 & & \\
\hline & 232 & 0.375 & 0.214 & & 0.357 & & \\
\hline & 236 & 0.125 & 0.286 & & 0.143 & 0.100 & 0.400 \\
\hline & 240 & 0.188 & 0.143 & 0.300 & 0.286 & 0.150 & \\
\hline & 244 & & & & 0.071 & 0.025 & \\
\hline & 248 & & & & & 0.050 & \\
\hline & 252 & 0.125 & & & & 0.125 & 0.200 \\
\hline & 254 & & & & & & \\
\hline & 256 & & & 0.700 & & 0.275 & 0.150 \\
\hline & 260 & & & & 0.071 & 0.075 & 0.200 \\
\hline & 264 & 0.062 & & & & 0.125 & 0.050 \\
\hline & 268 & & & & & 0.025 & \\
\hline & 272 & & & & & & \\
\hline & 276 & & & & & 0.025 & \\
\hline Average Westslope & & 0.962 & 0.934 & 0.985 & 0.989 & 0.977 & 0.981 \\
\hline Average Rainbow & & 0.038 & 0.066 & 0.015 & 0.011 & 0.023 & 0.019 \\
\hline
\end{tabular}


Table 3

Allele frequencies at the diagnostic loci between westslope cutthroat and rainbow trout in samples showing evidence of hybridization between these fishes that do not appear to be hybrid swarms collected from Camp Creek, lower Inez Creek, upper Holloman Creek, Ninemile Creek, lower Packer Creek, North Fork Fish Creek, South Fork White Creek, Thompson Creek, Vaughn Creek, and White Creek. Alleles in bold are characteristic of rainbow trout.

\begin{tabular}{|c|c|c|c|c|c|c|}
\hline \multirow[b]{2}{*}{ Locus } & \multirow[b]{2}{*}{ Alleles } & \multicolumn{5}{|c|}{ Sample and allele frequencies } \\
\hline & & Camp & Inez & Holloman & Ninemile & Packer \\
\hline \multirow[t]{2}{*}{ Occ34* } & 215 & 0.083 & & 0.300 & 0.125 & 0.071 \\
\hline & 225 & 0.917 & 1.000 & 0.700 & 0.875 & 0.929 \\
\hline \multirow[t]{2}{*}{ Occ35* } & 200 & 0.042 & & 0.200 & & 0.071 \\
\hline & 230 & 0.958 & 1.000 & 0.800 & 1.000 & 0.929 \\
\hline \multirow[t]{3}{*}{ Occ36* } & 275 & & & 0.300 & 0.167 & 0.071 \\
\hline & 324 & 0.167 & 0.071 & & 0.500 & \\
\hline & 325 & 0.833 & 0.929 & 0.700 & 0.333 & 0.929 \\
\hline \multirow[t]{2}{*}{$\operatorname{Occ} 37^{*}$} & 260 & & & 0.350 & & 0.071 \\
\hline & 270 & 1.000 & 1.000 & 0.650 & 1.000 & 0.929 \\
\hline \multirow[t]{2}{*}{$0 \operatorname{cc} 38^{*}$} & 150 & & & 0.300 & 0.125 & \\
\hline & 175 & 1.000 & 1.000 & 0.700 & 0.875 & 1.000 \\
\hline \multirow[t]{2}{*}{ Occ42* } & 160 & & & 0.300 & & 0.071 \\
\hline & 190 & 1.000 & 1.000 & 0.700 & 1.000 & 0.929 \\
\hline \multirow[t]{4}{*}{ Om55* } & 199 & & & 0.100 & & \\
\hline & 200 & & & 0.250 & 0.200 & \\
\hline & 220 & 0.625 & 1.000 & 0.650 & 0.800 & 0.786 \\
\hline & 221 & 0.375 & & & & 0.214 \\
\hline \multirow[t]{4}{*}{ Ssa408* } & 178 & 0.042 & & & & \\
\hline & 182 & & & 0.150 & 0.125 & \\
\hline & 190 & & 0.125 & & & \\
\hline & 195 & 0.958 & 0.875 & 0.850 & 0.875 & 1.000 \\
\hline \multirow[t]{7}{*}{ Omm1037-1 * } & 135 & 0.083 & & & & 0.071 \\
\hline & 139 & 0.292 & 0.500 & 0.650 & 0.667 & 0.714 \\
\hline & 143 & & & & & 0.071 \\
\hline & 147 & 0.042 & & & & \\
\hline & 151 & 0.542 & 0.500 & 0.300 & 0.167 & 0.071 \\
\hline & 159 & & & & & \\
\hline & 179 & 0.042 & & 0.050 & 0.167 & 0.071 \\
\hline \multirow[t]{3}{*}{ Omm1037-2* } & 98 & & 0.125 & & & \\
\hline & 100 & 0.083 & & 0.150 & 0.333 & 0.071 \\
\hline & 104 & 0.917 & 0.875 & 0.850 & 0.667 & 0.929 \\
\hline
\end{tabular}


Table 3-continued

\begin{tabular}{|c|c|c|c|c|c|c|}
\hline \multirow[b]{2}{*}{ Locus } & \multirow[b]{2}{*}{ Alleles } & \multicolumn{5}{|c|}{ Sample and allele frequencies } \\
\hline & & Camp & Inez & Holloman & Ninemile & Packe \\
\hline \multirow[t]{11}{*}{ Omm1050* } & 230 & 0.167 & 0.143 & 0.050 & & \\
\hline & 234 & 0.792 & 0.857 & 0.750 & 0.875 & 0.786 \\
\hline & 236 & & & & 0.125 & \\
\hline & 238 & & & & & \\
\hline & 256 & & & 0.050 & & \\
\hline & 269 & & & 0.050 & & \\
\hline & 273 & & & & & \\
\hline & 280 & 0.042 & & & & 0.071 \\
\hline & 281 & & & 0.100 & & \\
\hline & 300 & & & & & 0.071 \\
\hline & 328 & & & & & 0.071 \\
\hline \multirow[t]{8}{*}{ Omy0004* } & 77 & 1.000 & 0.875 & 0.750 & 0.713 & 0.929 \\
\hline & 137 & & & 0.100 & & \\
\hline & 139 & & & & 0.214 & \\
\hline & 141 & & & 0.050 & 0.071 & \\
\hline & 143 & & 0.063 & & & \\
\hline & 145 & & & & & 0.071 \\
\hline & 153 & & & 0.100 & & \\
\hline & 165 & & 0.063 & & & \\
\hline \multirow[t]{20}{*}{ Omy1001* } & 174 & & & 0.050 & & \\
\hline & 176 & 0.042 & & & & \\
\hline & 178 & & & 0.100 & & \\
\hline & 182 & & & 0.050 & & \\
\hline & 186 & & & 0.050 & 0.250 & \\
\hline & 190 & & & & & \\
\hline & 192 & & & & 0.167 & \\
\hline & 218 & & & & & 0.143 \\
\hline & 232 & & & & 0.083 & 0.071 \\
\hline & 236 & 0.333 & 0.143 & 0.200 & 0.083 & 0.429 \\
\hline & 240 & 0.292 & 0.429 & 0.050 & 0.167 & 0.071 \\
\hline & 244 & 0.083 & & & & \\
\hline & 248 & & & & & \\
\hline & 252 & & & & 0.083 & 0.214 \\
\hline & 256 & 0.042 & & 0.250 & & 0.071 \\
\hline & 260 & 0.208 & 0.357 & 0.100 & & \\
\hline & 264 & & & & 0.167 & \\
\hline & 268 & & 0.071 & & & \\
\hline & 272 & & & & & \\
\hline & 276 & & & 0.150 & & \\
\hline
\end{tabular}


Table 3-continued

\begin{tabular}{|c|c|c|c|c|c|c|}
\hline \multirow[b]{2}{*}{ Locus } & \multirow[b]{2}{*}{ Alleles } & \multicolumn{5}{|c|}{ Sample and allele frequencies } \\
\hline & & NF Fish & SF White & Thompson & Vaughn & White \\
\hline \multirow[t]{2}{*}{$0 \operatorname{cc} 34^{*}$} & 215 & 0.056 & & & & \\
\hline & 225 & 0.944 & 1.000 & 1.000 & 1.000 & 1.000 \\
\hline \multirow[t]{2}{*}{ Occ35* } & 200 & & & 0.050 & 0.028 & 0.067 \\
\hline & 230 & 1.000 & 1.000 & 0.950 & 0.972 & 0.933 \\
\hline \multirow[t]{3}{*}{ Occ36* } & 275 & & 0.063 & 0.050 & & \\
\hline & 324 & 0.056 & 0.063 & 0.100 & 0.083 & 0.067 \\
\hline & 325 & 0.944 & 0.875 & 0.850 & 0.917 & 0.933 \\
\hline \multirow[t]{2}{*}{$0 \operatorname{cc} 37^{*}$} & 260 & & & 0.050 & 0.056 & 0.067 \\
\hline & 270 & 1.000 & 1.000 & 0.950 & 0.944 & 0.933 \\
\hline \multirow[t]{2}{*}{$0 \operatorname{cc} 38^{*}$} & 150 & & & 0.050 & & \\
\hline & 175 & 1.000 & 1.000 & 0.950 & 1.000 & 1.000 \\
\hline \multirow[t]{3}{*}{ Occ42* } & 160 & & & & & \\
\hline & 190 & 1.000 & 1.000 & 1.000 & 1.000 & \\
\hline & & & & & & 1.000 \\
\hline \multirow[t]{4}{*}{ Om55* } & 199 & & & & 0.028 & \\
\hline & 200 & & 0.063 & 0.050 & & \\
\hline & 220 & 0.889 & 0.563 & 0.850 & 0.944 & 1.000 \\
\hline & 221 & 0.111 & 0.375 & 0.100 & 0.028 & \\
\hline \multirow[t]{4}{*}{ Ssa408* } & 178 & & & & & \\
\hline & 182 & & & & & \\
\hline & 190 & & & & & \\
\hline & 195 & 1.000 & 1.000 & 1.000 & 1.000 & 1.000 \\
\hline \multirow[t]{7}{*}{ Omm1037-1* } & 135 & & & & & \\
\hline & 139 & 0.500 & 0.438 & 0.400 & 0.611 & 0.188 \\
\hline & 143 & & & & & \\
\hline & 147 & & 0.063 & & & \\
\hline & 151 & 0.444 & 0.500 & 0.600 & 0.361 & 0.750 \\
\hline & 159 & & & & 0.028 & 0.063 \\
\hline & 179 & 0.056 & & & & \\
\hline \multirow[t]{3}{*}{ Omm1037-2* } & 98 & & & & & \\
\hline & 100 & 0.056 & & & & \\
\hline & 104 & 0.944 & 1.000 & 1.000 & 1.000 & 1.000 \\
\hline
\end{tabular}


Table 3-continued

\begin{tabular}{|c|c|c|c|c|c|c|}
\hline \multirow[b]{2}{*}{ Locus } & \multirow[b]{2}{*}{ Alleles } & \multicolumn{5}{|c|}{ Sample and allele frequencies } \\
\hline & & NF Fish & SF White & Thompson & Vaughn & White \\
\hline \multirow[t]{11}{*}{ Omm1050* } & 230 & 0.111 & & 0.050 & 0.083 & \\
\hline & 234 & 0.833 & 1.000 & 0.900 & 0.861 & 0.933 \\
\hline & 236 & & & & & \\
\hline & 238 & & & & 0.028 & \\
\hline & 256 & & & & & \\
\hline & 269 & & & & & \\
\hline & 273 & & & & 0.028 & 0.067 \\
\hline & 280 & 0.056 & & & & \\
\hline & 281 & & & & & \\
\hline & 300 & & & 0.050 & & \\
\hline & 328 & & & & & \\
\hline \multirow[t]{8}{*}{ Omy0004* } & 77 & 1.000 & 1.000 & 1.000 & 1.000 & 1.000 \\
\hline & 137 & & & & & \\
\hline & 139 & & & & & \\
\hline & 141 & & & & & \\
\hline & 143 & & & & & \\
\hline & 145 & & & & & \\
\hline & 153 & & & & & \\
\hline & 165 & & & & & \\
\hline \multirow[t]{20}{*}{ Omy1001* } & 174 & & & & 0.028 & \\
\hline & 176 & & & & & \\
\hline & 178 & & & & & \\
\hline & 182 & & & & & \\
\hline & 186 & & & & & \\
\hline & 190 & & & 0.050 & & \\
\hline & 192 & & & & & \\
\hline & 218 & & & & & \\
\hline & 232 & & & 0.200 & 0.111 & 0.188 \\
\hline & 236 & 0.444 & & 0.400 & 0.333 & 0.375 \\
\hline & 240 & 0.167 & 0.125 & 0.200 & 0.250 & 0.125 \\
\hline & 244 & 0.111 & & & 0.056 & 0.067 \\
\hline & 248 & & & & 0.083 & 0.188 \\
\hline & 252 & & & & & \\
\hline & 256 & 0.111 & 0.313 & 0.050 & 0.028 & 0.067 \\
\hline & 260 & 0.056 & 0.188 & & 0.056 & \\
\hline & 264 & 0.056 & 0.188 & 0.100 & & \\
\hline & 268 & & 0.188 & & & \\
\hline & 272 & & & & 0.028 & \\
\hline & 276 & 0.056 & & & 0.028 & \\
\hline
\end{tabular}


Frequencies of alleles characteristic of westslope cutthroat trout, Yellowstone cutthroat trout, both westslope and Yellowstone cutthroat trout (cutthroat), and rainbow trout in samples showing evidence of hybridization among these fishes collected from Deborta Creek, lower Murphy Creek, North Fork Blackfoot River above Deborta Creek, North Fork Blackfoot River below South Creek, North Fork Blackfoot River below Theodore Creek, and lower Richmond Creek. Averages are given only if the sample appears to have come from a hybrid swarm. Note averages do not sum to one because they are estimated only using a subset of all the loci analyzed.

\begin{tabular}{|c|c|c|c|c|c|c|c|}
\hline \multirow[b]{3}{*}{ Locus } & \multirow[b]{3}{*}{ Alleles } & \multicolumn{6}{|c|}{ Sample and allele frequencies } \\
\hline & & \multirow[b]{2}{*}{ Deborta } & \multirow[b]{2}{*}{ Murphy } & \multicolumn{3}{|c|}{ North Fork Blackfoot } & \multirow[b]{2}{*}{ Richmond } \\
\hline & & & & Deborta & South & Theodore & \\
\hline \multicolumn{8}{|c|}{ Cutthroat Alleles } \\
\hline Occ34* & 225 & 0.200 & 1.000 & & 0.250 & & 1.000 \\
\hline Occ35* & 230 & & 1.000 & & & & 1.000 \\
\hline \multirow[t]{2}{*}{ Occ36* } & 324 & & & & & & 0.083 \\
\hline & 325 & & 1.000 & & & & 0.875 \\
\hline $0 \operatorname{cc} 37^{*}$ & 270 & & 1.000 & & & & 1.000 \\
\hline $0 \operatorname{cc} 38^{*}$ & 175 & & 1.000 & 0.100 & & & 1.000 \\
\hline Occ $42^{*}$ & 190 & & 1.000 & & 0.250 & & 1.000 \\
\hline
\end{tabular}


Table 4-continued

\begin{tabular}{|c|c|c|c|c|c|c|c|}
\hline \multirow[b]{3}{*}{ Locus } & \multirow[b]{3}{*}{ Alleles } & \multicolumn{6}{|c|}{ Sample and allele frequencies } \\
\hline & & \multirow[b]{2}{*}{ Deborta } & \multirow[b]{2}{*}{ Murphy } & \multicolumn{3}{|c|}{ North Fork Blackfoot } & \multirow[b]{2}{*}{ Richmond } \\
\hline & & & & Deborta & South & Theodore & \\
\hline \multicolumn{8}{|l|}{ Westslope alleles } \\
\hline \multirow[t]{2}{*}{ Om55* } & 220 & & 0.818 & & & & 0.958 \\
\hline & 221 & & 0.091 & & & & \\
\hline Ssa408* & 195 & & 1.000 & & & & 1.000 \\
\hline \multirow[t]{3}{*}{ Omm1037-1* } & 139 & & 0.318 & 0.100 & & 0.500 & 0.333 \\
\hline & 147 & & & & 0.250 & & \\
\hline & 151 & & 0.682 & & & & 0.667 \\
\hline Omm1037-2* & 104 & & 1.000 & & & & 1.000 \\
\hline \multirow[t]{2}{*}{ Omm1050* } & 230 & & & & & & 0.042 \\
\hline & 234 & & 0.909 & & & & 0.958 \\
\hline Omy0004* & 77 & 0.400 & 1.000 & 0.200 & & 0.100 & 1.000 \\
\hline \multirow[t]{9}{*}{ Omy1001* } & 228 & & & & & & 0.042 \\
\hline & 232 & & 0.136 & & & & \\
\hline & 236 & & 0.136 & & & & 0.042 \\
\hline & 240 & & 0.091 & & & & 0.208 \\
\hline & 244 & & 0.091 & & & & \\
\hline & 256 & & 0.182 & & & & 0.417 \\
\hline & 260 & & 0.227 & & & & 0.208 \\
\hline & 264 & & 0.045 & & & & 0.042 \\
\hline & 268 & & 0.091 & & & & 0.042 \\
\hline Average Westslope & & & 0.974 & & & & 0.994 \\
\hline
\end{tabular}


Table 4-continued

\begin{tabular}{|c|c|c|c|c|c|c|c|}
\hline \multirow[b]{3}{*}{ Locus } & \multirow[b]{3}{*}{ Alleles } & \multicolumn{6}{|c|}{ Sample and allele frequencies } \\
\hline & & \multirow[b]{2}{*}{ Deborta } & \multirow[b]{2}{*}{ Murphy } & \multicolumn{3}{|c|}{ North Fork Blackfoot } & \multirow[b]{2}{*}{ Richmond } \\
\hline & & & & Deborta & South & Theodore & \\
\hline \multicolumn{8}{|l|}{ Yellowstone alleles } \\
\hline Om55* & 180 & 0.500 & 0.091 & & & 0.200 & 0.042 \\
\hline Ssa408* & 199 & 0.600 & & 0.200 & & & \\
\hline Oki10* & 165 & 0.100 & & & & & \\
\hline Omm1037-1* & 127 & 0.100 & & 0.200 & & 0.100 & \\
\hline Omm1037-2* & 106 & 0.400 & & 0.100 & 0.250 & & \\
\hline Omm1050* & 235 & & 0.045 & & & & \\
\hline Omy0004* & \multicolumn{7}{|c|}{ No Yellowstone alleles detected } \\
\hline Omy1001* & \multicolumn{7}{|c|}{ No Yellowstone alleles detected } \\
\hline Average Yellowstone & & & 0.017 & & & & 0.005 \\
\hline
\end{tabular}




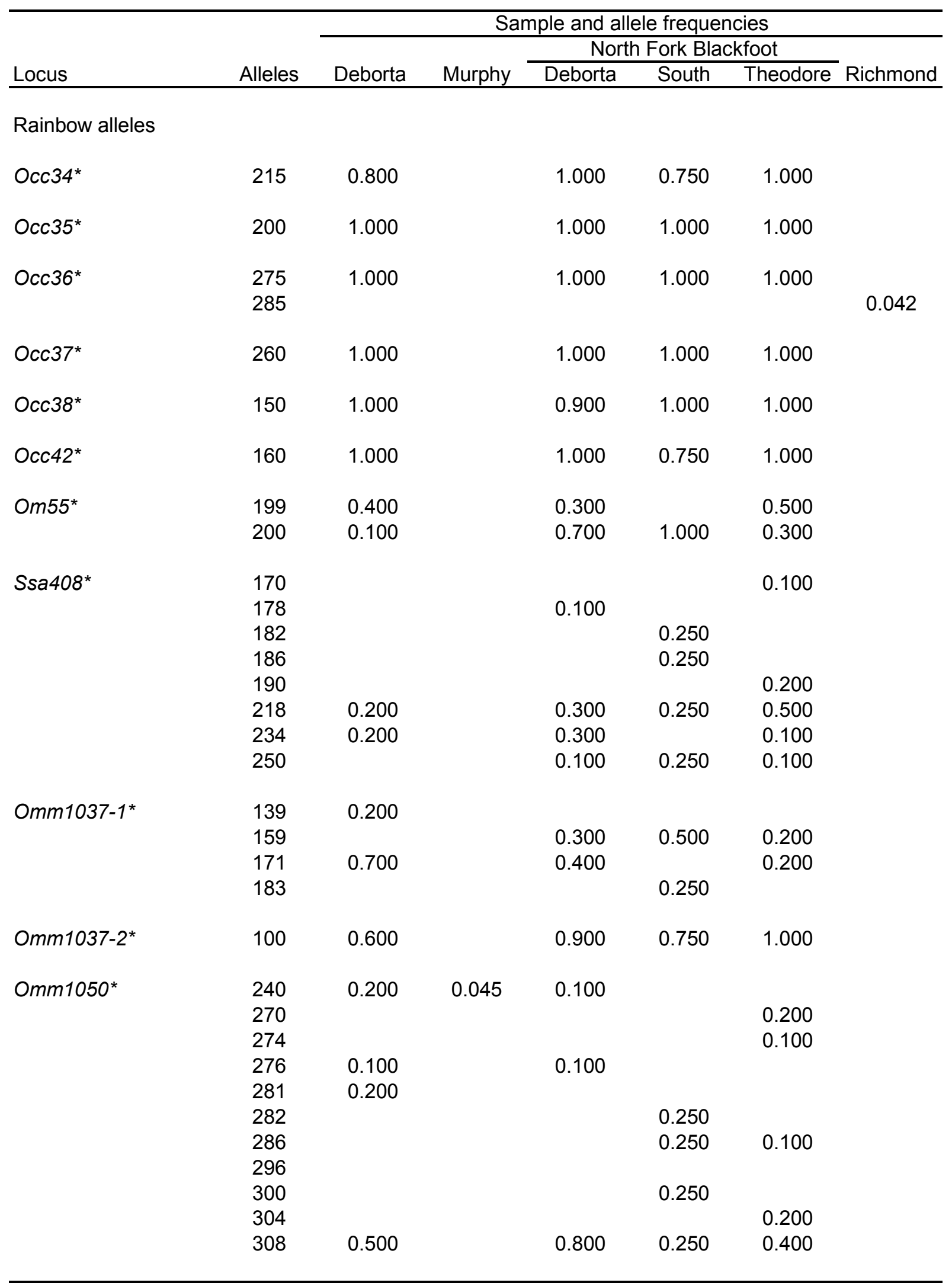


Table 4-continued

\begin{tabular}{|c|c|c|c|c|c|c|c|}
\hline \multirow[b]{3}{*}{ Locus } & \multirow[b]{3}{*}{ Alleles } & \multicolumn{6}{|c|}{ Sample and allele frequencies } \\
\hline & & \multirow[b]{2}{*}{ Deborta } & \multirow[b]{2}{*}{ Murphy } & \multicolumn{3}{|c|}{ North Fork Blackfoot } & \multirow[b]{2}{*}{ Richmond } \\
\hline & & & & Deborta & South & Theodore & \\
\hline \multicolumn{8}{|l|}{ Rainbow alleles } \\
\hline \multirow[t]{5}{*}{ Omy0004* } & 131 & & & 0.100 & & & \\
\hline & 137 & 0.600 & & 0.600 & 0.750 & 0.800 & \\
\hline & 139 & & & 0.100 & & & \\
\hline & 141 & & & & 0.250 & & \\
\hline & 153 & & & & & 0.100 & \\
\hline \multirow[t]{8}{*}{ Omy1001* } & 186 & & & & & 0.300 & \\
\hline & 190 & 0.600 & & 0.600 & 0.250 & 0.200 & \\
\hline & 192 & 0.200 & & & 0.500 & 0.100 & \\
\hline & 198 & 0.100 & & 0.100 & & & \\
\hline & 200 & & & 0.100 & & 0.100 & \\
\hline & 202 & & & 0.100 & 0.250 & 0.100 & \\
\hline & 206 & 0.100 & & & & 0.200 & \\
\hline & 214 & & & 0.100 & & & \\
\hline Average Rainbow & & & 0.003 & & & & 0.003 \\
\hline
\end{tabular}


Allele frequencies at the loci showing evidence of genetic variation in samples from what appear to be non-hybridized westslope cutthroat trout collected from Butler Creek, Canyon Creek, East Fork Indian Creek, East Fork Morrell Creek, Findell Creek, lower Holloman Creek, upper Inez Creek, Irish Creek, lower Mill Creek, upper Mill Creek, Miller Creek, Montana Creek, lower Mormon Creek, upper Mormon Creek, upper Murphy Creek, upper Packer Creek, upper Richmond Creek, upper Trail Creek, West Fork Clearwater River, and West Fork Indian Creek

\begin{tabular}{|c|c|c|c|c|c|c|c|}
\hline \multirow[b]{2}{*}{ Locus } & \multirow[b]{2}{*}{ Alleles } & \multicolumn{6}{|c|}{ Sample and allele frequencies } \\
\hline & & Butler & Canyon & EF Indian & EF Morrell & Findell & Holloman \\
\hline \multirow[t]{2}{*}{ Occ36* } & 324 & 0.450 & 0.360 & & 0.024 & 0.136 & \\
\hline & 325 & 0.550 & 0.640 & 1.000 & 0.976 & 0.864 & 1.000 \\
\hline \multirow[t]{3}{*}{ Om55* } & 199 & & & & & 0.023 & \\
\hline & 220 & 1.000 & 1.000 & 1.000 & 1.000 & 0.864 & 0.944 \\
\hline & 221 & & & & & 0.114 & 0.056 \\
\hline \multirow[t]{2}{*}{ Ssa408* } & 195 & 0.983 & 1.000 & 1.000 & 1.000 & 1.000 & 1.000 \\
\hline & 282 & 0.017 & & & & & \\
\hline \multirow[t]{16}{*}{ Oki10* } & 97 & & & & & & \\
\hline & 101 & 0.117 & & & & & \\
\hline & 105 & & 0.400 & & 0.024 & 0.273 & 0.167 \\
\hline & 109 & & & 0.833 & 0.238 & 0.045 & 0.111 \\
\hline & 113 & 0.217 & 0.260 & 0.167 & 0.286 & 0.159 & 0.278 \\
\hline & 117 & 0.567 & 0.320 & & 0.024 & 0.091 & \\
\hline & 121 & & & & & & \\
\hline & 125 & & & & 0.119 & 0.023 & 0.056 \\
\hline & 129 & & 0.020 & & 0.024 & 0.205 & 0.056 \\
\hline & 133 & & & & & 0.068 & 0.111 \\
\hline & 137 & & & & & & \\
\hline & 141 & 0.100 & & & & 0.114 & \\
\hline & 145 & & & & 0.214 & 0.023 & 0.222 \\
\hline & 149 & & & & & & \\
\hline & 153 & & & & 0.048 & & \\
\hline & 157 & & & & 0.024 & & \\
\hline \multirow[t]{5}{*}{ Omm1037-1 * } & 139 & 0.967 & 0.300 & 0.500 & 0.500 & 0.636 & 0.667 \\
\hline & 147 & & & & 0.048 & & 0.056 \\
\hline & 151 & 0.033 & 0.480 & 0.417 & 0.452 & 0.341 & 0.278 \\
\hline & 155 & & 0.020 & 0.083 & & 0.023 & \\
\hline & 163 & & 0.200 & & & & \\
\hline \multirow[t]{5}{*}{ Omm1050* } & 230 & & & & 0.429 & & 0.278 \\
\hline & 234 & 1.000 & & 1.000 & 0.429 & 0.909 & 0.722 \\
\hline & 235 & & & & & & \\
\hline & 236 & & & & & 0.091 & \\
\hline & 238 & & & & 0.143 & & \\
\hline
\end{tabular}


Table 5-continued

\begin{tabular}{|c|c|c|c|c|c|c|c|}
\hline \multirow[b]{2}{*}{ Locus } & \multirow[b]{2}{*}{ Alleles } & \multicolumn{6}{|c|}{ Sample and allele frequencies } \\
\hline & & Butler & Canyon & EF Indian & EF Morrell & Findell & Holloman \\
\hline \multirow[t]{14}{*}{ Omy1001* } & 219 & & & & & & \\
\hline & 228 & & & & & & \\
\hline & 232 & 0.467 & & 0.083 & & 0.227 & \\
\hline & 236 & 0.283 & 0.020 & 0.667 & 0.167 & 0.250 & 0.056 \\
\hline & 240 & & 0.060 & 0.167 & 0.357 & 0.227 & 0.167 \\
\hline & 244 & 0.150 & & 0.083 & 0.071 & 0.159 & 0.222 \\
\hline & 248 & & & & 0.048 & & \\
\hline & 252 & & 0.120 & & & & \\
\hline & 256 & & 0.340 & & 0.048 & & 0.222 \\
\hline & 260 & & 0.240 & & 0.095 & 0.091 & 0.111 \\
\hline & 264 & 0.100 & 0.100 & & 0.048 & 0.045 & 0.111 \\
\hline & 268 & & 0.120 & & & & \\
\hline & 272 & & & & 0.024 & & 0.056 \\
\hline & 276 & & & & 0.143 & & 0.056 \\
\hline
\end{tabular}


Table 5-continued

\begin{tabular}{|c|c|c|c|c|c|c|c|}
\hline \multirow[b]{2}{*}{ Locus } & \multirow[b]{2}{*}{ Alleles } & \multicolumn{6}{|c|}{ Sample and allele frequencies } \\
\hline & & Inez & Irish & L Mill & U Mill & Miller & Montana \\
\hline \multirow[t]{2}{*}{$0 \operatorname{0c} 36^{*}$} & 324 & 0.077 & 0.143 & 0.083 & & 0.500 & 0.125 \\
\hline & 325 & 0.923 & 0.857 & 0.917 & 1.000 & 0.500 & 0.875 \\
\hline \multirow[t]{3}{*}{ Om55* } & 199 & & & & & & \\
\hline & 220 & 0.577 & 1.000 & 1.000 & 1.000 & 1.000 & 0.750 \\
\hline & 221 & 0.423 & & & & & 0.250 \\
\hline \multirow[t]{2}{*}{ Ssa 408* } & 195 & 1.000 & 1.000 & 1.000 & 1.000 & 1.000 & 1.000 \\
\hline & 282 & & & & & & \\
\hline \multirow[t]{16}{*}{ Oki10* } & 97 & & & & & & 0.063 \\
\hline & 101 & & 0.071 & 0.083 & & & 0.063 \\
\hline & 105 & & 0.357 & 0.167 & & 0.250 & 0.063 \\
\hline & 109 & 0.577 & 0.071 & & & 0.150 & 0.313 \\
\hline & 113 & 0.308 & 0.500 & 0.500 & 0.800 & 0.600 & 0.438 \\
\hline & 117 & 0.115 & & 0.083 & 0.200 & & 0.063 \\
\hline & 121 & & & & & & \\
\hline & 125 & & & & & & \\
\hline & 129 & & & 0.083 & & & \\
\hline & 133 & & & 0.083 & & & \\
\hline & 137 & & & & & & \\
\hline & 141 & & & & & & \\
\hline & 145 & & & & & & \\
\hline & 149 & & & & & & \\
\hline & 153 & & & & & & \\
\hline & 157 & & & & & & \\
\hline \multirow[t]{5}{*}{ Omm1037-1* } & 139 & 0.538 & 0.500 & 0.417 & 0.833 & 0.500 & 0.313 \\
\hline & 147 & & & & & & 0.688 \\
\hline & 151 & 0.462 & 0.500 & 0.583 & 0.167 & 0.500 & \\
\hline & 155 & & & & & & \\
\hline & 163 & & & & & & \\
\hline \multirow[t]{5}{*}{ Omm1050* } & 230 & & & & & & 0.063 \\
\hline & 234 & 1.000 & 0.714 & 1.000 & 1.000 & 0.950 & 0.938 \\
\hline & 235 & & 0.286 & & & & \\
\hline & 236 & & & & & & \\
\hline & 238 & & & & & 0.050 & \\
\hline
\end{tabular}


Table 5-continued

\begin{tabular}{|c|c|c|c|c|c|c|c|}
\hline \multirow[b]{2}{*}{ Locus } & \multirow[b]{2}{*}{ Alleles } & \multicolumn{6}{|c|}{ Sample and allele frequencies } \\
\hline & & Inez & Irish & L Mill & U Mill & Miller & Montana \\
\hline \multirow[t]{14}{*}{ Omy1001* } & 219 & & & & & & \\
\hline & 228 & & & & & & \\
\hline & 232 & & 0.071 & 0.083 & & & 0.125 \\
\hline & 236 & 0.038 & & 0.833 & 0.667 & 0.200 & \\
\hline & 240 & 0.077 & 0.143 & & 0.300 & & 0.063 \\
\hline & 244 & & 0.143 & & 0.033 & 0.250 & \\
\hline & 248 & 0.269 & & & & 0.050 & \\
\hline & 252 & & & & & & \\
\hline & 256 & 0.154 & 0.571 & & & 0.150 & 0.063 \\
\hline & 260 & 0.154 & & & & 0.100 & 0.313 \\
\hline & 264 & 0.115 & 0.071 & 0.083 & & & 0.125 \\
\hline & 268 & 0.192 & & & & 0.050 & 0.188 \\
\hline & 272 & & & & & 0.150 & 0.125 \\
\hline & 276 & & & & & 0.050 & \\
\hline
\end{tabular}


Table 5-continued

\begin{tabular}{|c|c|c|c|c|c|c|c|}
\hline \multirow{2}{*}{ Locus } & \multirow[b]{2}{*}{ Alleles } & \multicolumn{6}{|c|}{ Sample and allele frequencies } \\
\hline & & L Mormon & U Mormon & Murphy & Packer & Richmond & Trail \\
\hline \multirow[t]{2}{*}{ Occ36* } & 324 & 0.067 & & & 0.143 & & 0.158 \\
\hline & 325 & 0.933 & 1.000 & 1.000 & 0.857 & 1.000 & 0.842 \\
\hline \multirow[t]{3}{*}{ Om55* } & 199 & & & & & & \\
\hline & 220 & 0.967 & 1.000 & 0.727 & 0.679 & 0.955 & 0.947 \\
\hline & 221 & 0.033 & & 0.273 & 0.321 & 0.045 & 0.053 \\
\hline \multirow[t]{2}{*}{ Ssa 408* } & 195 & 1.000 & 1.000 & 1.000 & 1.000 & 1.000 & 1.000 \\
\hline & 282 & & & & & & \\
\hline \multirow[t]{16}{*}{ Oki10* } & 97 & & & & & & \\
\hline & 101 & & & 0.182 & & & 0.158 \\
\hline & 105 & 0.536 & 0.429 & & 0.250 & & 0.184 \\
\hline & 109 & 0.071 & & & 0.071 & 0.273 & 0.184 \\
\hline & 113 & 0.250 & 0.500 & 0.818 & 0.214 & 0.727 & 0.211 \\
\hline & 117 & & & & 0.036 & & \\
\hline & 121 & & & & 0.036 & & \\
\hline & 125 & & & & & & \\
\hline & 129 & 0.036 & 0.071 & & 0.143 & & \\
\hline & 133 & & & & 0.071 & & \\
\hline & 137 & 0.071 & & & & & \\
\hline & 141 & 0.036 & & & & & \\
\hline & 145 & & & & & & 0.158 \\
\hline & 149 & & & & 0.179 & & \\
\hline & 153 & & & & & & 0.079 \\
\hline & 157 & & & & & & 0.026 \\
\hline \multirow[t]{5}{*}{ Omm1037-1* } & 139 & 0.464 & 1.000 & 0.864 & 0.679 & 0.227 & 0.342 \\
\hline & 147 & & & & & & 0.026 \\
\hline & 151 & 0.464 & & 0.136 & 0.321 & 0.773 & 0.631 \\
\hline & 155 & 0.071 & & & & & \\
\hline & 163 & & & & & & \\
\hline \multirow[t]{5}{*}{ Omm1050* } & 230 & & 0.071 & & 0.107 & & 0.184 \\
\hline & 234 & 0.679 & 0.929 & 1.000 & 0.857 & 1.000 & 0.763 \\
\hline & 235 & & & & & & \\
\hline & 236 & 0.321 & & & 0.036 & & 0.053 \\
\hline & 238 & & & & & & \\
\hline
\end{tabular}


Table 5-continued

\begin{tabular}{|c|c|c|c|c|c|c|c|}
\hline \multirow[b]{2}{*}{ Locus } & \multirow[b]{2}{*}{ Alleles } & \multicolumn{6}{|c|}{ Sample and allele frequencies } \\
\hline & & L Mormon & U Mormon & Murphy & Packer & Richmond & Trail \\
\hline \multirow[t]{14}{*}{ Omy1001* } & 219 & 0.250 & 0.214 & & & & \\
\hline & 228 & & & 0.045 & 0.036 & & \\
\hline & 232 & 0.214 & 0.071 & & 0.429 & & \\
\hline & 236 & 0.500 & 0.286 & & 0.393 & 0.182 & 0.105 \\
\hline & 240 & & & 0.273 & & & 0.263 \\
\hline & 244 & & & & & & 0.079 \\
\hline & 248 & & & & & 0.227 & 0.105 \\
\hline & 252 & 0.036 & 0.429 & & & & 0.053 \\
\hline & 256 & & & & 0.036 & & 0.105 \\
\hline & 260 & & & 0.682 & 0.071 & 0.591 & 0.079 \\
\hline & 264 & & & & 0.036 & & 0.053 \\
\hline & 268 & & & & & & 0.079 \\
\hline & 272 & & & & & & 0.026 \\
\hline & 276 & & & & & & 0.053 \\
\hline
\end{tabular}


Table 5-continued

\begin{tabular}{|c|c|c|c|}
\hline \multirow[b]{2}{*}{ Locus } & \multirow[b]{2}{*}{ Alleles } & \multicolumn{2}{|c|}{ Sample and allele frequencies } \\
\hline & & WF Clearwater & WF Indian \\
\hline \multirow[t]{2}{*}{ Occ36* } & 324 & 0.294 & \\
\hline & 325 & 0.706 & 1.000 \\
\hline \multirow[t]{3}{*}{ Om55* } & 199 & & \\
\hline & 220 & 0.706 & 1.000 \\
\hline & 221 & 0.294 & \\
\hline \multirow{2}{*}{ Ssa 408* } & 195 & 1.000 & 1.000 \\
\hline & 282 & & \\
\hline \multirow[t]{16}{*}{ Oki10* } & 97 & 0.118 & \\
\hline & 101 & 0.088 & \\
\hline & 105 & 0.029 & \\
\hline & 109 & 0.382 & 0.900 \\
\hline & 113 & 0.294 & 0.100 \\
\hline & 117 & 0.088 & \\
\hline & 121 & & \\
\hline & 125 & & \\
\hline & 129 & & \\
\hline & 133 & & \\
\hline & 137 & & \\
\hline & 141 & & \\
\hline & 145 & & \\
\hline & 149 & & \\
\hline & 153 & & \\
\hline & 157 & & \\
\hline \multirow[t]{5}{*}{ Omm1037-1* } & 139 & 0.735 & \\
\hline & 147 & & \\
\hline & 151 & 0.265 & 0.400 \\
\hline & 155 & & 0.600 \\
\hline & 163 & & \\
\hline \multirow[t]{5}{*}{ Omm1050* } & 230 & & \\
\hline & 234 & 1.000 & 1.000 \\
\hline & 235 & & \\
\hline & 236 & & \\
\hline & 238 & & \\
\hline
\end{tabular}


Table 5-continued

\begin{tabular}{lccc}
\hline & & \multicolumn{2}{c}{ Sample and allele frequencies } \\
\cline { 3 - 4 } Locus & Alleles & WF Clearwater & WF Indian \\
\hline \multirow{3}{*}{$219001^{*}$} & & \\
228 & 0.088 & \\
232 & & 0.700 \\
236 & 0.324 & 0.300 \\
240 & 0.353 & \\
244 & 0.029 & \\
248 & & \\
252 & 0.029 & \\
256 & 0.118 & \\
260 & 0.059 & \\
264 & & \\
268 & & \\
272 & & \\
276 & & \\
\end{tabular}




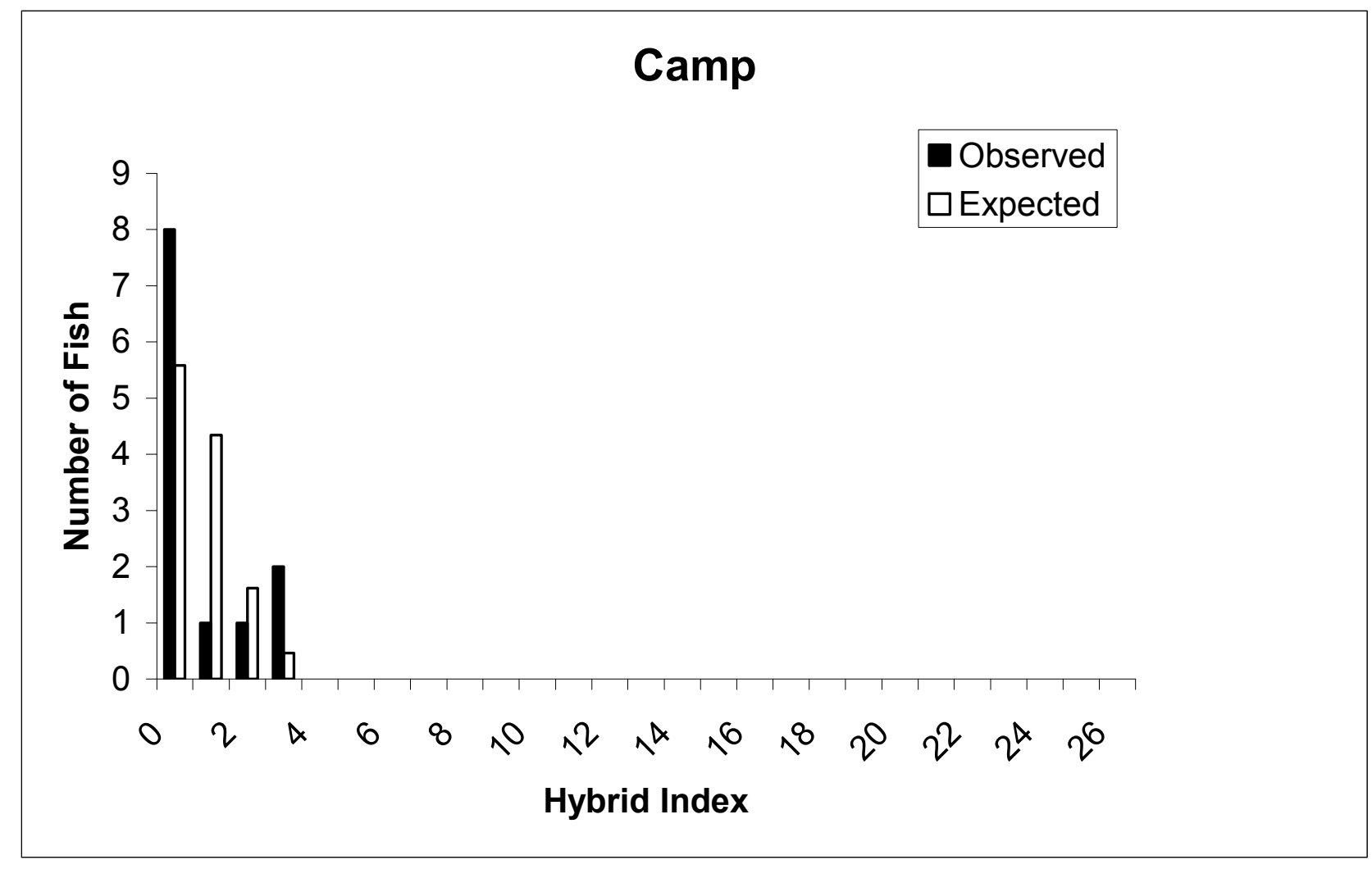

Figure1. Observed and expected random distribution of hybrid indices among the fish showing evidence of hybridization between westslope cutthroat and rainbow trout collected from Camp Creek. Note the observed distribution significantly differs $(\mathrm{P}<0.05)$ from the expected random distribution suggesting the sample did not come from a hybrid swarm. 


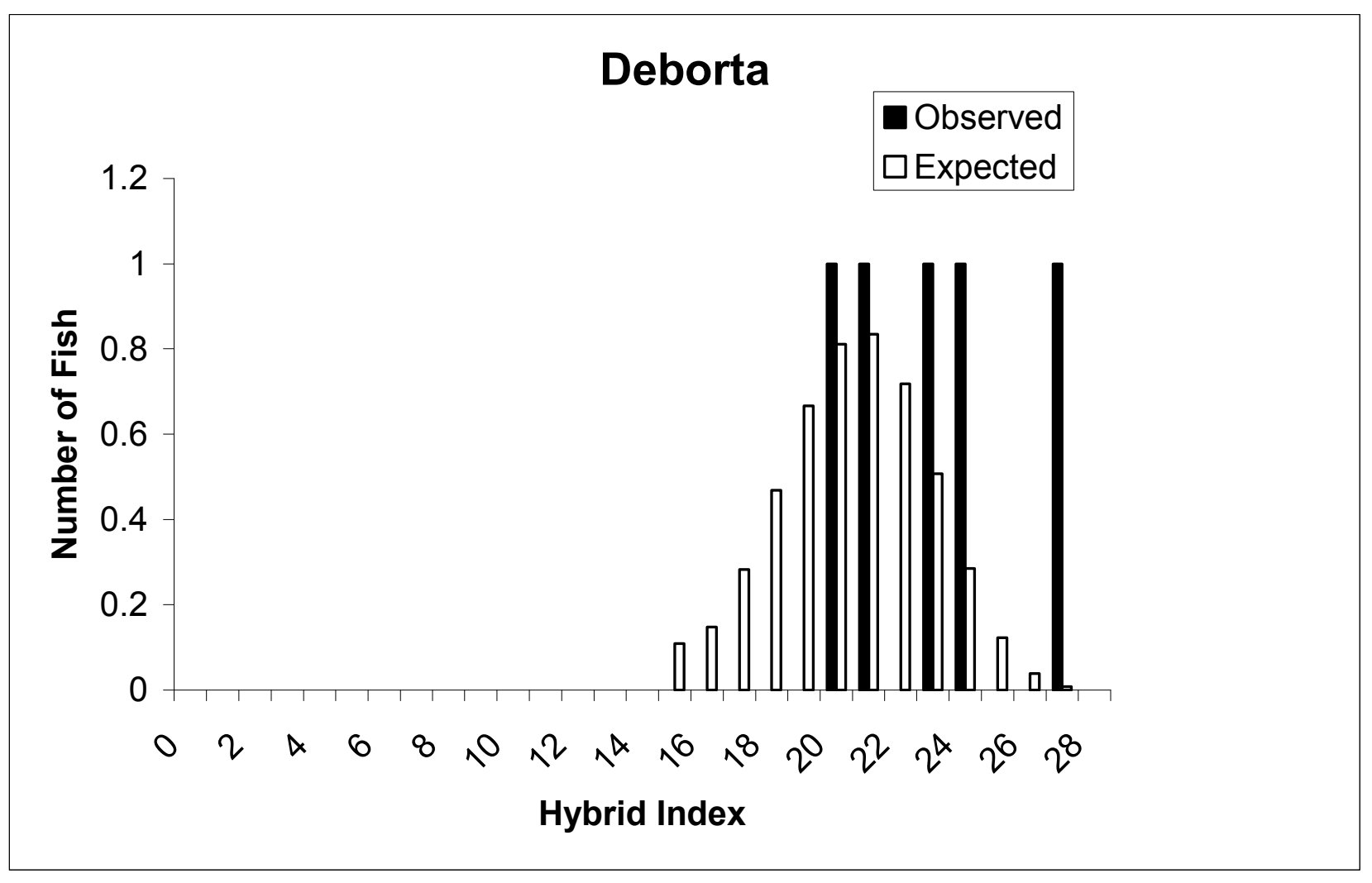

Figure 2. Observed and expected random distribution of hybrid indices among the fish showing evidence of hybridization among westslope cutthroat, Yellowstone cutthroat, and rainbow trout collected from Deborta Creek. Note the observed distribution significantly differs $(\mathrm{P}<0.05)$ from the expected random distribution suggesting the sample did not come from a hybrid swarm. 


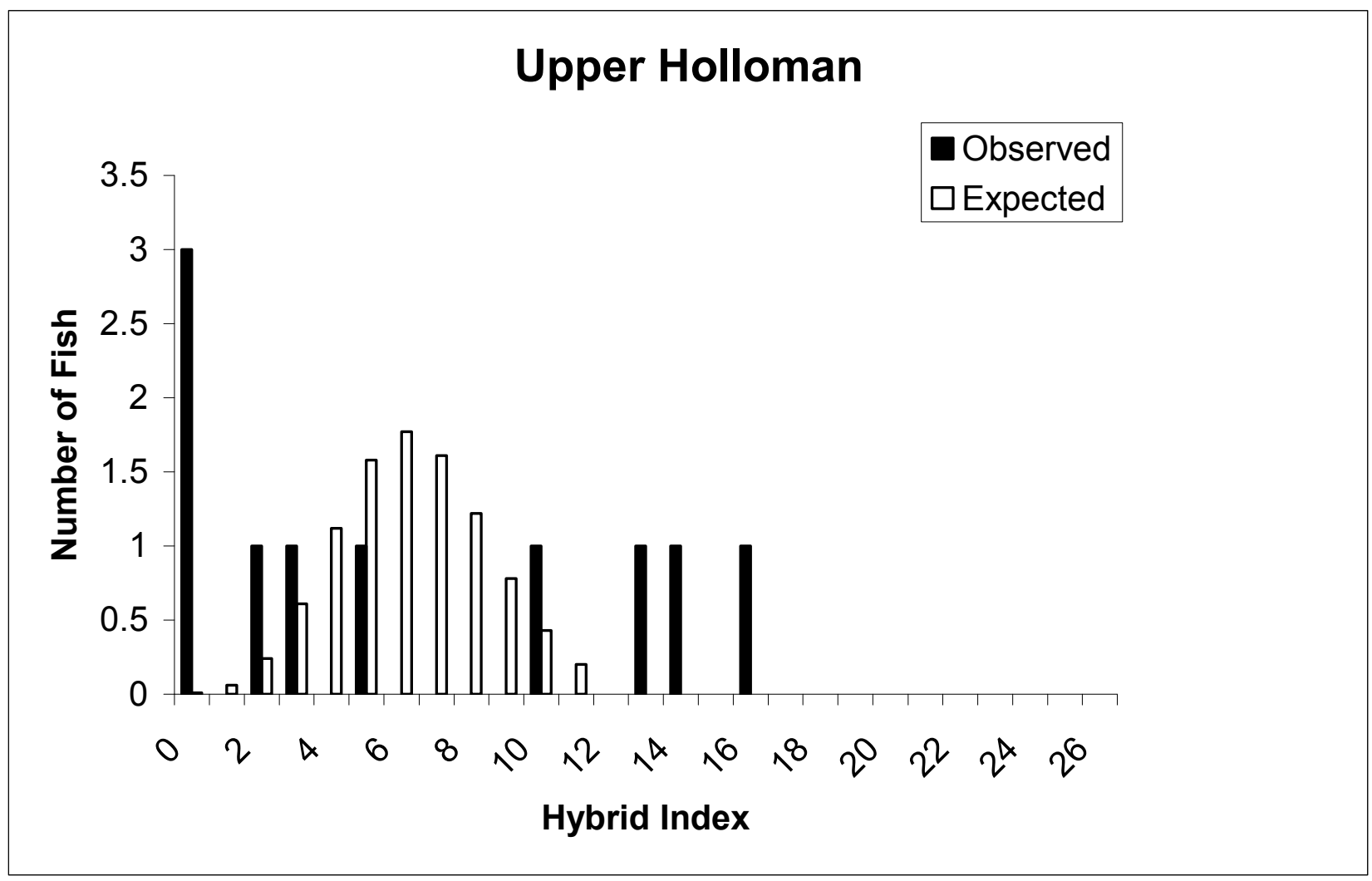

Figure 3. Observed and expected random distribution of hybrid indices among the fish showing evidence of hybridization between westslope cutthroat and rainbow trout collected from upper Holloman Creek. Note the observed distribution significantly differs $(\mathrm{P}<0.05)$ from the expected random distribution suggesting the sample did not come from a hybrid swarm. 


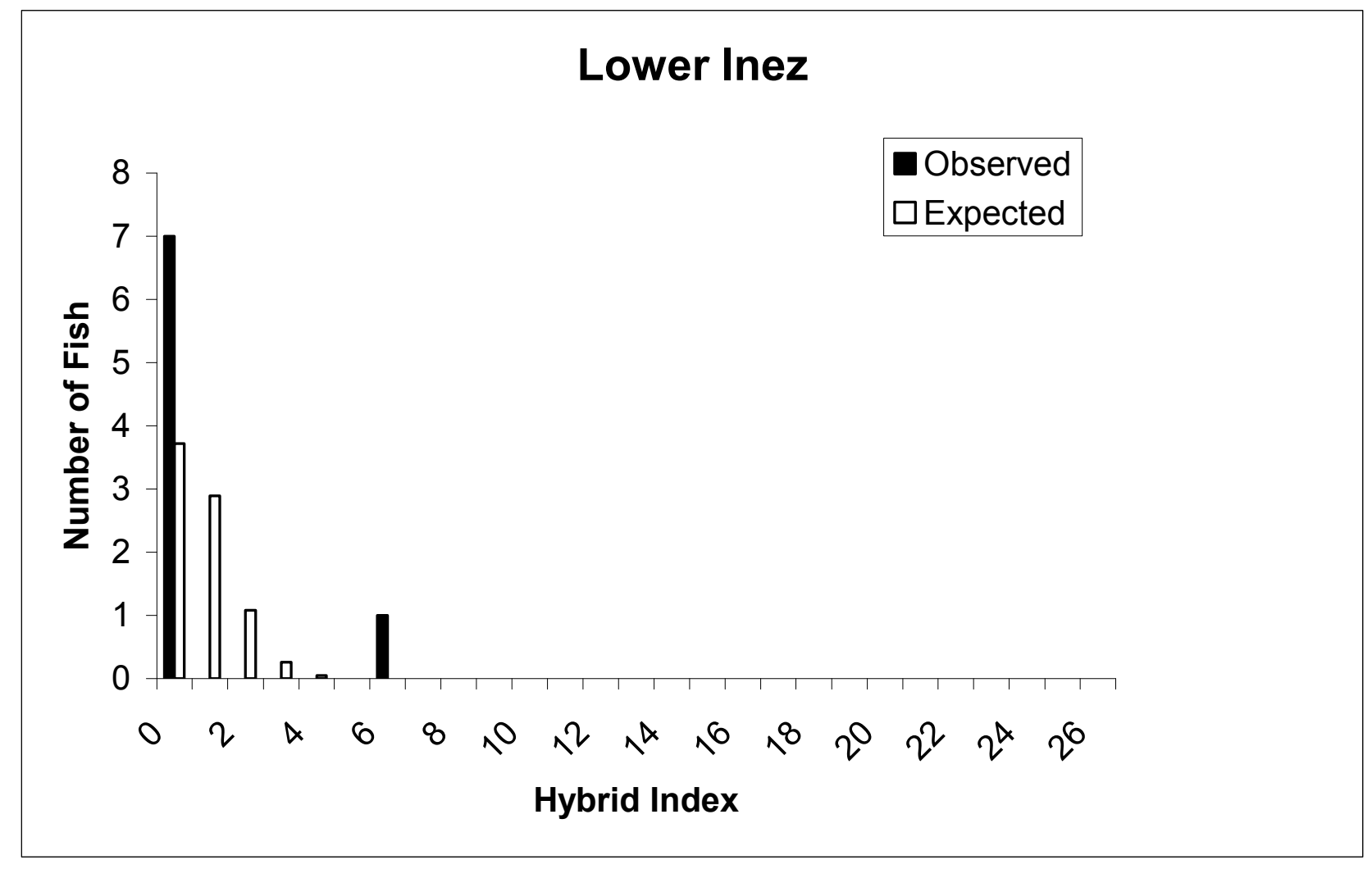

Figure 4. Observed and expected random distribution of hybrid indices among the fish showing evidence of hybridization between westslope cutthroat and rainbow trout collected from lower Inez Creek. Note the observed distribution significantly differs $(\mathrm{P}<0.05)$ from the expected random distribution suggesting the sample did not come from a hybrid swarm. 


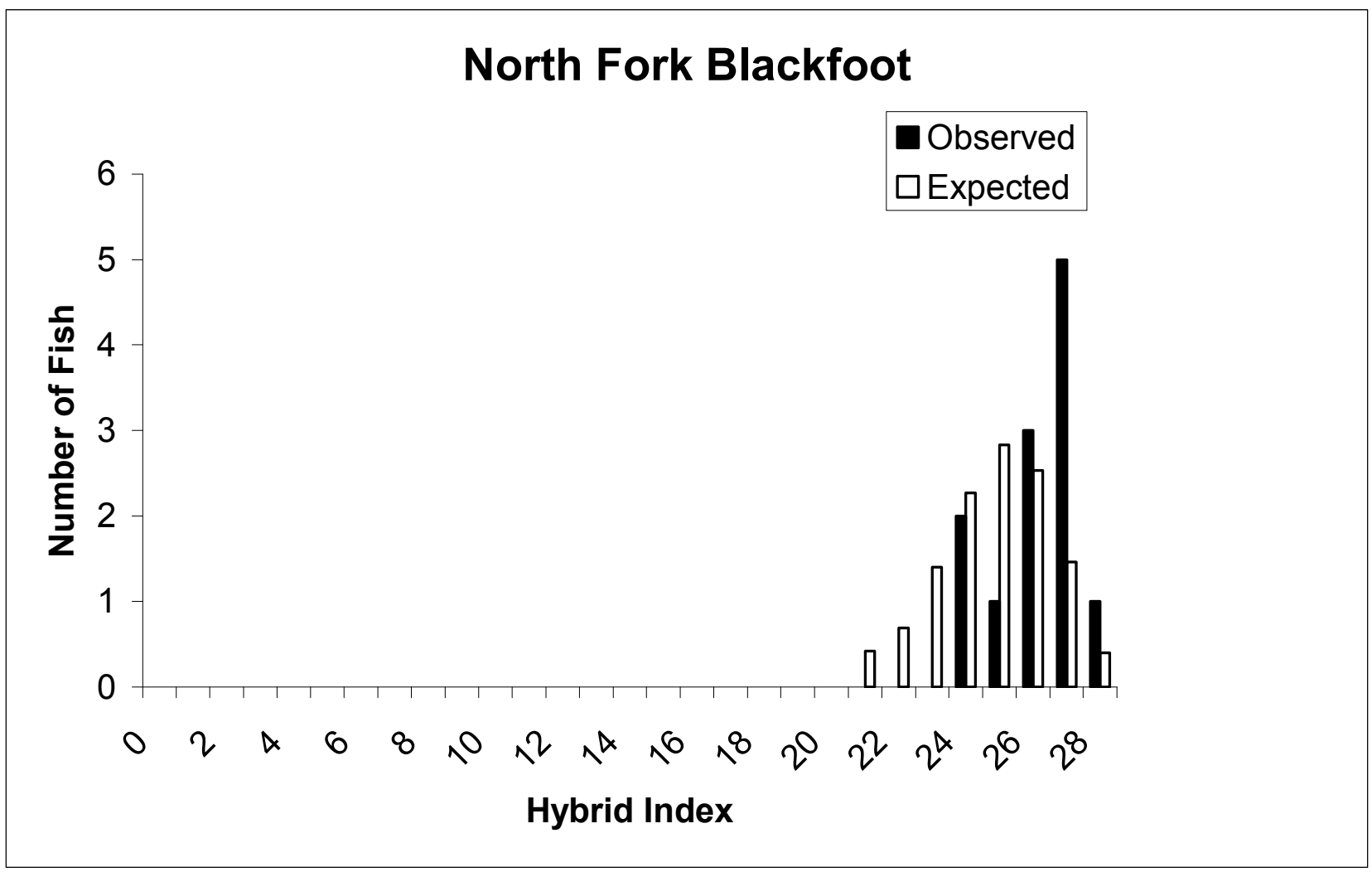

Figure 5. Observed and expected random distribution of hybrid indices among the fish showing evidence of hybridization among westslope cutthroat, Yellowstone cutthroat, and rainbow trout collected from the North Fork Blackfoot River. Note the observed distribution significantly differs $(\mathrm{P}<0.05)$ from the expected random distribution suggesting the sample did not come from a hybrid swarm. 


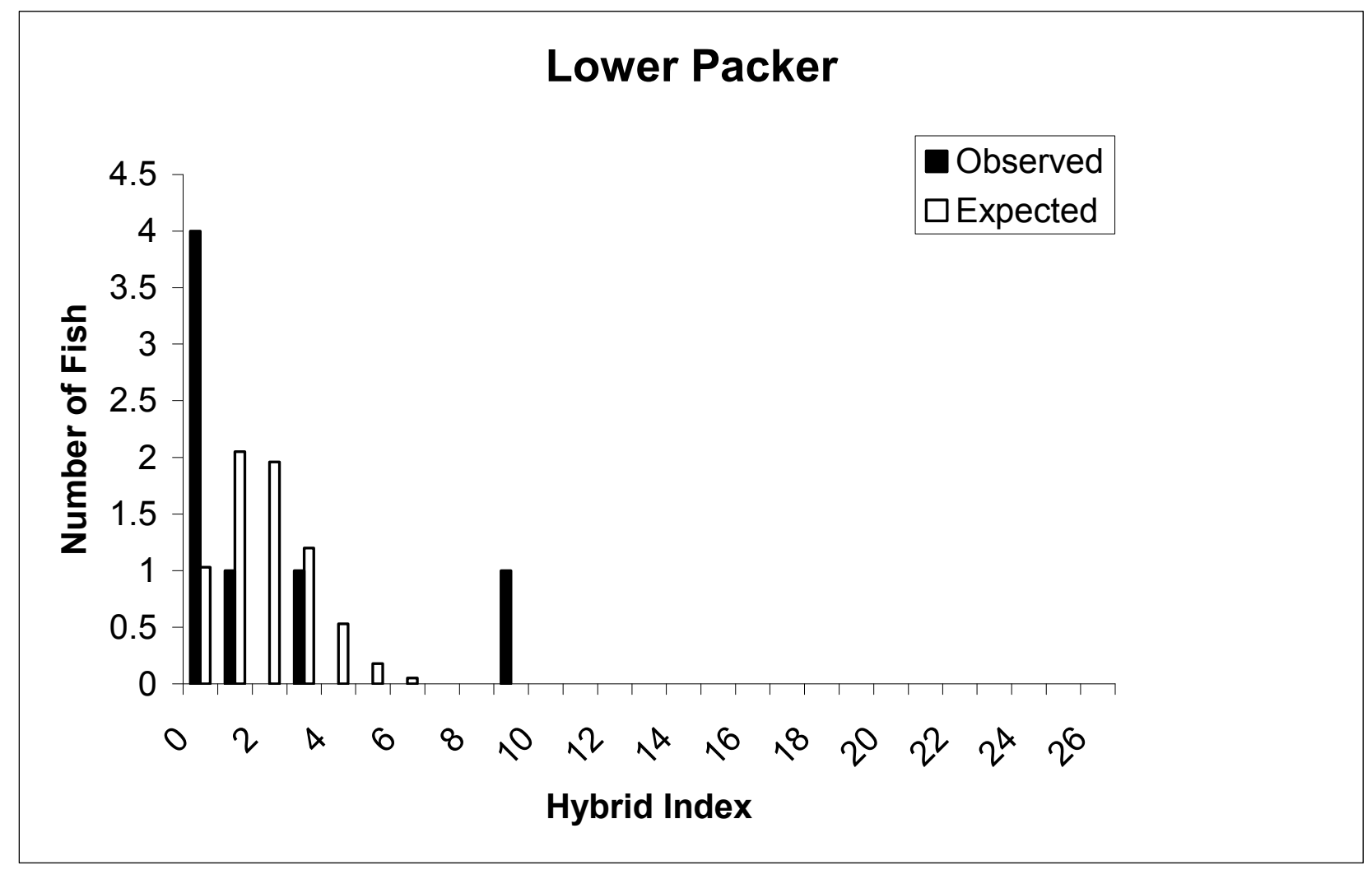

Figure 6. Observed and expected random distribution of hybrid indices among the fish showing evidence of hybridization between westslope cutthroat and rainbow trout collected from lower Packer Creek. Note the observed distribution significantly differs $(\mathrm{P}<0.05)$ from the expected random distribution suggesting the sample did not come from a hybrid swarm. 


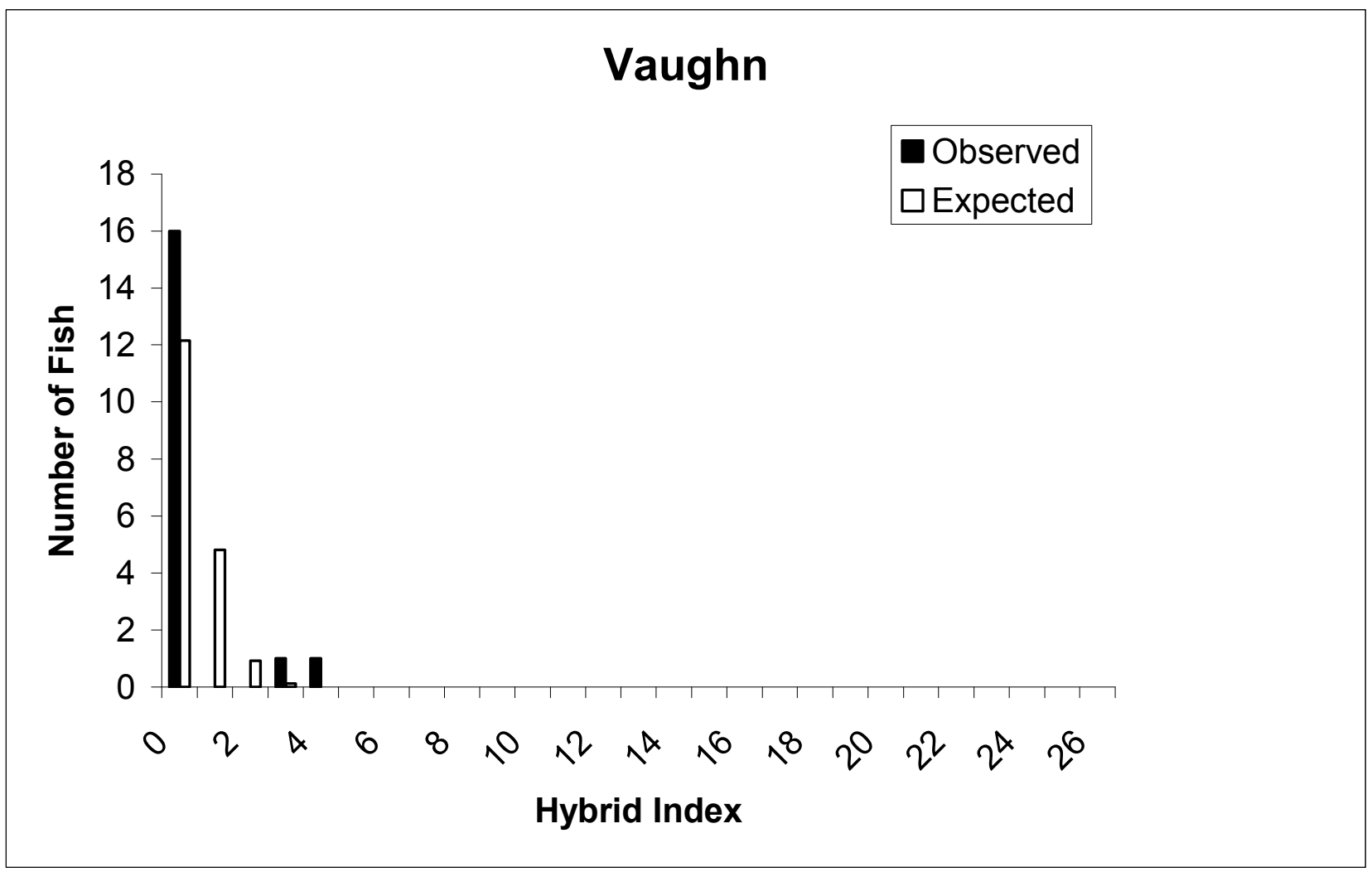

Figure 7. Observed and expected random distribution of hybrid indices among the fish showing evidence of hybridization between westslope cutthroat and rainbow trout collected from Vaughn Creek. Note the observed distribution significantly differs $(\mathrm{P}<0.05)$ from the expected random distribution suggesting the sample did not come from a hybrid swarm. 


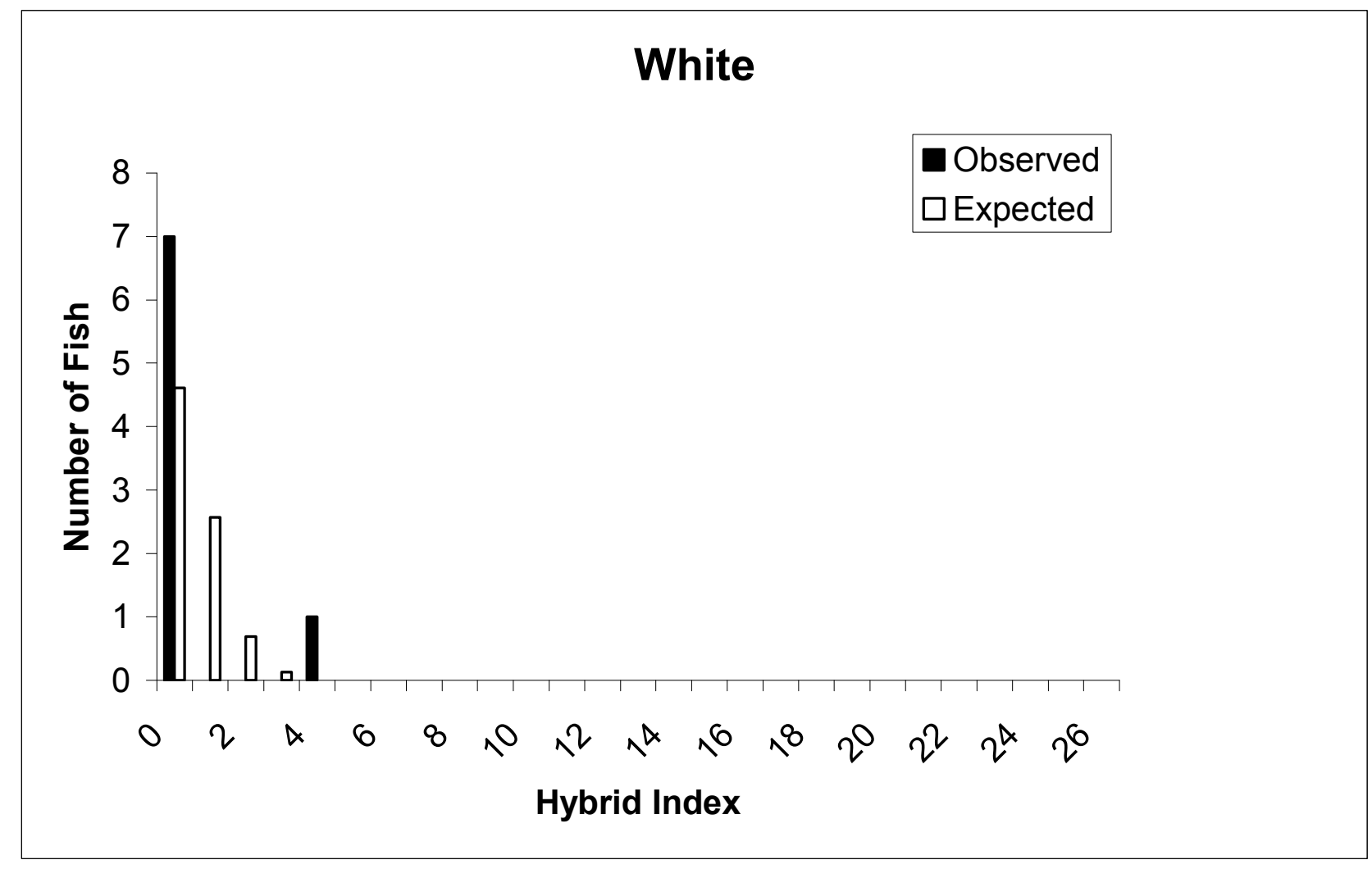

Figure 8. Observed and expected random distribution of hybrid indices among the fish showing evidence of hybridization between westslope cutthroat and rainbow trout collected from White Creek. Note the observed distribution significantly differs $(\mathrm{P}<0.05)$ from the expected random distribution suggesting the sample did not come from a hybrid swarm. 


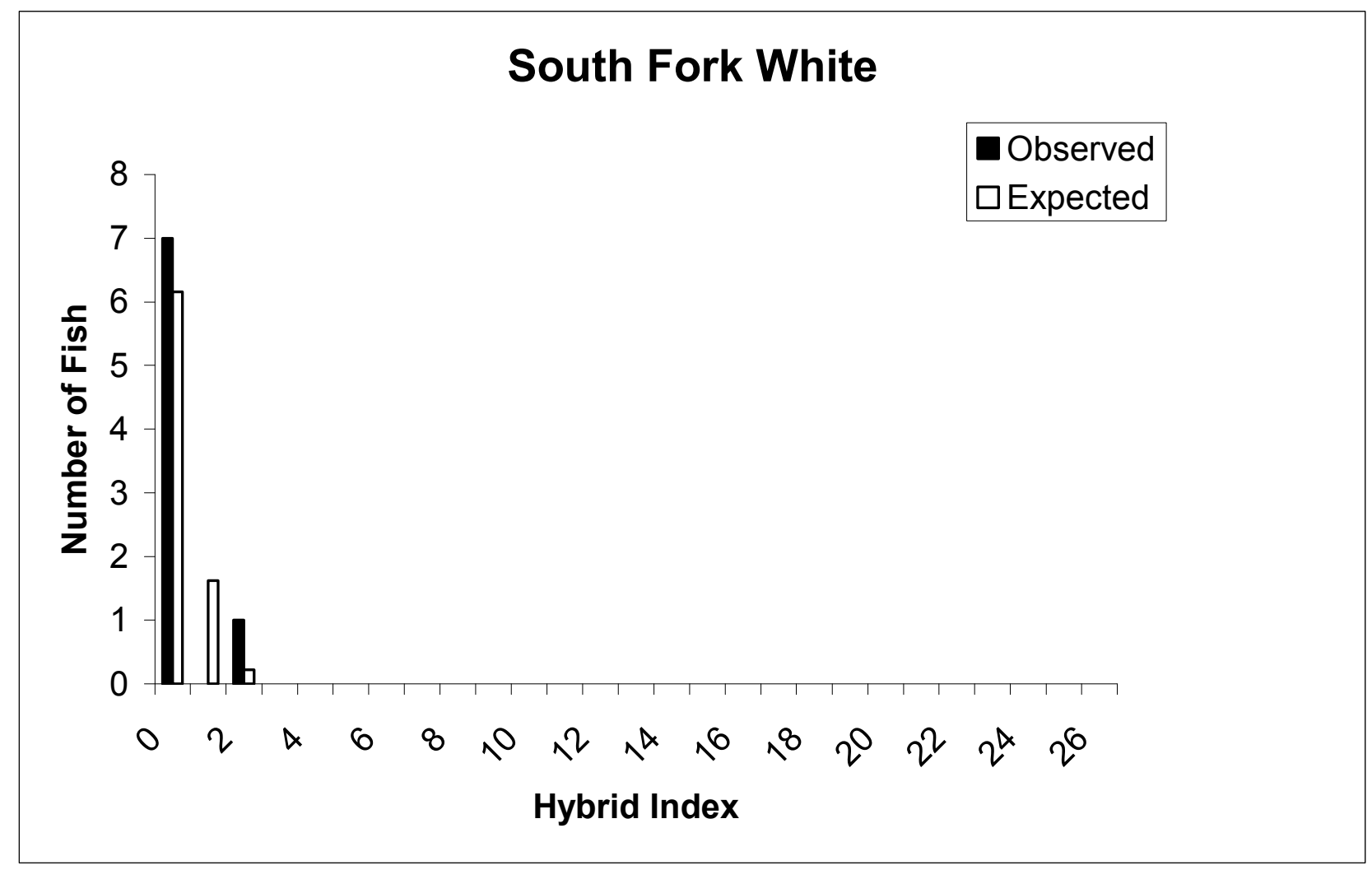

Figure 9. Observed and expected random distribution of hybrid indices among the fish showing evidence of hybridization between westslope cutthroat and rainbow trout collected from South Fork White Creek. Note the observed distribution significantly differs $(\mathrm{P}<0.05)$ from the expected random distribution suggesting the sample did not come from a hybrid swarm. 


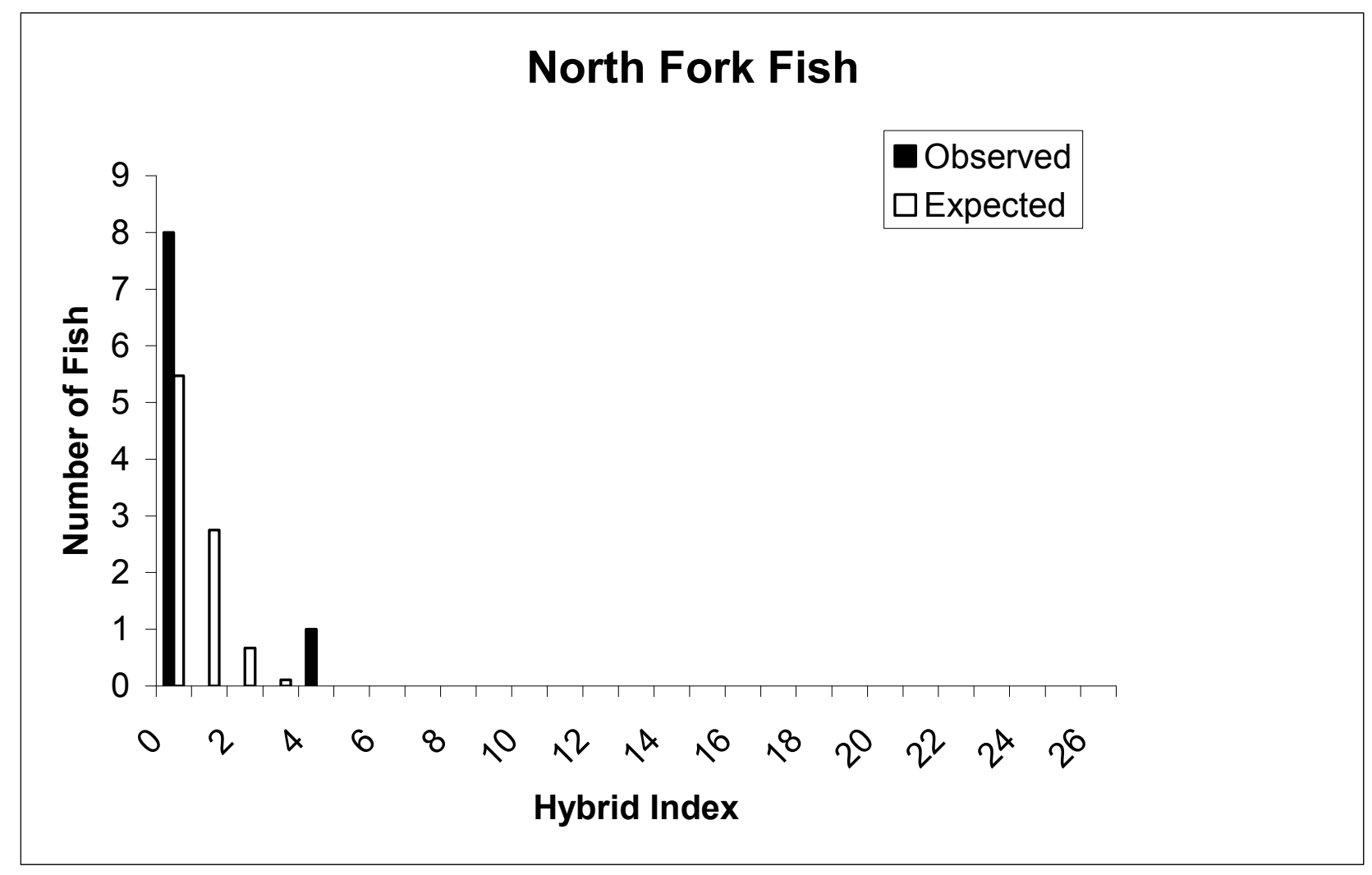

Figure10. Observed and expected random distribution of hybrid indices among the fish showing evidence of hybridization between westslope cutthroat and rainbow trout collected from North Fork Fish Creek. Note the observed distribution significantly differs $(\mathrm{P}<0.05)$ from the expected random distribution suggesting the sample did not come from a hybrid swarm. 


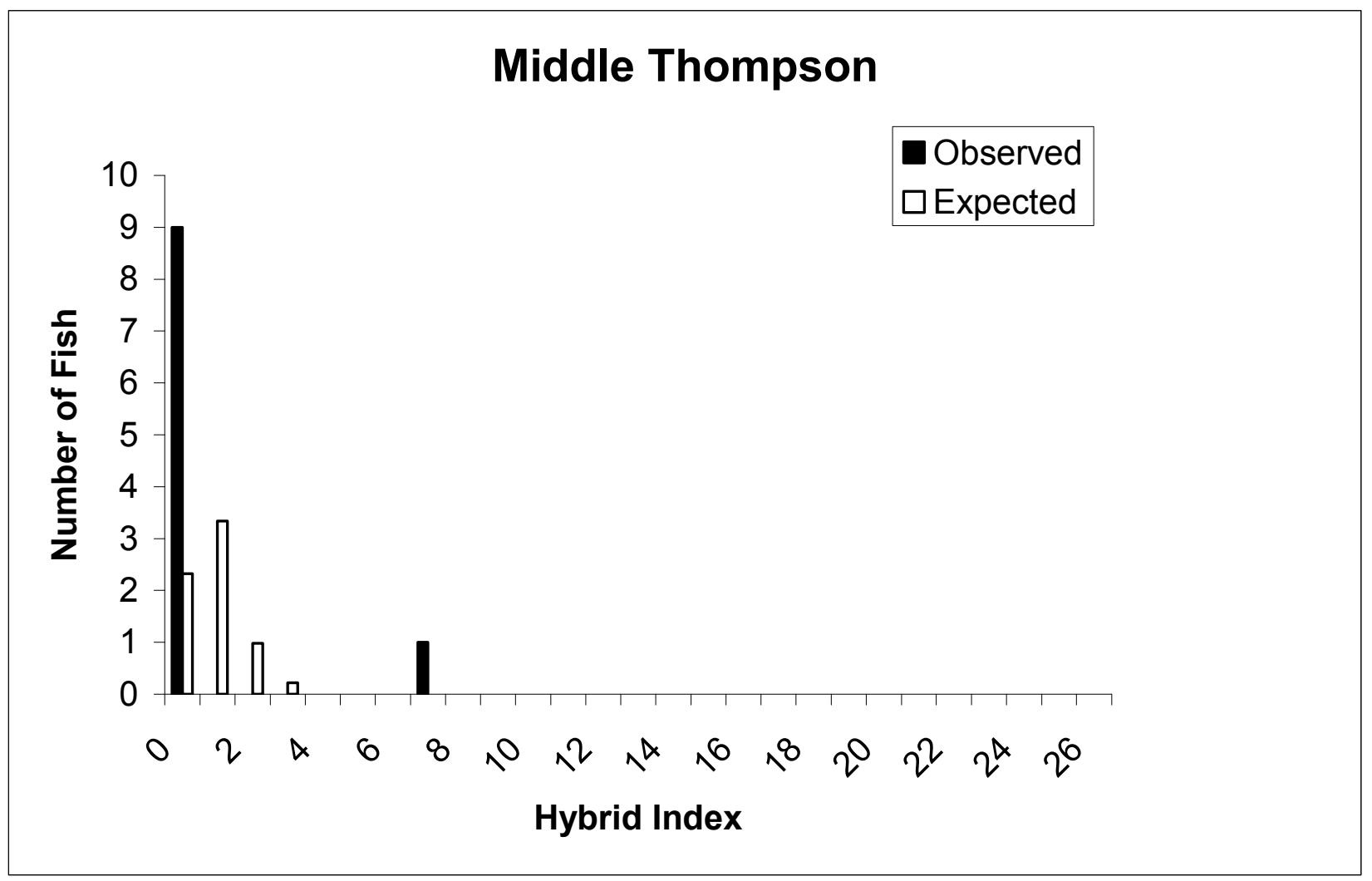

Figure11. Observed and expected random distribution of hybrid indices among the fish showing evidence of hybridization between westslope cutthroat and rainbow trout collected from middle Thompson Creek. Note the observed distribution significantly differs $(\mathrm{P}<0.05)$ from the expected random distribution suggesting the sample did not come from a hybrid swarm. 
Appendix K: Stream restoration prioritization sorted alphabetically by native species total

\begin{tabular}{|c|c|c|c|c|c|c|c|c|c|c|c|c|c|c|c|c|c|c|c|c|c|c|c|}
\hline Stream Name & $\begin{array}{l}\text { Blackfoot River } \\
\text { Drainage (BFR) } \\
\text { Clearwater River } \\
\text { Drainage (CWR) }\end{array}$ & $\begin{array}{c}\text { Bull trout } \\
\text { spawning } \\
\text { present }\end{array}$ & $\begin{array}{l}\text { Bull trout } \\
\text { rearing } \\
\text { present }\end{array}$ & $\begin{array}{l}\text { Bull } \\
\text { trout } \\
\text { core } \\
\text { area }\end{array}$ & $\begin{array}{c}\text { WSCT life } \\
\text { hisory } \\
\text { fluvial=20 } \\
\text { resident=10 } \\
\text { absent=0 }\end{array}$ & $\begin{array}{c}\text { Native } \\
\text { Species } \\
\text { Totals }\end{array}$ & $\begin{array}{c}\text { Sport fishery } \\
\text { value multiple } \\
\text { species }=20 \\
\text { single }=10 \\
\text { none }=0\end{array}$ & $\begin{array}{l}\text { Total } \\
\text { fisheries } \\
\text { score }\end{array}$ & \begin{tabular}{|c|} 
Technically \\
able to \\
address \\
entire stream \\
system
\end{tabular} & $\begin{array}{c}\text { Provide } \\
\text { increased } \\
\text { stream } \\
\text { flows to } \\
\text { BFR }\end{array}$ & $\begin{array}{c}\text { Dewatered } \\
(\mathrm{H}, \mathrm{N}, \mathrm{B})\end{array}$ & $\begin{array}{c}\text { Improves } \\
\text { downstream } \\
\text { water Quality } \\
\text { by reducing: } \\
\text { Sediment }\end{array}$ & $\begin{array}{c}\text { Improves } \\
\text { downstream } \\
\text { water Quality } \\
\text { by reducing: } \\
\text { Temp }\end{array}$ & $\begin{array}{c}\text { Improves } \\
\text { downstream } \\
\text { water Quality } \\
\text { by reducing: } \\
\text { Nutrients }\end{array}$ & $\begin{array}{l}\text { Water } \\
\text { Quality } \\
\text { Score }\end{array}$ & $\begin{array}{l}303(d) \\
\text { stream }\end{array}$ & \begin{tabular}{|l|} 
Water \\
Quality \\
Ranking
\end{tabular} & $\begin{array}{c}\text { Bio } \\
\text { score }\end{array}$ & $\begin{array}{c}\text { Land ownerl } \\
\text { Land manager } \\
\text { cooperation in } \\
\text { watershed }\end{array}$ & $\begin{array}{c}\text { Restoration } \\
\text { feasibility- } \\
\text { costlmile }\end{array}$ & $\mid \begin{array}{c}\text { Demol } \\
\text { Edu } \\
\text { value }\end{array}$ & $\begin{array}{l}\text { Social } \\
\text { score }\end{array}$ & $\begin{array}{l}\text { Total } \\
\text { Score }\end{array}$ \\
\hline Belmont Creek & BFR & 20 & 10 & 10 & 20 & 60 & 20 & 80 & 20 & & & 10 & 10 & & 20 & $Y$ & 2 & 120 & 20 & 10 & 10 & 40 & 160 \\
\hline Clearwater Section 2 & CWR & 20 & 10 & 10 & 20 & 60 & 20 & 80 & 20 & 20 & $B$ & 10 & 10 & 10 & 30 & & 1 & 150 & 10 & 20 & 10 & 40 & 190 \\
\hline Clearwater Section 3 & CWR & 20 & 10 & 10 & 20 & 60 & 20 & 80 & 20 & 20 & $B$ & & 10 & 10 & 20 & & 2 & 140 & 15 & 10 & 10 & 35 & 175 \\
\hline Copper Creek & BFR & 20 & 10 & 10 & 20 & 60 & 20 & 80 & 20 & & & & & & 0 & & 4 & 100 & 20 & 20 & 5 & 45 & 145 \\
\hline Cottonwood Cr. (R.M.43) & BFR & 20 & 10 & 10 & 20 & 60 & 20 & 80 & 20 & 20 & $B$ & 10 & & & 10 & & 3 & 130 & 15 & 10 & 10 & 35 & 165 \\
\hline Dunham Creek & BFR & 20 & 10 & 10 & 20 & 60 & 20 & 80 & 20 & & $B$ & 10 & & & 10 & & 3 & 110 & 20 & 10 & 10 & 40 & 150 \\
\hline E.F. Clearwater & CWR & 20 & 10 & 10 & 20 & 60 & 20 & 80 & 20 & & & 10 & & & 10 & & 3 & 110 & 20 & 20 & 10 & 50 & 160 \\
\hline Gold Creek & BFR & 20 & 10 & 10 & 20 & 60 & 20 & 80 & 20 & & & 10 & & & 10 & & 3 & 110 & 15 & 20 & 5 & 40 & 150 \\
\hline Gold Creek, W,F & BFR & 20 & 10 & 10 & 20 & 60 & 20 & 80 & 20 & & & 10 & & & 10 & & 3 & 110 & 20 & 20 & 5 & 45 & 155 \\
\hline \begin{tabular}{|l} 
Landers Fork \\
\end{tabular} & BFR & 20 & 10 & 10 & 20 & 60 & 20 & 80 & 20 & 20 & $\mathrm{~N}$ & 10 & 10 & & 20 & & 2 & 140 & 15 & 5 & 10 & 30 & 170 \\
\hline Monture Creek below the Falls & BFR & 20 & 10 & 10 & 20 & 60 & 20 & 80 & 20 & & $\mathrm{~N}$ & 10 & 10 & 10 & 30 & $Y$ & 1 & 130 & 15 & 20 & 10 & 45 & 175 \\
\hline North Fork below the Falls & BFR & 20 & 10 & 10 & 20 & 60 & 20 & 80 & 20 & 20 & $B$ & 10 & 10 & & 20 & & 2 & 140 & 15 & 10 & 10 & 35 & 175 \\
\hline W.F. Clearwater & CWR & 20 & 10 & 10 & 20 & 60 & 20 & 80 & 20 & & $\mathrm{~N}$ & 10 & 10 & & 20 & & 2 & 120 & 15 & 20 & 10 & 45 & 165 \\
\hline Alice Creek & BFR & 20 & 10 & & 20 & 50 & 10 & 60 & 20 & & & 10 & & & 10 & & 3 & 90 & 15 & 20 & 5 & 40 & 130 \\
\hline Arrastra Creek & BFR & 20 & 10 & & 20 & 50 & 20 & 70 & 20 & & $\mathrm{~N}$ & & & & 0 & Y & 4 & 90 & 10 & 5 & 10 & 25 & 115 \\
\hline Blackfoot River 1 & BFR & 20 & 10 & & 20 & 50 & 20 & 70 & 20 & & $B$ & 10 & & & 10 & $Y$ & 3 & 100 & 10 & 5 & 10 & 25 & 125 \\
\hline \begin{tabular}{|l|} 
Blackfoot River 2 \\
\end{tabular} & BFR & 20 & 10 & & 20 & 50 & 20 & 70 & 20 & & & 10 & & & 10 & $Y$ & 3 & 100 & 10 & 10 & 5 & 25 & 125 \\
\hline Blind Canyon Creek & CWR & 20 & 10 & & 20 & 50 & 10 & 60 & 20 & & & 10 & & & 10 & & 3 & 90 & 20 & 20 & 10 & 50 & 140 \\
\hline Boles Creek & CWR & 20 & 10 & & 20 & 50 & 20 & 70 & 20 & & & 10 & 10 & & 20 & & 2 & 110 & 15 & 10 & 10 & 35 & 145 \\
\hline Lodgepole Creek & BFR & 20 & 10 & 10 & 10 & 50 & 10 & 60 & 20 & & & & & & 0 & & 4 & 80 & 20 & 20 & 5 & 45 & 125 \\
\hline Poorman Creek & BFR & 20 & 10 & & 20 & 50 & 20 & 70 & 20 & 20 & $B$ & 10 & 10 & 10 & 30 & 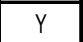 & 1 & 140 & 10 & 10 & 10 & 30 & 170 \\
\hline Cabin Creek & BFR & & 10 & 10 & 20 & 40 & 20 & 60 & 20 & & & & & & & & 4 & 80 & 20 & 5 & 10 & 35 & 115 \\
\hline Canyon Creek & BFR & & 10 & 10 & 20 & 40 & 20 & 60 & 20 & & & & & & & & 4 & 80 & 20 & 5 & 10 & 35 & 115 \\
\hline Clearwater Section 5 & CWR & & 10 & 10 & 20 & 40 & 10 & 50 & 20 & & & & & & 0 & & 4 & 70 & 20 & 20 & 10 & 50 & 120 \\
\hline Dry Creek & BFR & & 10 & 10 & 20 & 40 & 20 & 60 & 20 & & $\mathrm{~N}$ & 10 & 10 & & 20 & & & 100 & 20 & 20 & 5 & 45 & 145 \\
\hline Dry Fork of the North Fork & $\mathrm{BFR}$ & & 10 & 10 & 20 & 40 & 20 & 60 & 20 & & $\mathrm{~N}$ & & & & & & 4 & 80 & 20 & 5 & 10 & 35 & 115 \\
\hline East Fork of Monture & BFR & & 10 & 10 & 20 & 40 & 20 & 60 & 20 & & & & & & & & 4 & 80 & 20 & 20 & 5 & 45 & 125 \\
\hline Hayden Creek & BFR & & 10 & 10 & 20 & 40 & 20 & 60 & 20 & & & & & & & & 4 & 80 & 20 & 20 & 5 & 45 & 125 \\
\hline Nevada Cr.(upper) & BFR & 20 & 10 & & 10 & 40 & 0 & 40 & & & $\mathrm{~N}$ & 10 & 10 & 10 & 30 & $Y$ & 1 & 70 & 10 & 20 & 10 & 40 & 110 \\
\hline
\end{tabular}


Appendix K: Stream restoration prioritization sorted alphabetically by native species total (cont'd).

\begin{tabular}{|c|c|c|c|c|c|c|c|c|c|c|c|c|c|c|c|c|c|c|c|c|c|c|c|}
\hline Stream Name & $\begin{array}{l}\text { Blackfoot River } \\
\text { Drainage (BFR) } \\
\text { Clearwater River } \\
\text { Drainage (CWR) }\end{array}$ & $\begin{array}{c}\text { Bull trout } \\
\text { spawning } \\
\text { present }\end{array}$ & $\begin{array}{l}\text { Bull trout } \\
\text { rearing } \\
\text { present }\end{array}$ & $\begin{array}{l}\text { Bull } \\
\text { trout } \\
\text { core } \\
\text { area }\end{array}$ & \begin{tabular}{|c|} 
WSCT life \\
hisory \\
fluvial=20 \\
resident=10 \\
absent=0
\end{tabular} & $\begin{array}{c}\text { Native } \\
\text { Species } \\
\text { Totals }\end{array}$ & $\begin{array}{c}\text { Sport fishery } \\
\text { value multiple } \\
\text { species }=20 \\
\text { single }=10 \\
\text { none }=0\end{array}$ & $\begin{array}{l}\text { Total } \\
\text { fisheries } \\
\text { score }\end{array}$ & $\begin{array}{c}\text { Technically } \\
\text { able to } \\
\text { address } \\
\text { entire stream } \\
\text { system }\end{array}$ & $\begin{array}{c}\text { Provide } \\
\text { increased } \\
\text { stream } \\
\text { flows to } \\
\text { BFR }\end{array}$ & $\begin{array}{c}\text { Dewatered } \\
(\mathrm{H}, \mathrm{N}, \mathrm{B})\end{array}$ & $\begin{array}{c}\text { Improves } \\
\text { downstream } \\
\text { water Quality } \\
\text { by reducing: } \\
\text { Sediment }\end{array}$ & $\begin{array}{c}\text { Improves } \\
\text { downstream } \\
\text { water Quality } \\
\text { by reducing: } \\
\text { Temp }\end{array}$ & \begin{tabular}{|c|} 
Improves \\
downstream \\
water Quality \\
by reducing: \\
Nutrients
\end{tabular} & $\begin{array}{l}\text { Water } \\
\text { Quality } \\
\text { Score }\end{array}$ & $\begin{array}{l}303(d) \\
\text { stream }\end{array}$ & \begin{tabular}{|l|} 
Water \\
Quality \\
Ranking
\end{tabular} & $\begin{array}{c}\text { Bio } \\
\text { score }\end{array}$ & $\begin{array}{c}\text { Land ownerl } \\
\text { Land manager } \\
\text { cooperation in } \\
\text { watershed }\end{array}$ & $\begin{array}{c}\text { Restoration } \\
\text { feasibility- } \\
\text { cost/mile }\end{array}$ & $\mid \begin{array}{c}\text { Demol } \\
\text { Edu } \\
\text { value }\end{array}$ & $\begin{array}{l}\text { Social } \\
\text { score }\end{array}$ & $\begin{array}{l}\text { Total } \\
\text { Score }\end{array}$ \\
\hline Rock Creek & BFR & & 10 & 10 & 20 & 40 & 20 & 60 & 20 & 20 & $B$ & 10 & 10 & 10 & 30 & Y & 1 & 130 & 15 & 5 & 10 & 30 & 160 \\
\hline Salmon Creek & BFR & & 10 & 10 & 20 & 40 & 20 & 60 & 20 & 20 & $\mathrm{H}$ & & & & 0 & & 4 & 100 & 15 & 10 & 5 & 30 & 130 \\
\hline Snowbank Creek & BFR & & 10 & 10 & 20 & 40 & 20 & 60 & 20 & 20 & $\mathrm{H}$ & & & & 0 & & 4 & 100 & 20 & 20 & 10 & 50 & 150 \\
\hline Spring Creek (N.F.) & BFR & & 10 & 10 & 20 & 40 & 20 & 60 & 20 & 20 & $\mathrm{H}$ & 10 & & & 10 & & 3 & 110 & 15 & 10 & 5 & 30 & 140 \\
\hline Bear Creek (R.M.12.2) & BFR & & 10 & & 20 & 30 & 20 & 50 & 20 & & & 10 & & & 10 & & 3 & 80 & 20 & 20 & 5 & 45 & 125 \\
\hline Beaver Creek & BFR & & 10 & & 20 & 30 & 20 & 50 & 20 & 20 & & 10 & 10 & 10 & 30 & & 1 & 120 & 15 & 20 & 5 & 40 & 160 \\
\hline Blackfoot River 3 & BFR & & 10 & & 20 & 30 & 0 & 30 & 20 & 20 & $\mathrm{H}$ & 10 & 10 & & 20 & $Y$ & 2 & 90 & 10 & 20 & 5 & 35 & 125 \\
\hline Blackfoot River 4 & BFR & & 10 & & 20 & 30 & 0 & 30 & 20 & 20 & $\mathrm{H}$ & 10 & 10 & 10 & 30 & $Y$ & 1 & 100 & 10 & 20 & 5 & 35 & 135 \\
\hline Blackfoot River 5 & BFR & & 10 & & 20 & 30 & 0 & 30 & 20 & & & 10 & & & 10 & $Y$ & 3 & 60 & 20 & 20 & 5 & 45 & 105 \\
\hline Blackfoot River 6 & BFR & & 10 & & 20 & 30 & 0 & 30 & 20 & & & & & & 0 & $Y$ & 4 & 50 & 20 & 20 & 10 & 50 & 100 \\
\hline Burnt Cabin Creek & $\mathrm{BFR}$ & & & 10 & 20 & 30 & 10 & 40 & 20 & & & & & & & & 4 & 60 & 20 & 20 & 5 & 45 & 105 \\
\hline Camp Creek & CWR & & 10 & & 20 & 30 & 10 & 40 & 20 & & $\mathrm{~N}$ & 10 & 10 & & 20 & & 2 & 80 & 20 & 10 & 10 & 40 & 120 \\
\hline Deer Creek & CWR & & 10 & & 20 & 30 & 20 & 50 & 20 & & & 10 & 10 & & 20 & & 2 & 90 & 15 & 10 & 10 & 35 & 125 \\
\hline Dick Creek & BFR & & & 10 & 20 & 30 & 20 & 50 & 20 & 20 & $B$ & 10 & 10 & 10 & 30 & & 1 & 120 & 15 & 20 & 10 & 45 & 165 \\
\hline East Twin Creek & BFR & & 10 & & 20 & 30 & 20 & 50 & 20 & & & 10 & & & 10 & & 3 & 80 & 15 & 20 & 5 & 40 & 120 \\
\hline Ender's Spring Creek & $\mathrm{BFR}$ & & 10 & & 20 & 30 & 20 & 50 & 20 & 20 & & 10 & 10 & 10 & 30 & & 1 & 120 & 20 & 20 & 10 & 50 & 170 \\
\hline Grantier Spring $\mathrm{Cr}$. & BFR & & 10 & & 20 & 30 & 20 & 50 & & & & & & & 0 & & 4 & 50 & 20 & 20 & 10 & 50 & 100 \\
\hline Hogum Creek & $\mathrm{BFR}$ & & 10 & & 20 & 30 & 20 & 50 & 20 & & & 10 & & & 10 & & 3 & 80 & 10 & 20 & 5 & 35 & 115 \\
\hline Inez Creek & CWR & & 10 & & 20 & 30 & 10 & 40 & 20 & & & 10 & 10 & & 20 & & 2 & 80 & 15 & 10 & 10 & 35 & 115 \\
\hline Johnson Creek & $\mathrm{BFR}$ & & 10 & & 20 & 30 & 20 & 50 & 20 & & & 10 & & & 10 & & 3 & 80 & 15 & 20 & 5 & 40 & 120 \\
\hline McCabe Creek & $\mathrm{BFR}$ & & & 10 & 20 & 30 & 10 & 40 & 20 & 20 & $\mathrm{H}$ & 10 & & & 10 & & 3 & 90 & 20 & 20 & 5 & 45 & 135 \\
\hline Saurekraut Creek & BFR & & 10 & & 20 & 30 & 20 & 50 & 20 & & & 10 & 10 & & 20 & & 2 & 90 & 15 & 5 & 10 & 30 & 120 \\
\hline Spring Cr.(Cottonwood) & $\mathrm{BFR}$ & & 10 & 10 & 10 & 30 & 20 & 50 & 20 & 20 & $\mathrm{H}$ & 10 & & & 10 & & 3 & 100 & 10 & 10 & 10 & 30 & 130 \\
\hline Trail Creek & CWR & & 10 & & 20 & 30 & 10 & 40 & 20 & 20 & $\mathrm{H}$ & 10 & 10 & 10 & 30 & & 1 & 110 & 10 & 10 & 10 & 30 & 140 \\
\hline Unnamed tributary & $\mathrm{BFR}$ & & & 10 & 20 & 30 & 10 & 40 & 20 & & & & & & & & 4 & 60 & 20 & 20 & 5 & 45 & 105 \\
\hline West Twin Creek & $\mathrm{BFR}$ & & 10 & & 20 & 30 & 20 & 50 & 20 & & & 10 & & & 10 & & 3 & 80 & 15 & 20 & 5 & 40 & 120 \\
\hline Yellowjacket Creek & BFR & & & 10 & 20 & 30 & 10 & 40 & 20 & & & & & & & & 4 & 60 & 20 & 20 & 5 & 45 & 105 \\
\hline Basin Spring Creek & $\mathrm{BFR}$ & & & & 20 & 20 & 10 & 30 & 20 & & & 10 & & & 10 & & 3 & 60 & 20 & 20 & 10 & 50 & 110 \\
\hline Blanchard Creek & BFR & & & & 20 & 20 & 20 & 40 & 20 & 20 & $\mathrm{H}$ & 10 & 10 & 10 & 30 & $\mathrm{Y}$ & 1 & 110 & 15 & 10 & 10 & 35 & 145 \\
\hline
\end{tabular}


Appendix K: Stream restoration prioritization sorted alphabetically by native species total (cont'd).

\begin{tabular}{|c|c|c|c|c|c|c|c|c|c|c|c|c|c|c|c|c|c|c|c|c|c|c|c|}
\hline Stream Name & \begin{tabular}{|l|} 
Blackfoot River \\
Drainage (BFR) \\
Clearwater River \\
Drainage (CWR)
\end{tabular} & $\begin{array}{c}\text { Bull trout } \\
\text { spawning } \\
\text { present }\end{array}$ & $\begin{array}{c}\text { Bull trout } \\
\text { rearing } \\
\text { present }\end{array}$ & \begin{tabular}{|c|} 
Bull \\
trout \\
core \\
area
\end{tabular} & $\begin{array}{c}\text { WSCT life } \\
\text { hisory } \\
\text { fluvial=20 } \\
\text { resident=10 } \\
\text { absent=0 }\end{array}$ & $\begin{array}{c}\text { Native } \\
\text { Species } \\
\text { Totals }\end{array}$ & $\begin{array}{c}\text { Sport fishery } \\
\text { value multiple } \\
\text { species }=20 \\
\text { single }=10 \\
\text { none }=0\end{array}$ & $\begin{array}{c}\text { Total } \\
\text { fisheries } \\
\text { score }\end{array}$ & $\begin{array}{c}\text { Technically } \\
\text { able to } \\
\text { address } \\
\text { entire stream } \\
\text { system }\end{array}$ & $\begin{array}{c}\text { Provide } \\
\text { increased } \\
\text { stream } \\
\text { flows to } \\
\text { BFR }\end{array}$ & $\begin{array}{r}\text { Dewatered } \\
(\mathrm{H}, \mathrm{N}, \mathrm{B})\end{array}$ & $\begin{array}{c}\text { Improves } \\
\text { downstream } \\
\text { water Quality } \\
\text { by reducing: } \\
\text { Sediment }\end{array}$ & $\begin{array}{c}\text { Improves } \\
\text { downstream } \\
\text { water Quality } \\
\text { by reducing: } \\
\text { Temp }\end{array}$ & $\begin{array}{c}\text { Improves } \\
\text { downstream } \\
\text { water Quality } \\
\text { by reducing: } \\
\text { Nutrients }\end{array}$ & $\begin{array}{l}\text { Water } \\
\text { Quality } \\
\text { Score }\end{array}$ & $\begin{array}{l}\text { 303(d) } \\
\text { stream }\end{array}$ & \begin{tabular}{|l|} 
Water \\
Quality \\
Ranking
\end{tabular} & $\begin{array}{c}\text { Bio } \\
\text { score }\end{array}$ & $\begin{array}{c}\text { Land ownerl } \\
\text { Land manager } \\
\text { cooperation in } \\
\text { watershed }\end{array}$ & $\begin{array}{l}\text { Restoration } \\
\text { feasibility- } \\
\text { costlmile }\end{array}$ & $\begin{array}{c}\text { Demol } \\
\text { Edu } \\
\text { value }\end{array}$ & $\begin{array}{l}\text { Social } \\
\text { score }\end{array}$ & $\begin{array}{l}\text { Total } \\
\text { Score }\end{array}$ \\
\hline Chamberlain EF & BFR & & & & 20 & 20 & 10 & 30 & 20 & & & 10 & & & 10 & & 3 & 60 & 20 & 20 & 5 & 45 & 105 \\
\hline Chamberlain WF & BFR & & & & 20 & 20 & 10 & 30 & 20 & & & 10 & & & 10 & & 3 & 60 & 20 & 10 & 5 & 35 & 95 \\
\hline Clearwater Section 1 & CWR & & & & 20 & 20 & 20 & 40 & 0 & 20 & H & & 10 & 10 & 20 & & 2 & 80 & 15 & 20 & 10 & 45 & 125 \\
\hline Elk Creek & BFR & & & & 20 & 20 & 20 & 40 & 20 & 20 & $\mathrm{H}$ & 10 & 10 & 10 & 30 & $Y$ & 1 & 110 & 15 & 10 & 5 & 30 & 140 \\
\hline \begin{tabular}{|l|} 
Fawn Creek \\
\end{tabular} & CWR & & & & 20 & 20 & 10 & 30 & 20 & & $\mathrm{~N}$ & 10 & 10 & & 20 & & 2 & 70 & 15 & 10 & 5 & 30 & 100 \\
\hline Findell Creek & CWR & & & & 20 & 20 & 10 & 30 & 20 & & & & 10 & & 10 & & 3 & 60 & 20 & 10 & 5 & 35 & 95 \\
\hline Fish Creek & BFR & & & & 20 & 20 & 10 & 30 & 20 & 20 & $\mathrm{H}$ & & & & 0 & & 4 & 70 & 15 & 20 & 10 & 45 & 115 \\
\hline Keep Cool Creek & BFR & & & & 20 & 20 & 20 & 40 & 20 & & $\mathrm{H}$ & 10 & 10 & & 20 & & 2 & 80 & 15 & 20 & 5 & 40 & 120 \\
\hline Lincoln Spring $\mathrm{Cr}$. & $\mathrm{BFR}$ & & & & 20 & 20 & 20 & 40 & 20 & 20 & & & & 10 & 10 & & 3 & 90 & 10 & 5 & 10 & 25 & 115 \\
\hline Little Fish Creek & BFR & & & & 20 & 20 & 10 & 30 & 20 & 20 & $\mathrm{H}$ & 10 & & & 10 & & 3 & 80 & 15 & 20 & 10 & 45 & 125 \\
\hline Little Moose Creek & BFR & & & & 20 & 20 & 10 & 30 & 20 & & & & & & 0 & & 4 & 50 & 20 & 20 & 5 & 45 & 95 \\
\hline McDermott Creek & $\mathrm{BFR}$ & & & 10 & 10 & 20 & 0 & 20 & & & & & & & 0 & & 4 & 20 & 20 & 20 & 5 & 45 & 65 \\
\hline Middle Fork Monture Creek & BFR & & & 10 & 10 & 20 & 0 & 20 & 20 & & & & & & & & 4 & 40 & 20 & 20 & 5 & 45 & 85 \\
\hline Moose Creek & BFR & & & & 20 & 20 & 10 & 30 & 20 & & & 10 & & & 10 & & 3 & 60 & 20 & 20 & 5 & 45 & 105 \\
\hline N.F. Placid Creek & CWR & & & & 20 & 20 & 10 & 30 & 20 & 20 & $\mathrm{H}$ & 10 & 10 & & 20 & & 2 & 90 & 15 & 10 & 10 & 35 & 125 \\
\hline Nevada Spring $\mathrm{Cr}$. & BFR & & & & 20 & 20 & 0 & 20 & 20 & 20 & & 10 & 10 & 10 & 30 & $Y$ & 1 & 90 & 20 & 5 & 10 & 35 & 125 \\
\hline \begin{tabular}{|l} 
Pearson Creek \\
\end{tabular} & BFR & & & & 20 & 20 & 10 & 30 & 20 & & & 10 & 10 & & 20 & $Y$ & 2 & 70 & 20 & 20 & 10 & 50 & 120 \\
\hline Placid Creek & CWR & & & & 20 & 20 & 20 & 40 & 20 & & & 10 & 10 & & 20 & & 2 & 80 & 15 & 10 & 10 & 35 & 115 \\
\hline Seven up Pete Cr. & BFR & & & & 20 & 20 & 10 & 30 & 20 & & & 10 & & & 10 & & 3 & 60 & 15 & 20 & 5 & 40 & 100 \\
\hline Shanley Creek & BFR & & & 10 & 10 & 20 & 20 & 40 & 20 & & $\mathrm{H}$ & 10 & 10 & 10 & 30 & & 1 & 90 & 15 & 20 & 5 & 40 & 130 \\
\hline Wales Creek & BFR & & & & 20 & 20 & 20 & 40 & & 20 & $\mathrm{H}$ & 10 & 10 & 10 & 30 & $Y$ & 1 & 90 & 10 & 10 & 10 & 30 & 120 \\
\hline Wales Spring Creek & BFR & & & & 20 & 20 & 20 & 40 & 20 & & & 10 & 10 & 10 & 30 & & 1 & 90 & 10 & 20 & 10 & 40 & 130 \\
\hline \begin{tabular}{|l} 
Wasson Creek \\
\end{tabular} & BFR & & & & 20 & 20 & 0 & 20 & 20 & 20 & $\mathrm{H}$ & 10 & 10 & 10 & 30 & & 1 & 90 & 15 & 20 & 5 & 40 & 130 \\
\hline Willow Cr. (upper) & BFR & & & & 20 & 20 & 10 & 30 & 20 & & & 10 & 10 & 10 & 30 & $Y$ & 1 & 80 & 15 & 20 & 5 & 40 & 120 \\
\hline Yourname Creek & BFR & & & & 20 & 20 & 10 & 30 & 20 & 20 & $\mathrm{H}$ & 10 & 10 & 10 & 30 & $Y$ & 1 & 100 & 10 & 10 & 5 & 25 & 125 \\
\hline Anaconda Creek & BFR & & & & 10 & 10 & 0 & 10 & 20 & & & 10 & 10 & & 20 & & 2 & 50 & 20 & 5 & 10 & 35 & 85 \\
\hline Archibald Creek & CWR & & & & 10 & 10 & 0 & 10 & 20 & & $\mathrm{~N}$ & 10 & & & 10 & & 3 & 40 & 20 & 20 & 5 & 45 & 85 \\
\hline Arkansas Creek & BFR & & & & 10 & 10 & 0 & 10 & 20 & & $\mathrm{H}$ & 10 & 10 & & 20 & & 2 & 50 & 15 & 10 & 10 & 35 & 85 \\
\hline \begin{tabular}{|l|} 
Ashby Creek \\
\end{tabular} & BFR & & & & 10 & 10 & 0 & 10 & 20 & & $\mathrm{H}$ & 10 & 10 & 10 & 30 & $Y$ & 1 & 60 & 20 & 5 & 10 & 35 & 95 \\
\hline Bartlett Creek & BFR & & & & 10 & 10 & 0 & 10 & 20 & & & & 10 & & 10 & & 3 & 40 & 15 & 20 & 5 & 40 & 80 \\
\hline Bear Gulch & $\mathrm{BFR}$ & & & & 10 & 10 & 0 & 10 & 20 & & $\mathrm{H}$ & 10 & 10 & 10 & 30 & & 1 & 60 & 20 & 20 & 10 & 50 & 110 \\
\hline Bertha Creek & CWR & & & & 10 & 10 & 0 & 10 & 20 & 20 & $\mathrm{H}$ & 10 & 10 & 10 & 30 & & 1 & 80 & 10 & 10 & 10 & 30 & 110 \\
\hline Blanchard NF & BFR & & & & 10 & 10 & 0 & 10 & 20 & & & 10 & 10 & & 20 & & 2 & 50 & 20 & 10 & 10 & 40 & 90 \\
\hline
\end{tabular}


Appendix K: Stream restoration prioritization sorted alphabetically by native species total (cont'd).

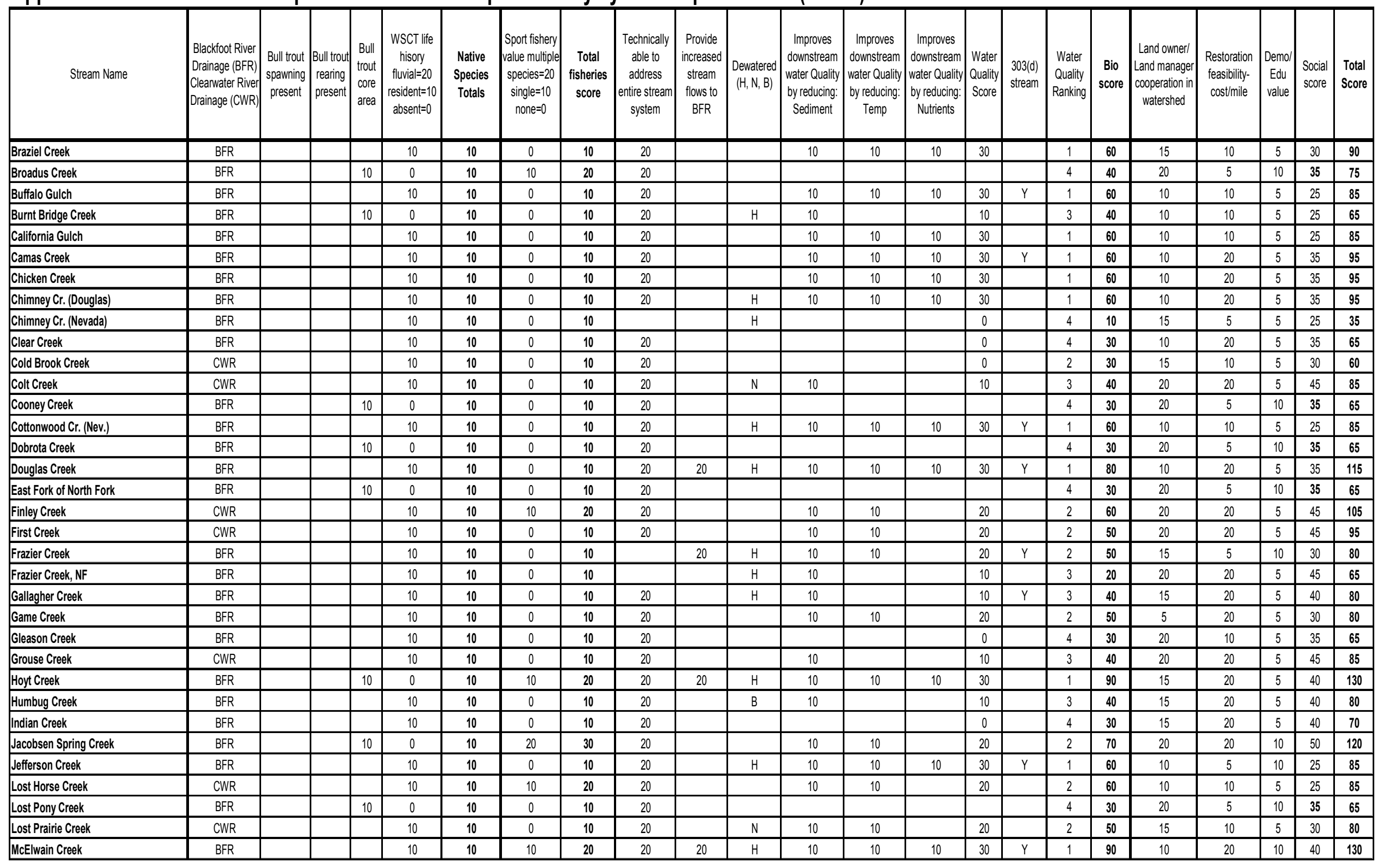


Appendix K: Stream restoration prioritization sorted alphabetically by native species total (cont'd).

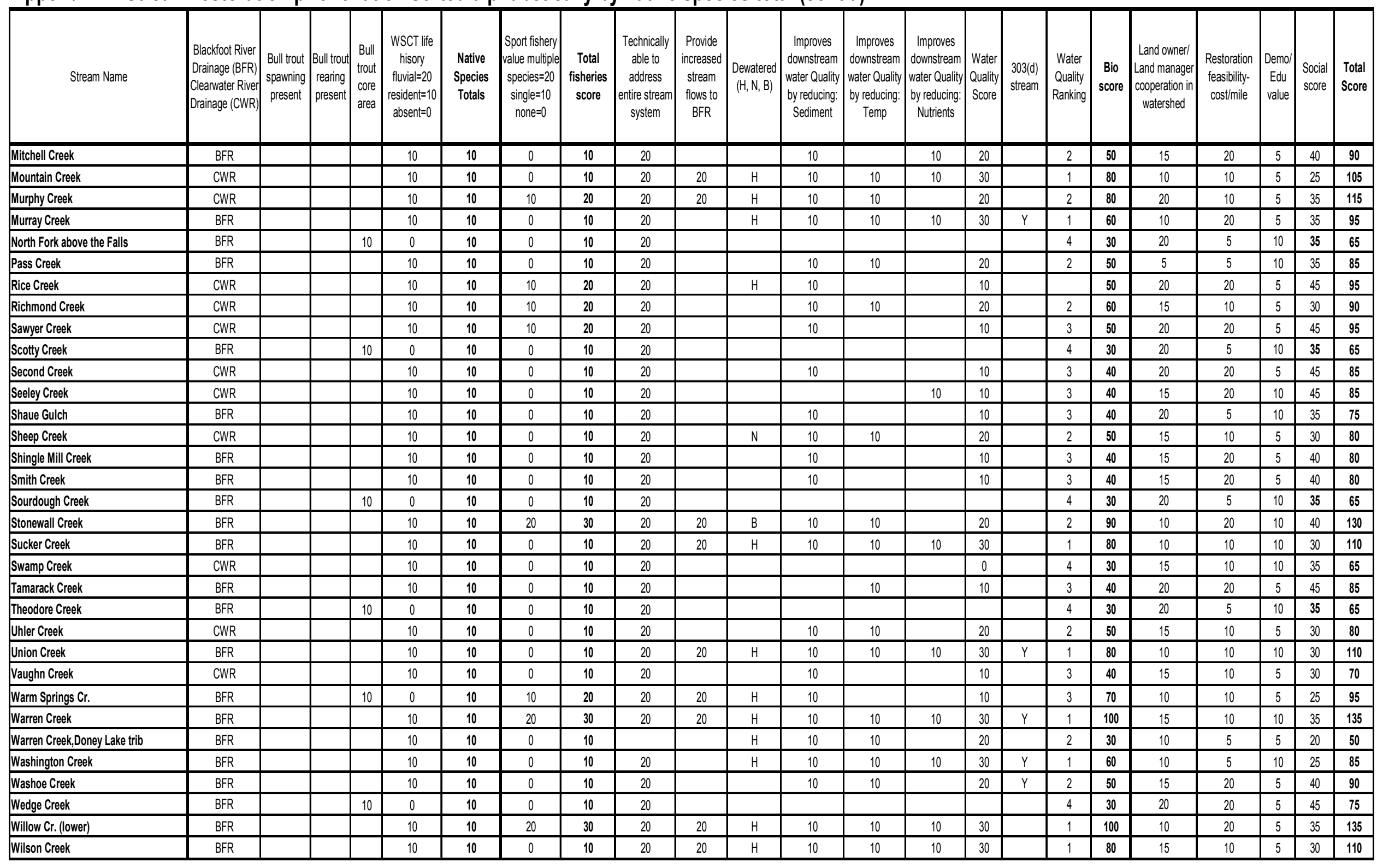


Appendix K: Stream restoration prioritization sorted alphabetically by native species total (cont'd).

\begin{tabular}{|c|c|c|c|c|c|c|c|c|c|c|c|c|c|c|c|c|c|c|c|c|c|c|c|}
\hline Stream Name & \begin{tabular}{|l|} 
Blackfoot River \\
Drainage (BFR) \\
Clearwater River \\
Drainage (CWR)
\end{tabular} & $\begin{array}{c}\text { Bull trout } \\
\text { spawning } \\
\text { present }\end{array}$ & $\begin{array}{l}\text { Bull trout } \\
\text { rearing } \\
\text { present }\end{array}$ & $\begin{array}{c}\text { Bull } \\
\text { trout } \\
\text { core } \\
\text { area }\end{array}$ & $\begin{array}{c}\text { WSCT life } \\
\text { hisory } \\
\text { fluvial=20 } \\
\text { resident=10 } \\
\text { absent=0 }\end{array}$ & $\begin{array}{c}\text { Native } \\
\text { Species } \\
\text { Totals }\end{array}$ & $\begin{array}{c}\text { Sport fishery } \\
\text { value multiple } \\
\text { species }=20 \\
\text { single }=10 \\
\text { none }=0\end{array}$ & $\begin{array}{l}\text { Total } \\
\text { fisheries } \\
\text { score }\end{array}$ & $\begin{array}{c}\text { Technically } \\
\text { able to } \\
\text { address } \\
\text { entire stream } \\
\text { system }\end{array}$ & $\begin{array}{c}\text { Provide } \\
\text { increased } \\
\text { stream } \\
\text { flows to } \\
\text { BFR }\end{array}$ & $\begin{array}{r}\text { Dewatered } \\
(\mathrm{H}, \mathrm{N}, \mathrm{B})\end{array}$ & $\begin{array}{c}\text { Improves } \\
\text { downstream } \\
\text { water Quality } \\
\text { by reducing: } \\
\text { Sediment }\end{array}$ & $\begin{array}{c}\text { Improves } \\
\text { downstream } \\
\text { water Quality } \\
\text { by reducing: } \\
\text { Temp }\end{array}$ & $\begin{array}{c}\text { Improves } \\
\text { downstream } \\
\text { water Quality } \\
\text { by reducing: } \\
\text { Nutrients }\end{array}$ & $\begin{array}{l}\text { Water } \\
\text { Quality } \\
\text { Score }\end{array}$ & $\begin{array}{l}\text { 303(d) } \\
\text { stream }\end{array}$ & \begin{tabular}{|l|} 
Water \\
Quality \\
Ranking
\end{tabular} & $\begin{array}{c}\text { Bio } \\
\text { score }\end{array}$ & $\begin{array}{c}\text { Land ownerl } \\
\text { Land manager } \\
\text { cooperation in } \\
\text { watershed }\end{array}$ & \begin{tabular}{|l} 
Restoration \\
feasibility- \\
costmile
\end{tabular} & $\mid \begin{array}{c}\text { Demol } \\
\text { Edu } \\
\text { value }\end{array}$ & $\begin{array}{l}\text { Social } \\
\text { score }\end{array}$ & $\begin{array}{l}\text { Total } \\
\text { Score }\end{array}$ \\
\hline Auggie Creek & CWR & & & & 0 & 0 & 0 & 0 & 20 & & $\mathrm{~N}$ & & & & 0 & & 4 & 20 & 20 & 20 & 5 & 45 & 65 \\
\hline Bear Trap Creek & $\mathrm{BFR}$ & & & & 0 & 0 & 0 & 0 & 20 & & & 10 & 10 & & 20 & & 2 & 40 & 20 & 5 & 10 & 35 & 75 \\
\hline Black Bear Creek & $\mathrm{BFR}$ & & & & 0 & 0 & 0 & 0 & 20 & & & 10 & 10 & 10 & 30 & $Y$ & 1 & 50 & 20 & 20 & 10 & 50 & 100 \\
\hline Buck Creek & CWR & & & & 0 & 0 & 0 & 0 & 20 & & & 10 & 10 & & 20 & & 2 & 40 & 15 & 10 & 5 & 30 & 70 \\
\hline Drew Creek & CWR & & & & 0 & 0 & 0 & 0 & & & $\mathrm{H}$ & 10 & 10 & 10 & 30 & & 1 & 30 & 5 & 5 & 5 & 15 & 45 \\
\hline Finn Creek & $\mathrm{BFR}$ & & & & 0 & 0 & 0 & 0 & 20 & & & 10 & 10 & 10 & 30 & & 1 & 50 & 15 & 20 & 5 & 40 & 90 \\
\hline Halfway Creek & $\mathrm{BFR}$ & & & & 0 & 0 & 0 & 0 & 20 & & & 10 & 10 & 10 & 30 & & 1 & 50 & 10 & 10 & 10 & 40 & 90 \\
\hline Horn Creek & CWR & & & & 0 & 0 & 0 & 0 & 20 & & $\mathrm{~N}$ & 10 & & & 10 & & 3 & 30 & 15 & 10 & 5 & 30 & 60 \\
\hline Mike Horse Creek & $\mathrm{BFR}$ & & & & 0 & 0 & 0 & 0 & 20 & & & 10 & 10 & & 20 & & 2 & 40 & 20 & 5 & 10 & 35 & 75 \\
\hline Nevada Cr. (lower) & $\mathrm{BFR}$ & & & & 0 & 0 & 0 & 0 & 20 & 20 & $\mathrm{H}$ & 10 & 10 & 10 & 30 & $Y$ & 1 & 70 & 15 & 10 & 10 & 35 & 105 \\
\hline Owl Creek & CWR & & & & 0 & 0 & 20 & 20 & 20 & 20 & $B$ & 10 & 10 & 10 & 30 & & 1 & 90 & 15 & 10 & 10 & 35 & 125 \\
\hline Paymaster Creek & $\mathrm{BFR}$ & & & & 0 & 0 & 0 & 0 & 20 & & & 10 & & & 10 & & 3 & 30 & 10 & 5 & 10 & 35 & 65 \\
\hline Sheep Creek & $\mathrm{BFR}$ & & & & 0 & 0 & 0 & 0 & 20 & & & 10 & 10 & 10 & 30 & & 1 & 50 & 20 & 20 & 5 & 45 & 95 \\
\hline Slippery John Creek & CWR & & & & 0 & 0 & 0 & 0 & 20 & & $\mathrm{~N}$ & & & & 0 & & 4 & 20 & 15 & 10 & 5 & 30 & 50 \\
\hline Strickland Creek & BFR & & & & 0 & 0 & 0 & 0 & 20 & & & 10 & 10 & 10 & 30 & & 1 & 50 & 10 & 10 & 5 & 25 & 75 \\
\hline Sturgeon Creek & $\mathrm{BFR}$ & & & & 0 & 0 & 0 & 0 & 20 & & & 10 & 10 & 10 & 30 & & 1 & 50 & 15 & 20 & 5 & 40 & 90 \\
\hline Ward Creek & $\mathrm{BFR}$ & & & & 0 & 0 & 0 & 0 & 20 & & $\mathrm{~N}$ & 10 & 10 & 10 & 30 & $Y$ & 1 & 50 & 10 & 10 & 5 & 25 & 75 \\
\hline
\end{tabular}

